- 中国自然观察专题・

\title{
中国最受关注濒危物种保护现状 快速评价的新方法探讨
}

\author{
顾 垒 ${ }^{1,2 *}$ 闻 丞 ${ }^{1,2}$ 罗 玫 ${ }^{1}$ 王 昊 ${ }^{1,2}$ 吕 植 1,2 \\ 1 (北京大学生命科学学院自然保护与社会发展研究中心, 北京 100871) \\ 2 (山水自然保护中心, 北京 100871)
}

\begin{abstract}
摘要: 本文尝试制订了一套评分标准, 对中国174 个国家I级保护动植物物种和IUCN物种红色名录中极危(CR)、濒 危(EN)级别的鸟类的保护成效进行了快速评价。选取种群数量和趋势、信息完善程度、模拟分布区中适宜生境面 积变化趋势和模拟分布区被保护区覆盖程度等 4 个指标进行评分。数据来源包括公开发表的研究文献、遥感数据、 实地调查和公众收集。结果表明, 174 个物种的保护状况整体呈变差趋势, 4项指标平均值均为负值。单个物种保护 状况改善的有26种, 维持原状的有32种, 变差的有116种。本文还对2000-2013年间发表的涉及746个受威胁物种的 9,338篇研究文献进行了梳理, 结果表明被研究物种数和文献数都逐年上升, 但每年被研究的物种不到 $1 / 3$ 。研究集 中于明星物种和有经济价值的物种, 如大熊猫(Ailuropoda melanoleuca)的文献占了全部的 $11.33 \%$, 大多数物种研 究不足。分析表明即使是集中了最多保护资源的濒危物种, 其保护状况仍然是变差的。
\end{abstract}

关键词: 濒危物种, 保护成效, 评价标准, 文献研究

\section{A rapid approach for assessing the conservation effectiveness of the most concerned endangered species in China}

\author{
Lei $\mathrm{Gu}^{1,2^{*}}$, Cheng Wen ${ }^{1,2}$, Mei Luo ${ }^{1}$, Hao Wang ${ }^{1,2}$, Zhi Lü ${ }^{1,2}$ \\ 1 Center for Nature and Society, School of Life Sciences, Peking University, Beijing 100871 \\ 2 Shanshui Conservation Center, Beijing 100871
}

\begin{abstract}
By establishing a set of grading standards, conservation effectiveness was assessed rapidly for 174 of the most concerned endangered species in China, including all the Category I National Protected plant and animal species, and avian species defined as CR and EN by the IUCN Red List. Based on the data from published research articles, satellite remote sensing, field surveys and information collected by citizen scientists, the assessment was obtained by grading population dynamics, information perfections, potential habitat changes and protected area coverage of simulated distributions. Results show that the overall conservation status deteriorated during 2000-2013. The average grades of all four indexes were negative. The conservation status of 26 species improved, while 32 species maintained their status and 116 species worsened. We also investigated the trends of 9,338 published research articles in reference to 746 threatened species during 2000-2013. The numbers of studied species and research articles increased every year, but less than $1 / 3$ of the total threatened species had been studied in any single year. Research concentrated on the star species and the species with economic value, for example, the giant panda (Ailuropoda melanoleuca) contributed to $11.33 \%$ of all research articles. On the other hand, scientific research and basic information were lacking in most other threatened species.
\end{abstract}

Key words: threatened species, conservation effectiveness, grading standard, literature review 
增多，民间的保护意识和保护行动也有很大发展， 然而目前并没有行之有效的手段评估这些投入带 来的成效。某个濒危物种保护得怎样, 数量是否增 多, 生境是否改善, 这些都是公众最感兴趣的关于 物种保护的问题, 但这样的问题往往没有答案。

濒危等级是确定物种优先保护顺序和制订濒 危物种保育策略的重要依据, 《生物多样性公约》、 相关国际组织和一些国家都把物种濒危状态的评 价作为生物多样性保护工作中的一个重要步骤(成 克武和藏润国, 2004)。IUCN红色名录的等级标准已 于2001年更新到3.1版本, 获得了国际的广泛认可 和应用, 很多国家包括中国的物种红色名录编制都 参照了它的定量评估体系和专家咨询方法。但这一 标准是评估物种濒危状态的, 用于保护成效评估时 并不方便(蒋志刚和刹恩源, 2003)。

1988年, 美国濒危物种法案(Endangered Species Act, ESA)修订后规定物种恢复计划 (species recovery plans)必须包含具体的成效评价指标。十余 年后, 学术界通过保护计划本身的成效评估了这些 指标体系的作用, 发现详尽的评价指标与濒危物种 种群的恢复有正相关性(Boersma et al., 2001; Clark et al., 2002; Gerber \& Hatch, 2002; Bottrill et al., 2011)。除美国以外, 加拿大、澳大利亚和新西兰也 曾对濒危物种保护成效进行定量评估(Cullena et al., 2005; Taylor et al., 2005)。中国目前尚无法律约 束具体的物种保护实践, 也没有评估保护成效的标 准, 这与社会逐渐增加的对物种保护的投入是不相 符的。

因此, 我们基于现阶段可获取的质量最好的数 据, 尝试制订了一套保护成效评分标准, 并以此对 中国最受关注的濒危物种的保护成效进行快速评 估。此外, 我们还对公开发表的濒危物种研究文献 进行了全面梳理 (Sutherland \& Woodroof, 2009; Sutherland et al., 2014), 为评估提供必要信息, 同时 期望了解中国濒危物种研究发展的整体趋势。

\section{1 方法}

\section{1 选定“最受关注的濒危物种”}

《国家重点保护野生动物名录》和《国家重点 保护野生植物名录》(以下简称《名录》) 共包含了 约529个物种(由于有些物种是整属列入, 近年来不 断有分类修订, 物种数量会有变动), 其中I级约 148
个, II级约381个。在已经进行过的较为科学和系统 化的评估中, 《中国物种红色名录》评估了10,211个 物种(含种下等级), IUCN物种红色名录评估了 6,207 个物种(含种下等级)。为在评估中涵盖更多濒危状 况较为严重的物种, 加入了 IUCN物种红色名录中 易危(VU)以上等级的物种。适逢IUCN五年一度的 数据库更新, 我们在2014年初启动评估工作时只确 认了 362 个物种的等级信息, 其中有 262 个与《名录》 重叠。此外北京大学自然保护与社会发展研究中心 积累的信息中还包括117个不在上述名录中的物种, 这部分数据我们也包括进来, 初步确定 746 个待评 估物种。

在对这746个物种进行文献检索时发现, 对多 数物种而言, 研究文献和积累数据无法提供评估所 需的足够信息。本次评估的一个重要目的是制订一 套行之有效的评估标准, 信息空缺太多的物种无法 对标准的有效与否产生反馈, 因此是没有意义的。 最终我们把用于评估物种保护状况的名单缩小到 文献和分布信息都相对完整的物种。《名录》是目 前国内濒危野生动植物物种保护唯一有效的法律 依据, 保护和科研的关注点大多集中在这些物种 上, 而一级保护的物种显然是重中之重。此外, 鸟 类的种群和分布信息是所有类群中最好的, 表明鸟 类受到了研究和保护工作者以及爱好者的较多关 注, 而其中极危(CR)和濒危(EN)等级的物种也有更 高的保护价值。上述物种代表了中国濒危物种保护 和科研的最高水平, 我们将其定义为“最受关注的 濒危物种”。物种名单见附录1, 共174种。

\section{2 物种保护状况评估标准的制订}

基于现阶段所能获得的最可靠的数据, 并部分 参照美国ESA物种恢复计划的评估标准, 我们设置 了 4 项指标对 174 个物种的保护状况进行评估(表1)。

(1)种群数量和趋势。定量指标, 来自文献、积 累的监测数据和咨询, 没有信息的则参照IUCN物 种红色名录的描述。

(2)适宜生境面积变化。定量指标, 来自遥感数 据和分布数据模拟。具体方法见1.4。

(3)信息完善程度。定性指标, 来自文献, 反映 物种的生物学信息被了解的程度。按分类学、种群 监测、栖息地变化、行为学、繁育系统和遗传多样 性这6类研究文献的有无进行评分。

(4)模拟分布区被保护区覆盖程度。定量指标, 
表1 濒危物种保护成效评分标准

Table 1 Grading standards of the conservation effectiveness

\begin{tabular}{|c|c|c|c|}
\hline $\begin{array}{c}\text { 评分标准 } \\
\text { Grading standard }\end{array}$ & 1 & 0 & -1 \\
\hline $\begin{array}{l}\text { 种群动态 } \\
\text { Population dynamics }\end{array}$ & $\begin{array}{l}\text { 数量稳定增长 } \\
\text { Increasing stably }\end{array}$ & $\begin{array}{l}\text { 数量变化不大 } \\
\text { No significant change }\end{array}$ & $\begin{array}{l}\text { 数量减少, 或极少而无恢复 } \\
\text { 迹象 } \\
\text { Significantly decreasing, or } \\
\text { extremely small population } \\
\text { without recovery }\end{array}$ \\
\hline $\begin{array}{l}\text { 适宜生境变化 } \\
\text { Potential habitat change }\end{array}$ & $\begin{array}{l}\text { 1\%以上像元改善 } \\
\text { Improving in }>1 \% \text { pixels }\end{array}$ & $\begin{array}{l}1 \% \text { 以内像元变化, 或不明 } \\
\text { Changing in } \pm 1 \% \text { pixels, or } \\
\text { unclear }\end{array}$ & $\begin{array}{l}1 \% \text { 以上像元恶化 } \\
\text { Worsening in }>1 \% \text { pixels }\end{array}$ \\
\hline $\begin{array}{l}\text { 信息完善程度 } \\
\text { Information perfection }\end{array}$ & $\begin{array}{l}\text { 有行为学、繁育系统或遗传多 } \\
\text { 样性文献 } \\
\text { Literatures in behavior, breed- } \\
\text { ing system or genetic diversity } \\
\text { published }\end{array}$ & $\begin{array}{l}\text { 有种群和栖息地文献 } \\
\text { Literatures in population and } \\
\text { habitat published }\end{array}$ & $\begin{array}{l}\text { 只有分类学文献 } \\
\text { Taxonomy literatures only }\end{array}$ \\
\hline $\begin{array}{l}\text { 模拟分布区被保护区覆盖情况 } \\
\text { Protected area coverage of simulated distribution }\end{array}$ & $\begin{array}{l}>15 \% \\
>15 \%\end{array}$ & $\begin{array}{l}5-15 \%, \text { 或不明 } \\
5-15 \% \text {, or unclear }\end{array}$ & $\begin{array}{l}<5 \% \\
<5 \%\end{array}$ \\
\hline
\end{tabular}

来自分布数据模拟，具体方法见闻丞等(2015)。

\section{3 物种研究文献的检索和信息提取}

在前述的4项指标中, 种群数量和趋势、信息完 善程度以及部分分布信息可以从公开发表的科研 文献中获取。此外科研文献自身的数量和增长趋势 也可以反映濒危物种被关注的程度。因此我们发起 了一项基于 746 个物种名单的研究文献检索和信息 提取活动, 在全国范围内招募志愿者, 按照如下规 则检索研究文献并提取信息。

文献来源: 英文文献以物种拉丁学名为关键词 在Google Scholar中搜寻, 中文文献以中文名为关 键词在维普和CNKI(中国期刊全文数据库)搜索, 检 索时均须下载全文。文章发表时间段为2000-2013 年。在文献检索中尽量去除纯粹研究利用价值, 或 以利用为目的的人工养殖和栽培等与保护无关的 文章。

文献信息提取: (1)种群信息: 记录文献中提及 的种群数量和变化趋势。(2)研究地点: 在论文的“研 究地点” 中提取, 地名精确到县一级, 如果有经纬 度则记录经纬度。这实际上是分布信息, 用于栖息 地模拟。(3)研究内容分类: 依据本研究需要, 对 IUCN评价物种濒危状况的体系做了简化和归并, 总结为一系列研究论文中经常关注的内容, 并分为 “现状”、“威胁”和“行动”三大类。

对从志愿者处返回的信息提取结果进行检查 和甄别, 发现正确率高于 $90 \%$ 。这证明了此套信息 提取方法足够简明, 即使非相关专业的使用者也不 会遇到障碍。

\section{4 栖息地的变化}

植被指数的变化趋势可以反映出生物赖以生 存的植被的变化趋势(Liu \& Gong, 2012; Lü et al., 2015)。利用由美国国家航空航天局(National Aeronautics and Space Administration, NASA)公开提供 的 Terra/MODIS 影像衍生的增强型植被指数 EVI(MOD13Q1数据集的一部分)分析了 2000-2013 年中国范围内植被的变化趋势。首先对每年夏季植 被最好阶段的 8 个时相，即从 5 月 25 日(闰年24日)至 9 月29日(闰年28日)的EVI数据取平均值, 使用线性 回归的方法对每个像素上2000-2013年的14个数据 进行线性回归, 检验回归方程的斜率和显著性, 斜 率为负且检验结果为显著的表明 $\mathrm{EVI}$ 平均值呈现出 显著下降的趋势, 对应着植被状况的显著变差; 相 反则对应着植被状况显著改善; 若斜率检验结果为 不显著, 则认为植被指数未发生明显变化(余晓等, 2011)。

同时, 综合了 5 套土地覆盖数据集, 将中国的 土地覆盖分为森林、草地、湿地、荒漠和裸地、冰 川、农田和城市用地 7 类, 然后和植被指数趋势分析 数据叠加, 得到每种土地覆盖类型的变化情况, 并 计算面积(像素数)的百分比。这 5 套土地覆盖数据集 分别是:

(1)由GLC2000 (Global Land Cover 2000, 全球 土地覆盖2000)项目开发的基于SPOT4卫星遥感数 据的全球土地覆盖数据的中国子集。

(2) 由 IGBP-DIS (International Geosphere-Biosphere Program: Data and Information System, 国际 
地理与生物圈项目数据信息系统)支持的基于AVHRR (Advanced Very High Resolution Radiometer, 先 进超高分辨率辐射计)遥感数据的全球土地覆盖数 据中国子集。

(3)MODIS (Moderate Resolution Imaging Spectroradiometer, 中分辨率成像光谱仪)全球土地覆盖 数据中国子集。

(4)由马里兰大学生产的基于 AVHRR数据和 NDVI (Normalized Difference Vegetation Index, 归 一化差值植被指数)数据的全球土地覆盖数据中国 子集。

(5)由中国科学院组织实施的中国2000年1： 100000 土地覆盖数据, 经合并和矢量栅格转换得到 的全国范围 $1 \mathrm{~km}$ 分辨率的土地利用数据产品,

最后将预测出的分布区与不同土地覆盖类型 植被指数变化的图层作叠加分析, 统计预测分布区 中各种生境植被指数的变化, 作为栖息地变化的评 价指标之一。由于不同物种生境不同、对生境中植 被的依赖程度也不同, 因此在评分时针对每个物种 给出特定的评分。例如, 栖息地是森林的物种, 以森 林植被面积增加作为改善标准; 栖息地是荒漠和裸 地的物种, 以荒漠和裸地植被面积减少为改善标准。

\section{2 结果}

\section{1 物种保护状况总体评分}

在所评估的 174 个物种中, 保护状况总体改善 的只有26种, 维持原状的32种, 变差的达 116 种, 具
体评分见附录 1 。各指标评分的算术平均值可以从 整体上反映这些物种的保护状况，4项指标的平均 值分别为: 种群数量和趋势为 -0.64 ; 适宜生境面积 变化为 -0.15 ; 信息完善程度为 -0.27 ; 模拟栖息地 被保护区覆盖程度为 -0.17 。所有指标都是负值, 说 明即使是集中了最多保护资源的濒危物种，其保护 状况仍然在恶化。

在 174 个物种中, 保护状况最好的物种如梅花 鹿 (Cervus nippon)、苏铁 (Cycas revoluta)、珙桐 (Davidia involucrata)、西藏野驴(Equus kiang)、独叶 草(Kingdonia uniflora)和分布于台湾的台湾镾羚 (Capricornis crispus)、台湾猴(Macaca cyclopis)均有 较大的种群数量, 并且近年来稳中有升, 而大熊猫 (Ailuropoda melanoleuca)、野牦牛(Bos mutus)、扭角 羚 (Budorcas taxicolor)、川金丝猴 (Rhinopithecus roxellana)则因物种和栖息地数据较为完备而获得 较高分数(表2)。受益于保护实践的物种很少, 174种 中目前只有大熊猫、扭角羚、川金丝猴和朱噮 (Nipponia nippon)。其中金丝猴和扭角羚作为与大熊 猫同域分布的物种，是大熊猫保护的受益者。

保护状况最差的物种中, 野马(Equus przewalskii)已经野外灭绝, 白暨豚(Lipotes vexillifer)和白 鲟(Psephurus gladius)很可能也已经灭绝。评分为 -3 以下的物种中, 华盖木(Manglietiastrum sinicum)、 云南蓝果树(Nyssa yunnanensis)和巧家五针松(Pinus squamata)是极小种群物种, 其他物种的信息完善 程度很低(表2)。

表2 保护评分最高和最低的物种

Table 2 Species with highest and lowest grades

\begin{tabular}{|c|c|c|c|c|c|}
\hline \multicolumn{3}{|c|}{ 评分最低的物种 Species with lowest grades } & \multicolumn{3}{|c|}{ 评分最高的物种 Species with highest grades } \\
\hline $\begin{array}{c}\text { 中文名 } \\
\text { Chinese name }\end{array}$ & $\begin{array}{c}\text { 学名 } \\
\text { Latin name }\end{array}$ & $\begin{array}{c}\text { 评分 } \\
\text { Grades }\end{array}$ & $\begin{array}{c}\text { 中文名 } \\
\text { Chinese name }\end{array}$ & $\begin{array}{c}\text { 学名 } \\
\text { Latin name }\end{array}$ & $\begin{array}{c}\text { 评分 } \\
\text { Grades }\end{array}$ \\
\hline 白暨豚 & Lipotes vexillifer & -4 & |西藏野驴 & Equus kiang & 4 \\
\hline 白鲟 & Psephurus gladius & -4 & |金雕 & Aquila chrysaetos & 3 \\
\hline 野马 & Equus przewalskii & -4 & 珙桐 & Davidia involucrata & 3 \\
\hline 豹 & Panthera pardus & -4 & 黑鹳 & Ciconia nigra & 2 \\
\hline 巧家五针松 & Pinus squamata & -4 & 东北红豆杉 & Taxus cuspidata & 2 \\
\hline 四川苏铁 & Cycas szechuanensis & -4 & |台湾猴 & Macaca cyclopis & 2 \\
\hline 中华水非 & Isoetes sinensis & -4 & |台湾鬛羚 & Capricornis crispus & 2 \\
\hline 野牛 & Bos gaurus & -4 & |伯乐树 & Bretschneidera sinensis & 2 \\
\hline 云豹 & Neofelis nebulosa & -3 & 独叶草 & Kingdonia uniflora & 2 \\
\hline 㒶 & Pelochelys bibroni & -3 & 斑尾榛鸡 & Tetrastes sewerzowi & 2 \\
\hline 华盖木 & Manglietiastrum sinicum & -3 & 梅花鹿 & Cervus nippon & 2 \\
\hline 灰腹角雉 & Tragopan blythii & -3 & 藏羚 & Pantholops hodgsonii & 2 \\
\hline 云南蓝果树 & Nyssa yunnanensis & -3 & 大熊猫 & Ailuropoda melanoleuca & 2 \\
\hline 儒艮 & Dugong dugon & -3 & 苏铁 & Cycas revoluta & 2 \\
\hline
\end{tabular}


其他低分物种都是只有零星的研究和目击记 录, 包括迁徙鸟类、分布于边境地区的哺乳动物以 及20余种苏铁和国家I级重点保护植物中的所有蒝 类物种, 这从一个侧面说明了这些物种的保护存在 较大盲区, 保护区覆盖不足, 缺乏种群和栖息地的 基本信息。

\section{2 物种保护状况单项指标评分}

\subsection{1 种群数量和趋势}

174 个物种中, 种群规模下降的有 118 个, 占 $67.82 \%$; 保持稳定的有 31 个，占 $17.82 \%$; 扩大的有 25 个, 占 $14.36 \%$ 。种群增长最多的物种有珙桐、苏 铁、西藏野驴等, 多数是本身数量较大的低危、无 危物种。种群评分最低的物种中, 巧家五针松、百 山祖冷杉(Abies beshanzuensis)等极小种群物种仍有 数量减少的趋势, 或数量极少而没有恢复迹象。

\subsection{2 适宜生境面积变化}

174 个物种中, 模拟分布区中适宜生境面积减 少超过 $1 \%$ 的有 33 个, 占 $18.97 \%$; 面积增减在 $1 \%$ 以 内的有 14 个, 占 $8.05 \%$; 面积增加超过 $1 \%$ 的有 16 个, 占9.20\%。有 101 个物种因为分布信息不全, 无法进 行分布区模拟，记为 0 分。

\subsection{3 信息完善程度}

174 个物种中, 基本信息不完备的有 89 个, 占 $51.15 \%$; 仅完善了分布、种群信息的有 40 个, 占 22.98\%; 在基本信息之外对栖息地状态、遗传多样 性、行为或繁殖生物学有研究的有 45 个, 占 $25.86 \%$ 。 信息较为完善的物种都是旗舰种或有经济价值的 物种。

\subsection{4 模拟分布区被保护区覆盖程度}

174 个物种中, 模拟分布区被保护区覆盖范围 在 $5 \%$ 以下的物种有 35 个, 占 $20.11 \%$; 在 $5-15 \%$ 的有 20 个, 占 $11.49 \%$; 高于 $15 \%$ 的有 18 个, 占 $10.35 \%$ 。有 101 个物种因为分布信息不全, 无法进行分布区模 拟, 记为 0 分。

\section{3 物种研究文献纵览}

为了给物种保护状况评估提供必要信息, 我们 对包括前述 174 个物种的 746 个物种进行了全面的 研究文献检索。检索共得到文献9,338篇(附录2)。其 中中文文献8,130篇, 英文文献1,208篇。总体来看, 中文文献占了研究文献中的绝大多数, 达 $87.06 \%$ 。 746 个物种中有 475 个物种有研究文献, 占 $63.67 \%$, 平均每个物种有文献19.66篇。
从2000年的96种328篇到2013年的212种 822 篇, 被研究的物种数和发表的研究文献篇数呈现逐年 增长的趋势(图1)。其中2003-2009年间增长较为迅 猛，其后放缓甚至有所回落。

将每年发表的研究文献数按物种数平均后, 平 均数由 2000 年的 3.42 篇到 2013 年的 3.88 篇, 最高值 是2009年的4.29篇, 变化趋势与总篇数以及被研究 物种数类似, 但增长幅度较为平缓。尽管每年受到 研究的物种数都在增加, 但截至2013年底, 每年也 只有不到 $1 / 3$ 的保护物种得到研究。

回归分析表明, 每年被研究的物种数和每年发 表的文献总篇数呈强线性相关 $\left(R^{2}=0.98339\right)$ (图2)。 说明每年新增的被研究物种的文献数量是比较稳 定而缓慢增加的。每年被研究的物种数量都远远小

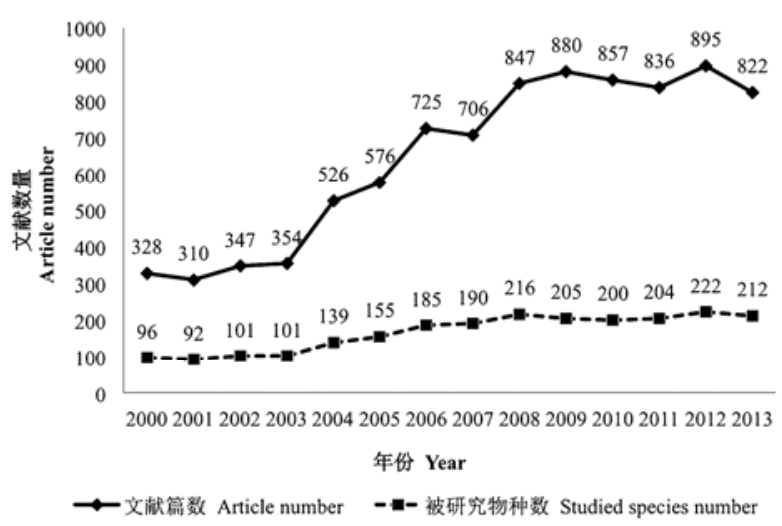

图12000-2013年间文献数量和被研究物种数量的年际 动态

Fig. 1 Annual dynamics of research articles and studied species during 2000-2013

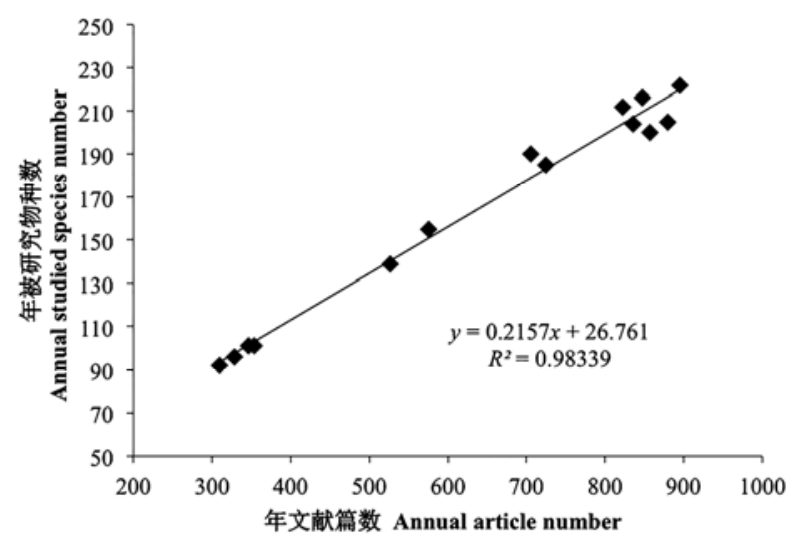

图2 2000-2013年间每年被研究物种数和文献篇数的相关性 Fig. 2 Correlation between annual numbers of studied species and articles during 2000-2013. 


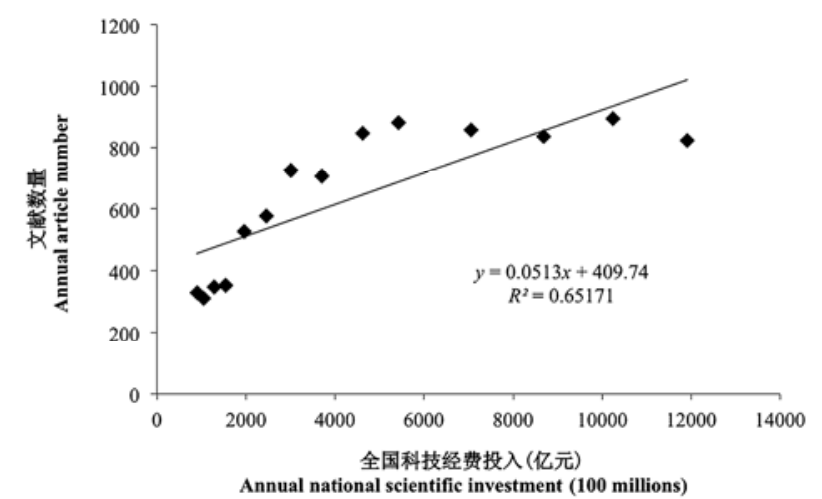

图3 2000-2013年间年文献数量和全国科技经费投入的相 关性

Fig. 3 Correlation between annual article numbers and annual national scientific investments during 2000-2013

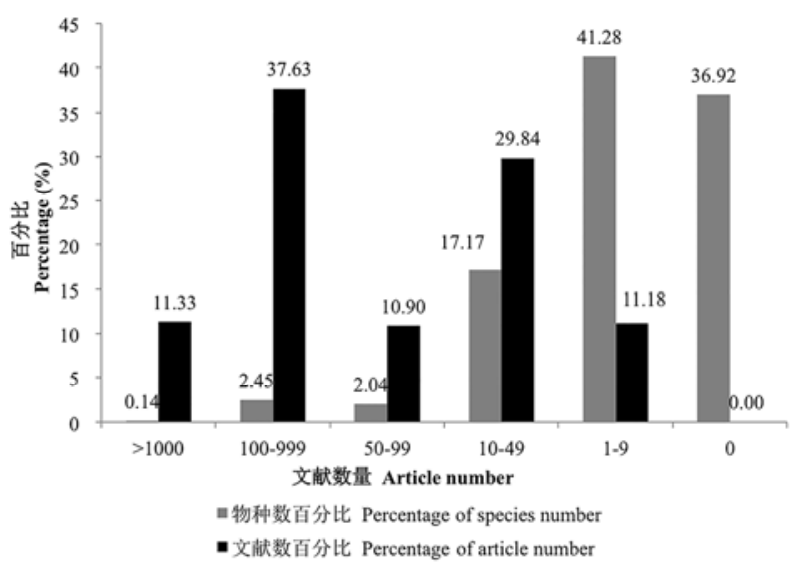

图4 文献的物种分布

Fig. 4 Distribution of research articles among species

于总的物种数量, 可知每年被研究的物种都有不 同，也就是说很多物种都没有持续多年的研究。

绝大多数研究论文的发表都受到科研经费的 支持，但2000-2013年间文献数量的增长与同期全 国科技经费投入(数据来自国家统计局2000-2013年 度统计公报)的增长相关性较弱 $\left(R^{2}=0.65171\right)$ (图3), 主要表现在2009年之后增速放缓。其原因可能包括 科研成本上升、研究者兴趣转移等, 需要进一步的 挖掘。

\section{4 被研究物种的分布}

文献在物种间的分布极不均衡。研究集中在一 些旗舰种和有经济利用价值的物种, 其余大部分物 种都缺乏研究。完全没有检索到文献的物种有271 个, 占总数(746)的 $36.92 \%$ 。

有研究文献的物种中, 文献数量超过 1,000 篇
的有 1 个物种, 即大熊猫 $(1,058$ 篇，占总数的 $11.33 \%)$ 。文献数量在100-999篇之间的有18种, 占 全部的 $2.45 \%$; 文献共 3,514 篇, 占总数的 $37.63 \%$ 。 其余物种中, 文献数量在50-99篇之间的有 15 种, 占全部的 $2.04 \% ; 10-49$ 篇的有 126 种, 占全部的 $17.17 \%$; 9 篇及以下的有 303 种，占全部的 $41.28 \%$ (图4)。

\section{3 讨论}

\section{1 国家重点保护物种名录的空缺}

在选择评估对象范围时, 我们统计了《名录》 与国际通行的IUCN物种红色名录所收录物种的差 异。由于信息的不足和更新的缓慢，《名录》目前未 能准确及时地包括我国应受到保护的濒危物种。

《名录》的发布时间分别是动物1989年, 植物1999 年, 之后只经历过轻微的修订 (动物2003年提高了 麾属 (Moschus) 的等级, 植物 2001年提高了发菜 (Nostoc commune var. flagelliforme) 的等级), 其中存 在较大空缺已成为共识。

《名录》目前收录了约529个物种, 而作为一个 由分类学和保护专家定期更新数据的体系, IUCN 物种红色名录目前收录的中国受胁物种(VU以上等 级)有792个, 与《名录》仅有约 262 个物种的重叠。 换言之, 《名录》未能包括国际上已界定的中国受 胁物种数量达 530 个之多(表3)。

《名录》空缺最严重的类群是鱼类, 只收录了 16 种, 而IUCN物种红色名录收录了129种。此外, 由于《名录》更新太慢, 新发表的狭域分布的潜在 濒危物种几乎被全面忽视。比如两栖动物被《名录》 收录了7种, IUCN物种红色名录收录了 88 种, 而 2000-2013年间新发表的两栖动物名称超过750个, 一些灭绝风险很高的物种未能包括在内。

\section{2 评估标准}

种群数量和变化趋势是反映濒危物种保护成 效的终极指标(成克武和藏润国, 2004; Bottrill et al., 2011)。然而由于缺乏针对性的调查和持续的种群监 测, 从研究文献中很难获得足够用于判断种群数量 和变化趋势的信息。国际上对于这一缺陷并没有很 好的解决方法, 如IUCN物种红色名录的濒危状况 评估也是主要采用咨询专家、凭经验判定的方式(蒋 志刚和㚞恩源, 2003)。同时, 来自不同物种的种群 数据精确程度不同, 种群变化的趋势强弱和具体驱 
表3 国家重点保护野生动植物名录与IUCN物种红色名录受 胁物种个数的比较

Table 3 Comparison of the threatened species numbers in the Chinese National Protected Animal and Plant Species Checklists and the IUCN Red List

\begin{tabular}{|c|c|c|c|c|}
\hline \multicolumn{2}{|c|}{$\begin{array}{c}\text { 国家重点保护野生动植物名录 } \\
\text { National Protected Animal and } \\
\text { Plant Species Checklists }\end{array}$} & \multicolumn{2}{|c|}{$\begin{array}{l}\text { IUCN物种红色名录 } \\
\text { IUCN Red List }\end{array}$} & \multirow[t]{3}{*}{$\begin{array}{c}\text { 重叠物种数 } \\
\text { Overlaps }\end{array}$} \\
\hline 分级 & 物种(类群)数 & 分级 & 物种数 & \\
\hline Category & $\begin{array}{c}\text { Species (taxa) } \\
\text { numbe }\end{array}$ & Category & $\begin{array}{l}\text { Species } \\
\text { number }\end{array}$ & \\
\hline $\mathrm{I}$ & 148 & CR & 118 & 81 \\
\hline \multirow[t]{4}{*}{ II } & 381 & EN & 281 & 181 \\
\hline & & VU & 388 & \\
\hline & & EW & 1 & \\
\hline & & EX & 4 & \\
\hline 总计 & 约529 & & 792 & 262 \\
\hline Total & Са. 529 & & & \\
\hline
\end{tabular}

动原因也不同, 评价体系可能因此变得复杂而成本 高昂。为了满足快速评估的需求, 我们将这些指标 进行模糊化处理, 只呈现了大略的变化趋势。另一 方面, 这套评估体系还需要很多实地数据进行校 验。在需要用到分布区模拟的两项指标中, 有 101 个物种因为分布信息不足以进行模拟而被记为 0 分, 等价于“满足平均水平”或“不变”, 需要进一步收集 数据以完善这两个指标的评分。模拟分布区内适宜 生境的面积变化也可能无法反映物种实际的分布 情况，比如遗鸥(Larus relictus)的栖息地在过去 10 多年时间发生了很大的萎缩, 最主要的栖息地都发 生了转移, 但模拟分布区内适宜生境的面积变化在 $1 \%$ 以内而被记为 0 分。这些问题都需要填补数据空 白之后才能解决。

生态区、国土或全球面积的保护区覆盖率达到 $10 \%$, 曾经经常被当作世界生物多样性保护的目标 (Brooks et al., 2004; Leverington et al., 2010)。截至 2013年底, 中国的陆域国土面积已经有14.95\%被保 护区覆盖。这个数据一定程度上可以解读为一个濒 危物种的栖息地至少要被保护区覆盖14.95\%才算 合格。由于保护区的划定对濒危物种栖息地有针对 性, 理论上对濒危物种潜在分布区的覆盖率应当高 于对国土面积的平均覆盖率。反之, 如果某一濒危 物种的潜在分布区被保护区覆盖低于上述标准, 则 表明针对这一物种的保护区设定不足。鉴于具体物 种的活动能力差异, 比如迁徙鸟类的实际活动区可 能远远大于保护区能够覆盖的范围, 我们在相应物
种上把标准下调到 $5 \%$ 。

ESA的成效评估涉及了 135 个保护计划181个物 种 (Boersma et al., 2001; Gerber \& Hatch, 2002; Bottrill et al., 2011), 物种数量和我们的174种相当, 意味着我们在这个数量的物种上尝试制订评价体 系是有意义的。这样的评估无疑需要积累大量长期 监测的种群信息，而这正是我们现在最为欠缺的。 不过这并不妨碍我们现在就建立一套框架, 随着数 据的积累不断验证并细化之, 最终起到全面了解中 国濒危物种保护的成效, 并促进中国濒危物种保护 的作用。

致谢: 本研究得到了山水自然保护中心的资助, 北 京大学自然保护与社会发展研究中心和中国观鸟 组织联合行动平台提供了部分基础数据。我们感谢 30 余位研究助理在文献检索和信息提取中的贡献。

\section{参考文献}

Boersma PD, Kareiva P, Fagan WF, Clark JA, Hoekstra JM (2001) How good are endangered species recovery plans? BioScience, 51, 643-649.

Bottrill MC, Walsh JC, Watson JEM, Josepha LN, Ortega-Arguetab A, Possinghama HP (2011) Does recovery planning improve the status of threatened species? Biological Conservation, 144, 1595-1601.

Brooks TM, Bakarr MI, Boucher T, Da Fonseca GAB, Hilton-Taylor C, Hoekstra JM, Moritz T, Olivieri S, Parrish J, Pressey RL, Rodrigues ASL, Sechrest W, Stattersfield A, Strahm W, Stuart SN (2004) Coverage provided by the global protected-area system: is it enough? BioScience, 54, 1081-1091.

Cheng KW (成克武), Zang RG (藏润国) (2004) Advances in species endangerment assessment. Biodiversity Science (生 物多样性), 12, 534-540. (in Chinese with English abstract)

Clark JA, Hoekstra JM, Boersma PD, Kareiva P (2002) Improving U.S. Endangered Species Act recovery plans: key findings and recommendations of the SCB recovery plan project. Conservation Biology, 16, 1510-1519.

Cullena R, Morana E, Hughey KFD (2005) Measuring the success and cost effectiveness of New Zealand multiple-species projects to the conservation of threatened species. Ecological Economics, 53, 311-323.

Gerber LR, Hatch LT (2002) Are we recovering? An evaluation of recovery criteria under the U.S. Endangered Species Act. Ecological Applications, 12, 669-673.

Jiang ZG (蒋志刚), Fan EY (訤恩源) (2003) Exploring the endangered species criteria: rethinking the IUCN Red List criteria. Biodiversity Science (生物多样性), 11, 383-392. (in Chinese with English abstract) 
Leverington F, Costa KL, Pavese H, Lisle A, Hockings M (2010) A global analysis of protected area management effectiveness. Environmental Management, 46, 685-698.

Liu S, Gong P (2012) Change of surface cover greenness in China between 2000 and 2010. Chinese Science Bulletin, 57, 2835-2845.

Lü YH, Zhang LW, Feng XM, Zeng Y, Fu BJ, Yao XL, Li JR, Wu BF (2015) Recent ecological transitions in China: greening, browning, and influential factors. Scientific Reports, 5, 8732.

Sutherland WJ, Clout M, Côté IM, Daszak P, Depledge MH, Fellman L, Fleishman E, Garthwaite R, Gibbons DW, De Lurio J, Impey AJ, Lickorish F, Lindenmayer D, Madgwick J, Margerison C, Maynard T, Peck LS, Pretty J, Prior S, Redford KH, Scharlemann JPW, Spalding M, Watkinson AR (2014) A horizon scan of global conservation issues for 2014. Trends in Ecology and Evolution, 29, 15-22.

Sutherland WJ, Woodroof HJ (2009) The need for environ- mental horizon scanning. Trends in Ecology and Evolution, 24, 523-527.

Taylor MFJ, Suckling KF, Rachlinski JJ (2005) The effectiveness of the endangered species act: a quantitative analysis. BioScience, 55, 360-367.

Wen C (闻丞), Gu L (顾垒), Wang H (王昊), Lü Z (吕植), Hu RC (胡若成), Zhong J (钟嘉) (2015) GAP analysis on national nature reserves in China based on the distribution of endangered species. Biodiversity Science (生物多样性), 23, 591-600. (in Chinese with English abstract)

Yu X (余晓), Li Z (李羽中), Wang H (王吴), Wang YC (王义成) (2011) Simulation of flood inundation and analysis on dynamic variation of wetlands for Argun River. Journal of Hydraulic Engineering (水利学报), 11, 1308-1315. (in Chinese with English abstract)

(责任编委: 李俊生 责任编辑: 间文杰)

\section{附录 Supplementary Material}

附录1 174个最受关注的濒危物种名单和保护成效评分

Appendix 1 The list and conservation effectiveness grading of the 174 most concerned endangered species http://www.biodiversity-science.net/fileup/PDF/w2015-115-1.pdf

附录2 746个受胁物种2000-2013年间发表的研究论文

Appendix 2 Research articles on 746 threatened species published during 2000-2013

http://www.biodiversity-science.net/fileup/PDF/w2015-115-2.pdf 
附录 1.174 个最受关注的濒危物种名单和保护成效评分

Appendix 1. The list and conservation effectiveness grading of the 174 most concerned endangered species.

\begin{tabular}{|c|c|c|c|c|c|c|}
\hline $\begin{array}{l}\text { 中文名 } \\
\text { Chinese name }\end{array}$ & $\begin{array}{l}\text { 学名 } \\
\text { Latin name }\end{array}$ & $\begin{array}{l}\text { 种群动态 } \\
\text { Population } \\
\text { dynamics }\end{array}$ & $\begin{array}{l}\text { 适宜生境变化 } \\
\text { Potential habitat } \\
\text { change }\end{array}$ & $\begin{array}{l}\text { 模拟分布区 } \\
\text { 被保护区覆 } \\
\text { 盖情况 } \\
\text { Protected area } \\
\text { coverage of } \\
\text { simulated } \\
\text { distribution }\end{array}$ & $\begin{array}{l}\text { 信息完善 } \\
\text { 程度 } \\
\text { Information } \\
\text { perfection }\end{array}$ & $\begin{array}{l}\text { 总计 } \\
\text { Total }\end{array}$ \\
\hline 白暨豚 & Lipotes vexillifer & -1 & -1 & -1 & -1 & -4 \\
\hline 白鲟 & Psephurus gladius & -1 & -1 & -1 & -1 & -4 \\
\hline 野马 & Equus przewalskii & -1 & -1 & -1 & -1 & -4 \\
\hline 豹 & Panthera pardus & -1 & -1 & -1 & -1 & -4 \\
\hline 巧家五针松 & Pinus squamata & -1 & -1 & -1 & -1 & -4 \\
\hline 四川苏铁 & Cycas szechuanensis & -1 & -1 & -1 & -1 & -4 \\
\hline 中华水非 & Isoetes sinensis & -1 & -1 & -1 & -1 & -4 \\
\hline 野牛 & Bos gaurus & -1 & -1 & -1 & -1 & -4 \\
\hline 云豹 & Neofelis nebulosa & -1 & -1 & 0 & -1 & -3 \\
\hline 輝 & Pelochelys bibroni & -1 & -1 & -1 & 0 & -3 \\
\hline 华盖木 & Manglietiastrum sinicum & -1 & -1 & 0 & -1 & -3 \\
\hline 灰腹角雉 & Tragopan blythii & -1 & -1 & -1 & 0 & -3 \\
\hline 云南蓝果树 & Nyssa yunnanensis & -1 & -1 & -1 & 0 & -3 \\
\hline 儒艮 & Dugong dugon & -1 & -1 & -1 & 0 & -3 \\
\hline 达氏鲟 & Acipenser dabryanus & -1 & 0 & 0 & -1 & -2 \\
\hline 玉龙蕨 & Sorolepidium glaciale & -1 & 0 & 0 & -1 & -2 \\
\hline 白腹军舰鸟 & Fregata andrewsi & -1 & 0 & 0 & -1 & -2 \\
\hline 白项长臂猿 & Nomascus leucogenys & -1 & 0 & 0 & -1 & -2 \\
\hline 波斑鸨 & Otis undulata & -1 & 0 & 0 & -1 & -2 \\
\hline 叉孢苏铁 & Cycas segmentifida & -1 & 0 & 0 & -1 & -2 \\
\hline 叉叶苏铁 & Cycas bifida & -1 & 0 & 0 & -1 & -2 \\
\hline 赤斑羚 & Naemorhedus cranbrooki & -1 & 0 & 0 & -1 & -2 \\
\hline 赤颈鹤 & Grus antigone & -1 & 0 & 0 & -1 & -2 \\
\hline
\end{tabular}




\begin{tabular}{|c|c|c|c|c|c|c|}
\hline 光叶蕨 & Cystoathyrium chinense & -1 & 0 & 0 & -1 & -2 \\
\hline 葫芦苏铁 & Cycas changjiangensis & -1 & 0 & 0 & -1 & -2 \\
\hline 虎头海雕 & Haliaeetus pelagicus & -1 & 0 & 0 & -1 & -2 \\
\hline 倭蜂猴 & Nycticebus pygmaeus & -1 & 0 & 0 & -1 & -2 \\
\hline 新疆大头鱼 & Aspiorhynchus laticeps & -1 & 0 & 0 & -1 & -2 \\
\hline 多毛坡垒 & Hopea mollissima & -1 & 0 & 0 & -1 & -2 \\
\hline 多歧苏铁 & Cycas multipinnata & -1 & 0 & 0 & -1 & -2 \\
\hline 蜂猴 & Nycticebus coucang & -1 & 0 & 0 & -1 & -2 \\
\hline 林鹿 & Moschus berezovskii & -1 & 0 & 0 & -1 & -2 \\
\hline 落叶木莲 & Manglietia decidua & -1 & 0 & 0 & -1 & -2 \\
\hline 貉藻 & Aldrovanda vesiculosa & -1 & 0 & 0 & -1 & -2 \\
\hline 坡垒 & Hopea hainanensis & -1 & 0 & 0 & -1 & -2 \\
\hline 水松 & Glyptostrobus pensilis & -1 & 0 & 0 & -1 & -2 \\
\hline 豚尾猴 & Macaca nemestrina & -1 & 0 & 0 & -1 & -2 \\
\hline 西藏红豆杉 & Taxus wallichiana & -1 & 0 & 0 & -1 & -2 \\
\hline 狭叶坡垒 & Hopea chinensis & -1 & 0 & 0 & -1 & -2 \\
\hline 峨眉拟单性木 & Parakmeria omeiensis & & & & & \\
\hline 兰 & & -1 & 0 & 0 & -1 & -2 \\
\hline 黑鹿 & Moschus fuscus & -1 & 0 & 0 & -1 & -2 \\
\hline \multirow{2}{*}{ 黑头角雉 } & Tragopan & & & & & \\
\hline & melanocephalus & -1 & 0 & 0 & -1 & -2 \\
\hline 马来熊 & Helarctos malayanus & -1 & 0 & 0 & -1 & -2 \\
\hline 普陀鹅耳枥 & Carpinus putoensis & -1 & -1 & -1 & 1 & -2 \\
\hline 四爪陆龟 & Testudo horsfieldi & -1 & -1 & -1 & 1 & -2 \\
\hline 台东苏铁 & Cycas taitungensis & -1 & 0 & 0 & -1 & -2 \\
\hline 台湾苏铁 & Cycas taiwaniana & -1 & 0 & 0 & -1 & -2 \\
\hline 蜥鳄 & Shinisaurus crocodilurus & -1 & 0 & 0 & -1 & -2 \\
\hline 膝柄木 & Bhesa sinensis & -1 & 0 & 0 & -1 & -2 \\
\hline 仙湖苏铁 & Cycas fairylakea & -1 & 0 & 0 & -1 & -2 \\
\hline 熊狸 & Arctictis binturong & -1 & 0 & 0 & -1 & -2 \\
\hline 玉带海雕 & Haliaeetus leucoryphus & -1 & 0 & 0 & -1 & -2 \\
\hline 云南苏铁 & Cycas tonkinensis & -1 & 0 & 0 & -1 & -2 \\
\hline
\end{tabular}




\begin{tabular}{|c|c|c|c|c|c|c|}
\hline \multirow[t]{2}{*}{ 长白松 } & \multicolumn{6}{|l|}{ Pinus sylvestris var. } \\
\hline & sylvestriformis & -1 & 0 & 0 & -1 & -2 \\
\hline 黑鹿 & Muntiacus crinifrons & -1 & 0 & 0 & -1 & -2 \\
\hline 虎 & Panthera tigris & -1 & 0 & 0 & -1 & -2 \\
\hline 绿孔雀 & Pavo muticus & -1 & 0 & 0 & -1 & -2 \\
\hline 绿尾虹雉 & Lophophorus lhuysii & -1 & 0 & 0 & -1 & -2 \\
\hline 蒙古野驴 & Equus hemionus & -1 & 0 & 0 & -1 & -2 \\
\hline 四川山麅鸪 & Arborophila rufipectus & -1 & 0 & 0 & -1 & -2 \\
\hline 台湾穗花杉 & Amentotaxus formosana & -1 & 0 & 0 & -1 & -2 \\
\hline 野骆驼 & Camelus ferus & -1 & 0 & 0 & -1 & -2 \\
\hline 银缕梅 & Shaniodendron & & & & & \\
\hline \multirow{3}{*}{ 云南穗花杉 } & subaequalum & -1 & 0 & 0 & -1 & -2 \\
\hline & Amentotaxus & & & & & \\
\hline & yunnanensis & -1 & 0 & 0 & -1 & -2 \\
\hline 长喙毛茛泽泻 & Ranalisma rostratum & -1 & 0 & 0 & -1 & -2 \\
\hline \multirow{2}{*}{ 长尾叶猴 } & Semnopithecus & & & & & \\
\hline & schistaceus & -1 & 0 & 0 & -1 & -2 \\
\hline 资源冷杉 & Abies ziyuanensis & -1 & 0 & 0 & -1 & -2 \\
\hline 白肩雕 & Aquila heliaca & -1 & 1 & -1 & -1 & -2 \\
\hline 豚鹿 & Cervus porcinus & -1 & 0 & 0 & -1 & -2 \\
\hline 马鹿 & Moschus chrysogaster & -1 & -1 & 1 & -1 & -2 \\
\hline 石山苏铁 & Cycas miquelii & 1 & -1 & -1 & -1 & -2 \\
\hline 高寒水非 & Isoetes hypsophila & 0 & -1 & -1 & 0 & -2 \\
\hline 革苞菊 & Tugarinovia mongolica & 0 & -1 & -1 & 0 & -2 \\
\hline 中华鲟 & Acipenser sinensis & -1 & -1 & -1 & 1 & -2 \\
\hline 丹顶鹤 & Grus japonensis & -1 & 0 & -1 & 0 & -2 \\
\hline 遗鸥 & Larus relictus & -1 & 0 & -1 & 0 & -2 \\
\hline 白头鹤 & Grus monacha & -1 & -1 & -1 & 1 & -2 \\
\hline 中华秋沙鸭 & Mergus squamatus & -1 & 0 & -1 & 0 & -2 \\
\hline 单羽苏铁 & Cycas simplicipinna & 0 & 0 & 0 & -1 & -1 \\
\hline 合柱金莲木 & Sinia rhodoleuca & 0 & 0 & 0 & -1 & -1 \\
\hline 单座苣苔 & Metabriggsia ovalifolia & 0 & 0 & 0 & -1 & -1 \\
\hline
\end{tabular}




\begin{tabular}{|c|c|c|c|c|c|c|}
\hline 海南苏铁 & Cycas hainanensis & -1 & 0 & 0 & 0 & -1 \\
\hline 华南苏铁 & Cycas rumphii & 0 & 0 & 0 & -1 & -1 \\
\hline 宽叶苏铁 & Cycas balansae & 0 & 0 & 0 & -1 & -1 \\
\hline 鹿鹿 & Elaphurus davidianus & -1 & 0 & 0 & 0 & -1 \\
\hline 天目铁木 & Ostrya rehderiana & -1 & 0 & 0 & 0 & -1 \\
\hline 萼翅藤 & Calycopteris floribunda & 0 & 0 & 0 & -1 & -1 \\
\hline 高鼻羚羊 & Saiga tatarica & -1 & 0 & 0 & 0 & -1 \\
\hline 蓝鸺 & Lophura swinhoii & 0 & 0 & 0 & -1 & -1 \\
\hline \multirow[t]{2}{*}{ 藤柊 } & Eleutharrhena & & & & & \\
\hline & macrocarpa & 0 & 0 & 0 & -1 & -1 \\
\hline 细嘴松鸡 & Tetrao parvirostris & 0 & 0 & 0 & -1 & -1 \\
\hline 锈毛苏铁 & Cycas ferruginea & 0 & 0 & 0 & -1 & -1 \\
\hline 瑶山苣苔 & Dayaoshania cotinifolia & -1 & 0 & 0 & 0 & -1 \\
\hline 长荵木兰 & Alcimandra cathcardii & 0 & 0 & 0 & -1 & -1 \\
\hline 雉敦 & Tetraophasis obscurus & -1 & 0 & 0 & 0 & -1 \\
\hline 德保苏铁 & Cycas debaoensis & -1 & 0 & 0 & 0 & -1 \\
\hline 东京龙脑香 & Dipterocarpus retusus & 0 & 0 & 0 & -1 & -1 \\
\hline 贵州苏铁 & Cycas guizhouensis & -1 & 0 & 0 & 0 & -1 \\
\hline 鼠奚鹿 & Tragulus javanicus & 0 & 0 & 0 & -1 & -1 \\
\hline 小铇 & Otis tetrax & 0 & 0 & 0 & -1 & -1 \\
\hline 白鹤 & Grus leucogeranus & -1 & 0 & -1 & 1 & -1 \\
\hline 海南山麅鸪 & Arborophila ardens & -1 & 0 & 0 & 0 & -1 \\
\hline 白尾梢虹雉 & Lophophorus sclateri & -1 & 0 & 0 & 0 & -1 \\
\hline 梵净山冷杉 & Abies fanjingshanensis & -1 & 0 & 0 & 0 & -1 \\
\hline \multirow[t]{2}{*}{ 红豆杉 } & Taxus wallichiana var. & & & & & \\
\hline & & -1 & -1 & 0 & 1 & -1 \\
\hline \multirow{2}{*}{ 孔雀雉 } & Polyplectron & & & & & \\
\hline & bicalcaratum & 1 & 0 & -1 & -1 & -1 \\
\hline \multirow[t]{2}{*}{ 南方红豆杉 } & Taxus wallichiana var. & & & & & \\
\hline & mairei & -1 & -1 & 0 & 1 & -1 \\
\hline 紫貂 & Martes zibellina & 1 & -1 & -1 & 0 & -1 \\
\hline 白眉长臂猿 & Bunopithecus hoolock & -1 & -1 & 0 & 1 & -1 \\
\hline
\end{tabular}




\begin{tabular}{|c|c|c|c|c|c|c|}
\hline \multirow[t]{2}{*}{ 华山新麦草 } & \multicolumn{6}{|l|}{ Psathyrostachys } \\
\hline & huashanica & 0 & -1 & -1 & 1 & -1 \\
\hline 熊猴 & Macaca assamensis & 0 & -1 & 0 & 0 & -1 \\
\hline 黑颈长尾雉 & Syrmaticus humiae & 0 & -1 & -1 & 1 & -1 \\
\hline 黄腹角雉 & Tragopan caboti & -1 & 1 & -1 & 0 & -1 \\
\hline 滇金丝猴 & Rhinopithecus bieti & -1 & -1 & 0 & 1 & -1 \\
\hline \multirow[t]{2}{*}{ 水杉 } & Metasequoia & & & & & \\
\hline & glyptostroboides & -1 & 0 & -1 & 1 & -1 \\
\hline 亚洲象 & Elephas maximus & -1 & -1 & 0 & 1 & -1 \\
\hline 秀叶苏铁 & Cycas gracilis & 1 & 0 & 0 & -1 & 0 \\
\hline 扬子鳄 & Alligator sinensis & -1 & 0 & 0 & 1 & 0 \\
\hline 坡鹿 & Cervus eldi & 0 & 0 & 0 & 0 & 0 \\
\hline 元宝山冷杉 & Abies yuanbaoshanensis & -1 & 0 & 1 & 0 & 0 \\
\hline \multirow{2}{*}{ 白头叶猴 } & Trachypithecus & & & & & \\
\hline & poliocephalus & -1 & 0 & 0 & 1 & 0 \\
\hline 报春苣苔 & Primulina tabacum & 0 & 0 & 0 & 0 & 0 \\
\hline 辐花苣苔 & Thamnocharis esquirolii & 0 & 0 & 0 & 0 & 0 \\
\hline 巨柏 & Cupressus gigantea & 0 & 0 & 0 & 0 & 0 \\
\hline 绿春苏铁 & Cycas tanqingii & 1 & 0 & 0 & -1 & 0 \\
\hline 白尾海雕 & Haliaeetus albcilla & 0 & 1 & 0 & -1 & 0 \\
\hline 单性木兰 & Kmeria septentrionalis & 0 & 0 & 0 & 0 & 0 \\
\hline 貂熊 & Gulo gulo & 1 & 0 & 0 & -1 & 0 \\
\hline 短尾信天翁 & Diomedea albatrus & 0 & 0 & 0 & 0 & 0 \\
\hline 河狸 & Castor fiber & 0 & 0 & 0 & 0 & 0 \\
\hline 黑长臂猿 & Nomascus concolor & -1 & 0 & 0 & 1 & 0 \\
\hline 黑长尾雉 & Syrmaticus mikado & 1 & 0 & 0 & -1 & 0 \\
\hline 塔尔羊 & Hemitragus jemlahicus & 0 & 0 & 0 & 0 & 0 \\
\hline \multirow[t]{2}{*}{ 掌叶木 } & Handeliodendron & & & & & \\
\hline & bodinieri & -1 & 0 & 0 & 1 & 0 \\
\hline 红胸角雉 & Tragopan satyra & 1 & 1 & -1 & -1 & 0 \\
\hline 白唇鹿 & Cervus albirostris & 1 & -1 & 1 & -1 & 0 \\
\hline 巨蜥 & Varanus salvator & 1 & 0 & 0 & -1 & 0 \\
\hline
\end{tabular}




\begin{tabular}{|c|c|c|c|c|c|c|}
\hline 普氏原羚 & Procapra przewalskii & -1 & 0 & 0 & 1 & 0 \\
\hline 银杉 & Cathaya argyrophylla & -1 & 0 & 0 & 1 & 0 \\
\hline 银杏 & Ginkgo biloba & -1 & 0 & 0 & 1 & 0 \\
\hline 黔金丝猴 & Rhinopithecus brelichi & -1 & 0 & 1 & 0 & 0 \\
\hline 攀枝花苏铁 & Cycas panzhihuaensis & -1 & 0 & 1 & 0 & 0 \\
\hline 白颈长尾雉 & Syrmaticus ewllioti & -1 & 1 & -1 & 1 & 0 \\
\hline 大鸨 & Otis tarda & -1 & 1 & -1 & 1 & 0 \\
\hline 望天树 & Parashorea chinensis & -1 & -1 & 1 & 1 & 0 \\
\hline \multirow{2}{*}{ 褐马鸡 } & Crossoptilon & & & & & \\
\hline & mantchuricum & -1 & 1 & -1 & 1 & 0 \\
\hline 黑叶猴 & Trachypithecus francoisi & -1 & 1 & -1 & 1 & 0 \\
\hline 朱噮 & Nipponia nippon & -1 & 0 & 1 & 0 & 0 \\
\hline 白鹳 & Ciconia ciconia & 1 & 0 & 0 & 0 & 1 \\
\hline 北山羊 & Capra ibex & 1 & 0 & 0 & 0 & 1 \\
\hline 蟒 & Python molurus & 1 & 0 & 0 & 0 & 1 \\
\hline 中华白海豚 & Sousa chinensis & 0 & 0 & 0 & 1 & 1 \\
\hline 莼菜 & Brasenia schreberi & 1 & 0 & 0 & 0 & 1 \\
\hline 百山祖冷杉 & Abies beshanzuensis & -1 & 0 & 1 & 1 & 1 \\
\hline 雪豹 & Panthera uncia & -1 & 0 & 1 & 1 & 1 \\
\hline 黑颈鹤 & Grus nigricollis & -1 & 1 & 1 & 0 & 1 \\
\hline 川金丝猴 & Rhinopithecus roxellana & -1 & 0 & 1 & 1 & 1 \\
\hline 扭角羚 & Budorcas taxicolor & -1 & 0 & 1 & 1 & 1 \\
\hline 野牦牛 & Bos mutus & -1 & 0 & 1 & 1 & 1 \\
\hline 黑鹳 & Ciconia nigra & 1 & 0 & 0 & 1 & 2 \\
\hline 胡兀熟 & Gypaetus barbatus & 1 & 1 & 1 & -1 & 2 \\
\hline 东北红豆杉 & Taxus cuspidata & 1 & 0 & 0 & 1 & 2 \\
\hline 台湾猴 & Macaca cyclopis & 1 & 0 & 0 & 1 & 2 \\
\hline 台湾鬣羚 & Capricornis crispus & 1 & 0 & 0 & 1 & 2 \\
\hline 伯乐树 & Bretschneidera sinensis & 0 & 1 & 0 & 1 & 2 \\
\hline 独叶草 & Kingdonia uniflora & 1 & 0 & 0 & 1 & 2 \\
\hline 斑尾榛鸡 & Tetrastes sewerzowi & 0 & 0 & 1 & 1 & 2 \\
\hline 梅花鹿 & Cervus nippon & 1 & 0 & 0 & 1 & 2 \\
\hline
\end{tabular}


顾垒，闻丞，罗玫，王昊，吕植. 中国最受关注濒危物种保护现状快速评价的新方法探讨. 生物多样性，2015，23 (5)：583-590. http://www. biodiversity-science. net/CN/article/downloadArticleFile. do?attachType=PDF\&id=10075

\begin{tabular}{|c|c|c|c|c|c|c|}
\hline 藏羚 & Pantholops hodgsonii & -1 & 1 & 1 & 1 & 2 \\
\hline 大熊猫 & Ailuropoda melanoleuca & -1 & 1 & 1 & 1 & 2 \\
\hline 苏铁 & Cycas revoluta & 1 & 0 & 0 & 1 & 2 \\
\hline 金雕 & Aquila chrysaetos & 1 & 1 & 0 & 1 & 3 \\
\hline 珙桐 & Davidia involucrata & 1 & 1 & 0 & 1 & 3 \\
\hline 西藏野驴 & Equus kiang & 1 & 1 & 1 & 1 & 4 \\
\hline
\end{tabular}


顾垒，闻丞，罗玫，王吴，吕植. 中国最受关注濒危物种保护现状快速评价的新方法探讨. 生物多样性，2015，23(5)：583-590. http://www biodiversity-science. net/CN/article/downloadArticleFile. do?attachType=PDF\&id=10075

附录2 746个受胁物种2000-2013年间发表的研究论文

Appendix 2 Research articles on 746 threatened species published during 2000-2013

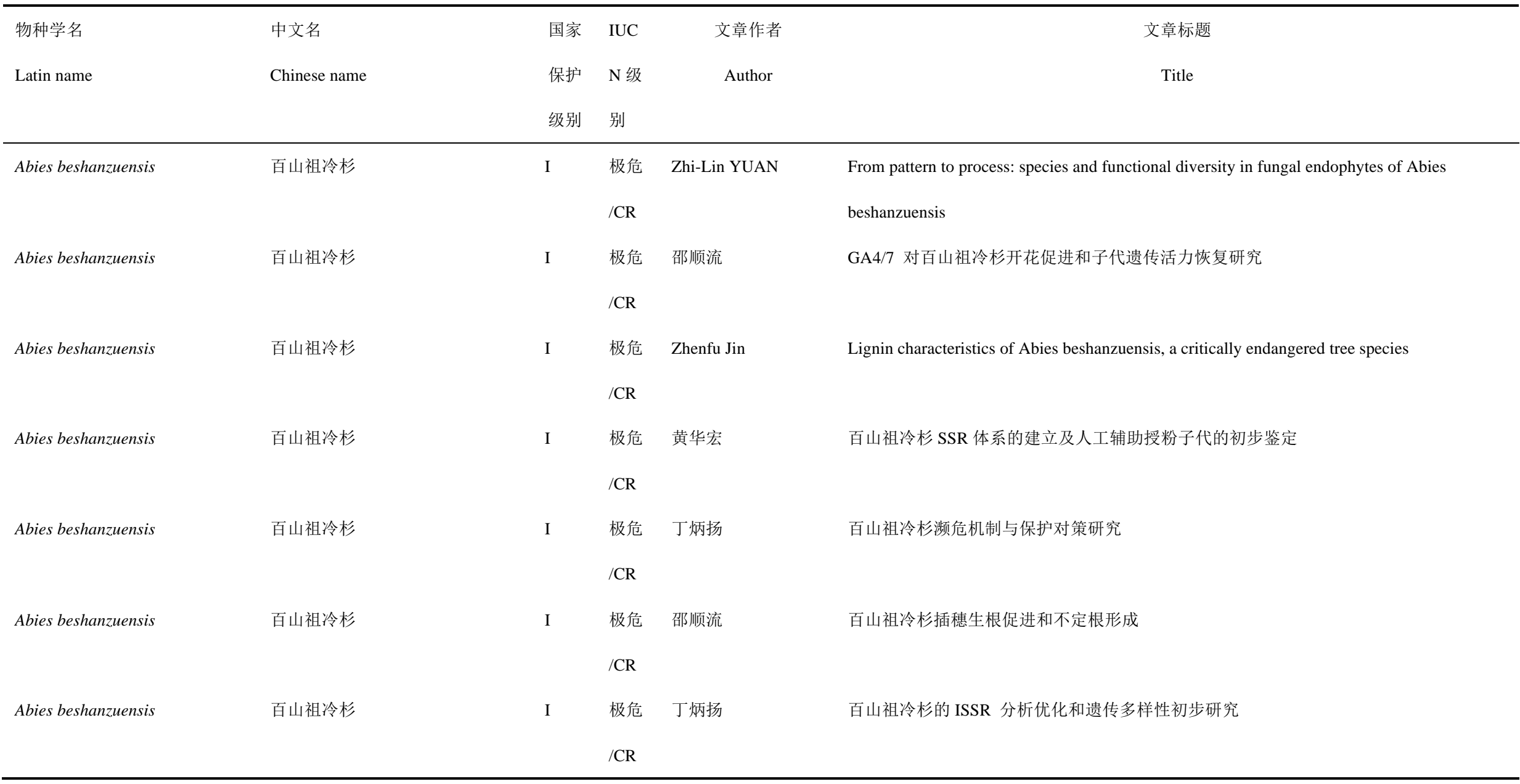


顾垒，闻丞，罗玫，王吴，吕植. 中国最受关注濒危物种保护现状快速评价的新方法探讨. 生物多样性，2015，23(5)：583-590. http://www. biodiversity-science. net/CN/article/downloadArticleFile. do?attachType=PDF\&id=10075

\begin{tabular}{|c|c|c|c|c|c|}
\hline \multirow[t]{2}{*}{ Abies beshanzuensis } & 百山祖冷杉 & I & 极危 & 胡伯智 & 百山祖冷杉森林植物群落的外貌与结构特征研究 \\
\hline & & & /CR & & \\
\hline \multirow[t]{2}{*}{ Abies beshanzuensis } & 百山祖冷杉 & I & 极危 & 吴友贵 & 百山祖冷杉小苗在不同生境下的生长比较研究 \\
\hline & & & /CR & & \\
\hline \multirow[t]{2}{*}{ Abies beshanzuensis } & 百山祖冷杉 & I & 极危 & 邵顺流 & 百山祖冷杉枝叶营养元素含量与适生立地土壤养分关系分析 \\
\hline & & & /CR & & \\
\hline \multirow[t]{2}{*}{ Abies beshanzuensis } & 百山祖冷杉 & I & 极危 & 刘亚群 & 百山祖冷杉枝叶主要营养元素特征分析 \\
\hline & & & /CR & & \\
\hline \multirow[t]{2}{*}{ Abies beshanzuensis } & 百山祖冷杉 & I & 极危 & 陈益泰 & 基于生物芯片标记技术的五种濒危冷杉保护遗传学研究 \\
\hline & & & /CR & & \\
\hline \multirow[t]{2}{*}{ Abies beshanzuensis } & 百山祖冷杉 & I & 极危 & 饶龙兵 & 极度濒危植物百山祖冷杉水培繁殖 \\
\hline & & & /CR & & \\
\hline \multirow[t]{2}{*}{ Abies beshanzuensis } & 百山祖冷杉 & I & 极危 & 崔国发 & 中国 5 种冷杉属植物生态濒危机制研究 \\
\hline & & & /CR & & \\
\hline \multirow[t]{2}{*}{ Abies beshanzuensis } & 百山祖冷杉 & I & 极危 & 崔国发 & 中国亚热带地区 4 种极危冷杉属植物的地理分布特征及其与气候的关系 \\
\hline & & & /CR & & \\
\hline \multirow[t]{2}{*}{ Abies chensiensis } & 秦岭冷杉 & II & 无危 & J-Q Liu & Species delimitation and biogeography of two fir species (Abies) in central China cytoplasmic \\
\hline & & & $/ \mathrm{LC}$ & & DNA variation \\
\hline Abies chensiensis & 秦岭冷杉 & II & 无危 & Zhang Wenhui & Study on reproduction ecology of endangered species Abies chensiensis \\
\hline
\end{tabular}


顾垒，闻丞，罗玫，王吴，吕植. 中国最受关注濒危物种保护现状快速评价的新方法探讨. 生物多样性，2015，23(5)：583-590. http://www. biodiversity-science. net/CN/article/downloadArticleFile. do?attachType=PDF\&id=10075

\begin{tabular}{|c|c|c|c|c|c|}
\hline & & & $/ \mathrm{LC}$ & & \\
\hline Abies chensiensis & 秦岭冷杉 & II & $\begin{array}{l}\text { 无危 } \\
\text { /LC }\end{array}$ & Xian-Wen Yang & Terpenoid Constituents of Abies chensiensis with Potential Anti-inflammatory Activity \\
\hline Abies chensiensis & 秦岭冷杉 & II & $\begin{array}{l}\text { 无危 } \\
\text { /LC }\end{array}$ & 杨亚萍 & 濒危植物秦岭冷杉补光育苗技术研究 \\
\hline Abies chensiensis & 秦岭冷杉 & II & $\begin{array}{l}\text { 无危 } \\
\text { /LC }\end{array}$ & 张文辉 & 濒危植物秦岭冷杉地理分布和生物生态学特性研究 \\
\hline Abies chensiensis & 秦岭冷杉 & II & $\begin{array}{l}\text { 无危 } \\
\text { /LC }\end{array}$ & 谢宗强 & 濒危植物秦岭冷杉结实特性的研究 \\
\hline Abies chensiensis & 秦岭冷杉 & II & $\begin{array}{l}\text { 无危 } \\
\text { /LC }\end{array}$ & 李为民 & 濒危植物秦岭冷杉群落结构及其遗传多样性的研究 \\
\hline Abies chensiensis & 秦岭冷杉 & II & $\begin{array}{l}\text { 无危 } \\
\text { /LC }\end{array}$ & 刘光武 & 濒危植物秦岭冷杉群落数量特征及其动态 \\
\hline Abies chensiensis & 秦岭冷杉 & II & $\begin{array}{l}\text { 无危 } \\
\text { /LC }\end{array}$ & 张文辉 & 濒危植物秦岭冷杉生殖生态学特征 \\
\hline Abies chensiensis & 秦岭冷杉 & II & $\begin{array}{l}\text { 无危 } \\
\text { /LC }\end{array}$ & 许晓波 & 濒危植物秦岭冷杉种群动态研究 \\
\hline Abies chensiensis & 秦岭冷杉 & II & $\begin{array}{l}\text { 无危 } \\
\text { /LC }\end{array}$ & 张文辉 & 濒危植物秦岭冷杉种群空间分布格局及动态 \\
\hline
\end{tabular}


顾垒，闻丞，罗玫，王吴，吕植. 中国最受关注濒危物种保护现状快速评价的新方法探讨. 生物多样性，2015，23(5)：583-590. http://www. biodiversity-science. net/CN/article/downloadArticleFile. do?attachType=PDF\&id=10075

\begin{tabular}{|c|c|c|c|c|c|}
\hline Abies chensiensis & 秦岭冷杉 & II & $\begin{array}{l}\text { 无危 } \\
\text { /LC }\end{array}$ & 张文辉 & 濒危植物秦岭冷杉种群数量动态 \\
\hline Abies chensiensis & 秦岭冷杉 & II & $\begin{array}{l}\text { 无危 } \\
\text { /LC }\end{array}$ & 谢宗强 & 濒危植物秦岭冷杉种子萌发特性的研究 \\
\hline Abies chensiensis & 秦岭冷杉 & II & $\begin{array}{l}\text { 无危 } \\
\text { /LC }\end{array}$ & 郭智慧 & 不同化学处理对秦岭冷杉种子发芽率的影响 \\
\hline Abies chensiensis & 秦岭冷杉 & II & $\begin{array}{l}\text { 无危 } \\
\text { /LC }\end{array}$ & 刘洪滨 & 采用秦岭冷杉年轮宽度重建陕西镇安 1755 年以来的初春温度 \\
\hline Abies chensiensis & 秦岭冷杉 & II & $\begin{array}{l}\text { 无危 } \\
\text { /LC }\end{array}$ & 程利红 & 超低温保存秦巴山区三种濒危植物组织细胞技术研究 \\
\hline Abies chensiensis & 秦岭冷杉 & II & $\begin{array}{l}\text { 无危 } \\
\text { /LC }\end{array}$ & 徐弹娟 & 刍议秦岭冷杉生殖生态学特征 \\
\hline Abies chensiensis & 秦岭冷杉 & II & $\begin{array}{l}\text { 无危 } \\
\text { /LC }\end{array}$ & 张荣 & 河南小秦岭国家级自然保护区秦岭冷杉就地保护研究 \\
\hline Abies chensiensis & 秦岭冷杉 & II & $\begin{array}{l}\text { 无危 } \\
\text { /LC }\end{array}$ & 王海亮 & 河南小秦岭国家级自然保护区秦岭冷杉生长调查与分析 \\
\hline Abies chensiensis & 秦岭冷杉 & II & $\begin{array}{l}\text { 无危 } \\
\text { /LC }\end{array}$ & 李庆梅 & 几种理化处理对秦岭冷杉种子萌发特性的影响 \\
\hline Abies chensiensis & 秦岭冷杉 & II & 无危 & 李思锋 & 利用 SSR 分子标记分析秦岭冷杉自然居群的遗传多样性 \\
\hline
\end{tabular}


顾垒，闻丞，罗玫，王吴，吕植. 中国最受关注濒危物种保护现状快速评价的新方法探讨. 生物多样性，2015，23(5)：583-590. http://www. biodiversity-science. net/CN/article/downloadArticleFile. do?attachType=PDF\&id=10075

\begin{tabular}{|c|c|c|c|c|c|}
\hline & & & $/ \mathrm{LC}$ & & \\
\hline \multirow[t]{2}{*}{ Abies chensiensis } & 秦岭冷杉 & II & 无危 & 刘洪滨 & 利用树轮重建秦岭地区历史时期初春温度变化 \\
\hline & & & $/ \mathrm{LC}$ & & \\
\hline \multirow[t]{2}{*}{ Abies chensiensis } & 秦岭冷杉 & II & 无危 & 吴建国 & 气候变化对 7 种乔木植物分布的潜在影响 \\
\hline & & & $/ \mathrm{LC}$ & & \\
\hline \multirow[t]{2}{*}{ Abies chensiensis } & 秦岭冷杉 & II & 无危 & 李庆梅 & 秦巴山地两种冷杉种实特性研究与秦岭冷杉濒危原因探讨 \\
\hline & & & $/ \mathrm{LC}$ & & \\
\hline \multirow[t]{2}{*}{ Abies chensiensis } & 秦岭冷杉 & II & 无危 & 席欣民 & 秦岭冷杉大田育苗及造林技术初探 \\
\hline & & & $/ \mathrm{LC}$ & & \\
\hline \multirow[t]{2}{*}{ Abies chensiensis } & 秦岭冷杉 & II & 无危 & 张启伟 & 秦岭冷杉和巴山冷杉的种群遗传结构及谱系地理学的比较研究 \\
\hline & & & $/ \mathrm{LC}$ & & \\
\hline \multirow[t]{2}{*}{ Abies chensiensis } & 秦岭冷杉 & II & 无危 & 王婧 & 秦岭冷杉和巴山冷杉物种分化和谱系地理学研究 \\
\hline & & & $/ \mathrm{LC}$ & & \\
\hline \multirow[t]{2}{*}{ Abies chensiensis } & 秦岭冷杉 & II & 无危 & 张文辉 & 秦岭冷杉和巴山冷杉种群年龄结构及动态的比较分析 \\
\hline & & & $/ \mathrm{LC}$ & & \\
\hline \multirow[t]{2}{*}{ Abies chensiensis } & 秦岭冷杉 & II & 无危 & 李永利 & 秦岭冷杉化学成分及其生物活性研究 \\
\hline & & & $/ \mathrm{LC}$ & & \\
\hline \multirow[t]{2}{*}{ Abies chensiensis } & 秦岭冷杉 & II & 无危 & 杨开宝 & 秦岭冷杉嫩枝扞插育苗技术研究 \\
\hline & & & $/ \mathrm{LC}$ & & \\
\hline
\end{tabular}


顾垒，闻丞，罗玫，王吴，吕植. 中国最受关注濒危物种保护现状快速评价的新方法探讨. 生物多样性，2015，23(5)：583-590. http://www. biodiversity-science. net/CN/article/downloadArticleFile. do?attachType=PDF\&id=10075

\begin{tabular}{|c|c|c|c|c|c|}
\hline Abies chensiensis & 秦岭冷杉 & II & $\begin{array}{l}\text { 无危 } \\
\text { /LC }\end{array}$ & 赵卫卫 & 秦岭冷杉培育基地示范项目建设工作初探 \\
\hline Abies chensiensis & 秦岭冷杉 & II & $\begin{array}{l}\text { 无危 } \\
\text { /LC }\end{array}$ & 谢宗强 & 秦岭冷杉球果与种子的形态变异 \\
\hline Abies chensiensis & 秦岭冷杉 & II & $\begin{array}{l}\text { 无危 } \\
\text { /LC }\end{array}$ & 张文辉 & 秦岭冷杉群落主要种群生态位研究 \\
\hline Abies chensiensis & 秦岭冷杉 & II & $\begin{array}{l}\text { 无危 } \\
\text { /LC }\end{array}$ & 李庆梅 & 秦岭冷杉幼苗适应性的研究 \\
\hline Abies chensiensis & 秦岭冷杉 & II & $\begin{array}{l}\text { 无危 } \\
\text { /LC }\end{array}$ & 史小华 & 秦岭冷杉与巴山冷杉种群动态比较研究 \\
\hline Abies chensiensis & 秦岭冷杉 & II & $\begin{array}{l}\text { 无危 } \\
\text { /LC }\end{array}$ & 孙会忠 & 秦岭冷杉种群生殖生态学研究 \\
\hline Abies chensiensis & 秦岭冷杉 & II & $\begin{array}{l}\text { 无危 } \\
\text { /LC }\end{array}$ & 李思锋 & 秦岭山地濒危植物秦岭冷杉群落结构特征研究 \\
\hline Abies chensiensis & 秦岭冷杉 & II & $\begin{array}{l}\text { 无危 } \\
\text { /LC }\end{array}$ & 刘洪滨 & 秦岭镇安和佛坪地区树轮宽度年表的建立 \\
\hline Abies chensiensis & 秦岭冷杉 & II & $\begin{array}{l}\text { 无危 } \\
\text { /LC }\end{array}$ & 孙玉玲 & 秦岭镇安和佛坪地区树轮宽度年表的建立 \\
\hline Abies chensiensis & 秦岭冷杉 & II & 无危 & 王罗荣 & 神农架秦岭冷杉种质资源保存与开发利用对策研究 \\
\hline
\end{tabular}


顾垒，闻丞，罗玫，王吴，吕植. 中国最受关注濒危物种保护现状快速评价的新方法探讨. 生物多样性，2015，23(5)：583-590. http://www. biodiversity-science. net/CN/article/downloadArticleFile. do?attachType=PDF\&id=10075

\begin{tabular}{|c|c|c|c|c|c|}
\hline & & & $/ \mathrm{LC}$ & & \\
\hline \multirow[t]{2}{*}{ Abies chensiensis } & 秦岭冷杉 & II & 无危 & 詹志伟 & 石人山秦岭冷杉死亡原因与救治对策 \\
\hline & & & $/ \mathrm{LC}$ & & \\
\hline \multirow[t]{2}{*}{ Abies chensiensis } & 秦岭冷杉 & II & 无危 & 茹广欣 & 石人山自然保护区秦岭冷杉群落物种多样性和稳定性研究 \\
\hline & & & $/ \mathrm{LC}$ & & \\
\hline \multirow[t]{2}{*}{ Abies chensiensis } & 秦岭冷杉 & II & 无危 & 郭小龙 & 小陇山林区秦岭冷杉生命表分析 \\
\hline & & & $/ \mathrm{LC}$ & & \\
\hline \multirow[t]{2}{*}{ Abies chensiensis } & 秦岭冷杉 & II & 无危 & 刘禹 & 以树轮宽度重建九寨沟 1750 年以来+冬半年平均最低温度 \\
\hline & & & $/ \mathrm{LC}$ & & \\
\hline \multirow[t]{2}{*}{ Abies chensiensis } & 秦岭冷杉 & II & 无危 & 邢树堂 & 银杉、秦岭冷杉人工菌根诱导系的建立 \\
\hline & & & $/ \mathrm{LC}$ & & \\
\hline \multirow[t]{2}{*}{ Abies chensiensis } & 秦岭冷杉 & II & 无危 & 孙雪 & 银杉再生体系、拟菌根诱导系及秦岭冷杉菌根诱导系的建 \\
\hline & & & $/ \mathrm{LC}$ & & \\
\hline \multirow[t]{2}{*}{ Abies chensiensis } & 秦岭冷杉 & II & 无危 & 李晓笑 & 中国 5 种冷杉属植物生态濒危机制研究 \\
\hline & & & $/ \mathrm{LC}$ & & \\
\hline \multirow[t]{2}{*}{ Abies fanjingshanensis } & 梵净山冷杉 & I & 濒危 & 王清春 & 濒危植物梵净山冷杉野生种群结构及动态特征 \\
\hline & & & /EN & & \\
\hline \multirow[t]{2}{*}{ Abies fanjingshanensis } & 梵净山冷杉 & I & 濒危 & 唐绍清 & 梵净山冷杉的保护遗传学研究 \\
\hline & & & /EN & & \\
\hline
\end{tabular}


顾垒，闻丞，罗玫，王吴，吕植. 中国最受关注濒危物种保护现状快速评价的新方法探讨. 生物多样性，2015，23(5)：583-590. http://www biodiversity-science. net/CN/article/downloadArticleFile. do?attachType=PDF\&id=10075

\begin{tabular}{|c|c|c|c|c|c|}
\hline Abies fanjingshanensis & 梵净山冷杉 & I & $\begin{array}{l}\text { 濒危 } \\
\text { /EN }\end{array}$ & 黄威廉 & 梵净山冷杉林的发现及其科学意义 \\
\hline Abies fanjingshanensis & 梵净山冷杉 & I & $\begin{array}{l}\text { 濒危 } \\
\text { /EN }\end{array}$ & 陈益泰 & 基于生物芯片标记技术的五种濒危冷杉保护遗传学研究 \\
\hline Abies fanjingshanensis & 梵净山冷杉 & I & $\begin{array}{l}\text { 濒危 } \\
\text { /EN }\end{array}$ & 吉成均 & 我国南部 5 种冷杉植物木材的比较解剖学研究 \\
\hline Abies fanjingshanensis & 梵净山冷杉 & I & $\begin{array}{l}\text { 濒危 } \\
\text { /EN }\end{array}$ & 崔国发 & 中国 5 种冷杉属植物生态濒危机制研究 \\
\hline Abies fanjingshanensis & 梵净山冷杉 & I & $\begin{array}{l}\text { 濒危 } \\
\text { /EN }\end{array}$ & 崔国发 & 中国亚热带地区 4 种极危冷杉属植物的地理分布特征及其与气候的关系 \\
\hline Abies georgei var. smithii & 急尖长苞冷杉 & $\begin{array}{l}\text { 未列 } \\
\text { 入 }\end{array}$ & $\begin{array}{l}\text { 未评 } \\
\text { 价 } \\
\text { /NE }\end{array}$ & Eryuan Liang & $\begin{array}{l}\text { Growth variation inAbies georgeivar.smithiialong altitudinal gradients in the Sygera } \\
\text { Mountains, southeastern Tibetan Plateau }\end{array}$ \\
\hline Abies georgei var. smithii & 急尖长苞冷杉 & $\begin{array}{l}\text { 未列 } \\
\lambda\end{array}$ & $\begin{array}{l}\text { 未评 } \\
\text { 价 } \\
\text { /NE }\end{array}$ & 卢杰 & 濒危植物急尖长苞冷杉种群结构及空间分布格局 \\
\hline Abies georgei var. smithii & 急尖长苞冷杉 & $\begin{array}{l}\text { 未列 } \\
\text { 入 }\end{array}$ & $\begin{array}{l}\text { 未评 } \\
\text { 价 } \\
\text { /NE }\end{array}$ & 卢杰 & 濒危植物急尖长苞冷杉种群生命表分析 \\
\hline
\end{tabular}


顾垒，闻丞，罗玫，王吴，吕植. 中国最受关注濒危物种保护现状快速评价的新方法探讨. 生物多样性，2015，23(5)：583-590. http://www. biodiversity-science. net/CN/article/downloadArticleFile. do?attachType=PDF\&id=10075

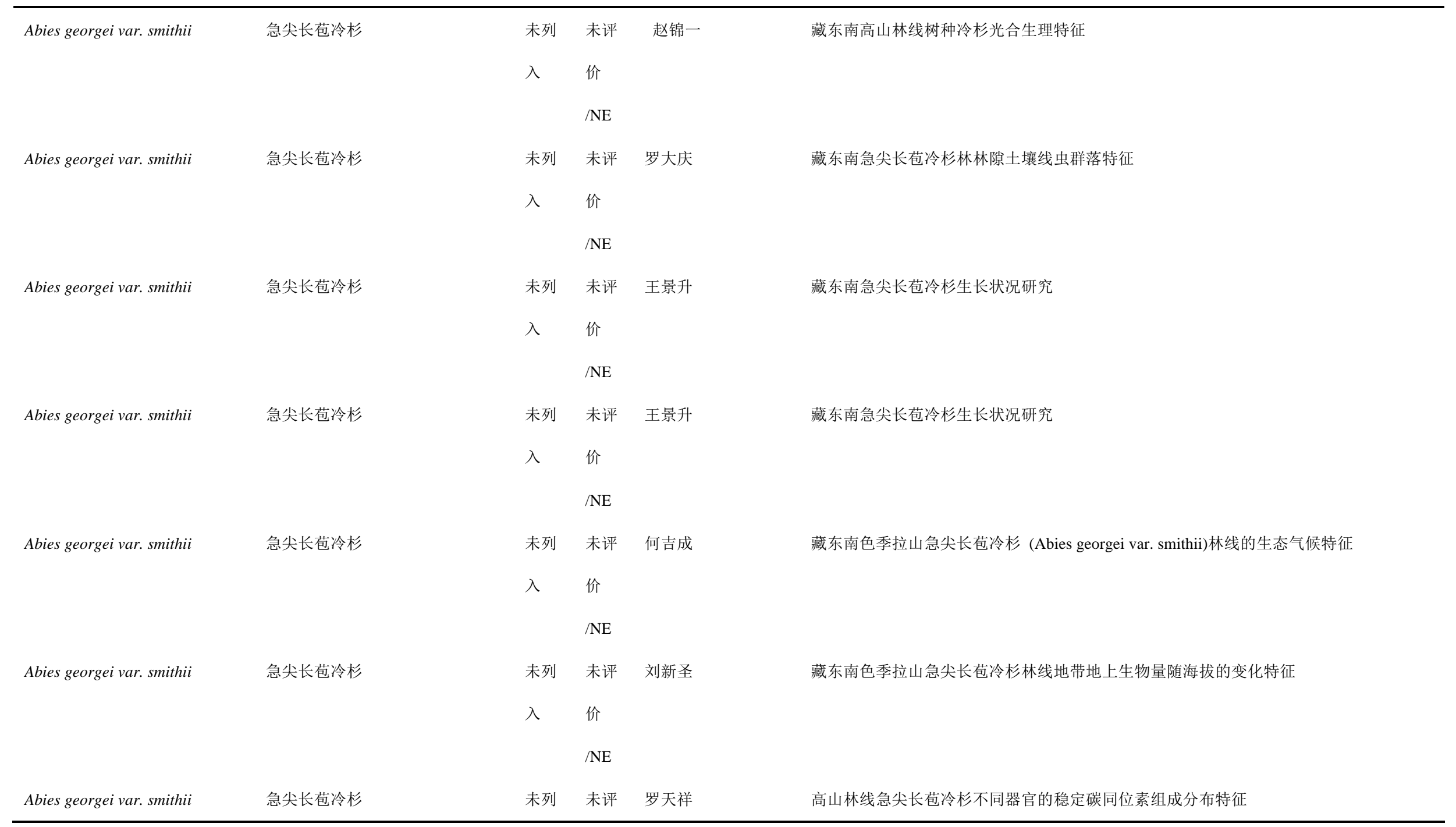


顾垒，闻丞，罗玫，王吴，吕植. 中国最受关注濒危物种保护现状快速评价的新方法探讨. 生物多样性，2015，23(5)：583-590. http://www. biodiversity-science. net/CN/article/downloadArticleFile. do?attachType=PDF\&id=10075

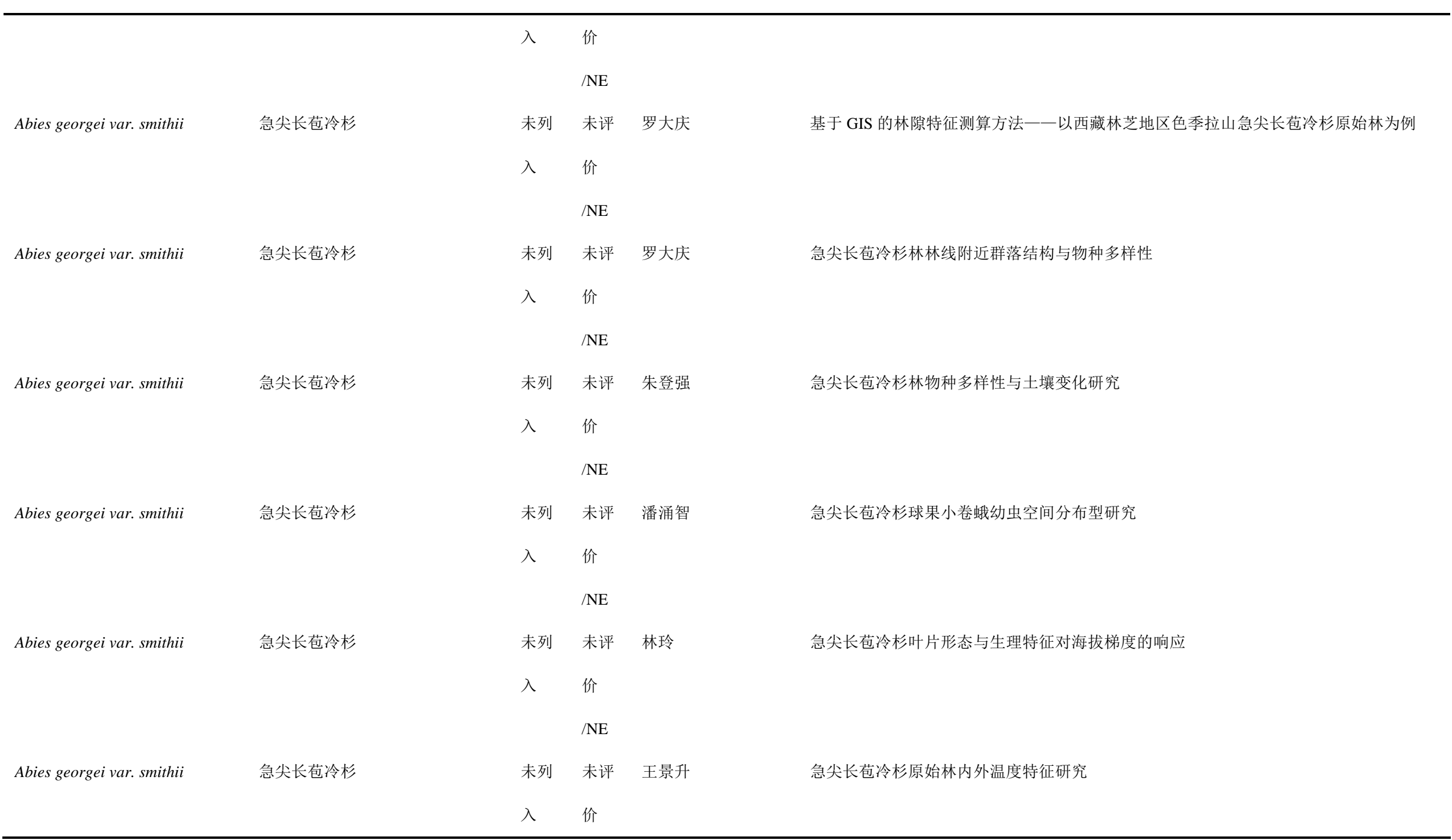


顾垒，闻丞，罗玫，王吴，吕植. 中国最受关注濒危物种保护现状快速评价的新方法探讨. 生物多样性，2015，23(5)：583-590. http://www. biodiversity-science. net/CN/article/downloadArticleFile. do?attachType=PDF\&id=10075

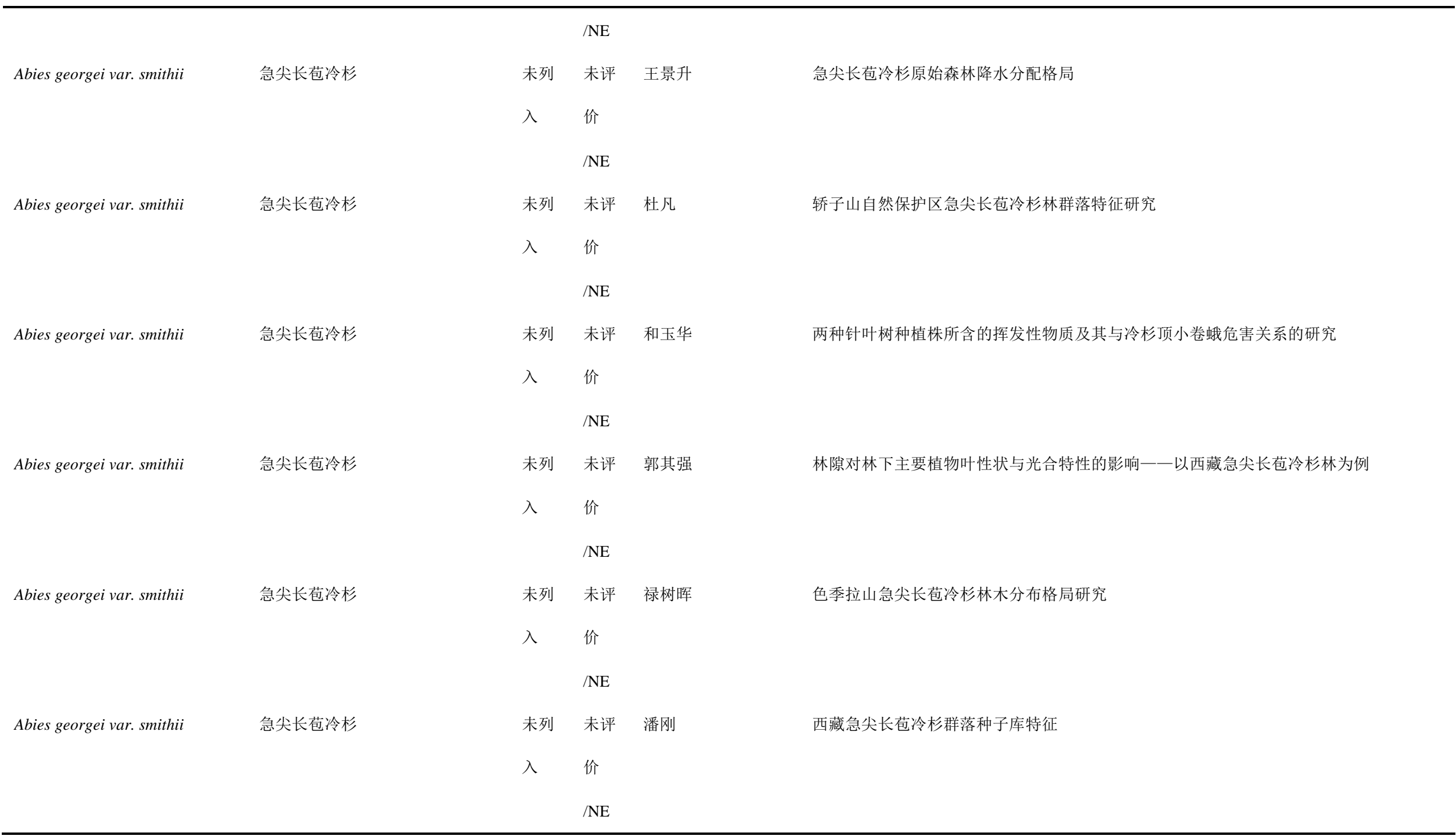


顾垒，闻丞，罗玫，王吴，吕植. 中国最受关注濒危物种保护现状快速评价的新方法探讨. 生物多样性，2015，23(5)：583-590. http://www. biodiversity-science. net/CN/article/downloadArticleFile. do?attachType=PDF\&id=10075

\begin{tabular}{|c|c|c|c|c|c|}
\hline Abies georgei var. smithii & 急尖长苍冷杉 & $\begin{array}{l}\text { 未列 } \\
\text { 入 }\end{array}$ & $\begin{array}{l}\text { 未评 } \\
\text { 价 } \\
\text { /NE }\end{array}$ & 赵长明 & 西藏急尖长苞冷杉与川滇高山栋叶片 $\delta 13 \mathrm{C}$ 和 LMA 沿海拔梯度变化趋势 \\
\hline Abies georgei var. smithii & 急尖长苍冷杉 & $\begin{array}{l}\text { 未列 } \\
入\end{array}$ & $\begin{array}{l}\text { 未评 } \\
\text { 价 } \\
\text { /NE }\end{array}$ & 赵长明 & 西藏急尖长苞冷杉与川滇高山栎叶片 $\delta 13 \mathrm{C}$ 沿海拔梯度的变化 \\
\hline Abies georgei var. smithii & 急尖长苞冷杉 & $\begin{array}{l}\text { 未列 } \\
入\end{array}$ & $\begin{array}{l}\text { 未评 } \\
\text { 价 } \\
\text { /NE }\end{array}$ & 任青山 & 西藏冷杉原始森林土壤物理性质特征分析 \\
\hline Abies georgei var. smithii & 急尖长苍冷杉 & $\begin{array}{l}\text { 未列 } \\
\lambda\end{array}$ & $\begin{array}{l}\text { 未评 } \\
\text { 价 } \\
\text { /NE }\end{array}$ & 罗大庆 & 西藏色季拉山东坡急尖长苍冷杉林的结实特性 \\
\hline Abies georgei var. smithii & 急尖长苞冷杉 & $\begin{array}{l}\text { 未列 } \\
\text { 入 }\end{array}$ & $\begin{array}{l}\text { 未评 } \\
\text { 价 } \\
\text { /NE }\end{array}$ & 张守攻 & 西藏色季拉山东西坡急尖长苞冷杉林群落物种多样性与土壤因子的关系 \\
\hline Abies georgei var. smithii & 急尖长苍冷杉 & $\begin{array}{l}\text { 未列 } \\
入\end{array}$ & $\begin{array}{l}\text { 未评 } \\
\text { 价 } \\
\text { /NE }\end{array}$ & 茹广欣 & 西藏色季拉山急尖长苍冷杉林地的物种多样性与土壤养分特征 \\
\hline Abies georgei var. smithii & 急尖长苍冷杉 & 未列 & 未评 & 潘刚 & 西藏色季拉山急尖长苍冷杉林枯枝落叶及苔蘚层的生物量与持水性能 \\
\hline
\end{tabular}


顾垒，闻丞，罗玫，王吴，吕植. 中国最受关注濒危物种保护现状快速评价的新方法探讨. 生物多样性，2015，23(5)：583-590. http://www. biodiversity-science. net/CN/article/downloadArticleFile. do?attachType=PDF\&id=10075

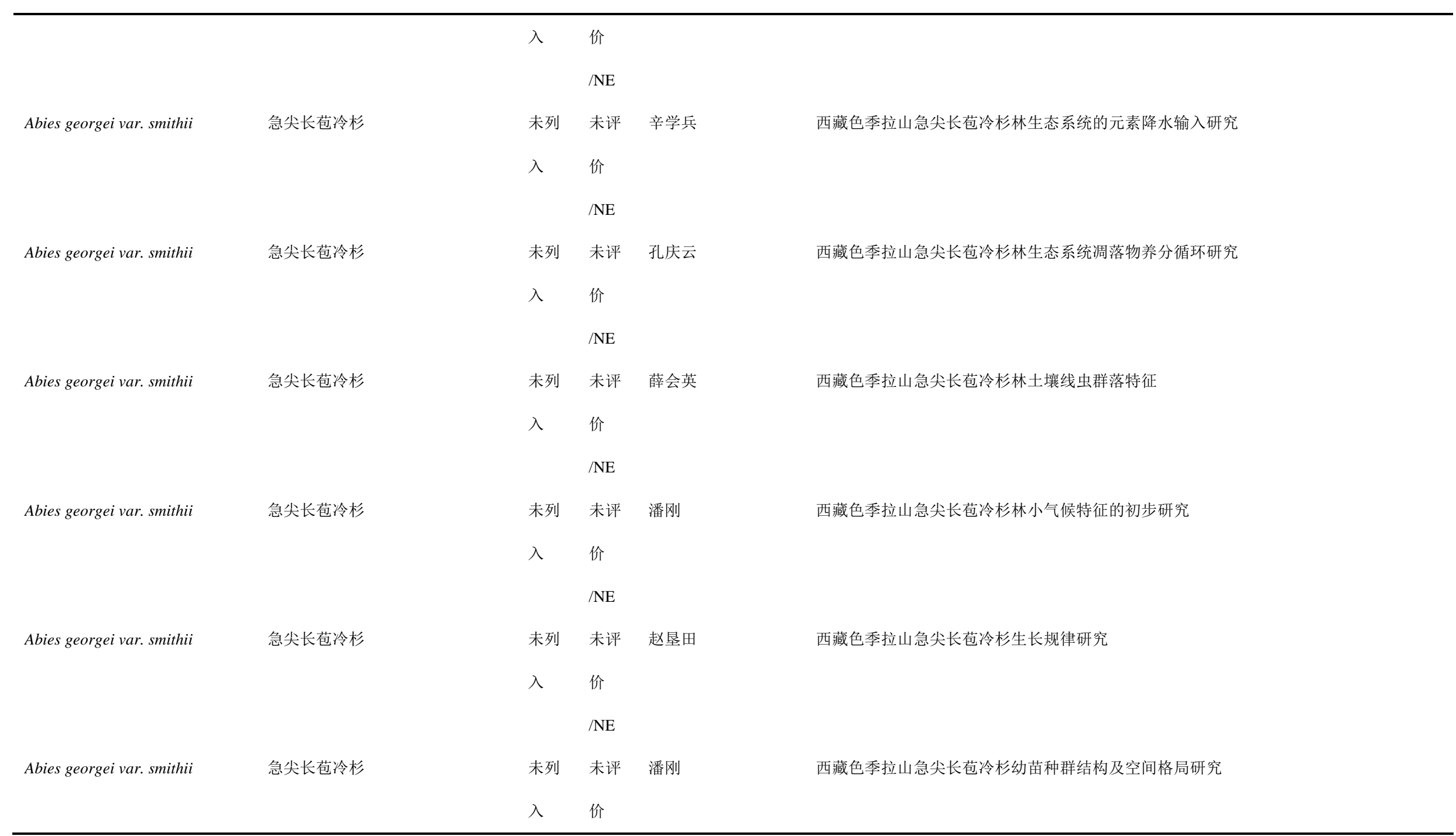


顾垒，闻丞，罗玫，王吴，吕植. 中国最受关注濒危物种保护现状快速评价的新方法探讨. 生物多样性，2015，23(5)：583-590. http://www. biodiversity-science. net/CN/article/downloadArticleFile. do?attachType=PDF\&id=10075

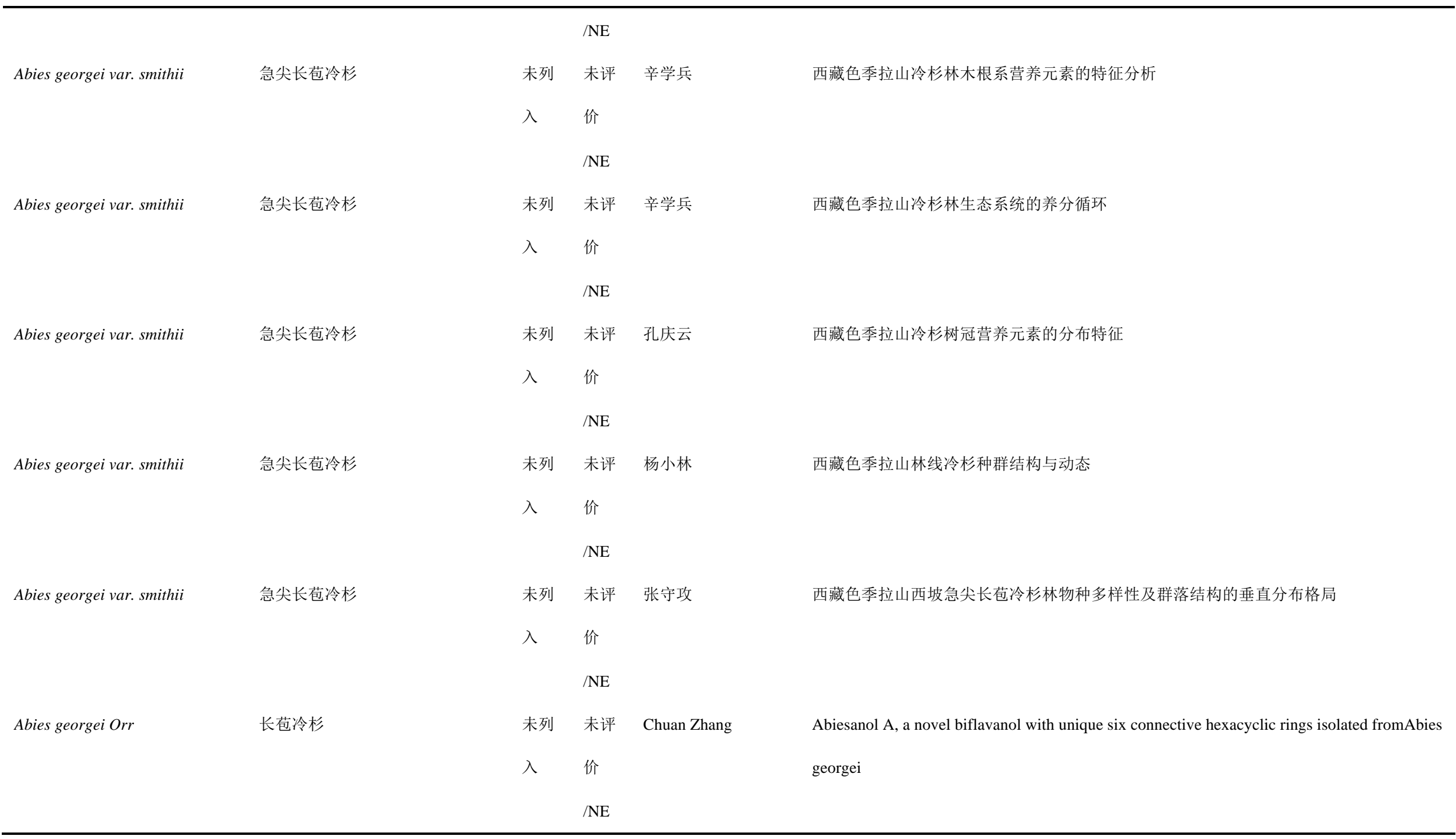


顾垒，闻丞，罗玫，王吴，吕植. 中国最受关注濒危物种保护现状快速评价的新方法探讨. 生物多样性，2015，23(5)：583-590. http://www. biodiversity-science. net/CN/article/downloadArticleFile. do?attachType=PDF\&id=10075

\begin{tabular}{|c|c|c|c|c|c|}
\hline \multirow[t]{2}{*}{ Abies georgei Orr } & 长苞冷杉 & 未列 & 未评 & Wei-Dong Zhang & Anti-inflammatory and anti-tumour effects of Abies georgeiextracts \\
\hline & & 入 & $\begin{array}{l}\text { 价 } \\
\text { /NE }\end{array}$ & & \\
\hline \multirow[t]{3}{*}{ Abies georgei Orr } & 长苍冷杉 & 未列 & 未评 & Wu Ning & Ecological characteristics of Abies georgeipopulation at timberline on the north-facing slope of \\
\hline & & 入 & 价 & & Baima Snow Mountain, Southwest China \\
\hline & & & $/ \mathrm{NE}$ & & \\
\hline \multirow[t]{3}{*}{ Abies georgei Orr } & 长苍冷杉 & 未列 & 未评 & Wei-Dong Zhang & Isolation, structure, and bioactivities of abiesadines A - Y, 25 new diterpenes from Abies \\
\hline & & 入 & 价 & & georgeiOrr \\
\hline & & & $/ \mathrm{NE}$ & & \\
\hline \multirow[t]{3}{*}{ Abies georgei Orr } & 长苞冷杉 & 未列 & 未评 & 吴宁 & 白马雪山阴坡林线长苍冷杉(Abies georgei)种群结构特征 \\
\hline & & 入 & 价 & & \\
\hline & & & $/ \mathrm{NE}$ & & \\
\hline \multirow[t]{3}{*}{ Abies georgei Orr } & 长苞冷杉 & 未列 & 未评 & 刘庆 & 滇西北白马雪山西坡长苍冷杉林群落特征的研究 \\
\hline & & 入 & 价 & & \\
\hline & & & $/ \mathrm{NE}$ & & \\
\hline \multirow[t]{3}{*}{ Abies georgei Orr } & 长苞冷杉 & 未列 & 未评 & 刘庆 & 林窗对长苞冷杉自然更新幼苗存活和生长的影响 \\
\hline & & 入 & 价 & & \\
\hline & & & $/ \mathrm{NE}$ & & \\
\hline Abies georgei Orr & 长苞冷杉 & 未列 & 未评 & 刘庆 & 林窗对长苞冷杉自然更新幼苗存活和生长的影响 \\
\hline
\end{tabular}


顾垒，闻丞，罗玫，王吴，吕植. 中国最受关注濒危物种保护现状快速评价的新方法探讨. 生物多样性，2015，23(5)：583-590. http://www. biodiversity-science. net/CN/article/downloadArticleFile. do?attachType=PDF\&id=10075

\begin{tabular}{|c|c|c|c|c|c|}
\hline & & 入 & 价 & & \\
\hline & & & $/ \mathrm{NE}$ & & \\
\hline \multirow[t]{2}{*}{ Abies squamata } & 鳞皮冷杉 & 未列 & 易危 & 罗辑 & 贡嘎山暗针叶林不同林型的优势木生长动态 \\
\hline & & 入 & /VU & & \\
\hline \multirow[t]{2}{*}{ Abies squamata } & 鳞皮冷杉 & 未列 & 易危 & 张华丽 & 六种冷杉补光育苗技术研究 \\
\hline & & 入 & $/ \mathrm{VU}$ & & \\
\hline \multirow[t]{2}{*}{ Abies squamata } & 鳞皮冷杉 & 未列 & 易危 & 吴普 & 五个中国特有针叶树种树轮宽度对气候变化的敏感性 \\
\hline & & 入 & $/ \mathrm{VU}$ & & \\
\hline \multirow[t]{2}{*}{ Abies yuanbaoshanensis } & 元宝山冷杉 & I & 极危 & 唐绍清 & 濒危植物元宝山冷杉的保护遗传学研究 \\
\hline & & & $/ \mathrm{CR}$ & & \\
\hline \multirow[t]{2}{*}{ Abies yuanbaoshanensis } & 元宝山冷杉 & I & 极危 & 唐绍清 & 濒危植物元宝山冷杉的遗传多样性研究 \\
\hline & & & $/ \mathrm{CR}$ & & \\
\hline \multirow[t]{2}{*}{ Abies yuanbaoshanensis } & 元宝山冷杉 & I & 极危 & 李先琨 & 濒危植物元宝山冷杉结实特性与种子繁殖力初探 \\
\hline & & & $/ \mathrm{CR}$ & & \\
\hline \multirow[t]{2}{*}{ Abies yuanbaoshanensis } & 元宝山冷杉 & I & 极危 & 李先琨 & 濒危植物元宝山冷杉种群结构与分布格局 \\
\hline & & & $/ \mathrm{CR}$ & & \\
\hline \multirow[t]{2}{*}{ Abies yuanbaoshanensis } & 元宝山冷杉 & I & 极危 & 李先琨 & 濒危植物元宝山冷杉种群生命表分析 \\
\hline & & & $/ \mathrm{CR}$ & & \\
\hline Abies yuanbaoshanensis & 元宝山冷杉 & I & 极危 & 陈益泰 & 基于生物芯片标记技术的五种濒危冷杉保护遗传学研究 \\
\hline
\end{tabular}


顾垒，闻丞，罗玫，王吴，吕植. 中国最受关注濒危物种保护现状快速评价的新方法探讨. 生物多样性，2015，23(5)：583-590. http://www. biodiversity-science. net/CN/article/downloadArticleFile. do?attachType=PDF\&id=10075

\begin{tabular}{|c|c|c|c|c|c|}
\hline & & & /CR & & \\
\hline \multirow[t]{2}{*}{ Abies yuanbaoshanensis } & 元宝山冷杉 & I & 极危 & 吉成均 & 我国南部 5 种冷杉植物木材的比较解剖学研究 \\
\hline & & & /CR & & \\
\hline \multirow[t]{2}{*}{ Abies yuanbaoshanensis } & 元宝山冷杉 & I & 极危 & 吴颖瑞 & 元宝山冷杉化学成分的研究 \\
\hline & & & /CR & & \\
\hline \multirow[t]{2}{*}{ Abies yuanbaoshanensis } & 元宝山冷杉 & I & 极危 & 李先琨 & 元宝山冷杉群落学特点的研究 \\
\hline & & & /CR & & \\
\hline \multirow[t]{2}{*}{ Abies yuanbaoshanensis } & 元宝山冷杉 & I & 极危 & 李先琨 & 元宝山冷杉群落种内与种间竞争的数量关系 \\
\hline & & & /CR & & \\
\hline \multirow[t]{2}{*}{ Abies yuanbaoshanensis } & 元宝山冷杉 & I & 极危 & 李先琨 & 元宝山冷杉群落主要树木种群间联结关系的研究 \\
\hline & & & /CR & & \\
\hline \multirow[t]{2}{*}{ Abies yuanbaoshanensis } & 元宝山冷杉 & I & 极危 & 李先琨 & 元宝山冷杉群落主要树木种群生态位的初步研究 \\
\hline & & & /CR & & \\
\hline \multirow[t]{2}{*}{ Abies yuanbaoshanensis } & 元宝山冷杉 & I & 极危 & 李先琨 & 元宝山冷杉种群濒危原因与保护对策 \\
\hline & & & /CR & & \\
\hline \multirow[t]{2}{*}{ Abies yuanbaoshanensis } & 元宝山冷杉 & I & 极危 & 唐绍清 & 元宝山冷杉种群的遗传多样性研究 \\
\hline & & & /CR & & \\
\hline \multirow[t]{2}{*}{ Abies yuanbaoshanensis } & 元宝山冷杉 & I & 极危 & 梁凌林 & 元宝山冷杉资源现状及保护初探 \\
\hline & & & /CR & & \\
\hline
\end{tabular}


顾垒，闻丞，罗玫，王吴，吕植. 中国最受关注濒危物种保护现状快速评价的新方法探讨. 生物多样性，2015，23(5)：583-590. http://www. biodiversity-science. net/CN/article/downloadArticleFile. do?attachType=PDF\&id=10075

\begin{tabular}{|c|c|c|c|c|c|}
\hline \multirow[t]{2}{*}{ Abies yuanbaoshanensis } & 元宝山冷杉 & I & 极危 & 崔国发 & 中国 5 种冷杉属植物生态濒危机制研究 \\
\hline & & & /CR & & \\
\hline \multirow[t]{2}{*}{ Abies yuanbaoshanensis } & 元宝山冷杉 & I & 极危 & 崔国发 & 中国亚热带地区 4 种极危冷杉属植物的地理分布特征及其与气候的关系 \\
\hline & & & /CR & & \\
\hline \multirow[t]{2}{*}{ Abies ziyuanensis } & 资源冷杉 & I & 濒危 & Shaoqing Tang & Genetic diversity of relictual and endangered plant Abies ziyuanensis (Pinaceae) revealed by \\
\hline & & & /EN & & AFLP and SSR markers \\
\hline \multirow[t]{2}{*}{ Abies ziyuanensis } & 资源冷杉 & I & 濒危 & 张玉荣 & 濒危植物资源冷杉的种群保育研究 \\
\hline & & & /EN & & \\
\hline \multirow[t]{2}{*}{ Abies ziyuanensis } & 资源冷杉 & I & 濒危 & 唐绍清 & 濒危植物资源冷杉遗传多样性研究 \\
\hline & & & /EN & & \\
\hline \multirow[t]{2}{*}{ Abies ziyuanensis } & 资源冷杉 & I & 濒危 & 唐绍清 & 大院资源冷杉种群的空间分布格局分析 \\
\hline & & & /EN & & \\
\hline \multirow[t]{2}{*}{ Abies ziyuanensis } & 资源冷杉 & I & 濒危 & 宁世江 & 广西银竹老山资源冷杉种群退化机制初探 \\
\hline & & & /EN & & \\
\hline \multirow[t]{2}{*}{ Abies ziyuanensis } & 资源冷杉 & I & 濒危 & 唐绍清 & 湖南炎陵县大院濒危植物资源冷杉种群结构研究 \\
\hline & & & /EN & & \\
\hline \multirow[t]{2}{*}{ Abies ziyuanensis } & 资源冷杉 & I & 濒危 & 唐绍清 & 基于 nrDNA GapC 基因内含子序列的资源冷杉遗传多样性研究 \\
\hline & & & /EN & & \\
\hline Abies ziyuanensis & 资源冷杉 & I & 濒危 & 陈益泰 & 基于生物芯片标记技术的五种濒危冷杉保护遗传学研究 \\
\hline
\end{tabular}


顾垒，闻丞，罗玫，王吴，吕植. 中国最受关注濒危物种保护现状快速评价的新方法探讨. 生物多样性，2015，23(5)：583-590. http://www. biodiversity-science. net/CN/article/downloadArticleFile. do?attachType=PDF\&id=10075

\begin{tabular}{|c|c|c|c|c|c|}
\hline & & & /EN & & \\
\hline \multirow[t]{2}{*}{ Abies ziyuanensis } & 资源冷杉 & I & 濒危 & 廖文波 & 江西南风面濒危植物资源冷杉生存状况及所在群落特征 \\
\hline & & & /EN & & \\
\hline \multirow[t]{2}{*}{ Abies ziyuanensis } & 资源冷杉 & I & 濒危 & 曹受金 & 利用树木年轮研究湖南炎陵气温变化情况—- 1840 年以来 $5 \sim 7$ 月份气温变化情况重建 \\
\hline & & & /EN & & \\
\hline \multirow[t]{2}{*}{ Abies ziyuanensis } & 资源冷杉 & I & 濒危 & 吉成均 & 我国南部 5 种冷杉植物木材的比较解剖学研究 \\
\hline & & & /EN & & \\
\hline \multirow[t]{2}{*}{ Abies ziyuanensis } & 资源冷杉 & I & 濒危 & 唐绍清 & 叶绿体微卫星分析濒危植物资源冷杉的遗传多样性 \\
\hline & & & /EN & & \\
\hline \multirow[t]{2}{*}{ Abies ziyuanensis } & 资源冷杉 & I & 濒危 & 崔国发 & 中国 5 种冷杉属植物生态濒危机制研究 \\
\hline & & & /EN & & \\
\hline \multirow[t]{2}{*}{ Abies ziyuanensis } & 资源冷杉 & I & 濒危 & 崔国发 & 中国亚热带地区 4 种极危冷杉属植物的地理分布特征及其与气候的关系 \\
\hline & & & /EN & & \\
\hline \multirow[t]{2}{*}{ Abies ziyuanensis } & 资源冷杉 & I & 濒危 & 唐绍清 & 资源冷杉大院种群的小尺度空间遗传结构分析 \\
\hline & & & /EN & & \\
\hline \multirow[t]{2}{*}{ Abies ziyuanensis } & 资源冷杉 & I & 濒危 & 唐绍清 & 资源冷杉大院种群遗传结构研究 \\
\hline & & & /EN & & \\
\hline \multirow[t]{2}{*}{ Abies ziyuanensis } & 资源冷杉 & I & 濒危 & 唐绍清 & 资源冷杉的保护遗传学研究 \\
\hline & & & /EN & & \\
\hline
\end{tabular}


顾垒，闻丞，罗玫，王吴，吕植. 中国最受关注濒危物种保护现状快速评价的新方法探讨. 生物多样性，2015，23(5)：583-590. http://www. biodiversity-science. net/CN/article/downloadArticleFile. do?attachType=PDF\&id=10075

\begin{tabular}{|c|c|c|c|c|c|}
\hline Abies ziyuanensis & 资源冷杉 & I & 濒危 & 张玉荣 & 资源冷杉的濒危机制与种群保育研究 \\
\hline & & & /EN & & \\
\hline \multirow[t]{2}{*}{ Abies ziyuanensis } & 资源冷杉 & I & 濒危 & 宁世江 & 资源冷杉现状及保护措施研究 \\
\hline & & & /EN & & \\
\hline \multirow[t]{2}{*}{ Abies ziyuanensis } & 资源冷杉 & I & 濒危 & 张玉荣 & 资源冷杉遗传多样性的 ISSR 分析 \\
\hline & & & /EN & & \\
\hline \multirow[t]{3}{*}{ Acer catalpifolium } & 梓叶棫 & II & 未评 & 余道平 & 梓叶械种子生物学特性研究 \\
\hline & & & 价 & & \\
\hline & & & $/ \mathrm{NE}$ & & \\
\hline \multirow[t]{2}{*}{ Acipenser sinensis } & 中华鲟 & I & 濒危 & 陈锦辉 & "狂游症"中华鲟幼鱼血液生化指标初步研究 \\
\hline & & & /EN & & \\
\hline \multirow[t]{2}{*}{ Acipenser sinensis } & 中华鲟 & I & 濒危 & 甘芳 & $\mathrm{Na}+、 \mathrm{~K}+、 \mathrm{Mg} 2+、 \mathrm{Ca} 2+$ 和葡萄糖溶液作为授精-激活介质对中华鲟精子受精率的影响 \\
\hline & & & /EN & & \\
\hline \multirow[t]{2}{*}{ Acipenser sinensis } & 中华鲟 & I & 濒危 & 杜浩 & 苯酚、Cu2+、亚硝酸盐和总氨氮对中华鲟稚鱼的急性毒性 \\
\hline & & & /EN & & \\
\hline \multirow[t]{2}{*}{ Acipenser sinensis } & 中华鲟 & I & 濒危 & 王远坤 & 变流量条件下中华鲟产卵场涡强特征研究 \\
\hline & & & /EN & & \\
\hline \multirow[t]{2}{*}{ Acipenser sinensis } & 中华鲟 & I & 濒危 & 邵昭君 & 铲鲟微卫星引物对中华鲟的适用性研究 \\
\hline & & & /EN & & \\
\hline
\end{tabular}


顾垒，闻丞，罗玫，王吴，吕植. 中国最受关注濒危物种保护现状快速评价的新方法探讨. 生物多样性，2015，23(5)：583-590. http://www. biodiversity-science. net/CN/article/downloadArticleFile. do?attachType=PDF\&id=10075

\begin{tabular}{|c|c|c|c|c|c|}
\hline Acipenser sinensis & 中华鲟 & I & $\begin{array}{l}\text { 濒危 } \\
\text { /EN }\end{array}$ & 彭秀华 & 大坝运行对中华鲟自然繁殖影响及修复措施研究 \\
\hline Acipenser sinensis & 中华鲟 & I & $\begin{array}{l}\text { 濒危 } \\
\text { /EN }\end{array}$ & 班璇 & 大型水利工程对中华鲟生态水文学特征的影响 \\
\hline Acipenser sinensis & 中华鲟 & I & $\begin{array}{l}\text { 濒危 } \\
\text { /EN }\end{array}$ & 林永兵 & 非繁殖季节中华鲟繁殖群体在长江中分布与降海洄游初步研究 \\
\hline Acipenser sinensis & 中华鲟 & I & $\begin{array}{l}\text { 濒危 } \\
\text { /EN }\end{array}$ & 常剑波 & 葛洲坝产卵场中华鲟繁殖群体数量与繁殖规模估算及其变动趋势分析 \\
\hline Acipenser sinensis & 中华鲟 & I & $\begin{array}{l}\text { 濒危 } \\
\text { /EN }\end{array}$ & 黄明海 & 葛洲坝电厂调度对中华鲟产卵场水流条件的影响 \\
\hline Acipenser sinensis & 中华鲟 & I & $\begin{array}{l}\text { 濒危 } \\
\text { /EN }\end{array}$ & 危起伟 & 葛洲坝截流 24 年来中华鲟产卵群体结构的变化 \\
\hline Acipenser sinensis & 中华鲟 & I & $\begin{array}{l}\text { 濒危 } \\
\text { /EN }\end{array}$ & 虞功亮 & 葛洲坝下游江段中华鲟产卵场食卵鱼类资源量估算 \\
\hline Acipenser sinensis & 中华鲟 & I & $\begin{array}{l}\text { 濒危 } \\
\text { /EN }\end{array}$ & 夏自强 & 葛洲坝下游江心堤对中华鲟产卵场河道动能梯度影响 \\
\hline Acipenser sinensis & 中华鲟 & I & $\begin{array}{l}\text { 濒危 } \\
\text { /EN }\end{array}$ & 张辉 & 葛洲坝下游中华鲟(Acipenser sinensis)产卵场地形分析 \\
\hline Acipenser sinensis & 中华鲟 & I & 濒危 & 班璇 & 葛洲坝下游中华鲟产卵场的多参数生态水文学模型 \\
\hline
\end{tabular}


顾垒，闻丞，罗玫，王吴，吕植. 中国最受关注濒危物种保护现状快速评价的新方法探讨. 生物多样性，2015，23(5)：583-590. http://www. biodiversity-science. net/CN/article/downloadArticleFile. do?attachType=PDF\&id=10075

\begin{tabular}{|c|c|c|c|c|c|}
\hline & & & /EN & & \\
\hline \multirow[t]{2}{*}{ Acipenser sinensis } & 中华鲟 & I & 濒危 & 危起伟 & 葛洲坝下游中华鲟产卵场的水文学模型 \\
\hline & & & $/$ EN & & \\
\hline \multirow[t]{2}{*}{ Acipenser sinensis } & 中华鲟 & I & 濒危 & 杨德国 & 葛洲坝下游中华鲟产卵场的水文状况及其与繁殖活动的关系 \\
\hline & & & /EN & & \\
\hline \multirow[t]{2}{*}{ Acipenser sinensis } & 中华鲟 & I & 濒危 & 付小莉 & 葛洲坝下游中华鲟产卵场流场计算和分析 \\
\hline & & & /EN & & \\
\hline \multirow[t]{2}{*}{ Acipenser sinensis } & 中华鲟 & I & 濒危 & 王远坤 & 葛洲坝下游中华鲟产卵场流场模拟与分析 \\
\hline & & & /EN & & \\
\hline \multirow[t]{2}{*}{ Acipenser sinensis } & 中华鲟 & I & 濒危 & 吴凤燕 & 葛洲坝下游中华鲟产卵场三维流场的数值模拟 \\
\hline & & & /EN & & \\
\hline \multirow[t]{2}{*}{ Acipenser sinensis } & 中华鲟 & I & 濒危 & 付小莉 & 葛洲坝下游中华鲟产卵河段的流场计算与分析 \\
\hline & & & /EN & & \\
\hline \multirow[t]{2}{*}{ Acipenser sinensis } & 中华鲟 & I & 濒危 & 班璇 & 葛洲坝下游中华鲟产卵栖息地适宜度标准研究 \\
\hline & & & /EN & & \\
\hline \multirow[t]{2}{*}{ Acipenser sinensis } & 中华鲟 & I & 濒危 & 杜浩 & 葛洲坝下中华鲟产卵场初次水下视频观察 \\
\hline & & & /EN & & \\
\hline \multirow[t]{2}{*}{ Acipenser sinensis } & 中华鲟 & I & 濒危 & 杨宇 & 葛洲坝下中华鲟产卵场卵苗输移过程的数值模拟 \\
\hline & & & /EN & & \\
\hline
\end{tabular}


顾垒，闻丞，罗玫，王吴，吕植. 中国最受关注濒危物种保护现状快速评价的新方法探讨. 生物多样性，2015，23(5)：583-590. http://www. biodiversity-science. net/CN/article/downloadArticleFile. do?attachType=PDF\&id=10075

\begin{tabular}{|c|c|c|c|c|c|}
\hline Acipenser sinensis & 中华鲟 & I & $\begin{array}{l}\text { 濒危 } \\
\text { /EN }\end{array}$ & 危起伟 & 葛洲坝下中华鲟繁殖生物学特性及其人工繁殖效果 \\
\hline Acipenser sinensis & 中华鲟 & I & $\begin{array}{l}\text { 濒危 } \\
\text { /EN }\end{array}$ & 陈细华 & 葛洲坝下中华鲟自然产卵胚胎正常发育的证据 \\
\hline Acipenser sinensis & 中华鲟 & I & $\begin{array}{l}\text { 濒危 } \\
\text { /EN }\end{array}$ & 危起伟 & 葛洲坝下中华鲟自然繁殖流速场的初步观测 \\
\hline Acipenser sinensis & 中华鲟 & I & $\begin{array}{l}\text { 濒危 } \\
\text { /EN }\end{array}$ & 刘松岩 & 环境胁迫对中华鲟体内自由基水平和抗氧化酶活力的影响 \\
\hline Acipenser sinensis & 中华鲟 & I & $\begin{array}{l}\text { 濒危 } \\
\text { /EN }\end{array}$ & 蔡玉鹏 & 基于栖息地模拟法的中华鲟自然繁殖适合生态流量分析 \\
\hline Acipenser sinensis & 中华鲟 & I & $\begin{array}{l}\text { 濒危 } \\
\text { /EN }\end{array}$ & 赵娜 & 基于微卫星标记的中华鲟繁殖群体遗传学分析与人工繁殖对自然幼鲟群体的贡献评估 \\
\hline Acipenser sinensis & 中华鲟 & I & $\begin{array}{l}\text { 濒危 } \\
\text { /EN }\end{array}$ & 刘鉴毅 & 几种不同浓度的离子及单糖对中华鲟精子活力的影响 \\
\hline Acipenser sinensis & 中华鲟 & I & $\begin{array}{l}\text { 濒危 } \\
\text { /EN }\end{array}$ & 柴毅 & 金属离子和葡萄糖对中华鲟子一代精子活力的影响 \\
\hline Acipenser sinensis & 中华鲟 & I & $\begin{array}{l}\text { 濒危 } \\
\text { /EN }\end{array}$ & 刘涛 & 埋植雌二醇对雌性中华鲟幼鱼血清生理指标及卵巢发育的影响 \\
\hline Acipenser sinensis & 中华鲟 & I & 濒危 & 王兆印 & 栖息地适合度模型在中华鲟产卵场适合度中的应用 \\
\hline
\end{tabular}


顾垒，闻丞，罗玫，王吴，吕植. 中国最受关注濒危物种保护现状快速评价的新方法探讨. 生物多样性，2015，23(5)：583-590. http://www. biodiversity-science. net/CN/article/downloadArticleFile. do?attachType=PDF\&id=10075

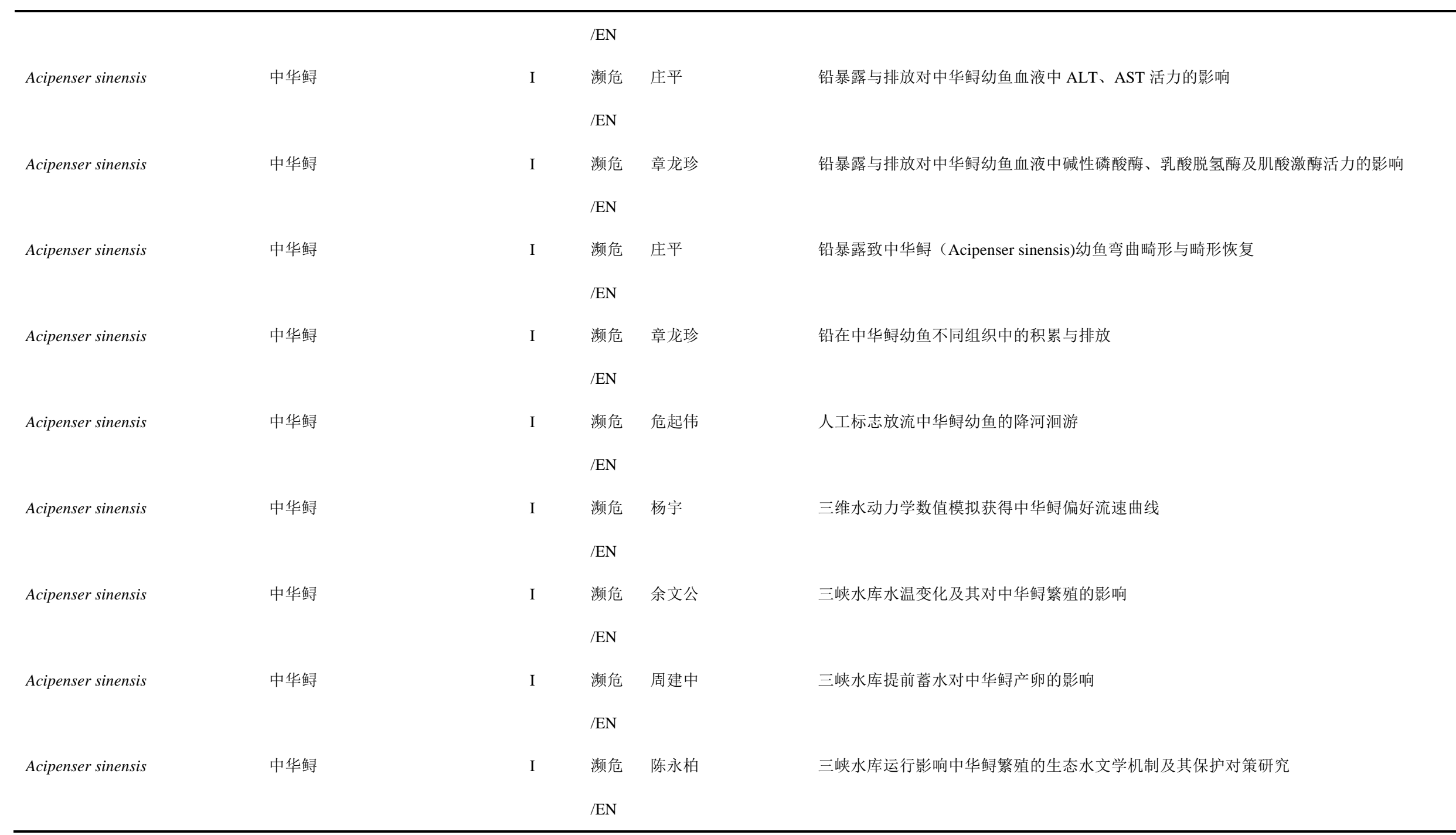


顾垒，闻丞，罗玫，王吴，吕植. 中国最受关注濒危物种保护现状快速评价的新方法探讨. 生物多样性，2015，23(5)：583-590. http://www. biodiversity-science. net/CN/article/downloadArticleFile. do?attachType=PDF\&id=10075

\begin{tabular}{|c|c|c|c|c|c|}
\hline Acipenser sinensis & 中华鲟 & I & $\begin{array}{l}\text { 濒危 } \\
\text { /EN }\end{array}$ & 王显 & 三峡蓄水运行后中华鲟产卵场水动力特性分析 \\
\hline Acipenser sinensis & 中华鲟 & I & $\begin{array}{l}\text { 濒危 } \\
\text { /EN }\end{array}$ & 付容 & 上海长江口中华鲟自然保护区立法研究 \\
\hline Acipenser sinensis & 中华鲟 & I & $\begin{array}{l}\text { 濒危 } \\
\text { /EN }\end{array}$ & 姜翠玲 & 水环境变化对中华鲟的影响 \\
\hline Acipenser sinensis & 中华鲟 & I & $\begin{array}{l}\text { 濒危 } \\
\text { /EN }\end{array}$ & 章龙珍 & 水体中铜对中华鲟幼鱼血液生化指标的影响 \\
\hline Acipenser sinensis & 中华鲟 & I & $\begin{array}{l}\text { 濒危 } \\
\text { /EN }\end{array}$ & 谢从新 & 水温对中华鲟血清活性氧含量及抗氧化防御系统的影响 \\
\hline Acipenser sinensis & 中华鲟 & I & $\begin{array}{l}\text { 濒危 } \\
\text { /EN }\end{array}$ & 章龙珍 & 铜暴露对中华鲟幼鱼的生长_消化酶活性和组织中铜积累的影响 \\
\hline Acipenser sinensis & 中华鲟 & I & $\begin{array}{l}\text { 濒危 } \\
\text { /EN }\end{array}$ & 章龙珍 & 铜对中华鲟幼鱼的急性毒性及对肝脏抗氧化酶活性的影响 \\
\hline Acipenser sinensis & 中华鲟 & I & $\begin{array}{l}\text { 濒危 } \\
\text { /EN }\end{array}$ & 刘鉴毅 & 温度对中华鲟精子、卵子短期保存的影响 \\
\hline Acipenser sinensis & 中华鲟 & I & $\begin{array}{l}\text { 濒危 } \\
\text { /EN }\end{array}$ & 庄平 & 温度对中华鲟幼鱼代谢酶和抗氧化酶活性的影响 \\
\hline Acipenser sinensis & 中华鲟 & I & 濒危 & 庄平 & 温度对中华鲟幼鱼血液生化指标的影响 \\
\hline
\end{tabular}


顾垒，闻丞，罗玫，王吴，吕植. 中国最受关注濒危物种保护现状快速评价的新方法探讨. 生物多样性，2015，23(5)：583-590. http://www. biodiversity-science. net/CN/article/downloadArticleFile. do?attachType=PDF\&id=10075

\begin{tabular}{|c|c|c|c|c|c|}
\hline & & & /EN & & \\
\hline \multirow[t]{2}{*}{ Acipenser sinensis } & 中华鲟 & I & 濒危 & 庄平 & 野生中华鲟成鱼与幼鱼肌肉成分比较 \\
\hline & & & $/$ EN & & \\
\hline \multirow[t]{2}{*}{ Acipenser sinensis } & 中华鲟 & I & 濒危 & 王显 & 优化中华鲟产卵生境的水库生态调度研究 \\
\hline & & & /EN & & \\
\hline \multirow[t]{2}{*}{ Acipenser sinensis } & 中华鲟 & I & 濒危 & 丁骏 & 长江口中华鲟栖息地景观格局变化及其适宜性评价 \\
\hline & & & /EN & & \\
\hline \multirow[t]{2}{*}{ Acipenser sinensis } & 中华鲟 & I & 濒危 & 杨红 & 长江口中华鲟幼鲟栖息地适宜性评价 \\
\hline & & & /EN & & \\
\hline \multirow[t]{2}{*}{ Acipenser sinensis } & 中华鲟 & I & 濒危 & 毛翠凤 & 长江口中华鲟幼鱼的生长特性 \\
\hline & & & /EN & & \\
\hline \multirow[t]{2}{*}{ Acipenser sinensis } & 中华鲟 & I & 濒危 & 庄平 & 长江口中华鲟幼鱼的食物组成及摄食习性 \\
\hline & & & /EN & & \\
\hline \multirow[t]{2}{*}{ Acipenser sinensis } & 中华鲟 & I & 濒危 & 庄平 & 长江口中华鲟幼鱼对底质的选择 \\
\hline & & & /EN & & \\
\hline \multirow[t]{2}{*}{ Acipenser sinensis } & 中华鲟 & I & 濒危 & 庄平 & 长江口中华鲟幼鱼感觉器官在摄食行为中的作用 \\
\hline & & & /EN & & \\
\hline \multirow[t]{2}{*}{ Acipenser sinensis } & 中华鲟 & I & 濒危 & 赵峰 & 长江口中华鲟幼鱼血液水分、渗透压及离子浓度的变化规律 \\
\hline & & & /EN & & \\
\hline
\end{tabular}


顾垒，闻丞，罗玫，王吴，吕植. 中国最受关注濒危物种保护现状快速评价的新方法探讨. 生物多样性，2015，23(5)：583-590. http://www. biodiversity-science. net/CN/article/downloadArticleFile. do?attachType=PDF\&id=10075

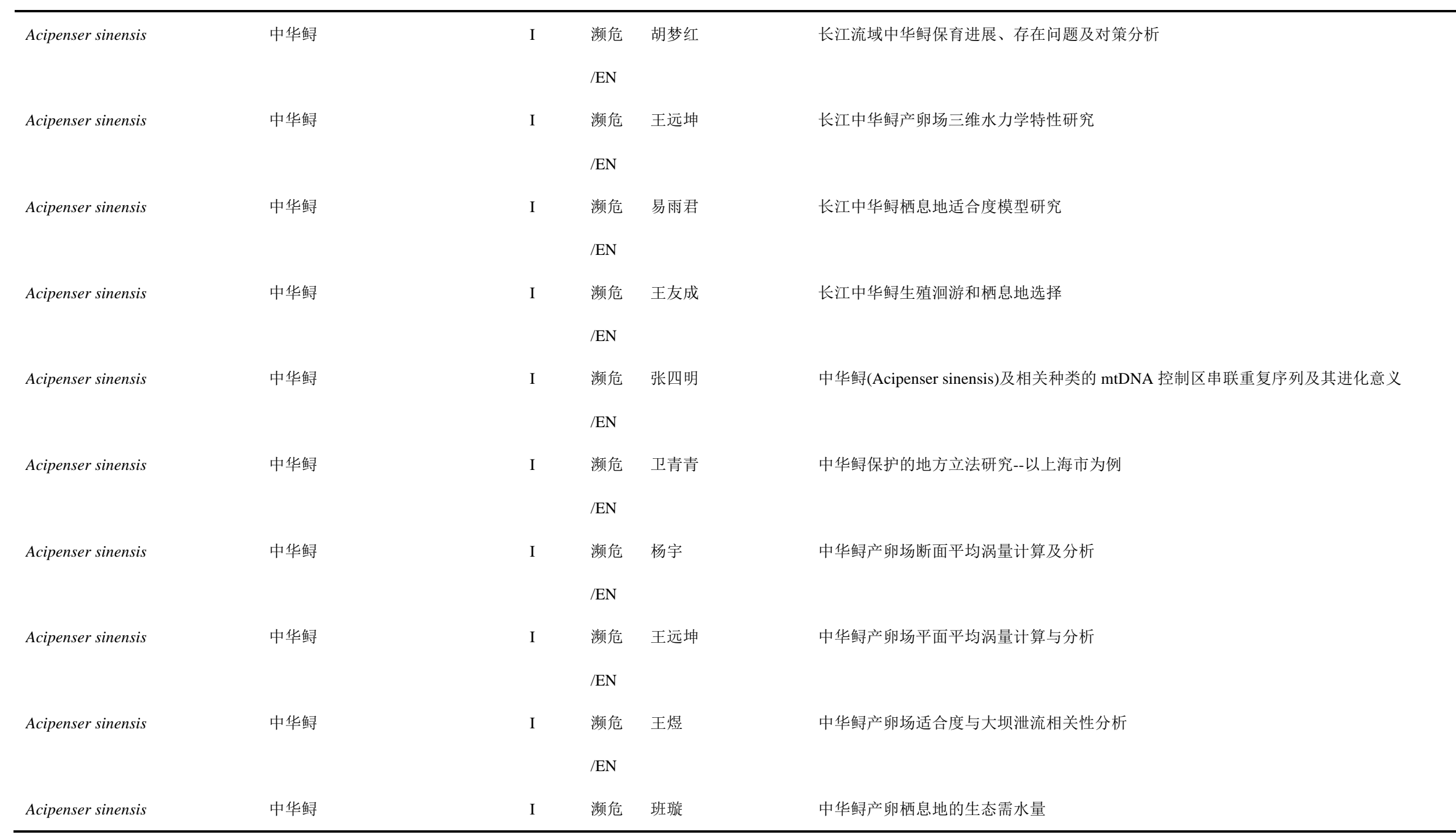


顾垒，闻丞，罗玫，王吴，吕植. 中国最受关注濒危物种保护现状快速评价的新方法探讨. 生物多样性，2015，23(5)：583-590. http://www. biodiversity-science. net/CN/article/downloadArticleFile. do?attachType=PDF\&id=10075

\begin{tabular}{|c|c|c|c|c|c|}
\hline & & & /EN & & \\
\hline \multirow[t]{2}{*}{ Acipenser sinensis } & 中华鲟 & I & 濒危 & 班璇 & 中华鲟产卵栖息地的生态需水量 \\
\hline & & & $/$ EN & & \\
\hline \multirow[t]{2}{*}{ Acipenser sinensis } & 中华鲟 & I & 濒危 & 谢健 & 中华鲟产卵栖息地与流量关系的数值模拟研究 \\
\hline & & & /EN & & \\
\hline \multirow[t]{2}{*}{ Acipenser sinensis } & 中华鲟 & I & 濒危 & 蔡玉鹏 & 中华鲟产卵区水流特征分析及二维数值模拟 \\
\hline & & & /EN & & \\
\hline \multirow[t]{2}{*}{ Acipenser sinensis } & 中华鲟 & I & 濒危 & 谢从新 & 中华鲟成体消化系统的形态学和组织学研究 \\
\hline & & & /EN & & \\
\hline \multirow[t]{2}{*}{ Acipenser sinensis } & 中华鲟 & I & 濒危 & 王彩理 & 中华鲟的繁育特性及开发利用 \\
\hline & & & /EN & & \\
\hline \multirow[t]{2}{*}{ Acipenser sinensis } & 中华鲟 & I & 濒危 & 周兴华 & 中华鲟的研究进展 \\
\hline & & & /EN & & \\
\hline \multirow[t]{2}{*}{ Acipenser sinensis } & 中华鲟 & I & 濒危 & 李锦光 & 中华鲟电感觉及化学感觉行为研究及其器官结构电镜观察 \\
\hline & & & /EN & & \\
\hline \multirow[t]{2}{*}{ Acipenser sinensis } & 中华鲟 & I & 濒危 & 杨严鸥 & 中华鲟繁殖力的主成分分析研究 \\
\hline & & & /EN & & \\
\hline \multirow[t]{2}{*}{ Acipenser sinensis } & 中华鲟 & I & 濒危 & 柴毅 & 中华鲟感觉器官的早期发育及其行为机能研究 \\
\hline & & & /EN & & \\
\hline
\end{tabular}


顾垒，闻丞，罗玫，王吴，吕植. 中国最受关注濒危物种保护现状快速评价的新方法探讨. 生物多样性，2015，23(5)：583-590. http://www. biodiversity-science. net/CN/article/downloadArticleFile. do?attachType=PDF\&id=10075

\begin{tabular}{|c|c|c|c|c|c|}
\hline Acipenser sinensis & 中华鲟 & I & $\begin{array}{l}\text { 濒危 } \\
\text { /EN }\end{array}$ & 杨宇 & 中华鲟葛洲坝栖息地水力特性研究 \\
\hline Acipenser sinensis & 中华鲟 & I & $\begin{array}{l}\text { 濒危 } \\
\text { /EN }\end{array}$ & 何绪刚 & 中华鲟海水适应过程中生理变化及盐度选择行为研究 \\
\hline Acipenser sinensis & 中华鲟 & I & $\begin{array}{l}\text { 濒危 } \\
\text { /EN }\end{array}$ & 常剑波 & 中华鲟回声信号判别分析及其在葛洲坝产卵场的空间分布 \\
\hline Acipenser sinensis & 中华鲟 & I & $\begin{array}{l}\text { 濒危 } \\
\text { /EN }\end{array}$ & 叶欢 & 中华鲟几个生殖细胞相关基因的克隆和表达特征研究 \\
\hline Acipenser sinensis & 中华鲟 & I & $\begin{array}{l}\text { 濒危 } \\
\text { /EN }\end{array}$ & 危起伟 & 中华鲟精卵特征及精子入卵早期过程观察 \\
\hline Acipenser sinensis & 中华鲟 & I & $\begin{array}{l}\text { 濒危 } \\
\text { /EN }\end{array}$ & 厉萍 & 中华鲟精子结构特征及其精液超低温冷冻保存技术研究 \\
\hline Acipenser sinensis & 中华鲟 & I & $\begin{array}{l}\text { 濒危 } \\
\text { /EN }\end{array}$ & 郑跃平 & 中华鲟精子生理生态特性研究 \\
\hline Acipenser sinensis & 中华鲟 & I & $\begin{array}{l}\text { 濒危 } \\
\text { /EN }\end{array}$ & 潘连德 & 中华鲟烂鰓并发胃充气病的组织病理观察 \\
\hline Acipenser sinensis & 中华鲟 & I & $\begin{array}{l}\text { 濒危 } \\
\text { /EN }\end{array}$ & 余来宁 & 中华鲟囊胚细胞的长期保存及其克隆胚胎发育观察 \\
\hline Acipenser sinensis & 中华鲟 & I & 濒危 & 柴毅 & 中华鲟脑的形态学观察 \\
\hline
\end{tabular}


顾垒，闻丞，罗玫，王吴，吕植. 中国最受关注濒危物种保护现状快速评价的新方法探讨. 生物多样性，2015，23(5)：583-590. http://www. biodiversity-science. net/CN/article/downloadArticleFile. do?attachType=PDF\&id=10075

\begin{tabular}{|c|c|c|c|c|c|}
\hline & & & /EN & & \\
\hline \multirow[t]{2}{*}{ Acipenser sinensis } & 中华鲟 & I & 濒危 & 邱实 & 中华鲟内部器官超声成像识别技术的研究 \\
\hline & & & $/$ EN & & \\
\hline \multirow[t]{2}{*}{ Acipenser sinensis } & 中华鲟 & I & 濒危 & 危起伟 & 中华鲟肧胎的耗氧率 \\
\hline & & & /EN & & \\
\hline \multirow[t]{2}{*}{ Acipenser sinensis } & 中华鲟 & I & 濒危 & 唐国盘 & 中华鲟胚胎发育和早期生活史阶段耗氧率的研究 \\
\hline & & & /EN & & \\
\hline \multirow[t]{2}{*}{ Acipenser sinensis } & 中华鲟 & I & 濒危 & 柴毅 & 中华鲟视网膜早期发育及趋光行为观察 \\
\hline & & & /EN & & \\
\hline \multirow[t]{2}{*}{ Acipenser sinensis } & 中华鲟 & I & 濒危 & 张四明 & 中华鲟随机扩增多态性 DNA 及遗传多样性研究 \\
\hline & & & /EN & & \\
\hline \multirow[t]{2}{*}{ Acipenser sinensis } & 中华鲟 & I & 濒危 & 柴毅 & 中华鲟吻须部味蕾的早期发育 \\
\hline & & & /EN & & \\
\hline \multirow[t]{2}{*}{ Acipenser sinensis } & 中华鲟 & I & 濒危 & 李瑾 & 中华鲟消化酶活性分布的研究 \\
\hline & & & /EN & & \\
\hline \multirow[t]{2}{*}{ Acipenser sinensis } & 中华鲟 & I & 濒危 & 李瑾 & 中华鲟消化系统内消化酶活性分布 \\
\hline & & & /EN & & \\
\hline \multirow[t]{2}{*}{ Acipenser sinensis } & 中华鲟 & I & 濒危 & 危起伟 & 中华鲟心脏的超声成像研究 \\
\hline & & & /EN & & \\
\hline
\end{tabular}


顾垒，闻丞，罗玫，王吴，吕植. 中国最受关注濒危物种保护现状快速评价的新方法探讨. 生物多样性，2015，23(5)：583-590. http://www. biodiversity-science. net/CN/article/downloadArticleFile. do?attachType=PDF\&id=10075

\begin{tabular}{|c|c|c|c|c|c|}
\hline Acipenser sinensis & 中华鲟 & I & $\begin{array}{l}\text { 濒危 } \\
\text { /EN }\end{array}$ & 陈细华 & 中华鲟血清卵黄蛋白原水平的初步观察 \\
\hline Acipenser sinensis & 中华鲟 & I & $\begin{array}{l}\text { 濒危 } \\
\text { /EN }\end{array}$ & 谢从新 & 中华鲟眼球的早期发育 \\
\hline Acipenser sinensis & 中华鲟 & I & $\begin{array}{l}\text { 濒危 } \\
\text { /EN }\end{array}$ & 郑卫东 & 中华鲟幼鱼的血液生化特性 \\
\hline Acipenser sinensis & 中华鲟 & I & $\begin{array}{l}\text { 濒危 } \\
\text { /EN }\end{array}$ & 陈细华 & 中华鲟早期发育中 17 - 雌二醇和睪酮水平变化的初步观察 \\
\hline Acipenser sinensis & 中华鲟 & I & $\begin{array}{l}\text { 濒危 } \\
\text { /EN }\end{array}$ & 潘连德 & 中华鲟主要病害临床诊断及控制技术 \\
\hline Acipenser sinensis & 中华鲟 & I & $\begin{array}{l}\text { 濒危 } \\
\text { /EN }\end{array}$ & 周栓林 & 中华鲟主要特征及我省中华鲟保护和管理措施探讨 \\
\hline Acipenser sinensis & 中华鲟 & I & $\begin{array}{l}\text { 濒危 } \\
\text { /EN }\end{array}$ & 张辉 & 中华鲟自然繁殖的非生物环境 \\
\hline Acipenser sinensis & 中华鲟 & I & $\begin{array}{l}\text { 濒危 } \\
\text { /EN }\end{array}$ & 危起伟 & 中华鲟自然繁殖的水文状况适合度研究 \\
\hline Acipenser sinensis & 中华鲟 & I & $\begin{array}{l}\text { 濒危 } \\
\text { /EN }\end{array}$ & 张辉 & 中华鲟自然繁殖行为发生与气象状况的关系 \\
\hline Acipenser sinensis & 中华鲟 & I & 濒危 & 刘向伟 & 重建长江上游中华鲟种群的可行性: 底栖动物调查及放流试验 \\
\hline
\end{tabular}


顾垒，闻丞，罗玫，王吴，吕植. 中国最受关注濒危物种保护现状快速评价的新方法探讨. 生物多样性，2015，23(5)：583-590. http://www. biodiversity-science. net/CN/article/downloadArticleFile. do?attachType=PDF\&id=10075

\begin{tabular}{|c|c|c|c|c|c|}
\hline & & & /EN & & \\
\hline \multirow[t]{2}{*}{ Aegolius funereus } & 鬼鸮 & II & 无危 & 孙悦华 & 甘肃省莲花山鬼鸮繁殖巢址记述 \\
\hline & & & $/ \mathrm{LC}$ & & \\
\hline \multirow[t]{2}{*}{ Aegolius funereus } & 鬼鸮 & II & 无危 & 古远 & 鬼鸮甘肃亚种繁殖期叫声研究 \\
\hline & & & $/ \mathrm{LC}$ & & \\
\hline \multirow[t]{2}{*}{ Aegolius funereus } & 鬼鸮 & II & 无危 & 方克艰 & 黑龙江嫩江高峰林区鸟类环志监测报告 \\
\hline & & & $/ \mathrm{LC}$ & & \\
\hline \multirow[t]{2}{*}{ Aegolius funereus } & 鬼鸮 & II & 无危 & 邓秋香 & 吉林省鸟类新分布一一一鬼鸮 \\
\hline & & & $/ \mathrm{LC}$ & & \\
\hline \multirow[t]{2}{*}{ Aegolius funereus } & 鬼鸮 & II & 无危 & 赵格日乐图 & 内蒙古达麥湖国家级自然保护区鸟类群落结构和动态研究 \\
\hline & & & $/ \mathrm{LC}$ & & \\
\hline \multirow[t]{2}{*}{ Aegolius funereus } & 鬼鸮 & II & 无危 & 柳文斌 & 太子山自然保护区生物多样性区系分析 \\
\hline & & & $/ \mathrm{LC}$ & & \\
\hline \multirow[t]{2}{*}{ Aegolius funereus } & 鬼鸮 & II & 无危 & 田振环 & 图牧吉国家级自然保护区鸟类资源 \\
\hline & & & $/ \mathrm{LC}$ & & \\
\hline \multirow[t]{2}{*}{ Ailuropoda melandeuca } & 大熊猫 & I & 濒危 & Ya-ping Zhang & Phylogeny of the bears (Ursidae) based on nuclear and mitochondrial genes \\
\hline & & & /EN & & \\
\hline
\end{tabular}


顾垒，闻丞，罗玫，王吴，吕植. 中国最受关注濒危物种保护现状快速评价的新方法探讨. 生物多样性，2015，23(5)：583-590. http://www. biodiversity-science. net/CN/article/downloadArticleFile. do?attachType=PDF\&id=10075

\begin{tabular}{|c|c|c|c|c|c|}
\hline Ailuropoda melanoleuca & 大熊猫 & I & $\begin{array}{l}\text { 濒危 } \\
\text { /EN }\end{array}$ & 宋国华 & “林木、主食竹和大熊猫” 非线性动力学模型的周期解 \\
\hline Ailuropoda melanoleuca & 大熊猫 & I & $\begin{array}{l}\text { 濒危 } \\
\text { /EN }\end{array}$ & 张洪峰 & 108 国道秦岭生物走廊带大熊猫主要伴生动物调查 \\
\hline Ailuropoda melanoleuca & 大熊猫 & I & $\begin{array}{l}\text { 濒危 } \\
\text { /EN }\end{array}$ & 赵鹏鹏 & 2 只繁育期雌性大熊猫尿中雌二醇、孕酮含量的变化 \\
\hline Ailuropoda melanoleuca & 大熊猫 & I & $\begin{array}{l}\text { 濒危 } \\
\text { /EN }\end{array}$ & 姜瑞婕 & 2 只 1_5 岁龄大熊猫在采血训练中的行为差异研究 \\
\hline Ailuropoda melanoleuca & 大熊猫 & I & $\begin{array}{l}\text { 濒危 } \\
\text { /EN }\end{array}$ & 胡德夫 & 30 年来秦岭大熊猫栖息地变化研究 \\
\hline Ailuropoda melanoleuca & 大熊猫 & I & $\begin{array}{l}\text { 濒危 } \\
\text { /EN }\end{array}$ & 赵永涛 & $5 \cdot 12$ 地震一大熊猫栖息地灾后生态修复重建探讨 \\
\hline Ailuropoda melanoleuca & 大熊猫 & I & $\begin{array}{l}\text { 濒危 } \\
\text { /EN }\end{array}$ & 丁叶 & 9 例大熊猫肝脏和肾脏的器官病理学观察 \\
\hline Ailuropoda melanoleuca & 大熊猫 & I & $\begin{array}{l}\text { 濒危 } \\
\text { /EN }\end{array}$ & Wanqin Yang & A comparison on ecosystem services beforeafter 5.12 Wenchuan earthquake \\
\hline
\end{tabular}


顾垒，闻丞，罗玫，王昊，吕植. 中国最受关注濒危物种保护现状快速评价的新方法探讨．生物多样性，2015，23(5)：583-590. http://www. biodiversity-science. net/CN/article/downloadArticleFile. do?attachType=PDF\&id=10075

\begin{tabular}{|c|c|c|c|c|c|}
\hline Ailuropoda melanoleuca & 大熊猫 & I & $\begin{array}{l}\text { 濒危 } \\
/ \mathrm{EN}\end{array}$ & ZHANG HeMin & $\begin{array}{l}\text { A fast and effective method to perform paternity testing for Wolong } \\
\text { giant pandas }\end{array}$ \\
\hline Ailuropoda melanoleuca & 大熊猫 & I & $\begin{array}{l}\text { 濒危 } \\
/ \mathrm{EN}\end{array}$ & Yong Wang & $\begin{array}{l}\text { A Genome-Wide Survey on Basic Helix-Loop-Helix } \\
\text { Transcription Factors in Giant Panda }\end{array}$ \\
\hline Ailuropoda melanoleuca & 大熊猫 & I & $\begin{array}{l}\text { 濒危 } \\
/ \mathrm{EN}\end{array}$ & Zhiyun Ouyang & $\begin{array}{l}\text { A Graph-theoretic Analysis of Stressors Confronting Giant Panda Habitat across Minshan } \\
\text { Mountain Region, China }\end{array}$ \\
\hline Ailuropoda melanoleuca & 大熊猫 & I & $\begin{array}{l}\text { 濒危 } \\
/ \mathrm{EN}\end{array}$ & OUYANG Zhiyun & $\begin{array}{l}\text { A Graph-theoretic Analysis of Stressors Confronting Giant Panda } \\
\text { Habitat across Minshan Mountain Region, China }\end{array}$ \\
\hline Ailuropoda melanoleuca & 大熊猫 & I & $\begin{array}{l}\text { 濒危 } \\
/ \mathrm{EN}\end{array}$ & Xiang-yun Shi & $\begin{array}{l}\text { A Mathematical Model with Pulse Effect for Three Populations of the Giant Panda and Two } \\
\text { Kinds of Bamboo }\end{array}$ \\
\hline Ailuropoda melanoleuca & 大熊猫 & I & $\begin{array}{l}\text { 濒危 } \\
/ \mathrm{EN}\end{array}$ & PÉREZ-CLAROS & $\begin{array}{l}\text { A morphometric characterization of cranial shape in terrestrial carnivorans based on fourier } \\
\text { analysis }\end{array}$ \\
\hline Ailuropoda melanoleuca & 大熊猫 & I & $\begin{array}{l}\text { 濒危 } \\
/ \mathrm{EN}\end{array}$ & Guangneng Peng & $\begin{array}{l}\text { A morphometric characterization of cranial shape in terrestrial carnivorans based on fourier } \\
\text { analysis }\end{array}$ \\
\hline Ailuropoda melanoleuca & 大熊猫 & I & $\begin{array}{l}\text { 濒危 } \\
/ \mathrm{EN}\end{array}$ & Guangneng Peng & A new genotype of Cryptosporidium from giant panda (Ailuropoda melanoleuca) in China \\
\hline Ailuropoda melanoleuca & 大熊猫 & I & $\begin{array}{l}\text { 濒危 } \\
/ \mathrm{EN}\end{array}$ & Guangneng Peng & A new genotype of Cryptosporidium from giant panda (Ailuropoda melanoleuca) in China \\
\hline Ailuropoda melanoleuca & 大熊猫 & I & 濒危 & Alex D. Greenwood & A novel endogenous betaretrovirus group characterized from polar bears ( Ursus maritimus) \\
\hline
\end{tabular}


顾垒，闻丞，罗玫，王昊，吕植. 中国最受关注濒危物种保护现状快速评价的新方法探讨．生物多样性，2015，23(5)：583-590.

\begin{tabular}{|c|c|c|c|c|c|}
\hline & & & /EN & & and giant pandas ( Ailuropoda melanoleuca) \\
\hline \multirow[t]{2}{*}{ Ailuropoda melanoleuca } & 大熊猫 & I & 濒危 & AlexD.Greenwood & A novel endogenous betaretrovirus group characterized from polar bears ( Ursus maritimus) \\
\hline & & & /EN & & and giant pandas ( Ailuropoda melanoleuca) \\
\hline \multirow[t]{2}{*}{ Ailuropoda melanoleuca } & 大熊猫 & I & 濒危 & Xiao Xu & A reliable, non-invasive PCR method for giant panda (Ailuropoda melanoleuca) sex \\
\hline & & & /EN & & identification \\
\hline \multirow[t]{2}{*}{ Ailuropoda melanoleuca } & 大熊猫 & I & 濒危 & TOBIAS BIDON & A sensitive and specific multiplex PCR approach for sex identification of ursine and \\
\hline & & & /EN & & tremarctine bears suitable for non - invasive samples \\
\hline \multirow[t]{2}{*}{ Ailuropoda melanoleuca } & 大熊猫 & I & 濒危 & Catherine.Hanni & A system for sex determination from degraded DNA a useful tool for palaeogenetics and \\
\hline & & & /EN & & conservation genetics of ursids \\
\hline \multirow[t]{2}{*}{ Ailuropoda melanoleuca } & 大熊猫 & I & 濒危 & Zhan Xiangjiang & Accurate population size estimates are vital parameters for conserving the giant panda \\
\hline & & & /EN & & \\
\hline \multirow[t]{2}{*}{ Ailuropoda melanoleuca } & 大熊猫 & I & 濒危 & Zhan Xiangjiang & Accurate population size estimates are vital parameters for conserving the giant panda \\
\hline & & & $/ \mathrm{EN}$ & & \\
\hline \multirow[t]{2}{*}{ Ailuropoda melanoleuca } & 大熊猫 & I & 濒危 & Zhan Xiangjiang & Accurate population size estimates are vital parameters for conserving the giant panda \\
\hline & & & $/ \mathrm{EN}$ & & \\
\hline \multirow[t]{2}{*}{ Ailuropoda melanoleuca } & 大熊猫 & I & 濒危 & R. E. Spindler & Acrosomal integrity and capacitation are not influenced by sperm cryopreservation in the giant \\
\hline & & & $/ \mathrm{EN}$ & & panda \\
\hline \multirow[t]{2}{*}{ Ailuropoda melanoleuca } & 大熊猫 & I & 濒危 & De-Xiang Wang & Altitudinal distribution of seed plants in Foping and Changqing, Qinling Mountains, China \\
\hline & & & /EN & & \\
\hline
\end{tabular}


顾垒，闻丞，罗玫，王昊，吕植. 中国最受关注濒危物种保护现状快速评价的新方法探讨．生物多样性，2015，23(5)：583-590.

http://www. biodiversity-science. net/CN/article/downloadArticleFile. do?attachType=PDF\&id=10075

\begin{tabular}{|c|c|c|c|c|c|}
\hline Ailuropoda melanoleuca & 大熊猫 & I & $\begin{array}{l}\text { 濒危 } \\
\text { /EN }\end{array}$ & De-Xiang Wang & Altitudinal distribution of seed plants in Foping and Changqing, Qinling Mountains, China \\
\hline Ailuropoda melanoleuca & 大熊猫 & I & $\begin{array}{l}\text { 濒危 } \\
\text { /EN }\end{array}$ & Frances Reed & Anaesthesia of a captive, male giant panda (Ailuropoda melanoleuca) \\
\hline Ailuropoda melanoleuca & 大熊猫 & I & $\begin{array}{l}\text { 濒危 } \\
\text { /EN }\end{array}$ & M.J.Salesa & $\begin{array}{l}\text { Anatomy of the “alse thumb” of Tremarctos ornatus (Carnivora, Ursidae, Tremarctinae) } \\
\text { phylogenetic and functional implications }\end{array}$ \\
\hline Ailuropoda melanoleuca & 大熊猫 & I & $\begin{array}{l}\text { 濒危 } \\
\text { /EN }\end{array}$ & Hong Yuan & Anogenital gland secretions code for sex and age in the giant panda,Ailuropoda melanoleuca \\
\hline Ailuropoda melanoleuca & 大熊猫 & I & $\begin{array}{l}\text { 濒危 } \\
\text { /EN }\end{array}$ & Ouyang Zhiyun & $\begin{array}{l}\text { Application of ecological-niche factor analysis in habitat } \\
\text { assessment of giant pandas }\end{array}$ \\
\hline Ailuropoda melanoleuca & 大熊猫 & I & $\begin{array}{l}\text { 濒危 } \\
\text { /EN }\end{array}$ & Ouyang Zhiyun & $\begin{array}{l}\text { Application of ecological-niche factor analysis in habitat } \\
\text { assessment of giant pandas }\end{array}$ \\
\hline Ailuropoda melanoleuca & 大熊猫 & I & $\begin{array}{l}\text { 濒危 } \\
\text { /EN }\end{array}$ & Ouyang Zhiyun & $\begin{array}{l}\text { Application of ecological-niche factor analysis in habitat } \\
\text { assessment of giant pandas }\end{array}$ \\
\hline Ailuropoda melanoleuca & 大熊猫 & I & $\begin{array}{l}\text { 濒危 } \\
\text { /EN }\end{array}$ & Dihua Li & $\begin{array}{l}\text { Application of least-cost path model to identify a giant panda dispersal corridor network after } \\
\text { the Wenchuan earthquake-Case study of Wolong Nature Reserve }\end{array}$ \\
\hline Ailuropoda melanoleuca & 大熊猫 & I & $\begin{array}{l}\text { 濒危 } \\
\text { /EN }\end{array}$ & 贾建华 & ArcGIS 在秦岭大熊猫巡护监测中的应用 \\
\hline Ailuropoda melanoleuca & 大熊猫 & I & 濒危 & 刘群秀 & ARIMA 模型在大熊猫取食行为研究中的应用 \\
\hline
\end{tabular}


顾垒，闻丞，罗玫，王昊，吕植. 中国最受关注濒危物种保护现状快速评价的新方法探讨．生物多样性，2015，23(5)：583-590. http://www. biodiversity-science. net/CN/article/downloadArticleFile. do?attachType=PDF\&id=10075

Ailuropoda melanoleuca

大熊猫

大熊猫

Ailuropoda melanoleuca

Ailuropoda melanoleuca

大熊猫

Ailuropoda melanoleuca

大熊猫

Ailuropoda melanoleuca

大熊猫

Ailuropoda melanoleuca

大熊猫

Ailuropoda melanoleuca

大熊猫

Ailuropoda melanoleuca

大熊猫

Ailuropoda melanoleuca

大熊猫

/EN

/EN

I

濒危 Sheng Li

/EN

频危 Sheng Li

EN

I

贱危 Sheng Li

$/$ EN

I 濒危 Sheng Li

/EN

I 濒危 Sheng Li

/EN

I 濒危 Sheng Li

/EN

I 濒危 Sheng Li

/EN uangming He

Balancing Human Energy Needs and Conservation of Panda Habitat

Beyond pandas, the need for a standardized monitoring protocol for large mammals in Chinese nature reserves

Beyond pandas, the need for a standardized monitoring protocol for large mammals in Chinese nature reserves

Beyond pandas, the need for a standardized monitoring protocol for large mammals in Chinese

nature reserves

Beyond pandas, the need for a standardized monitoring protocol for large mammals in Chines

nature reserves

Beyond pandas, the need for a standardized monitoring protocol for large mammals in Chinese nature reserves

Beyond pandas, the need for a standardized monitoring protocol for large mammals in Chinese nature reserves

Beyond pandas, the need for a standardized monitoring protocol for large mammals in Chinese nature reserves

Beyond pandas, the need for a standardized monitoring protocol for large mammals in Chinese nature reserves 
顾垒，闻丞，罗玫，王昊，吕植. 中国最受关注濒危物种保护现状快速评价的新方法探讨．生物多样性，2015，23(5)：583-590.

\begin{tabular}{|c|c|c|c|c|c|}
\hline Ailuropoda melanoleuca & 大熊猫 & I & $\begin{array}{l}\text { 濒危 } \\
\text { /EN }\end{array}$ & Sheng Li & $\begin{array}{l}\text { Beyond pandas, the need for a standardized monitoring protocol for large mammals in Chinese } \\
\text { nature reserves }\end{array}$ \\
\hline Ailuropoda melanoleuca & 大熊猫 & I & $\begin{array}{l}\text { 濒危 } \\
\text { /EN }\end{array}$ & Sheng Li & $\begin{array}{l}\text { Beyond pandas, the need for a standardized monitoring protocol for large mammals in Chinese } \\
\text { nature reserves }\end{array}$ \\
\hline Ailuropoda melanoleuca & 大熊猫 & I & $\begin{array}{l}\text { 濒危 } \\
\text { /EN }\end{array}$ & Sheng Li & $\begin{array}{l}\text { Beyond pandas, the need for a standardized monitoring protocol for large mammals in Chinese } \\
\text { nature reserves }\end{array}$ \\
\hline Ailuropoda melanoleuca & 大熊猫 & I & $\begin{array}{l}\text { 濒危 } \\
\text { /EN }\end{array}$ & Sheng Li & $\begin{array}{l}\text { Beyond pandas, the need for a standardized monitoring protocol for large mammals in Chinese } \\
\text { nature reserves }\end{array}$ \\
\hline Ailuropoda melanoleuca & 大熊猫 & I & $\begin{array}{l}\text { 濒危 } \\
\text { /EN }\end{array}$ & Sheng Li & $\begin{array}{l}\text { Beyond pandas, the need for a standardized monitoring protocol for large mammals in Chinese } \\
\text { nature reserves }\end{array}$ \\
\hline Ailuropoda melanoleuca & 大熊猫 & I & $\begin{array}{l}\text { 濒危 } \\
\text { /EN }\end{array}$ & Sheng Li & $\begin{array}{l}\text { Beyond pandas, the need for a standardized monitoring protocol for large mammals in Chinese } \\
\text { nature reserves }\end{array}$ \\
\hline Ailuropoda melanoleuca & 大熊猫 & I & $\begin{array}{l}\text { 濒危 } \\
\text { /EN }\end{array}$ & Sheng Li & $\begin{array}{l}\text { Beyond pandas, the need for a standardized monitoring protocol for large mammals in Chinese } \\
\text { nature reserves }\end{array}$ \\
\hline Ailuropoda melanoleuca & 大熊猫 & I & $\begin{array}{l}\text { 濒危 } \\
\text { /EN }\end{array}$ & Sheng Li & $\begin{array}{l}\text { Beyond pandas, the need for a standardized monitoring protocol for large mammals in Chinese } \\
\text { nature reserves }\end{array}$ \\
\hline Ailuropoda melanoleuca & 大熊猫 & I & $\begin{array}{l}\text { 濒危 } \\
\text { /EN }\end{array}$ & Zhiwen Xu & Bioinformatics Analysis and Characteristics of the giant panda Interferon-alpha \\
\hline Ailuropoda melanoleuca & 大熊猫 & I & 濒危 & Fuwen Wei & Black and white and read all over the past, present and future of giant panda genetics \\
\hline
\end{tabular}


顾垒，闻丞，罗玫，王昊，吕植. 中国最受关注濒危物种保护现状快速评价的新方法探讨．生物多样性，2015，23(5)：583-590. http://www. biodiversity-science. net/CN/article/downloadArticleFile. do?attachType=PDF\&id=10075

Ailuropoda melanoleuca

大熊猫

大熊猫

Ailuropoda melanoleuca

Ailuropoda melanoleuca

大熊猫

Ailuropoda melanoleuca

大熊猫

Ailuropoda melanoleuca

大熊猫

Ailuropoda melanoleuca

Ailuropoda melanoleuca

大熊猫

Ailuropoda melanoleuca

大熊猫

大熊猫

濒危

/EN U

濒危Ｄongwei Kang

I

频危 Dongwei Kang

I 濒危 Ronald R

/EN SWAISGOOD

I 濒危 Yi-ling Hou

EN

I 濒危 Yi-ling Hou

EN

I 濒危 Wanru Hou /EN

I 濒危 Wanru Hou

Ailuropoda melanoleuca

濒危 Wan-ru Hou
Brominated Flame Retardants, Polychlorinated Biphenyls, and Organochlorine Pesticides in

Captive Giant Panda (Ailuropoda melanoleuca) and Red Panda (Ailurus fulgens) from China

Can conservation of single surrogate species protect co-occurring species

Can conservation of single surrogate species protect co-occurring species

Can science save the giant panda (Ailuropoda melanoleuca)?

Unifying science and policy in an adaptive management

paradigm

cDNA cloning and overexpression of ribosomal protein S19 gene (RPS19) from the giant panda

cDNA, genomic sequence and overexpression of crystallin alpha-B Gene

(CRYAB) of the Giant Panda

cDNA, genomic sequence cloning and analysis of the ribosomal protein L37A gene (RPL37A)

from the giant panda (Ailuropoda melanoleuca) and its overexpression

cDNA, genomic sequence cloning and overexpression of cytochrome c oxidase gene (COX6b1)

from the Ailuropoda melanoleuca

cDNA, genomic sequence cloning and overexpression of ribosomal protein s20 gene (RPS20) 
顾垒，闻丞，罗玫，王昊，吕植. 中国最受关注濒危物种保护现状快速评价的新方法探讨．生物多样性，2015，23(5)：583-590. http://www, biodiversity-science, net/CN/article/downloadArticleFile. do?attachType=PDF\&id=10075

\begin{tabular}{|c|c|c|c|c|c|}
\hline & & & /EN & & from the Giant Panda (Ailuropoda melanoleuca) \\
\hline Ailuropoda melanoleuca & 大熊猫 & I & $\begin{array}{l}\text { 濒危 } \\
\text { /EN }\end{array}$ & Wan-ru Hou & $\begin{array}{l}\text { cDNA, genomic sequence cloning and overexpression of ribosomal protein S25 gene (RPS25) } \\
\text { from the Giant Panda }\end{array}$ \\
\hline Ailuropoda melanoleuca & 大熊猫 & I & 濒危 & Wanru Hou & $\begin{array}{l}\text { cDNA, Genomic sequence cloning and over-expression } \\
\text { of ribosomal protein L15 gene (RPL15) from the giant } \\
\text { panda }\end{array}$ \\
\hline Ailuropoda melanoleuca & 大熊猫 & I & $\begin{array}{l}\text { 濒危 } \\
\text { /EN }\end{array}$ & W.-R. Hou & $\begin{array}{l}\text { cDNA, genomic sequence cloning and } \\
\text { overexpression of the ribosomal protein S13 gene in the giant panda (Ailuropoda melanoleuca) }\end{array}$ \\
\hline Ailuropoda melanoleuca & 大熊猫 & I & $\begin{array}{l}\text { 濒危 } \\
\text { /EN }\end{array}$ & $\begin{array}{l}\text { Julio De Le Fuente } \\
\text { Martinez }\end{array}$ & $\begin{array}{l}\text { Characteristics and In Vitro Fertilizing Ability of Giant Panda(Ailuropoda melanoleuca) } \\
\text { Frozen-Thawed Epididymal Spermatozoa Obtained } 4 \text { Hours Postmortem:A Case Report }\end{array}$ \\
\hline Ailuropoda melanoleuca & 大熊猫 & I & $\begin{array}{l}\text { 濒危 } \\
\text { /EN }\end{array}$ & Yuliang Liu & Characteristics of Mesenchymal Stem Cells Isolated from Bone Marrow of Giant Panda \\
\hline Ailuropoda melanoleuca & 大熊猫 & I & $\begin{array}{l}\text { 濒危 } \\
\text { /EN }\end{array}$ & Guang-hui Zhao & $\begin{array}{l}\text { Characterization of Haemaphysalis flava (Acari Ixodidae) from Qingling Subspecies of Giant } \\
\text { Panda (Ailuropoda melanoleuca qinlingensis) in Qinling Mountains (Central China) by } \\
\text { Morphology and Molecular Markers. }\end{array}$ \\
\hline Ailuropoda melanoleuca & 大熊猫 & I & 濒危 & Xingping Ye & $\begin{array}{l}\text { Characterizing the Spatial Distribution of Giant Pandas in China using MODIS Data and } \\
\text { Landscape Metrics }\end{array}$ \\
\hline Ailuropoda melanoleuca & 大熊猫 & I & $\begin{array}{l}\text { 濒危 } \\
\text { /EN }\end{array}$ & X.P. Ye & $\begin{array}{l}\text { CHARACTERIZING THE SPATIAL DISTRIBUTION OF GIANT PANDAS IN CHINA } \\
\text { USING MULTITEMPORAL MODIS DATA AND LANDSCAPE METRICS }\end{array}$ \\
\hline
\end{tabular}


顾垒，闻丞，罗玫，王昊，吕植. 中国最受关注濒危物种保护现状快速评价的新方法探讨．生物多样性，2015，23(5)：583-590. http://www. biodiversity-science. net/CN/article/downloadArticleFile. do?attachType=PDF\&id=10075

\begin{tabular}{|c|c|c|c|c|c|}
\hline Ailuropoda melanoleuca & 大熊猫 & I & $\begin{array}{l}\text { 濒危 } \\
\text { /EN }\end{array}$ & Ronald R. Swaisgood & Chemical Communication in Giant Pandas Experimentation and Application \\
\hline Ailuropoda melanoleuca & 大熊猫 & I & $\begin{array}{l}\text { 濒危 } \\
\text { /EN }\end{array}$ & W. Nie & $\begin{array}{l}\text { Chromosomal rearrangements and karyotype evolution in carnivores revealed by chromosome } \\
\text { painting }\end{array}$ \\
\hline Ailuropoda melanoleuca & 大熊猫 & I & $\begin{array}{l}\text { 濒危 } \\
\text { /EN }\end{array}$ & Jianguo Liu & $\begin{array}{l}\text { Climate-change impacts on understorey bamboo species and giant pandas in China's Qinling } \\
\text { Mountains }\end{array}$ \\
\hline Ailuropoda melanoleuca & 大熊猫 & I & $\begin{array}{l}\text { 濒危 } \\
\text { /EN }\end{array}$ & Qi-gui YAN & $\begin{array}{l}\text { Cloning and phylogenetic analysis of the NSP1 5 genes of giant panda rotavirus strain CH-1 } \\
\text { isolated in China }\end{array}$ \\
\hline Ailuropoda melanoleuca & 大熊猫 & I & $\begin{array}{l}\text { 濒危 } \\
\text { /EN }\end{array}$ & Wan-ru Hou & $\begin{array}{l}\text { Cloning and sequence analysis of translocase of inner mitochondrial membrane } 10 \text { homolog } \\
\text { (yeast) gene (TIMM10) from the giant panda. }\end{array}$ \\
\hline Ailuropoda melanoleuca & 大熊猫 & I & $\begin{array}{l}\text { 濒危 } \\
\text { /EN }\end{array}$ & M.Y.Zhu & $\begin{array}{l}\text { Cloning, expression and tissue distribution of IGF-1 from giant panda (Ailuropoda } \\
\text { melanoleuca) }\end{array}$ \\
\hline Ailuropoda melanoleuca & 大熊猫 & I & $\begin{array}{l}\text { 濒危 } \\
\text { /EN }\end{array}$ & YI-ZHENG ZHANG & $\begin{array}{l}\text { Cloning, Sequence, and Function Analyses of Giant } \\
\text { Panda (Ailuropoda melanoleuca) CD9 Gene }\end{array}$ \\
\hline Ailuropoda melanoleuca & 大熊猫 & I & $\begin{array}{l}\text { 濒危 } \\
\text { /EN }\end{array}$ & Z.-W. Xu & $\begin{array}{l}\text { Coexpression of interleukin- } 6 \text { and-2 from giant panda in Escherichia coli and the biological } \\
\text { activity of the fusion protein. }\end{array}$ \\
\hline Ailuropoda melanoleuca & 大熊猫 & $\mathrm{I}$ & $\begin{array}{l}\text { 濒危 } \\
\text { /EN }\end{array}$ & Catherine Ha ${ }^{*}$ nni & $\begin{array}{l}\text { Combined analysis of fourteen nuclear genes refines } \\
\text { the Ursidae phylogeny }\end{array}$ \\
\hline Ailuropoda melanoleuca & 大熊猫 & I & 濒危 & W.R. Hou & Comparative analysis and molecular characterization of genomic sequences and proteins of \\
\hline
\end{tabular}


顾垒，闻丞，罗玫，王昊，吕植. 中国最受关注濒危物种保护现状快速评价的新方法探讨．生物多样性，2015，23(5)：583-590. http://www, biodiversity-science, net/CN/article/downloadArticleFile. do?attachType=PDF\&id=10075

\begin{tabular}{|c|c|c|c|c|c|}
\hline & & & /EN & & FABP4 and FABP5 from the giant panda (Ailuropoda melanoleuca) \\
\hline Ailuropoda melanoleuca & 大熊猫 & I & $\begin{array}{l}\text { 濒危 } \\
\text { /EN }\end{array}$ & Roger S. Holmes & $\begin{array}{l}\text { Comparative genomics, molecular evolution and computational modeling of ALDH1B1 and } \\
\text { ALDH2 }\end{array}$ \\
\hline AILUROPODA & 熊猫 & I & 濒危 & Liu Xuanzhen & Composition of Captive Giant Panda Milk \\
\hline MELANOLEUCA & & & /EN & & \\
\hline Ailuropoda melanoleuca & 大熊猫 & I & $\begin{array}{l}\text { 濒危 } \\
\text { /EN }\end{array}$ & Fuwen Wei & $\begin{array}{l}\text { Conservation implications of drastic reductions in the smallest and most isolated populations of } \\
\text { giant pandas }\end{array}$ \\
\hline Ailuropoda melanoleuca & 大熊猫 & I & $\begin{array}{l}\text { 濒危 } \\
\text { /EN }\end{array}$ & Zhiyun Ouyang & Conservation of giant panda habitat in South Minshan, China, after the May 2008 earthquake \\
\hline Ailuropoda melanoleuca & 大熊猫 & I & $\begin{array}{l}\text { 濒危 } \\
\text { /EN }\end{array}$ & Zhiyun Ouyang & Conservation of giant panda habitat in South Minshan, China, after the May 2009 earthquake \\
\hline Ailuropoda melanoleuca & 大熊猫 & I & $\begin{array}{l}\text { 濒危 } \\
\text { /EN }\end{array}$ & Zhiyun Ouyang & Conservation of giant panda habitat in South Minshan, China, after the May 2010 earthquake \\
\hline Ailuropoda melanoleuca & 大熊猫 & I & $\begin{array}{l}\text { 濒危 } \\
\text { /EN }\end{array}$ & Zhiyun Ouyang & Conservation of giant panda habitat in South Minshan, China, after the May 2011 earthquake \\
\hline Ailuropoda melanoleuca & 大熊猫 & I & $\begin{array}{l}\text { 濒危 } \\
\text { /EN }\end{array}$ & B ISONG Y UE & $\begin{array}{l}\text { Conservation of the endangered giant panda Ailuropoda melanoleuca in China successes and } \\
\text { challenges }\end{array}$ \\
\hline Ailuropoda melanoleuca & 大熊猫 & I & $\begin{array}{l}\text { 濒危 } \\
\text { /EN }\end{array}$ & Ning Li & $\begin{array}{l}\text { Construction of a } 7 \text {-fold BAC library and cytogenetic mapping of } 10 \text { genes in the giant panda } \\
\text { (Ailuropoda melanoleuca) }\end{array}$ \\
\hline
\end{tabular}


顾垒，闻丞，罗玫，王昊，吕植. 中国最受关注濒危物种保护现状快速评价的新方法探讨．生物多样性，2015，23(5)：583-590. http://www. biodiversity-science. net/CN/article/downloadArticleFile. do?attachType=PDF\&id=10075

\begin{tabular}{|c|c|c|c|c|c|}
\hline Ailuropoda melanoleuca & 大熊猫 & I & $\begin{array}{l}\text { 濒危 } \\
\text { /EN }\end{array}$ & Yan Xie & $\begin{array}{l}\text { Corridor connecting giant panda habitats from north to south in the Min Mountains, Sichuan, } \\
\text { China }\end{array}$ \\
\hline Ailuropoda melanoleuca & 大熊猫 & I & $\begin{array}{l}\text { 濒危 } \\
\text { /EN }\end{array}$ & Borja Figueirido & $\begin{array}{l}\text { Cranial shape transformation in the evolution of the giant } \\
\text { panda (Ailuropoda melanoleuca) }\end{array}$ \\
\hline Ailuropoda melanoleuca & 大熊猫 & I & $\begin{array}{l}\text { 濒危 } \\
\text { /EN }\end{array}$ & Dingzhen Liu & Cross-modal signaling in giant pandas \\
\hline Ailuropoda melanoleuca & 大熊猫 & I & $\begin{array}{l}\text { 濒危 } \\
\text { /EN }\end{array}$ & $\begin{array}{l}\text { Nathalie France } \\
\text { Mauroo }\end{array}$ & Cutaneous Hemangioma in a Giant Panda (Ailuropoda melanoleuca) \\
\hline Ailuropoda melanoleuca & 大熊猫 & I & $\begin{array}{l}\text { 濒危 } \\
\text { /EN }\end{array}$ & Desheng Li & Delayed implantation in giant pandas the first comprehensive empirical evidence \\
\hline Ailuropoda melanoleuca & 大熊猫 & I & $\begin{array}{l}\text { 濒危 } \\
\text { /EN }\end{array}$ & Zhiyun Ouyang & $\begin{array}{l}\text { Designing a conservation plan for protecting the habitat for giant pandas in the Qionglai } \\
\text { mountain range, China }\end{array}$ \\
\hline Ailuropoda melanoleuca & 大熊猫 & I & $\begin{array}{l}\text { 濒危 } \\
\text { /EN }\end{array}$ & Natsuki HAMA & $\begin{array}{l}\text { Development and Evaluation of a Rapid Enzyme-immunoassay System } \\
\text { for Measurement of the Urinary Concentration of Estrone-3- } \\
\text { glucuronide in a Female Giant Panda (Ailuropoda melanoleuca) }\end{array}$ \\
\hline Ailuropoda melanoleuca & 大熊猫 & I & $\begin{array}{l}\text { 濒危 } \\
\text { /EN }\end{array}$ & Natsuki HAMA & $\begin{array}{l}\text { Development of an enzyme immunoassay for urinary pregnanediol-3-glucuronide in a female } \\
\text { giant panda (Ailuropoda melanoleuca). }\end{array}$ \\
\hline Ailuropoda melanoleuca & 大熊猫 & I & $\begin{array}{l}\text { 濒危 } \\
\text { /EN }\end{array}$ & Natsuki HAMA & $\begin{array}{l}\text { Development of an Enzyme Immunoassay for Urinary Pregnanediol-3-Glucuronide } \\
\text { in a Female Giant Panda (Ailuropoda melanoleuca) }\end{array}$ \\
\hline
\end{tabular}


顾垒，闻丞，罗玫，王昊，吕植. 中国最受关注濒危物种保护现状快速评价的新方法探讨．生物多样性，2015，23(5)：583-590. http://www. biodiversity-science. net/CN/article/downloadArticleFile. do?attachType=PDF\&id=10075

\begin{tabular}{|c|c|c|c|c|c|}
\hline Ailuropoda melanoleuca & 大熊猫 & I & $\begin{array}{l}\text { 濒危 } \\
\text { /EN }\end{array}$ & Bisong Yue & $\begin{array}{l}\text { Development of new tetranucleotide microsatellite loci and assessment of genetic variation of } \\
\text { giant panda in two largest giant panda captive breeding populations }\end{array}$ \\
\hline Ailuropoda melanoleuca & 大熊猫 & I & $\begin{array}{l}\text { 濒危 } \\
\text { /EN }\end{array}$ & A. Brown & Dietary shifts affect the gastrointestinal microflora of the giant panda (Ailuropoda melanoleuca) \\
\hline Ailuropoda melanoleuca & 大熊猫 & I & $\begin{array}{l}\text { 濒危 } \\
\text { /EN }\end{array}$ & Fuwen Wei & $\begin{array}{l}\text { Different habitat preferences of male and female giant } \\
\text { pandas }\end{array}$ \\
\hline Ailuropoda melanoleuca & 大熊猫 & I & $\begin{array}{l}\text { 濒危 } \\
\text { /EN }\end{array}$ & $\begin{array}{l}\text { Christopher J. } \\
\text { Danpure }\end{array}$ & Differential Enzyme Targeting As an Evolutionary Adaptation to Herbivory in Carnivora \\
\hline Ailuropoda melanoleuca & 大熊猫 & I & $\begin{array}{l}\text { 濒危 } \\
\text { /EN }\end{array}$ & Ludwig Huber & $\begin{array}{l}\text { Discrimination of Face-Like Patterns in the Giant Panda } \\
\text { (Ailuropoda melanoleuca) }\end{array}$ \\
\hline Ailuropoda melanoleuca & 大熊猫 & I & $\begin{array}{l}\text { 濒危 } \\
\text { /EN }\end{array}$ & Guangming He & $\begin{array}{l}\text { Distribution of Economic Benefits from Ecotourism: A Case Study } \\
\text { of Wolong Nature Reserve for Giant Pandas in China }\end{array}$ \\
\hline Ailuropoda melanoleuca & 大熊猫 & I & $\begin{array}{l}\text { 濒危 } \\
\text { /EN }\end{array}$ & $\begin{array}{l}\text { David L. } \\
\text { Garshelis1,4, }\end{array}$ & Do revised giant panda population estimates aid in their conservation? \\
\hline $\begin{array}{l}\text { AILUROPODA } \\
\text { MELANOLEUCA }\end{array}$ & 熊猫 & I & $\begin{array}{l}\text { 濒危 } \\
\text { /EN }\end{array}$ & 沈富军 & Dynal 磁珠富集大熊猫微卫星标记 \\
\hline Ailuropoda melanoleuca & 大熊猫 & I & $\begin{array}{l}\text { 濒危 } \\
\text { /EN }\end{array}$ & Megan A. Owen & $\begin{array}{l}\text { Dynamics of Male - Female Multimodal Signaling Behavior across the Estrous Cycle in Giant } \\
\text { Pandas (Ailuropoda melanoleuca) }\end{array}$ \\
\hline Ailuropoda melanoleuca & 大熊猫 & I & 濒危 & Fuwen Wei & Ecological niche modeling of the sympatric giant and red pandas on a mountain-range scale \\
\hline
\end{tabular}


顾垒，闻丞，罗玫，王昊，吕植. 中国最受关注濒危物种保护现状快速评价的新方法探讨．生物多样性，2015，23(5)：583-590. http://www. biodiversity-science. net/CN/article/downloadArticleFile. do?attachType=PDF\&id=10075

Ailuropoda melanoleuca

大熊猫

大熊猫

濒危

B. Figueirido

/EN

Ailuropoda melanoleuca

Ailuropoda melanoleuca

大熊猫

Ailuropoda melanoleuca

大熊猫

Ailuropoda melanoleuca

大熊猫

Ailuropoda melanoleuca

大熊猫

Ailuropoda melanoleuca

大熊猫

Ailuropoda melanoleuca

大熊猫

Ailuropoda melanoleuca

I 濒危

㸞危 WEI FuWen

沙危

WEI FuWen

I 濒危 Jianghong Ran

I 濒危 Jianghong Ran

/EN

I 濒危 Jianghong Ran

I 濒危 Jianghong Ran

/EN

I 濒危 Jianghong Ran
Ecomorphological correlates of craniodental variation in bears and paleobiological implications for extinct taxa an approach based on geometric morphometrics

Ecomorphological indicators of feeding behaviour in the bears(Carnivora:Ursidae)

Effect of China's rapid development on its iconic giant panda

Effect of China's rapid development on its iconic giant panda

Effect of the Wenchuan earthquake on habitat use patterns of the giant panda in the Minshan

Mountains, southwestern China

Effect of the Wenchuan earthquake on habitat use patterns of the giant panda in the Minshan

Mountains, southwestern China

Effect of the Wenchuan earthquake on habitat use patterns of the giant panda in the Minshan

Mountains, southwestern China

Effect of the Wenchuan earthquake on habitat use patterns of the giant panda in the Minshan

Mountains, southwestern China

Effect of the Wenchuan earthquake on habitat use patterns of the giant panda in the Minshan

Mountains, southwestern China 
顾垒，闻丞，罗玫，王昊，吕植. 中国最受关注濒危物种保护现状快速评价的新方法探讨．生物多样性，2015，23(5)：583-590. http://www. biodiversity-science. net/CN/article/downloadArticleFile. do?attachType=PDF\&id=10075

\begin{tabular}{|c|c|c|c|c|c|}
\hline Ailuropoda melanoleuca & 大熊猫 & I & 濒危 & Jianghong Ran & $\begin{array}{l}\text { Effect of the Wenchuan earthquake on habitat use patterns of the giant panda in the Minshan } \\
\text { Mountains, southwestern China }\end{array}$ \\
\hline Ailuropoda melanoleuca & 大熊猫 & I & 濒危 & $\mathrm{Yu} \quad \mathrm{Li}$ & Effects of conservation policies on forest cover change in giant panda habitat regions, China \\
\hline Ailuropoda melanoleuca & 大熊猫 & I & 濒危 & Scott Bearera & Effects of fuelwood collection and timber harvesting on giant panda habitat use \\
\hline Ailuropoda melanoleuca & 大熊猫 & I & 濒危 & Andre's viñ a, & $\begin{array}{l}\text { Effects of Natural Disasters on Conservation Policies: The Case } \\
\text { of the } 2008 \text { Wenchuan Earthquake, China }\end{array}$ \\
\hline Ailuropoda melanoleuca & 大熊猫 & I & 濒危 & Ming ZHANG & $\begin{array}{l}\text { Effects of pentoxifylline, platelet activating factor and prostaglandin F 2-alpha on Giant Panda } \\
\text { (Ailuropoda } \\
\text { melanoleuca) post-thawed sperm in vitro fertilizing capability }\end{array}$ \\
\hline Ailuropoda melanoleuca & 大熊猫 & I & 濒危 & Matthew E. Durnin & Effects of radiocollars on giant panda stress-related behavior and hormones \\
\hline Ailuropoda melanoleuca & 大熊猫 & I & 濒危 & Fuwei Wei & $\begin{array}{l}\text { Effects of season and social interaction on fecal testosterone metabolites in wild male giant } \\
\text { pandas implications for energetics and mating strategies }\end{array}$ \\
\hline Ailuropoda melanoleuca & 大熊猫 & I & 濒危 & M. Helander & Endophytic fungi and silica content of different bamboo species in giant panda diet \\
\hline Ailuropoda melanoleuca & 大熊猫 & I & $\begin{array}{l}\text { 濒危 } \\
\text { /EN }\end{array}$ & M. Helander & Endophytic fungi and silica content of different bamboo species in giant panda diet \\
\hline
\end{tabular}


顾垒，闻丞，罗玫，王昊，吕植. 中国最受关注濒危物种保护现状快速评价的新方法探讨．生物多样性，2015，23(5)：583-590. http://www. biodiversity-science. net/CN/article/downloadArticleFile. do?attachType=PDF\&id=10075

\begin{tabular}{|c|c|c|c|c|c|}
\hline Ailuropoda melanoleuca & 大熊猫 & I & $\begin{array}{l}\text { 濒危 } \\
\text { /EN }\end{array}$ & Tommy G. Finley, & $\begin{array}{l}\text { Energy Digestibility of Giant Pandas } \\
\text { on Bamboo-Only and on Supplemented } \\
\text { Diets }\end{array}$ \\
\hline Ailuropoda melanoleuca & 大熊猫 & I & $\begin{array}{l}\text { 濒危 } \\
\text { /EN }\end{array}$ & Dingzhen Liu & $\begin{array}{l}\text { Enhancing captive breeding in giant pandas (Ailuropoda melanoleuca) maintaining lactation } \\
\text { when cubs are rejected, and understanding variation in milk collection and Associated Factors }\end{array}$ \\
\hline Ailuropoda melanoleuca & 大熊猫 & I & $\begin{array}{l}\text { 濒危 } \\
\text { /EN }\end{array}$ & BOJIE FU & $\begin{array}{l}\text { Entangling the Complexity of Protected Area Management: The Case of Wolong Biosphere } \\
\text { Reserve, Southwestern China }\end{array}$ \\
\hline AILUROPODA & 熊猫 & I & 濒危 & 赵立平 & ERIC-PCR 分子杂交技术分析大熊猫肠道菌群结构 \\
\hline MELANOLEUCA & & & $/ \mathrm{EN}$ & & \\
\hline Ailuropoda melanoleuca & 大熊猫 & I & $\begin{array}{l}\text { 濒危 } \\
\text { /EN }\end{array}$ & Vanessa Hull & $\begin{array}{l}\text { Evaluating the efficacy of zoning designations for protected area } \\
\text { management }\end{array}$ \\
\hline Ailuropoda melanoleuca & 大熊猫 & I & $\begin{array}{l}\text { 濒危 } \\
\text { /EN }\end{array}$ & Ronald R. Swaisgood & $\begin{array}{l}\text { Evaluation of Behavioral Factors Influencing Reproductive Success and Failure in Captive } \\
\text { Giant Pandas }\end{array}$ \\
\hline Ailuropoda melanoleuca & 大熊猫 & I & $\begin{array}{l}\text { 濒危 } \\
\text { /EN }\end{array}$ & Yazhong Xiao & Evidence for Lignin Oxidation by the Giant Panda Fecal Microbiome \\
\hline Ailuropoda melanoleuca & 大熊猫 & I & $\begin{array}{l}\text { 濒危 } \\
\text { /EN }\end{array}$ & Manuel J.Salesa & Evidence of a false thumb in a fossil carnivore clarifies the evolution of pandas \\
\hline Ailuropoda melanoleuca & 大熊猫 & I & $\begin{array}{l}\text { 濒危 } \\
\text { /EN }\end{array}$ & Lifeng Zhua & $\begin{array}{l}\text { Evidence of cellulose metabolism by the giant } \\
\text { panda gut microbiome }\end{array}$ \\
\hline
\end{tabular}


顾垒，闻丞，罗玫，王昊，吕植. 中国最受关注濒危物种保护现状快速评价的新方法探讨．生物多样性，2015，23(5)：583-590.

http://www. biodiversity-science. net/CN/article/downloadArticleFile. do?attachType=PDF\&id=10075

\begin{tabular}{|c|c|c|c|c|c|}
\hline Ailuropoda melanoleuca & 大熊猫 & I & $\begin{array}{l}\text { 濒危 } \\
\text { /EN }\end{array}$ & Jennifer Golbach & $\begin{array}{l}\text { Evolution of maternal investment strategies for the Panda Bear, Ailuropoda melanoeuca, based } \\
\text { on environmental risk factors. }\end{array}$ \\
\hline Ailuropoda melanoleuca & 大熊猫 & I & $\begin{array}{l}\text { 濒危 } \\
\text { /EN }\end{array}$ & Yoshiki Yasukochi & Evolution of the CYP2D cluster in humans and four non-human primates \\
\hline Ailuropoda melanoleuca & 大熊猫 & I & $\begin{array}{l}\text { 濒危 } \\
\text { /EN }\end{array}$ & Manuel J.Salesa & $\begin{array}{l}\text { Evolution oftheFamilyAiluridae: } \\
\text { Origins andOld-WorldFossilRecord }\end{array}$ \\
\hline Ailuropoda melanoleuca & 大熊猫 & I & $\begin{array}{l}\text { 濒危 } \\
\text { /EN }\end{array}$ & Dingzhen Liu & Exposure to Odors of Rivals Enhances Sexual Motivation in Male Giant Pandas \\
\hline Ailuropoda melanoleuca & 大熊猫 & I & $\begin{array}{l}\text { 濒危 } \\
\text { /EN }\end{array}$ & Zhigang Jiang & $\begin{array}{l}\text { Factors affecting crop damage by wild boar and methods } \\
\text { of mitigation in a giant panda reserve }\end{array}$ \\
\hline Ailuropoda melanoleuca & 大熊猫 & I & $\begin{array}{l}\text { 濒危 } \\
\text { /EN }\end{array}$ & RAN JiangHong & $\begin{array}{l}\text { Factors influencing the natural regeneration of arrow bamboo in giant panda habitat of the north } \\
\text { Minshan Mountains, southwestern China }\end{array}$ \\
\hline Ailuropoda melanoleuca & 大熊猫 & I & $\begin{array}{l}\text { 濒危 } \\
\text { /EN }\end{array}$ & RAN JiangHong & $\begin{array}{l}\text { Factors influencing the natural regeneration of arrow bamboo in giant panda habitat of the north } \\
\text { Minshan Mountains, southwestern China }\end{array}$ \\
\hline Ailuropoda melanoleuca & 大熊猫 & I & $\begin{array}{l}\text { 濒危 } \\
\text { /EN }\end{array}$ & Per Christiansen* & Feeding Ecology and Morphology of the Upper Canines in Bears (Carnivora: Ursidae) \\
\hline Ailuropoda melanoleuca & 大熊猫 & I & $\begin{array}{l}\text { 濒危 } \\
\text { /EN }\end{array}$ & Stephen Wroe & $\begin{array}{l}\text { Finite element analysis of ursid cranial mechanics and the prediction of feeding behaviour in } \\
\text { the extinct giant Agriotherium africanum }\end{array}$ \\
\hline Ailuropoda melanoleuca & 大熊猫 & I & 濒危 & Diann E. Gaalema & Food Preference, Keeper Ratings, \\
\hline
\end{tabular}


顾垒，闻丞，罗玫，王昊，吕植. 中国最受关注濒危物种保护现状快速评价的新方法探讨．生物多样性，2015，23(5)：583-590.

Ailuropoda melanoleuca

Ailuropoda melanoleuca

Ailuropoda melanoleuca

Ailuropoda melanoleuca

Ailuropoda melanoleuca

Ailuropoda melanoleuca

Ailuropoda melanoleuca

Ailuropoda melanoleuca

\section{大熊猫}

大熊猫

大熊猫

大熊猫

大熊猫

大熊猫

大熊猫

大熊猫

and Reinforcer Effectiveness in

Exotic Animals: The Value of

Systematic Testing

Gauging the impact of management expertise on the distribution of large mammals across

\section{protected areas}

Genetic consequences of historical anthropogenic and ecological events on giant pandas

I 濒危 FuWen Wei

/EN

I 濒危 Bisong Yue

/EN

I 濒危 Fuwen Wei

/EN

I 濒危 P. Palmqvis

/EN

I 濒危 Rebecca E.Spindler

/EN

I 濒危 Sheng-Guo Fang

/EN

I 濒危 Y Song
Genetic diversities of the giant panda (Ailuropoda melanoleuca) in Wanglang and Baoxing

\section{Nature Reserves}

Genetic evidence of recent population contraction in the southernmost population of gian pandas

Geometric morphometrics shows differences and similarities in skull shape between the red and giant pandas

Giant panda (Ailuropoda melanoleuca) spermatozoon decondensation in vitro is not compromised by cryopreservation

Giant panda genomic data provide insight into the birth-and-death process of mammalian major histocompatibility complex class II genes

Giant panda habitat networks and conservation: Is this species adequately protected? 
顾垒，闻丞，罗玫，王吴，吕植. 中国最受关注濒危物种保护现状快速评价的新方法探讨. 生物多样性，2015，23(5)：583-590. http://www. biodiversity-science. net/CN/article/downloadArticleFile. do?attachType=PDF\&id=10075

\begin{tabular}{|c|c|c|c|c|c|}
\hline Ailuropoda melanoleuca & 大熊猫 & I & $\begin{array}{l}\text { 濒危 } \\
\text { /EN }\end{array}$ & Fuwen Wei & Giant panda scent-marking strategies in the wild role of season, sex and marking surface \\
\hline Ailuropoda melanoleuca & 大熊猫 & I & $\begin{array}{l}\text { 濒危 } \\
\text { /EN }\end{array}$ & Wanru Hou & $\begin{array}{l}\text { Giant pandaribosomal protein s14 cDNA, genomic sequence cloning, sequence analysis, and } \\
\text { overexpression }\end{array}$ \\
\hline Ailuropoda melanoleuca & 大熊猫 & I & $\begin{array}{l}\text { 濒危 } \\
\text { /EN }\end{array}$ & B. D. Charlton & Giant pandas attend to androgen-related variation in male bleats \\
\hline Ailuropoda melanoleuca & 大熊猫 & I & $\begin{array}{l}\text { 濒危 } \\
\text { /EN }\end{array}$ & Donald Lindburg & GIANT PANDAS BIOLOGY AND CONSERVATION \\
\hline Ailuropoda melanoleuca & 大熊猫 & I & $\begin{array}{l}\text { 濒危 } \\
\text { /EN }\end{array}$ & Benjamin D. Charlton & Giant pandas perceive and attend to formant frequency variation in male bleats \\
\hline AILUROPODA & 熊猫 & I & 濒危 & XUEHUA LIU & GIANTP ANDAH ABITASTE LECTIONIN FOPINGN ATURER ESERVE,CHINA \\
\hline MELANOLEUCA & & & $/ \mathrm{EN}$ & & \\
\hline Ailuropoda melanoleuca & 大熊猫 & I & $\begin{array}{l}\text { 濒危 } \\
\text { /EN }\end{array}$ & 孟祥明 & GIS 技术在平河梁自然保护区大熊猫野外监测中的应用 \\
\hline Ailuropoda melanoleuca & 大熊猫 & I & $\begin{array}{l}\text { 濒危 } \\
\text { /EN }\end{array}$ & 周世强 & GIS 在卧龙野生大熊猫种群动态及栖息地监测中的应用 \\
\hline Ailuropoda melanoleuca & 大熊猫 & I & $\begin{array}{l}\text { 濒危 } \\
\text { /EN }\end{array}$ & 赵德怀 & GIS 在野生大熊猫种群监测分析中的应用 \\
\hline Ailuropoda melanoleuca & 大熊猫 & I & 濒危 & Nathaniel Shiers & Graphical inequality diagnostics for phylogenetic trees \\
\hline
\end{tabular}


顾垒，闻丞，罗玫，王昊，吕植. 中国最受关注濒危物种保护现状快速评价的新方法探讨．生物多样性，2015，23(5)：583-590. http://www, biodiversity-science, net/CN/article/downloadArticleFile. do?attachType=PDF\&id=10075

Ailuropoda melanoleuca

Ailuropoda melanoleuca

Ailuropoda melanoleuca

Ailuropoda melanoleuca

Ailuropoda melanoleuca

AILUROPODA

MELANOLEUCA

Ailuropoda melanoleuca

AILUROPODA

MELANOLEUCA

Ailuropoda melanoleuca
大熊猫

大熊猫

大熊猫

大熊猫

大熊猫

濒危 /EN

濒危 Fuwen Wei

I

濒危 Fuwen Wei

I

贱危 Jun-Qing Li

/EN

I 濒危 Muyuan Zhu

I 濒危 Ronald R. Swaisgood

濒危

/EN

濒危

/EN

大熊猫 ei Wang

Growth of bamboo Fargesia qinlingensis and regeneration of trees in a mixed hardwood-conifer forest in the Qinling Mountains, Chin

Habitat assessment for giant pandas in the Qinling Mountain Region of China

Habitat assessment for giant pandas in the Qinling Mountain Region of China

Habitat use by giant pandas Ailuropoda melanoleuca in the Wanglang Nature Reserve, Sichuan,

China

High-level secretory expression, purification and characterization of Ailuropoda melanoleuca

growth hormone in Pichia pastoris

How Do Giant Pandas (Ailuropoda melanoleuca) Respond to Varying Properties of

Enrichments? Five Enrichment ItemsA Comparison of Behavioral Profiles Among

HS_SPME_GC_MS 在大熊猫尿液化学成分检测中的应用

Hybrid Embryos Produced by Transferring Panda or Cat Somatic Nuclei Into Rabbit MII

Oocytes Can Develop to Blastocyst In Vitro

Identification and characterization of microRNAs in Baylisascaris schroederi of the giant panda 
顾垒，闻丞，罗玫，王昊，吕植. 中国最受关注濒危物种保护现状快速评价的新方法探讨．生物多样性，2015，23(5)：583-590.

http://www. biodiversity-science. net/CN/article/downloadArticleFile. do?attachType=PDF\&id=10075

\begin{tabular}{|c|c|c|c|c|c|}
\hline Ailuropoda melanoleuca & 大熊猫 & I & $\begin{array}{l}\text { 濒危 } \\
\text { /EN }\end{array}$ & Qi-gui Yan1 & $\begin{array}{l}\text { Identification and genotypic analysis of Streptococcus spp. isolated from Giant Pandas in China } \\
\text { by PCR-based methods }\end{array}$ \\
\hline Ailuropoda melanoleuca & 大熊猫 & I & $\begin{array}{l}\text { 濒危 } \\
\text { /EN }\end{array}$ & Qi-gui Yan & $\begin{array}{l}\text { Identification of canine parvovirus with the Q370R point mutation in the VP2 gene from a giant } \\
\text { panda (Ailuropoda melanoleuca) }\end{array}$ \\
\hline Ailuropoda melanoleuca & 大熊猫 & I & $\begin{array}{l}\text { 濒危 } \\
\text { /EN }\end{array}$ & Avindra Fernando & Identification of transposable elements of the giant panda (Ailuropoda melanoleuca) genome \\
\hline Ailuropoda melanoleuca & 大熊猫 & I & $\begin{array}{l}\text { 濒危 } \\
\text { /EN }\end{array}$ & Jianjun Peng & $\begin{array}{l}\text { Impact of activity space on the reproductive behaviour of giant panda (Ailuropoda } \\
\text { melanoleuca) in captivity }\end{array}$ \\
\hline Ailuropoda melanoleuca & 大熊猫 & I & $\begin{array}{l}\text { 濒危 } \\
\text { /EN }\end{array}$ & Weihua Xu & Impact of China's May 12 earthquake on Giant Panda habitat in Wenchuan County \\
\hline Ailuropoda melanoleuca & 大熊猫 & I & $\begin{array}{l}\text { 濒危 } \\
\text { /EN }\end{array}$ & Weihua Xu & Impact of China's May 13 earthquake on Giant Panda habitat in Wenchuan County \\
\hline Ailuropoda melanoleuca & 大熊猫 & I & $\begin{array}{l}\text { 濒危 } \\
\text { /EN }\end{array}$ & Junsheng Li & $\begin{array}{l}\text { Impact of road construction on giant panda’ s habitat and its carrying } \\
\text { capacity in Qinling Mountains }\end{array}$ \\
\hline Ailuropoda melanoleuca & 大熊猫 & I & $\begin{array}{l}\text { 濒危 } \\
\text { /EN }\end{array}$ & Jindong Zhang & $\begin{array}{l}\text { Impact of the } 2008 \text { Wenchuan earthquake on biodiversity } \\
\text { and giant panda habitat in Wolong Nature Reserve, China }\end{array}$ \\
\hline Ailuropoda melanoleuca & 大熊猫 & I & $\begin{array}{l}\text { 濒危 } \\
\text { /EN }\end{array}$ & LI AN & $\begin{array}{l}\text { Impacts of demographic and socioeconomic factors on spatio-temporal dynamics of panda } \\
\text { habitat }\end{array}$ \\
\hline Ailuropoda melanoleuca & 大熊猫 & I & 濒危 & Mauricio Antón & Implications of the functional anatomy of the hand and forearm of Ailurus fulgens (Carnivora, \\
\hline
\end{tabular}


顾垒，闻丞，罗玫，王昊，吕植. 中国最受关注濒危物种保护现状快速评价的新方法探讨．生物多样性，2015，23(5)：583-590.

\begin{tabular}{|c|c|c|c|c|c|c|}
\hline \multirow{3}{*}{ Ailuropoda melanoleuca } & \multirow{3}{*}{ 大熊猫 } & \multirow{3}{*}{ I } & \multicolumn{3}{|l|}{ /EN } & \multirow{3}{*}{$\begin{array}{l}\text { Ailuridae) for the evolution of the 鈥政 alse-thumb 鈥_in pandas } \\
\text { Implications of Vocalizations during giant panda breeding encounters }\end{array}$} \\
\hline & & & 濒危 & \multicolumn{2}{|c|}{ Jennifer L.Keating } & \\
\hline & & & /EN & & & \\
\hline \multirow[t]{2}{*}{ Ailuropoda melanoleuca } & 大熊猫 & I & 濒危 & \multicolumn{2}{|c|}{ Minghao GONG } & Important population viability analysis parameters for giant pandas(Aliuropoda melanoleuca) \\
\hline & & & /EN & & & \\
\hline \multirow[t]{2}{*}{ Ailuropoda melanoleuca } & 大熊猫 & I & 濒危 & \multicolumn{2}{|c|}{ Richard B. HARRIS } & Insights into population dynamics of giant pandas gained from studies in North America \\
\hline & & & /EN & & & \\
\hline \multirow[t]{2}{*}{ Ailuropoda melanoleuca } & 大熊猫 & I & 濒危 & Zhiyun & Ouyang & Integrating population size analysis into habitat suitability assessment implications for giant \\
\hline & & & /EN & & & panda conservation in the Minshan Mountains, China \\
\hline \multirow[t]{2}{*}{ Ailuropoda melanoleuca } & 大熊猫 & I & 濒危 & Zhiyun & Ouyang & Integrating population size analysis into habitat suitability assessment implications for giant \\
\hline & & & /EN & & & panda conservation in the Minshan Mountains, China \\
\hline \multirow[t]{2}{*}{ Ailuropoda melanoleuca } & 大熊猫 & I & 濒危 & Zhiyun & Ouyang & Integrating population size analysis into habitat suitability assessment implications for giant \\
\hline & & & /EN & & & panda conservation in the Minshan Mountains, China \\
\hline \multirow[t]{2}{*}{ Ailuropoda melanoleuca } & 大熊猫 & I & 濒危 & Zhiyun & Ouyang & Integrating population size analysis into habitat suitability assessment implications for giant \\
\hline & & & /EN & & & panda conservation in the Minshan Mountains, China \\
\hline \multirow[t]{2}{*}{ Ailuropoda melanoleuca } & 大熊猫 & I & 濒危 & Zhiyun & Ouyang & Integrating population size analysis into habitat suitability assessment implications for giant \\
\hline & & & /EN & & & panda conservation in the Minshan Mountains, China \\
\hline \multirow[t]{2}{*}{ Ailuropoda melanoleuca } & 大熊猫 & I & 濒危 & Zhiyun & Ouyang & Integrating population size analysis into habitat suitability assessment implications for giant \\
\hline & & & /EN & & & panda conservation in the Minshan Mountains, China \\
\hline
\end{tabular}


顾垒，闻丞，罗玫，王昊，吕植. 中国最受关注濒危物种保护现状快速评价的新方法探讨．生物多样性，2015，23(5)：583-590.

\begin{tabular}{|c|c|c|c|c|c|}
\hline Ailuropoda melanoleuca & 大熊猫 & I & 濒危 & Zhiyun Ouyang & $\begin{array}{l}\text { Integrating population size analysis into habitat suitability assessment implications for giant } \\
\text { panda conservation in the Minshan Mountains, China }\end{array}$ \\
\hline Ailuropoda melanoleuca & 大熊猫 & I & 濒危 & Zhiyun Ouyang & $\begin{array}{l}\text { Integrating population size analysis into habitat suitability assessment implications for giant } \\
\text { panda conservation in the Minshan Mountains, China }\end{array}$ \\
\hline Ailuropoda melanoleuca & 大熊猫 & I & 濒危 & WAN QiuHong & $\begin{array}{l}\text { Isolation and characterization of class I MHC genes in the giant panda (Ailuropoda } \\
\text { melanoleuca) }\end{array}$ \\
\hline Ailuropoda melanoleuca & 大熊猫 & I & 濒危 & Gui-Xue Hu & $\begin{array}{l}\text { Isolation and identification of a canine coronavirus strain from giant pandas (Ailuropoda } \\
\text { melanoleuca) }\end{array}$ \\
\hline Ailuropoda melanoleuca & 大熊猫 & I & $\begin{array}{l}\text { 濒危 } \\
\text { /EN }\end{array}$ & Juan Abella & Kretzoiarctos gen. nov., the Oldest Member of the Giant Panda Clade. \\
\hline Ailuropoda melanoleuca & 大熊猫 & I & $\begin{array}{l}\text { 濒危 } \\
\text { /EN }\end{array}$ & Yuanman Hu & $\begin{array}{l}\text { Land use and land cover change analysis and prediction in the upper reaches of the Minjiang } \\
\text { River, China }\end{array}$ \\
\hline Ailuropoda melanoleuca & 大熊猫 & I & 濒危 & Fuwen Wei & $\begin{array}{l}\text { Landscape features influence gene flow as measured by cost-distance and genetic analyses a } \\
\text { case study for giant pandas in the Daxiangling and Xiaoxiangling Mountains }\end{array}$ \\
\hline Ailuropoda melanoleuca & 大熊猫 & I & $\begin{array}{l}\text { 濒危 } \\
\text { /EN }\end{array}$ & Wei Zhang & Landscape pattern and driving forces in the upper reaches of Minjiang River, China \\
\hline Ailuropoda melanoleuca & 大熊猫 & I & 濒危 & Jianguo Liu & Linking social norms to efficient conservation investment in payments for ecosystem services \\
\hline Ailuropoda melanoleuca & 大熊猫 & I & 濒危 & Liding Chen & Local people's perceptions as decision support for protected area management in Wolong \\
\hline
\end{tabular}


顾垒，闻丞，罗玫，王昊，吕植. 中国最受关注濒危物种保护现状快速评价的新方法探讨．生物多样性，2015，23(5)：583-590.

\begin{tabular}{|c|c|c|c|c|c|}
\hline & & & /EN & & Biosphere Reserve, China \\
\hline \multirow[t]{2}{*}{ Ailuropoda melanoleuca } & 大熊猫 & I & 濒危 & Li An & Long-term effects of family planning and other determinants of fertility on population and \\
\hline & & & /EN & & environment agent-based modeling evidence from Wolong Nature Reserve, China \\
\hline \multirow[t]{2}{*}{ Ailuropoda melanoleuca } & 大熊猫 & I & 濒危 & Katharina Bastl & Low - magnification microwear in Carnivora and dietary diversity in Hyaenodon (Mammalia \\
\hline & & & /EN & & Hyaenodontidae) with additional information on its enamel microstructure \\
\hline \multirow[t]{2}{*}{ Ailuropoda melanoleuca } & 大熊猫 & I & 濒危 & QIU-HONG WAN & Major histocompatibility complex class II variation in the giant panda ( Ailuropoda \\
\hline & & & /EN & & melanoleuca). \\
\hline \multirow[t]{2}{*}{ Ailuropoda melanoleuca } & 大熊猫 & I & 濒危 & Bian Meng & Mapping the Distribution and Biomass of Bamboo in the Forest Under-Storey of Qinling \\
\hline & & & /EN & & Mountains, a Remote Sensing Approach \\
\hline \multirow[t]{2}{*}{ Ailuropoda melanoleuca } & 大熊猫 & I & 濒危 & HONG JIANG & Mapping the vegetation changes in giant panda habitat using \\
\hline & & & /EN & & Landsat remotely sensed data \\
\hline \multirow[t]{2}{*}{ Ailuropoda melanoleuca } & 大熊猫 & I & 濒危 & Jianjun Peng & Mate choice in giant panda (Ailuropoda melanoleuca) \\
\hline & & & /EN & & \\
\hline \multirow[t]{2}{*}{ Ailuropoda melanoleuca } & 大熊猫 & I & 濒危 & Jianjun PENG & Mate preference and sexual selection in giant panda, ailuropoda melanoleuca in captivity \\
\hline & & & /EN & & \\
\hline \multirow[t]{2}{*}{ Ailuropoda melanoleuca } & 大熊猫 & I & 濒危 & Zejun Zhang & Microhabitat separation during winter among sympatric giant pandas, red pandas, and tufted \\
\hline & & & /EN & & deer: the effects of diet, body size, and energy metabolism \\
\hline \multirow[t]{2}{*}{ Ailuropoda melanoleuca } & 大熊猫 & I & 濒危 & Qing ZHU & Microsatellite variability reveals high genetic diversity and \\
\hline & & & /EN & & low genetic differentiation in a critical giant panda population \\
\hline
\end{tabular}


顾垒，闻丞，罗玫，王昊，吕植. 中国最受关注濒危物种保护现状快速评价的新方法探讨．生物多样性，2015，23(5)：583-590.

\begin{tabular}{|c|c|c|c|c|c|}
\hline Ailuropoda melanoleuca & 大熊猫 & I & $\begin{array}{l}\text { 濒危 } \\
\text { /EN }\end{array}$ & Qing Zhu & $\begin{array}{l}\text { Microsatellite variability reveals significant genetic differentiation of giant pandas (Ailuropoda } \\
\text { melanoleuca) in the Minshan A habitat }\end{array}$ \\
\hline Ailuropoda melanoleuca & 大熊猫 & I & $\begin{array}{l}\text { 濒危 } \\
\text { /EN }\end{array}$ & Qing Zhu & $\begin{array}{l}\text { Microsatellite variability reveals significant genetic differentiation of giant pandas (Ailuropoda } \\
\text { melanoleuca) in the Minshan A habitat }\end{array}$ \\
\hline Ailuropoda melanoleuca & 大熊猫 & I & $\begin{array}{l}\text { 濒危 } \\
\text { /EN }\end{array}$ & Bisong Yue & $\begin{array}{l}\text { Microsatellite variability reveals the necessity for genetic input from wild giant pandas } \\
\text { (Ailuropoda melanoleuca) into the captive population }\end{array}$ \\
\hline Ailuropoda melanoleuca & 大熊猫 & I & $\begin{array}{l}\text { 濒危 } \\
\text { /EN }\end{array}$ & Bisong Yue & $\begin{array}{l}\text { Microsatellite variability reveals the necessity for genetic input from wild giant pandas } \\
\text { (Ailuropoda melanoleuca) into the captive population }\end{array}$ \\
\hline Ailuropoda melanoleuca & 大熊猫 & I & $\begin{array}{l}\text { 濒危 } \\
\text { /EN }\end{array}$ & Bisong Yue & $\begin{array}{l}\text { Microsatellite variability reveals the necessity for genetic input from wild giant pandas } \\
\text { (Ailuropoda melanoleuca) into the captive population }\end{array}$ \\
\hline Ailuropoda melanoleuca & 大熊猫 & I & $\begin{array}{l}\text { 濒危 } \\
\text { /EN }\end{array}$ & Bisong Yue & $\begin{array}{l}\text { Microsatellite variability reveals the necessity for genetic input from wild giant pandas } \\
\text { (Ailuropoda melanoleuca) into the captive population }\end{array}$ \\
\hline Ailuropoda melanoleuca & 大熊猫 & I & $\begin{array}{l}\text { 濒危 } \\
\text { /EN }\end{array}$ & Bernard Knoops & $\begin{array}{l}\text { Mitochondrial targeting of peroxiredoxin } 5 \text { is preserved from annelids to mammals } \\
\text { but is absent in pig Sus scrofa domesticus }\end{array}$ \\
\hline $\begin{array}{l}\text { AILUROPODA } \\
\text { MELANOLEUCA }\end{array}$ & 熊猫 & I & $\begin{array}{l}\text { 濒危 } \\
\text { /EN }\end{array}$ & Marc A. Linderman & $\begin{array}{l}\text { Modeling the spatio-temporal dynamics and interactions of households, landscapes, and giant } \\
\text { panda habitat }\end{array}$ \\
\hline Ailuropoda melanoleuca & 大熊猫 & I & $\begin{array}{l}\text { 濒危 } \\
\text { /EN }\end{array}$ & GUANGYOU YANG & $\begin{array}{l}\text { Molecular characterization and phylogenetic analysis of ascarid nematodes from twenty-one } \\
\text { species of captive wild mammals based on mitochondrial and nuclear sequences }\end{array}$ \\
\hline Ailuropoda melanoleuca & 大熊猫 & I & 濒危 & Wan-ru Hou & Molecular characterization of a gene POLR2H encoded an essential subunit for RNA \\
\hline
\end{tabular}


顾垒，闻丞，罗玫，王昊，吕植. 中国最受关注濒危物种保护现状快速评价的新方法探讨．生物多样性，2015，23(5)：583-590.

\begin{tabular}{|c|c|c|c|c|c|}
\hline & & & /EN & & polymerase II from the Giant Panda (Ailuropoda Melanoleuca) \\
\hline Ailuropoda melanoleuca & 大熊猫 & I & 濒危 & Sheng-Guo Fang & $\begin{array}{l}\text { Molecular characterization of major histocompatibility complex class I genes from the giant } \\
\text { panda (Ailuropoda melanoleuca) }\end{array}$ \\
\hline Ailuropoda melanoleuca & 大熊猫 & I & 濒危 & Mohamed S. Elrobh & $\begin{array}{l}\text { Molecular Cloning and Characterization of cDNA Encoding a Putative Stress-Induced } \\
\text { Heat-Shock Protein from Camelus dromedarius }\end{array}$ \\
\hline Ailuropoda melanoleuca & 大熊猫 & I & $\begin{array}{l}\text { 濒危 } \\
\text { /EN }\end{array}$ & Fangdong Zou & $\begin{array}{l}\text { Molecular cloning and sequence analysis of the gene encoding interleukin- } 6 \text { of the giant panda } \\
\text { (Ailuropoda melanoleuca) }\end{array}$ \\
\hline Ailuropoda melanoleuca & 大熊猫 & I & 濒危 & Qi-gui Yan & Molecular cloning and sequence analysis of VP6 gene of giant panda rotavirus strain $\mathrm{CH}-1$ \\
\hline AILUROPODA & 熊猫 & I & 濒危 & Zhu Mu-Yuan & MOLECULAR CLONING OF GIANT PANDA PITUITARY PROLACTIN CDNA AND ITS \\
\hline MELANOLEUCA & & & $/$ EN & & EXPRESSION IN Escherichia coli \\
\hline Ailuropoda melanoleuca & 大熊猫 & I & $\begin{array}{l}\text { 濒危 } \\
\text { /EN }\end{array}$ & Wan-ru Hou & $\begin{array}{l}\text { Molecular cloning of ribosomal protein L26 (RPL26) cDNA from Ailuropoda melanoleuca and } \\
\text { its potential value in phylogenetic study }\end{array}$ \\
\hline Ailuropoda melanoleuca & 大熊猫 & I & 濒危 & Guang-you Yang & $\begin{array}{l}\text { Molecular Diagnosis of Baylisascaris schroederi Infections in Giant Panda (Ailuropoda } \\
\text { melanoleuca) Feces Using PCR }\end{array}$ \\
\hline Ailuropoda melanoleuca & 大熊猫 & I & $\begin{array}{l}\text { 濒危 } \\
\text { /EN }\end{array}$ & YANG Guangyou & $\begin{array}{l}\text { Molecular phylogenetic studies on ascarid nematodes from Ailuropoda melanoleuca and seven } \\
\text { other species of captive wild mammals based on ND1 genes }\end{array}$ \\
\hline Ailuropoda melanoleuca & 大熊猫 & I & $\begin{array}{l}\text { 濒危 } \\
\text { /EN }\end{array}$ & Megan A. Owen & $\begin{array}{l}\text { Monitoring Stress in Captive Giant Pandas(Ailuropoda melanoleuca):Behavioral and Hormonal } \\
\text { Responses to Ambient Noise }\end{array}$ \\
\hline
\end{tabular}


顾垒，闻丞，罗玫，王昊，吕植. 中国最受关注濒危物种保护现状快速评价的新方法探讨．生物多样性，2015，23(5)：583-590. http://www. biodiversity-science. net/CN/article/downloadArticleFile. do?attachType=PDF\&id=10075

\begin{tabular}{|c|c|c|c|c|c|}
\hline Ailuropoda melanoleuca & 大熊猫 & I & 濒危 & PASQUALE RAIA & Morphological correlates of tough food consumption in large land carnivores \\
\hline Ailuropoda melanoleuca & 大熊猫 & I & 濒危 & Shengguo Fang & $\begin{array}{l}\text { Natural selection coupled with intragenic recombination shapes diversity patterns in the major } \\
\text { histocompatibility complex class II genes of the giant panda }\end{array}$ \\
\hline Ailuropoda melanoleuca & 大熊猫 & I & 濒危 & Junqing Li & $\begin{array}{l}\text { Nature reserve group planning for conservation of giant pandas in North } \\
\text { Minshan, China }\end{array}$ \\
\hline Ailuropoda melanoleuca & 大熊猫 & I & 濒危 & De-Fu Hu & $\begin{array}{l}\text { Non-invasive determination of fecal steroid hormones } \\
\text { relating to conservation practice in giant panda } \\
\text { (Ailuropoda melanoleuca) }\end{array}$ \\
\hline Ailuropoda melanoleuca & 大熊猫 & I & 濒危 & Fuwen Wei & Old-growth forest is what giant pandas really need \\
\hline Ailuropoda melanoleuca & 大熊猫 & I & $\begin{array}{l}\text { 濒危 } \\
\text { /EN }\end{array}$ & P Comizzoli & On the Horizon for Fertility Preservation in Domestic and Wild Carnivores \\
\hline Ailuropoda melanoleuca & 大熊猫 & I & 濒危 & W. Hou & $\begin{array}{l}\text { Overexpression, purification, and pharmacologic evaluation of anticancer activity of ribosomal } \\
\text { protein L24 from the giant panda (Ailuropoda melanoleuca) }\end{array}$ \\
\hline Ailuropoda melanoleuca & 大熊猫 & I & 濒危 & 张守信 & PAF 和 PAF-AH 监测对大熊猫（Ailuropoda melanoleuca）早孕诊断的可行性研究 \\
\hline Ailuropoda melanoleuca & 大熊猫 & I & 濒危 & Shuyi Zhang & Parasite Threat to Panda Conservation \\
\hline
\end{tabular}


顾垒，闻丞，罗玫，王昊，吕植. 中国最受关注濒危物种保护现状快速评价的新方法探讨．生物多样性，2015，23(5)：583-590.

http://www. biodiversity-science. net/CN/article/downloadArticleFile. do?attachType=PDF\&id=10075

\begin{tabular}{|c|c|c|c|c|c|}
\hline Ailuropoda melanoleuca & 大熊猫 & I & $\begin{array}{l}\text { 濒危 } \\
\text { /EN }\end{array}$ & Sheng-Guo Fang & $\begin{array}{l}\text { Patterns of adaptive and neutral diversity identify the Xiaoxiangling Mountains as a refuge for } \\
\text { the giant panda }\end{array}$ \\
\hline Ailuropoda melanoleuca & 大熊猫 & I & $\begin{array}{l}\text { 濒危 } \\
\text { /EN }\end{array}$ & Sheng-Guo Fang & $\begin{array}{l}\text { Patterns of genetic differentiation at MHC class I genes and microsatellites identify } \\
\text { conservation units in the giant panda }\end{array}$ \\
\hline Ailuropoda melanoleuca & 大熊猫 & I & $\begin{array}{l}\text { 濒危 } \\
\text { /EN }\end{array}$ & JIAYIN DAI & Perfluorooctanesulfonate and perfluorooctanoate in red panda and giant panda from China \\
\hline Ailuropoda melanoleuca & 大熊猫 & I & $\begin{array}{l}\text { 濒危 } \\
\text { /EN }\end{array}$ & Wu Yang & Performance and prospects of payments for ecosystem services programs Evidence from China \\
\hline Ailuropoda melanoleuca & 大熊猫 & I & $\begin{array}{l}\text { 濒危 } \\
\text { /EN }\end{array}$ & Xiaoping Ma & $\begin{array}{l}\text { Phaeohyphomycotic dermatitis in a giant panda (Ailuropoda melanoleuca) caused by } \\
\text { Cladosporium cladosporioides }\end{array}$ \\
\hline Ailuropoda melanoleuca & 大熊猫 & I & $\begin{array}{l}\text { 濒危 } \\
\text { /EN }\end{array}$ & Sarita Keski-Saa & $\begin{array}{l}\text { Phenolics from the culms of five bamboo species in the Tangjiahe and Wolong Giant Panda } \\
\text { Reserves, Sichuan, China }\end{array}$ \\
\hline Ailuropoda melanoleuca & 大熊猫 & I & $\begin{array}{l}\text { 濒危 } \\
\text { /EN }\end{array}$ & Sarita Keski-Saa & $\begin{array}{l}\text { Phenolics from the culms of five bamboo species in the Tangjiahe and Wolong Giant Panda } \\
\text { Reserves, Sichuan, China }\end{array}$ \\
\hline Ailuropoda melanoleuca & 大熊猫 & I & $\begin{array}{l}\text { 濒危 } \\
\text { /EN }\end{array}$ & Hong-Ning Wang & $\begin{array}{l}\text { Phenotypic and genotypic characterisation of antimicrobial resistance in faecal bacteria from } 30 \\
\text { Giant pandas }\end{array}$ \\
\hline Ailuropoda melanoleuca & 大熊猫 & I & $\begin{array}{l}\text { 濒危 } \\
\text { /EN }\end{array}$ & Qi-gui Yan & $\begin{array}{l}\text { Phylogenetic analysis of the haemagglutinin gene of canine distemper virus strains detected } \\
\text { from giant panda and raccoon dogs in China }\end{array}$ \\
\hline Ailuropoda melanoleuca & 大熊猫 & I & 濒危 & Ya-ping Zhang & Phylogenetic relationships within mammalian order Carnivora indicated by sequences of two \\
\hline
\end{tabular}


顾垒，闻丞，罗玫，王昊，吕植. 中国最受关注濒危物种保护现状快速评价的新方法探讨．生物多样性，2015，23(5)：583-590. http://www. biodiversity-science. net/CN/article/downloadArticleFile. do?attachType=PDF\&id=10075

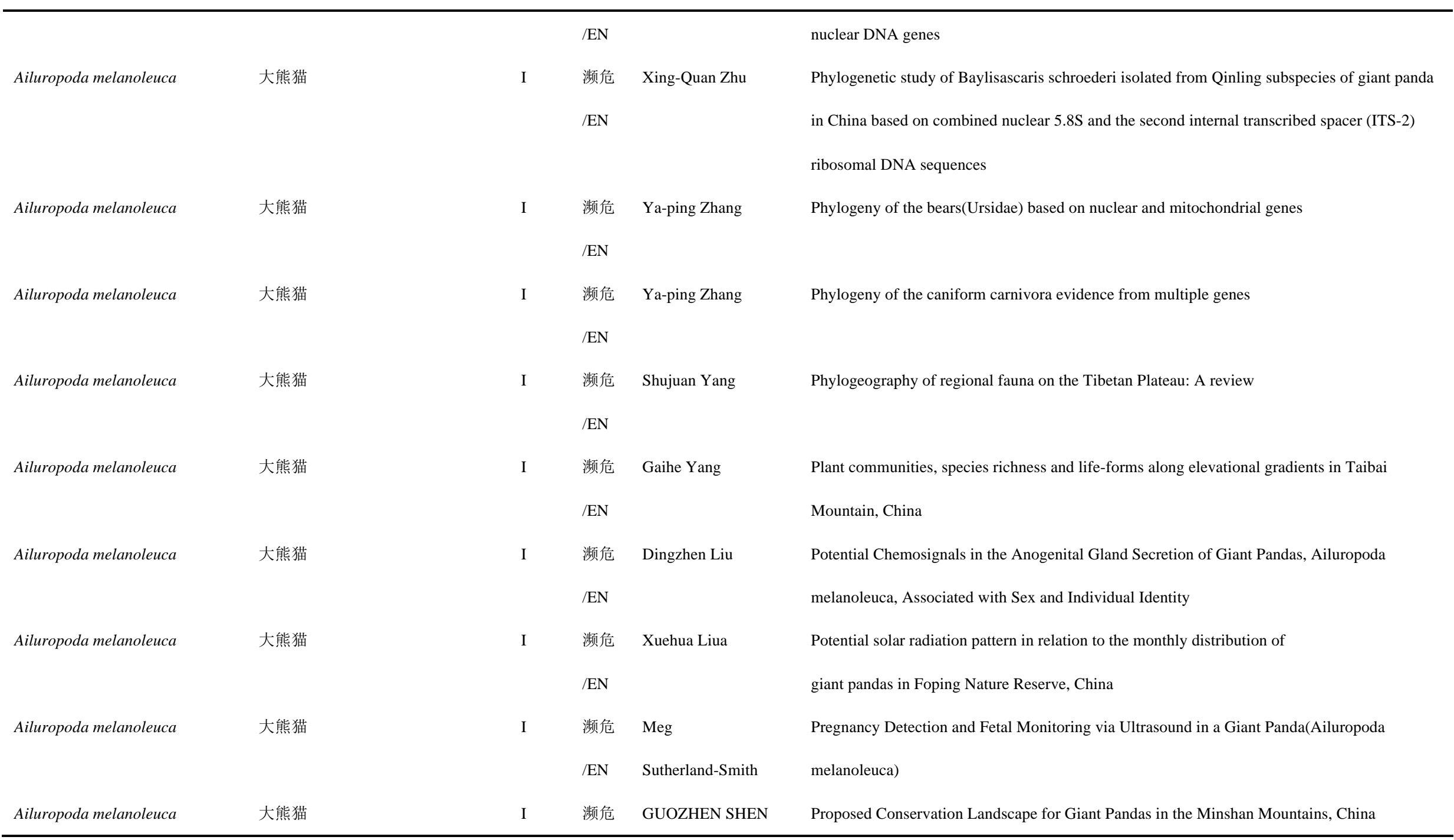


顾垒，闻丞，罗玫，王昊，吕植. 中国最受关注濒危物种保护现状快速评价的新方法探讨．生物多样性，2015，23(5)：583-590. http://www. biodiversity-science. net/CN/article/downloadArticleFile. do?attachType=PDF\&id=10075

Ailuropoda melanoleuca

Ailuropoda melanoleuca

Ailuropoda melanoleuca

Ailuropoda melanoleuca

Ailuropoda melanoleuca

Ailuropoda melanoleuca

Ailuropoda melanoleuca

Ailuropoda melanoleuca

Ailuropoda melanoleuca
大熊猫

大熊猫

大熊猫

大熊猫

大熊猫

大熊猫

大熊猫

大熊猫

濒危

GUOZHEN SHEN

EN

濒危

C. Aitken-Palmer EN

Andrés Viña

EN

Cyrielle Goillot

I 濒危 Nina G. Jablonski

/EN

I 濒危 David C. Kersey

/EN

I 濒危 F. Wei

/EN

大熊猫
濒危 Defu HU
Proposed Conservation Landscape for Giant Pandas in the Minshan Mountains, China

Protracted Reproductive Seasonality in the Male Giant Panda (Ailuropoda melanoleuca)

Reflected by Patterns in Androgen Profiles, Ejaculate Characteristics, and Selected Behaviors

Range-wide analysis of wildlife habitat implications for conservation

Relationships between dental microwear and diet in Carnivora (Mammalia) - Implications for

the reconstruction of the diet of extinct taxa

Reliable genetic analyses based on formalin-fixed materials a new noninvasive sampling

perspective for the giant panda

Remains of Holocene giant pandas from Jiangdong Mountain (Yunnan, China) and their

relevance to the evolution of quaternary environments in south-western ...

Reproductive and Adrenal Endocrinology of the Giant Panda (Ailuropoda melanoleuca)

Reproductive competition and fecal testosterone in wild male giant pandas (Ailuropoda

melanoleuca)

Research on methods of preserving fecal steroid hormones in giant panda (Ailuropoda

melanoleuca) 
顾垒，闻丞，罗玫，王昊，吕植. 中国最受关注濒危物种保护现状快速评价的新方法探讨．生物多样性，2015，23(5)：583-590. http://www. biodiversity-science. net/CN/article/downloadArticleFile. do?attachType=PDF\&id=10075

\begin{tabular}{|c|c|c|c|c|c|}
\hline Ailuropoda melanoleuca & 大熊猫 & I & 濒危 & Christopher J. Norton & $\begin{array}{l}\text { Rethinking the Palearctic-Oriental Biogeographic Boundary } \\
\text { in Quaternary China }\end{array}$ \\
\hline Ailuropoda melanoleuca & 大熊猫 & I & 濒危 & David C. Kersey & $\begin{array}{l}\text { Rising fecal glucocorticoid concentrations track reproductive activity } \\
\text { in the female giant panda (Ailuropoda melanoleuca) }\end{array}$ \\
\hline Ailuropoda melanoleuca & 大熊猫 & I & 濒危 & Gregory A. Petsko & Rising in the East \\
\hline Ailuropoda melanoleuca & 大熊猫 & I & 濒危 & Luo Yaofeng & Role of traditional beliefs of Baima Tibetans in biodiversity conservation in China \\
\hline Ailuropoda melanoleuca & 大熊猫 & I & $\begin{array}{l}\text { 濒危 } \\
\text { /EN }\end{array}$ & Wan-ru Hou & $\begin{array}{l}\text { Sequence analysis and over-expression of ribosomal protein S28 gene (RPS28) from the Giant } \\
\text { Panda }\end{array}$ \\
\hline Ailuropoda melanoleuca & 大熊猫 & I & $\begin{array}{l}\text { 濒危 } \\
\text { /EN }\end{array}$ & Guangyou Yang & $\begin{array}{l}\text { Sequence analysis of Bs-Ag2 gene from Baylisascaris schroederi of giant panda and evaluation } \\
\text { of the efficacy of a recombinant Bs-Ag2 antigen in mice }\end{array}$ \\
\hline Ailuropoda melanoleuca & 大熊猫 & I & 濒危 & Guangzhi He & $\begin{array}{l}\text { Sequence analysis of the Bs-Ag1 gene of Baylisascaris schroederi from the giant panda and an } \\
\text { evaluation of the efficacy of a recombinant Baylisascaris schroederi Bs }\end{array}$ \\
\hline Ailuropoda melanoleuca & 大熊猫 & I & $\begin{array}{l}\text { 濒危 } \\
\text { /EN }\end{array}$ & Alberto J. León & Sequencing, Annotation, and Characterization of the Influenza Ferret Infectome \\
\hline Ailuropoda melanoleuca & 大熊猫 & I & 濒危 & QIAO Jun & Serological survey on canine coronavirus antibodies in giant pandas by virus neutralization test \\
\hline Ailuropoda melanoleuca & 大熊猫 & I & 濒危 & Qigui Yan & Serotypes, Virulence Factors, and Antimicrobial Susceptibilities of Vaginal and Fecal Isolates \\
\hline
\end{tabular}


顾垒，闻丞，罗玫，王吴，吕植. 中国最受关注濒危物种保护现状快速评价的新方法探讨. 生物多样性，2015，23(5)：583-590. http://www, biodiversity-science, net/CN/article/downloadArticleFile. do?attachType=PDF\&id=10075

\begin{tabular}{|c|c|c|c|c|c|}
\hline & & & /EN & & of Escherichia coli from Giant Pandas \\
\hline Ailuropoda melanoleuca & 大熊猫 & I & $\begin{array}{l}\text { 濒危 } \\
\text { /EN }\end{array}$ & LIFENG ZHU & $\begin{array}{l}\text { Significant genetic boundaries and spatial dynamics of } \\
\text { giant pandas occupying fragmented habitat across }\end{array}$ \\
\hline & & & & & southwest China \\
\hline Ailuropoda melanoleuca & 大熊猫 & I & $\begin{array}{l}\text { 濒危 } \\
\text { /EN }\end{array}$ & G.H. Song & $\begin{array}{l}\text { Simulation study on giant panda population dynamics model with due consideration for } \\
\text { deforestation }\end{array}$ \\
\hline Ailuropoda melanoleuca & 大熊猫 & I & $\begin{array}{l}\text { 濒危 } \\
\text { /EN }\end{array}$ & Sheng-Guo Fang & Sixteen novel microsatellite loci developed for the giant panda (Ailuropoda melanoleuca) \\
\hline Ailuropoda melanoleuca & 大熊猫 & I & $\begin{array}{l}\text { 濒危 } \\
\text { /EN }\end{array}$ & Guangming He & $\begin{array}{l}\text { Spatial and temporal patterns of fuelwood collection in Wolong Nature Reserve Implications } \\
\text { for panda conservation }\end{array}$ \\
\hline Ailuropoda melanoleuca & 大熊猫 & I & $\begin{array}{l}\text { 濒危 } \\
\text { /EN }\end{array}$ & Fuwen Wei & Spatial genetic structure and dispersal of giant pandas on a mountain-range scale \\
\hline Ailuropoda melanoleuca & 大熊猫 & I & $\begin{array}{l}\text { 濒危 } \\
\text { /EN }\end{array}$ & Bonnie M. Perdue & $\begin{array}{l}\text { SPATIAL MEMORY RECALL IN THE GIANT PANDA （AILUROPODA } \\
\text { MELANOLEUCA) }\end{array}$ \\
\hline Ailuropoda melanoleuca & 大熊猫 & I & $\begin{array}{l}\text { 濒危 } \\
\text { /EN }\end{array}$ & Kodzue Kinoshita & Spectral pattern of urinary water as a biomarker of estrus in the giant panda \\
\hline Ailuropoda melanoleuca & 大熊猫 & I & $\begin{array}{l}\text { 濒危 } \\
\text { /EN }\end{array}$ & Dingzhen Liu & $\begin{array}{l}\text { Stereotypic behavior and fecal cortisol level in captive giant pandas in relation to environmental } \\
\text { enrichment }\end{array}$ \\
\hline Ailuropoda melanoleuca & 大熊猫 & I & 濒危 & Ellen S. & Supplemental iodine as a key to reproduction in pandas \\
\hline
\end{tabular}


顾垒，闻丞，罗玫，王昊，吕植. 中国最受关注濒危物种保护现状快速评价的新方法探讨．生物多样性，2015，23(5)：583-590. http://www, biodiversity-science, net/CN/article/downloadArticleFile. do?attachType=PDF\&id=10075

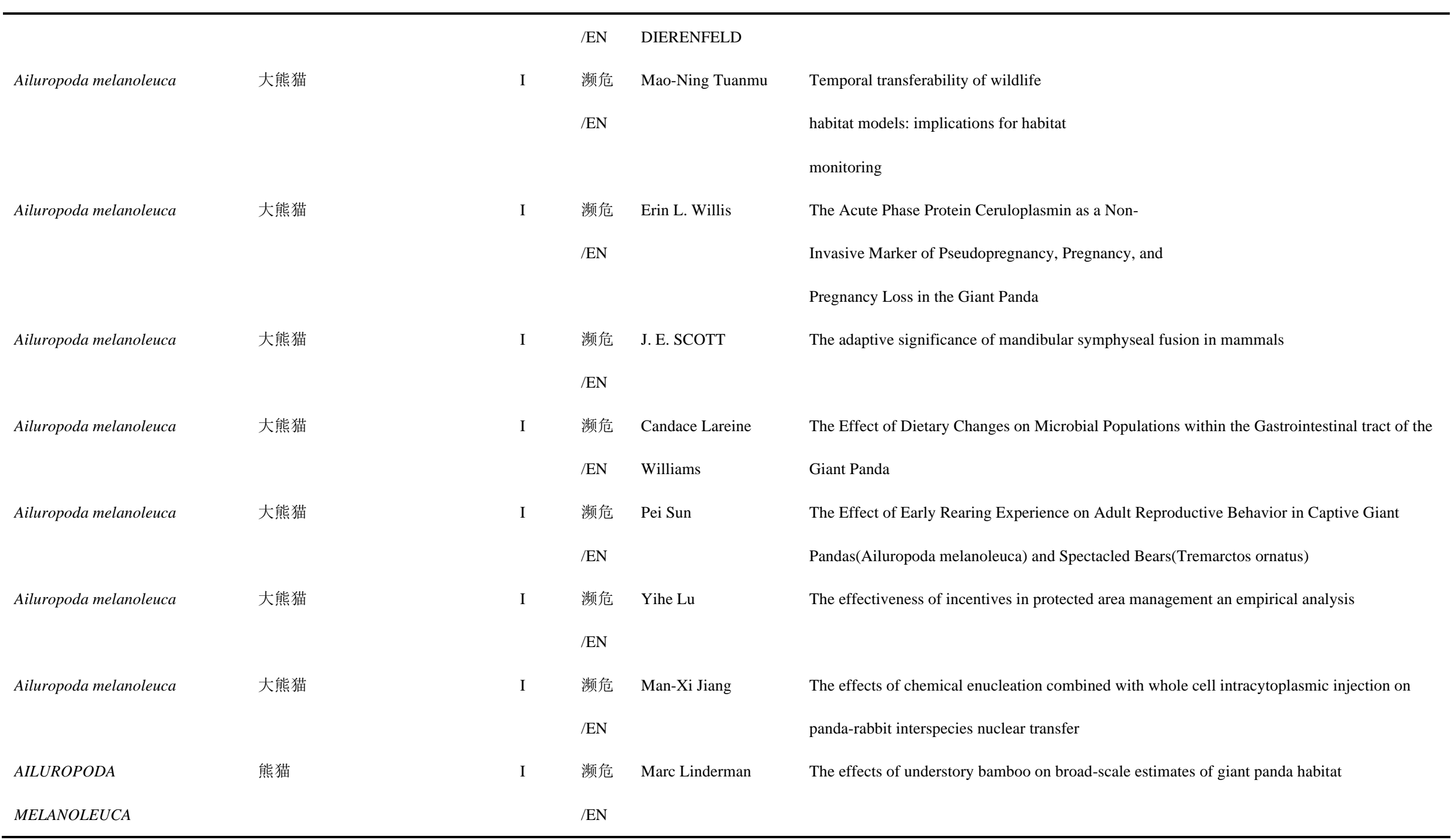


顾垒，闻丞，罗玫，王昊，吕植. 中国最受关注濒危物种保护现状快速评价的新方法探讨．生物多样性，2015，23(5)：583-590. http://www. biodiversity-science. net/CN/article/downloadArticleFile. do?attachType=PDF\&id=10075

\begin{tabular}{|c|c|c|c|c|c|}
\hline Ailuropoda melanoleuca & 大熊猫 & I & $\begin{array}{l}\text { 濒危 } \\
\text { /EN }\end{array}$ & Julien Louys & The future of mammals in Southeast Asia Conservation insights from the fossil record \\
\hline Ailuropoda melanoleuca & 大熊猫 & I & $\begin{array}{l}\text { 濒危 } \\
\text { /EN }\end{array}$ & Vanessa Hull & $\begin{array}{l}\text { The impact of giant panda foraging on bamboo dynamics } \\
\text { in an isolated environment }\end{array}$ \\
\hline Ailuropoda melanoleuca & 大熊猫 & I & $\begin{array}{l}\text { 濒危 } \\
\text { /EN }\end{array}$ & Jianjun PENG & $\begin{array}{l}\text { The Influence of Activity Space on the Behavior of Giant Pandas(Ailuropoda melanoleuca ) in } \\
\text { Captivity }\end{array}$ \\
\hline Ailuropoda melanoleuca & 大熊猫 & I & $\begin{array}{l}\text { 濒危 } \\
\text { /EN }\end{array}$ & D. Charlton & $\begin{array}{l}\text { The information content of giant panda, Ailuropoda melanoleuca, bleats acoustic cues to sex, } \\
\text { age and size }\end{array}$ \\
\hline Ailuropoda melanoleuca & 大熊猫 & I & $\begin{array}{l}\text { 濒危 } \\
\text { /EN }\end{array}$ & JACEY BEDFORD & The loneliness of the long-distance panda \\
\hline Ailuropoda melanoleuca & 大熊猫 & I & $\begin{array}{l}\text { 濒危 } \\
\text { /EN }\end{array}$ & Eugenia V. Gurevich & The origin and evolution of G protein-coupled receptor kinases \\
\hline $\begin{array}{l}\text { AILUROPODA } \\
\text { MELANOLEUCA }\end{array}$ & 熊猫 & I & $\begin{array}{l}\text { 濒危 } \\
\text { /EN }\end{array}$ & Fuwen Wei & $\begin{array}{l}\text { THE PARASITES OF GIANT PANDAS: INDIVIDUAL-BASED MEASUREMENT IN } \\
\text { WILD ANIMALS }\end{array}$ \\
\hline Ailuropoda melanoleuca & 大熊猫 & I & $\begin{array}{l}\text { 濒危 } \\
\text { /EN }\end{array}$ & Anna M. Claxton & $\begin{array}{l}\text { The potential of the human - animal relationship as an environmental } \\
\text { enrichment for the welfare of zoo-housed animals }\end{array}$ \\
\hline Ailuropoda melanoleuca & 大熊猫 & I & $\begin{array}{l}\text { 濒危 } \\
\text { /EN }\end{array}$ & Hao Wu1 & $\begin{array}{l}\text { The RIP1RIP3 Necrosome Forms a Functional Amyloid Signaling Complex Required for } \\
\text { Programmed Necrosis }\end{array}$ \\
\hline Ailuropoda melanoleuca & 大熊猫 & I & 濒危 & Zhiyun Ouyang & The role of fairness norms the household-based natural forest conservation The case of \\
\hline
\end{tabular}


顾垒，闻丞，罗玫，王吴，吕植. 中国最受关注濒危物种保护现状快速评价的新方法探讨. 生物多样性，2015，23(5)：583-590. http://www. biodiversity-science. net/CN/article/downloadArticleFile. do?attachType=PDF\&id=10075

\begin{tabular}{|c|c|c|c|c|c|}
\hline & & & $/ \mathrm{EN}$ & & Wolong, China \\
\hline \multirow[t]{2}{*}{ Ailuropoda melanoleuca } & 大熊猫 & I & 濒危 & Jun Wang & The sequence and de novo assembly of the giant panda genome \\
\hline & & & $/ \mathrm{EN}$ & & \\
\hline \multirow[t]{2}{*}{ Ailuropoda melanoleuca } & 大熊猫 & I & 濒危 & Fu-Wen Wei & Thirty-three microsatellite loci for noninvasive genetic studies of the giant panda (Ailuropoda \\
\hline & & & $/ \mathrm{EN}$ & & melanoleuca) \\
\hline \multirow[t]{2}{*}{ Ailuropoda melanoleuca } & 大熊猫 & I & 濒危 & Bei Tong & Three Decades of Change in Giant Panda Habitat Around and Within Foping Nature Reserve, \\
\hline & & & $/ \mathrm{EN}$ & & China \\
\hline \multirow[t]{2}{*}{ Ailuropoda melanoleuca } & 大熊猫 & I & 濒危 & KORNELIUS & Tooth root morphology as an indicator for dietary specialization in carnivores (Mammalia \\
\hline & & & /EN & KUPCZIK & Carnivora) \\
\hline \multirow[t]{3}{*}{ Ailuropoda melanoleuca } & 大熊猫 & I & 濒危 & Ming-Hao Gong & Topographic habitat features preferred by the \\
\hline & & & /EN & & Endangered giant panda Ailuropoda melanoleuca: \\
\hline & & & & & implications for reserve design and management \\
\hline \multirow[t]{2}{*}{ Ailuropoda melanoleuca } & 大熊猫 & I & 濒危 & R.R. Swaisgood & Urinary chemosignals in giant pandas(Ailuropoda melanoleuca):seasonal and developmental \\
\hline & & & $/ \mathrm{EN}$ & & effects on signal discrimination \\
\hline \multirow[t]{3}{*}{ Ailuropoda melanoleuca } & 大熊猫 & I & 濒危 & ERIN WIEDOWER & USE OF NEAR INFRARED REFLECTANCE SPECTROSCOPY (NIRS) TO INVESTIGATE \\
\hline & & & /EN & & SELECTION AND NUTRIENT UTILIZATION OF BAMBOO AND TO MONITOR THE \\
\hline & & & & & PHYSIOLOGICAL STATUS OF GIANT PANDAS \\
\hline \multirow[t]{2}{*}{ Ailuropoda melanoleuca } & 大熊猫 & I & 濒危 & M. LINDERMAN & Using artificial neural networks to map the spatial distribution of understorey bamboo from \\
\hline & & & /EN & & remote sensing data \\
\hline
\end{tabular}


顾垒，闻丞，罗玫，王昊，吕植. 中国最受关注濒危物种保护现状快速评价的新方法探讨．生物多样性，2015，23(5)：583-590.

http://www. biodiversity-science. net/CN/article/downloadArticleFile. do?attachType=PDF\&id=10075

\begin{tabular}{|c|c|c|c|c|c|}
\hline Ailuropoda melanoleuca & 大熊猫 & I & $\begin{array}{l}\text { 濒危 } \\
\text { /EN }\end{array}$ & Xiaodong Chen & $\begin{array}{l}\text { Using Cost - Effective Targeting to Enhance the Efficiency of Conservation Investments in } \\
\text { Payments for Ecosystem Services }\end{array}$ \\
\hline Ailuropoda melanoleuca & 大熊猫 & I & $\begin{array}{l}\text { 濒危 } \\
\text { /EN }\end{array}$ & Emma C. Teeling & $\begin{array}{l}\text { Using Illumina next generation sequencing technologies to sequence multigene families in de } \\
\text { novo species }\end{array}$ \\
\hline Ailuropoda melanoleuca & 大熊猫 & I & $\begin{array}{l}\text { 濒危 } \\
\text { /EN }\end{array}$ & Estelle A. Sandhaus & $\begin{array}{l}\text { VARIATION OF FEEDING REGIMES: EFFECTS ON GIANT PANDA(AILUROPDA } \\
\text { MELANOLEUCA) BEHAVIOR }\end{array}$ \\
\hline Ailuropoda melanoleuca & 大熊猫 & I & $\begin{array}{l}\text { 濒危 } \\
\text { /EN }\end{array}$ & Quanfa Zhang & $\begin{array}{l}\text { Vegetation community and soil characteristics of abandoned agricultural land and pine } \\
\text { plantation in the Qinling Mountains, China }\end{array}$ \\
\hline Ailuropoda melanoleuca & 大熊猫 & I & $\begin{array}{l}\text { 濒危 } \\
\text { /EN }\end{array}$ & Wei Dong & $\begin{array}{l}\text { Virtual cranial endocast of the oldest giant panda (Ailuropoda microta) reveals great similarity } \\
\text { to that of its extant relative }\end{array}$ \\
\hline Ailuropoda melanoleuca & 大熊猫 & I & $\begin{array}{l}\text { 濒危 } \\
\text { /EN }\end{array}$ & Wei Dong & $\begin{array}{l}\text { Virtual cranial endocast of the oldest giant panda (Ailuropoda microta) reveals great similarity } \\
\text { to that of its extant relative }\end{array}$ \\
\hline Ailuropoda melanoleuca & 大熊猫 & I & $\begin{array}{l}\text { 濒危 } \\
\text { /EN }\end{array}$ & Benjamin D. Charlton & Vocal cues to identity and relatedness in giant pandas (Ailuropoda melanoleuca) \\
\hline Ailuropoda melanoleuca & 大熊猫 & I & $\begin{array}{l}\text { 濒危 } \\
\text { /EN }\end{array}$ & Benjamin D. Charlton & Vocal cues to identity and relatedness in giant pandas (Ailuropoda melanoleuca) \\
\hline Ailuropoda melanoleuca & 大熊猫 & I & $\begin{array}{l}\text { 濒危 } \\
\text { /EN }\end{array}$ & Benjamin D. Charlton & Vocal cues to male androgen levels in giant pandas \\
\hline Ailuropoda melanoleuca & 大熊猫 & I & 濒危 & Benjamin D. Charlton & Vocal discrimination of potential mates by female giant pandas (Ailuropoda melanoleuca) \\
\hline
\end{tabular}


顾垒，闻丞，罗玫，王吴，吕植. 中国最受关注濒危物种保护现状快速评价的新方法探讨. 生物多样性，2015，23(5)：583-590. http://www biodiversity-science. net/CN/article/downloadArticleFile. do?attachType=PDF\&id=10075

\begin{tabular}{|c|c|c|c|c|c|}
\hline & & & /EN & & \\
\hline Ailuropoda melanoleuca & 大熊猫 & I & $\begin{array}{l}\text { 濒危 } \\
\text { /EN }\end{array}$ & Qing Xu & $\begin{array}{l}\text { Water use patterns of three species in subalpine forest, } \\
\text { Southwest China: the deuterium isotope approach }\end{array}$ \\
\hline Ailuropoda melanoleuca & 大熊猫 & I & $\begin{array}{l}\text { 濒危 } \\
\text { /EN }\end{array}$ & Song Cheng & $\begin{array}{l}\text { Wenchuan } 512 \text { earthquake and giant panda habitat in Wolong, China: A review of } \\
\text { strong earthquakeeffects }\end{array}$ \\
\hline Ailuropoda melanoleuca & 大熊猫 & I & $\begin{array}{l}\text { 濒危 } \\
\text { /EN }\end{array}$ & Fuwen Wei & $\begin{array}{l}\text { What determines selection and abandonment of a foraging patch by wild giant pandas } \\
\text { (Ailuropoda melanoleuca) in winter }\end{array}$ \\
\hline Ailuropoda melanoleuca & 大熊猫 & I & $\begin{array}{l}\text { 濒危 } \\
\text { /EN }\end{array}$ & Fuwen Wei & $\begin{array}{l}\text { Whole-genome sequencing of giant pandas provides insights into demographic history and } \\
\text { local adaptation }\end{array}$ \\
\hline Ailuropoda melanoleuca & 大熊猫 & I & $\begin{array}{l}\text { 濒危 } \\
\text { /EN }\end{array}$ & Yang Zhong & $\begin{array}{l}\text { Why Does the Giant Panda Eat Bamboo? A Comparative } \\
\text { Analysis of Appetite-Reward-Related Genes among }\end{array}$ \\
\hline Ailuropoda melanoleuca & 大熊猫 & I & $\begin{array}{l}\text { 濒危 } \\
\text { /EN }\end{array}$ & 黄治 & $\begin{array}{l}\text { Mammals } \\
\text { 爱心饲养对大熊猫心理健康及配种受乃率的影响 }\end{array}$ \\
\hline Ailuropoda melanoleuca & 大熊猫 & I & $\begin{array}{l}\text { 濒危 } \\
\text { /EN }\end{array}$ & 卢志军 & 巴山木竹发笋和大熊猫取食的时空格局及相关性分析 \\
\hline Ailuropoda melanoleuca & 大熊猫 & I & $\begin{array}{l}\text { 濒危 } \\
\text { /EN }\end{array}$ & 江华明 & 宝兴县大熊猫对生境的选择 \\
\hline Ailuropoda melanoleuca & 大熊猫 & I & 濒危 & 江华明 & 宝兴县大熊猫种群动态及变动原因分析 \\
\hline
\end{tabular}


顾垒，闻丞，罗玫，王吴，吕植. 中国最受关注濒危物种保护现状快速评价的新方法探讨. 生物多样性，2015，23(5)：583-590. http://www. biodiversity-science. net/CN/article/downloadArticleFile. do?attachType=PDF\&id=10075

\begin{tabular}{|c|c|c|c|c|c|}
\hline \multirow[b]{2}{*}{ Ailuropoda melanoleuca } & \multirow[b]{2}{*}{ 大熊猫 } & \multirow[b]{2}{*}{ I } & \multicolumn{2}{|l|}{ /EN } & \multirow{3}{*}{ 表皮生长因子和胰岛素对大熊猫体外培养皮肤成纤维细胞生物学特性的影响 } \\
\hline & & & 濒危 & 朱庆 & \\
\hline & & & $/$ EN & & \\
\hline AILUROPODA & 熊猫 & I & 濒危 & 龙小海 & 病毒融合的大熊猫的多核巨细胞合胞体 \\
\hline MELANOLEUCA & & & /EN & & \\
\hline \multirow[t]{2}{*}{ Ailuropoda melanoleuca } & 大熊猫 & I & 濒危 & 李伟 & 不等距 Leslie 矩阵及其对唐家河地区大熊猫种群动态的应用 \\
\hline & & & /EN & & \\
\hline \multirow[t]{2}{*}{ Ailuropoda melanoleuca } & 大熊猫 & I & 濒危 & 张明 & 不同 EGF 和胰岛素水平对体外培养的大熊猫皮肤成纤维细胞的影响 \\
\hline & & & /EN & & \\
\hline \multirow[t]{2}{*}{ Ailuropoda melanoleuca } & 大熊猫 & I & 濒危 & 刘学锋 & 不同哺育方式对大熊猫幼崽生长发育的影响 \\
\hline & & & /EN & & \\
\hline \multirow[t]{2}{*}{ Ailuropoda melanoleuca } & 大熊猫 & I & 濒危 & 邹兴淮 & 不同加工方法对大熊猫饲粮营养素及能量消化率的影响 \\
\hline & & & /EN & & \\
\hline AILUROPODA & 熊猫 & I & 濒危 & 周世强 & 不同山系大熊猫栖息地植物区系特征的定量分析 \\
\hline MELANOLEUCA & & & /EN & & \\
\hline \multirow[t]{2}{*}{ Ailuropoda melanoleuca } & 大熊猫 & I & 濒危 & 李祥龙 & 不同物种 TYRP2 基因完整编码区生物信息学分析 \\
\hline & & & /EN & & \\
\hline \multirow[t]{2}{*}{ Ailuropoda melanoleuca } & 大熊猫 & I & 濒危 & 刘香东 & 采笋对大熊猫主食竹八月竹竹笋生长的影响 \\
\hline & & & /EN & & \\
\hline
\end{tabular}


顾垒，闻丞，罗玫，王吴，吕植. 中国最受关注濒危物种保护现状快速评价的新方法探讨. 生物多样性，2015，23(5)：583-590. http://www biodiversity-science. net/CN/article/downloadArticleFile. do?attachType=PDF\&id=10075

\begin{tabular}{|c|c|c|c|c|c|}
\hline Ailuropoda melanoleuca & 大熊猫 & I & $\begin{array}{l}\text { 濒危 } \\
/ \mathrm{EN}\end{array}$ & 李键 & 产仔大熊猫孕激素变化规律研究 \\
\hline Ailuropoda melanoleuca & 大熊猫 & I & $\begin{array}{l}\text { 濒危 } \\
\text { /EN }\end{array}$ & 房伟 & 肠道微生物协助大熊猫转化降解木质素的证据 \\
\hline Ailuropoda melanoleuca & 大熊猫 & I & $\begin{array}{l}\text { 濒危 } \\
/ \mathrm{EN}\end{array}$ & 邓林华 & 超声检查技术对大熊猫的应用 \\
\hline Ailuropoda melanoleuca & 大熊猫 & I & $\begin{array}{l}\text { 濒危 } \\
/ \mathrm{EN}\end{array}$ & 李德生 & 超声诊断大熊猫肠梗阻 \\
\hline Ailuropoda melanoleuca & 大熊猫 & I & $\begin{array}{l}\text { 濒危 } \\
/ \mathrm{EN}\end{array}$ & 程安春 & 成年大熊猫肠道菌群多样性的 16SrDNA_RFLP 分析 \\
\hline Ailuropoda melanoleuca & 大熊猫 & I & $\begin{array}{l}\text { 濒危 } \\
\text { /EN }\end{array}$ & 王晓艳 & 成年与老年大熊猫肠道菌群 $16 \mathrm{~S}$ rDNA-RFLP 技术分析 \\
\hline Ailuropoda melanoleuca & 大熊猫 & I & $\begin{array}{l}\text { 濒危 } \\
/ \mathrm{EN}\end{array}$ & 唐蓉 & 崇州市大熊猫自然保护区生态环境调查报告 \\
\hline Ailuropoda melanoleuca & 大熊猫 & I & $\begin{array}{l}\text { 濒危 } \\
/ \mathrm{EN}\end{array}$ & 杨光友 & 出入境大熊猫常见体内外寄生虫病与检验检疫防控 \\
\hline Ailuropoda melanoleuca & 大熊猫 & I & $\begin{array}{l}\text { 濒危 } \\
/ \mathrm{EN}\end{array}$ & 鲁叶江 & 川西亚高山箭竹密度对土壤碳、氮库的影响 \\
\hline Ailuropoda melanoleuca & 大熊猫 & I & 濒危 & 刘定震 & 传统圈养和半自然散放环境亚成年大熊猫的行为差异 \\
\hline
\end{tabular}


顾垒，闻丞，罗玫，王吴，吕植. 中国最受关注濒危物种保护现状快速评价的新方法探讨. 生物多样性，2015，23(5)：583-590. http://www. biodiversity-science. net/CN/article/downloadArticleFile. do?attachType=PDF\&id=10075

\begin{tabular}{|c|c|c|c|c|c|}
\hline & & & /EN & & \\
\hline Ailuropoda melanoleuca & 大熊猫 & I & $\begin{array}{l}\text { 濒危 } \\
\text { /EN }\end{array}$ & 刘丽 & 春季动物园大熊猫粪便可培养真菌鉴定与分析 \\
\hline Ailuropoda melanoleuca & 大熊猫 & I & $\begin{array}{l}\text { 濒危 } \\
\text { /EN }\end{array}$ & 赵鹏鹏 & 雌性大熊猫繁殖期尿中雌二醇_孕酮水平变化的研究 \\
\hline AILUROPODA & 熊猫 & I & 濒危 & 吴周虎 & 从熊猫腹泻便中检出侵袭性大肠杆菌和豚鼠气单胞菌 \\
\hline MELANOLEUCA & & & $/ \mathrm{EN}$ & & \\
\hline Ailuropoda melanoleuca & 大熊猫 & I & $\begin{array}{l}\text { 濒危 } \\
\text { /EN }\end{array}$ & 张泽钧 & 从长期监测数据看佛坪自然保护区大熊猫种群的发展趋势与生态习性 \\
\hline Ailuropoda melanoleuca & 大熊猫 & I & $\begin{array}{l}\text { 濒危 } \\
\text { /EN }\end{array}$ & 徐卫华 & 大相岭山系大熊猫生境评价与保护对策研究 \\
\hline AILUROPODA & 熊猫 & I & 濒危 & 欧阳志云 & 大相岭山系大熊猫生境评价与保护对策研究 \\
\hline MELANOLEUCA & & & $/ \mathrm{EN}$ & & \\
\hline AILUROPODA & 熊猫 & I & 濒危 & 王小明 & 大熊猫( Ailuropoda melanoleuca) 生境选择研究进展 \\
\hline MELANOLEUCA & & & /EN & & \\
\hline Ailuropoda melanoleuca & 大熊猫 & I & $\begin{array}{l}\text { 濒危 } \\
\text { /EN }\end{array}$ & 侯万儒 & 大熊猫(Ailuropoda melanoleuca)RPS24 基因 cDNA \\
\hline Ailuropoda melanoleuca & 大熊猫 & I & $\begin{array}{l}\text { 濒危 } \\
\text { /EN }\end{array}$ & 魏桂芳 & 大熊猫(Ailuropoda melanoleuca) 肠道菌落结构分子生态学研究 \\
\hline
\end{tabular}


顾垒，闻丞，罗玫，王吴，吕植. 中国最受关注濒危物种保护现状快速评价的新方法探讨. 生物多样性，2015，23(5)：583-590. http://www biodiversity-science. net/CN/article/downloadArticleFile. do?attachType=PDF\&id=10075

\begin{tabular}{|c|c|c|c|c|c|}
\hline Ailuropoda melanoleuca & 大熊猫 & I & $\begin{array}{l}\text { 濒危 } \\
/ \mathrm{EN}\end{array}$ & 范维江 & 大熊猫（Ailuropoda melanoleuca）下丘脑 cDNA 文库的构建 \\
\hline Ailuropoda melanoleuca & 大熊猫 & I & $\begin{array}{l}\text { 濒危 } \\
\text { /EN }\end{array}$ & 杨波 & 大熊猫 (Ailuropoda melanoleuca)线粒体基因组研究及圈养种群遗传多样性分析 \\
\hline Ailuropoda melanoleuca & 大熊猫 & I & $\begin{array}{l}\text { 濒危 } \\
/ \mathrm{EN}\end{array}$ & 李骏 & 大熊猫（Ailuropoda melanoleuca）应激初步研究 \\
\hline AILUROPODA & 熊猫 & I & 濒危 & 吴开波 & 大熊猫、小熊猫注射犬六联弱毒疫苗后四种病毒抗体消长规律研究 \\
\hline MELANOLEUCA & & & $/ \mathrm{EN}$ & & \\
\hline Ailuropoda melanoleuca & 大熊猫 & I & $\begin{array}{l}\text { 濒危 } \\
/ \mathrm{EN}\end{array}$ & 朱英 & 大熊猫_类 MHC 分子标记系统的建立及其适应性进化研究 \\
\hline Ailuropoda melanoleuca & 大熊猫 & I & $\begin{array}{l}\text { 濒危 } \\
\text { /EN }\end{array}$ & 陈艺燕 & 大熊猫_类 MHC 功能基因的分离及适应性进化研究 \\
\hline Ailuropoda melanoleuca & 大熊猫 & I & $\begin{array}{l}\text { 濒危 } \\
/ \mathrm{EN}\end{array}$ & 王俊 & 大熊猫 9 个 BAC 的测序、注释和进化分析 \\
\hline Ailuropoda melanoleuca & 大熊猫 & I & $\begin{array}{l}\text { 濒危 } \\
/ \mathrm{EN}\end{array}$ & 侯万儒 & 大熊猫 AP2S1 基因 cDNA 克隆及分析 \\
\hline Ailuropoda melanoleuca & 大熊猫 & I & $\begin{array}{l}\text { 濒危 } \\
/ \mathrm{EN}\end{array}$ & 李校 & 大熊猫 bHLH 基因家族的识别与分析 \\
\hline Ailuropoda melanoleuca & 大熊猫 & I & 濒危 & 侯怡铃 & 大熊猫 CRYAB 基因及大熊猫和四_省略_熊 TNNC1 基因的克隆和相关研究 \\
\hline
\end{tabular}


顾垒，闻丞，罗玫，王吴，吕植. 中国最受关注濒危物种保护现状快速评价的新方法探讨. 生物多样性，2015，23(5)：583-590. http://www. biodiversity-science. net/CN/article/downloadArticleFile. do?attachType=PDF\&id=10075

\begin{tabular}{|c|c|c|c|c|c|}
\hline & & & /EN & & \\
\hline \multirow[t]{2}{*}{ Ailuropoda melanoleuca } & 大熊猫 & I & 濒危 & 周荣家 & 大熊猫 Dmrt 基因家族 4 个成员基因的克隆 \\
\hline & & & $/$ EN & & \\
\hline \multirow[t]{2}{*}{ Ailuropoda melanoleuca } & 大熊猫 & I & 濒危 & 邹方东 & 大熊猫 FOXL2 基因的克隆_序列分析及表达 \\
\hline & & & /EN & & \\
\hline \multirow[t]{2}{*}{ Ailuropoda melanoleuca } & 大熊猫 & I & 濒危 & 徐志文 & 大熊猫 GM_CSF 基因的克隆与分析及 GM_CSF 生物学活性的检测 \\
\hline & & & /EN & & \\
\hline \multirow[t]{2}{*}{ Ailuropoda melanoleuca } & 大熊猫 & I & 濒危 & 侯蓉 & 大熊猫 IgG 双抗体夹心 ELISA 定量检测方法的建立 \\
\hline & & & /EN & & \\
\hline AILUROPODA & 熊猫 & I & 濒危 & 王讯 & 大熊猫 IgG 测定方法的建立与初步应用 \\
\hline MELANOLEUCA & & & /EN & & \\
\hline \multirow[t]{2}{*}{ Ailuropoda melanoleuca } & 大熊猫 & I & 濒危 & 杨光友 & 大熊猫 IL24 基因的克隆与序列分析 \\
\hline & & & /EN & & \\
\hline \multirow[t]{2}{*}{ Ailuropoda melanoleuca } & 大熊猫 & I & 濒危 & 万秋红 & 大熊猫 $\mathrm{I}$ 类 MHC 基因的分离及分型技术的建立 \\
\hline & & & /EN & & \\
\hline \multirow[t]{2}{*}{ Ailuropoda melanoleuca } & 大熊猫 & I & 濒危 & 杨光友 & 大熊猫 L-2 基因的克隆与序列分析 \\
\hline & & & /EN & & \\
\hline \multirow[t]{2}{*}{ Ailuropoda melanoleuca } & 大熊猫 & I & 濒危 & 黄道超 & 大熊猫 L-4 基因的克隆与序列分析 \\
\hline & & & /EN & & \\
\hline
\end{tabular}


顾垒，闻丞，罗玫，王吴，吕植. 中国最受关注濒危物种保护现状快速评价的新方法探讨. 生物多样性，2015，23(5)：583-590. http://www biodiversity-science. net/CN/article/downloadArticleFile. do?attachType=PDF\&id=10075

\begin{tabular}{|c|c|c|c|c|c|}
\hline Ailuropoda melanoleuca & 大熊猫 & I & $\begin{array}{l}\text { 濒危 } \\
\text { /EN }\end{array}$ & 徐庆刚 & 大熊猫 Leptin_Ghreli_省略_表达及胃和脾脏 cDNA 文库的构建 \\
\hline Ailuropoda melanoleuca & 大熊猫 & I & $\begin{array}{l}\text { 濒危 } \\
\text { /EN }\end{array}$ & 侯蓉 & 大熊猫 LH 酶联免疫检测的初步研究 \\
\hline Ailuropoda melanoleuca & 大熊猫 & I & $\begin{array}{l}\text { 濒危 } \\
\text { /EN }\end{array}$ & 蔡志刚 & 大熊猫 LH 酶联免疫检测的初步研究 \\
\hline Ailuropoda melanoleuca & 大熊猫 & I & $\begin{array}{l}\text { 濒危 } \\
\text { /EN }\end{array}$ & 侯万儒 & 大熊猫 LSM3CDNA 序列的克隆及序列分析 \\
\hline AILUROPODA & 熊猫 & I & 濒危 & 张婷 & 大熊猫 mtDNA 控制区和核 DNA MHC 及伪虎鲸 mtDNA 控制区序列变异分析 \\
\hline MELANOLEUCA & & & $/ \mathrm{EN}$ & & \\
\hline Ailuropoda melanoleuca & 大熊猫 & I & $\begin{array}{l}\text { 濒危 } \\
\text { /EN }\end{array}$ & 侯万儒 & 大熊猫 NADH - 辅酶 $\mathrm{Q}$ 氧化还原酶铁硫蛋白亚基 6 基因(NDUFS6) 的序列分析 \\
\hline Ailuropoda melanoleuca & 大熊猫 & I & $\begin{array}{l}\text { 濒危 } \\
\text { /EN }\end{array}$ & 侯万儒 & 大熊猫 RPS15 cDNA 的克隆及序列分析 \\
\hline Ailuropoda melanoleuca & 大熊猫 & I & $\begin{array}{l}\text { 濒危 } \\
\text { /EN }\end{array}$ & 侯怡铃 & 大熊猫 Sjogren 综合症/硬皮病自身抗原 1 基因( SSSCA 1)的克隆及比较 \\
\hline AILUROPODA & 熊猫 & I & 濒危 & 黄道超, & 大熊猫 $\mathrm{y}$ 一干扰素基因的克隆与序列分析 \\
\hline MELANOLEUCA & & & $/ \mathrm{EN}$ & & \\
\hline Ailuropoda melanoleuca & 大熊猫 & I & 濒危 & 杨光友 & 大熊猫 $\gamma$-干扰素基因的克隆与序列分析 \\
\hline
\end{tabular}


顾垒，闻丞，罗玫，王吴，吕植. 中国最受关注濒危物种保护现状快速评价的新方法探讨. 生物多样性，2015，23(5)：583-590. http://www. biodiversity-science. net/CN/article/downloadArticleFile. do?attachType=PDF\&id=10075

\begin{tabular}{|c|c|c|c|c|c|}
\hline & & & /EN & & \\
\hline \multirow[t]{2}{*}{ Ailuropoda melanoleuca } & 大熊猫 & I & 濒危 & 金学林 & 大熊猫白内障的手术治疗 \\
\hline & & & $/$ EN & & \\
\hline \multirow[t]{2}{*}{ Ailuropoda melanoleuca } & 大熊猫 & I & 濒危 & 孟永安 & 大熊猫白内障手术临床研究 \\
\hline & & & /EN & & \\
\hline AILUROPODA & 熊猫 & I & 濒危 & 陈玉村 & 大熊猫白内障手术摘除的探讨 \\
\hline MELANOLEUCA & & & /EN & & \\
\hline \multirow[t]{2}{*}{ Ailuropoda melanoleuca } & 大熊猫 & I & 濒危 & 谭雪梅 & 大熊猫白细胞介素-18 功能分析 \\
\hline & & & /EN & & \\
\hline \multirow[t]{2}{*}{ Ailuropoda melanoleuca } & 大熊猫 & I & 濒危 & 唐秀萍 & 大熊猫保护的法制建设 \\
\hline & & & /EN & & \\
\hline \multirow[t]{2}{*}{ Ailuropoda melanoleuca } & 大熊猫 & I & 濒危 & 李蓓 & 大熊猫肠道大肠杆菌的分离_鉴定及其耐药性分析 \\
\hline & & & /EN & & \\
\hline \multirow[t]{2}{*}{ Ailuropoda melanoleuca } & 大熊猫 & I & 濒危 & 张志和 & 大熊猫肠道菌群结构研究 \\
\hline & & & /EN & & \\
\hline \multirow[t]{2}{*}{ Ailuropoda melanoleuca } & 大熊猫 & I & 濒危 & 刘成君 & 大熊猫肠道微生态的研究进展 \\
\hline & & & /EN & & \\
\hline \multirow[t]{2}{*}{ Ailuropoda melanoleuca } & 大熊猫 & I & 濒危 & 吴琦 & 大熊猫肠道纤维素分解菌的分离鉴定及产酶性质 \\
\hline & & & /EN & & \\
\hline
\end{tabular}


顾垒，闻丞，罗玫，王吴，吕植. 中国最受关注濒危物种保护现状快速评价的新方法探讨. 生物多样性，2015，23(5)：583-590. http://www biodiversity-science. net/CN/article/downloadArticleFile. do?attachType=PDF\&id=10075

\begin{tabular}{|c|c|c|c|c|c|}
\hline Ailuropoda melanoleuca & 大熊猫 & I & $\begin{array}{l}\text { 濒危 } \\
\text { /EN }\end{array}$ & 彭广能 & 大熊猫肠道芽狍杆菌的分离鉴定及其抗逆性研究 \\
\hline Ailuropoda melanoleuca & 大熊猫 & I & $\begin{array}{l}\text { 濒危 } \\
\text { /EN }\end{array}$ & 费立松 & 大熊猫肠道中几种厌氧菌的构成 \\
\hline AILUROPODA & 熊猫 & I & 濒危 & 王爱民 & 大熊猫常食竹类的 “双效” 作用及保护对策 \\
\hline MELANOLEUCA & & & /EN & & \\
\hline Ailuropoda melanoleuca & 大熊猫 & I & $\begin{array}{l}\text { 濒危 } \\
\text { /EN }\end{array}$ & 黄祥明 & 大熊猫超轻初生幼仔的成功哺育 \\
\hline Ailuropoda melanoleuca & 大熊猫 & I & $\begin{array}{l}\text { 濒危 } \\
\text { /EN }\end{array}$ & 王强 & 大熊猫初生胎儿及幼仔组织器官的病理学研究 \\
\hline Ailuropoda melanoleuca & 大熊猫 & I & $\begin{array}{l}\text { 濒危 } \\
\text { /EN }\end{array}$ & 朱睦元 & 大熊猫垂体泌乳素（PRL）cDNA 的克隆与表达 \\
\hline Ailuropoda melanoleuca & 大熊猫 & I & $\begin{array}{l}\text { 濒危 } \\
\text { /EN }\end{array}$ & 邓旭 & 大熊猫垂体泌乳素（PRL）cDNA 的克隆与表达 \\
\hline Ailuropoda melanoleuca & 大熊猫 & I & $\begin{array}{l}\text { 濒危 } \\
\text { /EN }\end{array}$ & 李涛 & 大熊猫的分类与演化综述 \\
\hline Ailuropoda melanoleuca & 大熊猫 & I & $\begin{array}{l}\text { 濒危 } \\
\text { /EN }\end{array}$ & 胡锦堙 & 大熊猫的过去、现在与未来 \\
\hline Ailuropoda melanoleuca & 大熊猫 & I & 濒危 & 黄炎 & 大熊猫的行为发育及饲养管理中的影响因素 \\
\hline
\end{tabular}


顾垒，闻丞，罗玫，王吴，吕植. 中国最受关注濒危物种保护现状快速评价的新方法探讨. 生物多样性，2015，23(5)：583-590. http://www. biodiversity-science. net/CN/article/downloadArticleFile. do?attachType=PDF\&id=10075

\begin{tabular}{|c|c|c|c|c|c|}
\hline & & & $/ \mathrm{EN}$ & & \\
\hline \multirow[t]{2}{*}{ Ailuropoda melanoleuca } & 大熊猫 & I & 濒危 & 周晓 & 大熊猫的行为和保护研究 \\
\hline & & & \multicolumn{2}{|l|}{ /EN } & \\
\hline AILUROPODA & 熊猫 & I & 濒危 & 杨春花 & 大熊猫的刻板行为及其矫正对策一一丰富圈养环境举措 \\
\hline \multicolumn{2}{|l|}{ MELANOLEUCA } & & \multicolumn{2}{|l|}{ /EN } & \\
\hline AILUROPODA & 熊猫 & I & 濒危 & 李华 & 大熊猫的偶食性食物 \\
\hline \multicolumn{2}{|l|}{ MELANOLEUCA } & & \multicolumn{2}{|l|}{ /EN } & \\
\hline \multirow[t]{2}{*}{ Ailuropoda melanoleuca } & 大熊猫 & I & 濒危 & 胡锦真 & 大熊猫的起源与演化 \\
\hline & & & /EN & & \\
\hline \multirow[t]{2}{*}{ Ailuropoda melanoleuca } & 大熊猫 & I & 濒危 & 李俊清 & 大熊猫的生境选择特征 \\
\hline & & & /EN & & \\
\hline \multirow[t]{2}{*}{ Ailuropoda melanoleuca } & 大熊猫 & I & 濒危 & 王承东 & 大熊猫的运输及福利 \\
\hline & & & /EN & & \\
\hline \multirow[t]{2}{*}{ Ailuropoda melanoleuca } & 大熊猫 & I & 濒危 & 杨光友 & 大熊猫等八种野生珍稀动物蛔虫 ITS22 基因的序列分析 \\
\hline & & & /EN & & \\
\hline \multirow[t]{2}{*}{ Ailuropoda melanoleuca } & 大熊猫 & I & 濒危 & 廖鸣娟 & 大熊猫等濒危动物 FSH 和 LH 基因的克隆及其表达研究 \\
\hline & & & /EN & & \\
\hline \multirow[t]{2}{*}{ Ailuropoda melanoleuca } & 大熊猫 & I & 濒危 & 胡细连 & 大熊猫等濒危动物 IGF-I 基因的克隆、表达与组织分布研究 \\
\hline & & & /EN & & \\
\hline
\end{tabular}


顾垒，闻丞，罗玫，王吴，吕植. 中国最受关注濒危物种保护现状快速评价的新方法探讨. 生物多样性，2015，23(5)：583-590. http://www biodiversity-science. net/CN/article/downloadArticleFile. do?attachType=PDF\&id=10075

\begin{tabular}{|c|c|c|c|c|c|}
\hline Ailuropoda melanoleuca & 大熊猫 & I & $\begin{array}{l}\text { 濒危 } \\
\text { /EN }\end{array}$ & 张泽钧 & 大熊猫地史分布变迁初步研究 \\
\hline AILUROPODA & 熊猫 & I & 濒危 & 汪开毓 & 大熊猫多器官功能障碍综合征的病理学观察 \\
\hline MELANOLEUCA & & & /EN & & \\
\hline Ailuropoda melanoleuca & 大熊猫 & I & $\begin{array}{l}\text { 濒危 } \\
\text { /EN }\end{array}$ & 刘学锋 & 大熊猫发情高峰期唾液涂片的观察与研究 \\
\hline Ailuropoda melanoleuca & 大熊猫 & I & $\begin{array}{l}\text { 濒危 } \\
\text { /EN }\end{array}$ & 王小明 & 大熊猫放归计划框架与操作程序初探 \\
\hline Ailuropoda melanoleuca & 大熊猫 & I & $\begin{array}{l}\text { 濒危 } \\
\text { /EN }\end{array}$ & 张志敏 & 大熊猫非损伤性取样法提取 DNA 和 SSRs 标记的篮选 \\
\hline Ailuropoda melanoleuca & 大熊猫 & I & $\begin{array}{l}\text { 濒危 } \\
\text { /EN }\end{array}$ & 钟华 & 大熊猫非损伤性样品 DNA 的提取和 SSR 标记的分离 \\
\hline Ailuropoda melanoleuca & 大熊猫 & I & $\begin{array}{l}\text { 濒危 } \\
\text { /EN }\end{array}$ & 魏辅文 & 大熊猫粪便宽径与咬节平均长度的关系 \\
\hline Ailuropoda melanoleuca & 大熊猫 & I & $\begin{array}{l}\text { 濒危 } \\
\text { /EN }\end{array}$ & 胡 德 夫 & 大熊猫粪便类固醇激素研究进展 \\
\hline Ailuropoda melanoleuca & 大熊猫 & I & $\begin{array}{l}\text { 濒危 } \\
\text { /EN }\end{array}$ & 于小杰 & 大熊猫粪团表层和内部类固醇激素含量比较 \\
\hline Ailuropoda melanoleuca & 大熊猫 & I & 濒危 & 崔媛媛 & 大熊猫粪样内类固醇激素保存方法及应用研究 \\
\hline
\end{tabular}


顾垒，闻丞，罗玫，王吴，吕植. 中国最受关注濒危物种保护现状快速评价的新方法探讨. 生物多样性，2015，23(5)：583-590. http://www. biodiversity-science. net/CN/article/downloadArticleFile. do?attachType=PDF\&id=10075

\begin{tabular}{|c|c|c|c|c|c|}
\hline & & & /EN & & \\
\hline \multirow[t]{2}{*}{ Ailuropoda melanoleuca } & 大熊猫 & I & 濒危 & 杨光友 & 大熊猫粪样西氏贝蛔虫虫卵 PCR 检测方法的建立 \\
\hline & & & $/$ EN & & \\
\hline AILUROPODA & 熊猫 & I & 濒危 & 邓林华 & 大熊猫腹泻及其防治原则 \\
\hline MELANOLEUCA & & & /EN & & \\
\hline \multirow[t]{2}{*}{ Ailuropoda melanoleuca } & 大熊猫 & I & 濒危 & 胡桂学 & 大熊猫肝脏分离病毒部分特性的研究 \\
\hline & & & /EN & & \\
\hline AILUROPODA & 熊猫 & I & 濒危 & 王成东 & 大熊猫感染性泌尿生殖道血尿症病原一肺炎克雷伯氏杆菌 \\
\hline MELANOLEUCA & & & /EN & & \\
\hline \multirow[t]{2}{*}{ Ailuropoda melanoleuca } & 大熊猫 & I & 濒危 & 李明喜 & 大熊猫高纤维饼干饲料取代传统饲料的实验 \\
\hline & & & /EN & & \\
\hline AILUROPODA & 熊猫 & I & 濒危 & 胡玉萱 & 大熊猫高血压病的诊治 \\
\hline MELANOLEUCA & & & /EN & & \\
\hline \multirow[t]{2}{*}{ Ailuropoda melanoleuca } & 大熊猫 & I & 濒危 & 杨光友 & 大熊猫钩口线虫的研究 \\
\hline & & & /EN & & \\
\hline \multirow[t]{2}{*}{ Ailuropoda melanoleuca } & 大熊猫 & I & 濒危 & 汪涛 & 大熊猫和川西称猴胃肠道寄生虫研究 \\
\hline & & & /EN & & \\
\hline \multirow[t]{2}{*}{ Ailuropoda melanoleuca } & 大熊猫 & I & 濒危 & 于小杰 & 大熊猫和普氏野马类固醇激素及免疫球蛋白水平的非损伤研究 \\
\hline & & & /EN & & \\
\hline
\end{tabular}


顾垒，闻丞，罗玫，王吴，吕植. 中国最受关注濒危物种保护现状快速评价的新方法探讨. 生物多样性，2015，23(5)：583-590. http://www biodiversity-science. net/CN/article/downloadArticleFile. do?attachType=PDF\&id=10075

\begin{tabular}{|c|c|c|c|c|c|}
\hline Ailuropoda melanoleuca & 大熊猫 & I & 濒危 & 魏辅文 & 大熊猫和小熊猫粪便 DNA 提取的简单方法 \\
\hline & & & \multicolumn{3}{|l|}{ /EN } \\
\hline AILUROPODA & 熊猫 & I & 濒危 & 韩宗先 & 大熊猫和小熊猫共存机制研究进展 \\
\hline \multicolumn{3}{|l|}{ MELANOLEUCA } & \multicolumn{3}{|l|}{ /EN } \\
\hline AILUROPODA & 熊猫 & I & 濒危 & 王成东 & 大熊猫和小熊猫犬瘟热病与疫苗免疫现状 \\
\hline \multicolumn{3}{|l|}{ MELANOLEUCA } & \multicolumn{3}{|l|}{ /EN } \\
\hline \multirow[t]{2}{*}{ Ailuropoda melanoleuca } & 大熊猫 & I & 濒危 & 侯万儒 & 大熊猫和亚洲黑熊 TNNC1 基因的克隆_表达与序列分析 \\
\hline & & & $/ \mathrm{EN}$ & & \\
\hline \multirow[t]{2}{*}{ Ailuropoda melanoleuca } & 大熊猫 & I & 濒危 & 侯万儒 & 大熊猫核糖体蛋白 L10 亚基基因的 cDNA 克隆及序列分析 \\
\hline & & & /EN & & \\
\hline \multirow[t]{2}{*}{ Ailuropoda melanoleuca } & 大熊猫 & I & 濒危 & 杜玉杰 & 大熊猫核糖体蛋白 L 34 基因 c D N A 克隆与蛋白特性 \\
\hline & & & $/ \mathrm{EN}$ & & \\
\hline \multirow[t]{2}{*}{ Ailuropoda melanoleuca } & 大熊猫 & I & 濒危 & 侯万儒 & 大熊猫核糖体蛋白 RPL5 基因的克隆、表达与比较分析 \\
\hline & & & /EN & & \\
\hline \multirow[t]{2}{*}{ Ailuropoda melanoleuca } & 大熊猫 & I & 濒危 & 孙冰 & 大熊猫核糖体蛋白 S11 亚基基因(RPS11) cDNA 的克隆及序列分析 \\
\hline & & & /EN & & \\
\hline \multirow[t]{2}{*}{ Ailuropoda melanoleuca } & 大熊猫 & I & 濒危 & 侯万儒 & 大熊猫核糖体蛋白 S12 亚基基因 RPS12_的 cDNA 克隆及序列分析 \\
\hline & & & /EN & & \\
\hline Ailuropoda melanoleuca & 大熊猫 & I & 濒危 & 侯 万儒 & 大熊猫核糖体蛋白 S17 亚基基因_rps17_的克隆及序列分析 \\
\hline
\end{tabular}


顾垒，闻丞，罗玫，王吴，吕植. 中国最受关注濒危物种保护现状快速评价的新方法探讨. 生物多样性，2015，23(5)：583-590. http://www. biodiversity-science. net/CN/article/downloadArticleFile. do?attachType=PDF\&id=10075

\begin{tabular}{|c|c|c|c|c|c|}
\hline & & & /EN & & \\
\hline \multirow[t]{2}{*}{ Ailuropoda melanoleuca } & 大熊猫 & I & 濒危 & 侯怡铃 & 大熊猫核糖体蛋白 S26 亚基基因( rps26)的 cDNA 克隆及序列分析 \\
\hline & & & $/$ EN & & \\
\hline \multirow[t]{2}{*}{ Ailuropoda melanoleuca } & 大熊猫 & I & 濒危 & 侯 万儒 & 大熊猫核糖体蛋白 S26 亚基基因_rps26_的 cDNA 克隆及序列分析 \\
\hline & & & /EN & & \\
\hline \multirow[t]{2}{*}{ Ailuropoda melanoleuca } & 大熊猫 & I & 濒危 & 侯万儒 & 大熊猫核糖体蛋白亚基 RPS7 基因的克隆及序列分析 \\
\hline & & & /EN & & \\
\hline \multirow[t]{2}{*}{ Ailuropoda melanoleuca } & 大熊猫 & I & 濒危 & 李德生 & 大熊猫呼吸道感染阴沟肠杆菌 1 例 \\
\hline & & & /EN & & \\
\hline \multirow[t]{2}{*}{ Ailuropoda melanoleuca } & 大熊猫 & I & 濒危 & 董 为 & 大熊猫化石副鼻窦的 3 维成像及其虚拟解剖 \\
\hline & & & /EN & & \\
\hline AILUROPODA & 熊猫 & I & 濒危 & 余建秋 & 大熊猫基因资源库构建及粪便高质量 DNA 提取方法的建立 \\
\hline MELANOLEUCA & & & /EN & & \\
\hline \multirow[t]{2}{*}{ Ailuropoda melanoleuca } & 大熊猫 & I & 濒危 & 林羽 & 大熊猫基因组 DNA 文库的构建 \\
\hline & & & /EN & & \\
\hline \multirow[t]{2}{*}{ Ailuropoda melanoleuca } & 大熊猫 & I & 濒危 & & 大熊猫基因组测序和从头组装 \\
\hline & & & /EN & & \\
\hline \multirow[t]{2}{*}{ Ailuropoda melanoleuca } & 大熊猫 & I & 濒危 & 岳碧松 & 大熊猫基因组微卫星序列的分布特征分析 \\
\hline & & & /EN & & \\
\hline
\end{tabular}


顾垒，闻丞，罗玫，王吴，吕植. 中国最受关注濒危物种保护现状快速评价的新方法探讨. 生物多样性，2015，23(5)：583-590. http://www biodiversity-science. net/CN/article/downloadArticleFile. do?attachType=PDF\&id=10075

\begin{tabular}{|c|c|c|c|c|c|}
\hline Ailuropoda melanoleuca & 大熊猫 & I & $\begin{array}{l}\text { 濒危 } \\
\text { /EN }\end{array}$ & 潘秀森 & 大熊猫急性病毒性肝炎的病理解剖观察 \\
\hline Ailuropoda melanoleuca & 大熊猫 & I & $\begin{array}{l}\text { 濒危 } \\
\text { /EN }\end{array}$ & 潘秀森 & 大熊猫急性病毒性黄㾝型肝炎及全胃大出血的病理解剖研究 \\
\hline AILUROPODA & 熊猫 & I & 濒危 & 汤纯香 & 大熊猫急性剧烈腹胀的救治一例 \\
\hline MELANOLEUCA & & & /EN & & \\
\hline Ailuropoda melanoleuca & 大熊猫 & I & $\begin{array}{l}\text { 濒危 } \\
\text { /EN }\end{array}$ & 李才武 & 大熊猫急性尿路感染诊治一例 \\
\hline Ailuropoda melanoleuca & 大熊猫 & I & $\begin{array}{l}\text { 濒危 } \\
\text { /EN }\end{array}$ & 侯志军 & 大熊猫寄生虫病研究现状 \\
\hline Ailuropoda melanoleuca & 大熊猫 & I & $\begin{array}{l}\text { 濒危 } \\
\text { /EN }\end{array}$ & 张华 & 大熊猫寄生虫病综述 \\
\hline Ailuropoda melanoleuca & 大熊猫 & I & $\begin{array}{l}\text { 濒危 } \\
\text { /EN }\end{array}$ & 鲜红 & 大熊猫精浆成分与精液质量关系及提高大熊猫冷冻精子体外受精能力的研究 \\
\hline AILUROPODA & 熊猫 & I & 濒危 & 侯蓉 & 大熊猫精浆蛋白的 SDS-PAGE 电泳研究 \\
\hline MELANOLEUCA & & & $/ \mathrm{EN}$ & & \\
\hline Ailuropoda melanoleuca & 大熊猫 & I & $\begin{array}{l}\text { 濒危 } \\
\text { /EN }\end{array}$ & 朱 庆 & 大熊猫精浆中 PAF-AH 和 GOT 水平与精液质量的关系 \\
\hline AILUROPODA & 熊猫 & I & 濒危 & 鲜红 & 大熊猫精清血小板激活因子乙酰水解酶(PAF-AH)活性影响因素的初步探讨 \\
\hline
\end{tabular}


顾垒，闻丞，罗玫，王吴，吕植. 中国最受关注濒危物种保护现状快速评价的新方法探讨. 生物多样性，2015，23(5)：583-590. http://www. biodiversity-science. net/CN/article/downloadArticleFile. do?attachType=PDF\&id=10075

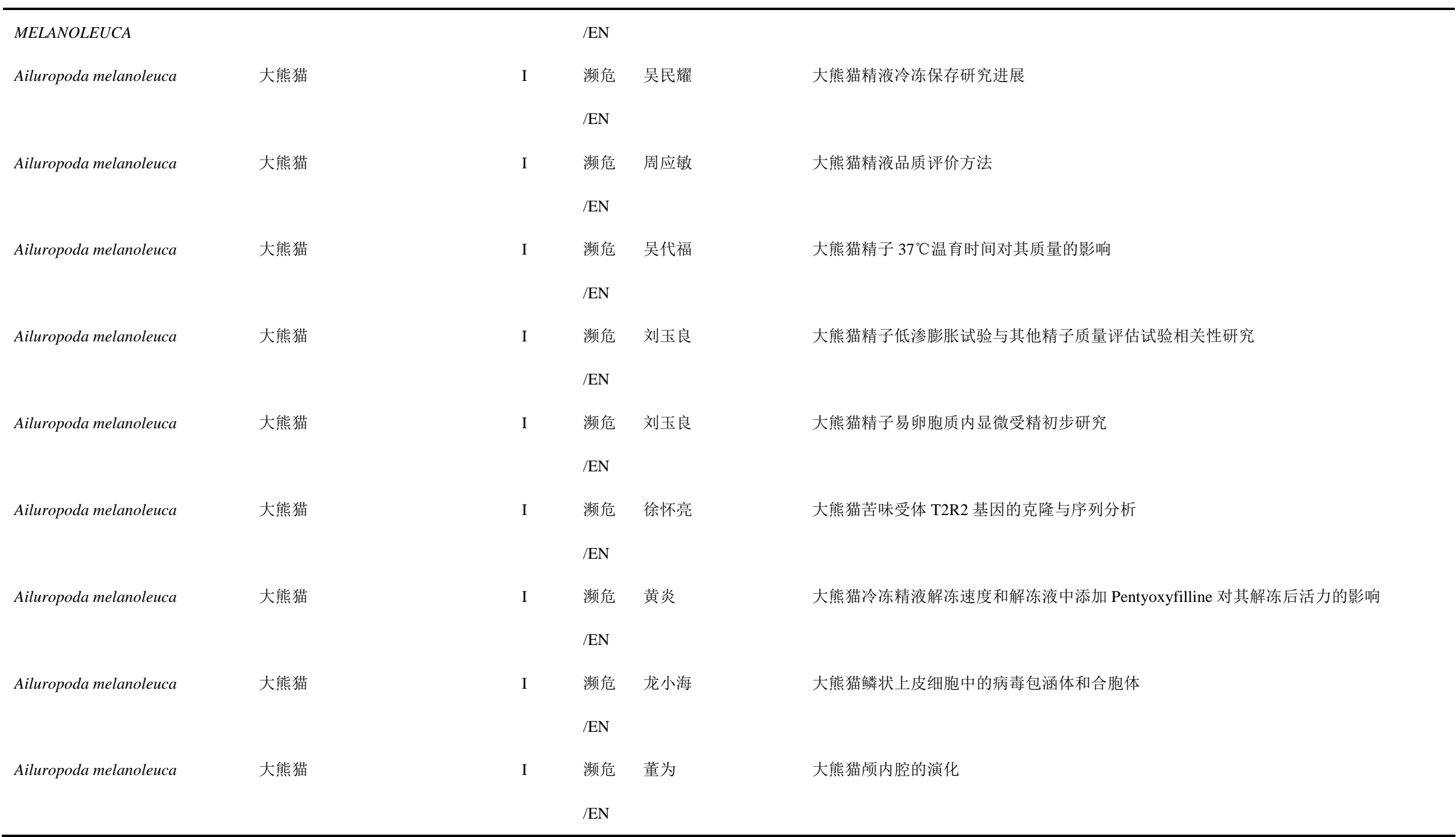


顾垒，闻丞，罗玫，王吴，吕植. 中国最受关注濒危物种保护现状快速评价的新方法探讨. 生物多样性，2015，23(5)：583-590. http://www biodiversity-science. net/CN/article/downloadArticleFile. do?attachType=PDF\&id=10075

\begin{tabular}{|c|c|c|c|c|c|}
\hline Ailuropoda melanoleuca & 大熊猫 & I & $\begin{array}{l}\text { 濒危 } \\
\text { /EN }\end{array}$ & 雷燕 & 大熊猫轮状病毒 CH_1 株基因克隆及分子解析 \\
\hline Ailuropoda melanoleuca & 大熊猫 & I & $\begin{array}{l}\text { 濒危 } \\
\text { /EN }\end{array}$ & 颜其贵 & 大熊猫轮状病毒 CH_1 株外衣壳蛋白 VP4 基因的克隆与生物信息学分析 \\
\hline Ailuropoda melanoleuca & 大熊猫 & I & $\begin{array}{l}\text { 濒危 } \\
\text { /EN }\end{array}$ & 雷燕 & 大熊猫轮状病毒 RT2PCR 检测方法的建立 \\
\hline Ailuropoda melanoleuca & 大熊猫 & I & $\begin{array}{l}\text { 濒危 } \\
\text { /EN }\end{array}$ & 郭广洋 & 大熊猫轮状病毒的研究进展 \\
\hline Ailuropoda melanoleuca & 大熊猫 & I & $\begin{array}{l}\text { 濒危 } \\
\text { /EN }\end{array}$ & 周世强 & 大熊猫受食行为的栖息地管理策略 \\
\hline Ailuropoda melanoleuca & 大熊猫 & I & $\begin{array}{l}\text { 濒危 } \\
\text { /EN }\end{array}$ & 袁施涁 & 大熊猫能量和蛋白质营养需要研究进展及策略 \\
\hline Ailuropoda melanoleuca & 大熊猫 & I & $\begin{array}{l}\text { 濒危 } \\
\text { /EN }\end{array}$ & 胡德夫 & 大熊猫尿液类固醇激素研究现状及展望 \\
\hline Ailuropoda melanoleuca & 大熊猫 & I & $\begin{array}{l}\text { 濒危 } \\
\text { /EN }\end{array}$ & 张锐 & 大熊猫排粘性血便的治疗 \\
\hline Ailuropoda melanoleuca & 大熊猫 & I & $\begin{array}{l}\text { 濒危 } \\
\text { /EN }\end{array}$ & 李德生 & 大熊猫胚胎延迟着床: 首次综合实验验证 \\
\hline Ailuropoda melanoleuca & 大熊猫 & I & 濒危 & 朱庆 & 大熊猫皮肤成纤维细胞系的建立和冷冻保存 \\
\hline
\end{tabular}


顾垒，闻丞，罗玫，王吴，吕植. 中国最受关注濒危物种保护现状快速评价的新方法探讨. 生物多样性，2015，23(5)：583-590. http://www. biodiversity-science. net/CN/article/downloadArticleFile. do?attachType=PDF\&id=10075

\begin{tabular}{|c|c|c|c|c|c|}
\hline & & & /EN & & \\
\hline \multirow[t]{2}{*}{ Ailuropoda melanoleuca } & 大熊猫 & I & 濒危 & 朱庆 & 大熊猫皮肤成纤维细胞在不同培养液中的生物学特性研究 \\
\hline & & & /EN & & \\
\hline \multirow[t]{2}{*}{ Ailuropoda melanoleuca } & 大熊猫 & I & 濒危 & 张明 & 大熊猫皮肤组织酶解分离效果研究 \\
\hline & & & /EN & & \\
\hline \multirow[t]{2}{*}{ Ailuropoda melanoleuca } & 大熊猫 & I & 濒危 & 王刚 & 大熊猫栖息地评价研究进展 \\
\hline & & & /EN & & \\
\hline \multirow[t]{2}{*}{ Ailuropoda melanoleuca } & 大熊猫 & I & 濒危 & 周洁敏 & 大熊猫栖息地评价指标体系初探 \\
\hline & & & /EN & & \\
\hline \multirow[t]{2}{*}{ Ailuropoda melanoleuca } & 大熊猫 & I & 濒危 & 欧阳志云 & 大熊猫取食竹笋期间的昼夜活动节律和强度 \\
\hline & & & /EN & & \\
\hline \multirow[t]{2}{*}{ Ailuropoda melanoleuca } & 大熊猫 & I & 濒危 & 何东阳 & 大熊猫取食竹选择、消化率及营养和能量对策的研究 \\
\hline & & & /EN & & \\
\hline \multirow[t]{2}{*}{ Ailuropoda melanoleuca } & 大熊猫 & I & 濒危 & 胡桂学 & 大熊猫犬冠状病毒 $\mathrm{s}$ 基因的扩增、克隆与序列分析 \\
\hline & & & /EN & & \\
\hline \multirow[t]{2}{*}{ Ailuropoda melanoleuca } & 大熊猫 & I & 濒危 & 关振宏 & 大熊猫犬冠状病毒 $\mathrm{s}$ 基因的扩增、克隆与序列分析 \\
\hline & & & /EN & & \\
\hline \multirow[t]{2}{*}{ Ailuropoda melanoleuca } & 大熊猫 & I & 濒危 & 胡桂学 & 大熊猫犬冠状病毒部分 $\mathrm{S}$ 基因的克隆与全 $\mathrm{S}$ 基因序列分析 \\
\hline & & & /EN & & \\
\hline
\end{tabular}


顾垒，闻丞，罗玫，王吴，吕植. 中国最受关注濒危物种保护现状快速评价的新方法探讨. 生物多样性，2015，23(5)：583-590. http://www biodiversity-science. net/CN/article/downloadArticleFile. do?attachType=PDF\&id=10075

\begin{tabular}{|c|c|c|c|c|c|}
\hline Ailuropoda melanoleuca & 大熊猫 & I & $\begin{array}{l}\text { 濒危 } \\
\text { /EN }\end{array}$ & 胡桂学 & 大熊猫犬冠状病毒的分离与鉴定 \\
\hline Ailuropoda melanoleuca & 大熊猫 & I & $\begin{array}{l}\text { 濒危 } \\
\text { /EN }\end{array}$ & 逢博 & 大熊猫犬冠状病毒动物感染实验及其荧光检测方法的建立 \\
\hline Ailuropoda melanoleuca & 大熊猫 & I & $\begin{array}{l}\text { 濒危 } \\
\text { /EN }\end{array}$ & 胡桂学 & 大熊猫犬冠状病毒感染幼犬组织病理学研究 \\
\hline Ailuropoda melanoleuca & 大熊猫 & I & $\begin{array}{l}\text { 濒危 } \\
\text { /EN }\end{array}$ & 刘选珍 & 大熊猫乳汁水解氨基酸含量的测定分析 \\
\hline Ailuropoda melanoleuca & 大熊猫 & I & $\begin{array}{l}\text { 濒危 } \\
\text { /EN }\end{array}$ & 郑玉才 & 大熊猫乳汁中富含游离精氨酸 \\
\hline Ailuropoda melanoleuca & 大熊猫 & I & $\begin{array}{l}\text { 濒危 } \\
\text { /EN }\end{array}$ & 费立松 & 大熊猫乳中酶的活力与激素含量分析 \\
\hline Ailuropoda melanoleuca & 大熊猫 & I & $\begin{array}{l}\text { 濒危 } \\
\text { /EN }\end{array}$ & 费立松 & 大熊猫乳中酶的活力与激素含量分析 \\
\hline Ailuropoda melanoleuca & 大熊猫 & I & $\begin{array}{l}\text { 濒危 } \\
\text { /EN }\end{array}$ & 方盛国 & 大熊猫神经营养素-4 基因在大肠杆菌中的表达 \\
\hline Ailuropoda melanoleuca & 大熊猫 & I & $\begin{array}{l}\text { 濒危 } \\
\text { /EN }\end{array}$ & 杨武年 & 大熊猫生境评估系统的设计与实现 \\
\hline Ailuropoda melanoleuca & 大熊猫 & I & 濒危 & 肖烨 & 大熊猫生境适宜性评价和景观格局分析 \\
\hline
\end{tabular}


顾垒，闻丞，罗玫，王吴，吕植. 中国最受关注濒危物种保护现状快速评价的新方法探讨. 生物多样性，2015，23(5)：583-590. http://www. biodiversity-science. net/CN/article/downloadArticleFile. do?attachType=PDF\&id=10075

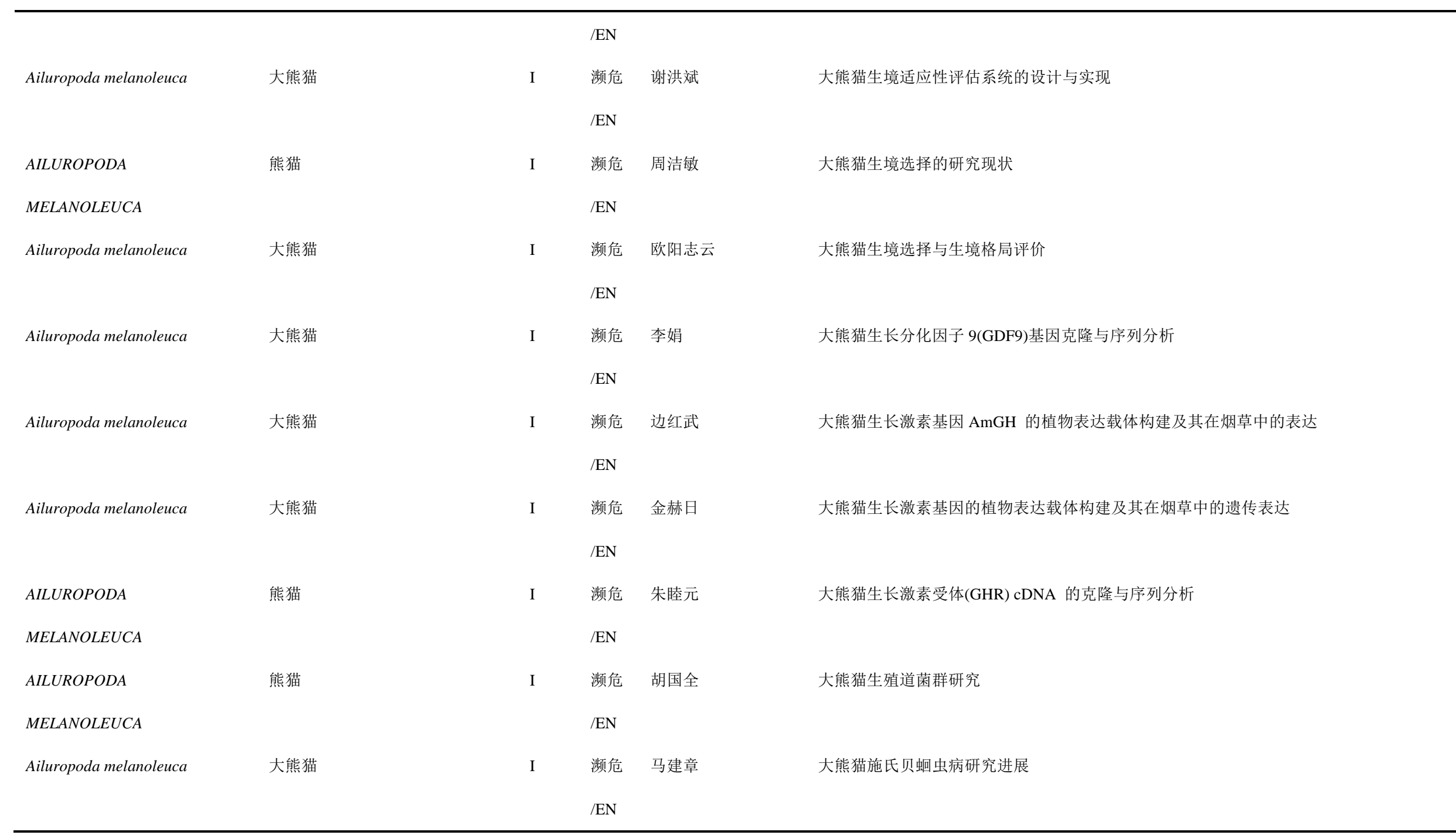


顾垒，闻丞，罗玫，王吴，吕植. 中国最受关注濒危物种保护现状快速评价的新方法探讨. 生物多样性，2015，23(5)：583-590. http://www. biodiversity-science. net/CN/article/downloadArticleFile. do?attachType=PDF\&id=10075

\begin{tabular}{|c|c|c|c|c|c|}
\hline Ailuropoda melanoleuca & 大熊猫 & I & $\begin{array}{l}\text { 濒危 } \\
\text { /EN }\end{array}$ & 汤纯香 & 大熊猫拾到梗阻一例报告 \\
\hline Ailuropoda melanoleuca & 大熊猫 & I & $\begin{array}{l}\text { 濒危 } \\
\text { /EN }\end{array}$ & 张志和 & 大熊猫食用竹笋营养初步研究 \\
\hline Ailuropoda melanoleuca & 大熊猫 & I & $\begin{array}{l}\text { 濒危 } \\
\text { /EN }\end{array}$ & 侯万儒 & 大熊猫酸性核糖体磷酸蛋白 P1 基因 cDNA 克隆及序列分析 \\
\hline Ailuropoda melanoleuca & 大熊猫 & I & $\begin{array}{l}\text { 濒危 } \\
\text { /EN }\end{array}$ & 修云芳 & 大熊猫铜绿假单胞菌呼吸道感染继发白色念珠菌性肠炎的诊治 \\
\hline Ailuropoda melanoleuca & 大熊猫 & I & $\begin{array}{l}\text { 濒危 } \\
\text { /EN }\end{array}$ & 沈富军 & 大熊猫微卫星分型数据库的建立 \\
\hline Ailuropoda melanoleuca & 大熊猫 & I & $\begin{array}{l}\text { 濒危 } \\
\text { /EN }\end{array}$ & 范志勇 & 大熊猫未来长期保护策略研究 \\
\hline Ailuropoda melanoleuca & 大熊猫 & I & $\begin{array}{l}\text { 濒危 } \\
\text { /EN }\end{array}$ & 郑玉才 & 大熊猫胃肠道中消化酶的活力分析 \\
\hline Ailuropoda melanoleuca & 大熊猫 & I & $\begin{array}{l}\text { 濒危 } \\
\text { /EN }\end{array}$ & 费立松 & 大熊猫胃肠道中消化酶活力的分析 \\
\hline AILUROPODA & 熊猫 & I & 濒危 & 杨光友 & 大熊猫胃内纤毛虫检测初报 \\
\hline MELANOLEUCA & & & $/ \mathrm{EN}$ & & \\
\hline Ailuropoda melanoleuca & 大熊猫 & I & 濒危 & 章鹦鹦 & 大熊猫卧龙圈养种群亲子鉴定及种群奠基者效应研究 \\
\hline
\end{tabular}


顾垒，闻丞，罗玫，王吴，吕植. 中国最受关注濒危物种保护现状快速评价的新方法探讨. 生物多样性，2015，23(5)：583-590. http://www. biodiversity-science. net/CN/article/downloadArticleFile. do?attachType=PDF\&id=10075

\begin{tabular}{|c|c|c|c|c|c|}
\hline & & & /EN & & \\
\hline \multirow[t]{2}{*}{ Ailuropoda melanoleuca } & 大熊猫 & I & 濒危 & 杨光友 & 大熊猫西氏贝蛔虫线粒体全基因组研究 \\
\hline & & & $/$ EN & & \\
\hline \multirow[t]{2}{*}{ Ailuropoda melanoleuca } & 大熊猫 & I & 濒危 & 王成东 & 大熊猫吸入麻醉操作技术与监护方法 \\
\hline & & & /EN & & \\
\hline AILUROPODA & 熊猫 & I & 濒危 & 侯蓉 & 大熊猫细管冻精制备程序的建立与应用 \\
\hline MELANOLEUCA & & & /EN & & \\
\hline \multirow[t]{2}{*}{ Ailuropoda melanoleuca } & 大熊猫 & I & 濒危 & 马清义 & 大熊猫消化道正常菌群的分离鉴定及药敏性研究 \\
\hline & & & /EN & & \\
\hline \multirow[t]{2}{*}{ Ailuropoda melanoleuca } & 大熊猫 & I & 濒危 & 夏茂华 & 大熊猫小肠扭转死亡的病例分析 \\
\hline & & & /EN & & \\
\hline \multirow[t]{2}{*}{ Ailuropoda melanoleuca } & 大熊猫 & I & 濒危 & 王丽华 & 大熊猫嗅味树调查 \\
\hline & & & /EN & & \\
\hline AILUROPODA & 熊猫 & I & 濒危 & 高玉伟 & 大熊猫血清犬瘟热病毒中和抗体调查 \\
\hline MELANOLEUCA & & & /EN & & \\
\hline \multirow[t]{2}{*}{ Ailuropoda melanoleuca } & 大熊猫 & I & 濒危 & 李德生 & 大熊猫血液标本放置时间对全血细胞计数的影响 \\
\hline & & & /EN & & \\
\hline \multirow[t]{2}{*}{ Ailuropoda melanoleuca } & 大熊猫 & I & 濒危 & 李德生 & 大熊猫血液生理指标的测定 \\
\hline & & & /EN & & \\
\hline
\end{tabular}


顾垒，闻丞，罗玫，王吴，吕植. 中国最受关注濒危物种保护现状快速评价的新方法探讨. 生物多样性，2015，23(5)：583-590. http://www. biodiversity-science. net/CN/article/downloadArticleFile. do?attachType=PDF\&id=10075

\begin{tabular}{|c|c|c|c|c|c|}
\hline Ailuropoda melanoleuca & 大熊猫 & I & $\begin{array}{l}\text { 濒危 } \\
\text { /EN }\end{array}$ & 李才武 & 大熊猫血液生理指标的测定分析 \\
\hline Ailuropoda melanoleuca & 大熊猫 & I & $\begin{array}{l}\text { 濒危 } \\
\text { /EN }\end{array}$ & 黄炎 & 大熊猫野化放归中的遗传学分析 \\
\hline AILUROPODA & 熊猫 & I & 濒危 & 周世强 & 大熊猫野化培训圈森林植物群落多样性研究 \\
\hline MELANOLEUCA & & & /EN & & \\
\hline Ailuropoda melanoleuca & 大熊猫 & I & $\begin{array}{l}\text { 濒危 } \\
\text { /EN }\end{array}$ & 周世强 & 大熊猫野生培训圈主食竹种生长发育特性及生物量结构调查 \\
\hline Ailuropoda melanoleuca & 大熊猫 & I & $\begin{array}{l}\text { 濒危 } \\
\text { /EN }\end{array}$ & 陈武 & 大熊猫医疗行为训练 \\
\hline Ailuropoda melanoleuca & 大熊猫 & I & $\begin{array}{l}\text { 濒危 } \\
\text { /EN }\end{array}$ & 周应敏 & 大熊猫义母育幼培驯一例 \\
\hline Ailuropoda melanoleuca & 大熊猫 & I & $\begin{array}{l}\text { 濒危 } \\
\text { /EN }\end{array}$ & 周应敏 & 大熊猫异常发情一例 \\
\hline Ailuropoda melanoleuca & 大熊猫 & I & $\begin{array}{l}\text { 濒危 } \\
\text { /EN }\end{array}$ & 彭广能 & 大熊猫隐孢子虫的分离鉴定 \\
\hline Ailuropoda melanoleuca & 大熊猫 & I & $\begin{array}{l}\text { 濒危 } \\
\text { /EN }\end{array}$ & 王成东 & 大熊猫幼兽腹鸡粪便分离出的轮状病毒鉴定 \\
\hline Ailuropoda melanoleuca & 大熊猫 & I & 濒危 & 邓林华 & 大熊猫幼崽眼球意外脱出救治一例 \\
\hline
\end{tabular}


顾垒，闻丞，罗玫，王吴，吕植. 中国最受关注濒危物种保护现状快速评价的新方法探讨. 生物多样性，2015，23(5)：583-590. http://www. biodiversity-science. net/CN/article/downloadArticleFile. do?attachType=PDF\&id=10075

\begin{tabular}{|c|c|c|c|c|c|}
\hline & & & /EN & & \\
\hline \multirow[t]{2}{*}{ Ailuropoda melanoleuca } & 大熊猫 & I & 濒危 & 李晓鸿 & 大熊猫与伴生动物竹林活动踪迹辨别 \\
\hline & & & $/$ EN & & \\
\hline \multirow[t]{2}{*}{ Ailuropoda melanoleuca } & 大熊猫 & I & 濒危 & 赵德明 & 大熊猫与牦牛和奶牛朊病毒蛋白全基因序列分析 \\
\hline & & & /EN & & \\
\hline \multirow[t]{2}{*}{ Ailuropoda melanoleuca } & 大熊猫 & I & 濒危 & 张泽钧 & 大熊猫与小熊猫生态习性的比较:食物、体型大小及系统发育的影响 \\
\hline & & & /EN & & \\
\hline \multirow[t]{2}{*}{ Ailuropoda melanoleuca } & 大熊猫 & I & 濒危 & 李德生 & 大熊猫源 H1N1 流感病毒的分离鉴 \\
\hline & & & /EN & & \\
\hline \multirow[t]{2}{*}{ Ailuropoda melanoleuca } & 大熊猫 & I & 濒危 & 朱玲 & 大熊猫源肺炎双球菌的分离鉴定 \\
\hline & & & /EN & & \\
\hline \multirow[t]{2}{*}{ Ailuropoda melanoleuca } & 大熊猫 & I & 濒危 & 梁萌 & 大熊猫源细小病毒的分离鉴定与遗传进化分析 \\
\hline & & & /EN & & \\
\hline \multirow[t]{2}{*}{ Ailuropoda melanoleuca } & 大熊猫 & I & 濒危 & 马晓平 & 大熊猫源枝狍样枝狍霉的分离鉴定 \\
\hline & & & /EN & & \\
\hline \multirow[t]{2}{*}{ Ailuropoda melanoleuca } & 大熊猫 & I & 濒危 & 马晓平 & 大熊猫源枝狍样枝孢霉的生物学特性 \\
\hline & & & /EN & & \\
\hline \multirow[t]{2}{*}{ Ailuropoda melanoleuca } & 大熊猫 & I & 濒危 & 高洁 & 大熊猫运动和齿系骨骼系统功能形态学分析及其所反映的环境学问题 \\
\hline & & & /EN & & \\
\hline
\end{tabular}


顾垒，闻丞，罗玫，王吴，吕植. 中国最受关注濒危物种保护现状快速评价的新方法探讨. 生物多样性，2015，23(5)：583-590. http://www biodiversity-science. net/CN/article/downloadArticleFile. do?attachType=PDF\&id=10075

\begin{tabular}{|c|c|c|c|c|c|}
\hline Ailuropoda melanoleuca & 大熊猫 & I & $\begin{array}{l}\text { 濒危 } \\
\text { /EN }\end{array}$ & 再江洪 & 大熊猫在原始林和次生林中生境利用的比较研究 \\
\hline Ailuropoda melanoleuca & 大熊猫 & I & $\begin{array}{l}\text { 濒危 } \\
\text { /EN }\end{array}$ & 李德生 & 大熊猫直肠脱出手术治疗 1 例 \\
\hline Ailuropoda melanoleuca & 大熊猫 & I & $\begin{array}{l}\text { 濒危 } \\
\text { /EN }\end{array}$ & 王成东 & 大熊猫致病性催产克雷伯菌的分离鉴定 \\
\hline Ailuropoda melanoleuca & 大熊猫 & I & $\begin{array}{l}\text { 濒危 } \\
\text { /EN }\end{array}$ & 宋国华 & 大熊猫种群在小区域之间扩散对持续生存的影响 \\
\hline Ailuropoda melanoleuca & 大熊猫 & I & $\begin{array}{l}\text { 濒危 } \\
\text { /EN }\end{array}$ & 宋国华 & 大熊猫种群在小区域之间扩散对持续生存的影响 \\
\hline Ailuropoda melanoleuca & 大熊猫 & I & $\begin{array}{l}\text { 濒危 } \\
\text { /EN }\end{array}$ & 宋国华 & 大熊猫种群在小区域之间扩散对持续生存的影响 \\
\hline Ailuropoda melanoleuca & 大熊猫 & I & $\begin{array}{l}\text { 濒危 } \\
\text { /EN }\end{array}$ & 宋国华 & 大熊猫种群在小区域之间扩散对持续生存的影响 \\
\hline Ailuropoda melanoleuca & 大熊猫 & I & $\begin{array}{l}\text { 濒危 } \\
\text { /EN }\end{array}$ & 宋国华 & 大熊猫种群在小区域之间扩散对持续生存的影响 \\
\hline Ailuropoda melanoleuca & 大熊猫 & I & $\begin{array}{l}\text { 濒危 } \\
\text { /EN }\end{array}$ & 康东伟 & 大熊猫主食竹一一缺苍箭竹的生境与干扰状况研究 \\
\hline Ailuropoda melanoleuca & 大熊猫 & I & 濒危 & 钟伟伟 & 大熊猫主食竹研究进展 \\
\hline
\end{tabular}


顾垒，闻丞，罗玫，王吴，吕植. 中国最受关注濒危物种保护现状快速评价的新方法探讨. 生物多样性，2015，23(5)：583-590. http://www. biodiversity-science. net/CN/article/downloadArticleFile. do?attachType=PDF\&id=10075

\begin{tabular}{|c|c|c|c|c|c|}
\hline & & & /EN & & \\
\hline AILUROPODA & 熊猫 & I & 濒危 & 周世强 & 大熊猫主食竹种的研究与进展 \\
\hline MELANOLEUCA & & & /EN & & \\
\hline \multirow[t]{2}{*}{ Ailuropoda melanoleuca } & 大熊猫 & I & 濒危 & 易同培 & 大熊猫主食竹种及其生物多样性 \\
\hline & & & $/ \mathrm{EN}$ & & \\
\hline \multirow[t]{2}{*}{ Ailuropoda melanoleuca } & 大熊猫 & I & 濒危 & 王逸之 & 大熊猫主食竹种研究综述 \\
\hline & & & /EN & & \\
\hline \multirow[t]{2}{*}{ Ailuropoda melanoleuca } & 大熊猫 & I & 濒危 & 朱亮 & 大熊猫主要组织相容性复合体 II 类基因研究 \\
\hline & & & /EN & & \\
\hline \multirow[t]{2}{*}{ Ailuropoda melanoleuca } & 大熊猫 & I & 濒危 & 李明喜 & 大熊猫专用饲料调制工艺的研究 \\
\hline & & & /EN & & \\
\hline \multirow[t]{2}{*}{ Ailuropoda melanoleuca } & 大熊猫 & I & 濒危 & 征蜀歧 & 大熊猫自然保护区监测工作管理探索 \\
\hline & & & $/$ EN & & \\
\hline AILUROPODA & 熊猫 & I & 濒危 & 严旬 & 大熊猫自然保护区体系研究 \\
\hline MELANOLEUCA & & & /EN & & \\
\hline \multirow[t]{2}{*}{ Ailuropoda melanoleuca } & 大熊猫 & I & 濒危 & 王承东 & 大熊猫左后肢截肢术及右后肢残端修复术 1 例 \\
\hline & & & $/ \mathrm{EN}$ & & \\
\hline \multirow[t]{2}{*}{ Ailuropoda melanoleuca } & 大熊猫 & I & 濒危 & 傅之屏 & 地震后大熊猫潜在栖息地恢复的初步研究 \\
\hline & & & /EN & & \\
\hline
\end{tabular}


顾垒，闻丞，罗玫，王吴，吕植. 中国最受关注濒危物种保护现状快速评价的新方法探讨. 生物多样性，2015，23(5)：583-590. http://www biodiversity-science. net/CN/article/downloadArticleFile. do?attachType=PDF\&id=10075

\begin{tabular}{|c|c|c|c|c|c|}
\hline Ailuropoda melanoleuca & 大熊猫 & I & $\begin{array}{l}\text { 濒危 } \\
/ \mathrm{EN}\end{array}$ & 傅之屏 & 地震后大熊猫潜在栖息地恢复的初步研究 \\
\hline Ailuropoda melanoleuca & 大熊猫 & I & $\begin{array}{l}\text { 濒危 } \\
/ \mathrm{EN}\end{array}$ & 李晓鸿 & 迭部县大熊猫栖息地的变化 \\
\hline Ailuropoda melanoleuca & 大熊猫 & I & $\begin{array}{l}\text { 濒危 } \\
/ \mathrm{EN}\end{array}$ & 刘玉良 & 顶空固相微萃取-气相色谱-质谱联用分析发情期雌性大熊猫尿液中挥发性成分 \\
\hline AILUROPODA & 熊猫 & I & 濒危 & 王昊 & 对大熊猫数量调查方法中咬节区分机制的准确性评价 \\
\hline MELANOLEUCA & & & $/ \mathrm{EN}$ & & \\
\hline Ailuropoda melanoleuca & 大熊猫 & I & 濒危 & 王红宁 & 多重 PCR 对大熊猫和野生动物肠道分离菌氨基糖苷类抗生素耐药基因检测研究 \\
\hline Ailuropoda melanoleuca & 大熊猫 & I & $\begin{array}{l}\text { 濒危 } \\
/ \mathrm{EN}\end{array}$ & 张和民 & 峨眉山和神农架地区森林环境与野生大熊猫栖息地特征的比较 \\
\hline Ailuropoda melanoleuca & 大熊猫 & I & 濒危 & 刘定震 & 发情期大熊猫_Ailuropod_省略_noleuca_交互模态信号通讯 \\
\hline Ailuropoda melanoleuca & 大熊猫 & I & $\begin{array}{l}\text { 濒危 } \\
/ \mathrm{EN}\end{array}$ & 侯 蓉 & 发情期大熊猫宫颈黏液结晶周期性变化研究 \\
\hline Ailuropoda melanoleuca & 大熊猫 & I & $\begin{array}{l}\text { 濒危 } \\
/ \mathrm{EN}\end{array}$ & 刘学锋 & 发情期大熊猫阴道分泌物细菌分析 \\
\hline Ailuropoda melanoleuca & 大熊猫 & I & 濒危 & 古晓东 & 放归大熊猫 “盛林 1 号” 的活动范围和活动节律监测 \\
\hline
\end{tabular}


顾垒，闻丞，罗玫，王吴，吕植. 中国最受关注濒危物种保护现状快速评价的新方法探讨. 生物多样性，2015，23(5)：583-590. http://www. biodiversity-science. net/CN/article/downloadArticleFile. do?attachType=PDF\&id=10075

\begin{tabular}{|c|c|c|c|c|c|}
\hline & & & /EN & & \\
\hline \multirow[t]{2}{*}{ Ailuropoda melanoleuca } & 大熊猫 & I & 濒危 & 何晓光 & 分布区最北缘大熊猫生存威胁因素与保护对策 \\
\hline & & & $/$ EN & & \\
\hline \multirow[t]{2}{*}{ Ailuropoda melanoleuca } & 大熊猫 & I & 濒危 & 岳碧松 & 分子手段的大熊猫性别鉴定技术 \\
\hline & & & /EN & & \\
\hline \multirow[t]{2}{*}{ Ailuropoda melanoleuca } & 大熊猫 & I & 濒危 & 侯蓉 & 粪样在大熊猫研究上的应用 \\
\hline & & & /EN & & \\
\hline \multirow[t]{2}{*}{ Ailuropoda melanoleuca } & 大熊猫 & I & 濒危 & 郑晓燕 & 佛坪保护区大熊猫取笋区域内的巴山木竹林现状分析 \\
\hline & & & /EN & & \\
\hline \multirow[t]{2}{*}{ Ailuropoda melanoleuca } & 大熊猫 & I & 濒危 & 曹庆 & 佛坪保护区社区共管的现状、问题于对策的研究 \\
\hline & & & /EN & & \\
\hline \multirow[t]{2}{*}{ Ailuropoda melanoleuca } & 大熊猫 & I & 濒危 & 曹 庆 & 佛坪大熊猫冬季栖息地的功能和面临的主要问题 \\
\hline & & & /EN & & \\
\hline \multirow[t]{2}{*}{ Ailuropoda melanoleuca } & 大熊猫 & I & 濒危 & 刘定震 & 佛坪自然保护区野生大熊猫对保护区内简易建筑的利用 \\
\hline & & & /EN & & \\
\hline \multirow[t]{2}{*}{ Ailuropoda melanoleuca } & 大熊猫 & I & 濒危 & 魏辅文 & 佛坪自然保护区野生大熊猫交配行为的观察 \\
\hline & & & /EN & & \\
\hline \multirow[t]{2}{*}{ Ailuropoda melanoleuca } & 大熊猫 & I & 濒危 & 张泽钧 & 佛坪自然保护区野生大熊猫食性及对受食位点的选择 \\
\hline & & & /EN & & \\
\hline
\end{tabular}


顾垒，闻丞，罗玫，王吴，吕植. 中国最受关注濒危物种保护现状快速评价的新方法探讨. 生物多样性，2015，23(5)：583-590. http://www. biodiversity-science. net/CN/article/downloadArticleFile. do?attachType=PDF\&id=10075

\begin{tabular}{|c|c|c|c|c|c|}
\hline Ailuropoda melanoleuca & 大熊猫 & I & $\begin{array}{l}\text { 濒危 } \\
\text { /EN }\end{array}$ & 夏未铭 & 佛坪自然保护区野生动物资源动态研究 \\
\hline Ailuropoda melanoleuca & 大熊猫 & I & $\begin{array}{l}\text { 濒危 } \\
\text { /EN }\end{array}$ & 王建宏 & 甘肃白水江保护区西段大熊猫对神经的选择 \\
\hline Ailuropoda melanoleuca & 大熊猫 & I & $\begin{array}{l}\text { 濒危 } \\
\text { /EN }\end{array}$ & 滕继荣 & 甘肃白水江国家自然保护区大熊猫研究进展一一为纪念我国建立自然保护区 50 周年而作 \\
\hline Ailuropoda melanoleuca & 大熊猫 & I & $\begin{array}{l}\text { 濒危 } \\
\text { /EN }\end{array}$ & 滕继荣 & 甘肃白水江自然保护区大熊猫栖息地生境特征初步分析 \\
\hline Ailuropoda melanoleuca & 大熊猫 & I & $\begin{array}{l}\text { 濒危 } \\
\text { /EN }\end{array}$ & 张琼 & 甘肃峮山大熊猫生境选择研究 \\
\hline AILUROPODA & 熊猫 & I & 濒危 & 巩文 & 甘肃省大熊猫栖息地生境分析 \\
\hline MELANOLEUCA & & & $/ \mathrm{EN}$ & & \\
\hline Ailuropoda melanoleuca & 大熊猫 & I & $\begin{array}{l}\text { 濒危 } \\
\text { /EN }\end{array}$ & 任继文 & 甘肃省大熊猫栖息地植被类型研究 \\
\hline Ailuropoda melanoleuca & 大熊猫 & I & $\begin{array}{l}\text { 濒危 } \\
\text { /EN }\end{array}$ & 巩文 & 甘肃省大熊猫生境分析 \\
\hline AILUROPODA & 熊猫 & I & 濒危 & 李晓鸿 & 甘肃省大熊猫数量及栖息地现状 \\
\hline MELANOLEUCA & & & $/ \mathrm{EN}$ & & \\
\hline Ailuropoda melanoleuca & 大熊猫 & I & 濒危 & 邢东兴 & 甘肃省自然保护区建设与管理现状评析 \\
\hline
\end{tabular}


顾垒，闻丞，罗玫，王吴，吕植. 中国最受关注濒危物种保护现状快速评价的新方法探讨. 生物多样性，2015，23(5)：583-590. http://www. biodiversity-science. net/CN/article/downloadArticleFile. do?attachType=PDF\&id=10075

\begin{tabular}{|c|c|c|c|c|c|}
\hline & & & /EN & & \\
\hline \multirow[t]{2}{*}{ Ailuropoda melanoleuca } & 大熊猫 & I & 濒危 & 周杰珑 & 高海拔地区昆明野生动物园大熊猫春季刻板行为探究 \\
\hline & & & $/$ EN & & \\
\hline \multirow[t]{2}{*}{ Ailuropoda melanoleuca } & 大熊猫 & I & 濒危 & 张和民 & 高山峡谷地区无线电遥测与 GPS 空间定位的比较:野外放归大熊猫的跟踪定位 \\
\hline & & & /EN & & \\
\hline \multirow[t]{2}{*}{ Ailuropoda melanoleuca } & 大熊猫 & I & 濒危 & 张和民 & 环境因子对野化培训大熊猫在生境斑块中行为表现的影响 \\
\hline & & & /EN & & \\
\hline \multirow[t]{2}{*}{ Ailuropoda melanoleuca } & 大熊猫 & I & 濒危 & 胡德夫 & 黄金周游客干扰对圈养大熊猫应激影响初探 \\
\hline & & & /EN & & \\
\hline \multirow[t]{2}{*}{ Ailuropoda melanoleuca } & 大熊猫 & I & 濒危 & 王芸 & 基于 GIS 的陕西青木川自然保护区大熊猫生境评价研究 \\
\hline & & & /EN & & \\
\hline \multirow[t]{2}{*}{ Ailuropoda melanoleuca } & 大熊猫 & I & 濒危 & 崔婷婷 & 基于 16SrDNA_RFLP 技术_省略_年大熊猫秋季肠道菌群多样性的研究 \\
\hline & & & $/ \mathrm{EN}$ & & \\
\hline \multirow[t]{2}{*}{ Ailuropoda melanoleuca } & 大熊猫 & I & 濒危 & 鲁海峰 & 基于 ERIC-PCR 的分子杂交技术对大熊猫肠道菌落结构的分析 \\
\hline & & & /EN & & \\
\hline \multirow[t]{2}{*}{ Ailuropoda melanoleuca } & 大熊猫 & I & 濒危 & 赵鹏祥 & 基于 GIS 的大熊猫监测研究 \\
\hline & & & /EN & & \\
\hline AILUROPODA & 熊猫 & I & 濒危 & 李军锋 & 基于 GIS 的秦岭地区大熊猫栖息地质量因子研究 \\
\hline MELANOLEUCA & & & /EN & & \\
\hline
\end{tabular}


顾垒，闻丞，罗玫，王吴，吕植. 中国最受关注濒危物种保护现状快速评价的新方法探讨. 生物多样性，2015，23(5)：583-590. http://www biodiversity-science. net/CN/article/downloadArticleFile. do?attachType=PDF\&id=10075

\begin{tabular}{|c|c|c|c|c|c|}
\hline Ailuropoda melanoleuca & 大熊猫 & I & $\begin{array}{l}\text { 濒危 } \\
\text { /EN }\end{array}$ & 陈利顶 & 基于参与性调查的退耕还林侦测可持续性评价 \\
\hline AILUROPODA & 熊猫 & I & 濒危 & 李军锋 & 基于层次分析法的秦岭地区大熊猫栖息地质量评价 \\
\hline MELANOLEUCA & & & $/ \mathrm{EN}$ & & \\
\hline Ailuropoda melanoleuca & 大熊猫 & I & $\begin{array}{l}\text { 濒危 } \\
\text { /EN }\end{array}$ & 李红梅 & 基于核糖体基因对大熊猫秦岭亚种施氏贝蜔虫的分子分类研究 \\
\hline Ailuropoda melanoleuca & 大熊猫 & I & $\begin{array}{l}\text { 濒危 } \\
\text { /EN }\end{array}$ & 王维 & 基于生境适宜度的成都震后大熊猫生境评价 \\
\hline Ailuropoda melanoleuca & 大熊猫 & I & $\begin{array}{l}\text { 濒危 } \\
\text { /EN }\end{array}$ & 崔国发 & 基于条件价值法的大熊猫(Ailuropoda melanoleuca)存在价值评估 \\
\hline Ailuropoda melanoleuca & 大熊猫 & I & $\begin{array}{l}\text { 濒危 } \\
\text { /EN }\end{array}$ & 徐卫华 & 基于遥感和 GIS 的秦岭山系大熊猫生境评价 \\
\hline Ailuropoda melanoleuca & 大熊猫 & I & $\begin{array}{l}\text { 濒危 } \\
\text { /EN }\end{array}$ & 李华东 & 基于主成分分析法和层次分析法的大熊猫生存环境因子研究 \\
\hline Ailuropoda melanoleuca & 大熊猫 & I & $\begin{array}{l}\text { 濒危 } \\
\text { /EN }\end{array}$ & 刘雪华 & 基于最小阻力模型的秦岭大熊猫扩散路线研究 \\
\hline Ailuropoda melanoleuca & 大熊猫 & I & $\begin{array}{l}\text { 濒危 } \\
\text { /EN }\end{array}$ & 刘雪华 & 基于最小阻力模型的秦岭大熊猫扩散路线研究 \\
\hline Ailuropoda melanoleuca & 大熊猫 & I & 濒危 & 刘雪华 & 基于最小阻力模型的秦岭大熊猫扩散路线研究 \\
\hline
\end{tabular}


顾垒，闻丞，罗玫，王吴，吕植. 中国最受关注濒危物种保护现状快速评价的新方法探讨. 生物多样性，2015，23(5)：583-590. http://www. biodiversity-science. net/CN/article/downloadArticleFile. do?attachType=PDF\&id=10075

\begin{tabular}{|c|c|c|c|c|c|}
\hline & & & /EN & & \\
\hline \multirow[t]{2}{*}{ Ailuropoda melanoleuca } & 大熊猫 & I & 濒危 & 刘雪华 & 基于最小阻力模型的秦岭大熊猫扩散路线研究 \\
\hline & & & /EN & & \\
\hline \multirow[t]{2}{*}{ Ailuropoda melanoleuca } & 大熊猫 & I & 濒危 & 刘雪华 & 基于最小阻力模型的秦岭大熊猫扩散路线研究 \\
\hline & & & /EN & & \\
\hline \multirow[t]{2}{*}{ Ailuropoda melanoleuca } & 大熊猫 & I & 濒危 & 刘雪华 & 集成的专家系统和神经网络应用于大熊猫生境评价 \\
\hline & & & /EN & & \\
\hline \multirow[t]{2}{*}{ Ailuropoda melanoleuca } & 大熊猫 & I & 濒危 & 王青 & 夹金山脉大熊猫栖息地生态风险评价 \\
\hline & & & /EN & & \\
\hline \multirow[t]{2}{*}{ Ailuropoda melanoleuca } & 大熊猫 & I & 濒危 & 刘选珍 & 降低圈养大熊猫粘液排泄措施的初步探讨 \\
\hline & & & /EN & & \\
\hline \multirow[t]{2}{*}{ Ailuropoda melanoleuca } & 大熊猫 & I & 濒危 & 黄炎 & 解冻速度和添加 Pentyoxyfilline 来提高大熊猫冷冻精液解冻后活力的研究 \\
\hline & & & $/ \mathrm{EN}$ & & \\
\hline AILUROPODA & 熊猫 & I & 濒危 & 邹兴淮 & 精料的蛋白质水平及能量浓度对成体大熊猫日粮消化率的影响 \\
\hline MELANOLEUCA & & & /EN & & \\
\hline \multirow[t]{2}{*}{ Ailuropoda melanoleuca } & 大熊猫 & I & 濒危 & 周应敏 & 精清对大熊猫精子质量的影响 \\
\hline & & & /EN & & \\
\hline \multirow[t]{2}{*}{ Ailuropoda melanoleuca } & 大熊猫 & I & 濒危 & 周应敏 & 精子在雌性大熊猫体内存活 $26 \mathrm{~h}$ 的报道 \\
\hline & & & /EN & & \\
\hline
\end{tabular}


顾垒，闻丞，罗玫，王吴，吕植. 中国最受关注濒危物种保护现状快速评价的新方法探讨. 生物多样性，2015，23(5)：583-590. http://www biodiversity-science. net/CN/article/downloadArticleFile. do?attachType=PDF\&id=10075

\begin{tabular}{|c|c|c|c|c|c|}
\hline Ailuropoda melanoleuca & 大熊猫 & I & $\begin{array}{l}\text { 濒危 } \\
/ \mathrm{EN}\end{array}$ & 江 洪 & 九寨沟保护区植被景观变化与生境破碎化研究 \\
\hline Ailuropoda melanoleuca & 大熊猫 & I & $\begin{array}{l}\text { 濒危 } \\
\text { /EN }\end{array}$ & 宋延龄 & 兰渝高速公路和兰渝铁路对大熊猫活动及其栖息地保护的影响 \\
\hline Ailuropoda melanoleuca & 大熊猫 & I & $\begin{array}{l}\text { 濒危 } \\
\text { /EN }\end{array}$ & 孙欣 & 历史时期川渝鄂地区大熊猫的分布及其变迁 \\
\hline Ailuropoda melanoleuca & 大熊猫 & I & $\begin{array}{l}\text { 濒危 } \\
/ \mathrm{EN}\end{array}$ & 魏辅文 & 历史时期人类侵蚀对大熊猫种群的影响 \\
\hline Ailuropoda melanoleuca & 大熊猫 & I & $\begin{array}{l}\text { 濒危 } \\
/ \mathrm{EN}\end{array}$ & 李才武 & 利用超声诊断大熊猫胆囊炎一例 \\
\hline Ailuropoda melanoleuca & 大熊猫 & I & $\begin{array}{l}\text { 濒危 } \\
/ \mathrm{EN}\end{array}$ & 侯蓉 & 联合使用电刺激采精与直肠按摩对大熊猫精液采集的影响 \\
\hline AILUROPODA & 熊猫 & I & 濒危 & 朱印酒 & 凉山山系大熊猫, 小熊猫及林㭩的生境选择 \\
\hline MELANOLEUCA & & & $/ \mathrm{EN}$ & & \\
\hline Ailuropoda melanoleuca & 大熊猫 & I & $\begin{array}{l}\text { 濒危 } \\
/ \mathrm{EN}\end{array}$ & 范隆庆 & 凉山山系大熊猫栖息地的景观格局 \\
\hline Ailuropoda melanoleuca & 大熊猫 & I & $\begin{array}{l}\text { 濒危 } \\
/ \mathrm{EN}\end{array}$ & 邓林华 & 氯胺酮麻醉致大熊猫喷射性呕吐 1 例 \\
\hline Ailuropoda melanoleuca & 大熊猫 & I & 濒危 & 刘定震 & 毛细管电泳法测定大熊猫尿肌䣶 \\
\hline
\end{tabular}


顾垒，闻丞，罗玫，王吴，吕植. 中国最受关注濒危物种保护现状快速评价的新方法探讨. 生物多样性，2015，23(5)：583-590. http://www. biodiversity-science. net/CN/article/downloadArticleFile. do?attachType=PDF\&id=10075

\begin{tabular}{|c|c|c|c|c|c|}
\hline & & & /EN & & \\
\hline \multirow[t]{2}{*}{ Ailuropoda melanoleuca } & 大熊猫 & I & 濒危 & 邓涛 & 免疫分析技术在圈养大熊猫繁殖研究中的应用 \\
\hline & & & $/$ EN & & \\
\hline \multirow[t]{2}{*}{ Ailuropoda melanoleuca } & 大熊猫 & I & 濒危 & 再江洪 & 岷山北部大熊猫主食竹天然更新与生态因子的关系 \\
\hline & & & /EN & & \\
\hline \multirow[t]{2}{*}{ Ailuropoda melanoleuca } & 大熊猫 & I & 濒危 & 再江洪 & 岷山北部大熊猫主食竹天然更新与生态因子的关系 \\
\hline & & & /EN & & \\
\hline \multirow[t]{2}{*}{ Ailuropoda melanoleuca } & 大熊猫 & I & 濒危 & 再江洪 & 岷山北部竹类开花状况及对大熊猫的影响调查 \\
\hline & & & /EN & & \\
\hline \multirow[t]{2}{*}{ Ailuropoda melanoleuca } & 大熊猫 & I & 濒危 & 欧阳志云 & 峎山地区大熊猫(Ailuropoda melanoleuca)生境影响因子连通性及主导因子 \\
\hline & & & /EN & & \\
\hline \multirow[t]{2}{*}{ Ailuropoda melanoleuca } & 大熊猫 & I & 濒危 & 欧阳志云 & 岷山地区大熊猫生境评价与保护对策研究 \\
\hline & & & $/ \mathrm{EN}$ & & \\
\hline AILUROPODA & 熊猫 & I & 濒危 & 古晓东 & 峮山山系大熊猫自然保护区 2003 年生物多样性监测 \\
\hline MELANOLEUCA & & & /EN & & \\
\hline \multirow[t]{2}{*}{ Ailuropoda melanoleuca } & 大熊猫 & I & 濒危 & 欧阳志云 & 农用地时空变化对大熊猫生境的影响：以岷山中部地区的白草河流域为例 \\
\hline & & & /EN & & \\
\hline \multirow[t]{2}{*}{ Ailuropoda melanoleuca } & 大熊猫 & I & 濒危 & 欧阳志云 & 农用地时空变化对大熊猫生境的影响：以岷山中部地区的白草河流域为例 \\
\hline & & & /EN & & \\
\hline
\end{tabular}


顾垒，闻丞，罗玫，王吴，吕植. 中国最受关注濒危物种保护现状快速评价的新方法探讨. 生物多样性，2015，23(5)：583-590. http://www biodiversity-science. net/CN/article/downloadArticleFile. do?attachType=PDF\&id=10075

\begin{tabular}{|c|c|c|c|c|c|}
\hline Ailuropoda melanoleuca & 大熊猫 & I & $\begin{array}{l}\text { 濒危 } \\
\text { /EN }\end{array}$ & 欧阳志云 & 农用地时空变化对大熊猫生境的影响：以岷山中部地区的白草河流域为例 \\
\hline Ailuropoda melanoleuca & 大熊猫 & I & $\begin{array}{l}\text { 濒危 } \\
\text { /EN }\end{array}$ & 欧阳志云 & 农用地时空变化对大熊猫生境的影响：以岷山中部地区的白草河流域为例 \\
\hline Ailuropoda melanoleuca & 大熊猫 & I & $\begin{array}{l}\text { 濒危 } \\
\text { /EN }\end{array}$ & 欧阳志云 & 农用地时空变化对大熊猫生境的影响：以岷山中部地区的白草河流域为例 \\
\hline Ailuropoda melanoleuca & 大熊猫 & I & $\begin{array}{l}\text { 濒危 } \\
\text { /EN }\end{array}$ & 符建荣 & 平陡沟水电站对四川白羊自然保护区野生动植物资源影响的评价及对策 \\
\hline Ailuropoda melanoleuca & 大熊猫 & I & $\begin{array}{l}\text { 濒危 } \\
\text { /EN }\end{array}$ & 蒋俊明 & 平武大熊猫栖息地干扰强度分区 \\
\hline Ailuropoda melanoleuca & 大熊猫 & I & $\begin{array}{l}\text { 濒危 } \\
\text { /EN }\end{array}$ & 胡锦鲰 & 评估动物栖息地适宜性的两种方法法比较: 以大相岭山系大熊猫种群为例 \\
\hline Ailuropoda melanoleuca & 大熊猫 & I & $\begin{array}{l}\text { 濒危 } \\
\text { /EN }\end{array}$ & 吴建国 & 气候变化对大熊猫分布的潜在影响 \\
\hline Ailuropoda melanoleuca & 大熊猫 & I & $\begin{array}{l}\text { 濒危 } \\
\text { /EN }\end{array}$ & 刘艳萍 & 气候变化对峮山大熊猫及栖息地的影响 \\
\hline Ailuropoda melanoleuca & 大熊猫 & I & $\begin{array}{l}\text { 濒危 } \\
\text { /EN }\end{array}$ & 王锐婷 & 气候变化对四川大熊猫栖息地的影响 \\
\hline Ailuropoda melanoleuca & 大熊猫 & I & 濒危 & 朱庆 & 前列腺素 PGF2 对冷冻保存的大熊猫精子受精能力的影响 \\
\hline
\end{tabular}


顾垒，闻丞，罗玫，王吴，吕植. 中国最受关注濒危物种保护现状快速评价的新方法探讨. 生物多样性，2015，23(5)：583-590. http://www. biodiversity-science. net/CN/article/downloadArticleFile. do?attachType=PDF\&id=10075

\begin{tabular}{|c|c|c|c|c|c|}
\hline & & & /EN & & \\
\hline \multirow[t]{2}{*}{ Ailuropoda melanoleuca } & 大熊猫 & I & 濒危 & 李德生 & 浅谈大熊猫采血及血清分离技术 \\
\hline & & & $/$ EN & & \\
\hline \multirow[t]{2}{*}{ Ailuropoda melanoleuca } & 大熊猫 & I & 濒危 & 屈兴奎 & 浅谈秦岭林区新建自然保护区的管理与发展 \\
\hline & & & /EN & & \\
\hline \multirow[t]{2}{*}{ Ailuropoda melanoleuca } & 大熊猫 & I & 濒危 & 孙宜然 & 秦岭巴山木竹微量元素及营养成分分析 \\
\hline & & & /EN & & \\
\hline \multirow[t]{2}{*}{ Ailuropoda melanoleuca } & 大熊猫 & I & 濒危 & 杨振民 & 秦岭北麓大熊猫主食竹矿物元素含量分析 \\
\hline & & & /EN & & \\
\hline \multirow[t]{2}{*}{ Ailuropoda melanoleuca } & 大熊猫 & I & 濒危 & 张泽钧 & 秦岭产仔大熊猫年龄与下迁时间的关系_对产仔洞穴的占据及其适应意义 \\
\hline & & & /EN & & \\
\hline \multirow[t]{2}{*}{ Ailuropoda melanoleuca } & 大熊猫 & I & 濒危 & 朱辉 & 秦岭大熊猫 IFN-C 基因的克隆! 表达及免疫活性研究 \\
\hline & & & $/ \mathrm{EN}$ & & \\
\hline \multirow[t]{2}{*}{ Ailuropoda melanoleuca } & 大熊猫 & I & 濒危 & 李宇 & 秦岭大熊猫(A ilu ropoda melanoleuca)对产仔育幼洞穴的选择 \\
\hline & & & /EN & & \\
\hline \multirow[t]{2}{*}{ Ailuropoda melanoleuca } & 大熊猫 & I & 濒危 & 曹庆 & 秦岭大熊猫保护抢救案例分析 \\
\hline & & & /EN & & \\
\hline \multirow[t]{2}{*}{ Ailuropoda melanoleuca } & 大熊猫 & I & 濒危 & 金学林 & 秦岭大熊猫的保护现状及易地保护研究 \\
\hline & & & /EN & & \\
\hline
\end{tabular}


顾垒，闻丞，罗玫，王吴，吕植. 中国最受关注濒危物种保护现状快速评价的新方法探讨. 生物多样性，2015，23(5)：583-590. http://www. biodiversity-science. net/CN/article/downloadArticleFile. do?attachType=PDF\&id=10075

\begin{tabular}{|c|c|c|c|c|c|}
\hline Ailuropoda melanoleuca & 大熊猫 & I & $\begin{array}{l}\text { 濒危 } \\
\text { /EN }\end{array}$ & 刘定震 & 秦岭大熊猫冬春季节对巴山木竹竹林生长指标的选择 \\
\hline Ailuropoda melanoleuca & 大熊猫 & I & $\begin{array}{l}\text { 濒危 } \\
\text { /EN }\end{array}$ & 宋成军 & 秦岭大熊猫家域的季节、性别和年龄效应 \\
\hline Ailuropoda melanoleuca & 大熊猫 & I & $\begin{array}{l}\text { 濒危 } \\
\text { /EN }\end{array}$ & 孙承寒 & 秦岭大熊猫局域种群的划分及数量分布 \\
\hline Ailuropoda melanoleuca & 大熊猫 & I & $\begin{array}{l}\text { 濒危 } \\
\text { /EN }\end{array}$ & 孙承寒 & 秦岭大熊猫局域种群的划分及数量分布 \\
\hline Ailuropoda melanoleuca & 大熊猫 & I & $\begin{array}{l}\text { 濒危 } \\
\text { /EN }\end{array}$ & 孙承寒 & 秦岭大熊猫局域种群的划分及数量分布 \\
\hline Ailuropoda melanoleuca & 大熊猫 & I & $\begin{array}{l}\text { 濒危 } \\
\text { /EN }\end{array}$ & 孙承寒 & 秦岭大熊猫局域种群的划分及数量分布 \\
\hline Ailuropoda melanoleuca & 大熊猫 & I & $\begin{array}{l}\text { 濒危 } \\
\text { /EN }\end{array}$ & 孙承寒 & 秦岭大熊猫局域种群的划分及数量分布 \\
\hline AILUROPODA & 熊猫 & I & 濒危 & 孙承寒 & 秦岭大熊猫局域种群的划分及数量分布 \\
\hline MELANOLEUCA & & & $/ \mathrm{EN}$ & & \\
\hline Ailuropoda melanoleuca & 大熊猫 & I & $\begin{array}{l}\text { 濒危 } \\
\text { /EN }\end{array}$ & 㚞金拴 & 秦岭大熊猫栖息地保护现状、问题与对策 \\
\hline Ailuropoda melanoleuca & 大熊猫 & I & 濒危 & 王小红 & 秦岭大熊猫栖息地及其干扰因素评价体体系的研究 \\
\hline
\end{tabular}


顾垒，闻丞，罗玫，王吴，吕植. 中国最受关注濒危物种保护现状快速评价的新方法探讨. 生物多样性，2015，23(5)：583-590. http://www. biodiversity-science. net/CN/article/downloadArticleFile. do?attachType=PDF\&id=10075

\begin{tabular}{|c|c|c|c|c|c|}
\hline & & & /EN & & \\
\hline \multirow[t]{2}{*}{ Ailuropoda melanoleuca } & 大熊猫 & I & 濒危 & 胡桃 & 秦岭大熊猫栖息地气味特征研究 \\
\hline & & & $/$ EN & & \\
\hline \multirow[t]{2}{*}{ Ailuropoda melanoleuca } & 大熊猫 & I & 濒危 & 森金拴 & 秦岭大熊猫栖息地生态环境特征的初步研究 \\
\hline & & & /EN & & \\
\hline \multirow[t]{2}{*}{ Ailuropoda melanoleuca } & 大熊猫 & I & 濒危 & 樊金拴 & 秦岭大熊猫栖息地生态环境特征的初步研究 \\
\hline & & & /EN & & \\
\hline \multirow[t]{2}{*}{ Ailuropoda melanoleuca } & 大熊猫 & I & 濒危 & 樊金拴 & 秦岭大熊猫栖息地生态环境特征的初步研究 \\
\hline & & & /EN & & \\
\hline \multirow[t]{2}{*}{ Ailuropoda melanoleuca } & 大熊猫 & I & 濒危 & 张锋锋 & 秦岭大熊猫栖息地生态环境特征研究 \\
\hline & & & /EN & & \\
\hline \multirow[t]{2}{*}{ Ailuropoda melanoleuca } & 大熊猫 & I & 濒危 & 党坤良 & 秦岭大熊猫栖息地选择与森林群落 \\
\hline & & & /EN & & \\
\hline \multirow[t]{2}{*}{ Ailuropoda melanoleuca } & 大熊猫 & I & 濒危 & 党坤良 & 秦岭大熊猫栖息地选择与森林群落 \\
\hline & & & /EN & & \\
\hline \multirow[t]{2}{*}{ Ailuropoda melanoleuca } & 大熊猫 & I & 濒危 & 党坤良 & 秦岭大熊猫栖息地选择与森林群落 \\
\hline & & & /EN & & \\
\hline \multirow[t]{2}{*}{ Ailuropoda melanoleuca } & 大熊猫 & I & 濒危 & 王笑坤 & 秦岭大熊猫取食点微生境研究 \\
\hline & & & /EN & & \\
\hline
\end{tabular}


顾垒，闻丞，罗玫，王吴，吕植. 中国最受关注濒危物种保护现状快速评价的新方法探讨. 生物多样性，2015，23(5)：583-590. http://www biodiversity-science. net/CN/article/downloadArticleFile. do?attachType=PDF\&id=10075

\begin{tabular}{|c|c|c|c|c|c|}
\hline Ailuropoda melanoleuca & 大熊猫 & I & $\begin{array}{l}\text { 濒危 } \\
\text { /EN }\end{array}$ & 金学林 & 秦岭大熊猫生存状态的监测参数体系建立及其应用 \\
\hline Ailuropoda melanoleuca & 大熊猫 & I & $\begin{array}{l}\text { 濒危 } \\
\text { /EN }\end{array}$ & 陈俊㜆 & 秦岭大熊猫喜居森林群落巴山木竹与秦岭箭竹生物量研究 \\
\hline Ailuropoda melanoleuca & 大熊猫 & I & $\begin{array}{l}\text { 濒危 } \\
\text { /EN }\end{array}$ & 党坤良 & 秦岭大熊猫喜居森林群落的基本特征 \\
\hline Ailuropoda melanoleuca & 大熊猫 & I & $\begin{array}{l}\text { 濒危 } \\
\text { /EN }\end{array}$ & 杨栓 & 秦岭大熊猫喜居森林群落结构特征研究 \\
\hline Ailuropoda melanoleuca & 大熊猫 & I & $\begin{array}{l}\text { 濒危 } \\
\text { /EN }\end{array}$ & 刘双云 & 秦岭大熊猫牙齿形态学研究 \\
\hline Ailuropoda melanoleuca & 大熊猫 & I & $\begin{array}{l}\text { 濒危 } \\
\text { /EN }\end{array}$ & 雍立军 & 秦岭大熊猫野外饮水行为特征 \\
\hline Ailuropoda melanoleuca & 大熊猫 & I & $\begin{array}{l}\text { 濒危 } \\
\text { /EN }\end{array}$ & 樊金拴 & 秦岭大熊猫主食竹氨基酸含量的测定及营养评价 \\
\hline Ailuropoda melanoleuca & 大熊猫 & I & $\begin{array}{l}\text { 濒危 } \\
\text { /EN }\end{array}$ & 温亚利 & 秦岭大熊猫自然保护区与社区发展中的问题与对策一以长青自然保护区为例 \\
\hline Ailuropoda melanoleuca & 大熊猫 & I & $\begin{array}{l}\text { 濒危 } \\
\text { /EN }\end{array}$ & 傅金和 & 秦岭地区圈养大熊猫对投食竹种的选择研究 \\
\hline AILUROPODA & 熊猫 & I & 濒危 & 高新宇 & 秦岭佛坪自然保护区大熊猫冬春季节对巴山木竹竹林生长指标的选择分析 \\
\hline
\end{tabular}


顾垒，闻丞，罗玫，王吴，吕植. 中国最受关注濒危物种保护现状快速评价的新方法探讨. 生物多样性，2015，23(5)：583-590. http://www. biodiversity-science. net/CN/article/downloadArticleFile. do?attachType=PDF\&id=10075

\begin{tabular}{|c|c|c|c|c|c|}
\hline MELANOLEUCA & & & $/ \mathrm{EN}$ & & \\
\hline Ailuropoda melanoleuca & 大熊猫 & I & $\begin{array}{l}\text { 濒危 } \\
\text { /EN }\end{array}$ & 张改霞 & 秦岭黄柏塬地区大熊猫保护现状浅析 \\
\hline Ailuropoda melanoleuca & 大熊猫 & I & $\begin{array}{l}\text { 濒危 } \\
\text { /EN }\end{array}$ & 赵德怀 & 秦岭南坡大熊猫繁殖交配期生境选择研究 \\
\hline Ailuropoda melanoleuca & 大熊猫 & I & $\begin{array}{l}\text { 濒危 } \\
\text { /EN }\end{array}$ & 刘雪华 & 秦岭南坡两个大熊猫活动密集区的生境特征及大熊猫对生境的选择 \\
\hline Ailuropoda melanoleuca & 大熊猫 & I & $\begin{array}{l}\text { 濒危 } \\
\text { /EN }\end{array}$ & 刘雪华 & 秦岭南坡两个大熊猫活动密集区的生境特征及大熊猫对生境的选择 \\
\hline AILUROPODA & 熊猫 & I & 濒危 & 赵德怀 & 秦岭南坡野生大熊猫繁殖交配期的生境选择 \\
\hline MELANOLEUCA & & & $/ \mathrm{EN}$ & & \\
\hline Ailuropoda melanoleuca & 大熊猫 & I & $\begin{array}{l}\text { 濒危 } \\
\text { /EN }\end{array}$ & 韩保付 & 秦岭圈养大熊猫的行为训练 \\
\hline Ailuropoda melanoleuca & 大熊猫 & I & $\begin{array}{l}\text { 濒危 } \\
\text { /EN }\end{array}$ & 李宇 & 秦岭山系大熊猫在不同地理区域和生活史特殊阶段的生境选择研究 \\
\hline Ailuropoda melanoleuca & 大熊猫 & I & $\begin{array}{l}\text { 濒危 } \\
\text { /EN }\end{array}$ & 李宇 & 秦岭山系大熊猫在不同地理区域和生活史特殊阶段的生境选择研究 \\
\hline Ailuropoda melanoleuca & 大熊猫 & I & $\begin{array}{l}\text { 濒危 } \\
\text { /EN }\end{array}$ & 李宇 & 秦岭山系大熊猫在不同地理区域和生活史特殊阶段的生境选择研究 \\
\hline
\end{tabular}


顾垒，闻丞，罗玫，王吴，吕植. 中国最受关注濒危物种保护现状快速评价的新方法探讨. 生物多样性，2015，23(5)：583-590. http://www biodiversity-science. net/CN/article/downloadArticleFile. do?attachType=PDF\&id=10075

\begin{tabular}{|c|c|c|c|c|c|}
\hline Ailuropoda melanoleuca & 大熊猫 & I & $\begin{array}{l}\text { 濒危 } \\
\text { /EN }\end{array}$ & 赵伟 & 秦岭湑水河流域大熊猫生境特征研究 \\
\hline Ailuropoda melanoleuca & 大熊猫 & I & $\begin{array}{l}\text { 濒危 } \\
\text { /EN }\end{array}$ & 陈永进 & 秦岭野生大熊猫牙齿的形态机能 \\
\hline Ailuropoda melanoleuca & 大熊猫 & I & $\begin{array}{l}\text { 濒危 } \\
\text { /EN }\end{array}$ & 刘雪华 & 秦岭中段南坡景观格局与大熊猫栖息地的关系 \\
\hline Ailuropoda melanoleuca & 大熊猫 & I & $\begin{array}{l}\text { 濒危 } \\
\text { /EN }\end{array}$ & 赵鹏祥 & 青木川自然保护区大熊猫生境评价 \\
\hline Ailuropoda melanoleuca & 大熊猫 & I & $\begin{array}{l}\text { 濒危 } \\
\text { /EN }\end{array}$ & 李颖岳 & 邛崃山系 3 种主食竹单宁及营养成分含量对大熊猫取食选择性的影响 \\
\hline Ailuropoda melanoleuca & 大熊猫 & I & $\begin{array}{l}\text { 濒危 } \\
\text { /EN }\end{array}$ & 徐卫华 & 区域自然保护区群规划———以秦岭山系为例 \\
\hline Ailuropoda melanoleuca & 大熊猫 & I & $\begin{array}{l}\text { 濒危 } \\
\text { /EN }\end{array}$ & 张晓华 & 圈养大熊猫（Ailuropoda melanoleuca）受食行为的初步观察 \\
\hline Ailuropoda melanoleuca & 大熊猫 & I & $\begin{array}{l}\text { 濒危 } \\
\text { /EN }\end{array}$ & 何绍纯 & 圈养大熊猫的行为训练 \\
\hline Ailuropoda melanoleuca & 大熊猫 & I & $\begin{array}{l}\text { 濒危 } \\
\text { /EN }\end{array}$ & 刘长国 & 圈养大熊猫对雷竹笋营养成分的表观消化率 \\
\hline Ailuropoda melanoleuca & 大熊猫 & I & 濒危 & 刘长国 & 圈养大熊猫对乌哺鸡竹笋营养成分的表观消化率 \\
\hline
\end{tabular}


顾垒，闻丞，罗玫，王吴，吕植. 中国最受关注濒危物种保护现状快速评价的新方法探讨. 生物多样性，2015，23(5)：583-590. http://www. biodiversity-science. net/CN/article/downloadArticleFile. do?attachType=PDF\&id=10075

\begin{tabular}{|c|c|c|c|c|c|}
\hline & & & /EN & & \\
\hline AILUROPODA & 熊猫 & I & 濒危 & 刘定震 & 圈养大熊猫刻板行为观察及其激素水平测定 \\
\hline MELANOLEUCA & & & /EN & & \\
\hline \multirow[t]{2}{*}{ Ailuropoda melanoleuca } & 大熊猫 & I & 濒危 & 张志和 & 圈养大熊猫麻疹病毒易感性流行病学调查 \\
\hline & & & /EN & & \\
\hline \multirow[t]{2}{*}{ Ailuropoda melanoleuca } & 大熊猫 & I & 濒危 & 刘选珍 & 圈养大熊猫母乳营养成分及其变化规律 \\
\hline & & & /EN & & \\
\hline AILUROPODA & 熊猫 & I & 濒危 & 黄祥明 & 圈养大熊猫母兽成功哺育双胞胎成活初探 \\
\hline MELANOLEUCA & & & /EN & & \\
\hline \multirow[t]{2}{*}{ Ailuropoda melanoleuca } & 大熊猫 & I & 濒危 & 张和民 & 圈养大熊猫母兽带仔野化培训研究第一阶段 \\
\hline & & & /EN & & \\
\hline \multirow[t]{2}{*}{ Ailuropoda melanoleuca } & 大熊猫 & $\mathrm{I}$ & 濒危 & 孙小雅 & 圈养大熊猫群体间的基因流状况分析 \\
\hline & & & /EN & & \\
\hline \multirow[t]{2}{*}{ Ailuropoda melanoleuca } & 大熊猫 & I & 濒危 & 黄祥明 & 圈养大熊猫乳中氨基酸组成的研究 \\
\hline & & & /EN & & \\
\hline \multirow[t]{2}{*}{ Ailuropoda melanoleuca } & 大熊猫 & I & 濒危 & 王承东 & 圈养大熊猫舌头撕裂外伤一例 \\
\hline & & & /EN & & \\
\hline \multirow[t]{2}{*}{ Ailuropoda melanoleuca } & 大熊猫 & I & 濒危 & 吴孔菊 & 圈养大熊猫食物丰容对其行为影响的研究 \\
\hline & & & /EN & & \\
\hline
\end{tabular}


顾垒，闻丞，罗玫，王吴，吕植. 中国最受关注濒危物种保护现状快速评价的新方法探讨. 生物多样性，2015，23(5)：583-590. http://www. biodiversity-science. net/CN/article/downloadArticleFile. do?attachType=PDF\&id=10075

\begin{tabular}{|c|c|c|c|c|c|}
\hline AILUROPODA & 熊猫 & I & 濒危 & 黄祥明 & 圈养大熊猫受配后的行为研究 \\
\hline MELANOLEUCA & & & $/ \mathrm{EN}$ & & \\
\hline \multirow[t]{2}{*}{ Ailuropoda melanoleuca } & 大熊猫 & I & 濒危 & 张成林 & 圈养大熊猫戊型肝炎病毒感染调查 \\
\hline & & & /EN & & \\
\hline \multirow[t]{2}{*}{ Ailuropoda melanoleuca } & 大熊猫 & I & 濒危 & David POWELL & 圈养大熊猫性情、饲养管理和社群- 性行为的关系 \\
\hline & & & $/ \mathrm{EN}$ & & \\
\hline \multirow[t]{2}{*}{ Ailuropoda melanoleuca } & 大熊猫 & I & 濒危 & 张万诚 & 圈养大熊猫血清中无机元素的研究 \\
\hline & & & $/ \mathrm{EN}$ & & \\
\hline \multirow[t]{2}{*}{ Ailuropoda melanoleuca } & 大熊猫 & I & 濒危 & 张和民 & 圈养大熊猫野化培训期的生境选择特征 \\
\hline & & & /EN & & \\
\hline \multirow[t]{2}{*}{ Ailuropoda melanoleuca } & 大熊猫 & I & 濒危 & 王小雅 & 圈养大熊猫遗传结构研究 \\
\hline & & & $/ \mathrm{EN}$ & & \\
\hline AILUROPODA & 熊猫 & I & 濒危 & 周小平 & 圈养大熊猫在兽舍与半野外条件下的行为和习性的初步比较 \\
\hline MELANOLEUCA & & & $/ \mathrm{EN}$ & & \\
\hline \multirow[t]{2}{*}{ Ailuropoda melanoleuca } & 大熊猫 & I & 濒危 & 刘选珍 & 圈养大熊猫粘液排泄现象的观察 \\
\hline & & & /EN & & \\
\hline \multirow[t]{2}{*}{ Ailuropoda melanoleuca } & 大熊猫 & I & 濒危 & 刘选珍 & 圈养大熊猫粘液排泄现象的观察 \\
\hline & & & $/ \mathrm{EN}$ & & \\
\hline Ailuropoda melanoleuca & 大熊猫 & I & 濒危 & 刘选珍 & 圈养大熊猫粘液水解氨基酸含量的初步研究 \\
\hline
\end{tabular}


顾垒，闻丞，罗玫，王吴，吕植. 中国最受关注濒危物种保护现状快速评价的新方法探讨. 生物多样性，2015，23(5)：583-590. http://www. biodiversity-science. net/CN/article/downloadArticleFile. do?attachType=PDF\&id=10075

\begin{tabular}{|c|c|c|c|c|c|}
\hline & & & /EN & & \\
\hline AILUROPODA & 熊猫 & I & 濒危 & 王鹏彦 & 圈养大熊猫种群的动态及发展趋势 \\
\hline MELANOLEUCA & & & $/$ EN & & \\
\hline AILUROPODA & 熊猫 & I & 濒危 & 刘选珍 & 圈养大熊猫主食竹的氨基酸分析 \\
\hline MELANOLEUCA & & & /EN & & \\
\hline \multirow[t]{2}{*}{ Ailuropoda melanoleuca } & 大熊猫 & I & 濒危 & 胡德夫 & 圈养大熊猫主食竹消化率的两种测定方法比较 \\
\hline & & & /EN & & \\
\hline \multirow[t]{2}{*}{ Ailuropoda melanoleuca } & 大熊猫 & I & 濒危 & 杨振民 & 圈养大熊猫主食竹营养成分含量与采食的关系 \\
\hline & & & /EN & & \\
\hline \multirow[t]{2}{*}{ Ailuropoda melanoleuca } & 大熊猫 & I & 濒危 & 莫晓燕 & 圈养秦岭大熊猫 2 种主食竹叶维生素 C 含量分析 \\
\hline & & & /EN & & \\
\hline \multirow[t]{2}{*}{ Ailuropoda melanoleuca } & 大熊猫 & I & 濒危 & 莫晓燕 & 圈养秦岭大熊猫两种主食竹中元素含量初探 \\
\hline & & & /EN & & \\
\hline \multirow[t]{2}{*}{ Ailuropoda melanoleuca } & 大熊猫 & I & 濒危 & 刘群秀 & 圈养亚成体大熊猫(Ailuropoda melanoleuca)春、夏季行为节律的研究 \\
\hline & & & /EN & & \\
\hline \multirow[t]{2}{*}{ Ailuropoda melanoleuca } & 大熊猫 & I & 濒危 & 郑光美 & 全国大熊猫及其栖息地监测刍论 \\
\hline & & & /EN & & \\
\hline \multirow[t]{2}{*}{ Ailuropoda melanoleuca } & 大熊猫 & I & 濒危 & 郑光美 & 全国大熊猫及其栖息地监测技术探讨 \\
\hline & & & /EN & & \\
\hline
\end{tabular}


顾垒，闻丞，罗玫，王吴，吕植. 中国最受关注濒危物种保护现状快速评价的新方法探讨. 生物多样性，2015，23(5)：583-590. http://www. biodiversity-science. net/CN/article/downloadArticleFile. do?attachType=PDF\&id=10075

\begin{tabular}{|c|c|c|c|c|c|}
\hline AILUROPODA & 熊猫 & I & 濒危 & 乔军 & 犬冠状病毒大熊猫株核蛋白基因的克隆、序列分析及其在 E.coli 中的高效表达 \\
\hline MELANOLEUCA & & & $/ \mathrm{EN}$ & & \\
\hline \multirow[t]{2}{*}{ Ailuropoda melanoleuca } & 大熊猫 & I & 濒危 & 李凤琴 & 犬瘟热病毒 $\mathrm{N}$ 蛋白基因核酸疫苗的构 \\
\hline & & & $/ \mathrm{EN}$ & & \\
\hline \multirow[t]{2}{*}{ Ailuropoda melanoleuca } & 大熊猫 & I & 濒危 & 王成东 & 犬瘟热弱毒疫苗对大熊猫的免疫效果评价 \\
\hline & & & $/ \mathrm{EN}$ & & \\
\hline \multirow[t]{2}{*}{ Ailuropoda melanoleuca } & 大熊猫 & I & 濒危 & 颜其贵 & 犬细小病毒 PCR 诊断方法的建立及对大熊猫粪便的检测 \\
\hline & & & $/ \mathrm{EN}$ & & \\
\hline \multirow[t]{2}{*}{ Ailuropoda melanoleuca } & 大熊猫 & I & 濒危 & 李腾飞 & 缺苞箭竹总酚含量及其对大熊猫采食的影响 \\
\hline & & & $/ \mathrm{EN}$ & & \\
\hline \multirow[t]{2}{*}{ Ailuropoda melanoleuca } & 大熊猫 & I & 濒危 & 赵鹏鹏 & 人工辅助措施对大熊猫幼仔生长发育的影响 \\
\hline & & & $/ \mathrm{EN}$ & & \\
\hline AILUROPODA & 熊猫 & I & 濒危 & 黄祥明 & 人工辅助大熊猫母兽哺乳幼仔研究 \\
\hline MELANOLEUCA & & & $/ \mathrm{EN}$ & & \\
\hline \multirow[t]{2}{*}{ Ailuropoda melanoleuca } & 大熊猫 & I & 濒危 & 唐新成 & 人工落叶松林对大熊猫栖息地影响的风险评估 \\
\hline & & & $/ \mathrm{EN}$ & & \\
\hline \multirow[t]{2}{*}{ Ailuropoda melanoleuca } & 大熊猫 & I & 濒危 & 马清义 & 人工饲养大熊猫消化道正常菌群分离与鉴定研究 \\
\hline & & & $/ \mathrm{EN}$ & & \\
\hline Ailuropoda melanoleuca & 大熊猫 & I & 濒危 & 石燕文 & 人类活动对野生大熊猫粪便皮质醇水平的影响及圈养个体的比较 \\
\hline
\end{tabular}


顾垒，闻丞，罗玫，王吴，吕植. 中国最受关注濒危物种保护现状快速评价的新方法探讨. 生物多样性，2015，23(5)：583-590. http://www. biodiversity-science. net/CN/article/downloadArticleFile. do?attachType=PDF\&id=10075

\begin{tabular}{|c|c|c|c|c|c|}
\hline & & & /EN & & \\
\hline \multirow[t]{2}{*}{ Ailuropoda melanoleuca } & 大熊猫 & I & 濒危 & 刘学锋 & 妊娠期雌性大熊猫尿中生殖激素的初步研究 \\
\hline & & & $/$ EN & & \\
\hline \multirow[t]{2}{*}{ Ailuropoda melanoleuca } & 大熊猫 & I & 濒危 & 周世明 & 桑园国家级自然保护区大熊猫种群及其栖息地保护对策 \\
\hline & & & /EN & & \\
\hline \multirow[t]{2}{*}{ Ailuropoda melanoleuca } & 大熊猫 & I & 濒危 & 宋国华 & 森林_竹子_大熊猫_非线性动力系统的周期解与混沌奇怪吸引子 \\
\hline & & & /EN & & \\
\hline AILUROPODA & 熊猫 & I & 濒危 & 彭培好 & 森林采伐对大熊猫栖息地环境的影响 \\
\hline MELANOLEUCA & & & /EN & & \\
\hline AILUROPODA & 熊猫 & I & 濒危 & 顾海军 & 森林采伐对平武大熊猫栖息地的影响 \\
\hline MELANOLEUCA & & & /EN & & \\
\hline \multirow[t]{2}{*}{ Ailuropoda melanoleuca } & 大熊猫 & I & 濒危 & 王军 & 陕西大熊猫及其栖息地监测评估 \\
\hline & & & /EN & & \\
\hline \multirow[t]{2}{*}{ Ailuropoda melanoleuca } & 大熊猫 & I & 濒危 & 邓怀庆 & 陕西佛坪大熊猫栖息地质量评价及保护管理研究 \\
\hline & & & /EN & & \\
\hline \multirow[t]{2}{*}{ Ailuropoda melanoleuca } & 大熊猫 & I & 濒危 & 邓怀庆 & 陕西佛坪大熊猫栖息地质量评价及保护管理研究 \\
\hline & & & /EN & & \\
\hline \multirow[t]{2}{*}{ Ailuropoda melanoleuca } & 大熊猫 & I & 濒危 & 周伟 & 陕西佛坪国家级自然保护区管理现状调查与评价 \\
\hline & & & /EN & & \\
\hline
\end{tabular}


顾垒，闻丞，罗玫，王吴，吕植. 中国最受关注濒危物种保护现状快速评价的新方法探讨. 生物多样性，2015，23(5)：583-590. http://www biodiversity-science. net/CN/article/downloadArticleFile. do?attachType=PDF\&id=10075

\begin{tabular}{|c|c|c|c|c|c|}
\hline Ailuropoda melanoleuca & 大熊猫 & I & $\begin{array}{l}\text { 濒危 } \\
\text { /EN }\end{array}$ & 程平西 & 陕西观音山自然保护区自然资源评价与保护对策 \\
\hline Ailuropoda melanoleuca & 大熊猫 & I & $\begin{array}{l}\text { 濒危 } \\
\text { /EN }\end{array}$ & 葛文官 & 陕西黄柏源自然保护区可持续发展战略研究 \\
\hline Ailuropoda melanoleuca & 大熊猫 & I & $\begin{array}{l}\text { 濒危 } \\
\text { /EN }\end{array}$ & 冯利国 & 陕西秦岭大熊猫栖息地管理区划与对策 \\
\hline Ailuropoda melanoleuca & 大熊猫 & I & $\begin{array}{l}\text { 濒危 } \\
\text { /EN }\end{array}$ & 冯利国 & 陕西秦岭大熊猫自然保护区建设与整合 \\
\hline Ailuropoda melanoleuca & 大熊猫 & I & $\begin{array}{l}\text { 濒危 } \\
\text { /EN }\end{array}$ & 程平西 & 陕西省观音山自然保护区资源评价与保护对策 \\
\hline Ailuropoda melanoleuca & 大熊猫 & I & $\begin{array}{l}\text { 濒危 } \\
\text { /EN }\end{array}$ & 李谫博 & 陕西省自然保护区建设现状及其对策研究 \\
\hline Ailuropoda melanoleuca & 大熊猫 & I & $\begin{array}{l}\text { 濒危 } \\
\text { /EN }\end{array}$ & 杜选长 & 陕西天华山国家级自然保护区兽类资源区系特性及其分布 \\
\hline Ailuropoda melanoleuca & 大熊猫 & I & $\begin{array}{l}\text { 濒危 } \\
\text { /EN }\end{array}$ & 王笑坤 & 陕西长青自然保护区春季大熊猫取食微生境特征研究 \\
\hline Ailuropoda melanoleuca & 大熊猫 & I & $\begin{array}{l}\text { 濒危 } \\
\text { /EN }\end{array}$ & 李俊清 & 生态补偿对大熊猫栖息地周边农户生态足迹的影响 \\
\hline Ailuropoda melanoleuca & 大熊猫 & I & 濒危 & 欧阳志云 & 生态位因子分析在大熊猫(Ailuropoda melanoleuca)生境评价中的应用 \\
\hline
\end{tabular}


顾垒，闻丞，罗玫，王吴，吕植. 中国最受关注濒危物种保护现状快速评价的新方法探讨. 生物多样性，2015，23(5)：583-590. http://www. biodiversity-science. net/CN/article/downloadArticleFile. do?attachType=PDF\&id=10075

\begin{tabular}{|c|c|c|c|c|c|}
\hline & & & /EN & & \\
\hline \multirow[t]{2}{*}{ Ailuropoda melanoleuca } & 大熊猫 & I & 濒危 & 张泽钧 & 食肉动物的扩散模式_后果及对大熊猫生态学研究的启示 \\
\hline & & & /EN & & \\
\hline \multirow[t]{2}{*}{ Ailuropoda melanoleuca } & 大熊猫 & I & 濒危 & 王承东 & 手术治疗结合胃管插管饲喂救助初生外伤大熊猫 \\
\hline & & & /EN & & \\
\hline \multirow[t]{2}{*}{ Ailuropoda melanoleuca } & 大熊猫 & I & 濒危 & 魏荣平 & 首例圈养大熊猫产后出血的治疗及初生幼仔长途运输初探 \\
\hline & & & /EN & & \\
\hline AILUROPODA & 熊猫 & I & 濒危 & 王成东 & 首例圈养大熊猫难产的治疗与原因分析 \\
\hline MELANOLEUCA & & & /EN & & \\
\hline \multirow[t]{2}{*}{ Ailuropoda melanoleuca } & 大熊猫 & I & 濒危 & 汪太福 & 四川宝顶沟大熊猫自然保护区发展管理策略讨论 \\
\hline & & & /EN & & \\
\hline \multirow[t]{2}{*}{ Ailuropoda melanoleuca } & 大熊猫 & I & 濒危 & 江华明 & 四川宝兴县大熊猫种群生存力分析 \\
\hline & & & /EN & & \\
\hline \multirow[t]{2}{*}{ Ailuropoda melanoleuca } & 大熊猫 & I & 濒危 & 再江红 & 四川大相岭大熊猫种群及栖息地调查 \\
\hline & & & /EN & & \\
\hline \multirow[t]{2}{*}{ Ailuropoda melanoleuca } & 大熊猫 & I & 濒危 & 扶志宏 & 四川大相岭自然保护区野生动物生存现状及保护对策研究 \\
\hline & & & /EN & & \\
\hline \multirow[t]{2}{*}{ Ailuropoda melanoleuca } & 大熊猫 & I & 濒危 & 古晓东 & 四川省大熊猫保护区生态监测现状分析 \\
\hline & & & /EN & & \\
\hline
\end{tabular}


顾垒，闻丞，罗玫，王吴，吕植. 中国最受关注濒危物种保护现状快速评价的新方法探讨. 生物多样性，2015，23(5)：583-590. http://www biodiversity-science. net/CN/article/downloadArticleFile. do?attachType=PDF\&id=10075

\begin{tabular}{|c|c|c|c|c|c|}
\hline Ailuropoda melanoleuca & 大熊猫 & I & $\begin{array}{l}\text { 濒危 } \\
\text { /EN }\end{array}$ & 康东伟 & 四川王朗国家级自然保护区大熊猫与家畜竞争关系 \\
\hline Ailuropoda melanoleuca & 大熊猫 & I & $\begin{array}{l}\text { 濒危 } \\
\text { /EN }\end{array}$ & 顾志凌 & 四川卧龙大熊猫园生态旅游规划设计 \\
\hline AILUROPODA & 熊猫 & I & 濒危 & 再江洪 & 四川小相岭山系大熊猫种群及栖息地调查 \\
\hline MELANOLEUCA & & & /EN & & \\
\hline AILUROPODA & 熊猫 & I & 濒危 & 陈光升 & 四川小寨子沟自然保护区大熊猫生境植物群落结构特征 \\
\hline MELANOLEUCA & & & $/ \mathrm{EN}$ & & \\
\hline Ailuropoda melanoleuca & 大熊猫 & I & $\begin{array}{l}\text { 濒危 } \\
\text { /EN }\end{array}$ & 张泽钧 & 四川与秦岭野生大熊猫在形态和生态习性上的差异 \\
\hline Ailuropoda melanoleuca & 大熊猫 & I & $\begin{array}{l}\text { 濒危 } \\
\text { /EN }\end{array}$ & 宋成军 & 太白山大熊猫在单主食竹生境下的受食生态学研究 \\
\hline Ailuropoda melanoleuca & 大熊猫 & I & $\begin{array}{l}\text { 濒危 } \\
\text { /EN }\end{array}$ & 何晓军 & 太白山国家级自然保护区资源保护管理现状与对策 \\
\hline Ailuropoda melanoleuca & 大熊猫 & I & $\begin{array}{l}\text { 濒危 } \\
\text { /EN }\end{array}$ & 赵清 & 太白山自然保护区大熊猫景观分布格局研究 \\
\hline Ailuropoda melanoleuca & 大熊猫 & I & $\begin{array}{l}\text { 濒危 } \\
\text { /EN }\end{array}$ & 杨佳 & 太白山自然保护区大熊猫生存干扰因素及其博亦分析 \\
\hline Ailuropoda melanoleuca & 大熊猫 & I & 濒危 & 牀金拴 & 太白县湑水河流域大熊猫生境选择 \\
\hline
\end{tabular}


顾垒，闻丞，罗玫，王吴，吕植. 中国最受关注濒危物种保护现状快速评价的新方法探讨. 生物多样性，2015，23(5)：583-590. http://www. biodiversity-science. net/CN/article/downloadArticleFile. do?attachType=PDF\&id=10075

\begin{tabular}{|c|c|c|c|c|c|}
\hline \multirow[b]{2}{*}{ Ailuropoda melanoleuca } & \multirow[b]{2}{*}{ 大熊猫 } & \multicolumn{3}{|c|}{$/ \mathrm{EN}$} & \multirow[b]{2}{*}{ 唐家河保护区大熊猫的家庭网络及当代基因流的评价 } \\
\hline & & I & 濒危 & 方盛国 & \\
\hline & & & $/$ EN & & \\
\hline AILUROPODA & 熊猫 & I & 濒危 & 方盛国 & 唐家河保护区大熊猫的家庭网络及当代基因流的评价 \\
\hline MELANOLEUCA & & & /EN & & \\
\hline \multirow[t]{2}{*}{ Ailuropoda melanoleuca } & 大熊猫 & I & 濒危 & 张泽钧 & 唐家河与蜂桶寨自然保护区大熊猫生境选择初步比较 \\
\hline & & & /EN & & \\
\hline \multirow[t]{2}{*}{ Ailuropoda melanoleuca } & 大熊猫 & I & 濒危 & 董琪 & 添加酶制剂对大熊猫日粮养分消化率影响的研究 \\
\hline & & & /EN & & \\
\hline \multirow[t]{2}{*}{ Ailuropoda melanoleuca } & 大熊猫 & I & 濒危 & 李德生 & 外源激素诱导大熊猫发情排卵及受乃效果 \\
\hline & & & /EN & & \\
\hline \multirow[t]{2}{*}{ Ailuropoda melanoleuca } & 大熊猫 & I & 濒危 & 邹兴淮 & 外源酶对大熊猫日粮营养物质消化率影响的研究 \\
\hline & & & /EN & & \\
\hline \multirow[t]{2}{*}{ Ailuropoda melanoleuca } & 大熊猫 & I & 濒危 & 李俊清 & 王朗、小河沟自然保护区大熊猫越冬生境利用比较研究 \\
\hline & & & /EN & & \\
\hline \multirow[t]{2}{*}{ Ailuropoda melanoleuca } & 大熊猫 & I & 濒危 & 李俊清 & 王朗、小河沟自然保护区大熊猫越冬生境利用比较研究 \\
\hline & & & /EN & & \\
\hline \multirow[t]{2}{*}{ Ailuropoda melanoleuca } & 大熊猫 & I & 濒危 & 李俊清 & 王朗自然保护区大熊猫生境选择 \\
\hline & & & /EN & & \\
\hline
\end{tabular}


顾垒，闻丞，罗玫，王吴，吕植. 中国最受关注濒危物种保护现状快速评价的新方法探讨. 生物多样性，2015，23(5)：583-590. http://www. biodiversity-science. net/CN/article/downloadArticleFile. do?attachType=PDF\&id=10075

\begin{tabular}{|c|c|c|c|c|c|}
\hline AILUROPODA & 熊猫 & I & 濒危 & 王 昊 & 王朗自然保护区中大熊猫发情场的嗅味树和嗅味标记调查 \\
\hline MELANOLEUCA & & & $/ \mathrm{EN}$ & & \\
\hline \multirow[t]{2}{*}{ Ailuropoda melanoleuca } & 大熊猫 & I & 濒危 & 李悦 & 维生素 C 缓解圈养大熊猫热应激机理研究 \\
\hline & & & /EN & & \\
\hline \multirow[t]{2}{*}{ Ailuropoda melanoleuca } & 大熊猫 & I & 濒危 & 欧阳志云 & 汶川大地震对生态系统的影响 \\
\hline & & & $/ \mathrm{EN}$ & & \\
\hline \multirow[t]{2}{*}{ Ailuropoda melanoleuca } & 大熊猫 & I & 濒危 & 程颂 & 汶川大地震对四川卧龙国家自然保护区大熊猫栖息地的影响 \\
\hline & & & $/ \mathrm{EN}$ & & \\
\hline \multirow[t]{2}{*}{ Ailuropoda melanoleuca } & 大熊猫 & I & 濒危 & 谢宗强 & 汶川地震对大熊猫栖息地的影响与恢复对策 \\
\hline & & & $/ \mathrm{EN}$ & & \\
\hline \multirow[t]{2}{*}{ Ailuropoda melanoleuca } & 大熊猫 & I & 濒危 & 再江洪 & 汶川地震对大熊猫栖息地利用格局的影响 \\
\hline & & & $/ \mathrm{EN}$ & & \\
\hline \multirow[t]{2}{*}{ Ailuropoda melanoleuca } & 大熊猫 & I & 濒危 & 再江洪 & 汶川地震对大熊猫栖息地利用格局的影响 \\
\hline & & & /EN & & \\
\hline \multirow[t]{2}{*}{ Ailuropoda melanoleuca } & 大熊猫 & I & 濒危 & 舟江洪 & 汶川地震对大熊猫栖息地利用格局的影响 \\
\hline & & & $/$ EN & & \\
\hline \multirow[t]{2}{*}{ Ailuropoda melanoleuca } & 大熊猫 & I & 濒危 & 再江洪 & 汶川地震对大熊猫栖息地利用格局的影响 \\
\hline & & & $/ \mathrm{EN}$ & & \\
\hline Ailuropoda melanoleuca & 大熊猫 & I & 濒危 & 再江洪 & 汶川地震对大熊猫栖息地利用格局的影响 \\
\hline
\end{tabular}


顾垒，闻丞，罗玫，王吴，吕植. 中国最受关注濒危物种保护现状快速评价的新方法探讨. 生物多样性，2015，23(5)：583-590. http://www. biodiversity-science. net/CN/article/downloadArticleFile. do?attachType=PDF\&id=10075

\begin{tabular}{|c|c|c|c|c|c|}
\hline & & & /EN & & \\
\hline \multirow[t]{2}{*}{ Ailuropoda melanoleuca } & 大熊猫 & I & 濒危 & 再江洪 & 汶川地震对大熊猫栖息地利用格局的影响 \\
\hline & & & /EN & & \\
\hline \multirow[t]{2}{*}{ Ailuropoda melanoleuca } & 大熊猫 & I & 濒危 & 徐卫华 & 汶川地震对大熊猫生境的影响评枯 \\
\hline & & & /EN & & \\
\hline \multirow[t]{2}{*}{ Ailuropoda melanoleuca } & 大熊猫 & I & 濒危 & 再江洪 & 汶川地震对大熊猫主食竹_拐棍竹竹笋生长发育的影响 \\
\hline & & & /EN & & \\
\hline \multirow[t]{2}{*}{ Ailuropoda melanoleuca } & 大熊猫 & I & 濒危 & 欧阳志云 & 汶川地震对都江堰地区大熊猫生境的影响 \\
\hline & & & /EN & & \\
\hline \multirow[t]{2}{*}{ Ailuropoda melanoleuca } & 大熊猫 & I & 濒危 & 再江洪 & 汶川地震对四川龙溪一虹口和唐家河自然保护区大熊猫栖息地利用格局的影响 \\
\hline & & & /EN & & \\
\hline \multirow[t]{2}{*}{ Ailuropoda melanoleuca } & 大熊猫 & I & 濒危 & 欧阳志云 & 汶川地震后野生动物及栖息地的调查一一一以龙溪虹口和千佛山自然保护区为例 \\
\hline & & & /EN & & \\
\hline \multirow[t]{2}{*}{ Ailuropoda melanoleuca } & 大熊猫 & I & 濒危 & 李 怡 & 汶川地震前后峮山 A 种群大熊猫栖息地状况研究 \\
\hline & & & /EN & & \\
\hline \multirow[t]{2}{*}{ Ailuropoda melanoleuca } & 大熊猫 & I & 濒危 & 徐新良 & 汶川地震灾害核心区生态环境影响评估 \\
\hline & & & /EN & & \\
\hline \multirow[t]{2}{*}{ Ailuropoda melanoleuca } & 大熊猫 & I & 濒危 & 刘兴良 & 汶川地震灾区森林植被恢复问题及其生态对策 \\
\hline & & & /EN & & \\
\hline
\end{tabular}


顾垒，闻丞，罗玫，王吴，吕植. 中国最受关注濒危物种保护现状快速评价的新方法探讨. 生物多样性，2015，23(5)：583-590. http://www biodiversity-science. net/CN/article/downloadArticleFile. do?attachType=PDF\&id=10075

\begin{tabular}{|c|c|c|c|c|c|}
\hline Ailuropoda melanoleuca & 大熊猫 & I & $\begin{array}{l}\text { 濒危 } \\
\text { /EN }\end{array}$ & 严阳 & 汶川震后大熊猫生存状况研究——雅安碧峰峡基地圈养大熊猫调查 \\
\hline Ailuropoda melanoleuca & 大熊猫 & I & $\begin{array}{l}\text { 濒危 } \\
\text { /EN }\end{array}$ & 许秀 & 我国大熊猫的保护现状与展望 \\
\hline Ailuropoda melanoleuca & 大熊猫 & I & $\begin{array}{l}\text { 濒危 } \\
/ \mathrm{EN}\end{array}$ & 施晓刚 & 卧龙保护区三江片区大熊猫嗅味树分布初步调查 \\
\hline Ailuropoda melanoleuca & 大熊猫 & I & $\begin{array}{l}\text { 濒危 } \\
/ \mathrm{EN}\end{array}$ & 周世强 & 卧龙大熊猫食物基地的竹子种群密度及生物量 \\
\hline Ailuropoda melanoleuca & 大熊猫 & I & $\begin{array}{l}\text { 濒危 } \\
/ \mathrm{EN}\end{array}$ & 杨娟 & 卧龙地区流域突然覆盖变化及其对大熊猫潜在生境的影响 \\
\hline Ailuropoda melanoleuca & 大熊猫 & I & $\begin{array}{l}\text { 濒危 } \\
\text { /EN }\end{array}$ & 胡锦量 & 卧龙及草坡自然保护区大熊猫的种群与保护 \\
\hline Ailuropoda melanoleuca & 大熊猫 & I & $\begin{array}{l}\text { 濒危 } \\
/ \mathrm{EN}\end{array}$ & 陈琳 & 卧龙圈养雌性大熊猫发情行为观察 \\
\hline Ailuropoda melanoleuca & 大熊猫 & I & $\begin{array}{l}\text { 濒危 } \\
/ \mathrm{EN}\end{array}$ & 何延美 & 卧龙圈养大熊猫的周期行为节律 \\
\hline Ailuropoda melanoleuca & 大熊猫 & I & $\begin{array}{l}\text { 濒危 } \\
/ \mathrm{EN}\end{array}$ & 张 和 民 & 卧龙圈养大熊猫母兽带仔野化培训 \\
\hline Ailuropoda melanoleuca & 大熊猫 & I & 濒危 & 李明 & 卧龙圈养大熊猫遗传多样性现状及预测 \\
\hline
\end{tabular}


顾垒，闻丞，罗玫，王吴，吕植. 中国最受关注濒危物种保护现状快速评价的新方法探讨. 生物多样性，2015，23(5)：583-590. http://www. biodiversity-science. net/CN/article/downloadArticleFile. do?attachType=PDF\&id=10075

\begin{tabular}{|c|c|c|c|c|c|}
\hline & & & /EN & & \\
\hline AILUROPODA & 熊猫 & I & 濒危 & 周世强 & 卧龙特区大熊猫竹子基地栽培成效调查报告 \\
\hline MELANOLEUCA & & & /EN & & \\
\hline \multirow[t]{2}{*}{ Ailuropoda melanoleuca } & 大熊猫 & I & 濒危 & 李华 & 卧龙自然保护区大熊猫栖息地管理研究的初步系统评价 \\
\hline & & & /EN & & \\
\hline \multirow[t]{2}{*}{ Ailuropoda melanoleuca } & 大熊猫 & I & 濒危 & 周世强 & 卧龙自然保护区大熊猫栖息地植物群落多样性研究IV认为干扰对群落物种多样性的影响 \\
\hline & & & /EN & & \\
\hline \multirow[t]{2}{*}{ Ailuropoda melanoleuca } & 大熊猫 & I & 濒危 & 李树信 & 卧龙自然保护区社区参与生态旅游的对策研究 \\
\hline & & & /EN & & \\
\hline \multirow[t]{2}{*}{ Ailuropoda melanoleuca } & 大熊猫 & I & 濒危 & 沈茂英 & 卧龙自然保护区生态建设与社区发展研究 \\
\hline & & & /EN & & \\
\hline AILUROPODA & 熊猫 & I & 濒危 & 刘记 & 卧龙自然保护区生态旅游开发研究 \\
\hline MELANOLEUCA & & & /EN & & \\
\hline \multirow[t]{2}{*}{ Ailuropoda melanoleuca } & 大熊猫 & I & 濒危 & 苗 鸿 & 卧龙自然保护区与当地社区关系模式探讨 \\
\hline & & & /EN & & \\
\hline \multirow[t]{2}{*}{ Ailuropoda melanoleuca } & 大熊猫 & I & 濒危 & 刘雪华 & 无线电颈圈定位数据应用于卧龙大熊猫移动规律的研究 \\
\hline & & & /EN & & \\
\hline \multirow[t]{2}{*}{ Ailuropoda melanoleuca } & 大熊猫 & I & 濒危 & 杜有顺 & 武汉动物园大熊猫饲养管理与疾病防治研究 \\
\hline & & & /EN & & \\
\hline
\end{tabular}


顾垒，闻丞，罗玫，王吴，吕植. 中国最受关注濒危物种保护现状快速评价的新方法探讨. 生物多样性，2015，23(5)：583-590. http://www. biodiversity-science. net/CN/article/downloadArticleFile. do?attachType=PDF\&id=10075

\begin{tabular}{|c|c|c|c|c|c|}
\hline Ailuropoda melanoleuca & 大熊猫 & I & $\begin{array}{l}\text { 濒危 } \\
\text { /EN }\end{array}$ & 孟涛 & 相岭山系大熊猫栖息地的历史变迁 \\
\hline Ailuropoda melanoleuca & 大熊猫 & I & $\begin{array}{l}\text { 濒危 } \\
\text { /EN }\end{array}$ & 再江洪 & 小相岭大熊猫种群生态学和保护策略研究 \\
\hline Ailuropoda melanoleuca & 大熊猫 & I & $\begin{array}{l}\text { 濒危 } \\
\text { /EN }\end{array}$ & 曾宗永 & 小相岭大熊栖息地干扰调查 \\
\hline Ailuropoda melanoleuca & 大熊猫 & I & $\begin{array}{l}\text { 濒危 } \\
\text { /EN }\end{array}$ & 朱 否 & 小相岭山系大熊猫种群生存力分析 \\
\hline AILUROPODA & 熊猫 & I & 濒危 & 张美佳 & 心钠肽对猪卵母细胞成熟、受精和大熊猫精子功能的影响 \\
\hline MELANOLEUCA & & & $/ \mathrm{EN}$ & & \\
\hline Ailuropoda melanoleuca & 大熊猫 & I & $\begin{array}{l}\text { 濒危 } \\
\text { /EN }\end{array}$ & 刘定震 & 雄性大熊猫(Ailuropoda melanoleuca)尿液中包含亲缘关系的信息 \\
\hline Ailuropoda melanoleuca & 大熊猫 & I & $\begin{array}{l}\text { 濒危 } \\
\text { /EN }\end{array}$ & 牛 锋 & 熊猫粪便中乳酸菌的分离鉴定与降胆固醇作用研究 \\
\hline AILUROPODA & 熊猫 & I & 濒危 & 马亦生 & 湑水河流域孟家沟大熊猫及其栖息地的发现与观察 \\
\hline MELANOLEUCA & & & $/ \mathrm{EN}$ & & \\
\hline Ailuropoda melanoleuca & 大熊猫 & I & $\begin{array}{l}\text { 濒危 } \\
\text { /EN }\end{array}$ & 孙大江 & 雅安地区生态旅游资源现状与发展对策 \\
\hline AILUROPODA & 熊猫 & I & 濒危 & 罗娌 & 亚成体大熊猫金黄色葡萄球菌性呼吸道感染一例 \\
\hline
\end{tabular}


顾垒，闻丞，罗玫，王吴，吕植. 中国最受关注濒危物种保护现状快速评价的新方法探讨. 生物多样性，2015，23(5)：583-590. http://www. biodiversity-science. net/CN/article/downloadArticleFile. do?attachType=PDF\&id=10075

\begin{tabular}{|c|c|c|c|c|c|}
\hline MELANOLEUCA & & & /EN & & \\
\hline \multirow[t]{2}{*}{ Ailuropoda melanoleuca } & 大熊猫 & I & 濒危 & 宋延龄 & 洋太公路对秦岭大熊猫活动及其栖息地保护的影响 \\
\hline & & & $/ \mathrm{EN}$ & & \\
\hline \multirow[t]{2}{*}{ Ailuropoda melanoleuca } & 大熊猫 & I & 濒危 & 李俊生 & 洋太公路对秦岭大熊猫栖息地景观格局的影响 \\
\hline & & & $/ \mathrm{EN}$ & & \\
\hline AILUROPODA & 熊猫 & I & 濒危 & 林鸿荣 & 也谈大熊猫之今古称谓 \\
\hline MELANOLEUCA & & & $/ \mathrm{EN}$ & & \\
\hline \multirow[t]{2}{*}{ Ailuropoda melanoleuca } & 大熊猫 & I & 濒危 & 王大勇 & 冶勒自然保护区大熊猫及其栖息地保护现状与管理对策 \\
\hline & & & $/ \mathrm{EN}$ & & \\
\hline \multirow[t]{2}{*}{ Ailuropoda melanoleuca } & 大熊猫 & I & 濒危 & 张和民 & 野化培训大熊猫采食和人为砍伐对拐棍竹无性系种群更新的影响 \\
\hline & & & /EN & & \\
\hline \multirow[t]{2}{*}{ Ailuropoda melanoleuca } & 大熊猫 & I & 濒危 & 周世强 & 野化培训大熊猫采食和人为砍伐对拐棍竹无性系种群结 \\
\hline & & & $/ \mathrm{EN}$ & & \\
\hline \multirow[t]{2}{*}{ Ailuropoda melanoleuca } & 大熊猫 & I & 濒危 & 谢浩 & 野化培训大熊猫的采食动态及食物利用率 \\
\hline & & & /EN & & \\
\hline \multirow[t]{2}{*}{ Ailuropoda melanoleuca } & 大熊猫 & I & 濒危 & 周世强 & 野化培训大熊猫的食性及其对拐棍竹的选择利用 \\
\hline & & & $/ \mathrm{EN}$ & & \\
\hline \multirow[t]{2}{*}{ Ailuropoda melanoleuca } & 大熊猫 & I & 濒危 & 周世强 & 野化培训大熊猫对生境斑块的利用频率及其与斑块资源的关系 \\
\hline & & & $/ \mathrm{EN}$ & & \\
\hline
\end{tabular}


顾垒，闻丞，罗玫，王吴，吕植. 中国最受关注濒危物种保护现状快速评价的新方法探讨. 生物多样性，2015，23(5)：583-590. http://www biodiversity-science. net/CN/article/downloadArticleFile. do?attachType=PDF\&id=10075

\begin{tabular}{|c|c|c|c|c|c|}
\hline Ailuropoda melanoleuca & 大熊猫 & I & $\begin{array}{l}\text { 濒危 } \\
\text { /EN }\end{array}$ & 周世强 & 野化培训大熊猫利用后用拐棍竹残桩与丢弃部分的关系 \\
\hline Ailuropoda melanoleuca & 大熊猫 & I & $\begin{array}{l}\text { 濒危 } \\
\text { /EN }\end{array}$ & 周世强 & 野化培训大熊猫食物利用率的初步研究 \\
\hline Ailuropoda melanoleuca & 大熊猫 & I & $\begin{array}{l}\text { 濒危 } \\
\text { /EN }\end{array}$ & 谢浩 & 野化培训大熊猫夜宿地结构特征的初步观察 \\
\hline Ailuropoda melanoleuca & 大熊猫 & I & $\begin{array}{l}\text { 濒危 } \\
\text { /EN }\end{array}$ & 谢浩 & 野化培训大熊猫在过渡期的采食时间分配及影响因素 \\
\hline Ailuropoda melanoleuca & 大熊猫 & I & $\begin{array}{l}\text { 濒危 } \\
\text { /EN }\end{array}$ & 周世强 & 野生大熊猫地理分布格局的空间尺度分析 \\
\hline Ailuropoda melanoleuca & 大熊猫 & I & $\begin{array}{l}\text { 濒危 } \\
\text { /EN }\end{array}$ & 魏辅文 & 野生大熊猫生态学研究进展与前瞻 \\
\hline AILUROPODA & 熊猫 & I & 濒危 & 严 旬 & 野生大熊猫现状、面临的挑战及展望 \\
\hline MELANOLEUCA & & & $/ \mathrm{EN}$ & & \\
\hline Ailuropoda melanoleuca & 大熊猫 & I & $\begin{array}{l}\text { 濒危 } \\
\text { /EN }\end{array}$ & 余锐萍 & 一例大熊猫出血性坏死性胃肠炎的病理学观察和病原学诊断 \\
\hline AILUROPODA & 熊猫 & I & 濒危 & 马清义 & 一例大熊猫急性肾炎的诊治 \\
\hline MELANOLEUCA & & & $/$ EN & & \\
\hline Ailuropoda melanoleuca & 大熊猫 & I & 濒危 & 赵彩云 & 一例大熊猫误食野山芋中毒的诊治报告 \\
\hline
\end{tabular}


顾垒，闻丞，罗玫，王吴，吕植. 中国最受关注濒危物种保护现状快速评价的新方法探讨. 生物多样性，2015，23(5)：583-590. http://www. biodiversity-science. net/CN/article/downloadArticleFile. do?attachType=PDF\&id=10075

\begin{tabular}{|c|c|c|c|c|c|}
\hline & & & /EN & & \\
\hline \multirow[t]{2}{*}{ Ailuropoda melanoleuca } & 大熊猫 & I & 濒危 & 赵鹏鹏, & 一例未成年大熊猫假孕* \\
\hline & & & /EN & & \\
\hline \multirow[t]{2}{*}{ Ailuropoda melanoleuca } & 大熊猫 & I & 濒危 & 马清义 & 一例左前掌缺失雌性大熊猫发情交配异常行为的观察 \\
\hline & & & /EN & & \\
\hline \multirow[t]{2}{*}{ Ailuropoda melanoleuca } & 大熊猫 & I & 濒危 & 侯蓉 & 一种大熊猫亲子鉴定试剂盒的研制 \\
\hline & & & /EN & & \\
\hline \multirow[t]{2}{*}{ Ailuropoda melanoleuca } & 大熊猫 & I & 濒危 & 谭雪梅 & 一株大熊猫肠道耐药性细菌基因组的分析 \\
\hline & & & /EN & & \\
\hline \multirow[t]{2}{*}{ Ailuropoda melanoleuca } & 大熊猫 & I & 濒危 & 荣华 & 一株大熊猫肠道纤维素菌的生物学特性与系统发育分析 \\
\hline & & & /EN & & \\
\hline \multirow[t]{2}{*}{ Ailuropoda melanoleuca } & 大熊猫 & I & 濒危 & 徐恒 & 一株大熊猫肠道厌氧纤维素菌的分离鉴定、系统发育分析及生物学特性的研究 \\
\hline & & & /EN & & \\
\hline \multirow[t]{2}{*}{ Ailuropoda melanoleuca } & 大熊猫 & I & 濒危 & 杨水云 & 依赖粪便材料的大熊猫肠道耶尔森氏菌的检测 \\
\hline & & & /EN & & \\
\hline \multirow[t]{2}{*}{ Ailuropoda melanoleuca } & 大熊猫 & I & 濒危 & 魏辅文 & 移地与圈养大熊猫野外放归的探讨 \\
\hline & & & /EN & & \\
\hline \multirow[t]{2}{*}{ Ailuropoda melanoleuca } & 大熊猫 & I & 濒危 & 郑亚江 & 以落叶松为主的外来物种对大熊猫生存环境影响及对策研究 \\
\hline & & & /EN & & \\
\hline
\end{tabular}


顾垒，闻丞，罗玫，王吴，吕植. 中国最受关注濒危物种保护现状快速评价的新方法探讨. 生物多样性，2015，23(5)：583-590. http://www biodiversity-science. net/CN/article/downloadArticleFile. do?attachType=PDF\&id=10075

\begin{tabular}{|c|c|c|c|c|c|}
\hline Ailuropoda melanoleuca & 大熊猫 & I & $\begin{array}{l}\text { 濒危 } \\
\text { /EN }\end{array}$ & 鲍楠 & 应用分子生物学方法研究大熊猫肠道微生态 \\
\hline AILUROPODA & 熊猫 & I & 濒危 & 张志和 & 应用微卫星方法进行大熊猫父亲鉴定 \\
\hline MELANOLEUCA & & & $/ \mathrm{EN}$ & & \\
\hline Ailuropoda melanoleuca & 大熊猫 & I & $\begin{array}{l}\text { 濒危 } \\
\text { /EN }\end{array}$ & 郑玉才 & 用双向电泳-质谱初步分析大熊猫初乳和常乳中差异表达的乳清蛋白 \\
\hline Ailuropoda melanoleuca & 大熊猫 & I & $\begin{array}{l}\text { 濒危 } \\
\text { /EN }\end{array}$ & 王成东 & 幼龄大熊猫轮状病毒感染性腹泻的防治 \\
\hline Ailuropoda melanoleuca & 大熊猫 & I & $\begin{array}{l}\text { 濒危 } \\
\text { /EN }\end{array}$ & 李明喜 & 幼年大熊猫体重变化规律及适宜能量和蛋白质供给量的研究 \\
\hline Ailuropoda melanoleuca & 大熊猫 & I & $\begin{array}{l}\text { 濒危 } \\
\text { /EN }\end{array}$ & 张泽钧 & 原始林与次生林中大熊猫微生境结构的比较 \\
\hline Ailuropoda melanoleuca & 大熊猫 & I & $\begin{array}{l}\text { 濒危 } \\
\text { /EN }\end{array}$ & 吉学平 & 云南腾冲江东山小水井全新世大熊猫的发现及其意义* \\
\hline Ailuropoda melanoleuca & 大熊猫 & I & $\begin{array}{l}\text { 濒危 } \\
\text { /EN }\end{array}$ & & 长青保护区大熊猫及其伴生动物的种群动态监测 \\
\hline Ailuropoda melanoleuca & 大熊猫 & I & $\begin{array}{l}\text { 濒危 } \\
\text { /EN }\end{array}$ & 郑 晓 燕 & 长青自然保护区生态旅游产业竞争力初探 \\
\hline Ailuropoda melanoleuca & 大熊猫 & I & 濒危 & 高素萍 & 震后卧龙_蜂桶寨生态廊道大熊猫主食竹选择与配置规划 \\
\hline
\end{tabular}


顾垒，闻丞，罗玫，王吴，吕植. 中国最受关注濒危物种保护现状快速评价的新方法探讨. 生物多样性，2015，23(5)：583-590. http://www. biodiversity-science. net/CN/article/downloadArticleFile. do?attachType=PDF\&id=10075

\begin{tabular}{|c|c|c|c|c|c|}
\hline & & & /EN & & \\
\hline \multirow[t]{2}{*}{ Ailuropoda melanoleuca } & 大熊猫 & I & 濒危 & 高素萍 & 震后卧龙_蜂桶寨生态廊道大熊猫主食竹选择与配置规划 \\
\hline & & & $/ \mathrm{EN}$ & & \\
\hline \multirow[t]{2}{*}{ Ailuropoda melanoleuca } & 大熊猫 & I & 濒危 & 韩文 & 震后卧龙自然保护区大熊猫生境评价和恢复研究 \\
\hline & & & /EN & & \\
\hline \multirow[t]{2}{*}{ Ailuropoda melanoleuca } & 大熊猫 & I & 濒危 & 胡锦真 & 中国大熊猫保护区发展历史 现状及前瞻 \\
\hline & & & $/ \mathrm{EN}$ & & \\
\hline \multirow[t]{2}{*}{ Ailuropoda melanoleuca } & 大熊猫 & I & 濒危 & 贺超 & 中国大熊猫保护体系的建立 \\
\hline & & & /EN & & \\
\hline AILUROPODA & 熊猫 & I & 濒危 & 严旬 & 中国大熊猫保护战略探讨 \\
\hline MELANOLEUCA & & & /EN & & \\
\hline \multirow[t]{2}{*}{ Ailuropoda melanoleuca } & 大熊猫 & I & 濒危 & 王小红 & 竹子开花对大熊猫生存影响分析 \\
\hline & & & /EN & & \\
\hline \multirow[t]{2}{*}{ Ailuropoda melanoleuca } & 大熊猫 & I & 濒危 & 陈梅丽 & 转录组学研究人肿瘤细胞的表达调控机制和大熊猫基因组重注释 \\
\hline & & & $/ \mathrm{EN}$ & & \\
\hline AILUROPODA & 熊猫 & I & 濒危 & 蒋志刚 & 自动感应照相系统在大熊猫以及同域分布的野生动物研究中的应用 \\
\hline MELANOLEUCA & & & $/ \mathrm{EN}$ & & \\
\hline AILUROPODA & 熊猫 & I & 濒危 & 李纪宏 & 自然保护区功能分区指标体系的构建研究一一以陕西老县城大熊猫自然保护区为例 \\
\hline MELANOLEUCA & & & /EN & & \\
\hline
\end{tabular}


顾垒，闻丞，罗玫，王昊，吕植. 中国最受关注濒危物种保护现状快速评价的新方法探讨．生物多样性，2015，23(5)：583-590. http://www. biodiversity-science. net/CN/article/downloadArticleFile. do?attachType=PDF\&id=10075

\begin{tabular}{|c|c|c|c|c|c|}
\hline Ailurus fulgens & 小熊猫 & II & $\begin{array}{l}\text { 易危 } \\
\text { /VU }\end{array}$ & 李明杰 & 1 例小熊猫大肠杆菌性脓血症的诊断 \\
\hline Ailurus fulgens & 小熊猫 & II & $\begin{array}{l}\text { 易危 } \\
\text { /VU }\end{array}$ & Naveen K & $\begin{array}{l}\text { A long-team community-based monitoring and xonservation program for red panda in } \\
\text { unprotected forests of eastern nepal }\end{array}$ \\
\hline Ailurus fulgens & 小熊猫 & II & $\begin{array}{l}\text { 易危 } \\
\text { /VU }\end{array}$ & G. B. SCHROERING & An early claim of Red Panda Ailurus fulgens from Vietnam \\
\hline Ailurus fulgens & 小熊猫 & II & $\begin{array}{l}\text { 易危 } \\
\text { /VU }\end{array}$ & Ying Li & Characterization of the Gut Microbiota in the Red Panda(Ailurus fulgens) \\
\hline Ailurus fulgens & 小熊猫 & II & $\begin{array}{l}\text { 易危 } \\
\text { /VU }\end{array}$ & N. W. Dyer & Chromobacteriosis in a Chinese red panda (Ailurus fulgens styani) \\
\hline Ailurus fulgens & 小熊猫 & II & $\begin{array}{l}\text { 易危 } \\
\text { /VU }\end{array}$ & Kamal Kandel & $\begin{array}{l}\text { COMMUNITY BASED RED PANDA STUDY IN BHOTKHOLA AREA, } \\
\text { SANKHUWASABHA DISTRICT, NEPAL }\end{array}$ \\
\hline Ailurus fulgens & 小熊猫 & II & $\begin{array}{l}\text { 易危 } \\
\text { /VU }\end{array}$ & Guangyou Yang & $\begin{array}{l}\text { Complete mitochondrial genomes of Baylisascaris schroederi, Baylisascaris ailuri and } \\
\text { Baylisascaris transfuga from giant panda, red panda and polar bear }\end{array}$ \\
\hline Ailurus fulgens & 小熊猫 & II & $\begin{array}{l}\text { 易危 } \\
\text { /VU }\end{array}$ & Hari Prasad & $\begin{array}{l}\text { Distribution and observations of Red Pandas Ailurus fulgens fulgens in Dhorpatan Hunting } \\
\text { Reserve, Nepal }\end{array}$ \\
\hline Ailurus fulgens & 小熊猫 & II & $\begin{array}{l}\text { 易危 } \\
\text { /VU }\end{array}$ & $\begin{array}{l}\text { Naveen Kumar } \\
\text { Mahato }\end{array}$ & $\begin{array}{l}\text { DISTRIBUTION OF THE RED PANDA AILURUS FULGENS (CUVIER, 1825) IN NEPAL } \\
\text { BASED ON A PREDICTIVE MODEL }\end{array}$ \\
\hline Ailurus fulgens & 小熊猫 & II & 易危 & Mads F. Bertelsen & Diversity and prevalence of metastrongyloid nematodes infecting the red panda (Ailurus \\
\hline
\end{tabular}


顾垒，闻丞，罗玫，王昊，吕植. 中国最受关注濒危物种保护现状快速评价的新方法探讨．生物多样性，2015，23(5)：583-590. http://www, biodiversity-science, net/CN/article/downloadArticleFile. do?attachType=PDF\&id=10075

\begin{tabular}{|c|c|c|c|c|c|}
\hline & & & /VU & & fulgens) in European zoos \\
\hline \multirow[t]{2}{*}{ Ailurus fulgens } & 小熊猫 & II & 易危 & Kristen Rebecca Jule & Effects of captivity and implications for ex situ conservation: with special reference to the \\
\hline & & & /VU & & redpanda (Ailurus fulgens) \\
\hline \multirow[t]{2}{*}{ Ailurus fulgens } & 小熊猫 & II & 易危 & F. Wei & Genotyping faeces of red pandas (Ailurus fulgens):implications for population estimation \\
\hline & & & $/ \mathrm{VU}$ & & \\
\hline \multirow[t]{2}{*}{ Ailurus fulgens } & 小熊猫 & II & 易危 & Karl Vernes & Habitat Correlates of the Red Panda in the Temperate Forests of Bhutan \\
\hline & & & $/ \mathrm{VU}$ & & \\
\hline \multirow[t]{2}{*}{ Ailurus fulgens } & 小熊猫 & II & 易危 & Josefina Zidar & Keeping red pandas in captivity \\
\hline & & & /VU & & \\
\hline \multirow[t]{2}{*}{ Ailurus fulgens } & 小熊猫 & II & 易危 & Janet C. & Pneumonia from Angiostrongylus vasorum infection in a red panda (Ailurus fulgens fulgens) \\
\hline & & & /VU & Patterson-Kane & \\
\hline \multirow[t]{2}{*}{ Ailurus fulgens } & 小熊猫 & II & 易危 & Rabindra Man Joshi & Potential Habitat, Estimated Population and Hot Spot of Red Panda (Ailurus fulgens) in \\
\hline & & & /VU & & Bhotkhola Area, Sankhuwasabha District, Nepal \\
\hline \multirow[t]{2}{*}{ Ailurus fulgens } & 小熊猫 & II & 易危 & Q. Qin & Sequence analysis of a canine parvovirus isolated from a red panda (Ailurus fulgens) in China \\
\hline & & & /VU & & \\
\hline \multirow[t]{2}{*}{ Ailurus fulgens } & 小熊猫 & II & 易危 & Jayanta Kumar & Status of Red Panda Ailurus fulgens in Neora Valley National Park, Darjeeling District, West \\
\hline & & & /VU & MALLICK & Bengal, India \\
\hline \multirow[t]{2}{*}{ Ailurus fulgens } & 小熊猫 & II & 易危 & Achyut Aryal & Summer Diet and Distribution of the Red Panda (Ailurus fulgens fulgens)in Dhorpatan Hunting \\
\hline & & & /VU & & Reserve, Nepal \\
\hline
\end{tabular}


顾垒，闻丞，罗玫，王吴，吕植. 中国最受关注濒危物种保护现状快速评价的新方法探讨. 生物多样性，2015，23(5)：583-590. http://www biodiversity-science. net/CN/article/downloadArticleFile. do?attachType=PDF\&id=10075

\begin{tabular}{|c|c|c|c|c|c|}
\hline Ailurus fulgens & 小熊猫 & II & $\begin{array}{l}\text { 易危 } \\
\text { /VU }\end{array}$ & Rebecca E. Fisher & The phylogeny of the red panda (Ailurus fulgens):evidence from the hindlimb \\
\hline Ailurus fulgens & 小熊猫 & II & $\begin{array}{l}\text { 易危 } \\
\text { /VU }\end{array}$ & Katja N. Koeppel & $\begin{array}{l}\text { The use of the gonadotropin-releasing hormone analog deslorelin for short-term contraception } \\
\text { in red pandas (Ailurus fulgens) }\end{array}$ \\
\hline Ailurus fulgens & 小熊猫 & II & $\begin{array}{l}\text { 易危 } \\
\text { /VU }\end{array}$ & Sangay Dorji & $\begin{array}{l}\text { The Vulnerable red panda Ailurus fulgens in Bhutan: distribution,conservation status and } \\
\text { management recommendations }\end{array}$ \\
\hline Ailurus fulgens & 小熊猫 & II & $\begin{array}{l}\text { 易危 } \\
\text { /VU }\end{array}$ & Guangyou Yang & $\begin{array}{l}\text { Treatment and prevention of natural heartworm (Dirofilaria immitis) infections in red pandas } \\
\text { (Ailurus fulgens) with selamectin and ivermectin }\end{array}$ \\
\hline Ailurus fulgens & 小熊猫 & II & $\begin{array}{l}\text { 易危 } \\
\text { /VU }\end{array}$ & 陈武 & 啊毒疫苗接冲导致小熊猫犬瘟热病毒感染的诊断 \\
\hline Ailurus fulgens & 小熊猫 & II & $\begin{array}{l}\text { 易危 } \\
\text { /VU }\end{array}$ & 杨风堂 & 比较染色体涂色显示小熊猫(Ailurus fulgens)具有高度保守的核型 \\
\hline Ailurus fulgens & 小熊猫 & II & $\begin{array}{l}\text { 易危 } \\
\text { /VU }\end{array}$ & 修云芳 & 成体雌性小熊猫卵巢组织学观察 \\
\hline Ailurus fulgens & 小熊猫 & II & $\begin{array}{l}\text { 易危 } \\
\text { /VU }\end{array}$ & 李春 & 雌性小熊猫粪样中雌二醇与孕酮水平的变化与繁殖启动的关系 \\
\hline Ailurus fulgens & 小熊猫 & II & $\begin{array}{l}\text { 易危 } \\
\text { /VU }\end{array}$ & 修云芳 & 雌性小熊猫血清类固醇激素水平的变化 \\
\hline Ailurus fulgens & 小熊猫 & II & 濒危 & 胡细连 & 大熊猫等濒危动物 IGF-I 基因的克隆、表达与组织分布研究 \\
\hline
\end{tabular}


顾垒，闻丞，罗玫，王吴，吕植. 中国最受关注濒危物种保护现状快速评价的新方法探讨. 生物多样性，2015，23(5)：583-590. http://www. biodiversity-science. net/CN/article/downloadArticleFile. do?attachType=PDF\&id=10075

\begin{tabular}{|c|c|c|c|c|c|}
\hline & & & /EN & & \\
\hline \multirow[t]{2}{*}{ Ailurus fulgens } & 小熊猫 & II & 易危 & 魏辅文 & 大熊猫和小熊猫粪便 DNA 提取的简易方法 \\
\hline & & & $/ \mathrm{VU}$ & & \\
\hline \multirow[t]{2}{*}{ Ailurus fulgens } & 小熊猫 & II & 易危 & 韩宗先 & 大熊猫和小熊猫共存机制研究进展 \\
\hline & & & /VU & & \\
\hline \multirow[t]{2}{*}{ Ailurus fulgens } & 小熊猫 & II & 易危 & 王成东 & 大熊猫和小熊猫犬瘟热病与疫苗免疫现状 \\
\hline & & & /VU & & \\
\hline \multirow[t]{2}{*}{ Ailurus fulgens } & 小熊猫 & II & 易危 & 张泽钧 & 大熊猫生境选择及与小熊猫在生境上的分割 \\
\hline & & & $/ \mathrm{VU}$ & & \\
\hline \multirow[t]{2}{*}{ Ailurus fulgens } & 小熊猫 & II & 易危 & 张泽钧 & 大熊猫与小熊猫生态习性的比较：食物、体型大小及系统发育的影响 \\
\hline & & & /VU & & \\
\hline \multirow[t]{2}{*}{ Ailurus fulgens } & 小熊猫 & II & 易危 & 魏辅文 & 蜂桶寨自然保护区小熊猫巢域初步研究 \\
\hline & & & /VU & & \\
\hline \multirow[t]{2}{*}{ Ailurus fulgens } & 小熊猫 & II & 易危 & 魏辅文 & 蜂桶寨自然保护区小熊猫对生境的选择 \\
\hline & & & /VU & & \\
\hline \multirow[t]{2}{*}{ Ailurus fulgens } & 小熊猫 & II & 易危 & 魏辅文 & 蜂桶寨自然保护区小熊猫受食特征和营养对策 \\
\hline & & & /VU & & \\
\hline \multirow[t]{2}{*}{ Ailurus fulgens } & 小熊猫 & II & 易危 & 修云芳 & 福州地区圈养小熊猫的饲养与繁殖 \\
\hline & & & /VU & & \\
\hline
\end{tabular}


顾垒，闻丞，罗玫，王吴，吕植. 中国最受关注濒危物种保护现状快速评价的新方法探讨. 生物多样性，2015，23(5)：583-590. http://www. biodiversity-science. net/CN/article/downloadArticleFile. do?attachType=PDF\&id=10075

\begin{tabular}{|c|c|c|c|c|c|}
\hline Ailurus fulgens & 小熊猫 & II & $\begin{array}{l}\text { 易危 } \\
\text { /VU }\end{array}$ & 刘健鬼 & 高纬度地区小熊猫的饲养与繁殖 \\
\hline Ailurus fulgens & 小熊猫 & II & $\begin{array}{l}\text { 易危 } \\
\text { /VU }\end{array}$ & 陈武 & 几种犬瘟热疫苗接种小熊猫的免疫效果比较 \\
\hline Ailurus fulgens & 小熊猫 & II & $\begin{array}{l}\text { 易危 } \\
\text { /VU }\end{array}$ & 再江洪 & 凉山山系小熊猫 (Ailurus fulgens) 分布区景观格局 \\
\hline Ailurus fulgens & 小熊猫 & II & $\begin{array}{l}\text { 易危 } \\
\text { /VU }\end{array}$ & 李华静 & 冕宁县小熊猫饲养管理存在的问题及建议 \\
\hline Ailurus fulgens & 小熊猫 & II & $\begin{array}{l}\text { 易危 } \\
\text { /VU }\end{array}$ & 修云芳 & 奇异变形杆菌引发小熊猫急性腹江性疾病 \\
\hline Ailurus fulgens & 小熊猫 & II & $\begin{array}{l}\text { 易危 } \\
\text { /VU }\end{array}$ & 李明 & 邛崃和相岭山系小熊猫种群的遗传结构 \\
\hline Ailurus fulgens & 小熊猫 & II & $\begin{array}{l}\text { 易危 } \\
\text { /VU }\end{array}$ & 张泽钧 & 扔崃山系大熊猫和小熊猫生境选择的比较 \\
\hline Ailurus fulgens & 小熊猫 & II & $\begin{array}{l}\text { 易危 } \\
\text { /VU }\end{array}$ & 刘振生 & 圈养条件下小熊猫指名亚种旱季的活动规律 \\
\hline Ailurus fulgens & 小熊猫 & II & $\begin{array}{l}\text { 易危 } \\
\text { /VU }\end{array}$ & 刘振生 & 圈养条件下小熊猫指名亚种雨季的活动规律 \\
\hline Ailurus fulgens & 小熊猫 & II & 易危 & 王兴金 & 圈养小熊猫的疾病 \\
\hline
\end{tabular}


顾垒，闻丞，罗玫，王吴，吕植. 中国最受关注濒危物种保护现状快速评价的新方法探讨. 生物多样性，2015，23(5)：583-590. http://www. biodiversity-science. net/CN/article/downloadArticleFile. do?attachType=PDF\&id=10075

\begin{tabular}{|c|c|c|c|c|c|}
\hline & & & /VU & & \\
\hline \multirow[t]{2}{*}{ Ailurus fulgens } & 小熊猫 & II & 易危 & 贾琳琳 & 圈养小熊猫的饲养与繁殖 \\
\hline & & & /VU & & \\
\hline \multirow[t]{2}{*}{ Ailurus fulgens } & 小熊猫 & II & 易危 & 魏辅文 & 圈养小熊猫的昼夜活动节律 \\
\hline & & & /VU & & \\
\hline \multirow[t]{2}{*}{ Ailurus fulgens } & 小熊猫 & II & 易危 & 王兴金 & 圈养小熊猫对栖息地点的选择及其行为观察 \\
\hline & & & /VU & & \\
\hline \multirow[t]{2}{*}{ Ailurus fulgens } & 小熊猫 & II & 易危 & 魏辅文 & 圈养小熊猫繁殖行为变化及繁殖行为对策 \\
\hline & & & /VU & & \\
\hline \multirow[t]{2}{*}{ Ailurus fulgens } & 小熊猫 & II & 易危 & 魏辅文 & 圈养小熊猫几种病毒的 PCR 检测 \\
\hline & & & /VU & & \\
\hline \multirow[t]{2}{*}{ Ailurus fulgens } & 小熊猫 & II & 易危 & 张利娜 & 圈养小熊猫脱毛症的诊疗 \\
\hline & & & /VU & & \\
\hline \multirow[t]{2}{*}{ Ailurus fulgens } & 小熊猫 & II & 易危 & 徐素慧 & 圈养小熊猫血液生理及生化指标的检测分析 \\
\hline & & & /VU & & \\
\hline \multirow[t]{2}{*}{ Ailurus fulgens } & 小熊猫 & II & 易危 & 魏辅文 & 圈养小熊猫育幼行为的初步观察 \\
\hline & & & /VU & & \\
\hline \multirow[t]{2}{*}{ Ailurus fulgens } & 小熊猫 & II & 易危 & 何洪涁 & 犬瘟热病毒小熊猫株 (LP) 的动物感染试验 \\
\hline & & & /VU & & \\
\hline
\end{tabular}


顾垒，闻丞，罗玫，王吴，吕植. 中国最受关注濒危物种保护现状快速评价的新方法探讨. 生物多样性，2015，23(5)：583-590. http://www. biodiversity-science. net/CN/article/downloadArticleFile. do?attachType=PDF\&id=10075

\begin{tabular}{|c|c|c|c|c|c|}
\hline Ailurus fulgens & 小熊猫 & II & $\begin{array}{l}\text { 易危 } \\
\text { /VU }\end{array}$ & 间芳 & 犬瘟热病毒小熊猫株 $\mathrm{H} 、 \mathrm{~F}$ 和 $\mathrm{N}$ 基因的克隆及表达 \\
\hline Ailurus fulgens & 小熊猫 & II & $\begin{array}{l}\text { 易危 } \\
\text { /VU }\end{array}$ & 何洪涁 & 犬瘟热病毒小熊猫株的驯化致弱及其免疫研究 \\
\hline Ailurus fulgens & 小熊猫 & II & $\begin{array}{l}\text { 易危 } \\
\text { /VU }\end{array}$ & 夏咸柱 & 犬瘟热病毒小熊猫株反向遗传系统 \\
\hline Ailurus fulgens & 小熊猫 & II & $\begin{array}{l}\text { 易危 } \\
\text { /VU }\end{array}$ & 夏咸柱 & 犬瘟热病毒小熊猫株核蛋白和融合蛋白基因克隆及序列分析 \\
\hline Ailurus fulgens & 小熊猫 & II & $\begin{array}{l}\text { 易危 } \\
/ \mathrm{VU}\end{array}$ & 夏咸柱 & 犬瘟热减毒疫苗对小熊猫安全-眭与免疫原性研究 \\
\hline Ailurus fulgens & 小熊猫 & II & $\begin{array}{l}\text { 易危 } \\
\text { /VU }\end{array}$ & 邵良平 & 日粮中霉菌毒素引发小熊猫中毒性肝炎的临床调查 \\
\hline Ailurus fulgens & 小熊猫 & II & $\begin{array}{l}\text { 易危 } \\
\text { /VU }\end{array}$ & 再江洪 & 四川邛崃山系小熊猫分布 \\
\hline Ailurus fulgens & 小熊猫 & II & $\begin{array}{l}\text { 易危 } \\
/ \mathrm{VU}\end{array}$ & 彭琳 & 温度对圈养小熊猫行为影响的观察 \\
\hline Ailurus fulgens & 小熊猫 & II & $\begin{array}{l}\text { 易危 } \\
\text { /VU }\end{array}$ & 李呈军 & 小熊猫巴氏杆菌病的诊治 \\
\hline Ailurus fulgens & 小熊猫 & II & 易危 & 王印 & 小熊猫败血性肺炎病原的分离鉴定 \\
\hline
\end{tabular}


顾垒，闻丞，罗玫，王吴，吕植. 中国最受关注濒危物种保护现状快速评价的新方法探讨. 生物多样性，2015，23(5)：583-590. http://www. biodiversity-science. net/CN/article/downloadArticleFile. do?attachType=PDF\&id=10075

\begin{tabular}{|c|c|c|c|c|c|}
\hline & & & /VU & & \\
\hline \multirow[t]{2}{*}{ Ailurus fulgens } & 小熊猫 & II & 易危 & 汪丽芬 & 小熊猫的常规行为训练 \\
\hline & & & /VU & & \\
\hline \multirow[t]{2}{*}{ Ailurus fulgens } & 小熊猫 & II & 易危 & 王兴金 & 小熊猫的圈养繁殖 \\
\hline & & & /VU & & \\
\hline \multirow[t]{2}{*}{ Ailurus fulgens } & 小熊猫 & II & 易危 & 黄炎 & 小熊猫的人工育幼 \\
\hline & & & /VU & & \\
\hline \multirow[t]{2}{*}{ Ailurus fulgens } & 小熊猫 & II & 易危 & 黄炎 & 小熊猫的饲养管理 \\
\hline & & & /VU & & \\
\hline \multirow[t]{2}{*}{ Ailurus fulgens } & 小熊猫 & II & 易危 & 李莉 & 小熊猫对不同日粮的消化试验 \\
\hline & & & /VU & & \\
\hline \multirow[t]{2}{*}{ Ailurus fulgens } & 小熊猫 & II & 易危 & 王小明 & 小熊猫对同性和异性气味的行为反应 \\
\hline & & & /VU & & \\
\hline \multirow[t]{2}{*}{ Ailurus fulgens } & 小熊猫 & II & 易危 & 章孝荣 & 小熊猫耳部成纤维细胞的培养和冷冻保存 \\
\hline & & & /VU & & \\
\hline \multirow[t]{2}{*}{ Ailurus fulgens } & 小熊猫 & II & 易危 & 修云芳 & 小熊猫繁殖周期血清雌二醇和孕酮含量变化 \\
\hline & & & /VU & & \\
\hline \multirow[t]{2}{*}{ Ailurus fulgens } & 小熊猫 & II & 易危 & 孙利丽 & 小熊猫附体红细胞体病的治疗 \\
\hline & & & /VU & & \\
\hline
\end{tabular}


顾垒，闻丞，罗玫，王吴，吕植. 中国最受关注濒危物种保护现状快速评价的新方法探讨. 生物多样性，2015，23(5)：583-590. http://www. biodiversity-science. net/CN/article/downloadArticleFile. do?attachType=PDF\&id=10075

\begin{tabular}{|c|c|c|c|c|c|}
\hline Ailurus fulgens & 小熊猫 & II & $\begin{array}{l}\text { 易危 } \\
\text { /VU }\end{array}$ & 叶永孟 & 小熊猫肝炎诊治 \\
\hline Ailurus fulgens & 小熊猫 & II & $\begin{array}{l}\text { 易危 } \\
\text { /VU }\end{array}$ & 米志平 & 小熊猫肝脏和胆囊的解剖研究 \\
\hline Ailurus fulgens & 小熊猫 & II & $\begin{array}{l}\text { 易危 } \\
\text { /VU }\end{array}$ & 陈武 & 小熊猫蛔虫 ITS 及 $5.8 \mathrm{~S}$ rDNA 序列的克隆与分析 \\
\hline Ailurus fulgens & 小熊猫 & II & $\begin{array}{l}\text { 易危 } \\
\text { /VU }\end{array}$ & 修云芳 & 小熊猫急性肝炎并发急性胰腺炎病例报告 \\
\hline Ailurus fulgens & 小熊猫 & II & $\begin{array}{l}\text { 易危 } \\
\text { /VU }\end{array}$ & 杨光友 & 小熊猫寄生虫与寄生虫病研究进展 \\
\hline Ailurus fulgens & 小熊猫 & II & $\begin{array}{l}\text { 易危 } \\
\text { /VU }\end{array}$ & 米志平 & 小熊猫甲状腺的组织解剖学观察 \\
\hline Ailurus fulgens & 小熊猫 & II & $\begin{array}{l}\text { 易危 } \\
\text { /VU }\end{array}$ & 李世宗 & 小熊猫接种犬瘟热弱毒疫苗的效果分析 \\
\hline Ailurus fulgens & 小熊猫 & II & $\begin{array}{l}\text { 易危 } \\
\text { /VU }\end{array}$ & 余星明 & 小熊猫绿脓杆菌的诊断 \\
\hline Ailurus fulgens & 小熊猫 & II & $\begin{array}{l}\text { 易危 } \\
\text { /VU }\end{array}$ & 彭小琴 & 小熊猫慢性肝炎病的诊治 \\
\hline Ailurus fulgens & 小熊猫 & II & 易危 & 梁金平 & 小熊猫猫瘟热的诊断与治疗 \\
\hline
\end{tabular}


顾垒，闻丞，罗玫，王吴，吕植. 中国最受关注濒危物种保护现状快速评价的新方法探讨. 生物多样性，2015，23(5)：583-590. http://www. biodiversity-science. net/CN/article/downloadArticleFile. do?attachType=PDF\&id=10075

\begin{tabular}{|c|c|c|c|c|c|}
\hline & & & $/ \mathrm{VU}$ & & \\
\hline \multirow[t]{2}{*}{ Ailurus fulgens } & 小熊猫 & II & 易危 & 陈武 & 小熊猫奇异变形杆菌病的诊治 \\
\hline & & & /VU & & \\
\hline \multirow[t]{2}{*}{ Ailurus fulgens } & 小熊猫 & II & 易危 & 李光汉 & 小熊猫圈养种群遗传多样性及其影响因子 \\
\hline & & & /VU & & \\
\hline \multirow[t]{2}{*}{ Ailurus fulgens } & 小熊猫 & II & 易危 & 张晓明 & 小熊猫犬瘟热病毒的分离鉴定及分子特点 \\
\hline & & & /VU & & \\
\hline \multirow[t]{2}{*}{ Ailurus fulgens } & 小熊猫 & II & 易危 & 赵沁昆 & 小熊猫犬瘟热病毒感染的诊断 \\
\hline & & & /VU & & \\
\hline \multirow[t]{2}{*}{ Ailurus fulgens } & 小熊猫 & II & 易危 & 熊焰 & 小熊猫犬瘟热病及病原研究 \\
\hline & & & /VU & & \\
\hline \multirow[t]{2}{*}{ Ailurus fulgens } & 小熊猫 & II & 易危 & 王印 & 小熊猫犬瘟热的诊断和防治 \\
\hline & & & $/ \mathrm{VU}$ & & \\
\hline \multirow[t]{2}{*}{ Ailurus fulgens } & 小熊猫 & II & 易危 & 汪明权 & 小熊猫犬瘟热的诊疗 \\
\hline & & & /VU & & \\
\hline \multirow[t]{2}{*}{ Ailurus fulgens } & 小熊猫 & II & 易危 & 昊宣 & 小熊猫犬瘟热继发大肠杆菌的诊治 \\
\hline & & & /VU & & \\
\hline \multirow[t]{2}{*}{ Ailurus fulgens } & 小熊猫 & II & 易危 & 鲁兆宁 & 小熊猫热应激病例的综合防治 \\
\hline & & & /VU & & \\
\hline
\end{tabular}


顾垒，闻丞，罗玫，王吴，吕植. 中国最受关注濒危物种保护现状快速评价的新方法探讨. 生物多样性，2015，23(5)：583-590. http://www. biodiversity-science. net/CN/article/downloadArticleFile. do?attachType=PDF\&id=10075

\begin{tabular}{|c|c|c|c|c|c|}
\hline Ailurus fulgens & 小熊猫 & II & $\begin{array}{l}\text { 易危 } \\
\text { /VU }\end{array}$ & 黄松 & 小熊猫人工育幼的研究 \\
\hline Ailurus fulgens & 小熊猫 & II & $\begin{array}{l}\text { 易危 } \\
\text { /VU }\end{array}$ & 李春 & 小熊猫妊娠期粪便中孕酮、雌二醇的水平变化 \\
\hline Ailurus fulgens & 小熊猫 & II & $\begin{array}{l}\text { 易危 } \\
\text { /VU }\end{array}$ & 李莉 & 小熊猫日粮营养成分分析 \\
\hline Ailurus fulgens & 小熊猫 & II & $\begin{array}{l}\text { 易危 } \\
\text { /VU }\end{array}$ & 米志平 & 小熊猫舌粘膜和口腔粘膜的组织学研究 \\
\hline Ailurus fulgens & 小熊猫 & II & $\begin{array}{l}\text { 易危 } \\
\text { /VU }\end{array}$ & 米志平 & 小熊猫肾脏和输尿管的组织学研究 \\
\hline Ailurus fulgens & 小熊猫 & II & $\begin{array}{l}\text { 易危 } \\
\text { /VU }\end{array}$ & 米志平 & 小熊猫唾液腺的研究 \\
\hline Ailurus fulgens & 小熊猫 & II & $\begin{array}{l}\text { 易危 } \\
\text { /VU }\end{array}$ & 米志平 & 小熊猫胃的解剖和组织结构研究 \\
\hline Ailurus fulgens & 小熊猫 & II & $\begin{array}{l}\text { 易危 } \\
\text { /VU }\end{array}$ & 韩宗先 & 小熊猫夏秋季的昼夜活动节律 \\
\hline Ailurus fulgens & 小熊猫 & II & $\begin{array}{l}\text { 易危 } \\
\text { /VU }\end{array}$ & 俞诗源 & 小熊猫小脑皮层的组织结构及 RT. 97、 KGF 和 Bax 蛋白在小脑皮层的表达 \\
\hline Ailurus fulgens & 小熊猫 & II & 易危 & 李岱容 & 小熊猫血液 30 项生化指标参考值的调查 \\
\hline
\end{tabular}


顾垒，闻丞，罗玫，王吴，吕植. 中国最受关注濒危物种保护现状快速评价的新方法探讨. 生物多样性，2015，23(5)：583-590. http://www. biodiversity-science. net/CN/article/downloadArticleFile. do?attachType=PDF\&id=10075

\begin{tabular}{|c|c|c|c|c|c|}
\hline & & & /VU & & \\
\hline \multirow[t]{2}{*}{ Ailurus fulgens } & 小熊猫 & II & 易危 & 邵良平 & 小熊猫血液生理生化指标的测定 \\
\hline & & & /VU & & \\
\hline \multirow[t]{2}{*}{ Ailurus fulgens } & 小熊猫 & II & 易危 & 米志平 & 小熊猫咽和食管的组织学研究 \\
\hline & & & /VU & & \\
\hline \multirow[t]{2}{*}{ Ailurus fulgens } & 小熊猫 & II & 易危 & 顾建宏 & 小熊猫眼线虫病的诊治 \\
\hline & & & /VU & & \\
\hline \multirow[t]{2}{*}{ Ailurus fulgens } & 小熊猫 & II & 易危 & 米志平 & 小熊猫胰的组织解剖学研究 \\
\hline & & & /VU & & \\
\hline \multirow[t]{2}{*}{ Ailurus fulgens } & 小熊猫 & II & 易危 & 苏克炳 & 小熊猫胰腺炎的诊治 \\
\hline & & & /VU & & \\
\hline \multirow[t]{2}{*}{ Ailurus fulgens } & 小熊猫 & II & 易危 & 王否 & 小熊猫源犬瘟热病毒全基因序列的克隆及序列分析 \\
\hline & & & /VU & & \\
\hline \multirow[t]{2}{*}{ Ailurus fulgens } & 小熊猫 & II & 易危 & 李家开 & 小熊猫中暑 \\
\hline & & & $/ \mathrm{VU}$ & & \\
\hline \multirow[t]{2}{*}{ Ailurus fulgens } & 小熊猫 & II & 易危 & 徐素慧 & 小熊猫中暑的临床诊治 \\
\hline & & & /VU & & \\
\hline \multirow[t]{2}{*}{ Ailurus fulgens } & 小熊猫 & II & 易危 & 魏辅文 & 小熊猫种内遗传及亚种分化研究 \\
\hline & & & /VU & & \\
\hline
\end{tabular}


顾垒，闻丞，罗玫，王吴，吕植. 中国最受关注濒危物种保护现状快速评价的新方法探讨. 生物多样性，2015，23(5)：583-590. http://www. biodiversity-science. net/CN/article/downloadArticleFile. do?attachType=PDF\&id=10075

\begin{tabular}{|c|c|c|c|c|c|}
\hline Ailurus fulgens & 小熊猫 & II & $\begin{array}{l}\text { 易危 } \\
\text { /VU }\end{array}$ & 魏辅文 & 小熊猫种群遗传结构和地理分化 \\
\hline Ailurus fulgens & 小熊猫 & II & $\begin{array}{l}\text { 易危 } \\
\text { /VU }\end{array}$ & 韩宗先 & 小熊猫资源现状与保护 \\
\hline Ailurus fulgens & 小熊猫 & II & $\begin{array}{l}\text { 易危 } \\
\text { /VU }\end{array}$ & 魏辅文 & 雄性小熊猫粪便中睪酮水平的变化与繁殖周期的关系 \\
\hline Ailurus fulgens & 小熊猫 & II & $\begin{array}{l}\text { 易危 } \\
\text { /VU }\end{array}$ & 徐素慧 & 一例小熊猫胫腓骨骨折的诊治 \\
\hline Ailurus fulgens & 小熊猫 & II & $\begin{array}{l}\text { 易危 } \\
\text { /VU }\end{array}$ & 左珂菁 & 一例小熊猫尾部外伤化脓感染的手术治疗 \\
\hline Ailurus fulgens & 小熊猫 & II & $\begin{array}{l}\text { 易危 } \\
\text { /VU }\end{array}$ & 李明 & 一种笁选微卫星位点的改进方法及其在小熊猫微卫星基因文库构建上的应用 \\
\hline Ailurus fulgens & 小熊猫 & II & $\begin{array}{l}\text { 易危 } \\
\text { /VU }\end{array}$ & 杨光友 & 应用 ITS-2 基因对小熊猫源恶丝虫虫种的鉴定 \\
\hline Ailurus fulgens & 小熊猫 & II & $\begin{array}{l}\text { 易危 } \\
\text { /VU }\end{array}$ & 胡刚 & 云南省小熊猫(Ailurus fulgens)资源分布及保护现状 \\
\hline Ailurus fulgens & 小熊猫 & II & $\begin{array}{l}\text { 易危 } \\
\text { /VU }\end{array}$ & 刘振生 & 中国小熊猫生态学现状 \\
\hline Ailurus fulgens & 小熊猫 & II & 易危 & 吴登虎 & 中药麦芽对圈养小熊猫繁殖力的影响观察 \\
\hline
\end{tabular}


顾垒，闻丞，罗玫，王吴，吕植. 中国最受关注濒危物种保护现状快速评价的新方法探讨. 生物多样性，2015，23(5)：583-590. http://www. biodiversity-science. net/CN/article/downloadArticleFile. do?attachType=PDF\&id=10075

\begin{tabular}{|c|c|c|c|c|c|}
\hline & & & /VU & & \\
\hline \multirow[t]{2}{*}{ Ailurus fulgens } & 小熊猫 & II & 易危 & 魏辅文 & 种群能流分析冶勒自然保护区大熊猫和小熊猫 \\
\hline & & & /VU & & \\
\hline \multirow[t]{2}{*}{ Ailurus fulgens } & 小熊猫 & II & 易危 & 邵良平 & 紫色色杆菌感染小熊猫引起肺炎的临床调查 \\
\hline & & & /VU & & \\
\hline \multirow[t]{2}{*}{ Ailurus fulgens } & 小熊猫 & II & 易危 & 耿毅 & 自然感染犬瘟热病毒小熊猫的病理学观察 \\
\hline & & & /VU & & \\
\hline \multirow[t]{3}{*}{ Alcippe davidi } & 灰眶雀哃 & 未列 & 数据 & 韦福民 & 大盘山国家级自然保护区鸟类群落及其分布特征 \\
\hline & & 入 & 不足 & & \\
\hline & & & $/ \mathrm{DD}$ & & \\
\hline \multirow[t]{3}{*}{ Alcippe davidi } & 灰眶雀倜 & 未列 & 数据 & 姜明敏 & 都江堰林区取食樱桃果实_种子_的鸟类及其种子扩散作用 \\
\hline & & 入 & 不足 & & \\
\hline & & & $/ \mathrm{DD}$ & & \\
\hline \multirow[t]{3}{*}{ Alcippe davidi } & 灰眶雀倜 & 未列 & 数据 & 谢少和 & 福建武夷山自然保护区挂墩鸟类资源现状的初步研究 \\
\hline & & 入 & 不足 & & \\
\hline & & & $/ \mathrm{DD}$ & & \\
\hline \multirow[t]{3}{*}{ Alcippe davidi } & 灰眶雀倜 & 未列 & 数据 & 佟富春 & 广东车八岭常绿阔叶林林下鸟群落组成和结构 \\
\hline & & 入 & 不足 & & \\
\hline & & & $/ \mathrm{DD}$ & & \\
\hline
\end{tabular}


顾垒，闻丞，罗玫，王吴，吕植. 中国最受关注濒危物种保护现状快速评价的新方法探讨. 生物多样性，2015，23(5)：583-590. http://www. biodiversity-science. net/CN/article/downloadArticleFile. do?attachType=PDF\&id=10075

\begin{tabular}{|c|c|c|c|c|c|}
\hline Alcippe davidi & 灰眶雀鹤 & 未列 & 数据 & 粟通萍 & 广西猫儿山地区鸟类组成及垂直分布格局 \\
\hline & & $\lambda$ & $\begin{array}{l}\text { 不足 } \\
\text { /DD }\end{array}$ & & \\
\hline \multirow[t]{3}{*}{ Alcippe davidi } & 灰眶雀倜 & 未列 & 数据 & 罗祖奎 & 贵州省云台山林下鸟类群落特征 \\
\hline & & $\lambda$ & 不足 & & \\
\hline & & & $/ \mathrm{DD}$ & & \\
\hline \multirow[t]{3}{*}{ Alcippe davidi } & 灰眶雀鸤 & 未列 & 数据 & 邹发生 & 海南岛尖峰岭热带森林中几种雀形目鸟的移动 \\
\hline & & 入 & 不足 & & \\
\hline & & & $/ \mathrm{DD}$ & & \\
\hline \multirow[t]{3}{*}{ Alcippe davidi } & 灰眶雀倜 & 未列 & 数据 & 邹发生 & 海南岛尖峰岭热带山地雨林林下鸟类群落研究 \\
\hline & & 入 & 不足 & & \\
\hline & & & $/ \mathrm{DD}$ & & \\
\hline \multirow[t]{3}{*}{ Alcippe davidi } & 灰眶雀鸤 & 未列 & 数据 & 承勇 & 江西井冈山国家级自然保护区鸟类资源调查与分析 \\
\hline & & 入 & 不足 & & \\
\hline & & & $/ \mathrm{DD}$ & & \\
\hline \multirow[t]{3}{*}{ Alcippe davidi } & 灰眶雀屓 & 未列 & 数据 & 陈 宇 & 天童常绿阔叶林样地中优势鸟类食性与采食地点植物的关系 \\
\hline & & 入 & 不足 & & \\
\hline & & & $/ \mathrm{DD}$ & & \\
\hline Alcippe davidi & 灰眶雀鹤 & 未列 & 数据 & 李自君 & 乌云界自然保护区鸟类资源及夏季鸟类群落生态学研究 \\
\hline
\end{tabular}


顾垒，闻丞，罗玫，王吴，吕植. 中国最受关注濒危物种保护现状快速评价的新方法探讨. 生物多样性，2015，23(5)：583-590. http://www. biodiversity-science. net/CN/article/downloadArticleFile. do?attachType=PDF\&id=10075

\begin{tabular}{|c|c|c|c|c|c|}
\hline & & 入 & 不足 & & \\
\hline & & & $/ \mathrm{DD}$ & & \\
\hline \multirow[t]{3}{*}{ Alcippe davidi } & 灰眶雀鹛 & 未列 & 数据 & 王德良 & 五龙河自然保护区鸟类群落冬春食性特征分析 \\
\hline & & 入 & 不足 & & \\
\hline & & & /DD & & \\
\hline \multirow[t]{3}{*}{ Alcippe davidi } & 灰眶雀䴗 & 未列 & 数据 & 韩联宪 & 云南哀牢山徐家坝常绿阔叶林的鸟类取食集团 \\
\hline & & 入 & 不足 & & \\
\hline & & & $/ \mathrm{DD}$ & & \\
\hline \multirow[t]{3}{*}{ Alcippe davidi } & 灰眶雀䴗 & 未列 & 数据 & 苏栋栋 & 云南大围山和鸡足山常绿阔叶林林下鸟类群落比较 \\
\hline & & 入 & 不足 & & \\
\hline & & & $/ \mathrm{DD}$ & & \\
\hline \multirow[t]{3}{*}{ Alcippe davidi } & 灰眶雀䴗 & 未列 & 数据 & 王军馝 & 浙江天童国家森林公园鸟类生态位格局 \\
\hline & & 入 & 不足 & & \\
\hline & & & /DD & & \\
\hline \multirow[t]{2}{*}{ Alcippe variegaticeps } & 金额雀鹤 & 未列 & 易危 & 粟通平 & 广西猫儿山地区鸟类组成及垂直分布格局 \\
\hline & & 入 & $/ \mathrm{VU}$ & & \\
\hline \multirow[t]{2}{*}{ Alcippe variegaticeps } & 金额雀飽 & 未列 & 易危 & 王绍能 & 广西猫儿山自然保护区珍稀鸟类资源及保护对策 \\
\hline & & 入 & $/ \mathrm{VU}$ & & \\
\hline Alcippe variegaticeps & 金额雀倜 & 未列 & 易危 & 陈本平 & 四川老君山国家级自然保护区的鸟类资源概况 \\
\hline
\end{tabular}


顾垒，闻丞，罗玫，王吴，吕植. 中国最受关注濒危物种保护现状快速评价的新方法探讨. 生物多样性，2015，23(5)：583-590. http://www. biodiversity-science. net/CN/article/downloadArticleFile. do?attachType=PDF\&id=10075

\begin{tabular}{|c|c|c|c|c|c|}
\hline & & 入 & $/ \mathrm{VU}$ & & \\
\hline \multirow[t]{2}{*}{ Alcippe variegaticeps } & 金额雀鸤 & 未列 & 易危 & 杨杰 & 四川老君山自然保护区不同生境鸟类多样性研究 \\
\hline & & 入 & $/ \mathrm{VU}$ & & \\
\hline \multirow[t]{2}{*}{ Alcippe variegaticeps } & 金额雀鹏 & 未列 & 易危 & 唐平 & 四川省盐边县鸟类多样性调查 \\
\hline & & 入 & $/ \mathrm{VU}$ & & \\
\hline \multirow[t]{2}{*}{ Alcippe variegaticeps } & 金额雀鹋 & 未列 & 易危 & 李晶晶 & 珠穆朗玛峰国家级自然保护区鸟类区系及其垂直分布特征 \\
\hline & & 入 & $/ \mathrm{VU}$ & & \\
\hline \multirow[t]{3}{*}{ Alsophila spinulosa } & 杪椤 & II & 未评 & 宋培勇 & 4 株杪椤内生细菌的分离鉴定及系统发育分析 \\
\hline & & & 价 & & \\
\hline & & & $/ \mathrm{NE}$ & & \\
\hline \multirow[t]{3}{*}{ Alsophila spinulosa } & 棑椤 & II & 未评 & Ying-Juan Su & Complete chloroplast genome sequence of a tree fern Alsophila spinulosa insights into \\
\hline & & & 价 & & evolutionary changes in fern chloroplast genomes \\
\hline & & & $/ \mathrm{NE}$ & & \\
\hline \multirow[t]{3}{*}{ Alsophila spinulosa } & 杪椤 & II & 未评 & Chunlin Long & Food uses of ferns in China: a review \\
\hline & & & 价 & & \\
\hline & & & $/ \mathrm{NE}$ & & \\
\hline \multirow[t]{3}{*}{ Alsophila spinulosa } & 桫椤 & II & 未评 & Ting Wang & Genetic differentiation of relictual populations of Alsophila spinulosa in southern China \\
\hline & & & 价 & & inferred from cpDNA trnL - F noncoding sequences \\
\hline & & & $/ \mathrm{NE}$ & & \\
\hline
\end{tabular}


顾垒，闻丞，罗玫，王吴，吕植. 中国最受关注濒危物种保护现状快速评价的新方法探讨. 生物多样性，2015，23(5)：583-590. http://www. biodiversity-science. net/CN/article/downloadArticleFile. do?attachType=PDF\&id=10075

\begin{tabular}{|c|c|c|c|c|c|}
\hline \multirow[t]{3}{*}{ Alsophila spinulosa } & 杪椤 & II & 未评 & Ting Wang & Genetic structure and variation in the relict populations of Alsophila spinulosa from southern \\
\hline & & & 价 & & China based on RAPD markers and cpDNA atpB-rbcL sequence data \\
\hline & & & $/ \mathrm{NE}$ & & \\
\hline \multirow[t]{3}{*}{ Alsophila spinulosa } & 誩椤 & II & 未评 & Ting Wang & Isolation and Characterization of Microsatellite Loci in the Tree Fern Alsophila spinulosa \\
\hline & & & 价 & & \\
\hline & & & $/ \mathrm{NE}$ & & \\
\hline \multirow[t]{3}{*}{ Alsophila spinulosa } & 杪椤 & II & 未评 & Ting Wang & Population genetic structure and phylogeographical pattern of a relict tree fern, Alsophila \\
\hline & & & 价 & & spinulosa (Cyatheaceae), inferred from cpDNA atpB- rbcL intergenic spacers \\
\hline & & & $/ \mathrm{NE}$ & & \\
\hline \multirow[t]{3}{*}{ Alsophila spinulosa } & 誩椤 & II & 未评 & Yingjuan Su & Population Genetic Variation in the Tree Fern: Alsophila spinulosa (Cyatheaceae) Effects of \\
\hline & & & 价 & & Reproductive Strategy \\
\hline & & & $/ \mathrm{NE}$ & & \\
\hline \multirow[t]{3}{*}{ Alsophila spinulosa } & 杪椤 & II & 未评 & ZI-JUAN WANG & Spore Morphology of Cyatheaceae in China \\
\hline & & & 价 & & \\
\hline & & & $/ \mathrm{NE}$ & & \\
\hline \multirow[t]{3}{*}{ Alsophila spinulosa } & 杪椤 & II & 未评 & 叶林奇 & 濒危植物杪椤（Cyathcace）POD 同工酶比较及其分离纯化和性质的研究 \\
\hline & & & 价 & & \\
\hline & & & $/ \mathrm{NE}$ & & \\
\hline Alsophila spinulosa & 杪椤 & II & 未评 & 陈封政 & 濒危植物杪椤不同部位化学组分的比较研究 \\
\hline
\end{tabular}


顾垒，闻丞，罗玫，王吴，吕植. 中国最受关注濒危物种保护现状快速评价的新方法探讨. 生物多样性，2015，23(5)：583-590. http://www. biodiversity-science. net/CN/article/downloadArticleFile. do?attachType=PDF\&id=10075

\begin{tabular}{|c|c|c|c|c|c|}
\hline & & & 价 & & \\
\hline Alsophila spinulosa & 杪椤 & II & $\begin{array}{l}\text { /NE } \\
\text { 未评 } \\
\text { 价 }\end{array}$ & 洪伟 & 濒危植物杪椤个体生态场的研究 \\
\hline Alsophila spinulosa & 杪椤 & II & $\begin{array}{l}\text { /NE } \\
\text { 未评 } \\
\text { 价 }\end{array}$ & 洪伟 & 濒危植物杪椤个体生态场梯度的研究 \\
\hline Alsophila spinulosa & 杪椤 & II & $\begin{array}{l}/ \mathrm{NE} \\
\text { 未评 } \\
\text { 价 }\end{array}$ & 陈封政 & 濒危植物杪椤叶和茎干中可溶性糖和总黄酮含量的研究 \\
\hline Alsophila spinulosa & 杪椤 & II & $\begin{array}{l}\text { /NE } \\
\text { 未评 } \\
\text { 价 }\end{array}$ & 洪伟 & 濒危植物杪椤种群格局的分形特征 \\
\hline Alsophila spinulosa & 杪椤 & II & $\begin{array}{l}\text { /NE } \\
\text { 未评 } \\
\text { 价 }\end{array}$ & 洪伟 & 濒危植物杪椤种群生态场研究 \\
\hline Alsophila spinulosa & 杪椤 & II & $\begin{array}{l}/ \mathrm{NE} \\
\text { 未评 } \\
\text { 价 }\end{array}$ & 宋萍 & 濒危植物杪椤种群生态学与生态场特性研究 \\
\hline
\end{tabular}


顾垒，闻丞，罗玫，王吴，吕植. 中国最受关注濒危物种保护现状快速评价的新方法探讨. 生物多样性，2015，23(5)：583-590. http://www. biodiversity-science. net/CN/article/downloadArticleFile. do?attachType=PDF\&id=10075

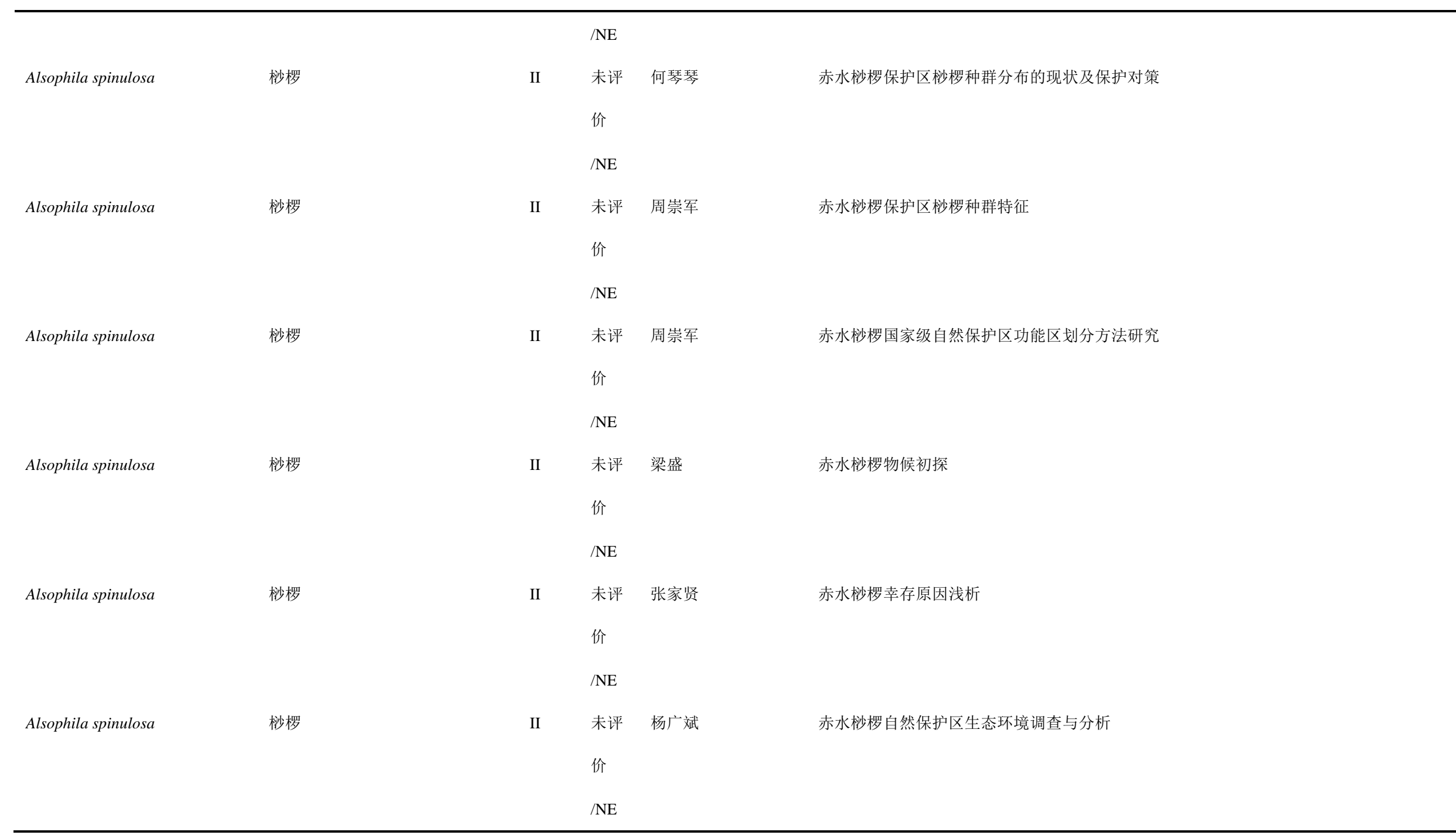


顾垒，闻丞，罗玫，王吴，吕植. 中国最受关注濒危物种保护现状快速评价的新方法探讨. 生物多样性，2015，23(5)：583-590. http://www. biodiversity-science. net/CN/article/downloadArticleFile. do?attachType=PDF\&id=10075

\begin{tabular}{|c|c|c|c|c|c|}
\hline Alsophila spinulosa & 杪椤 & II & $\begin{array}{l}\text { 未评 } \\
\text { 价 } \\
\text { /NE }\end{array}$ & 孙亚莉 & 赤水杪椤自然保护区受危物种现状及保护 \\
\hline Alsophila spinulosa & 杪椤 & II & $\begin{array}{l}\text { 未评 } \\
\text { 价 } \\
\text { /NE }\end{array}$ & 何跃军 & 丹霞地貌杪椤群落结构特征及其多样性的垂直变化 \\
\hline Alsophila spinulosa & 杪椤 & II & $\begin{array}{l}\text { 未评 } \\
\text { 价 } \\
\text { /NE }\end{array}$ & 石胜友 & 涪陵磨盘沟杪椤种群格局的分形特征-信息维数 \\
\hline Alsophila spinulosa & 杪椤 & II & $\begin{array}{l}\text { 未评 } \\
\text { 价 } \\
\text { /NE }\end{array}$ & 石胜友 & 涪陵磨盘沟自然保护区杪椤种群分布格局的分形特征 \\
\hline Alsophila spinulosa & 杪椤 & II & $\begin{array}{l}\text { 未评 } \\
\text { 价 } \\
\text { /NE }\end{array}$ & 黄铃荣 & 福安瓜溪杪椤保护区生态环境分析 \\
\hline Alsophila spinulosa & 杪椤 & II & $\begin{array}{l}\text { 未评 } \\
\text { 价 } \\
\text { /NE }\end{array}$ & 林细平 & 福安市瓜溪杪椤自然保护区的现状与发展对策 \\
\hline Alsophila spinulosa & 杪椤 & II & 未评 & 张思玉 & 福建永定杪椤群落内主要灌木种群的种间联结性研究 \\
\hline
\end{tabular}


顾垒，闻丞，罗玫，王吴，吕植. 中国最受关注濒危物种保护现状快速评价的新方法探讨. 生物多样性，2015，23(5)：583-590. http://www. biodiversity-science. net/CN/article/downloadArticleFile. do?attachType=PDF\&id=10075

NE

Alsophila spinulosa

桫椤

杪椤

Alsophila spinulosa

杪椤

Alsophila spinulosa

杪椤

桫椤

Alsophila spinulosa

Alsophila spinulosa

杪椤

价

NE

价

/NE

II 未评 尹兰

价

$/ \mathrm{NE}$

未评$$
\text { 价 }
$$

Alsophila spinulosa
未评

未评 杜红红

高信芬

/NE

$/ \mathrm{NE}$

\section{张思玉}

福建永定县笔架山杪椤群落物种多样性研究

光照、温度和 $\mathrm{pH}$ 值对 4 种杪椤科植物狍子萌发及早期配子体发育的影响

国内杪椤研究的文献计量分析

画稿溪国家级自然保护区珍稀植物杪椤种群结构与更新

活化石植物杪椤的资源开发及保护

未评杨明照
基于 $\mathrm{cpDNA}$ atpB-rbcL 贵州赤水杪椤国家级自然保护区为例 
顾垒，闻丞，罗玫，王吴，吕植. 中国最受关注濒危物种保护现状快速评价的新方法探讨. 生物多样性，2015，23(5)：583-590. http://www. biodiversity-science. net/CN/article/downloadArticleFile. do?attachType=PDF\&id=10075

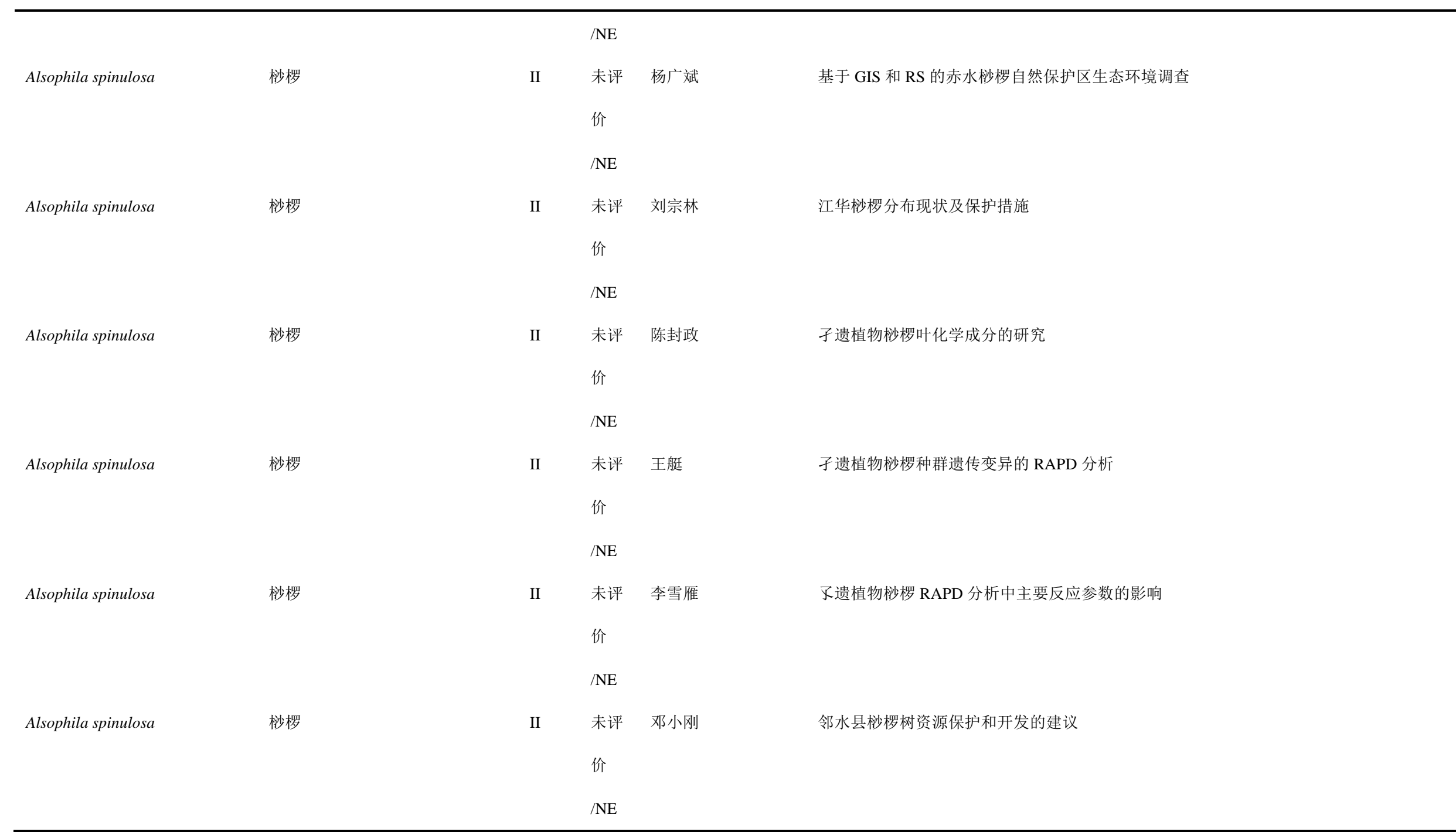


顾垒，闻丞，罗玫，王吴，吕植. 中国最受关注濒危物种保护现状快速评价的新方法探讨. 生物多样性，2015，23(5)：583-590. http://www. biodiversity-science. net/CN/article/downloadArticleFile. do?attachType=PDF\&id=10075

\begin{tabular}{|c|c|c|c|c|c|}
\hline Alsophila spinulosa & 杪椤 & II & $\begin{array}{l}\text { 未评 } \\
\text { 价 } \\
\text { /NE }\end{array}$ & 刘红丽 & 龙利叶和杪椤的化学成分及杪椤指纹图谱的研究 \\
\hline Alsophila spinulosa & 杪椤 & II & $\begin{array}{l}\text { 未评 } \\
\text { 价 } \\
\text { /NE }\end{array}$ & 娄金华 & 黔北杪椤特征特性及栽培技术 \\
\hline Alsophila spinulosa & 杪椤 & II & $\begin{array}{l}\text { 未评 } \\
\text { 价 } \\
\text { /NE }\end{array}$ & 李旭光 & 人为干扰对杪椤群落植物种间协变影响的研究 \\
\hline Alsophila spinulosa & 杪椤 & II & $\begin{array}{l}\text { 未评 } \\
\text { 价 } \\
\text { /NE }\end{array}$ & 郭治友 & 三都尧人山国家级森林公园杪椤种群分布新记录 \\
\hline Alsophila spinulosa & 杪椤 & II & $\begin{array}{l}\text { 未评 } \\
\text { 价 } \\
\text { /NE }\end{array}$ & 苏应娟 & 深圳塘朗山杪椤子遗种群的遗传分化研究 \\
\hline Alsophila spinulosa & 杪椤 & II & $\begin{array}{l}\text { 未评 } \\
\text { 价 } \\
\text { /NE }\end{array}$ & 张玲 & 深圳梧桐山风景区杪椤种群现状及其生态保护对策 \\
\hline Alsophila spinulosa & 杪椤 & II & 未评 & 施利祥 & 树型蕨类杪椤生物学特征初探 \\
\hline
\end{tabular}


顾垒，闻丞，罗玫，王吴，吕植. 中国最受关注濒危物种保护现状快速评价的新方法探讨. 生物多样性，2015，23(5)：583-590. http://www. biodiversity-science. net/CN/article/downloadArticleFile. do?attachType=PDF\&id=10075

\begin{tabular}{|c|c|c|c|c|c|}
\hline & & & 价 & & \\
\hline Alsophila spinulosa & 杪椤 & II & $\begin{array}{l}/ \mathrm{NE} \\
\text { 未评 } \\
\text { 价 }\end{array}$ & 张金伟 & 四川胖为县杪椤资源现状及利用对策 \\
\hline Alsophila spinulosa & 杪椤 & II & $\begin{array}{l}\text { /NE } \\
\text { 未评 } \\
\text { 价 }\end{array}$ & 周云娟 & 四川荣县金花乡杪椤自然保护区杪椤（Alsophila spinulosa）种群结构与动态分析 \\
\hline Alsophila spinulosa & 杪椤 & II & $\begin{array}{l}/ \mathrm{NE} \\
\text { 未评 } \\
\text { 价 }\end{array}$ & 敖光辉 & 四川省荣县杪椤自然保护区杪椤群落研究 \\
\hline Alsophila spinulosa & 杪椤 & II & $\begin{array}{l}/ \mathrm{NE} \\
\text { 未评 } \\
\text { 价 }\end{array}$ & 李媛 & 杪椤 atpB-rbcL 序列 2 种测序方法的比较分析 \\
\hline Alsophila spinulosa & 杪椤 & II & $\begin{array}{l}\text { /NE } \\
\text { 未评 } \\
\text { 价 }\end{array}$ & 周志琼 & 杪椤的生物学研究进展 \\
\hline Alsophila spinulosa & 杪椤 & II & $\begin{array}{l}/ \mathrm{NE} \\
\text { 未评 } \\
\text { 价 }\end{array}$ & 谢金兰 & 杪椤的特征特性及栽培技术 \\
\hline
\end{tabular}


顾垒，闻丞，罗玫，王吴，吕植. 中国最受关注濒危物种保护现状快速评价的新方法探讨. 生物多样性，2015，23(5)：583-590. http://www. biodiversity-science. net/CN/article/downloadArticleFile. do?attachType=PDF\&id=10075

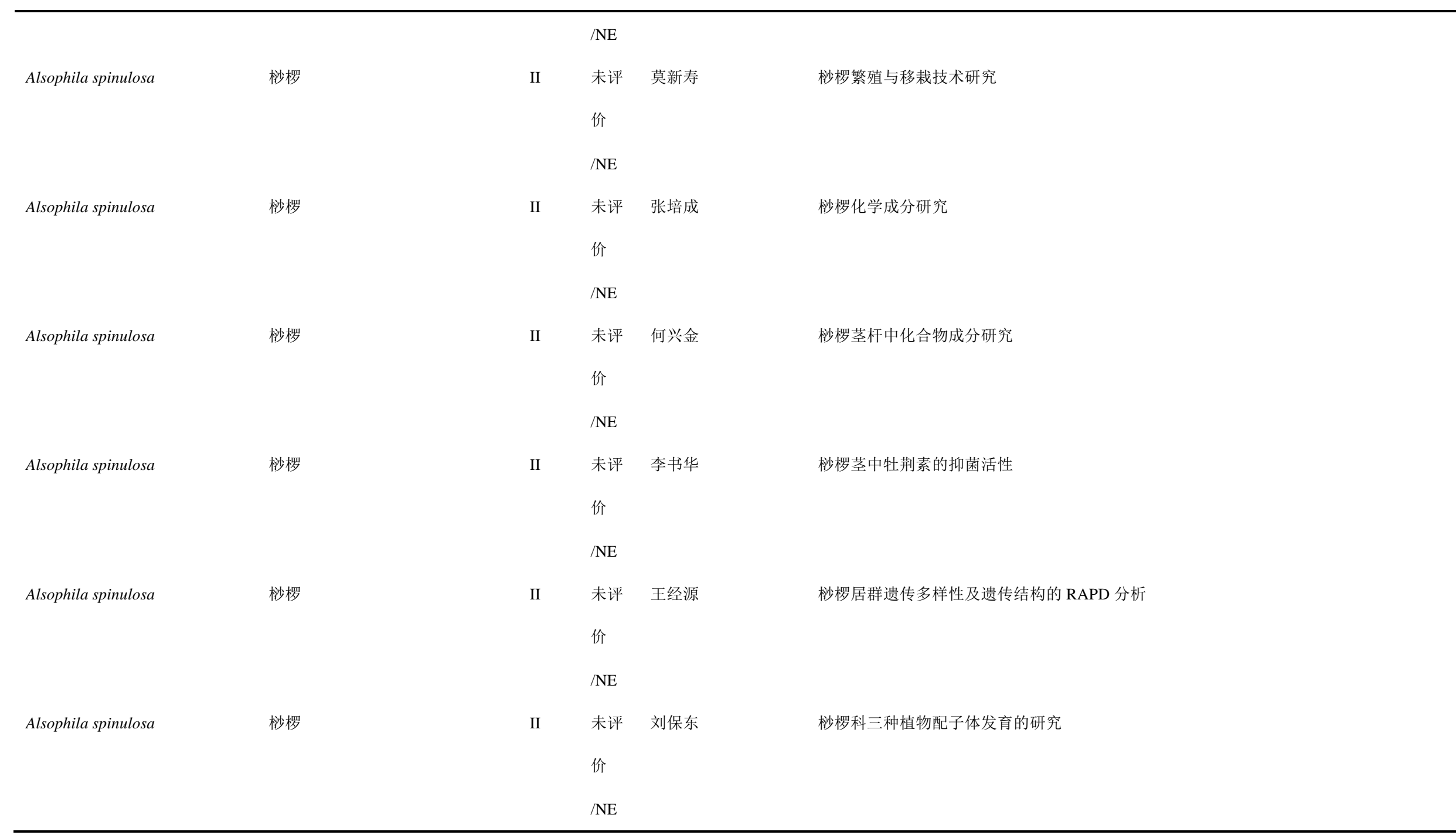


顾垒，闻丞，罗玫，王吴，吕植. 中国最受关注濒危物种保护现状快速评价的新方法探讨. 生物多样性，2015，23(5)：583-590. http://www. biodiversity-science. net/CN/article/downloadArticleFile. do?attachType=PDF\&id=10075

\begin{tabular}{|c|c|c|c|c|c|}
\hline Alsophila spinulosa & 杪椤 & II & $\begin{array}{l}\text { 未评 } \\
\text { 价 } \\
\text { /NE }\end{array}$ & 刘济明 & 桫椤群落的种内种间竞争研究 \\
\hline Alsophila spinulosa & 杪椤 & II & $\begin{array}{l}\text { 未评 } \\
\text { 价 } \\
\text { /NE }\end{array}$ & 张思玉 & 杪椤群落内主要乔木种群的种间联结性 \\
\hline Alsophila spinulosa & 杪椤 & II & $\begin{array}{l}\text { 未评 } \\
\text { 价 } \\
\text { /NE }\end{array}$ & 江洪 & 杪椤生态系统的土壤呼吸特征 \\
\hline Alsophila spinulosa & 杪椤 & II & $\begin{array}{l}\text { 未评 } \\
\text { 价 } \\
\text { /NE }\end{array}$ & 江洪 & 杪椤生态系统生物量与生产力 \\
\hline Alsophila spinulosa & 杪椤 & II & $\begin{array}{l}\text { 未评 } \\
\text { 价 } \\
\text { /NE }\end{array}$ & 秦建蓉 & 杪椤生物学研究现状分析 \\
\hline Alsophila spinulosa & 杪椤 & II & $\begin{array}{l}\text { 未评 } \\
\text { 价 } \\
\text { /NE }\end{array}$ & 王世清 & 杪椤叶的生药学研究 \\
\hline Alsophila spinulosa & 杪椤 & II & 未评 & 罗天虎 & 杪椤叶杆生长规律的研究 \\
\hline
\end{tabular}


顾垒，闻丞，罗玫，王吴，吕植. 中国最受关注濒危物种保护现状快速评价的新方法探讨. 生物多样性，2015，23(5)：583-590. http://www. biodiversity-science. net/CN/article/downloadArticleFile. do?attachType=PDF\&id=10075

\begin{tabular}{|c|c|c|c|c|c|}
\hline \multirow[b]{2}{*}{ Alsophila spinulosa } & \multirow[b]{2}{*}{ 帅椤 } & & \multicolumn{3}{|l|}{ 价 } \\
\hline & & II & $\begin{array}{l}\text { /NE } \\
\text { 未评 } \\
\text { 价 }\end{array}$ & 弓加文 & 杪椤叶和茎干抑菌活性初探 \\
\hline Alsophila spinulosa & 杪椤 & II & $\begin{array}{l}\text { /NE } \\
\text { 未评 } \\
\text { 价 }\end{array}$ & 邬秉左 & 杪椤引种栽培初报 \\
\hline Alsophila spinulosa & 杪椤 & II & $\begin{array}{l}/ \mathrm{NE} \\
\text { 未评 } \\
\text { 价 }\end{array}$ & 张祖荣 & 杪椤与荷叶铁线藓的孢子繁殖技术研究 \\
\hline Alsophila spinulosa & 杪椤 & II & $\begin{array}{l}\text { /NE } \\
\text { 未评 } \\
\text { 价 }\end{array}$ & 肖小君 & 杪椤原叶体增殖及幼狍子体形成试验 \\
\hline Alsophila spinulosa & 杪椤 & II & $\begin{array}{l}\text { /NE } \\
\text { 未评 } \\
\text { 价 }\end{array}$ & 江洪 & 杪椤植物群落区系进化保守性 \\
\hline Alsophila spinulosa & 杪椤 & II & $\begin{array}{l}/ \mathrm{NE} \\
\text { 未评 } \\
\text { 价 }\end{array}$ & 袁守良 & 杪椤最适宜生长因子初探 \\
\hline
\end{tabular}


顾垒，闻丞，罗玫，王吴，吕植. 中国最受关注濒危物种保护现状快速评价的新方法探讨. 生物多样性，2015，23(5)：583-590. http://www. biodiversity-science. net/CN/article/downloadArticleFile. do?attachType=PDF\&id=10075

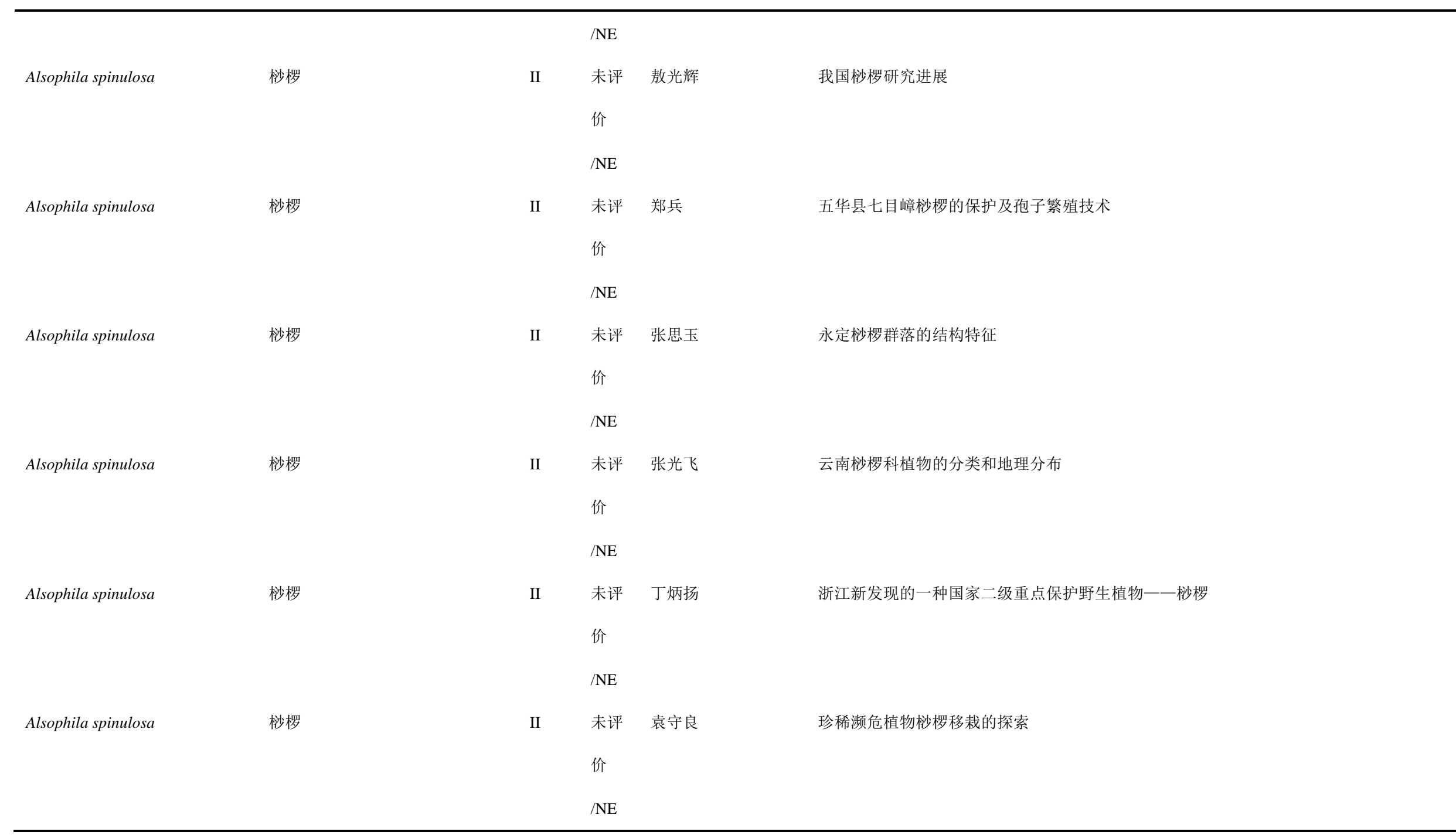


顾垒，闻丞，罗玫，王吴，吕植. 中国最受关注濒危物种保护现状快速评价的新方法探讨. 生物多样性，2015，23(5)：583-590. http://www. biodiversity-science. net/CN/article/downloadArticleFile. do?attachType=PDF\&id=10075

\begin{tabular}{|c|c|c|c|c|c|}
\hline Alsophila spinulosa & 杪椤 & II & $\begin{array}{l}\text { 未评 } \\
\text { 价 } \\
\text { /NE }\end{array}$ & 洪伟 & 珍稀濒危植物杪椤种群结构与动态研究 \\
\hline Alsophila spinulosa & 杪椤 & II & $\begin{array}{l}\text { 未评 } \\
\text { 价 } \\
\text { /NE }\end{array}$ & 洪伟 & 珍稀濒危植物杪椤种群生命过程及谱分析 \\
\hline Alsophila spinulosa & 杪椤 & II & $\begin{array}{l}\text { 未评 } \\
\text { 价 } \\
\text { /NE }\end{array}$ & 王全喜 & 中国蕨类植物狍子的形态 VII. 杪椤科 \\
\hline Alsophila spinulosa & 杪椤 & II & $\begin{array}{l}\text { 未评 } \\
\text { 价 } \\
\text { /NE }\end{array}$ & 王艇 & 中国杪椤科 6 种植物的 RAPD 分析 \\
\hline Alsophila spinulosa & 杪椤 & II & $\begin{array}{l}\text { 未评 } \\
\text { 价 } \\
\text { /NE }\end{array}$ & 王艇 & 中国杪椤科植物叶绿体 trnL 内含子和 trnL-trnF 基因间隔区序列的系统发育分析 \\
\hline Alsophila spinulosa & 杪椤 & II & $\begin{array}{l}\text { 未评 } \\
\text { 价 } \\
\text { /NE }\end{array}$ & 代正福 & 中国野生杪椤科植物种类及其生境类型 \\
\hline Alsophila spinulosa & 杪椤 & II & 未评 & 李旭光 & 重庆涪陵磨盘沟不同生境中杪椤群落的物种多样性研究 \\
\hline
\end{tabular}


顾垒，闻丞，罗玫，王吴，吕植. 中国最受关注濒危物种保护现状快速评价的新方法探讨. 生物多样性，2015，23(5)：583-590. http://www. biodiversity-science. net/CN/article/downloadArticleFile. do?attachType=PDF\&id=10075

$/ \mathrm{NE}$

Alsophila spinulosa

桫椤

杪椤

Alsophila spinulosa

杪椤

Alsophila spinulosa

Amentotaxus argotaenia

Amentotaxus argotaenia

穗花杉

穗花杉

未评

旭光

价

未评尚进

价

/NE

II 未评 李旭光

价

$/ \mathrm{NE}$

价

$/ \mathrm{NE}$

未列近危陈兆风

入 $/ \mathrm{NT}$

未列近危 Xue-Jun Ge

入 $/ \mathrm{NT}$

Amentotaxus argotaenia

未列近危朱柏芳
重庆涪陵磨盘沟杪椤群落特征的初步研究

重庆涪陵磨盘沟杪椤群落主要种群间联结性研究

重庆涪陵磨盘沟杪椤种群结构与分布格局研究

竹类入侵干扰对杪椤种群空间分布格局的影响

ABT1 号生根粉在穗花杉扞插生根试验中的应用

Low genetic diversity and significant population structuring in the relict Amentotaxus

argotaenia complex (Taxaceae) based on ISSR fingerprinting

RAPD 法研究穗花杉遗传多样性的反应条件优化 
顾垒，闻丞，罗玫，王吴，吕植. 中国最受关注濒危物种保护现状快速评价的新方法探讨. 生物多样性，2015，23(5)：583-590. http://www. biodiversity-science. net/CN/article/downloadArticleFile. do?attachType=PDF\&id=10075

\begin{tabular}{|c|c|c|c|c|c|}
\hline & & 入 & /NT & & \\
\hline \multirow[t]{2}{*}{ Amentotaxus argotaenia } & 穗花杉 & 未列 & 近危 & 周敏 & 濒危植物穗花杉生物学、生物普特性研究 \\
\hline & & 入 & /NT & & \\
\hline \multirow[t]{2}{*}{ Amentotaxus argotaenia } & 穗花杉 & 未列 & 近危 & 喻晓雁 & 濒危植物穗花杉组织培养研究及其园林应用可行性的探讨 \\
\hline & & 入 & /NT & & \\
\hline \multirow[t]{2}{*}{ Amentotaxus argotaenia } & 穗花杉 & 未列 & 近危 & 王艇 & 红豆杉科植物 RAPD 分析及其系统学意义 \\
\hline & & 入 & /NT & & \\
\hline \multirow[t]{2}{*}{ Amentotaxus argotaenia } & 穗花杉 & 未列 & 近危 & 廖文波 & 江西井冈山穗花杉群落及其物种多样性研究 \\
\hline & & 入 & /NT & & \\
\hline \multirow[t]{2}{*}{ Amentotaxus argotaenia } & 穗花杉 & 未列 & 近危 & 朱笃 & 江西穗花杉自然居群遗传多样性的 ISSR 分析 \\
\hline & & 入 & /NT & & \\
\hline \multirow[t]{2}{*}{ Amentotaxus argotaenia } & 穗花杉 & 未列 & 近危 & 何飞 & 江西宜丰县官山穗花杉群落特征初步研究 \\
\hline & & 入 & /NT & & \\
\hline \multirow[t]{2}{*}{ Amentotaxus argotaenia } & 穗花杉 & 未列 & 近危 & 贺利中 & 七溪岭自然保护区珍稀濒危植物穗花杉群落结构特征及物种多样性研究 \\
\hline & & 入 & /NT & & \\
\hline \multirow[t]{2}{*}{ Amentotaxus argotaenia } & 穗花杉 & 未列 & 近危 & 朱笃 & 穗花杉 ISSR 引物反应条件的优化与篮选 \\
\hline & & 入 & /NT & & \\
\hline \multirow[t]{2}{*}{ Amentotaxus argotaenia } & 穗花杉 & 未列 & 近危 & 刘本同 & 穗花杉扞插繁殖育苗技术研究 \\
\hline & & 入 & /NT & & \\
\hline
\end{tabular}


顾垒，闻丞，罗玫，王吴，吕植. 中国最受关注濒危物种保护现状快速评价的新方法探讨. 生物多样性，2015，23(5)：583-590. http://www. biodiversity-science. net/CN/article/downloadArticleFile. do?attachType=PDF\&id=10075

\begin{tabular}{|c|c|c|c|c|c|}
\hline \multirow[t]{2}{*}{ Amentotaxus argotaenia } & 穗花杉 & 未列 & 近危 & 刘克旺 & 穗花杉群落演替研究 \\
\hline & & 入 & /NT & & \\
\hline \multirow[t]{2}{*}{ Amentotaxus argotaenia } & 穗花杉 & 未列 & 近危 & 顾志建 & 穗花杉属的核形态及其系统位置的探讨 \\
\hline & & 入 & /NT & & \\
\hline \multirow[t]{2}{*}{ Amentotaxus argotaenia } & 穗花杉 & 未列 & 近危 & 刘克旺 & 穗花杉种群结种规律探讨 \\
\hline & & $\lambda$ & /NT & & \\
\hline \multirow[t]{2}{*}{ Amentotaxus argotaenia } & 穗花杉 & 未列 & 近危 & 刘宗林 & 穗花杉种子繁殖试验初报 \\
\hline & & 入 & $/ \mathrm{NT}$ & & \\
\hline \multirow[t]{2}{*}{ Amentotaxus argotaenia } & 穗花杉 & 未列 & 近危 & 喻晓雁 & 穗花杉组织培养初步研究 \\
\hline & & 入 & /NT & & \\
\hline \multirow[t]{2}{*}{ Amentotaxus argotaenia } & 穗花杉 & 未列 & 近危 & 喻晓雁 & 穗花杉组织培养初探 \\
\hline & & 入 & $/ \mathrm{NT}$ & & \\
\hline \multirow[t]{2}{*}{ Amentotaxus argotaenia } & 穗花杉 & 未列 & 近危 & 何飞 & 珍稀濒危植物穗花杉的研究进展 \\
\hline & & 入 & $/ \mathrm{NT}$ & & \\
\hline \multirow[t]{2}{*}{ Amentotaxus argotaenia } & 穗花杉 & 未列 & 近危 & 朱柏芳 & 中国特有濒危植物穗花杉的遗传多样性分析及其保育 \\
\hline & & 入 & /NT & & \\
\hline \multirow[t]{2}{*}{ Amentotaxus yunnanensis } & 云南穗花杉 & I & 易危 & Hong-Jie Zhang & Chemical Constituents from Amentotaxus yunnanensis and Torreya yunnanensis \\
\hline & & & $/ \mathrm{VU}$ & & \\
\hline Amentotaxus yunnanensis & 云南穗花杉 & I & 易危 & 王艇 & 红豆杉科植物 RAPD 分析及其系统学意义 \\
\hline
\end{tabular}


顾垒，闻丞，罗玫，王吴，吕植. 中国最受关注濒危物种保护现状快速评价的新方法探讨. 生物多样性，2015，23(5)：583-590. http://www biodiversity-science. net/CN/article/downloadArticleFile. do?attachType=PDF\&id=10075

\begin{tabular}{|c|c|c|c|c|c|}
\hline & & & /VU & & \\
\hline \multirow[t]{2}{*}{ Amentotaxus yunnanensis } & 云南穗花杉 & I & 易危 & 顾志建 & 穗花杉属的核形态及其系统位置的探讨 \\
\hline & & & /VU & & \\
\hline \multirow[t]{2}{*}{ Amentotaxus yunnanensis } & 云南穗花杉 & I & 易危 & 葛学军 & 云南穗花杉的遗传多样性研究 \\
\hline & & & /VU & & \\
\hline \multirow[t]{2}{*}{ Amitostigma hemipilioides } & 卵叶无柱兰 & II & 濒危 & Qin Yang & Genetic diversity and differentiation in the critically endangered orchid (Amitostigma \\
\hline & & & /EN & & hemipilioides): implications for conservation \\
\hline \multirow[t]{2}{*}{ Amitostigma hemipilioides } & 卵叶无柱兰 & II & 濒危 & 张方钢 & 浙江省种子植物新记录 \\
\hline & & & /EN & & \\
\hline \multirow[t]{2}{*}{ Amolops lifanensis } & 理县湍蛙 & 未列 & 近危 & 廖文波 & 理县湍蛙的年龄结构初探 \\
\hline & & 入 & $/ \mathrm{NT}$ & & \\
\hline \multirow[t]{2}{*}{ Amolops loloensis } & 棕点湍蛙 & 未列 & 易危 & Ren Lai & A novel algesic peptide derived from skin secretions of the frog Amolops loloensis \\
\hline & & 入 & /VU & & \\
\hline \multirow[t]{2}{*}{ Amolops loloensis } & 棕点湍蛙 & 未列 & 易危 & Ren Lai & A novel bradykinin-like peptide from skin secretions of rufous-spotted torrent frog,Amolops \\
\hline & & 入 & /VU & & loloensis \\
\hline \multirow[t]{2}{*}{ Amolops loloensis } & 棕点湍蛙 & 未列 & 易危 & Ren Lai & A novel family of antimicrobial peptides from the skin of Amolops loloensis \\
\hline & & 入 & /VU & & \\
\hline \multirow[t]{2}{*}{ Amolops loloensis } & 棕点湍蛙 & 未列 & 易危 & Ren Lai & Five novel antimicrobial peptides from skin secretions of the frog,Amolops loloensis \\
\hline & & 入 & /VU & & \\
\hline
\end{tabular}


顾垒，闻丞，罗玫，王吴，吕植. 中国最受关注濒危物种保护现状快速评价的新方法探讨. 生物多样性，2015，23(5)：583-590. http://www biodiversity-science. net/CN/article/downloadArticleFile. do?attachType=PDF\&id=10075

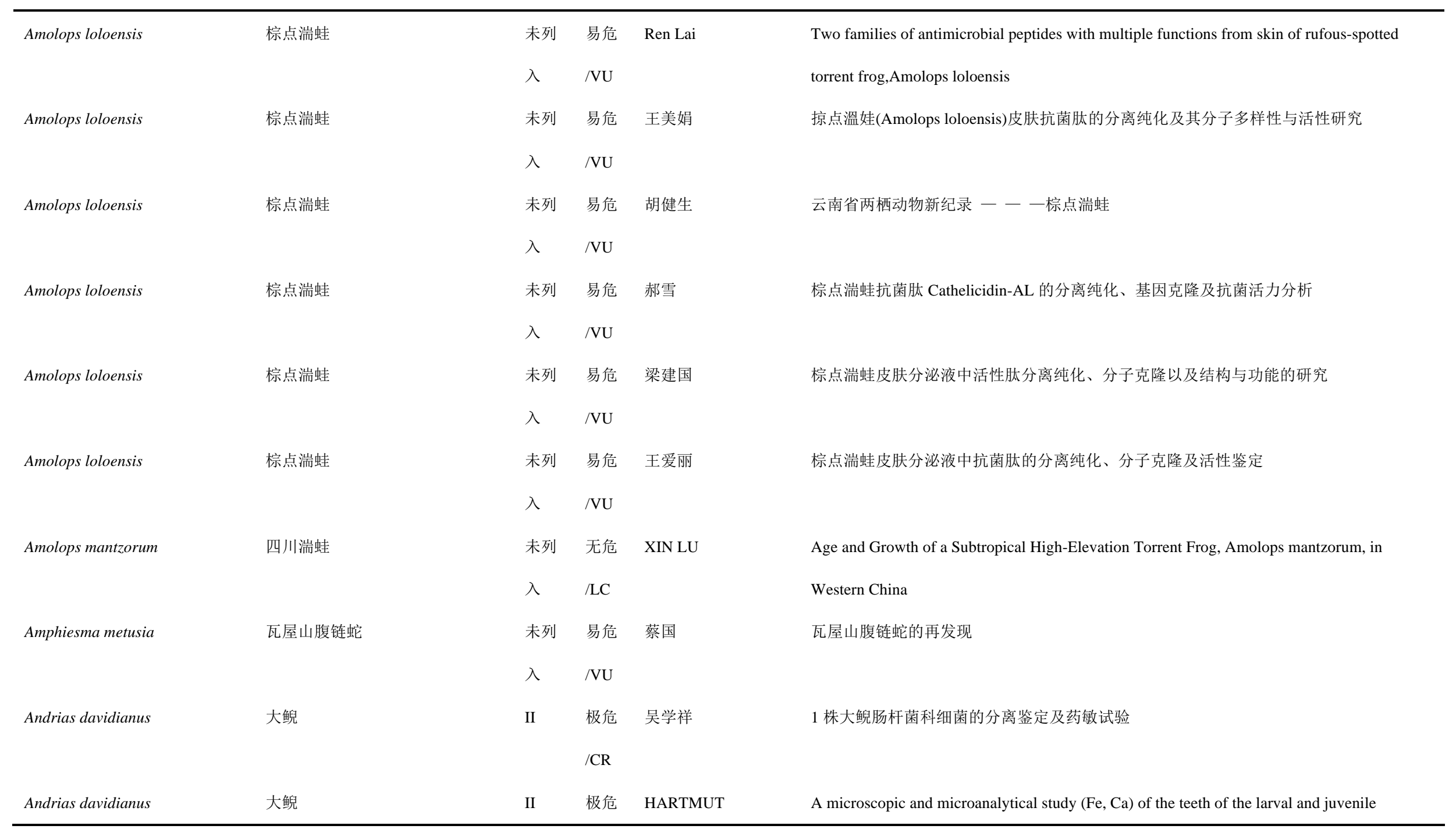


顾垒，闻丞，罗玫，王昊，吕植. 中国最受关注濒危物种保护现状快速评价的新方法探讨．生物多样性，2015，23(5)：583-590.

\begin{tabular}{|c|c|c|c|c|c|}
\hline & & & /CR & GREVEN & Ambystoma mexicanum (Amphibia: Urodela: Ambystomatidae) \\
\hline \multirow[t]{2}{*}{ Andrias davidianus } & 大鲵 & II & 极危 & CHEN Li-jing & Advances in research of Chinese giant salamander \\
\hline & & & $/ \mathrm{CR}$ & & \\
\hline \multirow[t]{2}{*}{ Andrias davidianus } & 大鲵 & II & 极危 & Egon Heiss & Biomechanics and hydrodynamics of prey capture in the Chinese giant salamander reveal a \\
\hline & & & /CR & & high-performance jaw-powered suction feeding mechanism \\
\hline \multirow[t]{2}{*}{ Andrias davidianus } & 大鲵 & II & 极危 & Zhou Z.Y. & Characterization of a ranavirus isolated from the Chinese giant salamander ( Andrias \\
\hline & & & /CR & & davidianus, Blanchard, 1871) in China \\
\hline \multirow[t]{2}{*}{ Andrias davidianus } & 大鲵 & II & 极危 & John J. Wiens & Digit reduction, body size, and paedomorphosis in salamanders \\
\hline & & & /CR & & \\
\hline \multirow[t]{2}{*}{ Andrias davidianus } & 大鲵 & II & 极危 & Liu Yun & Embryonic development and organogenesis of Chinese giant salamander , Andrias davidianus \\
\hline & & & /CR & & \\
\hline \multirow[t]{2}{*}{ Andrias davidianus } & 大鲵 & II & 极危 & Liu Yun & Embryonic development and organogenesis of Chinese giant salamander 。Andri 拄 s davidianus \\
\hline & & & /CR & & \\
\hline \multirow[t]{2}{*}{ Andrias davidianus } & 大鲵 & II & 极危 & Jianguo Wang & First report of two Balantidium species from the Chinese giant salamander, Andrias davidianus: \\
\hline & & & /CR & & Balantidium sinensis Nie 1935 and Balantidium andianusis n. sp. \\
\hline \multirow[t]{2}{*}{ Andrias davidianus } & 大鲵 & II & 极危 & ROBERT W. & Genetic variability among endangered Chinese giant salamanders, Andrias davidianus \\
\hline & & & /CR & MURPHY & \\
\hline \multirow[t]{2}{*}{ Andrias davidianus } & 大鲵 & II & 极危 & Zhongyuan Chen & Genome architecture changes and major gene variations of Andrias davidianus ranavirus \\
\hline & & & /CR & & (ADRV) \\
\hline
\end{tabular}


顾垒，闻丞，罗玫，王昊，吕植。中国最受关注濒危物种保护现状快速评价的新方法探讨．生物多样性，2015，23(5)：583-590.

http://www. biodiversity-science. net/CN/article/downloadArticleFile. do?attachType=PDF\&id=10075

\begin{tabular}{|c|c|c|c|c|c|}
\hline Andrias davidianus & 大鲵 & II & $\begin{array}{l}\text { 极危 } \\
\text { /CR }\end{array}$ & Haoran Lin & $\begin{array}{l}\text { Growth hormone and prolactin in Andrias davidianus: cDNA cloning, tissue distribution and } \\
\text { phylogenetic analysis }\end{array}$ \\
\hline Andrias davidianus & 大鲵 & II & 极危 & CHEN YouHua & $\begin{array}{l}\text { Habitat suitability modeling of amphibian species in southern and central China environmental } \\
\text { correlates and potential richness mapping }\end{array}$ \\
\hline Andrias davidianus & 大鲵 & II & $\begin{array}{l}\text { 极危 } \\
\text { /CR }\end{array}$ & Madelaine Böhme & $\begin{array}{l}\text { Habitat tracking, range dynamics and palaeoclimatic significance of Eurasian giant salamanders } \\
\text { (Cryptobranchidae)—indications for elevated Central Asian humidity during Cenozoic global } \\
\text { warm periods }\end{array}$ \\
\hline Andrias davidianus & 大鲵 & II & 极危 & XU Cun-shuan & Kinds and Activities of the Proteases of 4 Reproducitve Organs of Andrias davidianus \\
\hline Andrias davidianus & 大鲵 & II & $\begin{array}{l}\text { 极危 } \\
\text { /CR }\end{array}$ & Wentao Guo & $\begin{array}{l}\text { Major biological activities of the skin secretion of the Chinese giant salamander, Andrias } \\
\text { davidianus }\end{array}$ \\
\hline Andrias davidianus & 大鲵 & II & 极危 & Wu Yun & Mapping Amphibian Distribution at National Scale, Using Species Environmental Models \\
\hline Andrias davidianus & 大鲵 & II & 极危 & Gordon R. Ultsch & Metabolism, gas exchange, and acid-base balance of giant salamanders \\
\hline Andrias davidianus & 大鲵 & II & 极危 & ZHANG Yu-Hui & $\begin{array}{l}\text { Microstructure and ultrastructure of atretic follicles in the Chinese giant salamander Andrias } \\
\text { davidianus }\end{array}$ \\
\hline Andrias davidianus & 大鲵 & II & $\begin{array}{l}\text { 极危 } \\
\text { /CR }\end{array}$ & Yong WEI & $\begin{array}{l}\text { Molecular Characterization and Virulence Genes of Aeromonas hydrophila Isolated from the } \\
\text { Chinese Giant Salamander (Andrias davidianus) }\end{array}$ \\
\hline
\end{tabular}


顾垒，闻丞，罗玫，王昊，吕植. 中国最受关注濒危物种保护现状快速评价的新方法探讨．生物多样性，2015，23(5)：583-590. http://www. biodiversity-science. net/CN/article/downloadArticleFile. do?attachType=PDF\&id=10075

\begin{tabular}{|c|c|c|c|c|c|}
\hline Andrias davidianus & 大鲵 & II & $\begin{array}{l}\text { 极危 } \\
\text { /CR }\end{array}$ & $\begin{array}{l}\text { DAVID W. } \\
\text { WEISROCK }\end{array}$ & $\begin{array}{l}\text { Molecular phylogenetic reconstruction of the endemic Asian salamander family Hynobiidae } \\
\text { (Amphibia, Caudata) }\end{array}$ \\
\hline Andrias davidianus & 大鲵 & II & $\begin{array}{l}\text { 极危 } \\
\text { /CR }\end{array}$ & 王启军 & PIT 标记技术在幼鲵标记中的应用研究 \\
\hline Andrias davidianus & 大鲵 & II & $\begin{array}{l}\text { 极危 } \\
\text { /CR }\end{array}$ & LI Pei-qing & $\begin{array}{l}\text { Sex identification of Chinese giant salamander (Andrias davidianus) by Doppler B-ultrasound } \\
\text { method }\end{array}$ \\
\hline Andrias davidianus & 大鲵 & II & $\begin{array}{l}\text { 极危 } \\
\text { /CR }\end{array}$ & WANG Xiaoming & $\begin{array}{l}\text { Telemetric Data Reveals Ecolgoically Adaptive Behavior of Captive Raised Chinese Giant } \\
\text { Salamanders When Reintroduced into Their Native Habitat }\end{array}$ \\
\hline Andrias davidianus & 大鲵 & II & 极危 & Yue-Qin Chen & $\begin{array}{l}\text { The complete mitochondrial genome of the Chinese giant salamander, Andrias davidianus } \\
\text { (Amphibia: Caudata) }\end{array}$ \\
\hline Andrias davidianus & 大鲵 & II & $\begin{array}{l}\text { 极危 } \\
\text { /CR }\end{array}$ & Xiao-ming Wang & $\begin{array}{l}\text { The decline of the Chinese giant salamander Andrias davidianus and implications for its } \\
\text { conservation }\end{array}$ \\
\hline Andrias davidianus & 大鲵 & II & $\begin{array}{l}\text { 极危 } \\
\text { /CR }\end{array}$ & Wenzhi Liu & $\begin{array}{l}\text { The immunological responses and protection in Chinese giant salamander, Andrias davidianus } \\
\text { induced by the inactivated iridovirus }\end{array}$ \\
\hline Andrias davidianus & 大鲵 & II & $\begin{array}{l}\text { 极危 } \\
\text { /CR }\end{array}$ & BICAI ZHU & The karyotype of the caudate amphibian Andrias daidianus \\
\hline Andrias davidianus & 大鲵 & II & $\begin{array}{l}\text { 极危 } \\
\text { /CR }\end{array}$ & Amy K. Samuels & $\begin{array}{l}\text { Transcriptional and phylogenetic analysis of five complete ambystomatid salamander } \\
\text { mitochondrial genomes }\end{array}$ \\
\hline Andrias davidianus & 大鲵 & II & 极危 & Harold Heatwole & Ultrastructure of the Skin Mechanoreceptors of the Chinese Giant Salamander, Andrias \\
\hline
\end{tabular}


顾垒，闻丞，罗玫，王吴，吕植. 中国最受关注濒危物种保护现状快速评价的新方法探讨. 生物多样性，2015，23(5)：583-590. http://www biodiversity-science. net/CN/article/downloadArticleFile. do?attachType=PDF\&id=10075

\begin{tabular}{|c|c|c|c|c|c|}
\hline & & & /CR & & davidianus \\
\hline Andrias davidianus & 大鲵 & II & 极危 & William E. Evans & $\begin{array}{l}\text { Underwater sounds and associated behavior of the Chinese giant salamander Andrias } \\
\text { davidianus }\end{array}$ \\
\hline Andrias davidianus & 大鲵 & II & $\begin{array}{l}\text { 极危 } \\
\text { /CR }\end{array}$ & 王丕贤 & 保护大鲵的栖息环境 \\
\hline Andrias davidianus & 大鲵 & II & $\begin{array}{l}\text { 极危 } \\
\text { /CR }\end{array}$ & 许宝红 & 大鲵 2 个 Sox 基因 HMG-box 的克隆及分析 \\
\hline Andrias davidianus & 大鲵 & II & 极危 & 马跃岗 & 大鲵 2 个驯养群体 ITS2 遗传多样性分析 \\
\hline Andrias davidianus & 大鲵 & II & $\begin{array}{l}\text { 极危 } \\
\text { /CR }\end{array}$ & 许宝红 & 大鲵 Dmrt2 基因 cDNA 的克隆与表达分析 \\
\hline Andrias davidianus & 大鲵 & II & $\begin{array}{l}\text { 极危 } \\
\text { /CR }\end{array}$ & 杨辉 & 大鲵 MIF 基因和 FTH 基因的生物信息学分析与表达研究 \\
\hline Andrias davidianus & 大鲵 & II & $\begin{array}{l}\text { 极危 } \\
\text { /CR }\end{array}$ & 杨辉 & 大鲵 a 1 - 血红蛋白基因的生物信息学分析及组织表达研究 \\
\hline Andrias davidianus & 大鲵 & II & $\begin{array}{l}\text { 极危 } \\
\text { /CR }\end{array}$ & 王小明 & 大鲵保护生物学及其研究进展 \\
\hline Andrias davidianus & 大鲵 & II & $\begin{array}{l}\text { 极危 } \\
\text { /CR }\end{array}$ & 陈苏维 & 大鲵的繁殖生物学及其今后研究方向 \\
\hline
\end{tabular}


顾垒，闻丞，罗玫，王吴，吕植. 中国最受关注濒危物种保护现状快速评价的新方法探讨. 生物多样性，2015，23(5)：583-590. http://www. biodiversity-science. net/CN/article/downloadArticleFile. do?attachType=PDF\&id=10075

\begin{tabular}{|c|c|c|c|c|c|}
\hline Andrias davidianus & 大鲵 & II & $\begin{array}{l}\text { 极危 } \\
\text { /CR }\end{array}$ & 陈云祥 & 大鲵的分类、行为学及养殖研究综述 \\
\hline Andrias davidianus & 大鲵 & II & $\begin{array}{l}\text { 极危 } \\
\text { /CR }\end{array}$ & 黄松 & 大鲵的身体测量 \\
\hline Andrias davidianus & 大鲵 & II & $\begin{array}{l}\text { 极危 } \\
\text { /CR }\end{array}$ & 周海燕 & 大鲵的性腺发育规律及人工繁殖 \\
\hline Andrias davidianus & 大鲵 & II & $\begin{array}{l}\text { 极危 } \\
\text { /CR }\end{array}$ & 王文林 & 大鲵的自然繁殖习性调查 \\
\hline Andrias davidianus & 大鲵 & II & $\begin{array}{l}\text { 极危 } \\
\text { /CR }\end{array}$ & 李骏珉 & 大鲵的自然受精试验 \\
\hline Andrias davidianus & 大鲵 & II & $\begin{array}{l}\text { 极危 } \\
\text { /CR }\end{array}$ & 王文林 & 大鲵繁殖生物学初探 \\
\hline Andrias davidianus & 大鲵 & II & $\begin{array}{l}\text { 极危 } \\
\text { /CR }\end{array}$ & 贺智敏 & 大鲵肝脏组织定向 cDNA 文库的构建及鉴定 \\
\hline Andrias davidianus & 大鲵 & II & $\begin{array}{l}\text { 极危 } \\
\text { /CR }\end{array}$ & 贺智敏 & 大鲵肝脏组织定向 cDNA 文库的构建及鉴定 \\
\hline Andrias davidianus & 大鲵 & II & $\begin{array}{l}\text { 极危 } \\
\text { /CR }\end{array}$ & 刘进辉 & 大鲵精巢的解剖及组织形态结构研究 \\
\hline Andrias davidianus & 大鲵 & II & 极危 & 高峰 & 大鲵精液的离体保存 \\
\hline
\end{tabular}


顾垒，闻丞，罗玫，王吴，吕植. 中国最受关注濒危物种保护现状快速评价的新方法探讨. 生物多样性，2015，23(5)：583-590. http://www. biodiversity-science. net/CN/article/downloadArticleFile. do?attachType=PDF\&id=10075

\begin{tabular}{|c|c|c|c|c|c|}
\hline & & & /CR & & \\
\hline \multirow[t]{2}{*}{ Andrias davidianus } & 大鲵 & II & 极危 & 赵虎 & 大鲵精液离体保存的初步研究 \\
\hline & & & /CR & & \\
\hline \multirow[t]{2}{*}{ Andrias davidianus } & 大鲵 & II & 极危 & 刘篏 & 大鲵精子的超微结构研究 \\
\hline & & & /CR & & \\
\hline \multirow[t]{2}{*}{ Andrias davidianus } & 大鲵 & II & 极危 & 王海文 & 大鲵精子体外活力的初步观察 \\
\hline & & & /CR & & \\
\hline \multirow[t]{2}{*}{ Andrias davidianus } & 大鲵 & II & 极危 & 赖勤 & 大鲵卵巢发育和输卵管组织学结构的研究 \\
\hline & & & /CR & & \\
\hline \multirow[t]{2}{*}{ Andrias davidianus } & 大鲵 & II & 极危 & 邹忠义 & 大鲵尿液性激素水平季节变化及其与繁殖的关系 \\
\hline & & & /CR & & \\
\hline \multirow[t]{2}{*}{ Andrias davidianus } & 大鲵 & II & 极危 & 王利锋 & 大欿皮肤分泌液中抗菌肽的鉴定及生物活性研究 \\
\hline & & & /CR & & \\
\hline \multirow[t]{2}{*}{ Andrias davidianus } & 大鲵 & II & 极危 & 王小明 & 大鲵栖息地环境的初步研究 \\
\hline & & & /CR & & \\
\hline \multirow[t]{2}{*}{ Andrias davidianus } & 大鲵 & II & 极危 & 牟洪民 & 大鲵生物学研究的新进展 \\
\hline & & & /CR & & \\
\hline \multirow[t]{2}{*}{ Andrias davidianus } & 大鲵 & II & 极危 & 杨楚涁 & 大鲵生殖管道及精巢的发育组织学变化和人工繁殖技术的研究 \\
\hline & & & /CR & & \\
\hline
\end{tabular}


顾垒，闻丞，罗玫，王吴，吕植. 中国最受关注濒危物种保护现状快速评价的新方法探讨. 生物多样性，2015，23(5)：583-590. http://www. biodiversity-science. net/CN/article/downloadArticleFile. do?attachType=PDF\&id=10075

\begin{tabular}{|c|c|c|c|c|c|}
\hline Andrias davidianus & 大鲵 & II & $\begin{array}{l}\text { 极危 } \\
\text { /CR }\end{array}$ & 杨楚涁 & 大鲵输卵管的基本组织结构及其发育变化 \\
\hline Andrias davidianus & 大鲵 & II & $\begin{array}{l}\text { 极危 } \\
\text { /CR }\end{array}$ & 刘筠 & 大鲵输卵管组织学结构观察 \\
\hline Andrias davidianus & 大鲵 & II & $\begin{array}{l}\text { 极危 } \\
\text { /CR }\end{array}$ & 成芳 & 大鳃胃蛋白酶分离纯化及其性质的研究 \\
\hline Andrias davidianus & 大鲵 & II & $\begin{array}{l}\text { 极危 } \\
\text { /CR }\end{array}$ & 江建平 & 大鲵形态量度分析 \\
\hline Andrias davidianus & 大鲵 & II & $\begin{array}{l}\text { 极危 } \\
\text { /CR }\end{array}$ & 艾闽 & 大鲵胸腺素 $\beta-4$ 全长基因的分离与表达研究 \\
\hline Andrias davidianus & 大鲵 & II & $\begin{array}{l}\text { 极危 } \\
\text { /CR }\end{array}$ & 刘笏 & 大鲵雄性生殖系统的组织学和超微结构研究 \\
\hline Andrias davidianus & 大鲵 & II & $\begin{array}{l}\text { 极危 } \\
\text { /CR }\end{array}$ & 牛泽清 & 大鲵血清蛋白成分及其分子量的测定 \\
\hline Andrias davidianus & 大鲵 & II & $\begin{array}{l}\text { 极危 } \\
\text { /CR }\end{array}$ & 牛泽清 & 大鲵血细胞发生的初步研究 \\
\hline Andrias davidianus & 大鲵 & II & $\begin{array}{l}\text { 极危 } \\
\text { /CR }\end{array}$ & 肖汉兵 & 大鲵遗传多样性分析 \\
\hline Andrias davidianus & 大鲵 & II & 极危 & 郭文蹈 & 大鲵遗传多样性及皮肤附属物特性研究 \\
\hline
\end{tabular}


顾垒，闻丞，罗玫，王吴，吕植. 中国最受关注濒危物种保护现状快速评价的新方法探讨. 生物多样性，2015，23(5)：583-590. http://www. biodiversity-science. net/CN/article/downloadArticleFile. do?attachType=PDF\&id=10075

\begin{tabular}{|c|c|c|c|c|c|}
\hline & & & /CR & & \\
\hline \multirow[t]{2}{*}{ Andrias davidianus } & 大鲵 & II & 极危 & 潘鸿春 & 大鲵右眼隐于皮下一例 \\
\hline & & & /CR & & \\
\hline \multirow[t]{2}{*}{ Andrias davidianus } & 大鲵 & II & 极危 & 肯林森 & 大鲵脂肪组织分布及其理化特性 \\
\hline & & & /CR & & \\
\hline \multirow[t]{2}{*}{ Andrias davidianus } & 大鲵 & II & 极危 & 霍军 & 大鱿部分器官组织学观察 \\
\hline & & & /CR & & \\
\hline \multirow[t]{2}{*}{ Andrias davidianus } & 大鲵 & II & 极危 & 彭亮跃 & 低温和超低温保存对中国大鲵成熟精子的影响 \\
\hline & & & /CR & & \\
\hline \multirow[t]{2}{*}{ Andrias davidianus } & 大鲵 & II & 极危 & 戈婷婷 & 俄勒冈海岸河流的沿海幼鲵 (Dicamptodon tenebrosus )生存和生长的研究 \\
\hline & & & /CR & & \\
\hline \multirow[t]{2}{*}{ Andrias davidianus } & 大鲵 & II & 极危 & 徐文刚 & 繁殖前期大鲵的冲凉与求偶行为及 PAE 编码 \\
\hline & & & /CR & & \\
\hline \multirow[t]{2}{*}{ Andrias davidianus } & 大鲵 & II & 极危 & 徐文刚 & 繁殖前期中国大鲵雄性成体的冲凉行为及其意义 \\
\hline & & & /CR & & \\
\hline \multirow[t]{2}{*}{ Andrias davidianus } & 大鲵 & II & 极危 & 赵小强 & 甘肃秦州大鲵自然保护区生境调查研究意义 \\
\hline & & & /CR & & \\
\hline \multirow[t]{2}{*}{ Andrias davidianus } & 大鲵 & II & 极危 & 穆彪 & 贵定县岩下乡大鲵自然保护区气候生态资源研究 \\
\hline & & & /CR & & \\
\hline
\end{tabular}


顾垒，闻丞，罗玫，王吴，吕植. 中国最受关注濒危物种保护现状快速评价的新方法探讨. 生物多样性，2015，23(5)：583-590. http://www. biodiversity-science. net/CN/article/downloadArticleFile. do?attachType=PDF\&id=10075

\begin{tabular}{|c|c|c|c|c|c|}
\hline Andrias davidianus & 大鲵 & II & $\begin{array}{l}\text { 极危 } \\
\text { /CR }\end{array}$ & 朱玲 & 贵州省大鲵资源现状及其保护对策 \\
\hline Andrias davidianus & 大鲵 & II & $\begin{array}{l}\text { 极危 } \\
\text { /CR }\end{array}$ & 喻理飞 & 贵州岩下自然保护区的野生大鲵资源现状及历史动态 \\
\hline Andrias davidianus & 大鲵 & II & $\begin{array}{l}\text { 极危 } \\
\text { /CR }\end{array}$ & 粟海军 & 贵州岩下自然保护区的野生大鲵资源现状及历史动态 \\
\hline Andrias davidianus & 大鲵 & II & $\begin{array}{l}\text { 极危 } \\
\text { /CR }\end{array}$ & 郑和勋 & 河南省卢氏县大鲵种群生态学及生态适应特征研究 \\
\hline Andrias davidianus & 大鲵 & II & $\begin{array}{l}\text { 极危 } \\
\text { /CR }\end{array}$ & 吴方同 & 壶瓶山大鲵栖息地水环境因子的调查分析 \\
\hline Andrias davidianus & 大鲵 & II & $\begin{array}{l}\text { 极危 } \\
\text { /CR }\end{array}$ & 罗庆华 & 湖南张家界市大鲵资源调查 \\
\hline Andrias davidianus & 大鲵 & II & $\begin{array}{l}\text { 极危 } \\
\text { /CR }\end{array}$ & 黄立群 & 历山中国大鲵线粒体片段序列的测定及其遗传差异研究 \\
\hline Andrias davidianus & 大鲵 & II & $\begin{array}{l}\text { 极危 } \\
\text { /CR }\end{array}$ & 王小明 & 卢氏县大鲵种群年龄结构和性比的初步研究 \\
\hline Andrias davidianus & 大鲵 & II & $\begin{array}{l}\text { 极危 } \\
\text { /CR }\end{array}$ & 王小明 & 卢氏县大蜕资源变化和致危因素分析 \\
\hline Andrias davidianus & 大鲵 & II & 极危 & 王启军 & 秦岭黑河沙梁子野生大鲵出苗点生境调查 \\
\hline
\end{tabular}


顾垒，闻丞，罗玫，王吴，吕植. 中国最受关注濒危物种保护现状快速评价的新方法探讨. 生物多样性，2015，23(5)：583-590. http://www. biodiversity-science. net/CN/article/downloadArticleFile. do?attachType=PDF\&id=10075

\begin{tabular}{|c|c|c|c|c|c|}
\hline & & & /CR & & \\
\hline \multirow[t]{2}{*}{ Andrias davidianus } & 大鲵 & II & 极危 & 张红星 & 秦岭山区大鲵生态繁育及其生态环境保护的意义 \\
\hline & & & /CR & & \\
\hline \multirow[t]{2}{*}{ Andrias davidianus } & 大鲵 & II & 极危 & 张红星 & 秦岭山区大鲵生态学研究现状与保护利用技术应用 \\
\hline & & & /CR & & \\
\hline \multirow[t]{2}{*}{ Andrias davidianus } & 大鲵 & II & 极危 & 张红星 & 秦岭山区大鲵生物多样性可持续利用技术研究 \\
\hline & & & /CR & & \\
\hline \multirow[t]{2}{*}{ Andrias davidianus } & 大鲵 & II & 极危 & 罗庆华 & 桑植县大鲵资源调查 \\
\hline & & & /CR & & \\
\hline \multirow[t]{2}{*}{ Andrias davidianus } & 大鲵 & II & 极危 & 连晋 & 山西大鲵资源保护现状及对策 \\
\hline & & & /CR & & \\
\hline \multirow[t]{2}{*}{ Andrias davidianus } & 大鲵 & II & 极危 & 张建军 & 山西历山自然保护区 \\
\hline & & & /CR & & \\
\hline \multirow[t]{2}{*}{ Andrias davidianus } & 大鲵 & II & 极危 & 郭军 & 山西省野生大鲵资源现状及栖息地生境特征研究 \\
\hline & & & /CR & & \\
\hline \multirow[t]{2}{*}{ Andrias davidianus } & 大鲵 & II & 极危 & 刘爱华 & 陕西省大鲵资源保护及管理初探 \\
\hline & & & /CR & & \\
\hline \multirow[t]{2}{*}{ Andrias davidianus } & 大鲵 & II & 极危 & 王启军 & 陕西省太白县大鲵资源调查及其变动情况分析 \\
\hline & & & /CR & & \\
\hline
\end{tabular}


顾垒，闻丞，罗玫，王吴，吕植. 中国最受关注濒危物种保护现状快速评价的新方法探讨. 生物多样性，2015，23(5)：583-590. http://www biodiversity-science. net/CN/article/downloadArticleFile. do?attachType=PDF\&id=10075

\begin{tabular}{|c|c|c|c|c|c|}
\hline Andrias davidianus & 大鲵 & II & $\begin{array}{l}\text { 极危 } \\
\text { /CR }\end{array}$ & 王身立 & 四川省兴文县大鲵洞的大鲵种群中白化基因的频率 \\
\hline Andrias davidianus & 大鲵 & II & $\begin{array}{l}\text { 极危 } \\
\text { /CR }\end{array}$ & 李成 & 四川省兴文县大鲵种群与生态环境考察 \\
\hline Andrias davidianus & 大鲵 & II & $\begin{array}{l}\text { 极危 } \\
\text { /CR }\end{array}$ & 王海文 & 我国大鲵 Megalobatrachus davidianus (Blanchard) 研究现状与发展前景的探讨 \\
\hline Andrias davidianus & 大鲵 & II & $\begin{array}{l}\text { 极危 } \\
\text { /CR }\end{array}$ & 原居林 & 五种免疫相关酶在不同年龄组中国大鲵组织内的分布及活性比较研究 \\
\hline Andrias davidianus & 大鲵 & II & $\begin{array}{l}\text { 极危 } \\
\text { /CR }\end{array}$ & 杨瑞 & 岩下大鲵自然保护区不同植被及其涵水功能初探 \\
\hline Andrias davidianus & 大鲵 & II & $\begin{array}{l}\text { 极危 } \\
\text { /CR }\end{array}$ & 罗庆华 & 野生大鲵繁殖洞穴生态环境的初步研究 \\
\hline Andrias davidianus & 大鲵 & II & $\begin{array}{l}\text { 极危 } \\
\text { /CR }\end{array}$ & 肖汉兵 & 野生大鲵及其人工繁殖后代的遗传多样性分析 \\
\hline Andrias davidianus & 大鲵 & II & $\begin{array}{l}\text { 极危 } \\
\text { /CR }\end{array}$ & 肖汉兵 & 野生和养殖大鲵群体遗传多样性的微卫星分析 \\
\hline Andrias davidianus & 大鲵 & II & $\begin{array}{l}\text { 极危 } \\
\text { /CR }\end{array}$ & 朱必才 & 野生中国大鲵 Sox 基因的克隆与序列分析 \\
\hline Andrias davidianus & 大鲵 & II & 极危 & 刘鉴毅 & 野生中国大鲵与人工繁殖子一代雄性形态及精液特性的比较 \\
\hline
\end{tabular}


顾垒，闻丞，罗玫，王吴，吕植. 中国最受关注濒危物种保护现状快速评价的新方法探讨. 生物多样性，2015，23(5)：583-590. http://www biodiversity-science. net/CN/article/downloadArticleFile. do?attachType=PDF\&id=10075

\begin{tabular}{|c|c|c|c|c|c|}
\hline & & & /CR & & \\
\hline \multirow[t]{2}{*}{ Andrias davidianus } & 大鲵 & II & 极危 & 乔志刚 & 用生理的方法促使大鲵产卵的研究 \\
\hline & & & /CR & & \\
\hline \multirow[t]{2}{*}{ Andrias davidianus } & 大鲵 & II & 极危 & 罗庆华 & 张家界大鲵人工放流效果及其影响因素分析 \\
\hline & & & /CR & & \\
\hline \multirow[t]{2}{*}{ Andrias davidianus } & 大鲵 & II & 极危 & 罗庆华 & 张家界大鲵生境特征 \\
\hline & & & /CR & & \\
\hline \multirow[t]{2}{*}{ Andrias davidianus } & 大鲵 & II & 极危 & 罗庆华 & 张家界国家森林公园金鞭溪河段大鲵栖息地特征 \\
\hline & & & /CR & & \\
\hline \multirow[t]{2}{*}{ Andrias davidianus } & 大鲵 & II & 极危 & 罗庆华 & 张家界市大鲵资源保护・增殖现状与对策 \\
\hline & & & /CR & & \\
\hline \multirow[t]{2}{*}{ Andrias davidianus } & 大鲵 & II & 极危 & 刘筠 & 中国大鲵 (Andrias davidianus)的胚胎发育 \\
\hline & & & /CR & & \\
\hline \multirow[t]{2}{*}{ Andrias davidianus } & 大鲵 & II & 极危 & 徐存拴 & 中国大鲵 (Andrias davidianus) 7 种组织器官蛋白水解酶的种类和活性分析 \\
\hline & & & /CR & & \\
\hline \multirow[t]{2}{*}{ Andrias davidianus } & 大鲵 & II & 极危 & 肖亚梅 & 中国大鲵(Andrias davidianus)产卵期输卵管分泌特征及卵外胶膜研究 \\
\hline & & & /CR & & \\
\hline \multirow[t]{2}{*}{ Andrias davidianus } & 大鲵 & II & 极危 & 沈国民 & 中国大鲵(Andrias davidianus)二十四种组织器官的碱性磷酸酶 (AKP) 初步分析 \\
\hline & & & /CR & & \\
\hline
\end{tabular}


顾垒，闻丞，罗玫，王吴，吕植. 中国最受关注濒危物种保护现状快速评价的新方法探讨. 生物多样性，2015，23(5)：583-590. http://www biodiversity-science. net/CN/article/downloadArticleFile. do?attachType=PDF\&id=10075

\begin{tabular}{|c|c|c|c|c|c|}
\hline Andrias davidianus & 大鲵 & II & $\begin{array}{l}\text { 极危 } \\
\text { /CR }\end{array}$ & 杨丽萍 & 中国大鲵 5 个野生种群的 AFLP 分析 \\
\hline Andrias davidianus & 大鲵 & II & $\begin{array}{l}\text { 极危 } \\
\text { /CR }\end{array}$ & 崔树良, 章怀云 & 中国大鲵 Dm rt 基因 DM 结构域的克隆及序列分析 \\
\hline Andrias davidianus & 大鲵 & II & $\begin{array}{l}\text { 极危 } \\
\text { /CR }\end{array}$ & 徐丽娟 & 中国大鲵 Dmrt2 基因的克隆与表达 \\
\hline Andrias davidianus & 大鲵 & II & $\begin{array}{l}\text { 极危 } \\
\text { /CR }\end{array}$ & 吴宝林 & 中国大鲵 Sox HMG-box 区与 Dmrt DM 结构域的克隆及序列分析 \\
\hline Andrias davidianus & 大鲵 & II & $\begin{array}{l}\text { 极危 } \\
\text { /CR }\end{array}$ & 何青 & 中国大鲵 Sox2 和 Sox19 基因 cDNA 全长克隆及其组织表达分析 \\
\hline Andrias davidianus & 大鲵 & II & $\begin{array}{l}\text { 极危 } \\
\text { /CR }\end{array}$ & 肖真明 & 中国大鲵 Sox 基因的研究 \\
\hline Andrias davidianus & 大鲵 & II & $\begin{array}{l}\text { 极危 } \\
\text { /CR }\end{array}$ & 刘筠 & 中国大鲵不同组织同工酶的比较研究 \\
\hline Andrias davidianus & 大鲵 & II & $\begin{array}{l}\text { 极危 } \\
\text { /CR }\end{array}$ & 罗亚平 & 中国大鲵雌性生殖系统的解剖学和组织学研究 \\
\hline Andrias davidianus & 大鲵 & II & $\begin{array}{l}\text { 极危 } \\
\text { /CR }\end{array}$ & 王勤 & 中国大鲵促甲状腺激素受体的克隆及序列分析 \\
\hline Andrias davidianus & 大鲵 & II & 极危 & 梁刚 & 中国大鲵的活动节律及繁殖行为描记 \\
\hline
\end{tabular}


顾垒，闻丞，罗玫，王吴，吕植. 中国最受关注濒危物种保护现状快速评价的新方法探讨. 生物多样性，2015，23(5)：583-590. http://www. biodiversity-science. net/CN/article/downloadArticleFile. do?attachType=PDF\&id=10075

\begin{tabular}{|c|c|c|c|c|c|}
\hline & & & /CR & & \\
\hline \multirow[t]{2}{*}{ Andrias davidianus } & 大鲵 & II & 极危 & 于虎虎 & 中国大鲵繁殖前期夜间活动节律及其与环境因子的关系 \\
\hline & & & /CR & & \\
\hline \multirow[t]{2}{*}{ Andrias davidianus } & 大鲵 & II & 极危 & 罗庆华 & 中国大鲵繁殖生物学研究进展 \\
\hline & & & /CR & & \\
\hline \multirow[t]{2}{*}{ Andrias davidianus } & 大鲵 & II & 极危 & 方展强 & 中国大鲵肺脏的显微和超微结构 \\
\hline & & & /CR & & \\
\hline \multirow[t]{2}{*}{ Andrias davidianus } & 大鲵 & II & 极危 & 朱必才 & 中国大鲵核型特征研究 \\
\hline & & & /CR & & \\
\hline \multirow[t]{2}{*}{ Andrias davidianus } & 大鲵 & II & 极危 & 常小娟 & 中国大鲵呼吸器官胚后发育的形态学研究 \\
\hline & & & /CR & & \\
\hline \multirow[t]{2}{*}{ Andrias davidianus } & 大鲵 & II & 极危 & 程红 & 中国大鲵机械感受器的超微结构 \\
\hline & & & /CR & & \\
\hline \multirow[t]{2}{*}{ Andrias davidianus } & 大鲵 & II & 极危 & 彭亮跃 & 中国大鲵基础生物学及其进化的研究 \\
\hline & & & /CR & & \\
\hline \multirow[t]{2}{*}{ Andrias davidianus } & 大鲵 & II & 极危 & 林浩然 & 中国大鲵脑 $\mathrm{cDNA}$ 文库构建及促甲状腺激素 $\beta$ 亚基基因 $\mathrm{cDNA}$ 的克隆和序列分析 \\
\hline & & & /CR & & \\
\hline \multirow[t]{2}{*}{ Andrias davidianus } & 大鲵 & II & 极危 & 姚一涁 & 中国大鲵胚胎发育形态特性比较研究 \\
\hline & & & /CR & & \\
\hline
\end{tabular}


顾垒，闻丞，罗玫，王吴，吕植. 中国最受关注濒危物种保护现状快速评价的新方法探讨. 生物多样性，2015，23(5)：583-590. http://www biodiversity-science. net/CN/article/downloadArticleFile. do?attachType=PDF\&id=10075

\begin{tabular}{|c|c|c|c|c|c|}
\hline Andrias davidianus & 大鲵 & II & $\begin{array}{l}\text { 极危 } \\
\text { /CR }\end{array}$ & 张蕾 & 中国大鲵肾与生殖腺胚后发育的形态学研究 \\
\hline Andrias davidianus & 大鲵 & II & $\begin{array}{l}\text { 极危 } \\
\text { /CR }\end{array}$ & 刘巧巧 & 中国大鲵肾脏与生殖腺发生的解剖学和组织学观察 \\
\hline Andrias davidianus & 大鲵 & II & $\begin{array}{l}\text { 极危 } \\
\text { /CR }\end{array}$ & 朱必才 & 中国大鲵生殖激素的初步研究 \\
\hline Andrias davidianus & 大鲵 & II & $\begin{array}{l}\text { 极危 } \\
\text { /CR }\end{array}$ & 郭永灿 & 中国大鲵生殖生理研究进展 \\
\hline Andrias davidianus & 大鲵 & II & $\begin{array}{l}\text { 极危 } \\
\text { /CR }\end{array}$ & 郭利伟 & 中国大鲵生殖腺胚后发育的形态学观察 \\
\hline Andrias davidianus & 大鲵 & II & $\begin{array}{l}\text { 极危 } \\
\text { /CR }\end{array}$ & 王小明 & 中国大鲵四种群的遗传结构和地理分化 \\
\hline Andrias davidianus & 大鲵 & II & $\begin{array}{l}\text { 极危 } \\
\text { /CR }\end{array}$ & 李宁 & 中国大鲵胃肠道的胚后发育及其 5-HT 细胞的发生 \\
\hline Andrias davidianus & 大鲵 & II & $\begin{array}{l}\text { 极危 } \\
\text { /CR }\end{array}$ & 李宁 & 中国大鲵胃肠道胚后发育的解剖学与组织学观察 \\
\hline Andrias davidianus & 大鲵 & II & $\begin{array}{l}\text { 极危 } \\
\text { /CR }\end{array}$ & 张丽萍 & 中国大鲵胃肠道胚后发育的组织学观察 \\
\hline Andrias davidianus & 大鲵 & II & 极危 & 王小明 & 中国大鲵五地理种群 Cyt b 基因全序列及其遗传关系分析 \\
\hline
\end{tabular}


顾垒，闻丞，罗玫，王吴，吕植. 中国最受关注濒危物种保护现状快速评价的新方法探讨. 生物多样性，2015，23(5)：583-590. http://www. biodiversity-science. net/CN/article/downloadArticleFile. do?attachType=PDF\&id=10075

\begin{tabular}{|c|c|c|c|c|c|}
\hline & & & /CR & & \\
\hline \multirow[t]{2}{*}{ Andrias davidianus } & 大鲵 & II & 极危 & 徐存拴 & 中国大鲵消化系统 13 种器官的蛋白水解酶种类和活性分析 \\
\hline & & & /CR & & \\
\hline \multirow[t]{2}{*}{ Andrias davidianus } & 大鲵 & II & 极危 & 王尚洪 & 中国大鲵小肠和胰脏的超微结构观察 \\
\hline & & & /CR & & \\
\hline \multirow[t]{2}{*}{ Andrias davidianus } & 大鲵 & II & 极危 & 黄华苑 & 中国大鲵心脏及主动脉干的解剖学研究 \\
\hline & & & /CR & & \\
\hline \multirow[t]{2}{*}{ Andrias davidianus } & 大鲵 & II & 极危 & 何晓 & 中国大鲵嗅觉系统和眼球胚后发育的组织学观察 \\
\hline & & & /CR & & \\
\hline \multirow[t]{2}{*}{ Andrias davidianus } & 大鲵 & II & 极危 & 黄华苑 & 中国大鲵循环系统的解剖与组织学研究 \\
\hline & & & /CR & & \\
\hline \multirow[t]{2}{*}{ Andrias davidianus } & 大鲵 & II & 极危 & 朱必才 & 中国大鲵研究进展 \\
\hline & & & /CR & & \\
\hline \multirow[t]{2}{*}{ Andrias davidianus } & 大鲵 & II & 极危 & & 中国大鲵资源现状及保护遗传学研究进展 \\
\hline & & & /CR & & \\
\hline \multirow[t]{2}{*}{ Andrias davidianus } & 大鲵 & II & 极危 & 文立华 & 中国大鲵自然资源现状及管理对策 \\
\hline & & & /CR & & \\
\hline \multirow[t]{2}{*}{ Andrias davidianus } & 大鲵 & II & 极危 & 罗亚平 & 中国雄性大鲵生殖系统的解剖学和组织学研究 \\
\hline & & & /CR & & \\
\hline
\end{tabular}


顾垒，闻丞，罗玫，王吴，吕植. 中国最受关注濒危物种保护现状快速评价的新方法探讨. 生物多样性，2015，23(5)：583-590. http://www. biodiversity-science. net/CN/article/downloadArticleFile. do?attachType=PDF\&id=10075

\begin{tabular}{|c|c|c|c|c|c|}
\hline Andrias davidianus & 大鲵 & II & $\begin{array}{l}\text { 极危 } \\
\text { /CR }\end{array}$ & 李学英 & 煮沸裂解法快速提取大鲵 DNA \\
\hline Annamocarya sinensis & 潒核桃 & II & $\begin{array}{l}\text { 濒危 } \\
\text { /EN }\end{array}$ & Ying.Yue. Li & Conservation genetics of Annamocarya sinensis (Dode) Leroy, an endangered endemic species \\
\hline Annamocarya sinensis & 喙核桃 & II & $\begin{array}{l}\text { 濒危 } \\
\text { /EN }\end{array}$ & Ying.Yue. Li & Conservation genetics of Annamocarya sinensis (Dode) Leroy, an endangered endemic species \\
\hline Annamocarya sinensis & 剝核桃 & II & $\begin{array}{l}\text { 濒危 } \\
\text { /EN }\end{array}$ & Ying.Yue. Li & Conservation genetics of Annamocarya sinensis (Dode) Leroy, an endangered endemic species \\
\hline Annamocarya sinensis & 剝核桃 & II & $\begin{array}{l}\text { 濒危 } \\
\text { /EN }\end{array}$ & Ying.Yue. Li & Conservation genetics of Annamocarya sinensis (Dode) Leroy, an endangered endemic species \\
\hline Annamocarya sinensis & 喙核桃 & II & $\begin{array}{l}\text { 濒危 } \\
\text { /EN }\end{array}$ & Ying.Yue. Li & Conservation genetics of Annamocarya sinensis (Dode) Leroy, an endangered endemic species \\
\hline Annamocarya sinensis & 剝核桃 & II & $\begin{array}{l}\text { 濒危 } \\
\text { /EN }\end{array}$ & Ying.Yue. Li & Conservation genetics of Annamocarya sinensis (Dode) Leroy, an endangered endemic species \\
\hline Annamocarya sinensis & 㖨核桃 & II & $\begin{array}{l}\text { 濒危 } \\
\text { /EN }\end{array}$ & 龙秀琴 & 贵州珍稀树种 - 喙核桃 \\
\hline Annamocarya sinensis & 剝核桃 & II & $\begin{array}{l}\text { 濒危 } \\
\text { /EN }\end{array}$ & 张智勇 & 核桃 EST-SSR 引物开发及其在嚎核桃保育遗传学中的应用 \\
\hline Annamocarya sinensis & 剝核桃 & II & 濒危 & 江莎 & 胡桃科植物研究进展 \\
\hline
\end{tabular}


顾垒，闻丞，罗玫，王吴，吕植. 中国最受关注濒危物种保护现状快速评价的新方法探讨. 生物多样性，2015，23(5)：583-590. http://www biodiversity-science. net/CN/article/downloadArticleFile. do?attachType=PDF\&id=10075

Anser cygnoides

Anser cygnoides

Anser cygnoides

Anser cygnoides

Anser cygnoides

Anser cygnoides

Anser cygnoides

Anser cygnoides

Anser erythropus
鸿雁

鸿雁

鸿雁

鸿雁

鸿雁
未列易危

入 $/ \mathrm{VU}$

未列易危

入 $/ \mathrm{VU}$

未列易危

入 $/ \mathrm{VU}$

未列易危

入 $/ \mathrm{VU}$

未列易危

入 $/ \mathrm{VU}$

未列易危

入 $/ \mathrm{VU}$

未列易危

入 $/ \mathrm{VU}$

未列易危

入 $/ \mathrm{VU}$

未列易危

入 $/ \mathrm{VU}$
cDNA cloning, genomic structure and expression analysis of the goose (Anser cygnoides)

\section{MHC class I gene}

Changing distribution and abundance of Swan Goose Anser cygnoides in the Yangtze River

floodplain_the likely loss of a very important wintering site

Feeding Ecology of Two Wintering Geese Species at Poyang Lake, China

Functional analysis and induction of four novel goose (Anser cygnoides) avian $\beta$-defensins in

response to salmonella enteritidis infection

Patterns of variation of the major histocompatibility complex class IIB loci in Chinese goose

(Anser Cygnoides)

Preliminary observations of diurnal feeding patterns of Swan Geese Anser cygnoides using two different habitats at Province, China Shengjin Lake, Anhui

鸿雁繁殖生态的初步研究

内蒙古呼伦贝尔东部地区春季鸿雁巢址选择研究

Changes in the distribution and abundance of wintering Lesser White-fronted Geese Anser

erythropus in eastern China 
顾垒，闻丞，罗玫，王吴，吕植. 中国最受关注濒危物种保护现状快速评价的新方法探讨. 生物多样性，2015，23(5)：583-590. http://www biodiversity-science. net/CN/article/downloadArticleFile. do?attachType=PDF\&id=10075

\begin{tabular}{|c|c|c|c|c|c|}
\hline \multirow[t]{2}{*}{ Anser erythropus } & 小白额雁 & 未列 & 易危 & & Food constraints explain the restricted distribution of wintering Lesser White-fronted Geese \\
\hline & & 入 & /VU & & Anser erythropus in China \\
\hline \multirow[t]{2}{*}{ Anser erythropus } & 小白额雁 & 未列 & 易危 & & Lesser White-fronted Goose survey at the East Dongting and Poyang lakes in China, February \\
\hline & & 入 & $/ \mathrm{VU}$ & & 1999 \\
\hline \multirow[t]{2}{*}{ Aonyx cinereus } & 小爪水獭 & II & 易危 & 李玉春 & 海南岛兽类名录整理 \\
\hline & & & $/ \mathrm{VU}$ & & \\
\hline \multirow[t]{2}{*}{ Aonyx cinereus } & 小爪水獭 & II & 易危 & 胡锦毒 & 黄石坳保护区的兽类初步研究 \\
\hline & & & /VU & & \\
\hline \multirow[t]{2}{*}{ Aonyx cinereus } & 小爪水獭 & II & 易危 & 李玉春 & 水獭的研究与保护现状 \\
\hline & & & /VU & & \\
\hline \multirow[t]{2}{*}{ Aonyx cinereus } & 小爪水獭 & II & 易危 & 刘少英 & 四川海子山自然保护区大中型兽类多样性调查 \\
\hline & & & /VU & & \\
\hline \multirow[t]{2}{*}{ Aonyx cinereus } & 小爪水獭 & II & 易危 & 王铁 & 四川卡莎湖自然保护区兽类资源调查 \\
\hline & & & /VU & & \\
\hline \multirow[t]{2}{*}{ Aonyx cinereus } & 小爪水獭 & II & 易危 & 杨道德 & 西藏珠穆朗玛峰国家级自然保护区哺乳动物区系及其垂直变化 \\
\hline & & & /VU & & \\
\hline \multirow[t]{2}{*}{ Aonyx cinereus } & 小爪水獭 & II & 易危 & 雷伟 & 小型水电站建设对海南岛河流生态系统及水獭的影响 \\
\hline & & & $/ \mathrm{VU}$ & & \\
\hline Arborophila ardens & 海南山麅鸪 & I & 易危 & & Conservation status of endemic Galliformes on Hainan Island, China \\
\hline
\end{tabular}


顾垒，闻丞，罗玫，王吴，吕植. 中国最受关注濒危物种保护现状快速评价的新方法探讨. 生物多样性，2015，23(5)：583-590. http://www. biodiversity-science. net/CN/article/downloadArticleFile. do?attachType=PDF\&id=10075

\begin{tabular}{|c|c|c|c|c|c|}
\hline & & & /VU & & \\
\hline \multirow[t]{2}{*}{ Arborophila ardens } & 海南山麅鸪 & I & 易危 & & Coupling Genetic and Species Distribution Models to Examine the Response of the Hainan \\
\hline & & & /VU & & Partridge (Arborophila ardens) to Late Quaternary Climate \\
\hline \multirow[t]{2}{*}{ Arborophila ardens } & 海南山麅鸪 & I & 易危 & & Female Crowing and Differential Responses to Simulated Conspecific Intrusion in Male and \\
\hline & & & /VU & & Female Hainan Partridge (Arborophila ardens) \\
\hline \multirow[t]{2}{*}{ Arborophila ardens } & 海南山麅鸪 & I & 易危 & & 海南霸王岭自然保护区海南山麅鸪的种群数量 \\
\hline & & & /VU & & \\
\hline \multirow[t]{2}{*}{ Arborophila gingica } & 白眉山麅鸪 & 未列 & 近危 & 杨 岗 & 白眉山麅鸪冬季受食地选择 \\
\hline & & 入 & $/ \mathrm{NT}$ & & \\
\hline \multirow[t]{2}{*}{ Arborophila gingica } & 白眉山麅鸪 & 未列 & 近危 & 周 放 & 白眉山麅鸪一新亚种 \\
\hline & & 入 & /NT & & \\
\hline \multirow[t]{2}{*}{ Arborophila gingica } & 白眉山麅鸪 & 未列 & 近危 & 粟通萍 & 广西猫儿山地区鸟类组成及垂直分布格局 \\
\hline & & 入 & /NT & & \\
\hline \multirow[t]{2}{*}{ Arborophila gingica } & 白眉山麅鸪 & 未列 & 近危 & 郑伟成 & 红外相机技术监测九龙山国家级自然保护区鸟兽多样性 \\
\hline & & 入 & /NT & & \\
\hline \multirow[t]{2}{*}{ Arborophila gingica } & 白眉山麅鸪 & 未列 & 近危 & 黄晓凤 & 江西齐云山自然保护区鸟类区系与多样性分析 \\
\hline & & 入 & /NT & & \\
\hline \multirow[t]{2}{*}{ Arborophila gingica } & 白眉山麅鸪 & 未列 & 近危 & 程松林 & 江西武夷山国家级自然保护区鸟类多样性调查 \\
\hline & & 入 & $/ \mathrm{NT}$ & & \\
\hline
\end{tabular}


顾垒，闻丞，罗玫，王吴，吕植. 中国最受关注濒危物种保护现状快速评价的新方法探讨. 生物多样性，2015，23(5)：583-590. http://www. biodiversity-science. net/CN/article/downloadArticleFile. do?attachType=PDF\&id=10075

\begin{tabular}{|c|c|c|c|c|c|}
\hline \multirow[t]{2}{*}{ Arborophila gingica } & 白眉山麅鸪 & 未列 & 近危 & 程松林 & 江西武夷山雉科鸟类研究初报 \\
\hline & & 入 & /NT & & \\
\hline \multirow{2}{*}{ Arborophila gingica } & 白眉山麅鸪 & 未列 & 近危 & 程松林 & 江西武夷山自然保护区的雉类资源及其保护 \\
\hline & & 入 & /NT & & \\
\hline \multirow[t]{2}{*}{ Arborophila rufipectus } & 四川山麅鸪 & II & 极危 & 季婷 & 老君山自然保护区四川山麅鸪繁殖巢址记述 \\
\hline & & & $/ \mathrm{CR}$ & & \\
\hline \multirow[t]{2}{*}{ Arborophila rufipectus } & 四川山麅鸪 & II & 极危 & 廖文波 & 老君山自然保护区四川山鹧鸪非繁殖期对栖息地的利用 \\
\hline & & & /CR & & \\
\hline \multirow[t]{2}{*}{ Arborophila rufipectus } & 四川山府鸪 & II & 极危 & 刘金波 & 麻咪泽自然保护区的动植物资源及保护 \\
\hline & & & /CR & & \\
\hline \multirow[t]{2}{*}{ Arborophila rufipectus } & 四川山麻鸪 & II & 极危 & 陈本平 & 四川老君山国家级自然保护区的鸟类资源概况 \\
\hline & & & $/ \mathrm{CR}$ & & \\
\hline \multirow[t]{2}{*}{ Arborophila rufipectus } & 四川山麅鸪 & II & 极危 & 杨杰 & 四川老君山自然保护区不同生境鸟类多样性研究 \\
\hline & & & $/ \mathrm{CR}$ & & \\
\hline \multirow[t]{2}{*}{ Arborophila rufipectus } & 四川山麻鸪 & II & 极危 & 陆钢 & 四川老君山自然保护区的鸡形目种群密度研究 \\
\hline & & & $/ \mathrm{CR}$ & & \\
\hline \multirow[t]{2}{*}{ Arborophila rufipectus } & 四川山府鸪 & II & 极危 & 李仁贵 & 四川麻咪泽自然保护区雉类资源调查 \\
\hline & & & /CR & & \\
\hline Arborophila rufipectus & 四川山麅鸪 & II & 极危 & 李国金 & 四川马鞍山自然保护区保护管理浅析 \\
\hline
\end{tabular}


顾垒，闻丞，罗玫，王吴，吕植. 中国最受关注濒危物种保护现状快速评价的新方法探讨. 生物多样性，2015，23(5)：583-590. http://www. biodiversity-science. net/CN/article/downloadArticleFile. do?attachType=PDF\&id=10075

\begin{tabular}{|c|c|c|c|c|c|}
\hline & & & /CR & & \\
\hline \multirow[t]{2}{*}{ Arborophila rufipectus } & 四川山麅鸪 & II & 极危 & 廖文波 & 四川山鹤鸪繁殖期的鸣声行为特征 \\
\hline & & & /CR & & \\
\hline \multirow[t]{2}{*}{ Arborophila rufipectus } & 四川山麅鸪 & II & 极危 & 廖文波 & 四川山府鸪生态习性研究进展 \\
\hline & & & /CR & & \\
\hline \multirow[t]{2}{*}{ Arborophila rufipectus } & 四川山麅鸪 & II & 极危 & 廖文波 & 四川山捬鸪育雉期幼体鸣声行为 \\
\hline & & & /CR & & \\
\hline \multirow[t]{2}{*}{ Arborophila rufipectus } & 四川山麅鸪 & II & 极危 & 唐平 & 四川省盐边县鸟类多样性调查 \\
\hline & & & /CR & & \\
\hline \multirow[t]{2}{*}{ Arborophila rufipectus } & 四川山麅鸪 & II & 极危 & 何芬奇 & 再谈四川山麅鸪的模式产地 \\
\hline & & & /CR & & \\
\hline \multirow[t]{2}{*}{ Aristolochia cucurbitoides } & 葫芦叶马兒铃 & 未列 & 易危 & 邱运平 & 葫芦叶马兒铃化学成分的分离 \\
\hline & & 入 & /VU & & \\
\hline \multirow[t]{2}{*}{ Artocarpus hypargyreus } & 白桂木 & 未列 & 易危 & 马祥庆 & 白桂木的种群结构和空间分布格局研究 \\
\hline & & 入 & /VU & & \\
\hline \multirow[t]{2}{*}{ Artocarpus hypargyreus } & 白桂木 & 未列 & 易危 & 范繁荣 & 白桂木生殖物候和繁育系统研究 \\
\hline & & 入 & /VU & & \\
\hline \multirow[t]{2}{*}{ Artocarpus hypargyreus } & 白桂木 & 未列 & 易危 & 黄云鹏 & 濒危植物白桂木 土壤种子库的特征及动态 \\
\hline & & 入 & /VU & & \\
\hline
\end{tabular}


顾垒，闻丞，罗玫，王吴，吕植. 中国最受关注濒危物种保护现状快速评价的新方法探讨. 生物多样性，2015，23(5)：583-590. http://www. biodiversity-science. net/CN/article/downloadArticleFile. do?attachType=PDF\&id=10075

\begin{tabular}{|c|c|c|c|c|c|}
\hline \multirow[t]{2}{*}{ Artocarpus hypargyreus } & 白桂木 & 未列 & 易危 & 范繁荣 & 濒危植物白桂木的濒危机制与迁地保育研究 \\
\hline & & 入 & $/ \mathrm{VU}$ & & \\
\hline \multirow[t]{2}{*}{ Artocarpus hypargyreus } & 白桂木 & 未列 & 易危 & 范繁荣 & 濒危植物白桂木的遗传多样性研究 \\
\hline & & 入 & $/ \mathrm{VU}$ & & \\
\hline \multirow[t]{2}{*}{ Artocarpus hypargyreus } & 白桂木 & 未列 & 易危 & 范繁荣 & 濒危植物白桂木种子繁殖苗年生长规律研究 \\
\hline & & $\lambda$ & $/ \mathrm{VU}$ & & \\
\hline \multirow[t]{2}{*}{ Artocarpus hypargyreus } & 白桂木 & 未列 & 易危 & 沈琼桃 & 濒危植物白桂木种子萌发生理研究 \\
\hline & & 入 & $/ \mathrm{VU}$ & & \\
\hline \multirow[t]{2}{*}{ Artocarpus hypargyreus } & 白桂木 & 未列 & 易危 & 黎国运 & 濒危植物白桂木种子育苗技术研究 \\
\hline & & 入 & $/ \mathrm{VU}$ & & \\
\hline \multirow[t]{2}{*}{ Artocarpus hypargyreus } & 白桂木 & 未列 & 易危 & 黎国运 & 濒危植物白桂木组培育苗技术研究 \\
\hline & & $\lambda$ & $/ \mathrm{VU}$ & & \\
\hline \multirow[t]{2}{*}{ Artocarpus hypargyreus } & 白桂木 & 未列 & 易危 & 马祥庆 & 运用种间联结分析濒危植物白桂木在群落中的地位 \\
\hline & & 入 & $/ \mathrm{VU}$ & & \\
\hline \multirow[t]{2}{*}{ Asarum crispulatum } & 皱花细辛 & 未列 & 易危 & 胡世俊 & 濒危植物坡花细辛的组织培养 \\
\hline & & 入 & $/ \mathrm{VU}$ & & \\
\hline \multirow[t]{2}{*}{ Asarum maximum } & 大花细辛 & II & 易危 & 杨波 & 大花细辛的组织培养 \\
\hline & & & $/ \mathrm{VU}$ & & \\
\hline Asarum maximum & 大花细辛 & II & 易危 & 陈春亮 & 大花细辛挥发油化学成分 GC-MS 分析 \\
\hline
\end{tabular}


顾垒，闻丞，罗玫，王吴，吕植. 中国最受关注濒危物种保护现状快速评价的新方法探讨. 生物多样性，2015，23(5)：583-590. http://www. biodiversity-science. net/CN/article/downloadArticleFile. do?attachType=PDF\&id=10075

\begin{tabular}{|c|c|c|c|c|c|}
\hline & & & /VU & & \\
\hline \multirow[t]{2}{*}{ Asarum maximum } & 大花细辛 & II & 易危 & 王璇 & 大叶马蹄香根的化学成分研究 \\
\hline & & & $/ \mathrm{VU}$ & & \\
\hline \multirow[t]{2}{*}{ Asarum maximum } & 大花细辛 & II & 易危 & 王璇 & 大叶马蹄香根中的黄酮类成分 \\
\hline & & & $/ \mathrm{VU}$ & & \\
\hline \multirow[t]{2}{*}{ Asarum maximum } & 大花细辛 & II & 易危 & 董力 & 细辛属植物资源开发应用 \\
\hline & & & /VU & & \\
\hline \multirow[t]{2}{*}{ Asio flammeus } & 短耳鸮 & II & 无危 & 王 霞 & 短耳鸮种群数量调查 \\
\hline & & & $/ \mathrm{LC}$ & & \\
\hline \multirow[t]{2}{*}{ Asio flammeus } & 短耳鸮 & II & 无危 & 江建国 & 鄂西野三河自然保护区鸟类资源调查报告 \\
\hline & & & $/ \mathrm{LC}$ & & \\
\hline \multirow[t]{2}{*}{ Asio flammeus } & 短耳鸮 & II & 无危 & 陆 舟 & 广西鸟类新纪录_短耳鸮 \\
\hline & & & $/ \mathrm{LC}$ & & \\
\hline \multirow[t]{2}{*}{ Asio flammeus } & 短耳鸮 & II & 无危 & 李晓娟 & 南充高坪机场短耳鸮越冬期的食性分析和习性观察 \\
\hline & & & $/ \mathrm{LC}$ & & \\
\hline \multirow[t]{2}{*}{ Asio flammeus } & 短耳鸮 & II & 无危 & 郭相亿 & 牛姆林自然保护区野生动物资源现状及保护对策 \\
\hline & & & $/ \mathrm{LC}$ & & \\
\hline \multirow[t]{2}{*}{ Asio flammeus } & 短耳鸮 & II & 无危 & 田振环 & 图牧吉国家级自然保护区鸟类资源 \\
\hline & & & /LC & & \\
\hline
\end{tabular}


顾垒，闻丞，罗玫，王吴，吕植. 中国最受关注濒危物种保护现状快速评价的新方法探讨. 生物多样性，2015，23(5)：583-590. http://www. biodiversity-science. net/CN/article/downloadArticleFile. do?attachType=PDF\&id=10075

\begin{tabular}{|c|c|c|c|c|c|}
\hline Asio otus & 长耳鸮 & II & $\begin{array}{l}\text { 无危 } \\
\text { /LC }\end{array}$ & 袁 梨 & 北京市越冬长耳鸮食物中的蝙蝠成分 \\
\hline Asio otus & 长耳鸮 & II & $\begin{array}{l}\text { 无危 } \\
\text { /LC }\end{array}$ & 鲍伟东 & 北京市越冬长耳鸮食物中鼠类成分调查 \\
\hline Asio otus & 长耳鸮 & II & $\begin{array}{l}\text { 无危 } \\
\text { /LC }\end{array}$ & 张雨嘉 & 不同栖居地和越冬时期长耳鸮的食物组成 \\
\hline Asio otus & 长耳鸮 & II & $\begin{array}{l}\text { 无危 } \\
\text { /LC }\end{array}$ & 江建国 & 鄂西野三河自然保护区鸟类资源调查报告 \\
\hline Asio otus & 长耳鸮 & II & $\begin{array}{l}\text { 无危 } \\
\text { /LC }\end{array}$ & 李元刚 & 宁夏鸣翠湖国家湿地公园鸟类群落组成及多样性分析 \\
\hline Asio otus & 长耳鸮 & II & $\begin{array}{l}\text { 无危 } \\
\text { /LC }\end{array}$ & 汪 洋 & 乌鲁木齐市区越冬期长耳鸮的食性分析 \\
\hline Asio otus & 长耳鸮 & II & $\begin{array}{l}\text { 无危 } \\
\text { /LC }\end{array}$ & 郝 映 春 & 阳圪台林场范围长耳鸮种群数量调查 \\
\hline Athene noctua & 纵纹腹小鸮 & II & $\begin{array}{l}\text { 无危 } \\
\text { /LC }\end{array}$ & 赵忠俊 & 阿夏自然保护区鸟类资源现状及保护策略 \\
\hline Athene noctua & 纵纹腹小鸮 & II & $\begin{array}{l}\text { 无危 } \\
\text { /LC }\end{array}$ & 陈 卫 & 北京糜鹿苑脊椎动物调查报告 \\
\hline Athene noctua & 纵纹腹小鸮 & II & 无危 & 代雪玲 & 敦煌阳关国家级自然保护区生物多样性及保护对策分析 \\
\hline
\end{tabular}


顾垒，闻丞，罗玫，王吴，吕植. 中国最受关注濒危物种保护现状快速评价的新方法探讨. 生物多样性，2015，23(5)：583-590. http://www. biodiversity-science. net/CN/article/downloadArticleFile. do?attachType=PDF\&id=10075

\begin{tabular}{|c|c|c|c|c|c|}
\hline & & & $/ \mathrm{LC}$ & & \\
\hline \multirow[t]{2}{*}{ Athene noctua } & 纵纹腹小鸮 & II & 无危 & 牟迈 & 敦煌阳关自然保护区鸟类多样性调查及分析 \\
\hline & & & $/ \mathrm{LC}$ & & \\
\hline \multirow[t]{2}{*}{ Athene noctua } & 纵纹腹小鸮 & II & 无危 & 姚积生 & 甘肃安南坝野骆驼国家级自然保护区野骆驼现状及其保护对策 \\
\hline & & & $/ \mathrm{LC}$ & & \\
\hline \multirow[t]{2}{*}{ Athene noctua } & 纵纹腹小鸮 & II & 无危 & 赵 伟 & 甘肃民勤治沙站纵纹腹小鸮食性的季节变化 \\
\hline & & & $/ \mathrm{LC}$ & & \\
\hline \multirow[t]{2}{*}{ Athene noctua } & 纵纹腹小鸮 & II & 无危 & 吉木斯 & 哈腾套海国家级自然保护区野生动物区系调查研究 \\
\hline & & & $/ \mathrm{LC}$ & & \\
\hline \multirow[t]{2}{*}{ Athene noctua } & 纵纹腹小鸮 & II & 无危 & 张 波 & 河北省昌黎县城北外环至碣石山脚下鸟类初步调查 \\
\hline & & & $/ \mathrm{LC}$ & & \\
\hline \multirow[t]{2}{*}{ Athene noctua } & 纵纹腹小鸮 & II & 无危 & 牛俊英 & 河南黄河湿地国家级自然保护区鸟类多样性及动态变化的研究 \\
\hline & & & $/ \mathrm{LC}$ & & \\
\hline \multirow[t]{2}{*}{ Athene noctua } & 纵纹腹小鸮 & II & 无危 & 牛俊英 & 河南黄河湿地国家级自然保护区鸟类资源调查 \\
\hline & & & $/ \mathrm{LC}$ & & \\
\hline \multirow[t]{2}{*}{ Athene nосtua } & 纵纹腹小鸮 & II & 无危 & 朱良艳 & 湖北野三河自然保护区功能区划研究 \\
\hline & & & /LC & & \\
\hline \multirow[t]{2}{*}{ Athene noctua } & 纵纹腹小鸮 & II & 无危 & 龚大洁 & 荒漠地区鸟类群落结构及多样性分析_以金塔县为例 \\
\hline & & & /LC & & \\
\hline
\end{tabular}


顾垒，闻丞，罗玫，王吴，吕植. 中国最受关注濒危物种保护现状快速评价的新方法探讨. 生物多样性，2015，23(5)：583-590. http://www. biodiversity-science. net/CN/article/downloadArticleFile. do?attachType=PDF\&id=10075

\begin{tabular}{|c|c|c|c|c|c|}
\hline Athene noctua & 纵纹腹小鸮 & II & $\begin{array}{l}\text { 无危 } \\
\text { /LC }\end{array}$ & 侯英才 & 黄河源头约古宗列湿地保护现状及思考 \\
\hline Athene noctua & 纵纹腹小鸮 & II & $\begin{array}{l}\text { 无危 } \\
\text { /LC }\end{array}$ & 赵格日乐图 & 内蒙古达春湖国家级自然保护区鸟类群落结构和动态研究 \\
\hline Athene noctua & 纵纹腹小鸮 & II & $\begin{array}{l}\text { 无危 } \\
\text { /LC }\end{array}$ & 那顺得力格尔 & 内蒙古赛罕乌拉自然保护区冬季鸟类多样性调查 \\
\hline Athene noctua & 纵纹腹小鸮 & II & $\begin{array}{l}\text { 无危 } \\
\text { /LC }\end{array}$ & 李 敏 & 内蒙古乌海民航机场鸟类多样性与鸟撞防范 \\
\hline Athene noctua & 纵纹腹小鸮 & II & $\begin{array}{l}\text { 无危 } \\
\text { /LC }\end{array}$ & 杜天奎 & 宁夏大学校园鸟类群落组成及多样性研究 \\
\hline Athene noctua & 纵纹腹小鸮 & II & $\begin{array}{l}\text { 无危 } \\
\text { /LC }\end{array}$ & 徐怀寿 & 宁夏中卫沙坡头国家级自然保护区重点保护类群落结构及其季节动态的调查研究 \\
\hline Athene noctua & 纵纹腹小鸮 & II & $\begin{array}{l}\text { 无危 } \\
\text { /LC }\end{array}$ & 张 阳 & 平河梁自然保护区夏季鸟类及其群落结构 \\
\hline Athene noctua & 纵纹腹小鸮 & II & $\begin{array}{l}\text { 无危 } \\
\text { /LC }\end{array}$ & 任月恒 & 山东农业大学南校区校园鸟类多样性初步研究 \\
\hline Athene noctua & 纵纹腹小鸮 & II & $\begin{array}{l}\text { 无危 } \\
\text { /LC }\end{array}$ & 郝映红 & 山西庞泉沟保护区三种鸮的繁殖生态特性研究 \\
\hline Athene noctua & 纵纹腹小鸮 & II & 无危 & 吴逸群 & 陕西黄河湿地夏季鸟类资源调查 \\
\hline
\end{tabular}


顾垒，闻丞，罗玫，王吴，吕植. 中国最受关注濒危物种保护现状快速评价的新方法探讨. 生物多样性，2015，23(5)：583-590. http://www. biodiversity-science. net/CN/article/downloadArticleFile. do?attachType=PDF\&id=10075

\begin{tabular}{|c|c|c|c|c|c|}
\hline & & & $/ \mathrm{LC}$ & & \\
\hline \multirow[t]{2}{*}{ Athene noctua } & 纵纹腹小鸮 & II & 无危 & 梁金花 & 试论扶余自然保护区野生动物资源及保护对策 \\
\hline & & & $/ \mathrm{LC}$ & & \\
\hline \multirow[t]{2}{*}{ Athene noctua } & 纵纹腹小鸮 & II & 无危 & 张 君 & 四川东阳沟自然保护区鸟类区系初步调查 \\
\hline & & & $/ \mathrm{LC}$ & & \\
\hline \multirow[t]{2}{*}{ Athene noctua } & 纵纹腹小鸮 & II & 无危 & 符建荣 & 四川海子山自然保护区鸟类资源及区系 \\
\hline & & & $/ \mathrm{LC}$ & & \\
\hline \multirow[t]{2}{*}{ Athene noctua } & 纵纹腹小鸮 & II & 无危 & 陈顺德 & 四川壤塘县绰斯甲河段鸟类资源初步调查及区系分析 \\
\hline & & & $/ \mathrm{LC}$ & & \\
\hline \multirow[t]{2}{*}{ Athene noctua } & 纵纹腹小鸮 & II & 无危 & 符建荣 & 四川长沙贡玛自然保护区的鸟类资源 \\
\hline & & & $/ \mathrm{LC}$ & & \\
\hline \multirow[t]{2}{*}{ Athene noctua } & 纵纹腹小鸮 & II & 无危 & 田振环 & 图牧吉国家级自然保护区鸟类资源 \\
\hline & & & $/ \mathrm{LC}$ & & \\
\hline \multirow[t]{2}{*}{ Athene noctua } & 纵纹腹小鸮 & II & 无危 & 夏亚军 & 雾灵山动物垂直分布 \\
\hline & & & $/ \mathrm{LC}$ & & \\
\hline \multirow[t]{2}{*}{ Athene nосtua } & 纵纹腹小鸮 & II & 无危 & 葛岩芬 & 榆阳国际机场鸟类调查及防范建议初探 \\
\hline & & & $/ \mathrm{LC}$ & & \\
\hline \multirow[t]{2}{*}{ Aythya baeri } & 青头潜鸭 & 未列 & 极危 & 马艳菊 & 广西北仑河口国家级自然保护区秋冬季水鸟调查 \\
\hline & & 入 & /CR & & \\
\hline
\end{tabular}


顾垒，闻丞，罗玫，王吴，吕植. 中国最受关注濒危物种保护现状快速评价的新方法探讨. 生物多样性，2015，23(5)：583-590. http://www. biodiversity-science. net/CN/article/downloadArticleFile. do?attachType=PDF\&id=10075

\begin{tabular}{|c|c|c|c|c|c|}
\hline \multirow[t]{2}{*}{ Aythya baeri } & 青头潜鸭 & 未列 & 极危 & 涂业苟 & 鄱阳湖区域越冬雁鸭类分布与数量 \\
\hline & & 入 & $/ \mathrm{CR}$ & & \\
\hline \multirow[t]{2}{*}{ Aythya baeri } & 青头潜鸭 & 未列 & 极危 & 何冰 & 陕西黄河湿地鸟类资源调查分析与研究 \\
\hline & & 入 & $/ \mathrm{CR}$ & & \\
\hline \multirow[t]{2}{*}{ Aythya baeri } & 青头潜鸭 & 未列 & 极危 & 巩会生 & 陕西秦岭及大巴山地区的鸟类资源调查 \\
\hline & & 入 & $/ \mathrm{CR}$ & & \\
\hline \multirow[t]{2}{*}{ Aythya baeri } & 青头潜鸭 & 未列 & 极危 & 沙剑斌 & 扎龙湿地游禽类数量变动及原因分析 \\
\hline & & 入 & $/ \mathrm{CR}$ & & \\
\hline \multirow[t]{2}{*}{ Azemiops feae } & 白头蛏 & 未列 & 无危 & 龚大洁 & 保护古老珍稀蛇类一一白头蛏 \\
\hline & & 入 & $/ \mathrm{LC}$ & & \\
\hline \multirow[t]{2}{*}{ Azemiops feae } & 白头蛏 & 未列 & 无危 & 罗键 & 广东发现白头蝰及其分布现状 \\
\hline & & 入 & $/ \mathrm{LC}$ & & \\
\hline \multirow[t]{2}{*}{ Azemiops feae } & 白头蛏 & 未列 & 无危 & 傅悦 & 湖北恩施白头蝰的发现及蛇类概况 \\
\hline & & 入 & $/ \mathrm{LC}$ & & \\
\hline \multirow[t]{2}{*}{ Azemiops feae } & 白头蛏 & 未列 & 无危 & 向明喜 & 湖北省发现蛇类新纪录一一白头蛏 \\
\hline & & 入 & $/ \mathrm{LC}$ & & \\
\hline \multirow[t]{3}{*}{ Bambusicola thoracica } & 灰胸竹鸡 & 未列 & 数据 & 江建国 & 鄂西野三河自然保护区鸟类资源调查报告 \\
\hline & & 入 & 不足 & & \\
\hline & & & $/ \mathrm{DD}$ & & \\
\hline
\end{tabular}


顾垒，闻丞，罗玫，王吴，吕植. 中国最受关注濒危物种保护现状快速评价的新方法探讨. 生物多样性，2015，23(5)：583-590. http://www. biodiversity-science. net/CN/article/downloadArticleFile. do?attachType=PDF\&id=10075

\begin{tabular}{|c|c|c|c|c|c|}
\hline \multirow[t]{2}{*}{ Bambusicola thoracica } & 灰胸竹鸡 & 未列 & 数据 & 王德良 & 高望界自然保护区鸟类多样性研究和资源评价 \\
\hline & & 入 & $\begin{array}{l}\text { 不足 } \\
\text { /DD }\end{array}$ & & \\
\hline \multirow[t]{3}{*}{ Bambusicola thoracica } & 灰胸竹鸡 & 未列 & 数据 & 郭新亮 & 贵州宽阔水自然保护区 3 种雉科鸟类的种群繁殖密度 \\
\hline & & 入 & 不足 & & \\
\hline & & & $/ \mathrm{DD}$ & & \\
\hline \multirow[t]{3}{*}{ Bambusicola thoracica } & 灰胸竹鸡 & 未列 & 数据 & 熊志斌 & 贵州茂兰自然保护区的雉类资源及其保护 \\
\hline & & 入 & 不足 & & \\
\hline & & & $/ \mathrm{DD}$ & & \\
\hline \multirow[t]{3}{*}{ Bambusicola thoracica } & 灰胸竹鸡 & 未列 & 数据 & 罗祖奎 & 贵州省云台山林下鸟类捕获与雾网放置场所的关系 \\
\hline & & 入 & 不足 & & \\
\hline & & & $/ \mathrm{DD}$ & & \\
\hline \multirow[t]{3}{*}{ Bambusicola thoracica } & 灰胸竹鸡 & 未列 & 数据 & 杨书香 & 湖北省七姊妹山夏季鸟类多样性研究及生境分析 \\
\hline & & 入 & 不足 & & \\
\hline & & & $/ \mathrm{DD}$ & & \\
\hline \multirow[t]{3}{*}{ Bambusicola thoracica } & 灰胸竹鸡 & 未列 & 数据 & 任 巍 & 湖南舜皇山自然保护区鸟类区系及物种多样性研究 \\
\hline & & 入 & 不足 & & \\
\hline & & & $/ \mathrm{DD}$ & & \\
\hline Bambusicola thoracica & 灰胸竹鸡 & 未列 & 数据 & 白西红 & 灰胸竹鸡种群扩散模式的初步研究 \\
\hline
\end{tabular}


顾垒，闻丞，罗玫，王吴，吕植. 中国最受关注濒危物种保护现状快速评价的新方法探讨. 生物多样性，2015，23(5)：583-590. http://www. biodiversity-science. net/CN/article/downloadArticleFile. do?attachType=PDF\&id=10075

\begin{tabular}{|c|c|c|c|c|c|}
\hline & & 入 & 不足 & & \\
\hline Bambusicola thoracica & 灰胸竹鸡 & $\begin{array}{l}\text { 未列 } \\
\text { 入 }\end{array}$ & $\begin{array}{l}\text { /DD } \\
\text { 数据 } \\
\text { 不足 }\end{array}$ & 刘 鹏 & 江西官山自然保护区四种雉类的生境选择差异 \\
\hline Bambusicola thoracica & 灰胸竹鸡 & $\begin{array}{l}\text { 未列 } \\
\text { 入 }\end{array}$ & $\begin{array}{l}/ \mathrm{DD} \\
\text { 数据 } \\
\text { 不足 }\end{array}$ & 程松林 & 江西武夷山自然保护区的雉类资源及其保护 \\
\hline Bambusicola thoracica & 灰胸竹鸡 & $\begin{array}{l}\text { 未列 } \\
\lambda\end{array}$ & $\begin{array}{l}/ \mathrm{DD} \\
\text { 数据 } \\
\text { 不足 }\end{array}$ & 黄族豪 & 井冈山国家级自然保护区鸟类资源研究 \\
\hline Bambusicola thoracica & 灰胸竹鸡 & $\begin{array}{l}\text { 未列 } \\
\text { 入 }\end{array}$ & $\begin{array}{l}\text { /DD } \\
\text { 数据 } \\
\text { 不足 }\end{array}$ & 巩会生 & 陕西米仓山自然保护区鸟类组成与分布格局 \\
\hline Bambusicola thoracica & 灰胸竹鸡 & $\begin{array}{l}\text { 未列 } \\
\text { 入 }\end{array}$ & $\begin{array}{l}/ \mathrm{DD} \\
\text { 数据 } \\
\text { 不足 }\end{array}$ & 符建荣 & 四川大相岭自然保护区的鸟类资源 \\
\hline Bambusicola thoracica & 灰胸竹鸡 & $\begin{array}{l}\text { 未列 } \\
\text { 入 }\end{array}$ & $\begin{array}{l}/ \mathrm{DD} \\
\text { 数据 } \\
\text { 不足 }\end{array}$ & 张 君 & 四川东阳沟自然保护区鸟类区系初步调查 \\
\hline
\end{tabular}


顾垒，闻丞，罗玫，王吴，吕植. 中国最受关注濒危物种保护现状快速评价的新方法探讨. 生物多样性，2015，23(5)：583-590. http://www. biodiversity-science. net/CN/article/downloadArticleFile. do?attachType=PDF\&id=10075

\begin{tabular}{|c|c|c|c|c|c|}
\hline & & & /DD & & \\
\hline \multirow[t]{3}{*}{ Bambusicola thoracica } & 灰胸竹鸡 & 未列 & 数据 & 孙 岳 & 武夷山鸡形目鸟类多样性及冰冻灾害对其影响研究 \\
\hline & & 入 & 不足 & & \\
\hline & & & /DD & & \\
\hline \multirow[t]{3}{*}{ Bambusicola thoracica } & 灰胸竹鸡 & 未列 & 数据 & 蔡音亭 & 西天目山低山地区人工与自然生境夏季鸟类群落比较 \\
\hline & & 入 & 不足 & & \\
\hline & & & /DD & & \\
\hline \multirow[t]{3}{*}{ Bambusicola thoracica } & 灰胸竹鸡 & 未列 & 数据 & 周 毅 & 长沙县大山冲鸟类群落结构调查及多样性研究 \\
\hline & & 入 & 不足 & & \\
\hline & & & /DD & & \\
\hline \multirow[t]{2}{*}{ Batrachuperus longdongensis } & 龙洞山溪鲵 & 未列 & 濒危 & 郑中华 & 龙洞山溪鲵精子的超微结构 \\
\hline & & 入 & /EN & & \\
\hline \multirow[t]{2}{*}{ Batrachuperus pinchonii } & 山溪鲵 & 未列 & 易危 & Zhang Yuhui & MICROSTRUCTURE AND ULTRASTRUCTURE OF VITELLOGENESIS IN OOCYTES \\
\hline & & 入 & /VU & & OF THE STREAM SALAMANDER( BATRACHUPERUS PINCHON II ) \\
\hline \multirow[t]{2}{*}{ Batrachuperus pinchonii } & 山溪鲵 & 未列 & 易危 & 梁佳轩 & 基于 cytb 和 D 一 loop 区序列分析太白山溪鲤的谱系地理学 \\
\hline & & 入 & /VU & & \\
\hline \multirow[t]{2}{*}{ Batrachuperus pinchonii } & 山溪鲵 & 未列 & 易危 & 刘绍龙 & 山溪鲵的骨骼系统 \\
\hline & & 入 & /VU & & \\
\hline Batrachuperus pinchonii & 山溪鲵 & 未列 & 易危 & 王宏元 & 山溪鲵精巢的显微与超微结构研究 \\
\hline
\end{tabular}


顾垒，闻丞，罗玫，王吴，吕植. 中国最受关注濒危物种保护现状快速评价的新方法探讨. 生物多样性，2015，23(5)：583-590. http://www biodiversity-science. net/CN/article/downloadArticleFile. do?attachType=PDF\&id=10075

\begin{tabular}{|c|c|c|c|c|c|}
\hline & & 入 & $/ \mathrm{VU}$ & & \\
\hline \multirow[t]{2}{*}{ Batrachuperus pinchonii } & 山溪鲵 & 未列 & 易危 & 贾林芝 & 山溪鲵卵巢滤泡细胞的显微与超微结构 \\
\hline & & 入 & $/ \mathrm{VU}$ & & \\
\hline \multirow[t]{2}{*}{ Batrachuperus pinchonii } & 山溪鯢 & 未列 & 易危 & 吴婷婷 & 山溪鲵皮肤 $\beta$ - microseminoprotein 样蛋白的分离纯化及其 cDNA 克隆 \\
\hline & & 入 & $/ \mathrm{VU}$ & & \\
\hline \multirow[t]{2}{*}{ Batrachuperus pinchonii } & 山溪鲵 & 未列 & 易危 & 赵尔宓 & 山溪鲵头部肌肉大体解剖 \\
\hline & & 入 & $/ \mathrm{VU}$ & & \\
\hline \multirow[t]{2}{*}{ Batrachuperus pinchonii } & 山溪鯢 & 未列 & 易危 & 李仲杰 & 山溪鲵消化道粘膜上皮的扫描电镜研究 \\
\hline & & 入 & $/ \mathrm{VU}$ & & \\
\hline \multirow[t]{2}{*}{ Batrachuperus pinchonii } & 山溪鲵 & 未列 & 易危 & 李仲杰 & 山溪鲵消化系统组织学的初步研究 \\
\hline & & 入 & /VU & & \\
\hline Batrachuperus pinchonii \& Rana & 山溪鲵 和 无指盘臭蛙 & 未列 & 易危 & 韩曜平 & 无指盘臭蛙和山溪鲵皮肤及卵中 3 种生物活性多肽的分离鉴定和克隆 \\
\hline grahami & & 入 & $/ \mathrm{VU}$ & & \\
\hline \multirow[t]{2}{*}{ Batrachuperus tibetanus } & 北方山溪鲵 & 未列 & 易危 & 张育辉 & c-fos 和 c-myc 在北方山溪鲵精子发生中的表达 \\
\hline & & 入 & $/ \mathrm{VU}$ & & \\
\hline \multirow[t]{2}{*}{ Batrachuperus tibetanus } & 北方山溪鲵 & 未列 & 易危 & 张育辉 & c-myc 和 c-fos 在隆肛蛙与北方山溪鲵卵巢中的表达 \\
\hline & & 入 & $/ \mathrm{VU}$ & & \\
\hline \multirow[t]{2}{*}{ Batrachuperus tibetanus } & 北方山溪鲵 & 未列 & 易危 & 王贵虎 & 北方山溪鲵的谱系地理学研究 \\
\hline & & 入 & $/ \mathrm{VU}$ & & \\
\hline
\end{tabular}


顾垒，闻丞，罗玫，王吴，吕植. 中国最受关注濒危物种保护现状快速评价的新方法探讨. 生物多样性，2015，23(5)：583-590. http://www biodiversity-science. net/CN/article/downloadArticleFile. do?attachType=PDF\&id=10075

\begin{tabular}{|c|c|c|c|c|c|}
\hline \multirow[t]{2}{*}{ Batrachuperus tibetanus } & 北方山溪鲵 & 未列 & 易危 & 张育辉 & 北方山溪鲵端脑细胞构筑的组织学观察 \\
\hline & & 入 & /VU & & \\
\hline \multirow[t]{2}{*}{ Batrachuperus tibetanus } & 北方山溪鲵 & 未列 & 易危 & 李亚琳 & 北方山溪鲵和隆肛蛙精巢的组织学和免疫组织化学研究 \\
\hline & & 入 & /VU & & \\
\hline \multirow[t]{2}{*}{ Batrachuperus tibetanus } & 北方山溪鲵 & 未列 & 易危 & 张育辉 & 北方山溪鲵精巢间质细胞的超微结构研究 \\
\hline & & 入 & /VU & & \\
\hline \multirow[t]{2}{*}{ Batrachuperus tibetanus } & 北方山溪鲵 & 未列 & 易危 & 张育辉 & 北方山溪鲵精巢生精小叶与间质区在繁殖周期中显微结构的变化 \\
\hline & & 入 & $/ \mathrm{VU}$ & & \\
\hline \multirow[t]{2}{*}{ Batrachuperus tibetanus } & 北方山溪鲵 & 未列 & 易危 & 张育辉 & 北方山溪鲵精巢显微结构的年周期变化 \\
\hline & & 入 & $/ \mathrm{VU}$ & & \\
\hline \multirow[t]{2}{*}{ Batrachuperus tibetanus } & 北方山溪鲵 & 未列 & 易危 & 张育辉 & 北方山溪鲵精巢支持细胞的显微与超微结构观察 \\
\hline & & 入 & $/ \mathrm{VU}$ & & \\
\hline \multirow[t]{2}{*}{ Batrachuperus tibetanus } & 北方山溪鲵 & 未列 & 易危 & 李亚琳 & 北方山溪鲵精巢中性类固醇激素的免疫细胞化学研究 \\
\hline & & 入 & $/ \mathrm{VU}$ & & \\
\hline \multirow[t]{2}{*}{ Batrachuperus tibetanus } & 北方山溪鲵 & 未列 & 易危 & 张育辉 & 北方山溪鲵精子发生不同阶段的显微与超微结构 \\
\hline & & 入 & $/ \mathrm{VU}$ & & \\
\hline \multirow[t]{2}{*}{ Batrachuperus tibetanus } & 北方山溪鲵 & 未列 & 易危 & 张育辉 & 北方山溪鲵外周血细胞的组织学观察 \\
\hline & & 入 & $/ \mathrm{VU}$ & & \\
\hline Batrachuperus tibetanus & 北方山溪鲵 & 未列 & 易危 & 张育辉 & 北方山溪鲵嗅觉感受器的组织结构 \\
\hline
\end{tabular}


顾垒，闻丞，罗玫，王吴，吕植. 中国最受关注濒危物种保护现状快速评价的新方法探讨. 生物多样性，2015，23(5)：583-590. http://www biodiversity-science. net/CN/article/downloadArticleFile. do?attachType=PDF\&id=10075

\begin{tabular}{|c|c|c|c|c|c|}
\hline & & 入 & $/ \mathrm{VU}$ & & \\
\hline \multirow[t]{2}{*}{ Batrachuperus tibetanus } & 北方山溪鲵 & 未列 & 易危 & 张育辉 & 北方山溪鲵与隆肛蛙视网膜显微结构的观察比较 \\
\hline & & 入 & $/ \mathrm{VU}$ & & \\
\hline \multirow[t]{2}{*}{ Batrachuperus tibetanus } & 北方山溪鲵 & 未列 & 易危 & 张育辉 & 雌二醇及其受体在北方山溪鲵精巢中的周期性分布 \\
\hline & & 入 & /VU & & \\
\hline \multirow[t]{2}{*}{ Batrachuperus tibetanus } & 北方山溪鲵 & 未列 & 易危 & 张育辉 & 睪酮在北方山溪鲵精巢发育周期中的分布 \\
\hline & & 入 & $/ \mathrm{VU}$ & & \\
\hline \multirow[t]{2}{*}{ Batrachuperus tibetanus } & 北方山溪鲵 & 未列 & 易危 & 马爽 & 急性温度应激对北方山溪鲵脑内 c 一 Fos 和 5-HTIA 受体表达的影响 \\
\hline & & 入 & $/ \mathrm{VU}$ & & \\
\hline \multirow[t]{2}{*}{ Batrachuperus tibetanus } & 北方山溪鲵 & 未列 & 易危 & 雷忻 & 隆肛蛙和北方山溪鲵卵巢组织学及免疫细胞化学研究 \\
\hline & & 入 & $/ \mathrm{VU}$ & & \\
\hline \multirow[t]{2}{*}{ Batrachuperus tibetanus } & 西藏山溪鲵 & 未列 & 易危 & 韩曜平 & 秦岭地区西藏山溪鲵种群结构及保护 \\
\hline & & 入 & /VU & & \\
\hline \multirow[t]{2}{*}{ Batrachuperus tibetanus } & 西藏山溪鲵 & 未列 & 易危 & 申志新 & 青海省玛柯河西藏山溪鲵研究 \\
\hline & & 入 & /VU & & \\
\hline \multirow[t]{2}{*}{ Batrachuperus tibetanus } & 西藏山溪鲵 & 未列 & 易危 & 杨莉 & 太子山西藏山溪鲵种群生态学及保护研究 \\
\hline & & 入 & /VU & & \\
\hline \multirow[t]{2}{*}{ Batrachuperus tibetanus } & 西藏山溪鲵 & 未列 & 易危 & 谢锋 & 西藏山溪鲵精子的形态 \\
\hline & & 入 & /VU & & \\
\hline
\end{tabular}


顾垒，闻丞，罗玫，王吴，吕植. 中国最受关注濒危物种保护现状快速评价的新方法探讨. 生物多样性，2015，23(5)：583-590. http://www. biodiversity-science. net/CN/article/downloadArticleFile. do?attachType=PDF\&id=10075

\begin{tabular}{|c|c|c|c|c|c|}
\hline \multirow[t]{2}{*}{ Batrachuperus tibetanus } & 西藏山溪鲵 & 未列 & 易危 & 韩曜平 & 西藏山溪鲵乳酸脱氢酶同工酶(LDH)的初步研究 \\
\hline & & 入 & /VU & & \\
\hline \multirow[t]{2}{*}{ Batrachuperus tibetanus } & 西藏山溪鲵 & 未列 & 易危 & 夏继刚 & 西藏山溪鱿热适应性与热应激的生理效应 \\
\hline & & 入 & /VU & & \\
\hline \multirow[t]{2}{*}{ Begonia } & 秋海棠属 & 未列 & 易危 & 管开云 & 云南八种秋海棠属植物的染色体数目 \\
\hline & & 入 & /VU & & \\
\hline \multirow[t]{2}{*}{ Begonia peltatifolia } & 盾叶秋海棠 & 未列 & 易危 & 徐红林 & 野生盾叶秋海棠引种驯 化及应用研究 \\
\hline & & 入 & /VU & & \\
\hline \multirow[t]{2}{*}{ Belostemma yunnanense } & 镰药藤 & 未列 & 易危 & 李秉滔 & 《中国植物志》第 63 卷 561 页 \\
\hline & & 入 & /VU & & \\
\hline \multirow[t]{2}{*}{ Berberis candidula } & 单花小檗 & 未列 & 易危 & 韦毅刚 & 广西植物二新种 \\
\hline & & 入 & $/ \mathrm{VU}$ & & \\
\hline \multirow[t]{2}{*}{ Berberis iteophylla } & 柳叶小檗 & 未列 & 濒危 & 应俊生 & 《中国植物志》第 29 卷 123 页 \\
\hline & & 入 & $/ \mathrm{EN}$ & & \\
\hline \multirow[t]{2}{*}{ Berberis johannis } & 腰果小檗 & 未列 & 易危 & 应俊生 & 《中国植物志》第 29 卷 152 页 \\
\hline & & 入 & /VU & & \\
\hline \multirow[t]{2}{*}{ Berberis taronensis } & 独龙小檗 & 未列 & 易危 & 应俊生 & 《中国植物志》第 29 卷 126 页 \\
\hline & & 入 & $/ \mathrm{VU}$ & & \\
\hline Berberis woomungensis & 乌蒙小檗 & 未列 & 易危 & 应俊生 & 《中国植物志》第 29 卷 078 页 \\
\hline
\end{tabular}


顾垒，闻丞，罗玫，王吴，吕植. 中国最受关注濒危物种保护现状快速评价的新方法探讨. 生物多样性，2015，23(5)：583-590. http://www. biodiversity-science. net/CN/article/downloadArticleFile. do?attachType=PDF\&id=10075

\begin{tabular}{|c|c|c|c|c|c|}
\hline & & 入 & $/ \mathrm{VU}$ & & \\
\hline \multirow[t]{2}{*}{ Biondia chinensis } & 秦岭藤 & 未列 & 易危 & 李秉滔 & 《中国植物志》第 63 卷 397 页 \\
\hline & & 入 & $/ \mathrm{VU}$ & & \\
\hline \multirow[t]{2}{*}{ Bonasa sewerzowi } & 斑尾榛鸡 & I & 近危 & 金祥龙 & 阿夏自然保护区鸟类群落研究 \\
\hline & & & /NT & & \\
\hline \multirow[t]{2}{*}{ Bonasa sewerzowi } & 斑尾榛鸡 & I & 近危 & 格玛江初 & 白马雪山自然保护区德钦分局鸡类多样性及保护管理研究 \\
\hline & & & /NT & & \\
\hline \multirow[t]{2}{*}{ Bonasa sewerzowi } & 斑尾榛鸡 & I & 近危 & 王 杰 & 斑尾棒鸡的婚外配检验及原因探讨 \\
\hline & & & /NT & & \\
\hline \multirow[t]{2}{*}{ Bonasa sewerzowi } & 斑尾榛鸡 & I & 近危 & 王 杰 & 斑尾棒鸡对雌雄后代的投资比较 \\
\hline & & & /NT & & \\
\hline \multirow[t]{2}{*}{ Bonasa sewerzowi } & 斑尾榛鸡 & I & 近危 & 赵金明 & 斑尾棒鸡育雏期移动模式和活动范围 \\
\hline & & & /NT & & \\
\hline \multirow[t]{2}{*}{ Bonasa sewerzowi } & 斑尾榛鸡 & I & 近危 & 孙悦华 & 斑尾榛鸡的生活史特征、行为和保护 \\
\hline & & & /NT & & \\
\hline \multirow[t]{2}{*}{ Bonasa sewerzowi } & 斑尾榛鸡 & I & 近危 & 石美 & 甘肃莲花山斑尾榛鸡春季领域保护行为和四川林鸮繁殖生态观察 \\
\hline & & & /NT & & \\
\hline \multirow[t]{2}{*}{ Bonasa sewerzowi } & 斑尾榛鸡 & I & 近危 & 石美 & 甘肃莲花山斑尾榛鸡的春季领域行为 \\
\hline & & & /NT & & \\
\hline
\end{tabular}


顾垒，闻丞，罗玫，王吴，吕植. 中国最受关注濒危物种保护现状快速评价的新方法探讨. 生物多样性，2015，23(5)：583-590. http://www. biodiversity-science. net/CN/article/downloadArticleFile. do?attachType=PDF\&id=10075

\begin{tabular}{|c|c|c|c|c|c|}
\hline Bonasa sewerzowi & 斑尾榛鸡 & I & $\begin{array}{l}\text { 近危 } \\
\text { /NT }\end{array}$ & 季 婷 & 莲花山斑尾榛鸡春季栖息地选择 \\
\hline Bonasa sewerzowi & 斑尾榛鸡 & I & $\begin{array}{l}\text { 近危 } \\
\text { /NT }\end{array}$ & 符建荣 & 米亚罗自然保护区的鸟类资源 \\
\hline Bonasa sewerzowi & 斑尾榛鸡 & I & $\begin{array}{l}\text { 近危 } \\
\text { /NT }\end{array}$ & Siegfried KLAUS & 破碎化景观下斑尾榛鸡(Tetrastes sewerzowi)斑块占有率分析 \\
\hline Bonasa sewerzowi & 斑尾榛鸡 & I & $\begin{array}{l}\text { 近危 } \\
\text { /NT }\end{array}$ & 程文达 & 破碎化生境下结合栖息地质量的斑尾棒鸡种群生存力分析 \\
\hline Bonasa sewerzowi & 斑尾榛鸡 & I & $\begin{array}{l}\text { 近危 } \\
\text { /NT }\end{array}$ & 符建荣 & 四川海子山自然保护区鸟类资源及区系 \\
\hline Bonasa sewerzowi & 斑尾榛鸡 & I & $\begin{array}{l}\text { 近危 } \\
\text { /NT }\end{array}$ & 再江洪 & 四川九寨沟自然保护区的鸟类资源及区系 \\
\hline Bos gaurus & 野牛 & I & $\begin{array}{l}\text { 易危 } \\
\text { /VU }\end{array}$ & 冯子山 & 澜沧县野生动物肇事情况调查报告 \\
\hline Bos grunniens & 野牦牛 & I & $\begin{array}{l}\text { 易危 } \\
\text { /VU }\end{array}$ & 刘英 & 1 日龄牦牛肺泡毛细血管的扫描电镜观察 \\
\hline Bos grunniens & 野牦牛 & I & $\begin{array}{l}\text { 濒危 } \\
/ \mathrm{EN}\end{array}$ & 江明锋 & AFLP 分子标记在牦牛遗传分析中的初探 \\
\hline Bos grunniens & 野牦牛 & I & 易危 & Y. Liu & Anatomic peculiarities of the cerebral arterial system and blood supply in the yak \\
\hline
\end{tabular}


顾垒，闻丞，罗玫，王昊，吕植. 中国最受关注濒危物种保护现状快速评价的新方法探讨．生物多样性，2015，23(5)：583-590. http://www, biodiversity-science, net/CN/article/downloadArticleFile. do?attachType=PDF\&id=10075

\section{VU}

Bos grunniens

野牦牛

野牦牛

Bos grunniens

Bos grunniens

Bos grunniens

野牦牛

野牦牛

Bos grunniens

Bos grunniens

Bos grunniens

Bos grunniens

Bos grunniens

/VU

/VU

I 易危 Y.C. Zheng

/VU

易危 Jianquan Liu

/VU

I

易危

H. J. Yang

$/ \mathrm{VU}$

I 易危 Yucai Zheng

/VU

I 易危 Yan Cui,

/VU

I 易危 Jianquan Liu

/VU

I 易危 J. L. Han

/VU

I 易危 Yucai Zheng
Cloning and molecular characterization of a yak a -lactalbumin cDNA from mammary tissue

Comparison of enzyme activities and gene expression profiling between yak and bovine

skeletal muscles

Domestication Relaxed Selective Constraints on the Yak Mitochondrial Genome

Enzymatic characteristics of crude feruloyl and acetyl esterases of rumen fungus

Neocallimastix sp. YAK11 isolated from yak (Bos grunniens)

High-Altitude Adaptation of Yak Based on Genetic Variants and Activity of Lactat

Dehydrogenase-1

Histochemical and ultrastructural observations of respiratory epithelium and gland in yak (Bos grunniens)

Phylogeographical analyses of domestic and wild yaks based on mitochondrial DNA: new data and reappraisal

Polymorphic but highly conserved Bogr-DRA gene in yak(Bos grunniens)

Quantitation of alternative splicing variants of lactate dehydrogenase C gene in testes of adult

yak, sexually immature yak calf and sterile male hybrid of yak 
顾垒，闻丞，罗玫，王吴，吕植. 中国最受关注濒危物种保护现状快速评价的新方法探讨. 生物多样性，2015，23(5)：583-590. http://www. biodiversity-science. net/CN/article/downloadArticleFile. do?attachType=PDF\&id=10075

\begin{tabular}{|c|c|c|c|c|c|}
\hline Bos grunniens & 野牦牛 & I & $\begin{array}{l}\text { 易危 } \\
\text { /VU }\end{array}$ & Jianquan Liu & The yak genome and adaptation to life at high altitude \\
\hline Bos grunniens & 野牦牛 & I & $\begin{array}{l}\text { 易危 } \\
\text { /VU }\end{array}$ & Qiang Qiu & $\begin{array}{l}\text { The Yak genome database an integrative database for studying yak biology and high-altitude } \\
\text { adaption }\end{array}$ \\
\hline Bos grunniens & 野牦牛 & I & $\begin{array}{l}\text { 易危 } \\
\text { /VU }\end{array}$ & 马元梅 & 不同冷冻温度对野牦牛精液品质的影响 \\
\hline Bos grunniens & 野牦牛 & I & $\begin{array}{l}\text { 濒危 } \\
/ \mathrm{EN}\end{array}$ & 刘强 & $\begin{array}{l}\text { 从线粒体细胞色素 b 基因和 D_LOOP 控制区序列差异研究野牦牛和家牦牛的系统进化关 } \\
\text { 系 }\end{array}$ \\
\hline Bos grunniens & 野牦牛 & I & 濒危 & 宫昌海 & 导入野牦牛血液对新疆牦牛影响效果之浅析 \\
\hline Bos grunniens & 野牦牛 & I & 濒危 & 王志军 & 对纯种野牦牛驯化期间人工管理工作浅谈 \\
\hline Bos grunniens & 野牦牛 & I & $\begin{array}{l}\text { 濒危 } \\
/ \mathrm{EN}\end{array}$ & 吉全风 & 甘南牦牛资源的现状及开发利用途径 \\
\hline Bos grunniens & 野牦牛 & I & $\begin{array}{l}\text { 濒危 } \\
\text { /EN }\end{array}$ & 卓玛 & 高原野牦牛剖腹产一例 \\
\hline Bos grunniens & 野牦牛 & I & $\begin{array}{l}\text { 易危 } \\
\text { /VU }\end{array}$ & 刘振生 & 贺兰山牦牛冬春季的生境选择 \\
\hline Bos grunniens & 野牦牛 & I & 易危 & 刘振生 & 贺兰山野化牦牛冬季昼间行为的时间分配 \\
\hline
\end{tabular}


顾垒，闻丞，罗玫，王吴，吕植. 中国最受关注濒危物种保护现状快速评价的新方法探讨. 生物多样性，2015，23(5)：583-590. http://www. biodiversity-science. net/CN/article/downloadArticleFile. do?attachType=PDF\&id=10075

\begin{tabular}{|c|c|c|c|c|c|}
\hline & & & /VU & & \\
\hline \multirow[t]{2}{*}{ Bos grunniens } & 野牦牛 & I & 濒危 & 曹伊凡 & 可可西里藏羚羊、野牦牛、藏野驴和藏原羚冬季蠕虫卵粪检研究初报 \\
\hline & & & /EN & & \\
\hline \multirow[t]{2}{*}{ Bos grunniens } & 野牦牛 & I & 濒危 & 林金杏 & 冷冻保存对野牦牛精子酶活性的影响 \\
\hline & & & /EN & & \\
\hline \multirow[t]{2}{*}{ Bos grunniens } & 野牦牛 & I & 易危 & 钟金城 & 牦牛 mtDNA 编码蛋白质的基因密码子偏好性研究及聚类分析 \\
\hline & & & /VU & & \\
\hline \multirow[t]{2}{*}{ Bos grunniens } & 野牦牛 & I & 濒危 & 张瑞强 & 牦牛肠道与粪便乳酸菌的分离鉴定及 PCR_16 S rDNA 鉴定 \\
\hline & & & /EN & & \\
\hline \multirow[t]{2}{*}{ Bos grunniens } & 野牦牛 & I & 易危 & 杨奇森 & 牦牛的分布及保护 \\
\hline & & & /VU & & \\
\hline \multirow[t]{2}{*}{ Bos grunniens } & 野牦牛 & I & 濒危 & 赵新全 & 牦牛的分类学地位及起源研究 mtDNAD_loop 序列的分析 \\
\hline & & & $/ \mathrm{EN}$ & & \\
\hline \multirow[t]{2}{*}{ Bos grunniens } & 野牦牛 & I & 易危 & 宋大伟 & 牦牛的起源与系统发育分析 \\
\hline & & & /VU & & \\
\hline \multirow[t]{2}{*}{ Bos grunniens } & 野牦牛 & I & 濒危 & 陈秋生 & 牦牛肺脏高原适应性的结构研究 \\
\hline & & & /EN & & \\
\hline \multirow[t]{2}{*}{ Bos grunniens } & 野牦牛 & I & 易危 & 宋海峰 & 牦牛黑素皮质素受体-4（MC4R）基因的克隆测序及其多态性分析 \\
\hline & & & /VU & & \\
\hline
\end{tabular}


顾垒，闻丞，罗玫，王吴，吕植. 中国最受关注濒危物种保护现状快速评价的新方法探讨. 生物多样性，2015，23(5)：583-590. http://www. biodiversity-science. net/CN/article/downloadArticleFile. do?attachType=PDF\&id=10075

\begin{tabular}{|c|c|c|c|c|c|}
\hline Bos grunniens & 野牦牛 & I & $\begin{array}{l}\text { 易危 } \\
\text { /VU }\end{array}$ & 郁枫 & 牦牛睫毛毛囊的形态发生及其 Shh 与 $\beta$ 2catenin 的时空表达 \\
\hline Bos grunniens & 野牦牛 & I & $\begin{array}{l}\text { 易危 } \\
\text { /VU }\end{array}$ & 李静 & 牦牛睫毛毛囊的形态发生及其 SHH 与 $\beta$-catenin 的表达 \\
\hline Bos grunniens & 野牦牛 & I & $\begin{array}{l}\text { 濒危 } \\
\text { /EN }\end{array}$ & 崔燕 & 牦牛卵泡细胞及其卵母细胞不同发育时期的结构变化 \\
\hline Bos grunniens & 野牦牛 & I & $\begin{array}{l}\text { 濒危 } \\
\text { /EN }\end{array}$ & 袁青妍 & 牦牛血红蛋白的基因克隆和同源模建 \\
\hline Bos grunniens & 野牦牛 & I & $\begin{array}{l}\text { 易危 } \\
\text { /VU }\end{array}$ & 王召锋 & 牦牛驯化和适应_线粒体基因组证据 \\
\hline Bos grunniens & 野牦牛 & I & $\begin{array}{l}\text { 濒危 } \\
\text { /EN }\end{array}$ & 王建林 & 牦牛眼的动脉分布 \\
\hline Bos grunniens & 野牦牛 & I & $\begin{array}{l}\text { 濒危 } \\
\text { /EN }\end{array}$ & 钟金城 & 牦牛遗传育种学研究 \\
\hline Bos grunniens & 野牦牛 & I & $\begin{array}{l}\text { 濒危 } \\
\text { /EN }\end{array}$ & 李齐发 & 牛亚科 MHCDRB3 基因 exon2 的序列变异分析 \\
\hline Bos grunniens & 野牦牛 & I & $\begin{array}{l}\text { 易危 } \\
\text { /VU }\end{array}$ & 杨海英 & 祁连野牦牛引种适应性观察 \\
\hline Bos grunniens & 野牦牛 & I & 易危 & 蒋小怀 & 浅谈新疆野牦牛资源的开发与利用 \\
\hline
\end{tabular}


顾垒，闻丞，罗玫，王吴，吕植. 中国最受关注濒危物种保护现状快速评价的新方法探讨. 生物多样性，2015，23(5)：583-590. http://www. biodiversity-science. net/CN/article/downloadArticleFile. do?attachType=PDF\&id=10075

\begin{tabular}{|c|c|c|c|c|c|}
\hline & & & /VU & & \\
\hline \multirow[t]{2}{*}{ Bos grunniens } & 野牦牛 & I & 濒危 & 刘务林 & 浅谈野牦牛的起源与现状 \\
\hline & & & /EN & & \\
\hline \multirow[t]{2}{*}{ Bos grunniens } & 野牦牛 & I & 濒危 & 杨博辉 & 美塘自然保护区阿鲁盆地野牦牛种群生存力分析 \\
\hline & & & /EN & & \\
\hline \multirow[t]{2}{*}{ Bos grunniens } & 野牦牛 & I & 濒危 & 潘和平 & 青藏高原牦牛遗传资源的利用与保护 \\
\hline & & & /EN & & \\
\hline \multirow[t]{2}{*}{ Bos grunniens } & 野牦牛 & I & 易危 & 徐先军 & 青海高原牦牛的现状及发展建议 \\
\hline & & & /VU & & \\
\hline \multirow[t]{2}{*}{ Bos grunniens } & 野牦牛 & I & 濒危 & 邹文辉 & 青海果洛地区野血牦牛生长发育测定 \\
\hline & & & /EN & & \\
\hline \multirow[t]{2}{*}{ Bos grunniens } & 野牦牛 & I & 易危 & 苏建平 & 青海省可可西里地区几种有蹄类动物的食物重叠初步分析 \\
\hline & & & /VU & & \\
\hline \multirow[t]{2}{*}{ Bos grunniens } & 野牦牛 & I & 易危 & 周继章 & 青海天峻县野牦牛衣原体病和布氏杆病的血清学调查 \\
\hline & & & /VU & & \\
\hline \multirow[t]{2}{*}{ Bos grunniens } & 野牦牛 & I & 濒危 & 任晓刚 & 青海野牦牛种群恢复 \\
\hline & & & /EN & & \\
\hline \multirow[t]{2}{*}{ Bos grunniens } & 野牦牛 & I & 易危 & 胡宁胥 & 青海野血牦牛种公牛最佳采精期的研究 \\
\hline & & & /VU & & \\
\hline
\end{tabular}


顾垒，闻丞，罗玫，王吴，吕植. 中国最受关注濒危物种保护现状快速评价的新方法探讨. 生物多样性，2015，23(5)：583-590. http://www. biodiversity-science. net/CN/article/downloadArticleFile. do?attachType=PDF\&id=10075

\begin{tabular}{|c|c|c|c|c|c|}
\hline Bos grunniens & 野牦牛 & I & $\begin{array}{l}\text { 濒危 } \\
\text { /EN }\end{array}$ & 蒲敬伟 & 人工放养野牦牛布鲁氏菌病感染情况调查 \\
\hline Bos grunniens & 野牦牛 & I & $\begin{array}{l}\text { 易危 } \\
\text { /VU }\end{array}$ & 张发慧 & 肃南牦牛资源现状及发展前景探析 \\
\hline Bos grunniens & 野牦牛 & I & $\begin{array}{l}\text { 易危 } \\
\text { /VU }\end{array}$ & 阎萍 & 褪黑素受体在发情季节牦牛生殖内分泌器官中的表达研究 \\
\hline Bos grunniens & 野牦牛 & I & $\begin{array}{l}\text { 易危 } \\
\text { /VU }\end{array}$ & 钟金城 & 西藏牦牛遗传资源保护与利用 \\
\hline Bos grunniens & 野牦牛 & I & $\begin{array}{l}\text { 易危 } \\
\text { /VU }\end{array}$ & 常洪 & 新疆巴州牦牛种群线粒体 DNA 遗传多样性及其系统发育分析 \\
\hline Bos grunniens & 野牦牛 & I & $\begin{array}{l}\text { 易危 } \\
\text { /VU }\end{array}$ & 钟金城 & 野耗牛线粒体基因组的结构及其系统进化研究 \\
\hline Bos grunniens & 野牦牛 & I & $\begin{array}{l}\text { 濒危 } \\
\text { /EN }\end{array}$ & 胡江 & 野牦牛、家牦牛及其杂交种的生物学特性和遗传多样性研究 \\
\hline Bos grunniens & 野牦牛 & I & $\begin{array}{l}\text { 濒危 } \\
\text { /EN }\end{array}$ & 徐建平 & 野牦牛暴发败血型巴氏杆菌病 \\
\hline Bos grunniens & 野牦牛 & I & $\begin{array}{l}\text { 易危 } \\
\text { /VU }\end{array}$ & 蒲敬伟 & 野牦牛布鲁氏菌病感染情况调查 \\
\hline Bos grunniens & 野牦牛 & I & 濒危 & 袁立岗 & 野牛牛布鲁氏菌病感染情况调查 \\
\hline
\end{tabular}


顾垒，闻丞，罗玫，王吴，吕植. 中国最受关注濒危物种保护现状快速评价的新方法探讨. 生物多样性，2015，23(5)：583-590. http://www. biodiversity-science. net/CN/article/downloadArticleFile. do?attachType=PDF\&id=10075

\begin{tabular}{|c|c|c|c|c|c|}
\hline & & & $/ \mathrm{EN}$ & & \\
\hline \multirow[t]{2}{*}{ Bos grunniens } & 野牦牛 & I & 易危 & 郭志林 & 野牦牛成纤维细胞的分离培养与传代 \\
\hline & & & $/ \mathrm{VU}$ & & \\
\hline \multirow[t]{2}{*}{ Bos grunniens } & 野牦牛 & I & 易危 & 郭志林 & 野牦牛成纤维细胞分离培养与部分生物学特性观察 \\
\hline & & & $/ \mathrm{VU}$ & & \\
\hline \multirow[t]{2}{*}{ Bos grunniens } & 野牦牛 & I & 濒危 & 刘务林 & 野牦牛的分布和现状 \\
\hline & & & /EN & & \\
\hline \multirow[t]{2}{*}{ Bos grunniens } & 野牦牛 & I & 易危 & 朱新书 & 野牦牛的抗逆性与牦牛的抗逆育种研究 \\
\hline & & & $/ \mathrm{VU}$ & & \\
\hline \multirow[t]{2}{*}{ Bos grunniens } & 野牦牛 & I & 濒危 & 李加太 & 野牦牛的驯养及利用 \\
\hline & & & $/ \mathrm{EN}$ & & \\
\hline \multirow[t]{2}{*}{ Bos grunniens } & 野牦牛 & $\mathrm{I}$ & 濒危 & 梁春年 & 野牦牛的资源价值与保护策略 \\
\hline & & & /EN & & \\
\hline \multirow[t]{2}{*}{ Bos grunniens } & 野牦牛 & I & 易危 & 尚有安 & 野牛牛改良家牦牛的生产性能效果试验研究 \\
\hline & & & /VU & & \\
\hline \multirow[t]{2}{*}{ Bos grunniens } & 野牦牛 & I & 易危 & 常明华 & 野牦牛行为及其环境关系的研究 \\
\hline & & & $/ \mathrm{VU}$ & & \\
\hline \multirow[t]{2}{*}{ Bos grunniens } & 野牦牛 & I & 濒危 & 陈少平 & 野牦牛接种疫苗后暴发巴氏杆菌病的诊治 \\
\hline & & & /EN & & \\
\hline
\end{tabular}


顾垒，闻丞，罗玫，王吴，吕植. 中国最受关注濒危物种保护现状快速评价的新方法探讨. 生物多样性，2015，23(5)：583-590. http://www. biodiversity-science. net/CN/article/downloadArticleFile. do?attachType=PDF\&id=10075

\begin{tabular}{|c|c|c|c|c|c|}
\hline Bos grunniens & 野牦牛 & I & $\begin{array}{l}\text { 易危 } \\
\text { /VU }\end{array}$ & 林金杏 & 野牛牛精子超微结构和精液蛋白组分的研究 \\
\hline Bos grunniens & 野牦牛 & I & $\begin{array}{l}\text { 易危 } \\
\text { /VU }\end{array}$ & 王伟 & 野牦牛生长发育规律的研究 \\
\hline Bos grunniens & 野牦牛 & I & $\begin{array}{l}\text { 濒危 } \\
\text { /EN }\end{array}$ & 韩志辉 & 野牦牛魏氏梭菌性肠炎的诊治 \\
\hline Bos grunniens & 野牦牛 & I & $\begin{array}{l}\text { 易危 } \\
\text { /VU }\end{array}$ & 钟金城 & 野牦牛线粒体基因组结构及其系统进化研究 \\
\hline Bos grunniens & 野牦牛 & I & $\begin{array}{l}\text { 易危 } \\
\text { /VU }\end{array}$ & 杨尔旦 & 野牦牛驯养管理技术措施 \\
\hline Bos grunniens & 野牦牛 & I & $\begin{array}{l}\text { 易危 } \\
\text { /VU }\end{array}$ & 马国军 & 野牦牛与大通牦牛初生重的比较研究 \\
\hline Bos grunniens & 野牦牛 & I & $\begin{array}{l}\text { 濒危 } \\
\text { /EN }\end{array}$ & 阎萍 & 野牦牛种质特性的研究与利用 \\
\hline Bos grunniens & 野牦牛 & I & $\begin{array}{l}\text { 濒危 } \\
\text { /EN }\end{array}$ & 陈爱云 & 野牦牛资源研究利用现状 \\
\hline Bos grunniens & 野牦牛 & I & $\begin{array}{l}\text { 易危 } \\
\text { /VU }\end{array}$ & 廖世梅 & 野血牦牛和本地牦牛舍饲育肥试验 \\
\hline Bos grunniens & 野牦牛 & I & 濒危 & 罗晓林 & 野血牦牛和家牦牛种质特性及野牦牛利用研究 \\
\hline
\end{tabular}


顾垒，闻丞，罗玫，王吴，吕植. 中国最受关注濒危物种保护现状快速评价的新方法探讨. 生物多样性，2015，23(5)：583-590. http://www. biodiversity-science. net/CN/article/downloadArticleFile. do?attachType=PDF\&id=10075

\begin{tabular}{|c|c|c|c|c|c|}
\hline & & & /EN & & \\
\hline \multirow[t]{2}{*}{ Bos grunniens } & 野牦牛 & I & 易危 & 陈励芳 & 野血牦牛与家牦牛暖季放牧育肥及屠宰试验 \\
\hline & & & /VU & & \\
\hline \multirow[t]{2}{*}{ Bos grunniens } & 野牦牛 & I & 濒危 & 吴建平 & 应用 nested 和 touch down PCR 技术分离牦牛 CAPN1 大亚基基因 EST \\
\hline & & & /EN & & \\
\hline \multirow[t]{2}{*}{ Bos grunniens } & 野牦牛 & I & 濒危 & 吴润 & 原核表达牦牛朊蛋白的纯化及其活性测定 \\
\hline & & & /EN & & \\
\hline \multirow[t]{2}{*}{ Bos grunniens } & 野牦牛 & I & 易危 & 谷朝勇 & 中国牦牛的血液蛋白多态与聚类分析 \\
\hline & & & $/ \mathrm{VU}$ & & \\
\hline \multirow[t]{2}{*}{ Bos grunniens } & 野牦牛 & I & 濒危 & 姚军 & 中国野牦牛栖息地环境及种群行为分析 \\
\hline & & & /EN & & \\
\hline \multirow[t]{2}{*}{ Bos grunniens } & 野牦牛 & I & 易危 & 郭宪 & 中国野牦牛遗传资源的保存与利用 \\
\hline & & & /VU & & \\
\hline \multirow[t]{2}{*}{ Bos grunniens } & 野牦牛 & I & 濒危 & 杨博辉 & 中国野牦牛遗传资源全息体系的建立及利用评价 \\
\hline & & & /EN & & \\
\hline \multirow[t]{2}{*}{ Bos grunniens } & 野牦牛 & I & 濒危 & 杨博辉 & 中国野牦牛种质资源库体系的建立 \\
\hline & & & /EN & & \\
\hline \multirow[t]{2}{*}{ Branta ruficollis } & 红胸黑雁 & II & 濒危 & 牛俊英 & 河南省鸟类新纪录_震旦鸦雀_红胸黑雁 \\
\hline & & & /EN & & \\
\hline
\end{tabular}


顾垒，闻丞，罗玫，王吴，吕植. 中国最受关注濒危物种保护现状快速评价的新方法探讨. 生物多样性，2015，23(5)：583-590. http://www biodiversity-science. net/CN/article/downloadArticleFile. do?attachType=PDF\&id=10075

\begin{tabular}{|c|c|c|c|c|c|}
\hline Branta ruficollis & 红胸黑雁 & II & 濒危 & 徐昌新 & 鄱阳湖越冬鸟类种群动态与保护研究 \\
\hline & & & /EN & & \\
\hline \multirow[t]{2}{*}{ Branta ruficollis } & 红胸黑雁 & II & 濒危 & 顾海军 & 四川省鸟类新纪录-红胸黑雁 \\
\hline & & & /EN & & \\
\hline \multirow[t]{2}{*}{ Brassaiopsis acuminata } & 尖叶罗伞 & 未列 & 濒危 & 何景 & 《中国植物志》第 54 卷 126 页 \\
\hline & & 入 & /EN & & \\
\hline \multirow[t]{2}{*}{ Bretschneidera sinensis } & 伯乐树 & I & 濒危 & HONGFENG CHEN & POLLINATION ECOLOGY OF BRETSCHNEIDERA SINENSIS (HEMSLEY),A RARE \\
\hline & & & /EN & & AND ENDANGERED TREE IN CHINA \\
\hline \multirow[t]{2}{*}{ Bretschneidera sinensis } & 伯乐树 & I & 濒危 & Bi-Cai Guan & Sixteen microsatellite markers developed from sinensis (Bretschneideraceae)Bretschneidera \\
\hline & & & /EN & & \\
\hline \multirow[t]{2}{*}{ Bretschneidera sinensis } & 伯乐树 & I & 濒危 & 黄华宏 & 濒危植物伯乐树遗传多样性的初步研究 \\
\hline & & & /EN & & \\
\hline \multirow[t]{2}{*}{ Bretschneidera sinensis } & 伯乐树 & I & 濒危 & 陈红锋 & 伯乐树 1 年生幼苗的光响应特征 \\
\hline & & & /EN & & \\
\hline \multirow[t]{2}{*}{ Bretschneidera sinensis } & 伯乐树 & I & 濒危 & 徐刚标 & 伯乐树 cpDNA-PCR 反应体系的优化与引物篮选 \\
\hline & & & /EN & & \\
\hline \multirow[t]{2}{*}{ Bretschneidera sinensis } & 伯乐树 & I & 濒危 & 赵良成 & 伯乐树不同发育阶段叶片表面附属结构特征 \\
\hline & & & /EN & & \\
\hline Bretschneidera sinensis & 伯乐树 & I & 濒危 & 唐邦权 & 伯乐树繁殖技术研究 \\
\hline
\end{tabular}


顾垒，闻丞，罗玫，王吴，吕植. 中国最受关注濒危物种保护现状快速评价的新方法探讨. 生物多样性，2015，23(5)：583-590. http://www. biodiversity-science. net/CN/article/downloadArticleFile. do?attachType=PDF\&id=10075

\begin{tabular}{|c|c|c|c|c|c|}
\hline & & & /EN & & \\
\hline \multirow[t]{2}{*}{ Bretschneidera sinensis } & 伯乐树 & I & 濒危 & 刘仁林 & 伯乐树生长发育节律与物候特征研究 \\
\hline & & & $/$ EN & & \\
\hline \multirow[t]{2}{*}{ Bretschneidera sinensis } & 伯乐树 & I & 濒危 & 唐邦权 & 伯乐树实生播种育苗技术 \\
\hline & & & /EN & & \\
\hline \multirow[t]{2}{*}{ Bretschneidera sinensis } & 伯乐树 & I & 濒危 & 吴彩新 & 伯乐树栽培技术及应用 \\
\hline & & & /EN & & \\
\hline \multirow[t]{2}{*}{ Bretschneidera sinensis } & 伯乐树 & I & 濒危 & 徐刚标 & 伯乐树种群遗传多样性及遗传结构 \\
\hline & & & /EN & & \\
\hline \multirow[t]{2}{*}{ Bretschneidera sinensis } & 伯乐树 & I & 濒危 & 李坊贞 & 伯乐树种子萌发与根组织分化规律的研究 \\
\hline & & & /EN & & \\
\hline \multirow[t]{2}{*}{ Bretschneidera sinensis } & 伯乐树 & I & 濒危 & 伍铭凯 & 伯乐树种子育苗试验 \\
\hline & & & /EN & & \\
\hline \multirow[t]{2}{*}{ Bretschneidera sinensis } & 伯乐树 & I & 濒危 & 欧阳献 & 伯乐树组织培养快繁技术研究 \\
\hline & & & /EN & & \\
\hline \multirow[t]{2}{*}{ Bretschneidera sinensis } & 伯乐树 & I & 濒危 & 徐刚标 & 南岭山地伯乐树天然种群和人工种群遗传多样性比较 \\
\hline & & & /EN & & \\
\hline \multirow[t]{2}{*}{ Bretschneidera sinensis } & 伯乐树 & I & 濒危 & 刘仁林 & 天然群落枯枝落叶浸提液与其它处理对伯乐树种子发芽的比较研究 \\
\hline & & & /EN & & \\
\hline
\end{tabular}


顾垒，闻丞，罗玫，王吴，吕植. 中国最受关注濒危物种保护现状快速评价的新方法探讨. 生物多样性，2015，23(5)：583-590. http://www biodiversity-science. net/CN/article/downloadArticleFile. do?attachType=PDF\&id=10075

\begin{tabular}{|c|c|c|c|c|c|}
\hline Bretschneidera sinensis & 伯乐树 & I & $\begin{array}{l}\text { 濒危 } \\
\text { /EN }\end{array}$ & 金孝锋 & 浙江九龙山国家级自然保护区伯乐树群落特征及种群结构分析 \\
\hline Bretschneidera sinensis & 伯乐树 & I & $\begin{array}{l}\text { 濒危 } \\
\text { /EN }\end{array}$ & 季梅 & 珍贵木本蔬菜伯乐树幼嫩叶芽营养成分分析与评价 \\
\hline Bretschneidera sinensis & 伯乐树 & I & $\begin{array}{l}\text { 濒危 } \\
\text { /EN }\end{array}$ & 黄健锋 & 珍稀植物伯乐树和半枫荷的生物学特性及园林应用 \\
\hline Bretschneidera sinensis & 伯乐树 & I & $\begin{array}{l}\text { 濒危 } \\
\text { /EN }\end{array}$ & 陈红锋 & 珍稀植物伯乐树一年生更新幼苗的死亡原因和保育策略 \\
\hline Bretschneidera sinensis & 伯乐树 & I & $\begin{array}{l}\text { 濒危 } \\
\text { /EN }\end{array}$ & 陈红锋 & 中国特有濒危植物伯乐树根的生态解剖学研究 \\
\hline Bretschneidera sinensis & 伯乐树 & I & $\begin{array}{l}\text { 濒危 } \\
\text { /EN }\end{array}$ & 陈红锋 & 中国特有濒危植物伯乐树叶的结构特征 \\
\hline Bubo bubo & 雕鸮 & II & $\begin{array}{l}\text { 无危 } \\
\text { /LC }\end{array}$ & 李 叶 & 阿尔金山国家级自然保护区食肉鸟兽调查 \\
\hline Bubo bubo & 雕鸮 & II & $\begin{array}{l}\text { 无危 } \\
\text { /LC }\end{array}$ & 赵忠俊 & 阿夏自然保护区鸟类资源现状及保护策略 \\
\hline Bubo bubo & 雕鸮 & II & $\begin{array}{l}\text { 无危 } \\
\text { /LC }\end{array}$ & 姚积生 & 甘肃安南坝野骆驼国家级自然保护区野骆驼现状及其保护对策 \\
\hline Bubo bubo & 雕鸮 & II & 无危 & 陈 红 & 贵州省六盘水明湖国家湿地公园脊椎动物资源调查研究 \\
\hline
\end{tabular}


顾垒，闻丞，罗玫，王吴，吕植. 中国最受关注濒危物种保护现状快速评价的新方法探讨. 生物多样性，2015，23(5)：583-590. http://www. biodiversity-science. net/CN/article/downloadArticleFile. do?attachType=PDF\&id=10075

\begin{tabular}{|c|c|c|c|c|c|}
\hline & & & $/ \mathrm{LC}$ & & \\
\hline \multirow[t]{2}{*}{ Bubo bubo } & 雕鸮 & II & 无危 & 余丽江 & 桂西南青龙山自然保护区鸟类多样性和区系分析 \\
\hline & & & $/ \mathrm{LC}$ & & \\
\hline \multirow[t]{2}{*}{ Bubo bubo } & 雕鸮 & II & 无危 & 牛俊英 & 河南黄河湿地国家级自然保护区鸟类资源调查 \\
\hline & & & $/ \mathrm{LC}$ & & \\
\hline \multirow[t]{2}{*}{ Bubo bubo } & 雕鸮 & II & 无危 & 张佰莲 & 黑龙江大沾河湿地自然保护区鸟类群落结构调查及其多样性分析 \\
\hline & & & $/ \mathrm{LC}$ & & \\
\hline \multirow[t]{2}{*}{ Bubo bubo } & 雕鸮 & II & 无危 & 蒲发光 & 金寨天马国家级自然保护区鸟类多样性监测 \\
\hline & & & $/ \mathrm{LC}$ & & \\
\hline \multirow[t]{2}{*}{ Bubo bubo } & 雕鸮 & II & 无危 & 袁继林 & 雷公山自然保护区交密辖区鸟类多样性 \\
\hline & & & $/ \mathrm{LC}$ & & \\
\hline \multirow[t]{2}{*}{ Bubo bubo } & 雕鸮 & II & 无危 & 符建荣 & 米亚罗自然保护区的鸟类资源 \\
\hline & & & $/ \mathrm{LC}$ & & \\
\hline \multirow[t]{2}{*}{ Bubo bubo } & 雕鸮 & II & 无危 & 金志民 & 牡丹江海浪机场鸟类资源调查及鸟撞防范对策 \\
\hline & & & $/ \mathrm{LC}$ & & \\
\hline \multirow[t]{2}{*}{ Bubo bubo } & 雕鸮 & II & 无危 & 乌日罕 & 内蒙古阿尔山市北部鸟类区系组成及群落结构 \\
\hline & & & /LC & & \\
\hline \multirow[t]{2}{*}{ Bubo bubo } & 雕鸮 & II & 无危 & 那顺得力格尔 & 内蒙古赛罕乌拉自然保护区冬季鸟类多样性调查 \\
\hline & & & /LC & & \\
\hline
\end{tabular}


顾垒，闻丞，罗玫，王吴，吕植. 中国最受关注濒危物种保护现状快速评价的新方法探讨. 生物多样性，2015，23(5)：583-590. http://www, biodiversity-science. net/CN/article/downloadArticleFile. do?attachType=PDF\&id=10075

\begin{tabular}{|c|c|c|c|c|c|}
\hline Bubo bubo & 雕鸮 & II & $\begin{array}{l}\text { 无危 } \\
\text { /LC }\end{array}$ & 李元刚 & 宁夏贺兰山东麓荒漠草原区春季鸟类群落结构及多样性 \\
\hline Bubo bubo & 雕鸮 & II & $\begin{array}{l}\text { 无危 } \\
\text { /LC }\end{array}$ & 李元刚 & 宁夏贺兰山国家级自然保护区鸟类区系组成及其特征研究 \\
\hline Bubo bubo & 雕鸮 & II & $\begin{array}{l}\text { 无危 } \\
\text { /LC }\end{array}$ & 郝映红 & 山西庞泉沟保护区三种鸮的繁殖生态特性研究 \\
\hline Bubo bubo & 雕鸮 & II & $\begin{array}{l}\text { 无危 } \\
\text { /LC }\end{array}$ & 温战强 & 陕西米仓山自然保护区夏秋季鸟类调查 \\
\hline Bubo bubo & 雕鸮 & II & $\begin{array}{l}\text { 无危 } \\
\text { /LC }\end{array}$ & 杜雷军 & 陕西省黄柏塬自然保护区鸟类动物资源与区系特征分析 \\
\hline Bubo bubo & 雕鸮 & II & $\begin{array}{l}\text { 无危 } \\
\text { /LC }\end{array}$ & 符建荣 & 四川长沙贡玛自然保护区的鸟类资源 \\
\hline Bubo bubo & 雕鸮 & II & $\begin{array}{l}\text { 无危 } \\
\text { /LC }\end{array}$ & 舒 实 & 薤山自然保护区珍稀濒危野生脊椎动物调查 \\
\hline Budorcas taxicolor & 羚牛 & I & $\begin{array}{l}\text { 易危 } \\
\text { /VU }\end{array}$ & 侯盟 & GIS 在甘肃白水江国家级保护区多目标物种保护中的应用 \\
\hline Budorcas taxicolor & 羚牛 & I & $\begin{array}{l}\text { 易危 } \\
\text { /VU }\end{array}$ & 王静 & 羚牛分子系统地理学初探 \\
\hline Budorcas taxicolor & 羚牛 & I & 易危 & 麻应太 & 210 国道对牛背梁保 1 护区羚牛东西扩散影响的研究 (3) - 210 国道对羚牛东西扩散的 \\
\hline
\end{tabular}


顾垒，闻丞，罗玫，王吴，吕植. 中国最受关注濒危物种保护现状快速评价的新方法探讨. 生物多样性，2015，23(5)：583-590. http://www, biodiversity-science, net/CN/article/downloadArticleFile. do?attachType=PDF\&id=10075

\begin{tabular}{|c|c|c|c|c|c|}
\hline & & & $/ \mathrm{VU}$ & & 影响 \\
\hline Budorcas taxicolor & 羚牛 & I & $\begin{array}{l}\text { 易危 } \\
\text { /VU }\end{array}$ & 麻应太 & $\begin{array}{l}210 \text { 国道对牛背梁保护区羚牛东西扩散影响的研究 (1) - } 210 \text { 国道两侧羚牛东西扩散特 } \\
\text { 征 }\end{array}$ \\
\hline Budorcas taxicolor & 羚牛 & I & $\begin{array}{l}\text { 易危 } \\
\text { /VU }\end{array}$ & 麻应太 & 210 国道对牛背梁保护区羚牛东西扩散影响的研究 (2) - 210 国道车流量变化规律 \\
\hline Budorcas taxicolor & 扭角羚 & I & $\begin{array}{l}\text { 易危 } \\
\text { /VU }\end{array}$ & Dongwei Kang & Can conservation of single surrogate species protect co-occurring species \\
\hline Budorcas taxicolor & 羚牛 & I & $\begin{array}{l}\text { 易危 } \\
\text { /VU }\end{array}$ & Ning Li & $\begin{array}{l}\text { Cloned Endangered Species Takin (Budorcas taxicolor) by Inter-Species Nuclear Transfer and } \\
\text { Comparison of the Blastocyst Development With Yak (Bos grunniens) and Bovine }\end{array}$ \\
\hline Budorcas taxicolor & 羚牛 & I & $\begin{array}{l}\text { 易危 } \\
\text { /VU }\end{array}$ & LEI Chu-zhao & $\begin{array}{l}\text { Diurnal activity rhythms and time budgets of captive Qinling golden takin (Budorcas taxicolor } \\
\text { bedfordi) in the Qinling Mountains, Shaanxi, China }\end{array}$ \\
\hline Budorcas taxicolor & 羚牛 & I & $\begin{array}{l}\text { 易危 } \\
\text { /VU }\end{array}$ & Yan Ling Song & $\begin{array}{l}\text { Does a temperate ungulate that breeds in summer exhibit rut-induced hypophagia? Analysis of } \\
\text { time budgets of male takin (Budorcas taxicolor) in Sichuan, China }\end{array}$ \\
\hline Budorcas taxicolor & 羚牛 & I & $\begin{array}{l}\text { 易危 } \\
\text { /VU }\end{array}$ & 李石华 & DTM 在高黎贡山羚牛潜在生境研究中的应用 \\
\hline Budorcas taxicolor & 羚牛 & I & $\begin{array}{l}\text { 易危 } \\
\text { /VU }\end{array}$ & Yan-Ling Song & $\begin{array}{l}\text { Effects of an earthquake on wildlife behavior: a case study of takin (Budorcas taxicolor) in } \\
\text { Tangjiahe National Nature Reserve, China }\end{array}$ \\
\hline Budorcas taxicolor & 羚牛 & I & $\begin{array}{l}\text { 易危 } \\
\text { /VU }\end{array}$ & Fuwen Wei & $\begin{array}{l}\text { Genetic structure and phylogeography of the takin (Budorcas taxicolor) as inferred from } \\
\text { mitochondrial DNA sequences }\end{array}$ \\
\hline
\end{tabular}


顾垒，闻丞，罗玫，王吴，吕植. 中国最受关注濒危物种保护现状快速评价的新方法探讨. 生物多样性，2015，23(5)：583-590. http://www. biodiversity-science. net/CN/article/downloadArticleFile. do?attachType=PDF\&id=10075

\begin{tabular}{|c|c|c|c|c|c|}
\hline Budorcas taxicolor & 羚牛 & I & $\begin{array}{l}\text { 易危 } \\
\text { /VU }\end{array}$ & Yan-Ling Song & Isolation and characterization of nine microsatellite loci for the takin (Budorcas taxicolor) \\
\hline Budorcas taxicolor & 羚牛 & I & $\begin{array}{l}\text { 易危 } \\
\text { /VU }\end{array}$ & Yulin Chen & $\begin{array}{l}\text { Simultaneous cloning and expression of two cellulase genes from Bacillus subtilis newly } \\
\text { isolated from Golden Takin (Budorcas taxicolor Bedfordi) }\end{array}$ \\
\hline Budorcas taxicolor & 羚牛 & I & $\begin{array}{l}\text { 易危 } \\
\text { /VU }\end{array}$ & 张恩迪 & 藏东南地区羚牛和镾羚栖息地利用的种间关系 \\
\hline Budorcas taxicolor & 羚牛 & I & $\begin{array}{l}\text { 易危 } \\
\text { /VU }\end{array}$ & 宋延龄 & 地形因素对羚牛家域估算的影响分析一以固定核域法与最小凸边形法为例 \\
\hline Budorcas taxicolor & 羚牛 & I & $\begin{array}{l}\text { 易危 } \\
\text { /VU }\end{array}$ & 夏未铭 & 佛坪自然保护区野生动物资源动态研究 \\
\hline Budorcas taxicolor & 羚牛 & I & $\begin{array}{l}\text { 易危 } \\
\text { /VU }\end{array}$ & 李石华 & 高黎贡山北段羚牛生境 DTM 数据分析与评价应用 \\
\hline Budorcas taxicolor & 羚牛 & I & $\begin{array}{l}\text { 易危 } \\
\text { /VU }\end{array}$ & 陈姚 & 高黎贡山羚牛生境恢复及优化研究 \\
\hline Budorcas taxicolor & 羚牛 & I & $\begin{array}{l}\text { 易危 } \\
\text { /VU }\end{array}$ & 李石华 & 高黎贡山羚牛生境选择初步研究 \\
\hline Budorcas taxicolor & 羚牛 & I & $\begin{array}{l}\text { 易危 } \\
\text { /VU }\end{array}$ & 杨芳 & 光头山地区羚牛种群分布与变化 \\
\hline Budorcas taxicolor & 羚牛 & I & 易危 & 宋延龄 & 羚牛 \\
\hline
\end{tabular}


顾垒，闻丞，罗玫，王吴，吕植. 中国最受关注濒危物种保护现状快速评价的新方法探讨. 生物多样性，2015，23(5)：583-590. http://www. biodiversity-science. net/CN/article/downloadArticleFile. do?attachType=PDF\&id=10075

\begin{tabular}{|c|c|c|c|c|c|}
\hline & & & $/ \mathrm{VU}$ & & \\
\hline \multirow[t]{2}{*}{ Budorcas taxicolor } & 羚牛 & I & 易危 & 魏辅文 & 羚牛的遗传多样性及其种群遗传结构分析 \\
\hline & & & $/ \mathrm{VU}$ & & \\
\hline \multirow[t]{2}{*}{ Budorcas taxicolor } & 羚牛 & I & 易危 & 宋延龄 & 羚牛股骨密质骨力学性能的实验研究 \\
\hline & & & /VU & & \\
\hline \multirow[t]{2}{*}{ Budorcas taxicolor } & 羚牛 & I & 易危 & 宋延龄 & 羚牛生态生物学研究现状 \\
\hline & & & $/ \mathrm{VU}$ & & \\
\hline \multirow[t]{2}{*}{ Budorcas taxicolor } & 羚牛 & I & 易危 & 蒙世杰 & 羚牛细胞色素 b 基因序列分析和系统进化研究 \\
\hline & & & $/ \mathrm{VU}$ & & \\
\hline \multirow[t]{2}{*}{ Budorcas taxicolor } & 羚牛 & I & 易危 & 高德贵 & 羚牛线粒体 DNA 和系统进化研究 \\
\hline & & & $/ \mathrm{VU}$ & & \\
\hline \multirow[t]{2}{*}{ Budorcas taxicolor } & 羚牛 & I & 易危 & 艾怀森 & 羚牛在中国的地理分布与生态研究现状 \\
\hline & & & /VU & & \\
\hline \multirow[t]{2}{*}{ Budorcas taxicolor } & 羚牛 & I & 易危 & 邵建斌 & 牛背梁国家级自然保护区羚牛种群状况及濒危原因分析 \\
\hline & & & /VU & & \\
\hline \multirow[t]{2}{*}{ Budorcas taxicolor } & 羚牛 & I & 易危 & 宋延龄 & 陕西佛坪国家级自然保护区羚牛的容纳量 \\
\hline & & & /VU & & \\
\hline \multirow[t]{2}{*}{ Budorcas taxicolor } & 羚牛 & I & 易危 & 冯成利 & 陕西省羚牛 mtDNA 控制区序列结构和种群遗传多样性分析 \\
\hline & & & /VU & & \\
\hline
\end{tabular}


顾垒，闻丞，罗玫，王吴，吕植. 中国最受关注濒危物种保护现状快速评价的新方法探讨. 生物多样性，2015，23(5)：583-590. http://www, biodiversity-science. net/CN/article/downloadArticleFile. do?attachType=PDF\&id=10075

\begin{tabular}{|c|c|c|c|c|c|}
\hline Budorcas taxicolor & 羚牛 & I & $\begin{array}{l}\text { 易危 } \\
\text { /VU }\end{array}$ & 袁朝晖 & 陕西长青自然保护区羚牛冬春季对栖息地的选择 \\
\hline Budorcas taxicolor & 羚牛 & I & $\begin{array}{l}\text { 易危 } \\
\text { /VU }\end{array}$ & 康蔼黎 & 饲养条件下羚牛母幼行为的初步研究 \\
\hline Budorcas taxicolor & 羚牛 & I & $\begin{array}{l}\text { 易危 } \\
\text { /VU }\end{array}$ & 马世平 & 天华山国家级保护区羚牛种群分布现状调查 \\
\hline Budorcas taxicolor & 羚牛 & I & $\begin{array}{l}\text { 易危 } \\
\text { /VU }\end{array}$ & 张恩迪 & 西藏慈巴沟自然保护区羚牛集群现象初探 \\
\hline Budorcas taxicolor & 羚牛 & I & $\begin{array}{l}\text { 易危 } \\
\text { /VU }\end{array}$ & 张恩迪 & 西藏慈巴沟自然保护区羚牛栖息地选择 \\
\hline Budorcas taxicolor & 羚牛 & I & $\begin{array}{l}\text { 易危 } \\
\text { /VU }\end{array}$ & 张恩迪 & 西藏慈巴沟自然保护区主要偶蹄类动物春季垂直分布和栖息地分化 \\
\hline Budorcas taxicolor & 羚牛 & I & $\begin{array}{l}\text { 易危 } \\
\text { /VU }\end{array}$ & 麻奎太 & 夏秋季羚牛对长青自然保护区境内栖息地的选择初报 \\
\hline Budorcas taxicolor & 羚牛 & I & $\begin{array}{l}\text { 易危 } \\
\text { /VU }\end{array}$ & 李玉梅 & 雅鲁藏布大峡谷羚牛牙齿珐琅质碳、氧同位素组成及其环境意义 \\
\hline Budorcas taxicolor & 羚牛 & I & $\begin{array}{l}\text { 易危 } \\
\text { /VU }\end{array}$ & 冯成利 & 应用线粒体 DNA 序列探讨羚牛分类地位 \\
\hline Budorcas taxicolor & 羚牛 & I & 易危 & 魏辅文 & 用 mtDNA 序列探讨羚牛亚种分类 \\
\hline
\end{tabular}


顾垒，闻丞，罗玫，王吴，吕植. 中国最受关注濒危物种保护现状快速评价的新方法探讨. 生物多样性，2015，23(5)：583-590. http://www. biodiversity-science. net/CN/article/downloadArticleFile. do?attachType=PDF\&id=10075

\begin{tabular}{|c|c|c|c|c|c|}
\hline & & & $/ \mathrm{VU}$ & & \\
\hline \multirow[t]{2}{*}{ Budorcas taxicolor } & 羚牛 & I & 易危 & 张国珺 & 云南境内羚牛分布的研究 \\
\hline & & & /VU & & \\
\hline \multirow[t]{2}{*}{ Budorcas taxicolor } & 羚牛 & I & 易危 & 李晓晨 & 中国早更新世羚牛化石记述 \\
\hline & & & /VU & & \\
\hline \multirow[t]{2}{*}{ Budorcas taxicolor bedfordi } & 扭角羚 & I & 易危 & Yanling Song & Effects of plant phenology and solar radiation on seasonal movement of golden takin in the \\
\hline & & & /VU & & Qinling Mountains, China \\
\hline \multirow[t]{2}{*}{ Bulleyia yunnanensis } & 蜂腰兰 & II & 濒危 & 杨俊波 & 云南蜂腰兰的快速繁殖和离体保存 \\
\hline & & & /EN & & \\
\hline \multirow[t]{3}{*}{ Bungarus fasciatus } & 金环蛇 & 未列 & 末评 & Ren Lai and Jingze & A novel serine protease inhibitor from Bungarus fasciatus venom \\
\hline & & 入 & 价 & Liu & \\
\hline & & & $/ \mathrm{NE}$ & & \\
\hline \multirow[t]{3}{*}{ Bungarus fasciatus } & 金环蛇 & 未列 & 未评 & Lai Ren & A novel trypsin inhibitor from bungarus fasciatus venom \\
\hline & & 入 & 价 & & \\
\hline & & & $/ \mathrm{NE}$ & & \\
\hline \multirow[t]{3}{*}{ Bungarus fasciatus } & 金环蛇 & 未列 & 未评 & Y. Zhang & Cloning of cDNAs encoding C-type lectins from Elapidae snakes Bungarus fasciatus and \\
\hline & & 入 & 价 & & Bungarus multicinctus \\
\hline & & & $/ \mathrm{NE}$ & & \\
\hline Bungarus fasciatus & 金环蛇 & 未列 & 未评 & Shao-Heng He & Purification, characterization and biological activities of the L-amino acid oxidase from \\
\hline
\end{tabular}


顾垒，闻丞，罗玫，王吴，吕植. 中国最受关注濒危物种保护现状快速评价的新方法探讨. 生物多样性，2015，23(5)：583-590. http://www. biodiversity-science. net/CN/article/downloadArticleFile. do?attachType=PDF\&id=10075

\begin{tabular}{|c|c|c|c|c|c|}
\hline & & 入 & 价 & & Bungarus fasciatus snake venom \\
\hline Bungarus fasciatus & 金环蛇 & $\begin{array}{l}\text { 未列 } \\
\text { 入 }\end{array}$ & $\begin{array}{l}/ \mathrm{NE} \\
\text { 未评 } \\
\text { 价 }\end{array}$ & 张云 & Sepharose 4B 一步法对金环蛇蛇毒磷脂酶 A2 的分离纯化 \\
\hline Bungarus fasciatus & 金环蛇 & $\begin{array}{l}\text { 未列 } \\
\lambda\end{array}$ & $\begin{array}{l}/ \mathrm{NE} \\
\text { 未评 } \\
\text { 价 }\end{array}$ & $\begin{array}{l}\text { Ren Lai and Donghai } \\
\text { Lin }\end{array}$ & Snake Cathelicidin from Bungarus fasciatus Is a Potent Peptide Antibiotics \\
\hline Bungarus fasciatus & 金环蛇 & $\begin{array}{l}\text { 未列 } \\
\lambda\end{array}$ & $\begin{array}{l}/ \mathrm{NE} \\
\text { 未评 } \\
\text { 价 }\end{array}$ & 何韶衡 & 金环蛇 L-氨基酸氧化酶诱导人脐静脉内皮细胞凋亡的研究 \\
\hline Bungarus fasciatus & 金环蛇 & $\begin{array}{l}\text { 未列 } \\
入\end{array}$ & $\begin{array}{l}/ \mathrm{NE} \\
\text { 未评 } \\
\text { 价 }\end{array}$ & 肖月 & 金环蛇毒细胞毒素的分离纯化及其抗肿瘤作用的实验研究 \\
\hline Bungarus fasciatus & 金环蛇 & $\begin{array}{l}\text { 未列 } \\
\text { 入 }\end{array}$ & $\begin{array}{l}/ \mathrm{NE} \\
\text { 未评 } \\
\text { 价 }\end{array}$ & 肖月 & 金环蛇毒细胞毒素抗肿瘤研究现状的分析 \\
\hline Bungarus fasciatus & 金环蛇 & $\begin{array}{l}\text { 未列 } \\
\lambda\end{array}$ & $\begin{array}{l}/ \mathrm{NE} \\
\text { 未评 } \\
\text { 价 }\end{array}$ & 徐春花 & 金环蛇蛇毒磷脂酶 A2 的分离纯化、分子克隆以及生理活性研究 \\
\hline
\end{tabular}


顾垒，闻丞，罗玫，王吴，吕植. 中国最受关注濒危物种保护现状快速评价的新方法探讨. 生物多样性，2015，23(5)：583-590. http://www. biodiversity-science. net/CN/article/downloadArticleFile. do?attachType=PDF\&id=10075

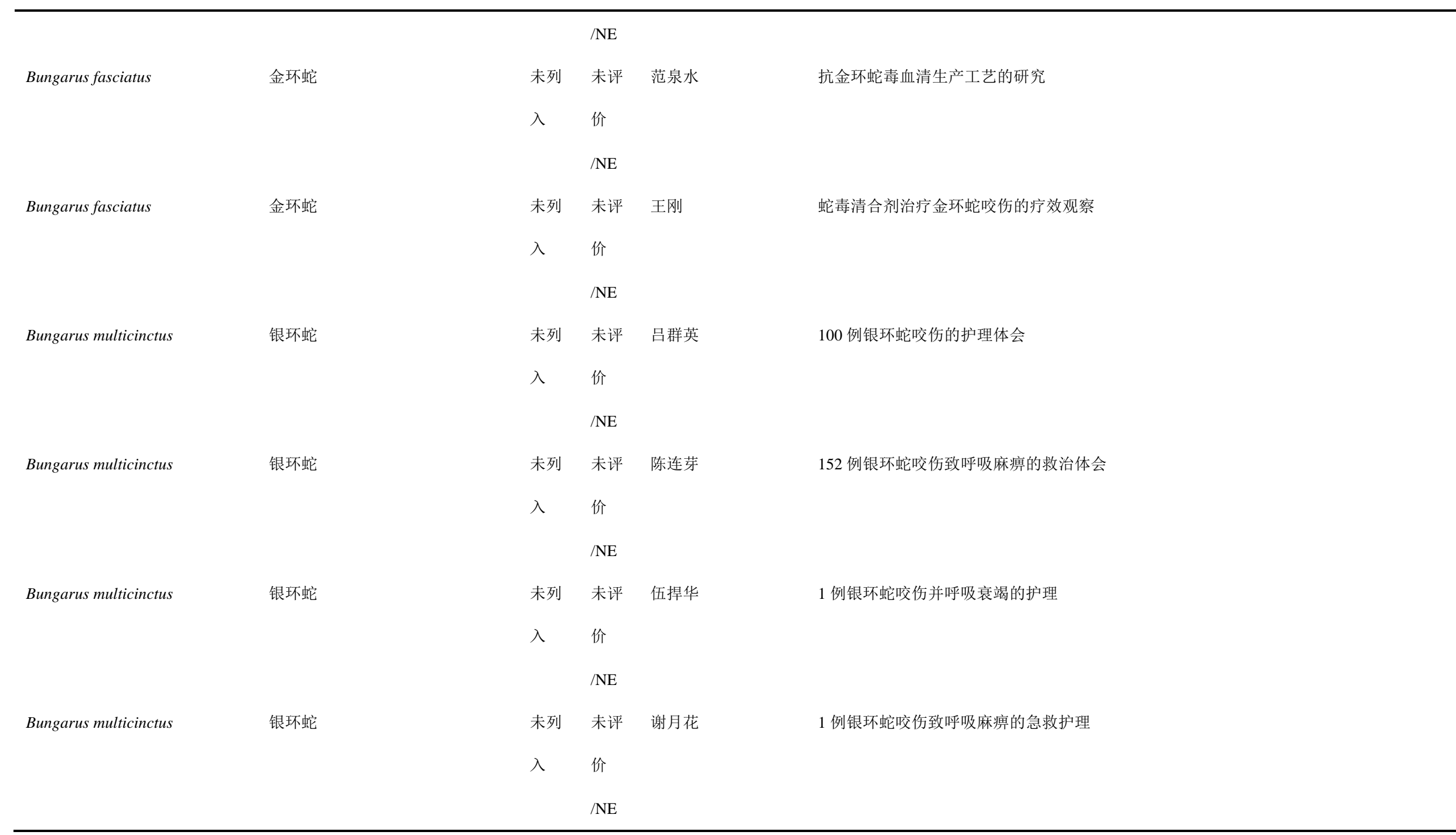


顾垒，闻丞，罗玫，王吴，吕植. 中国最受关注濒危物种保护现状快速评价的新方法探讨. 生物多样性，2015，23(5)：583-590. http://www. biodiversity-science. net/CN/article/downloadArticleFile. do?attachType=PDF\&id=10075

\begin{tabular}{|c|c|c|c|c|c|}
\hline \multirow[t]{2}{*}{ Bungarus multicinctus } & 银环蛇 & 未列 & 未评 & 杜洁 & 1 例银环蛇咬伤致心跳骤停及呼吸衰竭的护理 \\
\hline & & 入 & $\begin{array}{l}\text { 价 } \\
/ \mathrm{NE}\end{array}$ & & \\
\hline \multirow[t]{3}{*}{ Bungarus multicinctus } & 银环蛇 & 未列 & 未评 & 颜月花 & 1 例银环蛇咬伤致心跳骤停及呼吸衰竭的护理体会 \\
\hline & & 入 & 价 & & \\
\hline & & & $/ \mathrm{NE}$ & & \\
\hline \multirow[t]{3}{*}{ Bungarus multicinctus } & 银环蛇 & 未列 & 未评 & 徐诗玉 & 1 例银环蛇咬伤致严重呼吸衰竭的救治体会 \\
\hline & & 入 & 价 & & \\
\hline & & & $/ \mathrm{NE}$ & & \\
\hline \multirow[t]{3}{*}{ Bungarus multicinctus } & 银环蛇 & 未列 & 未评 & 蓝顶琴 & 1 例银环蛇咬伤致自主呼吸停止的抢救 \\
\hline & & 入 & 价 & & \\
\hline & & & $/ \mathrm{NE}$ & & \\
\hline \multirow[t]{3}{*}{ Bungarus multicinctus } & 银环蛇 & 未列 & 未评 & 邱芙蓉 & 1 例银环蛇咬伤中毒患者的抢救与护理 \\
\hline & & 入 & 价 & & \\
\hline & & & $/ \mathrm{NE}$ & & \\
\hline \multirow[t]{3}{*}{ Bungarus multicinctus } & 银环蛇 & 未列 & 未评 & 蒋风莲 & 21 例银环蛇咬伤病人的急救观察和护理 \\
\hline & & 入 & 价 & & \\
\hline & & & $/ \mathrm{NE}$ & & \\
\hline Bungarus multicinctus & 银环蛇 & 未列 & 未评 & 黄雪梅 & 28 例银环蛇咬伤致呼吸衰竭病人的抢救及护理 \\
\hline
\end{tabular}


顾垒，闻丞，罗玫，王吴，吕植. 中国最受关注濒危物种保护现状快速评价的新方法探讨. 生物多样性，2015，23(5)：583-590. http://www. biodiversity-science. net/CN/article/downloadArticleFile. do?attachType=PDF\&id=10075

\begin{tabular}{|c|c|c|c|c|c|}
\hline & & 入 & 价 & & \\
\hline & & & $/ \mathrm{NE}$ & & \\
\hline \multirow[t]{2}{*}{ Bungarus multicinctus } & 银环蛇 & 未列 & 无危 & 陈爱亮 & B-银环蛇毒素研究进展 \\
\hline & & 入 & $/ \mathrm{LC}$ & & \\
\hline \multirow[t]{2}{*}{ Bungarus multicinctus } & 银环蛇 & 未列 & 无危 & Yi-Quan Wang & Cloning, expression and characterization of two C-type lectins from the venom gland of \\
\hline & & 入 & $/ \mathrm{LC}$ & & Bungarus multicinctus \\
\hline \multirow[t]{2}{*}{ Bungarus multicinctus } & 银环蛇 & 未列 & 无危 & Naisheng ZHANG & Induced Expression and Optimal Expression Conditions of Recombinant Alpha-bungarotoxin \\
\hline & & 入 & $/ \mathrm{LC}$ & & Gene Fusion Protein \\
\hline \multirow[t]{2}{*}{ Bungarus multicinctus } & 银环蛇 & 未列 & 无危 & QIAN You-cun & MOLECULAR CLONING AND FUNCTIONAL EXPRESSION OF a -BUNGAROTOXIN \\
\hline & & 入 & $/ \mathrm{LC}$ & & (V31)FROM CHINESE CONTINENTAL BANDED KRAIT \\
\hline \multirow[t]{2}{*}{ Bungarus multicinctus } & 银环蛇 & 未列 & 无危 & 谢光洪 & $a-$-银环蛇毒素单克隆抗体的研究进展 \\
\hline & & 入 & $/ \mathrm{LC}$ & & \\
\hline \multirow[t]{3}{*}{ Bungarus multicinctus } & 银环蛇 & 未列 & 未评 & 范泉水 & $\alpha-$-银环蛇毒素和 $\beta$-银环蛇毒素的研究进展 \\
\hline & & 入 & 价 & & \\
\hline & & & $/ \mathrm{NE}$ & & \\
\hline \multirow[t]{2}{*}{ Bungarus multicinctus } & 银环蛇 & 未列 & 无危 & 胡延春 & $\alpha$-银环蛇毒素基因的克隆及其非融合型原核表达 \\
\hline & & 入 & $/ \mathrm{LC}$ & & \\
\hline \multirow[t]{2}{*}{ Bungarus multicinctus } & 银环蛇 & 未列 & 无危 & 胡延春 & $\alpha$-银环蛇毒素融合基因表达载体的构建及原核表达 \\
\hline & & 入 & $/ \mathrm{LC}$ & & \\
\hline
\end{tabular}


顾垒，闻丞，罗玫，王吴，吕植. 中国最受关注濒危物种保护现状快速评价的新方法探讨. 生物多样性，2015，23(5)：583-590. http://www. biodiversity-science. net/CN/article/downloadArticleFile. do?attachType=PDF\&id=10075

\begin{tabular}{|c|c|c|c|c|c|}
\hline \multirow[t]{2}{*}{ Bungarus multicinctus } & 银环蛇 & 未列 & 无危 & 王义权 & $a-$-银环蛇毒素同工毒素基因的克隆和表达 \\
\hline & & 入 & $/ \mathrm{LC}$ & & \\
\hline \multirow[t]{3}{*}{ Bungarus multicinctus } & 银环蛇 & 未列 & 未评 & 邓清委 & $\beta$-银环蛇毒素对神经系统的影响及其作用机理 \\
\hline & & 入 & 价 & & \\
\hline & & & $/ \mathrm{NE}$ & & \\
\hline \multirow[t]{3}{*}{ Bungarus multicinctus } & 银环蛇 & 未列 & 未评 & 陈爱亮 & $\beta$-银环蛇毒素研究进展 \\
\hline & & 入 & 价 & & \\
\hline & & & $/ \mathrm{NE}$ & & \\
\hline \multirow[t]{2}{*}{ Bungarus multicinctus } & 银环蛇 & 未列 & 无危 & 沈国光 & $\beta$-银环蛇神经毒素结合蛋白的分离纯化 \\
\hline & & 入 & $/ \mathrm{LC}$ & & \\
\hline \multirow[t]{3}{*}{ Bungarus multicinctus } & 银环蛇 & 未列 & 未评 & 孔天翰 & 变异银环蛇的蛇毒及 DNA 分析研究 \\
\hline & & 入 & 价 & & \\
\hline & & & $/ \mathrm{NE}$ & & \\
\hline \multirow[t]{2}{*}{ Bungarus multicinctus } & 银环蛇 & 未列 & 无危 & 高荣凯 & 蛋白III- $\alpha$-银环蛇毒素融合蛋白表达质粒的构建及表达 \\
\hline & & 入 & $/ \mathrm{LC}$ & & \\
\hline \multirow[t]{3}{*}{ Bungarus multicinctus } & 银环蛇 & 未列 & 未评 & 廖辉奇 & 儿童银环蛇咬伤 46 例诊治 \\
\hline & & 入 & 价 & & \\
\hline & & & $/ \mathrm{NE}$ & & \\
\hline Bungarus multicinctus & 银环蛇 & 未列 & 未评 & 邓海霞 & 广西银环蛇咬伤中毒 147 例临床观察 \\
\hline
\end{tabular}


顾垒，闻丞，罗玫，王吴，吕植. 中国最受关注濒危物种保护现状快速评价的新方法探讨. 生物多样性，2015，23(5)：583-590. http.//www, biodiversity-science. net/CN/article/downloadArticleFile. do?attachType=PDF\&id=10075

\begin{tabular}{|c|c|c|c|c|c|}
\hline & & 入 & $\begin{array}{l}\text { 价 } \\
/ \mathrm{NE}\end{array}$ & & \\
\hline Bungarus multicinctus & 银环蛇 & $\begin{array}{l}\text { 未列 } \\
入\end{array}$ & $\begin{array}{l}\text { 无危 } \\
\text { /LC }\end{array}$ & 魏刚 & 贵州蛇类新记录———银环蛇云南亚种 \\
\hline Bungarus multicinctus & 银环蛇 & $\begin{array}{l}\text { 未列 } \\
\lambda\end{array}$ & $\begin{array}{l}\text { 未评 } \\
\text { 价 } \\
\text { /NE }\end{array}$ & 袁麟标 & 呼吸机治疗银环蛇咬伤 20 例 \\
\hline Bungarus multicinctus & 银环蛇 & $\begin{array}{l}\text { 未列 } \\
入\end{array}$ & $\begin{array}{l}\text { 未评 } \\
\text { 价 } \\
\text { /NE }\end{array}$ & 张剑锋 & 机械通气辅助抗蛇毒血清抢救银环蛇咬伤致呼吸衰竭的临床分析 \\
\hline Bungarus multicinctus & 银环蛇 & $\begin{array}{l}\text { 未列 } \\
入\end{array}$ & $\begin{array}{l}\text { 未评 } \\
\text { 价 } \\
\text { /NE }\end{array}$ & 李宏键 & 机械通气救治 4 例银环蛇咬伤急性呼吸衰竭 \\
\hline Bungarus multicinctus & 银环蛇 & $\begin{array}{l}\text { 未列 } \\
\text { 入 }\end{array}$ & $\begin{array}{l}\text { 未评 } \\
\text { 价 } \\
\text { /NE }\end{array}$ & 刘宏伟 & 机械通气在银环蛇咬伤致急性呼吸衰竭中的临床疗效观察 \\
\hline Bungarus multicinctus & 银环蛇 & $\begin{array}{l}\text { 未列 } \\
入\end{array}$ & $\begin{array}{l}\text { 未评 } \\
\text { 价 } \\
\text { /NE }\end{array}$ & 谢丽玲 & 江西产银环蛇毒中 K-神经毒素的分离纯化 \\
\hline
\end{tabular}


顾垒，闻丞，罗玫，王吴，吕植. 中国最受关注濒危物种保护现状快速评价的新方法探讨. 生物多样性，2015，23(5)：583-590. http://www. biodiversity-science. net/CN/article/downloadArticleFile. do?attachType=PDF\&id=10075

\begin{tabular}{|c|c|c|c|c|c|}
\hline \multirow[t]{3}{*}{ Bungarus multicinctus } & 银环蛇 & 未列 & 未评 & 李权怀 & 救治银环蛇咬伤致呼吸衰竭 1 例报告 \\
\hline & & 入 & 价 & & \\
\hline & & & $/ \mathrm{NE}$ & & \\
\hline \multirow[t]{2}{*}{ Bungarus multicinctus } & 银环蛇 & 未列 & 无危 & 王义权 & 两个蛇毒基因克隆及 cDNA 序列多态性再分析 \\
\hline & & 入 & $/ \mathrm{LC}$ & & \\
\hline \multirow[t]{2}{*}{ Bungarus multicinctus } & 银环蛇 & 未列 & 无危 & 张曼 & 色变银环蛇与正常银环蛇的形态学及毒性比较研究 \\
\hline & & 入 & $/ \mathrm{LC}$ & & \\
\hline \multirow[t]{3}{*}{ Bungarus multicinctus } & 银环蛇 & 未列 & 未评 & 张曼 & 色变银环蛇与正常银环蛇的形态学及毒性比较研究 \\
\hline & & 入 & 价 & & \\
\hline & & & $/ \mathrm{NE}$ & & \\
\hline \multirow[t]{3}{*}{ Bungarus multicinctus } & 银环蛇 & 未列 & 未评 & 邓念强 & 纤支镜常规治疗银环蛇咬伤中毒机械通气患者的临床价值 \\
\hline & & 入 & 价 & & \\
\hline & & & $/ \mathrm{NE}$ & & \\
\hline \multirow[t]{3}{*}{ Bungarus multicinctus } & 银环蛇 & 未列 & 未评 & 周柯 & 纤支镜引导经鼻气管插管治疗银环蛇咬伤患者的效果观察 \\
\hline & & 入 & 价 & & \\
\hline & & & $/ \mathrm{NE}$ & & \\
\hline \multirow[t]{3}{*}{ Bungarus multicinctus } & 银环蛇 & 未列 & 未评 & 王云生 & 血液灌流加血液透析抢救银环蛇咬伤中毒 1 例 \\
\hline & & 入 & 价 & & \\
\hline & & & $/ \mathrm{NE}$ & & \\
\hline
\end{tabular}


顾垒，闻丞，罗玫，王吴，吕植. 中国最受关注濒危物种保护现状快速评价的新方法探讨. 生物多样性，2015，23(5)：583-590. http://www. biodiversity-science. net/CN/article/downloadArticleFile. do?attachType=PDF\&id=10075

\begin{tabular}{|c|c|c|c|c|c|}
\hline \multirow[t]{3}{*}{ Bungarus multicinctus } & 银环蛇 & 未列 & 未评 & 任菡霖 & 一例银环蛇咬伤致呼吸衰竭病人的抢救及护理 \\
\hline & & 入 & 价 & & \\
\hline & & & $/ \mathrm{NE}$ & & \\
\hline \multirow[t]{3}{*}{ Bungarus multicinctus } & 银环蛇 & 未列 & 未评 & 林俊敏 & 银环毒蛇咬伤综合救治 40 例 \\
\hline & & 入 & 价 & & \\
\hline & & & $/ \mathrm{NE}$ & & \\
\hline \multirow[t]{3}{*}{ Bungarus multicinctus } & 银环蛇 & 未列 & 未评 & 刘洁生 & 银环蛇粗毒若干有效成分对 SWO 细胞的作用 \\
\hline & & 入 & 价 & & \\
\hline & & & $/ \mathrm{NE}$ & & \\
\hline \multirow[t]{2}{*}{ Bungarus multicinctus } & 银环蛇 & 未列 & 无危 & 刘刚 & 银环蛇的人工饲养 \\
\hline & & 入 & $/ \mathrm{LC}$ & & \\
\hline \multirow[t]{2}{*}{ Bungarus multicinctus } & 银环蛇 & 未列 & 无危 & 陈永德 & 银环蛇的人工养殖技术 \\
\hline & & 入 & $/ \mathrm{LC}$ & & \\
\hline \multirow[t]{3}{*}{ Bungarus multicinctus } & 银环蛇 & 未列 & 未评 & 陈勇 & 银环蛇毒素对白血病 K562 细胞株的毒性作用研究 \\
\hline & & 入 & 价 & & \\
\hline & & & $/ \mathrm{NE}$ & & \\
\hline \multirow[t]{3}{*}{ Bungarus multicinctus } & 银环蛇 & 未列 & 未评 & 陈勇 & 银环蛇毒素对白血病 K562 细胞株调亡诱导作用的研究 \\
\hline & & 入 & 价 & & \\
\hline & & & $/ \mathrm{NE}$ & & \\
\hline
\end{tabular}


顾垒，闻丞，罗玫，王吴，吕植. 中国最受关注濒危物种保护现状快速评价的新方法探讨. 生物多样性，2015，23(5)：583-590. http://www. biodiversity-science. net/CN/article/downloadArticleFile. do?attachType=PDF\&id=10075

\begin{tabular}{|c|c|c|c|c|c|}
\hline \multirow[t]{2}{*}{ Bungarus multicinctus } & 银环蛇 & 未列 & 无危 & 胡延春 & 银环蛇毒素及其基因工程研究进展 \\
\hline & & 入 & $/ \mathrm{LC}$ & & \\
\hline \multirow[t]{2}{*}{ Bungarus multicinctus } & 银环蛇 & 未列 & 无危 & 陈勇 & 银环蛇毒素若干组分诱导人慢性粒细胞白血病 K562 肿瘤细胞的调亡研究 \\
\hline & & 入 & $/ \mathrm{LC}$ & & \\
\hline \multirow[t]{3}{*}{ Bungarus multicinctus } & 银环蛇 & 未列 & 未评 & 陈勇 & 银环蛇毒素若干组分诱导人慢性粒细胞白血病 K562 肿瘤细胞的凋亡研究 \\
\hline & & 入 & 价 & & \\
\hline & & & $/ \mathrm{NE}$ & & \\
\hline \multirow[t]{3}{*}{ Bungarus multicinctus } & 银环蛇 & 未列 & 未评 & 朱豫珊 & 银环蛇酒治疗风湿痛㿎 100 例疗效观察 \\
\hline & & 入 & 价 & & \\
\hline & & & $/ \mathrm{NE}$ & & \\
\hline \multirow[t]{2}{*}{ Bungarus multicinctus } & 银环蛇 & 未列 & 无危 & 曾芸 & 银环蛇奇异变形杆菌的分离鉴定与药敏试验 \\
\hline & & 入 & $/ \mathrm{LC}$ & & \\
\hline \multirow[t]{3}{*}{ Bungarus multicinctus } & 银环蛇 & 未列 & 未评 & 李力、曾芸 & 银环蛇奇异变形杆菌的分离鉴定与药敏试验 \\
\hline & & 入 & 价 & & \\
\hline & & & $/ \mathrm{NE}$ & & \\
\hline \multirow[t]{3}{*}{ Bungarus multicinctus } & 银环蛇 & 未列 & 未评 & 梁平 & 银环蛇伤中毒致呼吸衰竭行气管切开术时机选择的研究 \\
\hline & & 入 & 价 & & \\
\hline & & & $/ \mathrm{NE}$ & & \\
\hline Bungarus multicinctus & 银环蛇 & 未列 & 未评 & 陈姘 & 银环蛇蛇毒毛细管电泳分离与鉴定 \\
\hline
\end{tabular}


顾垒，闻丞，罗玫，王吴，吕植. 中国最受关注濒危物种保护现状快速评价的新方法探讨. 生物多样性，2015，23(5)：583-590. http://www. biodiversity-science. net/CN/article/downloadArticleFile. do?attachType=PDF\&id=10075

\begin{tabular}{|c|c|c|c|c|c|}
\hline & & 入 & 价 & & \\
\hline & & & $/ \mathrm{NE}$ & & \\
\hline \multirow[t]{2}{*}{ Bungarus multicinctus } & 银环蛇 & 未列 & 无危 & 林鲁萍 & 银环蛇蛇毒相关基因的克隆和表达研究 \\
\hline & & 入 & $/ \mathrm{LC}$ & & \\
\hline \multirow[t]{3}{*}{ Bungarus multicinctus } & 银环蛇 & 未列 & 未评 & 陈红红 & 银环蛇蛇蜕的化学成分研究_脂肪酸和氨基酸组分 \\
\hline & & 入 & 价 & & \\
\hline & & & $/ \mathrm{NE}$ & & \\
\hline \multirow[t]{3}{*}{ Bungarus multicinctus } & 银环蛇 & 未列 & 未评 & 张浩晨 & 银环蛇神经毒素的生物信息学研究 \\
\hline & & 入 & 价 & & \\
\hline & & & $/ \mathrm{NE}$ & & \\
\hline \multirow[t]{2}{*}{ Bungarus multicinctus } & 银环蛇 & 未列 & 无危 & 赵树进 & 银环蛇线粒体基因组全序列分析 \\
\hline & & 入 & $/ \mathrm{LC}$ & & \\
\hline \multirow[t]{3}{*}{ Bungarus multicinctus } & 银环蛇 & 未列 & 未评 & 赵树进 & 银环蛇线粒体基因组全序列分析 \\
\hline & & 入 & 价 & & \\
\hline & & & $/ \mathrm{NE}$ & & \\
\hline \multirow[t]{2}{*}{ Bungarus multicinctus } & 银环蛇 & 未列 & 无危 & 汪芳 & 银环蛇心脏毒素类似物 cDNA 的克隆 \\
\hline & & 入 & $/ \mathrm{LC}$ & & \\
\hline \multirow[t]{2}{*}{ Bungarus multicinctus } & 银环蛇 & 未列 & 未评 & 李水胜 & 银环蛇咬伤 257 例临床分析 \\
\hline & & 入 & 价 & & \\
\hline
\end{tabular}


顾垒，闻丞，罗玫，王吴，吕植. 中国最受关注濒危物种保护现状快速评价的新方法探讨．生物多样性，2015，23(5)：583-590。 http://www. biodiversity-science. net/CN/article/downloadArticleFile. do?attachType=PDF\&id=10075

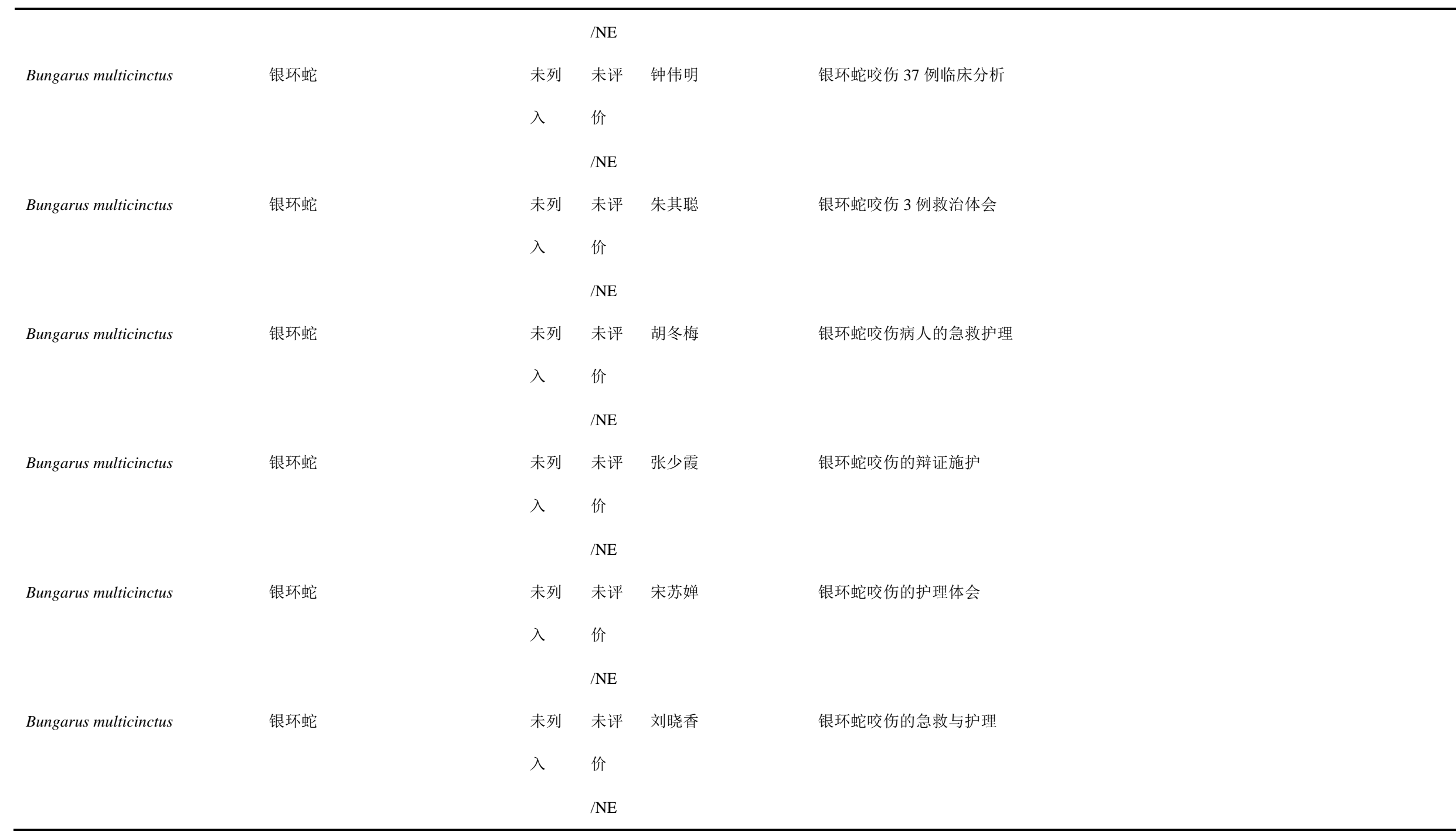


顾垒，闻丞，罗玫，王吴，吕植. 中国最受关注濒危物种保护现状快速评价的新方法探讨. 生物多样性，2015，23(5)：583-590.

http://www. biodiversity-science. net/CN/article/downloadArticleFile. do?attachType=PDF\&id=10075

\begin{tabular}{|c|c|c|c|c|c|}
\hline \multirow[t]{2}{*}{ Bungarus multicinctus } & 银环蛇 & 未列 & 未评 & 罗学宏 & 银环蛇咬伤的诊治 \\
\hline & & 入 & $\begin{array}{l}\text { 价 } \\
\text { /NE }\end{array}$ & & \\
\hline \multirow[t]{3}{*}{ Bungarus multicinctus } & 银环蛇 & 未列 & 未评 & 徐红琴 & 银环蛇咬伤患者的急救与护理 \\
\hline & & 入 & 价 & & \\
\hline & & & $/ \mathrm{NE}$ & & \\
\hline \multirow[t]{3}{*}{ Bungarus multicinctus } & 银环蛇 & 未列 & 未评 & 游剑明 & 银环蛇咬伤患者的救治 \\
\hline & & 入 & 价 & & \\
\hline & & & $/ \mathrm{NE}$ & & \\
\hline \multirow[t]{3}{*}{ Bungarus multicinctus } & 银环蛇 & 未列 & 未评 & 吴莹荣 & 银环蛇咬伤患者的治疗与护理 \\
\hline & & 入 & 价 & & \\
\hline & & & $/ \mathrm{NE}$ & & \\
\hline \multirow[t]{3}{*}{ Bungarus multicinctus } & 银环蛇 & 未列 & 未评 & 邢丽娟 & 银环蛇咬伤患者血液透析与灌流的护理 \\
\hline & & 入 & 价 & & \\
\hline & & & $/ \mathrm{NE}$ & & \\
\hline \multirow[t]{3}{*}{ Bungarus multicinctus } & 银环蛇 & 未列 & 未评 & 梁永源 & 银环蛇咬伤急诊救治的临床研究 \\
\hline & & 入 & 价 & & \\
\hline & & & $/ \mathrm{NE}$ & & \\
\hline Bungarus multicinctus & 银环蛇 & 未列 & 未评 & 李宏键 & 银环蛇咬伤救治及研究进展 \\
\hline
\end{tabular}


顾垒，闻丞，罗玫，王吴，吕植. 中国最受关注濒危物种保护现状快速评价的新方法探讨. 生物多样性，2015，23(5)：583-590. http://www. biodiversity-science. net/CN/article/downloadArticleFile. do?attachType=PDF\&id=10075

\begin{tabular}{|c|c|c|c|c|c|}
\hline & & $\lambda$ & 价 & & \\
\hline Bungarus multicinctus & 银环蛇 & $\begin{array}{l}\text { 未列 } \\
入\end{array}$ & $\begin{array}{l}/ \mathrm{NE} \\
\text { 未评 } \\
\text { 价 }\end{array}$ & 童小英 & 银环蛇咬伤致呼吸麻㿎的急救和护理 1 例 \\
\hline Bungarus multicinctus & 银环蛇 & $\begin{array}{l}\text { 未列 } \\
入\end{array}$ & $\begin{array}{l}\text { /NE } \\
\text { 未评 } \\
\text { 价 }\end{array}$ & 柯将琼 & 银环蛇咬伤致呼吸衰竭、低钠血症救治 1 例 \\
\hline Bungarus multicinctus & 银环蛇 & $\begin{array}{l}\text { 未列 } \\
入\end{array}$ & $\begin{array}{l}\text { /NE } \\
\text { 未评 } \\
\text { 价 }\end{array}$ & 程雪娟 & 银环蛇咬伤致呼吸衰竭 1 例的抢救和护理体会 \\
\hline Bungarus multicinctus & 银环蛇 & $\begin{array}{l}\text { 未列 } \\
入\end{array}$ & $\begin{array}{l}\text { /NE } \\
\text { 未评 } \\
\text { 价 }\end{array}$ & 黄春会 & 银环蛇咬伤致呼吸衰竭的护理体会 \\
\hline Bungarus multicinctus & 银环蛇 & $\begin{array}{l}\text { 未列 } \\
入\end{array}$ & $\begin{array}{l}\text { /NE } \\
\text { 未评 } \\
\text { 价 }\end{array}$ & 廖辉奇 & 银环蛇咬伤致呼吸衰竭抢救成功 1 例 \\
\hline Bungarus multicinctus & 银环蛇 & $\begin{array}{l}\text { 未列 } \\
\text { 入 }\end{array}$ & $\begin{array}{l}\text { /NE } \\
\text { 未评 } \\
\text { 价 }\end{array}$ & 陈莉萍 & 银环蛇咬伤致呼吸停止患者的呼吸机应用与护理 \\
\hline
\end{tabular}


顾垒，闻丞，罗玫，王吴，吕植. 中国最受关注濒危物种保护现状快速评价的新方法探讨. 生物多样性，2015，23(5)：583-590. http://www. biodiversity-science. net/CN/article/downloadArticleFile. do?attachType=PDF\&id=10075

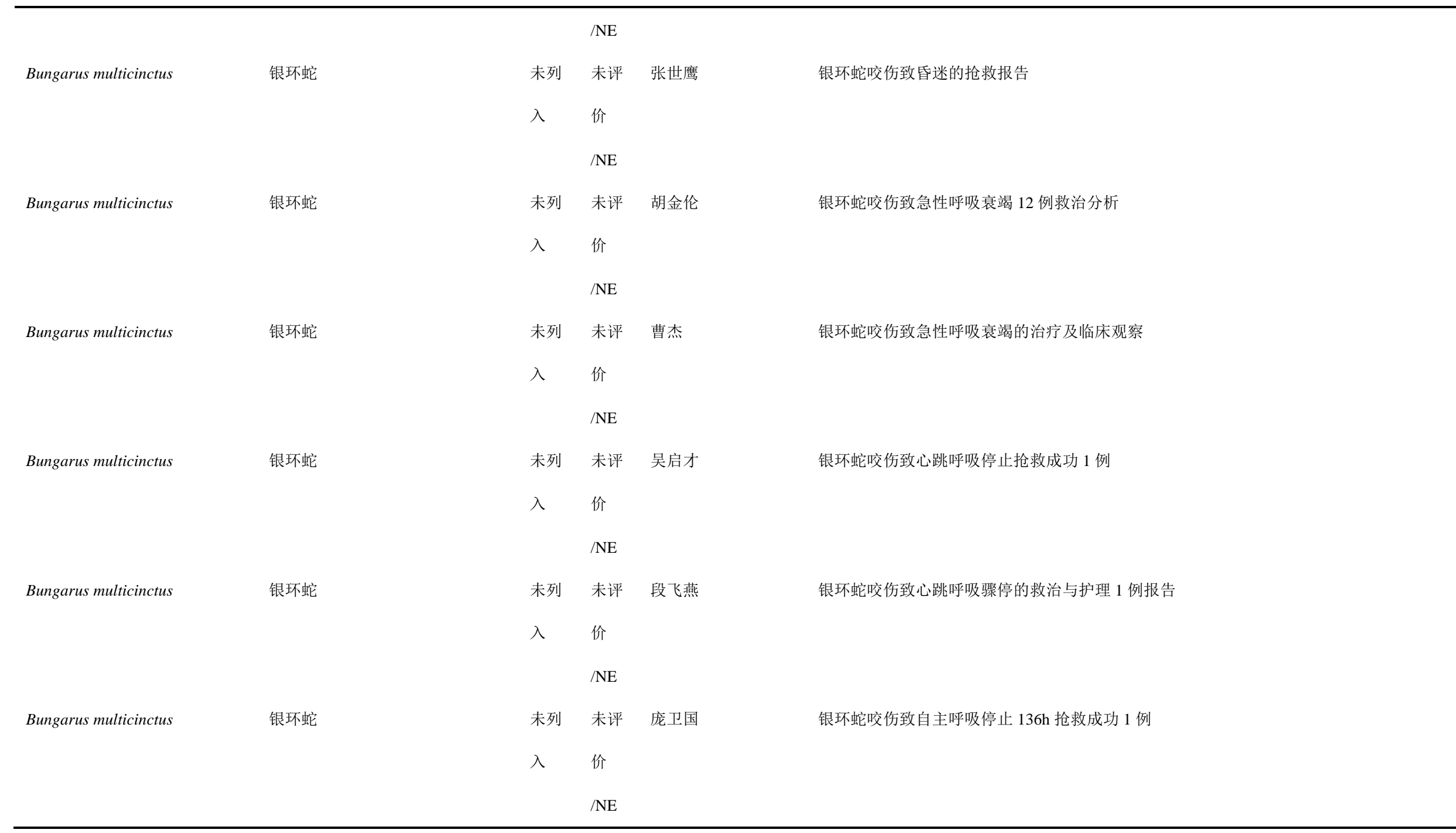


顾垒，闻丞，罗玫，王吴，吕植. 中国最受关注濒危物种保护现状快速评价的新方法探讨. 生物多样性，2015，23(5)：583-590. http://www. biodiversity-science. net/CN/article/downloadArticleFile. do?attachType=PDF\&id=10075

\begin{tabular}{|c|c|c|c|c|c|}
\hline \multirow[t]{2}{*}{ Bungarus multicinctus } & 银环蛇 & 未列 & 未评 & 罗来喜 & 银环蛇咬伤中毒的急救与护理 \\
\hline & & 入 & $\begin{array}{l}\text { 价 } \\
/ \mathrm{NE}\end{array}$ & & \\
\hline \multirow[t]{3}{*}{ Bungarus multicinctus } & 银环蛇 & 未列 & 未评 & 邓海霞 & 银环蛇咬伤中毒发病机制和治疗的研究进展 \\
\hline & & 入 & 价 & & \\
\hline & & & $/ \mathrm{NE}$ & & \\
\hline \multirow[t]{3}{*}{ Bungarus multicinctus } & 银环蛇 & 未列 & 未评 & 刘海燕 & 银环蛇咬伤中毒治验 \\
\hline & & 入 & 价 & & \\
\hline & & & $/ \mathrm{NE}$ & & \\
\hline \multirow[t]{3}{*}{ Bungarus multicinctus } & 银环蛇 & 未列 & 未评 & 胡协心 & 中西结合治疗银环蛇伤 87 例 \\
\hline & & 入 & 价 & & \\
\hline & & & $/ \mathrm{NE}$ & & \\
\hline \multirow[t]{3}{*}{ Bungarus multicinctus } & 银环蛇 & 未列 & 未评 & 陈连芽 & 中西医结合救治银环蛇咬伤 127 例体会 \\
\hline & & 入 & 价 & & \\
\hline & & & $/ \mathrm{NE}$ & & \\
\hline \multirow[t]{3}{*}{ Bungarus multicinctus } & 银环蛇 & 未列 & 未评 & 陈连芽 & 中西医结合救治银环蛇咬伤 78 例 \\
\hline & & 入 & 价 & & \\
\hline & & & $/ \mathrm{NE}$ & & \\
\hline Bungarus multicinctus & 银环蛇 & 未列 & 未评 & 庞家善 & 中西医结合治疗银环蛇咬伤 182 例 \\
\hline
\end{tabular}


顾垒，闻丞，罗玫，王吴，吕植. 中国最受关注濒危物种保护现状快速评价的新方法探讨. 生物多样性，2015，23(5)：583-590. http://www. biodiversity-science. net/CN/article/downloadArticleFile. do?attachType=PDF\&id=10075

\begin{tabular}{|c|c|c|c|c|c|}
\hline & & 入 & 价 & & \\
\hline & & & $/ \mathrm{NE}$ & & \\
\hline \multirow[t]{3}{*}{ Bungarus multicinctus } & 银环蛇 & 未列 & 未评 & 庞卫国 & 中西医结合治疗银环蛇咬伤 322 例 \\
\hline & & 入 & 价 & & \\
\hline & & & $/ \mathrm{NE}$ & & \\
\hline \multirow[t]{3}{*}{ Bungarus multicinctus } & 银环蛇 & 未列 & 未评 & 高雪珍 & 中西医结合治疗银环蛇咬伤 32 例分析 \\
\hline & & 入 & 价 & & \\
\hline & & & $/ \mathrm{NE}$ & & \\
\hline \multirow[t]{3}{*}{ Bungarus multicinctus } & 银环蛇 & 未列 & 未评 & 李著 & 重症银环蛇咬伤的临床救治 \\
\hline & & 入 & 价 & & \\
\hline & & & $/ \mathrm{NE}$ & & \\
\hline \multirow[t]{2}{*}{ Bungarus multicinctus } & 银环蛇 & 未列 & 无危 & 王义权 & 重组 $\alpha$-银环蛇毒素 P22-A31 的原核表达及功能分析 \\
\hline & & 入 & $/ \mathrm{LC}$ & & \\
\hline \multirow[t]{3}{*}{ Bungarus multicinctus } & 银环蛇 & 未列 & 未评 & 卢春喜 & 综合治疗银环蛇咬伤 82 例 \\
\hline & & 入 & 价 & & \\
\hline & & & $/ \mathrm{NE}$ & & \\
\hline \multirow[t]{2}{*}{ Bunopithecus hoolock } & 白眉长臂猿 & I & 濒危 & 范朋飞 & Distribution and conservation status of the Vulnerable eastern hoolock gibbon Hoolock \\
\hline & & & /EN & & leuconedys in China \\
\hline Bunopithecus hoolock & 白眉长臂猿 & I & 濒危 & 周伟 & 白眉长臂猿野外交配行为一一云南高黎贡山的案例研究 \\
\hline
\end{tabular}


顾垒，闻丞，罗玫，王吴，吕植. 中国最受关注濒危物种保护现状快速评价的新方法探讨. 生物多样性，2015，23(5)：583-590. http://www biodiversity-science. net/CN/article/downloadArticleFile. do?attachType=PDF\&id=10075

/EN

Bunopithecus hoolock

白眉长臂猿

白眉长臂猿

白眉长臂猿

白眉长臂猿

Bunopithecus hoolock

Bunopithecus hoolock

白眉长臂猿

Bunopithecus hoolock

白眉长臂猿

Bunopithecus hoolock

白眉长臂猿

Bunopithecus hoolock

白眉长臂猿

Bunopithecus hoolock

白眉长臂猿
I

濒危

周伟

/EN

濒危 周伟

/EN

I

濒危 周伟

/EN

I 濒危 周伟

/EN

I 濒危 周伟

/EN

I 濒危李旭

/EN

I 濒危

/EN

I 濒危 周伟

/EN

濒危 周伟
高黎贡山大塘白眉长臂猿春季栖息地利用

高黎贡山大塘白眉长臂猿春季栖息地利用与郝穴的比较

高黎贡山郝元白眉长臂猿（Hoolock hoolock）春秋季食物资源可利用性与取食

高黎贡山赧元白眉长臂猿春季栖息地利用

高黎贡山郝六白眉长臂猿春季食物选择

高黎贡山赧元白眉长臂猿春秋季活动范围变化

高黎贡山郝六白眉长臂猿春秋季主要食物营养成分比较

高黎贡山郝六白眉长臂猿栖息地选择利用

高黎贡山郝六白眉长臂猿食性及日取食量 
顾垒，闻丞，罗玫，王吴，吕植. 中国最受关注濒危物种保护现状快速评价的新方法探讨. 生物多样性，2015，23(5)：583-590. http://www biodiversity-science. net/CN/article/downloadArticleFile. do?attachType=PDF\&id=10075

\begin{tabular}{|c|c|c|c|c|c|}
\hline Bunopithecus hoolock & 白眉长臂猿 & I & $\begin{array}{l}\text { 濒危 } \\
\text { /EN }\end{array}$ & 周伟 & 高黎贡山郝光白眉长臂猿受胁因子分析及其缓解对策探讨 \\
\hline Bunopithecus hoolock & 白眉长臂猿 & I & $\begin{array}{l}\text { 濒危 } \\
\text { /EN }\end{array}$ & 周伟 & 高黎贡山郝元白眉长臂猿营养容纳量研究 \\
\hline Bunopithecus hoolock & 白眉长臂猿 & I & $\begin{array}{l}\text { 濒危 } \\
\text { /EN }\end{array}$ & 周伟 & 高黎贡山郝亢森林资源利用与白眉长臂猿保护 \\
\hline Bunopithecus hoolock & 白眉长臂猿 & $\mathrm{I}$ & $\begin{array}{l}\text { 濒危 } \\
\text { /EN }\end{array}$ & 崔亮伟 & 云南高黎贡山大塘东部白眉长臂猿鸣叫行为 \\
\hline Bunopithecus hoolock & 白眉长臂猿 & I & $\begin{array}{l}\text { 濒危 } \\
\text { /EN }\end{array}$ & 周伟 & 云南高黎贡山郝元白眉长臂猿春季食谱及活动时间分配初探 \\
\hline Bunopithecus hoolock & 白眉长臂猿 & I & $\begin{array}{l}\text { 濒危 } \\
\text { /EN }\end{array}$ & 周伟 & 云南高黎贡山自然保护区白眉长臂猿种群及数量现状初报 \\
\hline Bunopithecus hoolock & 白眉长臂猿 & I & $\begin{array}{l}\text { 濒危 } \\
\text { /EN }\end{array}$ & 周伟 & 中国高黎贡山郝亢东白眉长臂猿春秋季栖息地利用比较 \\
\hline Burretiodendron esquirolii & 柄翅果 & II & $\begin{array}{l}\text { 易危 } \\
\text { /VU }\end{array}$ & 唐亚 & 锦葵目蚬木属和柄翅果属的木材解剖学研究及其系统学意义 \\
\hline Burretiodendron esquirolii & 柄翅果 & II & $\begin{array}{l}\text { 易危 } \\
\text { /VU }\end{array}$ & 马鸣 & 浅谈柄翅果栽培技术分析 \\
\hline Calanthe delavayi & 少花虾脊兰 & II & 易危 & Fu-Wu Xing & A new phylogenetic analysis sheds new light on the relationships in the Calanthe alliance \\
\hline
\end{tabular}


顾垒，闻丞，罗玫，王吴，吕植. 中国最受关注濒危物种保护现状快速评价的新方法探讨. 生物多样性，2015，23(5)：583-590. http://www biodiversity-science. net/CN/article/downloadArticleFile. do?attachType=PDF\&id=10075

\begin{tabular}{|c|c|c|c|c|c|}
\hline & & & /VU & & (Orchidaceae) in China \\
\hline \multirow[t]{2}{*}{ Calanthe henryi } & 疏花虾脊兰 & II & 易危 & 喻勋林 & 湖南省新记录植物 \\
\hline & & & /VU & & \\
\hline \multirow[t]{2}{*}{ Calidris tenuirostris } & 大滨㛚 & 未列 & 易危 & & Diet of Great Knots (Calidris tenuirostris ) during spring stopover at Chongming \\
\hline & & 入 & /VU & & DongtanChina \\
\hline \multirow[t]{2}{*}{ Calidris tenuirostris } & 大滨鹬 & 未列 & 易危 & & 吉林省鸟类新纪录一一大滨鹬 \\
\hline & & 入 & /VU & & \\
\hline \multirow[t]{2}{*}{ Callosciurus pygerythrus } & 蓝腹松鼠 & 未列 & 无危 & M. S. Pradhan & A CECKLIST OF VALID INDIAN RODENT TAXA(MAMMALIA : RODENTIA) \\
\hline & & 入 & $/ \mathrm{LC}$ & & \\
\hline \multirow[t]{2}{*}{ Callosciurus pygerythrus } & 蓝腹松鼠 & 未列 & 无危 & Small Mammals & \multirow[t]{2}{*}{ An Overview Report on Squirrel (Sciuridae: Rodentia) of Nepal } \\
\hline & & 入 & $/ \mathrm{LC}$ & Conservation and & \\
\hline \multirow{3}{*}{ Callosciurus pygerythrus } & & & & Research Foundation & \multirow{3}{*}{ Biodiversity Significance of North East India } \\
\hline & 蓝腹松鼠 & 未列 & 无危 & & \\
\hline & & 入 & $/ \mathrm{LC}$ & & \\
\hline \multirow[t]{2}{*}{ Callosciurus pygerythrus } & 蓝腹松鼠 & 未列 & 无危 & Prodip Kr. Sahoo & Study on Rodent Diversity in and around Marat Longri Wildlife Sanctury, Karbi Anglong \\
\hline & & 入 & $/ \mathrm{LC}$ & & Distict of Assam, India \\
\hline \multirow[t]{2}{*}{ Callosciurus pygerythrus } & 蓝腹松鼠 & 未列 & 无危 & P. K. Sahoo & Study on rodent diversity in Karbi Anglong district of Assam, India \\
\hline & & 入 & $/ \mathrm{LC}$ & & \\
\hline Callosciurus pygerythrus & 蓝腹松鼠 & 未列 & 无危 & Joy Krishna De & Tricho-taxonomic study of Dorsal Guard Hairs of Indian Species of Rodents Belonging to \\
\hline
\end{tabular}


顾垒，闻丞，罗玫，王吴，吕植. 中国最受关注濒危物种保护现状快速评价的新方法探讨. 生物多样性，2015，23(5)：583-590. http://www, biodiversity-science, net/CN/article/downloadArticleFile. do?attachType=PDF\&id=10075

\begin{tabular}{|c|c|c|c|c|c|}
\hline & & 入 & $/ \mathrm{LC}$ & & Subfamily- Sciurinae(Sciuridae: Rodentia: Mammalia) \\
\hline \multirow[t]{2}{*}{ Callosciurus quinquestriatus } & 五纹松鼠 & 未列 & 近危 & Archana Bahuguna & A Review on the Molecular Study of the Species of Family Sciuridae (Rodentia: Mammalia) \\
\hline & & 入 & /NT & & \\
\hline \multirow[t]{2}{*}{ Calocedrus macrolepis } & 翠柏 & II & 近危 & Xue-Jun Ge & Genetic diversity of Calocedrus macrolepis (Cupressaceae) in southwestern China \\
\hline & & & /NT & & \\
\hline \multirow[t]{2}{*}{ Calocedrus macrolepis } & 翠柏 & II & 近危 & Bo Tian & Isolation and Characterization of Polymorphic Microsatellite Markers in Calocedrus macrolepis \\
\hline & & & /NT & & Kurz (Cupressaceae) \\
\hline \multirow[t]{2}{*}{ Calocedrus macrolepis } & 翠柏 & II & 近危 & Liu-Dong Song & Labdane diterpenoids and lignans from Calocedrus macrolepis \\
\hline & & & /NT & & \\
\hline \multirow[t]{2}{*}{ Calocedrus macrolepis } & 翠柏 & II & 近危 & 刘方炎 & 濒危植物翠柏的个体生长动态及种群结构与种内竞争 \\
\hline & & & /NT & & \\
\hline \multirow[t]{2}{*}{ Calocedrus macrolepis } & 翠柏 & II & 近危 & 廖声熙 & 濒危植物翠柏个体生长特性研究 \\
\hline & & & /NT & & \\
\hline \multirow[t]{2}{*}{ Calocedrus macrolepis } & 翠柏 & II & 近危 & 梁璐璐 & 翠柏的栽培技术及应用 \\
\hline & & & $/ \mathrm{NT}$ & & \\
\hline \multirow[t]{2}{*}{ Calocedrus macrolepis } & 翠柏 & II & 近危 & 杨振寅 & 翠柏木材管胞特性及结晶度的径向变异分析 \\
\hline & & & /NT & & \\
\hline \multirow[t]{2}{*}{ Calocedrus macrolepis } & 翠柏 & II & 近危 & 崔凯 & 翠柏木材管胞形态和结晶度的株内变异 \\
\hline & & & /NT & & \\
\hline
\end{tabular}


顾垒，闻丞，罗玫，王吴，吕植. 中国最受关注濒危物种保护现状快速评价的新方法探讨. 生物多样性，2015，23(5)：583-590. http://www. biodiversity-science. net/CN/article/downloadArticleFile. do?attachType=PDF\&id=10075

\begin{tabular}{|c|c|c|c|c|c|}
\hline Calocedrus macrolepis & 翠柏 & II & $\begin{array}{l}\text { 近危 } \\
\text { /NT }\end{array}$ & 廖声熙 & 翠柏木材解剖性质和结晶度的径向变异及化学性质 \\
\hline Calocedrus macrolepis & 翠柏 & II & $\begin{array}{l}\text { 近危 } \\
\text { /NT }\end{array}$ & 许为斌 & 广西翠柏属( 柏科) 植物小志 \\
\hline Calocedrus macrolepis & 翠柏 & II & $\begin{array}{l}\text { 近危 } \\
\text { /NT }\end{array}$ & 邓艳 & 广西木论两种珍稀濒危植物的元素背景值比较 \\
\hline Calocedrus macrolepis & 翠柏 & II & $\begin{array}{l}\text { 近危 } \\
\text { /NT }\end{array}$ & 陈文红 & 云南易门翠柏和黄杉的群落调查及保护・ \\
\hline Calycopteris floribunda & 萝翅藤 & I & $\begin{array}{l}\text { 未评 } \\
\text { 价 } \\
\text { /NE }\end{array}$ & LIU Jia-jia & Chemical component and antimicrobial activity of volatile oil of Calycopteris floribunda \\
\hline Calycopteris floribunda & 萝翅藤 & I & $\begin{array}{l}\text { 未评 } \\
\text { 价 } \\
\text { /NE }\end{array}$ & 龚洵 & 葽翅藤的核型研究 \\
\hline Calycopteris floribunda & 蓦翅藤 & I & $\begin{array}{l}\text { 未评 } \\
\text { 价 } \\
\text { /NE }\end{array}$ & 张艳 & 萝翅藤枝叶挥发油及其抗菌活性的研究 \\
\hline Calycopteris floribunda & 萝翅藤 & I & $\begin{array}{l}\text { 未评 } \\
\text { 价 }\end{array}$ & 杨栋梁 & 蓦翅藤中功能性化学成份的初步研究 \\
\hline
\end{tabular}


顾垒，闻丞，罗玫，王吴，吕植. 中国最受关注濒危物种保护现状快速评价的新方法探讨. 生物多样性，2015，23(5)：583-590.

\begin{tabular}{|c|c|c|c|c|c|}
\hline & & & $/ \mathrm{NE}$ & & \\
\hline \multirow[t]{2}{*}{ Canis lupus } & 狼 & II & 无危 & 张居农 & 3 个品种犬与狼麻醉效果的观察 \\
\hline & & & $/ \mathrm{LC}$ & & \\
\hline \multirow[t]{3}{*}{ Canis lupus } & 狼 & II & 无危 & Quan Zhao & Characterization of Toxascaris leonina and Tococara canis from cougar (Panthera leo) and \\
\hline & & & $/ \mathrm{LC}$ & & common wolf (Canis lupus) by nuclear ribosomal DNA sequences of internal transcribed \\
\hline & & & & & spacers \\
\hline \multirow[t]{2}{*}{ Canis lupus } & 狼 & II & 无危 & ZHANG Hong-hai & Comparison of the fraction of olfactory receptor pseudogenes in wolf ( Canis lupus ) with \\
\hline & & & $/ \mathrm{LC}$ & & domestic dog ( Canis familiaris) \\
\hline \multirow[t]{2}{*}{ Canis lupus } & 狼 & II & 无危 & Honghai Zhang & Complete mitochondrial genome of Canis lupus campestris \\
\hline & & & $/ \mathrm{LC}$ & & \\
\hline \multirow[t]{2}{*}{ Canis lupus } & 狼 & II & 无危 & Zhigang JIANG & Diet composition of wolves Canis lupus in the \\
\hline & & & $/ \mathrm{LC}$ & & northeastern Qinghai-Tibet Plateau, China \\
\hline \multirow[t]{2}{*}{ Canis lupus } & 狼 & II & 无危 & Ya-Ping Zhang & Differences in Selection Drive Olfactory Receptor Genes in \\
\hline & & & $/ \mathrm{LC}$ & & Different Directions in Dogs and Wolf \\
\hline \multirow[t]{2}{*}{ Canis lupus } & 狼 & II & 无危 & ZHANG Hong-hai & Fecal progesterone and estradiol changes during the breeding season in \\
\hline & & & $/ \mathrm{LC}$ & & captive female wolf \\
\hline \multirow[t]{2}{*}{ Canis lupus } & 狼 & II & 无危 & ZHIJIE JACK & Mandibular biomechanics of Crocuta crocuta, Canis lupus, and the late Miocene Dinocrocuta \\
\hline & & & $/ \mathrm{LC}$ & TSENG & gigantea (Carnivora, Mammalia) \\
\hline Canis lupus & 狼 & II & 无危 & HONGHAI ZHANG & Mitochondr ial genome of the Tibetan wolf \\
\hline
\end{tabular}


顾垒，闻丞，罗玫，王吴，吕植. 中国最受关注濒危物种保护现状快速评价的新方法探讨．生物多样性，2015，23(5)：583-590。 http://www biodiversity-science. net/CN/article/downloadArticleFile. do?attachType=PDF\&id=10075

$/ \mathrm{LC}$

Canis lupus

Canis lupus

Canis lupus

Canis lupus

Canis lupus

Canis lupus

Canis lupus
狼
无危

$/ \mathrm{LC}$

无危 Yong-Xiang Li

$/ \mathrm{LC}$

刘真超

/LC

无危

张洪海

/LC

II

/LC

$/ \mathrm{LC}$

II
GUANGYOU YANG Molecular characterization and phylogenetic analysis of ascarid nematodes from twenty-one species of captive wild mammals based on mitochondrial and nuclear sequences

Phylogenetic analysis of 16S rRNA gene sequences reveals distal

gut bacterial diversity in wild wolves ( Canis lupus )

The complete mitochondrial genome of Chinese Shinjang wolf

The composition of three mammal faunas and environmental evolution in the las

glacial maximum, Guanzhong area, Shaanxi Province, China

初探狼前肢皮毛整圈被撕失的治疗

大、小兴安岭地区狼的食性

黑龙江省圈养狼交配行为的初步观察

呼伦贝尔草原冬季狼的巢域和生境利用

狼、狗裂齿与毛齿的测量值、变量值研究

LC 
顾垒，闻丞，罗玫，王吴，吕植. 中国最受关注濒危物种保护现状快速评价的新方法探讨. 生物多样性，2015，23(5)：583-590. http://www. biodiversity-science. net/CN/article/downloadArticleFile. do?attachType=PDF\&id=10075

\begin{tabular}{|c|c|c|c|c|c|}
\hline Canis lupus & 狼 & II & $\begin{array}{l}\text { 无危 } \\
\text { /LC }\end{array}$ & 陈否 & $\begin{array}{l}\text { 狼肠道菌群生态及犬科线粒体基因组比较 } \\
\text { 和系统发育 }\end{array}$ \\
\hline Canis lupus & 狼 & II & $\begin{array}{l}\text { 无危 } \\
\text { /LC }\end{array}$ & 谢鹏贵 & 狼电刺激采精及其精液特征的研究 \\
\hline Canis lupus & 狼 & II & $\begin{array}{l}\text { 无危 } \\
\text { /LC }\end{array}$ & 汪 晓 飞 & 狼多杀性巴氏杆菌和肺炎双球菌混合感染的诊断 \\
\hline Canis lupus & 狼 & II & $\begin{array}{l}\text { 无危 } \\
\text { /LC }\end{array}$ & 张洪海 & 狼和家犬消化道内分泌细胞免疫组织化学研究 \\
\hline Canis lupus & 狼 & II & $\begin{array}{l}\text { 无危 } \\
\text { /LC }\end{array}$ & 张晓军 & 狼头部和背部针毛表面超微结构的比较研究 \\
\hline Canis lupus & 狼 & II & $\begin{array}{l}\text { 无危 } \\
\text { /LC }\end{array}$ & 陈否 & 狼与家犬消化道形态学及其消化道内分泌细胞免疫组织化学研究 \\
\hline Canis lupus & 狼 & II & $\begin{array}{l}\text { 无危 } \\
\text { /LC }\end{array}$ & 张洪海 & 蒙古狼线粒体基因组序列分析及其系统发育地位 \\
\hline Canis lupus & 狼 & II & $\begin{array}{l}\text { 无危 } \\
\text { /LC }\end{array}$ & 刘丙万 & 内蒙古达妻湖保护区狼与牧民冲突研究 \\
\hline Canis lupus & 狼 & II & $\begin{array}{l}\text { 无危 } \\
\text { /LC }\end{array}$ & 窦华山 & 内蒙古达㐘湖国家级自然保护区狼捕食家畜现状 \\
\hline Canis lupus & 狼 & II & 无危 & 张洪海 & 内蒙古达㐘湖自然保护区狼捕食家畜初报 \\
\hline
\end{tabular}


顾垒，闻丞，罗玫，王吴，吕植. 中国最受关注濒危物种保护现状快速评价的新方法探讨. 生物多样性，2015，23(5)：583-590. http://www. biodiversity-science. net/CN/article/downloadArticleFile. do?attachType=PDF\&id=10075

\begin{tabular}{|c|c|c|c|c|c|}
\hline & & & $/ \mathrm{LC}$ & & \\
\hline \multirow[t]{2}{*}{ Canis lupus } & 狼 & II & 无危 & 张洪海 & 内蒙古达秉湖自然保护区狼冬季的生境选择 \\
\hline & & & $/ \mathrm{LC}$ & & \\
\hline \multirow[t]{2}{*}{ Canis lupus } & 狼 & II & 无危 & 张洪海 & 内蒙古达㐘湖自然保护区狼食性的季节性变化 \\
\hline & & & $/ \mathrm{LC}$ & & \\
\hline \multirow[t]{2}{*}{ Canis lupus } & 狼 & II & 无危 & 杨红军 & 内蒙古东部草原地区狼的家域及其生境选择 \\
\hline & & & $/ \mathrm{LC}$ & & \\
\hline \multirow[t]{2}{*}{ Canis lupus } & 狼 & II & 无危 & 窦华山 & 内蒙古东部草原三种犬科动物春季洞穴选择 \\
\hline & & & $/ \mathrm{LC}$ & & \\
\hline \multirow[t]{2}{*}{ Canis lupus } & 狼 & II & 无危 & 邹业爱 & 内蒙古东部达妻湖地区狼(Canis lupus)的生境适宜性评价 \\
\hline & & & $/ \mathrm{LC}$ & & \\
\hline \multirow[t]{2}{*}{ Canis lupus } & 狼 & II & 无危 & 翟红昌 & 内蒙古东部地区狼（Canislupus）的冬季家域 \\
\hline & & & $/ \mathrm{LC}$ & & \\
\hline \multirow[t]{2}{*}{ Canis lupus } & 狼 & II & 无危 & 刘新平 & 内蒙古东部地区三种犬科动物食性及食物生态位重叠研究 \\
\hline & & & $/ \mathrm{LC}$ & & \\
\hline \multirow[t]{2}{*}{ Canis lupus } & 狼 & II & 无危 & 鲍伟东 & 内蒙古赛罕乌拉自然保护区狼的数量分布和食物组成 \\
\hline & & & /LC & & \\
\hline \multirow[t]{2}{*}{ Canis lupus } & 狼 & II & 无危 & 孔繁繁 & 圈养狼 (Canislupus) 的繁殖行为与性激素关系的研究 \\
\hline & & & /LC & & \\
\hline
\end{tabular}


顾垒，闻丞，罗玫，王吴，吕植. 中国最受关注濒危物种保护现状快速评价的新方法探讨. 生物多样性，2015，23(5)：583-590. http://www. biodiversity-science. net/CN/article/downloadArticleFile. do?attachType=PDF\&id=10075

\begin{tabular}{|c|c|c|c|c|c|}
\hline Canis lupus & 狼 & II & $\begin{array}{l}\text { 无危 } \\
\text { /LC }\end{array}$ & 孔鹏 & 圈养狼发声的特征分析 \\
\hline Canis lupus & 狼 & II & $\begin{array}{l}\text { 无危 } \\
\text { /LC }\end{array}$ & 张洪海 & 圈养狼行为活动的时间分配 \\
\hline Canis lupus & 狼 & II & $\begin{array}{l}\text { 无危 } \\
\text { /LC }\end{array}$ & 沈秀清 & 圈养狼育幼期行为初探 \\
\hline Canis lupus & 狼 & II & $\begin{array}{l}\text { 无危 } \\
\text { /LC }\end{array}$ & 孟超 & 犬科及部分食肉目动物线粒体全基因组研究 \\
\hline Canis lupus & 狼 & II & $\begin{array}{l}\text { 无危 } \\
\text { /LC }\end{array}$ & 张洪海 & 三种犬科动物春季洞穴特征 \\
\hline Canis lupus & 狼 & II & $\begin{array}{l}\text { 无危 } \\
\text { /LC }\end{array}$ & 方 海 & 散放条件下狼的饲养与繁殖 \\
\hline Canis lupus & 狼 & II & $\begin{array}{l}\text { 无危 } \\
\text { /LC }\end{array}$ & 裴文 & 饲养方式对狼食物结构和繁殖的影响 \\
\hline Canis lupus & 狼 & II & $\begin{array}{l}\text { 无危 } \\
\text { /LC }\end{array}$ & 张洪海 & 幼狼血液生理生化及激素参考值 \\
\hline Canis lupus & 狼 & II & $\begin{array}{l}\text { 无危 } \\
\text { /LC }\end{array}$ & 张洪海 & $\begin{array}{l}\text { 中国狼不同地理种群遗传多样性及系统进 } \\
\text { 化分析 }\end{array}$ \\
\hline Canis lupus & 狼 & II & 无危 & 罗理杨 & 中国狼的种内系统发育关系与亚种分化 \\
\hline
\end{tabular}


顾垒，闻丞，罗玫，王吴，吕植. 中国最受关注濒危物种保护现状快速评价的新方法探讨. 生物多样性，2015，23(5)：583-590. http://www. biodiversity-science. net/CN/article/downloadArticleFile. do?attachType=PDF\&id=10075

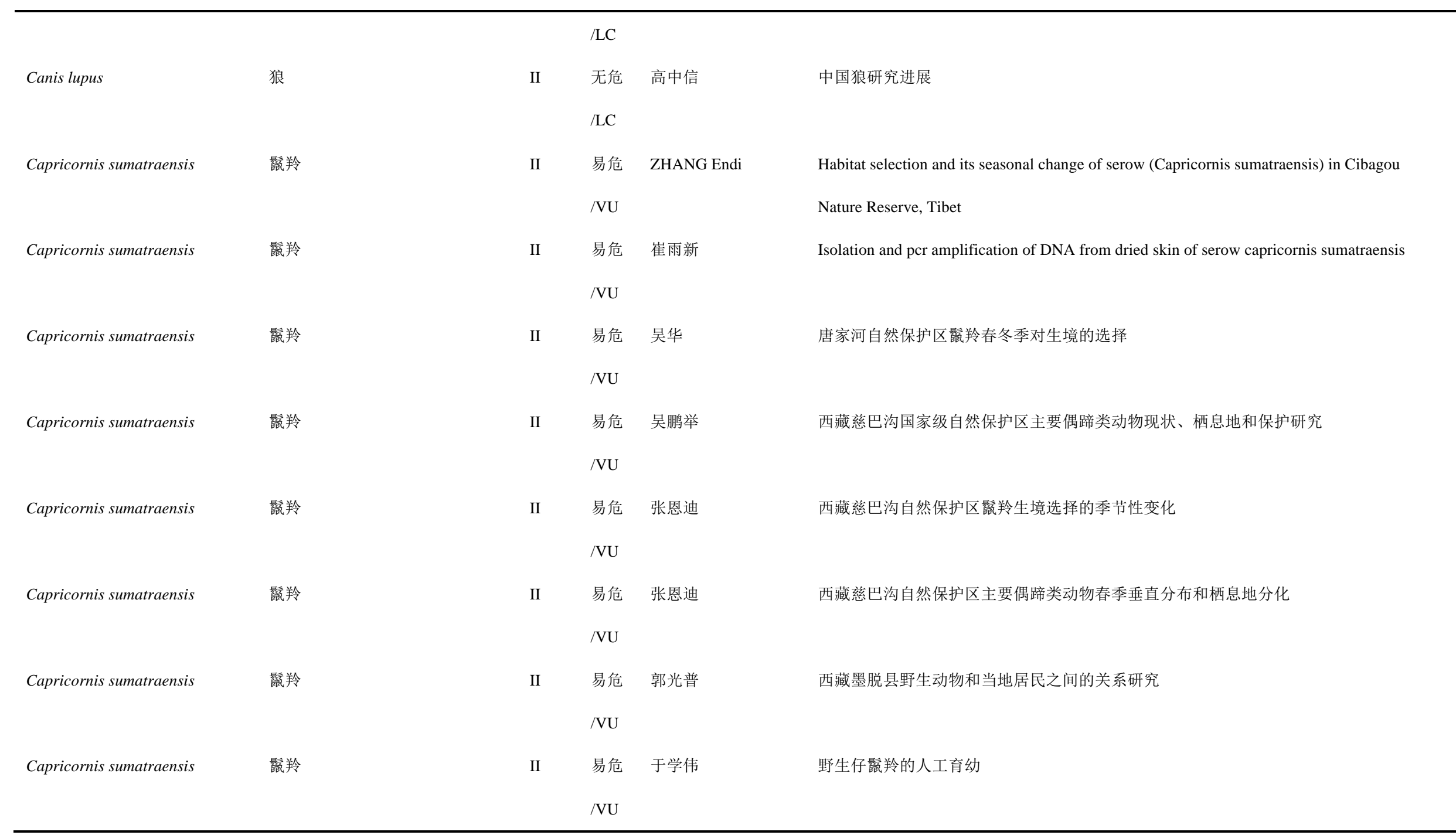


顾垒，闻丞，罗玫，王吴，吕植. 中国最受关注濒危物种保护现状快速评价的新方法探讨. 生物多样性，2015，23(5)：583-590. http://www. biodiversity-science. net/CN/article/downloadArticleFile. do?attachType=PDF\&id=10075

\begin{tabular}{|c|c|c|c|c|c|}
\hline Capricornis sumatraensis & 瓺羚 & II & $\begin{array}{l}\text { 易危 } \\
\text { /VU }\end{array}$ & 吴海龙 & 一种鹿科动物标本的分子鉴定 \\
\hline Capricornis sumatraensis & 鬛羚 & II & $\begin{array}{l}\text { 易危 } \\
\text { /VU }\end{array}$ & 崔雨新 & 在线粒体 DNA 细胞色素 $\mathrm{b}$ 基因序列水平上对鬛羚系统发育的研究 \\
\hline Cathaya argyrophylla & 银杉 & I & $\begin{array}{l}\text { 易危 } \\
\text { /VU }\end{array}$ & 易思荣 & 濒危植物银杉根际微生物群落动态变化研究 \\
\hline Cathaya argyrophylla & 银杉 & I & $\begin{array}{l}\text { 易危 } \\
\text { /VU }\end{array}$ & 谢宗强 & 濒危植物银杉幼树对生长光强的季节性光合响应 \\
\hline Cathaya argyrophylla & 银杉 & I & $\begin{array}{l}\text { 易危 } \\
\text { /VU }\end{array}$ & 谢宗强 & 濒危植物银杉种子特性的研究 \\
\hline Cathaya argyrophylla & 银杉 & I & $\begin{array}{l}\text { 易危 } \\
\text { /VU }\end{array}$ & 谢强 & 广西银杉林主要树种种群生态位分析 \\
\hline Cathaya argyrophylla & 银杉 & I & $\begin{array}{l}\text { 易危 } \\
\text { /VU }\end{array}$ & 冯育才 & 贵州大沙河自然保护区银杉种群结构初步研究 \\
\hline Cathaya argyrophylla & 银杉 & I & $\begin{array}{l}\text { 易危 } \\
\text { /VU }\end{array}$ & 赵颖茹 & 两株银杉根际土壤真菌的分离与分子鉴定 \\
\hline Cathaya argyrophylla & 银杉 & I & $\begin{array}{l}\text { 易危 } \\
\text { /VU }\end{array}$ & 谢宗强 & 沿林冠开度梯度的银杉幼树对光的适应性 \\
\hline Cathaya argyrophylla & 银杉 & I & 易危 & 瓦里奥禄敏 & 一种有效地提高银杉人工菌根苗诱导率的方法 \\
\hline
\end{tabular}


顾垒，闻丞，罗玫，王吴，吕植. 中国最受关注濒危物种保护现状快速评价的新方法探讨. 生物多样性，2015，23(5)：583-590. http://www. biodiversity-science. net/CN/article/downloadArticleFile. do?attachType=PDF\&id=10075

\begin{tabular}{|c|c|c|c|c|c|}
\hline & & & $/ \mathrm{VU}$ & & \\
\hline \multirow[t]{2}{*}{ Cathaya argyrophylla } & 银杉 & I & 易危 & 王玉杰 & 银杉的光合特性 \\
\hline & & & $/ \mathrm{VU}$ & & \\
\hline \multirow[t]{2}{*}{ Cathaya argyrophylla } & 银杉 & I & 易危 & 易思荣 & 银杉根际微生物群落结构初步研究 \\
\hline & & & /VU & & \\
\hline \multirow[t]{2}{*}{ Cathaya argyrophylla } & 银杉 & I & 易危 & 葛颂 & 银杉花粉生命力及其变异 \\
\hline & & & /VU & & \\
\hline \multirow[t]{2}{*}{ Cathaya argyrophylla } & 银杉 & I & 易危 & 黄华艳 & 银杉落针病的初步研究 \\
\hline & & & $/ \mathrm{VU}$ & & \\
\hline \multirow[t]{2}{*}{ Cathaya argyrophylla } & 银杉 & I & 易危 & 罗建举 & 银杉木材构造美学价值 \\
\hline & & & $/ \mathrm{VU}$ & & \\
\hline \multirow[t]{2}{*}{ Cathaya argyrophylla } & 银杉 & I & 易危 & 黄华艳 & 银杉人工林病虫害种类调查初报 \\
\hline & & & /VU & & \\
\hline \multirow[t]{2}{*}{ Cathaya argyrophylla } & 银杉 & I & 易危 & 邢树堂 & 银杉外生菌根形态观察法探讨 \\
\hline & & & /VU & & \\
\hline \multirow[t]{2}{*}{ Cathaya argyrophylla } & 银杉 & I & 易危 & 周盼 & 银杉种质资源的保护与利用探讨 \\
\hline & & & /VU & & \\
\hline \multirow[t]{2}{*}{ Cathaya argyrophylla } & 银杉 & I & 易危 & 黄华艳 & 银杉重大害虫-思茅松毛虫的生物学特性及综合治理技术研究 \\
\hline & & & /VU & & \\
\hline
\end{tabular}


顾垒，闻丞，罗玫，王吴，吕植. 中国最受关注濒危物种保护现状快速评价的新方法探讨. 生物多样性，2015，23(5)：583-590. http://www biodiversity-science. net/CN/article/downloadArticleFile. do?attachType=PDF\&id=10075

\begin{tabular}{|c|c|c|c|c|c|}
\hline Cathaya argyrophylla & 银杉 & I & $\begin{array}{l}\text { 易危 } \\
\text { /VU }\end{array}$ & 刘春林 & 珍稀植物银杉的种子萌发特性 \\
\hline Catopuma temminckii & 金猫 & II & $\begin{array}{l}\text { 近危 } \\
\text { /NT }\end{array}$ & 陈鹏 & 长青自然保护区金猫垂直分布和季节性活动规律研究 \\
\hline Centropus bengalensis & 小鸦鹃 & II & $\begin{array}{l}\text { 无危 } \\
\text { /LC }\end{array}$ & 范洪敏 & 广东担杆岛鸟类多样性的季节变化 \\
\hline Centropus bengalensis & 小鸦鹃 & II & $\begin{array}{l}\text { 无危 } \\
\text { /LC }\end{array}$ & 陈后东 & 广东连南板洞自然保护区动植物资源综述 \\
\hline Centropus bengalensis & 小鸦鹃 & II & $\begin{array}{l}\text { 无危 } \\
\text { /LC }\end{array}$ & 张尚文 & 桂林两江国际机场夏季鸟类生态及鸟撞预防研究 \\
\hline Centropus bengalensis & 小鸦鹃 & II & $\begin{array}{l}\text { 无危 } \\
\text { /LC }\end{array}$ & 刘振生 & 海南大田国家级自然保护区鸟类考察初报 \\
\hline Centropus bengalensis & 小鸦鹃 & II & $\begin{array}{l}\text { 无危 } \\
\text { /LC }\end{array}$ & 黄族豪 & 井冈山国家级自然保护区鸟类资源研究 \\
\hline Centropus bengalensis & 小鸦鹃 & II & $\begin{array}{l}\text { 无危 } \\
\text { /LC }\end{array}$ & 黄超甫 & 闽清黄楮林自然保护区鸟类区系研究 \\
\hline Centropus bengalensis & 小鸦鹃 & II & $\begin{array}{l}\text { 无危 } \\
\text { /LC }\end{array}$ & 谢光勇 & 鄱阳湖都昌候鸟自然保护区夏季鸟类群落结构 \\
\hline Centropus bengalensis & 小鸦鹃 & II & 无危 & 李仕宁 & 茄新省级森林经营所鸟类资源调查 \\
\hline
\end{tabular}


顾垒，闻丞，罗玫，王吴，吕植. 中国最受关注濒危物种保护现状快速评价的新方法探讨. 生物多样性，2015，23(5)：583-590. http://www. biodiversity-science. net/CN/article/downloadArticleFile. do?attachType=PDF\&id=10075

\begin{tabular}{|c|c|c|c|c|c|}
\hline & & & $/ \mathrm{LC}$ & & \\
\hline \multirow[t]{2}{*}{ Centropus bengalensis } & 小鸦鹃 & II & 无危 & 庄 馨 & 深圳大鹏半岛国家地质公园野生脊椎动物资源调查 \\
\hline & & & $/ \mathrm{LC}$ & & \\
\hline \multirow[t]{2}{*}{ Centropus bengalensis } & 小鸦鹃 & II & 无危 & 刘昌利 & 皖西学院 ( 本部) 校园鸟类资源的初步调查 \\
\hline & & & $/ \mathrm{LC}$ & & \\
\hline \multirow[t]{2}{*}{ Centropus sinensis } & 褐翅鸦鹃 & II & 无危 & 常弘 & 2005 2009 年广州南沙湿地鸟类的群落结构及数量动态 \\
\hline & & & $/ \mathrm{LC}$ & & \\
\hline \multirow[t]{2}{*}{ Centropus sinensis } & 褐翅鸦鹃 & II & 无危 & 范洪敏 & 广东担杆岛鸟类多样性的季节变化 \\
\hline & & & $/ \mathrm{LC}$ & & \\
\hline \multirow[t]{2}{*}{ Centropus sinensis } & 褐翅鸦鹃 & II & 无危 & 曾向武 & 广东海丰鸟类自然保护区褐翅鸦鹃数量调查 \\
\hline & & & $/ \mathrm{LC}$ & & \\
\hline \multirow[t]{2}{*}{ Centropus sinensis } & 褐翅鸦鹃 & II & 无危 & 付海真 & 广东揭东桑浦双麓自然保护区鸟类资源初步调查 \\
\hline & & & $/ \mathrm{LC}$ & & \\
\hline \multirow[t]{2}{*}{ Centropus sinensis } & 褐翅鸦鹃 & II & 无危 & 王海京 & 广西田东县作登林区珍稀濒危野生动物资源初步调查 \\
\hline & & & $/ \mathrm{LC}$ & & \\
\hline \multirow[t]{2}{*}{ Centropus sinensis } & 褐翅鸦鹃 & II & 无危 & 刘振生 & 海南大田国家级自然保护区鸟类考察初报 \\
\hline & & & /LC & & \\
\hline \multirow[t]{2}{*}{ Centropus sinensis } & 褐翅鸦鹃 & II & 无危 & 王 晶 & 湖北仙桃沙湖湿地自然保护区夏季鸟类群落结构及多样性分析 \\
\hline & & & /LC & & \\
\hline
\end{tabular}


顾垒，闻丞，罗玫，王吴，吕植. 中国最受关注濒危物种保护现状快速评价的新方法探讨. 生物多样性，2015，23(5)：583-590. http://www. biodiversity-science. net/CN/article/downloadArticleFile. do?attachType=PDF\&id=10075

\begin{tabular}{|c|c|c|c|c|c|}
\hline Centropus sinensis & 褐翅鸦鹃 & II & $\begin{array}{l}\text { 无危 } \\
\text { /LC }\end{array}$ & 倐富春 & 华南农业大学校园鸟类多样性初步调查 \\
\hline Centropus sinensis & 褐翅鸦鹃 & II & $\begin{array}{l}\text { 无危 } \\
\text { /LC }\end{array}$ & 黄族豪 & 井冈山国家级自然保护区鸟类资源研究 \\
\hline Centropus sinensis & 褐翅鸦鹃 & II & $\begin{array}{l}\text { 无危 } \\
\text { /LC }\end{array}$ & 黄超甫 & 闽清黄楮林自然保护区鸟类区系研究 \\
\hline Centropus sinensis & 褐翅鸦鹃 & II & $\begin{array}{l}\text { 无危 } \\
\text { /LC }\end{array}$ & 谢光勇 & 鄱阳湖都昌候鸟自然保护区夏季鸟类群落结构 \\
\hline Centropus sinensis & 褐翅鸦鹃 & II & $\begin{array}{l}\text { 无危 } \\
\text { /LC }\end{array}$ & 李仕宁 & 茄新省级森林经营所鸟类资源调查 \\
\hline Centropus sinensis & 褐翅鸦鹃 & II & $\begin{array}{l}\text { 无危 } \\
\text { /LC }\end{array}$ & 陈若海 & 泉州湾河口湿地自然保护区珍稀濒危鸟类的分布特点及其保护 \\
\hline Centropus sinensis & 褐翅鸦鹃 & II & $\begin{array}{l}\text { 无危 } \\
\text { /LC }\end{array}$ & 李仕宁 & 三亚青梅港红树林自然保护区鸟类资源调查 \\
\hline Centropus sinensis & 褐翅鸦鹃 & II & $\begin{array}{l}\text { 无危 } \\
\text { /LC }\end{array}$ & 庄 馨 & 深圳大鹏半岛国家地质公园野生脊椎动物资源调查 \\
\hline Centropus sinensis & 褐翅鸦鹃 & II & $\begin{array}{l}\text { 无危 } \\
\text { /LC }\end{array}$ & 黄清柏 & 四川南充市郊褐翅鸦鹃的生境选择初探 \\
\hline Centropus sinensis & 褐翅鸦鹃 & II & 无危 & 郭延蜀 & 四川省南充市郊发现褐翅鸦鹃 \\
\hline
\end{tabular}


顾垒，闻丞，罗玫，王吴，吕植. 中国最受关注濒危物种保护现状快速评价的新方法探讨. 生物多样性，2015，23(5)：583-590. http://www biodiversity-science. net/CN/article/downloadArticleFile. do?attachType=PDF\&id=10075

LC

Cephalotaxus lanceolata

贡山三尖杉

贡山三尖杉

Cephalotaxus lanceolato

Cephalotaxus lanceolato

贡山三尖杉

Cephalotaxus lanceolata

贡山三尖杉

Cephalotaxus oliver

Cephalotaxus oliver

Cephalotaxus oliveri

Cephalotaxus oliver

Cephalotaxus oliveri

$$
\text { 篦子三尖杉 }
$$

$$
\text { 篦子三尖杉 }
$$

篦子三尖杉

篦子三尖杉

篦子三尖杉
濒危 E

濒危

苏建荣

濒危陈业高

EN

/EN

II

易危

ZENG LINGBIN

/VU

II

易危 Wanqin Yang

/VU

II

易危 Jianrong Su

/VU

易危 HAN Jie

/VU
CHEMICAL COMPOSITION OF THE ESSENTIAL OIL OF Cephalotaxus lanceolata FRESH LEAVES

贡山三尖杉的新名称及分类地位

火焰原子吸收光谱法对贡山三尖杉中 6 种金属元素含量的测定

三尖杉属系统分类学研究

An investigation on the bioactive properties of the chemical components and endophytic fungi

of Cephalotaxus oliveri Mast

Changes in soil microbial biomass and bacterial diversity during the transition from winter to

growing season in the subalpinealpine forests

Characterization of 15 Polymorphic Microsatellite Loci for Cephalotaxus oliveri

(Cephalotaxaceae), a Conifer of Medicinal Importance

Components Analysis of HHT Produced by Endophytic Fungi Strain gyzy-20 and Optimization

of Fermentation Conditions

Conflicting phylogenies of Larix (Pinaceae) based on cytoplasmic and nuclear DNA 
顾垒，闻丞，罗玫，王昊，吕植. 中国最受关注濒危物种保护现状快速评价的新方法探讨．生物多样性，2015，23(5)：583-590. http://www. biodiversity-science. net/CN/article/downloadArticleFile. do?attachType=PDF\&id=10075

\begin{tabular}{|c|c|c|c|c|c|}
\hline Cephalotaxus oliveri & 篦子三尖杉 & II & $\begin{array}{l}\text { 易危 } \\
\text { /VU }\end{array}$ & Hua-Wei Pan & $\begin{array}{l}\text { Development of microsatellite loci for Cephalotaxus oliveri (Cephalotaxaceae) and } \\
\text { cross-amplification in Cephalotaxus }\end{array}$ \\
\hline Cephalotaxus oliveri & 篦子三尖杉 & II & $\begin{array}{l}\text { 易危 } \\
\text { /VU }\end{array}$ & Xiao-Quan Wang & Evolution of 4-coumarate coenzyme A ligase (4CL) gene and divergence of Larix(Pinaceae) \\
\hline Cephalotaxus oliveri & 篦子三尖杉 & II & $\begin{array}{l}\text { 易危 } \\
\text { /VU }\end{array}$ & C. J. QUINN & $\begin{array}{l}\text { Familial concepts and relationships in the conifer based on rbcL and matK sequence } \\
\text { comparisons }\end{array}$ \\
\hline Cephalotaxus oliveri & 篦子三尖杉 & II & $\begin{array}{l}\text { 易危 } \\
\text { /VU }\end{array}$ & DUAN JianPing & Growth characteristics and response to climate change of Larix Miller tree-ring in China \\
\hline Cephalotaxus oliveri & 篦子三尖杉 & II & $\begin{array}{l}\text { 易危 } \\
\text { /VU }\end{array}$ & Ling Yang & $\begin{array}{l}\text { Interspecific relationships and origins of Taxaceae and Cephalotaxaceae revealed by partitioned } \\
\text { Bayesian analyses of chloroplast and nuclear DNA sequences }\end{array}$ \\
\hline Cephalotaxus oliveri & 篦子三尖杉 & II & $\begin{array}{l}\text { 易危 } \\
\text { /VU }\end{array}$ & X.-X. Wei & Phylogenetic split of Larix: evidence from paternally inherited cpDNA trnT-trnF region \\
\hline Cephalotaxus oliveri & 篦子三尖杉 & II & $\begin{array}{l}\text { 易危 } \\
\text { /VU }\end{array}$ & XIAO-XIN WEI & $\begin{array}{l}\text { Recolonization and radiation in Larix (Pinaceae) evidence from nuclear ribosomal DNA } \\
\text { paralogues }\end{array}$ \\
\hline Cephalotaxus oliveri & 篦子三尖杉 & II & $\begin{array}{l}\text { 易危 } \\
\text { /VU }\end{array}$ & D.C. Нао & $\begin{array}{l}\text { Sequence characteristics and divergent evolution of the chloroplastpsbA-trnH noncoding region } \\
\text { in gymnosperms }\end{array}$ \\
\hline Cephalotaxus oliveri & 篦子三尖杉 & II & $\begin{array}{l}\text { 易危 } \\
\text { /VU }\end{array}$ & Wan-qin Yang & $\begin{array}{l}\text { Soil biochemical dynamics at three elevations during the soil thawing period, Eastern Tibetan } \\
\text { Plateau nutrient availabilities, microbial properties and enzyme }\end{array}$ \\
\hline Cephalotaxus oliveri & 篦子三尖杉 & II & 易危 & Nathalie Isabel & Species-diagnostic markers in Larix spp. based on RAPDs and nuclear, cpDNA, and mtDNA \\
\hline
\end{tabular}


顾垒，闻丞，罗玫，王吴，吕植. 中国最受关注濒危物种保护现状快速评价的新方法探讨. 生物多样性，2015，23(5)：583-590. http://www biodiversity-science. net/CN/article/downloadArticleFile. do?attachType=PDF\&id=10075

\begin{tabular}{|c|c|c|c|c|c|}
\hline & & & /VU & & gene sequences, and their phylogenetic implications \\
\hline \multirow[t]{3}{*}{ Cephalotaxus oliveri } & 篦子三尖杉 & II & 易危 & Ting Wang & The Complete Chloroplast Genome Sequence of Cephalotaxus oliveri (Cephalotaxaceae) \\
\hline & & & /VU & & Evolutionary Comparison of Cephalotaxus Chloroplast DNAs and Insights into the Loss of \\
\hline & & & & & Inverted Repeat Copies in Gymnosperms \\
\hline \multirow[t]{2}{*}{ Cephalotaxus oliveri } & 篦子三尖杉 & II & 易危 & Jianrong Su & The Taxonomic History and Original Literatures Arrangements of Living Cephalotaxus \\
\hline & & & /VU & & (Cephalotaxaceae) \\
\hline \multirow[t]{2}{*}{ Cephalotaxus oliveri } & 篦子三尖杉 & II & 易危 & 邹露 & 蓖子三尖杉的组织培养及生物碱检测 \\
\hline & & & /VU & & \\
\hline \multirow[t]{2}{*}{ Cephalotaxus oliveri } & 篦子三尖杉 & II & 易危 & 应站明 & 篦子三尖杉 ISSR - PCR 体系优化 \\
\hline & & & /VU & & \\
\hline \multirow[t]{2}{*}{ Cephalotaxus oliveri } & 篦子三尖杉 & II & 易危 & 韩洁 & 篦子三尖杉产高三尖杉酯碱内生真菌的分离和篮选 \\
\hline & & & /VU & & \\
\hline \multirow[t]{2}{*}{ Cephalotaxus oliveri } & 篦子三尖杉 & II & 易危 & 韩洁 & 篦子三尖杉产高三尖杉酯碱内生真菌的分离与鉴定 \\
\hline & & & /VU & & \\
\hline \multirow[t]{2}{*}{ Cephalotaxus oliveri } & 篦子三尖杉 & II & 易危 & 周远超 & 篦子三尖杉的濒危程度及其保护工作现状 \\
\hline & & & /VU & & \\
\hline \multirow[t]{2}{*}{ Cephalotaxus oliveri } & 篦子三尖杉 & II & 易危 & 戴晓勇 & 篦子三尖杉的扞插繁殖研究 \\
\hline & & & /VU & & \\
\hline Cephalotaxus oliveri & 篦子三尖杉 & II & 易危 & 苏应娟 & 篦子三尖杉的亲缘地理学研究 \\
\hline
\end{tabular}


顾垒，闻丞，罗玫，王吴，吕植. 中国最受关注濒危物种保护现状快速评价的新方法探讨. 生物多样性，2015，23(5)：583-590. http://www. biodiversity-science. net/CN/article/downloadArticleFile. do?attachType=PDF\&id=10075

\begin{tabular}{|c|c|c|c|c|c|}
\hline & & & $/ \mathrm{VU}$ & & \\
\hline \multirow[t]{2}{*}{ Cephalotaxus oliveri } & 篦子三尖杉 & II & 易危 & 艾启芳 & 篦子三尖杉的研究进展 \\
\hline & & & $/ \mathrm{VU}$ & & \\
\hline \multirow[t]{2}{*}{ Cephalotaxus oliveri } & 篦子三尖杉 & II & 易危 & 陈少瑜 & 篦子三尖杉的遗传多样性及濒危原因 \\
\hline & & & /VU & & \\
\hline \multirow[t]{2}{*}{ Cephalotaxus oliveri } & 篦子三尖杉 & II & 易危 & 吕梅 & 篦子三尖杉繁殖技术研究 \\
\hline & & & $/ \mathrm{VU}$ & & \\
\hline \multirow[t]{2}{*}{ Cephalotaxus oliveri } & 篦子三尖杉 & II & 易危 & 韩洁 & 篦子三尖杉内生真菌 gyzy_9 的鉴定及其抑菌活性研究 \\
\hline & & & $/ \mathrm{VU}$ & & \\
\hline \multirow[t]{2}{*}{ Cephalotaxus oliveri } & 篦子三尖杉 & II & 易危 & 曹基武 & 篦子三尖杉生物学特性和繁殖技术 \\
\hline & & & $/ \mathrm{VU}$ & & \\
\hline \multirow[t]{2}{*}{ Cephalotaxus oliveri } & 篦子三尖杉 & II & 易危 & 伍铭凯 & 篦子三尖杉育苗技术 \\
\hline & & & /VU & & \\
\hline \multirow[t]{2}{*}{ Cephalotaxus oliveri } & 篦子三尖杉 & II & 易危 & 曹福祥 & 篦子三尖杉愈伤组织的诱导 \\
\hline & & & /VU & & \\
\hline \multirow[t]{2}{*}{ Cephalotaxus oliveri } & 篦子三尖杉 & II & 易危 & 吕梅 & 篦子三尖杉愈伤组织的诱导 \\
\hline & & & /VU & & \\
\hline \multirow[t]{2}{*}{ Cephalotaxus oliveri } & 篦子三尖杉 & II & 易危 & 易思荣 & 篦子三尖杉种子繁殖技术 \\
\hline & & & /VU & & \\
\hline
\end{tabular}


顾垒，闻丞，罗玫，王吴，吕植. 中国最受关注濒危物种保护现状快速评价的新方法探讨. 生物多样性，2015，23(5)：583-590. http://www biodiversity-science. net/CN/article/downloadArticleFile. do?attachType=PDF\&id=10075

\begin{tabular}{|c|c|c|c|c|c|}
\hline Cephalotaxus oliveri & 篦子三尖杉 & II & $\begin{array}{l}\text { 易危 } \\
\text { /VU }\end{array}$ & 易思荣 & 篦子三尖杉种子繁殖取得成功 \\
\hline Cephalotaxus oliveri & 篦子三尖杉 & II & $\begin{array}{l}\text { 易危 } \\
\text { /VU }\end{array}$ & 戴晓勇 & 篦子三尖杉种子育苗技术研究 \\
\hline Cephalotaxus oliveri & 篦子三尖杉 & II & $\begin{array}{l}\text { 易危 } \\
\text { /VU }\end{array}$ & 苏应娟 & 濒危植物篦子三尖杉的遗传多样性分析 \\
\hline Cephalotaxus oliveri & 篦子三尖杉 & II & $\begin{array}{l}\text { 易危 } \\
\text { /VU }\end{array}$ & 康冀川 & 红豆杉及其近缘植物中产紫杉烷类化合物内生真菌的篮选 \\
\hline Cephalotaxus oliveri & 篦子三尖杉 & II & $\begin{array}{l}\text { 易危 } \\
\text { /VU }\end{array}$ & 王艇 & 红豆杉科及其相关类群的 RAPD 分析 \\
\hline Cephalotaxus oliveri & 篦子三尖杉 & II & $\begin{array}{l}\text { 易危 } \\
\text { /VU }\end{array}$ & 王艇 & 红豆杉科及其相关类群的 rbcL 基因 RAPD 分析 \\
\hline Cephalotaxus oliveri & 篦子三尖杉 & II & $\begin{array}{l}\text { 易危 } \\
\text { /VU }\end{array}$ & 王艇 & 红豆杉科及相关类群叶绿体 rbcL 基因与 trnL_trnF 间隔区序列的分支分析 \\
\hline Cephalotaxus oliveri & 篦子三尖杉 & II & $\begin{array}{l}\text { 易危 } \\
\text { /VU }\end{array}$ & 郑博 & 红豆杉科及相关类群叶绿体 rbcL 基因与 trnL_trnF 间隔区序列的分支分析 \\
\hline Cephalotaxus oliveri & 篦子三尖杉 & II & $\begin{array}{l}\text { 易危 } \\
\text { /VU }\end{array}$ & 杨万勤 & 季节性雪被对高山森林调落物分解的影响 \\
\hline Cephalotaxus oliveri & 篦子三尖杉 & II & 易危 & 黎桂芳 & 江西武功山篦子三尖杉资源的调查研究 \\
\hline
\end{tabular}


顾垒，闻丞，罗玫，王吴，吕植. 中国最受关注濒危物种保护现状快速评价的新方法探讨. 生物多样性，2015，23(5)：583-590. http://www. biodiversity-science. net/CN/article/downloadArticleFile. do?attachType=PDF\&id=10075

\begin{tabular}{|c|c|c|c|c|c|}
\hline & & & $/ \mathrm{VU}$ & & \\
\hline \multirow[t]{2}{*}{ Cephalotaxus oliveri } & 篦子三尖杉 & II & 易危 & 康冀川 & 两种近缘植物内生真菌的分离鉴定及次生代谢物的初步研究 \\
\hline & & & /VU & & \\
\hline \multirow[t]{2}{*}{ Cephalotaxus oliveri } & 篦子三尖杉 & II & 易危 & 王艇 & 裸子植物中光敏色素 PHY-PAS1 结构域的适应性进化 \\
\hline & & & /VU & & \\
\hline \multirow[t]{2}{*}{ Cephalotaxus oliveri } & 篦子三尖杉 & II & 易危 & 潘春霞 & 三尖杉不同种源苗期生长性状分析 \\
\hline & & & /VU & & \\
\hline \multirow[t]{2}{*}{ Cephalotaxus oliveri } & 篦子三尖杉 & II & 易危 & 秦路平 & 三尖杉碱类化合物的来源、药理作用及临床应用研究进展 \\
\hline & & & /VU & & \\
\hline \multirow[t]{2}{*}{ Cephalotaxus oliveri } & 篦子三尖杉 & II & 易危 & 汪劲武 & 三尖杉科独立有理 \\
\hline & & & /VU & & \\
\hline \multirow[t]{2}{*}{ Cephalotaxus oliveri } & 篦子三尖杉 & II & 易危 & 郎学东 & 三尖杉属系统分类学研究 \\
\hline & & & /VU & & \\
\hline \multirow[t]{2}{*}{ Cephalotaxus oliveri } & 篦子三尖杉 & II & 易危 & 陈少瑜 & 三尖杉属植物的同工酶分析 \\
\hline & & & /VU & & \\
\hline \multirow[t]{2}{*}{ Cephalotaxus oliveri } & 篦子三尖杉 & II & 易危 & 陈名慧 & 修文石灰岩山地篦子三尖杉灌从群落多样性研究 \\
\hline & & & /VU & & \\
\hline \multirow[t]{2}{*}{ Cephalotaxus oliveri } & 篦子三尖杉 & II & 易危 & 陈少瑜 & 云南省篦子三尖杉濒危原因及保护措施 \\
\hline & & & /VU & & \\
\hline
\end{tabular}


顾垒，闻丞，罗玫，王吴，吕植. 中国最受关注濒危物种保护现状快速评价的新方法探讨. 生物多样性，2015，23(5)：583-590. http://www biodiversity-science. net/CN/article/downloadArticleFile. do?attachType=PDF\&id=10075

\begin{tabular}{|c|c|c|c|c|c|}
\hline \multirow[t]{2}{*}{ Cephalotaxus oliveri } & 篦子三尖杉 & II & 易危 & 司马永康 & 云南省三尖杉属植物的地理分布与环境因子的关系 \\
\hline & & & $/ \mathrm{VU}$ & & \\
\hline \multirow[t]{2}{*}{ Cephalotaxus oliveri } & 篦子三尖杉 & II & 易危 & 段建平 & 中国落叶松属树木年轮生长特性及其对气候变化的响应 \\
\hline & & & /VU & & \\
\hline \multirow[t]{2}{*}{ Cephalotaxus oliveri } & 篦子三尖杉 & II & 易危 & 高中松 & 紫外可见分光光度法测定篦子三尖杉碱总生物含量 \\
\hline & & & $/ \mathrm{VU}$ & & \\
\hline \multirow[t]{2}{*}{ Cercidiphyllum japonicum } & 连香树 & II & 近危 & 万涛 & 10 年生连香树人工群落平均个体生长规律研究 \\
\hline & & & /NT & & \\
\hline \multirow[t]{2}{*}{ Cercidiphyllum japonicum } & 连香树 & II & 近危 & Dong He & A dendroclimatic investigation of radial growth - climate relationships for the riparian species \\
\hline & & & /NT & & Cercidiphyllum japonicum in the Shennongjia area, central China \\
\hline \multirow[t]{2}{*}{ Cercidiphyllum japonicum } & 连香树 & II & 近危 & Xiao-Ling Yan & Morphogenesis of Pistillate Flowers of Cercidiphyllum japonicum (Cercidiphyllaceae) \\
\hline & & & /NT & & \\
\hline \multirow[t]{2}{*}{ Cercidiphyllum japonicum } & 连香树 & II & 近危 & 麦苗苗 & PEG 处理对连香树种子萌发与芽苗生长的影响 \\
\hline & & & /NT & & \\
\hline \multirow[t]{2}{*}{ Cercidiphyllum japonicum } & 连香树 & II & 近危 & 黄绍辉 & 安徽歌县连香树群落的植物区系特征分析 \\
\hline & & & /NT & & \\
\hline \multirow[t]{2}{*}{ Cercidiphyllum japonicum } & 连香树 & II & 近危 & 翁关成 & 濒危物种连香树的利用价值与繁育技术 \\
\hline & & & $/ \mathrm{NT}$ & & \\
\hline Cercidiphyllum japonicum & 连香树 & II & 近危 & 袁丽洁 & 濒危植物连香树的传粉生物学研究 \\
\hline
\end{tabular}


顾垒，闻丞，罗玫，王吴，吕植. 中国最受关注濒危物种保护现状快速评价的新方法探讨. 生物多样性，2015，23(5)：583-590. http://www biodiversity-science. net/CN/article/downloadArticleFile. do?attachType=PDF\&id=10075

\begin{tabular}{|c|c|c|c|c|c|}
\hline & & & $/ \mathrm{NT}$ & & \\
\hline \multirow[t]{2}{*}{ Cercidiphyllum japonicum } & 连香树 & II & 近危 & 王静 & 濒危植物连香树居群的遗传多样性和遗传分化研究 \\
\hline & & & $/ \mathrm{NT}$ & & \\
\hline \multirow[t]{2}{*}{ Cercidiphyllum japonicum } & 连香树 & II & 近危 & 黄绍辉 & 濒危植物连香树遗传多样性研究 \\
\hline & & & /NT & & \\
\hline \multirow[t]{2}{*}{ Cercidiphyllum japonicum } & 连香树 & II & 近危 & 刘光华 & 濒危植物连香树种群结构与动态研究 \\
\hline & & & $/ \mathrm{NT}$ & & \\
\hline \multirow[t]{2}{*}{ Cercidiphyllum japonicum } & 连香树 & II & 近危 & 刘光华 & 濒危植物连香树种群空间分布格局分析 \\
\hline & & & /NT & & \\
\hline \multirow[t]{2}{*}{ Cercidiphyllum japonicum } & 连香树 & II & 近危 & 李伟 & 不同种源连香树对干旱胁迫的生理响应研究 (硕士毕业论文) \\
\hline & & & /NT & & \\
\hline \multirow[t]{2}{*}{ Cercidiphyllum japonicum } & 连香树 & II & 近危 & 王显 & 湖北省连香树自然种群分布研究 \\
\hline & & & $/ \mathrm{NT}$ & & \\
\hline \multirow[t]{2}{*}{ Cercidiphyllum japonicum } & 连香树 & II & 近危 & 杨欣超 & 湖南省野生连香树生境调查及濒危原因分析 \\
\hline & & & $/ \mathrm{NT}$ & & \\
\hline \multirow[t]{2}{*}{ Cercidiphyllum japonicum } & 连香树 & II & 近危 & 蒋莉 & 连香树播种育苗技术 \\
\hline & & & /NT & & \\
\hline \multirow[t]{2}{*}{ Cercidiphyllum japonicum } & 连香树 & II & 近危 & 杨荣慧 & 连香树播种育苗试验 \\
\hline & & & /NT & & \\
\hline
\end{tabular}


顾垒，闻丞，罗玫，王吴，吕植. 中国最受关注濒危物种保护现状快速评价的新方法探讨. 生物多样性，2015，23(5)：583-590. http://www biodiversity-science. net/CN/article/downloadArticleFile. do?attachType=PDF\&id=10075

\begin{tabular}{|c|c|c|c|c|c|}
\hline Cercidiphyllum japonicum & 连香树 & II & $\begin{array}{l}\text { 近危 } \\
\text { /NT }\end{array}$ & 陶应时 & 连香树雌雄株叶片形态及生理生化指标比较 \\
\hline Cercidiphyllum japonicum & 连香树 & II & $\begin{array}{l}\text { 近危 } \\
\text { /NT }\end{array}$ & 李俊 & 连香树的培育与利用 \\
\hline Cercidiphyllum japonicum & 连香树 & II & $\begin{array}{l}\text { 近危 } \\
\text { /NT }\end{array}$ & 曹基武 & 连香树的森林群落调查及栽培技术 \\
\hline Cercidiphyllum japonicum & 连香树 & II & $\begin{array}{l}\text { 近危 } \\
\text { /NT }\end{array}$ & 吴甘霖 & 连香树的生物学特性及其资源保护 \\
\hline Cercidiphyllum japonicum & 连香树 & II & $\begin{array}{l}\text { 近危 } \\
\text { /NT }\end{array}$ & 麦苗苗 & 连香树的组织培养和快速繁殖 \\
\hline Cercidiphyllum japonicum & 连香树 & II & $\begin{array}{l}\text { 近危 } \\
\text { /NT }\end{array}$ & 丁峰 & 连香树丰产栽培技术 \\
\hline Cercidiphyllum japonicum & 连香树 & II & $\begin{array}{l}\text { 近危 } \\
\text { /NT }\end{array}$ & 麦苗苗 & 连香树干旱胁迫过程中的生理变化与基因差异表达分析（博士毕业论文） \\
\hline Cercidiphyllum japonicum & 连香树 & II & $\begin{array}{l}\text { 近危 } \\
\text { /NT }\end{array}$ & 毕波 & 连香树和榉树容器苗苗木分级标准研究 \\
\hline Cercidiphyllum japonicum & 连香树 & II & $\begin{array}{l}\text { 近危 } \\
\text { /NT }\end{array}$ & 陈荣珠 & 连香树快速繁殖及生根过程中内源激素含量的测定 \\
\hline Cercidiphyllum japonicum & 连香树 & II & 近危 & 麦苗苗 & 连香树快速扩繁途径的研究 (硕士毕业论文) \\
\hline
\end{tabular}


顾垒，闻丞，罗玫，王吴，吕植. 中国最受关注濒危物种保护现状快速评价的新方法探讨. 生物多样性，2015，23(5)：583-590. http://www. biodiversity-science. net/CN/article/downloadArticleFile. do?attachType=PDF\&id=10075

\begin{tabular}{|c|c|c|c|c|c|}
\hline & & & $/ \mathrm{NT}$ & & \\
\hline \multirow[t]{2}{*}{ Cercidiphyllum japonicum } & 连香树 & II & 近危 & 麦苗苗 & 连香树离体快繁初步研究 \\
\hline & & & /NT & & \\
\hline \multirow[t]{2}{*}{ Cercidiphyllum japonicum } & 连香树 & II & 近危 & 崔仕权 & 连香树嫩枝扞插繁殖技术 \\
\hline & & & /NT & & \\
\hline \multirow[t]{2}{*}{ Cercidiphyllum japonicum } & 连香树 & II & 近危 & 麦苗苗 & 连香树嫩枝扦插繁殖技术研究 \\
\hline & & & /NT & & \\
\hline \multirow[t]{2}{*}{ Cercidiphyllum japonicum } & 连香树 & II & 近危 & 石方 & 连香树扞插育苗密度研究 \\
\hline & & & $/ \mathrm{NT}$ & & \\
\hline \multirow[t]{2}{*}{ Cercidiphyllum japonicum } & 连香树 & II & 近危 & 潘开文 & 连香树人工幼林群落营养元素含量、积累分配和循环 \\
\hline & & & /NT & & \\
\hline \multirow[t]{2}{*}{ Cercidiphyllum japonicum } & 连香树 & II & 近危 & 廖兴利 & 连香树生理生化物质随海拔的变化及其适应性研究 \\
\hline & & & /NT & & \\
\hline \multirow[t]{2}{*}{ Cercidiphyllum japonicum } & 连香树 & II & 近危 & 黎明 & 连香树营养器官的解剖学研究 \\
\hline & & & $/ \mathrm{NT}$ & & \\
\hline \multirow[t]{2}{*}{ Cercidiphyllum japonicum } & 连香树 & II & 近危 & 黄绍辉 & 连香树幼树各器官相关性和回归分析 \\
\hline & & & $/ \mathrm{NT}$ & & \\
\hline \multirow[t]{2}{*}{ Cercidiphyllum japonicum } & 连香树 & II & 近危 & 焦永社 & 连香树育苗技术 \\
\hline & & & /NT & & \\
\hline
\end{tabular}


顾垒，闻丞，罗玫，王吴，吕植. 中国最受关注濒危物种保护现状快速评价的新方法探讨. 生物多样性，2015，23(5)：583-590. http://www biodiversity-science. net/CN/article/downloadArticleFile. do?attachType=PDF\&id=10075

\begin{tabular}{|c|c|c|c|c|c|}
\hline Cercidiphyllum japonicum & 连香树 & II & $\begin{array}{l}\text { 近危 } \\
\text { /NT }\end{array}$ & 赵秋玲 & 连香树育苗试验研究 \\
\hline Cercidiphyllum japonicum & 连香树 & II & $\begin{array}{l}\text { 近危 } \\
\text { /NT }\end{array}$ & 张先云 & 连香树再生体系的建立 \\
\hline Cercidiphyllum japonicum & 连香树 & II & $\begin{array}{l}\text { 近危 } \\
\text { /NT }\end{array}$ & 刘光华 & 连香树种群生殖生态学研究（硕士毕业论文） \\
\hline Cercidiphyllum japonicum & 连香树 & II & $\begin{array}{l}\text { 近危 } \\
\text { /NT }\end{array}$ & 刘光华 & 连香树种子大小分布及其变异研究 \\
\hline Cercidiphyllum japonicum & 连香树 & II & $\begin{array}{l}\text { 近危 } \\
\text { /NT }\end{array}$ & 陈荣珠 & 连香树组织培养及其生根过程中内源激素变化研究 (硕士毕业论文) \\
\hline Cercidiphyllum japonicum & 连香树 & II & $\begin{array}{l}\text { 近危 } \\
\text { /NT }\end{array}$ & 夏霖辉 & 密度对连香树幼苗生长及生物量的影响 \\
\hline Cercidiphyllum japonicum & 连香树 & II & $\begin{array}{l}\text { 近危 } \\
\text { /NT }\end{array}$ & 杨荣慧 & 秦岭地区连香树分布现状与濒危机理 \\
\hline Cercidiphyllum japonicum & 连香树 & II & $\begin{array}{l}\text { 近危 } \\
\text { /NT }\end{array}$ & 何东 & 神农架山地河岸带连香树的种群结构与动态 \\
\hline Cercidiphyllum japonicum & 连香树 & II & $\begin{array}{l}\text { 近危 } \\
\text { /NT }\end{array}$ & 袁珊 & 神农架山体对濒危植物连香树遗传结构影响的研究 \\
\hline Cercidiphyllum japonicum & 连香树 & II & 近危 & 麦苗苗 & 渗透胁迫对连香树幼树生理特性的影响 \\
\hline
\end{tabular}


顾垒，闻丞，罗玫，王吴，吕植. 中国最受关注濒危物种保护现状快速评价的新方法探讨. 生物多样性，2015，23(5)：583-590. http://www. biodiversity-science. net/CN/article/downloadArticleFile. do?attachType=PDF\&id=10075

\begin{tabular}{|c|c|c|c|c|c|}
\hline & & & $/ \mathrm{NT}$ & & \\
\hline \multirow[t]{2}{*}{ Cercidiphyllum japonicum } & 连香树 & II & 近危 & 万猛 & 太行山南麓连香树的生长过程分析 \\
\hline & & & /NT & & \\
\hline \multirow[t]{2}{*}{ Cercidiphyllum japonicum } & 连香树 & II & 近危 & 潘开文 & 用关联度和聚类分析法研究连香树人工群落与环境的关系 \\
\hline & & & /NT & & \\
\hline \multirow[t]{2}{*}{ Cercidiphyllum japonicum } & 连香树 & II & 近危 & 杨欣超 & 珍稀濒危树种连香树繁育技术研究 \\
\hline & & & /NT & & \\
\hline \multirow[t]{2}{*}{ Cercidiphyllum japonicum } & 连香树 & II & 近危 & 王立安 & 珍稀濒危树种连香树造林试验 \\
\hline & & & $/ \mathrm{NT}$ & & \\
\hline \multirow[t]{2}{*}{ Cercidiphyllum japonicum } & 连香树 & II & 近危 & 刘美 & 珍稀濒危物种连香树研究进展 \\
\hline & & & $/ \mathrm{NT}$ & & \\
\hline \multirow[t]{2}{*}{ Cercidiphyllum japonicum } & 连香树 & II & 近危 & 黄绍辉 & 珍稀濒危植物连香树的物种生物学研究（博士毕业论文） \\
\hline & & & /NT & & \\
\hline \multirow[t]{2}{*}{ Cercidiphyllum japonicum } & 连香树 & II & 近危 & 杜晓华 & 珍稀濒危植物一连香树研究进展 \\
\hline & & & /NT & & \\
\hline \multirow[t]{2}{*}{ Cercidiphyllum japonicum } & 连香树 & II & 近危 & 熊丹 & 珍稀濒危植物连香树种子萌发的研究 \\
\hline & & & /NT & & \\
\hline \multirow[t]{2}{*}{ Cercidiphyllum japonicum } & 连香树 & II & 近危 & 冯朝元 & 珍稀树种连香树种子发芽特性的研究 \\
\hline & & & /NT & & \\
\hline
\end{tabular}


顾垒，闻丞，罗玫，王吴，吕植. 中国最受关注濒危物种保护现状快速评价的新方法探讨. 生物多样性，2015，23(5)：583-590. http://www biodiversity-science. net/CN/article/downloadArticleFile. do?attachType=PDF\&id=10075

\begin{tabular}{|c|c|c|c|c|c|}
\hline Cercidiphyllum japonicum & 连香树 & II & $\begin{array}{l}\text { 近危 } \\
\text { /NT }\end{array}$ & 李文良 & 珍稀植物连香树(Cercidiphyllum japonicum) 的种子萌发特性 \\
\hline Cercidiphyllum japonicum & 连香树 & II & $\begin{array}{l}\text { 近危 } \\
\text { /NT }\end{array}$ & 袁丽洁 & 珍稀植物连香树组织培养技术体系研究 \\
\hline Certhia tianquanensis & 四川旋木雀 & $\begin{array}{l}\text { 未列 } \\
入\end{array}$ & $\begin{array}{l}\text { 近危 } \\
\text { /NT }\end{array}$ & 孙悦华 & 陕西秦岭发现四川旋木雀 \\
\hline Certhia tianquanensis & 四川旋木雀 & $\begin{array}{l}\text { 未列 } \\
入\end{array}$ & $\begin{array}{l}\text { 近危 } \\
\text { /NT }\end{array}$ & 杜雷军 & 陕西省黄柏塬自然保护区鸟类动物资源与区系特征分析 \\
\hline Cervus albirostris & 白唇鹿 & I & $\begin{array}{l}\text { 易危 } \\
\text { /VU }\end{array}$ & 群吉 & 白唇鹿巴氏杆菌病的防治 \\
\hline Cervus albirostris & 白唇鹿 & I & $\begin{array}{l}\text { 易危 } \\
\text { /VU }\end{array}$ & 谢幼新 & 白唇鹿白肌病的诊断及治疗 \\
\hline Cervus albirostris & 白唇鹿 & I & $\begin{array}{l}\text { 易危 } \\
\text { /VU }\end{array}$ & 群吉 & 白唇鹿肠毒血症的综合防治 \\
\hline Cervus albirostris & 白唇鹿 & I & $\begin{array}{l}\text { 易危 } \\
\text { /VU }\end{array}$ & 吴孔菊 & 白唇鹿的人工幼育 \\
\hline Cervus albirostris & 白唇鹿 & I & $\begin{array}{l}\text { 易危 } \\
\text { /VU }\end{array}$ & 任战军 & 白唇鹿的微卫星遗传多态性分析 \\
\hline Cervus albirostris & 白唇鹿 & I & 易危 & 吴 祥 & 白唇鹿结核病变态反应试验 \\
\hline
\end{tabular}


顾垒，闻丞，罗玫，王吴，吕植. 中国最受关注濒危物种保护现状快速评价的新方法探讨. 生物多样性，2015，23(5)：583-590. http://www. biodiversity-science. net/CN/article/downloadArticleFile. do?attachType=PDF\&id=10075

\begin{tabular}{|c|c|c|c|c|c|}
\hline & & & /VU & & \\
\hline \multirow[t]{2}{*}{ Cervus albirostris } & 白唇鹿 & I & 易危 & 张旭静 & 白唇鹿结核病的病理学诊断 \\
\hline & & & $/ \mathrm{VU}$ & & \\
\hline \multirow[t]{2}{*}{ Cervus albirostris } & 白唇鹿 & I & 易危 & 张西云 & 白唇鹿结核病的病原分离 \\
\hline & & & $/ \mathrm{VU}$ & & \\
\hline \multirow[t]{2}{*}{ Cervus albirostris } & 白唇鹿 & I & 易危 & 刘成录 & 白唇鹿血清淀粉酶的活性测定 \\
\hline & & & /VU & & \\
\hline \multirow[t]{2}{*}{ Cervus albirostris } & 白唇鹿 & I & 易危 & 苏力 & 白唇鹿在华南炎热地区的饲养及繁殖 \\
\hline & & & /VU & & \\
\hline \multirow[t]{2}{*}{ Cervus albirostris } & 白唇鹿 & I & 易危 & 何利军 & 半圈养条件下白唇鹿行为时间 \\
\hline & & & /VU & & 分配及活动规律的研究 \\
\hline \multirow[t]{2}{*}{ Cervus albirostris } & 白唇鹿 & I & 易危 & 王进隆 & 不同时期断奶对白唇鹿 \\
\hline & & & /VU & & 母鹿繁殖性能及仔鹿繁活影响 \\
\hline \multirow[t]{2}{*}{ Cervus albirostris } & 白唇鹿 & I & 易危 & 陈维刚 & 坏死杆菌感染引起白唇鹿腐蹄病的诊治 \\
\hline & & & /VU & & \\
\hline \multirow[t]{2}{*}{ Cervus albirostris } & 白唇鹿 & I & 易危 & 李一清 & 青海省祁连县驯养白唇鹿现状调查 \\
\hline & & & /VU & & \\
\hline \multirow[t]{2}{*}{ Cervus albirostris } & 白唇鹿 & I & 易危 & 钟灵 & 圈养白唇鹿的饲养管理与繁殖 \\
\hline & & & /VU & & \\
\hline
\end{tabular}


顾垒，闻丞，罗玫，王吴，吕植. 中国最受关注濒危物种保护现状快速评价的新方法探讨. 生物多样性，2015，23(5)：583-590. http://www, biodiversity-science. net/CN/article/downloadArticleFile. do?attachType=PDF\&id=10075

\begin{tabular}{|c|c|c|c|c|c|}
\hline Cervus albirostris & 白唇鹿 & I & $\begin{array}{l}\text { 易危 } \\
\text { /VU }\end{array}$ & 何利军 & 圈养条件下白唇鹿行为观察 \\
\hline Cervus albirostris & 白唇鹿 & I & $\begin{array}{l}\text { 易危 } \\
\text { /VU }\end{array}$ & 涂朝勇 & $\begin{array}{l}\text { 圈养状态下白唇鹿(Cervus albirostris) } \\
\text { 昼间行为节律初步研究 }\end{array}$ \\
\hline Cervus albirostris & 白唇鹿 & I & $\begin{array}{l}\text { 易危 } \\
\text { /VU }\end{array}$ & 王进龙 & 速补钙磷对 白唇鹿发病率的影响 \\
\hline Cervus albirostris & 白唇鹿 & I & $\begin{array}{l}\text { 易危 } \\
\text { /VU }\end{array}$ & 刘汀 & 西藏工布江达白唇鹿自然保护区白唇鹿分布及其生活习性调查 \\
\hline Cervus albirostris & 白唇鹿 & I & $\begin{array}{l}\text { 易危 } \\
\text { /VU }\end{array}$ & 张旭静 & 小种群白唇鹿结核病的流行与诊断 \\
\hline Cervus albirostris & 白唇鹿 & I & $\begin{array}{l}\text { 易危 } \\
\text { /VU }\end{array}$ & 张丽 & $\begin{array}{l}\text { 应用 mtDNA CytB 基因全序列分析白唇鹿和五个马鹿亚种的遗传 } \\
\text { 多样性与系统进化 }\end{array}$ \\
\hline Cervus albirostris & 白唇鹿 & I & $\begin{array}{l}\text { 易危 } \\
\text { /VU }\end{array}$ & 邓济苏 & 重庆地区圈羊白唇鹿血液细胞和血液化学指标测定 \\
\hline Cervus nippon & 梅花鹿 & I & $\begin{array}{l}\text { 无危 } \\
\text { /LC }\end{array}$ & 魏海军 & CIDR 和 PMSG 诱导东北梅花鹿同期发情的初步研究 \\
\hline Cervus nippon & 梅花鹿 & I & $\begin{array}{l}\text { 无危 } \\
\text { /LC }\end{array}$ & 张才骏 & 白唇鹿、马鹿和梅花鹿血红蛋白和运铁蛋白的电泳研究 \\
\hline Cervus nippon & 梅花鹿 & I & 无危 & 王全凯 & 北方三省区梅花鹿间布鲁氏茵病的流行病学调查 \\
\hline
\end{tabular}


顾垒，闻丞，罗玫，王吴，吕植. 中国最受关注濒危物种保护现状快速评价的新方法探讨. 生物多样性，2015，23(5)：583-590. http://www. biodiversity-science. net/CN/article/downloadArticleFile. do?attachType=PDF\&id=10075

\begin{tabular}{|c|c|c|c|c|c|}
\hline & & & $/ \mathrm{LC}$ & & \\
\hline \multirow[t]{2}{*}{ Cervus nippon } & 梅花鹿 & I & 无危 & 李光玉 & 不同蛋白质水平对育成早期梅花鹿消化代谢的影响 \\
\hline & & & $/ \mathrm{LC}$ & & \\
\hline \multirow[t]{2}{*}{ Cervus nippon } & 梅花鹿 & I & 无危 & 王凯英 & 不同精粗比全混合日粮 (TMR) 对雄性梅花鹿生产性能及血液生化指标的影响 \\
\hline & & & $/ \mathrm{LC}$ & & \\
\hline \multirow[t]{2}{*}{ Cervus nippon } & 梅花鹿 & I & 无危 & 马泽芳 & 不同饲养时期雄性梅花鹿血中尿嘧啶和次黄嘌呤含量的 HPLC 分析 \\
\hline & & & $/ \mathrm{LC}$ & & \\
\hline \multirow[t]{2}{*}{ Cervus nippon } & 梅花鹿 & I & 无危 & 吕慎金 & 不同饲养条件下成年公梅花鹿的行为节律研究 \\
\hline & & & $/ \mathrm{LC}$ & & \\
\hline \multirow[t]{2}{*}{ Cervus nippon } & 梅花鹿 & I & 无危 & 李光玉 & 常用饲料原料蛋白质在梅花鹿瘤胃内降解率的测定 \\
\hline & & & $/ \mathrm{LC}$ & & \\
\hline \multirow[t]{2}{*}{ Cervus nippon } & 梅花鹿 & I & 无危 & 汪树理 & 带血与排血梅花鹿茸骨片游离氨基酸含量的比较分析 \\
\hline & & & $/ \mathrm{LC}$ & & \\
\hline \multirow[t]{2}{*}{ Cervus nippon } & 梅花鹿 & I & 无危 & 宁超群 & 东北梅花鹿、猪和牛血粉氨基酸、胆固醇、钙 \\
\hline & & & $/ \mathrm{LC}$ & & 和磷含量的比较分析 \\
\hline \multirow[t]{2}{*}{ Cervus nippon } & 梅花鹿 & I & 无危 & 于超 & 东北梅花鹿放归和半散放种群冬季栖息地选择 \\
\hline & & & /LC & & \\
\hline \multirow[t]{2}{*}{ Cervus nippon } & 梅花鹿 & I & 无危 & 李和平 & 东北梅花鹿鹿茸尖端组织全长 cDNA 文库的构建 \\
\hline & & & /LC & & \\
\hline
\end{tabular}


顾垒，闻丞，罗玫，王吴，吕植. 中国最受关注濒危物种保护现状快速评价的新方法探讨. 生物多样性，2015，23(5)：583-590. http://www. biodiversity-science. net/CN/article/downloadArticleFile. do?attachType=PDF\&id=10075

\begin{tabular}{|c|c|c|c|c|c|}
\hline Cervus nippon & 梅花鹿 & I & $\begin{array}{l}\text { 无危 } \\
\text { /LC }\end{array}$ & 马泽芳 & 东北梅花鹿卵泡发育的显微结构 \\
\hline Cervus nippon & 梅花鹿 & I & $\begin{array}{l}\text { 无危 } \\
\text { /LC }\end{array}$ & 王艳梅 & 东北梅花鹿茸不同部位多糖与无机元素质量分数的差异 \\
\hline Cervus nippon & 梅花鹿 & I & $\begin{array}{l}\text { 无危 } \\
\text { /LC }\end{array}$ & 王艳梅 & 东北梅花鹿茸不同部位水解氨基酸含量的比较分析 \\
\hline Cervus nippon & 梅花鹿 & I & $\begin{array}{l}\text { 无危 } \\
\text { /LC }\end{array}$ & 王艳红 & 东北梅花鹿茸二杜与三权茸中总磷脂和牛磺酸含量的比较分析 \\
\hline Cervus nippon & 梅花鹿 & I & $\begin{array}{l}\text { 无危 } \\
\text { /LC }\end{array}$ & 王守平 & 复方增茸剂对梅花鹿茸产量与品 质的影响 \\
\hline Cervus nippon & 梅花鹿 & I & $\begin{array}{l}\text { 无危 } \\
\text { /LC }\end{array}$ & 杨月伟 & 华南梅花鹿冬春栖息地的特征 \\
\hline Cervus nippon & 梅花鹿 & I & $\begin{array}{l}\text { 无危 } \\
\text { /LC }\end{array}$ & 黄晓凤 & 江西省桃红岭梅花鹿自然保护区梅花鹿现状和保护对策 \\
\hline Cervus nippon & 梅花鹿 & I & $\begin{array}{l}\text { 无危 } \\
\text { /LC }\end{array}$ & 吴问国 & 江西桃红岭梅花鹿自然保护区生物多样性现状 \\
\hline Cervus nippon & 梅花鹿 & I & $\begin{array}{l}\text { 无危 } \\
\text { /LC }\end{array}$ & 付义强 & 江西桃红岭自然保护区夏季梅花鹿对生境的选择性 \\
\hline Cervus nippon & 梅花鹿 & I & 无危 & 杨若明 & 穈鹿茸、马鹿茸和梅花鹿茸营养成分的分析比较研究 \\
\hline
\end{tabular}


顾垒，闻丞，罗玫，王吴，吕植. 中国最受关注濒危物种保护现状快速评价的新方法探讨. 生物多样性，2015，23(5)：583-590. http://www. biodiversity-science. net/CN/article/downloadArticleFile. do?attachType=PDF\&id=10075

\begin{tabular}{|c|c|c|c|c|c|}
\hline & & & $/ \mathrm{LC}$ & & \\
\hline \multirow[t]{2}{*}{ Cervus nippon } & 梅花鹿 & I & 无危 & 胡刚 & 昆明动物园圈养水鹿、梅花鹿的饲养及行为观察 \\
\hline & & & $/ \mathrm{LC}$ & & \\
\hline \multirow[t]{2}{*}{ Cervus nippon } & 梅花鹿 & I & 无危 & 郭远强 & 鹿茸化学成分和药理活性研究进展 \\
\hline & & & $/ \mathrm{LC}$ & & \\
\hline \multirow[t]{2}{*}{ Cervus nippon } & 梅花鹿 & I & 无危 & 白根本 & 鹿源类中药材 DNA 序列分析及马鹿和梅花鹿的 PCR 鉴定 \\
\hline & & & $/ \mathrm{LC}$ & & \\
\hline \multirow[t]{2}{*}{ Cervus nippon } & 梅花鹿 & I & 无危 & 高橘芳幸 & 卵巢运输保存温度和时间对野生梅花鹿卵母细胞体外成熟的影响 \\
\hline & & & $/ \mathrm{LC}$ & & \\
\hline \multirow[t]{2}{*}{ Cervus nippon } & 梅花鹿 & I & 无危 & 董万超 & 马鹿茸、梅花鹿茸不同部位无机元素含量测定分析 \\
\hline & & & $/ \mathrm{LC}$ & & \\
\hline \multirow[t]{2}{*}{ Cervus nippon } & 梅花鹿 & I & 无危 & 张明海 & 梅花鹿(Cervus nippon)保护遗传学研究现状及其保护愿景展望 \\
\hline & & & $/ \mathrm{LC}$ & & \\
\hline \multirow[t]{2}{*}{ Cervus nippon } & 梅花鹿 & I & 无危 & 郑兴涛 & 梅花鹿、马鹿及杂种鹿茸料比的分析 \\
\hline & & & $/ \mathrm{LC}$ & & \\
\hline \multirow[t]{2}{*}{ Cervus nippon } & 梅花鹿 & I & 无危 & 都惠中 & 梅花鹿 XY 精子分选及冷冻精液制备 \\
\hline & & & $/ \mathrm{LC}$ & & \\
\hline \multirow[t]{2}{*}{ Cervus nippon } & 梅花鹿 & I & 无危 & 刘颖 & 梅花鹿 $\gamma$ 干扰素克隆表达及抗病毒活性测定 \\
\hline & & & /LC & & \\
\hline
\end{tabular}


顾垒，闻丞，罗玫，王吴，吕植. 中国最受关注濒危物种保护现状快速评价的新方法探讨. 生物多样性，2015，23(5)：583-590. http://www. biodiversity-science. net/CN/article/downloadArticleFile. do?attachType=PDF\&id=10075

\begin{tabular}{|c|c|c|c|c|c|}
\hline Cervus nippon & 梅花鹿 & I & $\begin{array}{l}\text { 无危 } \\
\text { /LC }\end{array}$ & 李爱国 & 梅花鹿的生活习性、繁殖特点及鹿茸的生长发育 \\
\hline Cervus nippon & 梅花鹿 & I & $\begin{array}{l}\text { 无危 } \\
\text { /LC }\end{array}$ & 吴逸群 & 梅花鹿的生态生物学研究进展 \\
\hline Cervus nippon & 梅花鹿 & I & $\begin{array}{l}\text { 无危 } \\
\text { /LC }\end{array}$ & 方盛国 & 梅花鹿的微卫星多态性及种群的遗传结构 \\
\hline Cervus nippon & 梅花鹿 & I & $\begin{array}{l}\text { 无危 } \\
\text { /LC }\end{array}$ & 李光玉 & 梅花鹿季节性营养规律研究 \\
\hline Cervus nippon & 梅花鹿 & I & $\begin{array}{l}\text { 无危 } \\
\text { /LC }\end{array}$ & 王全凯 & 梅花鹿锯茸时出血特点及止血药物的研究 \\
\hline Cervus nippon & 梅花鹿 & I & $\begin{array}{l}\text { 无危 } \\
\text { /LC }\end{array}$ & 赵雨 & 梅花鹿鹿筋胶原蛋白提取工艺条件优化 \\
\hline Cervus nippon & 梅花鹿 & I & $\begin{array}{l}\text { 无危 } \\
\text { /LC }\end{array}$ & 李泽鸿 & 梅花鹿鹿茸不同产品中氨基酸含量的比较 \\
\hline Cervus nippon & 梅花鹿 & I & $\begin{array}{l}\text { 无危 } \\
\text { /LC }\end{array}$ & 徐桂英 & 梅花鹿鹿茸多糖优选提取工艺条件的研究 \\
\hline Cervus nippon & 梅花鹿 & I & $\begin{array}{l}\text { 无危 } \\
\text { /LC }\end{array}$ & 刘静波 & 梅花鹿鹿茸活性多肽的提取及免疫功效的初步研究 \\
\hline Cervus nippon & 梅花鹿 & I & 无危 & 严铭铭 & 梅花鹿鹿茸中促进海马神经细胞增殖蛋白的分离纯化 \\
\hline
\end{tabular}


顾垒，闻丞，罗玫，王吴，吕植. 中国最受关注濒危物种保护现状快速评价的新方法探讨. 生物多样性，2015，23(5)：583-590. http://www. biodiversity-science. net/CN/article/downloadArticleFile. do?attachType=PDF\&id=10075

\begin{tabular}{|c|c|c|c|c|c|}
\hline & & & $/ \mathrm{LC}$ & & \\
\hline \multirow[t]{2}{*}{ Cervus nippon } & 梅花鹿 & I & 无危 & 王柏林 & 梅花鹿人工授精配套新技术研究 \\
\hline & & & $/ \mathrm{LC}$ & & \\
\hline \multirow[t]{2}{*}{ Cervus nippon } & 梅花鹿 & I & 无危 & 罗剑通 & 梅花鹿人工授精实验报告 \\
\hline & & & $/ \mathrm{LC}$ & & \\
\hline \multirow[t]{2}{*}{ Cervus nippon } & 梅花鹿 & I & 无危 & 鞠贵春 & 梅花鹿茸的化学成分和生理活性研究进展 \\
\hline & & & $/ \mathrm{LC}$ & & \\
\hline \multirow[t]{2}{*}{ Cervus nippon } & 梅花鹿 & I & 无危 & 钟英杰 & 梅花鹿茸的化学成分及药理作用研究进展 \\
\hline & & & $/ \mathrm{LC}$ & & \\
\hline \multirow[t]{2}{*}{ Cervus nippon } & 梅花鹿 & I & 无危 & 段冷昕 & 梅花鹿茸多肽的化学结构及其抗肝纤维化作用 \\
\hline & & & $/ \mathrm{LC}$ & & \\
\hline \multirow[t]{2}{*}{ Cervus nippon } & 梅花鹿 & I & 无危 & 董万超 & 梅花鹿茸多肽新成分的提取分离及其生物效应研究 \\
\hline & & & $/ \mathrm{LC}$ & & \\
\hline \multirow[t]{2}{*}{ Cervus nippon } & 梅花鹿 & I & 无危 & 周秋丽 & 梅花鹿茸和马鹿茸多肽化学性质及生物活性比较 \\
\hline & & & $/ \mathrm{LC}$ & & \\
\hline \multirow[t]{2}{*}{ Cervus nippon } & 梅花鹿 & I & 无危 & 李银清 & 梅花鹿茸胶原的分离提取及活性研究 \\
\hline & & & $/ \mathrm{LC}$ & & \\
\hline \multirow[t]{2}{*}{ Cervus nippon } & 梅花鹿 & I & 无危 & 李长生 & 梅花鹿茸角生长规律与体内激素关系的研究进展 \\
\hline & & & /LC & & \\
\hline
\end{tabular}


顾垒，闻丞，罗玫，王吴，吕植. 中国最受关注濒危物种保护现状快速评价的新方法探讨. 生物多样性，2015，23(5)：583-590. http://www. biodiversity-science. net/CN/article/downloadArticleFile. do?attachType=PDF\&id=10075

\begin{tabular}{|c|c|c|c|c|c|}
\hline Cervus nippon & 梅花鹿 & I & $\begin{array}{l}\text { 无危 } \\
\text { /LC }\end{array}$ & 王艳梅 & $\begin{array}{l}\text { 梅花鹿茸血中胆固醇含量与梅花鹿血、 } \\
\text { 猪血和鸡血的比较分析 }\end{array}$ \\
\hline Cervus nippon & 梅花鹿 & I & $\begin{array}{l}\text { 无危 } \\
\text { /LC }\end{array}$ & 严铭铭 & 梅花鹿茸中活性多肽的纯化、测序及功能研究 \\
\hline Cervus nippon & 梅花鹿 & I & $\begin{array}{l}\text { 无危 } \\
\text { /LC }\end{array}$ & 李秋玲 & 梅花鹿肉营养价值及肉质评价方法研究进展 \\
\hline Cervus nippon & 梅花鹿 & I & $\begin{array}{l}\text { 无危 } \\
\text { /LC }\end{array}$ & 姚玉霞 & $\begin{array}{l}\text { 梅花鹿三权茸、二杜茸、角盘中 } \\
\text { 钲、磷含量比较 }\end{array}$ \\
\hline Cervus nippon & 梅花鹿 & I & $\begin{array}{l}\text { 无危 } \\
\text { /LC }\end{array}$ & 董万超 & 梅花鹿三种深加工制品的营养保健成分研究 \\
\hline Cervus nippon & 梅花鹿 & I & $\begin{array}{l}\text { 无危 } \\
\text { /LC }\end{array}$ & 熊彩云 & 梅花鹿生态学研究进展 \\
\hline Cervus nippon & 梅花鹿 & I & $\begin{array}{l}\text { 无危 } \\
\text { /LC }\end{array}$ & 白秀娟 & 梅花鹿生长激素基因的克隆及序列分析 \\
\hline Cervus nippon & 梅花鹿 & I & $\begin{array}{l}\text { 无危 } \\
\text { /LC }\end{array}$ & 吴建平 & 梅花鹿食性分析中粪便分析法的研究 \\
\hline Cervus nippon & 梅花鹿 & I & $\begin{array}{l}\text { 无危 } \\
\text { /LC }\end{array}$ & 赵列平 & 梅花鹿受胎率主要影响因素分析 \\
\hline Cervus nippon & 梅花鹿 & I & 无危 & 郜玉刚 & 梅花鹿饲粮糊化淀粉尿素氨水平对营养物质消化、代谢的影响 \\
\hline
\end{tabular}


顾垒，闻丞，罗玫，王吴，吕植. 中国最受关注濒危物种保护现状快速评价的新方法探讨. 生物多样性，2015，23(5)：583-590. http://www. biodiversity-science. net/CN/article/downloadArticleFile. do?attachType=PDF\&id=10075

\begin{tabular}{|c|c|c|c|c|c|}
\hline & & & $/ \mathrm{LC}$ & & \\
\hline \multirow[t]{2}{*}{ Cervus nippon } & 梅花鹿 & I & 无危 & 郜玉刚 & 梅花鹿饲粮适宜精粗比的研究 \\
\hline & & & $/ \mathrm{LC}$ & & \\
\hline \multirow[t]{2}{*}{ Cervus nippon } & 梅花鹿 & I & 无危 & 李云红 & 梅花鹿饲养管理技术 \\
\hline & & & $/ \mathrm{LC}$ & & \\
\hline \multirow[t]{2}{*}{ Cervus nippon } & 梅花鹿 & I & 无危 & 胡风庆 & 梅花鹿胎盘免疫调节因子制备工艺 \\
\hline & & & $/ \mathrm{LC}$ & & \\
\hline \multirow[t]{2}{*}{ Cervus nippon } & 梅花鹿 & I & 无危 & 张文兴 & 梅花鹿胃肠炎诊断与防治 \\
\hline & & & $/ \mathrm{LC}$ & & \\
\hline \multirow[t]{3}{*}{ Cervus nippon } & 梅花鹿 & I & 无危 & 张启迪 & 梅花鹿血液中卵磷脂含量的 \\
\hline & & & $/ \mathrm{LC}$ & & 高效液相色谱法测定研究 \\
\hline & & & & & 张启 \\
\hline \multirow[t]{2}{*}{ Cervus nippon } & 梅花鹿 & I & 无危 & 崔丽春 & 梅花鹿血液中三种抗衰老成分的动态分析 \\
\hline & & & $/ \mathrm{LC}$ & & \\
\hline \multirow[t]{2}{*}{ Cervus nippon } & 梅花鹿 & I & 无危 & 郭素华 & 梅花鹿药用产品的研究现状 \\
\hline & & & $/ \mathrm{LC}$ & & \\
\hline \multirow[t]{2}{*}{ Cervus nippon } & 梅花鹿 & I & 无危 & 李和平 & 梅花鹿优良品种(品系)产茸性能研究 \\
\hline & & & $/ \mathrm{LC}$ & & \\
\hline Cervus nippon & 梅花鹿 & I & 无危 & 郜玉钢 & 梅花鹿源牛病毒性腹泻病毒分离与鉴定 \\
\hline
\end{tabular}


顾垒，闻丞，罗玫，王吴，吕植. 中国最受关注濒危物种保护现状快速评价的新方法探讨. 生物多样性，2015，23(5)：583-590. http://www. biodiversity-science. net/CN/article/downloadArticleFile. do?attachType=PDF\&id=10075

\begin{tabular}{|c|c|c|c|c|c|}
\hline & & & $/ \mathrm{LC}$ & & \\
\hline \multirow[t]{2}{*}{ Cervus nippon } & 梅花鹿 & I & 无危 & 张经华 & 糜鹿 梅花鹿和马鹿鹿茸中微量元素的分析测定 \\
\hline & & & $/ \mathrm{LC}$ & & \\
\hline \multirow[t]{2}{*}{ Cervus nippon } & 梅花鹿 & I & 无危 & 李华 & 内蒙古阿尔山市国有林区濒危野生动物一一梅花鹿的保护与繁育 \\
\hline & & & $/ \mathrm{LC}$ & & \\
\hline \multirow[t]{2}{*}{ Cervus nippon } & 梅花鹿 & I & 无危 & 李光玉 & 尿嘌呤衍生物排出量的影响 \\
\hline & & & $/ \mathrm{LC}$ & & \\
\hline \multirow[t]{2}{*}{ Cervus nippon } & 梅花鹿 & I & 无危 & 吴海龙 & 宁国市万家乡梅花鹿资源现状 \\
\hline & & & $/ \mathrm{LC}$ & & \\
\hline \multirow[t]{2}{*}{ Cervus nippon } & 梅花鹿 & I & 无危 & 胡顺福 & 浅谈梅花鹿前后盘吸虫和肝片吸虫病混合感染的诊治 \\
\hline & & & $/ \mathrm{LC}$ & & \\
\hline \multirow[t]{2}{*}{ Cervus nippon } & 梅花鹿 & I & 无危 & 郑兴涛 & 浅谈选育梅花鹿和马鹿繁殖速度及其应用 \\
\hline & & & $/ \mathrm{LC}$ & & \\
\hline \multirow[t]{2}{*}{ Cervus nippon } & 梅花鹿 & I & 无危 & 游卫云 & 清凉峰华南梅花鹿冬季食物资源特征研究 \\
\hline & & & $/ \mathrm{LC}$ & & \\
\hline \multirow[t]{2}{*}{ Cervus nippon } & 梅花鹿 & I & 无危 & 于江傲 & 清凉峰自然保护区华南梅花鹿种群数量与分布研究 \\
\hline & & & /LC & & \\
\hline \multirow[t]{2}{*}{ Cervus nippon } & 梅花鹿 & I & 无危 & 马继飞 & 清凉峰自然保护区梅花鹿秋季对栖息地利用的初步分析 \\
\hline & & & /LC & & \\
\hline
\end{tabular}


顾垒，闻丞，罗玫，王吴，吕植. 中国最受关注濒危物种保护现状快速评价的新方法探讨. 生物多样性，2015，23(5)：583-590. http://www. biodiversity-science. net/CN/article/downloadArticleFile. do?attachType=PDF\&id=10075

\begin{tabular}{|c|c|c|c|c|c|}
\hline Cervus nippon & 梅花鹿 & I & $\begin{array}{l}\text { 无危 } \\
\text { /LC }\end{array}$ & 郑兴涛 & 圈养优良梅花鹿经济效益的分析 \\
\hline Cervus nippon & 梅花鹿 & I & $\begin{array}{l}\text { 无危 } \\
\text { /LC }\end{array}$ & 吕慎金 & 圈养与半散放条件下梅花鹿成年母鹿的行为节律比较 \\
\hline Cervus nippon & 梅花鹿 & I & $\begin{array}{l}\text { 无危 } \\
\text { /LC }\end{array}$ & 张连学 & 人参对梅花鹿精液品质及产仔率的影响 \\
\hline Cervus nippon & 梅花鹿 & I & $\begin{array}{l}\text { 无危 } \\
\text { /LC }\end{array}$ & 高秀华 & 日粮蛋白质水平对梅花鹿营养物质消化代谢的影响 \\
\hline Cervus nippon & 梅花鹿 & I & $\begin{array}{l}\text { 无危 } \\
\text { /LC }\end{array}$ & 郜玉刚 & 日粮䥻水平对生茸期梅花鹿营养消化代谢的影响 \\
\hline Cervus nippon & 梅花鹿 & I & $\begin{array}{l}\text { 无危 } \\
\text { /LC }\end{array}$ & 袁平珍 & 日月山梅花鹿公鹿血清生理指标研究 \\
\hline Cervus nippon & 梅花鹿 & I & $\begin{array}{l}\text { 无危 } \\
\text { /LC }\end{array}$ & 周长福 & 咠鹿人工授精的意义及措施 \\
\hline Cervus nippon & 梅花鹿 & I & $\begin{array}{l}\text { 无危 } \\
\text { /LC }\end{array}$ & 赵世臻 & 如何评定梅花鹿人工授精情期受胎率 \\
\hline Cervus nippon & 梅花鹿 & I & $\begin{array}{l}\text { 无危 } \\
\text { /LC }\end{array}$ & 赵波 & 四川地区梅花鹿 $4 \mathrm{O}$ 项血液生理生化指标的测定 \\
\hline Cervus nippon & 梅花鹿 & I & 无危 & 郭延蜀 & 四川梅花鹿产仔换茸期声行为的研究 \\
\hline
\end{tabular}


顾垒，闻丞，罗玫，王吴，吕植. 中国最受关注濒危物种保护现状快速评价的新方法探讨. 生物多样性，2015，23(5)：583-590. http://www. biodiversity-science. net/CN/article/downloadArticleFile. do?attachType=PDF\&id=10075

\begin{tabular}{|c|c|c|c|c|c|}
\hline & & & $/ \mathrm{LC}$ & & \\
\hline \multirow[t]{2}{*}{ Cervus nippon } & 梅花鹿 & I & 无危 & 刘昊 & 四川梅花鹿春季昼夜活动节律与时间分配 \\
\hline & & & $/ \mathrm{LC}$ & & \\
\hline \multirow[t]{2}{*}{ Cervus nippon } & 梅花鹿 & I & 无危 & 郭廷蜀 & 四川梅花鹿的分布、数量及 \\
\hline & & & $/ \mathrm{LC}$ & & 栖息环境的调查 \\
\hline \multirow[t]{2}{*}{ Cervus nippon } & 梅花鹿 & I & 无危 & 郭廷蜀 & 四川梅花鹿的昼夜活动节律与时间分配 \\
\hline & & & $/ \mathrm{LC}$ & & \\
\hline \multirow[t]{2}{*}{ Cervus nippon } & 梅花鹿 & I & 无危 & 郭延蜀 & 四川梅花鹿发情期的几种发声行为 \\
\hline & & & $/ \mathrm{LC}$ & & \\
\hline \multirow[t]{2}{*}{ Cervus nippon } & 梅花鹿 & I & 无危 & 郭廷蜀 & 四川梅花鹿食性的研究 \\
\hline & & & $/ \mathrm{LC}$ & & \\
\hline \multirow[t]{2}{*}{ Cervus nippon } & 梅花鹿 & I & 无危 & 王伟月 & 四川梅花鹿昼夜活动的谱分析 \\
\hline & & & $/ \mathrm{LC}$ & & \\
\hline \multirow[t]{2}{*}{ Cervus nippon } & 梅花鹿 & $\mathrm{I}$ & 无危 & 高秀华 & 饲粮不同蛋白质能量水平对四岁梅花鹿生茸的影响 \\
\hline & & & $/ \mathrm{LC}$ & & \\
\hline \multirow[t]{2}{*}{ Cervus nippon } & 梅花鹿 & I & 无危 & 高秀华 & 饲粮营养水平对五岁以上生茸期梅花鹿公鹿的影响 \\
\hline & & & $/ \mathrm{LC}$ & & \\
\hline \multirow[t]{2}{*}{ Cervus nippon } & 梅花鹿 & I & 无危 & 任航行 & 塔里木马鹿、天山马鹿和梅花鹿同期发情调控技术研究 \\
\hline & & & $/ \mathrm{LC}$ & & \\
\hline
\end{tabular}


顾垒，闻丞，罗玫，王吴，吕植. 中国最受关注濒危物种保护现状快速评价的新方法探讨. 生物多样性，2015，23(5)：583-590. http://www. biodiversity-science. net/CN/article/downloadArticleFile. do?attachType=PDF\&id=10075

\begin{tabular}{|c|c|c|c|c|c|}
\hline Cervus nippon & 梅花鹿 & I & $\begin{array}{l}\text { 无危 } \\
\text { /LC }\end{array}$ & 蒋志刚 & 桃红岭国家级自然保护区梅花鹿种群现状 \\
\hline Cervus nippon & 梅花鹿 & I & $\begin{array}{l}\text { 无危 } \\
\text { /LC }\end{array}$ & 付义强 & 桃红岭自然保护区梅花鹿对春季栖息地的利用 \\
\hline Cervus nippon & 梅花鹿 & I & $\begin{array}{l}\text { 无危 } \\
\text { /LC }\end{array}$ & 赵列平 & 同期发情技术在梅花鹿繁殖上的应用 \\
\hline Cervus nippon & 梅花鹿 & I & $\begin{array}{l}\text { 无危 } \\
\text { /LC }\end{array}$ & 赵屎臻 & 我国饲养的主要茸用鹿种类 \\
\hline Cervus nippon & 梅花鹿 & I & $\begin{array}{l}\text { 无危 } \\
\text { /LC }\end{array}$ & 熊建杰 & 西北地区 4 个中国特有鹿种的微卫星遗传多样性研究 \\
\hline Cervus nippon & 梅花鹿 & I & $\begin{array}{l}\text { 无危 } \\
\text { /LC }\end{array}$ & 赵蒙 & 西丰梅花鹿种公鹿葺重性状表型参数的统计分析 \\
\hline Cervus nippon & 梅花鹿 & I & $\begin{array}{l}\text { 无危 } \\
\text { /LC }\end{array}$ & 马生良 & 兴凯湖梅花鹿鹿茸几种化学成分分析 \\
\hline Cervus nippon & 梅花鹿 & I & $\begin{array}{l}\text { 无危 } \\
\text { /LC }\end{array}$ & 王忠武 & 兴凯湖梅花鹿品种选育研究 \\
\hline Cervus nippon & 梅花鹿 & I & $\begin{array}{l}\text { 无危 } \\
\text { /LC }\end{array}$ & 李 馨 & 兴凯湖梅花鹿微卫星遗传多样性与鲜茸重相关性分析 \\
\hline Cervus nippon & 梅花鹿 & I & 无危 & 刘伟石 & 野化梅花鹿冬季食物组成和健康状况的评估 \\
\hline
\end{tabular}


顾垒，闻丞，罗玫，王吴，吕植. 中国最受关注濒危物种保护现状快速评价的新方法探讨. 生物多样性，2015，23(5)：583-590. http://www. biodiversity-science. net/CN/article/downloadArticleFile. do?attachType=PDF\&id=10075

\begin{tabular}{|c|c|c|c|c|c|}
\hline & & & $/ \mathrm{LC}$ & & \\
\hline \multirow[t]{2}{*}{ Cervus nippon } & 梅花鹿 & I & 无危 & 董大利 & 一例梅花鹿弓形虫病的诊治 \\
\hline & & & $/ \mathrm{LC}$ & & \\
\hline \multirow[t]{2}{*}{ Cervus nippon } & 梅花鹿 & I & 无危 & 刘昌龙 & 一起梅花鹿肝片吸虫病的诊治 \\
\hline & & & $/ \mathrm{LC}$ & & \\
\hline \multirow[t]{2}{*}{ Cervus nippon } & 梅花鹿 & I & 无危 & 张小荣 & 一株致梅花鹿猝死症 $\mathrm{A}$ 型产气英膜梭菌的分离与基因分型研究 \\
\hline & & & $/ \mathrm{LC}$ & & \\
\hline \multirow[t]{2}{*}{ Cervus nippon } & 梅花鹿 & I & 无危 & 金立明 & 益生素对梅花鹿仔鹿和羔羊日粮 \\
\hline & & & $/ \mathrm{LC}$ & & 营养物质消化率的影响 \\
\hline \multirow[t]{2}{*}{ Cervus nippon } & 梅花鹿 & I & 无危 & 马泽芳 & 育成雄性梅花鹿越冬期配合颗粒饲料的研究 \\
\hline & & & $/ \mathrm{LC}$ & & \\
\hline \multirow[t]{2}{*}{ Cervus nippon } & 梅花鹿 & I & 无危 & 刘佳佳 & 原子吸收光谱法测定不同鹿龄梅花鹿角盘矿质元素含量 \\
\hline & & & $/ \mathrm{LC}$ & & \\
\hline \multirow[t]{2}{*}{ Cervus nippon } & 梅花鹿 & I & 无危 & 宋延龄 & 珍稀动物一一 梅花鹿及其研究 \\
\hline & & & $/ \mathrm{LC}$ & & \\
\hline \multirow[t]{2}{*}{ Cervus nippon } & 梅花鹿 & I & 无危 & 刘海 & 中国大陆梅花鹿 mtDNA 控制区序列变异 \\
\hline & & & $/ \mathrm{LC}$ & & 及种群遗传结构分析 \\
\hline \multirow[t]{2}{*}{ Cervus nippon } & 梅花鹿 & I & 无危 & 王美楠 & 中国东北梅花鹿种群遗传多样性初步研究 \\
\hline & & & /LC & & \\
\hline
\end{tabular}


顾垒，闻丞，罗玫，王吴，吕植. 中国最受关注濒危物种保护现状快速评价的新方法探讨. 生物多样性，2015，23(5)：583-590. http://www. biodiversity-science. net/CN/article/downloadArticleFile. do?attachType=PDF\&id=10075

\begin{tabular}{|c|c|c|c|c|c|}
\hline Cervus nippon & 梅花鹿 & I & 无危 & 金一 & 中国梅花鹿种群演化史研究进展 \\
\hline Cervus nippon & 梅花鹿 & I & $\begin{array}{l}\text { 无危 } \\
\text { /LC }\end{array}$ & 吴华 & 中国圈养梅花鹿的遗传多样性和遗传结构 \\
\hline Chalcophaps indica & 绿翅金扸 & $\begin{array}{l}\text { 未列 } \\
\text { 入 }\end{array}$ & $\begin{array}{l}\text { 无危 } \\
\text { /LC }\end{array}$ & 邹发生 & 海南岛尖峰岭热带山地雨林林下鸟类群落研究 \\
\hline Chalcophaps indica & 绿翅金鸭 & $\begin{array}{l}\text { 未列 } \\
\text { 入 }\end{array}$ & $\begin{array}{l}\text { 无危 } \\
\text { /LC }\end{array}$ & 李仕宁 & 茄新省级森林经营所鸟类资源调查 \\
\hline Changnienia amoena & 独花兰 & II & 濒危 & GE Song & A Preliminary Study on Conservation Genetics of Three Endangered Orchid Species \\
\hline Changnienia amoena & 独花兰 & II & 濒危 & GE Song & $\begin{array}{l}\text { A Preliminary Study on Pollination Biology of an Endangered Orchid, Changnienia amoena, in } \\
\text { Shennongjia }\end{array}$ \\
\hline Changnienia amoena & 独花兰 & II & $\begin{array}{l}\text { 濒危 } \\
/ \mathrm{EN}\end{array}$ & A. $\mathrm{Li}$ & $\begin{array}{l}\text { Genetic variation and conservation of Changnienia amoena, an endangered orchid endemic to } \\
\text { China }\end{array}$ \\
\hline Changnienia amoena & 独花兰 & II & 濒危 & GE Song & Pollination biology of the deceptive orchid Changnienia amoena \\
\hline Changnienia amoena & 独花兰 & II & 濒危 & HAI-QIN SUN & $\begin{array}{l}\text { Positive effects of flower abundance and synchronous flowering on pollination success, and } \\
\text { pollinia dispersal in rewardless Changnienia amoena (Orchidaceae) }\end{array}$ \\
\hline Changnienia amoena & 独花兰 & II & 濒危 & FU ChengXin & Studies on in vitro regeneration competence of pseudobulb cultures in Changnienia amoena \\
\hline
\end{tabular}


顾垒，闻丞，罗玫，王吴，吕植. 中国最受关注濒危物种保护现状快速评价的新方法探讨. 生物多样性，2015，23(5)：583-590. http://www. biodiversity-science. net/CN/article/downloadArticleFile. do?attachType=PDF\&id=10075

\begin{tabular}{|c|c|c|c|c|c|}
\hline & & & /EN & & Chien \\
\hline \multirow[t]{2}{*}{ Changnienia amoena } & 独花兰 & II & 濒危 & 杨玉珍 & 宝天曼自然保护区几种珍稀濒危兰科植物调查研究 \\
\hline & & & $/$ EN & & \\
\hline \multirow[t]{2}{*}{ Changnienia amoena } & 独花兰 & II & 濒危 & 葛 颂 & 濒危植物独花兰的形态变异及其适应意义 \\
\hline & & & /EN & & \\
\hline \multirow[t]{2}{*}{ Changnienia amoena } & 独花兰 & II & 濒危 & 葛 颂 & 采用空间自相关分析研究两种兰科植物的群体遗传结构 \\
\hline & & & /EN & & \\
\hline \multirow[t]{2}{*}{ Changnienia amoena } & 独花兰 & II & 濒危 & 陈霜 & 城口县发现稀有濒危花卉独花兰 \\
\hline & & & /EN & & \\
\hline \multirow[t]{2}{*}{ Changnienia amoena } & 独花兰 & II & 濒危 & 葛 颂 & 独花兰和扇脉杓兰的传粉生态学 \\
\hline & & & /EN & & \\
\hline \multirow[t]{2}{*}{ Changnienia amoena } & 独花兰 & II & 濒危 & 刘红霞 & 独花兰菌根的初步研究 \\
\hline & & & /EN & & \\
\hline \multirow[t]{2}{*}{ Changnienia amoena } & 独花兰 & II & 濒危 & 熊治廷 & 独花兰野生种群研究一一 开花与营养体状态的关系 \\
\hline & & & /EN & & \\
\hline \multirow[t]{2}{*}{ Changnienia amoena } & 独花兰 & II & 濒危 & 刘国顺 & 独花兰组织培养研究 \\
\hline & & & /EN & & \\
\hline \multirow[t]{2}{*}{ Changnienia amoena } & 独花兰 & II & 濒危 & 刘赛思 & 独花兰组织培养研究 \\
\hline & & & /EN & & \\
\hline
\end{tabular}


顾垒，闻丞，罗玫，王吴，吕植. 中国最受关注濒危物种保护现状快速评价的新方法探讨. 生物多样性，2015，23(5)：583-590. http://www biodiversity-science. net/CN/article/downloadArticleFile. do?attachType=PDF\&id=10075

\begin{tabular}{|c|c|c|c|c|c|}
\hline Changnienia amoena & 独花兰 & II & 濒危 & 高 丽 & 独花兰组织培养与快速繁殖(简报) \\
\hline & & & /EN & & \\
\hline \multirow[t]{2}{*}{ Changnienia amoena } & 独花兰 & II & 濒危 & 杨传东 & 贵州兰科一新纪录属种_独花兰属_独花兰 \\
\hline & & & /EN & & \\
\hline \multirow[t]{2}{*}{ Changnienia amoena } & 独花兰 & II & 濒危 & 姜运力 & 贵州省兰科植物地理新分布 \\
\hline & & & /EN & & \\
\hline \multirow[t]{2}{*}{ Changnienia amoena } & 独花兰 & II & 濒危 & 葛颂 & 三种兰科植物的保护遗传学研究 \\
\hline & & & /EN & & \\
\hline \multirow[t]{2}{*}{ Changnienia amoena } & 独花兰 & II & 濒危 & 谢宗强 & 神农架南坡珍稀植物独花兰的物候、繁殖及分布的群落特征 \\
\hline & & & $/ \mathrm{EN}$ & & \\
\hline \multirow[t]{2}{*}{ Changnienia amoena } & 独花兰 & II & 濒危 & 宋要强 & 珍稀植物独花兰在陕西省重新发现 \\
\hline & & & /EN & & \\
\hline \multirow[t]{2}{*}{ chinemys nigricans } & 广东乌龟 & 未列 & 濒危 & 费春平 & 黑颈乌龟形态性状对体重的影响效果分析_费春平 \\
\hline & & 入 & /EN & & \\
\hline \multirow[t]{2}{*}{ Chinemys reebesii } & 乌龟 & 未列 & 濒危 & Cuijuan NIU & Effect of Dietary Vitamin C on the Antioxidant Defense System of Hibernating Juvenile \\
\hline & & 入 & /EN & & Three-keeled Pond Turtles (-I-Chinemys reevesii--I-) \\
\hline \multirow[t]{2}{*}{ Chinemys reebesii } & 乌龟 & 未列 & 濒危 & 章芸 & 两种淡水龟微卫星标记的筛选及乌龟养殖群体遗传多样性分析_章芸 \\
\hline & & 入 & /EN & & \\
\hline Chinemys reebesii & 乌龟 & 未列 & 濒危 & 陈晓艳 & 55 种中草药对广东乌龟水霉病致病菌的抑制作用_陈晓艳 \\
\hline
\end{tabular}


顾垒，闻丞，罗玫，王吴，吕植. 中国最受关注濒危物种保护现状快速评价的新方法探讨. 生物多样性，2015，23(5)：583-590. http://www biodiversity-science. net/CN/article/downloadArticleFile. do?attachType=PDF\&id=10075

\begin{tabular}{|c|c|c|c|c|c|}
\hline & & 入 & /EN & & \\
\hline \multirow[t]{2}{*}{ Chinemys reebesii } & 乌龟 & 未列 & 濒危 & Cuijuan Niu & Compensatory Growth in Juvenile Freshwater Turtles, Chinemys reevesii, Following Feed \\
\hline & & 入 & /EN & & Deprivation \\
\hline \multirow[t]{2}{*}{ Chinemys reebesii } & 乌龟 & 未列 & 濒危 & Wei-Guo Du & Effects of incubation temperature on embryonic development rate, sex ratio and post-hatching \\
\hline & & 入 & /EN & & growth in the Chinese three-keeled pond turtle, Chinemys reevesii \\
\hline \multirow[t]{2}{*}{ Chinemys reebesii } & 乌龟 & 未列 & 濒危 & Wei-Guo Du & Embryonic development rate and hatchling phenotypes in the Chinese three-keeled pond turtle \\
\hline & & 入 & /EN & & (Chinemys reevesii) The influence of fluctuating temperature versus constant temperature \\
\hline \multirow[t]{2}{*}{ Chinemys reebesii } & 乌龟 & 未列 & 濒危 & Rongquan Zheng & Polymorphic microsatellite loci in the Chinese pond turtle (Chinemys reevesii) \\
\hline & & 入 & /EN & & \\
\hline \multirow[t]{2}{*}{ Chinemys reebesii } & 乌龟 & 未列 & 濒危 & WEI-GUO DU & The Influence of Incubation Temperature on Morphology, Locomotor Performance, and Cold \\
\hline & & 入 & /EN & & Tolerance of Hatchling Chinese Three-Keeled Pond Turtles, Chinemys reevesii \\
\hline \multirow[t]{2}{*}{ Chinemys reebesii } & 乌龟 & 未列 & 濒危 & 杜卫国 & 孵化温度对乌龟胚胎能量利用及矿物质代谢的影响_郑荣泉 \\
\hline & & 入 & /EN & & \\
\hline \multirow[t]{2}{*}{ Chinemys reebesii } & 乌龟 & 未列 & 濒危 & 汤文琦 & 睬化温度对乌龟性别决定基因表达的影响_汤文琦 \\
\hline & & 入 & /EN & & \\
\hline \multirow[t]{2}{*}{ Chinemys reebesii } & 乌龟 & 未列 & 濒危 & 杜卫国 & 睬化温度与性别对乌龟幼体大小和生长的影响_杜卫国 \\
\hline & & 入 & /EN & & \\
\hline \multirow[t]{2}{*}{ Chinemys reebesii } & 乌龟 & 未列 & 濒危 & 张力群 & 两种龟消化道形态结构及乌龟细胞的抗辐射研究_张力群 \\
\hline & & 入 & /EN & & \\
\hline
\end{tabular}


顾垒，闻丞，罗玫，王吴，吕植. 中国最受关注濒危物种保护现状快速评价的新方法探讨. 生物多样性，2015，23(5)：583-590. http://www. biodiversity-science. net/CN/article/downloadArticleFile. do?attachType=PDF\&id=10075

\begin{tabular}{|c|c|c|c|c|c|}
\hline \multirow[t]{2}{*}{ Chinemys reebesii } & 乌龟 & 未列 & 濒危 & 潘凤莲 & 配合饲料中 $a$-淀粉与生淀粉比例对乌龟生长的影响_潘风莲 \\
\hline & & 入 & $/$ EN & & \\
\hline \multirow[t]{2}{*}{ Chinemys reebesii } & 乌龟 & 未列 & 濒危 & 洪一江 & 鄱阳湖乌龟不同组织的同工酶_王诚远 \\
\hline & & 入 & $/$ EN & & \\
\hline \multirow[t]{2}{*}{ Chinemys reebesii } & 乌龟 & 未列 & 濒危 & 曾柳根 & 鄱阳湖乌龟的生物学特征及生长研究_曾柳根 \\
\hline & & 入 & $/ \mathrm{EN}$ & & \\
\hline \multirow[t]{2}{*}{ Chinemys reebesii } & 乌龟 & 未列 & 濒危 & 姜德勋 & 水生动物乌龟和福寿螺细胞培养_姜德勋 \\
\hline & & 入 & $/ \mathrm{EN}$ & & \\
\hline \multirow[t]{2}{*}{ Chinemys reebesii } & 乌龟 & 未列 & 濒危 & 郑荣泉 & 微卫星标记分析乌龟养殖群体的遗传多样性_章芸 \\
\hline & & 入 & /EN & & \\
\hline \multirow[t]{2}{*}{ Chinemys reebesii } & 乌龟 & 未列 & 濒危 & 李红敬 & 温度对乌龟孵育和性比的影响_李红敬 \\
\hline & & 入 & $/ \mathrm{EN}$ & & \\
\hline \multirow[t]{2}{*}{ Chinemys reebesii } & 乌龟 & 未列 & 濒危 & 吴孝兵 & 乌龟 MHC_类 B 基因第二外显子的克隆及序列分析_李恩 \\
\hline & & 入 & /EN & & \\
\hline \multirow[t]{2}{*}{ Chinemys reebesii } & 乌龟 & 未列 & 濒危 & 刘加跟 & 乌龟 $X$ 射线照射后的组织病理学及生理生化研究 \\
\hline & & 入 & $/ \mathrm{EN}$ & & \\
\hline \multirow[t]{2}{*}{ Chinemys reebesii } & 乌龟 & 未列 & 濒危 & 贺刚 & 乌龟蛋品质分析_杨雪海 \\
\hline & & 入 & $/ \mathrm{EN}$ & & \\
\hline Chinemys reebesii & 乌龟 & 未列 & 濒危 & 刘毅辉 & 乌龟的年龄与生长_刘毅辉 \\
\hline
\end{tabular}


顾垒，闻丞，罗玫，王吴，吕植. 中国最受关注濒危物种保护现状快速评价的新方法探讨. 生物多样性，2015，23(5)：583-590. http://www. biodiversity-science. net/CN/article/downloadArticleFile. do?attachType=PDF\&id=10075

\begin{tabular}{|c|c|c|c|c|c|}
\hline & & 入 & /EN & & \\
\hline \multirow[t]{2}{*}{ Chinemys reebesii } & 乌龟 & 未列 & 濒危 & 李贵生 & 乌龟肝和脾受 X 射线辐射后的组织病理学变化_李贵生 \\
\hline & & 入 & /EN & & \\
\hline \multirow[t]{2}{*}{ Chinemys reebesii } & 乌龟 & 未列 & 濒危 & 蒲友光 & 乌龟和金头闭壳龟线粒体基因组全序列分析研究_蒲友光 \\
\hline & & 入 & /EN & & \\
\hline \multirow[t]{2}{*}{ Chinemys reebesii } & 乌龟 & 未列 & 濒危 & 严福祥 & 乌龟孔雀石绿浸泡后的组织病理学研究及肝脏全长 $\mathrm{cDNA}$ 文库的构建与鉴定_严福祥 \\
\hline & & 入 & /EN & & \\
\hline \multirow[t]{2}{*}{ Chinemys reebesii } & 乌龟 & 未列 & 濒危 & 刘文生 & 乌龟脑垂体显微及其腺垂体超微结构的研究_刘文生 \\
\hline & & 入 & /EN & & \\
\hline \multirow[t]{2}{*}{ Chinemys reebesii } & 乌龟 & 未列 & 濒危 & 李贵生 & 乌龟脑和肝组织细胞的体外培养_李贵生 \\
\hline & & 入 & /EN & & \\
\hline \multirow[t]{2}{*}{ Chinemys reebesii } & 乌龟 & 未列 & 濒危 & 石岳香 & 乌龟胚胎发育的实验观察_石岳香 \\
\hline & & 入 & /EN & & \\
\hline \multirow[t]{2}{*}{ Chinemys reebesii } & 乌龟 & 未列 & 濒危 & 潘凤莲 & 乌龟配合饲料中几种营养因子对其生长的影响_潘风莲 \\
\hline & & 入 & /EN & & \\
\hline \multirow[t]{2}{*}{ Chinemys reebesii } & 乌龟 & 未列 & 濒危 & 潘凤莲 & 乌龟配合饲料中最适动植物蛋白比的研究_潘风莲 \\
\hline & & 入 & $/ \mathrm{EN}$ & & \\
\hline \multirow[t]{2}{*}{ Chinemys reebesii } & 乌龟 & 未列 & 濒危 & 印大中 & 乌龟潜水呼吸代谢及龟皮胶原蛋白成分的分析研究 \\
\hline & & 入 & /EN & & \\
\hline
\end{tabular}


顾垒，闻丞，罗玫，王吴，吕植. 中国最受关注濒危物种保护现状快速评价的新方法探讨. 生物多样性，2015，23(5)：583-590. http://www. biodiversity-science. net/CN/article/downloadArticleFile. do?attachType=PDF\&id=10075

\begin{tabular}{|c|c|c|c|c|c|}
\hline \multirow[t]{2}{*}{ Chinemys reebesii } & 乌龟 & 未列 & 濒危 & 万全 & 乌龟人工繁殖和稚龟培育方法研究_万全 \\
\hline & & 入 & $/$ EN & & \\
\hline \multirow[t]{2}{*}{ Chinemys reebesii } & 乌龟 & 未列 & 濒危 & 周瑞龙 & 乌龟受精卵睬化套孵化及雌雄稚龟比例控制技术_周瑞龙 \\
\hline & & 入 & $/$ EN & & \\
\hline \multirow[t]{2}{*}{ Chinemys reebesii } & 乌龟 & 未列 & 濒危 & 吴孝兵 & 乌龟胃肠胰系统内分泌细胞的免疫组织化学研究_黄徐根 \\
\hline & & 入 & $/ \mathrm{EN}$ & & \\
\hline \multirow[t]{2}{*}{ Chinemys reebesii } & 乌龟 & 未列 & 濒危 & 聂刘旺 & 乌龟线粒体全基因组序列和结构分析_蒲友光 \\
\hline & & 入 & $/ \mathrm{EN}$ & & \\
\hline \multirow[t]{2}{*}{ Chinemys reebesii } & 乌龟 & 未列 & 濒危 & 何中央 & 乌龟线粒体细胞色素 b 基因片段的初步研究_何中央 \\
\hline & & 入 & $/$ EN & & \\
\hline \multirow[t]{2}{*}{ Chinemys reebesii } & 乌龟 & 未列 & 濒危 & 洪一江 & 乌龟形态性状对体重的影响效果 \\
\hline & & 入 & $/ \mathrm{EN}$ & & \\
\hline \multirow[t]{2}{*}{ Chinemys reebesii } & 乌龟 & 未列 & 濒危 & 刘文生 & 乌龟血液生物化学指标的初步研究_刘文生 \\
\hline & & 入 & /EN & & \\
\hline \multirow[t]{2}{*}{ Chinemys reebesii } & 乌龟 & 未列 & 濒危 & 朱新平 & 乌龟遗传多样性的 RAPD 分析_朱新平 \\
\hline & & 入 & $/ \mathrm{EN}$ & & \\
\hline \multirow[t]{2}{*}{ Chinemys reebesii } & 乌龟 & 未列 & 濒危 & 赵振云 & 乌龟原代细胞培养及其对电离辐射抗性的初步研究_赵振云 \\
\hline & & 入 & $/ \mathrm{EN}$ & & \\
\hline Chinemys reebesii & 乌龟 & 未列 & 濒危 & 李贵生 & 乌龟稚龟的生长研究_李贵生 \\
\hline
\end{tabular}


顾垒，闻丞，罗玫，王吴，吕植. 中国最受关注濒危物种保护现状快速评价的新方法探讨. 生物多样性，2015，23(5)：583-590. http://www. biodiversity-science. net/CN/article/downloadArticleFile. do?attachType=PDF\&id=10075

\begin{tabular}{|c|c|c|c|c|c|}
\hline & & 入 & $/$ EN & & \\
\hline \multirow[t]{2}{*}{ Chinemys reebesii } & 乌龟 & 未列 & 濒危 & 于博 & 一例乌龟皮下新生物病理学诊断_侯月娥 \\
\hline & & 入 & $/ \mathrm{EN}$ & & \\
\hline \multirow[t]{2}{*}{ Chinemys reevesii } & 乌龟 & 未列 & 濒危 & 李珊 & 稃化温度对乌龟性别分化影响的研究 \\
\hline & & 入 & $/$ EN & & \\
\hline \multirow[t]{2}{*}{ Chinemys reevesii } & 乌龟 & 未列 & 濒危 & 周贵潭 & 1 龄乌龟与黄喉拟水龟生长的初步研究 \\
\hline & & 入 & /EN & & \\
\hline \multirow[t]{2}{*}{ Chinemys reevesii } & 乌龟 & 未列 & 濒危 & 杜卫国 & 不同孵化湿度下的乌龟卵睬化成功率 \\
\hline & & 入 & $/$ EN & & 及新生幼体特征 \\
\hline \multirow[t]{2}{*}{ Chinemys reevesii } & 乌龟 & 未列 & 濒危 & 印大中 & 冬眠状态乌龟尿液的生物学特性及生化分析 \\
\hline & & 入 & $/$ EN & & \\
\hline \multirow[t]{2}{*}{ Chinemys reevesii } & 乌龟 & 未列 & 濒危 & 方壁 & 孵化温度对乌龟性比的影响 \\
\hline & & 入 & /EN & & \\
\hline \multirow[t]{2}{*}{ Chinemys reevesii } & 乌龟 & 未列 & 濒危 & 李应森 & 工厂化饲养乌龟的探讨 \\
\hline & & 入 & $/$ EN & & \\
\hline \multirow[t]{2}{*}{ Chinemys reevesii } & 乌龟 & 未列 & 濒危 & 刘 丽 & 加温养殖下乌龟精巢发育的研究 \\
\hline & & 入 & $/$ EN & & \\
\hline \multirow[t]{2}{*}{ Chinemys reevesii } & 乌龟 & 未列 & 濒危 & 江耀明 & 平胸龟、乌龟和四爪陆龟盾片变异 \\
\hline & & 入 & /EN & & \\
\hline
\end{tabular}


顾垒，闻丞，罗玫，王吴，吕植. 中国最受关注濒危物种保护现状快速评价的新方法探讨. 生物多样性，2015，23(5)：583-590. http://www. biodiversity-science. net/CN/article/downloadArticleFile. do?attachType=PDF\&id=10075

\begin{tabular}{|c|c|c|c|c|c|}
\hline \multirow[t]{2}{*}{ Chinemys reevesii } & 乌龟 & 未列 & 濒危 & 周贵谭 & 乌龟、黄喉拟水鱼及黄缘盒龟生长特征的比较 \\
\hline & & 入 & $/$ EN & & \\
\hline \multirow[t]{2}{*}{ Chinemys reevesii } & 乌龟 & 未列 & 濒危 & 张海军 & 乌龟 Sox gene 的 PCR 扩增及其条件 \\
\hline & & 入 & $/$ EN & & \\
\hline \multirow[t]{2}{*}{ Chinemys reevesii } & 乌龟 & 未列 & 濒危 & 聂刘旺 & 乌龟 Sox 基因的克隆及测序 \\
\hline & & 入 & $/$ EN & & \\
\hline \multirow[t]{2}{*}{ Chinemys reevesii } & 乌龟 & 未列 & 濒危 & 李长玲 & 乌龟白血细胞发育过程的观察 \\
\hline & & 入 & $/$ EN & & \\
\hline \multirow[t]{2}{*}{ Chinemys reevesii } & 乌龟 & 未列 & 濒危 & 李杰森 & 乌龟的电磁学研究 \\
\hline & & 入 & /EN & & \\
\hline \multirow[t]{2}{*}{ Chinemys reevesii } & 乌龟 & 未列 & 濒危 & 周贵谭 & 乌龟的繁育技术 \\
\hline & & 入 & $/ \mathrm{EN}$ & & \\
\hline \multirow[t]{2}{*}{ Chinemys reevesii } & 乌龟 & 未列 & 濒危 & 葛雷 & 乌龟的营养成分研究 \\
\hline & & 入 & $/ \mathrm{EN}$ & & \\
\hline \multirow[t]{2}{*}{ Chinemys reevesii } & 乌龟 & 未列 & 濒危 & 刘 娇 & 乌龟各生长期的养殖技术 \\
\hline & & 入 & $/ \mathrm{EN}$ & & \\
\hline \multirow[t]{2}{*}{ Chinemys reevesii } & 乌龟 & 未列 & 濒危 & 李应森 & 乌龟工厂化饲养试验报告 \\
\hline & & 入 & $/ \mathrm{EN}$ & & \\
\hline Chinemys reevesii & 乌龟 & 未列 & 濒危 & 李长玲 & 乌龟红血细胞发生研究 \\
\hline
\end{tabular}


顾垒，闻丞，罗玫，王吴，吕植．中国最受关注濒危物种保护现状快速评价的新方法探讨．生物多样性，2015，23 (5)：583-590。 http://www. biodiversity-science. net/CN/article/downloadArticleFile. do?attachType=PDF\&id=10075

\begin{tabular}{|c|c|c|c|c|c|}
\hline & & 入 & $/$ EN & & \\
\hline \multirow[t]{2}{*}{ Chinemys reevesii } & 乌龟 & 未列 & 濒危 & 李良华 & 乌龟寄生性鳃蛭病的防治探讨 \\
\hline & & 入 & $/ \mathrm{EN}$ & & \\
\hline \multirow[t]{2}{*}{ Chinemys reevesii } & 乌龟 & 未列 & 濒危 & 陈关平 & 乌龟烂尾病病原的鉴定 \\
\hline & & 入 & $/$ EN & & \\
\hline \multirow[t]{2}{*}{ Chinemys reevesii } & 乌龟 & 未列 & 濒危 & 夏忠国 & 乌龟苗种繁育技术研究 \\
\hline & & 入 & $/ \mathrm{EN}$ & & \\
\hline \multirow[t]{2}{*}{ Chinemys reevesii } & 乌龟 & 未列 & 濒危 & 谭立军 & 乌龟胚胎发育的研究 \\
\hline & & 入 & $/$ EN & & \\
\hline \multirow[t]{2}{*}{ Chinemys reevesii } & 乌龟 & 未列 & 濒危 & 周贵谭 & 乌龟配合饲料动植物蛋白比的研究 \\
\hline & & 入 & $/$ EN & & \\
\hline \multirow[t]{2}{*}{ Chinemys reevesii } & 乌龟 & 未列 & 濒危 & 周贵谭 & 乌龟配合饲料钻磷比与适宜量的研究 \\
\hline & & 入 & /EN & & \\
\hline \multirow[t]{2}{*}{ Chinemys reevesii } & 乌龟 & 未列 & 濒危 & 周贵谭 & 乌龟配合饲料能量蛋白比的研究 \\
\hline & & 入 & $/$ EN & & \\
\hline \multirow[t]{2}{*}{ Chinemys reevesii } & 乌龟 & 未列 & 濒危 & 贾 虹 & 乌龟脱肛的治疗 \\
\hline & & 入 & $/ \mathrm{EN}$ & & \\
\hline \multirow[t]{2}{*}{ Chinemys reevesii } & 乌龟 & 未列 & 濒危 & 曹伏君 & 乌龟外周血细胞的显微和超微结构 \\
\hline & & 入 & /EN & & \\
\hline
\end{tabular}


顾垒，闻丞，罗玫，王吴，吕植. 中国最受关注濒危物种保护现状快速评价的新方法探讨. 生物多样性，2015，23(5)：583-590. http://www. biodiversity-science. net/CN/article/downloadArticleFile. do?attachType=PDF\&id=10075

\begin{tabular}{|c|c|c|c|c|c|}
\hline \multirow[t]{2}{*}{ Chinemys reevesii } & 乌龟 & 未列 & 濒危 & 曹伏君 & 乌龟外周血细胞在光镜和扫描电镜下的结构 \\
\hline & & 入 & $/ \mathrm{EN}$ & & \\
\hline \multirow[t]{2}{*}{ Chinemys reevesii } & 乌龟 & 未列 & 濒危 & 李贵生 & 乌龟与黄喉拟水龟稚龟的比较 \\
\hline & & 入 & $/ \mathrm{EN}$ & & \\
\hline \multirow[t]{2}{*}{ Chinemys reevesii } & 乌龟 & 未列 & 濒危 & 吴遵霖 & 幼乌龟 Chinemys reevesii 配合饲料蛋白质最适含量的研究 \\
\hline & & $\lambda$ & $/ \mathrm{EN}$ & & \\
\hline \multirow[t]{2}{*}{ Chlamydotis macqueenii } & 波斑铇 & I & 无危 & 乔建芳 & 波斑铇维鸟生长发育初步研究 \\
\hline & & & $/ \mathrm{LC}$ & & \\
\hline \multirow[t]{2}{*}{ Chlamydotis macqueenii } & 波斑铇 & I & 无危 & 杨维康 & 新疆木垒波斑铇生态学研究 \\
\hline & & & $/ \mathrm{LC}$ & & \\
\hline \multirow[t]{2}{*}{ Chlidonias niger } & 黑浮鸥 & II & 无危 & 宋江平 & 宁夏沙坡头国家级自然保护区湿地水禽多样性动态 \\
\hline & & & $/ \mathrm{LC}$ & & \\
\hline \multirow[t]{2}{*}{ Chroicocephalus saundersi } & 黑嘴鸥 & 未列 & 易危 & & 1998-2008 年黄河三角洲黑嘴鸥繁殖种群数量及其繁殖生境动态变化 \\
\hline & & 入 & /VU & & \\
\hline \multirow[t]{2}{*}{ Chroicocephalus saundersi } & 黑嘴鸥 & 未列 & 易危 & & 河北省首次发现黑嘴鸥繁殖种群 \\
\hline & & 入 & $/ \mathrm{VU}$ & & \\
\hline \multirow[t]{2}{*}{ Chroicocephalus saundersi } & 黑嘴鸥 & 未列 & 易危 & & 黑嘴鸥巢址的时空变化 \\
\hline & & 入 & $/ \mathrm{VU}$ & & \\
\hline Chroicocephalus saundersi & 黑嘴鸥 & 未列 & 易危 & & 黄河三角洲黑嘴鸥的生境评估及其建议 \\
\hline
\end{tabular}


顾垒，闻丞，罗玫，王吴，吕植. 中国最受关注濒危物种保护现状快速评价的新方法探讨. 生物多样性，2015，23(5)：583-590. http://www. biodiversity-science. net/CN/article/downloadArticleFile. do?attachType=PDF\&id=10075

\begin{tabular}{|c|c|c|c|c|}
\hline & & 入 & $/ \mathrm{VU}$ & \\
\hline \multirow[t]{2}{*}{ Chroicocephalus saundersi } & 黑嘴鸥 & 未列 & 易危 & 江苏如东沿海发现黑嘴鸥新繁殖地 \\
\hline & & 入 & $/ \mathrm{VU}$ & \\
\hline \multirow[t]{2}{*}{ Chroicocephalus saundersi } & 黑嘴鸥 & 未列 & 易危 & 江苏盐城黑嘴鸥的繁殖栖息地选择 \\
\hline & & 入 & /VU & \\
\hline \multirow[t]{2}{*}{ Chroicocephalus saundersi } & 黑嘴鸥 & 未列 & 易危 & 江苏盐城黑嘴鸥繁殖期不同阶段行为时间分配及活动规律 \\
\hline & & 入 & $/ \mathrm{VU}$ & \\
\hline \multirow[t]{2}{*}{ Chroicocephalus saundersi } & 黑嘴鸥 & 未列 & 易危 & 辽宁黑嘴鸥调查报告 \\
\hline & & 入 & $/ \mathrm{VU}$ & \\
\hline \multirow[t]{2}{*}{ Chroicocephalus saundersi } & 黑嘴鸥 & 未列 & 易危 & 辽宁双台河口黑嘴鸥的迁徙模式与种群生存率 \\
\hline & & 入 & /VU & \\
\hline \multirow[t]{2}{*}{ Chroicocephalus saundersi } & 黑嘴鸥 & 未列 & 易危 & 㴒河口黑嘴鸥巢位生态位研究 \\
\hline & & 入 & /VU & \\
\hline \multirow[t]{2}{*}{ Chroicocephalus saundersi } & 黑嘴鸥 & 未列 & 易危 & 㴒河口黑嘴鸥繁殖群的保护 \\
\hline & & 入 & /VU & \\
\hline \multirow[t]{2}{*}{ Chroicocephalus saundersi } & 黑嘴鸥 & 未列 & 易危 & 㴒河口湿地环境因子变化对黑嘴鸥繁殖影响研究 \\
\hline & & 入 & /VU & \\
\hline \multirow[t]{2}{*}{ Chroicocephalus saundersi } & 黑嘴鸥 & 未列 & 易危 & 鸭绿江口湿地首次发现大型黑嘴鸥繁殖群 \\
\hline & & 入 & /VU & \\
\hline
\end{tabular}


顾垒，闻丞，罗玫，王吴，吕植. 中国最受关注濒危物种保护现状快速评价的新方法探讨. 生物多样性，2015，23(5)：583-590. http://www. biodiversity-science. net/CN/article/downloadArticleFile. do?attachType=PDF\&id=10075

\begin{tabular}{|c|c|c|c|c|c|}
\hline Ciconia boyciana & 东方白鹳 & I & $\begin{array}{l}\text { 濒危 } \\
\text { /EN }\end{array}$ & 刘观华 & 2012 年冬季鄱阳湖大型越冬水鸟数量与分布 \\
\hline Ciconia boyciana & 东方白鹳 & I & $\begin{array}{l}\text { 濒危 } \\
\text { /EN }\end{array}$ & 李 健 & 八岔岛国家级自然保护区保护现状及对策研究 \\
\hline Ciconia boyciana & 东方白鹳 & I & $\begin{array}{l}\text { 濒危 } \\
\text { /EN }\end{array}$ & 关 霞 & 北京野鸭湖湿地自然保护区鸟类资源及其保护 \\
\hline Ciconia boyciana & 东方白鹳 & I & $\begin{array}{l}\text { 濒危 } \\
\text { /EN }\end{array}$ & 陈宏宇 & 达里诺尔自然保护区鸟类区系组成及生态分布 \\
\hline Ciconia boyciana & 东方白鹳 & I & $\begin{array}{l}\text { 濒危 } \\
\text { /EN }\end{array}$ & 刘 涁 & 大丰糜鹿保护区东方白鹳的繁殖行为及筑巢特征研究 \\
\hline Ciconia boyciana & 东方白鹳 & I & $\begin{array}{l}\text { 濒危 } \\
\text { /EN }\end{array}$ & 李林格 & 大连地区乌类新纪录 \\
\hline Ciconia boyciana & 东方白鹳 & I & $\begin{array}{l}\text { 濒危 } \\
\text { /EN }\end{array}$ & 杨礼平 & 东方红湿地国家级自然保护区首现国家珍稀鸟类_东方白鹳 \\
\hline Ciconia boyciana & 东方白鹳 & I & $\begin{array}{l}\text { 濒危 } \\
\text { /EN }\end{array}$ & 储 小 感 & 国家级自然保护区一一一安徽升金湖的保护价值刍议 \\
\hline Ciconia boyciana & 东方白鹳 & I & $\begin{array}{l}\text { 濒危 } \\
\text { /EN }\end{array}$ & 孙砚峰 & 河北省滹沦河中游湿地鸟类多样性研究 \\
\hline Ciconia boyciana & 东方白鹳 & I & 濒危 & 马朝红 & 河南黄河湿地国家级自然保护区孟津段水鸟资源调查 \\
\hline
\end{tabular}


顾垒，闻丞，罗玫，王吴，吕植. 中国最受关注濒危物种保护现状快速评价的新方法探讨. 生物多样性，2015，23(5)：583-590. http://www. biodiversity-science. net/CN/article/downloadArticleFile. do?attachType=PDF\&id=10075

\begin{tabular}{|c|c|c|c|c|c|}
\hline & & & /EN & & \\
\hline \multirow[t]{2}{*}{ Ciconia boyciana } & 东方白鹳 & I & 濒危 & 牛俊英 & 河南黄河湿地国家级自然保护区鸟类资源调查 \\
\hline & & & $/$ EN & & \\
\hline \multirow[t]{2}{*}{ Ciconia boyciana } & 东方白鹳 & I & 濒危 & 张佰莲 & 黑龙江大沾河湿地自然保护区鸟类群落结构调查及其多样性分析 \\
\hline & & & /EN & & \\
\hline \multirow[t]{2}{*}{ Ciconia boyciana } & 东方白鹳 & I & 濒危 & 宋丽萍 & 黑龙江红星自然保护区湿地保护价值评价 \\
\hline & & & /EN & & \\
\hline \multirow[t]{2}{*}{ Ciconia boyciana } & 东方白鹳 & I & 濒危 & 李彦杰 & 黑龙江洪河自然保护区东方白鹳巢址生境选择初探 \\
\hline & & & /EN & & \\
\hline \multirow[t]{2}{*}{ Ciconia boyciana } & 东方白鹳 & I & 濒危 & 张立芝 & 黑龙江库尔滨河湿地自然保护区湿地及野生动植物资源 \\
\hline & & & /EN & & \\
\hline \multirow[t]{2}{*}{ Ciconia boyciana } & 东方白鹳 & I & 濒危 & 黄守华 & 黑龙江龙风湿地自然保护区鸟类研究 \\
\hline & & & /EN & & \\
\hline \multirow[t]{2}{*}{ Ciconia boyciana } & 东方白鹳 & I & 濒危 & 邱胜荣 & 黑龙江省朗乡自然保护区鸟类区系初步分析 \\
\hline & & & /EN & & \\
\hline \multirow[t]{2}{*}{ Ciconia boyciana } & 东方白鹳 & I & 濒危 & 焦 洋 & 洪河自然保护区东方白鹳孵化期行为研究 \\
\hline & & & /EN & & \\
\hline \multirow[t]{2}{*}{ Ciconia boyciana } & 东方白鹳 & I & 濒危 & 段玉宝 & 黄河三角洲东方白鹳繁殖期受食栖息地的利用 \\
\hline & & & /EN & & \\
\hline
\end{tabular}


顾垒，闻丞，罗玫，王吴，吕植. 中国最受关注濒危物种保护现状快速评价的新方法探讨. 生物多样性，2015，23(5)：583-590. http://www. biodiversity-science. net/CN/article/downloadArticleFile. do?attachType=PDF\&id=10075

\begin{tabular}{|c|c|c|c|c|c|}
\hline Ciconia boyciana & 东方白鹳 & I & $\begin{array}{l}\text { 濒危 } \\
\text { /EN }\end{array}$ & 王立冬 & 黄河三角洲东方白鹳繁殖研究 \\
\hline Ciconia boyciana & 东方白鹳 & I & $\begin{array}{l}\text { 濒危 } \\
\text { /EN }\end{array}$ & 杨兵兵 & 吉林莫莫格国家级自然保护区的鸟类资源 \\
\hline Ciconia boyciana & 东方白鹳 & I & $\begin{array}{l}\text { 濒危 } \\
\text { /EN }\end{array}$ & 冯照军 & 江苏骆马湖湿地鸟类资源及其保护 \\
\hline Ciconia boyciana & 东方白鹳 & I & $\begin{array}{l}\text { 濒危 } \\
\text { /EN }\end{array}$ & 章旭日 & 江西南矶山国家级自然保护区非繁殖期鸟类多样性研究 \\
\hline Ciconia boyciana & 东方白鹳 & I & $\begin{array}{l}\text { 濒危 } \\
\text { /EN }\end{array}$ & 盛显和 & 康山湖区候鸟自然保护区鸟类资源现状及保护 \\
\hline Ciconia boyciana & 东方白鹳 & I & $\begin{array}{l}\text { 濒危 } \\
\text { /EN }\end{array}$ & 张峻华 & 科尔沈国家级自然保护区湿地类型及保护对策 \\
\hline Ciconia boyciana & 东方白鹳 & I & $\begin{array}{l}\text { 濒危 } \\
\text { /EN }\end{array}$ & 于晶晶 & 辽宁獾子洞湿地水鸟春秋迁徙研究 \\
\hline Ciconia boyciana & 东方白鹳 & I & $\begin{array}{l}\text { 濒危 } \\
\text { /EN }\end{array}$ & 唐博雅 & 辽宁双台河口自然保护区景观破碎化研究 \\
\hline Ciconia boyciana & 东方白鹳 & I & $\begin{array}{l}\text { 濒危 } \\
\text { /EN }\end{array}$ & 梅玫 & 辽宁双台河口自然保护区旅游区鸟类群落结构分析 \\
\hline Ciconia boyciana & 东方白鹳 & I & 濒危 & 潘胜东 & 龙感湖国家级湿地自然保护区建设管理现状及保护对策 \\
\hline
\end{tabular}


顾垒，闻丞，罗玫，王吴，吕植. 中国最受关注濒危物种保护现状快速评价的新方法探讨. 生物多样性，2015，23(5)：583-590. http://www. biodiversity-science. net/CN/article/downloadArticleFile. do?attachType=PDF\&id=10075

\begin{tabular}{|c|c|c|c|c|c|}
\hline & & & /EN & & \\
\hline \multirow[t]{2}{*}{ Ciconia boyciana } & 东方白鹳 & I & 濒危 & 孔洋阳 & 莫莫格国家级自然保护区生态评价 \\
\hline & & & /EN & & \\
\hline \multirow[t]{2}{*}{ Ciconia boyciana } & 东方白鹳 & I & 濒危 & 李自亲 & 牡丹峰自然保护区与牡丹江市公园夏季鸟类多样性比较分析 \\
\hline & & & /EN & & \\
\hline \multirow[t]{2}{*}{ Ciconia boyciana } & 东方白鹳 & I & 濒危 & 杨 帆 & 内蒙古鄂尔多斯高原鸟类区系组成及其特征 \\
\hline & & & /EN & & \\
\hline \multirow[t]{2}{*}{ Ciconia boyciana } & 东方白鹳 & I & 濒危 & 周景英 & 内蒙古图牧吉自然保护区春季迁徙水鸟多样性研究 \\
\hline & & & /EN & & \\
\hline \multirow[t]{2}{*}{ Ciconia boyciana } & 东方白鹳 & I & 濒危 & 朱奇 & 鄱阳湖国家级自然保护区白鹤、东方白鹳和小天鹅种群数量与分布 \\
\hline & & & /EN & & \\
\hline \multirow[t]{2}{*}{ Ciconia boyciana } & 东方白鹳 & I & 濒危 & 缪泸君 & 鄱阳湖国家级自然保护区东方白鹳（Ciconia boyciana）种群数量变化与气候的关系 \\
\hline & & & /EN & & \\
\hline \multirow[t]{2}{*}{ Ciconia boyciana } & 东方白鹳 & I & 濒危 & 应 钦 & 鄱阳湖吴城半岛鸟类群落组成及多样性分析 \\
\hline & & & /EN & & \\
\hline \multirow[t]{2}{*}{ Ciconia boyciana } & 东方白鹳 & I & 濒危 & 徐昌新 & 鄱阳湖越冬鸟类种群动态与保护研究 \\
\hline & & & /EN & & \\
\hline \multirow[t]{2}{*}{ Ciconia boyciana } & 东方白鹳 & I & 濒危 & 李言阔 & 气候因子和水位变化对鄱阳湖东方白鹳越冬种群数量的影响 \\
\hline & & & /EN & & \\
\hline
\end{tabular}


顾垒，闻丞，罗玫，王吴，吕植. 中国最受关注濒危物种保护现状快速评价的新方法探讨. 生物多样性，2015，23(5)：583-590. http://www. biodiversity-science. net/CN/article/downloadArticleFile. do?attachType=PDF\&id=10075

\begin{tabular}{|c|c|c|c|c|c|}
\hline Ciconia boyciana & 东方白鹳 & I & $\begin{array}{l}\text { 濒危 } \\
\text { /EN }\end{array}$ & 连海燕 & 山东黄河三角洲国家级自然保护区东方白鹳种群恢复与保护现状 \\
\hline Ciconia boyciana & 东方白鹳 & I & $\begin{array}{l}\text { 濒危 } \\
\text { /EN }\end{array}$ & 何冰 & 陕西黄河湿地鸟类资源调查分析与研究 \\
\hline Ciconia boyciana & 东方白鹳 & I & $\begin{array}{l}\text { 濒危 } \\
/ \mathrm{EN}\end{array}$ & 巩会生 & 陕西秦岭及大巴山地区的鸟类资源调查 \\
\hline Ciconia boyciana & 东方白鹳 & I & $\begin{array}{l}\text { 濒危 } \\
\text { /EN }\end{array}$ & 毛伟伟 & 沈阳辽中仙子湖自然保护区的保护对象和功能区的划分 \\
\hline Ciconia boyciana & 东方白鹳 & I & $\begin{array}{l}\text { 濒危 } \\
/ \mathrm{EN}\end{array}$ & 韩丽萍 & 唐海湿地和鸟类省级自然保护区鸟类资源调查研究 \\
\hline Ciconia boyciana & 东方白鹳 & I & $\begin{array}{l}\text { 濒危 } \\
\text { /EN }\end{array}$ & 李春燕 & 天津大黄堡湿地鸟类资源现状及保护对策 \\
\hline Ciconia boyciana & 东方白鹳 & I & $\begin{array}{l}\text { 濒危 } \\
/ \mathrm{EN}\end{array}$ & 田振环 & 图牧吉国家级自然保护区鸟类资源 \\
\hline Ciconia boyciana & 东方白鹳 & I & $\begin{array}{l}\text { 濒危 } \\
/ \mathrm{EN}\end{array}$ & 郡伟庚 & 扎龙自然保护区春季水禽的调查 \\
\hline Ciconia boyciana & 东方白鹳 & I & $\begin{array}{l}\text { 濒危 } \\
/ \mathrm{EN}\end{array}$ & 王振斌 & 珍宝岛国家级自然保护区湿地资源现状与保护对策 \\
\hline Ciconia boyciana & 东方白鹳 & I & 濒危 & 李长看 & 郑州黄河湿地省级自然保护区鸟类区系和多样性 \\
\hline
\end{tabular}


顾垒，闻丞，罗玫，王吴，吕植. 中国最受关注濒危物种保护现状快速评价的新方法探讨. 生物多样性，2015，23(5)：583-590. http://www. biodiversity-science. net/CN/article/downloadArticleFile. do?attachType=PDF\&id=10075

\begin{tabular}{|c|c|c|c|c|c|}
\hline & & & /EN & & \\
\hline \multirow[t]{2}{*}{ Cinnamomum mairei } & 银叶桂 & 未列 & 濒危 & 李锡文 & 《中国植物志》第 31 卷 220 页 \\
\hline & & 入 & /EN & & \\
\hline \multirow[t]{3}{*}{ Circaeaster agrestis } & 星叶草 & 未列 & 未评 & X.-H. Tian & Number of floral organs in Circaeaster agrestis (Circaeasteraceae) and possible homeosis \\
\hline & & 入 & 价 & & among floral organs \\
\hline & & & $/ \mathrm{NE}$ & & \\
\hline \multirow[t]{3}{*}{ Circaeaster agrestis } & 星叶草 & 未列 & 未评 & 冯虎元 & 濒危植物星叶草和桃儿七 AMF 季节性变化研究 \\
\hline & & 入 & 价 & & \\
\hline & & & $/ \mathrm{NE}$ & & \\
\hline \multirow[t]{3}{*}{ Circaeaster agrestis } & 星叶草 & 未列 & 未评 & 操国兴 & 不同局部密度下星叶草生殖成功 \\
\hline & & 入 & 价 & & \\
\hline & & & $/ \mathrm{NE}$ & & \\
\hline \multirow[t]{3}{*}{ Circaeaster agrestis } & 星叶草 & 未列 & 未评 & 任毅 & 基于形态学资料星叶草属系统位置的探讨 \\
\hline & & 入 & 价 & & \\
\hline & & & $/ \mathrm{NE}$ & & \\
\hline \multirow[t]{3}{*}{ Circaeaster agrestis } & 星叶草 & 未列 & 未评 & 吴建国 & 气候变化对我国 7 种植物潜在分布的影响 \\
\hline & & 入 & 价 & & \\
\hline & & & $/ \mathrm{NE}$ & & \\
\hline Circaeaster agrestis & 星叶草 & 未列 & 未评 & 姬志勤 & 星叶草内生菌抑菌活性研究 \\
\hline
\end{tabular}


顾垒，闻丞，罗玫，王吴，吕植. 中国最受关注濒危物种保护现状快速评价的新方法探讨. 生物多样性，2015，23(5)：583-590. http://www. biodiversity-science. net/CN/article/downloadArticleFile. do?attachType=PDF\&id=10075

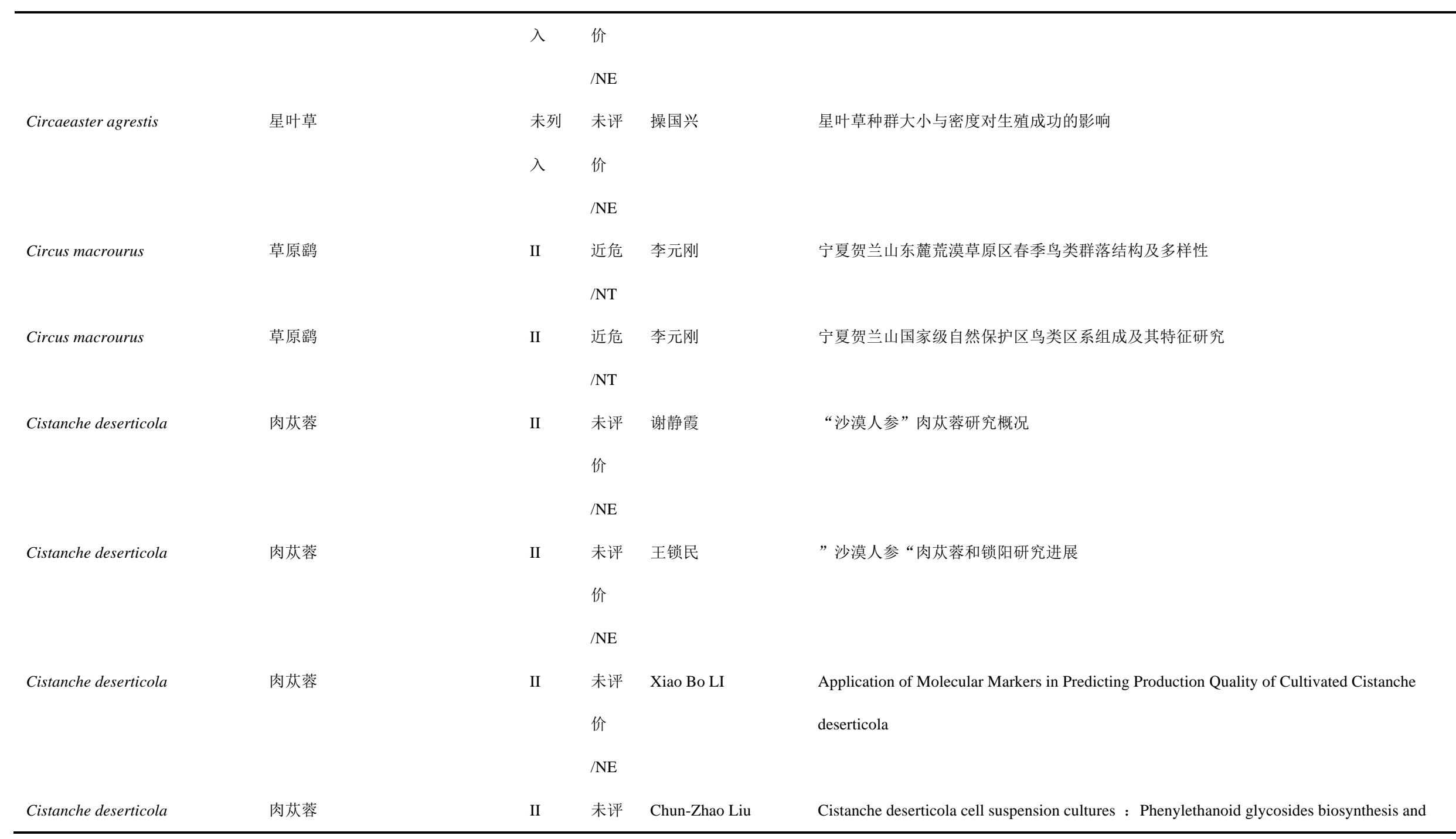


顾垒，闻丞，罗玫，王吴，吕植. 中国最受关注濒危物种保护现状快速评价的新方法探讨. 生物多样性，2015，23(5)：583-590.

\begin{tabular}{|c|c|c|c|c|c|}
\hline & & & 价 & & antioxidant activity \\
\hline Cistanche deserticola & 肉苁蓉 & II & $\begin{array}{l}\text { /NE } \\
\text { 未评 } \\
\text { 价 }\end{array}$ & Jun Chen & Cistanche deserticola Ma cultivated as a new crop in China \\
\hline Cistanche deserticola & 肉苁蓉 & II & $\begin{array}{l}\text { /NE } \\
\text { 未评 } \\
\text { 价 }\end{array}$ & Jianqiang Li & $\begin{array}{l}\text { Complete Chloroplast Genome Sequence of Holoparasite Cistanche deserticola } \\
\text { (Orobanchaceae) Reveals Gene Loss and Horizontal Gene Transfer from Its Host Haloxylon }\end{array}$ \\
\hline Cistanche deserticola & 肉苁蓉 & II & $\begin{array}{l}\text { /NE } \\
\text { 未评 } \\
\text { 价 }\end{array}$ & Doh Hoon Kim & $\begin{array}{l}\text { ammodendron (Chenopodiaceae) } \\
\text { Effects of 2-aminoindan-2-phosphonic acid treatment on the accumulation of salidroside and } \\
\text { four phenylethanoid glycosides in suspension cell culture of Cistanche deserticola }\end{array}$ \\
\hline Cistanche deserticola & 肉苁蓉 & II & $\begin{array}{l}\text { /NE } \\
\text { 未评 } \\
\text { 价 }\end{array}$ & Yuchun Wang & $\begin{array}{l}\text { Effects of rare earth elements on the growth of Cistanche deserticola cells and the production of } \\
\text { phenylethanoid glycosides }\end{array}$ \\
\hline Cistanche deserticola & 肉苁蓉 & II & $\begin{array}{l}\text { /NE } \\
\text { 未评 } \\
\text { 价 }\end{array}$ & Chun-Zhao Liu & $\begin{array}{l}\text { Enhancement of phenylethanoid glycosides biosynthesis in cell cultures of Cistanche } \\
\text { deserticola by osmotic stress }\end{array}$ \\
\hline Cistanche deserticola & 肉苁蓉 & II & $\begin{array}{l}/ \mathrm{NE} \\
\text { 未评 } \\
\text { 价 }\end{array}$ & Yu-chun Wang & Formation of phenylethanoid glycosides by Cistanche deserticola callus grown on solid media \\
\hline
\end{tabular}


顾垒，闻丞，罗玫，王昊，吕植. 中国最受关注濒危物种保护现状快速评价的新方法探讨．生物多样性，2015，23(5)：583-590.

Cistanche deserticola

肉苁蓉

肉苁蓉

Cistanche deserticola

istanche deserticola

Cistanche deserticola

Cistanche deserticola

肉苁蓉

Cistanche deserticola
X.B. $\mathrm{Li}$

价

/NE

未评 CHEN Shi-lin

价

$/ \mathrm{NE}$

未评 Jie Ouyang

价

/NE

II 未评 Yu-chun Wang 价

未评

Chun-Zhao Liu

价

$/ \mathrm{NE}$
Genetic differentiation induced by spaceflight treatment of Cistanche deserticola and

identification of inter-simple sequence repeat markers associated with its medicinal constituent

contents

Identification of Cistanche species (Orobanchaceae) based on sequences of the plastid

psbA-trnH intergenic region

Improved production of phenylethanoid glycosides by Cistanche deserticola cells cultured in an

internal loop airlift bioreactor with sifter riser

Improvement of echinacoside and acteoside production by two-stage elicitation in cell

suspension culture of Cistanche deserticola

Improvement of phenylethanoid glycosides biosynthesis in Cistanche deserticola cell

suspension cultures by chitosan elicitor

Improvement of phenylethanoid glycosides production by a fungal elicitor in cell suspension

culture of Cistanche deserticola 
顾垒，闻丞，罗玫，王吴，吕植. 中国最受关注濒危物种保护现状快速评价的新方法探讨. 生物多样性，2015，23(5)：583-590. http://www. biodiversity-science. net/CN/article/downloadArticleFile. do?attachType=PDF\&id=10075

\begin{tabular}{|c|c|c|c|c|c|}
\hline \multirow[t]{3}{*}{ Cistanche deserticola } & 肉苁蓉 & II & 未评 & Yu-chun Wang & Light intensity and spectral quality influencing the callus growth of Cistanche deserticola and \\
\hline & & & 价 & & biosynthesis of phenylethanoid glycosides \\
\hline & & & $/ \mathrm{NE}$ & & \\
\hline \multirow[t]{3}{*}{ Cistanche deserticola } & 肉苁蓉 & II & 未评 & Doh Hoon Kim & Molecular characterization of phenylalanine ammonia lyase gene from Cistanche deserticola \\
\hline & & & 价 & & \\
\hline & & & $/ \mathrm{NE}$ & & \\
\hline \multirow[t]{3}{*}{ Cistanche deserticola } & 肉苁蓉 & II & 未评 & 高岩 & $\mathrm{N}+$ 注入诱导肉苁蓉种子萌发的研究 \\
\hline & & & 价 & & \\
\hline & & & $/ \mathrm{NE}$ & & \\
\hline \multirow[t]{3}{*}{ Cistanche deserticola } & 肉苁蓉 & II & 未评 & Chun-Zhao Liu & Repeated elicitation enhances phenylethanoid glycosides accumulation in cell suspension \\
\hline & & & 价 & & cultures of Cistanche deserticola \\
\hline & & & $/ \mathrm{NE}$ & & \\
\hline \multirow[t]{3}{*}{ Cistanche deserticola } & 肉苁蓉 & II & 未评 & 陈培 & SDS-PAGE 电泳在肉苁蓉种间鉴定中的应用 \\
\hline & & & 价 & & \\
\hline & & & $/ \mathrm{NE}$ & & \\
\hline \multirow[t]{3}{*}{ Cistanche deserticola } & 肉苁蓉 & II & 未评 & Su-qin Sun & The study of Cistanche deserticola using Fourier transform infrared spectroscopy combined \\
\hline & & & 价 & & with two-dimensional correlation infrared spectroscopy \\
\hline & & & $/ \mathrm{NE}$ & & \\
\hline Cistanche deserticola & 肉苁蓉 & II & 未评 & 黄小方 & TXRF 法测定不同施肥模式下肉苁蓉矿质元素的分配特征 \\
\hline
\end{tabular}


顾垒，闻丞，罗玫，王吴，吕植. 中国最受关注濒危物种保护现状快速评价的新方法探讨. 生物多样性，2015，23(5)：583-590. http://www. biodiversity-science. net/CN/article/downloadArticleFile. do?attachType=PDF\&id=10075

\begin{tabular}{|c|c|c|c|c|c|}
\hline \multirow[b]{2}{*}{ Cistanche deserticola } & \multirow[b]{2}{*}{ 肉荻蓉 } & \multirow[b]{2}{*}{ II } & \multicolumn{3}{|l|}{ 价 } \\
\hline & & & $\begin{array}{l}\text { /NE } \\
\text { 未评 } \\
\text { 价 }\end{array}$ & 刘宏义 & 阿拉善荒漠地区肉苁蓉人工栽培技术 \\
\hline Cistanche deserticola & 肉获蓉 & II & $\begin{array}{l}\text { /NE } \\
\text { 未评 } \\
\text { 价 }\end{array}$ & 武瑞东 & 阿拉善盟肉苁蓉产品供给服务评估 \\
\hline Cistanche deserticola & 肉荻蓉 & II & $\begin{array}{l}\text { /NE } \\
\text { 未评 } \\
\text { 价 }\end{array}$ & 李春 & 氨基酸对无外源激素悬浮培养肉苁蓉细胞合成苯乙醇苷的影响 \\
\hline Cistanche deserticola & 肉荻蓉 & II & $\begin{array}{l}\text { /NE } \\
\text { 未评 } \\
\text { 价 }\end{array}$ & 白伟本 & 北疆地区肉苁蓉人工接种栽培技术 \\
\hline Cistanche deserticola & 肉荻蓉 & II & $\begin{array}{l}\text { /NE } \\
\text { 未评 } \\
\text { 价 }\end{array}$ & 宋玉霞 & 濒危植物肉苁蓉 (Cistanche deserticol) 繁育系统研究 \\
\hline Cistanche deserticola & 肉荻蓉 & II & $\begin{array}{l}/ \mathrm{NE} \\
\text { 未评 } \\
\text { 价 }\end{array}$ & 郭卫红 & 不同产地肉苁蓉中麦角甾苷含量测定 \\
\hline
\end{tabular}


顾垒，闻丞，罗玫，王吴，吕植. 中国最受关注濒危物种保护现状快速评价的新方法探讨. 生物多样性，2015，23(5)：583-590. http://www. biodiversity-science. net/CN/article/downloadArticleFile. do?attachType=PDF\&id=10075

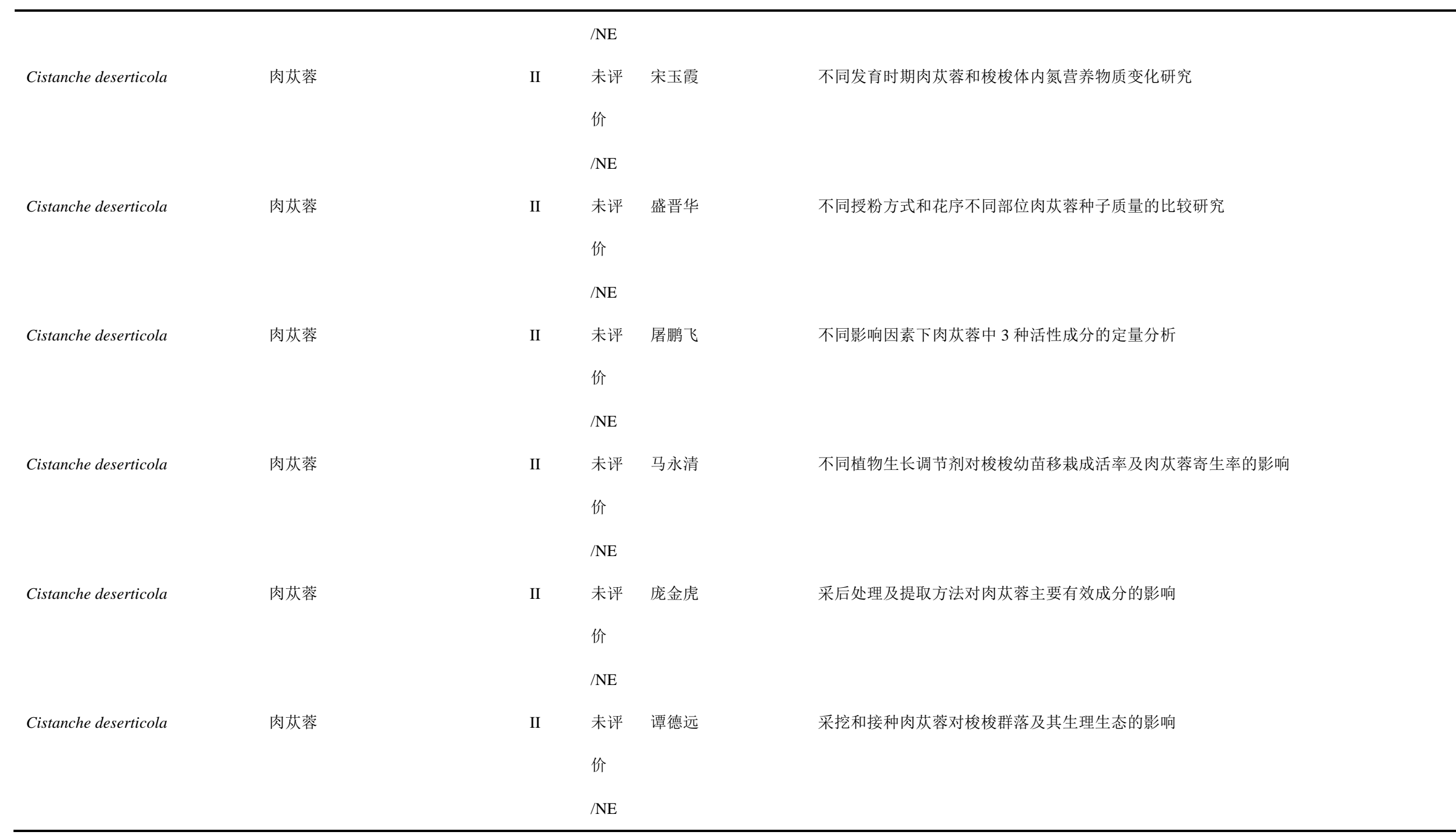


顾垒，闻丞，罗玫，王吴，吕植. 中国最受关注濒危物种保护现状快速评价的新方法探讨. 生物多样性，2015，23(5)：583-590. http://www. biodiversity-science. net/CN/article/downloadArticleFile. do?attachType=PDF\&id=10075

\begin{tabular}{|c|c|c|c|c|c|}
\hline Cistanche deserticola & 肉苁蓉 & II & $\begin{array}{l}\text { 未评 } \\
\text { 价 } \\
\text { /NE }\end{array}$ & 陈君 & 层积处理对肉苁蓉种子形态的影响 \\
\hline Cistanche deserticola & 肉苁蓉 & II & $\begin{array}{l}\text { 未评 } \\
\text { 价 } \\
\text { /NE }\end{array}$ & 盛晋华 & 层积对肉苁蓉种子后熟作用的研究 \\
\hline Cistanche deserticola & 肉苁蓉 & II & $\begin{array}{l}\text { 未评 } \\
\text { 价 } \\
\text { /NE }\end{array}$ & 陈君 & 层积前后肉苁蓉种子成分的红外光谱分析 \\
\hline Cistanche deserticola & 肉苁蓉 & II & $\begin{array}{l}\text { 未评 } \\
\text { 价 } \\
\text { /NE }\end{array}$ & 吕扬 & 差示扫描量热法与红外光谱法快速鉴别肉苁蓉药材的对比研究 \\
\hline Cistanche deserticola & 肉苁蓉 & II & $\begin{array}{l}\text { 未评 } \\
\text { 价 } \\
\text { /NE }\end{array}$ & 郭玉海 & 打顶对肉苁蓉种子产量和质量的影响研究 \\
\hline Cistanche deserticola & 肉苁蓉 & II & $\begin{array}{l}\text { 未评 } \\
\text { 价 } \\
\text { /NE }\end{array}$ & 袁彦 & 磴口地区肉苁蓉质量研究 \\
\hline Cistanche deserticola & 肉苁蓉 & II & 未评 & 郭玉海 & 低温层积与外源 GA3 对肉苁蓉种子萌发及其内源 $\mathrm{GA}$ 和 $\mathrm{ABA}$ 含量的影响 \\
\hline
\end{tabular}


顾垒，闻丞，罗玫，王吴，吕植. 中国最受关注濒危物种保护现状快速评价的新方法探讨. 生物多样性，2015，23(5)：583-590. http://www. biodiversity-science. net/CN/article/downloadArticleFile. do?attachType=PDF\&id=10075

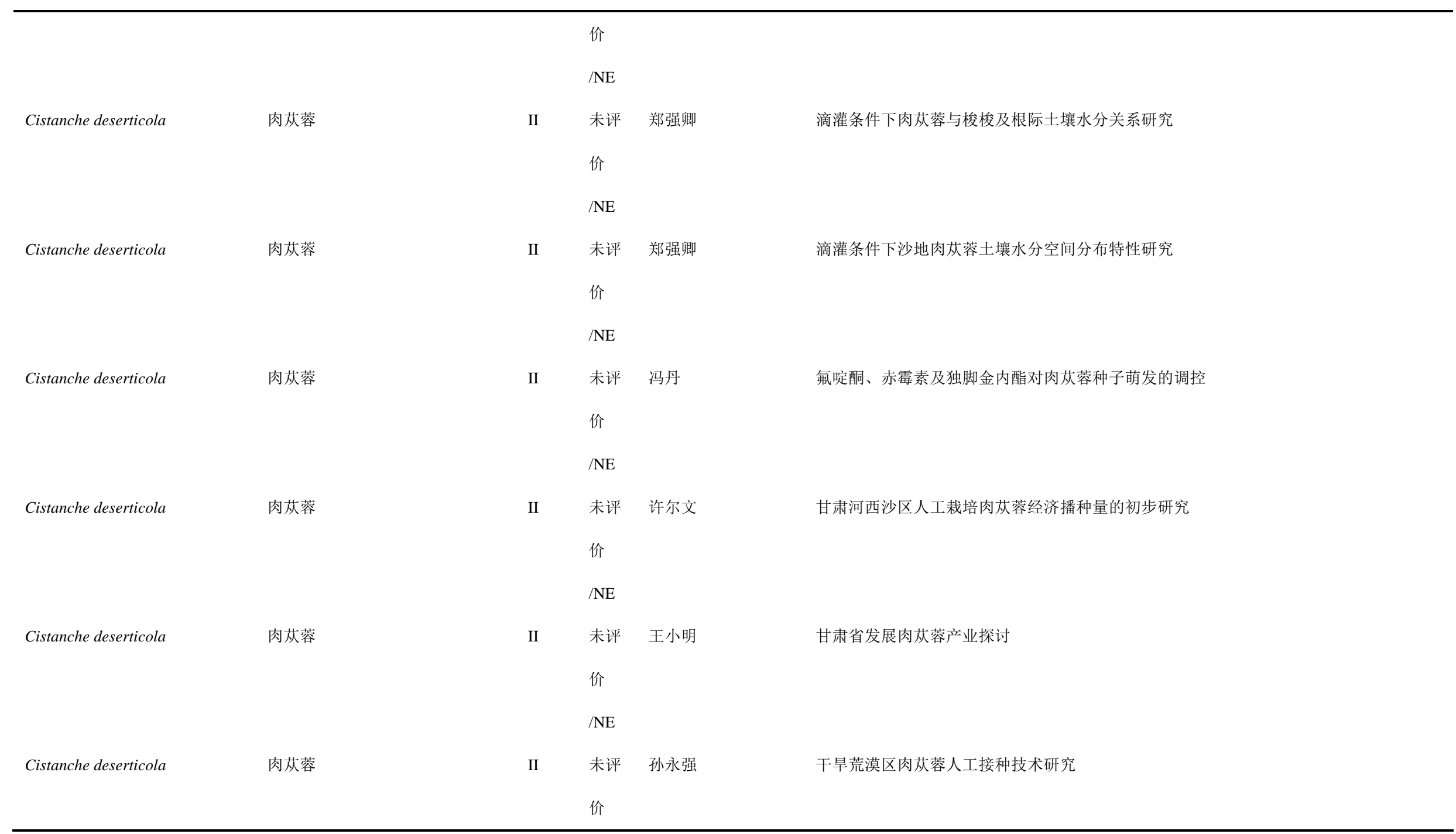


顾垒，闻丞，罗玫，王吴，吕植. 中国最受关注濒危物种保护现状快速评价的新方法探讨. 生物多样性，2015，23(5)：583-590. http://www. biodiversity-science. net/CN/article/downloadArticleFile. do?attachType=PDF\&id=10075

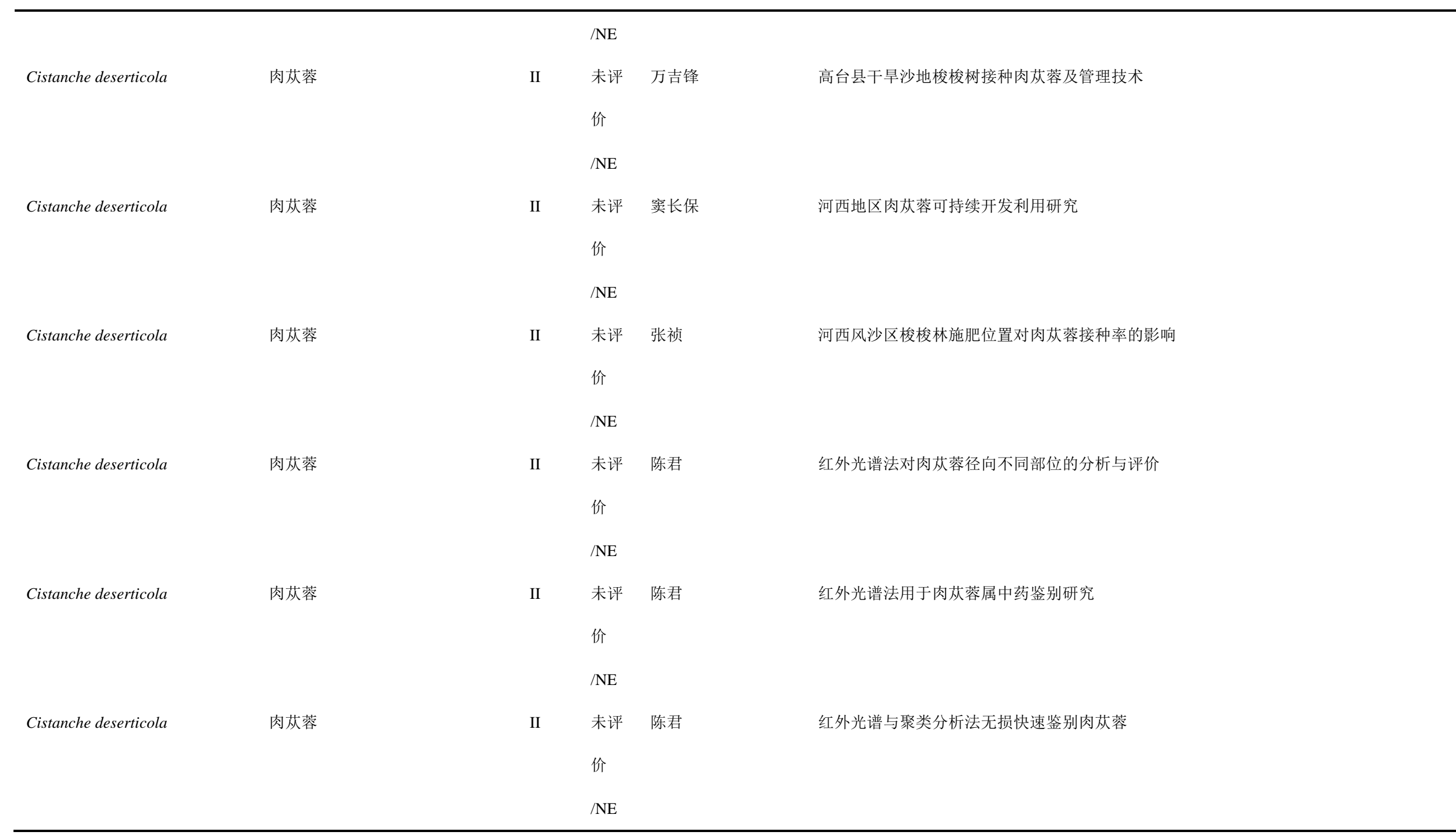


顾垒，闻丞，罗玫，王吴，吕植. 中国最受关注濒危物种保护现状快速评价的新方法探讨. 生物多样性，2015，23(5)：583-590. http://www. biodiversity-science. net/CN/article/downloadArticleFile. do?attachType=PDF\&id=10075

\begin{tabular}{|c|c|c|c|c|c|}
\hline Cistanche deserticola & 肉荻蓉 & II & $\begin{array}{l}\text { 未评 } \\
\text { 价 } \\
\text { /NE }\end{array}$ & 陈君 & 荒漠肉苁蓉茎腐病的初步研究 \\
\hline Cistanche deserticola & 肉苁蓉 & II & $\begin{array}{l}\text { 未评 } \\
\text { 价 } \\
\text { /NE }\end{array}$ & 盛晋华 & 荒漠肉苁蓉生活史研究 \\
\hline Cistanche deserticola & 肉苁蓉 & II & $\begin{array}{l}\text { 未评 } \\
\text { 价 } \\
\text { /NE }\end{array}$ & 马琴 & 基于 ISSR 分子标记的肉从蓉遗传多样性分析 \\
\hline Cistanche deserticola & 肉苁蓉 & II & $\begin{array}{l}\text { 未评 } \\
\text { 价 } \\
\text { /NE }\end{array}$ & 陈士林 & 基于化学成分及分子特征中药材肉苁蓉生态型研究 \\
\hline Cistanche deserticola & 肉苁蓉 & II & $\begin{array}{l}\text { 未评 } \\
\text { 价 } \\
\text { /NE }\end{array}$ & 李春 & 基于无外源激素下肉苁蓉细胞悬浮培养的研究 \\
\hline Cistanche deserticola & 肉苁蓉 & II & $\begin{array}{l}\text { 未评 } \\
\text { 价 } \\
\text { /NE }\end{array}$ & 王泽 & 基于遗传神经网络的中药肉苁蓉模式识别研究 \\
\hline Cistanche deserticola & 肉苁蓉 & II & 未评 & 李雅丽 & 寄生药用植物肉苁蓉与锁阳的比较研究 \\
\hline
\end{tabular}


顾垒，闻丞，罗玫，王吴，吕植. 中国最受关注濒危物种保护现状快速评价的新方法探讨. 生物多样性，2015，23(5)：583-590. http://www. biodiversity-science. net/CN/article/downloadArticleFile. do?attachType=PDF\&id=10075

\begin{tabular}{|c|c|c|c|c|c|}
\hline \multirow[b]{2}{*}{ Cistanche deserticola } & \multirow[b]{2}{*}{ 肉苁蓉 } & \multirow[b]{2}{*}{ II } & \multicolumn{2}{|l|}{$\begin{array}{l}\text { 价 } \\
\text { /NE }\end{array}$} & \multirow[b]{2}{*}{ 寄生植物肉苁蓉对寄主梭梭生长及生物量的影响研究 } \\
\hline & & & $\begin{array}{l}/ \mathrm{NE} \\
\text { 未评 } \\
\text { 价 }\end{array}$ & 谭德远 & \\
\hline Cistanche deserticola & 肉苁蓉 & II & $\begin{array}{l}\text { /NE } \\
\text { 未评 } \\
\text { 价 }\end{array}$ & 刘江华 & 加速人工种植肉苁蓉技术研究 \\
\hline Cistanche deserticola & 肉苁蓉 & II & $\begin{array}{l}/ \mathrm{NE} \\
\text { 未评 } \\
\text { 价 }\end{array}$ & 魏涛 & 酵母诱导子对肉苁蓉细胞悬浮培养影响的研究 \\
\hline Cistanche deserticola & 肉苁蓉 & II & $\begin{array}{l}/ \mathrm{NE} \\
\text { 未评 } \\
\text { 价 }\end{array}$ & 郭泉水 & 接种肉苁蓉对梭梭天然林的影响研究 \\
\hline Cistanche deserticola & 肉苁蓉 & II & $\begin{array}{l}\text { /NE } \\
\text { 未评 } \\
\text { 价 }\end{array}$ & 罗廷森 & 克拉玛依肉苁蓉生长特征的调查 \\
\hline Cistanche deserticola & 肉苁蓉 & II & $\begin{array}{l}/ \mathrm{NE} \\
\text { 未评 } \\
\text { 价 }\end{array}$ & 陈君 & 空间诱变对肉苁蓉种子生活力和寄生情况的影响 \\
\hline
\end{tabular}


顾垒，闻丞，罗玫，王吴，吕植. 中国最受关注濒危物种保护现状快速评价的新方法探讨. 生物多样性，2015，23(5)：583-590. http://www. biodiversity-science. net/CN/article/downloadArticleFile. do?attachType=PDF\&id=10075

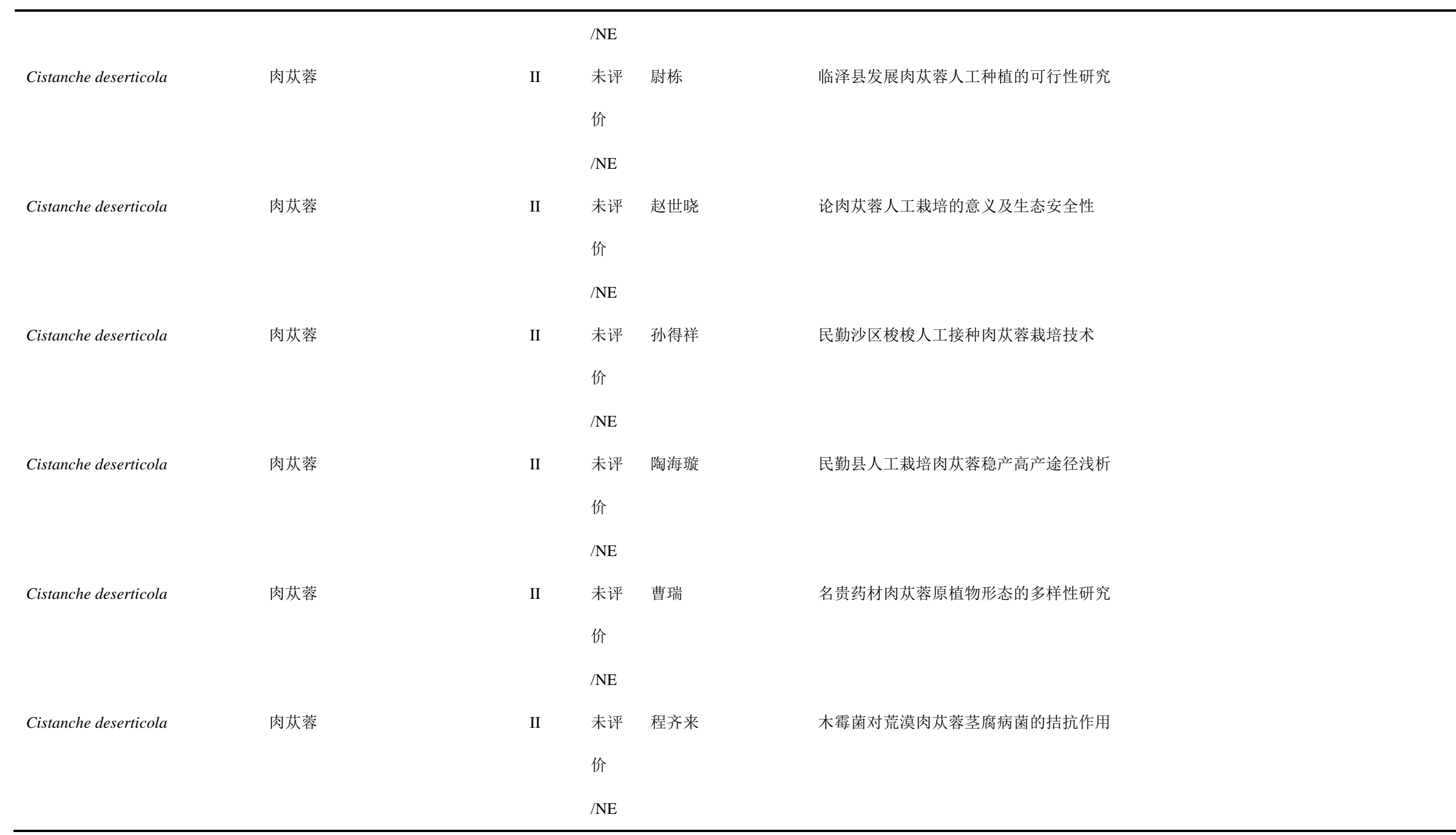


顾垒，闻丞，罗玫，王吴，吕植. 中国最受关注濒危物种保护现状快速评价的新方法探讨. 生物多样性，2015，23(5)：583-590. http://www. biodiversity-science. net/CN/article/downloadArticleFile. do?attachType=PDF\&id=10075

\begin{tabular}{|c|c|c|c|c|c|}
\hline Cistanche deserticola & 肉苁蓉 & II & $\begin{array}{l}\text { 未评 } \\
\text { 价 } \\
\text { /NE }\end{array}$ & 董占元 & 内蒙古肉苁蓉 (Cistanche deserticola Ma emend Ma) 花器官的细胞组织学观察研究 (一) \\
\hline Cistanche deserticola & 肉苁蓉 & II & $\begin{array}{l}\text { 未评 } \\
\text { 价 } \\
\text { /NE }\end{array}$ & 吴晓丽 & 内蒙古肉苁蓉接种及栽培技术 \\
\hline Cistanche deserticola & 肉苁蓉 & II & $\begin{array}{l}\text { 未评 } \\
\text { 价 } \\
\text { /NE }\end{array}$ & 包金英 & 内蒙古肉苁蓉开发研究现状及其对策 \\
\hline Cistanche deserticola & 肉苁蓉 & II & $\begin{array}{l}\text { 未评 } \\
\text { 价 } \\
\text { /NE }\end{array}$ & 热娜・卡斯木 & 尿囊素在肉苁蓉属植物分类中的应用 \\
\hline Cistanche deserticola & 肉苁蓉 & II & $\begin{array}{l}\text { 未评 } \\
\text { 价 } \\
\text { /NE }\end{array}$ & 徐荣 & 宁夏地区肉苁蓉人工栽培居群生殖分配规律的初步研究 \\
\hline Cistanche deserticola & 肉苁蓉 & II & $\begin{array}{l}\text { 未评 } \\
\text { 价 } \\
\text { /NE }\end{array}$ & 贾景明 & 前体饲喂和真菌诱导子对肉苁蓉悬浮培养细胞次生代谢产物的影响 \\
\hline Cistanche deserticola & 肉苁蓉 & II & 未评 & 钟俐 & 前体物及诱导剂对肉荻蓉松果菊苷含量的影响 \\
\hline
\end{tabular}


顾垒，闻丞，罗玫，王吴，吕植. 中国最受关注濒危物种保护现状快速评价的新方法探讨. 生物多样性，2015，23(5)：583-590. http://www. biodiversity-science. net/CN/article/downloadArticleFile. do?attachType=PDF\&id=10075

\begin{tabular}{|c|c|c|c|c|c|}
\hline \multirow[b]{2}{*}{ Cistanche deserticola } & \multirow[b]{2}{*}{ 肉荻蓉 } & \multirow[b]{2}{*}{ II } & \multicolumn{3}{|l|}{ 价 } \\
\hline & & & $\begin{array}{l}\text { /NE } \\
\text { 未评 } \\
\text { 价 }\end{array}$ & 赵文蹈 & 浅谈人工栽培肉苁蓉和产业化发展的可行性 \\
\hline Cistanche deserticola & 肉苁蓉 & II & $\begin{array}{l}\text { /NE } \\
\text { 未评 } \\
\text { 价 }\end{array}$ & 赵海军 & 浅析人工栽培肉苁蓉产业化发展在乌拉特后旗的可行性 \\
\hline Cistanche deserticola & 肉苁蓉 & II & $\begin{array}{l}/ \mathrm{NE} \\
\text { 未评 } \\
\text { 价 }\end{array}$ & 温源 & 人工梭梭林接种肉苁蓉相关性研究 \\
\hline Cistanche deserticola & 肉获蓉 & II & $\begin{array}{l}\text { /NE } \\
\text { 未评 } \\
\text { 价 }\end{array}$ & 曹瑞 & 肉苁蓉(Cistanche deserticola)种内的变异式样 \\
\hline Cistanche deserticola & 肉荻蓉 & II & $\begin{array}{l}\text { /NE } \\
\text { 未评 } \\
\text { 价 }\end{array}$ & 刘洋 & 肉荻蓉、草获蓉活性成分和指纹图谱研究 \\
\hline Cistanche deserticola & 肉荻蓉 & II & $\begin{array}{l}/ \mathrm{NE} \\
\text { 未评 } \\
\text { 价 }\end{array}$ & 郭玉海 & 肉苁蓉不同生育阶段矿质元素含量 \\
\hline
\end{tabular}


顾垒，闻丞，罗玫，王吴，吕植. 中国最受关注濒危物种保护现状快速评价的新方法探讨．生物多样性，2015，23(5)：583-590。 http://www. biodiversity-science. net/CN/article/downloadArticleFile. do?attachType=PDF\&id=10075

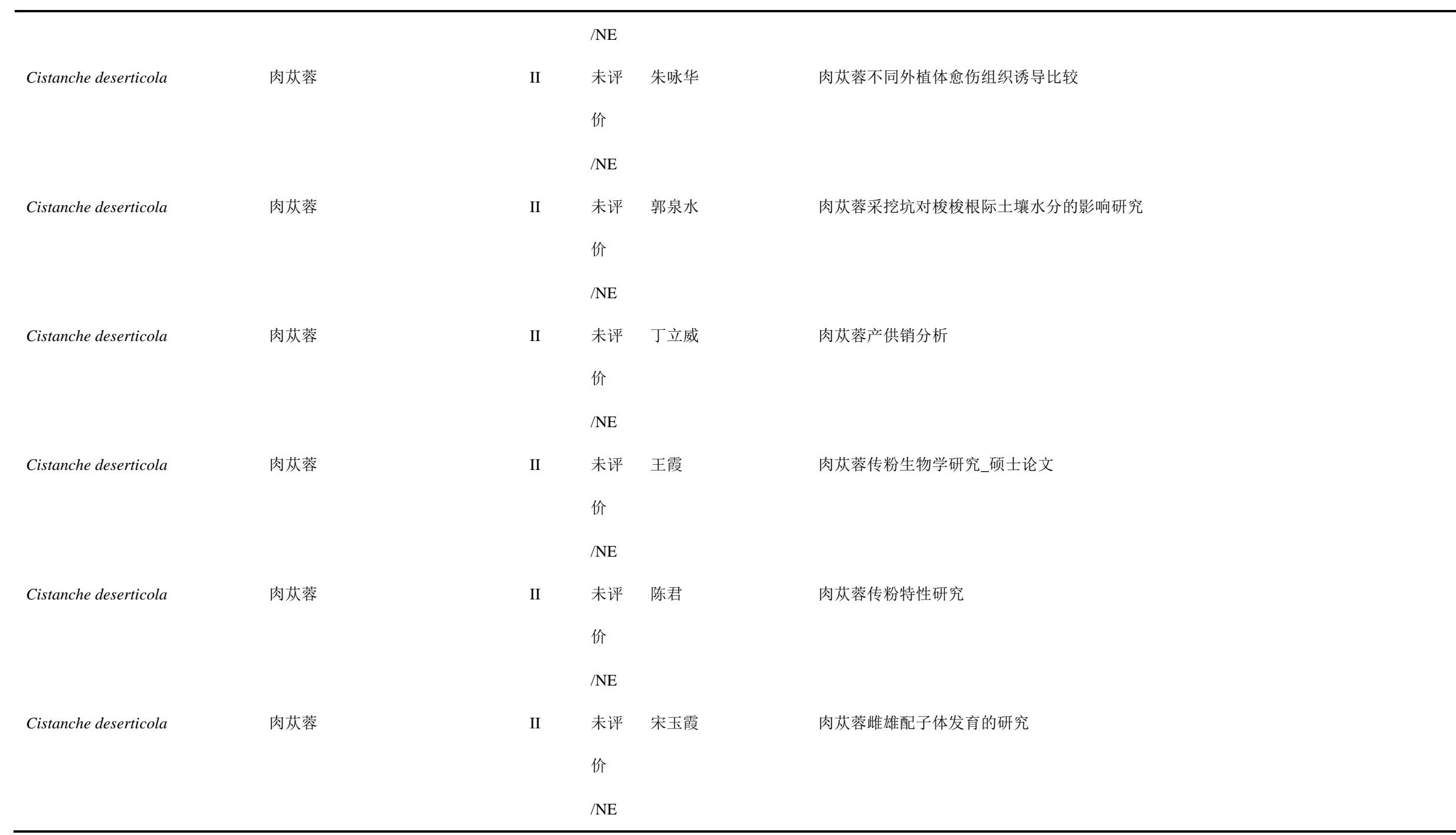


顾垒，闻丞，罗玫，王吴，吕植. 中国最受关注濒危物种保护现状快速评价的新方法探讨. 生物多样性，2015，23(5)：583-590. http://www. biodiversity-science. net/CN/article/downloadArticleFile. do?attachType=PDF\&id=10075

\begin{tabular}{|c|c|c|c|c|c|}
\hline Cistanche deserticola & 肉荻蓉 & II & $\begin{array}{l}\text { 未评 } \\
\text { 价 } \\
\text { /NE }\end{array}$ & 夏鹏霄 & 肉苁蓉的 HPLC 指纹图谱研究 \\
\hline Cistanche deserticola & 肉苁蓉 & II & $\begin{array}{l}\text { 未评 } \\
\text { 价 } \\
\text { /NE }\end{array}$ & 周峰 & 肉苁蓉的内生真菌分离鉴定及其种子萌发条件的初步研究 \\
\hline Cistanche deserticola & 肉苁蓉 & II & $\begin{array}{l}\text { 未评 } \\
\text { 价 } \\
\text { /NE }\end{array}$ & 郭建军 & 肉苁蓉的培育与接种技术 \\
\hline Cistanche deserticola & 肉苁蓉 & II & $\begin{array}{l}\text { 未评 } \\
\text { 价 } \\
\text { /NE }\end{array}$ & 杨海红 & 肉苁蓉的特性及人工种植技术 \\
\hline Cistanche deserticola & 肉苁蓉 & II & $\begin{array}{l}\text { 未评 } \\
\text { 价 } \\
\text { /NE }\end{array}$ & 张铁军 & 肉苁蓉的研究进展 \\
\hline Cistanche deserticola & 肉苁蓉 & II & $\begin{array}{l}\text { 未评 } \\
\text { 价 } \\
\text { /NE }\end{array}$ & 朱咏华 & 肉苁蓉的研究进展及前景分析 \\
\hline Cistanche deserticola & 肉苁蓉 & II & 未评 & 宋加录 & 肉苁蓉的栽培与采收 \\
\hline
\end{tabular}


顾垒，闻丞，罗玫，王吴，吕植. 中国最受关注濒危物种保护现状快速评价的新方法探讨. 生物多样性，2015，23(5)：583-590. http://www. biodiversity-science. net/CN/article/downloadArticleFile. do?attachType=PDF\&id=10075

\begin{tabular}{|c|c|c|c|c|c|}
\hline & & & 价 & & \\
\hline Cistanche deserticola & 肉苁蓉 & II & $\begin{array}{l}/ \mathrm{NE} \\
\text { 未评 } \\
\text { 价 }\end{array}$ & 訤文颖 & 肉苁蓉繁殖器官结构初探 \\
\hline Cistanche deserticola & 肉苁蓉 & II & $\begin{array}{l}\text { /NE } \\
\text { 未评 } \\
\text { 价 }\end{array}$ & 陈君 & 肉苁蓉访花昆虫种类研究 \\
\hline Cistanche deserticola & 肉苁蓉 & II & $\begin{array}{l}/ \mathrm{NE} \\
\text { 未评 } \\
\text { 价 }\end{array}$ & 宋玉霞 & 肉苁蓉和寄主梭梭体内可溶性糖分积累与蔗糖代谢相关酶活性研究 \\
\hline Cistanche deserticola & 肉苁蓉 & II & $\begin{array}{l}/ \mathrm{NE} \\
\text { 未评 } \\
\text { 价 }\end{array}$ & 陈君 & 肉苁蓉花粉活力与柱头可授性研究 \\
\hline Cistanche deserticola & 肉苁蓉 & II & $\begin{array}{l}\text { /NE } \\
\text { 未评 } \\
\text { 价 }\end{array}$ & 宋玉霞 & 肉苁蓉花粉生活力测定研究 \\
\hline Cistanche deserticola & 肉苁蓉 & II & $\begin{array}{l}/ \mathrm{NE} \\
\text { 未评 } \\
\text { 价 }\end{array}$ & 徐荣 & 肉苁蓉花粉原位萌发与自交不亲和性初步研究 \\
\hline
\end{tabular}


顾垒，闻丞，罗玫，王吴，吕植. 中国最受关注濒危物种保护现状快速评价的新方法探讨. 生物多样性，2015，23(5)：583-590. http://www. biodiversity-science. net/CN/article/downloadArticleFile. do?attachType=PDF\&id=10075

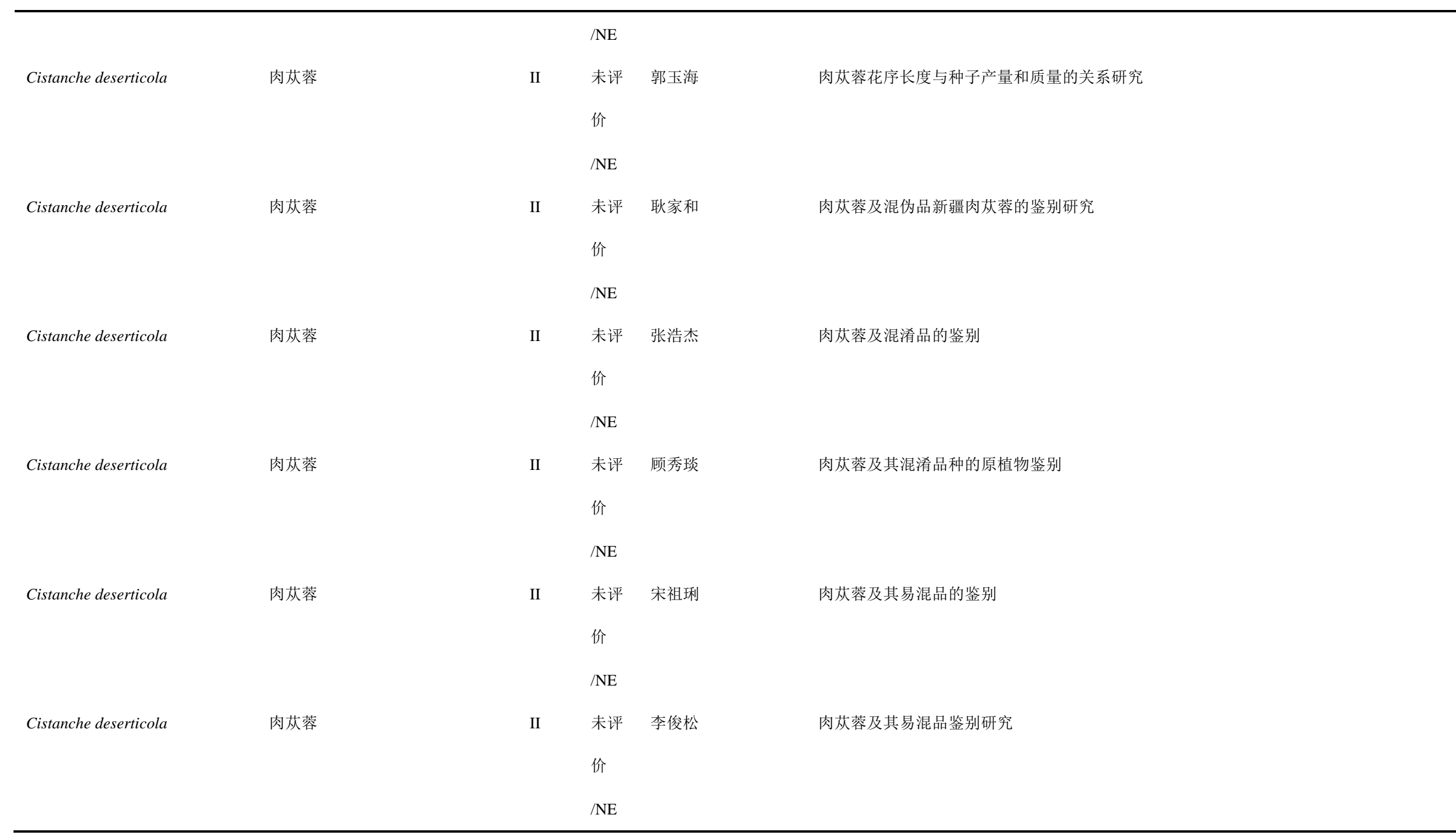


顾垒，闻丞，罗玫，王吴，吕植. 中国最受关注濒危物种保护现状快速评价的新方法探讨. 生物多样性，2015，23(5)：583-590. http://www. biodiversity-science. net/CN/article/downloadArticleFile. do?attachType=PDF\&id=10075

\begin{tabular}{|c|c|c|c|c|c|}
\hline Cistanche deserticola & 肉荻蓉 & II & $\begin{array}{l}\text { 未评 } \\
\text { 价 } \\
\text { /NE }\end{array}$ & 宋玉霞 & 肉苁蓉寄生对寄主梭梭体内主要矿质元素含量的影响 \\
\hline Cistanche deserticola & 肉苁蓉 & II & $\begin{array}{l}\text { 未评 } \\
\text { 价 } \\
\text { /NE }\end{array}$ & 郭玉海 & 肉苁蓉寄生对梭梭 $N 、 P 、 K$ 积累和分配的影响 \\
\hline Cistanche deserticola & 肉苁蓉 & II & $\begin{array}{l}\text { 未评 } \\
\text { 价 } \\
\text { /NE }\end{array}$ & 郭玉海 & 肉苁蓉寄生对梭梭生物量和碳水化合物含量的影响 \\
\hline Cistanche deserticola & 肉苁蓉 & II & $\begin{array}{l}\text { 未评 } \\
\text { 价 } \\
\text { /NE }\end{array}$ & 周玲玲 & 肉苁蓉寄生对梭梭生长的影响研究 \\
\hline Cistanche deserticola & 肉苁蓉 & II & $\begin{array}{l}\text { 未评 } \\
\text { 价 } \\
\text { /NE }\end{array}$ & 马永清 & 肉苁蓉寄生对梭梭幼苗保护酶活性及渗透调节物质的影响 \\
\hline Cistanche deserticola & 肉苁蓉 & II & $\begin{array}{l}\text { 未评 } \\
\text { 价 } \\
\text { /NE }\end{array}$ & 马永清 & 肉苁蓉寄生对梭梭幼苗水分生理特征及生长的影响 \\
\hline Cistanche deserticola & 肉苁蓉 & II & 未评 & 郭玉海 & 肉苁蓉寄生生物学的研究 \\
\hline
\end{tabular}


顾垒，闻丞，罗玫，王吴，吕植. 中国最受关注濒危物种保护现状快速评价的新方法探讨．生物多样性，2015，23(5)：583-590。 http://www. biodiversity-science. net/CN/article/downloadArticleFile. do?attachType=PDF\&id=10075

\begin{tabular}{|c|c|c|c|c|c|}
\hline \multirow[b]{2}{*}{ Cistanche deserticola } & \multirow[b]{2}{*}{ 肉苁蓉 } & \multirow[b]{2}{*}{ II } & \multicolumn{3}{|l|}{ 价 } \\
\hline & & & $\begin{array}{l}\text { /NE } \\
\text { 未评 } \\
\text { 价 }\end{array}$ & 马永清 & 肉苁蓉寄生生长形态发育 \\
\hline Cistanche deserticola & 肉苁蓉 & II & $\begin{array}{l}\text { /NE } \\
\text { 未评 } \\
\text { 价 }\end{array}$ & 乔海峰 & 肉苁蓉寄生生长与产量品质形成研究 \\
\hline Cistanche deserticola & 肉获蓉 & II & $\begin{array}{l}/ \mathrm{NE} \\
\text { 未评 } \\
\text { 价 }\end{array}$ & 高山 & 肉苁蓉接种技术 \\
\hline Cistanche deserticola & 肉荻蓉 & II & $\begin{array}{l}\text { /NE } \\
\text { 未评 } \\
\text { 价 }\end{array}$ & 郭玉海 & 肉苁蓉开花习性观察 \\
\hline Cistanche deserticola & 肉苁蓉 & II & $\begin{array}{l}\text { /NE } \\
\text { 未评 } \\
\text { 价 }\end{array}$ & 陈君 & 肉苁蓉内生真菌多样性研究 \\
\hline Cistanche deserticola & 肉苁蓉 & II & $\begin{array}{l}/ \mathrm{NE} \\
\text { 未评 } \\
\text { 价 }\end{array}$ & 郭玉海 & 肉苁蓉全生育期物质成分动态变化研究 \\
\hline
\end{tabular}


顾垒，闻丞，罗玫，王吴，吕植. 中国最受关注濒危物种保护现状快速评价的新方法探讨．生物多样性，2015，23(5)：583-590。 http://www. biodiversity-science. net/CN/article/downloadArticleFile. do?attachType=PDF\&id=10075

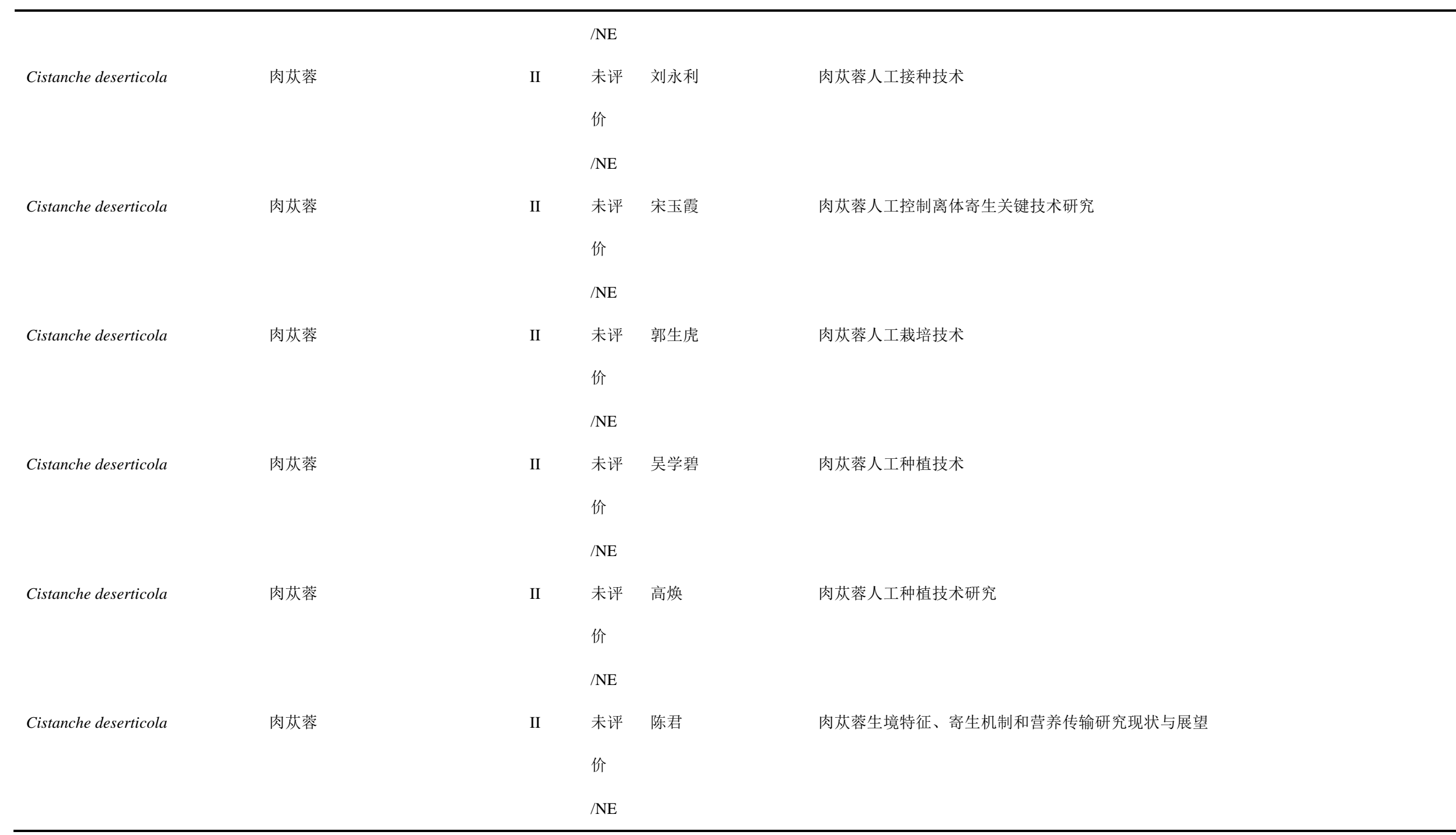


顾垒，闻丞，罗玫，王吴，吕植. 中国最受关注濒危物种保护现状快速评价的新方法探讨. 生物多样性，2015，23(5)：583-590. http://www. biodiversity-science. net/CN/article/downloadArticleFile. do?attachType=PDF\&id=10075

\begin{tabular}{|c|c|c|c|c|c|}
\hline Cistanche deserticola & 肉荻蓉 & II & $\begin{array}{l}\text { 未评 } \\
\text { 价 } \\
\text { /NE }\end{array}$ & 陈君 & 肉苁蓉生殖生物学初步研究 I一一出土与开花 \\
\hline Cistanche deserticola & 肉苁蓉 & II & $\begin{array}{l}\text { 未评 } \\
\text { 价 } \\
\text { /NE }\end{array}$ & 陈君 & 肉苁蓉属及其寄主植物病虫害种类调查及防治研究 \\
\hline Cistanche deserticola & 肉苁蓉 & II & $\begin{array}{l}\text { 未评 } \\
\text { 价 } \\
\text { /NE }\end{array}$ & 石婷婷 & 肉苁蓉属植物的研究进展 \\
\hline Cistanche deserticola & 肉苁蓉 & II & $\begin{array}{l}\text { 未评 } \\
\text { 价 } \\
\text { /NE }\end{array}$ & 郭玉海 & 肉苁蓉蒴果与种子发育研究 \\
\hline Cistanche deserticola & 肉苁蓉 & II & $\begin{array}{l}\text { 未评 } \\
\text { 价 } \\
\text { /NE }\end{array}$ & 李春 & 肉苁蓉细胞继代培养过程中的褐变控制 \\
\hline Cistanche deserticola & 肉苁蓉 & II & $\begin{array}{l}\text { 未评 } \\
\text { 价 } \\
\text { /NE }\end{array}$ & 李春 & 肉苁蓉细胞悬浮培养的代谢动力学研究 \\
\hline Cistanche deserticola & 肉苁蓉 & II & 未评 & 欧阳杰 & 肉苁蓉细胞悬浮培养动力学研究 \\
\hline
\end{tabular}


顾垒，闻丞，罗玫，王吴，吕植. 中国最受关注濒危物种保护现状快速评价的新方法探讨．生物多样性，2015，23(5)：583-590。 http://www. biodiversity-science. net/CN/article/downloadArticleFile. do?attachType=PDF\&id=10075

\begin{tabular}{|c|c|c|c|c|c|}
\hline \multirow[b]{2}{*}{ Cistanche deserticola } & \multirow[b]{2}{*}{ 肉苁蓉 } & \multirow[b]{2}{*}{ II } & \multicolumn{2}{|l|}{$\begin{array}{l}\text { 价 } \\
\text { /NE }\end{array}$} & \multirow[b]{2}{*}{ 肉苁蓉细胞悬浮培养体系的建立 } \\
\hline & & & $\begin{array}{l}/ \mathrm{NE} \\
\text { 未评 } \\
\text { 价 }\end{array}$ & 欧阳杰 & \\
\hline Cistanche deserticola & 肉苁蓉 & II & $\begin{array}{l}\text { /NE } \\
\text { 未评 } \\
\text { 价 }\end{array}$ & 屠鹏飞 & 肉苁蓉研究及其产业发展 \\
\hline Cistanche deserticola & 肉苁蓉 & II & $\begin{array}{l}/ \mathrm{NE} \\
\text { 未评 } \\
\text { 价 }\end{array}$ & 杨翠平 & 肉苁蓉研究进展 \\
\hline Cistanche deserticola & 肉苁蓉 & II & $\begin{array}{l}\text { /NE } \\
\text { 未评 } \\
\text { 价 }\end{array}$ & 罗廷涁 & 肉苁蓉研究进展 \\
\hline Cistanche deserticola & 肉苁蓉 & II & $\begin{array}{l}\text { /NE } \\
\text { 未评 } \\
\text { 价 }\end{array}$ & 刘春朝 & 肉苁蓉研究进展 \\
\hline Cistanche deserticola & 肉苁蓉 & II & $\begin{array}{l}/ \mathrm{NE} \\
\text { 未评 } \\
\text { 价 }\end{array}$ & 马虹 & 肉苁蓉营养器官的比较解剖学研究 \\
\hline
\end{tabular}


顾垒，闻丞，罗玫，王吴，吕植. 中国最受关注濒危物种保护现状快速评价的新方法探讨. 生物多样性，2015，23(5)：583-590. http://www. biodiversity-science. net/CN/article/downloadArticleFile. do?attachType=PDF\&id=10075

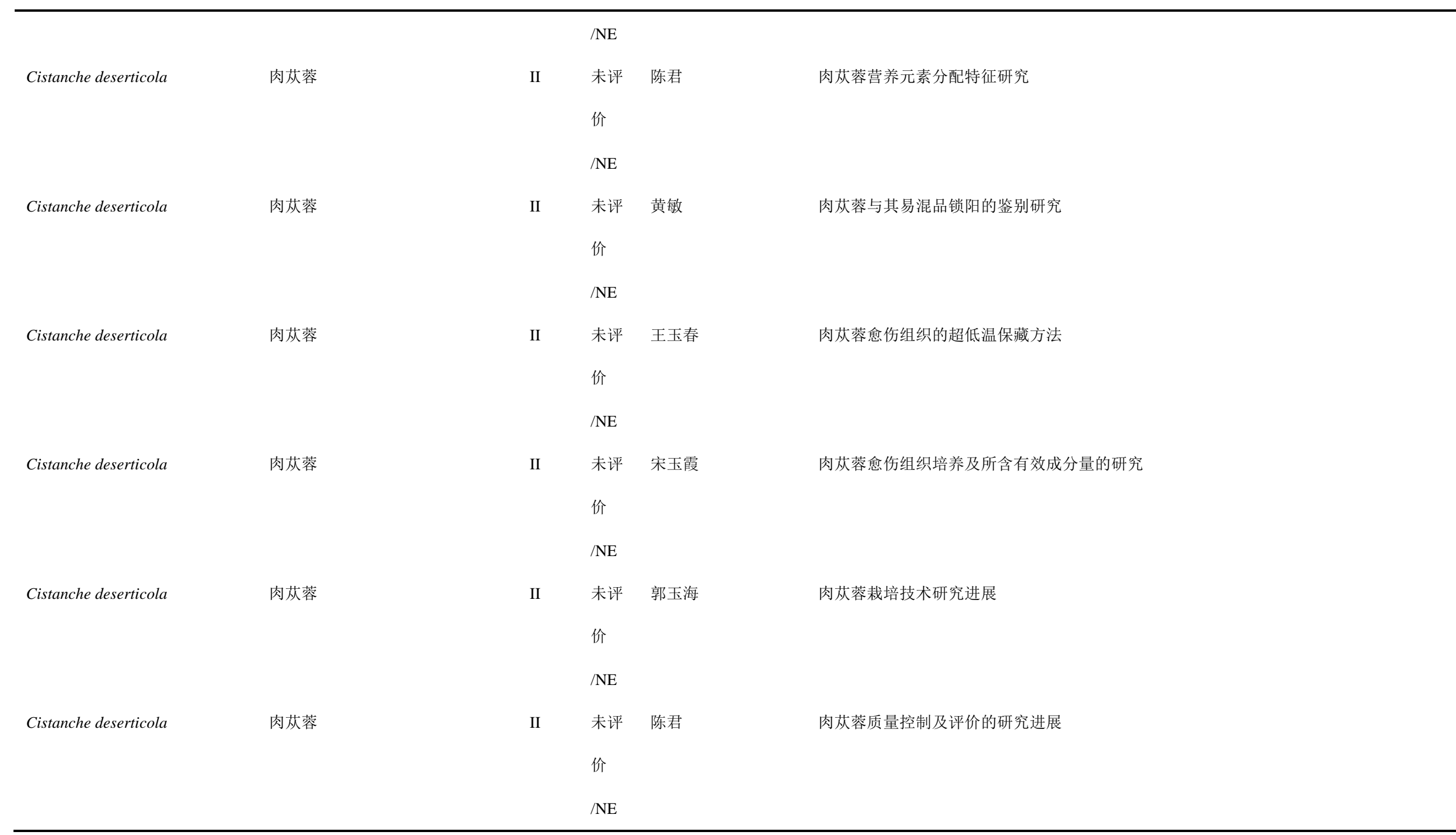


顾垒，闻丞，罗玫，王吴，吕植. 中国最受关注濒危物种保护现状快速评价的新方法探讨. 生物多样性，2015，23(5)：583-590. http://www. biodiversity-science. net/CN/article/downloadArticleFile. do?attachType=PDF\&id=10075

\begin{tabular}{|c|c|c|c|c|c|}
\hline Cistanche deserticola & 肉荻蓉 & II & $\begin{array}{l}\text { 未评 } \\
\text { 价 } \\
\text { /NE }\end{array}$ & 宋玉霞 & 肉苁蓉种内变异的 AFLP 标记研究 \\
\hline Cistanche deserticola & 肉苁蓉 & II & $\begin{array}{l}\text { 未评 } \\
\text { 价 } \\
\text { /NE }\end{array}$ & 陈君 & 肉苁蓉种质主要性状的变异和相关分析 \\
\hline Cistanche deserticola & 肉苁蓉 & II & $\begin{array}{l}\text { 未评 } \\
\text { 价 } \\
\text { /NE }\end{array}$ & 陈君 & 肉苁蓉种质资源多样性的 AFLP 分析 \\
\hline Cistanche deserticola & 肉苁蓉 & II & $\begin{array}{l}\text { 未评 } \\
\text { 价 } \\
\text { /NE }\end{array}$ & 陈君 & 肉苁蓉种子产量构成因子分析 \\
\hline Cistanche deserticola & 肉苁蓉 & II & $\begin{array}{l}\text { 未评 } \\
\text { 价 } \\
\text { /NE }\end{array}$ & 陈君 & 肉苁蓉种子成分及活力的红外光谱分析 \\
\hline Cistanche deserticola & 肉苁蓉 & II & $\begin{array}{l}\text { 未评 } \\
\text { 价 } \\
\text { /NE }\end{array}$ & 陈君 & 肉苁蓉种子带菌检测研究 \\
\hline Cistanche deserticola & 肉苁蓉 & II & 未评 & 郭玉海 & 肉苁蓉种子的活力研究 \\
\hline
\end{tabular}


顾垒，闻丞，罗玫，王吴，吕植. 中国最受关注濒危物种保护现状快速评价的新方法探讨. 生物多样性，2015，23(5)：583-590. http://www. biodiversity-science. net/CN/article/downloadArticleFile. do?attachType=PDF\&id=10075

\begin{tabular}{|c|c|c|c|c|c|}
\hline \multirow[b]{2}{*}{ Cistanche deserticola } & \multirow[b]{2}{*}{ 肉苁蓉 } & \multirow[b]{2}{*}{ II } & \multicolumn{2}{|l|}{$\begin{array}{l}\text { 价 } \\
\text { /NE }\end{array}$} & \multirow[b]{2}{*}{ 肉苁蓉种子发芽条件研究 } \\
\hline & & & $\begin{array}{l}/ \mathrm{NE} \\
\text { 未评 } \\
\text { 价 }\end{array}$ & 郭玉海 & \\
\hline Cistanche deserticola & 肉苁蓉 & II & $\begin{array}{l}\text { /NE } \\
\text { 未评 } \\
\text { 价 }\end{array}$ & 盛晋华 & 肉苁蓉种子后熟阶段内源激素含量变化 \\
\hline Cistanche deserticola & 肉苁蓉 & II & $\begin{array}{l}/ \mathrm{NE} \\
\text { 未评 } \\
\text { 价 }\end{array}$ & 白静 & 肉苁蓉种子萌发和牙管形成的物理信号调控 \\
\hline Cistanche deserticola & 肉苁蓉 & II & $\begin{array}{l}/ \mathrm{NE} \\
\text { 未评 } \\
\text { 价 }\end{array}$ & 高岩 & 肉苁蓉种子萌发与吸器形成的化学物质诱导 \\
\hline Cistanche deserticola & 肉苁蓉 & II & $\begin{array}{l}\text { /NE } \\
\text { 未评 } \\
\text { 价 }\end{array}$ & 陈君 & 肉苁蓉种子生活力快速测定方法研究 \\
\hline Cistanche deserticola & 肉苁蓉 & II & $\begin{array}{l}/ \mathrm{NE} \\
\text { 未评 } \\
\text { 价 }\end{array}$ & 宋玉霞 & 肉荻蓉种子休眠与萌发特性的初步研究 \\
\hline
\end{tabular}


顾垒，闻丞，罗玫，王吴，吕植. 中国最受关注濒危物种保护现状快速评价的新方法探讨. 生物多样性，2015，23(5)：583-590. http://www. biodiversity-science. net/CN/article/downloadArticleFile. do?attachType=PDF\&id=10075

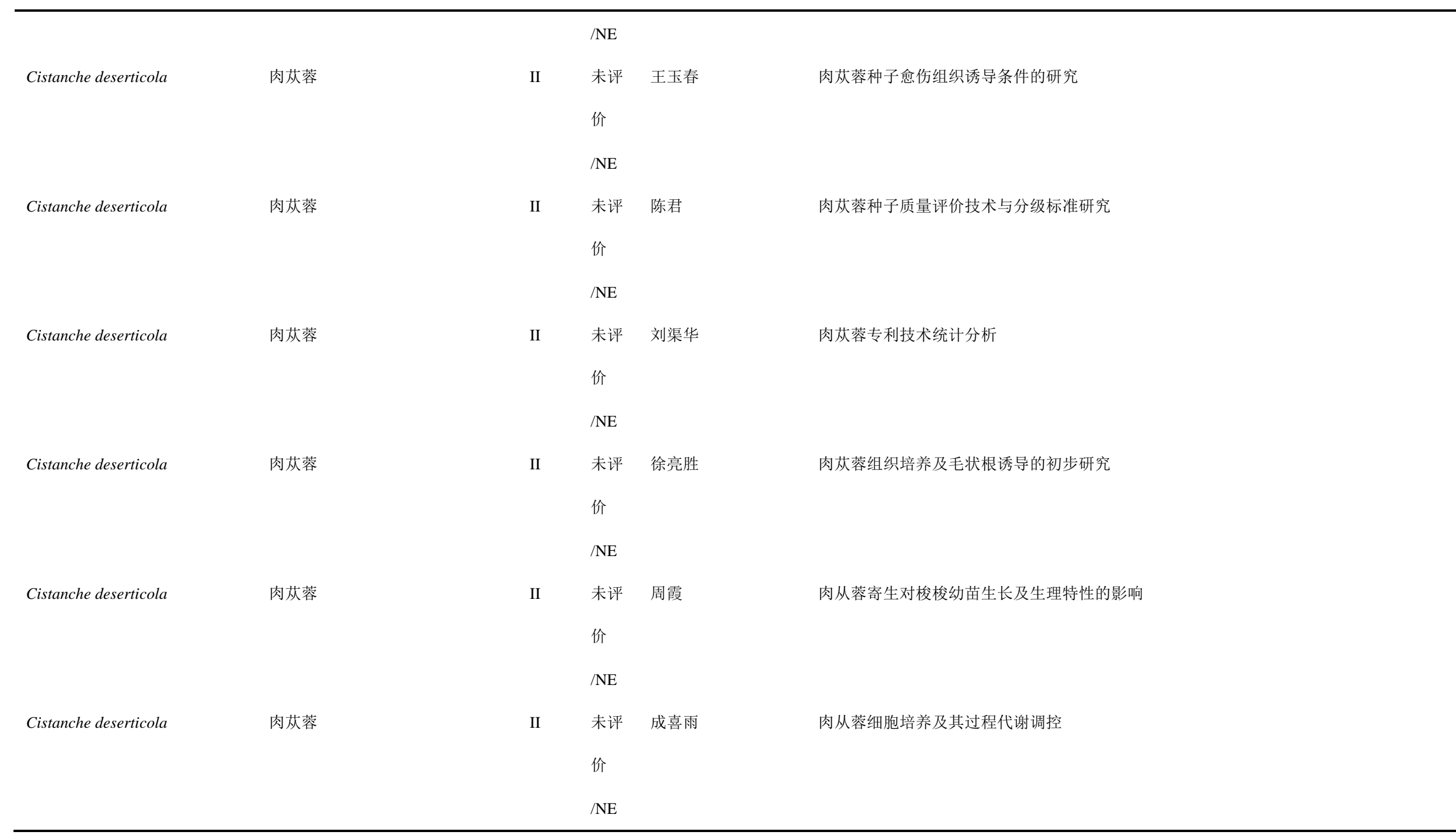


顾垒，闻丞，罗玫，王吴，吕植. 中国最受关注濒危物种保护现状快速评价的新方法探讨. 生物多样性，2015，23(5)：583-590. http://www. biodiversity-science. net/CN/article/downloadArticleFile. do?attachType=PDF\&id=10075

\begin{tabular}{|c|c|c|c|c|c|}
\hline Cistanche deserticola & 肉荻蓉 & II & $\begin{array}{l}\text { 未评 } \\
\text { 价 } \\
\text { /NE }\end{array}$ & 吕建军 & 肉从蓉细胞培养与次生代谢物形成的研究 \\
\hline Cistanche deserticola & 肉苁蓉 & II & $\begin{array}{l}\text { 未评 } \\
\text { 价 } \\
\text { /NE }\end{array}$ & 陈宏伟 & 肉茱蓉种子萌发与吸器形成的化学信号调控 \\
\hline Cistanche deserticola & 肉苁蓉 & II & $\begin{array}{l}\text { 未评 } \\
\text { 价 } \\
\text { /NE }\end{array}$ & 王晶晶 & 沙地肉苁蓉人工水分补偿对寄主梭梭的生理影响 \\
\hline Cistanche deserticola & 肉苁蓉 & II & $\begin{array}{l}\text { 未评 } \\
\text { 价 } \\
\text { /NE }\end{array}$ & 袁彦 & 沙漠地区肉苁蓉产业发展探讨 \\
\hline Cistanche deserticola & 肉苁蓉 & II & $\begin{array}{l}\text { 未评 } \\
\text { 价 } \\
\text { /NE }\end{array}$ & 张凯 & 沙漠肉苁蓉基因组 DNA 的提取方法比较 \\
\hline Cistanche deserticola & 肉苁蓉 & II & $\begin{array}{l}\text { 未评 } \\
\text { 价 } \\
\text { /NE }\end{array}$ & 盛晋华 & 生长年限和采收季节对肉苁蓉中有效成分的影响 \\
\hline Cistanche deserticola & 肉苁蓉 & II & 未评 & 张丹 & 梭梭根系分泌物组成成分及诱导肉苁蓉种子形成吸器的研究 \\
\hline
\end{tabular}


顾垒，闻丞，罗玫，王吴，吕植. 中国最受关注濒危物种保护现状快速评价的新方法探讨. 生物多样性，2015，23(5)：583-590. http://www. biodiversity-science. net/CN/article/downloadArticleFile. do?attachType=PDF\&id=10075

\begin{tabular}{|c|c|c|c|c|c|}
\hline \multirow[b]{2}{*}{ Cistanche deserticola } & \multirow[b]{2}{*}{ 肉苁蓉 } & \multirow[b]{2}{*}{ II } & \multicolumn{2}{|l|}{$\begin{array}{l}\text { 价 } \\
\text { /NE }\end{array}$} & \multirow[b]{2}{*}{ 梭梭人工接种肉苁蓉技术试验研究 } \\
\hline & & & $\begin{array}{l}/ \mathrm{NE} \\
\text { 未评 } \\
\text { 价 }\end{array}$ & 孙慧琴 & \\
\hline Cistanche deserticola & 肉苁蓉 & II & $\begin{array}{l}\text { /NE } \\
\text { 未评 } \\
\text { 价 }\end{array}$ & 苏彦萍 & 梭梭人工造林及肉苁蓉人工栽培技术 \\
\hline Cistanche deserticola & 肉苁蓉 & II & $\begin{array}{l}/ \mathrm{NE} \\
\text { 未评 } \\
\text { 价 }\end{array}$ & 郭玉海 & 梭梭树龄与肉苁蓉种子产量关系的研究 \\
\hline Cistanche deserticola & 肉苁蓉 & II & $\begin{array}{l}\text { /NE } \\
\text { 未评 } \\
\text { 价 }\end{array}$ & 崔旭盛 & 梭梭物质生产和梭梭一肉苁蓉间物质分配调节研究 \\
\hline Cistanche deserticola & 肉苁蓉 & II & $\begin{array}{l}\text { /NE } \\
\text { 未评 } \\
\text { 价 }\end{array}$ & 李丙文 & 塔克拉玛干沙漠腹地滴灌种植肉苁蓉的试验研究 \\
\hline Cistanche deserticola & 肉苁蓉 & II & $\begin{array}{l}/ \mathrm{NE} \\
\text { 未评 } \\
\text { 价 }\end{array}$ & 张祯 & 腾格里沙漠东部梭梭树龄对肉苁蓉接种率的影响 \\
\hline
\end{tabular}


顾垒，闻丞，罗玫，王吴，吕植. 中国最受关注濒危物种保护现状快速评价的新方法探讨. 生物多样性，2015，23(5)：583-590. http://www. biodiversity-science. net/CN/article/downloadArticleFile. do?attachType=PDF\&id=10075

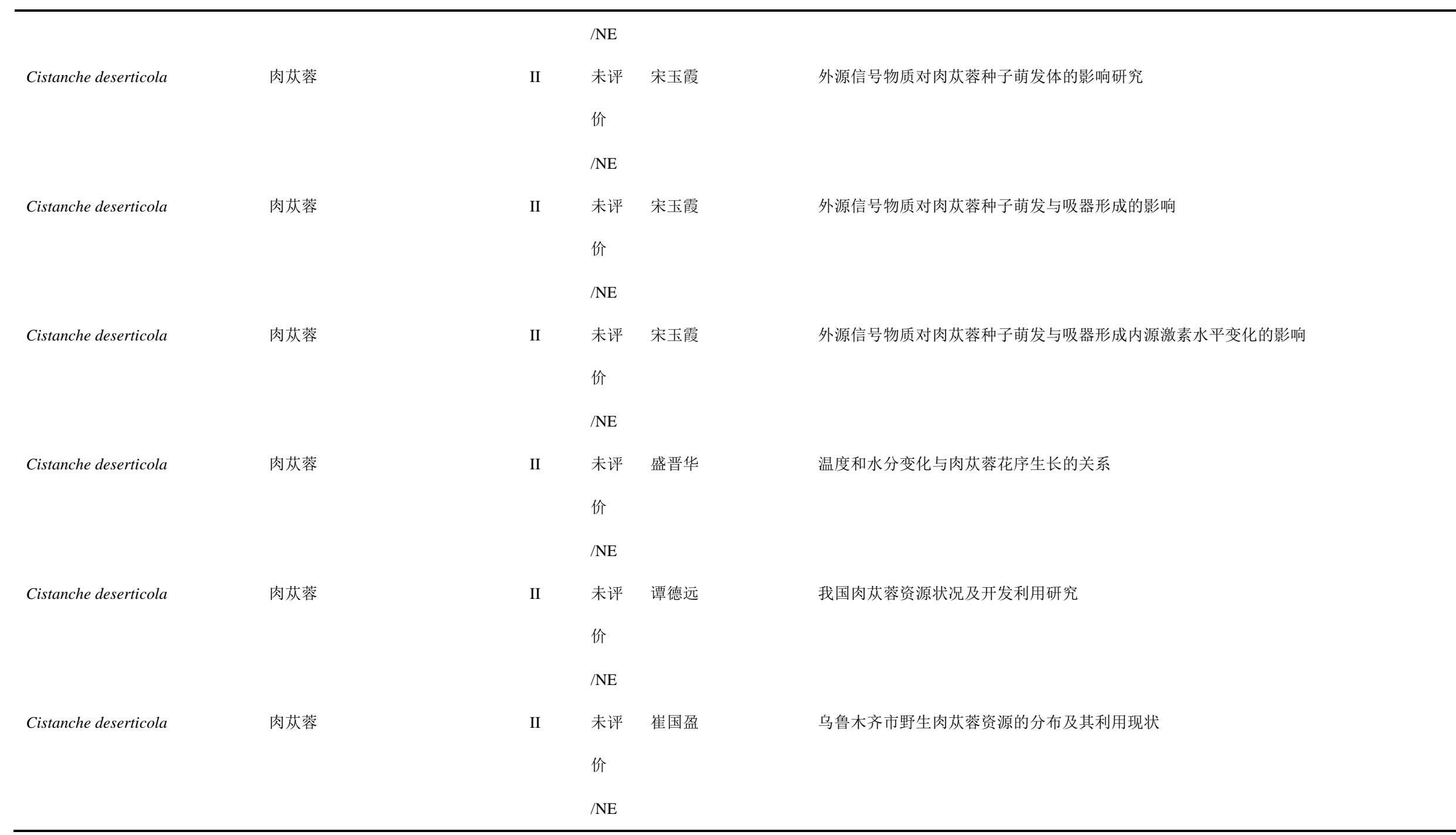


顾垒，闻丞，罗玫，王吴，吕植. 中国最受关注濒危物种保护现状快速评价的新方法探讨. 生物多样性，2015，23(5)：583-590. http://www. biodiversity-science. net/CN/article/downloadArticleFile. do?attachType=PDF\&id=10075

\begin{tabular}{|c|c|c|c|c|c|}
\hline Cistanche deserticola & 肉荻蓉 & II & $\begin{array}{l}\text { 未评 } \\
\text { 价 } \\
\text { /NE }\end{array}$ & 汪永洋 & 无人工灌溉梭梭接种肉苁蓉技术研究 \\
\hline Cistanche deserticola & 肉苁蓉 & II & $\begin{array}{l}\text { 未评 } \\
\text { 价 } \\
\text { /NE }\end{array}$ & 郝玉光 & 西部沙区肉苁蓉人工种植技术 \\
\hline Cistanche deserticola & 肉苁蓉 & II & $\begin{array}{l}\text { 未评 } \\
\text { 价 } \\
\text { /NE }\end{array}$ & 党荣理 & 新疆产中药肉苁蓉的 RAPD 分析 \\
\hline Cistanche deserticola & 肉苁蓉 & II & $\begin{array}{l}\text { 未评 } \\
\text { 价 } \\
\text { /NE }\end{array}$ & 贾晓光 & 新疆地产三种肉苁蓉的显微鉴别研究 \\
\hline Cistanche deserticola & 肉苁蓉 & II & $\begin{array}{l}\text { 未评 } \\
\text { 价 } \\
\text { /NE }\end{array}$ & 孙永强 & 新疆肉苁蓉资源及人工种植研究初探 \\
\hline Cistanche deserticola & 肉苁蓉 & II & $\begin{array}{l}\text { 未评 } \\
\text { 价 } \\
\text { /NE }\end{array}$ & 贾景明 & 一氧化氮、茉莉酸甲酯与水杨酸对肉苁蓉悬浮细胞生长及苯乙醇甘苷生物合成的影响 \\
\hline Cistanche deserticola & 肉苁蓉 & II & 未评 & 徐荣 & 应用红外光谱法鉴别肉苁蓉及其混淆品草获蓉和锁阳 \\
\hline
\end{tabular}


顾垒，闻丞，罗玫，王吴，吕植. 中国最受关注濒危物种保护现状快速评价的新方法探讨. 生物多样性，2015，23(5)：583-590. http://www. biodiversity-science. net/CN/article/downloadArticleFile. do?attachType=PDF\&id=10075

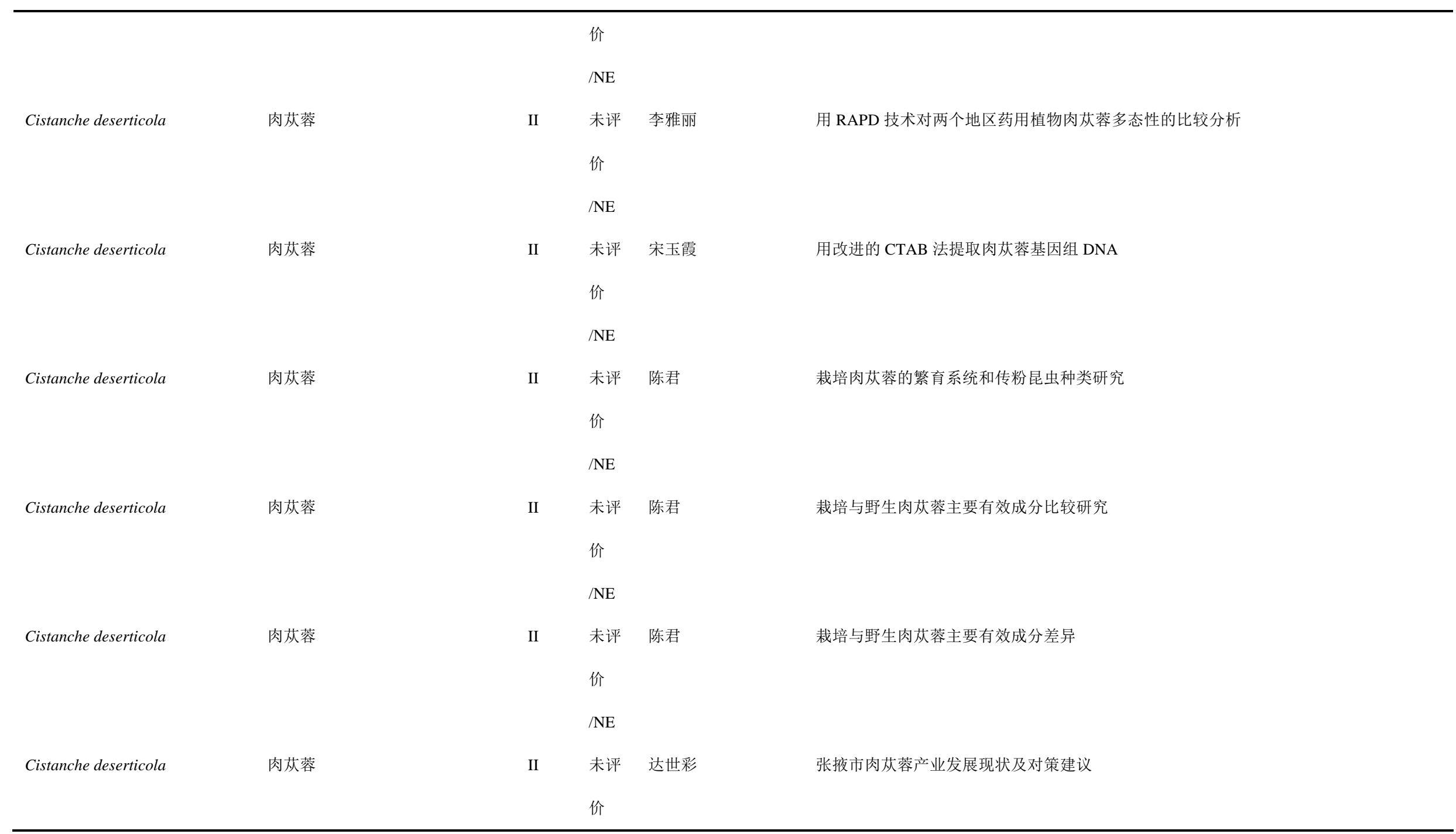


顾垒，闻丞，罗玫，王吴，吕植. 中国最受关注濒危物种保护现状快速评价的新方法探讨. 生物多样性，2015，23(5)：583-590. http://www. biodiversity-science. net/CN/article/downloadArticleFile. do?attachType=PDF\&id=10075

\begin{tabular}{|c|c|c|c|c|c|}
\hline \multirow[b]{2}{*}{ Cistanche deserticola } & \multirow[b]{2}{*}{ 肉苁蓉 } & \multirow[b]{2}{*}{ II } & \multicolumn{2}{|l|}{$/ \mathrm{NE}$} & \multirow[b]{2}{*}{ 蔗糖对悬浮培养肉苁蓉细胞的生长及苯乙醇苷合成的影响 } \\
\hline & & & $\begin{array}{l}\text { 未评 } \\
\text { 价 }\end{array}$ & 李春 & \\
\hline Cistanche deserticola & 肉苁蓉 & II & $\begin{array}{l}\text { /NE } \\
\text { 未评 } \\
\text { 价 }\end{array}$ & 郭玉海 & 植物生长调节物质对梭梭和肉苁蓉生长的调节作用 \\
\hline Cistanche deserticola & 肉苁蓉 & II & $\begin{array}{l}\text { /NE } \\
\text { 未评 } \\
\text { 价 }\end{array}$ & 吴忠 & 中药肉苁蓉的化学模式识别研究 \\
\hline Cistanche deserticola & 肉苁蓉 & II & $\begin{array}{l}\text { /NE } \\
\text { 未评 } \\
\text { 价 }\end{array}$ & 王虔 & 中药肉苁蓉接种技术与柽柳根系活力研究 \\
\hline Cleidiocarpon cavaleriei & 蝴蝶果 & $\begin{array}{l}\text { 未列 } \\
\lambda\end{array}$ & $\begin{array}{l}\text { /NE } \\
\text { 易危 } \\
\text { /VU }\end{array}$ & 周正邦 & 蝴蝶果的特性及栽培利用探讨 \\
\hline Cleidiocarpon cavaleriei & 蝴蝶果 & $\begin{array}{l}\text { 未列 } \\
入\end{array}$ & $\begin{array}{l}\text { 易危 } \\
\text { /VU }\end{array}$ & 王延平 & 蝴蝶果人工栽培及经济价值 \\
\hline Cleidiocarpon cavaleriei & 蝴蝶果 & $\begin{array}{l}\text { 未列 } \\
\lambda\end{array}$ & $\begin{array}{l}\text { 易危 } \\
\text { /VU }\end{array}$ & 刘敏学 & 蝴蝶果栽培丰产技术 \\
\hline
\end{tabular}


顾垒，闻丞，罗玫，王吴，吕植. 中国最受关注濒危物种保护现状快速评价的新方法探讨. 生物多样性，2015，23(5)：583-590. http://www. biodiversity-science. net/CN/article/downloadArticleFile. do?attachType=PDF\&id=10075

\begin{tabular}{|c|c|c|c|c|c|}
\hline Coptis omeiensis & 峨眉黄连 & II & $\begin{array}{l}\text { 未评 } \\
\text { 价 } \\
\text { /NE }\end{array}$ & 傅体华 & 3 种黄连叶片表皮特征研究 \\
\hline Coptis omeiensis & 峨眉黄连 & II & $\begin{array}{l}\text { 未评 } \\
\text { 价 } \\
\text { /NE }\end{array}$ & 傅体华 & 四川道地黄连的生理形态及细胞遗传研究 \\
\hline Cornus schindleri & 曲瓣梾木 & $\begin{array}{l}\text { 未列 } \\
\text { 入 }\end{array}$ & $\begin{array}{l}\text { 易危 } \\
\text { /VU }\end{array}$ & 方文培 & 《中国植物志》第 56 卷 064 页 \\
\hline Cotinus nana & 矮黄栌 & $\begin{array}{l}\text { 未列 } \\
\text { 入 }\end{array}$ & $\begin{array}{l}\text { 濒危 } \\
\text { /EN }\end{array}$ & 闵天禄 & 《中国植物志》第 45(1)卷 098 页 \\
\hline Crex crex & 长脚秧鸡 & II & $\begin{array}{l}\text { 无危 } \\
\text { /LC }\end{array}$ & 袁玉川 & 2011 年南涧风凰山夜间鸟类环志研究 \\
\hline Crex crex & 长脚秧鸡 & II & $\begin{array}{l}\text { 无危 } \\
\text { /LC }\end{array}$ & 袁玉川 & 云南鸟类新纪录———长脚种鸡 \\
\hline Crossoptilon crossoptilon & 白马鸡 & $\begin{array}{l}\text { 未列 } \\
\lambda\end{array}$ & $\begin{array}{l}\text { 近危 } \\
\text { /NT }\end{array}$ & 王楠 & Pheasants in sacred and other forests in western Sichuan: their cultural conservation \\
\hline Crossoptilon crossoptilon & 白马鸡 & $\begin{array}{l}\text { 未列 } \\
\lambda\end{array}$ & $\begin{array}{l}\text { 近危 } \\
\text { /NT }\end{array}$ & 王楠 & 白马鸡配对期两性行为的比较 \\
\hline Crossoptilon crossoptilon & 白马鸡 & 未列 & 近危 & 符建荣 & 米亚罗自然保护区的鸟类资源 \\
\hline
\end{tabular}


顾垒，闻丞，罗玫，王吴，吕植. 中国最受关注濒危物种保护现状快速评价的新方法探讨. 生物多样性，2015，23(5)：583-590. http://www biodiversity-science. net/CN/article/downloadArticleFile. do?attachType=PDF\&id=10075

\begin{tabular}{|c|c|c|c|c|c|}
\hline & & 入 & /NT & & \\
\hline \multirow[t]{2}{*}{ Crossoptilon crossoptilon } & 白马鸡 & 未列 & 近危 & 符建荣 & 四川海子山自然保护区鸟类资源及区系 \\
\hline & & 入 & /NT & & \\
\hline \multirow[t]{2}{*}{ Crossoptilon crossoptilon } & 白马鸡 & 未列 & 近危 & 符建荣 & 四川长沙贡玛自然保护区的鸟类资源 \\
\hline & & $\lambda$ & /NT & & \\
\hline \multirow[t]{2}{*}{ Crossoptilon harmani } & 藏马鸡 & II & 近危 & 陈顺德 & 四川壤塘县绰斯甲河段鸟类资源初步调查及区系分析 \\
\hline & & & /NT & & \\
\hline \multirow[t]{2}{*}{ Crossoptilon harmani } & 藏马鸡 & II & 近危 & 仓决卓玛 & 西藏林周县澎波河谷冬春季鸟类调查 \\
\hline & & & /NT & & \\
\hline \multirow[t]{2}{*}{ Crossoptilon mantchuricum } & 褐马鸡 & I & 易危 & 王红梅 & Biodiversity Sustainability Assessment of Principal Ecosystems in Hebei,china \\
\hline & & & /VU & & \\
\hline \multirow[t]{3}{*}{ Crossoptilon mantchuricum } & 褐马鸡 & I & 易危 & Dongming Li & MODEL TO ASSESS THE HABITAT SUITABILITY FOR ENDANGERED BIRD SPECIES \\
\hline & & & $/ \mathrm{VU}$ & & BROWN EARED-PHEASANT CROSSOPTILON MANTCHURICUM SWINHOE IN \\
\hline & & & & & XIAOWUTAISHAN RESERVE CHINA \\
\hline \multirow[t]{2}{*}{ Crossoptilon mantchuricum } & 褐马鸡 & I & 易危 & ZHAN-HONG & Relationship Between Tourism Development and Vegetated Landscapes in Luya Mountain \\
\hline & & & /VU & CHENG & Nature Reserve, Shanxi, China \\
\hline \multirow[t]{2}{*}{ Crossoptilon mantchuricum } & 褐马鸡 & I & 易危 & 安晓红 & 关帝山国家森林公园生物景观及其开发利用 \\
\hline & & & /VU & & \\
\hline Crossoptilon mantchuricum & 褐马鸡 & I & 易危 & 范世强 & 韩城褐马鸡栖息地特征及其保护对策 \\
\hline
\end{tabular}


顾垒，闻丞，罗玫，王吴，吕植. 中国最受关注濒危物种保护现状快速评价的新方法探讨. 生物多样性，2015，23(5)：583-590. http://www biodiversity-science. net/CN/article/downloadArticleFile. do?attachType=PDF\&id=10075

\begin{tabular}{|c|c|c|c|c|c|}
\hline & & & /VU & & \\
\hline \multirow[t]{2}{*}{ Crossoptilon mantchuricum } & 褐马鸡 & I & 易危 & 朱莉香 & 贺家山自然保护区自然资源现状评价 \\
\hline & & & $/ \mathrm{VU}$ & & \\
\hline \multirow[t]{2}{*}{ Crossoptilon mantchuricum } & 褐马鸡 & I & 易危 & 关志明 & 黑茶山自然保护区褐马鸡资源现状及保护对策 \\
\hline & & & /VU & & \\
\hline \multirow[t]{2}{*}{ Crossoptilon mantchuricum } & 褐马鸡 & I & 易危 & 秦廷松 & 黄土高原地区黄龙山白皮松林地土壤种子库研究 \\
\hline & & & /VU & & \\
\hline \multirow[t]{2}{*}{ Crossoptilon mantchuricum } & 褐马鸡 & I & 易危 & 王建春 & 芦芽山褐马鸡的生存现状及人类活动对其的影响 \\
\hline & & & $/ \mathrm{VU}$ & & \\
\hline \multirow[t]{2}{*}{ Crossoptilon mantchuricum } & 褐马鸡 & I & 易危 & 郭建荣 & 芦芽山自然保护区生物多样性概述 \\
\hline & & & /VU & & \\
\hline \multirow[t]{2}{*}{ Crossoptilon mantchuricum } & 褐马鸡 & I & 易危 & 张钦第 & 庞泉沟自然保护区华北落叶松种群生命表与谱分析 \\
\hline & & & /VU & & \\
\hline \multirow[t]{2}{*}{ Crossoptilon mantchuricum } & 褐马鸡 & I & 易危 & 张国钢 & 栖息地特征对褐马鸡种群密度和集群行为的影响 \\
\hline & & & /VU & & \\
\hline \multirow[t]{2}{*}{ Crossoptilon mantchuricum } & 褐马鸡 & I & 易危 & 白瑛 & 浅淡太岳山林区湿地公园的保护和利用 \\
\hline & & & /VU & & \\
\hline \multirow[t]{2}{*}{ Crossoptilon mantchuricum } & 褐马鸡 & I & 易危 & 程铁锁 & 浅析韩城黄龙山褐马鸡致危因素与保护对策 \\
\hline & & & /VU & & \\
\hline
\end{tabular}


顾垒，闻丞，罗玫，王吴，吕植. 中国最受关注濒危物种保护现状快速评价的新方法探讨. 生物多样性，2015，23(5)：583-590. http://www biodiversity-science. net/CN/article/downloadArticleFile. do?attachType=PDF\&id=10075

\begin{tabular}{|c|c|c|c|c|c|}
\hline Crossoptilon mantchuricum & 褐马鸡 & I & $\begin{array}{l}\text { 易危 } \\
\text { /VU }\end{array}$ & 王振军 & 山西黑茶山省级自然保护区褐马鸡资源调查 \\
\hline Crossoptilon mantchuricum & 褐马鸡 & I & $\begin{array}{l}\text { 易危 } \\
\text { /VU }\end{array}$ & 李宝堂 & 山西凌井沟自然保护区生物多样性研究 \\
\hline Crossoptilon mantchuricum & 褐马鸡 & I & $\begin{array}{l}\text { 易危 } \\
\text { /VU }\end{array}$ & 毛银凤 & 山西凌井沟自然保护区自然资源评价 \\
\hline Crossoptilon mantchuricum & 褐马鸡 & I & $\begin{array}{l}\text { 易危 } \\
\text { /VU }\end{array}$ & 张国钢 & 山西五鹿山自然保护区褐马鸡栖息地的选择 \\
\hline Crossoptilon mantchuricum & 褐马鸡 & I & $\begin{array}{l}\text { 易危 } \\
\text { /VU }\end{array}$ & 张国钢 & 山西五台山地区褐马鸡的再引入 \\
\hline Crossoptilon mantchuricum & 褐马鸡 & I & $\begin{array}{l}\text { 易危 } \\
\text { /VU }\end{array}$ & 谢超杰 & 陕西韩城黄龙山褐马鸡自然保护区野生动植物资源现状及其保护对策 \\
\hline Crossoptilon mantchuricum & 褐马鸡 & I & $\begin{array}{l}\text { 易危 } \\
\text { /VU }\end{array}$ & 李宏群 & 陕西黄龙山自然保护区冬季褐马鸡取食生境的选择 \\
\hline Crossoptilon mantchuricum & 褐马鸡 & I & $\begin{array}{l}\text { 易危 } \\
\text { /VU }\end{array}$ & 李宏群 & 陕西黄龙山自然保护区冬季褐马鸡沙浴地选择 \\
\hline Crossoptilon mantchuricum & 褐马鸡 & I & $\begin{array}{l}\text { 易危 } \\
\text { /VU }\end{array}$ & 李宏群 & 陕西黄龙山自然保护区褐马鸡秋季受食地选择 \\
\hline Crossoptilon mantchuricum & 褐马鸡 & I & 易危 & 李宏群 & 陕西延安黄龙山褐马鸡自然保护区鸟类资源调查 \\
\hline
\end{tabular}


顾垒，闻丞，罗玫，王吴，吕植. 中国最受关注濒危物种保护现状快速评价的新方法探讨. 生物多样性，2015，23(5)：583-590. http://www biodiversity-science. net/CN/article/downloadArticleFile. do?attachType=PDF\&id=10075

\begin{tabular}{|c|c|c|c|c|c|}
\hline & & & /VU & & \\
\hline \multirow[t]{2}{*}{ Crossoptilon mantchuricum } & 褐马鸡 & I & 易危 & 张晓玲 & 五鹿山国家级自然保护区生物多样性研究与发展对策 \\
\hline & & & /VU & & \\
\hline \multirow[t]{2}{*}{ Crossoptilon mantchuricum } & 褐马鸡 & I & 易危 & 李兰 & 小五台山褐马鸡的生存现状及人类活动对其的影响 \\
\hline & & & /VU & & \\
\hline \multirow[t]{2}{*}{ Crossoptilon mantchuricum } & 褐马鸡 & I & 易危 & 郑建旭 & 小五台山自保护区褐马鸡的天敌初探 \\
\hline & & & /VU & & \\
\hline \multirow[t]{2}{*}{ Crossoptilon mantchuricum } & 褐马鸡 & I & 易危 & 张金屯 & 自组织特征人工神经网络在庞泉沟自然保护区植物群落分类中的应用 \\
\hline & & & $/ \mathrm{VU}$ & & \\
\hline \multirow[t]{2}{*}{ Cuon alpinus } & 婇 & II & 濒危 & Honghai Zhang ; Lei & The complete mitochondrial genome of dhole Cuon alpinus:phylogenetic analysis and dating \\
\hline & & & /EN & Chen & evolutionary divergence within canidae \\
\hline \multirow[t]{2}{*}{ Cuon alpinus } & 然才 & II & 濒危 & 张晓军 & 豹针毛的扫描电镜观察分析 \\
\hline & & & /EN & & \\
\hline \multirow[t]{2}{*}{ Cuon alpinus } & 豹 & II & 濒危 & 陈否 & 狼肠道菌群生态及犬科线粒体基因组比较和系统发育 \\
\hline & & & /EN & & \\
\hline \multirow[t]{2}{*}{ Cuora pani } & 潘氏闭壳龟 & 未列 & 极危 & 黄斌 & 河南省龟类分布新记录: 潘氏闭壳龟 \\
\hline & & 入 & /CR & & \\
\hline \multirow[t]{2}{*}{ Cuora pani } & 潘氏闭壳龟 & 未列 & 极危 & 李东 & 潘氏闭壳龟在四川省的首次发现 \\
\hline & & $\lambda$ & /CR & & \\
\hline
\end{tabular}


顾垒，闻丞，罗玫，王吴，吕植. 中国最受关注濒危物种保护现状快速评价的新方法探讨. 生物多样性，2015，23(5)：583-590. http://www biodiversity-science. net/CN/article/downloadArticleFile. do?attachType=PDF\&id=10075

\begin{tabular}{|c|c|c|c|c|c|}
\hline \multirow[t]{2}{*}{ Cuora pani } & 潘氏闭壳龟 & 未列 & 极危 & 巫嘉伟 & 四川产潘氏闭壳龟繁殖一例及其面临的问题 \\
\hline & & 入 & /CR & & \\
\hline \multirow[t]{2}{*}{ Cuora yunnanensis } & 云南闭壳龟 & II & 极危 & 周婷 & 58 年来首次发现生活的云南闭壳龟及其描述 \\
\hline & & & /CR & & \\
\hline \multirow[t]{2}{*}{ Cuora yunnanensis } & 云南闭壳龟 & II & 极危 & ZHANG YaPing & Molecular identification and phylogenetic position of Cuora yunnanensis \\
\hline & & & /CR & & \\
\hline \multirow[t]{2}{*}{ Cuora yunnanensis } & 云南闭壳龟 & II & 极危 & 周婷 & 一只生活的雄性云南闭壳龟被发现 \\
\hline & & & /CR & & \\
\hline \multirow[t]{2}{*}{ Cuora yunnanensis } & 云南闭壳龟 & II & 极危 & 张亚平 & 云南闭壳龟(Cuora yunnanensis)的分子鉴定及进化地位研究 \\
\hline & & & /CR & & \\
\hline \multirow[t]{2}{*}{ Cupressus chengiana } & 岷江柏木 & II & 易危 & Wang Li & A Study of Conservation Genetics in Cupressus chengiana, an Endangered Endemic of China, \\
\hline & & & /VU & & Using ISSR Markers \\
\hline \multirow[t]{2}{*}{ Cupressus chengiana } & 岷江柏木 & II & 易危 & BAO Wei-Kai & Evaluation of Soil Fertility Under Different Cupressus chengiana Forests Using Multivariate \\
\hline & & & /VU & & Approach \\
\hline \multirow[t]{2}{*}{ Cupressus chengiana } & 岷江柏木 & II & 易危 & 郝冰清 & 濒危植物岷江柏的保护遗传学研究 \\
\hline & & & /VU & & \\
\hline \multirow[t]{2}{*}{ Cupressus chengiana } & 岷江柏木 & II & 易危 & 杨忠明 & 岷江柏木营养袋育苗技术 \\
\hline & & & $/ \mathrm{VU}$ & & \\
\hline Cupressus chengiana & 岷江柏木 & II & 易危 & 吴宗兴 & 岷江上游干旱河谷即江柏木幼林地绿肥种植研究 \\
\hline
\end{tabular}


顾垒，闻丞，罗玫，王吴，吕植. 中国最受关注濒危物种保护现状快速评价的新方法探讨．生物多样性，2015，23(5)：583-590。 http://www. biodiversity-science. net/CN/article/downloadArticleFile. do?attachType=PDF\&id=10075

\begin{tabular}{|c|c|c|c|c|c|}
\hline & & & /VU & & \\
\hline \multirow[t]{3}{*}{ Cupressus Ducloux iana Hickel } & 干香柏 & 未列 & 数据 & 李万金 & 广元滇柏引种培育技术 \\
\hline & & 入 & 不足 & & \\
\hline & & & /DD & & \\
\hline \multirow[t]{3}{*}{ Cupressus duclouxiana } & 干香柏 & 未列 & 数据 & 彭安林 & 滇柏的引种调查与分析 \\
\hline & & 入 & 不足 & & \\
\hline & & & /DD & & \\
\hline \multirow[t]{3}{*}{ Cupressus duclouxiana } & 干香柏 & 未列 & 数据 & 尹晓阳 & 滇柏容器育苗配套技术研究 \\
\hline & & 入 & 不足 & & \\
\hline & & & /DD & & \\
\hline \multirow[t]{3}{*}{ Cupressus duclouxiana } & 干香柏 & 未列 & 数据 & 张金池 & 干旱胁迫下接种菌根真菌对滇柏和楸树幼苗根系的影响 \\
\hline & & 入 & 不足 & & \\
\hline & & & /DD & & \\
\hline \multirow[t]{3}{*}{ Cupressus duclouxiana Hickel } & 干香柏 & 未列 & 数据 & 魏建国 & 攀西地区干香柏容器育苗技术研究 \\
\hline & & 入 & 不足 & & \\
\hline & & & /DD & & \\
\hline \multirow[t]{3}{*}{ Cupressus duclouxiana Hickel } & 干香柏 & 未列 & 数据 & 张光飞 & 紫茎泽兰的水浸提液对干香柏和藏柏种子萌发的影响 \\
\hline & & 入 & 不足 & & \\
\hline & & & /DD & & \\
\hline
\end{tabular}


顾垒，闻丞，罗玫，王吴，吕植. 中国最受关注濒危物种保护现状快速评价的新方法探讨. 生物多样性，2015，23(5)：583-590. http://www biodiversity-science. net/CN/article/downloadArticleFile. do?attachType=PDF\&id=10075

\begin{tabular}{|c|c|c|c|c|c|}
\hline Cupressus torulosa var. gigantea & 巨柏 & I & $\begin{array}{l}\text { 无危 } \\
\text { /LC }\end{array}$ & 索朗桑姆 & 不同巨柏林分调落物的养分变化研究 \\
\hline Cupressus torulosa var. gigantea & 巨柏 & I & $\begin{array}{l}\text { 无危 } \\
\text { /LC }\end{array}$ & 赵垦田 & 基于 Logistic 模型探究西藏巨柏播种苗生长规律 \\
\hline Cupressus torulosa var. gigantea & 巨柏 & I & $\begin{array}{l}\text { 无危 } \\
\text { /LC }\end{array}$ & 罗 建 & 巨柏群落特征的研究 \\
\hline Cupressus torulosa var. gigantea & 巨柏 & I & $\begin{array}{l}\text { 无危 } \\
\text { /LC }\end{array}$ & 张明生 & 巨柏细胞色素氧化酶同工酶变异分析 \\
\hline Cupressus torulosa var. gigantea & 巨柏 & I & $\begin{array}{l}\text { 无危 } \\
\text { /LC }\end{array}$ & 罗大庆 & 巨柏种群的生态地理分布与群落学特征 \\
\hline Cupressus torulosa var. gigantea & 巨柏 & I & $\begin{array}{l}\text { 无危 } \\
\text { /LC }\end{array}$ & 王景升 & 巨柏种子活力与濒危的关系 \\
\hline Cupressus torulosa var. gigantea & 巨柏 & I & $\begin{array}{l}\text { 无危 } \\
\text { /LC }\end{array}$ & 张玉钧 & 旅游干扰对西藏林芝巨柏林的影响 \\
\hline Cupressus torulosa var. gigantea & 巨柏 & I & $\begin{array}{l}\text { 无危 } \\
\text { /LC }\end{array}$ & 李乾振 & 闽东引种巨柏育苗试验初报 \\
\hline Cupressus torulosa var. gigantea & 巨柏 & I & $\begin{array}{l}\text { 无危 } \\
\text { /LC }\end{array}$ & 罗大庆 & 西藏濒危植物巨柏的生物学与生态学特性研究 \\
\hline Cupressus torulosa var. gigantea & 巨柏 & I & 无危 & 廖志华 & 西藏高原濒危植物西藏巨柏光合作用日进程 \\
\hline
\end{tabular}


顾垒，闻丞，罗玫，王吴，吕植. 中国最受关注濒危物种保护现状快速评价的新方法探讨. 生物多样性，2015，23(5)：583-590. http://www. biodiversity-science. net/CN/article/downloadArticleFile. do?attachType=PDF\&id=10075

\begin{tabular}{|c|c|c|c|c|c|}
\hline & & & $/ \mathrm{LC}$ & & \\
\hline \multirow[t]{2}{*}{ Cupressus torulosa var. gigantea } & 巨柏 & I & 无危 & 扎西次仁 & 西藏巨柏的遗传多样性与精油化学成分变异及其保护生物学意义 \\
\hline & & & $/ \mathrm{LC}$ & & \\
\hline \multirow[t]{2}{*}{ Cupressus torulosa var. gigantea } & 巨柏 & I & 无危 & 王景升李衡 & 西藏巨柏人工苗木生长研究 \\
\hline & & & $/ \mathrm{LC}$ & & \\
\hline \multirow[t]{2}{*}{ Cupressus torulosa var. gigantea } & 巨柏 & I & 无危 & 彭培好 & 西藏巨柏种群天然更新与群落特征研究 \\
\hline & & & $/ \mathrm{LC}$ & & \\
\hline \multirow[t]{2}{*}{ Cupressus torulosa var. gigantea } & 巨柏 & I & 无危 & 德庆措姆 & 西藏林芝地区巨柏育苗与造林试验 \\
\hline & & & $/ \mathrm{LC}$ & & \\
\hline \multirow[t]{2}{*}{ Cupressus torulosa var. gigantea } & 巨柏 & I & 无危 & 陈贻竹 & 西藏特有珍稀植物巨柏的研究进展与展望 \\
\hline & & & $/ \mathrm{LC}$ & & \\
\hline \multirow[t]{3}{*}{ Cyanoptila cumatilis } & 琉璃蓝鹟 & 未列 & 数据 & 程松林 & 江西武夷山国家级自然保护区鸟类多样性调查 \\
\hline & & 入 & 不足 & & \\
\hline & & & $/ \mathrm{DD}$ & & \\
\hline \multirow[t]{3}{*}{ Cyanoptila cumatilis } & 琉璃蓝鹟 & 未列 & 数据 & 谭家林 & 三峡大老岭秋季环志鸟类资源初步调查 \\
\hline & & 入 & 不足 & & \\
\hline & & & /DD & & \\
\hline \multirow[t]{2}{*}{ Cyanoptila cumatilis } & 琉璃蓝鹟 & 未列 & 数据 & 巩会生 & 陕西秦岭及大巴山地区的鸟类资源调查 \\
\hline & & 入 & 不足 & & \\
\hline
\end{tabular}


顾垒，闻丞，罗玫，王吴，吕植. 中国最受关注濒危物种保护现状快速评价的新方法探讨. 生物多样性，2015，23(5)：583-590. http://www. biodiversity-science. net/CN/article/downloadArticleFile. do?attachType=PDF\&id=10075

\begin{tabular}{|c|c|c|c|c|c|}
\hline \multirow{3}{*}{ Cycas acuminatissima } & \multirow{3}{*}{ 尖尾苏铁 } & \multicolumn{3}{|c|}{ /DD } & \multirow{3}{*}{ 尖尾苏铁根系类型与解剖结构研究 } \\
\hline & & 未列 & 未评 & 徐峰 & \\
\hline & & 入 & 价 & & \\
\hline \multirow{3}{*}{ Cycas balansae } & \multirow{3}{*}{ 宽叶苏铁 } & \multirow{3}{*}{ I } & $/ \mathrm{NE}$ & & \\
\hline & & & 近危 & XUN GONG & Genetic Differentiation and Relationships of Populations in the Cycas balansae Complex \\
\hline & & & /NT & & (Cycadaceae) and its Conservation Implications \\
\hline \multirow[t]{2}{*}{ Cycas changjiangensis } & \multirow[t]{2}{*}{ 葫芦苏铁 } & \multirow[t]{2}{*}{ I } & 濒危 & Zheng-Feng Wang & Isolation and characterization of microsatellite loci in endangered Cycas changjiangensis \\
\hline & & & /EN & & (Cycadaceae) \\
\hline \multirow[t]{2}{*}{ Cycas changjiangensis } & \multirow[t]{2}{*}{ 葫芦苏铁 } & \multirow[t]{2}{*}{ I } & 濒危 & 刘念 & 葫芦苏铁遗传多样性的等位酶分析 \\
\hline & & & $/ \mathrm{EN}$ & & \\
\hline \multirow[t]{2}{*}{ Cycas debaoensis } & \multirow[t]{2}{*}{ 德保苏铁 } & \multirow[t]{2}{*}{ I } & 极危 & XUN GONG & Isolation and characterization of microsatellite markers for Cycas debaoensis Y. C. Zhong et C. \\
\hline & & & /CR & & J. Chen (Cycadaceae) \\
\hline \multirow[t]{2}{*}{ Cycas debaoensis } & \multirow[t]{2}{*}{ 德保苏铁 } & \multirow[t]{2}{*}{ I } & 极危 & XUN GONG & Patterns of chloroplast DNA variation in Cycas debaoensis (Cycadaceae): conservation \\
\hline & & & /CR & & implications \\
\hline \multirow[t]{2}{*}{ Cycas debaoensis } & \multirow[t]{2}{*}{ 德保苏铁 } & \multirow[t]{2}{*}{ I } & 极危 & 骆文华 & 濒危植物德保苏铁种子休眠与萌发 \\
\hline & & & /CR & & \\
\hline \multirow[t]{2}{*}{ Cycas debaoensis } & \multirow[t]{2}{*}{ 德保苏铁 } & \multirow[t]{2}{*}{ I } & 极危 & 黄玉源 & 部分苏铁类植物的解剖结构特征及其与环境的适应性研究 \\
\hline & & & /CR & & \\
\hline Cycas debaoensis & 德保苏铁 & I & 极危 & 李楠 & 部分苏铁类植物水分利用率初探 \\
\hline
\end{tabular}


顾垒，闻丞，罗玫，王吴，吕植. 中国最受关注濒危物种保护现状快速评价的新方法探讨. 生物多样性，2015，23(5)：583-590. http://www. biodiversity-science. net/CN/article/downloadArticleFile. do?attachType=PDF\&id=10075

\begin{tabular}{|c|c|c|c|c|c|}
\hline & & & /CR & & \\
\hline \multirow[t]{2}{*}{ Cycas debaoensis } & 德保苏铁 & I & 极危 & 黄玉源 & 部分苏铁种类亲缘关系的 ISSR 分析及分类学研究 \\
\hline & & & /CR & & \\
\hline \multirow[t]{2}{*}{ Cycas debaoensis } & 德保苏铁 & I & 极危 & 李楠 & 德保苏铁传粉生物学研究 \\
\hline & & & /CR & & \\
\hline \multirow[t]{2}{*}{ Cycas debaoensis } & 德保苏铁 & I & 极危 & 邢福武 & 德保苏铁的核型分析 \\
\hline & & & /CR & & \\
\hline \multirow[t]{2}{*}{ Cycas debaoensis } & 德保苏铁 & I & 极危 & 李楠 & 德保苏铁扶平居群与 “回归项目” 居群的调查 \\
\hline & & & /CR & & \\
\hline \multirow[t]{2}{*}{ Cycas debaoensis } & 德保苏铁 & I & 极危 & 李楠 & 德保苏铁回归后几个生理指标的比较研究 \\
\hline & & & /CR & & \\
\hline \multirow[t]{2}{*}{ Cycas debaoensis } & 德保苏铁 & I & 极危 & 李楠 & 德保苏铁回归种群生态初探 \\
\hline & & & /CR & & \\
\hline \multirow[t]{2}{*}{ Cycas debaoensis } & 德保苏铁 & I & 极危 & 文祥凤 & 德保苏铁茎的解剖学研究 \\
\hline & & & /CR & & \\
\hline \multirow[t]{2}{*}{ Cycas debaoensis } & 德保苏铁 & I & 极危 & 薛跃规 & 德保苏铁居群生物学及其保护生物学研究 \\
\hline & & & /CR & & \\
\hline \multirow[t]{2}{*}{ Cycas debaoensis } & 德保苏铁 & I & 极危 & 刘念 & 德保苏铁居群特征及保护措施 \\
\hline & & & /CR & & \\
\hline
\end{tabular}


顾垒，闻丞，罗玫，王吴，吕植. 中国最受关注濒危物种保护现状快速评价的新方法探讨. 生物多样性，2015，23(5)：583-590. http://www biodiversity-science. net/CN/article/downloadArticleFile. do?attachType=PDF\&id=10075

\begin{tabular}{|c|c|c|c|c|c|}
\hline Cycas debaoensis & 德保苏铁 & I & $\begin{array}{l}\text { 极危 } \\
\text { /CR }\end{array}$ & 李楠 & 模拟酸雨对德保苏铁叶片光合作用及根系分泌有机酸的影响 \\
\hline Cycas debaoensis & 德保苏铁 & I & $\begin{array}{l}\text { 极危 } \\
\text { /CR }\end{array}$ & 薛跃规 & 社区参与德保苏铁保育与可持续发展模式研究 \\
\hline Cycas debaoensis & 德保苏铁 & I & $\begin{array}{l}\text { 极危 } \\
\text { /CR }\end{array}$ & 付广华 & 生物多样性保护的政治一一一基于德保苏铁案例的田野研究 \\
\hline Cycas debaoensis & 德保苏铁 & I & $\begin{array}{l}\text { 极危 } \\
\text { /CR }\end{array}$ & 林鉴钊 & 五种苏铁羽叶和羽片的生长发育 \\
\hline Cycas debaoensis & 德保苏铁 & I & $\begin{array}{l}\text { 极危 } \\
\text { /CR }\end{array}$ & 黄玉源 & 秀叶苏铁与德保苏铁调查研究 \\
\hline Cycas debaoensis & 德保苏铁 & I & $\begin{array}{l}\text { 极危 } \\
\text { /CR }\end{array}$ & 潘光波 & 野生德保苏铁植物地理分布及优先保护区域研究 \\
\hline Cycas fairylakea & 仙湖苏铁 & $\begin{array}{l}\text { 未列 } \\
\text { 入 }\end{array}$ & $\begin{array}{l}\text { 未评 } \\
\text { 价 } \\
\text { /NE }\end{array}$ & HAI REN & $\begin{array}{l}\text { Genetic variation in the endangered endemic species Cycas fairylakea (Cycadaceae) in China } \\
\text { and implications for conservation }\end{array}$ \\
\hline Cycas fairylakea & 仙湖苏铁 & $\begin{array}{l}\text { 未列 } \\
\text { 入 }\end{array}$ & $\begin{array}{l}\text { 未评 } \\
\text { 价 } \\
\text { /NE }\end{array}$ & 彭少麟 & 不同水平的仙湖苏铁种群在土壤资源上的生态位宽度 \\
\hline Cycas fairylakea & 仙湖苏铁 & 未列 & 未评 & 李楠 & 部分苏铁类植物水分利用率初探 \\
\hline
\end{tabular}


顾垒，闻丞，罗玫，王吴，吕植. 中国最受关注濒危物种保护现状快速评价的新方法探讨. 生物多样性，2015，23(5)：583-590. http://www. biodiversity-science. net/CN/article/downloadArticleFile. do?attachType=PDF\&id=10075

\begin{tabular}{|c|c|c|c|c|c|}
\hline \multirow[b]{2}{*}{ Cycas fairylakea } & \multirow[b]{2}{*}{ 仙湖苏铁 } & \multirow{2}{*}{$\begin{array}{l}\text { 入 } \\
\text { 未列 }\end{array}$} & \multicolumn{2}{|l|}{$\begin{array}{l}\text { 价 } \\
\text { /NE }\end{array}$} & \multirow[b]{2}{*}{ 广东省曲江县野生仙湖苏铁新种群及其保护 } \\
\hline & & & $\begin{array}{l}\text { /NE } \\
\text { 未评 } \\
\text { 价 }\end{array}$ & 刘念 & \\
\hline Cycas fairylakea & 仙湖苏铁 & $\begin{array}{l}\text { 未列 } \\
\text { 入 }\end{array}$ & $\begin{array}{l}\text { /NE } \\
\text { 未评 } \\
\text { 价 }\end{array}$ & 简曙光 & 广东省野生仙湖苏铁居群的生物学特性研究 \\
\hline Cycas fairylakea & 仙湖苏铁 & $\begin{array}{l}\text { 未列 } \\
入\end{array}$ & $\begin{array}{l}\text { /NE } \\
\text { 未评 } \\
\text { 价 }\end{array}$ & 汪殿蓓 & 基株和无性系水平上的仙湖苏铁种群分布格局 \\
\hline Cycas fairylakea & 仙湖苏铁 & $\begin{array}{l}\text { 未列 } \\
\text { 入 }\end{array}$ & $\begin{array}{l}\text { /NE } \\
\text { 未评 } \\
\text { 价 }\end{array}$ & 覃广泉 & 两种国产苏铁属植物的核型分析 \\
\hline Cycas fairylakea & 仙湖苏铁 & $\begin{array}{l}\text { 未列 } \\
入\end{array}$ & $\begin{array}{l}\text { /NE } \\
\text { 未评 } \\
\text { 价 }\end{array}$ & 唐源江 & 六种苏铁属植物的羽片比较解剖学研究 \\
\hline Cycas fairylakea & 仙湖苏铁 & $\begin{array}{l}\text { 未列 } \\
入\end{array}$ & $\begin{array}{l}/ \mathrm{NE} \\
\text { 未评 } \\
\text { 价 }\end{array}$ & 孙冰 & 深圳梅林仙湖苏铁的种群特征与保护研究 \\
\hline
\end{tabular}


顾垒，闻丞，罗玫，王吴，吕植. 中国最受关注濒危物种保护现状快速评价的新方法探讨. 生物多样性，2015，23(5)：583-590. http://www. biodiversity-science. net/CN/article/downloadArticleFile. do?attachType=PDF\&id=10075

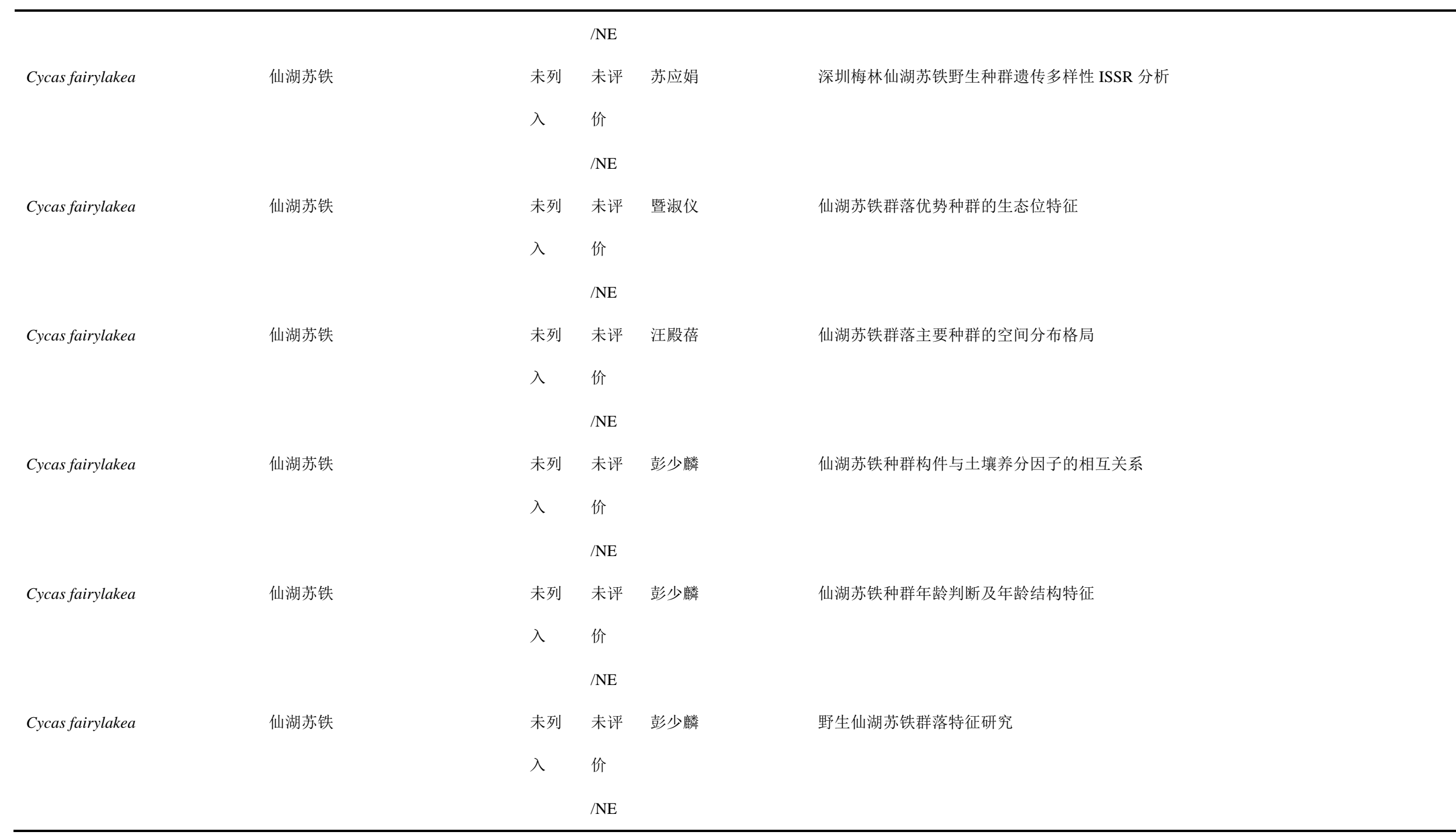


顾垒，闻丞，罗玫，王吴，吕植. 中国最受关注濒危物种保护现状快速评价的新方法探讨. 生物多样性，2015，23(5)：583-590. http://www. biodiversity-science. net/CN/article/downloadArticleFile. do?attachType=PDF\&id=10075

\begin{tabular}{|c|c|c|c|c|c|}
\hline \multirow[t]{2}{*}{ Cycas ferruginea } & 锈毛苏铁 & 未列 & 近危 & 黄玉源 & 部分苏铁类植物的解剖结构特征及其与环境的适应性研究 \\
\hline & & 入 & /NT & & \\
\hline \multirow[t]{2}{*}{ Cycas ferruginea } & 锈毛苏铁 & 未列 & 近危 & 黄玉源 & 部分苏铁种类亲缘关系的 ISSR 分析及分类学研究 \\
\hline & & 入 & /NT & & \\
\hline \multirow[t]{2}{*}{ Cycas ferruginea } & 锈毛苏铁 & 未列 & 近危 & 唐源江 & 六种苏铁属植物的羽片比较解剖学研究 \\
\hline & & 入 & /NT & & \\
\hline \multirow[t]{2}{*}{ Cycas ferruginea } & 锈毛苏铁 & 未列 & 近危 & 唐源江 & 石山苏铁与锈毛苏铁羽片解剖学研究 \\
\hline & & 入 & /NT & & \\
\hline \multirow[t]{2}{*}{ Cycas ferruginea } & 锈毛苏铁 & 未列 & 近危 & 黄玉源 & 我国两种特有苏铁的生态环境及叶片结构 \\
\hline & & 入 & /NT & & \\
\hline \multirow[t]{2}{*}{ Cycas ferruginea } & 锈毛苏铁 & 未列 & 近危 & 龚洵 & 五种中国苏铁属植物的核型分析 \\
\hline & & 入 & /NT & & \\
\hline \multirow[t]{3}{*}{ Cycas gracilis } & 秀叶苏铁 & 未列 & 未评 & 黄玉源 & 秀叶苏铁一一广西苏铁属一新种 \\
\hline & & 入 & 价 & & \\
\hline & & & $/ \mathrm{NE}$ & & \\
\hline \multirow[t]{3}{*}{ Cycas gracilis } & 秀叶苏铁 & 未列 & 未评 & 黄玉源 & 秀叶苏铁与德保苏铁调查研究 \\
\hline & & 入 & 价 & & \\
\hline & & & /NE & & \\
\hline Cycas guizhouensis & 贵州苏铁 & 未列 & 易危 & XUN GONG & ISSR Variation in the Endemic and Endangered Plant Cycas guizhouensis (Cycadaceae) \\
\hline
\end{tabular}


顾垒，闻丞，罗玫，王吴，吕植. 中国最受关注濒危物种保护现状快速评价的新方法探讨. 生物多样性，2015，23(5)：583-590. http://www. biodiversity-science. net/CN/article/downloadArticleFile. do?attachType=PDF\&id=10075

\begin{tabular}{|c|c|c|c|c|c|}
\hline & & 入 & $/ \mathrm{VU}$ & & \\
\hline \multirow[t]{2}{*}{ Cycas guizhouensis } & 贵州苏铁 & 未列 & 易危 & 邓朝义 & 广西金钟山林区贵州苏铁调查 \\
\hline & & 入 & /VU & & \\
\hline \multirow[t]{2}{*}{ Cycas guizhouensis } & 贵州苏铁 & 未列 & 易危 & 吴跃开 & 贵州苏铁白盾蚧的发生与防治 \\
\hline & & 入 & $/ \mathrm{VU}$ & & \\
\hline \multirow[t]{2}{*}{ Cycas guizhouensis } & 贵州苏铁 & 未列 & 易危 & 于曙明 & 贵州苏铁的生殖生物学特性与其物种保护策略 \\
\hline & & 入 & $/ \mathrm{VU}$ & & \\
\hline \multirow[t]{2}{*}{ Cycas guizhouensis } & 贵州苏铁 & 未列 & 易危 & 张华海 & 贵州苏铁负泥虫危害初报 \\
\hline & & 入 & $/ \mathrm{VU}$ & & \\
\hline \multirow[t]{2}{*}{ Cycas guizhouensis } & 贵州苏铁 & 未列 & 易危 & 黄玉源 & 贵州苏铁根的解剖学研究 \\
\hline & & 入 & /VU & & \\
\hline \multirow[t]{2}{*}{ Cycas guizhouensis } & 贵州苏铁 & 未列 & 易危 & 邓朝义 & 贵州苏铁属植物资源 \\
\hline & & 入 & /VU & & \\
\hline \multirow[t]{2}{*}{ Cycas guizhouensis } & 贵州苏铁 & 未列 & 易危 & 于曙明 & 贵州苏铁研究进展 \\
\hline & & 入 & $/ \mathrm{VU}$ & & \\
\hline \multirow[t]{2}{*}{ Cycas guizhouensis } & 贵州苏铁 & 未列 & 易危 & 罗在染 & 贵州苏铁野生居群径级构件与种群动态 \\
\hline & & 入 & $/ \mathrm{VU}$ & & \\
\hline \multirow[t]{2}{*}{ Cycas guizhouensis } & 贵州苏铁 & 未列 & 易危 & 龚洵 & 贵州苏铁遗传多样性研究 \\
\hline & & $\lambda$ & /VU & & \\
\hline
\end{tabular}


顾垒，闻丞，罗玫，王吴，吕植. 中国最受关注濒危物种保护现状快速评价的新方法探讨. 生物多样性，2015，23(5)：583-590. http://www. biodiversity-science. net/CN/article/downloadArticleFile. do?attachType=PDF\&id=10075

\begin{tabular}{|c|c|c|c|c|c|}
\hline \multirow[t]{2}{*}{ Cycas guizhouensis } & 贵州苏铁 & 未列 & 易危 & 朱军 & 贵州苏铁植株体内矿质养分含量特征分析 \\
\hline & & 入 & /VU & & \\
\hline \multirow[t]{2}{*}{ Cycas guizhouensis } & 贵州苏铁 & 未列 & 易危 & 罗在染 & 贵州苏铁种质资源现状及保护策略 \\
\hline & & 入 & /VU & & \\
\hline \multirow[t]{2}{*}{ Cycas guizhouensis } & 贵州苏铁 & 未列 & 易危 & 罗在染 & 贵州苏铁种子钲形态特性分析 \\
\hline & & 入 & /VU & & \\
\hline \multirow[t]{2}{*}{ Cycas guizhouensis } & 贵州苏铁 & 未列 & 易危 & 吴志文 & 贵州苏铁自然保护区森林群落稳定性研究 \\
\hline & & 入 & /VU & & \\
\hline \multirow[t]{2}{*}{ Cycas guizhouensis } & 贵州苏铁 & 未列 & 易危 & 吴志文 & 贵州苏铁自然保护区森林群落优势种群生命表与生存分析 \\
\hline & & 入 & /VU & & \\
\hline \multirow[t]{2}{*}{ Cycas guizhouensis } & 贵州苏铁 & 未列 & 易危 & 朱军 & 贵州苏铁组织培养研究 \\
\hline & & 入 & $/ \mathrm{VU}$ & & \\
\hline \multirow[t]{2}{*}{ Cycas guizhouensis } & 贵州苏铁 & 未列 & 易危 & 唐源江 & 六种苏铁属植物的羽片比较解剖学研究 \\
\hline & & 入 & /VU & & \\
\hline \multirow[t]{2}{*}{ Cycas guizhouensis } & 贵州苏铁 & 未列 & 易危 & 罗在染 & 珍稀濒危物种贵州苏铁种子育苗试验研究 \\
\hline & & 入 & /VU & & \\
\hline \multirow[t]{2}{*}{ Cycas hainanensis } & 海南苏铁 & I & 濒危 & 黄玉源 & 9 种苏铁类植物营养器官的解剖学研究 \\
\hline & & & $/$ EN & & \\
\hline Cycas hainanensis & 海南苏铁 & I & 濒危 & Zheng-Feng Wang & Identification and characterization of EST-SSRs and cpSSRs in endangered Cycas hainanensis \\
\hline
\end{tabular}


顾垒，闻丞，罗玫，王吴，吕植. 中国最受关注濒危物种保护现状快速评价的新方法探讨. 生物多样性，2015，23(5)：583-590. http://www. biodiversity-science. net/CN/article/downloadArticleFile. do?attachType=PDF\&id=10075

Cycas hainanensis

海南苏铁

海南苏铁

Cycas hainanensis

Cycas hainanensis

海南苏铁

海南苏铁

Cycas hainanensis

Cycas hainanensis

海南苏铁

Cycas hainanensis

海南苏铁

Cycas micholitzii

Cycas micholitzii

Cycas micholitzi
I

濒危 /EN

I

濒危

黄玉源

/EN

I

濒危黄玉源

/EN

I 濒危

覃广泉

/EN

I

唐源江

/EN

I

龚洵

/EN

I

郑芳勤

/VU

I

李楠

/VU

I 易危 黄玉源
两种国产苏铁属植物的核型分析

六种苏铁属植物的羽片比较解剖学研究

五种中国苏铁属植物的核型分析

5 种国产苏铁的核型和核型进化

Isolation and characterization of microsatellite markers for Cycas hainanensis C. J. Chen

\section{(Cycadaceae)}

八种苏铁植物叶轴的比较解剖研究

部分苏铁种类亲缘关系的 ISSR 分析及分类学研究

部分苏铁类植物水分利用率初探

部分苏铁种类亲缘关系的 ISSR 分析及分类学研究 
顾垒，闻丞，罗玫，王吴，吕植. 中国最受关注濒危物种保护现状快速评价的新方法探讨. 生物多样性，2015，23(5)：583-590. http://www. biodiversity-science. net/CN/article/downloadArticleFile. do?attachType=PDF\&id=10075

\begin{tabular}{|c|c|c|c|c|c|}
\hline Cycas micholitzii & 叉叶苏铁 & I & $\begin{array}{l}\text { 易危 } \\
\text { /VU }\end{array}$ & 郑芳勤 & 叉叶类苏铁是苏铁属植物中最进化的种群 \\
\hline Cycas micholitzii & 叉叶苏铁 & I & $\begin{array}{l}\text { 易危 } \\
\text { /VU }\end{array}$ & 黄玉源 & 利用正交设计法对叉叶苏铁 ISSR-PCR 反应体系的优化研究 \\
\hline Cycas micholitzii & 叉叶苏铁 & I & $\begin{array}{l}\text { 易危 } \\
\text { /VU }\end{array}$ & 刘念 & 苏铁属叉叶苏铁亚组国产种类的羽片比较解剖学研究 \\
\hline Cycas micholitzii & 叉叶苏铁 & I & $\begin{array}{l}\text { 易危 } \\
\text { /VU }\end{array}$ & 周小平 & 云南野生苏铁分布与濒危原因分析 \\
\hline Cycas micholitzii & 叉叶苏铁 & I & $\begin{array}{l}\text { 易危 } \\
\text { /VU }\end{array}$ & 郑芳勤 & 再论叉叶类苏铁的进化地位 \\
\hline Cycas miquelii & 石山苏铁（有称少刺苏铁） & $\begin{array}{l}\text { 未列 } \\
\lambda\end{array}$ & $\begin{array}{l}\text { 未评 } \\
\text { 价 } \\
\text { /NE }\end{array}$ & 李楠 & 部分苏铁类植物水分利用率初探 \\
\hline Cycas miquelii & 石山苏铁（有称少刺苏铁） & $\begin{array}{l}\text { 未列 } \\
\text { 入 }\end{array}$ & $\begin{array}{l}\text { 未评 } \\
\text { 价 } \\
\text { /NE }\end{array}$ & 黄玉源 & 部分苏铁类植物营养器官的解剖学研究 \\
\hline Cycas miquelii & 石山苏铁（有称少刺苏铁） & $\begin{array}{l}\text { 未列 } \\
\text { 入 }\end{array}$ & $\begin{array}{l}\text { 未评 } \\
\text { 价 } \\
\text { /NE }\end{array}$ & 黄玉源 & 部分苏铁种类亲缘关系的 ISSR 分析及分类学研究 \\
\hline
\end{tabular}


顾垒，闻丞，罗玫，王吴，吕植. 中国最受关注濒危物种保护现状快速评价的新方法探讨. 生物多样性，2015，23(5)：583-590. http://www. biodiversity-science. net/CN/article/downloadArticleFile. do?attachType=PDF\&id=10075

\begin{tabular}{|c|c|c|c|c|c|}
\hline Cycas miquelii & 石山苏铁 (有称少刺苏铁) & $\begin{array}{l}\text { 未列 } \\
\lambda\end{array}$ & $\begin{array}{l}\text { 未评 } \\
\text { 价 } \\
\text { /NE }\end{array}$ & 唐源江 & 六种苏铁属植物的羽片比较解剖学研究 \\
\hline Cycas miquelii & 石山苏铁（有称少刺苏铁） & $\begin{array}{l}\text { 未列 } \\
\text { 入 }\end{array}$ & $\begin{array}{l}\text { 未评 } \\
\text { 价 } \\
\text { /NE }\end{array}$ & 唐源江 & 石山苏铁与锈毛苏铁羽片解剖学研究 \\
\hline Cycas miquelii & 石山苏铁（有称少刺苏铁） & $\begin{array}{l}\text { 未列 } \\
入\end{array}$ & $\begin{array}{l}\text { 未评 } \\
\text { 价 } \\
\text { /NE }\end{array}$ & 崔大方 & 土壤理化性状及微量元素含量对少刺苏铁生长的影响 \\
\hline Cycas miquelii & 石山苏铁（有称少刺苏铁） & $\begin{array}{l}\text { 未列 } \\
\lambda\end{array}$ & $\begin{array}{l}\text { 未评 } \\
\text { 价 } \\
\text { /NE }\end{array}$ & 龚洵 & 五种苏铁属植物的核形态 \\
\hline Cycas miquelii & 石山苏铁（有称少刺苏铁） & $\begin{array}{l}\text { 未列 } \\
\text { 入 }\end{array}$ & $\begin{array}{l}\text { 未评 } \\
\text { 价 } \\
\text { /NE }\end{array}$ & 林鉴钊 & 五种苏铁羽叶和羽片的生长发育 \\
\hline Cycas multipinnata & 多歧苏铁 & I & $\begin{array}{l}\text { 濒危 } \\
\text { /EN }\end{array}$ & 郑芳勤 & 5 种国产苏铁的核型和核型进化 \\
\hline Cycas multipinnata & 多歧苏铁 & I & $\begin{array}{l}\text { 濒危 } \\
\text { /EN }\end{array}$ & 黄玉源 & 部分苏铁类植物营养器官的解剖学研究 \\
\hline
\end{tabular}


顾垒，闻丞，罗玫，王吴，吕植. 中国最受关注濒危物种保护现状快速评价的新方法探讨. 生物多样性，2015，23(5)：583-590. http://www biodiversity-science. net/CN/article/downloadArticleFile. do?attachType=PDF\&id=10075

\begin{tabular}{|c|c|c|c|c|c|}
\hline Cycas multipinnata & 多歧苏铁 & I & $\begin{array}{l}\text { 濒危 } \\
\text { /EN }\end{array}$ & 黄玉源 & 部分苏铁种类亲缘关系的 ISSR 分析及分类学研究 \\
\hline Cycas multipinnata & 多歧苏铁 & I & $\begin{array}{l}\text { 濒危 } \\
\text { /EN }\end{array}$ & 郑芳勤 & 叉叶类苏铁是苏铁属植物中最进化的种群 \\
\hline Cycas multipinnata & 多歧苏铁 & I & $\begin{array}{l}\text { 濒危 } \\
/ \mathrm{EN}\end{array}$ & 楚永兴 & 多歧苏铁和长柄叉叶苏铁杂交育种的初步研究 \\
\hline Cycas multipinnata & 多歧苏铁 & I & $\begin{array}{l}\text { 濒危 } \\
\text { /EN }\end{array}$ & 楚永兴 & 多歧苏铁人工辅助授粉的初步研究 \\
\hline Cycas multipinnata & 多歧苏铁 & I & $\begin{array}{l}\text { 濒危 } \\
\text { /EN }\end{array}$ & 龚洵 & 五种苏铁属植物的核形态 \\
\hline Cycas multipinnata & 多歧苏铁 & I & $\begin{array}{l}\text { 濒危 } \\
\text { /EN }\end{array}$ & 周小平 & 云南野生苏铁分布与濒危原因分析 \\
\hline Cycas multipinnata & 多歧苏铁 & I & $\begin{array}{l}\text { 濒危 } \\
\text { /EN }\end{array}$ & 郑芳勤 & 再论叉叶类苏铁的进化地位 \\
\hline Cycas panzhihuaensis & 攀枝花苏铁 & I & $\begin{array}{l}\text { 易危 } \\
\text { /VU }\end{array}$ & Yunheng Ji & $\begin{array}{l}\text { DEVELOPMENT OF SEVEN NOVEL EST - SSR MARKERS FROM CYCAS } \\
\text { PANZHIHUAENSIS (CYCADACEAE) }\end{array}$ \\
\hline Cycas panzhihuaensis & 攀枝花苏铁 & I & $\begin{array}{l}\text { 易危 } \\
\text { /VU }\end{array}$ & 李楠 & 部分苏铁类植物水分利用率初探 \\
\hline Cycas panzhihuaensis & 攀枝花苏铁 & I & 易危 & 黄玉源 & 部分苏铁种类亲缘关系的 ISSR 分析及分类学研究 \\
\hline
\end{tabular}


顾垒，闻丞，罗玫，王吴，吕植. 中国最受关注濒危物种保护现状快速评价的新方法探讨. 生物多样性，2015，23(5)：583-590. http://www. biodiversity-science. net/CN/article/downloadArticleFile. do?attachType=PDF\&id=10075

\begin{tabular}{|c|c|c|c|c|c|}
\hline & & & $/ \mathrm{VU}$ & & \\
\hline \multirow[t]{2}{*}{ Cycas panzhihuaensis } & 攀枝花苏铁 & I & 易危 & 余志祥 & 灰翅串珠环蝶对攀枝花苏铁的危害及其防治 \\
\hline & & & $/ \mathrm{VU}$ & & \\
\hline \multirow[t]{2}{*}{ Cycas panzhihuaensis } & 攀枝花苏铁 & I & 易危 & 刘庆 & 计划烧除攀枝花苏铁林区地面覆盖物对苏铁生长和土壤理化性质的影响 \\
\hline & & & $/ \mathrm{VU}$ & & \\
\hline \multirow[t]{2}{*}{ Cycas panzhihuaensis } & 攀枝花苏铁 & I & 易危 & 余志祥 & 攀枝花苏铁繁殖初探 \\
\hline & & & $/ \mathrm{VU}$ & & \\
\hline \multirow[t]{2}{*}{ Cycas panzhihuaensis } & 攀枝花苏铁 & I & 易危 & 郝云庆 & 攀枝花苏铁类群的种子植物区系地理研究 \\
\hline & & & $/ \mathrm{VU}$ & & \\
\hline \multirow[t]{2}{*}{ Cycas panzhihuaensis } & 攀枝花苏铁 & I & 易危 & 夏九成 & 攀枝花苏铁愈伤诱导研究 \\
\hline & & & $/ \mathrm{VU}$ & & \\
\hline \multirow[t]{2}{*}{ Cycas panzhihuaensis } & 攀枝花苏铁 & I & 易危 & 郑毅 & 攀枝花苏铁植物内生真菌多样性的初步研究 \\
\hline & & & /VU & & \\
\hline \multirow[t]{2}{*}{ Cycas panzhihuaensis } & 攀枝花苏铁 & I & 易危 & 周小平 & 云南野生苏铁分布与濒危原因分析 \\
\hline & & & /VU & & \\
\hline \multirow[t]{2}{*}{ Cycas panzhihuaensis } & 攀枝花苏铁 & I & 易危 & 吴俊 & 在攀枝花苏铁中发现导管 \\
\hline & & & $/ \mathrm{VU}$ & & \\
\hline \multirow[t]{2}{*}{ Cycas panzhihuaensis } & 攀枝花苏铁 & I & 易危 & 唐炎林 & 珍稀濒危植物攀枝花苏铁的研究现状与展望 \\
\hline & & & $/ \mathrm{VU}$ & & \\
\hline
\end{tabular}


顾垒，闻丞，罗玫，王吴，吕植. 中国最受关注濒危物种保护现状快速评价的新方法探讨. 生物多样性，2015，23(5)：583-590. http://www. biodiversity-science. net/CN/article/downloadArticleFile. do?attachType=PDF\&id=10075

\begin{tabular}{|c|c|c|c|c|c|}
\hline Cycas panzhihuaensis & 攀枝花苏铁 & I & $\begin{array}{l}\text { 易危 } \\
\text { /VU }\end{array}$ & 张颖 & 珍稀植物攀枝花苏铁 ISSR 扩增条件的优化 \\
\hline Cycas parvulus & 元江苏铁 & $\begin{array}{l}\text { 未列 } \\
\text { 入 }\end{array}$ & $\begin{array}{l}\text { 未评 } \\
\text { 价 } \\
\text { /NE }\end{array}$ & 黄玉源 & 9 种苏铁类植物营养器官的解剖学研究 \\
\hline Cycas parvulus & 元江苏铁 & $\begin{array}{l}\text { 未列 } \\
\text { 入 }\end{array}$ & $\begin{array}{l}\text { 未评 } \\
\text { 价 } \\
\text { /NE }\end{array}$ & 黄玉源 & 八种苏铁植物叶轴的比较解剖研究 \\
\hline Cycas parvulus & 元江苏铁 & $\begin{array}{l}\text { 未列 } \\
\lambda\end{array}$ & $\begin{array}{l}\text { 未评 } \\
\text { 价 } \\
\text { /NE }\end{array}$ & 黄玉源 & 部分苏铁种类亲缘关系的 ISSR 分析及分类学研究 \\
\hline Cycas parvulus & 元江苏铁 & $\begin{array}{l}\text { 未列 } \\
\text { 入 }\end{array}$ & $\begin{array}{l}\text { 未评 } \\
\text { 价 } \\
\text { /NE }\end{array}$ & 杜凡 & 恐龙河自然保护区元江苏铁种群结构 \\
\hline Cycas pectinata & 篦齿苏铁 & I & $\begin{array}{l}\text { 易危 } \\
\text { /VU }\end{array}$ & 黄玉源 & 部分苏铁种类亲缘关系的 ISSR 分析及分类学研究 \\
\hline Cycas pectinata & 篦齿苏铁 & I & $\begin{array}{l}\text { 易危 } \\
\text { /VU }\end{array}$ & 杜凡 & 澜沧江中下游篦齿苏铁种群结构及其保护对策 \\
\hline Cycas pectinata & 篦齿苏铁 & I & 易危 & 周小平 & 云南野生苏铁分布与濒危原因分析 \\
\hline
\end{tabular}


顾垒，闻丞，罗玫，王吴，吕植. 中国最受关注濒危物种保护现状快速评价的新方法探讨. 生物多样性，2015，23(5)：583-590. http://www. biodiversity-science. net/CN/article/downloadArticleFile. do?attachType=PDF\&id=10075

\begin{tabular}{|c|c|c|c|c|c|}
\hline & & & $/ \mathrm{VU}$ & & \\
\hline \multirow[t]{2}{*}{ Cycas revoluta } & 苏铁 & I & 无危 & 郑芳勤 & 5 种国产苏铁的核型和核型进化 \\
\hline & & & $/ \mathrm{LC}$ & & \\
\hline \multirow[t]{2}{*}{ Cycas revoluta } & 苏铁 & I & 无危 & 李小霞 & 5 种杀菌剂对苏铁叶枯病病菌的室内毒力测定 \\
\hline & & & $/ \mathrm{LC}$ & & \\
\hline \multirow[t]{2}{*}{ Cycas revoluta } & 苏铁 & I & 无危 & Chia-Jui Chen & Comments on Cycas, Dyerocycas and Epicycas (Cycadaceae) \\
\hline & & & $/ \mathrm{LC}$ & & \\
\hline \multirow[t]{2}{*}{ Cycas revoluta } & 苏铁 & I & 无危 & 李东亮 & CTAB 法提取苏铁基因组 DNA 的条件优化 \\
\hline & & & $/ \mathrm{LC}$ & & \\
\hline \multirow[t]{2}{*}{ Cycas revoluta } & 苏铁 & I & 无危 & Nan Li & Maternal inheritance of plastids and mitochondria in Cycas L. (Cycadaceae) \\
\hline & & & $/ \mathrm{LC}$ & & \\
\hline \multirow[t]{2}{*}{ Cycas revoluta } & 苏铁 & I & 无危 & 黄玉源 & 部分苏铁种类亲缘关系的 ISSR 分析及分类学研究 \\
\hline & & & $/ \mathrm{LC}$ & & \\
\hline \multirow[t]{2}{*}{ Cycas revoluta } & 苏铁 & I & 无危 & 张克昌 & 福建省苏铁属植物野生分布生境及保护现状研究 \\
\hline & & & $/ \mathrm{LC}$ & & \\
\hline \multirow[t]{2}{*}{ Cycas revoluta } & 苏铁 & I & 无危 & 赖钟雄 & 福建苏铁_Cycasrevoluta_ISSR 分子标记研究 \\
\hline & & & /LC & & \\
\hline \multirow[t]{2}{*}{ Cycas revoluta } & 苏铁 & I & 无危 & 郑芳勤 & 福建苏铁调查研究初报 \\
\hline & & & /LC & & \\
\hline
\end{tabular}


顾垒，闻丞，罗玫，王吴，吕植. 中国最受关注濒危物种保护现状快速评价的新方法探讨. 生物多样性，2015，23(5)：583-590. http://www. biodiversity-science. net/CN/article/downloadArticleFile. do?attachType=PDF\&id=10075

\begin{tabular}{|c|c|c|c|c|c|}
\hline Cycas revoluta & 苏铁 & I & $\begin{array}{l}\text { 无危 } \\
\text { /LC }\end{array}$ & 雷艳梅 & 广西南宁苏铁曲纹紫灰蝶的发生及防治 \\
\hline Cycas revoluta & 苏铁 & I & $\begin{array}{l}\text { 无危 } \\
\text { /LC }\end{array}$ & 黎德丘 & 广西野生苏铁资源现状与保护对策 \\
\hline Cycas revoluta & 苏铁 & I & $\begin{array}{l}\text { 无危 } \\
\text { /LC }\end{array}$ & 吴兴亮 & 贵州望谟苏铁自然保护区大型真菌种类及其生态特征 \\
\hline Cycas revoluta & 苏铁 & I & $\begin{array}{l}\text { 无危 } \\
\text { /LC }\end{array}$ & 穆彪 & 贵州望谟苏铁自然保护区气候生态资源 \\
\hline Cycas revoluta & 苏铁 & I & $\begin{array}{l}\text { 无危 } \\
\text { /LC }\end{array}$ & 韦堂灵 & 贵州望谟苏铁自然保护区珍稀濒危植物资源研究 \\
\hline Cycas revoluta & 苏铁 & I & $\begin{array}{l}\text { 无危 } \\
\text { /LC }\end{array}$ & 黄玉源 & 基于 RAPD 分析的中国苏铁属部分种类亲缘关系探讨 \\
\hline Cycas revoluta & 苏铁 & I & $\begin{array}{l}\text { 无危 } \\
\text { /LC }\end{array}$ & 宋铁英 & 几种引物对苏铁共生蓝细菌的 DN A 多态性分析 \\
\hline Cycas revoluta & 苏铁 & I & $\begin{array}{l}\text { 无危 } \\
\text { /LC }\end{array}$ & 陈军 & 进境苏铁种苗有害生物风险分析 \\
\hline Cycas revoluta & 苏铁 & I & $\begin{array}{l}\text { 无危 } \\
\text { /LC }\end{array}$ & 陈涁 & 蓝细菌与福建苏铁(Cycas revoluta) 的侵染性重组的研究 \\
\hline Cycas revoluta & 苏铁 & I & 无危 & 郑伟文 & 蓝细菌与苏铁重组的研究 \\
\hline
\end{tabular}


顾垒，闻丞，罗玫，王吴，吕植. 中国最受关注濒危物种保护现状快速评价的新方法探讨. 生物多样性，2015，23(5)：583-590. http://www. biodiversity-science. net/CN/article/downloadArticleFile. do?attachType=PDF\&id=10075

\begin{tabular}{|c|c|c|c|c|c|}
\hline & & & $/ \mathrm{LC}$ & & \\
\hline \multirow[t]{2}{*}{ Cycas revoluta } & 苏铁 & I & 无危 & 林庆良 & 离体培养诱导多头型苏铁 \\
\hline & & & $/ \mathrm{LC}$ & & \\
\hline \multirow[t]{2}{*}{ Cycas revoluta } & 苏铁 & I & 无危 & 周洁敏 & 论中国苏铁的现状及保护 \\
\hline & & & $/ \mathrm{LC}$ & & \\
\hline \multirow[t]{2}{*}{ Cycas revoluta } & 苏铁 & I & 无危 & 郑晓慧 & 攀西地区苏铁叶部真菌病害鉴定 \\
\hline & & & $/ \mathrm{LC}$ & & \\
\hline \multirow[t]{2}{*}{ Cycas revoluta } & 苏铁 & I & 无危 & 黄中强 & 攀枝花市苏铁植物保护与利用初探 \\
\hline & & & $/ \mathrm{LC}$ & & \\
\hline \multirow[t]{2}{*}{ Cycas revoluta } & 苏铁 & I & 无危 & 吴剑龙 & 浅析苏铁病虫害的防治 \\
\hline & & & $/ \mathrm{LC}$ & & \\
\hline \multirow[t]{2}{*}{ Cycas revoluta } & 苏铁 & $\mathrm{I}$ & 无危 & 陈达嵩 & 泉州市苏铁介壳虫加剧发生的原因与防治 \\
\hline & & & $/ \mathrm{LC}$ & & \\
\hline \multirow[t]{2}{*}{ Cycas revoluta } & 苏铁 & I & 无危 & 潘爱芳 & 苏铁( Cycas revoluta Thunb.) 种子的胚与肧乳解剖结构研究 \\
\hline & & & $/ \mathrm{LC}$ & & \\
\hline \multirow[t]{2}{*}{ Cycas revoluta } & 苏铁 & I & 无危 & 傅瑞树 & 苏铁( Cycas revoluta)研究的现状及展望 \\
\hline & & & /LC & & \\
\hline \multirow[t]{2}{*}{ Cycas revoluta } & 苏铁 & I & 无危 & 朱 华 & 苏铁 nrDNA ITS 区的序列多态性：不完全致同进化的证据 \\
\hline & & & /LC & & \\
\hline
\end{tabular}


顾垒，闻丞，罗玫，王吴，吕植. 中国最受关注濒危物种保护现状快速评价的新方法探讨. 生物多样性，2015，23(5)：583-590. http://www. biodiversity-science. net/CN/article/downloadArticleFile. do?attachType=PDF\&id=10075

\begin{tabular}{|c|c|c|c|c|c|}
\hline Cycas revoluta & 苏铁 & I & $\begin{array}{l}\text { 无危 } \\
\text { /LC }\end{array}$ & 阮志平 & 苏铁白盾蚧发生规律及综合治理的研究 \\
\hline Cycas revoluta & 苏铁 & I & $\begin{array}{l}\text { 无危 } \\
\text { /LC }\end{array}$ & 杨伟贤 & 苏铁白盾蚧生物学及防治试验 \\
\hline Cycas revoluta & 苏铁 & I & $\begin{array}{l}\text { 无危 } \\
\text { /LC }\end{array}$ & 洪跃明 & 苏铁的核型分析 \\
\hline Cycas revoluta & 苏铁 & I & $\begin{array}{l}\text { 无危 } \\
\text { /LC }\end{array}$ & 薛德乾 & 苏铁的一种新害虫曲纹紫灰蝶及其防治对策研究 \\
\hline Cycas revoluta & 苏铁 & I & $\begin{array}{l}\text { 无危 } \\
\text { /LC }\end{array}$ & 沙万友 & 苏铁盾蚧对攀枝花苏铁危害及防治初探 \\
\hline Cycas revoluta & 苏铁 & I & $\begin{array}{l}\text { 无危 } \\
\text { /LC }\end{array}$ & 李楠 & 苏铁光合特性的研究 \\
\hline Cycas revoluta & 苏铁 & I & $\begin{array}{l}\text { 无危 } \\
\text { /LC }\end{array}$ & 任如红 & 苏铁茎端分枝类型及其成因的观察研究 \\
\hline Cycas revoluta & 苏铁 & I & $\begin{array}{l}\text { 无危 } \\
\text { /LC }\end{array}$ & 傅瑞树 & 苏铁抗寒生理特性研究 \\
\hline Cycas revoluta & 苏铁 & I & $\begin{array}{l}\text { 无危 } \\
\text { /LC }\end{array}$ & 苏建英 & 苏铁类珊瑚根内藻胞层的解剖观察 \\
\hline Cycas revoluta & 苏铁 & I & 无危 & 黄玉源 & 苏铁类植物 4 个属的导管与被子植物导管结构特征的比较研究 \\
\hline
\end{tabular}


顾垒，闻丞，罗玫，王吴，吕植. 中国最受关注濒危物种保护现状快速评价的新方法探讨. 生物多样性，2015，23(5)：583-590. http://www. biodiversity-science. net/CN/article/downloadArticleFile. do?attachType=PDF\&id=10075

\begin{tabular}{|c|c|c|c|c|c|}
\hline & & & $/ \mathrm{LC}$ & & \\
\hline \multirow[t]{2}{*}{ Cycas revoluta } & 苏铁 & I & 无危 & 杨泉光 & 苏铁类植物传粉生物学研究进展(综述) \\
\hline & & & $/ \mathrm{LC}$ & & \\
\hline \multirow[t]{2}{*}{ Cycas revoluta } & 苏铁 & I & 无危 & 王新荣 & 苏铁镰刀菌球茎腐烂病化学防治技术研究 \\
\hline & & & $/ \mathrm{LC}$ & & \\
\hline \multirow[t]{2}{*}{ Cycas revoluta } & 苏铁 & I & 无危 & 李楠 & 苏铁镰刀菌球茎腐烂病症状及病原鉴定 \\
\hline & & & $/ \mathrm{LC}$ & & \\
\hline \multirow[t]{2}{*}{ Cycas revoluta } & 苏铁 & I & 无危 & 傅瑞树 & 苏铁耐旱、抗寒及光合生理特性研究 \\
\hline & & & $/ \mathrm{LC}$ & & \\
\hline \multirow[t]{2}{*}{ Cycas revoluta } & 苏铁 & I & 无危 & 蔡建武 & 苏铁曲纹紫灰蝶的发生与防治 \\
\hline & & & $/ \mathrm{LC}$ & & \\
\hline \multirow[t]{2}{*}{ Cycas revoluta } & 苏铁 & I & 无危 & 吴伟坚 & 苏铁曲纹紫灰蝶在广州严重发生的原因及防治对策 \\
\hline & & & $/ \mathrm{LC}$ & & \\
\hline \multirow[t]{2}{*}{ Cycas revoluta } & 苏铁 & I & 无危 & 满国杰 & 苏铁人工授粉有性繁殖技术初探 \\
\hline & & & $/ \mathrm{LC}$ & & \\
\hline \multirow[t]{2}{*}{ Cycas revoluta } & 苏铁 & I & 无危 & 伍建榕 & 苏铁珊瑚根结构观察及其内生放线菌分离 \\
\hline & & & /LC & & \\
\hline \multirow[t]{2}{*}{ Cycas revoluta } & 苏铁 & I & 无危 & 郑伟文 & 苏铁珊瑚状根及根周围土壤中蓝细菌的 PCR 指纹图谱 \\
\hline & & & /LC & & \\
\hline
\end{tabular}


顾垒，闻丞，罗玫，王吴，吕植. 中国最受关注濒危物种保护现状快速评价的新方法探讨. 生物多样性，2015，23(5)：583-590. http://www. biodiversity-science. net/CN/article/downloadArticleFile. do?attachType=PDF\&id=10075

\begin{tabular}{|c|c|c|c|c|c|}
\hline Cycas revoluta & 苏铁 & I & $\begin{array}{l}\text { 无危 } \\
\text { /LC }\end{array}$ & 李楠 & 苏铁属花粉萌发及保存条件研究 \\
\hline Cycas revoluta & 苏铁 & I & $\begin{array}{l}\text { 无危 } \\
\text { /LC }\end{array}$ & 李楠 & 苏铁属有性繁殖若干问题的研究 \\
\hline Cycas revoluta & 苏铁 & I & $\begin{array}{l}\text { 无危 } \\
\text { /LC }\end{array}$ & 黄玉源 & 苏铁属植物 RAPD 反应体系的优化及部分种类亲缘关系的探索 \\
\hline Cycas revoluta & 苏铁 & I & $\begin{array}{l}\text { 无危 } \\
\text { /LC }\end{array}$ & 郑品光 & 苏铁属植物大抱子叶特征研究 \\
\hline Cycas revoluta & 苏铁 & I & $\begin{array}{l}\text { 无危 } \\
\text { /LC }\end{array}$ & 徐峰 & 苏铁属植物的根系类型及肉质根的解剖研究 \\
\hline Cycas revoluta & 苏铁 & I & $\begin{array}{l}\text { 无危 } \\
\text { /LC }\end{array}$ & 朱雪良 & 苏铁小灰蝶的发生及防治 \\
\hline Cycas revoluta & 苏铁 & I & $\begin{array}{l}\text { 无危 } \\
\text { /LC }\end{array}$ & 刘春来 & 苏铁小灰蝶发生为害特点及防治技术初探 \\
\hline Cycas revoluta & 苏铁 & I & $\begin{array}{l}\text { 无危 } \\
\text { /LC }\end{array}$ & 陈涁 & 苏铁与蓝细菌的共生 \\
\hline Cycas revoluta & 苏铁 & I & $\begin{array}{l}\text { 无危 } \\
\text { /LC }\end{array}$ & 孔维民 & 苏铁与苏铁䕬的差异比较 \\
\hline Cycas revoluta & 苏铁 & I & 无危 & 伍群玉 & 苏铁植物无性繁殖技术研究 \\
\hline
\end{tabular}


顾垒，闻丞，罗玫，王吴，吕植. 中国最受关注濒危物种保护现状快速评价的新方法探讨. 生物多样性，2015，23(5)：583-590. http://www. biodiversity-science. net/CN/article/downloadArticleFile. do?attachType=PDF\&id=10075

\begin{tabular}{|c|c|c|c|c|c|}
\hline & & & $/ \mathrm{LC}$ & & \\
\hline \multirow[t]{2}{*}{ Cycas revoluta } & 苏铁 & I & 无危 & 丁立生 & 苏铁植物研究概况 \\
\hline & & & $/ \mathrm{LC}$ & & \\
\hline \multirow[t]{2}{*}{ Cycas revoluta } & 苏铁 & I & 无危 & 潘爱芳 & 苏铁种子的种皮结构特征研究 \\
\hline & & & $/ \mathrm{LC}$ & & \\
\hline \multirow[t]{2}{*}{ Cycas revoluta } & 苏铁 & I & 无危 & 王晶 & 苏铁主要病虫害的发生特点及防治措施 \\
\hline & & & $/ \mathrm{LC}$ & & \\
\hline \multirow[t]{2}{*}{ Cycas revoluta } & 苏铁 & I & 无危 & 秦元丽 & 苏铁主要病虫害及其防治对策 \\
\hline & & & $/ \mathrm{LC}$ & & \\
\hline \multirow[t]{2}{*}{ Cycas revoluta } & 苏铁 & I & 无危 & 吉成均 & 银杏和苏铁类植物的生殖特征比较 \\
\hline & & & $/ \mathrm{LC}$ & & \\
\hline \multirow[t]{2}{*}{ Cycas revoluta } & 苏铁 & I & 无危 & 丁艳 & 云南省苏铁属植物资源的保护及建议 \\
\hline & & & $/ \mathrm{LC}$ & & \\
\hline \multirow[t]{2}{*}{ Cycas revoluta } & 苏铁 & I & 无危 & 吴萍 & 云南苏铁植物的现状及保护对策 \\
\hline & & & $/ \mathrm{LC}$ & & \\
\hline \multirow[t]{2}{*}{ Cycas revoluta } & 苏铁 & I & 无危 & 何绍顺 & 云南野生苏铁就地保护区生境研究 \\
\hline & & & /LC & & \\
\hline \multirow[t]{2}{*}{ Cycas revoluta } & 苏铁 & I & 无危 & 蔡祖国 & 植物生长调节剂对苏铁水培生根诱导的影响 \\
\hline & & & /LC & & \\
\hline
\end{tabular}


顾垒，闻丞，罗玫，王吴，吕植. 中国最受关注濒危物种保护现状快速评价的新方法探讨. 生物多样性，2015，23(5)：583-590. http://www. biodiversity-science. net/CN/article/downloadArticleFile. do?attachType=PDF\&id=10075

\begin{tabular}{|c|c|c|c|c|c|}
\hline \multirow[t]{2}{*}{ Cycas revoluta } & 苏铁 & I & 无危 & 黄玉源 & 中国苏铁科部分种的 RAPD 分析及其亲缘关系的研究 \\
\hline & & & $/ \mathrm{LC}$ & & \\
\hline \multirow[t]{2}{*}{ Cycas revoluta } & 苏铁 & I & 无危 & 徐正会 & 中国苏铁科植物已知病虫害及其防治研究概况 \\
\hline & & & $/ \mathrm{LC}$ & & \\
\hline \multirow[t]{2}{*}{ Cycas revoluta } & 苏铁 & I & 无危 & 韦丽君 & 中国苏铁属植物保护现状与展望 \\
\hline & & & $/ \mathrm{LC}$ & & \\
\hline \multirow[t]{2}{*}{ Cycas revoluta } & 苏铁 & I & 无危 & 马永 & 中国苏铁属植物的分类学研究现状与展望 \\
\hline & & & $/ \mathrm{LC}$ & & \\
\hline \multirow[t]{2}{*}{ Cycas revoluta } & 苏铁 & I & 无危 & 雷朝云 & 中国野生苏铁观赏植物种质资源 \\
\hline & & & $/ \mathrm{LC}$ & & \\
\hline \multirow[t]{2}{*}{ Cycas rumphii } & 华南苏铁（有称刺叶苏铁, 存疑） & 未列 & 易危 & 黄玉源 & 部分苏铁种类亲缘关系的 ISSR 分析及分类学研究 \\
\hline & & 入 & /VU & & \\
\hline \multirow[t]{2}{*}{ Cycas rumphii } & 华南苏铁（有称刺叶苏铁, 存疑） & 未列 & 易危 & 李青青 & 刺叶苏铁 EST 序列中 SSR 信息分析 \\
\hline & & 入 & /VU & & \\
\hline \multirow[t]{2}{*}{ Cycas rumphii } & 华南苏铁（有称刺叶苏铁, 存疑） & 未列 & 易危 & 王定跃 & 一个被错误鉴定的苏铁名称———华南苏铁 \\
\hline & & 入 & /VU & & \\
\hline \multirow[t]{2}{*}{ Cycas segmentifida } & 叉孢苏铁 & I & 易危 & 黄玉源 & 部分苏铁类植物的解剖结构特征及其与环境的适应性研究 \\
\hline & & & $/ \mathrm{VU}$ & & \\
\hline Cycas segmentifida & 叉孢苏铁 & I & 易危 & 黄玉源 & 部分苏铁种类亲缘关系的 ISSR 分析及分类学研究 \\
\hline
\end{tabular}


顾垒，闻丞，罗玫，王吴，吕植. 中国最受关注濒危物种保护现状快速评价的新方法探讨. 生物多样性，2015，23(5)：583-590. http://www. biodiversity-science. net/CN/article/downloadArticleFile. do?attachType=PDF\&id=10075

\begin{tabular}{|c|c|c|c|c|c|}
\hline & & & $/ \mathrm{VU}$ & & \\
\hline \multirow[t]{2}{*}{ Cycas segmentifida } & 叉孢苏铁 & I & 易危 & 李楠 & 叉孢苏铁 ISSR 反应条件的优化及初步应用 \\
\hline & & & $/ \mathrm{VU}$ & & \\
\hline \multirow[t]{2}{*}{ Cycas segmentifida } & 叉孢苏铁 & I & 易危 & 黄玉源 & 叉孢苏铁茎的解剖学研究 \\
\hline & & & /VU & & \\
\hline \multirow[t]{2}{*}{ Cycas segmentifida } & 叉孢苏铁 & I & 易危 & 李楠 & 广西百色地区叉孢苏铁复合体的分类学与遗传多样性研究 \\
\hline & & & /VU & & \\
\hline \multirow[t]{2}{*}{ Cycas segmentifida } & 叉孢苏铁 & I & 易危 & 邓朝义 & 贵州苏铁属植物资源 \\
\hline & & & $/ \mathrm{VU}$ & & \\
\hline \multirow[t]{2}{*}{ Cycas segmentifida } & 叉孢苏铁 & I & 易危 & 黄玉源 & 我国两种特有苏铁的生态环境及叶片结构 \\
\hline & & & /VU & & \\
\hline \multirow[t]{2}{*}{ Cycas segmentifida } & 叉孢苏铁 & I & 易危 & 龚洵 & 五种中国苏铁属植物的核型分析 \\
\hline & & & /VU & & \\
\hline \multirow[t]{2}{*}{ Cycas siamensis } & 云南苏铁 & 未列 & 易危 & 黄玉源 & 暹罗苏铁茎的解剖学研究 \\
\hline & & 入 & /VU & & \\
\hline \multirow[t]{2}{*}{ Cycas siamensis } & 云南苏铁 & 未列 & 易危 & 吴萍 & 云南苏铁植物的现状及保护对策 \\
\hline & & 入 & /VU & & \\
\hline \multirow[t]{2}{*}{ Cycas simplicipinna } & 单羽苏铁 & 未列 & 近危 & 潘跃芝 & 濒危植物单羽苏铁 SSR 引物的篮选 \\
\hline & & 入 & /NT & & \\
\hline
\end{tabular}


顾垒，闻丞，罗玫，王吴，吕植. 中国最受关注濒危物种保护现状快速评价的新方法探讨. 生物多样性，2015，23(5)：583-590. http://www biodiversity-science. net/CN/article/downloadArticleFile. do?attachType=PDF\&id=10075

\begin{tabular}{|c|c|c|c|c|c|}
\hline \multirow[t]{2}{*}{ Cycas szechuanensis } & 四川苏铁 & I & 极危 & 李楠 & 部分苏铁类植物水分利用率初探 \\
\hline & & & /CR & & \\
\hline \multirow[t]{2}{*}{ Cycas szechuanensis } & 四川苏铁 & I & 极危 & 黄玉源 & 部分苏铁种类亲缘关系的 ISSR 分析及分类学研究 \\
\hline & & & /CR & & \\
\hline \multirow[t]{2}{*}{ Cycas szechuanensis } & 四川苏铁 & I & 极危 & 唐源江 & 六种苏铁属植物的羽片比较解剖学研究 \\
\hline & & & /CR & & \\
\hline \multirow[t]{2}{*}{ Cycas szechuanensis } & 四川苏铁 & I & 极危 & 肖德兴 & 四川苏铁(Cycas szechuanensis)营养器官的解剖结构研究 \\
\hline & & & /CR & & \\
\hline \multirow[t]{2}{*}{ Cycas szechuanensis } & 四川苏铁 & I & 极危 & 张纪卯 & 四川苏铁的生态环境及单性繁衍状况调查分析 \\
\hline & & & /CR & & \\
\hline \multirow[t]{2}{*}{ Cycas szechuanensis } & 四川苏铁 & I & 极危 & 李楠 & 四川苏铁的资源调查和遗传多样性研究及其保育策略 \\
\hline & & & /CR & & \\
\hline \multirow[t]{2}{*}{ Cycas szechuanensis } & 四川苏铁 & I & 极危 & 蒋延生 & 四川苏铁在福建的分布生长生境调查 \\
\hline & & & /CR & & \\
\hline \multirow[t]{2}{*}{ Cycas szechuanensis } & 四川苏铁 & I & 极危 & 间德祺 & 长尾滑刃线虫对四川苏铁的专一寄生性研究 \\
\hline & & & /CR & & \\
\hline \multirow[t]{2}{*}{ Cycas taitungensis } & 台东苏铁 & I & 濒危 & 郑芳勤 & 5 种国产苏铁的核型和核型进化 \\
\hline & & & $/ \mathrm{EN}$ & & \\
\hline Cycas taitungensis & 台东苏铁 & I & 濒危 & Jianing Yu & RNA Editing Sites Exist in Protein-coding Genes in the Chloroplast Genome of Cycas \\
\hline
\end{tabular}


顾垒，闻丞，罗玫，王吴，吕植. 中国最受关注濒危物种保护现状快速评价的新方法探讨. 生物多样性，2015，23(5)：583-590. http://www. biodiversity-science. net/CN/article/downloadArticleFile. do?attachType=PDF\&id=10075

\begin{tabular}{|c|c|c|c|c|c|}
\hline & & & /EN & & taitungensis \\
\hline \multirow[t]{2}{*}{ Cycas taitungensis } & 台东苏铁 & I & 濒危 & 黄玉源 & 部分苏铁种类亲缘关系的 ISSR 分析及分类学研究 \\
\hline & & & /EN & & \\
\hline \multirow[t]{2}{*}{ Cycas taitungensis } & 台东苏铁 & I & 濒危 & 周小平 & 云南野生苏铁分布与濒危原因分析 \\
\hline & & & $/ \mathrm{EN}$ & & \\
\hline \multirow[t]{2}{*}{ Cycas taiwaniana } & 台湾苏铁 & I & 濒危 & 郑芳勤 & 5 种国产苏铁的核型和核型进化 \\
\hline & & & /EN & & \\
\hline \multirow[t]{2}{*}{ Cycas taiwaniana } & 台湾苏铁 & I & 濒危 & 黄玉源 & 9 种苏铁类植物营养器官的解剖学研究 \\
\hline & & & /EN & & \\
\hline \multirow[t]{2}{*}{ Cycas taiwaniana } & 台湾苏铁 & I & 濒危 & 黄玉源 & 八种苏铁植物叶轴的比较解剖研究 \\
\hline & & & /EN & & \\
\hline \multirow[t]{2}{*}{ Cycas taiwaniana } & 台湾苏铁 & I & 濒危 & 黄玉源 & 部分苏铁种类亲缘关系的 ISSR 分析及分类学研究 \\
\hline & & & /EN & & \\
\hline \multirow[t]{2}{*}{ Cycas taiwaniana } & 台湾苏铁 & I & 濒危 & 谢建光 & 台湾苏铁的分布及模式产地 \\
\hline & & & /EN & & \\
\hline \multirow[t]{2}{*}{ Cycas taiwaniana } & 台湾苏铁 & I & 濒危 & 陈乌定 & 台湾苏铁生境地保护现状与对策 \\
\hline & & & /EN & & \\
\hline \multirow[t]{2}{*}{ Cycas tanqingii } & 谭清苏铁 & 未列 & 近危 & 何疆海 & 绿春县野生潭清苏铁资源分布调查及保护对策 \\
\hline & & 入 & /NT & & \\
\hline
\end{tabular}


顾垒，闻丞，罗玫，王吴，吕植. 中国最受关注濒危物种保护现状快速评价的新方法探讨. 生物多样性，2015，23(5)：583-590. http://www. biodiversity-science. net/CN/article/downloadArticleFile. do?attachType=PDF\&id=10075

\begin{tabular}{|c|c|c|c|c|c|}
\hline \multirow[t]{2}{*}{ Cycas tanqingii } & 谭清苏铁 & 未列 & 近危 & 景建洲 & 谭清苏铁性别连锁的 RAPD 和 SCAR 分子标记 \\
\hline & & $\lambda$ & /NT & & \\
\hline \multirow[t]{2}{*}{ Cycas tanqingii } & 谭清苏铁 & 未列 & 近危 & 景建洲 & 谭清苏铁性别相关的 RAPD 标记研究 \\
\hline & & 入 & /NT & & \\
\hline \multirow[t]{2}{*}{ Cycas tanqingii } & 谭清苏铁 & 未列 & 近危 & 龚洵 & 潭清苏铁的生境、种群结构与动态的研究 \\
\hline & & 入 & /NT & & \\
\hline \multirow[t]{2}{*}{ Cycas tanqingii } & 谭清苏铁 & 未列 & 近危 & 龚洵 & 五种苏铁属植物的核形态 \\
\hline & & 入 & /NT & & \\
\hline \multirow[t]{3}{*}{ Cyclobalanopsis rex } & 大果青冈 & 未列 & 数据 & 陈焕镛 & 《中国植物志》第 22 卷 291 页 \\
\hline & & 入 & 不足 & & \\
\hline & & & $/ \mathrm{DD}$ & & \\
\hline \multirow[t]{2}{*}{ Cymbidium nanulum } & 珍珠矮 & I & 濒危 & 李玉阁 & 4 种国产兰属植物的核型比较研究 \\
\hline & & & $/ \mathrm{EN}$ & & \\
\hline \multirow[t]{2}{*}{ Cymbidium nanulum } & 珍珠矮 & I & 濒危 & 周丽 & 兰花种间杂种的非共生萌发研究和 ISSR 分析 \\
\hline & & & /EN & & \\
\hline \multirow[t]{2}{*}{ Cymbidium nanulum } & 珍珠矮 & I & 濒危 & 王玉东 & 兰属和石斛属植物的遗传多样性研究 \\
\hline & & & $/ \mathrm{EN}$ & & \\
\hline Cymbidium nanulum & 珍珠矮 & I & 濒危 & 薛润光 & 兰属新种珍珠矮的组织培养与植株再生 \\
\hline
\end{tabular}


顾垒，闻丞，罗玫，王吴，吕植. 中国最受关注濒危物种保护现状快速评价的新方法探讨. 生物多样性，2015，23(5)：583-590. http://www. biodiversity-science. net/CN/article/downloadArticleFile. do?attachType=PDF\&id=10075

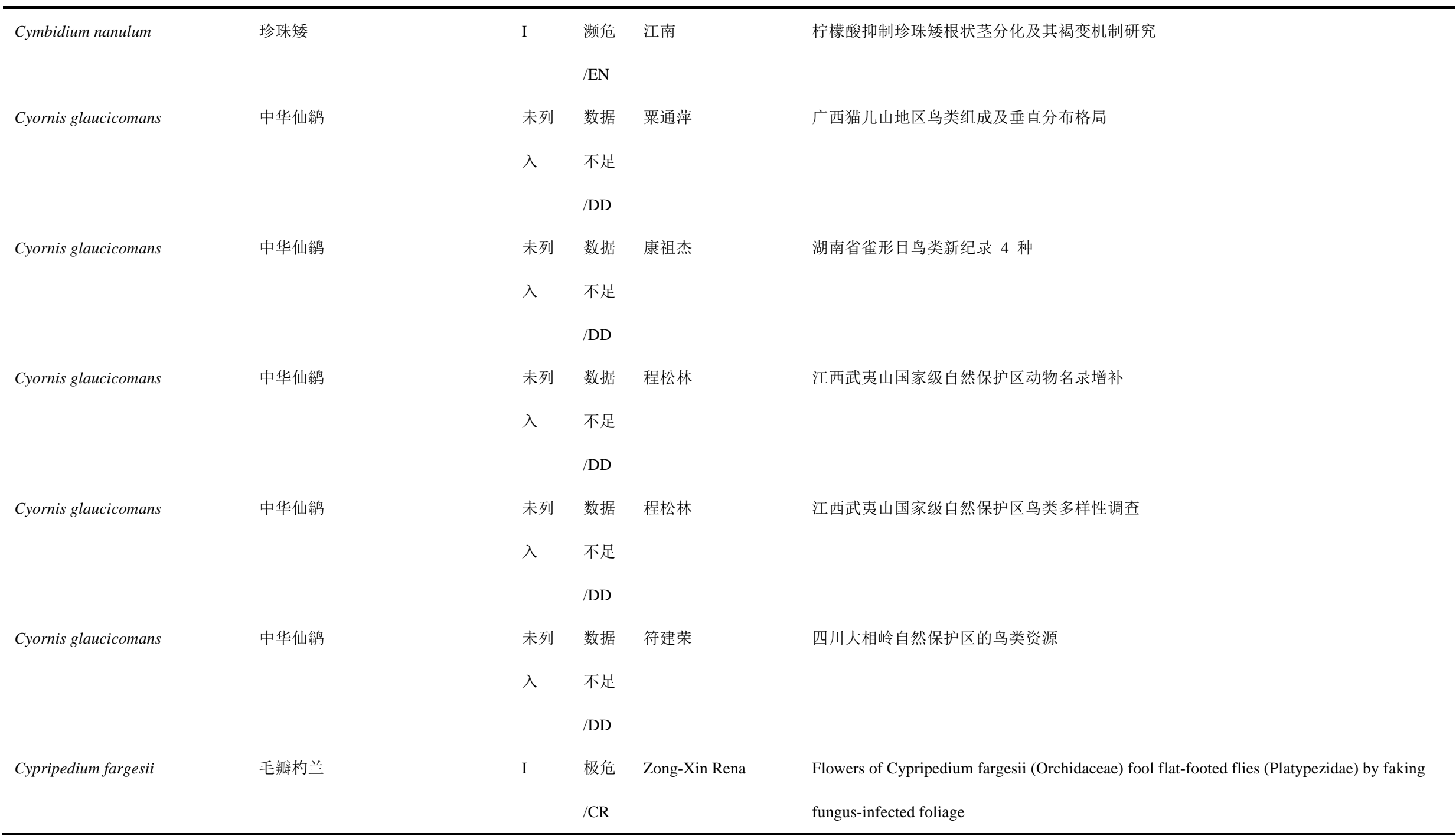


顾垒，闻丞，罗玫，王吴，吕植. 中国最受关注濒危物种保护现状快速评价的新方法探讨. 生物多样性，2015，23(5)：583-590. http://www biodiversity-science. net/CN/article/downloadArticleFile. do?attachType=PDF\&id=10075

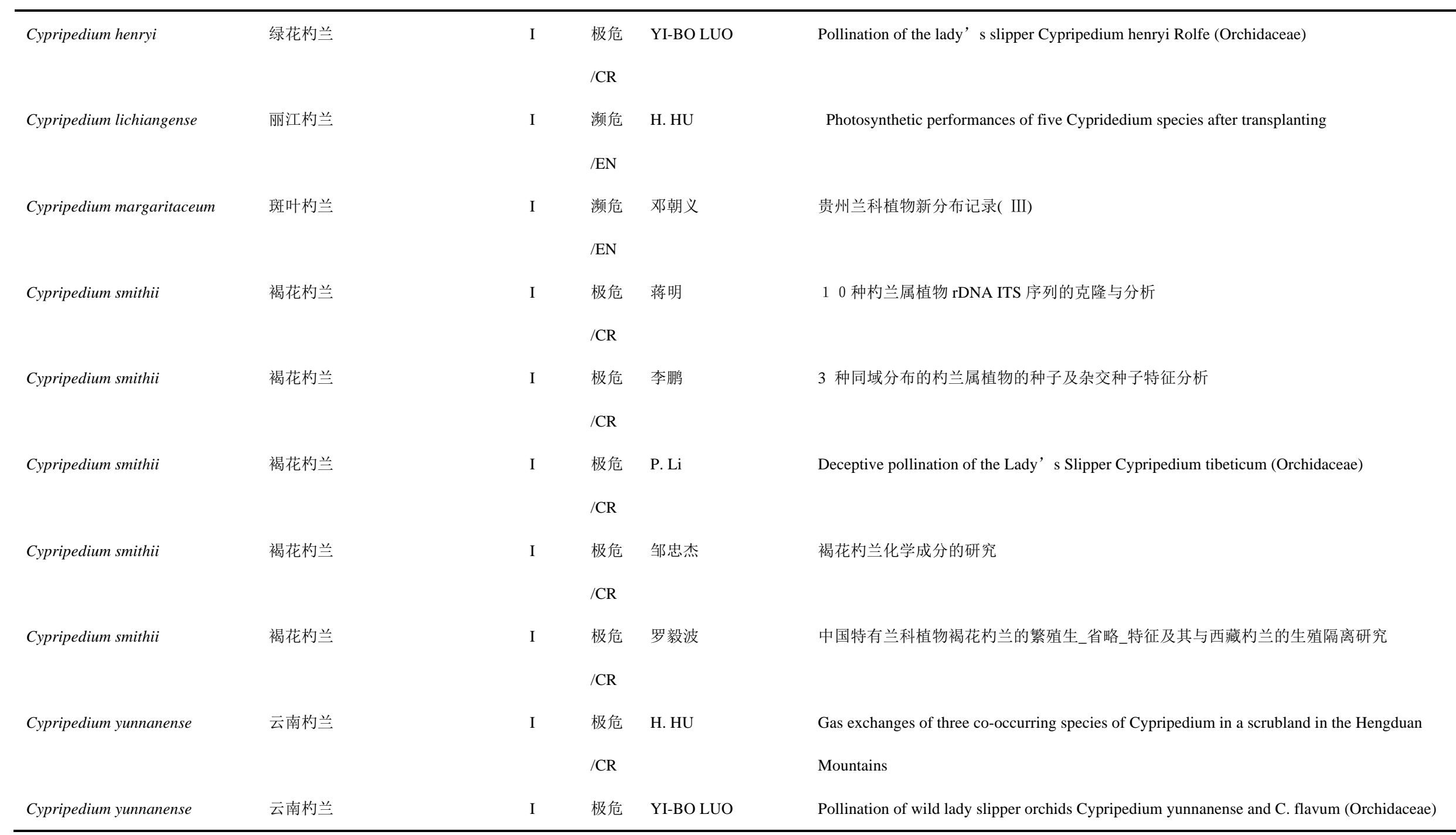


顾垒，闻丞，罗玫，王吴，吕植. 中国最受关注濒危物种保护现状快速评价的新方法探讨. 生物多样性，2015，23(5)：583-590. http://www biodiversity-science. net/CN/article/downloadArticleFile. do?attachType=PDF\&id=10075

\begin{tabular}{|c|c|c|c|c|c|}
\hline & & & /CR & & in south-west China: why are there no hybrids? \\
\hline \multirow[t]{3}{*}{ Cyrtodactylus khasiensis } & 卡西趾虎 & 未列 & 未评 & 李丕鹏 & 卡西裸趾虎一一新亚种记述 \\
\hline & & 入 & 价 & & \\
\hline & & & $/ \mathrm{NE}$ & & \\
\hline \multirow[t]{2}{*}{ Cyrtomium hemionitis } & 单叶贯众 & II & 濒危 & 成晓 & 贯众属 10 种植物染色体数目 \\
\hline & & & /EN & & \\
\hline \multirow[t]{2}{*}{ Cyrtomium nephrolepioides } & 低头贯众 & 未列 & 易危 & 郭治友 & 石灰岩地区偋类植物低头贯众的配子体发育研究 \\
\hline & & 入 & $/ \mathrm{VU}$ & & \\
\hline \multirow[t]{2}{*}{ Cystacanthus affinis } & 丽江鳔冠花 & 未列 & 濒危 & 胡嘉琪 & 《中国植物志》第 70 卷 212 页 \\
\hline & & 入 & /EN & & \\
\hline \multirow[t]{2}{*}{ Cystoathyrium chinense } & 光叶湠 & I & 极危 & Xian - Chun ZHANG & Rediscovery of Cystoathyrium chinense Ching (Cystopteridaceae) Phylogenetic placement of \\
\hline & & & /CR & & the critically endangered fern species endemic to China \\
\hline \multirow[t]{3}{*}{ Davidia involucrata } & 珙桐 & I & 未评 & WU Gang & Living characteristics of rare and endangered species-Davidia involucrata \\
\hline & & & 价 & & \\
\hline & & & $/ \mathrm{NE}$ & & \\
\hline \multirow[t]{3}{*}{ Davidia involucrata } & 珙桐 & I & 未评 & 罗柏青 & 滇东北珙桐群落结构特征研究 \\
\hline & & & 价 & & \\
\hline & & & $/ \mathrm{NE}$ & & \\
\hline Davidia involucrata & 珙桐 & I & 未评 & 吴明开 & 梵净山自然保护区珙桐天然种群生命表与生存分析 \\
\hline
\end{tabular}


顾垒，闻丞，罗玫，王吴，吕植. 中国最受关注濒危物种保护现状快速评价的新方法探讨．生物多样性，2015，23(5)：583-590。 http://www. biodiversity-science. net/CN/article/downloadArticleFile. do?attachType=PDF\&id=10075

\begin{tabular}{|c|c|c|c|c|c|}
\hline \multirow[b]{2}{*}{ Davidia involucrata } & \multirow[b]{2}{*}{ 珙桐 } & & \multicolumn{3}{|l|}{ 价 } \\
\hline & & I & $\begin{array}{l}\text { /NE } \\
\text { 未评 } \\
\text { 价 }\end{array}$ & 占玉燕 & 珙桐濒危原因研究现状及展望 \\
\hline Davidia involucrata & 琪桐 & I & $\begin{array}{l}\text { /NE } \\
\text { 未评 } \\
\text { 价 }\end{array}$ & 夏晗 & 珙桐初代培养研究 \\
\hline Davidia involucrata & 珙桐 & I & $\begin{array}{l}/ \mathrm{NE} \\
\text { 未评 } \\
\text { 价 }\end{array}$ & 胡进耀 & 珙桐传粉诱物花色 \\
\hline Davidia involucrata & 琪桐 & I & $\begin{array}{l}/ \mathrm{NE} \\
\text { 未评 } \\
\text { 价 }\end{array}$ & 陈迎辉 & 珙桐的生物生态特性和人工引种促花研究 \\
\hline Davidia involucrata & 珙桐 & I & $\begin{array}{l}\text { /NE } \\
\text { 未评 } \\
\text { 价 }\end{array}$ & 范川 & 珙桐的研究现状及展望 \\
\hline Davidia involucrata & 珙桐 & I & $\begin{array}{l}/ \mathrm{NE} \\
\text { 未评 } \\
\text { 价 }\end{array}$ & 彭红丽 & 珙桐花粉离体萌发及花粉管生长研究 \\
\hline
\end{tabular}


顾垒，闻丞，罗玫，王吴，吕植. 中国最受关注濒危物种保护现状快速评价的新方法探讨. 生物多样性，2015，23(5)：583-590. http://www. biodiversity-science. net/CN/article/downloadArticleFile. do?attachType=PDF\&id=10075

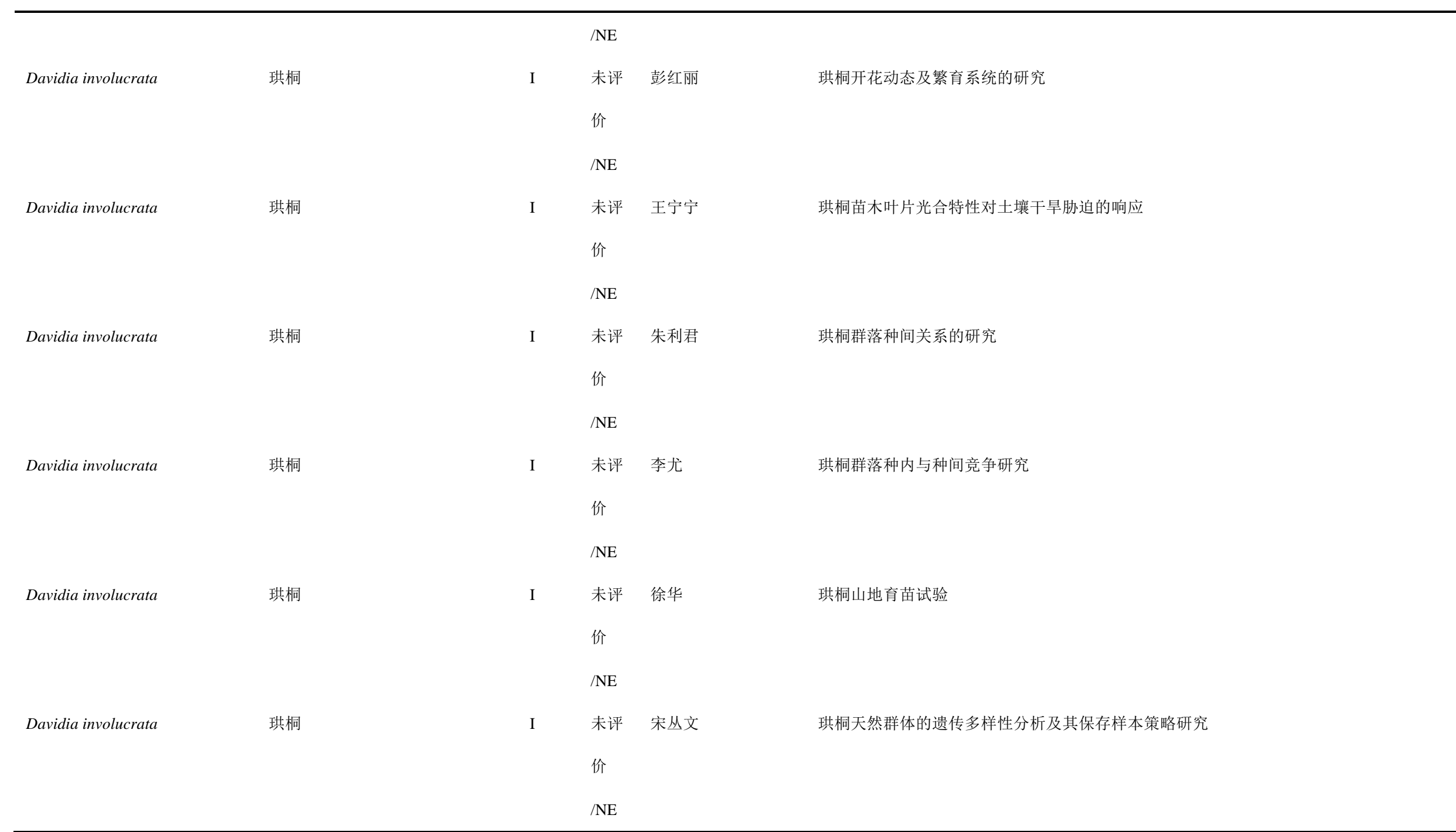


顾垒，闻丞，罗玫，王吴，吕植. 中国最受关注濒危物种保护现状快速评价的新方法探讨. 生物多样性，2015，23(5)：583-590. http://www. biodiversity-science. net/CN/article/downloadArticleFile. do?attachType=PDF\&id=10075

\begin{tabular}{|c|c|c|c|c|c|}
\hline Davidia involucrata & 珙桐 & I & $\begin{array}{l}\text { 未评 } \\
\text { 价 } \\
\text { /NE }\end{array}$ & 张玉梅 & 珙桐天然种群遗传多样性的 ISSR 标记分析 \\
\hline Davidia involucrata & 珙桐 & I & $\begin{array}{l}\text { 未评 } \\
\text { 价 } \\
\text { /NE }\end{array}$ & 范川 & 珙桐外中果皮对贮藏种子生活力的影响 \\
\hline Davidia involucrata & 珙桐 & I & $\begin{array}{l}\text { 未评 } \\
\text { 价 } \\
\text { /NE }\end{array}$ & 罗世家 & 珙桐芽体组织培养研究 \\
\hline Davidia involucrata & 珙桐 & I & $\begin{array}{l}\text { 未评 } \\
\text { 价 } \\
\text { /NE }\end{array}$ & 禹玉婷 & 珙桐研究进展 \\
\hline Davidia involucrata & 珙桐 & I & $\begin{array}{l}\text { 未评 } \\
\text { 价 } \\
\text { /NE }\end{array}$ & 李雪萍 & 珙桐遗传多样性的 AFLP 分析 \\
\hline Davidia involucrata & 珙桐 & I & $\begin{array}{l}\text { 未评 } \\
\text { 价 } \\
\text { /NE }\end{array}$ & 程芸 & 珙桐与光叶珙桐的生物学特性及群落结构研究 \\
\hline Davidia involucrata & 珙桐 & I & 未评 & 苏瑞军 & 珙桐种子散布、萌发及其种群龄级分配的关系研究 \\
\hline
\end{tabular}


顾垒，闻丞，罗玫，王吴，吕植. 中国最受关注濒危物种保护现状快速评价的新方法探讨. 生物多样性，2015，23(5)：583-590. http://www. biodiversity-science. net/CN/article/downloadArticleFile. do?attachType=PDF\&id=10075

$/ \mathrm{NE}$

Davidia involucrata

Davidia involucrata

珙桐

Davidia involucrata

珙桐

珙桐

珙桐

Davidia involucrata

I 未评

$/ \mathrm{NE}$

价

/NE

价

/NE

价

/NE
珙桐
夏晗

珙桐组织培养技术体系研究 (硕士毕业论文)

I 未评 罗世家

珙桐组织培养研究

I 未评 李轩

洪桐芽苗移栽育苗技术研究

壸瓶山自然保护区珍稀濒危植物珙桐群落的研究

I 未评 刘海洋

湖南珍稀濒危植物——琪桐种群数量动态

价

$/ \mathrm{NE}$

未评吴建国

气候变化对琪桐分布的潜在影响 
顾垒，闻丞，罗玫，王吴，吕植. 中国最受关注濒危物种保护现状快速评价的新方法探讨. 生物多样性，2015，23(5)：583-590. http://www. biodiversity-science. net/CN/article/downloadArticleFile. do?attachType=PDF\&id=10075

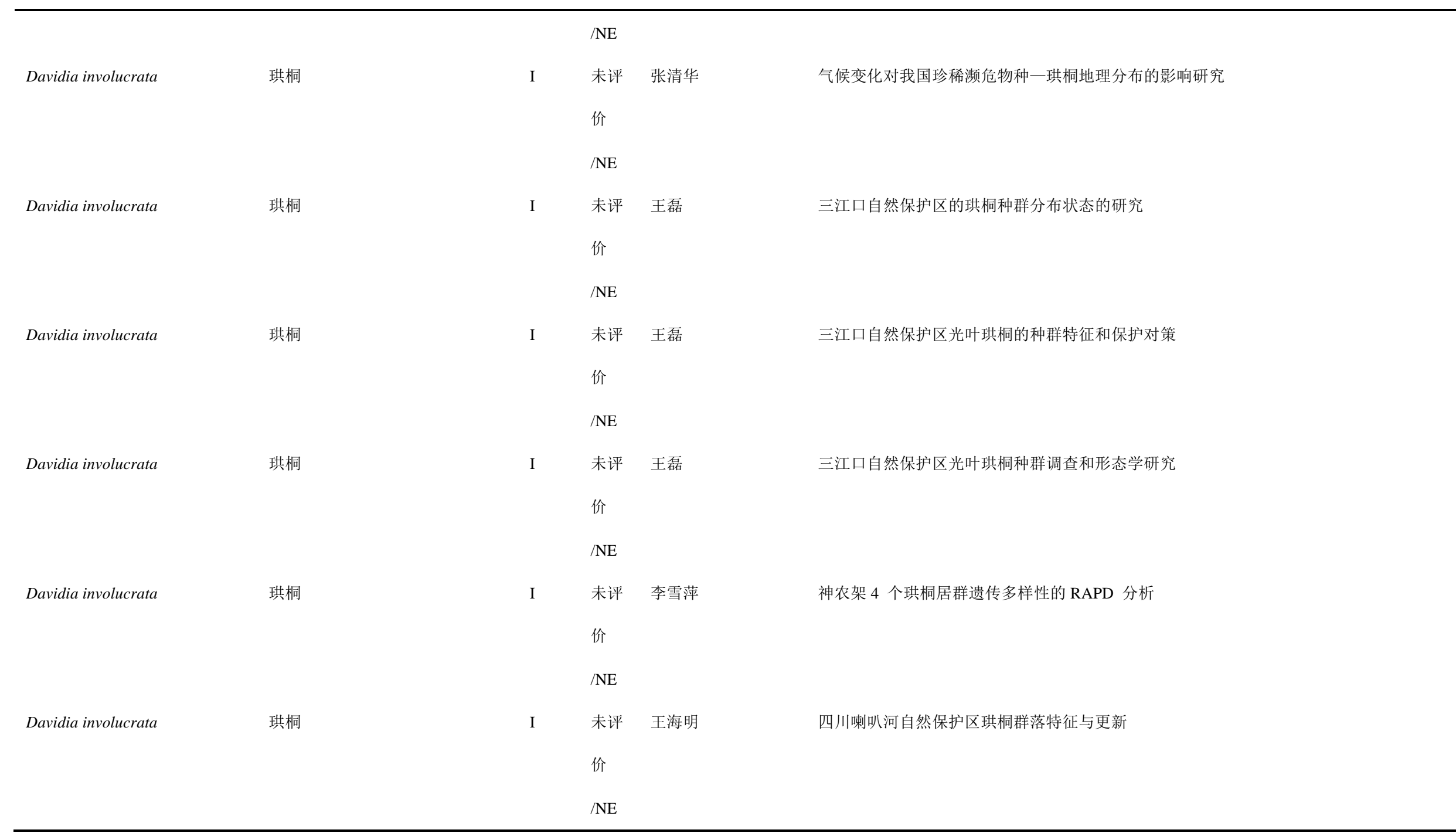


顾垒，闻丞，罗玫，王吴，吕植. 中国最受关注濒危物种保护现状快速评价的新方法探讨. 生物多样性，2015，23(5)：583-590. http://www. biodiversity-science. net/CN/article/downloadArticleFile. do?attachType=PDF\&id=10075

\begin{tabular}{|c|c|c|c|c|c|}
\hline Davidia involucrata & 珙桐 & I & $\begin{array}{l}\text { 未评 } \\
\text { 价 } \\
\text { /NE }\end{array}$ & 张望 & 四川省喇叭河自然保护区珙桐种群结构与分布格局 \\
\hline Davidia involucrata & 珙桐 & I & $\begin{array}{l}\text { 未评 } \\
\text { 价 } \\
\text { /NE }\end{array}$ & 苏瑞军 & 四川卧龙三江保护区琪桐群落边缘效应的研究 \\
\hline Davidia involucrata & 珙桐 & I & $\begin{array}{l}\text { 未评 } \\
\text { 价 } \\
\text { /NE }\end{array}$ & 张亚爽 & 四川卧龙自然保护区珙桐种群的空间分布格局 \\
\hline Davidia involucrata & 珙桐 & I & $\begin{array}{l}\text { 未评 } \\
\text { 价 } \\
\text { /NE }\end{array}$ & 雷妮娅 & 四川小凉山珙桐更新及种群稳定性研究 \\
\hline Davidia involucrata & 珙桐 & I & $\begin{array}{l}\text { 未评 } \\
\text { 价 } \\
\text { /NE }\end{array}$ & 宋丛文 & 天然珙桐群体的 RAPD 标记遗传多样性研究 \\
\hline Davidia involucrata & 基桐 & I & $\begin{array}{l}\text { 未评 } \\
\text { 价 } \\
\text { /NE }\end{array}$ & 朱利君 & 卧龙自然保护区三江珙桐群落种间关系的数量分析 \\
\hline Davidia involucrata & 珙桐 & I & 未评 & 郝云庆 & 巫溪县白果林场珙桐群落生态特征研究 \\
\hline
\end{tabular}


顾垒，闻丞，罗玫，王吴，吕植. 中国最受关注濒危物种保护现状快速评价的新方法探讨. 生物多样性，2015，23(5)：583-590. http://www. biodiversity-science. net/CN/article/downloadArticleFile. do?attachType=PDF\&id=10075

$/ \mathrm{NE}$

Davidia involucrata

Davidia involucrata

Davidia involucrata

Davidia involucrata
珙桐

珙桐

珙桐

珙桐
/NE

I

价

$/ \mathrm{NE}$

价

NE

价

$/ \mathrm{NE}$

I 未评

未评吴刚

I 未评＼cjkstart操国兴

I 未评 雷泞菲

I 未评 余阿梅

价

$/ \mathrm{NE}$

未评 金晓玲
珍稀濒危植物珙桐果实中的萌发抑制物质

珍稀濒危植物珙桐胚的萌发与快速繁殖

珍浠频危植物珙桐不同采收期的种子特性研究

珍稀濒危植物珙桐的生存与人为活动的关系

珍稀濒危植物珙桐繁育系统的初步研究

珍稀濒危植物洪桐离体快繁技术初步研究 
顾垒，闻丞，罗玫，王吴，吕植. 中国最受关注濒危物种保护现状快速评价的新方法探讨. 生物多样性，2015，23(5)：583-590. http://www. biodiversity-science. net/CN/article/downloadArticleFile. do?attachType=PDF\&id=10075

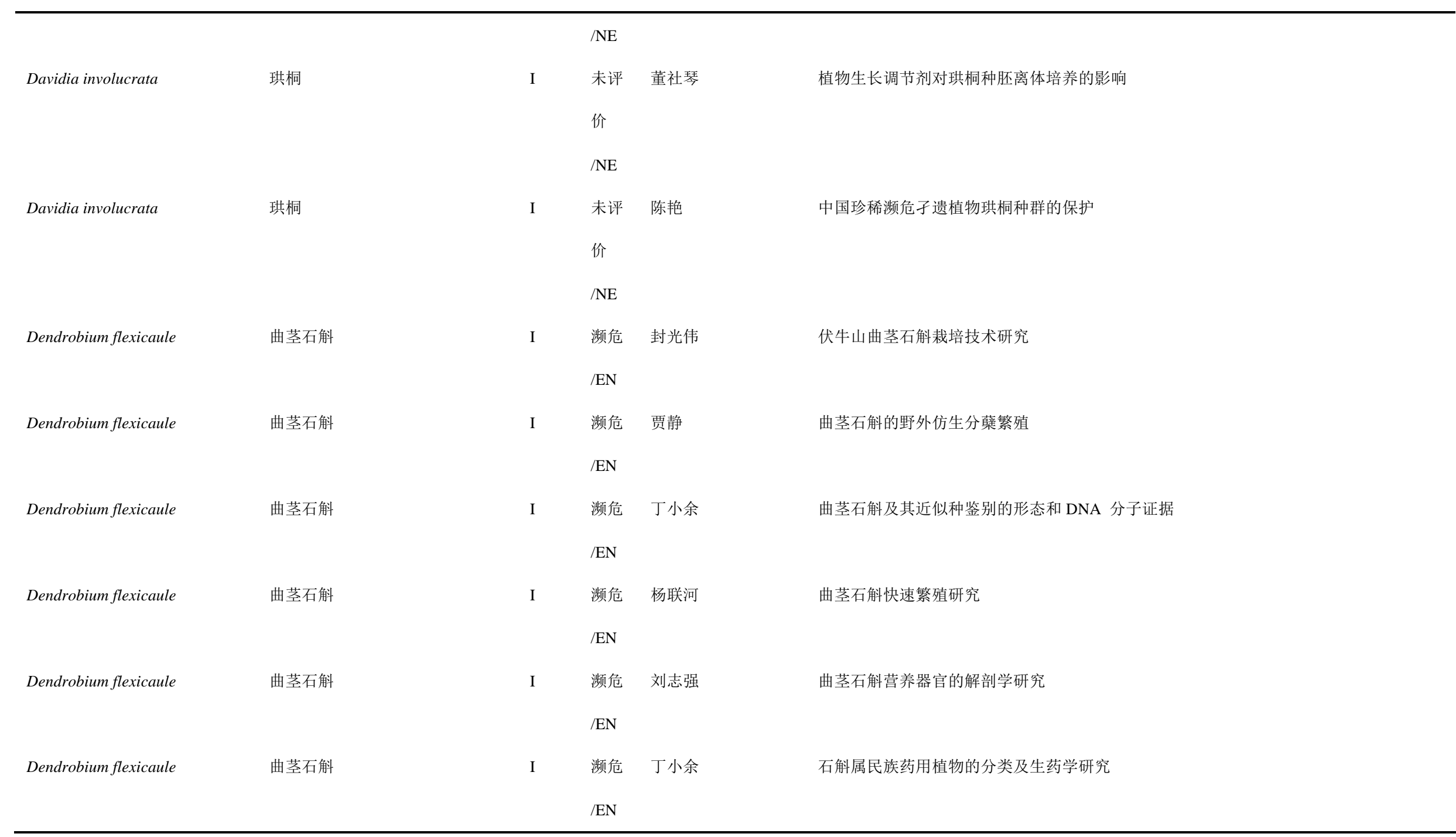


顾垒，闻丞，罗玫，王吴，吕植. 中国最受关注濒危物种保护现状快速评价的新方法探讨. 生物多样性，2015，23(5)：583-590. http://www biodiversity-science. net/CN/article/downloadArticleFile. do?attachType=PDF\&id=10075

\begin{tabular}{|c|c|c|c|c|c|}
\hline Dendrobium flexicaule & 曲茎石斛 & I & $\begin{array}{l}\text { 濒危 } \\
\text { /EN }\end{array}$ & 魏小勇 & 石斛属药用植物生物工程研究 \\
\hline Dendrobium flexicaule & 曲茎石斛 & I & $\begin{array}{l}\text { 濒危 } \\
\text { /EN }\end{array}$ & 淳 泽 & 四川石斛野生资源及其保护研究 \\
\hline Dendrobium flexicaule & 曲茎石斛 & I & $\begin{array}{l}\text { 濒危 } \\
\text { /EN }\end{array}$ & 张 伟 & 药用石斛的组织培养及管理研究 \\
\hline Dendrobium flexicaule & 曲茎石斛 & I & $\begin{array}{l}\text { 濒危 } \\
\text { /EN }\end{array}$ & 徐 红 & 药用石斛生物技术的研究概况 \\
\hline Dendrobium flexicaule & 曲茎石斛 & I & $\begin{array}{l}\text { 濒危 } \\
\text { /EN }\end{array}$ & 余晓丽 & 野生曲茎石斛的离体培养及再生体系研究 \\
\hline Dendrobium guangxiense & 滇桂石斛 & I & $\begin{array}{l}\text { 濒危 } \\
\text { /EN }\end{array}$ & 吕献康 & 11 种石斛植物的 FT IR 直接测定和主成分分析 \\
\hline Dendrobium guangxiense & 滇桂石斛 & I & $\begin{array}{l}\text { 濒危 } \\
\text { /EN }\end{array}$ & 王慧中 & 13 种石斛属植物遗传多样性的 AFLP 分析 \\
\hline Dendrobium guangxiense & 滇桂石斛 & I & $\begin{array}{l}\text { 濒危 } \\
\text { /EN }\end{array}$ & Jin Xiaohua & Taxonomic revision of Dendrobium moniliforme complex (Orchidaceae) \\
\hline Dendrobium guangxiense & 滇桂石斛 & I & $\begin{array}{l}\text { 濒危 } \\
\text { /EN }\end{array}$ & 包英华 & 滇桂石斛的离体培养和植株再生 \\
\hline Dendrobium guangxiense & 滇桂石斛 & I & 濒危 & 任羽 & 石斛属植物遗传多样性的 RSAP 分析 \\
\hline
\end{tabular}


顾垒，闻丞，罗玫，王吴，吕植. 中国最受关注濒危物种保护现状快速评价的新方法探讨. 生物多样性，2015，23(5)：583-590. http://www. biodiversity-science. net/CN/article/downloadArticleFile. do?attachType=PDF\&id=10075

\begin{tabular}{|c|c|c|c|c|c|}
\hline & & & /EN & & \\
\hline \multirow[t]{2}{*}{ Dendrobium guangxiense } & 滇桂石斛 & I & 濒危 & 武荣花 & 我国石斛属植物种质资源及其亲缘关系研究 \\
\hline & & & /EN & & \\
\hline \multirow[t]{2}{*}{ Dendrobium guangxiense } & 滇桂石斛 & I & 濒危 & 周庆 & 栽培基质和施肥方式对滇桂石斛引种栽培的影响 \\
\hline & & & /EN & & \\
\hline \multirow[t]{2}{*}{ Dipentodon sinicus } & 十齿花 & II & 无危 & 林长松 & 玉舍森林公园十齿花群落学特征研究 \\
\hline & & & $/ \mathrm{LC}$ & & \\
\hline \multirow[t]{2}{*}{ Dipentodon sinicus } & 十齿花 & II & 无危 & 林长松 & 珍稀植物十齿花种群结构与分布格局 \\
\hline & & & $/ \mathrm{LC}$ & & \\
\hline \multirow[t]{2}{*}{ Diplopanax stachyanthus } & 马蹄参 & 未列 & 易危 & 王丽 & 濒危植物马蹄参的研究现状和濒危原因分析 \\
\hline & & 入 & /VU & & \\
\hline \multirow[t]{2}{*}{ Diplopanax stachyanthus } & 马蹄参 & 未列 & 易危 & 杨泉 & 榕江月亮山珍稀植物马蹄参群落结构及资源研究 \\
\hline & & 入 & /VU & & \\
\hline \multirow[t]{2}{*}{ Diplopanax stachyanthus } & 马蹄参 & 未列 & 易危 & 王丽 & 珍稀濒危植物马蹄参的保护遗传学研究 \\
\hline & & 入 & /VU & & \\
\hline \multirow[t]{2}{*}{ Dipterocarpus retusus } & 盈江龙脑香 & 未列 & 易危 & 李锡文 & 《中国植物志》第 50(2)卷 116 页 \\
\hline & & 入 & /VU & & \\
\hline Dipteronia dyeriana & 云南金钱棫 & II & 未评 & 苏文华 & 濒危植物云南金钱槭对光、水环境的适应性 \\
\hline
\end{tabular}


顾垒，闻丞，罗玫，王吴，吕植. 中国最受关注濒危物种保护现状快速评价的新方法探讨. 生物多样性，2015，23(5)：583-590. http://www. biodiversity-science. net/CN/article/downloadArticleFile. do?attachType=PDF\&id=10075

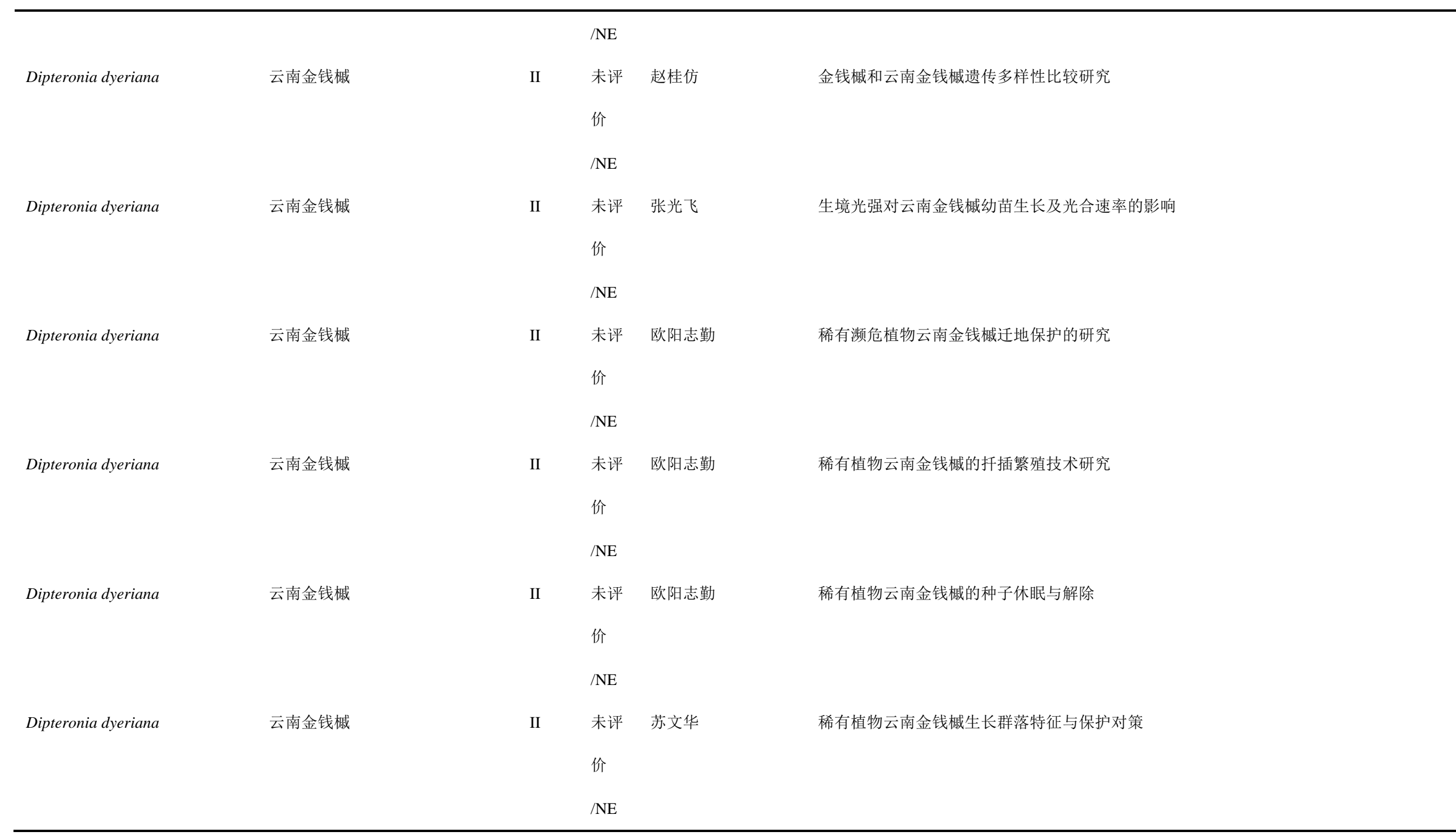


顾垒，闻丞，罗玫，王吴，吕植. 中国最受关注濒危物种保护现状快速评价的新方法探讨. 生物多样性，2015，23(5)：583-590. http://www. biodiversity-science. net/CN/article/downloadArticleFile. do?attachType=PDF\&id=10075

\begin{tabular}{|c|c|c|c|c|c|}
\hline Dipteronia dyeriana & 云南金钱槭 & II & $\begin{array}{l}\text { 未评 } \\
\text { 价 } \\
\text { /NE }\end{array}$ & 欧阳志勤 & 稀有植物云南金钱棫种子萌发特性的研究 \\
\hline Dipteronia dyeriana & 云南金钱槭 & II & $\begin{array}{l}\text { 未评 } \\
\text { 价 } \\
\text { /NE }\end{array}$ & 赵桂仿 & 云南金钱槭果实、种子形态分化研究 \\
\hline Dipteronia dyeriana & 云南金钱槭 & II & $\begin{array}{l}\text { 未评 } \\
\text { 价 } \\
\text { /NE }\end{array}$ & 欧阳志勤 & 云南金钱槭天然居群等位酶遗传多样性研究 \\
\hline Dipteronia dyeriana & 云南金钱槭 & II & $\begin{array}{l}\text { 未评 } \\
\text { 价 } \\
\text { /NE }\end{array}$ & 赵桂仿 & 云南金钱槭形态变异与遗传变异的相关性研究 \\
\hline Dracaena cochinchinensis & 剑叶龙血树 & II & $\begin{array}{l}\text { 未评 } \\
\text { 价 } \\
\text { /NE }\end{array}$ & 江东福 & 9568D 镰孢霉作用于死态龙血树形成血脂的研究 \\
\hline Dracaena cochinchinensis & 剑叶龙血树 & II & $\begin{array}{l}\text { 未评 } \\
\text { 价 } \\
\text { /NE }\end{array}$ & Tao Yi & $\begin{array}{l}\text { A Systematic Review of the Botanical, Phytochemical and Pharmacological Profile of } \\
\text { Dracaena cochinchinensis, a Plant Source of the Ethnomedicine “Dragon' s Blood" }\end{array}$ \\
\hline Dracaena cochinchinensis & 剑叶龙血树 & II & 未评 & Qiu’ e Cao & Enhanced dragon' s blood production in Dracaena cochinchinensis by elicitation of Fusarium \\
\hline
\end{tabular}


顾垒，闻丞，罗玫，王吴，吕植. 中国最受关注濒危物种保护现状快速评价的新方法探讨. 生物多样性，2015，23(5)：583-590. http://www. biodiversity-science. net/CN/article/downloadArticleFile. do?attachType=PDF\&id=10075

\begin{tabular}{|c|c|c|c|c|c|}
\hline & & & 价 & & oxysporum strains \\
\hline Dracaena cochinchinensis & 剑叶龙血树 & II & $\begin{array}{l}\text { /NE } \\
\text { 未评 } \\
\text { 价 }\end{array}$ & ChangHe Zhang & $\begin{array}{l}\text { Production of dragon's blood in Dracaena cochinchinensis plants by inoculation of Fusarium } \\
\text { proliferatum }\end{array}$ \\
\hline Dracaena cochinchinensis & 剑叶龙血树 & II & $\begin{array}{l}/ \mathrm{NE} \\
\text { 未评 } \\
\text { 价 }\end{array}$ & 王风珠 & 从文献计量学分析中国珍贵资源龙血竭的研究 \\
\hline Dracaena cochinchinensis & 剑叶龙血树 & II & $\begin{array}{l}\text { /NE } \\
\text { 未评 } \\
\text { 价 }\end{array}$ & 莫饶 & 海南地区剑叶龙血树种质资源遗传多样性分析 \\
\hline Dracaena cochinchinensis & 剑叶龙血树 & II & $\begin{array}{l}\text { /NE } \\
\text { 未评 } \\
\text { 价 }\end{array}$ & 杨松 & 海南省剑叶龙血树种群生境调查及其 ISSR 遗传多样性分析 \\
\hline Dracaena cochinchinensis & 剑叶龙血树 & II & $\begin{array}{l}\text { /NE } \\
\text { 未评 } \\
\text { 价 }\end{array}$ & 林芹 & 剑叶龙血树的质量标准研究 \\
\hline Dracaena cochinchinensis & 剑叶龙血树 & II & $\begin{array}{l}\text { /NE } \\
\text { 未评 } \\
\text { 价 }\end{array}$ & 陈国臣 & 剑叶龙血树芽外植体诱导分化 \\
\hline
\end{tabular}


顾垒，闻丞，罗玫，王吴，吕植. 中国最受关注濒危物种保护现状快速评价的新方法探讨. 生物多样性，2015，23(5)：583-590. http://www. biodiversity-science. net/CN/article/downloadArticleFile. do?attachType=PDF\&id=10075

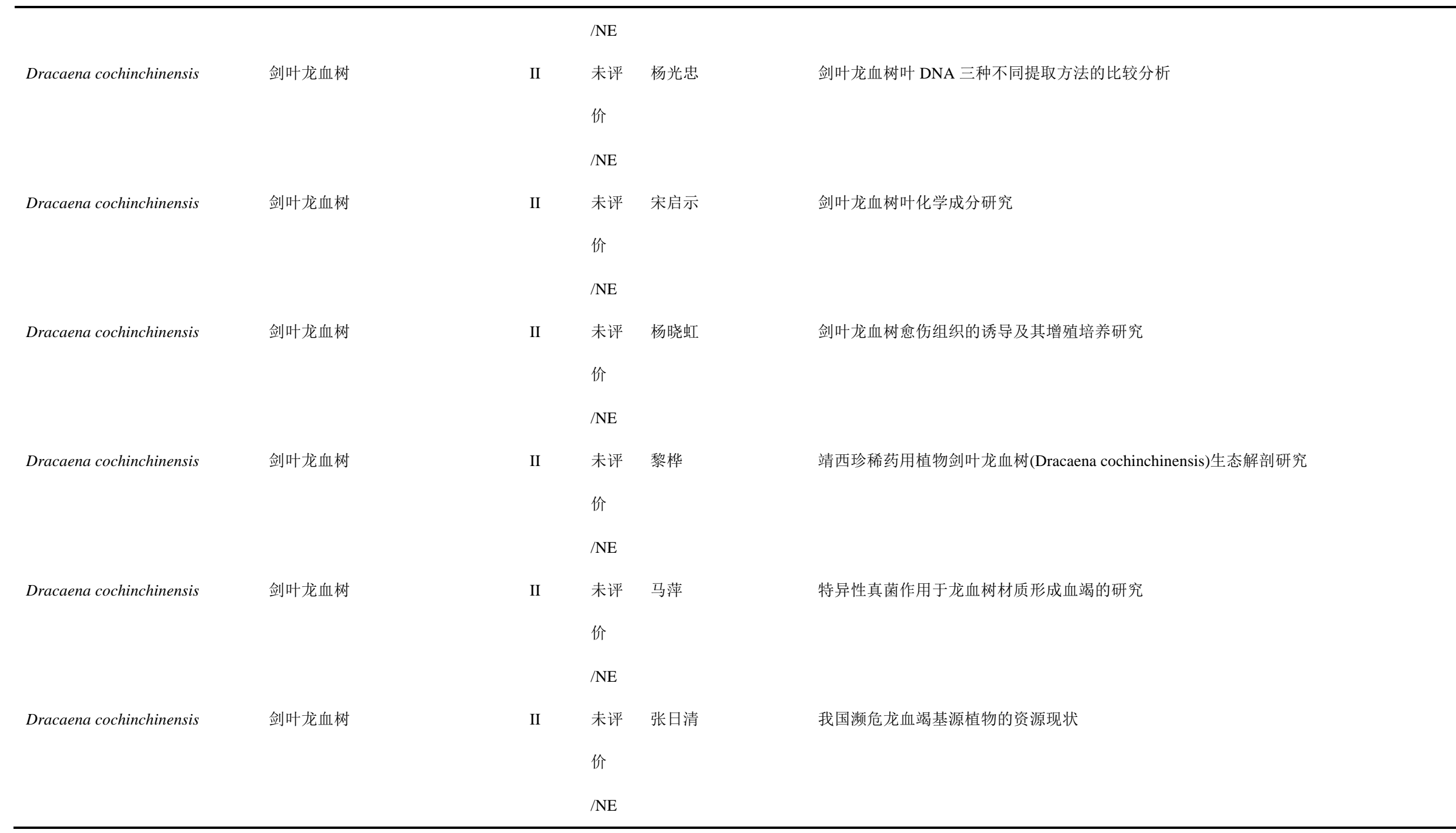


顾垒，闻丞，罗玫，王吴，吕植. 中国最受关注濒危物种保护现状快速评价的新方法探讨. 生物多样性，2015，23(5)：583-590. http://www. biodiversity-science. net/CN/article/downloadArticleFile. do?attachType=PDF\&id=10075

\begin{tabular}{|c|c|c|c|c|c|}
\hline Dracaena cochinchinensis & 剑叶龙血树 & II & $\begin{array}{l}\text { 未评 } \\
\text { 价 } \\
\text { /NE }\end{array}$ & 郑水 & 血竭诱导机制及几种龙血树分子分类的初步研究 \\
\hline Dracaena cochinchinensis & 剑叶龙血树 & II & $\begin{array}{l}\text { 未评 } \\
\text { 价 } \\
\text { /NE }\end{array}$ & 周仕顺 & 云南思茅翠云石灰岩山剑叶龙血树群落的研究 \\
\hline Dracaena cochinchinensis & 剑叶龙血树 & II & $\begin{array}{l}\text { 未评 } \\
\text { 价 } \\
\text { /NE }\end{array}$ & 罗文扬 & 珍稀濒危龙血竭基源植物-龙血树 \\
\hline Dracaena cochinchinensis & 剑叶龙血树 & II & $\begin{array}{l}\text { 未评 } \\
\text { 价 } \\
\text { /NE }\end{array}$ & 罗萍 & 珍稀濒危龙血竭基源植物龙血树的资源现状 \\
\hline Dracaena cochinchinensis & 剑叶龙血树 & II & $\begin{array}{l}\text { 未评 } \\
\text { 价 } \\
\text { /NE }\end{array}$ & 莫饶 & 中国龙血树属 SRAP 遗传多样性分析 \\
\hline Dracaena cochinchinensis & 剑叶龙血树 & II & $\begin{array}{l}\text { 未评 } \\
\text { 价 } \\
\text { /NE }\end{array}$ & 张治礼 & 中国血竭基源植物的研究与利用 \\
\hline Dracaena cochinchinensis & 剑叶龙血树 & II & 未评 & 陈虎彪 & 中药龙血竭原植物剑叶龙血树的形态学研究及所含树脂的分布和成分检测 \\
\hline
\end{tabular}


顾垒，闻丞，罗玫，王吴，吕植. 中国最受关注濒危物种保护现状快速评价的新方法探讨. 生物多样性，2015，23(5)：583-590. http://www. biodiversity-science. net/CN/article/downloadArticleFile. do?attachType=PDF\&id=10075

\begin{tabular}{|c|c|c|c|c|c|}
\hline & & & $\begin{array}{l}\text { 价 } \\
\text { /NE }\end{array}$ & & \\
\hline Dracontomelon macrocarpum & 大果人面子 & $\begin{array}{l}\text { 未列 } \\
\text { 入 }\end{array}$ & $\begin{array}{l}\text { 极危 } \\
\text { /CR }\end{array}$ & 李宏伟 & 西双版纳大果人面子群落的植物群落学研究 \\
\hline Dryocopus javensis & 白腹黑豚木鸟 & II & $\begin{array}{l}\text { 无危 } \\
\text { /LC }\end{array}$ & 何芬奇 & 白腹黑豚木鸟（Dryocopus javensis）在内蒙古暨福建的近期记录 \\
\hline Dryocopus javensis & 白腹黑豚木鸟 & II & $\begin{array}{l}\text { 无危 } \\
\text { /LC }\end{array}$ & 崔茂欢 & 兰坪云岭省级自然保护区及周边地区鸟类多样性 \\
\hline Dryocopus javensis & 白腹黑啄木鸟 & II & $\begin{array}{l}\text { 无危 } \\
\text { /LC }\end{array}$ & 杨彪 & 四川白坡山自然保护区冬季鸟类群落调查 \\
\hline Dryocopus javensis & 白腹黑豚木鸟 & II & $\begin{array}{l}\text { 无危 } \\
\text { /LC }\end{array}$ & 刘鲁明 & 云南省玉龙雪山自然保护区鸟类资源调查 \\
\hline Ducula aenea & 绿皇鸭 & II & $\begin{array}{l}\text { 无危 } \\
\text { /LC }\end{array}$ & 李仕宁 & 茄新省级森林经营所鸟类资源调查 \\
\hline Ducula badia & 皇鸭 & II & $\begin{array}{l}\text { 无危 } \\
\text { /LC }\end{array}$ & 李仕宁 & 茄新省级森林经营所鸟类资源调查 \\
\hline Dugong dugon & 儒艮 & I & $\begin{array}{l}\text { 易危 } \\
\text { /VU }\end{array}$ & 周开亚 & 北部湾儒艮现状的调查兼记印度洋白海豚 \\
\hline Dugong dugon & 儒艮 & I & 易危 & 邓超冰 & 广西北部湾珍稀海洋哺乳动物的保护及管理 \\
\hline
\end{tabular}


顾垒，闻丞，罗玫，王吴，吕植. 中国最受关注濒危物种保护现状快速评价的新方法探讨. 生物多样性，2015，23(5)：583-590. http://www. biodiversity-science. net/CN/article/downloadArticleFile. do?attachType=PDF\&id=10075

\begin{tabular}{|c|c|c|c|c|c|}
\hline & & & /VU & & \\
\hline \multirow[t]{2}{*}{ Dugong dugon } & 儒艮 & I & 易危 & 杨光 & 广西合浦儒艮国家级自然保护区及邻近水域鱼类种数及保护对策 \\
\hline & & & $/ \mathrm{VU}$ & & \\
\hline \multirow[t]{2}{*}{ Dugong dugon } & 儒艮 & I & 易危 & 张宏科 & 广西合浦儒艮国家级自然保护区生物多样性现状及保护对策 \\
\hline & & & /VU & & \\
\hline \multirow[t]{2}{*}{ Dugong dugon } & 儒艮 & I & 易危 & 邱广龙 & 海草生态系统与濒危海洋哺乳动物儒艮的相互关系 \\
\hline & & & /VU & & \\
\hline \multirow[t]{2}{*}{ Dugong dugon } & 儒艮 & I & 易危 & 王丕烈 & 海南省儒艮资源现状调查 \\
\hline & & & $/ \mathrm{VU}$ & & \\
\hline \multirow[t]{2}{*}{ Dugong dugon } & 儒艮 & I & 易危 & 史海涛 & 海南文昌椰林湾发现儒艮的尸体及死亡原因分析 \\
\hline & & & /VU & & \\
\hline \multirow[t]{2}{*}{ Dysosma aurantiocaulis } & 云南八角莲 & 未列 & 易危 & 杨春燕 & 云南八角莲内生真菌分离 、鉴定的初步探索 \\
\hline & & 入 & /VU & & \\
\hline Dysosma aurantiocaulis, & 云南八角莲、川八角莲 & 未列 & 易危 & 王兴红 & 两种八角莲内生真菌的生物活性研究 \\
\hline Dysosma veitchii & & 入 & /VU & & \\
\hline \multirow[t]{2}{*}{ Dysosma tsayuensis } & 西藏八角莲 & 未列 & 易危 & 马和平 & 濒危药用植物西藏八角莲的生态生物学 特性及其保育措施 \\
\hline & & 入 & /VU & & \\
\hline \multirow[t]{2}{*}{ Dysosma tsayuensis } & 西藏八角莲 & 未列 & 易危 & 马和平 & 西藏八角莲的生物学特性及其保育措施 \\
\hline & & 入 & /VU & & \\
\hline
\end{tabular}


顾垒，闻丞，罗玫，王吴，吕植. 中国最受关注濒危物种保护现状快速评价的新方法探讨. 生物多样性，2015，23(5)：583-590. http://www. biodiversity-science. net/CN/article/downloadArticleFile. do?attachType=PDF\&id=10075

\begin{tabular}{|c|c|c|c|c|c|}
\hline \multirow[t]{2}{*}{ Dysosma tsayuensis } & 西藏八角莲 & 未列 & 易危 & 鲍隆友 & 西藏八角莲的组织培养条件篮选 \\
\hline & & 入 & /VU & & \\
\hline \multirow[t]{2}{*}{ Dysosma tsayuensis } & 西藏八角莲 & 未列 & 易危 & 刘玉军 & 西藏八角莲生物学特性及 栽培技术简介 \\
\hline & & 入 & /VU & & \\
\hline \multirow[t]{2}{*}{ Dysosma tsayuensis } & 西藏八角莲 & 未列 & 易危 & 张格杰 & 西藏八角莲炭疽病病原鉴定及室内药剂篮选 \\
\hline & & 入 & /VU & & \\
\hline \multirow[t]{2}{*}{ Dysosma tsayuensis } & 西藏八角莲 & 未列 & 易危 & 何建清 & 西藏八角莲叶斑病鉴定及其生物学特性研究 \\
\hline & & 入 & /VU & & \\
\hline \multirow[t]{2}{*}{ Dysosma tsayuensis } & 西藏八角莲 & 未列 & 易危 & 何建清 & 西藏八角莲种胚愈伤诱导的初探 \\
\hline & & 入 & $/ \mathrm{VU}$ & & \\
\hline \multirow[t]{3}{*}{ Dysosma tsayuensis, } & 西藏八角莲, 广西八角莲, 贵州八 & 未列 & 易危 & 孙成仁 & 八角莲属植物根的比较解剖学研究 \\
\hline & 角莲, 小八角莲, 八角莲, 云南八 & 入 & $/ \mathrm{VU}$ & & \\
\hline & 角莲, 川八角莲 & & & & \\
\hline \multirow[t]{2}{*}{ Dysosma veitchii } & 川八角莲 & 未列 & 易危 & 张玲琪 & 川八角莲内生真菌及根际真菌的分离和鉴定 \\
\hline & & 入 & /VU & & \\
\hline \multirow[t]{2}{*}{ Dysosma veitchii } & 川八角莲 & 未列 & 易危 & 杨 耀 文 & 川八角莲的生药学研究 \\
\hline & & 入 & $/ \mathrm{VU}$ & & \\
\hline \multirow[t]{2}{*}{ Dysosma veitchii } & 川八角莲 & 未列 & 易危 & 马绍宾 & 川八角莲繁殖生态学初步研究 \\
\hline & & 入 & /VU & & \\
\hline
\end{tabular}


顾垒，闻丞，罗玫，王吴，吕植. 中国最受关注濒危物种保护现状快速评价的新方法探讨. 生物多样性，2015，23(5)：583-590. http://www biodiversity-science. net/CN/article/downloadArticleFile. do?attachType=PDF\&id=10075

\begin{tabular}{|c|c|c|c|c|c|}
\hline Dysosma veitchii & 川八角莲 & $\begin{array}{l}\text { 未列 } \\
\text { 入 }\end{array}$ & $\begin{array}{l}\text { 易危 } \\
\text { /VU }\end{array}$ & 张玲琪 & 川八角莲内生真菌产鬼臼毒素类似物的初步研究 \\
\hline $\begin{array}{l}\text { Dysosma veitchii , Dysosma } \\
\text { aurantiocaulis }\end{array}$ & 川八角莲, 云南八角莲 & $\begin{array}{l}\text { 未列 } \\
\text { 入 }\end{array}$ & $\begin{array}{l}\text { 易危 } \\
\text { /VU }\end{array}$ & 王兴红 & 两种八角莲内生真菌的生物活性研究 \\
\hline $\begin{array}{l}\text { Dysosma veitchii, Dysosma } \\
\text { aurantiocaulis }\end{array}$ & 川八角莲, 云南八角莲 & $\begin{array}{l}\text { 未列 } \\
\text { 入 }\end{array}$ & $\begin{array}{l}\text { 易危 } \\
\text { /VU }\end{array}$ & 李雪玲 & 两种八角莲属植物内生与根际真菌的多样性初探 \\
\hline $\begin{array}{l}\text { Dysosma veitchii, Dysosma } \\
\text { pleiantha, Dysosma furfuracea }\end{array}$ & 川八角莲, 六角莲, 粌鳞八角莲 & $\begin{array}{l}\text { 未列 } \\
\text { 入 }\end{array}$ & $\begin{array}{l}\text { 易危 } \\
\text { /VU }\end{array}$ & 施大文 & 三种八角莲的性状与显微鉴别 \\
\hline $\begin{array}{l}\text { Dysosma veitchii, Dysosma } \\
\text { versipellis, Dysosma } \\
\text { majorensis , Dysosma difformis }\end{array}$ & $\begin{array}{l}\text { 川八角莲, 八角莲, 贵州八角莲, } \\
\text { 小八角莲 }\end{array}$ & $\begin{array}{l}\text { 未列 } \\
\text { 入 }\end{array}$ & $\begin{array}{l}\text { 易危 } \\
\text { /VU }\end{array}$ & 万明香 & 贵州珍稀濒危药材八角莲属种质资源调查及质量研究 \\
\hline Dysosma versipellis & 八角莲 & $\begin{array}{l}\text { 未列 } \\
\text { 入 }\end{array}$ & $\begin{array}{l}\text { 易危 } \\
\text { /VU }\end{array}$ & 张洪彬 & 2 种八角莲中鬼臼毒素类化合物的研究 \\
\hline Dysosma versipellis & 八角莲 & II & $\begin{array}{l}\text { 易危 } \\
\text { /VU }\end{array}$ & 段韵 & $\mathrm{GC}-\mathrm{EI}-\mathrm{MS}$ 法定性分析八角莲中鬼臼毒素成分 \\
\hline Dysosma versipellis & 八角莲 & $\begin{array}{l}\text { 未列 } \\
\text { 入 }\end{array}$ & $\begin{array}{l}\text { 易危 } \\
\text { /VU }\end{array}$ & 周长新 & HPLC 比较不同产地生药八角莲中鬼臼类成分含量 \\
\hline Dysosma versipellis & 八角莲 & II & $\begin{array}{l}\text { 易危 } \\
\text { /VU }\end{array}$ & 王沛 & $\mathrm{Ri}$ 质粒介导的八角莲遗传转化及毛状根鬼臼毒素产生初步研究 \\
\hline
\end{tabular}


顾垒，闻丞，罗玫，王吴，吕植. 中国最受关注濒危物种保护现状快速评价的新方法探讨. 生物多样性，2015，23(5)：583-590. http://www. biodiversity-science. net/CN/article/downloadArticleFile. do?attachType=PDF\&id=10075

\begin{tabular}{|c|c|c|c|c|c|}
\hline Dysosma versipellis & 八角莲 & II & $\begin{array}{l}\text { 易危 } \\
\text { /VU }\end{array}$ & 杨光义 & UPLC 法测定八角莲药材中鬼臼毒素的含量 \\
\hline Dysosma versipellis & 八角莲 & $\begin{array}{l}\text { 未列 } \\
\text { 入 }\end{array}$ & $\begin{array}{l}\text { 易危 } \\
\text { /VU }\end{array}$ & 雷震 & UPLC 法测定八角莲药材中鬼臼毒素的含量 \\
\hline Dysosma versipellis & 八角莲 & II & $\begin{array}{l}\text { 易危 } \\
\text { /VU }\end{array}$ & 邓书端 & 八角莲不同部位鬼臼毒素分布的毛细管区带电泳研究 \\
\hline Dysosma versipellis & 八角莲 & II & $\begin{array}{l}\text { 易危 } \\
\text { /VU }\end{array}$ & 黄慧莲 & 八角莲从生芽分化及试管苗移栽技术研究 \\
\hline Dysosma versipellis & 八角莲 & $\begin{array}{l}\text { 未列 } \\
\text { 入 }\end{array}$ & $\begin{array}{l}\text { 易危 } \\
\text { /VU }\end{array}$ & 黄衡宇 & 八角莲大孢子发生和雌配子体形成 \\
\hline Dysosma versipellis & 八角莲 & $\begin{array}{l}\text { 未列 } \\
\text { 入 }\end{array}$ & $\begin{array}{l}\text { 易危 } \\
\text { /VU }\end{array}$ & 刘杰 & 八角莲的 HPLC 检验 \\
\hline Dysosma versipellis & 八角莲 & $\begin{array}{l}\text { 未列 } \\
\text { 入 }\end{array}$ & $\begin{array}{l}\text { 易危 } \\
\text { /VU }\end{array}$ & 张燕 & 八角莲的保护生物学研究进展 \\
\hline Dysosma versipellis & 八角莲 & II & $\begin{array}{l}\text { 易危 } \\
\text { /VU }\end{array}$ & 李思锋 & 八角莲的保护生物学研究进展(综述) \\
\hline Dysosma versipellis & 八角莲 & II & $\begin{array}{l}\text { 易危 } \\
\text { /VU }\end{array}$ & 张燕 & 八角莲的濒危成因剖析 \\
\hline Dysosma versipellis & 八角莲 & 未列 & 易危 & 徐祥 & 八角莲的毒理学研究现状 \\
\hline
\end{tabular}


顾垒，闻丞，罗玫，王吴，吕植. 中国最受关注濒危物种保护现状快速评价的新方法探讨. 生物多样性，2015，23(5)：583-590. http://www. biodiversity-science. net/CN/article/downloadArticleFile. do?attachType=PDF\&id=10075

\begin{tabular}{|c|c|c|c|c|c|}
\hline & & 入 & $/ \mathrm{VU}$ & & \\
\hline \multirow[t]{2}{*}{ Dysosma versipellis } & 八角莲 & II & 易危 & 姜飞 & 八角莲的化学成分及其主成分鬼臼毒素的结构修饰研究 \\
\hline & & & $/ \mathrm{VU}$ & & \\
\hline \multirow[t]{2}{*}{ Dysosma versipellis } & 八角莲 & II & 易危 & 江仁望 & 八角莲的化学成分研究 \\
\hline & & & /VU & & \\
\hline \multirow[t]{2}{*}{ Dysosma versipellis } & 八角莲 & II & 易危 & 魏鸿雁 & 八角莲的化学成分研究 \\
\hline & & & /VU & & \\
\hline \multirow[t]{2}{*}{ Dysosma versipellis } & 八角莲 & 未列 & 易危 & 熊元君 & 八角莲的化学成分预实验 \\
\hline & & 入 & $/ \mathrm{VU}$ & & \\
\hline \multirow[t]{2}{*}{ Dysosma versipellis } & 八角莲 & 未列 & 易危 & 潘琦 & 八角莲的离体快繁技术和化学成分分析研究 \\
\hline & & 入 & $/ \mathrm{VU}$ & & \\
\hline \multirow[t]{2}{*}{ Dysosma versipellis } & 八角莲 & 未列 & 易危 & 陈黎 & 八角莲的性状与显微鉴别 \\
\hline & & 入 & /VU & & \\
\hline \multirow[t]{2}{*}{ Dysosma versipellis } & 八角莲 & II & 易危 & 熊元君 & 八角莲的研究进展 \\
\hline & & & /VU & & \\
\hline \multirow[t]{2}{*}{ Dysosma versipellis } & 八角莲 & 未列 & 易危 & 熊元君 & 八角莲的研究进展 \\
\hline & & 入 & /VU & & \\
\hline \multirow[t]{2}{*}{ Dysosma versipellis } & 八角莲 & 未列 & 易危 & 卢军 & 八角莲的药理及临床应用 \\
\hline & & 入 & /VU & & \\
\hline
\end{tabular}


顾垒，闻丞，罗玫，王吴，吕植. 中国最受关注濒危物种保护现状快速评价的新方法探讨. 生物多样性，2015，23(5)：583-590. http://www biodiversity-science. net/CN/article/downloadArticleFile. do?attachType=PDF\&id=10075

\begin{tabular}{|c|c|c|c|c|c|}
\hline Dysosma versipellis & 八角莲 & II & $\begin{array}{l}\text { 易危 } \\
\text { /VU }\end{array}$ & 张燕 & 八角莲的引种栽培与应用开发前景 \\
\hline Dysosma versipellis & 八角莲 & II & $\begin{array}{l}\text { 易危 } \\
\text { /VU }\end{array}$ & 傅承新 & 八角莲的愈伤组织和组培根及野生根状茎的鬼自毒素含量比较研究 \\
\hline Dysosma versipellis & 八角莲 & $\begin{array}{l}\text { 未列 } \\
\text { 入 }\end{array}$ & $\begin{array}{l}\text { 易危 } \\
\text { /VU }\end{array}$ & 傅承新 & 八角莲的愈伤组织和组培根及野生根状茎的鬼臼毒素含量比较研究 \\
\hline Dysosma versipellis & 八角莲 & $\begin{array}{l}\text { 未列 } \\
\text { 入 }\end{array}$ & $\begin{array}{l}\text { 易危 } \\
\text { /VU }\end{array}$ & 潘琦 & 八角莲的植物化学成分和组织培养研究 \\
\hline Dysosma versipellis & 八角莲 & II & $\begin{array}{l}\text { 易危 } \\
\text { /VU }\end{array}$ & 陆炜强 & 八角莲规范化生产关键技术研究 \\
\hline Dysosma versipellis & 八角莲 & $\begin{array}{l}\text { 未列 } \\
\text { 入 }\end{array}$ & $\begin{array}{l}\text { 易危 } \\
\text { /VU }\end{array}$ & 梁钢 & 八角莲含药血清对人肝癌细胞 SMMC-7721 的抑制作用研究 \\
\hline Dysosma versipellis & 八角莲 & II & $\begin{array}{l}\text { 易危 } \\
\text { /VU }\end{array}$ & 程丽姣 & 八角莲化学成分分析互瓜种化合物细胞药理学活性研究 \\
\hline Dysosma versipellis & 八角莲 & $\begin{array}{l}\text { 未列 } \\
\text { 入 }\end{array}$ & $\begin{array}{l}\text { 易危 } \\
\text { /VU }\end{array}$ & 傅承新 & 八角莲挥发油化学成分的 GC-MS 研究 \\
\hline Dysosma versipellis & 八角莲 & $\begin{array}{l}\text { 未列 } \\
入\end{array}$ & $\begin{array}{l}\text { 易危 } \\
\text { /VU }\end{array}$ & 张艳君 & 八角莲活性成分鉴别及其抗癌活性研究 \\
\hline Dysosma versipellis & 八角莲 & 未列 & 易危 & 张敏 & 八角莲及其近缘植物中木脂素的分析 \\
\hline
\end{tabular}


顾垒，闻丞，罗玫，王吴，吕植. 中国最受关注濒危物种保护现状快速评价的新方法探讨. 生物多样性，2015，23(5)：583-590. http://www. biodiversity-science. net/CN/article/downloadArticleFile. do?attachType=PDF\&id=10075

\begin{tabular}{|c|c|c|c|c|c|}
\hline & & 入 & $/ \mathrm{VU}$ & & \\
\hline \multirow[t]{2}{*}{ Dysosma versipellis } & 八角莲 & II & 易危 & 傅承新 & 八角莲毛状根的诱导及其鬼臼毒素的产生 \\
\hline & & & $/ \mathrm{VU}$ & & \\
\hline \multirow[t]{2}{*}{ Dysosma versipellis } & 八角莲 & II & 易危 & 甘国菊 & 八角莲人工栽培技术 \\
\hline & & & /VU & & \\
\hline \multirow[t]{2}{*}{ Dysosma versipellis } & 八角莲 & 未列 & 易危 & 万明香 & 八角莲属 (小檗科) 药用植物的研究进展 \\
\hline & & 入 & $/ \mathrm{VU}$ & & \\
\hline \multirow[t]{2}{*}{ Dysosma versipellis } & 八角莲 & 未列 & 易危 & 邱明华 & 八角莲属药用植物化学成分及生理活性研究进展 \\
\hline & & 入 & $/ \mathrm{VU}$ & & \\
\hline \multirow[t]{2}{*}{ Dysosma versipellis } & 八角莲 & 未列 & 易危 & 张践 & 八角莲属植物根的比较解剖学研究 \\
\hline & & 入 & $/ \mathrm{VU}$ & & \\
\hline \multirow[t]{2}{*}{ Dysosma versipellis } & 八角莲 & 未列 & 易危 & 熊铁一 & 八角莲洗液制备及其杀菌作用研究 \\
\hline & & 入 & /VU & & \\
\hline \multirow[t]{2}{*}{ Dysosma versipellis } & 八角莲 & 未列 & 易危 & 黄衡宇 & 八角莲小孢子发生和雄配子形成 \\
\hline & & 入 & /VU & & \\
\hline \multirow[t]{2}{*}{ Dysosma versipellis } & 八角莲 & 未列 & 易危 & 刘汉珍 & 八角莲营养器官的显微构造 \\
\hline & & 入 & /VU & & \\
\hline \multirow[t]{2}{*}{ Dysosma versipellis } & 八角莲 & II & 易危 & 谭小明 & 八角莲愈伤组织诱导及分化研究 \\
\hline & & & $/ \mathrm{VU}$ & & \\
\hline
\end{tabular}


顾垒，闻丞，罗玫，王吴，吕植. 中国最受关注濒危物种保护现状快速评价的新方法探讨. 生物多样性，2015，23(5)：583-590. http://www. biodiversity-science. net/CN/article/downloadArticleFile. do?attachType=PDF\&id=10075

\begin{tabular}{|c|c|c|c|c|c|}
\hline \multirow[t]{2}{*}{ Dysosma versipellis } & 八角莲 & 未列 & 易危 & 李雪玲 & 八角莲植株地下茎内生真菌的分离 \\
\hline & & 入 & /VU & & \\
\hline \multirow[t]{2}{*}{ Dysosma versipellis } & 八角莲 & 未列 & 易危 & 由金文 & 八角莲致濒原因及其野生资源保护 \\
\hline & & 入 & /VU & & \\
\hline \multirow[t]{2}{*}{ Dysosma versipellis } & 八角莲 & 未列 & 易危 & 杨光义 & 八角莲中鬼臼毒素分离纯化与含量测定 \\
\hline & & 入 & /VU & & \\
\hline \multirow[t]{2}{*}{ Dysosma versipellis } & 八角莲 & 未列 & 易危 & 唐凤鸾 & 八角莲组织培养研究 \\
\hline & & 入 & /VU & & \\
\hline \multirow[t]{2}{*}{ Dysosma versipellis } & 八角莲 & II & 易危 & 刘燕琴 & 濒危药用植物八角莲的野生抚育技术研究 \\
\hline & & & $/ \mathrm{VU}$ & & \\
\hline \multirow[t]{2}{*}{ Dysosma versipellis } & 八角莲 & II & 易危 & 饶君凤 & 濒危药用植物八角莲繁殖与盆栽新技术 \\
\hline & & & /VU & & \\
\hline \multirow[t]{2}{*}{ Dysosma versipellis } & 八角莲 & II & 易危 & 刘燕琴 & 濒危药用植物八角莲茎节的生长特性初探 \\
\hline & & & /VU & & \\
\hline \multirow[t]{2}{*}{ Dysosma versipellis } & 八角莲 & II & 易危 & 周雅琴 & 濒危药用植物八角莲菌根的显微结构观察 \\
\hline & & & /VU & & \\
\hline \multirow[t]{2}{*}{ Dysosma versipellis } & 八角莲 & 未列 & 易危 & 李忠超 & 濒危药用植物八角莲生态生物学特征 \\
\hline & & 入 & $/ \mathrm{VU}$ & & \\
\hline Dysosma versipellis & 八角莲 & II & 易危 & 刘燕琴 & 濒危药用植物八角莲种子育苗技术研究 \\
\hline
\end{tabular}


顾垒，闻丞，罗玫，王吴，吕植. 中国最受关注濒危物种保护现状快速评价的新方法探讨. 生物多样性，2015，23(5)：583-590. http://www. biodiversity-science. net/CN/article/downloadArticleFile. do?attachType=PDF\&id=10075

\begin{tabular}{|c|c|c|c|c|c|}
\hline & & & /VU & & \\
\hline \multirow[t]{2}{*}{ Dysosma versipellis } & 八角莲 & II & 易危 & 邱英雄 & 濒危植物八角莲保护遗传学及八角莲属物种形成的研究 \\
\hline & & & $/ \mathrm{VU}$ & & \\
\hline \multirow[t]{2}{*}{ Dysosma versipellis } & 八角莲 & 未列 & 易危 & 余朝文 & 侗药八角莲药用民族植物学研究 \\
\hline & & 入 & /VU & & \\
\hline \multirow[t]{2}{*}{ Dysosma versipellis } & 八角莲 & 未列 & 易危 & 秦小波 & 峨眉八角莲多酚氧化酶活性与总酚含量的研究 \\
\hline & & 入 & /VU & & \\
\hline \multirow[t]{2}{*}{ Dysosma versipellis } & 八角莲 & II & 易危 & 廖朝林 & 恩施珍稀濒危药用植物八角莲资源调查报告 \\
\hline & & & /VU & & \\
\hline \multirow[t]{2}{*}{ Dysosma versipellis } & 八角莲 & 未列 & 易危 & 郑建斌 & 高效液相色谱-二极管阵列-电化学联用技术测定八角莲中 3 种成分的含量 \\
\hline & & 入 & /VU & & \\
\hline \multirow[t]{2}{*}{ Dysosma versipellis } & 八角莲 & 未列 & 易危 & 陈黎 & 高效液相色谱法测定八角莲中鬼臼毒素的含量 \\
\hline & & 入 & /VU & & \\
\hline \multirow[t]{2}{*}{ Dysosma versipellis } & 八角莲 & 未列 & 易危 & 孙晓菊 & 湖北八角莲属四种药用植物的生药学研究 \\
\hline & & 入 & /VU & & \\
\hline \multirow[t]{2}{*}{ Dysosma versipellis } & 八角莲 & 未列 & 易危 & 王兴红 & 两种八角莲内生真菌的生物活性研究 \\
\hline & & 入 & /VU & & \\
\hline \multirow[t]{2}{*}{ Dysosma versipellis } & 八角莲 & 未列 & 易危 & 李雪玲 & 两种八角莲属植物内生与根际真菌的多样性初探 \\
\hline & & 入 & /VU & & \\
\hline
\end{tabular}


顾垒，闻丞，罗玫，王吴，吕植. 中国最受关注濒危物种保护现状快速评价的新方法探讨. 生物多样性，2015，23(5)：583-590. http://www biodiversity-science. net/CN/article/downloadArticleFile. do?attachType=PDF\&id=10075

\begin{tabular}{|c|c|c|c|c|c|}
\hline Dysosma versipellis & 八角莲 & II & $\begin{array}{l}\text { 易危 } \\
\text { /VU }\end{array}$ & 杨松 & 黔产八角莲化学成分的研究 \\
\hline Dysosma versipellis & 八角莲 & II & $\begin{array}{l}\text { 易危 } \\
\text { /VU }\end{array}$ & 王铮敏 & 三明市八角莲内生真菌的初步分离 \\
\hline Dysosma versipellis & 八角莲 & $\begin{array}{l}\text { 未列 } \\
\text { 入 }\end{array}$ & $\begin{array}{l}\text { 易危 } \\
\text { /VU }\end{array}$ & 张敏 & 三种八角莲的性状与显微鉴别 \\
\hline Dysosma versipellis & 八角莲 & $\begin{array}{l}\text { 未列 } \\
\text { 入 }\end{array}$ & $\begin{array}{l}\text { 易危 } \\
\text { /VU }\end{array}$ & 王晓韵 & 特有濒危药用植物八角莲的快繁以及提高有限成分的研究 \\
\hline Dysosma versipellis & 八角莲 & II & $\begin{array}{l}\text { 易危 } \\
\text { /VU }\end{array}$ & 管毕财 & 特有濒危植物八角莲保护遗传学和分子亲缘地理学 \\
\hline Dysosma versipellis & 八角莲 & $\begin{array}{l}\text { 未列 } \\
\text { 入 }\end{array}$ & $\begin{array}{l}\text { 易危 } \\
\text { /VU }\end{array}$ & 李忠超 & 特有濒危植物八角莲遗传多样性研究 \\
\hline Dysosma versipellis & 八角莲 & $\begin{array}{l}\text { 未列 } \\
\text { 入 }\end{array}$ & $\begin{array}{l}\text { 易危 } \\
\text { /VU }\end{array}$ & 黄慧莲 & 液体振荡培养八角莲愈伤组织及其鬼臼毒素的含量测定 \\
\hline Dysosma versipellis & 八角莲 & $\begin{array}{l}\text { 未列 } \\
\text { 入 }\end{array}$ & $\begin{array}{l}\text { 易危 } \\
\text { /VU }\end{array}$ & 吕兆国 & 一株八角莲内生真菌次生代谢产物的化学成分及紫贻贝 HPLC 化学指纹图谱研究 \\
\hline Dysosma versipellis & 八角莲 & II & $\begin{array}{l}\text { 易危 } \\
\text { /VU }\end{array}$ & 叶耀辉 & 诱导八角莲愈伤组织的研究 \\
\hline Dysosma versipellis & 八角莲 & 未列 & 易危 & 叶耀辉 & 诱导八角莲愈伤组织的研究 \\
\hline
\end{tabular}


顾垒，闻丞，罗玫，王吴，吕植. 中国最受关注濒危物种保护现状快速评价的新方法探讨. 生物多样性，2015，23(5)：583-590. http://www. biodiversity-science. net/CN/article/downloadArticleFile. do?attachType=PDF\&id=10075

\begin{tabular}{|c|c|c|c|c|c|}
\hline & & 入 & $/ \mathrm{VU}$ & & \\
\hline \multirow[t]{2}{*}{ Dysosma versipellis } & 八角莲 & II & 易危 & 刘燕琴 & 运用人工授粉技术提高八角莲坐果率的研究 \\
\hline & & & $/ \mathrm{VU}$ & & \\
\hline \multirow[t]{2}{*}{ Dysosma versipellis } & 八角莲 & II & 易危 & 叶耀辉 & 珍稀濒危药用植物八角莲属的研究进展 \\
\hline & & & $/ \mathrm{VU}$ & & \\
\hline \multirow[t]{2}{*}{ Dysosma versipellis } & 八角莲 & 未列 & 易危 & 叶耀辉 & 珍稀濒危药用植物八角莲属的研究进展 \\
\hline & & 入 & $/ \mathrm{VU}$ & & \\
\hline \multirow[t]{2}{*}{ Dysosma versipellis } & 八角莲 & 未列 & 易危 & 周新闻 & 珍稀濒危植物八角莲的保护生物学研究 \\
\hline & & 入 & $/ \mathrm{VU}$ & & \\
\hline \multirow[t]{2}{*}{ Dysosma versipellis } & 八角莲 & II & 易危 & 秦小波 & 中国八角莲属植物的研究进展 \\
\hline & & & $/ \mathrm{VU}$ & & \\
\hline \multirow[t]{2}{*}{ Dysosma versipellis } & 八角莲 & 未列 & 易危 & 马邵宾 & 中国特有八角莲属的研究进展 \\
\hline & & 入 & /VU & & \\
\hline \multirow[t]{2}{*}{ Dysosma versipellis } & 八角莲 & 未列 & 易危 & 李天东 & 中国特有八角莲属植物种质资源研究 \\
\hline & & 入 & $/ \mathrm{VU}$ & & \\
\hline \multirow[t]{2}{*}{ Dysosma versipellis } & 八角莲 & 未列 & 易危 & 邱荷香 & 中国特有濒危植物八角莲的研究进展及其开发前景 \\
\hline & & 入 & $/ \mathrm{VU}$ & & \\
\hline Elaphe carinata & 王锦蛇 & II & 未评 & 张继 & 9 种蛇蜕的性状比较鉴定 \\
\hline
\end{tabular}


顾垒，闻丞，罗玫，王吴，吕植. 中国最受关注濒危物种保护现状快速评价的新方法探讨．生物多样性，2015，23(5)：583-590。 http://www. biodiversity-science. net/CN/article/downloadArticleFile. do?attachType=PDF\&id=10075

Elaphe carinata

王锦蛇

Elaphe carinata

王锦蛇

Elaphe carinata

王锦蛇

王锦蛇

Elaphe carinata

王锦蛇

Elaphe carinata

王锦蛇
价

$/ \mathrm{NE}$

\section{Peng GUO}

II 未评 Xiang Ji

价

$/ \mathrm{NE}$

II 未评 Xiang Ji

价

/NE

II 未评 Xiang Ji

价

/NE

价

$/ \mathrm{NE}$
Evaluation of the Validity of the Ratsnake Subspecies Elaphe carinata

deqenensis(Serpent:Colubridae)

Experimentally reducing clutch size reveals a fixed upper limit to egg size in snakes, evidence

from the king ratsnake,Elaphe carinata

Geographical variation in reproductive traits and trade-offs between size and number of eggs in

\section{the king ratsnakem,Elaphe carinata}

The effects of thermal and hydric environments on hatching success, embryonic use of energy

and hatchling traits in a colubrid snake, Elaphe carinata

福建邵武发现一例白化王锦蛇

宁夏蛇类一新纪录一一王锦蛇 
顾垒，闻丞，罗玫，王吴，吕植. 中国最受关注濒危物种保护现状快速评价的新方法探讨. 生物多样性，2015，23(5)：583-590. http://www. biodiversity-science. net/CN/article/downloadArticleFile. do?attachType=PDF\&id=10075

\begin{tabular}{|c|c|c|c|c|c|}
\hline Elaphe carinata & 王锦蛇 & II & $\begin{array}{l}\text { 未评 } \\
\text { 价 } \\
\text { /NE }\end{array}$ & 吴卯斌 & 三联浸泡法治疗王锦蛇急性肺炎疗效观察 \\
\hline Elaphe carinata & 王锦蛇 & II & $\begin{array}{l}\text { 未评 } \\
\text { 价 } \\
\text { /NE }\end{array}$ & 李丕鹏 & 山东半岛的王锦蛇 Elaphe carinata \\
\hline Elaphe carinata & 王锦蛇 & II & $\begin{array}{l}\text { 未评 } \\
\text { 价 } \\
\text { /NE }\end{array}$ & 张守富 & 山东日照发现王锦蛇 \\
\hline Elaphe carinata & 王锦蛇 & II & $\begin{array}{l}\text { 未评 } \\
\text { 价 } \\
\text { /NE }\end{array}$ & 杨超 & 王锦蛇 (Elaphe carinata)Sox 基因保守区的克隆及测序 \\
\hline Elaphe carinata & 王锦蛇 & II & $\begin{array}{l}\text { 未评 } \\
\text { 价 } \\
\text { /NE }\end{array}$ & 徐宁 & 王锦蛇, 红点锦蛇的形态、核型和 Ag-NORs 比较 \\
\hline Elaphe carinata & 王锦蛇 & II & $\begin{array}{l}\text { 未评 } \\
\text { 价 } \\
\text { /NE }\end{array}$ & 刘军 & 王锦蛇的高效饲养技术研究 \\
\hline Elaphe carinata & 王锦蛇 & II & 未评 & 张耀忠 & 王锦蛇的规模化人工生态繁殖技术研究 \\
\hline
\end{tabular}


顾垒，闻丞，罗玫，王吴，吕植. 中国最受关注濒危物种保护现状快速评价的新方法探讨．生物多样性，2015，23(5)：583-590。 http://www. biodiversity-science. net/CN/article/downloadArticleFile. do?attachType=PDF\&id=10075

\begin{tabular}{|c|c|c|c|c|c|}
\hline \multirow[b]{2}{*}{ Elaphe carinata } & \multirow[b]{2}{*}{ 王锦蛇 } & \multirow[b]{2}{*}{ II } & \multicolumn{3}{|l|}{ 价 } \\
\hline & & & $\begin{array}{l}\text { /NE } \\
\text { 未评 } \\
\text { 价 }\end{array}$ & 刘军 & 王锦蛇的人工睬化试验 \\
\hline Elaphe carinata & 王锦蛇 & II & $\begin{array}{l}\text { /NE } \\
\text { 未评 } \\
\text { 价 }\end{array}$ & 朱惠平 & 王锦蛇的人工养殖方法 \\
\hline Elaphe carinata & 王锦蛇 & II & $\begin{array}{l}/ \mathrm{NE} \\
\text { 未评 } \\
\text { 价 }\end{array}$ & 刘军 & 王锦蛇的无冬眠饲养试验 \\
\hline Elaphe carinata & 王锦蛇 & II & $\begin{array}{l}/ \mathrm{NE} \\
\text { 未评 } \\
\text { 价 }\end{array}$ & 张志强 & 王锦蛇消化道 5-羟色胺细胞的免疫组织化学定位 \\
\hline Elaphe carinata & 王锦蛇 & II & $\begin{array}{l}\text { /NE } \\
\text { 未评 } \\
\text { 价 }\end{array}$ & 刘军 & 王锦蛇幼蛇的饲养与子一代的繁育试验 \\
\hline Elaphe perlacea & 横斑锦蛇 & $\begin{array}{l}\text { 未列 } \\
\lambda\end{array}$ & $\begin{array}{l}\text { /NE } \\
\text { 易危 } \\
\text { /VU }\end{array}$ & 胡 杰 & 横斑锦蛇的现状 \\
\hline
\end{tabular}


顾垒，闻丞，罗玫，王吴，吕植. 中国最受关注濒危物种保护现状快速评价的新方法探讨. 生物多样性，2015，23(5)：583-590. http://www. biodiversity-science. net/CN/article/downloadArticleFile. do?attachType=PDF\&id=10075

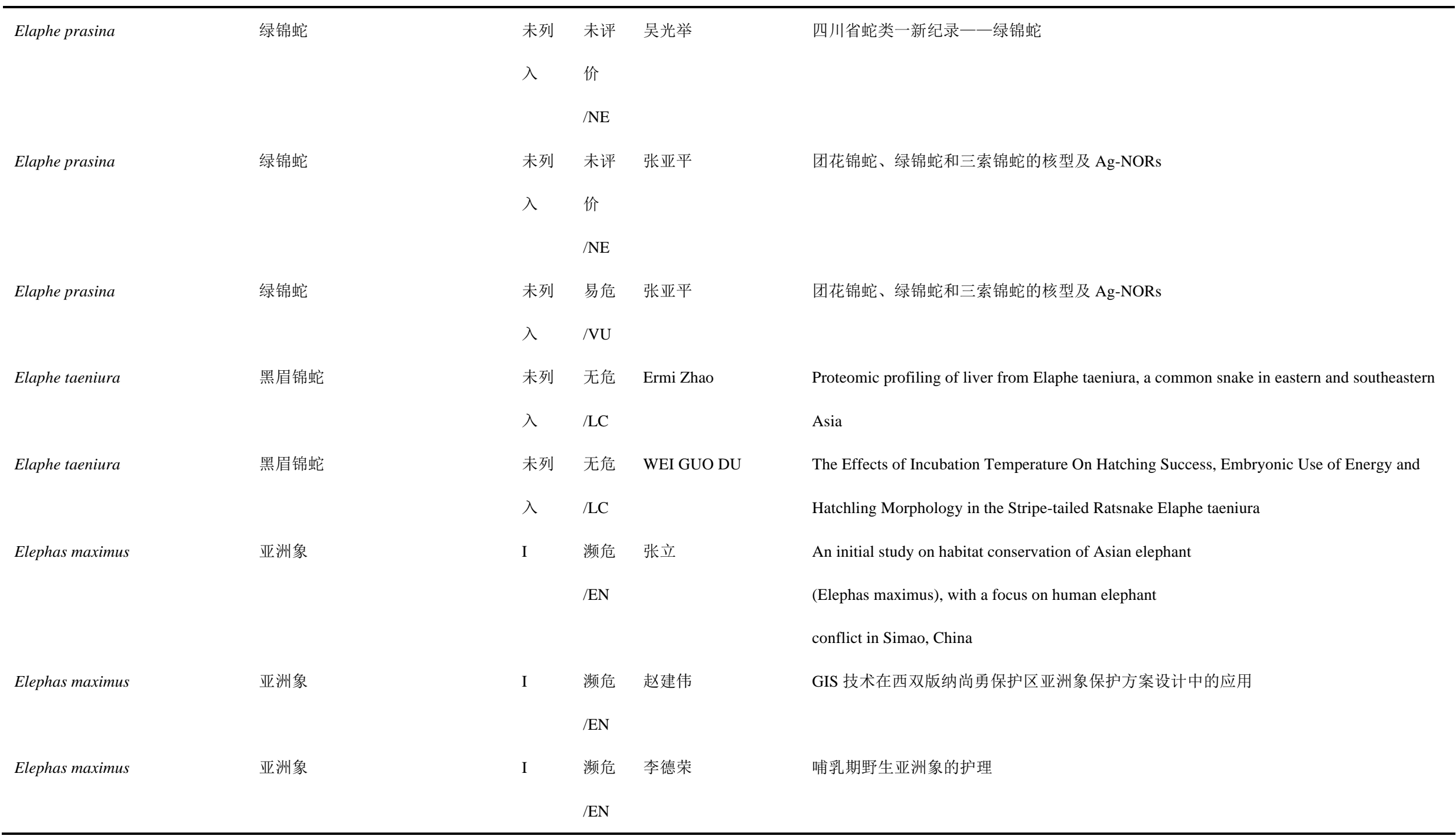


顾垒，闻丞，罗玫，王吴，吕植. 中国最受关注濒危物种保护现状快速评价的新方法探讨. 生物多样性，2015，23(5)：583-590. http://www. biodiversity-science. net/CN/article/downloadArticleFile. do?attachType=PDF\&id=10075

\begin{tabular}{|c|c|c|c|c|c|}
\hline Elephas maximus & 亚洲象 & I & $\begin{array}{l}\text { 濒危 } \\
\text { /EN }\end{array}$ & 马建章 & 基于条件价值评估法的中国亚洲象存在价值评估 \\
\hline Elephas maximus & 亚洲象 & I & $\begin{array}{l}\text { 濒危 } \\
\text { /EN }\end{array}$ & 刘欣 & 基于亚洲象保护的我国野生动物损害补偿机制研究 \\
\hline Elephas maximus & 亚洲象 & I & $\begin{array}{l}\text { 濒危 } \\
\text { /EN }\end{array}$ & 冯子山 & 澜沧县野生动物肇事情况调查报告 \\
\hline Elephas maximus & 亚洲象 & I & $\begin{array}{l}\text { 濒危 } \\
\text { /EN }\end{array}$ & 郭贤明 & 预腊保护区亚洲象活动变化及保护措施 \\
\hline Elephas maximus & 亚洲象 & I & $\begin{array}{l}\text { 濒危 } \\
\text { /EN }\end{array}$ & 郭贤明 & 预腊保护区亚洲象为害现状调查分析与对策 \\
\hline Elephas maximus & 亚洲象 & I & $\begin{array}{l}\text { 濒危 } \\
\text { /EN }\end{array}$ & 张立 & $\begin{array}{l}\text { 预养保护区亚洲象微卫星位点篮选 } \\
\text { 及种群遗传多样性分析 }\end{array}$ \\
\hline Elephas maximus & 亚洲象 & I & $\begin{array}{l}\text { 濒危 } \\
\text { /EN }\end{array}$ & 彭明春 & 南滚河流域亚洲象生境质量现状评价 \\
\hline Elephas maximus & 亚洲象 & I & $\begin{array}{l}\text { 濒危 } \\
\text { /EN }\end{array}$ & 曹亚康 & 浅谈西双版纳州野生亚洲象对人伤害的防范 \\
\hline Elephas maximus & 亚洲象 & I & $\begin{array}{l}\text { 濒危 } \\
\text { /EN }\end{array}$ & 李剑文 & 浅谈亚洲象保护中人象冲突现象的实质及对策 \\
\hline Elephas maximus & 亚洲象 & I & 濒危 & 吴兆录 & 生物保护廊道研究进展 \\
\hline
\end{tabular}


顾垒，闻丞，罗玫，王吴，吕植. 中国最受关注濒危物种保护现状快速评价的新方法探讨. 生物多样性，2015，23(5)：583-590. http://www. biodiversity-science. net/CN/article/downloadArticleFile. do?attachType=PDF\&id=10075

\begin{tabular}{|c|c|c|c|c|c|}
\hline & & & /EN & & \\
\hline \multirow[t]{2}{*}{ Elephas maximus } & 亚洲象 & I & 濒危 & 曹亚康 & 试论西双版纳州违规农村用电对 \\
\hline & & & /EN & & 野生亚洲象的危害 \\
\hline \multirow[t]{2}{*}{ Elephas maximus } & 亚洲象 & I & 濒危 & 杨正斌 & 西双版纳国家级自然保护区预养子保护区亚洲象生境现状分析 \\
\hline & & & /EN & & \\
\hline \multirow[t]{2}{*}{ Elephas maximus } & 亚洲象 & I & 濒危 & 张峻 & 西双版纳人象冲突的分析和缓解政策 \\
\hline & & & /EN & & \\
\hline \multirow[t]{2}{*}{ Elephas maximus } & 亚洲象 & I & 濒危 & 廖涛 & 西双版纳人象冲突及其防治措施探讨 \\
\hline & & & /EN & & \\
\hline \multirow[t]{2}{*}{ Elephas maximus } & 亚洲象 & I & 濒危 & 唐勤 & 西双版纳人象冲突与缓解对策 \\
\hline & & & /EN & & \\
\hline \multirow[t]{2}{*}{ Elephas maximus } & 亚洲象 & I & 濒危 & 张立 & 西双版纳三岔河地区野生亚洲象的个体识别、种群数量和活动特点 \\
\hline & & & /EN & & \\
\hline \multirow[t]{2}{*}{ Elephas maximus } & 亚洲象 & I & 濒危 & 邓晓保 & 西双版纳尚勇亚洲象的食物组成与取食生态 \\
\hline & & & /EN & & \\
\hline \multirow[t]{2}{*}{ Elephas maximus } & 亚洲象 & I & 濒危 & 吴兆录 & 西双版纳社区村民对亚洲象保护廊道建设 \\
\hline & & & /EN & & 的认知与态度 \\
\hline \multirow[t]{2}{*}{ Elephas maximus } & 亚洲象 & I & 濒危 & 何馨成 & 西双版纳社区居民对亚洲象肇事与保护的认知研究 \\
\hline & & & /EN & & \\
\hline
\end{tabular}


顾垒，闻丞，罗玫，王吴，吕植. 中国最受关注濒危物种保护现状快速评价的新方法探讨. 生物多样性，2015，23(5)：583-590. http://www. biodiversity-science. net/CN/article/downloadArticleFile. do?attachType=PDF\&id=10075

\begin{tabular}{|c|c|c|c|c|c|}
\hline \multirow[t]{2}{*}{ Elephas maximus } & 亚洲象 & I & 濒危 & 李正玲 & 西双版纳亚洲象保护廊道与社区发展关系研究 \\
\hline & & & $/$ EN & & \\
\hline \multirow[t]{2}{*}{ Elephas maximus } & 亚洲象 & I & 濒危 & 郭贤明 & 西双版纳亚洲象肇事原因分析及缓解对策探讨 \\
\hline & & & /EN & & \\
\hline \multirow[t]{2}{*}{ Elephas maximus } & 亚洲象 & I & 濒危 & 张立 & 西双版纳野生亚洲象的受食行为 \\
\hline & & & /EN & & \\
\hline \multirow[t]{2}{*}{ Elephas maximus } & 亚洲象 & I & 濒危 & 李中员 & 西双版纳野象谷景区游客行为意识分析 \\
\hline & & & $/ \mathrm{EN}$ & & \\
\hline \multirow[t]{2}{*}{ Elephas maximus } & 亚洲象 & I & 濒危 & 孟庆州 & 亚洲象的生境选择 \\
\hline & & & $/ \mathrm{EN}$ & & \\
\hline \multirow[t]{2}{*}{ Elephas maximus } & 亚洲象 & I & 濒危 & 杨士剑 & 亚洲象等野生动物对西双版纳尚勇自然保护区周边村寨的影响 \\
\hline & & & $/ \mathrm{EN}$ & & \\
\hline \multirow[t]{2}{*}{ Elephas maximus } & 亚洲象 & I & 濒危 & 李中员 & 亚洲象食物源基地建设对缓解人象冲突的作用 \\
\hline & & & $/ \mathrm{EN}$ & & \\
\hline \multirow[t]{2}{*}{ Elephas maximus } & 亚洲象 & I & 濒危 & 张立 & 亚洲象野外及圈养条件下食物成分分析 \\
\hline & & & $/ \mathrm{EN}$ & & \\
\hline \multirow[t]{2}{*}{ Elephas maximus } & 亚洲象 & I & 濒危 & 许再富 & 亚洲象与竹/蕉分布隔离的生态效果及其 \\
\hline & & & $/ \mathrm{EN}$ & & 保护对策探讨 \\
\hline Elephas maximus & 亚洲象 & I & 濒危 & 张立 & 云南南滚河国家级自然保护区亚洲象 \\
\hline
\end{tabular}


顾垒，闻丞，罗玫，王吴，吕植. 中国最受关注濒危物种保护现状快速评价的新方法探讨. 生物多样性，2015，23(5)：583-590. http://www. biodiversity-science. net/CN/article/downloadArticleFile. do?attachType=PDF\&id=10075

Elephas maximus

Elephas maximus

Elephas maximus

Elephas maximus

Elephas maximus

Elephas maximus

Elephas maximus

Elephas maximus

Emberiza aureola
亚洲象

亚洲象

亚洲象

亚洲象

亚洲象

亚洲象

亚洲象

亚洲象

黄胸鴊
濒危 张立

/EN

I

濒危 张 立

EN

濒危 张 立

EN

I

濒危 张 立

/EN

I

濒危 马建章

I

濒危 张 立

I

濒危

陈明勇

EN

I 濒危靳莉

/EN

未列濒危 李 健

入 /EN
种群早季生境选择及保护策略

云南思茅亚洲象对栖息地的选择与利用

云南西双版纳尚勇保护区亚洲象

新活动廊道的开辟和利用

云南西双版纳尚勇保护区亚洲象对栖息地的选择

在西双版纳国家级自然保护区用 3S 技术规划

亚洲象生态走廊带初探

中国亚洲象损害地区农户受偿意愿调查

中国亚洲象现状及研究进展

中国亚洲象与人类关系

中国亚洲象肇事原因和对策研究

内蒙古红花尔基地区草原_森林生态系统不同生境鸟类多样性 
顾垒，闻丞，罗玫，王吴，吕植. 中国最受关注濒危物种保护现状快速评价的新方法探讨. 生物多样性，2015，23(5)：583-590. http://www. biodiversity-science. net/CN/article/downloadArticleFile. do?attachType=PDF\&id=10075

\begin{tabular}{|c|c|c|c|c|c|}
\hline \multirow[t]{2}{*}{ Emberiza aureola } & 黄胸鸥 & 未列 & 濒危 & 徐兴军 & 扎龙国家自然保护区 6 种雀形目鸟类血液蛋白的遗传多态性 \\
\hline & & 入 & /EN & & \\
\hline \multirow[t]{2}{*}{ Emberiza jankowskii } & 栗斑腹鸥 & 未列 & 濒危 & 付建平 & 北京观鸟会 2013 年栗斑腹鸥调查发现分布点新记录 \\
\hline & & 入 & /EN & & \\
\hline \multirow[t]{2}{*}{ Emberiza jankowskii } & 栗斑腹鸥 & 未列 & 濒危 & 高玮 & 栗斑腹鸥的栖息地和巢址选择 \\
\hline & & 入 & /EN & & \\
\hline \multirow[t]{2}{*}{ Emberiza jankowskii } & 栗斑腹鸥 & 未列 & 濒危 & 刘子成 & 人类干扰导致的草原不同程度退化对繁殖鸟类多样性的影响 \\
\hline & & 入 & $/ \mathrm{EN}$ & & \\
\hline \multirow[t]{2}{*}{ Emberiza koslowi } & 藏㧰 & 未列 & 近危 & 居・扎西桑俄 & 藏鸪的自然历史、威胁和保护 \\
\hline & & 入 & /NT & & \\
\hline \multirow[t]{3}{*}{ Emmenopterys henryi } & 香果树 & II & 未评 & 尹明华 & 5 种植物生长抑制剂对香果树种质离体保存的影响 \\
\hline & & & 价 & & \\
\hline & & & $/ \mathrm{NE}$ & & \\
\hline \multirow[t]{3}{*}{ Emmenopterys henryi } & 香果树 & II & 未评 & YING-XIONG QIU & DEVELOPMENT AND CHARACTERIZATION OF MICROSATELLITE MARKERS FOR \\
\hline & & & 价 & & EMMENOPTERYS HENRYI (RUBIACEAE), A RARE TREE FROM CHINA \\
\hline & & & $/ \mathrm{NE}$ & & \\
\hline \multirow[t]{3}{*}{ Emmenopterys henryi } & 香果树 & II & 未评 & Ze-Xin Jin & Genetic structure of endangered Emmenopterys henryi Oliv. Based on ISSR polymorphism and \\
\hline & & & 价 & & implications for its conservation \\
\hline & & & $/ \mathrm{NE}$ & & \\
\hline
\end{tabular}


顾垒，闻丞，罗玫，王吴，吕植. 中国最受关注濒危物种保护现状快速评价的新方法探讨. 生物多样性，2015，23(5)：583-590. http://www. biodiversity-science. net/CN/article/downloadArticleFile. do?attachType=PDF\&id=10075

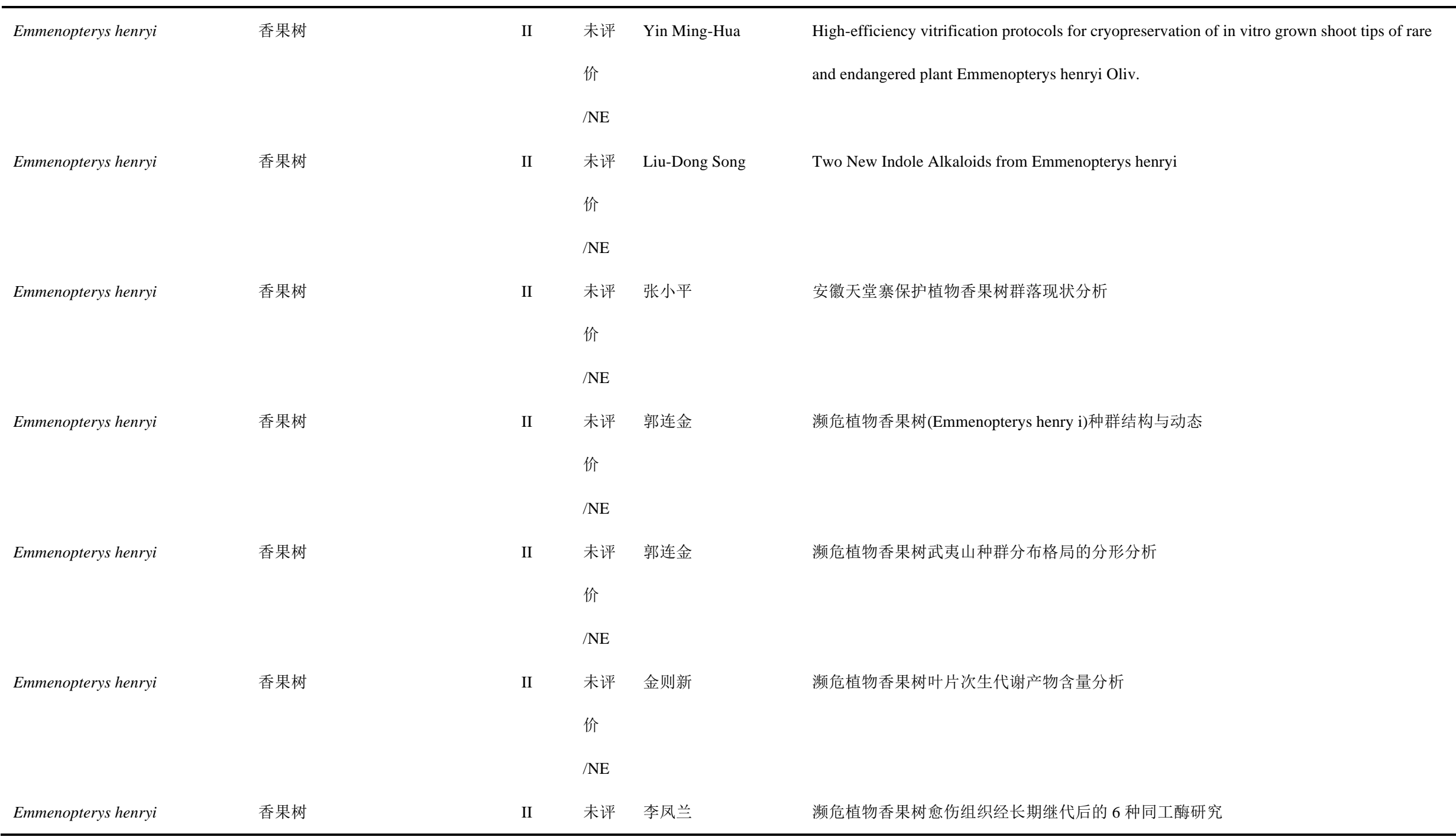


顾垒，闻丞，罗玫，王吴，吕植. 中国最受关注濒危物种保护现状快速评价的新方法探讨. 生物多样性，2015，23(5)：583-590. http://www. biodiversity-science. net/CN/article/downloadArticleFile. do?attachType=PDF\&id=10075

\begin{tabular}{|c|c|c|c|c|c|}
\hline & & & 价 & & \\
\hline Emmenopterys henryi & 香果树 & II & $\begin{array}{l}/ \mathrm{NE} \\
\text { 未评 } \\
\text { 价 }\end{array}$ & 康华靖 & 濒危植物香果树种子萌发及幼苗生长动态的比较 \\
\hline Emmenopterys henryi & 香果树 & II & $\begin{array}{l}\text { /NE } \\
\text { 未评 } \\
\text { 价 }\end{array}$ & 金则新 & 濒危植物香果树自然居群遗传多样性的 RAPD 分析 \\
\hline Emmenopterys henryi & 香果树 & II & $\begin{array}{l}/ \mathrm{NE} \\
\text { 未评 } \\
\text { 价 }\end{array}$ & 刘鹏 & 不同生境香果树种群的径级结构与分布格局 \\
\hline Emmenopterys henryi & 香果树 & II & $\begin{array}{l}\text { /NE } \\
\text { 未评 } \\
\text { 价 }\end{array}$ & 刘鹏 & 大盘山香果树(Emmenopterys henryi)种内及其与常见伴生种之间的竞争关系 \\
\hline Emmenopterys henryi & 香果树 & II & $\begin{array}{l}\text { /NE } \\
\text { 未评 } \\
\text { 价 }\end{array}$ & 刘鹏 & 大盘山自然保护区濒危植物香果树群落生态学的研究 \\
\hline Emmenopterys henryi & 香果树 & II & $\begin{array}{l}/ \mathrm{NE} \\
\text { 未评 } \\
\text { 价 }\end{array}$ & 刘鹏 & 大盘山自然保护区香果树对不同海拔生境的生理生态响应 \\
\hline
\end{tabular}


顾垒，闻丞，罗玫，王吴，吕植. 中国最受关注濒危物种保护现状快速评价的新方法探讨. 生物多样性，2015，23(5)：583-590. http://www. biodiversity-science. net/CN/article/downloadArticleFile. do?attachType=PDF\&id=10075

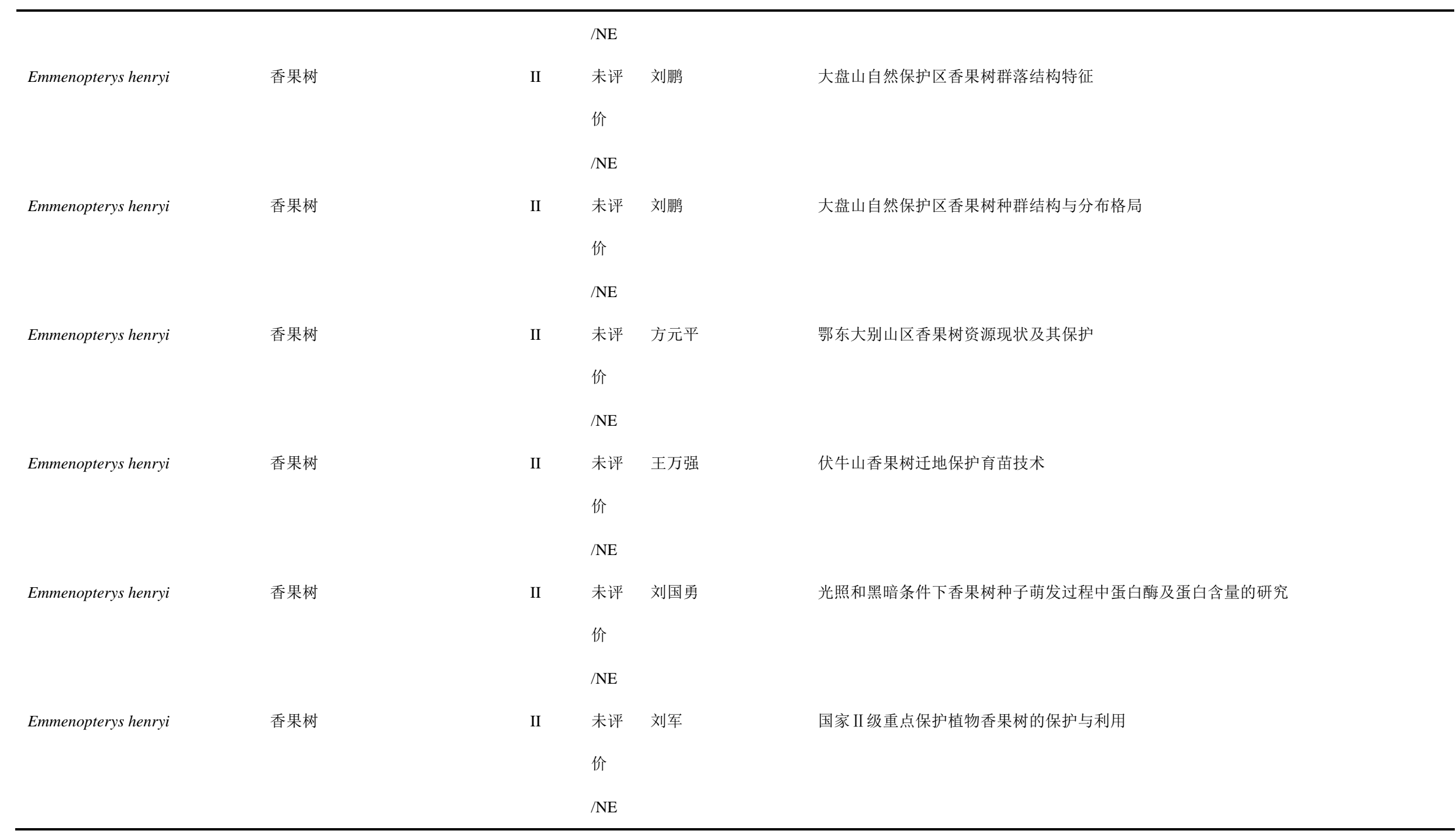


顾垒，闻丞，罗玫，王吴，吕植. 中国最受关注濒危物种保护现状快速评价的新方法探讨. 生物多样性，2015，23(5)：583-590. http://www. biodiversity-science. net/CN/article/downloadArticleFile. do?attachType=PDF\&id=10075

\begin{tabular}{|c|c|c|c|c|c|}
\hline Emmenopterys henryi & 香果树 & II & $\begin{array}{l}\text { 未评 } \\
\text { 价 } \\
\text { /NE }\end{array}$ & 叶永忠 & 国家重点保护植物香果树传粉生物学研究 \\
\hline Emmenopterys henryi & 香果树 & II & $\begin{array}{l}\text { 未评 } \\
\text { 价 } \\
\text { /NE }\end{array}$ & 孟庆法 & 河南桐柏山香果树资源分布与群落结构研究 \\
\hline Emmenopterys henryi & 香果树 & II & $\begin{array}{l}\text { 未评 } \\
\text { 价 } \\
\text { /NE }\end{array}$ & 徐小玉 & 湖北九宫山香果树群落结构特征研究 \\
\hline Emmenopterys henryi & 香果树 & II & $\begin{array}{l}\text { 未评 } \\
\text { 价 } \\
\text { /NE }\end{array}$ & 刘成一 & 湖南大围山香果树群落特征及物种多样性分析 \\
\hline Emmenopterys henryi & 香果树 & II & $\begin{array}{l}\text { 未评 } \\
\text { 价 } \\
\text { /NE }\end{array}$ & 刘鹏 & 基于主成分分析和聚类分析的 FTIR 不同地理居群香果树多样性分化研究 \\
\hline Emmenopterys henryi & 香果树 & II & $\begin{array}{l}\text { 未评 } \\
\text { 价 } \\
\text { /NE }\end{array}$ & 周赛霞 & 庐山香果树毛竹混交林空间格局研究 \\
\hline Emmenopterys henryi & 香果树 & II & 未评 & 满金山 & 七姊妹山国家级自然保护区香果树资源现状及保护 \\
\hline
\end{tabular}


顾垒，闻丞，罗玫，王吴，吕植. 中国最受关注濒危物种保护现状快速评价的新方法探讨. 生物多样性，2015，23(5)：583-590. http://www. biodiversity-science. net/CN/article/downloadArticleFile. do?attachType=PDF\&id=10075

\begin{tabular}{|c|c|c|c|c|c|}
\hline \multirow[b]{2}{*}{ Emmenopterys henryi } & \multirow[b]{2}{*}{ 香果树 } & \multirow[b]{2}{*}{ II } & \multicolumn{3}{|l|}{ 价 } \\
\hline & & & $\begin{array}{l}\text { /NE } \\
\text { 未评 } \\
\text { 价 }\end{array}$ & 陈发菊 & 神农架地区濒危植物香果树的遗传多样性研究 \\
\hline Emmenopterys henryi & 香果树 & II & $\begin{array}{l}\text { /NE } \\
\text { 未评 } \\
\text { 价 }\end{array}$ & 叶永忠 & 外种皮对香果树种子休眠的影响 \\
\hline Emmenopterys henryi & 香果树 & II & $\begin{array}{l}\text { /NE } \\
\text { 未评 } \\
\text { 价 }\end{array}$ & 徐卫红 & 武夷山香果树种群格局的分形特征一一信息维数 \\
\hline Emmenopterys henryi & 香果树 & II & $\begin{array}{l}\text { /NE } \\
\text { 未评 } \\
\text { 价 }\end{array}$ & 郭连金 & 武夷山香果树自然种群生殖构件特性研究 \\
\hline Emmenopterys henryi & 香果树 & II & $\begin{array}{l}\text { /NE } \\
\text { 未评 } \\
\text { 价 }\end{array}$ & 张小平 & 稀有植物香果树的保护生物学初步研究 \\
\hline Emmenopterys henryi & 香果树 & II & $\begin{array}{l}/ \mathrm{NE} \\
\text { 未评 } \\
\text { 价 }\end{array}$ & 张小平 & 稀有植物香果树的研究进展 \\
\hline
\end{tabular}


顾垒，闻丞，罗玫，王吴，吕植. 中国最受关注濒危物种保护现状快速评价的新方法探讨. 生物多样性，2015，23(5)：583-590. http://www. biodiversity-science. net/CN/article/downloadArticleFile. do?attachType=PDF\&id=10075

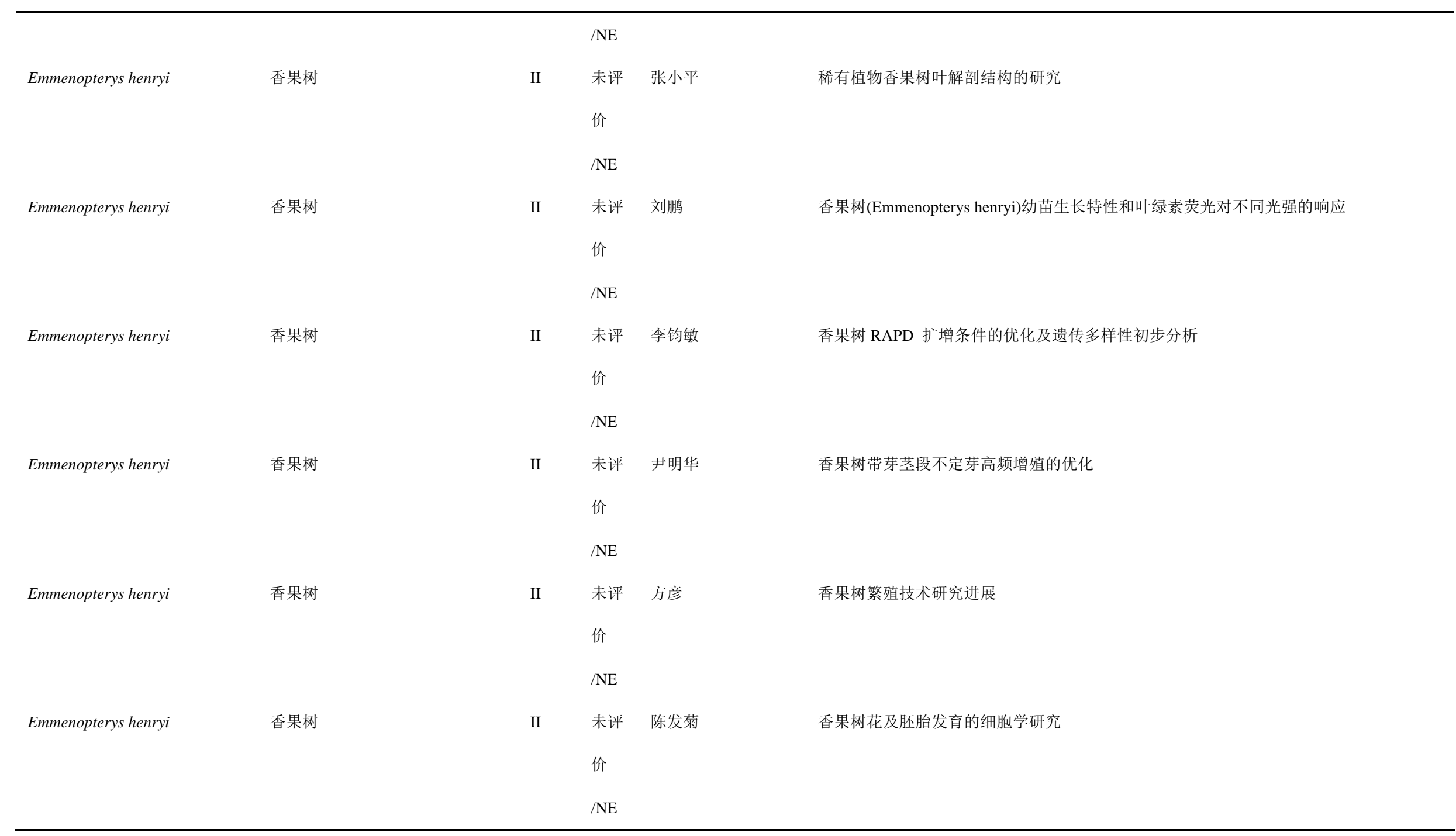


顾垒，闻丞，罗玫，王吴，吕植. 中国最受关注濒危物种保护现状快速评价的新方法探讨. 生物多样性，2015，23(5)：583-590. http://www. biodiversity-science. net/CN/article/downloadArticleFile. do?attachType=PDF\&id=10075

\begin{tabular}{|c|c|c|c|c|c|}
\hline Emmenopterys henryi & 香果树 & II & $\begin{array}{l}\text { 未评 } \\
\text { 价 } \\
\text { /NE }\end{array}$ & 周慧斌 & 香果树化学成分及其生物活性研究 \\
\hline Emmenopterys henryi & 香果树 & II & $\begin{array}{l}\text { 未评 } \\
\text { 价 } \\
\text { /NE }\end{array}$ & 汤庚国 & 香果树茎段和叶片的组织培养 \\
\hline Emmenopterys henryi & 香果树 & II & $\begin{array}{l}\text { 未评 } \\
\text { 价 } \\
\text { /NE }\end{array}$ & 魏亚平 & 香果树埋根育苗试验初探 \\
\hline Emmenopterys henryi & 香果树 & II & $\begin{array}{l}\text { 未评 } \\
\text { 价 } \\
\text { /NE }\end{array}$ & 俞惠林 & 香果树扞插育苗试验研究 \\
\hline Emmenopterys henryi & 香果树 & II & $\begin{array}{l}\text { 未评 } \\
\text { 价 } \\
\text { /NE }\end{array}$ & 韦小丽 & 香果树试管苗内外生根与移栽技术 \\
\hline Emmenopterys henryi & 香果树 & II & $\begin{array}{l}\text { 未评 } \\
\text { 价 } \\
\text { /NE }\end{array}$ & 吴成春 & 香果树属———秦岭北坡茜草科一新分布属 \\
\hline Emmenopterys henryi & 香果树 & II & 未评 & 李风兰 & 香果树体细胞胚胎发生 \\
\hline
\end{tabular}


顾垒，闻丞，罗玫，王吴，吕植. 中国最受关注濒危物种保护现状快速评价的新方法探讨. 生物多样性，2015，23(5)：583-590. http://www. biodiversity-science. net/CN/article/downloadArticleFile. do?attachType=PDF\&id=10075

\begin{tabular}{|c|c|c|c|c|c|}
\hline \multirow[b]{2}{*}{ Emmenopterys henryi } & \multirow[b]{2}{*}{ 香果树 } & \multirow[b]{2}{*}{ II } & \multicolumn{3}{|l|}{ 价 } \\
\hline & & & $\begin{array}{l}\text { /NE } \\
\text { 未评 } \\
\text { 价 }\end{array}$ & 陈发菊 & 香果树体细胞胚胎发生过程中 4 种同工酶的研究 \\
\hline Emmenopterys henryi & 香果树 & II & $\begin{array}{l}\text { /NE } \\
\text { 未评 } \\
\text { 价 }\end{array}$ & 黎明 & 香果树营养器官的解剖学研究 \\
\hline Emmenopterys henryi & 香果树 & II & $\begin{array}{l}/ \mathrm{NE} \\
\text { 未评 } \\
\text { 价 }\end{array}$ & 谢玉芳 & 香果树育苗技术 \\
\hline Emmenopterys henryi & 香果树 & II & $\begin{array}{l}\text { /NE } \\
\text { 未评 } \\
\text { 价 }\end{array}$ & 况娟 & 香果树种群分布与繁殖技术调查 \\
\hline Emmenopterys henryi & 香果树 & II & $\begin{array}{l}\text { /NE } \\
\text { 未评 } \\
\text { 价 }\end{array}$ & 邵红琼 & 香果树种质资源保存库建设要点 \\
\hline Emmenopterys henryi & 香果树 & II & $\begin{array}{l}/ \mathrm{NE} \\
\text { 未评 } \\
\text { 价 }\end{array}$ & 刘延惠 & 香果树种子发芽对水分胁迫的响应 \\
\hline
\end{tabular}


顾垒，闻丞，罗玫，王吴，吕植. 中国最受关注濒危物种保护现状快速评价的新方法探讨. 生物多样性，2015，23(5)：583-590. http://www. biodiversity-science. net/CN/article/downloadArticleFile. do?attachType=PDF\&id=10075

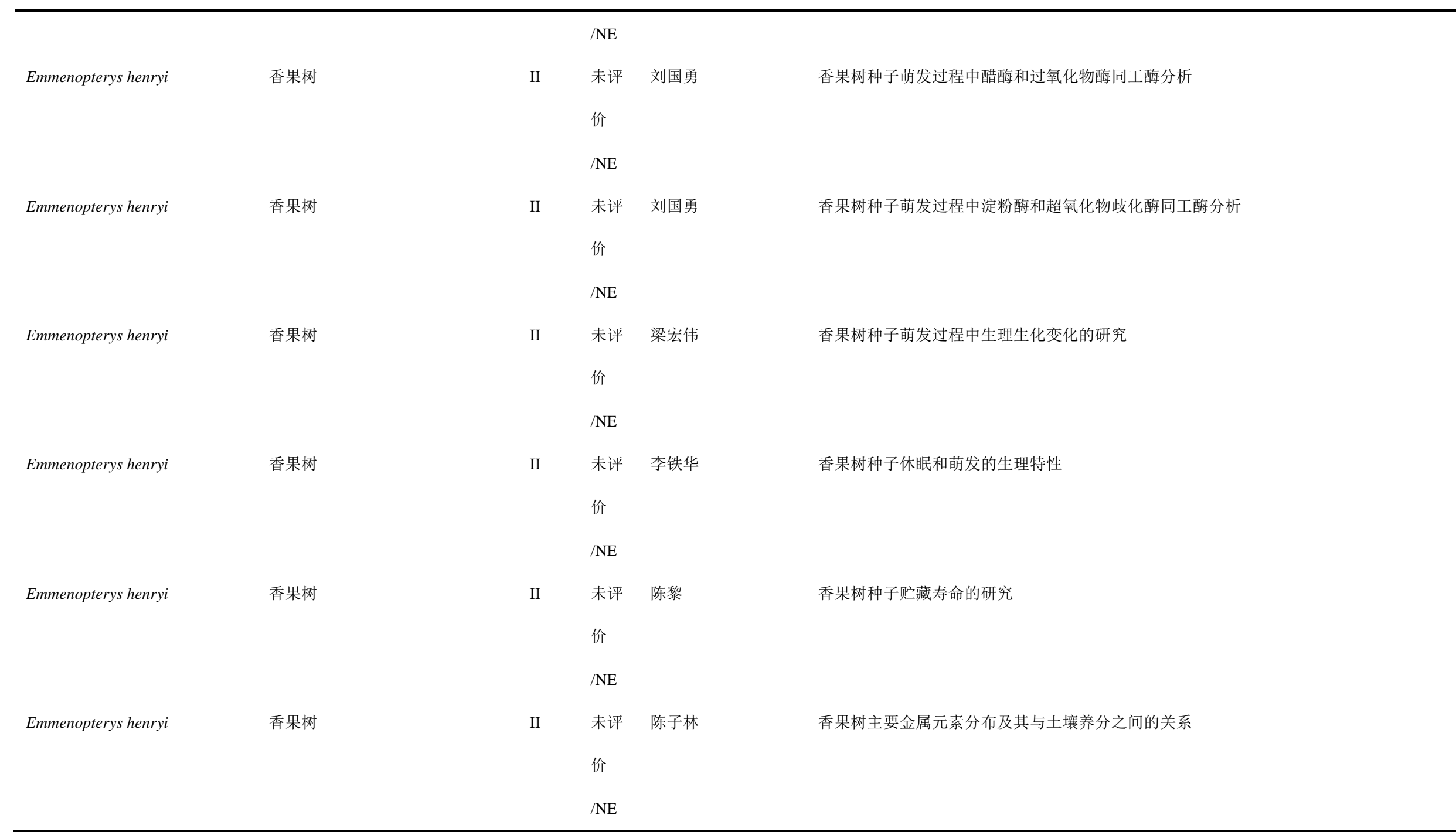


顾垒，闻丞，罗玫，王吴，吕植. 中国最受关注濒危物种保护现状快速评价的新方法探讨. 生物多样性，2015，23(5)：583-590. http://www. biodiversity-science. net/CN/article/downloadArticleFile. do?attachType=PDF\&id=10075

\begin{tabular}{|c|c|c|c|c|c|}
\hline Emmenopterys henryi & 香果树 & II & $\begin{array}{l}\text { 未评 } \\
\text { 价 } \\
\text { /NE }\end{array}$ & 陈发菊 & 香果树组织培养过程中遗传变异的 RAPD 分析 \\
\hline Emmenopterys henryi & 香果树 & II & $\begin{array}{l}\text { 未评 } \\
\text { 价 } \\
\text { /NE }\end{array}$ & 韦小丽 & 香果树组织培养技术研究 \\
\hline Emmenopterys henryi & 香果树 & II & $\begin{array}{l}\text { 未评 } \\
\text { 价 } \\
\text { /NE }\end{array}$ & 沈立新 & 野生香果的人工繁殖和栽培技术研究 \\
\hline Emmenopterys henryi & 香果树 & II & $\begin{array}{l}\text { 未评 } \\
\text { 价 } \\
\text { /NE }\end{array}$ & 王昌腾 & 野生香果树与繁育技术 \\
\hline Emmenopterys henryi & 香果树 & II & $\begin{array}{l}\text { 未评 } \\
\text { 价 } \\
\text { /NE }\end{array}$ & 王辉 & 豫南山区珍稀树种香果树的开发利用 \\
\hline Emmenopterys henryi & 香果树 & II & $\begin{array}{l}\text { 未评 } \\
\text { 价 } \\
\text { /NE }\end{array}$ & 陈子林 & 浙江大盘山香果树群落各层优势种叶片热值研究 \\
\hline Emmenopterys henryi & 香果树 & II & 未评 & 李钧敏 & 珍稀濒危植物香果树 ISSR-PCR 反应体系的笁选与优化 \\
\hline
\end{tabular}


顾垒，闻丞，罗玫，王吴，吕植. 中国最受关注濒危物种保护现状快速评价的新方法探讨. 生物多样性，2015，23(5)：583-590. http://www. biodiversity-science. net/CN/article/downloadArticleFile. do?attachType=PDF\&id=10075

\begin{tabular}{|c|c|c|c|c|c|}
\hline \multirow[b]{2}{*}{ Emmenopterys henryi } & \multirow[b]{2}{*}{ 香果树 } & \multirow[b]{2}{*}{ II } & \multicolumn{3}{|l|}{ 价 } \\
\hline & & & $\begin{array}{l}\text { /NE } \\
\text { 未评 } \\
\text { 价 }\end{array}$ & 杨敬元 & 珍稀濒危植物香果树 RAPD 反应条件的优化 \\
\hline Emmenopterys henryi & 香果树 & II & $\begin{array}{l}\text { /NE } \\
\text { 未评 } \\
\text { 价 }\end{array}$ & 陈发菊 & 珍稀濒危植物香果树胚性细胞悬浮系的建立和植株再生 \\
\hline Emmenopterys henryi & 香果树 & II & $\begin{array}{l}/ \mathrm{NE} \\
\text { 未评 } \\
\text { 价 }\end{array}$ & 尹明华 & 珍稀濒危植物香果树种质离体保存技术的研究 \\
\hline Emmenopterys henryi & 香果树 & II & $\begin{array}{l}/ \mathrm{NE} \\
\text { 未评 } \\
\text { 价 }\end{array}$ & 陈发菊 & 珍稀濒危植物香果树种子萌发特性研究 \\
\hline Emmenopterys henryi & 香果树 & II & $\begin{array}{l}\text { /NE } \\
\text { 未评 } \\
\text { 价 }\end{array}$ & 崔同林 & 珍稀树种香果树的利用价值及实用繁殖技术 \\
\hline Emmenopterys henryi & 香果树 & II & $\begin{array}{l}/ \mathrm{NE} \\
\text { 未评 } \\
\text { 价 }\end{array}$ & 柯世省 & 珍稀植物香果树光合作用日进程初步研究 \\
\hline
\end{tabular}


顾垒，闻丞，罗玫，王吴，吕植. 中国最受关注濒危物种保护现状快速评价的新方法探讨. 生物多样性，2015，23(5)：583-590. http://www. biodiversity-science. net/CN/article/downloadArticleFile. do?attachType=PDF\&id=10075

\begin{tabular}{|c|c|c|c|c|c|}
\hline & & & $/ \mathrm{NE}$ & & \\
\hline \multirow[t]{2}{*}{ Emmenopterys henryi } & 香果树 & II & $\begin{array}{l}\text { 未评 } \\
\text { 价 }\end{array}$ & 陈发菊 & 珍稀植物香果树植株再生体系的建立 \\
\hline & & & $/ \mathrm{NE}$ & & \\
\hline \multirow[t]{2}{*}{ Emmenopterys henryi } & 香果树 & II & $\begin{array}{l}\text { 未评 } \\
\text { 价 }\end{array}$ & 尹明华 & 正交实验法在香果树种质离体保存中的应用 \\
\hline & & & $/ \mathrm{NE}$ & & \\
\hline Equus kiang & 西藏野驴 & I & $\begin{array}{l}\text { 无危 } \\
\text { /LC }\end{array}$ & Joseph L. FOX & $\begin{array}{l}\text { Density of Tibetan antelope, Tibetan wild ass and Tibetan gazelle in relation to human presence } \\
\text { across the Chang Tang Nature Reserve of Tibet, China }\end{array}$ \\
\hline Equus kiang & 西藏野驴 & I & $\begin{array}{l}\text { 无危 } \\
\text { /LC }\end{array}$ & Wei Wanhong & Influence of the Qinghai-Tibetan railway and highway on the activities of wild animals \\
\hline Equus kiang & 西藏野驴 & I & $\begin{array}{l}\text { 无危 } \\
\text { /LC }\end{array}$ & 苏建平 & 可可西里藏羚羊、野牦牛、藏野驴和藏原羚冬季蠕虫卵粪检研究初报 \\
\hline Equus kiang & 西藏野驴 & I & $\begin{array}{l}\text { 无危 } \\
\text { /LC }\end{array}$ & 魏万红 & 青藏公路对藏羚羊、藏原羚和藏野驴活动的影响 \\
\hline Equus kiang & 西藏野驴 & I & $\begin{array}{l}\text { 无危 } \\
\text { /LC }\end{array}$ & 于智勇 & 青藏公路沿线藏羚羊、藏野驴和藏原羚的行为比较 \\
\hline Equus kiang & 西藏野驴 & I & $\begin{array}{l}\text { 无危 } \\
\text { /LC }\end{array}$ & 杨奇森 & 新疆阿尔金山自然保护区东部大型兽类数量和分布 \\
\hline
\end{tabular}


顾垒，闻丞，罗玫，王吴，吕植. 中国最受关注濒危物种保护现状快速评价的新方法探讨. 生物多样性，2015，23(5)：583-590. http://www biodiversity-science. net/CN/article/downloadArticleFile. do?attachType=PDF\&id=10075

\begin{tabular}{|c|c|c|c|c|c|}
\hline \multirow[t]{3}{*}{ Ermia mangshanensis } & 莽山烙铁头蛇 & 未列 & 未评 & SHI-PING GONG & Population status, distribution and conservation needs of the Endangered Mangshan pit viper \\
\hline & & 入 & 价 & & Protobothrops mangshanensis of China \\
\hline & & & $/ \mathrm{NE}$ & & \\
\hline \multirow[t]{3}{*}{ Ermia mangshanensis } & 莽山烙铁头蛇 & 未列 & 未评 & 谢和平 & 华南虎省级自然保护区莽山烙铁头蛇资源调查初报 \\
\hline & & 入 & 价 & & \\
\hline & & & $/ \mathrm{NE}$ & & \\
\hline \multirow[t]{3}{*}{ Ermia mangshanensis } & 莽山烙铁头蛇 & 未列 & 未评 & 陈远辉 & 莽山烙铁头蛇的保护窘境及存在问题 \\
\hline & & 入 & 价 & & \\
\hline & & & $/ \mathrm{NE}$ & & \\
\hline \multirow[t]{3}{*}{ Ermia mangshanensis } & 䒭山烙铁头蛇 & 未列 & 未评 & 陈斯㑆 & 莽山烙铁头蛇的保护生态学初步研究 \\
\hline & & 入 & 价 & & \\
\hline & & & $/ \mathrm{NE}$ & & \\
\hline \multirow[t]{3}{*}{ Ermia mangshanensis } & 䒭山烙铁头蛇 & 未列 & 未评 & 陈远辉 & 䒭山烙铁头蛇的养殖现状及存在问题 \\
\hline & & 入 & 价 & & \\
\hline & & & $/ \mathrm{NE}$ & & \\
\hline \multirow[t]{3}{*}{ Ermia mangshanensis } & 莽山烙铁头蛇 & 未列 & 未评 & 陈远辉 & 莽山烙铁头蛇的资源调查报告 \\
\hline & & 入 & 价 & & \\
\hline & & & $/ \mathrm{NE}$ & & \\
\hline Ermia mangshanensis & 莽山烙铁头蛇 & 未列 & 未评 & 陈远辉 & 莽山烙铁头蛇人工繁殖成功 \\
\hline
\end{tabular}


顾垒，闻丞，罗玫，王吴，吕植. 中国最受关注濒危物种保护现状快速评价的新方法探讨. 生物多样性，2015，23(5)：583-590. http://www biodiversity-science. net/CN/article/downloadArticleFile. do?attachType=PDF\&id=10075

\begin{tabular}{|c|c|c|c|c|c|}
\hline & & 入 & 价 & & \\
\hline & & & $/ \mathrm{NE}$ & & \\
\hline \multirow[t]{3}{*}{ Ermia mangshanensis } & 莽山烙铁头蛇 & 未列 & 未评 & 陈远辉 & 莽山烙铁头蛇专项 Ermia mangshanensis( Zhao, 1990) 调查结果 \\
\hline & & 入 & 价 & & \\
\hline & & & $/ \mathrm{NE}$ & & \\
\hline \multirow[t]{2}{*}{ Eucommia ulmoides } & 杜仲 & 未列 & 近危 & 陈双林 & 1 株杜仲内生真菌的抗氧化活性分析和菌种鉴定 \\
\hline & & 入 & /NT & & \\
\hline \multirow[t]{2}{*}{ Eucommia ulmoides } & 杜仲 & 未列 & 近危 & 沈繁宜 & 3 种树木节和节间导管接触角的研究 \\
\hline & & 入 & $/ \mathrm{NT}$ & & \\
\hline \multirow[t]{2}{*}{ Eucommia ulmoides } & 杜仲 & 未列 & 近危 & 㚞光辉 & 40 个杜仲无性系嫁接成活率与接芽萌发枝高生长量的比较试验 \\
\hline & & 入 & $/ \mathrm{NT}$ & & \\
\hline \multirow[t]{2}{*}{ Eucommia ulmoides } & 杜仲 & 未列 & 近危 & Xin-Hui Xing & A kinetic model for growth of callus derived from Eucommia ulmoides aiming at mass \\
\hline & & 入 & /NT & & production of a factor enhancing collagen synthesis of animal cells \\
\hline \multirow[t]{2}{*}{ Eucommia ulmoides } & 杜仲 & 未列 & 近危 & YUE-HU PEI & A NEW MONOTERPENE FROM THE BARK OF EUCOMMIA ULMOIDES \\
\hline & & 入 & /NT & & \\
\hline \multirow[t]{2}{*}{ Eucommia ulmoides } & 杜仲 & 未列 & 近危 & Dongming Zhang & A New Ursane-Type Nor-Triterpenoid from the Leaves of Eucommia ulmoides Oliv. \\
\hline & & 入 & $/ \mathrm{NT}$ & & \\
\hline \multirow[t]{2}{*}{ Eucommia ulmoides } & 杜仲 & 未列 & 近危 & Daofeng Chen & A protein-bound polysaccharide from the stem bark of Eucommia ulmoides and its \\
\hline & & 入 & /NT & & anti-complementary effect \\
\hline
\end{tabular}


顾垒，闻丞，罗玫，王昊，吕植. 中国最受关注濒危物种保护现状快速评价的新方法探讨．生物多样性，2015，23(5)：583-590. http://www. biodiversity-science. net/CN/article/downloadArticleFile. do?attachType=PDF\&id=10075

\begin{tabular}{|c|c|c|c|c|c|}
\hline \multirow[t]{2}{*}{ Eucommia ulmoides } & 杜仲 & 未列 & 近危 & Yuefei Wang & A rapid ultra performance liquid chromatography - tandem mass spectrometric method for the \\
\hline & & 入 & /NT & & qualitative and quantitative analysis of ten compounds in Eucommia ulmodies Oliv. \\
\hline \multirow[t]{2}{*}{ Eucommia ulmoides } & 杜仲 & 未列 & 近危 & Ke-Ming Cui & $\mathrm{ABP} 1$ expression regulated by IAA and $\mathrm{ABA}$ is associatedwith the cambium periodicity in \\
\hline & & 入 & $/ \mathrm{NT}$ & & Eucommia ulmoides Oliv. \\
\hline \multirow[t]{2}{*}{ Eucommia ulmoides } & 杜仲 & 未列 & 近危 & Junli Wang & Accumulation of chlorogenic acid in cell suspension cultures of Eucommia ulmoides \\
\hline & & 入 & /NT & & \\
\hline \multirow[t]{2}{*}{ Eucommia ulmoides } & 杜仲 & 未列 & 近危 & Bo Chen & Analysis of Nine Bioactive Compounds in Eucommia ulmoides Oliv. and Their Preparation by \\
\hline & & 入 & $/ \mathrm{NT}$ & & HPLC - Photodiode Array Detection and Mass Spectrometry \\
\hline \multirow[t]{2}{*}{ Eucommia ulmoides } & 杜仲 & 未列 & 近危 & 袁云香 & $\mathrm{Ca} 2+$ 对杜仲愈伤组织诱导及增殖效应的影响研究 \\
\hline & & 入 & /NT & & \\
\hline \multirow[t]{2}{*}{ Eucommia ulmoides } & 杜仲 & 未列 & 近危 & Chuan-Ling Si & CHEMICAL CONSTITUENTS OF THE ROOT BARKS OF Eucommia ulmoides \\
\hline & & 入 & /NT & & \\
\hline \multirow[t]{2}{*}{ Eucommia ulmoides } & 杜仲 & 未列 & 近危 & ZHANG Tai-ming & Comparative analysis of chemical components between barks and leaves of Eucommia \\
\hline & & 入 & $/ \mathrm{NT}$ & & ulmoides Oliver \\
\hline \multirow[t]{2}{*}{ Eucommia ulmoides } & 杜仲 & 未列 & 近危 & Da-Cheng Wang & Crystal structure of a novel antifungal protein distinct with five disulfide bridges from \\
\hline & & 入 & /NT & & Eucommia ulmoides Oliver at an atomic resolution \\
\hline \multirow[t]{2}{*}{ Eucommia ulmoides } & 杜仲 & 未列 & 近危 & Da-Cheng Wang & Crystallization and preliminary crystallographic studies of a novel antifungal protein with five \\
\hline & & 入 & /NT & & disulfide bridges from Eucommia ulmoides Oliver \\
\hline Eucommia ulmoides & 杜仲 & 未列 & 近危 & 袁云香 & $\mathrm{Cu} 2+$ 对杜仲愈伤组织诱导及增殖的影响研究 \\
\hline
\end{tabular}


顾垒，闻丞，罗玫，王昊，吕植. 中国最受关注濒危物种保护现状快速评价的新方法探讨．生物多样性，2015，23(5)：583-590. http://www. biodiversity-science. net/CN/article/downloadArticleFile. do?attachType=PDF\&id=10075

\begin{tabular}{|c|c|c|c|c|c|}
\hline & & 入 & $/ \mathrm{NT}$ & & \\
\hline \multirow[t]{2}{*}{ Eucommia ulmoides } & 杜仲 & 未列 & 近危 & HONGWEN & Development and characterization of microsatellite markers in Eucommia ulmoides Oliver \\
\hline & & 入 & /NT & HUANG & (Eucommiaceae) \\
\hline \multirow[t]{2}{*}{ Eucommia ulmoides } & 杜仲 & 未列 & 近危 & Juane Dong & Effects of green-keeping treatment on the functional constituents in flower tea of Eucommia \\
\hline & & 入 & /NT & & ulmoides \\
\hline \multirow[t]{2}{*}{ Eucommia ulmoides } & 杜仲 & 未列 & 近危 & Xihan Ma & Effects of growing location on the contents of secondary metabolites in the leaves of four \\
\hline & & 入 & /NT & & selected superior clones of Eucommia ulmoides \\
\hline \multirow[t]{2}{*}{ Eucommia ulmoides } & 杜仲 & 未列 & 近危 & Juane Dong & Effects of microwave drying on the contents of functional constituents of Eucommia ulmoides \\
\hline & & 入 & /NT & & flower tea \\
\hline \multirow[t]{2}{*}{ Eucommia ulmoides } & 杜仲 & 未列 & 近危 & Xiu-Mei Gao & Estrogenic properties of six compounds derived from Eucommia ulmoides Oliv. and their \\
\hline & & 入 & /NT & & differing biological activity through estrogen receptors a and $b$ \\
\hline \multirow[t]{2}{*}{ Eucommia ulmoides } & 杜仲 & 未列 & 近危 & 赵德刚 & EuFPS 基因表达载体构建及对杜仲遗传转化的研究 \\
\hline & & 入 & /NT & & \\
\hline \multirow[t]{2}{*}{ Eucommia ulmoides } & 杜仲 & 未列 & 近危 & JIANBO XIAO & EXTRACTION AND DETERMINATION OF MAJOR HYPOTENSIVE COMPOUNDS IN \\
\hline & & 入 & /NT & & BARK OF EUCOMMIA ULMOIDES OLIV. \\
\hline \multirow[t]{2}{*}{ Eucommia ulmoides } & 杜仲 & 未列 & 近危 & Run-Cang Sun & Fractional isolation and structural characterization of mild ball-milled lignin in high yield and \\
\hline & & 入 & /NT & & purity from Eucommia ulmoides Oliv \\
\hline \multirow[t]{2}{*}{ Eucommia ulmoides } & 杜仲 & 未列 & 近危 & Hongwen Huang & Genetic diversity in Eucommia ulmoides (Eucommiaceae), an endangered traditional Chinese \\
\hline & & 入 & /NT & & medicinal plant \\
\hline
\end{tabular}


顾垒，闻丞，罗玫，王昊，吕植。中国最受关注濒危物种保护现状快速评价的新方法探讨．生物多样性，2015，23(5)：583-590. http://www. biodiversity-science. net/CN/article/downloadArticleFile. do?attachType=PDF\&id=10075

\begin{tabular}{|c|c|c|c|c|c|}
\hline \multirow[t]{2}{*}{ Eucommia ulmoides } & 杜仲 & 未列 & 近危 & Zhou-Qi Li & Identification of a Male-Specific Amplified Fragment Length Polymorphism (AFLP) and a \\
\hline & & 入 & /NT & & Sequence Characterized Amplified Region (SCAR) Marker in Eucommia ulmoides Oliv. \\
\hline \multirow[t]{2}{*}{ Eucommia ulmoides } & 杜仲 & 未列 & 近危 & Yi-zeng Liang & Identification of the composition of fatty acids in Eucommia ulmoides seed oil by fraction \\
\hline & & 入 & $/ \mathrm{NT}$ & & chain length and mass spectrometry \\
\hline \multirow[t]{2}{*}{ Eucommia ulmoides } & 杜仲 & 未列 & 近危 & 赵德刚 & ipt 基因促进杜仲遗传转化不定芽再生 \\
\hline & & 入 & /NT & & \\
\hline \multirow[t]{2}{*}{ Eucommia ulmoides } & 杜仲 & 未列 & 近危 & Daofeng Chen & Isolation and characterization of an anti-complementary protein-bound polysaccharide from the \\
\hline & & 入 & $/ \mathrm{NT}$ & & stem barks of Eucommia ulmoides \\
\hline \multirow[t]{2}{*}{ Eucommia ulmoides } & 杜仲 & 未列 & 近危 & 王弦云 & ISSRs 在杜仲遗传多样性研究及性别鉴定中的应用 \\
\hline & & 入 & /NT & & \\
\hline \multirow[t]{2}{*}{ Eucommia ulmoides } & 杜仲 & 未列 & 近危 & XIAOHONG YAO & Microsatellite genetic variation in the Chinese endemic Eucommia ulmoides (Eucommiaceae): \\
\hline & & 入 & $/ \mathrm{NT}$ & & implications for conservation \\
\hline \multirow[t]{2}{*}{ Eucommia ulmoides } & 杜仲 & 未列 & 近危 & Jihong Jiang & Molecular Cloning of a HMG-CoA Reductase Gene from Eucommia ulmoides Oliver \\
\hline & & 入 & $/ \mathrm{NT}$ & & \\
\hline \multirow[t]{2}{*}{ Eucommia ulmoides } & 杜仲 & 未列 & 近危 & Xin-Qiang He & Phloem transdifferentiation from immature xylem cells during bark regeneration after girdling \\
\hline & & 入 & /NT & & in Eucommia ulmoides Oliv. \\
\hline \multirow[t]{2}{*}{ Eucommia ulmoides } & 杜仲 & 未列 & 近危 & ZHU Dengyun & Plant regeneration from dry mature endosperm cultures of Eucommia ulmoides Oliv . \\
\hline & & 入 & /NT & & \\
\hline Eucommia ulmoides & 杜仲 & 未列 & 近危 & Da-Cheng Wang & Primary structural determination of N-terminally blocked peptides from the bark of Eucommia \\
\hline
\end{tabular}


顾垒，闻丞，罗玫，王昊，吕植. 中国最受关注濒危物种保护现状快速评价的新方法探讨．生物多样性，2015，23(5)：583-590. http://www, biodiversity-science, net/CN/article/downloadArticleFile. do?attachType=PDF\&id=10075

\begin{tabular}{|c|c|c|c|c|c|}
\hline & & 入 & $/ \mathrm{NT}$ & & ulmoides Oliv by mass spectrometric analysis \\
\hline \multirow[t]{2}{*}{ Eucommia ulmoides } & 杜仲 & 未列 & 近危 & Zhonglin Yang & Protective effects of Eucommia ulmoides Oliv. bark and leaf on amyloid -induced \\
\hline & & 入 & /NT & & cytotoxicity \\
\hline \multirow[t]{2}{*}{ Eucommia ulmoides } & 杜仲 & 未列 & 近危 & Ke-Ming Cu & RAPD and SCAR markers linked to sex determination in Eucommia ulmoides Oliv. \\
\hline & & 入 & /NT & & \\
\hline \multirow[t]{2}{*}{ Eucommia ulmoides } & 杜仲 & 未列 & 近危 & Jingfang Zhang & Seasonal Difference in Antioxidant Capacity and Active Compounds Contents of Eucommia \\
\hline & & 入 & /NT & & ulmoides Oliver Leaf \\
\hline \multirow[t]{2}{*}{ Eucommia ulmoides } & 杜仲 & 未列 & 近危 & Yang-Min Ma & SECONDARY ANTI-FUNGI METABOLITES FROM THE ENDOPHYTIC FUNGUS \\
\hline & & 入 & /NT & & Fusarium sp. IN Eucommia ulmoides \\
\hline \multirow[t]{2}{*}{ Eucommia ulmoides } & 杜仲 & 未列 & 近危 & Junling Shi & Structure identification and fermentation characteristics of pinoresinol diglucoside produced by \\
\hline & & 入 & /NT & & Phomopsis sp. isolated from Eucommia ulmoides Oliv \\
\hline \multirow[t]{2}{*}{ Eucommia ulmoides } & 杜仲 & 未列 & 近危 & Linhan Bai & Studies on a chlorogenic acid-producing endophytic fungi isolated from Eucommia ulmoides \\
\hline & & 入 & /NT & & Oliver \\
\hline \multirow[t]{2}{*}{ Eucommia ulmoides } & 杜仲 & 未列 & 近危 & Xin-Qiang He & The Ca2+-dependent DNases are Involved in Secondary Xylem Development in Eucommia \\
\hline & & 入 & /NT & & ulmoides \\
\hline \multirow[t]{2}{*}{ Eucommia ulmoides } & 杜仲 & 未列 & 近危 & Da-Cheng Wanga & Two novel antifungal peptides distinct with a five-disulfide motif from the bark of Eucommia \\
\hline & & 入 & /NT & & ulmoides Oliv \\
\hline \multirow[t]{2}{*}{ Eucommia ulmoides } & 杜仲 & 未列 & 近危 & 袁云香 & Zn2+ 对杜仲愈伤组织诱导及增殖的影响 \\
\hline & & 入 & /NT & & \\
\hline
\end{tabular}


顾垒，闻丞，罗玫，王吴，吕植. 中国最受关注濒危物种保护现状快速评价的新方法探讨. 生物多样性，2015，23(5)：583-590. http://www biodiversity-science. net/CN/article/downloadArticleFile. do?attachType=PDF\&id=10075

\begin{tabular}{|c|c|c|c|c|c|}
\hline \multirow[t]{2}{*}{ Eucommia ulmoides } & 杜仲 & 未列 & 近危 & 李新宇 & 北京市 5 种园林树木蒸腾作用模拟研究 \\
\hline & & 入 & $/ \mathrm{NT}$ & & \\
\hline \multirow{2}{*}{ Eucommia ulmoides } & 杜仲 & 未列 & 近危 & 沈书庆 & 濒危药用植物杜仲产活性成分内生真菌的研究 \\
\hline & & 入 & $/ \mathrm{NT}$ & & \\
\hline \multirow[t]{2}{*}{ Eucommia ulmoides } & 杜仲 & 未列 & 近危 & 董娟娥 & 剥皮处理对杜仲树干生长及叶片内 3 种保护酶活性的影响 \\
\hline & & 入 & /NT & & \\
\hline \multirow[t]{2}{*}{ Eucommia ulmoides } & 杜仲 & 未列 & 近危 & 董娟娥 & 剥皮对杜仲生长期内生理特性及次生代谢物含量的影响 \\
\hline & & 入 & $/ \mathrm{NT}$ & & \\
\hline \multirow[t]{2}{*}{ Eucommia ulmoides } & 杜仲 & 未列 & 近危 & 杜红岩 & 不同变异类型杜仲皮中几种主要活性成分含量的比较 \\
\hline & & 入 & /NT & & \\
\hline \multirow[t]{2}{*}{ Eucommia ulmoides } & 杜仲 & 未列 & 近危 & 杜兰英 & 不同变异类型杜仲叶片含胶性状的变异规律 \\
\hline & & 入 & /NT & & \\
\hline \multirow[t]{2}{*}{ Eucommia ulmoides } & 杜仲 & 未列 & 近危 & 杜红岩 & 不同产地杜仲果实形态特征及含胶量的差异性研究 \\
\hline & & 入 & $/ \mathrm{NT}$ & & \\
\hline \multirow[t]{2}{*}{ Eucommia ulmoides } & 杜仲 & 未列 & 近危 & 杜红岩 & 不同产地杜仲叶含胶特性的变异规律 \\
\hline & & 入 & $/ \mathrm{NT}$ & & \\
\hline \multirow[t]{2}{*}{ Eucommia ulmoides } & 杜仲 & 未列 & 近危 & 李晓毓 & 不同方法制备的 R NA 模板对杜仲肉桂醇脱氢酶基因 5 七 RA CE 扩增的影响 \\
\hline & & 入 & /NT & & \\
\hline Eucommia ulmoides & 杜仲 & 未列 & 近危 & 郭宝林 & 不同基因型杜仲叶片中绿原酸含量的检测 \\
\hline
\end{tabular}


顾垒，闻丞，罗玫，王吴，吕植. 中国最受关注濒危物种保护现状快速评价的新方法探讨. 生物多样性，2015，23(5)：583-590. http://www. biodiversity-science. net/CN/article/downloadArticleFile. do?attachType=PDF\&id=10075

\begin{tabular}{|c|c|c|c|c|c|}
\hline & & 入 & /NT & & \\
\hline \multirow[t]{2}{*}{ Eucommia ulmoides } & 杜仲 & 未列 & 近危 & 李琰 & 不同培养基对杜仲愈伤组织诱导和生长的影响 \\
\hline & & 入 & /NT & & \\
\hline \multirow[t]{2}{*}{ Eucommia ulmoides } & 杜仲 & 未列 & 近危 & 苏印泉 & 不同品种杜仲叶中有效成分含量差异性研究 \\
\hline & & 入 & /NT & & \\
\hline \multirow[t]{2}{*}{ Eucommia ulmoides } & 杜仲 & 未列 & 近危 & 刘淑明 & 不同水分条件下皮叶两用杜仲林的生长效应 \\
\hline & & 入 & /NT & & \\
\hline \multirow[t]{2}{*}{ Eucommia ulmoides } & 杜仲 & 未列 & 近危 & 李琰 & 不同因子对杜仲愈伤组织继代培养的研究 \\
\hline & & 入 & /NT & & \\
\hline \multirow[t]{2}{*}{ Eucommia ulmoides } & 杜仲 & 未列 & 近危 & 张万锋 & 不同月份杜仲叶中绿原酸含量的研究 \\
\hline & & 入 & /NT & & \\
\hline \multirow[t]{2}{*}{ Eucommia ulmoides } & 杜仲 & 未列 & 近危 & 杨秀芳 & 不同栽培模式杜仲体绿原酸含量积累动态的研究 \\
\hline & & 入 & /NT & & \\
\hline \multirow[t]{2}{*}{ Eucommia ulmoides } & 杜仲 & 未列 & 近危 & 彭密军 & 不同栽培模式对杜仲叶及枝皮中多种活性成分含量的影响 \\
\hline & & 入 & /NT & & \\
\hline \multirow[t]{2}{*}{ Eucommia ulmoides } & 杜仲 & 未列 & 近危 & 李爱华 & 产 PDG 杜仲内生菌的分离_笛选及优化培养 \\
\hline & & 入 & $/ \mathrm{NT}$ & & \\
\hline \multirow[t]{2}{*}{ Eucommia ulmoides } & 杜仲 & 未列 & 近危 & 师俊玲 & 产 PDG 杜仲内生菌的分离筛选和分类鉴定及生长条件研究 \\
\hline & & 入 & /NT & & \\
\hline
\end{tabular}


顾垒，闻丞，罗玫，王吴，吕植. 中国最受关注濒危物种保护现状快速评价的新方法探讨. 生物多样性，2015，23(5)：583-590. http://www biodiversity-science. net/CN/article/downloadArticleFile. do?attachType=PDF\&id=10075

\begin{tabular}{|c|c|c|c|c|c|}
\hline \multirow[t]{2}{*}{ Eucommia ulmoides } & 杜仲 & 未列 & 近危 & 殷 红 & 产杜仲黄酮内生真菌的初步研究 \\
\hline & & 入 & /NT & & \\
\hline \multirow[t]{2}{*}{ Eucommia ulmoides } & 杜仲 & 未列 & 近危 & 梁宗锁 & 持续干旱及复水对杜仲幼苗保护酶活性和渗透调节物质的影响 \\
\hline & & 入 & $/ \mathrm{NT}$ & & \\
\hline \multirow[t]{2}{*}{ Eucommia ulmoides } & 杜仲 & 未列 & 近危 & 张博勇 & 初选 10 个杜仲优良无性系耐旱性的研究 \\
\hline & & 入 & /NT & & \\
\hline \multirow[t]{2}{*}{ Eucommia ulmoides } & 杜仲 & 未列 & 近危 & 高建社 & 氮磷肥配施效应对杜仲光合与蒸腾特性的影响 \\
\hline & & 入 & $/ \mathrm{NT}$ & & \\
\hline \multirow[t]{2}{*}{ Eucommia ulmoides } & 杜仲 & 未列 & 近危 & 郭军战 & 地面覆盖对皮叶两用杜仲(Eucomm ia ulmoides Oliv. )林冠层辐射能分布的影响 \\
\hline & & 入 & /NT & & \\
\hline \multirow[t]{2}{*}{ Eucommia ulmoides } & 杜仲 & 未列 & 近危 & 杜红岩 & 杜仲 1- 羟基-2- 甲基- 2- (E) -丁烯基- 4- 二磷酸合酶基因 cDNA 全长克隆与序列分析 \\
\hline & & 入 & /NT & & \\
\hline \multirow[t]{2}{*}{ Eucommia ulmoides } & 杜仲 & 未列 & 近危 & 张博勇 & 杜仲 15 个初选优良无性系抗寒性研究 \\
\hline & & 入 & $/ \mathrm{NT}$ & & \\
\hline \multirow[t]{2}{*}{ Eucommia ulmoides } & 杜仲 & 未列 & 近危 & 杜红岩 & 杜仲 1-脱氧-D-木酮糖-5-磷酸还原异构酶基因 cDNA 全长克隆与序列分析 \\
\hline & & 入 & /NT & & \\
\hline \multirow[t]{2}{*}{ Eucommia ulmoides } & 杜仲 & 未列 & 近危 & 李周岐 & 杜仲 9 个引种无性系的评价及种子诱导多倍体技术研究 \\
\hline & & 入 & /NT & & \\
\hline Eucommia ulmoides & 杜仲 & 未列 & 近危 & 李周岐 & 杜仲 AFLP 反应体系的建立及优化 \\
\hline
\end{tabular}


顾垒，闻丞，罗玫，王吴，吕植. 中国最受关注濒危物种保护现状快速评价的新方法探讨. 生物多样性，2015，23(5)：583-590. http://www biodiversity-science. net/CN/article/downloadArticleFile. do?attachType=PDF\&id=10075

\begin{tabular}{|c|c|c|c|c|c|}
\hline & & 入 & /NT & & \\
\hline \multirow[t]{2}{*}{ Eucommia ulmoides } & 杜仲 & 未列 & 近危 & 杜红岩 & 杜仲 EST_SSR 引物开发及遗传多样性研究 \\
\hline & & 入 & /NT & & \\
\hline \multirow[t]{2}{*}{ Eucommia ulmoides } & 杜仲 & 未列 & 近危 & 乌云塔娜 & 杜仲 EuACOTS 基因家族的鉴定及生物信息学分析 \\
\hline & & 入 & /NT & & \\
\hline \multirow[t]{2}{*}{ Eucommia ulmoides } & 杜仲 & 未列 & 近危 & 张延东 & 杜仲 Eucommia ulmoides 的核型分析 \\
\hline & & 入 & /NT & & \\
\hline \multirow[t]{2}{*}{ Eucommia ulmoides } & 杜仲 & 未列 & 近危 & 乌云塔娜 & 杜仲 EuHMGRS 基因家族的鉴定及生物信息学分析 \\
\hline & & 入 & /NT & & \\
\hline \multirow[t]{2}{*}{ Eucommia ulmoides } & 杜仲 & 未列 & 近危 & 李周岐 & 杜仲 Fls 基因克隆及原核表达 \\
\hline & & 入 & /NT & & \\
\hline \multirow[t]{2}{*}{ Eucommia ulmoides } & 杜仲 & 未列 & 近危 & 杜红岩 & 杜仲 $\mathrm{HD} R$ 基因全长 $\mathrm{cDNA}$ 克隆与序列分析 \\
\hline & & 入 & /NT & & \\
\hline \multirow[t]{2}{*}{ Eucommia ulmoides } & 杜仲 & 未列 & 近危 & 曹翠萍 & 杜仲 ISSR-PCR 反应体系的建立与引物筛选及其在遗传多样性研究中的应用 \\
\hline & & 入 & /NT & & \\
\hline \multirow[t]{2}{*}{ Eucommia ulmoides } & 杜仲 & 未列 & 近危 & 乌云塔娜 & 杜仲 ME P 途径系列基因的基因结构预测 \\
\hline & & 入 & /NT & & \\
\hline \multirow[t]{2}{*}{ Eucommia ulmoides } & 杜仲 & 未列 & 近危 & 乌云塔娜 & 杜仲 MEP 途径系列基因 5' 端非编码区的顺式作用元件 预测 \\
\hline & & 入 & /NT & & \\
\hline
\end{tabular}


顾垒，闻丞，罗玫，王吴，吕植. 中国最受关注濒危物种保护现状快速评价的新方法探讨. 生物多样性，2015，23(5)：583-590. http://www biodiversity-science. net/CN/article/downloadArticleFile. do?attachType=PDF\&id=10075

\begin{tabular}{|c|c|c|c|c|c|}
\hline \multirow[t]{2}{*}{ Eucommia ulmoides } & 杜仲 & 未列 & 近危 & 乌云塔娜 & 杜仲 MVA 途径相关基因的鉴定及苂光定量 PCR 引物篮选 \\
\hline & & 入 & /NT & & \\
\hline \multirow[t]{2}{*}{ Eucommia ulmoides } & 杜仲 & 未列 & 近危 & 乌云塔娜 & 杜仲 MVA 途径相关基因表达差异及全长 cDNA 序列特征 \\
\hline & & 入 & $/ \mathrm{NT}$ & & \\
\hline \multirow[t]{2}{*}{ Eucommia ulmoides } & 杜仲 & 未列 & 近危 & 王宏 & 杜仲 RAPD 反应体系的优化 \\
\hline & & 入 & /NT & & \\
\hline \multirow[t]{2}{*}{ Eucommia ulmoides } & 杜仲 & 未列 & 近危 & 曹翠萍 & 杜仲 SSR-PCR 反应体系建立及引物篮选 \\
\hline & & 入 & $/ \mathrm{NT}$ & & \\
\hline \multirow[t]{2}{*}{ Eucommia ulmoides } & 杜仲 & 未列 & 近危 & 杜红岩 & 杜仲 a - 亚麻酸生物合成相关基因的差异表达 \\
\hline & & 入 & /NT & & \\
\hline \multirow[t]{2}{*}{ Eucommia ulmoides } & 杜仲 & 未列 & 近危 & 杨美华 & 杜仲不同部位主要有效成分含量比较 \\
\hline & & 入 & $/ \mathrm{NT}$ & & \\
\hline \multirow[t]{2}{*}{ Eucommia ulmoides } & 杜仲 & 未列 & 近危 & 杨美华 & 杜仲不同采收期及不同部位中桃叶珊瑚苷的含量测定 \\
\hline & & 入 & $/ \mathrm{NT}$ & & \\
\hline \multirow[t]{2}{*}{ Eucommia ulmoides } & 杜仲 & 未列 & 近危 & 苏印泉 & 杜仲不同器官杜仲胶含量_相对分子质量及其分布的动态研究 \\
\hline & & 入 & /NT & & \\
\hline \multirow[t]{2}{*}{ Eucommia ulmoides } & 杜仲 & 未列 & 近危 & 杜红岩 & 杜仲不同器官含胶率的差异及其相关性分析 \\
\hline & & 入 & /NT & & \\
\hline Eucommia ulmoides & 杜仲 & 未列 & 近危 & 苏印泉 & 杜仲不同无性系叶中杜仲胶含量及相对分子质量研究 \\
\hline
\end{tabular}


顾垒，闻丞，罗玫，王吴，吕植. 中国最受关注濒危物种保护现状快速评价的新方法探讨. 生物多样性，2015，23(5)：583-590. http://www. biodiversity-science. net/CN/article/downloadArticleFile. do?attachType=PDF\&id=10075

\begin{tabular}{|c|c|c|c|c|c|}
\hline & & 入 & /NT & & \\
\hline \multirow[t]{2}{*}{ Eucommia ulmoides } & 杜仲 & 未列 & 近危 & 苏印泉 & 杜仲不同栽培模式的光合、水分生理及负离子效应对比 \\
\hline & & 入 & /NT & & \\
\hline \multirow[t]{2}{*}{ Eucommia ulmoides } & 杜仲 & 未列 & 近危 & 乌云塔娜 & 杜仲成熟果实和幼果 MVA 途径基因表达差异分析 \\
\hline & & 入 & /NT & & \\
\hline \multirow[t]{2}{*}{ Eucommia ulmoides } & 杜仲 & 未列 & 近危 & 张磊 & 杜仲成熟胚离体培养研究 \\
\hline & & 入 & /NT & & \\
\hline \multirow[t]{2}{*}{ Eucommia ulmoides } & 杜仲 & 未列 & 近危 & 金晓玲 & 杜仲成熟胚器官发生途径的研究 \\
\hline & & 入 & /NT & & \\
\hline \multirow[t]{2}{*}{ Eucommia ulmoides } & 杜仲 & 未列 & 近危 & 马惠玲 & 杜仲次生代谢物合成积累与物候期的研究 \\
\hline & & 入 & /NT & & \\
\hline \multirow[t]{2}{*}{ Eucommia ulmoides } & 杜仲 & 未列 & 近危 & 赖正武 & 杜仲丛状矮林丰产栽培试验研究 \\
\hline & & 入 & /NT & & \\
\hline \multirow[t]{2}{*}{ Eucommia ulmoides } & 杜仲 & 未列 & 近危 & 康向阳 & 杜仲大小孢子母细胞减数分裂进程对应关系的研究 \\
\hline & & 入 & /NT & & \\
\hline \multirow[t]{2}{*}{ Eucommia ulmoides } & 杜仲 & 未列 & 近危 & 罗丽 & 杜仲带芽茎段的快速繁殖 \\
\hline & & 入 & /NT & & \\
\hline \multirow[t]{2}{*}{ Eucommia ulmoides } & 杜仲 & 未列 & 近危 & 罗丽 & 杜仲带芽茎段的离体快速微繁殖研究 \\
\hline & & 入 & /NT & & \\
\hline
\end{tabular}


顾垒，闻丞，罗玫，王吴，吕植. 中国最受关注濒危物种保护现状快速评价的新方法探讨. 生物多样性，2015，23(5)：583-590. http://www biodiversity-science. net/CN/article/downloadArticleFile. do?attachType=PDF\&id=10075

\begin{tabular}{|c|c|c|c|c|c|}
\hline \multirow[t]{2}{*}{ Eucommia ulmoides } & 杜仲 & 未列 & 近危 & 罗丽 & 杜仲带芽茎段快速繁殖中的污染及控制 \\
\hline & & 入 & $/ \mathrm{NT}$ & & \\
\hline \multirow[t]{2}{*}{ Eucommia ulmoides } & 杜仲 & 未列 & 近危 & 刘叶蔓 & 杜仲带腋芽茎段组织培养的研究 \\
\hline & & 入 & $/ \mathrm{NT}$ & & \\
\hline \multirow[t]{2}{*}{ Eucommia ulmoides } & 杜仲 & 未列 & 近危 & 刘世会 & 杜仲蛋白纯化_序列分析及抗菌活性研究 \\
\hline & & 入 & $/ \mathrm{NT}$ & & \\
\hline \multirow[t]{2}{*}{ Eucommia ulmoides } & 杜仲 & 未列 & 近危 & 贾恢先 & 杜仲对盐胁迫反应的研究 \\
\hline & & 入 & $/ \mathrm{NT}$ & & \\
\hline \multirow[t]{2}{*}{ Eucommia ulmoides } & 杜仲 & 未列 & 近危 & 陈文德 & 杜仲对重金属元素富集特征研究 \\
\hline & & 入 & /NT & & \\
\hline \multirow[t]{2}{*}{ Eucommia ulmoides } & 杜仲 & 未列 & 近危 & 王彩霞 & 杜仲多倍体诱变育种的研究 \\
\hline & & 入 & /NT & & \\
\hline \multirow[t]{2}{*}{ Eucommia ulmoides } & 杜仲 & 未列 & 近危 & 张海风 & 杜仲多倍体诱导研究 \\
\hline & & 入 & $/ \mathrm{NT}$ & & \\
\hline \multirow[t]{2}{*}{ Eucommia ulmoides } & 杜仲 & 未列 & 近危 & 赵丹 & 杜仲法尼基焦磷酸合成酶基因超量表达对含胶细胞的影响研究 \\
\hline & & 入 & $/ \mathrm{NT}$ & & \\
\hline \multirow[t]{2}{*}{ Eucommia ulmoides } & 杜仲 & 未列 & 近危 & 李芳东 & 杜仲高产胶无性系遗传参数估计与改良效果分析 \\
\hline & & 入 & $/ \mathrm{NT}$ & & \\
\hline Eucommia ulmoides & 杜仲 & 未列 & 近危 & 杜红岩 & 杜仲高产胶优良无性系的选育 \\
\hline
\end{tabular}


顾垒，闻丞，罗玫，王吴，吕植. 中国最受关注濒危物种保护现状快速评价的新方法探讨. 生物多样性，2015，23(5)：583-590. http://www. biodiversity-science. net/CN/article/downloadArticleFile. do?attachType=PDF\&id=10075

\begin{tabular}{|c|c|c|c|c|c|}
\hline & & 入 & /NT & & \\
\hline \multirow[t]{2}{*}{ Eucommia ulmoides } & 杜仲 & 未列 & 近危 & 王茹 & 杜仲光合生理和蒸腾特性的研究 \\
\hline & & 入 & /NT & & \\
\hline \multirow[t]{2}{*}{ Eucommia ulmoides } & 杜仲 & 未列 & 近危 & 间文德 & 杜仲光合速率日变化及其与环境因子的关系 \\
\hline & & 入 & /NT & & \\
\hline \multirow[t]{2}{*}{ Eucommia ulmoides } & 杜仲 & 未列 & 近危 & 杜红岩 & 杜仲果实含胶特性的个体变异规律 \\
\hline & & 入 & /NT & & \\
\hline \multirow[t]{2}{*}{ Eucommia ulmoides } & 杜仲 & 未列 & 近危 & 杜红岩 & 杜仲果实和叶片转录组数据组装及基因功能注释 \\
\hline & & 入 & /NT & & \\
\hline \multirow[t]{2}{*}{ Eucommia ulmoides } & 杜仲 & 未列 & 近危 & 杜红岩 & 杜仲含胶特性及其变异规律与无性系选择的研究 \\
\hline & & 入 & /NT & & \\
\hline \multirow[t]{2}{*}{ Eucommia ulmoides } & 杜仲 & 未列 & 近危 & 申延 & 杜仲含胶细胞的整体观察 \\
\hline & & 入 & /NT & & \\
\hline \multirow[t]{2}{*}{ Eucommia ulmoides } & 杜仲 & 未列 & 近危 & 苏印泉 & 杜仲含胶细胞形态特征的研究 \\
\hline & & 入 & /NT & & \\
\hline \multirow[t]{2}{*}{ Eucommia ulmoides } & 杜仲 & 未列 & 近危 & 孙奎 & 杜仲和无花果内生真菌的初步研究 \\
\hline & & 入 & /NT & & \\
\hline \multirow[t]{2}{*}{ Eucommia ulmoides } & 杜仲 & 未列 & 近危 & 刘宁 & 杜仲花粉壁发育的超微结构观察 \\
\hline & & 入 & /NT & & \\
\hline
\end{tabular}


顾垒，闻丞，罗玫，王吴，吕植. 中国最受关注濒危物种保护现状快速评价的新方法探讨. 生物多样性，2015，23(5)：583-590. http://www biodiversity-science. net/CN/article/downloadArticleFile. do?attachType=PDF\&id=10075

\begin{tabular}{|c|c|c|c|c|c|}
\hline \multirow[t]{2}{*}{ Eucommia ulmoides } & 杜仲 & 未列 & 近危 & 马仁萍 & 杜仲花粉初生代谢物与次生代谢物的研究 \\
\hline & & 入 & $/ \mathrm{NT}$ & & \\
\hline \multirow[t]{2}{*}{ Eucommia ulmoides } & 杜仲 & 未列 & 近危 & 李周岐 & 杜仲花粉形态、贮藏及萌发性研究 \\
\hline & & 入 & $/ \mathrm{NT}$ & & \\
\hline \multirow[t]{2}{*}{ Eucommia ulmoides } & 杜仲 & 未列 & 近危 & 赵德义 & 杜仲花粉营养成分的研究 \\
\hline & & 入 & $/ \mathrm{NT}$ & & \\
\hline \multirow[t]{2}{*}{ Eucommia ulmoides } & 杜仲 & 未列 & 近危 & 赵德义 & 杜仲黄酮指纹图谱研究 \\
\hline & & 入 & /NT & & \\
\hline \multirow[t]{2}{*}{ Eucommia ulmoides } & 杜仲 & 未列 & 近危 & 孙志强 & 杜仲集约化栽培潜在的病虫灾害及其应对策略 \\
\hline & & 入 & /NT & & \\
\hline \multirow[t]{2}{*}{ Eucommia ulmoides } & 杜仲 & 未列 & 近危 & 杜红岩 & 杜仲胶的研究进展与发展前景 \\
\hline & & 入 & $/ \mathrm{NT}$ & & \\
\hline \multirow[t]{2}{*}{ Eucommia ulmoides } & 杜仲 & 未列 & 近危 & 赵德刚 & 杜仲胶合成相关基因 EuFPS 的克隆及序列分析 \\
\hline & & 入 & $/ \mathrm{NT}$ & & \\
\hline \multirow[t]{2}{*}{ Eucommia ulmoides } & 杜仲 & 未列 & 近危 & 赵红艳 & 杜仲胶在杜仲叶发育过程中的含量变化研究 \\
\hline & & 入 & $/ \mathrm{NT}$ & & \\
\hline \multirow[t]{2}{*}{ Eucommia ulmoides } & 杜仲 & 未列 & 近危 & 刘宇 & 杜仲茎尖离体培养的研究 \\
\hline & & 入 & $/ \mathrm{NT}$ & & \\
\hline Eucommia ulmoides & 杜仲 & 未列 & 近危 & 贾文庆 & 杜仲茎尖离体培养的研究 \\
\hline
\end{tabular}


顾垒，闻丞，罗玫，王吴，吕植. 中国最受关注濒危物种保护现状快速评价的新方法探讨. 生物多样性，2015，23(5)：583-590. http://www. biodiversity-science. net/CN/article/downloadArticleFile. do?attachType=PDF\&id=10075

\begin{tabular}{|c|c|c|c|c|c|}
\hline & & 入 & /NT & & \\
\hline \multirow[t]{2}{*}{ Eucommia ulmoides } & 杜仲 & 未列 & 近危 & 汪盛 & 杜仲抗真菌蛋白(EAFP)晶体动态生长研究 \\
\hline & & 入 & /NT & & \\
\hline \multirow[t]{2}{*}{ Eucommia ulmoides } & 杜仲 & 未列 & 近危 & 刘小烛 & 杜仲抗真菌蛋白的时空表达特性 \\
\hline & & 入 & /NT & & \\
\hline \multirow[t]{2}{*}{ Eucommia ulmoides } & 杜仲 & 未列 & 近危 & 王大成 & 杜仲抗真菌蛋白晶体生长的原子力显微成像研究一一快速生长与晶面生长速率 \\
\hline & & 入 & /NT & & \\
\hline \multirow[t]{2}{*}{ Eucommia ulmoides } & 杜仲 & 未列 & 近危 & 张博勇 & 杜仲良种篮选指标体系的建立 \\
\hline & & 入 & /NT & & \\
\hline \multirow[t]{2}{*}{ Eucommia ulmoides } & 杜仲 & 未列 & 近危 & 陈竹君 & 杜仲林地营养状况及施肥效应研究 \\
\hline & & 入 & /NT & & \\
\hline \multirow[t]{2}{*}{ Eucommia ulmoides } & 杜仲 & 未列 & 近危 & 杜建芳 & 杜仲磷酸醌酶的分离、纯化及特性分析 \\
\hline & & 入 & /NT & & \\
\hline \multirow[t]{2}{*}{ Eucommia ulmoides } & 杜仲 & 未列 & 近危 & 杜红岩 & 杜仲绿原酸生物合成途径相关基因的差异表达 \\
\hline & & 入 & /NT & & \\
\hline \multirow[t]{2}{*}{ Eucommia ulmoides } & 杜仲 & 未列 & 近危 & 武志波 & 杜仲萌动芽组织培养方法的研究 \\
\hline & & 入 & /NT & & \\
\hline \multirow[t]{2}{*}{ Eucommia ulmoides } & 杜仲 & 未列 & 近危 & 田丰登 & 杜仲密植栽培与常规栽培的产量对比分析 \\
\hline & & 入 & /NT & & \\
\hline
\end{tabular}


顾垒，闻丞，罗玫，王吴，吕植. 中国最受关注濒危物种保护现状快速评价的新方法探讨. 生物多样性，2015，23(5)：583-590. http://www biodiversity-science. net/CN/article/downloadArticleFile. do?attachType=PDF\&id=10075

\begin{tabular}{|c|c|c|c|c|c|}
\hline \multirow[t]{2}{*}{ Eucommia ulmoides } & 杜仲 & 未列 & 近危 & 訤明涛 & 杜仲内生菌的分离及产 PDG 菌株的篮选 \\
\hline & & 入 & /NT & & \\
\hline \multirow[t]{2}{*}{ Eucommia ulmoides } & 杜仲 & 未列 & 近危 & 陈双林 & 杜仲内生球毛壳菌的抗氧化活性研究 \\
\hline & & 入 & $/ \mathrm{NT}$ & & \\
\hline \multirow[t]{2}{*}{ Eucommia ulmoides } & 杜仲 & 未列 & 近危 & 江海洋 & 杜仲内生真菌 D ZJ0 3 发酵液生物活性的研究 \\
\hline & & 入 & /NT & & \\
\hline \multirow[t]{2}{*}{ Eucommia ulmoides } & 杜仲 & 未列 & 近危 & 杨明琰 & 杜仲内生真菌 D Z 05 的鉴定及抗菌生物活性研究 \\
\hline & & 入 & $/ \mathrm{NT}$ & & \\
\hline \multirow[t]{2}{*}{ Eucommia ulmoides } & 杜仲 & 未列 & 近危 & 姜交龙 & 杜仲内生真菌的分离及其代谢产物抑菌性质研究 \\
\hline & & 入 & /NT & & \\
\hline \multirow[t]{2}{*}{ Eucommia ulmoides } & 杜仲 & 未列 & 近危 & 孙奎 & 杜仲内生真菌的分离及其鉴定 \\
\hline & & 入 & $/ \mathrm{NT}$ & & \\
\hline \multirow[t]{2}{*}{ Eucommia ulmoides } & 杜仲 & 未列 & 近危 & 杨明琰 & 杜仲内生真菌的分离鉴定及抗菌活性研究 \\
\hline & & 入 & $/ \mathrm{NT}$ & & \\
\hline \multirow[t]{2}{*}{ Eucommia ulmoides } & 杜仲 & 未列 & 近危 & 白林含 & 杜仲内生真菌的分离鉴定及其抑菌活性研究 \\
\hline & & 入 & /NT & & \\
\hline \multirow[t]{2}{*}{ Eucommia ulmoides } & 杜仲 & 未列 & 近危 & 苏印泉 & 杜仲内生真菌的抑菌活性篮选 \\
\hline & & 入 & $/ \mathrm{NT}$ & & \\
\hline Eucommia ulmoides & 杜仲 & 未列 & 近危 & 苏印泉 & 杜仲内生真菌对植物病原真菌的抑菌活性研究 \\
\hline
\end{tabular}


顾垒，闻丞，罗玫，王吴，吕植. 中国最受关注濒危物种保护现状快速评价的新方法探讨. 生物多样性，2015，23(5)：583-590. http://www. biodiversity-science. net/CN/article/downloadArticleFile. do?attachType=PDF\&id=10075

\begin{tabular}{|c|c|c|c|c|c|}
\hline & & 入 & /NT & & \\
\hline \multirow[t]{2}{*}{ Eucommia ulmoides } & 杜仲 & 未列 & 近危 & 苏印泉 & 杜仲内生真菌活性物质的研究 \\
\hline & & 入 & /NT & & \\
\hline \multirow[t]{2}{*}{ Eucommia ulmoides } & 杜仲 & 未列 & 近危 & 陈双林 & 杜仲内生真菌类群与分布的初步研究 \\
\hline & & 入 & /NT & & \\
\hline \multirow[t]{2}{*}{ Eucommia ulmoides } & 杜仲 & 未列 & 近危 & 丁婷 & 杜仲内生真菌中抗苹果炭疽病活性菌株的篮选 \\
\hline & & 入 & /NT & & \\
\hline \multirow[t]{2}{*}{ Eucommia ulmoides } & 杜仲 & 未列 & 近危 & 霍娟 & 杜仲内生真菌资源和活性菌株生物学的初步研究 \\
\hline & & 入 & /NT & & \\
\hline \multirow[t]{2}{*}{ Eucommia ulmoides } & 杜仲 & 未列 & 近危 & 叶春 & 杜仲嫩叶成分分析 \\
\hline & & 入 & /NT & & \\
\hline \multirow[t]{2}{*}{ Eucommia ulmoides } & 杜仲 & 未列 & 近危 & 高鹏 & 杜仲配子与合子染色体加倍技术研究 \\
\hline & & 入 & /NT & & \\
\hline \multirow[t]{2}{*}{ Eucommia ulmoides } & 杜仲 & 未列 & 近危 & 石少澜 & 杜仲皮的组织结构及化学成分的比较研究 \\
\hline & & 入 & /NT & & \\
\hline \multirow[t]{2}{*}{ Eucommia ulmoides } & 杜仲 & 未列 & 近危 & 甄汉深 & 杜仲皮和叶中儿茶素含量差异的研究 \\
\hline & & 入 & /NT & & \\
\hline \multirow[t]{2}{*}{ Eucommia ulmoides } & 杜仲 & 未列 & 近危 & 杜红岩 & 杜仲皮内杜仲胶形成积累的规律 \\
\hline & & 入 & /NT & & \\
\hline
\end{tabular}


顾垒，闻丞，罗玫，王吴，吕植. 中国最受关注濒危物种保护现状快速评价的新方法探讨. 生物多样性，2015，23(5)：583-590. http://www. biodiversity-science. net/CN/article/downloadArticleFile. do?attachType=PDF\&id=10075

\begin{tabular}{|c|c|c|c|c|c|}
\hline \multirow[t]{2}{*}{ Eucommia ulmoides } & 杜仲 & 未列 & 近危 & 谭有禄 & 杜仲普通嫩枝扦插技术及管理措施 \\
\hline & & 入 & /NT & & \\
\hline \multirow[t]{2}{*}{ Eucommia ulmoides } & 杜仲 & 未列 & 近危 & 时军霞 & 杜仲扞插繁殖技术研究 \\
\hline & & 入 & $/ \mathrm{NT}$ & & \\
\hline \multirow[t]{2}{*}{ Eucommia ulmoides } & 杜仲 & 未列 & 近危 & 刘克斌 & 杜仲乔林密植作业初探 \\
\hline & & 入 & /NT & & \\
\hline \multirow[t]{2}{*}{ Eucommia ulmoides } & 杜仲 & 未列 & 近危 & 苏印泉 & 杜仲乔林与叶林树皮中次生代谢物含量的比较 \\
\hline & & 入 & $/ \mathrm{NT}$ & & \\
\hline \multirow[t]{2}{*}{ Eucommia ulmoides } & 杜仲 & 未列 & 近危 & 李荣伟 & 杜仲人工林林分直径分布研究 \\
\hline & & 入 & /NT & & \\
\hline \multirow[t]{2}{*}{ Eucommia ulmoides } & 杜仲 & 未列 & 近危 & 潘攀 & 杜仲人工林生物量和生产力研究 \\
\hline & & 入 & $/ \mathrm{NT}$ & & \\
\hline \multirow[t]{2}{*}{ Eucommia ulmoides } & 杜仲 & 未列 & 近危 & 张劲松 & 杜仲人工林蒸腾时间演变的分形特征及可预报时长 \\
\hline & & 入 & $/ \mathrm{NT}$ & & \\
\hline \multirow[t]{2}{*}{ Eucommia ulmoides } & 杜仲 & 未列 & 近危 & 潘攀 & 杜仲人工林中的邻体干扰 \\
\hline & & 入 & /NT & & \\
\hline \multirow[t]{2}{*}{ Eucommia ulmoides } & 杜仲 & 未列 & 近危 & 刘卫平 & 杜仲肉桂醇脱氢酶基因克隆及序列分析 \\
\hline & & 入 & $/ \mathrm{NT}$ & & \\
\hline Eucommia ulmoides & 杜仲 & 未列 & 近危 & 赵德刚 & 杜仲肉桂醇脱氢酶基因全长 $\mathrm{cDNA}$ 克隆及序列分析 \\
\hline
\end{tabular}


顾垒，闻丞，罗玫，王吴，吕植. 中国最受关注濒危物种保护现状快速评价的新方法探讨. 生物多样性，2015，23(5)：583-590. http://www. biodiversity-science. net/CN/article/downloadArticleFile. do?attachType=PDF\&id=10075

\begin{tabular}{|c|c|c|c|c|c|}
\hline & & 入 & /NT & & \\
\hline \multirow[t]{2}{*}{ Eucommia ulmoides } & 杜仲 & 未列 & 近危 & 何景峰 & 杜仲生长节律与施肥技术简报 \\
\hline & & 入 & /NT & & \\
\hline \multirow[t]{2}{*}{ Eucommia ulmoides } & 杜仲 & 未列 & 近危 & 肖新华 & 杜仲实生苗分级造林试验初报 \\
\hline & & 入 & /NT & & \\
\hline \multirow[t]{2}{*}{ Eucommia ulmoides } & 杜仲 & 未列 & 近危 & 惠彦文 & 杜仲瘦蚊的初步研究 \\
\hline & & 入 & /NT & & \\
\hline \multirow[t]{2}{*}{ Eucommia ulmoides } & 杜仲 & 未列 & 近危 & 朱笃 & 杜仲疏松愈伤组织诱导条件的优化笁选 \\
\hline & & 入 & /NT & & \\
\hline \multirow[t]{2}{*}{ Eucommia ulmoides } & 杜仲 & 未列 & 近危 & 周明兵 & 杜仲树皮 cDNA 文库的构建与分析 \\
\hline & & 入 & /NT & & \\
\hline \multirow[t]{2}{*}{ Eucommia ulmoides } & 杜仲 & 未列 & 近危 & 杜兰英 & 杜仲树皮含胶特性的个体变异规律 \\
\hline & & 入 & /NT & & \\
\hline \multirow[t]{2}{*}{ Eucommia ulmoides } & 杜仲 & 未列 & 近危 & 周光龙 & 杜仲树皮生长规律与剥皮再生技术 \\
\hline & & 入 & /NT & & \\
\hline \multirow[t]{2}{*}{ Eucommia ulmoides } & 杜仲 & 未列 & 近危 & 刘小烛 & 杜仲树皮总 RNA 提取方法的比较 \\
\hline & & 入 & /NT & & \\
\hline \multirow[t]{2}{*}{ Eucommia ulmoides } & 杜仲 & 未列 & 近危 & 陈竹君 & 杜仲树体矿质元素分布特点与需肥规律 \\
\hline & & 入 & /NT & & \\
\hline
\end{tabular}


顾垒，闻丞，罗玫，王吴，吕植. 中国最受关注濒危物种保护现状快速评价的新方法探讨. 生物多样性，2015，23(5)：583-590. http://www. biodiversity-science. net/CN/article/downloadArticleFile. do?attachType=PDF\&id=10075

\begin{tabular}{|c|c|c|c|c|c|}
\hline \multirow[t]{2}{*}{ Eucommia ulmoides } & 杜仲 & 未列 & 近危 & 郭宝林 & 杜仲四倍体的诱导与鉴定 \\
\hline & & 入 & /NT & & \\
\hline \multirow[t]{2}{*}{ Eucommia ulmoides } & 杜仲 & 未列 & 近危 & 郭宝林 & 杜仲四倍体叶绿素苂光参数的日变化研究 \\
\hline & & 入 & $/ \mathrm{NT}$ & & \\
\hline \multirow[t]{2}{*}{ Eucommia ulmoides } & 杜仲 & 未列 & 近危 & 郭宝林 & 杜仲四倍体与二倍体光合特性比较 \\
\hline & & 入 & /NT & & \\
\hline \multirow[t]{2}{*}{ Eucommia ulmoides } & 杜仲 & 未列 & 近危 & 姚启祥 & 杜仲速生丰产栽培技术研究 \\
\hline & & 入 & $/ \mathrm{NT}$ & & \\
\hline \multirow[t]{2}{*}{ Eucommia ulmoides } & 杜仲 & 未列 & 近危 & 校宏武 & 杜仲无性繁殖育苗技术 \\
\hline & & 入 & /NT & & \\
\hline \multirow[t]{2}{*}{ Eucommia ulmoides } & 杜仲 & 未列 & 近危 & 杜红岩 & 杜仲无性系叶片含胶特性的差异及其相关性分析 \\
\hline & & 入 & /NT & & \\
\hline \multirow[t]{2}{*}{ Eucommia ulmoides } & 杜仲 & 未列 & 近危 & 杨庆仙 & 杜仲细胞的悬浮培养技术 \\
\hline & & 入 & $/ \mathrm{NT}$ & & \\
\hline \multirow[t]{2}{*}{ Eucommia ulmoides } & 杜仲 & 未列 & 近危 & 朱笃 & 杜仲细胞悬浮培养产黄酮及其动力学研究 \\
\hline & & 入 & /NT & & \\
\hline \multirow[t]{2}{*}{ Eucommia ulmoides } & 杜仲 & 未列 & 近危 & 邱晓芳 & 杜仲细胞悬浮培养及主要次生代谢物积累的研究 \\
\hline & & 入 & $/ \mathrm{NT}$ & & \\
\hline Eucommia ulmoides & 杜仲 & 未列 & 近危 & 王亚琴 & 杜仲细胞悬浮培养生产绿原酸的初步研究 \\
\hline
\end{tabular}


顾垒，闻丞，罗玫，王吴，吕植. 中国最受关注濒危物种保护现状快速评价的新方法探讨. 生物多样性，2015，23(5)：583-590. http://www. biodiversity-science. net/CN/article/downloadArticleFile. do?attachType=PDF\&id=10075

\begin{tabular}{|c|c|c|c|c|c|}
\hline & & 入 & /NT & & \\
\hline \multirow[t]{2}{*}{ Eucommia ulmoides } & 杜仲 & 未列 & 近危 & 王亚琴 & 杜仲细胞悬浮培养生产桃叶珊瑚式的研究 \\
\hline & & 入 & /NT & & \\
\hline \multirow[t]{2}{*}{ Eucommia ulmoides } & 杜仲 & 未列 & 近危 & 刘严 & 杜仲雄花功能成分的提取_分离及活性研究 \\
\hline & & 入 & /NT & & \\
\hline \multirow[t]{2}{*}{ Eucommia ulmoides } & 杜仲 & 未列 & 近危 & 董娟娥 & 杜仲雄花提取物的体外抗氧化活性评价 \\
\hline & & 入 & /NT & & \\
\hline \multirow[t]{2}{*}{ Eucommia ulmoides } & 杜仲 & 未列 & 近危 & 董娟娥 & 杜仲雄花中次生代谢物合成积累的动态变化 \\
\hline & & 入 & /NT & & \\
\hline \multirow[t]{2}{*}{ Eucommia ulmoides } & 杜仲 & 未列 & 近危 & 张晓荣 & 杜仲雄花中矿质元素含量分析与评价 \\
\hline & & 入 & /NT & & \\
\hline \multirow[t]{2}{*}{ Eucommia ulmoides } & 杜仲 & 未列 & 近危 & 高锦明 & 杜仲叶次生代谢物季节和地域差异性研究 \\
\hline & & 入 & /NT & & \\
\hline \multirow[t]{2}{*}{ Eucommia ulmoides } & 杜仲 & 未列 & 近危 & 萄芳 & 杜仲叶发育过程中结构及杜仲胶含量变化研究 \\
\hline & & 入 & /NT & & \\
\hline \multirow[t]{2}{*}{ Eucommia ulmoides } & 杜仲 & 未列 & 近危 & 周明兵 & 杜仲叶和树皮总 RNA 的快速提取法 \\
\hline & & 入 & /NT & & \\
\hline \multirow[t]{2}{*}{ Eucommia ulmoides } & 杜仲 & 未列 & 近危 & 郭菡 & 杜仲叶活性成分的提取分离及活性鉴定 \\
\hline & & 入 & /NT & & \\
\hline
\end{tabular}


顾垒，闻丞，罗玫，王吴，吕植. 中国最受关注濒危物种保护现状快速评价的新方法探讨. 生物多样性，2015，23(5)：583-590. http://www. biodiversity-science. net/CN/article/downloadArticleFile. do?attachType=PDF\&id=10075

\begin{tabular}{|c|c|c|c|c|c|}
\hline \multirow[t]{2}{*}{ Eucommia ulmoides } & 杜仲 & 未列 & 近危 & 苏印泉 & 杜仲叶林枝木醋液化学成分及抑菌活性研究 \\
\hline & & 入 & $/ \mathrm{NT}$ & & \\
\hline \multirow[t]{2}{*}{ Eucommia ulmoides } & 杜仲 & 未列 & 近危 & 杨江峰 & 杜仲叶面肥试验初报 \\
\hline & & 入 & $/ \mathrm{NT}$ & & \\
\hline \multirow[t]{2}{*}{ Eucommia ulmoides } & 杜仲 & 未列 & 近危 & 杜红岩 & 杜仲叶内杜仲胶的形成积累规律 \\
\hline & & 入 & $/ \mathrm{NT}$ & & \\
\hline \multirow[t]{2}{*}{ Eucommia ulmoides } & 杜仲 & 未列 & 近危 & 苏印泉 & 杜仲叶内胶含量及分子质量动态变化研究 \\
\hline & & 入 & $/ \mathrm{NT}$ & & \\
\hline \multirow[t]{2}{*}{ Eucommia ulmoides } & 杜仲 & 未列 & 近危 & 朱登云 & 杜仲叶片和叶柄愈伤组织的诱导和植株再生 \\
\hline & & 入 & /NT & & \\
\hline \multirow[t]{2}{*}{ Eucommia ulmoides } & 杜仲 & 未列 & 近危 & 赵德刚 & 杜仲叶片为外植体的植株再生 \\
\hline & & 入 & $/ \mathrm{NT}$ & & \\
\hline \multirow[t]{2}{*}{ Eucommia ulmoides } & 杜仲 & 未列 & 近危 & 李琰 & 杜仲叶片愈伤组织诱导的激素优化研究 \\
\hline & & 入 & $/ \mathrm{NT}$ & & \\
\hline \multirow[t]{2}{*}{ Eucommia ulmoides } & 杜仲 & 未列 & 近危 & 赵红艳 & 杜仲叶生长发育过程中组织结构及指标成分含量的变化 \\
\hline & & 入 & $/ \mathrm{NT}$ & & \\
\hline \multirow[t]{2}{*}{ Eucommia ulmoides } & 杜仲 & 未列 & 近危 & 刘增文 & 杜仲叶水提取物对几种农作物的化感作用 \\
\hline & & 入 & $/ \mathrm{NT}$ & & \\
\hline Eucommia ulmoides & 杜仲 & 未列 & 近危 & 饶力群 & 杜仲叶桃叶珊瑚苷分离纯化研究 \\
\hline
\end{tabular}


顾垒，闻丞，罗玫，王吴，吕植. 中国最受关注濒危物种保护现状快速评价的新方法探讨. 生物多样性，2015，23(5)：583-590. http://www. biodiversity-science. net/CN/article/downloadArticleFile. do?attachType=PDF\&id=10075

\begin{tabular}{|c|c|c|c|c|c|}
\hline & & 入 & /NT & & \\
\hline \multirow[t]{2}{*}{ Eucommia ulmoides } & 杜仲 & 未列 & 近危 & 徐文俊 & 杜仲叶与皮中绿原酸的正交提取对比实验 \\
\hline & & 入 & /NT & & \\
\hline \multirow[t]{2}{*}{ Eucommia ulmoides } & 杜仲 & 未列 & 近危 & 杜红岩 & 杜仲叶中 3 种主要活性成分含量的季节变化 \\
\hline & & 入 & /NT & & \\
\hline \multirow[t]{2}{*}{ Eucommia ulmoides } & 杜仲 & 未列 & 近危 & 何文广 & 杜仲叶中杜仲胶含量与相对分子质量的动态变化 \\
\hline & & 入 & /NT & & \\
\hline \multirow[t]{2}{*}{ Eucommia ulmoides } & 杜仲 & 未列 & 近危 & 张万锋 & 杜仲叶中绿原酸的生物合成机理探究 \\
\hline & & 入 & /NT & & \\
\hline \multirow[t]{2}{*}{ Eucommia ulmoides } & 杜仲 & 未列 & 近危 & 张学俊 & 杜仲叶中绿原酸的研究进展 \\
\hline & & 入 & /NT & & \\
\hline \multirow[t]{2}{*}{ Eucommia ulmoides } & 杜仲 & 未列 & 近危 & 兰小艳 & 杜仲叶中绿原酸含量检测的研究 \\
\hline & & 入 & /NT & & \\
\hline \multirow[t]{2}{*}{ Eucommia ulmoides } & 杜仲 & 未列 & 近危 & 余继宏 & 杜仲叶中绿原酸稳定性研究及沉降试验 \\
\hline & & 入 & /NT & & \\
\hline \multirow[t]{2}{*}{ Eucommia ulmoides } & 杜仲 & 未列 & 近危 & 李周岐 & 杜仲遗传作图群体的建立 \\
\hline & & 入 & /NT & & \\
\hline \multirow[t]{2}{*}{ Eucommia ulmoides } & 杜仲 & 未列 & 近危 & 孙科才 & 杜仲引种试验研究 \\
\hline & & 入 & /NT & & \\
\hline
\end{tabular}


顾垒，闻丞，罗玫，王吴，吕植. 中国最受关注濒危物种保护现状快速评价的新方法探讨. 生物多样性，2015，23(5)：583-590. http://www biodiversity-science. net/CN/article/downloadArticleFile. do?attachType=PDF\&id=10075

\begin{tabular}{|c|c|c|c|c|c|}
\hline \multirow[t]{2}{*}{ Eucommia ulmoides } & 杜仲 & 未列 & 近危 & 王宏 & 杜仲优良品种_无性系_DNA 指纹图谱的构建 \\
\hline & & 入 & /NT & & \\
\hline \multirow[t]{2}{*}{ Eucommia ulmoides } & 杜仲 & 未列 & 近危 & 杨恩让 & 杜仲优良品种及无性系 D N A 指纹图谱的构建 \\
\hline & & 入 & $/ \mathrm{NT}$ & & \\
\hline \multirow[t]{2}{*}{ Eucommia ulmoides } & 杜仲 & 未列 & 近危 & 金晓玲 & 杜仲优良无性系快速微繁殖技术研究 \\
\hline & & 入 & /NT & & \\
\hline \multirow[t]{2}{*}{ Eucommia ulmoides } & 杜仲 & 未列 & 近危 & 张博勇 & 杜仲优良种源区与类型选择的研究 \\
\hline & & 入 & $/ \mathrm{NT}$ & & \\
\hline \multirow[t]{2}{*}{ Eucommia ulmoides } & 杜仲 & 未列 & 近危 & 弓㢶 & 杜仲优树的组培繁殖技术 \\
\hline & & 入 & /NT & & \\
\hline \multirow[t]{2}{*}{ Eucommia ulmoides } & 杜仲 & 未列 & 近危 & 李周岐 & 杜仲优树自由授粉家系遗传变异及苗期初选 \\
\hline & & 入 & $/ \mathrm{NT}$ & & \\
\hline \multirow[t]{2}{*}{ Eucommia ulmoides } & 杜仲 & 未列 & 近危 & 李周岐 & 杜仲优树自由授粉家系遗传变异及苗期选择 \\
\hline & & 入 & $/ \mathrm{NT}$ & & \\
\hline \multirow[t]{2}{*}{ Eucommia ulmoides } & 杜仲 & 未列 & 近危 & 董娟娥 & 杜仲优系有效成分性状稳定性与增长率的研究 \\
\hline & & 入 & /NT & & \\
\hline \multirow[t]{2}{*}{ Eucommia ulmoides } & 杜仲 & 未列 & 近危 & 李周岐 & 杜仲有性杂交与遗传作图群体的建立 \\
\hline & & 入 & $/ \mathrm{NT}$ & & \\
\hline Eucommia ulmoides & 杜仲 & 未列 & 近危 & 李铁柱 & 杜仲幼果和成熟果实转录组数据组装及基因功能注释 \\
\hline
\end{tabular}


顾垒，闻丞，罗玫，王吴，吕植. 中国最受关注濒危物种保护现状快速评价的新方法探讨. 生物多样性，2015，23(5)：583-590. http://www. biodiversity-science. net/CN/article/downloadArticleFile. do?attachType=PDF\&id=10075

\begin{tabular}{|c|c|c|c|c|c|}
\hline & & 入 & /NT & & \\
\hline \multirow[t]{2}{*}{ Eucommia ulmoides } & 杜仲 & 未列 & 近危 & 王鸣凤 & 杜仲幼林豹冨蛾的发生与防治 \\
\hline & & 入 & /NT & & \\
\hline \multirow[t]{2}{*}{ Eucommia ulmoides } & 杜仲 & 未列 & 近危 & 程月飞 & 杜仲育苗造林技术及开发利用的研究 \\
\hline & & 入 & /NT & & \\
\hline \multirow[t]{2}{*}{ Eucommia ulmoides } & 杜仲 & 未列 & 近危 & 黄勇 & 杜仲愈伤组织的诱导及增殖效应 \\
\hline & & 入 & /NT & & \\
\hline \multirow[t]{2}{*}{ Eucommia ulmoides } & 杜仲 & 未列 & 近危 & 何泼 & 杜仲愈伤组织培养过程中胶含量的动态变化 \\
\hline & & 入 & /NT & & \\
\hline \multirow[t]{2}{*}{ Eucommia ulmoides } & 杜仲 & 未列 & 近危 & 李琰 & 杜仲愈伤组织培养及次生代谢产物含量的研究 \\
\hline & & 入 & /NT & & \\
\hline \multirow[t]{2}{*}{ Eucommia ulmoides } & 杜仲 & 未列 & 近危 & 李琰 & 杜仲愈伤组织诱导的研究 \\
\hline & & 入 & /NT & & \\
\hline \multirow[t]{2}{*}{ Eucommia ulmoides } & 杜仲 & 未列 & 近危 & 罗丽 & 杜仲愈伤组织诱导与继代培养研究 \\
\hline & & 入 & /NT & & \\
\hline \multirow[t]{2}{*}{ Eucommia ulmoides } & 杜仲 & 未列 & 近危 & 何泼 & 杜仲愈伤组织诱导与增殖的研究 \\
\hline & & 入 & /NT & & \\
\hline \multirow[t]{2}{*}{ Eucommia ulmoides } & 杜仲 & 未列 & 近危 & 李琰 & 杜仲愈伤组织中次生代谢产物积累动态研究 \\
\hline & & 入 & /NT & & \\
\hline
\end{tabular}


顾垒，闻丞，罗玫，王吴，吕植. 中国最受关注濒危物种保护现状快速评价的新方法探讨. 生物多样性，2015，23(5)：583-590. http://www. biodiversity-science. net/CN/article/downloadArticleFile. do?attachType=PDF\&id=10075

\begin{tabular}{|c|c|c|c|c|c|}
\hline \multirow[t]{2}{*}{ Eucommia ulmoides } & 杜仲 & 未列 & 近危 & 李周岐 & 杜仲杂交子代的组织培养及无性系化 \\
\hline & & 入 & $/ \mathrm{NT}$ & & \\
\hline \multirow[t]{2}{*}{ Eucommia ulmoides } & 杜仲 & 未列 & 近危 & 李周岐 & 杜仲杂交子代苗期表型性状的遗传分析 \\
\hline & & 入 & $/ \mathrm{NT}$ & & \\
\hline \multirow[t]{2}{*}{ Eucommia ulmoides } & 杜仲 & 未列 & 近危 & 李周岐 & 杜仲杂交子代苗期表型性状遗传分析及选择 \\
\hline & & 入 & $/ \mathrm{NT}$ & & \\
\hline \multirow[t]{2}{*}{ Eucommia ulmoides } & 杜仲 & 未列 & 近危 & 李晨辉 & 杜仲栽培中营养与施肥问题的实验研究 \\
\hline & & 入 & $/ \mathrm{NT}$ & & \\
\hline \multirow[t]{2}{*}{ Eucommia ulmoides } & 杜仲 & 未列 & 近危 & 张劲松 & 杜仲蒸腾强度和气孔行为的初步研究 \\
\hline & & 入 & /NT & & \\
\hline \multirow[t]{2}{*}{ Eucommia ulmoides } & 杜仲 & 未列 & 近危 & 杜红岩 & 杜仲种仁桃叶珊瑚甘草量的测定及积累规律 \\
\hline & & 入 & $/ \mathrm{NT}$ & & \\
\hline \multirow[t]{2}{*}{ Eucommia ulmoides } & 杜仲 & 未列 & 近危 & 王跃华 & 杜仲种子的多倍体诱导研究 \\
\hline & & 入 & $/ \mathrm{NT}$ & & \\
\hline \multirow[t]{2}{*}{ Eucommia ulmoides } & 杜仲 & 未列 & 近危 & 杜竹静 & 杜仲种子繁殖栽培技术 \\
\hline & & 入 & $/ \mathrm{NT}$ & & \\
\hline \multirow[t]{2}{*}{ Eucommia ulmoides } & 杜仲 & 未列 & 近危 & 宁华 & 杜仲种子生命力与萌发率的快速测定 \\
\hline & & 入 & $/ \mathrm{NT}$ & & \\
\hline Eucommia ulmoides & 杜仲 & 未列 & 近危 & 李周岐 & 杜仲种子无菌苗的获得及染色体加倍技术研究 \\
\hline
\end{tabular}


顾垒，闻丞，罗玫，王吴，吕植. 中国最受关注濒危物种保护现状快速评价的新方法探讨. 生物多样性，2015，23(5)：583-590. http://www. biodiversity-science. net/CN/article/downloadArticleFile. do?attachType=PDF\&id=10075

\begin{tabular}{|c|c|c|c|c|c|}
\hline & & 入 & /NT & & \\
\hline \multirow[t]{2}{*}{ Eucommia ulmoides } & 杜仲 & 未列 & 近危 & 邓泽元 & 杜仲种子脂肪酸及氨基酸分析 \\
\hline & & 入 & /NT & & \\
\hline \multirow[t]{2}{*}{ Eucommia ulmoides } & 杜仲 & 未列 & 近危 & 杜红岩 & 杜仲主要活性成分形成积累及其营养调控技术研究 \\
\hline & & 入 & /NT & & \\
\hline \multirow[t]{2}{*}{ Eucommia ulmoides } & 杜仲 & 未列 & 近危 & 陈竹君 & 杜仲专用肥肥效试验 \\
\hline & & 入 & /NT & & \\
\hline \multirow[t]{2}{*}{ Eucommia ulmoides } & 杜仲 & 未列 & 近危 & 董娟娥 & 杜仲籽油中 A-亚麻酸的含量及其生理功能 \\
\hline & & 入 & /NT & & \\
\hline \multirow[t]{2}{*}{ Eucommia ulmoides } & 杜仲 & 未列 & 近危 & 吴永宏 & 杜仲紫根病发生规律及防治初探 \\
\hline & & 入 & /NT & & \\
\hline \multirow[t]{2}{*}{ Eucommia ulmoides } & 杜仲 & 未列 & 近危 & 陈之龙 & 杜仲自然类型( 表型) 分类调查及胶药品质评价 \\
\hline & & 入 & /NT & & \\
\hline \multirow[t]{2}{*}{ Eucommia ulmoides } & 杜仲 & 未列 & 近危 & 李琰 & 杜仲组培快繁的研究 \\
\hline & & 入 & /NT & & \\
\hline \multirow[t]{2}{*}{ Eucommia ulmoides } & 杜仲 & 未列 & 近危 & 王东良 & 杜仲组织离体培养研究 \\
\hline & & 入 & /NT & & \\
\hline \multirow[t]{2}{*}{ Eucommia ulmoides } & 杜仲 & 未列 & 近危 & 黄勇 & 杜仲组织培养的初步研究 \\
\hline & & 入 & /NT & & \\
\hline
\end{tabular}


顾垒，闻丞，罗玫，王吴，吕植. 中国最受关注濒危物种保护现状快速评价的新方法探讨. 生物多样性，2015，23(5)：583-590. http://www. biodiversity-science. net/CN/article/downloadArticleFile. do?attachType=PDF\&id=10075

\begin{tabular}{|c|c|c|c|c|c|}
\hline \multirow[t]{2}{*}{ Eucommia ulmoides } & 杜仲 & 未列 & 近危 & 何泼 & 杜仲组织培养的研究 \\
\hline & & 入 & /NT & & \\
\hline \multirow[t]{2}{*}{ Eucommia ulmoides } & 杜仲 & 未列 & 近危 & 袁云香 & 杜仲组织培养的研究 \\
\hline & & 入 & $/ \mathrm{NT}$ & & \\
\hline \multirow[t]{2}{*}{ Eucommia ulmoides } & 杜仲 & 未列 & 近危 & 金晓玲 & 杜仲组织培养的研究进展 \\
\hline & & 入 & /NT & & \\
\hline \multirow[t]{2}{*}{ Eucommia ulmoides } & 杜仲 & 未列 & 近危 & 何小力 & 杜仲组织培养过程中部分生理特征的变化研究 \\
\hline & & 入 & $/ \mathrm{NT}$ & & \\
\hline \multirow[t]{2}{*}{ Eucommia ulmoides } & 杜仲 & 未列 & 近危 & 蒋祥娥 & 杜仲组织培养技术的研究 \\
\hline & & 入 & /NT & & \\
\hline \multirow[t]{2}{*}{ Eucommia ulmoides } & 杜仲 & 未列 & 近危 & 李周岐 & 杜仲组织培养再生体系的优化 \\
\hline & & 入 & $/ \mathrm{NT}$ & & \\
\hline \multirow[t]{2}{*}{ Eucommia ulmoides } & 杜仲 & 未列 & 近危 & 李周岐 & 杜仲组织培养再生体系的优化与多倍体诱导 \\
\hline & & 入 & $/ \mathrm{NT}$ & & \\
\hline \multirow[t]{2}{*}{ Eucommia ulmoides } & 杜仲 & 未列 & 近危 & 廖朝林 & 多效唑对杜仲穴盘育苗质量的影响 \\
\hline & & 入 & $/ \mathrm{NT}$ & & \\
\hline \multirow[t]{2}{*}{ Eucommia ulmoides } & 杜仲 & 未列 & 近危 & 王柏泉 & 鄂西南山区杜仲叶部病害发生规律的研究 \\
\hline & & 入 & $/ \mathrm{NT}$ & & \\
\hline Eucommia ulmoides & 杜仲 & 未列 & 近危 & 王柏泉 & 鄂西南山区杜仲叶部病害发生规律研究 \\
\hline
\end{tabular}


顾垒，闻丞，罗玫，王吴，吕植. 中国最受关注濒危物种保护现状快速评价的新方法探讨. 生物多样性，2015，23(5)：583-590. http://www. biodiversity-science. net/CN/article/downloadArticleFile. do?attachType=PDF\&id=10075

\begin{tabular}{|c|c|c|c|c|c|}
\hline & & 入 & /NT & & \\
\hline \multirow[t]{2}{*}{ Eucommia ulmoides } & 杜仲 & 未列 & 近危 & 游景茂 & 恩施州杜仲病虫害发生情况及防治措施 \\
\hline & & 入 & /NT & & \\
\hline \multirow[t]{2}{*}{ Eucommia ulmoides } & 杜仲 & 未列 & 近危 & 王跃华 & 发根农杆菌 Ri 质粒 T-DNA 对杜仲的遗传转化研究 \\
\hline & & 入 & /NT & & \\
\hline \multirow[t]{2}{*}{ Eucommia ulmoides } & 杜仲 & 未列 & 近危 & 柢文举 & 甘肃省白水江自然保护区杜仲林生长现状及生态因子影响分析 \\
\hline & & 入 & /NT & & \\
\hline \multirow[t]{2}{*}{ Eucommia ulmoides } & 杜仲 & 未列 & 近危 & 朱笃 & 高产绿原酸杜仲细胞悬浮培养体系优化研究 \\
\hline & & 入 & /NT & & \\
\hline \multirow[t]{2}{*}{ Eucommia ulmoides } & 杜仲 & 未列 & 近危 & 康向阳 & 高温诱导杜仲 2n 花粉最佳处理条件研究 \\
\hline & & 入 & /NT & & \\
\hline \multirow[t]{2}{*}{ Eucommia ulmoides } & 杜仲 & 未列 & 近危 & 张磊 & 高温诱导杜仲花粉染色体加倍技术研究 \\
\hline & & 入 & /NT & & \\
\hline \multirow[t]{2}{*}{ Eucommia ulmoides } & 杜仲 & 未列 & 近危 & 毛彦科 & 高温诱导杜仲配子染色体加倍技术研究 \\
\hline & & 入 & /NT & & \\
\hline \multirow[t]{2}{*}{ Eucommia ulmoides } & 杜仲 & 未列 & 近危 & 袁云香 & 硅对杜仲愈伤组织诱导及增殖培养的影响 \\
\hline & & 入 & /NT & & \\
\hline \multirow[t]{2}{*}{ Eucommia ulmoides } & 杜仲 & 未列 & 近危 & 张鞍灵 & 花期冻害对杜仲花粉营养成分的影响 \\
\hline & & 入 & /NT & & \\
\hline
\end{tabular}


顾垒，闻丞，罗玫，王吴，吕植. 中国最受关注濒危物种保护现状快速评价的新方法探讨. 生物多样性，2015，23(5)：583-590. http://www biodiversity-science. net/CN/article/downloadArticleFile. do?attachType=PDF\&id=10075

\begin{tabular}{|c|c|c|c|c|c|}
\hline \multirow[t]{2}{*}{ Eucommia ulmoides } & 杜仲 & 未列 & 近危 & 张劲松 & 华北石质山区杜仲人工林蒸腾特征及水分供求关系 \\
\hline & & 入 & /NT & & \\
\hline \multirow[t]{2}{*}{ Eucommia ulmoides } & 杜仲 & 未列 & 近危 & 杜红岩 & 环剥与环割强度对果园化栽培条件下杜仲生长和结果的影响 \\
\hline & & 入 & $/ \mathrm{NT}$ & & \\
\hline \multirow[t]{2}{*}{ Eucommia ulmoides } & 杜仲 & 未列 & 近危 & 黄明远 & 黄连杜仲立体栽培试验 \\
\hline & & 入 & /NT & & \\
\hline \multirow[t]{2}{*}{ Eucommia ulmoides } & 杜仲 & 未列 & 近危 & 陈伟 & 黄土高原沟壑区山坡地杜仲造林技术试验研究初报 \\
\hline & & 入 & $/ \mathrm{NT}$ & & \\
\hline \multirow[t]{2}{*}{ Eucommia ulmoides } & 杜仲 & 未列 & 近危 & 曹翠萍 & 基于 ISSRs 的安徽省杜仲资源的遗传多样性研究 \\
\hline & & 入 & /NT & & \\
\hline \multirow[t]{2}{*}{ Eucommia ulmoides } & 杜仲 & 未列 & 近危 & 杜红岩 & 基于 SSR 分子标记的杜仲遗传多样性体系建立 \\
\hline & & 入 & $/ \mathrm{NT}$ & & \\
\hline \multirow[t]{2}{*}{ Eucommia ulmoides } & 杜仲 & 未列 & 近危 & 杜红岩 & 基于杜仲转录组序列的 SSR 分子标记的开发 \\
\hline & & 入 & $/ \mathrm{NT}$ & & \\
\hline \multirow[t]{2}{*}{ Eucommia ulmoides } & 杜仲 & 未列 & 近危 & 李琰 & 激素对杜仲幼茎愈伤组织诱导及生长的影响 \\
\hline & & 入 & /NT & & \\
\hline \multirow[t]{2}{*}{ Eucommia ulmoides } & 杜仲 & 未列 & 近危 & 陈功锡 & 吉首市杜仲病虫害调查及防治 \\
\hline & & 入 & $/ \mathrm{NT}$ & & \\
\hline Eucommia ulmoides & 杜仲 & 未列 & 近危 & 张檀 & 几种矿质元素对杜仲叶次生代谢物的影响初探 \\
\hline
\end{tabular}


顾垒，闻丞，罗玫，王吴，吕植. 中国最受关注濒危物种保护现状快速评价的新方法探讨. 生物多样性，2015，23(5)：583-590. http://www. biodiversity-science. net/CN/article/downloadArticleFile. do?attachType=PDF\&id=10075

\begin{tabular}{|c|c|c|c|c|c|}
\hline & & 入 & /NT & & \\
\hline \multirow[t]{2}{*}{ Eucommia ulmoides } & 杜仲 & 未列 & 近危 & 陈建 & 几种提取杜仲 RNA 方法的比较 \\
\hline & & 入 & /NT & & \\
\hline \multirow[t]{2}{*}{ Eucommia ulmoides } & 杜仲 & 未列 & 近危 & 刘芸 & 几种珍稀药用植物产活性成分内生真菌的初步研究 \\
\hline & & 入 & /NT & & \\
\hline \multirow[t]{2}{*}{ Eucommia ulmoides } & 杜仲 & 未列 & 近危 & 王懿君 & 江淮地区成土母岩与杜仲生长关系的研究 \\
\hline & & 入 & /NT & & \\
\hline \multirow[t]{2}{*}{ Eucommia ulmoides } & 杜仲 & 未列 & 近危 & 黄璐琦 & 子遗植物杜仲的遗传多样性 RAPD 分析和保护策略研究 \\
\hline & & 入 & /NT & & \\
\hline \multirow[t]{2}{*}{ Eucommia ulmoides } & 杜仲 & 未列 & 近危 & 余启高 & 解除杜仲种子休眠方法的研究 \\
\hline & & 入 & /NT & & \\
\hline \multirow[t]{2}{*}{ Eucommia ulmoides } & 杜仲 & 未列 & 近危 & 吾鲁木汗・那孜尔别 & 具有 ACC 脱氨酶活性的杜仲内生细菌的分离鉴定及其抗菌活性 \\
\hline & & 入 & /NT & 克 & \\
\hline \multirow[t]{2}{*}{ Eucommia ulmoides } & 杜仲 & 未列 & 近危 & 朱登云 & 聚乙二醇( PEG)对杜仲胚乳愈伤组织茎芽分化的影响 \\
\hline & & 入 & /NT & & \\
\hline \multirow[t]{2}{*}{ Eucommia ulmoides } & 杜仲 & 未列 & 近危 & 聂朝俊 & 喀斯特山地人工杜仲林枯落物和土壤持水特性初步研究 \\
\hline & & 入 & /NT & & \\
\hline \multirow[t]{2}{*}{ Eucommia ulmoides } & 杜仲 & 未列 & 近危 & 李莉 & 雷公山自然保护区杜仲根腐病的调查初报 \\
\hline & & 入 & /NT & & \\
\hline
\end{tabular}


顾垒，闻丞，罗玫，王吴，吕植. 中国最受关注濒危物种保护现状快速评价的新方法探讨. 生物多样性，2015，23(5)：583-590. http://www biodiversity-science. net/CN/article/downloadArticleFile. do?attachType=PDF\&id=10075

\begin{tabular}{|c|c|c|c|c|c|}
\hline \multirow[t]{2}{*}{ Eucommia ulmoides } & 杜仲 & 未列 & 近危 & 景新明 & 利用 EPR 技术快速预测不同含水量杜仲种子的玻璃化转变温度 \\
\hline & & 入 & /NT & & \\
\hline \multirow[t]{2}{*}{ Eucommia ulmoides } & 杜仲 & 未列 & 近危 & 唐萍 & 两种植物生长调节剂对杜仲幼苗生长的影响 \\
\hline & & 入 & /NT & & \\
\hline \multirow[t]{2}{*}{ Eucommia ulmoides } & 杜仲 & 未列 & 近危 & 贾恢先 & 论甘肃省杜仲产业化基础与开发途径 \\
\hline & & 入 & /NT & & \\
\hline \multirow[t]{2}{*}{ Eucommia ulmoides } & 杜仲 & 未列 & 近危 & 董志斌 & 马尾松、杜仲混交林的根系与生物量研究 \\
\hline & & 入 & $/ \mathrm{NT}$ & & \\
\hline \multirow[t]{2}{*}{ Eucommia ulmoides } & 杜仲 & 未列 & 近危 & 钟章成 & 模拟酸雨对杜仲的生理生态特性的影响 \\
\hline & & 入 & /NT & & \\
\hline \multirow[t]{2}{*}{ Eucommia ulmoides } & 杜仲 & 未列 & 近危 & 齐泽民 & 模拟酸雨对杜仲光合生理及生长的影响 \\
\hline & & 入 & $/ \mathrm{NT}$ & & \\
\hline \multirow[t]{2}{*}{ Eucommia ulmoides } & 杜仲 & 未列 & 近危 & 齐泽民 & 模拟酸雨对杜仲抗性生理及药用有效成分含量的影响 \\
\hline & & 入 & $/ \mathrm{NT}$ & & \\
\hline \multirow[t]{2}{*}{ Eucommia ulmoides } & 杜仲 & 未列 & 近危 & 钟章成 & 模拟酸雨对杜仲叶氮代谢的影响 \\
\hline & & 入 & /NT & & \\
\hline \multirow[t]{2}{*}{ Eucommia ulmoides } & 杜仲 & 未列 & 近危 & 齐泽民 & 模拟酸雨对杜仲叶膜脂过氧化及氮代谢的影响 \\
\hline & & 入 & $/ \mathrm{NT}$ & & \\
\hline Eucommia ulmoides & 杜仲 & 未列 & 近危 & 欧阳志云 & 南方红壤丘陵区杜仲人工林产流产沙与降雨特征关系 \\
\hline
\end{tabular}


顾垒，闻丞，罗玫，王吴，吕植. 中国最受关注濒危物种保护现状快速评价的新方法探讨. 生物多样性，2015，23(5)：583-590. http://www. biodiversity-science. net/CN/article/downloadArticleFile. do?attachType=PDF\&id=10075

\begin{tabular}{|c|c|c|c|c|c|}
\hline & & 入 & /NT & & \\
\hline \multirow[t]{2}{*}{ Eucommia ulmoides } & 杜仲 & 未列 & 近危 & 李锋瑞 & 南方红壤丘陵区杜仲人工林土壤水分动态 \\
\hline & & 入 & /NT & & \\
\hline \multirow[t]{2}{*}{ Eucommia ulmoides } & 杜仲 & 未列 & 近危 & 欧阳志云 & 南方红壤区杜仲( Eucommia ulmoides) 树干液流动态 \\
\hline & & 入 & /NT & & \\
\hline \multirow[t]{2}{*}{ Eucommia ulmoides } & 杜仲 & 未列 & 近危 & 张源润 & 宁夏杜仲引种试验初报 \\
\hline & & 入 & /NT & & \\
\hline \multirow[t]{2}{*}{ Eucommia ulmoides } & 杜仲 & 未列 & 近危 & 李琰 & 培养基成分对杜仲愈伤组织生长及次生代谢产物含量的影响 \\
\hline & & 入 & /NT & & \\
\hline \multirow[t]{2}{*}{ Eucommia ulmoides } & 杜仲 & 未列 & 近危 & 李琰 & 培养基及培养条件对杜仲愈伤组织生长及次生代谢产物含量的影响 \\
\hline & & 入 & /NT & & \\
\hline \multirow[t]{2}{*}{ Eucommia ulmoides } & 杜仲 & 未列 & 近危 & 唐建军 & 培养条件对杜仲愈伤组织形成及次生代谢过程的影响 \\
\hline & & 入 & /NT & & \\
\hline \multirow[t]{2}{*}{ Eucommia ulmoides } & 杜仲 & 未列 & 近危 & 杜红岩 & 配方施肥对杜仲雄花主要活性成分含量的影响 \\
\hline & & 入 & /NT & & \\
\hline \multirow[t]{2}{*}{ Eucommia ulmoides } & 杜仲 & 未列 & 近危 & 高鹏 & 切梢吸入式处理诱导杜仲 $2 n$ 花粉的研究 \\
\hline & & 入 & /NT & & \\
\hline \multirow[t]{2}{*}{ Eucommia ulmoides } & 杜仲 & 未列 & 近危 & 康向阳 & 秋水仙碱诱导杜仲花粉染色体加倍的研究 \\
\hline & & 入 & /NT & & \\
\hline
\end{tabular}


顾垒，闻丞，罗玫，王吴，吕植. 中国最受关注濒危物种保护现状快速评价的新方法探讨. 生物多样性，2015，23(5)：583-590. http://www biodiversity-science. net/CN/article/downloadArticleFile. do?attachType=PDF\&id=10075

\begin{tabular}{|c|c|c|c|c|c|}
\hline \multirow[t]{2}{*}{ Eucommia ulmoides } & 杜仲 & 未列 & 近危 & 李周岐 & 秋水仙素处理杜仲种子诱导多倍体的研究 \\
\hline & & 入 & /NT & & \\
\hline \multirow[t]{2}{*}{ Eucommia ulmoides } & 杜仲 & 未列 & 近危 & 李岩 & 热激启动子驱动基因删除及 ipt 基因遗传转化杜仲的研究 \\
\hline & & 入 & /NT & & \\
\hline \multirow[t]{2}{*}{ Eucommia ulmoides } & 杜仲 & 未列 & 近危 & 文建雷 & 三种杜仲无性系抗旱性比较 \\
\hline & & 入 & /NT & & \\
\hline \multirow[t]{2}{*}{ Eucommia ulmoides } & 杜仲 & 未列 & 近危 & 陈继富 & 沙藏及播期对杜仲种子萌芽及幼苗生长影响的研究 \\
\hline & & 入 & $/ \mathrm{NT}$ & & \\
\hline \multirow[t]{2}{*}{ Eucommia ulmoides } & 杜仲 & 未列 & 近危 & 李勇军 & 杉木杜仲混交林中杜仲平茬对比试验初报 \\
\hline & & 入 & /NT & & \\
\hline \multirow[t]{2}{*}{ Eucommia ulmoides } & 杜仲 & 未列 & 近危 & 董娟娥 & 陕北黄土丘陵区不同立地条件对杜仲生长及某些生理特性的影响 \\
\hline & & 入 & /NT & & \\
\hline \multirow[t]{2}{*}{ Eucommia ulmoides } & 杜仲 & 未列 & 近危 & 胡景江 & 陕北黄土丘陵区杜仲的生长规律与生理特性研究 \\
\hline & & 入 & $/ \mathrm{NT}$ & & \\
\hline \multirow[t]{2}{*}{ Eucommia ulmoides } & 杜仲 & 未列 & 近危 & 陈竹君 & 陕南杜仲林地土壤营养状况及施肥效应 \\
\hline & & 入 & /NT & & \\
\hline \multirow[t]{2}{*}{ Eucommia ulmoides } & 杜仲 & 未列 & 近危 & 白梅 & 陕西产杜仲中绿原酸含量测定研究 \\
\hline & & 入 & /NT & & \\
\hline Eucommia ulmoides & 杜仲 & 未列 & 近危 & 何景峰 & 陕西杜仲研究、开发现状及对策 \\
\hline
\end{tabular}


顾垒，闻丞，罗玫，王吴，吕植. 中国最受关注濒危物种保护现状快速评价的新方法探讨. 生物多样性，2015，23(5)：583-590. http://www. biodiversity-science. net/CN/article/downloadArticleFile. do?attachType=PDF\&id=10075

\begin{tabular}{|c|c|c|c|c|c|}
\hline & & 入 & /NT & & \\
\hline \multirow[t]{2}{*}{ Eucommia ulmoides } & 杜仲 & 未列 & 近危 & 袁云香 & 生长素对杜仲愈伤组织诱导及增殖的影响 \\
\hline & & 入 & /NT & & \\
\hline \multirow[t]{2}{*}{ Eucommia ulmoides } & 杜仲 & 未列 & 近危 & 杜红岩 & 施肥对果园化栽培条件下杜仲生长和结果的影响 \\
\hline & & 入 & /NT & & \\
\hline \multirow[t]{2}{*}{ Eucommia ulmoides } & 杜仲 & 未列 & 近危 & 董娟娥 & 水分对杜仲截干萌条光合特性及生长的影响 \\
\hline & & 入 & /NT & & \\
\hline \multirow[t]{2}{*}{ Eucommia ulmoides } & 杜仲 & 未列 & 近危 & 郭宝林 & 四倍体杜仲光合特性的研究 \\
\hline & & 入 & /NT & & \\
\hline \multirow[t]{2}{*}{ Eucommia ulmoides } & 杜仲 & 未列 & 近危 & 郭宝林 & 四倍体与二倍体杜仲生长_抗寒及主要药物成分的比较研究 \\
\hline & & 入 & /NT & & \\
\hline \multirow[t]{2}{*}{ Eucommia ulmoides } & 杜仲 & 未列 & 近危 & 刘开德 & 提高杜仲环剥成活率再生率和出皮量的试验研究 \\
\hline & & 入 & /NT & & \\
\hline \multirow[t]{2}{*}{ Eucommia ulmoides } & 杜仲 & 未列 & 近危 & 刘红云 & 土壤水分对杜仲生理特性和有效成分的影响 \\
\hline & & 入 & /NT & & \\
\hline \multirow[t]{2}{*}{ Eucommia ulmoides } & 杜仲 & 未列 & 近危 & 张劲松 & 土壤水分胁迫对杜仲叶片光合及水分利用特征的影响 \\
\hline & & 入 & /NT & & \\
\hline \multirow[t]{2}{*}{ Eucommia ulmoides } & 杜仲 & 未列 & 近危 & 徐咏梅 & 外源激素对杜仲次生代谢物含量的影响 \\
\hline & & 入 & /NT & & \\
\hline
\end{tabular}


顾垒，闻丞，罗玫，王吴，吕植. 中国最受关注濒危物种保护现状快速评价的新方法探讨. 生物多样性，2015，23(5)：583-590. http://www biodiversity-science. net/CN/article/downloadArticleFile. do?attachType=PDF\&id=10075

\begin{tabular}{|c|c|c|c|c|c|}
\hline \multirow[t]{2}{*}{ Eucommia ulmoides } & 杜仲 & 未列 & 近危 & 苏印泉 & 外源激素对杜仲胶含量和相对分子质量的影响 \\
\hline & & 入 & /NT & & \\
\hline \multirow[t]{2}{*}{ Eucommia ulmoides } & 杜仲 & 未列 & 近危 & 苏印泉 & 外源激素影响杜仲叶中次生代谢物含量的研究 \\
\hline & & 入 & $/ \mathrm{NT}$ & & \\
\hline \multirow[t]{2}{*}{ Eucommia ulmoides } & 杜仲 & 未列 & 近危 & 赵德刚 & 温度、pH 对杜仲抗真菌蛋白抗菌活性的影响 \\
\hline & & 入 & /NT & & \\
\hline \multirow[t]{2}{*}{ Eucommia ulmoides } & 杜仲 & 未列 & 近危 & 贾恢先 & 沿黄灌溉盐渍区杜仲引种的研究 \\
\hline & & 入 & $/ \mathrm{NT}$ & & \\
\hline \multirow[t]{2}{*}{ Eucommia ulmoides } & 杜仲 & 未列 & 近危 & 苏印泉 & 叶林模式杜仲生物量的动态研究 \\
\hline & & 入 & /NT & & \\
\hline \multirow[t]{2}{*}{ Eucommia ulmoides } & 杜仲 & 未列 & 近危 & 赵泾峰 & 一年生杜仲平茬枝木材纤维形态与密度的研究 \\
\hline & & 入 & /NT & & \\
\hline \multirow[t]{2}{*}{ Eucommia ulmoides } & 杜仲 & 未列 & 近危 & 黄宏文 & 一株具有特异 AFLP 指纹图谱的杜仲古树 \\
\hline & & 入 & $/ \mathrm{NT}$ & & \\
\hline \multirow[t]{2}{*}{ Eucommia ulmoides } & 杜仲 & 未列 & 近危 & 马柏林 & 医用激素与植物生长调节剂对杜仲皮增厚效应的比较研究 \\
\hline & & 入 & /NT & & \\
\hline \multirow[t]{2}{*}{ Eucommia ulmoides } & 杜仲 & 未列 & 近危 & 何泼 & 乙酸对杜仲愈伤组织胶含量的影响 \\
\hline & & 入 & /NT & & \\
\hline Eucommia ulmoides & 杜仲 & 未列 & 近危 & 王亚琴 & 引种地与原产地杜仲叶次生代谢物含量比较 \\
\hline
\end{tabular}


顾垒，闻丞，罗玫，王吴，吕植. 中国最受关注濒危物种保护现状快速评价的新方法探讨. 生物多样性，2015，23(5)：583-590. http://www. biodiversity-science. net/CN/article/downloadArticleFile. do?attachType=PDF\&id=10075

\begin{tabular}{|c|c|c|c|c|c|}
\hline & & 入 & /NT & & \\
\hline \multirow[t]{2}{*}{ Eucommia ulmoides } & 杜仲 & 未列 & 近危 & 王亚琴 & 影响杜仲悬浮细胞生产桃叶珊瑚式因素的研究 \\
\hline & & 入 & /NT & & \\
\hline \multirow[t]{2}{*}{ Eucommia ulmoides } & 杜仲 & 未列 & 近危 & 孙敏 & 应用正交设计建立杜仲无菌苗快速繁育体系 \\
\hline & & 入 & /NT & & \\
\hline \multirow[t]{2}{*}{ Eucommia ulmoides } & 杜仲 & 未列 & 近危 & 汪盛 & 用 AFM 研究杜仲抗真菌蛋白的晶体生长 \\
\hline & & 入 & /NT & & \\
\hline \multirow[t]{2}{*}{ Eucommia ulmoides } & 杜仲 & 未列 & 近危 & 马志杰 & 豫北浅山丘陵区杜仲引种栽培初步调查 \\
\hline & & 入 & /NT & & \\
\hline \multirow[t]{2}{*}{ Eucommia ulmoides } & 杜仲 & 未列 & 近危 & 苏印泉 & 栽培方式对杜仲皮次生代谢物含量的影响 \\
\hline & & 入 & /NT & & \\
\hline \multirow[t]{2}{*}{ Eucommia ulmoides } & 杜仲 & 未列 & 近危 & 刘月凤 & 张家界杜仲提取物的毒理学研究 \\
\hline & & 入 & /NT & & \\
\hline \multirow[t]{2}{*}{ Eucommia ulmoides } & 杜仲 & 未列 & 近危 & 马玉花 & 中国不同地区杜仲 rDNA 的 ITS 序列分析 \\
\hline & & 入 & /NT & & \\
\hline \multirow[t]{2}{*}{ Eucommia ulmoides } & 杜仲 & 未列 & 近危 & 马玉花 & 中国不同地区杜仲的遗传变异研究 \\
\hline & & 入 & /NT & & \\
\hline \multirow[t]{2}{*}{ Eucommia ulmoides } & 杜仲 & 未列 & 近危 & 马金花 & 重庆产杜仲叶的质量及指纹图谱研究 \\
\hline & & 入 & /NT & & \\
\hline
\end{tabular}


顾垒，闻丞，罗玫，王吴，吕植. 中国最受关注濒危物种保护现状快速评价的新方法探讨. 生物多样性，2015，23(5)：583-590. http://www. biodiversity-science. net/CN/article/downloadArticleFile. do?attachType=PDF\&id=10075

\begin{tabular}{|c|c|c|c|c|c|}
\hline \multirow[t]{2}{*}{ Eucommia ulmoides } & 杜仲 & 未列 & 近危 & 彭少兵 & 紫叶杜仲叶色变异研究 \\
\hline & & 入 & /NT & & \\
\hline \multirow[t]{2}{*}{ Eucommia ulmoides } & 杜仲 & 未列 & 近危 & 袁光宇 & 遵义县杜仲夜蛾的生物学特性观察及防治措施 \\
\hline & & 入 & $/ \mathrm{NT}$ & & \\
\hline \multirow[t]{2}{*}{ Euptelea pleiospermum } & 领春木 & 未列 & 无危 & M. JIANG & Development and characterization of 14 polymorphic microsatellite loci in the endangered tree \\
\hline & & 入 & $/ \mathrm{LC}$ & & Euptelea pleiospermum (Eupteleaceae) \\
\hline \multirow[t]{2}{*}{ Euptelea pleiospermum } & 领春木 & 未列 & 无危 & Mingxi Jiang & Landscape Genetic Structure of a Streamside Tree Species Euptelea pleiospermum \\
\hline & & 入 & $/ \mathrm{LC}$ & & (Eupteleaceae): Contrasting Roles of River Valley and Mountain Ridge \\
\hline \multirow[t]{2}{*}{ Euptelea pleiospermum } & 领春木 & 未列 & 无危 & Mingxi Jiang & Limited genetic impacts of habitat fragmentation in an old rare relict tree, Euptelea \\
\hline & & 入 & $/ \mathrm{LC}$ & & pleiospermum (Eupteleaceae) \\
\hline \multirow[t]{3}{*}{ Euptelea pleiospermum } & 领春木 & 未列 & 无危 & MingXiJiang & Relationships betweenenvironmentandmountainriparianplantcommunities associated \\
\hline & & 入 & $/ \mathrm{LC}$ & & withtworaretertiary-relicttreespecies, Euptelea pleiospermum (Eupteleaceae) and \\
\hline & & & & & Cercidiphyllum japonicum (Cercidiphyllaceae) \\
\hline \multirow[t]{2}{*}{ Euptelea pleiospermum } & 领春木 & 未列 & 无危 & Mingxi Jiang & Transient and asymptotic demographics of the riparian species Euptelea pleiospermum in the \\
\hline & & 入 & $/ \mathrm{LC}$ & & Shennongjia area, central China \\
\hline \multirow[t]{2}{*}{ Euptelea pleiospermum } & 领春木 & 未列 & 无危 & 田胜尼 & 安徽天堂寨领春木群落结构研究 \\
\hline & & 入 & $/ \mathrm{LC}$ & & \\
\hline \multirow[t]{2}{*}{ Euptelea pleiospermum } & 领春木 & 未列 & 无危 & 江明喜 & 从空间分布特征认识珍稀植物领春木的种群动态 \\
\hline & & 入 & $/ \mathrm{LC}$ & & \\
\hline
\end{tabular}


顾垒，闻丞，罗玫，王吴，吕植. 中国最受关注濒危物种保护现状快速评价的新方法探讨. 生物多样性，2015，23(5)：583-590. http://www biodiversity-science. net/CN/article/downloadArticleFile. do?attachType=PDF\&id=10075

\begin{tabular}{|c|c|c|c|c|c|}
\hline \multirow[t]{2}{*}{ Euptelea pleiospermum } & 领春木 & 未列 & 无危 & 田士林 & 多子领春木 RAPD 反应体系的研究 \\
\hline & & 入 & $/ \mathrm{LC}$ & & \\
\hline \multirow[t]{2}{*}{ Euptelea pleiospermum } & 领春木 & 未列 & 无危 & 陈坤浩 & 贵州大方喀斯特区领春木群落特征研究 \\
\hline & & 入 & $/ \mathrm{LC}$ & & \\
\hline \multirow[t]{2}{*}{ Euptelea pleiospermum } & 领春木 & 未列 & 无危 & 何平 & 子遗珍稀植物领春木群落生态和遗传多样性研究 \\
\hline & & 入 & $/ \mathrm{LC}$ & & \\
\hline \multirow[t]{2}{*}{ Euptelea pleiospermum } & 领春木 & 未列 & 无危 & 田先华 & 领春木(领春木科)导管穿孔板中纹孔膜残余的观察 \\
\hline & & 入 & $/ \mathrm{LC}$ & & \\
\hline \multirow[t]{2}{*}{ Euptelea pleiospermum } & 领春木 & 未列 & 无危 & 贺超锋 & 领春木的生长发育规律 \\
\hline & & 入 & $/ \mathrm{LC}$ & & \\
\hline \multirow[t]{2}{*}{ Euptelea pleiospermum } & 领春木 & 未列 & 无危 & 任毅 & 领春木茎次生木质部中导管穿孔板的变异 \\
\hline & & 入 & $/ \mathrm{LC}$ & & \\
\hline \multirow[t]{2}{*}{ Euptelea pleiospermum } & 领春木 & 未列 & 无危 & 任毅 & 领春木属_领春木科_的形态_结构_发育及系统位置的研究 \\
\hline & & 入 & $/ \mathrm{LC}$ & & \\
\hline \multirow[t]{2}{*}{ Euptelea pleiospermum } & 领春木 & 未列 & 无危 & 陈发菊 & 领春木体细胞胚胎发生及植株再生 \\
\hline & & 入 & $/ \mathrm{LC}$ & & \\
\hline \multirow[t]{2}{*}{ Euptelea pleiospermum } & 领春木 & 未列 & 无危 & 左娟 & 领春木幼苗形态及生物量分配对光环境的响应 \\
\hline & & 入 & $/ \mathrm{LC}$ & & \\
\hline Euptelea pleiospermum & 领春木 & 未列 & 无危 & 周佑勋 & 领春木种子休眠与萌发特性 \\
\hline
\end{tabular}


顾垒，闻丞，罗玫，王吴，吕植. 中国最受关注濒危物种保护现状快速评价的新方法探讨. 生物多样性，2015，23(5)：583-590. http://www. biodiversity-science. net/CN/article/downloadArticleFile. do?attachType=PDF\&id=10075

\begin{tabular}{|c|c|c|c|c|c|}
\hline & & 入 & $/ \mathrm{LC}$ & & \\
\hline \multirow[t]{2}{*}{ Euptelea pleiospermum } & 领春木 & 未列 & 无危 & 吴建国 & 气候变化对 7 种乔木植物分布的潜在影响 \\
\hline & & 入 & $/ \mathrm{LC}$ & & \\
\hline \multirow[t]{2}{*}{ Euptelea pleiospermum } & 领春木 & 未列 & 无危 & 江明喜 & 气候变暖对领春木沿海拔分布潜在影响的实验模拟 \\
\hline & & 入 & $/ \mathrm{LC}$ & & \\
\hline \multirow[t]{2}{*}{ Euptelea pleiospermum } & 领春木 & 未列 & 无危 & 方国富 & 清凉峰自然保护区领春木的分布调查与育苗试验 \\
\hline & & 入 & $/ \mathrm{LC}$ & & \\
\hline \multirow[t]{2}{*}{ Euptelea pleiospermum } & 领春木 & 未列 & 无危 & 江明喜 & 神农架地区河岸带中领春木种群数量特征与空间分布格局 \\
\hline & & 入 & $/ \mathrm{LC}$ & & \\
\hline \multirow[t]{2}{*}{ Euptelea pleiospermum } & 领春木 & 未列 & 无危 & 马建伟 & 小陇山林区濒危植物领春木种群生命表分析 \\
\hline & & 入 & $/ \mathrm{LC}$ & & \\
\hline \multirow[t]{2}{*}{ Euptelea pleiospermum } & 领春木 & 未列 & 无危 & 姬慧娟 & 小寨子沟自然保护区领春木种群数量特征与空间分布格局 \\
\hline & & 入 & $/ \mathrm{LC}$ & & \\
\hline \multirow[t]{2}{*}{ Euptelea pleiospermum } & 领春木 & 未列 & 无危 & 杨拴温 & 豫西熊耳山领春木分布规律调查研究 \\
\hline & & 入 & $/ \mathrm{LC}$ & & \\
\hline \multirow[t]{2}{*}{ Euptelea pleiospermum } & 领春木 & 未列 & 无危 & 邢世海 & 珍稀濒危植物领春木愈伤组织的培养 \\
\hline & & 入 & $/ \mathrm{LC}$ & & \\
\hline \multirow[t]{2}{*}{ Euptelea pleiospermum } & 领春木 & 未列 & 无危 & 江子糯 & 珍稀古老树种领春木的特性及繁殖技术 \\
\hline & & 入 & $/ \mathrm{LC}$ & & \\
\hline
\end{tabular}


顾垒，闻丞，罗玫，王昊，吕植. 中国最受关注濒危物种保护现状快速评价的新方法探讨．生物多样性，2015，23(5)：583-590.

\begin{tabular}{|c|c|c|c|c|c|}
\hline Eurycorymbus cavaleriei & 伞花木 & II & $\begin{array}{l}\text { 近危 } \\
\text { /NT }\end{array}$ & Hai-Bin Qu & A Novel Meroterpene from Eurycorymbus cavaleriei \\
\hline Eurycorymbus cavaleriei & 伞花木 & II & $\begin{array}{l}\text { 近危 } \\
\text { /NT }\end{array}$ & 乙引 & Ca2+ 胁迫下伞花木和华山松脯氨酸及可溶性蛋白质含量的变化 \\
\hline Eurycorymbus cavaleriei & 伞花木 & II & $\begin{array}{l}\text { 近危 } \\
\text { /NT }\end{array}$ & Hongwen Huang & $\begin{array}{l}\text { Contemporary pollen flow and mating patterns of a subtropical canopy tree Eurycorymbus } \\
\text { cavaleriei in a fragmented agricultural landscape }\end{array}$ \\
\hline Eurycorymbus cavaleriei & 半花木 & II & $\begin{array}{l}\text { 近危 } \\
\text { /NT }\end{array}$ & Zhongjun Ma & Eleven New Triterpenes from Eurycorymbus cavaleriei \\
\hline Eurycorymbus cavaleriei & 半花木 & II & $\begin{array}{l}\text { 近危 } \\
\text { /NT }\end{array}$ & H. HUANG & $\begin{array}{l}\text { Isolation and characterization of microsatellite loci in Eurycorymbus cavaleriei, a dioecious } \\
\text { endemic tree species in China }\end{array}$ \\
\hline Eurycorymbus cavaleriei & 伞花木 & II & $\begin{array}{l}\text { 近危 } \\
\text { /NT }\end{array}$ & Hongwen Huang & $\begin{array}{l}\text { Neither Biased Sex Ratio nor Spatial Segregation of the Sexes in the Subtropical Dioecious } \\
\text { Tree Eurycorymbus cavaleriei (Sapindaceae) }\end{array}$ \\
\hline Eurycorymbus cavaleriei & 伞花木 & II & $\begin{array}{l}\text { 近危 } \\
\text { /NT }\end{array}$ & Ming Kang & $\begin{array}{l}\text { Novel polymorphic microsatellite loci and patterns of pollen-mediated gene flow in an ex situ } \\
\text { population of Eurycorymbus cavaleriei (Sapindaceae) as revealed by categorical paternity } \\
\text { analysis }\end{array}$ \\
\hline Eurycorymbus cavaleriei & 半花木 & II & $\begin{array}{l}\text { 近危 } \\
\text { /NT }\end{array}$ & Hongwen Huang & $\begin{array}{l}\text { Refugia within refugia: the case study of a canopy tree (Eurycorymbus cavaleriei) in } \\
\text { subtropical China }\end{array}$ \\
\hline Eurycorymbus cavaleriei & 伞花木 & II & $\begin{array}{l}\text { 近危 } \\
\text { /NT }\end{array}$ & Zhongjun Ma & $\begin{array}{l}\text { Seven new benzeneacetic acid derivatives and their quinone reductase activity from } \\
\text { Eurycorymbus cavaleriei }\end{array}$ \\
\hline
\end{tabular}


顾垒，闻丞，罗玫，王吴，吕植. 中国最受关注濒危物种保护现状快速评价的新方法探讨. 生物多样性，2015，23(5)：583-590. http://www biodiversity-science. net/CN/article/downloadArticleFile. do?attachType=PDF\&id=10075

\begin{tabular}{|c|c|c|c|c|c|}
\hline Eurycorymbus cavaleriei & 伞花木 & II & $\begin{array}{l}\text { 近危 } \\
\text { /NT }\end{array}$ & Zhongjun Ma & $\begin{array}{l}\text { Three lignans and one coumarinolignoid with quinone reductase activity from Eurycorymbus } \\
\text { cavaleriei }\end{array}$ \\
\hline Eurycorymbus cavaleriei & 伞花木 & II & $\begin{array}{l}\text { 近危 } \\
\text { /NT }\end{array}$ & 黄宏文 & 雌雄异株稀有植物伞花木( Eurycorymbus caraleriei)自然居群的等位酶遗传多样性研究 \\
\hline Eurycorymbus cavaleriei & 伞花木 & II & $\begin{array}{l}\text { 近危 } \\
\text { /NT }\end{array}$ & 朱祥福 & 九连山伞花木群落结构特征分析 \\
\hline Eurycorymbus cavaleriei & 伞花木 & II & $\begin{array}{l}\text { 近危 } \\
\text { /NT }\end{array}$ & 薛建辉 & 喀斯特地区 4 种造林幼苗的抗旱性评价 \\
\hline Eurycorymbus cavaleriei & 伞花木 & II & $\begin{array}{l}\text { 近危 } \\
\text { /NT }\end{array}$ & 吴显芝 & 模拟干旱胁迫对喀斯特森林喜钻树种伞花木生理特征的影响 \\
\hline Eurycorymbus cavaleriei & 伞花木 & II & $\begin{array}{l}\text { 近危 } \\
\text { /NT }\end{array}$ & 吴显芝 & 模拟干旱胁迫下喀斯特地区 4 种幼苗的生理特征比较 \\
\hline Eurycorymbus cavaleriei & 伞花木 & II & $\begin{array}{l}\text { 近危 } \\
\text { /NT }\end{array}$ & 韦小丽 & 伞花木 1 年生播种苗生长规律及育苗技术研究 \\
\hline Eurycorymbus cavaleriei & 伞花木 & II & $\begin{array}{l}\text { 近危 } \\
\text { /NT }\end{array}$ & 耿云芬 & 伞花木播种育苗技术 \\
\hline Eurycorymbus cavaleriei & 伞花木 & II & $\begin{array}{l}\text { 近危 } \\
\text { /NT }\end{array}$ & 陈慈禄 & 伞花木木材物理力学性质初步分析 \\
\hline Eurycorymbus cavaleriei & 伞花木 & II & 近危 & 乙引 & 外源 $\mathrm{Ca} 2+$ 对伞花木和大白杜鹃生长及矿质元素含量代谢的影响 \\
\hline
\end{tabular}


顾垒，闻丞，罗玫，王吴，吕植. 中国最受关注濒危物种保护现状快速评价的新方法探讨. 生物多样性，2015，23(5)：583-590. http://www. biodiversity-science. net/CN/article/downloadArticleFile. do?attachType=PDF\&id=10075

Eurycorymbus cavalerie

伞花木

伞花木

猎隼

Falco cherrug

Falco cherrug

Falco cherrug

Falco cherrug

Falco cherrug

Falco cherrug

Falco cherrug
猎隼

猎隼
危

$/ \mathrm{N}$

近危

翏明

II 濒危 李 叶

II 濒危 赵忠俊

/EN

II 濒危 牟迈

II 濒危 姚积生

/EN

II

濒危

II

/EN

II 濒危 乌日空
喜钙和嫌钙植物对外源 $\mathrm{Ca} 2+$ 的生长生理响应

珍稀树种伞花木组织培养技术研究

阿尔金山国家级自然保护区食肉鸟兽调查

阿夏自然保护区鸟类资源现状及保护策略

敦煌阳关自然保护区乌类多样性调查及分析

甘肃安南坝野骆驼国家级自然保护区野骆驼现状及其保护对策

河北滦河口湿地鸟类多样性调查

昆仑山中段初冬鸟类调查及其多样性分析

内蒙古阿尔山市北部鸟类区系组成及群落结构 
顾垒，闻丞，罗玫，王吴，吕植. 中国最受关注濒危物种保护现状快速评价的新方法探讨. 生物多样性，2015，23(5)：583-590. http://www. biodiversity-science. net/CN/article/downloadArticleFile. do?attachType=PDF\&id=10075

\begin{tabular}{|c|c|c|c|c|c|}
\hline Falco cherrug & 猎隼 & II & $\begin{array}{l}\text { 濒危 } \\
\text { /EN }\end{array}$ & 陈文婧 & 内蒙古乌兰浩特市鸟类区系组成及群落结构分析 \\
\hline Falco cherrug & 猎隼 & II & $\begin{array}{l}\text { 濒危 } \\
\text { /EN }\end{array}$ & 李元刚 & 宁夏贺兰山东麓荒漠草原区春季鸟类群落结构及多样性 \\
\hline Falco cherrug & 猎隼 & II & $\begin{array}{l}\text { 濒危 } \\
\text { /EN }\end{array}$ & 李元刚 & 宁夏贺兰山国家级自然保护区鸟类区系组成及其特征研究 \\
\hline Falco cherrug & 猎隼 & II & $\begin{array}{l}\text { 濒危 } \\
\text { /EN }\end{array}$ & 杨贵军 & 宁夏罗山国家级自然保护区鸟类区系特征及群落结构 \\
\hline Falco cherrug & 猎隼 & II & $\begin{array}{l}\text { 濒危 } \\
\text { /EN }\end{array}$ & 王加园 & 宁夏苏峪口国家森林公园景观资源调查评价 \\
\hline Falco cherrug & 猎隼 & II & $\begin{array}{l}\text { 濒危 } \\
\text { /EN }\end{array}$ & 龚大洁 & 岐山县南北两山鸟类调查与 $G-F$ 指数分析 \\
\hline Falco cherrug & 猎隼 & II & $\begin{array}{l}\text { 濒危 } \\
\text { /EN }\end{array}$ & 符建荣 & 四川海子山自然保护区鸟类资源及区系 \\
\hline Falco cherrug & 猎隼 & II & $\begin{array}{l}\text { 濒危 } \\
\text { /EN }\end{array}$ & 符建荣 & 四川长沙贡玛自然保护区的鸟类资源 \\
\hline Falco cherrug & 猎隼 & II & $\begin{array}{l}\text { 濒危 } \\
\text { /EN }\end{array}$ & 赵忠 & 肃南肃北草原野生动物资源调查研究 \\
\hline Falco cherrug & 猎隼 & II & 濒危 & 罗否 & 太白山北坡冬、春季鸟类群落多样性 \\
\hline
\end{tabular}


顾垒，闻丞，罗玫，王吴，吕植. 中国最受关注濒危物种保护现状快速评价的新方法探讨. 生物多样性，2015，23(5)：583-590. http://www. biodiversity-science. net/CN/article/downloadArticleFile. do?attachType=PDF\&id=10075

\begin{tabular}{|c|c|c|c|c|c|}
\hline & & & /EN & & \\
\hline \multirow[t]{2}{*}{ Falco cherrug } & 猎隼 & II & 濒危 & 杨乐 & 西藏 “一江两河” 流域鸟类资源调查初报 \\
\hline & & & /EN & & \\
\hline \multirow[t]{2}{*}{ Falco cherrug } & 猎隼 & II & 濒危 & 杨乐 & 西藏山南地区鸟类资源调查初报 \\
\hline & & & /EN & & \\
\hline \multirow[t]{2}{*}{ Falco cherrug } & 猎隼 & II & 濒危 & 蔡新斌 & 新疆阿尔金山国家级自然保护区湿地资源调查初报 \\
\hline & & & /EN & & \\
\hline \multirow[t]{2}{*}{ Falco cherrug } & 猎隼 & II & 濒危 & 徐峰 & 新疆准噶尔盆地东南缘荒漠环境的鸟类 \\
\hline & & & /EN & & \\
\hline \multirow[t]{2}{*}{ Falco cherrug } & 猎隼 & II & 濒危 & 吴逸群 & 新疆准噶尔盆地东缘猎隼的繁殖生态 ${ }^{1}$ \\
\hline & & & /EN & & \\
\hline \multirow[t]{2}{*}{ Falco cherrug } & 猎隼 & II & 濒危 & 李长看 & 郑州黄河湿地省级自然保护区鸟类区系和多样性 \\
\hline & & & $/ \mathrm{EN}$ & & \\
\hline \multirow[t]{3}{*}{ Fargesia rufa } & 青川箭竹 & 未列 & 未评 & 张远涁 & CO2 浓度升高和模拟氮沉降对青川箭竹叶营养质量的影响 \\
\hline & & 入 & 价 & & \\
\hline & & & $/ \mathrm{NE}$ & & \\
\hline \multirow[t]{2}{*}{ Felis bieti } & 荒漠猫 & II & 易危 & Fuwen Wei & Distribution and conservation status of the endemic Chinese mountain cat Felis bieti \\
\hline & & & /VU & & \\
\hline Felis bieti & 荒漠猫 & II & 易危 & 李文靖 & 荒漠猫脊椎和管状骨的观察 \\
\hline
\end{tabular}


顾垒，闻丞，罗玫，王吴，吕植. 中国最受关注濒危物种保护现状快速评价的新方法探讨. 生物多样性，2015，23(5)：583-590. http://www. biodiversity-science. net/CN/article/downloadArticleFile. do?attachType=PDF\&id=10075

\begin{tabular}{|c|c|c|c|c|c|}
\hline & & & $/ \mathrm{VU}$ & & \\
\hline \multirow[t]{2}{*}{ Felis bieti } & 荒漠猫 & II & 易危 & 朱丽琳 & 人工饲养条件下荒漠猫的饲养与繁殖管理 \\
\hline & & & $/ \mathrm{VU}$ & & \\
\hline \multirow[t]{3}{*}{ Ficedula elisae } & 绿背姬暡 & 未列 & 数据 & 赵健 & 江西省鸟类新纪录一一一云南柳莺、绿背姬叙 \\
\hline & & 入 & 不足 & & \\
\hline & & & $/ \mathrm{DD}$ & & \\
\hline \multirow[t]{3}{*}{ Firmiana major } & 云南梧桐 & 未列 & 野外 & 余志祥 & 濒危植物云南梧桐( Firmiana major) 人工繁育研究 \\
\hline & & 入 & 灭绝 & & \\
\hline & & & $/ \mathrm{EW}$ & & \\
\hline \multirow[t]{3}{*}{ fulvetta striaticollis } & 高山雀鹤 & 未列 & 数据 & 陈燕 & 论四川道孚县传统藏文化对生物多样性保护的意义 \\
\hline & & 入 & 不足 & & \\
\hline & & & $/ \mathrm{DD}$ & & \\
\hline \multirow[t]{3}{*}{ fulvetta striaticollis } & 高山雀䴗 & 未列 & 数据 & 符建荣 & 米亚罗自然保护区的鸟类资源 \\
\hline & & 入 & 不足 & & \\
\hline & & & $/ \mathrm{DD}$ & & \\
\hline \multirow[t]{3}{*}{ fulvetta striaticollis } & 高山雀鹋 & 未列 & 数据 & 李忠秋 & 陕西老县城自然保护区的鸟类多样性及 G-F 指数分析 \\
\hline & & 入 & 不足 & & \\
\hline & & & $/ \mathrm{DD}$ & & \\
\hline fulvetta striaticollis & 高山雀觛 & 未列 & 数据 & 符建荣 & 四川海子山自然保护区鸟类资源及区系 \\
\hline
\end{tabular}


顾垒，闻丞，罗玫，王吴，吕植. 中国最受关注濒危物种保护现状快速评价的新方法探讨. 生物多样性，2015，23(5)：583-590. http://www. biodiversity-science. net/CN/article/downloadArticleFile. do?attachType=PDF\&id=10075

\begin{tabular}{|c|c|c|c|c|c|}
\hline & & 入 & 不足 & & \\
\hline & & & $/ \mathrm{DD}$ & & \\
\hline \multirow[t]{3}{*}{ fulvetta striaticollis } & 高山雀鹋 & 未列 & 数据 & 陈顺德 & 四川壤塘县绰斯甲河段鸟类资源初步调查及区系分析 \\
\hline & & 入 & 不足 & & \\
\hline & & & $/ \mathrm{DD}$ & & \\
\hline \multirow[t]{3}{*}{ fulvetta striaticollis } & 高山雀鹛 & 未列 & 数据 & 周友兵 & 四川小寨子沟自然保护区鸟类资源现状与保护 \\
\hline & & 入 & 不足 & & \\
\hline & & & $/ \mathrm{DD}$ & & \\
\hline \multirow[t]{3}{*}{ fulvetta striaticollis } & 高山雀鹋 & 未列 & 数据 & 张炎周 & 四川亿比措湿地生物地理特征与保护价值研究 \\
\hline & & 入 & 不足 & & \\
\hline & & & $/ \mathrm{DD}$ & & \\
\hline \multirow[t]{3}{*}{ fulvetta striaticollis } & 高山雀鹛 & 未列 & 数据 & 符建荣 & 四川长沙贡玛自然保护区的鸟类资源 \\
\hline & & 入 & 不足 & & \\
\hline & & & $/ \mathrm{DD}$ & & \\
\hline \multirow[t]{2}{*}{ Garcinia paucinervis } & & II & 濒危 & 曹坤芳 & 四种热带雨林树种光合和形态解剖特征对不同生长光强的适应 \\
\hline & & & /EN & & \\
\hline \multirow[t]{2}{*}{ Garrulax courtoisi } & 靛冠噪鹛 & 未列 & 极危 & 洪元华 & 鵌源黄喉噪鿬繁殖生境研究 \\
\hline & & 入 & /CR & & \\
\hline Garrulax courtoisi & 靛冠噪鹤 & 未列 & 极危 & 廖为明 & 鵌源黄喉噪鸤繁殖生态及其与村落风水林关系研究 \\
\hline
\end{tabular}


顾垒，闻丞，罗玫，王吴，吕植. 中国最受关注濒危物种保护现状快速评价的新方法探讨. 生物多样性，2015，23(5)：583-590. http://www. biodiversity-science. net/CN/article/downloadArticleFile. do?attachType=PDF\&id=10075

\begin{tabular}{|c|c|c|c|c|c|}
\hline & & 入 & /CR & & \\
\hline \multirow[t]{2}{*}{ Garrulax courtoisi } & 靛冠噪鹤 & 未列 & 极危 & 何芬奇 & 棨源鸟类纪录解析 \\
\hline & & 入 & /CR & & \\
\hline \multirow[t]{2}{*}{ Garrulax sukatschewi } & 黑额山噪鹛 & 未列 & 易危 & 金祥龙 & 阿夏自然保护区鸟类群落研究 \\
\hline & & 入 & /VU & & \\
\hline \multirow[t]{2}{*}{ Garrulax sukatschewi } & 黑额山噪眤 & 未列 & 易危 & 赵忠俊 & 阿夏自然保护区鸟类资源现状及保护策略 \\
\hline & & 入 & $/ \mathrm{VU}$ & & \\
\hline \multirow[t]{2}{*}{ Garrulax sukatschewi } & 黑额山噪鹤 & 未列 & 易危 & 陈昌笃 & 甘肃省麦积山景区一一一生态过渡带自然和文化遗产杰出范例 \\
\hline & & 入 & $/ \mathrm{VU}$ & & \\
\hline \multirow[t]{2}{*}{ Garrulax sukatschewi } & 黑额山噪鹤 & 未列 & 易危 & 张君 & 四川东阳沟自然保护区鸟类区系初步调查 \\
\hline & & 入 & $/ \mathrm{VU}$ & & \\
\hline \multirow[t]{2}{*}{ Garrulax sukatschewi } & 黑额山噪鹤 & 未列 & 易危 & 符建荣 & 四川千佛山自然保护区的鸟类资源 \\
\hline & & 入 & /VU & & \\
\hline \multirow[t]{2}{*}{ Garrulax sukatschewi } & 黑额山噪煝 & 未列 & 易危 & 符建荣 & 四川雪宝顶自然保护区的鸟类资源 \\
\hline & & 入 & /VU & & \\
\hline \multirow[t]{2}{*}{ Garrulax sukatschewi } & 黑额山噪倜 & 未列 & 易危 & 顾人和 & 王朗自然保护区的大自然景观类型分析与评价 \\
\hline & & 入 & /VU & & \\
\hline \multirow[t]{2}{*}{ Geoclemys reevesii } & 乌龟 & 未列 & 濒危 & 王家沛 & 乌龟肠道微生物对鱼病的抑菌作用研究_王家沛 \\
\hline & & 入 & $/ \mathrm{EN}$ & & \\
\hline
\end{tabular}


顾垒，闻丞，罗玫，王吴，吕植. 中国最受关注濒危物种保护现状快速评价的新方法探讨. 生物多样性，2015，23(5)：583-590. http://www biodiversity-science. net/CN/article/downloadArticleFile. do?attachType=PDF\&id=10075

\begin{tabular}{|c|c|c|c|c|c|}
\hline \multirow[t]{2}{*}{ Geoclemys reevesii } & 乌龟 & 未列 & 濒危 & 李能树 & 乌龟肠道微生物区系和排泄物抗菌研究_李能树 \\
\hline & & 入 & $/ \mathrm{EN}$ & & \\
\hline \multirow[t]{2}{*}{ Geoclemysreevesii } & 乌龟 & 未列 & 濒危 & 黄文 & 温度和光照对乌龟非肺呼吸耗氧量的影响_黄文 \\
\hline & & 入 & /EN & & \\
\hline \multirow[t]{2}{*}{ Geoclemysreevesii } & 乌龟 & 未列 & 濒危 & 印大中 & 乌龟缺氧潜水呼吸的耐受性及巴西龟血液生理生化特性的研究_詹球 \\
\hline & & 入 & /EN & & \\
\hline \multirow[t]{2}{*}{ Ginkgo biloba } & 银杏 & I & 濒危 & 梁红 & 32 个银杏品种的 RAPD 遗传多态性及其分类 \\
\hline & & & /EN & & \\
\hline \multirow[t]{2}{*}{ Ginkgo biloba } & 银杏 & I & 濒危 & 曹福亮 & 33 个银杏无性系种核形态特征分析 \\
\hline & & & /EN & & \\
\hline \multirow[t]{2}{*}{ Ginkgo biloba } & 银杏 & I & 濒危 & Xiao-Yong Chen & Assessing Genetic Diversity of Ginkgo biloba L. (Ginkgoaceae) Populations From China by \\
\hline & & & /EN & & RAPD Markers \\
\hline \multirow[t]{2}{*}{ Ginkgo biloba } & 银杏 & I & 濒危 & 朱宇林 & $\mathrm{Cd} 、 \mathrm{~Pb}$ 处理对银杏种子萌发的影响 \\
\hline & & & /EN & & \\
\hline \multirow[t]{2}{*}{ Ginkgo biloba } & 银杏 & I & 濒危 & 朱宇林 & $\mathrm{Cd} 、 \mathrm{~Pb}$ 对银杏根系离子微域分布影响研究 \\
\hline & & & /EN & & \\
\hline \multirow[t]{2}{*}{ Ginkgo biloba } & 银杏 & I & 濒危 & 曹福亮 & $\mathrm{Cd} 、 \mathrm{~Pb}$ 胁迫对银杏光合特性的影响 \\
\hline & & & /EN & & \\
\hline Ginkgo biloba & 银杏 & I & 濒危 & 朱宇林 & $\mathrm{Cd}$ 单一及其与 $\mathrm{Pb}$ 复合胁迫对银杏叶抗氧化保护酶活性的影响 \\
\hline
\end{tabular}


顾垒，闻丞，罗玫，王吴，吕植. 中国最受关注濒危物种保护现状快速评价的新方法探讨. 生物多样性，2015，23(5)：583-590. http://www biodiversity-science. net/CN/article/downloadArticleFile. do?attachType=PDF\&id=10075

Ginkgo biloba

银杏

银杏

Ginkgo biloba

Ginkgo biloba

银杏

Ginkgo biloba

银杏

Ginkgo biloba

Ginkgo biloba

Ginkgo biloba

Ginkgo biloba

Ginkgo biloba
濒危

Hai Lu

EN

I

I 频危Ｓ.-L.FU

濒危 Fuliang Cao

/EN

I 濒危 赵天宏

I 濒危 赵天宏

I 濒危 何兴元

EN

I 濒危

/EN

濒危 付士磊
Change of season-specific telomere lengths in Ginkgo biloba L.

Change of secondary metabolites in leaves of Ginkgo biloba L. in response to UV-B induction

Changes in effects of ozone exposure on growth, photosynthesis, and respiration of Ginkgo biloba in Shenyang urban area

Cloning and Expression of Stearoyl-ACP Desaturase and Two Oleate Desaturases Genes from Ginkgo biloba L.

CO_2 和 O_3 浓度升高及其复合作用对银杏光合机理的影响

$\mathrm{CO} 2$ 和 $\mathrm{O} 3$ 体积分数升高对银杏希尔反应活力和叶绿体 ATP 酶活性的影响

$\mathrm{CO} 2$ 浓度倍增对城市银杏(Ginkgo biloba)叶片膜脂过氧化与抗氧化酶活性的影响

$\mathrm{CO} 2$ 浓度短期倍增对银杏叶片光合特性的影响

$\mathrm{CO} 2$ 质量浓度对沈阳市银杏生长及光合固碳能力的影响 
顾垒，闻丞，罗玫，王昊，吕植。中国最受关注濒危物种保护现状快速评价的新方法探讨．生物多样性，2015，23(5)：583-590. http://www. biodiversity-science. net/CN/article/downloadArticleFile. do?attachType=PDF\&id=10075

\begin{tabular}{|c|c|c|c|c|c|}
\hline Ginkgo biloba & 银杏 & I & $\begin{array}{l}\text { 濒危 } \\
\text { /EN }\end{array}$ & Hai Lu & $\begin{array}{l}\text { Comparative analysis of telomeric restriction fragment lengths in different tissues of Ginkgo } \\
\text { biloba trees of different age }\end{array}$ \\
\hline Ginkgo biloba & 银杏 & I & $\begin{array}{l}\text { 濒危 } \\
\text { /EN }\end{array}$ & Yan LI & Cytoskeleton in Pollen and Pollen Tubes of Ginkgo biloba L. \\
\hline Ginkgo biloba & 银杏 & I & $\begin{array}{l}\text { 濒危 } \\
\text { /EN }\end{array}$ & Xueduan Liu & $\begin{array}{l}\text { Development and application of SCAR markers for sex identification in the dioecious species } \\
\text { Ginkgo biloba L. }\end{array}$ \\
\hline Ginkgo biloba & 银杏 & I & $\begin{array}{l}\text { 濒危 } \\
\text { /EN }\end{array}$ & C . L. LIAN & Development of microsatellite markers in ginkgo(Ginkgo biloba L.) \\
\hline Ginkgo biloba & 银杏 & I & $\begin{array}{l}\text { 濒危 } \\
\text { /EN }\end{array}$ & Xiao-Yong Chen & Development of polymorphic microsatellite markers for Ginkgo biloba L. by database mining \\
\hline Ginkgo biloba & 银杏 & I & $\begin{array}{l}\text { 濒危 } \\
\text { /EN }\end{array}$ & YUN-PENG ZHAO & Development of the First Chloroplast Microsatellite Loci in Ginkgo biloba (Ginkgoaceae) \\
\hline Ginkgo biloba & 银杏 & I & $\begin{array}{l}\text { 濒危 } \\
\text { /EN }\end{array}$ & Zhongming Zhang & $\begin{array}{l}\text { Developmental synchronization of male and female gametophytes in Ginkgo biloba and its } \\
\text { neck mother cell division prior to fertilization }\end{array}$ \\
\hline Ginkgo biloba & 银杏 & I & $\begin{array}{l}\text { 濒危 } \\
\text { /EN }\end{array}$ & 舒常庆 & DNA 分子标记在银杏中的应用 \\
\hline Ginkgo biloba & 银杏 & I & $\begin{array}{l}\text { 濒危 } \\
\text { /EN }\end{array}$ & XueMei Li & $\begin{array}{l}\text { Effects of elevated carbon dioxide and/or ozone on endogenous plant hormones in the leaves of } \\
\text { Ginkgo biloba }\end{array}$ \\
\hline Ginkgo biloba & 银杏 & I & 濒危 & Xingyuan He & Effects of Elevated $\mathrm{O} 3$ and/or Elevated CO2 on Lipid Peroxidation and Antioxidant Systems in \\
\hline
\end{tabular}


顾垒，闻丞，罗玫，王吴，吕植. 中国最受关注濒危物种保护现状快速评价的新方法探讨. 生物多样性，2015，23(5)：583-590. http://www, biodiversity-science, net/CN/article/downloadArticleFile. do?attachType=PDF\&id=10075

\begin{tabular}{|c|c|c|c|c|c|}
\hline & & & /EN & & Ginkgo biloba Leaves \\
\hline \multirow[t]{2}{*}{ Ginkgo biloba } & 银杏 & I & 濒危 & Cheng-Xin Fu & Eleven novel microsatellite markers developed from the living fossil Ginkgo biloba \\
\hline & & & /EN & & (Ginkgoaceae) \\
\hline \multirow[t]{2}{*}{ Ginkgo biloba } & 银杏 & I & 濒危 & Fuliang Cao & Expression of Selected Ginkgo biloba Heat Shock Protein Genes After Cold Treatment Could \\
\hline & & & /EN & & Be Induced by Other Abiotic Stress \\
\hline \multirow[t]{2}{*}{ Ginkgo biloba } & 银杏 & I & 濒危 & Shuiyuan Cheng & Expression patterns of a cinnamyl alcohol dehydrogenase gene involved in lignin biosynthesis \\
\hline & & & /EN & & and environmental stress in Ginkgo biloba \\
\hline \multirow{2}{*}{ Ginkgo biloba } & 银杏 & I & 濒危 & Fuliang Cao & Expression patterns of an isoflavone reductase-like gene and its possible roles in secondary \\
\hline & & & /EN & & metabolism in Ginkgo biloba \\
\hline \multirow[t]{2}{*}{ Ginkgo biloba } & 银杏 & I & 濒危 & Da-Hui Li & Formation of archegonium chamber is associated with nucellar-cell programmed cell death in \\
\hline & & & /EN & & Ginkgo biloba \\
\hline \multirow[t]{2}{*}{ Ginkgo biloba } & 银杏 & I & 濒危 & X-Y Chen & Genetic variation of Ginkgo biloba L. (Ginkgoaceae) based on cpDNA PCR-RFLPs: inference \\
\hline & & & /EN & & of glacial refugia \\
\hline \multirow[t]{2}{*}{ Ginkgo biloba } & 银杏 & I & 濒危 & Cheng-Xin Fu & Glacial Refugia of Ginkgo biloba and Human Impact on Its Genetic Diversity: Evidence from \\
\hline & & & /EN & & Chloroplast DNA \\
\hline \multirow[t]{2}{*}{ Ginkgo biloba } & 银杏 & I & 濒危 & Yi Shi & Impact of Elevated CO2 and O3 Concentrations on Biogenic Volatile Organic Compounds \\
\hline & & & /EN & & Emissions from Ginkgo biloba \\
\hline \multirow[t]{2}{*}{ Ginkgo biloba } & 银杏 & I & 濒危 & Lingfang Du & Isolation of RNA of high quality and yield from Ginkgo biloba leaves \\
\hline & & & /EN & & \\
\hline
\end{tabular}


顾垒，闻丞，罗玫，王昊，吕植。中国最受关注濒危物种保护现状快速评价的新方法探讨．生物多样性，2015，23(5)：583-590. http://www biodiversity-science. net/CN/article/downloadArticleFile. do?attachType=PDF\&id=10075

\begin{tabular}{|c|c|c|c|c|c|}
\hline Ginkgo biloba & 银杏 & I & $\begin{array}{l}\text { 濒危 } \\
\text { /EN }\end{array}$ & Feng Xu & $\begin{array}{l}\text { Isolation, characterization, and function analysis of a flavonol synthase gene from Ginkgo } \\
\text { biloba }\end{array}$ \\
\hline Ginkgo biloba & 银杏 & I & $\begin{array}{l}\text { 濒危 } \\
\text { /EN }\end{array}$ & S.Y. Cheng & $\begin{array}{l}\text { Molecular cloning and characterization of GbDXS and GbGGPPS gene promoters from Ginkgo } \\
\text { biloba }\end{array}$ \\
\hline Ginkgo biloba & 银杏 & I & $\begin{array}{l}\text { 濒危 } \\
\text { /EN }\end{array}$ & Kexuan Tang & Molecular cloning, characterization and expression of a novel Asr gene from Ginkgo biloba \\
\hline Ginkgo biloba & 银杏 & I & $\begin{array}{l}\text { 濒危 } \\
\text { /EN }\end{array}$ & Kexuan Tang & $\begin{array}{l}\text { Molecular cloning, characterization and expression of a novel jasmonate-dependent defensin } \\
\text { gene from Ginkgo biloba }\end{array}$ \\
\hline Ginkgo biloba & 银杏 & I & $\begin{array}{l}\text { 濒危 } \\
\text { /EN }\end{array}$ & 程水源 & $\mathrm{NaCl}$ 胁迫对银杏光合作用的影响 \\
\hline Ginkgo biloba & 银杏 & I & $\begin{array}{l}\text { 濒危 } \\
\text { /EN }\end{array}$ & Maojun Xu & $\begin{array}{l}\text { Ozone induces flavonol production of Ginkgo biloba cells dependently on nitrate } \\
\text { reductase-mediated nitric oxide signaling }\end{array}$ \\
\hline Ginkgo biloba & 银杏 & I & $\begin{array}{l}\text { 濒危 } \\
\text { /EN }\end{array}$ & Cheng-Xin Fu & $\begin{array}{l}\text { Phylogeography of a living fossil: Pleistocene glaciations forced Ginkgo biloba L. } \\
\text { (Ginkgoaceae) into two refuge areas in China with limited subsequent postglacial expansion }\end{array}$ \\
\hline Ginkgo biloba & 银杏 & I & $\begin{array}{l}\text { 濒危 } \\
\text { /EN }\end{array}$ & Li Wang & The mechanism of pollination drop withdrawal in Ginkgo biloba L. \\
\hline Ginkgo biloba & 银杏 & I & $\begin{array}{l}\text { 濒危 } \\
\text { /EN }\end{array}$ & CHENG Shui-Yuan & Time Course of Expression of Chalcone Synthase Gene in Ginkgo biloba \\
\hline Ginkgo biloba & 银杏 & I & 濒危 & 程水源 & 矮壮素对银杏叶片光合代谢与萜内酯生物合成的影响 \\
\hline
\end{tabular}


顾垒，闻丞，罗玫，王吴，吕植. 中国最受关注濒危物种保护现状快速评价的新方法探讨. 生物多样性，2015，23(5)：583-590. http://www. biodiversity-science. net/CN/article/downloadArticleFile. do?attachType=PDF\&id=10075

\begin{tabular}{|c|c|c|c|c|c|}
\hline & & & /EN & & \\
\hline \multirow[t]{2}{*}{ Ginkgo biloba } & 银杏 & I & 濒危 & 田秀玲 & 鞍山地区银杏茎腐病病情调查初报 \\
\hline & & & $/$ EN & & \\
\hline \multirow[t]{2}{*}{ Ginkgo biloba } & 银杏 & I & 濒危 & 刘桂林 & 北方部分城市银杏树夏季焦叶影响因子的研究 \\
\hline & & & /EN & & \\
\hline \multirow[t]{2}{*}{ Ginkgo biloba } & 银杏 & I & 濒危 & 曹福亮 & 不同氮素形态及配比对生育后期银杏叶品质的影响 \\
\hline & & & /EN & & \\
\hline \multirow[t]{2}{*}{ Ginkgo biloba } & 银杏 & I & 濒危 & 王国霞 & 不同地区银杏古树开花生物学特性研究 1一一开花物候期和花穗特征分析 \\
\hline & & & /EN & & \\
\hline \multirow[t]{2}{*}{ Ginkgo biloba } & 银杏 & I & 濒危 & 王国霞 & 不同地区银杏古树开花生物学特性研究 2-一花药及花粉生物学特征分析 \\
\hline & & & /EN & & \\
\hline \multirow[t]{2}{*}{ Ginkgo biloba } & 银杏 & I & 濒危 & 曹福亮 & 不同地区银杏花粉黄酮和内酯含量的差异性 \\
\hline & & & /EN & & \\
\hline \multirow[t]{2}{*}{ Ginkgo biloba } & 银杏 & I & 濒危 & 赵春香 & 不同后熟条件对银杏种子萌发的影响 \\
\hline & & & /EN & & \\
\hline \multirow[t]{2}{*}{ Ginkgo biloba } & 银杏 & I & 濒危 & 付玉东 & 不同生态因子对银杏生长的影响 \\
\hline & & & /EN & & \\
\hline \multirow[t]{2}{*}{ Ginkgo biloba } & 银杏 & I & 濒危 & 何丙辉 & 不同养分条件对银杏枝种群构件生长影响研究 \\
\hline & & & /EN & & \\
\hline
\end{tabular}


顾垒，闻丞，罗玫，王吴，吕植. 中国最受关注濒危物种保护现状快速评价的新方法探讨. 生物多样性，2015，23(5)：583-590. http://www. biodiversity-science. net/CN/article/downloadArticleFile. do?attachType=PDF\&id=10075

\begin{tabular}{|c|c|c|c|c|c|}
\hline Ginkgo biloba & 银杏 & I & $\begin{array}{l}\text { 濒危 } \\
\text { /EN }\end{array}$ & 姚延梼 & 不同叶面肥料对银杏花芽分化期生理特性的影响 \\
\hline Ginkgo biloba & 银杏 & I & $\begin{array}{l}\text { 濒危 } \\
\text { /EN }\end{array}$ & 杨永川 & 残存银杏群落的结构及种群更新特征 \\
\hline Ginkgo biloba & 银杏 & I & $\begin{array}{l}\text { 濒危 } \\
\text { /EN }\end{array}$ & 孙绪艮 & 茶黄蓟马危害对银杏生长及生理生化的影响 \\
\hline Ginkgo biloba & 银杏 & I & $\begin{array}{l}\text { 濒危 } \\
\text { /EN }\end{array}$ & 赵天宏 & 臭氧浓度升高对银杏光合作用的影响 \\
\hline Ginkgo biloba & 银杏 & I & $\begin{array}{l}\text { 濒危 } \\
\text { /EN }\end{array}$ & 王双明 & 雌雄银杏植株叶片生理生化特性的比较研究 \\
\hline Ginkgo biloba & 银杏 & I & $\begin{array}{l}\text { 濒危 } \\
\text { /EN }\end{array}$ & 何兴元 & 大气 CO2 和 $\mathrm{O} 3$ 浓度升高对银杏构件生长的影响 \\
\hline Ginkgo biloba & 银杏 & I & $\begin{array}{l}\text { 濒危 } \\
\text { /EN }\end{array}$ & 何兴元 & 大气中 CO2、O3 浓度升高对银杏成年叶片气孔数量特征的影响 \\
\hline Ginkgo biloba & 银杏 & I & $\begin{array}{l}\text { 濒危 } \\
\text { /EN }\end{array}$ & 张往祥 & 氮磷钾三要素对银杏光合性能的影响 \\
\hline Ginkgo biloba & 银杏 & I & $\begin{array}{l}\text { 濒危 } \\
\text { /EN }\end{array}$ & 郁万文 & 低温胁迫下银杏活性氧代谢与膜伤害的关系 \\
\hline Ginkgo biloba & 银杏 & I & 濒危 & 孙守家 & 断根程度、时间以及抑制蒸腾措施对银杏树体水分状况的影响 \\
\hline
\end{tabular}


顾垒，闻丞，罗玫，王吴，吕植. 中国最受关注濒危物种保护现状快速评价的新方法探讨. 生物多样性，2015，23(5)：583-590. http://www. biodiversity-science. net/CN/article/downloadArticleFile. do?attachType=PDF\&id=10075

\begin{tabular}{|c|c|c|c|c|c|}
\hline & & & /EN & & \\
\hline \multirow[t]{2}{*}{ Ginkgo biloba } & 银杏 & I & 濒危 & 高俊平 & 断根处理对银杏树体水力特征及生长的影响 \\
\hline & & & $/$ EN & & \\
\hline \multirow[t]{2}{*}{ Ginkgo biloba } & 银杏 & I & 濒危 & 曹帮华 & 断胚根处理对银杏种子发芽成苗影响的研究 \\
\hline & & & /EN & & \\
\hline \multirow[t]{2}{*}{ Ginkgo biloba } & 银杏 & I & 濒危 & 陈国祥 & 干旱对银杏生理生化特性及叶绿体超微结构的影响 \\
\hline & & & /EN & & \\
\hline \multirow[t]{2}{*}{ Ginkgo biloba } & 银杏 & I & 濒危 & 陈国祥 & 干旱胁迫对银杏衰老期叶片生理生化特性的影响 \\
\hline & & & /EN & & \\
\hline \multirow[t]{2}{*}{ Ginkgo biloba } & 银杏 & I & 濒危 & 曹福亮 & 干旱胁迫对银杏叶类黄酮年动态变化的影响 \\
\hline & & & /EN & & \\
\hline \multirow[t]{2}{*}{ Ginkgo biloba } & 银杏 & I & 濒危 & 陈国祥 & 干旱胁迫对银杏叶片部分生理过程的影响 \\
\hline & & & /EN & & \\
\hline \multirow[t]{2}{*}{ Ginkgo biloba } & 银杏 & I & 濒危 & 陈国祥 & 干旱胁迫对银杏叶片光合系统 II 荧光特性的影响 \\
\hline & & & /EN & & \\
\hline \multirow[t]{2}{*}{ Ginkgo biloba } & 银杏 & I & 濒危 & 曹福亮 & 干旱胁迫对银杏叶萜内酯年动态变化的影响 \\
\hline & & & /EN & & \\
\hline \multirow[t]{2}{*}{ Ginkgo biloba } & 银杏 & I & 濒危 & 曹福亮 & 高温对银杏品种主要生理指标的影响 \\
\hline & & & /EN & & \\
\hline
\end{tabular}


顾垒，闻丞，罗玫，王吴，吕植. 中国最受关注濒危物种保护现状快速评价的新方法探讨. 生物多样性，2015，23(5)：583-590. http://www. biodiversity-science. net/CN/article/downloadArticleFile. do?attachType=PDF\&id=10075

\begin{tabular}{|c|c|c|c|c|c|}
\hline Ginkgo biloba & 银杏 & I & $\begin{array}{l}\text { 濒危 } \\
\text { /EN }\end{array}$ & 张成军 & 高温和干旱对银杏光合作用、叶片中黄酮苷和萜类内酯含量的影响 \\
\hline Ginkgo biloba & 银杏 & I & $\begin{array}{l}\text { 濒危 } \\
\text { /EN }\end{array}$ & 张往祥 & 高温期间水分对银杏光合作用和光化学效率的影响 \\
\hline Ginkgo biloba & 银杏 & I & $\begin{array}{l}\text { 濒危 } \\
\text { /EN }\end{array}$ & 曹福亮 & 高温胁迫下银杏形态及生理生化指标的变化 \\
\hline Ginkgo biloba & 银杏 & I & $\begin{array}{l}\text { 濒危 } \\
\text { /EN }\end{array}$ & 曹福亮 & 高温胁迫下银杏叶片部分渗透调节物质的动态变化 \\
\hline Ginkgo biloba & 银杏 & I & $\begin{array}{l}\text { 濒危 } \\
\text { /EN }\end{array}$ & 丁彦芬 & 古银杏复壮技术的研究 \\
\hline Ginkgo biloba & 银杏 & I & $\begin{array}{l}\text { 濒危 } \\
\text { /EN }\end{array}$ & 赵琦 & 古银杏和古槐衰弱特性的研究 \\
\hline Ginkgo biloba & 银杏 & I & $\begin{array}{l}\text { 濒危 } \\
\text { /EN }\end{array}$ & 曹福亮 & 古银杏雄株的 ISSR 遗传多样性分析 \\
\hline Ginkgo biloba & 银杏 & I & $\begin{array}{l}\text { 濒危 } \\
\text { /EN }\end{array}$ & 曹福亮 & 古银杏雄株花粉超微形态特征类型 \\
\hline Ginkgo biloba & 银杏 & I & $\begin{array}{l}\text { 濒危 } \\
\text { /EN }\end{array}$ & 曹福亮 & 古银杏雄株遗传多样性的 ISSR 分析及花粉用优良单株初步选育研究 \\
\hline Ginkgo biloba & 银杏 & I & 濒危 & 王利 & 古银杏种质亲缘关系及遗传多样性的 ISSR 分析 \\
\hline
\end{tabular}


顾垒，闻丞，罗玫，王吴，吕植. 中国最受关注濒危物种保护现状快速评价的新方法探讨. 生物多样性，2015，23(5)：583-590. http://www. biodiversity-science. net/CN/article/downloadArticleFile. do?attachType=PDF\&id=10075

\begin{tabular}{|c|c|c|c|c|c|}
\hline & & & /EN & & \\
\hline \multirow[t]{2}{*}{ Ginkgo biloba } & 银杏 & I & 濒危 & 王利 & 古银杏种质遗传关系及特异种质的 AFLP 分析 \\
\hline & & & $/$ EN & & \\
\hline \multirow[t]{2}{*}{ Ginkgo biloba } & 银杏 & I & 濒危 & 张黎华 & 关于气温对银杏生长影响的探讨 \\
\hline & & & /EN & & \\
\hline \multirow[t]{2}{*}{ Ginkgo biloba } & 银杏 & I & 濒危 & 张往祥 & 光强对银杏光合作用和光化学效率的影响 \\
\hline & & & /EN & & \\
\hline \multirow[t]{2}{*}{ Ginkgo biloba } & 银杏 & I & 濒危 & 冷平生 & 光强与光质对银杏光合作用及黄酮苷与萜类内酯含量的影响 \\
\hline & & & /EN & & \\
\hline \multirow[t]{2}{*}{ Ginkgo biloba } & 银杏 & I & 濒危 & 王华田 & 光照强度对银杏叶片发育及黄酮和内酯含量的影响 \\
\hline & & & /EN & & \\
\hline \multirow[t]{2}{*}{ Ginkgo biloba } & 银杏 & I & 濒危 & 梁红 & 广东银杏遗传多态性的 RAPD 分析 \\
\hline & & & /EN & & \\
\hline \multirow[t]{2}{*}{ Ginkgo biloba } & 银杏 & I & 濒危 & 唐紹清 & 桂林古银杏的保护遗传学研究 \\
\hline & & & /EN & & \\
\hline \multirow[t]{2}{*}{ Ginkgo biloba } & 银杏 & I & 濒危 & 舒常庆 & 湖北省大别山区银杏古树种核变异的研究 \\
\hline & & & /EN & & \\
\hline \multirow[t]{2}{*}{ Ginkgo biloba } & 银杏 & I & 濒危 & 舒常庆 & 湖北省三大区域群体银杏古树遗传多样性的 ISSR 分析 \\
\hline & & & /EN & & \\
\hline
\end{tabular}


顾垒，闻丞，罗玫，王吴，吕植. 中国最受关注濒危物种保护现状快速评价的新方法探讨. 生物多样性，2015，23(5)：583-590. http://www. biodiversity-science. net/CN/article/downloadArticleFile. do?attachType=PDF\&id=10075

\begin{tabular}{|c|c|c|c|c|c|}
\hline Ginkgo biloba & 银杏 & I & $\begin{array}{l}\text { 濒危 } \\
\text { /EN }\end{array}$ & 张往祥 & 环境因子对银杏光合作用的影响 \\
\hline Ginkgo biloba & 银杏 & I & $\begin{array}{l}\text { 濒危 } \\
\text { /EN }\end{array}$ & 顾鹏展 & 黄刺蛾对银杏的危害和防治 \\
\hline Ginkgo biloba & 银杏 & I & $\begin{array}{l}\text { 濒危 } \\
\text { /EN }\end{array}$ & 郁万文 & 黄叶银杏叶色发育及光合特性研究 \\
\hline Ginkgo biloba & 银杏 & I & $\begin{array}{l}\text { 濒危 } \\
\text { /EN }\end{array}$ & 傅承新 & 基于 cpDNA 单倍型的银杏群体遗传与谱系分析 \\
\hline Ginkgo biloba & 银杏 & I & $\begin{array}{l}\text { 濒危 } \\
\text { /EN }\end{array}$ & 王义强 & 基于 EST 银杏光合作用相关基因表达分析 \\
\hline Ginkgo biloba & 银杏 & I & $\begin{array}{l}\text { 濒危 } \\
\text { /EN }\end{array}$ & 陈力耕 & 建立银杏遗传转化受体系统的研究 \\
\hline Ginkgo biloba & 银杏 & I & $\begin{array}{l}\text { 濒危 } \\
\text { /EN }\end{array}$ & 江洪 & 子遗植物银杏(Ginkgo biloba L. )伴性光合生理特征与进化生态 \\
\hline Ginkgo biloba & 银杏 & I & $\begin{array}{l}\text { 濒危 } \\
\text { /EN }\end{array}$ & 江洪 & 子遗植物银杏(Ginkgo biloba L. ) 雌雄株水分生理特征研究 \\
\hline Ginkgo biloba & 银杏 & I & $\begin{array}{l}\text { 濒危 } \\
\text { /EN }\end{array}$ & 傅承新 & 子遗植物银杏的分子亲缘地理学研究 \\
\hline Ginkgo biloba & 银杏 & I & 濒危 & 傅承新 & 子遗植物银杏群体遗传多样性的 ISSR 分析 \\
\hline
\end{tabular}


顾垒，闻丞，罗玫，王吴，吕植. 中国最受关注濒危物种保护现状快速评价的新方法探讨. 生物多样性，2015，23(5)：583-590. http://www. biodiversity-science. net/CN/article/downloadArticleFile. do?attachType=PDF\&id=10075

\begin{tabular}{|c|c|c|c|c|c|}
\hline & & & /EN & & \\
\hline \multirow[t]{2}{*}{ Ginkgo biloba } & 银杏 & I & 濒危 & 傅承新 & 子遗植物银杏遗传多样性研究 \\
\hline & & & /EN & & \\
\hline \multirow[t]{2}{*}{ Ginkgo biloba } & 银杏 & I & 濒危 & 梁惠凌 & 近年广西银杏病虫害发生及防治对策 \\
\hline & & & /EN & & \\
\hline \multirow[t]{2}{*}{ Ginkgo biloba } & 银杏 & I & 濒危 & 周霞 & 空气污染对银杏和白蜡树上康氏粉蚧种群的影响 \\
\hline & & & /EN & & \\
\hline \multirow[t]{2}{*}{ Ginkgo biloba } & 银杏 & I & 濒危 & 王晓梅 & 利用 AFLP 技术笛选与银杏性别相关的分子标记 \\
\hline & & & /EN & & \\
\hline \multirow[t]{2}{*}{ Ginkgo biloba } & 银杏 & I & 濒危 & 赵天宏 & 连续两个生长季大气 CO2 浓度升高对银杏希尔反应活力和叶绿体 ATP 酶活性的影响 \\
\hline & & & /EN & & \\
\hline \multirow[t]{2}{*}{ Ginkgo biloba } & 银杏 & I & 濒危 & 陈国祥 & 两个银杏品种叶片衰老过程中叶绿体功能特性的比较 \\
\hline & & & /EN & & \\
\hline \multirow[t]{2}{*}{ Ginkgo biloba } & 银杏 & I & 濒危 & 邢世岩 & 临沂生生园复干银杏生长特性 \\
\hline & & & /EN & & \\
\hline \multirow[t]{2}{*}{ Ginkgo biloba } & 银杏 & I & 濒危 & 邓仕槐 & 模拟酸雨胁迫对银杏部分生理特性的影响 \\
\hline & & & /EN & & \\
\hline \multirow[t]{2}{*}{ Ginkgo biloba } & 银杏 & I & 濒危 & 赵世杰 & 强光胁迫下银杏叶片的光抑制及其防御机制 \\
\hline & & & /EN & & \\
\hline
\end{tabular}


顾垒，闻丞，罗玫，王吴，吕植. 中国最受关注濒危物种保护现状快速评价的新方法探讨. 生物多样性，2015，23(5)：583-590. http://www. biodiversity-science. net/CN/article/downloadArticleFile. do?attachType=PDF\&id=10075

\begin{tabular}{|c|c|c|c|c|c|}
\hline Ginkgo biloba & 银杏 & I & $\begin{array}{l}\text { 濒危 } \\
\text { /EN }\end{array}$ & 于新 & 曲霉及穗霉侵染对银杏种子采后生理的影响 \\
\hline Ginkgo biloba & 银杏 & I & $\begin{array}{l}\text { 濒危 } \\
\text { /EN }\end{array}$ & 张志翔 & 三峡库区银杏天然种群的发现及起源分析 \\
\hline Ginkgo biloba & 银杏 & I & $\begin{array}{l}\text { 濒危 } \\
\text { /EN }\end{array}$ & 王月 & 沈阳地区银杏病害的种类及其防治措施 \\
\hline Ginkgo biloba & 银杏 & I & $\begin{array}{l}\text { 濒危 } \\
\text { /EN }\end{array}$ & 丁之恩 & 生长在不同类型绿地的银杏光合生理特性的研究 \\
\hline Ginkgo biloba & 银杏 & I & $\begin{array}{l}\text { 濒危 } \\
\text { /EN }\end{array}$ & 汪贵斌 & 水分胁迫对银杏叶片叶肉细胞超微结构的影响 \\
\hline Ginkgo biloba & 银杏 & I & $\begin{array}{l}\text { 濒危 } \\
\text { /EN }\end{array}$ & 何嵩涛 & 水涝胁迫对银杏内源激素和细胞溶质含量的影响 \\
\hline Ginkgo biloba & 银杏 & I & $\begin{array}{l}\text { 濒危 } \\
\text { /EN }\end{array}$ & 曹福亮 & 水杨酸对银杏幼苗抗高温胁迫能力的影响 \\
\hline Ginkgo biloba & 银杏 & I & $\begin{array}{l}\text { 濒危 } \\
\text { /EN }\end{array}$ & 龚国淑 & 四川银杏叶部真菌病害调查与银杏轮斑病的研究 \\
\hline Ginkgo biloba & 银杏 & I & $\begin{array}{l}\text { 濒危 } \\
\text { /EN }\end{array}$ & 李忠芳 & 酸胁迫对银杏幼树生长状况的影响初探 \\
\hline Ginkgo biloba & 银杏 & I & 濒危 & 舒常庆 & 随州古银杏遗传多样性的 RAPD 及 ISSR 分析 \\
\hline
\end{tabular}


顾垒，闻丞，罗玫，王吴，吕植. 中国最受关注濒危物种保护现状快速评价的新方法探讨. 生物多样性，2015，23(5)：583-590. http://www. biodiversity-science. net/CN/article/downloadArticleFile. do?attachType=PDF\&id=10075

\begin{tabular}{|c|c|c|c|c|c|}
\hline & & & /EN & & \\
\hline \multirow[t]{2}{*}{ Ginkgo biloba } & 银杏 & I & 濒危 & 舒常庆 & 随州和安陆银杏古树种核变异的分子遗传基础 \\
\hline & & & $/$ EN & & \\
\hline \multirow[t]{2}{*}{ Ginkgo biloba } & 银杏 & I & 濒危 & 林协 & 天目山银杏种群起源分析 \\
\hline & & & /EN & & \\
\hline \multirow[t]{2}{*}{ Ginkgo biloba } & 银杏 & I & 濒危 & 张光富 & 天目山自然保护区银杏天然种群生命表 \\
\hline & & & /EN & & \\
\hline \multirow[t]{2}{*}{ Ginkgo biloba } & 银杏 & I & 濒危 & 曹福亮 & 土壤水分含量对银杏光合特性的影响 \\
\hline & & & /EN & & \\
\hline \multirow[t]{2}{*}{ Ginkgo biloba } & 银杏 & I & 濒危 & 汪贵斌 & 土壤水分胁迫对银杏无机营养元素含量的影响 \\
\hline & & & /EN & & \\
\hline \multirow[t]{2}{*}{ Ginkgo biloba } & 银杏 & I & 濒危 & 王华田 & 土壤水分状况对苗期银杏生长及生理特性影响的研究 \\
\hline & & & /EN & & \\
\hline \multirow[t]{2}{*}{ Ginkgo biloba } & 银杏 & I & 濒危 & 任士福 & 温度对银杏光系统 II 光抑制的影响 \\
\hline & & & /EN & & \\
\hline \multirow[t]{2}{*}{ Ginkgo biloba } & 银杏 & I & 濒危 & 汪贵斌 & 温度和土壤水分对银杏叶黄酮类化合物积累的影响 \\
\hline & & & /EN & & \\
\hline \multirow[t]{2}{*}{ Ginkgo biloba } & 银杏 & I & 濒危 & 汪贵斌 & 温度和土壤水分对银杏叶类黄酮合成的影响 \\
\hline & & & /EN & & \\
\hline
\end{tabular}


顾垒，闻丞，罗玫，王吴，吕植. 中国最受关注濒危物种保护现状快速评价的新方法探讨. 生物多样性，2015，23(5)：583-590. http://www. biodiversity-science. net/CN/article/downloadArticleFile. do?attachType=PDF\&id=10075

\begin{tabular}{|c|c|c|c|c|c|}
\hline Ginkgo biloba & 银杏 & I & $\begin{array}{l}\text { 濒危 } \\
\text { /EN }\end{array}$ & 王义强 & 淹水胁迫下银杏主要生化指标的变化 \\
\hline Ginkgo biloba & 银杏 & I & $\begin{array}{l}\text { 濒危 } \\
\text { /EN }\end{array}$ & 凌裕平 & 盐胁迫对银杏根_叶主要元素和形态结构影响的研究 \\
\hline Ginkgo biloba & 银杏 & I & $\begin{array}{l}\text { 濒危 } \\
\text { /EN }\end{array}$ & 胥晓 & 盐胁迫下外源脯氨酸对银杏雌雄幼苗生理生化特性的影响 \\
\hline Ginkgo biloba & 银杏 & I & $\begin{array}{l}\text { 濒危 } \\
\text { /EN }\end{array}$ & 曹福亮 & 野生银杏资源群体遗传多样性的 RAPD 分析 \\
\hline Ginkgo biloba & 银杏 & I & $\begin{array}{l}\text { 濒危 } \\
\text { /EN }\end{array}$ & 邢世岩 & 叶䊏银杏 matK 和 ITS 序列分析及系统发育研究 \\
\hline Ginkgo biloba & 银杏 & I & $\begin{array}{l}\text { 濒危 } \\
\text { /EN }\end{array}$ & 邢世岩 & 叶杼银杏 trnS_trnG 序列测定与分析 \\
\hline Ginkgo biloba & 银杏 & I & $\begin{array}{l}\text { 濒危 } \\
\text { /EN }\end{array}$ & 邢世岩 & 叶籽银杏成熟种子脱落特性及种子形态指标分析 \\
\hline Ginkgo biloba & 银杏 & I & $\begin{array}{l}\text { 濒危 } \\
\text { /EN }\end{array}$ & 邢世岩 & 叶籽银杏的发生及其个体与系统发育研究述评 \\
\hline Ginkgo biloba & 银杏 & I & $\begin{array}{l}\text { 濒危 } \\
\text { /EN }\end{array}$ & 邢世岩 & 叶籽银杏的形态发生和比较形态学研究 \\
\hline Ginkgo biloba & 银杏 & I & 濒危 & 邢世岩 & 叶籽银杏拟胚珠的形态发育及变异特性 \\
\hline
\end{tabular}


顾垒，闻丞，罗玫，王吴，吕植. 中国最受关注濒危物种保护现状快速评价的新方法探讨. 生物多样性，2015，23(5)：583-590. http://www. biodiversity-science. net/CN/article/downloadArticleFile. do?attachType=PDF\&id=10075

\begin{tabular}{|c|c|c|c|c|c|}
\hline & & & /EN & & \\
\hline \multirow[t]{2}{*}{ Ginkgo biloba } & 银杏 & I & 濒危 & 邢世岩 & 叶籽银杏胚乳淀粉特性及其系统学意义 \\
\hline & & & $/$ EN & & \\
\hline \multirow[t]{2}{*}{ Ginkgo biloba } & 银杏 & I & 濒危 & 邢世岩 & 叶籽银杏肧珠解剖发育过程中细胞的程序性死亡（PCD） \\
\hline & & & /EN & & \\
\hline \multirow[t]{2}{*}{ Ginkgo biloba } & 银杏 & I & 濒危 & 邢世岩 & 叶籽银杏叶的解剖结构及气孔特性 \\
\hline & & & /EN & & \\
\hline \multirow[t]{2}{*}{ Ginkgo biloba } & 银杏 & I & 濒危 & 邢世岩 & 叶籽银杏叶生胚珠的发育组织化学研究 \\
\hline & & & /EN & & \\
\hline \multirow[t]{2}{*}{ Ginkgo biloba } & 银杏 & I & 濒危 & 邢世岩 & 叶籽银杏与普通银杏木材比较解剖研究 \\
\hline & & & /EN & & \\
\hline \multirow[t]{2}{*}{ Ginkgo biloba } & 银杏 & I & 濒危 & 邢世岩 & 叶籽银杏正常种子与叶生种子中种皮及内种皮超微结构观察 \\
\hline & & & /EN & & \\
\hline \multirow[t]{2}{*}{ Ginkgo biloba } & 银杏 & I & 濒危 & 王利 & 叶䊏银杏种质遗传多样性的 AFLP 评价 \\
\hline & & & /EN & & \\
\hline \multirow[t]{2}{*}{ Ginkgo biloba } & 银杏 & I & 濒危 & 邢世岩 & 叶籽银杏种质资源染色体核型分析及进化趋势 \\
\hline & & & /EN & & \\
\hline \multirow[t]{2}{*}{ Ginkgo biloba } & 银杏 & I & 濒危 & 张怡轩 & 一株银杏内生真菌代谢产物的初步研究 \\
\hline & & & /EN & & \\
\hline
\end{tabular}


顾垒，闻丞，罗玫，王吴，吕植. 中国最受关注濒危物种保护现状快速评价的新方法探讨. 生物多样性，2015，23(5)：583-590. http://www. biodiversity-science. net/CN/article/downloadArticleFile. do?attachType=PDF\&id=10075

\begin{tabular}{|c|c|c|c|c|c|}
\hline Ginkgo biloba & 银杏 & I & $\begin{array}{l}\text { 濒危 } \\
\text { /EN }\end{array}$ & 梁 红 & 银杏 GAPDH 基因序列的初步克隆 \\
\hline Ginkgo biloba & 银杏 & I & $\begin{array}{l}\text { 濒危 } \\
\text { /EN }\end{array}$ & 廖志华 & 银杏 GGPPS 转运肽与 GFP 融合基因表达载体的构建 \\
\hline Ginkgo biloba & 银杏 & I & $\begin{array}{l}\text { 濒危 } \\
\text { /EN }\end{array}$ & 陈立群 & 银杏( Ginkgo biloba) 叶表皮特征及其气孔的发育 \\
\hline Ginkgo biloba & 银杏 & I & $\begin{array}{l}\text { 濒危 } \\
\text { /EN }\end{array}$ & 李显祥 & 银杏(Ginkgo biloba L .)大孢子的发生和形成 \\
\hline Ginkgo biloba & 银杏 & I & $\begin{array}{l}\text { 濒危 } \\
\text { /EN }\end{array}$ & 刘宁 & 银杏(Ginkgo biloba L.)叶片三个发育阶段光合特性的研究 \\
\hline Ginkgo biloba & 银杏 & I & $\begin{array}{l}\text { 濒危 } \\
\text { /EN }\end{array}$ & 蔡庆生 & 银杏(Ginkgo biloba L.)幼苗叶片光合特性及气孔参数对 CO2 浓度升高的响应 \\
\hline Ginkgo biloba & 银杏 & I & $\begin{array}{l}\text { 濒危 } \\
\text { /EN }\end{array}$ & 周兴文 & 银杏(Ginkgo biloba)叶的形态发育与演化 \\
\hline Ginkgo biloba & 银杏 & I & $\begin{array}{l}\text { 濒危 } \\
\text { /EN }\end{array}$ & 陈小勇 & 银杏_Ginkgo biloba_叶绿体 DNA 系统地理学研究 \\
\hline Ginkgo biloba & 银杏 & I & $\begin{array}{l}\text { 濒危 } \\
\text { /EN }\end{array}$ & 江洪 & 银杏_杨梅和毛竹的水分生理特性研究 \\
\hline Ginkgo biloba & 银杏 & I & 濒危 & 邢世岩 & 银杏 AFLP 反应体系的建立及优化 \\
\hline
\end{tabular}


顾垒，闻丞，罗玫，王吴，吕植. 中国最受关注濒危物种保护现状快速评价的新方法探讨. 生物多样性，2015，23(5)：583-590. http://www. biodiversity-science. net/CN/article/downloadArticleFile. do?attachType=PDF\&id=10075

\begin{tabular}{|c|c|c|c|c|c|}
\hline & & & /EN & & \\
\hline \multirow[t]{2}{*}{ Ginkgo biloba } & 银杏 & I & 濒危 & 梁红 & 银杏 DNA 提取及 RAPD 分析 \\
\hline & & & $/$ EN & & \\
\hline \multirow[t]{2}{*}{ Ginkgo biloba } & 银杏 & I & 濒危 & 程水源 & 银杏 EPSPS 基因克隆及表达分析 \\
\hline & & & /EN & & \\
\hline \multirow[t]{2}{*}{ Ginkgo biloba } & 银杏 & I & 濒危 & 林毅 & 银杏 EST 序列中微卫星的分布特征 \\
\hline & & & /EN & & \\
\hline \multirow[t]{2}{*}{ Ginkgo biloba } & 银杏 & I & 濒危 & 李广平 & 银杏 FLS 基因启动子克隆及序列分析 \\
\hline & & & /EN & & \\
\hline \multirow[t]{2}{*}{ Ginkgo biloba } & 银杏 & I & 濒危 & 郑方强 & 银杏 GAP 采叶园害虫及天敌种群与群落特征和茶黄蓟马防治技术研究 \\
\hline & & & /EN & & \\
\hline \multirow[t]{2}{*}{ Ginkgo biloba } & 银杏 & I & 濒危 & 白素兰 & 银杏 ISSR-PCR 扩增反应体系的建立与优化 \\
\hline & & & /EN & & \\
\hline \multirow[t]{2}{*}{ Ginkgo biloba } & 银杏 & I & 濒危 & 曹福亮 & 银杏 ISSR-PCR 扩增反应体系的优化 \\
\hline & & & /EN & & \\
\hline \multirow[t]{2}{*}{ Ginkgo biloba } & 银杏 & I & 濒危 & 陈力耕 & 银杏 LEAFY 同源基因的分离克隆及其相关基础研究 \\
\hline & & & /EN & & \\
\hline \multirow[t]{2}{*}{ Ginkgo biloba } & 银杏 & I & 濒危 & 程水源 & 银杏 MECT_MECPs 基因启动子克隆及植物表达载体构建 \\
\hline & & & /EN & & \\
\hline
\end{tabular}


顾垒，闻丞，罗玫，王吴，吕植. 中国最受关注濒危物种保护现状快速评价的新方法探讨. 生物多样性，2015，23(5)：583-590. http://www. biodiversity-science. net/CN/article/downloadArticleFile. do?attachType=PDF\&id=10075

\begin{tabular}{|c|c|c|c|c|c|}
\hline Ginkgo biloba & 银杏 & I & $\begin{array}{l}\text { 濒危 } \\
\text { /EN }\end{array}$ & 舒常庆 & 银杏半同胞家系遗传多样性的 SRAP 研究 \\
\hline Ginkgo biloba & 银杏 & I & $\begin{array}{l}\text { 濒危 } \\
\text { /EN }\end{array}$ & 凌裕平 & 银杏狍粉学分类及营养生理特性研究 \\
\hline Ginkgo biloba & 银杏 & I & $\begin{array}{l}\text { 濒危 } \\
\text { /EN }\end{array}$ & 梁惠凌 & 银杏病虫害调查与综合防治对策 \\
\hline Ginkgo biloba & 银杏 & I & $\begin{array}{l}\text { 濒危 } \\
\text { /EN }\end{array}$ & 刘叔倩 & 银杏不同变异类型的 RAPD 指纹研究 \\
\hline Ginkgo biloba & 银杏 & I & $\begin{array}{l}\text { 濒危 } \\
\text { /EN }\end{array}$ & 王秀珍 & 银杏不同部位叶片叶绿素荧光参数动态变化规律研究 \\
\hline Ginkgo biloba & 银杏 & I & $\begin{array}{l}\text { 濒危 } \\
\text { /EN }\end{array}$ & 王改萍 & 银杏不同器官蛋白质动态变化的电泳分析 \\
\hline Ginkgo biloba & 银杏 & I & $\begin{array}{l}\text { 濒危 } \\
\text { /EN }\end{array}$ & 陈 颖 & 银杏不同外植体的细胞学观察——体胚发生不定芽诱导及不定根的发生过程 \\
\hline Ginkgo biloba & 银杏 & I & $\begin{array}{l}\text { 濒危 } \\
\text { /EN }\end{array}$ & 杨春生 & 银杏超小卷叶蛾生物学特性、防治技术研究与示范 \\
\hline Ginkgo biloba & 银杏 & I & $\begin{array}{l}\text { 濒危 } \\
\text { /EN }\end{array}$ & 张仲鸣 & 银杏成熟花粉的形态、侧向萌发及其意义 \\
\hline Ginkgo biloba & 银杏 & I & 濒危 & 陈鹏 & 银杏传粉生物学研究进展 \\
\hline
\end{tabular}


顾垒，闻丞，罗玫，王吴，吕植. 中国最受关注濒危物种保护现状快速评价的新方法探讨. 生物多样性，2015，23(5)：583-590. http://www. biodiversity-science. net/CN/article/downloadArticleFile. do?attachType=PDF\&id=10075

\begin{tabular}{|c|c|c|c|c|c|}
\hline & & & /EN & & \\
\hline \multirow[t]{2}{*}{ Ginkgo biloba } & 银杏 & I & 濒危 & 邢世岩 & 银杏垂乳个体发生及系统学意义 \\
\hline & & & $/$ EN & & \\
\hline \multirow[t]{2}{*}{ Ginkgo biloba } & 银杏 & I & 濒危 & 史继孔 & 银杏雌花芽分化期间内源激素、碳水化合物和矿质营养的变化 \\
\hline & & & /EN & & \\
\hline \multirow[t]{2}{*}{ Ginkgo biloba } & 银杏 & I & 濒危 & 吉成均 & 银杏雌配子体的发育和受精作用的研究现状 \\
\hline & & & /EN & & \\
\hline \multirow[t]{2}{*}{ Ginkgo biloba } & 银杏 & I & 濒危 & 陈鹏 & 银杏雌配子体发育过程中淀粉和蛋白质的积累与代谢 \\
\hline & & & /EN & & \\
\hline \multirow[t]{2}{*}{ Ginkgo biloba } & 银杏 & I & 濒危 & 王义强 & 银杏雌树成熟叶 cDNA 文库的构建 \\
\hline & & & /EN & & \\
\hline \multirow[t]{2}{*}{ Ginkgo biloba } & 银杏 & I & 濒危 & 陈鹏 & 银杏雌性生殖器官发育过程的显微观察 \\
\hline & & & /EN & & \\
\hline \multirow[t]{2}{*}{ Ginkgo biloba } & 银杏 & I & 濒危 & 邢世岩 & 银杏雌雄花芽差异表达基因的分析和性别相关基因的鉴定 \\
\hline & & & /EN & & \\
\hline \multirow[t]{2}{*}{ Ginkgo biloba } & 银杏 & I & 濒危 & 张万萍 & 银杏雌雄花芽分化期内源多胺的变化 \\
\hline & & & /EN & & \\
\hline \multirow[t]{2}{*}{ Ginkgo biloba } & 银杏 & I & 濒危 & 王晓梅 & 银杏雌雄基因组 D N A 间的差异性分析 \\
\hline & & & /EN & & \\
\hline
\end{tabular}


顾垒，闻丞，罗玫，王吴，吕植. 中国最受关注濒危物种保护现状快速评价的新方法探讨. 生物多样性，2015，23(5)：583-590. http://www. biodiversity-science. net/CN/article/downloadArticleFile. do?attachType=PDF\&id=10075

\begin{tabular}{|c|c|c|c|c|c|}
\hline Ginkgo biloba & 银杏 & I & $\begin{array}{l}\text { 濒危 } \\
\text { /EN }\end{array}$ & 陈鹏 & 银杏雌雄配子体发育及胚胎形成的研究进展 \\
\hline Ginkgo biloba & 银杏 & I & $\begin{array}{l}\text { 濒危 } \\
\text { /EN }\end{array}$ & 温伟庆 & 银杏雌雄株过氧化物酶和过氧化氢酶活性差异研究 \\
\hline Ginkgo biloba & 银杏 & I & $\begin{array}{l}\text { 濒危 } \\
\text { /EN }\end{array}$ & 钟川 & 银杏雌雄株花期内源激素和养分含量动态变化规律 \\
\hline Ginkgo biloba & 银杏 & I & $\begin{array}{l}\text { 濒危 } \\
\text { /EN }\end{array}$ & 温银元 & 银杏雌雄株间多种同工酶和磷酸腺苷含量的差异 \\
\hline Ginkgo biloba & 银杏 & I & $\begin{array}{l}\text { 濒危 } \\
\text { /EN }\end{array}$ & 程晓建 & 银杏雌雄株性别鉴别研究进展 \\
\hline Ginkgo biloba & 银杏 & I & $\begin{array}{l}\text { 濒危 } \\
\text { /EN }\end{array}$ & 陈鹏 & 银杏雌雄株性别鉴定的分子标记研究 \\
\hline Ginkgo biloba & 银杏 & I & $\begin{array}{l}\text { 濒危 } \\
\text { /EN }\end{array}$ & 陶俊 & 银杏雌雄株叶片光合特性、蒸腾速率及产量的比较研究 \\
\hline Ginkgo biloba & 银杏 & I & $\begin{array}{l}\text { 濒危 } \\
\text { /EN }\end{array}$ & 邢世岩 & 银杏雌株种质遗传关系的 AFLP 分析 \\
\hline Ginkgo biloba & 银杏 & I & $\begin{array}{l}\text { 濒危 } \\
\text { /EN }\end{array}$ & 陈伟 & 银杏单染色体文库的建立与鉴定 \\
\hline Ginkgo biloba & 银杏 & I & 濒危 & 吕柳新 & 银杏第 1 染色体 DNA 文库的构建 \\
\hline
\end{tabular}


顾垒，闻丞，罗玫，王吴，吕植. 中国最受关注濒危物种保护现状快速评价的新方法探讨. 生物多样性，2015，23(5)：583-590. http://www. biodiversity-science. net/CN/article/downloadArticleFile. do?attachType=PDF\&id=10075

\begin{tabular}{|c|c|c|c|c|c|}
\hline & & & /EN & & \\
\hline \multirow[t]{2}{*}{ Ginkgo biloba } & 银杏 & I & 濒危 & 何嵩涛 & 银杏对水涝胁迫的生理反应 ( I ) 一一一水涝胁迫对银杏膜脂过氧化作用及保护酶活性的 \\
\hline & & & /EN & & 影响 \\
\hline \multirow[t]{2}{*}{ Ginkgo biloba } & 银杏 & I & 濒危 & 曹福亮 & 银杏对土壤水分胁迫的响应 \\
\hline & & & /EN & & \\
\hline \multirow[t]{2}{*}{ Ginkgo biloba } & 银杏 & I & 濒危 & 曹福亮 & 银杏对锡!铅及其复合污染的生理响应与杭性研究 \\
\hline & & & /EN & & \\
\hline \multirow[t]{2}{*}{ Ginkgo biloba } & 银杏 & I & 濒危 & 彭方仁 & 银杏分泌腔的超微结构特征及与分泌物积累的关系 \\
\hline & & & /EN & & \\
\hline \multirow[t]{2}{*}{ Ginkgo biloba } & 银杏 & I & 濒危 & 彭方仁 & 银杏分泌腔发生和发育的解剖学研究 \\
\hline & & & /EN & & \\
\hline \multirow[t]{2}{*}{ Ginkgo biloba } & 银杏 & I & 濒危 & 王利 & 银杏观赏品种遗传关系的 AFLP 分析 \\
\hline & & & /EN & & \\
\hline \multirow[t]{2}{*}{ Ginkgo biloba } & 银杏 & $\mathrm{I}$ & 濒危 & 李吉跃 & 银杏光合生理生态特性研究 \\
\hline & & & /EN & & \\
\hline \multirow[t]{2}{*}{ Ginkgo biloba } & 银杏 & I & 濒危 & 杨模华 & 银杏光合特性的日变化 \\
\hline & & & /EN & & \\
\hline \multirow[t]{2}{*}{ Ginkgo biloba } & 银杏 & I & 濒危 & 李继军 & 银杏光合作用的研究 \\
\hline & & & /EN & & \\
\hline
\end{tabular}


顾垒，闻丞，罗玫，王吴，吕植. 中国最受关注濒危物种保护现状快速评价的新方法探讨. 生物多样性，2015，23(5)：583-590. http://www. biodiversity-science. net/CN/article/downloadArticleFile. do?attachType=PDF\&id=10075

\begin{tabular}{|c|c|c|c|c|c|}
\hline Ginkgo biloba & 银杏 & I & 濒危 & 吉成均 & 银杏和苏铁类植物的生殖特征比较 \\
\hline & & & /EN & & \\
\hline \multirow[t]{2}{*}{ Ginkgo biloba } & 银杏 & I & 濒危 & 邢世岩 & 银杏和叶籽银杏 microRNA 的鉴定与分析 \\
\hline & & & /EN & & \\
\hline \multirow[t]{2}{*}{ Ginkgo biloba } & 银杏 & I & 濒危 & 桂仁意 & 银杏核糖体 DNA 内转录间隔序列初步分析 \\
\hline & & & /EN & & \\
\hline \multirow[t]{2}{*}{ Ginkgo biloba } & 银杏 & I & 濒危 & 张红 & 银杏花粉及花粉管内细胞骨架的研究 \\
\hline & & & /EN & & \\
\hline \multirow[t]{2}{*}{ Ginkgo biloba } & 银杏 & I & 濒危 & 王莉 & 银杏花粉萌发生长与分枝式花粉管形成的观察 \\
\hline & & & /EN & & \\
\hline \multirow[t]{2}{*}{ Ginkgo biloba } & 银杏 & I & 濒危 & 李云 & 银杏花粉染色体加倍的研究 \\
\hline & & & /EN & & \\
\hline \multirow[t]{2}{*}{ Ginkgo biloba } & 银杏 & I & 濒危 & 曹福亮 & 银杏花粉研究进展 \\
\hline & & & /EN & & \\
\hline \multirow[t]{2}{*}{ Ginkgo biloba } & 银杏 & I & 濒危 & 姜华 & 银杏黄化病发病原因及致病机理研究 \\
\hline & & & /EN & & \\
\hline \multirow[t]{2}{*}{ Ginkgo biloba } & 银杏 & I & 濒危 & 曹福亮 & 银杏黄酮和木质素代谢相关基因功能分析 \\
\hline & & & /EN & & \\
\hline Ginkgo biloba & 银杏 & I & 濒危 & 邢世岩 & 银杏基因组 DNA 甲基化修饰位点的 MSAP 分析 \\
\hline
\end{tabular}


顾垒，闻丞，罗玫，王吴，吕植. 中国最受关注濒危物种保护现状快速评价的新方法探讨. 生物多样性，2015，23(5)：583-590. http://www. biodiversity-science. net/CN/article/downloadArticleFile. do?attachType=PDF\&id=10075

\begin{tabular}{|c|c|c|c|c|c|}
\hline & & & /EN & & \\
\hline \multirow[t]{2}{*}{ Ginkgo biloba } & 银杏 & I & 濒危 & 罗言云 & 银杏茎段的组织培养及其植株再生 \\
\hline & & & $/$ EN & & \\
\hline \multirow[t]{2}{*}{ Ginkgo biloba } & 银杏 & I & 濒危 & 胡蕙露 & 银杏茎段试管培养条件笁选研究 \\
\hline & & & /EN & & \\
\hline \multirow[t]{2}{*}{ Ginkgo biloba } & 银杏 & I & 濒危 & 安丽华 & 银杏精细胞结构及受精作用的细胞学研究 \\
\hline & & & /EN & & \\
\hline \multirow[t]{2}{*}{ Ginkgo biloba } & 银杏 & I & 濒危 & 曹福亮 & 银杏抗寒机理及种质资源抗寒性评定的初步研究 \\
\hline & & & /EN & & \\
\hline \multirow[t]{2}{*}{ Ginkgo biloba } & 银杏 & I & 濒危 & 曹福亮 & 银杏抗氧化酶系统对短期梯度变温的响应 \\
\hline & & & /EN & & \\
\hline \multirow[t]{2}{*}{ Ginkgo biloba } & 银杏 & I & 濒危 & 陈鹏 & 银杏类黄酮 $\mathrm{O}$ - 甲基转移酶基因的克隆与表达分析 \\
\hline & & & /EN & & \\
\hline \multirow[t]{2}{*}{ Ginkgo biloba } & 银杏 & I & 濒危 & 陈鹏 & 银杏类黄酮糖基转移酶基因片段克隆与分析 \\
\hline & & & /EN & & \\
\hline \multirow[t]{2}{*}{ Ginkgo biloba } & 银杏 & I & 濒危 & 陈鹏 & 银杏类黄酮糖基转移酶基因全长序列克隆及表达分析 \\
\hline & & & /EN & & \\
\hline \multirow[t]{2}{*}{ Ginkgo biloba } & 银杏 & I & 濒危 & 张永福 & 银杏落叶前夕叶片和枝干生理生化物质变化规律的研究 \\
\hline & & & /EN & & \\
\hline
\end{tabular}


顾垒，闻丞，罗玫，王吴，吕植. 中国最受关注濒危物种保护现状快速评价的新方法探讨. 生物多样性，2015，23(5)：583-590. http://www. biodiversity-science. net/CN/article/downloadArticleFile. do?attachType=PDF\&id=10075

\begin{tabular}{|c|c|c|c|c|c|}
\hline Ginkgo biloba & 银杏 & I & $\begin{array}{l}\text { 濒危 } \\
\text { /EN }\end{array}$ & 莫昭展 & 银杏苗期生理生化指标的变异和选择研究 \\
\hline Ginkgo biloba & 银杏 & I & $\begin{array}{l}\text { 濒危 } \\
\text { /EN }\end{array}$ & 岳海梅 & 银杏内生小孢子链格孢的分离与鉴定 \\
\hline Ginkgo biloba & 银杏 & I & $\begin{array}{l}\text { 濒危 } \\
\text { /EN }\end{array}$ & 花日茂 & 银杏内生真菌 T4 抑菌活性及生物学特性的研究 \\
\hline Ginkgo biloba & 银杏 & I & $\begin{array}{l}\text { 濒危 } \\
\text { /EN }\end{array}$ & 韩晓丽 & 银杏内生真菌的分离鉴定及种群分布 \\
\hline Ginkgo biloba & 银杏 & I & $\begin{array}{l}\text { 濒危 } \\
\text { /EN }\end{array}$ & 陈晔 & 银杏内生真菌种群多样性的研究 \\
\hline Ginkgo biloba & 银杏 & I & $\begin{array}{l}\text { 濒危 } \\
\text { /EN }\end{array}$ & 吴圣进 & 银杏年周期内 $N 、 P 、 K$ 需求动态研究 \\
\hline Ginkgo biloba & 银杏 & I & $\begin{array}{l}\text { 濒危 } \\
\text { /EN }\end{array}$ & 王莉 & 银杏胚乳发育过程中养分积累规律的研究 \\
\hline Ginkgo biloba & 银杏 & I & $\begin{array}{l}\text { 濒危 } \\
\text { /EN }\end{array}$ & 陈鹏 & 银杏胚珠发育及胚乳细胞形成的机制研究 \\
\hline Ginkgo biloba & 银杏 & I & $\begin{array}{l}\text { 濒危 } \\
\text { /EN }\end{array}$ & 陈鹏 & 银杏胚珠发育及其传粉生物学意义 \\
\hline Ginkgo biloba & 银杏 & I & 濒危 & 陈鹏 & 银杏胚珠发育进程的解剖学研究 \\
\hline
\end{tabular}


顾垒，闻丞，罗玫，王吴，吕植. 中国最受关注濒危物种保护现状快速评价的新方法探讨. 生物多样性，2015，23(5)：583-590. http://www. biodiversity-science. net/CN/article/downloadArticleFile. do?attachType=PDF\&id=10075

\begin{tabular}{|c|c|c|c|c|c|}
\hline & & & /EN & & \\
\hline \multirow[t]{2}{*}{ Ginkgo biloba } & 银杏 & I & 濒危 & 曹福亮 & 银杏群体遗传多样性的 RAPD 和 ISSR 分析 \\
\hline & & & $/$ EN & & \\
\hline \multirow[t]{2}{*}{ Ginkgo biloba } & 银杏 & I & 濒危 & 高国兴 & 银杏人工授粉技术 \\
\hline & & & /EN & & \\
\hline \multirow[t]{2}{*}{ Ginkgo biloba } & 银杏 & I & 濒危 & 李庆康 & 银杏生长的土壤肥力变化研究 \\
\hline & & & /EN & & \\
\hline \multirow[t]{2}{*}{ Ginkgo biloba } & 银杏 & I & 濒危 & 凌裕平 & 银杏生殖器官光合产物分配规律及挥发性成分研究 \\
\hline & & & /EN & & \\
\hline \multirow[t]{2}{*}{ Ginkgo biloba } & 银杏 & I & 濒危 & 孙仲序 & 银杏实生群体变异的分析和选择 \\
\hline & & & /EN & & \\
\hline \multirow[t]{2}{*}{ Ginkgo biloba } & 银杏 & I & 濒危 & 胡东 & 银杏受精作用及胚胎发生 \\
\hline & & & /EN & & \\
\hline \multirow[t]{2}{*}{ Ginkgo biloba } & 银杏 & I & 濒危 & 凌裕平 & 银杏输导组织发育_跨细胞运输及水涝胁迫的影响 \\
\hline & & & /EN & & \\
\hline \multirow[t]{2}{*}{ Ginkgo biloba } & 银杏 & I & 濒危 & 高俊平 & 银杏树干茎流变化及其对抑制蒸腾措施的响应 \\
\hline & & & /EN & & \\
\hline \multirow[t]{2}{*}{ Ginkgo biloba } & 银杏 & I & 濒危 & 赵炳祥 & 银杏树体茎流变化及其对环境因子的响应 \\
\hline & & & /EN & & \\
\hline
\end{tabular}


顾垒，闻丞，罗玫，王吴，吕植. 中国最受关注濒危物种保护现状快速评价的新方法探讨. 生物多样性，2015，23(5)：583-590. http://www. biodiversity-science. net/CN/article/downloadArticleFile. do?attachType=PDF\&id=10075

\begin{tabular}{|c|c|c|c|c|c|}
\hline Ginkgo biloba & 银杏 & I & 濒危 & 向小琴 & 银杏水分输导过程研究 \\
\hline & & & /EN & & \\
\hline \multirow[t]{2}{*}{ Ginkgo biloba } & 银杏 & I & 濒危 & 黄炳金 & 银杏炭疽病菌的鉴定和生物学特性的研究 \\
\hline & & & /EN & & \\
\hline \multirow[t]{2}{*}{ Ginkgo biloba } & 银杏 & I & 濒危 & 邢世岩 & 银杏特异种质核型进化趋势 \\
\hline & & & /EN & & \\
\hline \multirow[t]{2}{*}{ Ginkgo biloba } & 银杏 & I & 濒危 & 赵肃清 & 银杏外种皮研究进展 \\
\hline & & & $/ \mathrm{EN}$ & & \\
\hline \multirow[t]{2}{*}{ Ginkgo biloba } & 银杏 & I & 濒危 & 傅承新 & 银杏微卫星文库的构建和遗传多样性分析 \\
\hline & & & /EN & & \\
\hline \multirow[t]{2}{*}{ Ginkgo biloba } & 银杏 & I & 濒危 & 曹必荣 & 银杏物候学研究进展 \\
\hline & & & /EN & & \\
\hline \multirow[t]{2}{*}{ Ginkgo biloba } & 银杏 & I & 濒危 & 凌裕平 & 银杏吸收根营养元素吸收及分配规律的能谱分析 \\
\hline & & & /EN & & \\
\hline \multirow[t]{2}{*}{ Ginkgo biloba } & 银杏 & I & 濒危 & 潘伟明 & 银杏夏季生长光温条件的初步研究 \\
\hline & & & /EN & & \\
\hline \multirow[t]{2}{*}{ Ginkgo biloba } & 银杏 & I & 濒危 & 李云 & 银杏小孢子发育进程及其染色体加倍方法研究 \\
\hline & & & /EN & & \\
\hline Ginkgo biloba & 银杏 & I & 濒危 & 王莉 & 银杏小狍子和花粉发育过程的超微结构观察 \\
\hline
\end{tabular}


顾垒，闻丞，罗玫，王吴，吕植. 中国最受关注濒危物种保护现状快速评价的新方法探讨. 生物多样性，2015，23(5)：583-590. http://www. biodiversity-science. net/CN/article/downloadArticleFile. do?attachType=PDF\&id=10075

\begin{tabular}{|c|c|c|c|c|c|}
\hline & & & /EN & & \\
\hline \multirow[t]{2}{*}{ Ginkgo biloba } & 银杏 & I & 濒危 & 陈国祥 & 银杏新梢叶片光合与荧光特性研究 \\
\hline & & & $/$ EN & & \\
\hline \multirow[t]{2}{*}{ Ginkgo biloba } & 银杏 & I & 濒危 & 陈国祥 & 银杏新梢叶片衰老过程中光能转化特性与抗氧化酶活性研究 \\
\hline & & & /EN & & \\
\hline \multirow[t]{2}{*}{ Ginkgo biloba } & 银杏 & I & 濒危 & 杨晓红 & 银杏性别特征表现与鉴别研究进展 \\
\hline & & & /EN & & \\
\hline \multirow[t]{2}{*}{ Ginkgo biloba } & 银杏 & I & 濒危 & 史继孔 & 银杏雄花芽的形态分化 \\
\hline & & & /EN & & \\
\hline \multirow[t]{2}{*}{ Ginkgo biloba } & 银杏 & I & 濒危 & 史继孔 & 银杏雄花芽分化期间内源激素、碳水化合物和矿质营养含量的变化 \\
\hline & & & /EN & & \\
\hline \multirow[t]{2}{*}{ Ginkgo biloba } & 银杏 & $\mathrm{I}$ & 濒危 & 张建业 & 银杏雄株 GinNdly 全长基因的分离克隆 \\
\hline & & & /EN & & \\
\hline \multirow[t]{2}{*}{ Ginkgo biloba } & 银杏 & I & 濒危 & 黄永高 & 银杏雄株光合与蒸腾特性的研究 \\
\hline & & & /EN & & \\
\hline \multirow[t]{2}{*}{ Ginkgo biloba } & 银杏 & I & 濒危 & 陈鹏 & 银杏雄株花粉的观测与分类研究 \\
\hline & & & /EN & & \\
\hline \multirow[t]{2}{*}{ Ginkgo biloba } & 银杏 & I & 濒危 & 陈鹏 & 银杏雄株花粉特征观察与分类研究 \\
\hline & & & /EN & & \\
\hline
\end{tabular}


顾垒，闻丞，罗玫，王吴，吕植. 中国最受关注濒危物种保护现状快速评价的新方法探讨. 生物多样性，2015，23(5)：583-590. http://www. biodiversity-science. net/CN/article/downloadArticleFile. do?attachType=PDF\&id=10075

\begin{tabular}{|c|c|c|c|c|c|}
\hline Ginkgo biloba & 银杏 & I & $\begin{array}{l}\text { 濒危 } \\
\text { /EN }\end{array}$ & 凌裕平 & 银杏雄株花粉形态特征及超微结构观察 \\
\hline Ginkgo biloba & 银杏 & I & $\begin{array}{l}\text { 濒危 } \\
\text { /EN }\end{array}$ & 邢世岩 & 银杏雄株开花生物学特性研究 \\
\hline Ginkgo biloba & 银杏 & I & $\begin{array}{l}\text { 濒危 } \\
/ \mathrm{EN}\end{array}$ & 邢世岩 & 银杏雄株亲缘关系的 AFLP 分析 \\
\hline Ginkgo biloba & 银杏 & I & $\begin{array}{l}\text { 濒危 } \\
\text { /EN }\end{array}$ & 邢世岩 & 银杏雄株遗传多样性的 AFLP 分析 \\
\hline Ginkgo biloba & 银杏 & I & $\begin{array}{l}\text { 濒危 } \\
\text { /EN }\end{array}$ & 陈鹏 & 银杏雄株种质资源遗传多样性分析 \\
\hline Ginkgo biloba & 银杏 & I & $\begin{array}{l}\text { 濒危 } \\
\text { /EN }\end{array}$ & 莫昭展 & 银杏雄株种质资源遗传多样性研究 \\
\hline Ginkgo biloba & 银杏 & I & $\begin{array}{l}\text { 濒危 } \\
\text { /EN }\end{array}$ & 陆静梅 & 银杏演化结构研究 \\
\hline Ginkgo biloba & 银杏 & I & $\begin{array}{l}\text { 濒危 } \\
/ \mathrm{EN}\end{array}$ & 梁立兴 & 银杏野生种群的争论 \\
\hline Ginkgo biloba & 银杏 & I & $\begin{array}{l}\text { 濒危 } \\
/ \mathrm{EN}\end{array}$ & 程水源 & 银杏叶苯丙氨酸解氨酶特性及其对叶黄酮含量调控的研究 \\
\hline Ginkgo biloba & 银杏 & I & 濒危 & 江德安 & 银杏叶部病害的发生与防治研究 \\
\hline
\end{tabular}


顾垒，闻丞，罗玫，王吴，吕植. 中国最受关注濒危物种保护现状快速评价的新方法探讨. 生物多样性，2015，23(5)：583-590. http://www. biodiversity-science. net/CN/article/downloadArticleFile. do?attachType=PDF\&id=10075

\begin{tabular}{|c|c|c|c|c|c|}
\hline & & & /EN & & \\
\hline \multirow[t]{2}{*}{ Ginkgo biloba } & 银杏 & I & 濒危 & 宋益民 & 银杏叶部病害诊断及其发生规律的初步研究 \\
\hline & & & $/$ EN & & \\
\hline \multirow[t]{2}{*}{ Ginkgo biloba } & 银杏 & I & 濒危 & 周志权 & 银杏叶枯病病原菌侵染特性的研究 \\
\hline & & & /EN & & \\
\hline \multirow[t]{2}{*}{ Ginkgo biloba } & 银杏 & I & 濒危 & 廖咏梅 & 银杏叶枯病发生规律的探讨 \\
\hline & & & /EN & & \\
\hline \multirow[t]{2}{*}{ Ginkgo biloba } & 银杏 & I & 濒危 & 唐蕾 & 银杏叶绿素降解酶的诱导表达研究 \\
\hline & & & /EN & & \\
\hline \multirow[t]{2}{*}{ Ginkgo biloba } & 银杏 & I & 濒危 & 程水源 & 银杏叶绿体 petD 基因的克隆与表达 \\
\hline & & & /EN & & \\
\hline \multirow[t]{2}{*}{ Ginkgo biloba } & 银杏 & $\mathrm{I}$ & 濒危 & 俞嘉宁 & 银杏叶绿体 ndhF RNA 编辑现象分析及 C290 位编辑对胁迫处理的响应 \\
\hline & & & $/ \mathrm{EN}$ & & \\
\hline \multirow[t]{2}{*}{ Ginkgo biloba } & 银杏 & I & 濒危 & 俞嘉宁 & 银杏叶绿体 ndhF 基因 RNA 编辑位点测定及编辑效率分析 \\
\hline & & & /EN & & \\
\hline \multirow[t]{2}{*}{ Ginkgo biloba } & 银杏 & I & 濒危 & 陈国祥 & 银杏叶绿体光能转化特性研究 \\
\hline & & & /EN & & \\
\hline \multirow[t]{2}{*}{ Ginkgo biloba } & 银杏 & I & 濒危 & 彭方仁 & 银杏叶片蛋白质含量动态变化的电泳分析 \\
\hline & & & /EN & & \\
\hline
\end{tabular}


顾垒，闻丞，罗玫，王吴，吕植. 中国最受关注濒危物种保护现状快速评价的新方法探讨. 生物多样性，2015，23(5)：583-590. http://www. biodiversity-science. net/CN/article/downloadArticleFile. do?attachType=PDF\&id=10075

\begin{tabular}{|c|c|c|c|c|c|}
\hline Ginkgo biloba & 银杏 & I & 濒危 & 凌裕平 & 银杏叶片光合特性和超微结构研究 \\
\hline & & & $/ \mathrm{EN}$ & & \\
\hline \multirow[t]{2}{*}{ Ginkgo biloba } & 银杏 & I & 濒危 & 凌裕平 & 银杏叶片光响应下气孔运动规律及机理研究 \\
\hline & & & $/ \mathrm{EN}$ & & \\
\hline \multirow[t]{2}{*}{ Ginkgo biloba } & 银杏 & I & 濒危 & 张喜焕 & 银杏叶片三个不同发育阶段光合特性对 CO2 浓度升高响应的比较研究 \\
\hline & & & $/ \mathrm{EN}$ & & \\
\hline \multirow[t]{2}{*}{ Ginkgo biloba } & 银杏 & I & 濒危 & 廖咏梅 & 银杏叶片三种酶活性变化与抗疫霰菌关系的研究 \\
\hline & & & /EN & & \\
\hline \multirow[t]{2}{*}{ Ginkgo biloba } & 银杏 & I & 濒危 & 王 扬 & 银杏叶片生长发育过程中生理生化指标动态变化 \\
\hline & & & $/ \mathrm{EN}$ & & \\
\hline \multirow[t]{2}{*}{ Ginkgo biloba } & 银杏 & I & 濒危 & 陈国祥 & 银杏叶片衰老过程中 PS II 苂光动力学特性变化 \\
\hline & & & /EN & & \\
\hline \multirow[t]{2}{*}{ Ginkgo biloba } & 银杏 & I & 濒危 & 杨贤松 & 银杏叶片衰老过程中的叶绿素苂光动力学 \\
\hline & & & $/ \mathrm{EN}$ & & \\
\hline \multirow[t]{2}{*}{ Ginkgo biloba } & 银杏 & I & 濒危 & 陈国祥 & 银杏叶片衰老过程中光合生理特性及叶绿体超微结构的变化 \\
\hline & & & /EN & & \\
\hline \multirow[t]{2}{*}{ Ginkgo biloba } & 银杏 & I & 濒危 & 苏冬梅 & 银杏叶片衰老与调节的生理生化变化 \\
\hline & & & $/ \mathrm{EN}$ & & \\
\hline Ginkgo biloba & 银杏 & I & 濒危 & 盛宝龙 & 银杏叶片形态研究 \\
\hline
\end{tabular}


顾垒，闻丞，罗玫，王吴，吕植. 中国最受关注濒危物种保护现状快速评价的新方法探讨. 生物多样性，2015，23(5)：583-590. http://www. biodiversity-science. net/CN/article/downloadArticleFile. do?attachType=PDF\&id=10075

\begin{tabular}{|c|c|c|c|c|c|}
\hline & & & /EN & & \\
\hline \multirow[t]{2}{*}{ Ginkgo biloba } & 银杏 & I & 濒危 & 陈国祥 & 银杏叶片叶绿体光能转换特性的变化 \\
\hline & & & $/$ EN & & \\
\hline \multirow[t]{2}{*}{ Ginkgo biloba } & 银杏 & I & 濒危 & 森卫国 & 银杏叶片中营养元素含量的季节性变化研究 \\
\hline & & & /EN & & \\
\hline \multirow[t]{2}{*}{ Ginkgo biloba } & 银杏 & I & 濒危 & 杨天秀 & 银杏叶生物学特性研究 \\
\hline & & & /EN & & \\
\hline \multirow[t]{2}{*}{ Ginkgo biloba } & 银杏 & I & 濒危 & 邢世岩 & 银杏叶生小孢子囊比较形态学及系统意义 \\
\hline & & & /EN & & \\
\hline \multirow[t]{2}{*}{ Ginkgo biloba } & 银杏 & I & 濒危 & 邢世岩 & 银杏叶数量性状的遗传分析 \\
\hline & & & /EN & & \\
\hline \multirow[t]{2}{*}{ Ginkgo biloba } & 银杏 & $\mathrm{I}$ & 濒危 & 宋卫平 & 银杏叶缘枯焦原因及预防措施 \\
\hline & & & /EN & & \\
\hline \multirow[t]{2}{*}{ Ginkgo biloba } & 银杏 & I & 濒危 & 周志权 & 银杏疫病病原种的鉴定 \\
\hline & & & /EN & & \\
\hline \multirow[t]{2}{*}{ Ginkgo biloba } & 银杏 & I & 濒危 & 吴彩娥 & 银杏营养贬藏蛋白的分离鉴定及特性研究 \\
\hline & & & /EN & & \\
\hline \multirow[t]{2}{*}{ Ginkgo biloba } & 银杏 & I & 濒危 & 彭方仁 & 银杏营养䛎藏蛋白质的 SDS-聚丙烯酰胺凝胶电泳研究 \\
\hline & & & /EN & & \\
\hline
\end{tabular}


顾垒，闻丞，罗玫，王吴，吕植. 中国最受关注濒危物种保护现状快速评价的新方法探讨. 生物多样性，2015，23(5)：583-590. http://www. biodiversity-science. net/CN/article/downloadArticleFile. do?attachType=PDF\&id=10075

\begin{tabular}{|c|c|c|c|c|c|}
\hline Ginkgo biloba & 银杏 & I & $\begin{array}{l}\text { 濒危 } \\
\text { /EN }\end{array}$ & 彭方仁 & 银杏营养贮藏蛋白质的变化规律研究 \\
\hline Ginkgo biloba & 银杏 & I & $\begin{array}{l}\text { 濒危 } \\
\text { /EN }\end{array}$ & 郭娟 & 银杏营养拒藏蛋白质的超微结构特征及季节变化 \\
\hline Ginkgo biloba & 银杏 & I & $\begin{array}{l}\text { 濒危 } \\
\text { /EN }\end{array}$ & 彭方仁 & 银杏营养贮藏蛋白质的分离鉴定及特性研究 \\
\hline Ginkgo biloba & 银杏 & I & $\begin{array}{l}\text { 濒危 } \\
\text { /EN }\end{array}$ & 彭方仁 & 银杏营养贮藏蛋白质的免疫细胞学研究 \\
\hline Ginkgo biloba & 银杏 & I & $\begin{array}{l}\text { 濒危 } \\
\text { /EN }\end{array}$ & 彭方仁 & 银杏营养拒藏蛋白质的细胞学及生物化学分析 \\
\hline Ginkgo biloba & 银杏 & I & $\begin{array}{l}\text { 濒危 } \\
\text { /EN }\end{array}$ & 彭方仁 & 银杏营养贮藏蛋白质的细胞学研究 \\
\hline Ginkgo biloba & 银杏 & I & $\begin{array}{l}\text { 濒危 } \\
\text { /EN }\end{array}$ & 陆静梅 & 银杏幼苗初生维管系统的解剖学研究 \\
\hline Ginkgo biloba & 银杏 & I & $\begin{array}{l}\text { 濒危 } \\
\text { /EN }\end{array}$ & 胥晓 & 银杏幼苗雌雄株对盐胁迫响应的差别 \\
\hline Ginkgo biloba & 银杏 & I & $\begin{array}{l}\text { 濒危 } \\
\text { /EN }\end{array}$ & 陈普红 & 银杏幼苗耐寒性及其他技术研究 \\
\hline Ginkgo biloba & 银杏 & I & 濒危 & 杨清 & 银杏幼嫩茎段培养诱导愈伤组织及其细胞学研究 \\
\hline
\end{tabular}


顾垒，闻丞，罗玫，王吴，吕植. 中国最受关注濒危物种保护现状快速评价的新方法探讨. 生物多样性，2015，23(5)：583-590. http://www. biodiversity-science. net/CN/article/downloadArticleFile. do?attachType=PDF\&id=10075

\begin{tabular}{|c|c|c|c|c|c|}
\hline & & & /EN & & \\
\hline \multirow[t]{2}{*}{ Ginkgo biloba } & 银杏 & I & 濒危 & 陈军 & 银杏与珊瑚树光合及蒸腾特性研究 \\
\hline & & & $/$ EN & & \\
\hline \multirow[t]{2}{*}{ Ginkgo biloba } & 银杏 & I & 濒危 & 邢世岩 & 银杏与叶籽银杏胚珠发育的组织化学比较研究 \\
\hline & & & /EN & & \\
\hline \multirow[t]{2}{*}{ Ginkgo biloba } & 银杏 & I & 濒危 & 邢世岩 & 银杏与叶籽银杏枝Y材管胞径向变异趋势 \\
\hline & & & /EN & & \\
\hline \multirow[t]{2}{*}{ Ginkgo biloba } & 银杏 & I & 濒危 & 王 建 & 银杏枝、花、种子在树冠上的分布格局及其相互关系研究 \\
\hline & & & /EN & & \\
\hline \multirow[t]{2}{*}{ Ginkgo biloba } & 银杏 & I & 濒危 & 彭方仁 & 银杏枝条营养贮藏蛋白质的免疫细胞化学鉴定 \\
\hline & & & /EN & & \\
\hline \multirow[t]{2}{*}{ Ginkgo biloba } & 银杏 & I & 濒危 & 金徉 & 银杏中种皮形态建成及结构特征 \\
\hline & & & /EN & & \\
\hline \multirow[t]{2}{*}{ Ginkgo biloba } & 银杏 & I & 濒危 & 凌裕平 & 银杏种壳超微结构的研究 \\
\hline & & & /EN & & \\
\hline \multirow[t]{2}{*}{ Ginkgo biloba } & 银杏 & I & 濒危 & 凌裕平 & 银杏种壳主要矿质元素成分的能谱分析 \\
\hline & & & /EN & & \\
\hline \multirow[t]{2}{*}{ Ginkgo biloba } & 银杏 & I & 濒危 & 陈鹏 & 银杏种实发育的解剖和超微结构观察 \\
\hline & & & /EN & & \\
\hline
\end{tabular}


顾垒，闻丞，罗玫，王吴，吕植. 中国最受关注濒危物种保护现状快速评价的新方法探讨. 生物多样性，2015，23(5)：583-590. http://www. biodiversity-science. net/CN/article/downloadArticleFile. do?attachType=PDF\&id=10075

\begin{tabular}{|c|c|c|c|c|c|}
\hline Ginkgo biloba & 银杏 & I & $\begin{array}{l}\text { 濒危 } \\
/ \mathrm{EN}\end{array}$ & 金譄 & 银杏种实发育过程中淀粉和蛋白质的积累与代谢 \\
\hline Ginkgo biloba & 银杏 & I & $\begin{array}{l}\text { 濒危 } \\
\text { /EN }\end{array}$ & 傅秀红 & 银杏种实发育过程中营养成分的动态变化研究 \\
\hline Ginkgo biloba & 银杏 & I & $\begin{array}{l}\text { 濒危 } \\
/ \mathrm{EN}\end{array}$ & 陈鹏 & 银杏种实发育过程中中种皮的解剖与超微结构观察 \\
\hline Ginkgo biloba & 银杏 & I & $\begin{array}{l}\text { 濒危 } \\
/ \mathrm{EN}\end{array}$ & 施婷婷 & 银杏种实生长发育过程中内源激素含量的变化 \\
\hline Ginkgo biloba & 银杏 & I & $\begin{array}{l}\text { 濒危 } \\
/ \mathrm{EN}\end{array}$ & 陈鹏 & 银杏种实生长发育过程中胚乳淀粉体发育观察 \\
\hline Ginkgo biloba & 银杏 & I & $\begin{array}{l}\text { 濒危 } \\
/ \mathrm{EN}\end{array}$ & 陈鹏 & 银杏种实生长发育中激素含量与组织结构变化的研究 \\
\hline Ginkgo biloba & 银杏 & I & $\begin{array}{l}\text { 濒危 } \\
\text { /EN }\end{array}$ & 徐刚标 & 银杏种质离体保存的研究 I. 银杏花粉咜存 \\
\hline Ginkgo biloba & 银杏 & I & $\begin{array}{l}\text { 濒危 } \\
/ \mathrm{EN}\end{array}$ & 徐刚标 & 银杏种质离体保存的研究 II. 银杏肧超低温保存 \\
\hline Ginkgo biloba & 银杏 & I & $\begin{array}{l}\text { 濒危 } \\
/ \mathrm{EN}\end{array}$ & 邢世岩 & 银杏种质遗传多样性研究评述 \\
\hline Ginkgo biloba & 银杏 & I & 濒危 & 邢世岩 & 银杏种质资源遗传多样性的 AFLP 研究 \\
\hline
\end{tabular}


顾垒，闻丞，罗玫，王吴，吕植. 中国最受关注濒危物种保护现状快速评价的新方法探讨. 生物多样性，2015，23(5)：583-590. http://www. biodiversity-science. net/CN/article/downloadArticleFile. do?attachType=PDF\&id=10075

\begin{tabular}{|c|c|c|c|c|c|}
\hline & & & /EN & & \\
\hline \multirow[t]{2}{*}{ Ginkgo biloba } & 银杏 & I & 濒危 & 颜世超 & 银杏种子发芽特性与含水量伧藏方式的关系 \\
\hline & & & $/$ EN & & \\
\hline \multirow[t]{2}{*}{ Ginkgo biloba } & 银杏 & I & 濒危 & 苪海云 & 银杏种子发育和后熟生理研究 \\
\hline & & & /EN & & \\
\hline \multirow[t]{2}{*}{ Ginkgo biloba } & 银杏 & I & 濒危 & 梁红 & 银杏种子和叶的蛋白质分析 \\
\hline & & & /EN & & \\
\hline \multirow[t]{2}{*}{ Ginkgo biloba } & 银杏 & I & 濒危 & 蔡春菊 & 银杏种子后熟生理的研究 \\
\hline & & & /EN & & \\
\hline \multirow[t]{2}{*}{ Ginkgo biloba } & 银杏 & I & 濒危 & 曹帮华 & 银杏种子后熟生理与内源激素变化的研究 \\
\hline & & & /EN & & \\
\hline \multirow[t]{2}{*}{ Ginkgo biloba } & 银杏 & I & 濒危 & 彭方仁 & 银杏种子萌发过程中蛋白质及 3 种氮代谢酶活性的变化 \\
\hline & & & /EN & & \\
\hline \multirow[t]{2}{*}{ Ginkgo biloba } & 银杏 & I & 濒危 & 彭方仁 & 银杏种子萌发过程中栬藏物质代谢机理的研究 \\
\hline & & & /EN & & \\
\hline \multirow[t]{2}{*}{ Ginkgo biloba } & 银杏 & I & 濒危 & 曹帮华 & 银杏种子生理研究进展 \\
\hline & & & /EN & & \\
\hline \multirow[t]{2}{*}{ Ginkgo biloba } & 银杏 & I & 濒危 & 王建 & 银杏种子生长、脱落及其与内源激素含量变化的关系 \\
\hline & & & /EN & & \\
\hline
\end{tabular}


顾垒，闻丞，罗玫，王吴，吕植. 中国最受关注濒危物种保护现状快速评价的新方法探讨. 生物多样性，2015，23(5)：583-590. http://www. biodiversity-science. net/CN/article/downloadArticleFile. do?attachType=PDF\&id=10075

\begin{tabular}{|c|c|c|c|c|c|}
\hline Ginkgo biloba & 银杏 & I & $\begin{array}{l}\text { 濒危 } \\
\text { /EN }\end{array}$ & 王 建 & 银杏种子生长特性及其生理变化的研究 \\
\hline Ginkgo biloba & 银杏 & I & $\begin{array}{l}\text { 濒危 } \\
\text { /EN }\end{array}$ & 邢世岩 & 银杏种子数量遗传分析及多性状选择 \\
\hline Ginkgo biloba & 银杏 & I & $\begin{array}{l}\text { 濒危 } \\
\text { /EN }\end{array}$ & 莫昭展 & 银杏种子性状的变异分析 \\
\hline Ginkgo biloba & 银杏 & I & $\begin{array}{l}\text { 濒危 } \\
\text { /EN }\end{array}$ & 周海平 & 银杏主要病虫害综合治理技术研究 \\
\hline Ginkgo biloba & 银杏 & I & $\begin{array}{l}\text { 濒危 } \\
\text { /EN }\end{array}$ & 邓荫伟 & 银杏主要病虫害综合治理技术应用 \\
\hline Ginkgo biloba & 银杏 & I & $\begin{array}{l}\text { 濒危 } \\
\text { /EN }\end{array}$ & 谭晓风 & 银杏主要栽培品种的 RAPD 分子鉴别 \\
\hline Ginkgo biloba & 银杏 & I & $\begin{array}{l}\text { 濒危 } \\
\text { /EN }\end{array}$ & 曹福亮 & 银杏主要栽培品种遗传多样性分析 \\
\hline Ginkgo biloba & 银杏 & I & $\begin{array}{l}\text { 濒危 } \\
\text { /EN }\end{array}$ & 杨雄 & 银杏贮粉室发生部位的珠心细胞程序性死亡的形态学观察 \\
\hline Ginkgo biloba & 银杏 & I & $\begin{array}{l}\text { 濒危 } \\
\text { /EN }\end{array}$ & 徐利均 & 银杏组培繁殖及黄酮糖苷的产生 \\
\hline Ginkgo biloba & 银杏 & I & 濒危 & 曹福亮 & 银杏组织培养研究进展 \\
\hline
\end{tabular}


顾垒，闻丞，罗玫，王吴，吕植. 中国最受关注濒危物种保护现状快速评价的新方法探讨. 生物多样性，2015，23(5)：583-590. http://www. biodiversity-science. net/CN/article/downloadArticleFile. do?attachType=PDF\&id=10075

\begin{tabular}{|c|c|c|c|c|c|}
\hline & & & /EN & & \\
\hline \multirow[t]{2}{*}{ Ginkgo biloba } & 银杏 & I & 濒危 & 李云 & 应用 LSCM 和 SEM 鉴定银杏花粉的倍性 \\
\hline & & & $/$ EN & & \\
\hline \multirow[t]{2}{*}{ Ginkgo biloba } & 银杏 & I & 濒危 & 陈小勇 & 优先保护种群的确定 II. 单倍型丰富度模型及在银杏中的应用 \\
\hline & & & /EN & & \\
\hline \multirow[t]{2}{*}{ Ginkgo biloba } & 银杏 & I & 濒危 & 黄玉源 & 在银杏类植物中发现导管初报 \\
\hline & & & /EN & & \\
\hline \multirow[t]{2}{*}{ Ginkgo biloba } & 银杏 & I & 濒危 & 向应海 & 浙江西天目山天然林及银杏种群考察报告 \\
\hline & & & /EN & & \\
\hline \multirow[t]{2}{*}{ Ginkgo biloba } & 银杏 & I & 濒危 & 向准 & 重庆市南川金佛山银杏天然资源考察报告 \\
\hline & & & /EN & & \\
\hline \multirow[t]{2}{*}{ Ginkgo biloba } & 银杏 & I & 濒危 & 刘清华 & 紫外线-B 对银杏光合生理指标的影响 \\
\hline & & & /EN & & \\
\hline \multirow[t]{2}{*}{ Ginkgo biloba } & 银杏 & I & 濒危 & 钟章成 & 紫外线-B 辐射对银杏活性氧代谢及膜系统的影响 \\
\hline & & & /EN & & \\
\hline \multirow[t]{2}{*}{ Glaucidium brodiei } & 领鸺鹠 & II & 无危 & 关贯勋 & 澳门鸟类资源调查报告 \\
\hline & & & /LC & & \\
\hline \multirow[t]{2}{*}{ Glaucidium brodiei } & 领㭤留鸟 & II & 无危 & 石妍 & 大理苍山洱海国家级自然保护区专项规划 2011-1020 \\
\hline & & & /LC & & \\
\hline
\end{tabular}


顾垒，闻丞，罗玫，王吴，吕植. 中国最受关注濒危物种保护现状快速评价的新方法探讨. 生物多样性，2015，23(5)：583-590. http://www, biodiversity-science. net/CN/article/downloadArticleFile. do?attachType=PDF\&id=10075

\begin{tabular}{|c|c|c|c|c|c|}
\hline Glaucidium brodiei & 领俩留鸟 & II & $\begin{array}{l}\text { 无危 } \\
\text { /LC }\end{array}$ & 陈静 & 清凉峰旅游区鸟类群落结构动态研究 \\
\hline Glaucidium brodiei & 领鸺鹠 & II & $\begin{array}{l}\text { 无危 } \\
\text { /LC }\end{array}$ & 庄 馨 & 深圳大鹏半岛国家地质公园野生脊椎动物资源调查 \\
\hline Glaucidium brodiei & 领鸺留 & II & $\begin{array}{l}\text { 无危 } \\
\text { /LC }\end{array}$ & 武丙琳 & 西天目山旅游区鸟类群落结构变化及保护对策研究 \\
\hline Glaucidium cuculoides & 斑头鸺鹠 & II & $\begin{array}{l}\text { 无危 } \\
\text { /LC }\end{array}$ & 关贯勋 & 澳门鸟类资源调查报告 \\
\hline Glaucidium cuculoides & 斑头鸺鹠 & II & $\begin{array}{l}\text { 无危 } \\
\text { /LC }\end{array}$ & 高 峰 & 北京鸟类新纪录_斑头鸺鹠 \\
\hline Glaucidium cuculoides & 斑头鸺留 & II & $\begin{array}{l}\text { 无危 } \\
\text { /LC }\end{array}$ & $\begin{array}{l}\text { 四川西部生物多样 } \\
\text { 性调查队 }\end{array}$ & 布拖乐安地区生物 多样性调查报告 \\
\hline Glaucidium cuculoides & 斑头鸺鹠 & II & $\begin{array}{l}\text { 无危 } \\
\text { /LC }\end{array}$ & 江建国 & 鄂西野三河自然保护区鸟类资源调查报告 \\
\hline Glaucidium cuculoides & 斑头佗鹠 & II & $\begin{array}{l}\text { 无危 } \\
\text { /LC }\end{array}$ & 陈静 & 清凉峰旅游区鸟类群落结构动态研究 \\
\hline Glaucidium cuculoides & 斑头鸺鹠 & II & $\begin{array}{l}\text { 无危 } \\
\text { /LC }\end{array}$ & 庄 馨 & 深圳大鹏半岛国家地质公园野生脊椎动物资源调查 \\
\hline Glaucidium cuculoides & 斑头㭤鹠 & II & 无危 & 武丙琳 & 西天目山旅游区鸟类群落结构变化及保护对策研究 \\
\hline
\end{tabular}


顾垒，闻丞，罗玫，王吴，吕植. 中国最受关注濒危物种保护现状快速评价的新方法探讨. 生物多样性，2015，23(5)：583-590. http://www. biodiversity-science. net/CN/article/downloadArticleFile. do?attachType=PDF\&id=10075

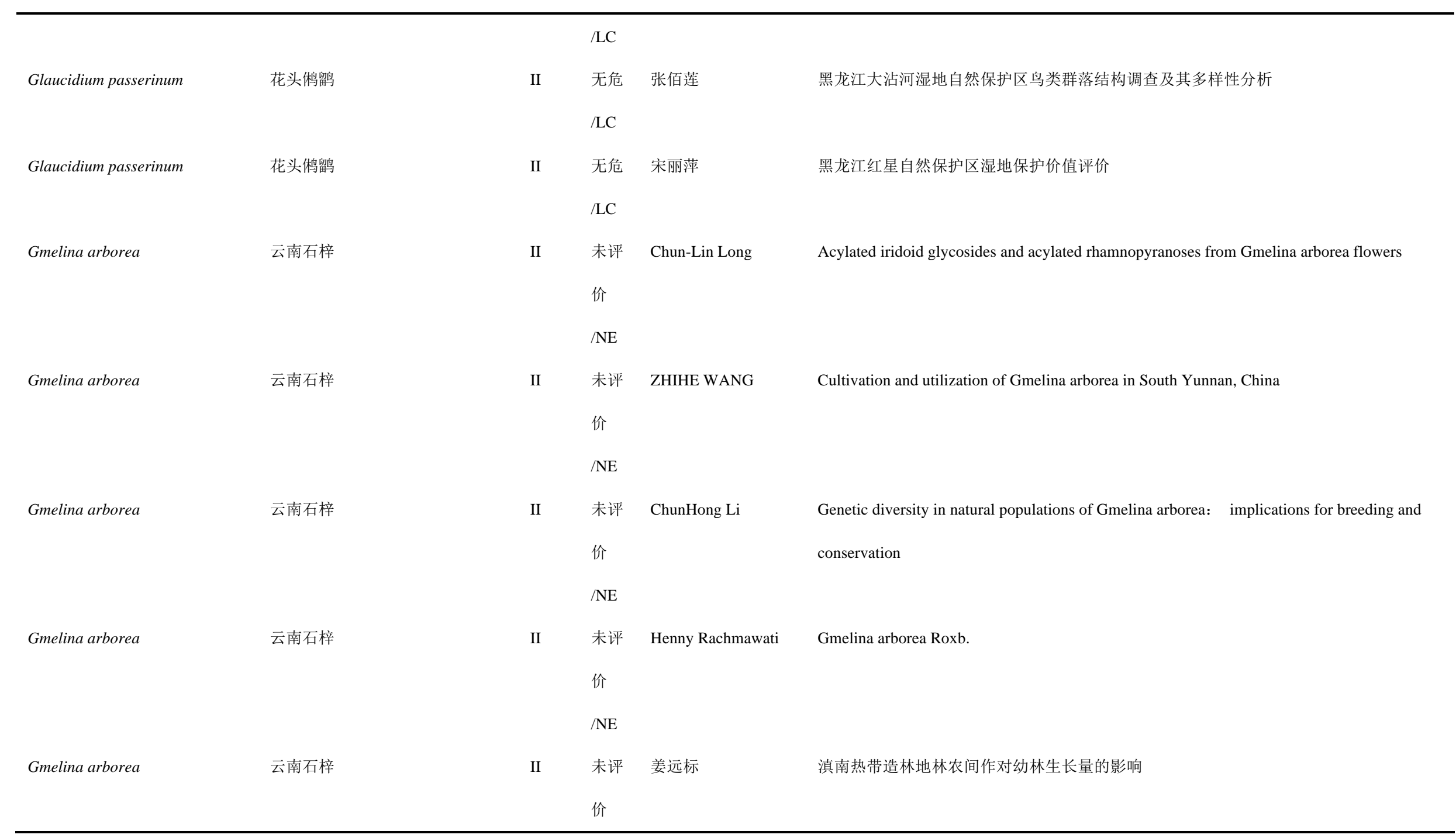


顾垒，闻丞，罗玫，王吴，吕植. 中国最受关注濒危物种保护现状快速评价的新方法探讨. 生物多样性，2015，23(5)：583-590. http://www. biodiversity-science. net/CN/article/downloadArticleFile. do?attachType=PDF\&id=10075

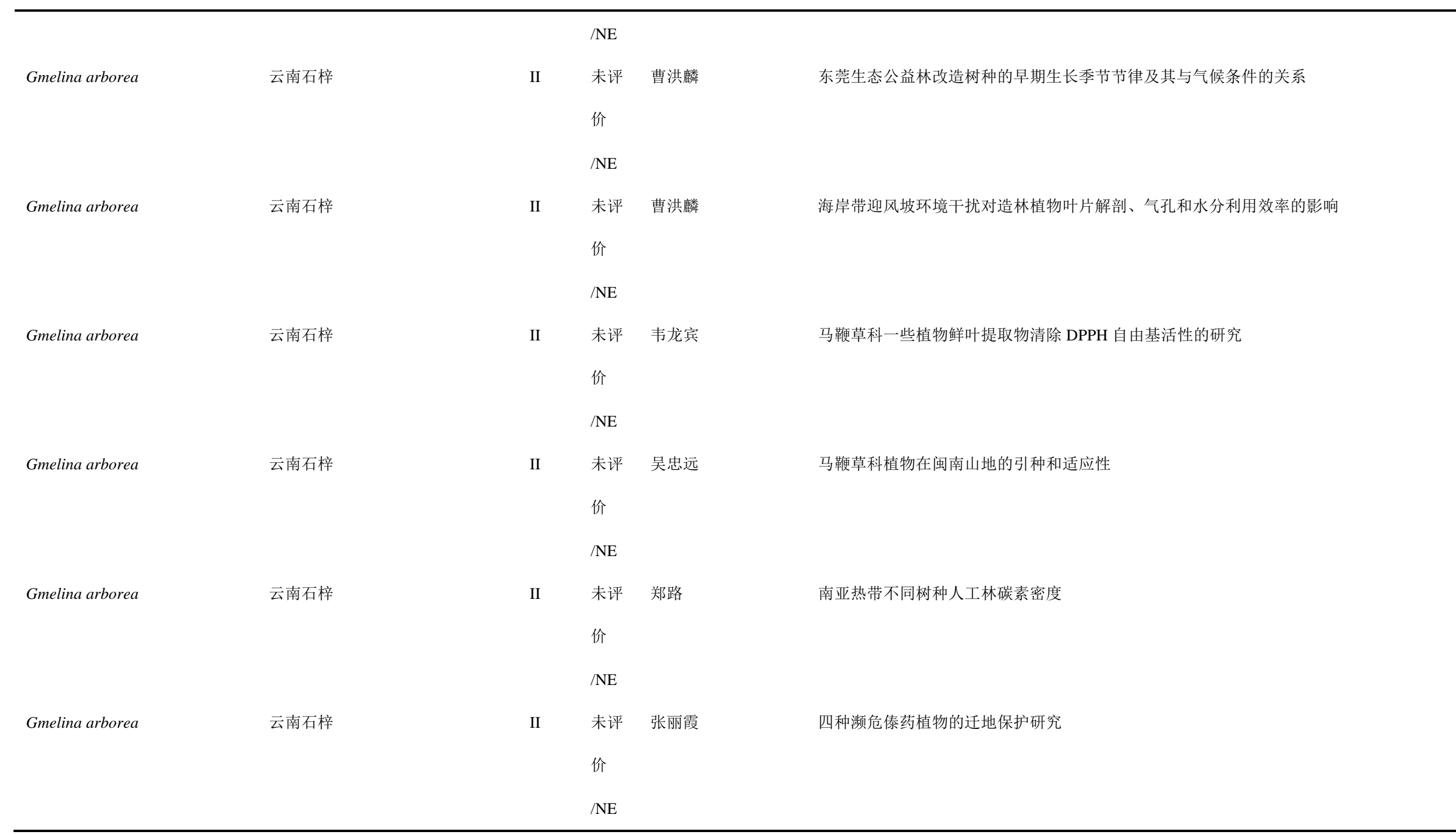


顾垒，闻丞，罗玫，王吴，吕植. 中国最受关注濒危物种保护现状快速评价的新方法探讨. 生物多样性，2015，23(5)：583-590. http://www. biodiversity-science. net/CN/article/downloadArticleFile. do?attachType=PDF\&id=10075

\begin{tabular}{|c|c|c|c|c|c|}
\hline Gmelina arborea & 云南石梓 & II & $\begin{array}{l}\text { 未评 } \\
\text { 价 } \\
\text { /NE }\end{array}$ & 古锦汉 & 印度紫檀等 5 树种在矿山迹地的生长表现 \\
\hline Gmelina arborea & 云南石梓 & II & $\begin{array}{l}\text { 未评 } \\
\text { 价 } \\
\text { /NE }\end{array}$ & 孔国辉 & 油页岩废渣场适生植物笁选及对重金属的净化研究 \\
\hline Gmelina arborea & 云南石梓 & II & $\begin{array}{l}\text { 未评 } \\
\text { 价 } \\
\text { /NE }\end{array}$ & 孔国辉 & 油页岩废渣场植物修复的生态效应 \\
\hline Gmelina arborea & 云南石梓 & II & $\begin{array}{l}\text { 未评 } \\
\text { 价 } \\
\text { /NE }\end{array}$ & 孔国辉 & 油页岩废渣地 12 种木本植物光合作用的季节变化 \\
\hline Gmelina arborea & 云南石梓 & II & $\begin{array}{l}\text { 未评 } \\
\text { 价 } \\
\text { /NE }\end{array}$ & 陈鹏 & 云南 6 种热带珍贵阔叶树主要害虫调查 \\
\hline Gmelina arborea & 云南石梓 & II & $\begin{array}{l}\text { 未评 } \\
\text { 价 } \\
\text { /NE }\end{array}$ & 张丽霞 & 云南石梓的生物学特性与利用 \\
\hline Gmelina arborea & 云南石梓 & II & 未评 & 王利勤 & 云南石梓花挥发性成分分析 \\
\hline
\end{tabular}


顾垒，闻丞，罗玫，王吴，吕植. 中国最受关注濒危物种保护现状快速评价的新方法探讨. 生物多样性，2015，23(5)：583-590. http://www biodiversity-science. net/CN/article/downloadArticleFile. do?attachType=PDF\&id=10075

$/ \mathrm{NE}$

Gmelina arborea

云南石梓

未评孙振令

价

Goniothalamus cheliensis

景洪哥纳香

Goniothalamus cheliensis

景洪哥纳香

Goniothalamus cheliensis

景洪哥纳香

Goniothalamus cheliensis

景洪哥纳香

Goniothalamus cheliensis

景洪哥纳香

Goniothalamus cheliensis

景洪哥纳香

Gorsachius goisagi
栗鳽
未列濒危

入 $/ \mathrm{EN}$

未列 濒危 Xin-Sheng Yao

入 /EN

未列濒危 Wen Hua Huang

入 $/ \mathrm{EN}$

未列 濒危 Xin-Sheng Yao

入 $/$ EN

未列濒危

顾正兵

入 $/$ EN

未列 濒危 顾正兵

入 $/ E N$

未列 濒危 蒋光伟

入 /EN
增强 UV-B 辐射和 SO2 作用下植物光合响应及其相对抗性

Alkaloids from the root barks of Goniothalamus cheliensis Miao Miao Jiang a, Xue Zhang b, Yi

Dai c, Hao Gao b,c, Hong Wei Liu d,

Furanofurone-type styryllactones from Goniothalamus cheliensis

Goniodilactone and gonioheptenolactone, two novel cytotoxic styryllactones from the leaves of

Goniothalamus cheliensis

Three new bis-styryllactones from Goniothalamus cheliensis

景洪哥纳香胺的分离和结构鉴定

景洪哥纳香中一新型生物碱的分离和结构

广西北部湾沿海地区水鸟多样性及季节变动 
顾垒，闻丞，罗玫，王吴，吕植. 中国最受关注濒危物种保护现状快速评价的新方法探讨. 生物多样性，2015，23(5)：583-590. http://www. biodiversity-science. net/CN/article/downloadArticleFile. do?attachType=PDF\&id=10075

\begin{tabular}{|c|c|c|c|c|c|}
\hline \multirow[t]{2}{*}{ Gorsachius goisagi } & 栗鳽 & 未列 & 濒危 & 何芬奇 & 鵌源鸟类纪录解析 \\
\hline & & 入 & $/ \mathrm{EN}$ & & \\
\hline \multirow[t]{2}{*}{ Gorsachius magnificus } & 海南鳽 & II & 濒危 & 高建云 & 广东北部海南鳽的繁殖行为观察 \\
\hline & & & $/ \mathrm{EN}$ & & \\
\hline \multirow[t]{2}{*}{ Gorsachius magnificus } & 海南鳽 & II & 濒危 & 余丽江 & 海南鳽的巢址选择 \\
\hline & & & /EN & & \\
\hline \multirow[t]{2}{*}{ Gorsachius magnificus } & 海南鳽 & II & 濒危 & 罗伟 & 海南鳽首次在十堰被发现 \\
\hline & & & /EN & & \\
\hline \multirow[t]{2}{*}{ Gorsachius magnificus } & 海南鳽 & II & 濒危 & 林清贤 & 江西靖安发现中华秋沙鸭和海南鳽 \\
\hline & & & /EN & & \\
\hline \multirow[t]{2}{*}{ Gorsachius magnificus } & 海南鳽 & II & 濒危 & 舒特生 & 九岭山国家级自然保护区鸟类资源的研究 \\
\hline & & & /EN & & \\
\hline Grus canadensis & 沙丘鹤 & II & LV & 张晓龙 & 黄河三角洲湿地生物多样性及其保护 \\
\hline Grus canadensis & 沙丘鹤 & II & $\mathrm{LV}$ & 王学民 & 黄河三角洲自然保护区鹤类南迁期迁徙规律研究 \\
\hline Grus canadensis & 沙丘鹤 & II & LV & 张希画 & 黄河三角洲自然保护区鹤类种类、数量动态监测初步分析 \\
\hline Grus canadensis & 沙丘鹤 & II & LV & 于国海 & 吉林省鸟类新纪录一一一沙丘鹤 \\
\hline Grus canadensis & 沙丘鹤 & II & LV & 程雅畅 & 辽宁省鸟类新纪录_沙丘鹤及其在国内的分布 \\
\hline Grus canadensis & 沙丘鹤 & II & LV & 钟业喜 & 鄱阳湖自然保护区生物多样性保护研究 \\
\hline Grus canadensis & 沙丘鹤 & II & $\mathrm{LV}$ & 马建华 & 扎龙保护区鹤类基本状况及保护对策 \\
\hline
\end{tabular}


顾垒，闻丞，罗玫，王吴，吕植. 中国最受关注濒危物种保护现状快速评价的新方法探讨. 生物多样性，2015，23(5)：583-590. http://www. biodiversity-science. net/CN/article/downloadArticleFile. do?attachType=PDF\&id=10075

\begin{tabular}{|c|c|c|c|c|c|}
\hline Grus grus & 灰鹤 & II & $\begin{array}{l}\text { 无危 } \\
\text { /LC }\end{array}$ & YANG Yang & Effects of Group Size on Vigilance Behavior of Wintering Common Cranes Grus grus \\
\hline Grus grus & 灰鹤 & II & $\begin{array}{l}\text { 无危 } \\
\text { /LC }\end{array}$ & Fengshan LI & Number and distribution of cranes wintering at Poyang Lake, China during 2011 - 2012 \\
\hline Grus grus & 灰鹤 & II & $\begin{array}{l}\text { 无危 } \\
\text { /LC }\end{array}$ & 战永佳 & 北京湿地越冬灰鹤食性的初步分析 \\
\hline Grus grus & 灰鹤 & II & $\begin{array}{l}\text { 无危 } \\
\text { /LC }\end{array}$ & 战永佳 & 北京野鸭湖湿地自然保护区灰鹤_Grusgrus_的越冬生态研究 \\
\hline Grus grus & 灰鹤 & II & $\begin{array}{l}\text { 无危 } \\
\text { /LC }\end{array}$ & 战永佳 & 北京野鸭湖湿地自然保护区越冬灰鹤受食栖息地选择研究 \\
\hline Grus grus & 灰鹤 & II & $\begin{array}{l}\text { 无危 } \\
\text { /LC }\end{array}$ & 黄炳辉 & 黄河湿地灰鹤越冬集群和受食地生境特征的研究 \\
\hline Grus grus & 灰鹤 & II & $\begin{array}{l}\text { 无危 } \\
\text { /LC }\end{array}$ & 张希明 & 灰鹤秋季迁徙行为研究 \\
\hline Grus grus & 灰鹤 & II & $\begin{array}{l}\text { 无危 } \\
\text { /LC }\end{array}$ & 董瑞伶 & 基于 3S 技术灰鹤冬季生境选择研究 \\
\hline Grus grus & 灰鹤 & II & $\begin{array}{l}\text { 无危 } \\
\text { /LC }\end{array}$ & 柴文志 & 内蒙古图牧吉夏季灰鹤受食地生境初步研究 \\
\hline Grus grus & 灰鹤 & II & 无危 & 单继红 & 鄱阳湖区灰鹤越冬种群数量与分布动态及其影响因素 \\
\hline
\end{tabular}


顾垒，闻丞，罗玫，王吴，吕植. 中国最受关注濒危物种保护现状快速评价的新方法探讨. 生物多样性，2015，23(5)：583-590. http://www. biodiversity-science. net/CN/article/downloadArticleFile. do?attachType=PDF\&id=10075

\begin{tabular}{|c|c|c|c|c|c|}
\hline & & & $/ \mathrm{LC}$ & & \\
\hline \multirow[t]{2}{*}{ Grus grus } & 灰鹤 & II & 无危 & 邵明勤 & 鄱阳湖越冬灰鹤和白枕鹤的数量与集群特征 \\
\hline & & & $/ \mathrm{LC}$ & & \\
\hline \multirow[t]{2}{*}{ Grus grus } & 灰鹤 & II & 无危 & 李忠秋 & 盐城灰鹤（Grus grus）越冬种群动态及行为观察 \\
\hline & & & $/ \mathrm{LC}$ & & \\
\hline \multirow[t]{2}{*}{ Grus grus } & 灰鹤 & II & 无危 & 李学友 & 云南拉市海灰鹤的越冬行为初步观察 \\
\hline & & & $/ \mathrm{LC}$ & & \\
\hline \multirow[t]{2}{*}{ Grus grus } & 灰鹤 & II & 无危 & 陈文华 & 云南丽江拉市海越冬前 、中期灰鹤(Grus grus)行为初步研究 \\
\hline & & & $/ \mathrm{LC}$ & & \\
\hline \multirow[t]{2}{*}{ Grus grus } & 灰鹤 & II & 无危 & 张文 & 云南省拉市海越冬灰鹤的生境利用研究 \\
\hline & & & $/ \mathrm{LC}$ & & \\
\hline \multirow[t]{2}{*}{ Grus japonensis } & 丹顶鹤 & I & 濒危 & 吴庆明 & 丹顶鹤春迁期受食栖息地多尺度选择一一一以双台河口保护区为例 \\
\hline & & & $/ \mathrm{EN}$ & & \\
\hline \multirow[t]{2}{*}{ Grus japonensis } & 丹顶鹤 & I & 濒危 & 张玉峰 & 河北㴒河口湿地鸟类多样性调查 \\
\hline & & & /EN & & \\
\hline \multirow[t]{2}{*}{ Grus japonensis } & 丹顶鹤 & I & 濒危 & 赵 越 & 洪河湿地夏季丹顶鹤受食生境初步研究 \\
\hline & & & /EN & & \\
\hline \multirow[t]{2}{*}{ Grus japonensis } & 丹顶鹤 & I & 濒危 & 吴海杰 & 基于 GIS、RS 的盐城国家级珍禽自然保护区丹顶鹤生态安全研究 \\
\hline & & & /EN & & \\
\hline
\end{tabular}


顾垒，闻丞，罗玫，王吴，吕植. 中国最受关注濒危物种保护现状快速评价的新方法探讨. 生物多样性，2015，23(5)：583-590. http://www. biodiversity-science. net/CN/article/downloadArticleFile. do?attachType=PDF\&id=10075

\begin{tabular}{|c|c|c|c|c|c|}
\hline Grus japonensis & 丹顶鹤 & I & $\begin{array}{l}\text { 濒危 } \\
\text { /EN }\end{array}$ & 王加连 & 江苏省盐城滩涂野生动物资源调查研究 \\
\hline Grus japonensis & 丹顶鹤 & I & $\begin{array}{l}\text { 濒危 } \\
\text { /EN }\end{array}$ & 孙贤斌 & 江苏盐城海滨区域丹顶鹤适宜越冬生境变化 \\
\hline Grus japonensis & 丹顶鹤 & I & $\begin{array}{l}\text { 濒危 } \\
\text { /EN }\end{array}$ & 唐博雅 & 辽宁双台河口自然保护区景观破碎化研究 \\
\hline Grus japonensis & 丹顶鹤 & I & $\begin{array}{l}\text { 濒危 } \\
\text { /EN }\end{array}$ & 周景英 & 内蒙古图牧吉自然保护区春季迁徙水鸟多样性研究 \\
\hline Grus japonensis & 丹顶鹤 & I & $\begin{array}{l}\text { 濒危 } \\
\text { /EN }\end{array}$ & 令狐克鸿 & 三江自然保护区丹顶鹤春季受食生境初步研究 \\
\hline Grus japonensis & 丹顶鹤 & I & $\begin{array}{l}\text { 濒危 } \\
\text { /EN }\end{array}$ & 李维平 & 陕西黄河湿地水鸟调查研究 \\
\hline Grus japonensis & 丹顶鹤 & I & $\begin{array}{l}\text { 濒危 } \\
\text { /EN }\end{array}$ & 邹红菲 & 扎龙自然保护区丹顶鹤巢的内分布型及巢域 \\
\hline Grus leucogeranus & 白鹤 & I & $\begin{array}{l}\text { 极危 } \\
\text { /CR }\end{array}$ & 李凤山 & 2011-2012 年冬季中国鄱阳湖越冬鹤类的数量和分布 \\
\hline Grus leucogeranus & 白鹤 & I & $\begin{array}{l}\text { 极危 } \\
\text { /CR }\end{array}$ & 刘观华 & 2012 年冬季鄱阳湖大型越冬水鸟数量与分布 \\
\hline Grus leucogeranus & 白鹤 & I & 极危 & 张希画 & 黄河三角洲自然保护区鹤类种类、数量动态监测初步分析 \\
\hline
\end{tabular}


顾垒，闻丞，罗玫，王吴，吕植. 中国最受关注濒危物种保护现状快速评价的新方法探讨. 生物多样性，2015，23(5)：583-590. http://www. biodiversity-science. net/CN/article/downloadArticleFile. do?attachType=PDF\&id=10075

\begin{tabular}{|c|c|c|c|c|c|}
\hline & & & /CR & & \\
\hline \multirow[t]{2}{*}{ Grus leucogeranus } & 白鹤 & I & 极危 & 单继红 & 近十年来鄱阳湖区越冬白鹤种群数量与分布 \\
\hline & & & /CR & & \\
\hline \multirow[t]{2}{*}{ Grus leucogeranus } & 白鹤 & I & 极危 & 舒特生 & 九岭山国家级自然保护区鸟类资源的研究 \\
\hline & & & /CR & & \\
\hline \multirow[t]{2}{*}{ Grus leucogeranus } & 白鹤 & I & 极危 & 盛显和 & 康山湖区候鸟自然保护区鸟类资源现状及保护 \\
\hline & & & /CR & & \\
\hline \multirow[t]{2}{*}{ Grus leucogeranus } & 白鹤 & I & 极危 & 孔维尧 & 莫莫格自然保护区白鹤秋季迁徙停歇期受食生境选择 \\
\hline & & & /CR & & \\
\hline \multirow[t]{2}{*}{ Grus leucogeranus } & 白鹤 & I & 极危 & 姜维军 & 内蒙古图牧吉春季白鹤受食地生境初步研究 \\
\hline & & & /CR & & \\
\hline \multirow[t]{2}{*}{ Grus leucogeranus } & 白鹤 & I & 极危 & 钱法文 & 鄱阳湖都昌候鸟自然保护区丰水期和枯水期鸟类多样性 \\
\hline & & & /CR & & \\
\hline \multirow[t]{2}{*}{ Grus leucogeranus } & 白鹤 & I & 极危 & 朱奇 & 鄱阳湖国家级自然保 护区 2007-2009 年越冬期水鸟数量与分 \\
\hline & & & /CR & & \\
\hline \multirow[t]{2}{*}{ Grus leucogeranus } & 白鹤 & I & 极危 & 朱奇 & 鄱阳湖国家级自然保护区白鹤、东方白鹳和小天鹅种群数量与分布 \\
\hline & & & /CR & & \\
\hline \multirow[t]{2}{*}{ Grus leucogeranus } & 白鹤 & I & 极危 & 陈冰 & 鄱阳湖国家级自然保护区食块茎鸟类种群数量与水位的关系 \\
\hline & & & /CR & & \\
\hline
\end{tabular}


顾垒，闻丞，罗玫，王吴，吕植. 中国最受关注濒危物种保护现状快速评价的新方法探讨. 生物多样性，2015，23(5)：583-590. http://www. biodiversity-science. net/CN/article/downloadArticleFile. do?attachType=PDF\&id=10075

\begin{tabular}{|c|c|c|c|c|c|}
\hline Grus leucogeranus & 白鹤 & I & $\begin{array}{l}\text { 极危 } \\
\text { /CR }\end{array}$ & 吴建东 & 鄱阳湖沙湖越冬白鹤的数量分布及其与食物和水深的关系 \\
\hline Grus leucogeranus & 白鹤 & I & $\begin{array}{l}\text { 极危 } \\
\text { /CR }\end{array}$ & 张琼 & 鄱阳湖越冬白鹤家庭行为 \\
\hline Grus leucogeranus & 白鹤 & I & $\begin{array}{l}\text { 极危 } \\
\text { /CR }\end{array}$ & 王 磊 & 图牧吉自然保护区白鹤秋季受食地生境初步研究 \\
\hline Grus leucogeranus & 白鹤 & I & $\begin{array}{l}\text { 极危 } \\
\text { /CR }\end{array}$ & 何芬奇 & 数源鸟类纪录解析 \\
\hline Grus leucogeranus & 白鹤 & I & $\begin{array}{l}\text { 极危 } \\
\text { /CR }\end{array}$ & 韩联宪 & 云南发现高原山鹑和白鹤 \\
\hline Grus leucogeranus & 白鹤 & I & $\begin{array}{l}\text { 极危 } \\
\text { /CR }\end{array}$ & 李 枫 & 扎龙湿地白鹤春季停歇地昼间行为时间分配及活动规律 \\
\hline Grus monacha & 白头鹤 & I & $\begin{array}{l}\text { 易危 } \\
\text { /VU }\end{array}$ & 李林 & 白头鹤繁殖地分布研究 \\
\hline Grus monacha & 白头鹤 & I & $\begin{array}{l}\text { 易危 } \\
\text { /VU }\end{array}$ & 曲媛媛 & 北京野鸭湖湿地自然保护区迁徙水鸟调查 \\
\hline Grus monacha & 白头鹤 & I & $\begin{array}{l}\text { 易危 } \\
\text { /VU }\end{array}$ & 周慧 & 崇明东滩冬季水鸟生态位分析 \\
\hline Grus monacha & 白头鹤 & I & 易危 & 张佰莲 & 崇明东滩越冬白头鹤生境适宜性评价 \\
\hline
\end{tabular}


顾垒，闻丞，罗玫，王吴，吕植. 中国最受关注濒危物种保护现状快速评价的新方法探讨. 生物多样性，2015，23(5)：583-590. http://www. biodiversity-science. net/CN/article/downloadArticleFile. do?attachType=PDF\&id=10075

\begin{tabular}{|c|c|c|c|c|c|}
\hline & & & $/ \mathrm{VU}$ & & \\
\hline \multirow[t]{2}{*}{ Grus monacha } & 白头鹤 & I & 易危 & 张佰莲 & 崇明东滩自然保护区越冬白头鹤警戒行为的观察 \\
\hline & & & $/ \mathrm{VU}$ & & \\
\hline \multirow[t]{2}{*}{ Grus monacha } & 白头鹤 & I & 易危 & 汪志刚 & 枞阳县生物多样性现状与保护对策 \\
\hline & & & /VU & & \\
\hline \multirow[t]{2}{*}{ Grus monacha } & 白头鹤 & I & 易危 & 赵格勒日图 & 达春湖自然保护区珍稀濒危水禽的分布特点及其保护研究 \\
\hline & & & $/ \mathrm{VU}$ & & \\
\hline \multirow[t]{2}{*}{ Grus monacha } & 白头鹤 & I & 易危 & 陈宏宇 & 达里诺尔自然保护区鸟类区系组成及生态分布 \\
\hline & & & $/ \mathrm{VU}$ & & \\
\hline \multirow[t]{2}{*}{ Grus monacha } & 白头鹤 & I & 易危 & 陈宏宇 & 达里诺尔自然保护区鸟类去洗组成及群落结构研究 \\
\hline & & & /VU & & \\
\hline \multirow[t]{2}{*}{ Grus monacha } & 白头鹤 & I & 易危 & 张广明 & 丹东鸭绿江口湿地自然保护区动物与生物多样性评价体系研究 \\
\hline & & & /VU & & \\
\hline \multirow[t]{2}{*}{ Grus monacha } & 白头鹤 & I & 易危 & 蒋科毅 & 杭州湾及钱塘江河口南岸滨海湿地鸟类群落多样性及其对滩涂围厓的响应 \\
\hline & & & /VU & & \\
\hline \multirow[t]{2}{*}{ Grus monacha } & 白头鹤 & I & 易危 & 贾久满 & 河北省唐海湿地生物多样性评价 \\
\hline & & & /VU & & \\
\hline \multirow[t]{2}{*}{ Grus monacha } & 白头鹤 & I & 易危 & 周绍春 & 黑龙江大沾河湿地国家级自然保护区鸟类多样性及其保护 \\
\hline & & & /VU & & \\
\hline
\end{tabular}


顾垒，闻丞，罗玫，王吴，吕植. 中国最受关注濒危物种保护现状快速评价的新方法探讨. 生物多样性，2015，23(5)：583-590. http://www. biodiversity-science. net/CN/article/downloadArticleFile. do?attachType=PDF\&id=10075

\begin{tabular}{|c|c|c|c|c|c|}
\hline Grus monacha & 白头鹤 & I & $\begin{array}{l}\text { 易危 } \\
\text { /VU }\end{array}$ & 张佰莲 & 黑龙江大沾河自然保护区白头鹤生境质量评价 \\
\hline Grus monacha & 白头鹤 & I & $\begin{array}{l}\text { 易危 } \\
\text { /VU }\end{array}$ & 张立芝 & 黑龙江库尔滨河湿地自然保护区湿地及野生动植物资源 \\
\hline Grus monacha & 白头鹤 & I & $\begin{array}{l}\text { 易危 } \\
\text { /VU }\end{array}$ & 王丽 & 黑龙江三江自然保护区春季水禽迁徙初步研究 \\
\hline Grus monacha & 白头鹤 & I & $\begin{array}{l}\text { 易危 } \\
\text { /VU }\end{array}$ & 曹国斌 & 湖北沉湖自然保护区鸟类多样性研究 \\
\hline Grus monacha & 白头鹤 & I & $\begin{array}{l}\text { 易危 } \\
\text { /VU }\end{array}$ & 楼利高 & 湖北上涉湖湿地自然保护区冬季鸟类物种多样性 \\
\hline Grus monacha & 白头鹤 & I & $\begin{array}{l}\text { 易危 } \\
\text { /VU }\end{array}$ & 李万德 & 湖北省龙感湖自然湿地保护区建设探讨 \\
\hline Grus monacha & 白头鹤 & I & $\begin{array}{l}\text { 易危 } \\
\text { /VU }\end{array}$ & 陈学涛 & 黄河三角洲国家级自然保护区越冬丹顶鹤警戒行为的观察 \\
\hline Grus monacha & 白头鹤 & I & $\begin{array}{l}\text { 易危 } \\
\text { /VU }\end{array}$ & 李福震 & 辉河自然保护区鸟类多样性保护现状与对策 \\
\hline Grus monacha & 白头鹤 & I & $\begin{array}{l}\text { 易危 } \\
\text { /VU }\end{array}$ & 李月秋 & 基于灰关联度的扎龙白头鹤停歇数量影响因素分析 \\
\hline Grus monacha & 白头鹤 & I & 易危 & 卜楠龙 & 吉林莫莫格国家级自然保护区春季水鸟多样性分析 \\
\hline
\end{tabular}


顾垒，闻丞，罗玫，王吴，吕植. 中国最受关注濒危物种保护现状快速评价的新方法探讨. 生物多样性，2015，23(5)：583-590. http://www. biodiversity-science. net/CN/article/downloadArticleFile. do?attachType=PDF\&id=10075

\begin{tabular}{|c|c|c|c|c|c|}
\hline & & & $/ \mathrm{VU}$ & & \\
\hline \multirow[t]{2}{*}{ Grus monacha } & 白头鹤 & I & 易危 & 姚桂萍 & 吉林向海国家级自然保护区湿地类型、湿地保护的重要性及保护对策 \\
\hline & & & /VU & & \\
\hline \multirow[t]{2}{*}{ Grus monacha } & 白头鹤 & I & 易危 & 胡利平 & 建立湖南横岭湖国家级湿地自然保护区的构想 \\
\hline & & & /VU & & \\
\hline \multirow[t]{2}{*}{ Grus monacha } & 白头鹤 & I & 易危 & 戴科伟 & 江苏盐城湿地珍禽国家级自然保护区生态安全研究 \\
\hline & & & /VU & & \\
\hline \multirow[t]{2}{*}{ Grus monacha } & 白头鹤 & I & 易危 & 戴年华 & 江西共青城市鄱阳湖区域非繁殖期鸟类多样性初步研究 \\
\hline & & & /VU & & \\
\hline \multirow[t]{2}{*}{ Grus monacha } & 白头鹤 & I & 易危 & 章旭日 & 江西南矶山国家级自然保护区非繁殖期鸟类多样性研究 \\
\hline & & & /VU & & \\
\hline \multirow[t]{2}{*}{ Grus monacha } & 白头鹤 & I & 易危 & 于晶晶 & 辽宁獾子洞湿地水鸟春秋迁徙研究 \\
\hline & & & /VU & & \\
\hline \multirow[t]{2}{*}{ Grus monacha } & 白头鹤 & I & 易危 & 乌力吉 & 蒙古达乌尔草原生态区的现状与保护 \\
\hline & & & /VU & & \\
\hline \multirow[t]{2}{*}{ Grus monacha } & 白头鹤 & I & 易危 & 周景英 & 内蒙古图牧吉自然保护区春季迁徙水鸟多样性研究 \\
\hline & & & /VU & & \\
\hline \multirow[t]{2}{*}{ Grus monacha } & 白头鹤 & I & 易危 & 钱法文 & 鄱阳湖都昌候鸟自然保护区丰水期和枯水期鸟类多样性 \\
\hline & & & /VU & & \\
\hline
\end{tabular}


顾垒，闻丞，罗玫，王吴，吕植. 中国最受关注濒危物种保护现状快速评价的新方法探讨. 生物多样性，2015，23(5)：583-590. http://www. biodiversity-science. net/CN/article/downloadArticleFile. do?attachType=PDF\&id=10075

\begin{tabular}{|c|c|c|c|c|c|}
\hline Grus monacha & 白头鹤 & I & $\begin{array}{l}\text { 易危 } \\
\text { /VU }\end{array}$ & 黄文杰 & 赛城湖冬候鸟分布之谜 \\
\hline Grus monacha & 白头鹤 & I & $\begin{array}{l}\text { 易危 } \\
\text { /VU }\end{array}$ & 彭宝明 & 赛罕乌拉自然保护区珍稀鸟兽多样性监测初步研究 \\
\hline Grus monacha & 白头鹤 & I & $\begin{array}{l}\text { 易危 } \\
\text { /VU }\end{array}$ & 郑聚峰 & 升金湖枯水期滩地土壤 CO_2_C 释放通量及有机碳稳定性研究 \\
\hline Grus monacha & 白头鹤 & I & $\begin{array}{l}\text { 易危 } \\
\text { /VU }\end{array}$ & 周波 & 升金湖越冬白头鹤集群变化及领域行为 \\
\hline Grus monacha & 白头鹤 & I & $\begin{array}{l}\text { 易危 } \\
\text { /VU }\end{array}$ & 胡徐文 & 试论贵池十八索保护区 资源现状及保护对策 \\
\hline Grus monacha & 白头鹤 & I & $\begin{array}{l}\text { 易危 } \\
\text { /VU }\end{array}$ & 钟福生 & 西洞庭湖湿地鸟类群落组成_多样性及保护对策 \\
\hline Grus monacha & 白头鹤 & I & $\begin{array}{l}\text { 易危 } \\
\text { /VU }\end{array}$ & 郭玉民 & 小兴安岭白头鹤繁殖地种群数量初步调查 \\
\hline Grus monacha & 白头鹤 & I & $\begin{array}{l}\text { 易危 } \\
\text { /VU }\end{array}$ & 陈亮 & 兴凯湖春季水鸟昼间迁徙研究 \\
\hline Grus monacha & 白头鹤 & I & $\begin{array}{l}\text { 易危 } \\
\text { /VU }\end{array}$ & 刘伯文 & 伊春市带岭区鸟类区系报告 \\
\hline Grus monacha & 白头鹤 & I & 易危 & 李长看 & 郑州黄河湿地省级自然保护区鸟类区系和多样性 \\
\hline
\end{tabular}


顾垒，闻丞，罗玫，王吴，吕植. 中国最受关注濒危物种保护现状快速评价的新方法探讨. 生物多样性，2015，23(5)：583-590. http://www biodiversity-science. net/CN/article/downloadArticleFile. do?attachType=PDF\&id=10075

\begin{tabular}{|c|c|c|c|c|c|}
\hline & & & /VU & & \\
\hline \multirow[t]{2}{*}{ Grus nigricollis } & 黑颈鹤 & I & 易危 & Mary A. BISHOP & Number and distribution of Black-necked Cranes wintering in Zhigatse Prefecture, Tibet \\
\hline & & & /VU & & \\
\hline \multirow[t]{2}{*}{ Grus nigricollis } & 黑颈鹤 & I & 易危 & 张同 & Status and behavior of the Black-necked Crane (Grus nigricollis) in the Altun Mountain \\
\hline & & & /VU & & Reserve, Xinjiang \\
\hline \multirow[t]{2}{*}{ Grus nigricollis } & 黑颈鹤 & I & 易危 & 马鸣 & 阿尔金山-昆仑山鸟类区系调查 \\
\hline & & & /VU & & \\
\hline \multirow[t]{2}{*}{ Grus nigricollis } & 黑颈鹤 & I & 易危 & 广粉良 & 藏北黑颈鹤繁殖前期的昼间活动时间分配 \\
\hline & & & /VU & & \\
\hline \multirow[t]{2}{*}{ Grus nigricollis } & 黑颈鹤 & I & 易危 & 罗祖奎 & 草海自然保护区春季鸟类群落结构及现存生物量 \\
\hline & & & /VU & & \\
\hline \multirow[t]{2}{*}{ Grus nigricollis } & 黑颈鹤 & I & 易危 & 包新康 & 大、小苏干湖湿地鸟类多样性季节变化 \\
\hline & & & /VU & & \\
\hline \multirow[t]{2}{*}{ Grus nigricollis } & 黑颈鹤 & I & 易危 & 高兴国 & 大山包越冬黑颈鹤种群数量变化与其栖息环境变迁的分析 \\
\hline & & & /VU & & \\
\hline \multirow[t]{2}{*}{ Grus nigricollis } & 黑颈鹤 & I & 易危 & 王显明 & 党河湿地黑颈鹤及其候鸟资源动态 \\
\hline & & & $/ \mathrm{VU}$ & & \\
\hline \multirow[t]{2}{*}{ Grus nigricollis } & 黑颈鹤 & I & 易危 & 张同 & 东昆仑_阿尔金山地区黑颈鹤种群分布与秋季数量变化 \\
\hline & & & /VU & & \\
\hline
\end{tabular}


顾垒，闻丞，罗玫，王吴，吕植. 中国最受关注濒危物种保护现状快速评价的新方法探讨. 生物多样性，2015，23(5)：583-590. http://www. biodiversity-science. net/CN/article/downloadArticleFile. do?attachType=PDF\&id=10075

\begin{tabular}{|c|c|c|c|c|c|}
\hline Grus nigricollis & 黑颈鹤 & I & $\begin{array}{l}\text { 易危 } \\
\text { /VU }\end{array}$ & 杨彦斌 & 甘肃玛曲湿地资源保护对策与建议 \\
\hline Grus nigricollis & 黑颈鹤 & I & $\begin{array}{l}\text { 易危 } \\
\text { /VU }\end{array}$ & 宝力德 & 甘肃盐池湾国家级自然保护区黑颈鹤繁殖习性的观察 \\
\hline Grus nigricollis & 黑颈鹤 & I & $\begin{array}{l}\text { 易危 } \\
\text { /VU }\end{array}$ & 张立勋 & 甘肃盐池湾自然保护区黑颈鹤繁殖生态学研究 \\
\hline Grus nigricollis & 黑颈鹤 & I & $\begin{array}{l}\text { 易危 } \\
\text { /VU }\end{array}$ & 代红炀 & 黑颈鹤的保护研究 \\
\hline Grus nigricollis & 黑颈鹤 & I & $\begin{array}{l}\text { 易危 } \\
\text { /VU }\end{array}$ & 马 鸣 & 黑颈鹤在新疆罗布泊和昆仑山分布及种群状况 \\
\hline Grus nigricollis & 黑颈鹤 & I & $\begin{array}{l}\text { 易危 } \\
\text { /VU }\end{array}$ & 黄瑞 & 会泽黑颈鹤国家级自然保护区生态旅游的 SWOT 分析及开发对策 \\
\hline Grus nigricollis & 黑颈鹤 & I & $\begin{array}{l}\text { 易危 } \\
\text { /VU }\end{array}$ & 路飞 & 基于动态管理的自然保护区功能分区_省略_初探_以寻甸黑颈鹤自然保护区为例 \\
\hline Grus nigricollis & 黑颈鹤 & I & $\begin{array}{l}\text { 易危 } \\
\text { /VU }\end{array}$ & 拉多 & 拉鲁湿地国家级自然保护区水鸟资源初报 \\
\hline Grus nigricollis & 黑颈鹤 & I & $\begin{array}{l}\text { 易危 } \\
\text { /VU }\end{array}$ & 马鸣 & 罗布泊野骆驼自然保护区的鸟类记录 \\
\hline Grus nigricollis & 黑颈鹤 & I & 易危 & 符建荣 & 米亚罗自然保护区的鸟类资源 \\
\hline
\end{tabular}


顾垒，闻丞，罗玫，王吴，吕植. 中国最受关注濒危物种保护现状快速评价的新方法探讨. 生物多样性，2015，23(5)：583-590. http://www. biodiversity-science. net/CN/article/downloadArticleFile. do?attachType=PDF\&id=10075

\begin{tabular}{|c|c|c|c|c|c|}
\hline & & & /VU & & \\
\hline \multirow[t]{2}{*}{ Grus nigricollis } & 黑颈鹤 & I & 易危 & 郭亚慧 & 内蒙古达里诺尔湿地与甘肃省尔海湿地鹤类的比较 \\
\hline & & & /VU & & \\
\hline \multirow[t]{2}{*}{ Grus nigricollis } & 黑颈鹤 & I & 易危 & 罗祖奎 & 莎草科植物植被恢复试验及其对黑颈鹤分布的影响 * \\
\hline & & & /VU & & \\
\hline \multirow[t]{2}{*}{ Grus nigricollis } & 黑颈鹤 & I & 易危 & 张秀雷 & 世界自然基金会青海玉树物种调查_黑颈鹤_雪豹_虫草咏叹调 \\
\hline & & & /VU & & \\
\hline \multirow[t]{2}{*}{ Grus nigricollis } & 黑颈鹤 & I & 易危 & 盛行军 & 四川茶垭沟湿地陆栖脊椎动物区系分析 \\
\hline & & & $/ \mathrm{VU}$ & & \\
\hline \multirow[t]{2}{*}{ Grus nigricollis } & 黑颈鹤 & I & 易危 & 王楠 & 四川海子山黑颈鹤繁殖种群的分布与数量 \\
\hline & & & /VU & & \\
\hline \multirow[t]{2}{*}{ Grus nigricollis } & 黑颈鹤 & I & 易危 & 符建荣 & 四川海子山自然保护区鸟类资源及区系 \\
\hline & & & /VU & & \\
\hline \multirow[t]{2}{*}{ Grus nigricollis } & 黑颈鹤 & I & 易危 & 窦亮 & 四川若尔盖湿地国家级自然保护区繁殖期黑颈鹤调查 \\
\hline & & & /VU & & \\
\hline \multirow[t]{2}{*}{ Grus nigricollis } & 黑颈鹤 & I & 易危 & 蒋政权 & 四川若尔盖湿地黑颈鹤繁殖调查初报 \\
\hline & & & $/ \mathrm{VU}$ & & \\
\hline \multirow[t]{2}{*}{ Grus nigricollis } & 黑颈鹤 & I & 易危 & 符建荣 & 四川长沙贡玛自然保护区的鸟类资源 \\
\hline & & & /VU & & \\
\hline
\end{tabular}


顾垒，闻丞，罗玫，王吴，吕植. 中国最受关注濒危物种保护现状快速评价的新方法探讨. 生物多样性，2015，23(5)：583-590. http://www. biodiversity-science. net/CN/article/downloadArticleFile. do?attachType=PDF\&id=10075

\begin{tabular}{|c|c|c|c|c|c|}
\hline Grus nigricollis & 黑颈鹤 & I & $\begin{array}{l}\text { 易危 } \\
\text { /VU }\end{array}$ & 唐金刚 & 威宁草海莎草科 5 种挺水植物种子萌发研究 \\
\hline Grus nigricollis & 黑颈鹤 & I & $\begin{array}{l}\text { 易危 } \\
\text { /VU }\end{array}$ & 格桑顿珠 & 西藏拉萨市拉鲁湿地自然保护区环境资源调查报告 \\
\hline Grus nigricollis & 黑颈鹤 & I & $\begin{array}{l}\text { 易危 } \\
\text { /VU }\end{array}$ & 雷桂林 & 西藏林周卡孜水库黑颈鹤夜宿特性研究 \\
\hline Grus nigricollis & 黑颈鹤 & I & $\begin{array}{l}\text { 易危 } \\
\text { /VU }\end{array}$ & 次仁顿珠 & 西藏澎波河谷越冬黑颈鹤的行为观察 \\
\hline Grus nigricollis & 黑颈鹤 & I & $\begin{array}{l}\text { 易危 } \\
\text { /VU }\end{array}$ & 王斌 & 西藏珠穆朗玛峰国家级自然保护区鸟类群落结构与多样性 \\
\hline Grus nigricollis & 黑颈鹤 & I & $\begin{array}{l}\text { 易危 } \\
\text { /VU }\end{array}$ & 萨根古丽 & 新疆罗布泊野骆驼国家级自然保护区生物多样性特点及保护对策 \\
\hline Grus nigricollis & 黑颈鹤 & I & $\begin{array}{l}\text { 易危 } \\
\text { /VU }\end{array}$ & 李小双 & 寻甸黑颈鹤自然保护区建设的必要性、存在问题及建议 \\
\hline Grus nigricollis & 黑颈鹤 & I & $\begin{array}{l}\text { 易危 } \\
\text { /VU }\end{array}$ & 仓决卓玛 & 雅鲁藏布江中游自然保护区澎波河谷核心区黑颈鹤种群动态和夜宿特性 \\
\hline Grus nigricollis & 黑颈鹤 & I & $\begin{array}{l}\text { 易危 } \\
\text { /VU }\end{array}$ & 刘强 & 云南纳帕海湿地越冬黑鹳种群动态和迁徙 \\
\hline Grus nigricollis & 黑颈鹤 & I & 易危 & 贺 鹏 & 云南纳帕海越冬黑颈鹤夜栖地特征 \\
\hline
\end{tabular}


顾垒，闻丞，罗玫，王吴，吕植. 中国最受关注濒危物种保护现状快速评价的新方法探讨. 生物多样性，2015，23(5)：583-590. http://www. biodiversity-science. net/CN/article/downloadArticleFile. do?attachType=PDF\&id=10075

\begin{tabular}{|c|c|c|c|c|c|}
\hline & & & $/ \mathrm{VU}$ & & \\
\hline \multirow[t]{2}{*}{ Grus nigricollis } & 黑颈鹤 & I & 易危 & 桑正林 & 云南省大山包黑颈鹤自然保护区生境破碎化调查研究 \\
\hline & & & /VU & & \\
\hline \multirow[t]{2}{*}{ Grus nigricollis } & 黑颈鹤 & I & 易危 & 李国刚 & 云南省巧家马树黑颈鹤越冬习性研究 \\
\hline & & & /VU & & \\
\hline \multirow[t]{2}{*}{ Grus vipio } & 白枕鹤 & II & 易危 & & Migratory stopover and wintering locations in eastern China used by White-naped Cranes Grus \\
\hline & & & /VU & & vipio and Hooded Cranes G. monacha as determined by satellite tracking \\
\hline \multirow[t]{2}{*}{ Grus vipio } & 白枕鹤 & II & 易危 & & 白枕鹤春季迁徙行为时间分配及活动规律 \\
\hline & & & $/ \mathrm{VU}$ & & \\
\hline \multirow[t]{2}{*}{ Grus vipio } & 白枕鹤 & II & 易危 & & 白枕鹤的核型分析 \\
\hline & & & $/ \mathrm{VU}$ & & \\
\hline \multirow[t]{2}{*}{ Grus vipio } & 白枕鹤 & II & 易危 & & 白枕鹤的呼吸系统及其生态适应 \\
\hline & & & /VU & & \\
\hline \multirow[t]{2}{*}{ Grus vipio } & 白枕鹤 & II & 易危 & & 白枕鹤的领域防御行为 \\
\hline & & & /VU & & \\
\hline \multirow[t]{2}{*}{ Grus vipio } & 白枕鹤 & II & 易危 & & 白枕鹤性别的分子鉴定方法 \\
\hline & & & /VU & & \\
\hline \multirow[t]{2}{*}{ Grus vipio } & 白枕鹤 & II & 易危 & & 白枕鹤在丹东首次被发现及食性迁徒规律的研究 \\
\hline & & & /VU & & \\
\hline
\end{tabular}


顾垒，闻丞，罗玫，王吴，吕植. 中国最受关注濒危物种保护现状快速评价的新方法探讨. 生物多样性，2015，23(5)：583-590. http://www. biodiversity-science. net/CN/article/downloadArticleFile. do?attachType=PDF\&id=10075

\begin{tabular}{|c|c|c|c|c|}
\hline Grus vipio & 白枕鹤 & II & $\begin{array}{l}\text { 易危 } \\
\text { /VU }\end{array}$ & 丹顶鹤与白枕鹤的领域比较研究 \\
\hline Grus vipio & 白枕鹤 & II & $\begin{array}{l}\text { 易危 } \\
\text { /VU }\end{array}$ & 丹顶鹤与白枕鹤语图结构分析及比较 \\
\hline Grus vipio & 白枕鹤 & II & $\begin{array}{l}\text { 易危 } \\
\text { /VU }\end{array}$ & 黑龙江七星河春季白枕鹤受食生境初步研究 \\
\hline Grus vipio & 白枕鹤 & II & $\begin{array}{l}\text { 易危 } \\
\text { /VU }\end{array}$ & 黑龙江扎龙自然保护区白枕鹤巢址选择特征 \\
\hline Grus vipio & 白枕鹤 & II & $\begin{array}{l}\text { 易危 } \\
\text { /VU }\end{array}$ & 挠力河流域丹顶鹤、白枕鹤种群动态及其与环境关系研究 \\
\hline Grus vipio & 白枕鹤 & II & $\begin{array}{l}\text { 易危 } \\
\text { /VU }\end{array}$ & 七星河湿地白枕鹤繁殖前期行为研究 \\
\hline Grus vipio & 白枕鹤 & II & $\begin{array}{l}\text { 易危 } \\
\text { /VU }\end{array}$ & 三江平原白枕鹤餒化期受食行为研究 \\
\hline Grus vipio & 白枕鹤 & II & $\begin{array}{l}\text { 易危 } \\
\text { /VU }\end{array}$ & 图牧吉春季白枕鹤受食生境初步研究 \\
\hline Grus vipio & 白枕鹤 & II & $\begin{array}{l}\text { 易危 } \\
\text { /VU }\end{array}$ & 扎龙保护区白枕鹤求偶期食性与采食偏好 \\
\hline Grus vipio & 白枕鹤 & II & 易危 & 扎龙湿地白枕鹤捊化期受食生境选择 \\
\hline
\end{tabular}


顾垒，闻丞，罗玫，王吴，吕植. 中国最受关注濒危物种保护现状快速评价的新方法探讨. 生物多样性，2015，23(5)：583-590. http://www. biodiversity-science. net/CN/article/downloadArticleFile. do?attachType=PDF\&id=10075

\begin{tabular}{|c|c|c|c|c|c|}
\hline & & & $/ \mathrm{VU}$ & & \\
\hline \multirow[t]{2}{*}{ Grus vipio } & 白枕鹤 & II & 易危 & & 扎龙湿地春季白枕鹤繁殖行为观察与分析 \\
\hline & & & /VU & & \\
\hline \multirow[t]{2}{*}{ Grus vipio } & 白枕鹤 & II & 易危 & & 扎龙湿地丹顶鹤和白枕鹤求偶期受食生境对比分析 \\
\hline & & & /VU & & \\
\hline \multirow[t]{2}{*}{ Grus vipio } & 白枕鹤 & II & 易危 & & 扎龙湿地野生与散养白枕鹤繁殖前期受食生境选择对比分析 \\
\hline & & & /VU & & \\
\hline \multirow[t]{2}{*}{ Grus virgo } & 㝨羽鹤 & II & 无危 & 张莉 & 白银库伦自然保护区鸟类区系组成及生态分布研究 \\
\hline & & & $/ \mathrm{LC}$ & & \\
\hline \multirow[t]{2}{*}{ Grus virgo } & 㝨羽鹤 & II & 无危 & 高 峰 & 北京发现㝨羽鹤 \\
\hline & & & $/ \mathrm{LC}$ & & \\
\hline \multirow[t]{2}{*}{ Grus virgo } & 㝨羽鹤 & II & 无危 & 赵格日乐图 & 达麥湖自然保护区珍稀濒危水禽的分布特点及其保护研究 \\
\hline & & & $/ \mathrm{LC}$ & & \\
\hline \multirow[t]{2}{*}{ Grus virgo } & 㝨羽鹤 & II & 无危 & 陈宏宇 & 达里诺尔自然保护区鸟类区系组成及生态分布 \\
\hline & & & $/ \mathrm{LC}$ & & \\
\hline \multirow[t]{2}{*}{ Grus virgo } & 蒿羽鹤 & II & 无危 & 赵格日乐图 & 内蒙古达㐘湖国家级自然保护区鸟类群落结构和动态研究 \\
\hline & & & $/ \mathrm{LC}$ & & \\
\hline \multirow[t]{2}{*}{ Grus virgo } & 䓯羽鹤 & II & 无危 & 宋江平 & 宁夏沙坡头国家级自然保护区湿地水禽多样性动态 \\
\hline & & & $/ \mathrm{LC}$ & & \\
\hline
\end{tabular}


顾垒，闻丞，罗玫，王吴，吕植. 中国最受关注濒危物种保护现状快速评价的新方法探讨. 生物多样性，2015，23(5)：583-590. http://www. biodiversity-science. net/CN/article/downloadArticleFile. do?attachType=PDF\&id=10075

\begin{tabular}{|c|c|c|c|c|c|}
\hline Grus virgo & 㝨羽鹤 & II & 无危 & 时 良 & 陕西省黄河湿地冬季鸟类群落初步研究 \\
\hline Grus virgo & 蓑羽鹤 & II & $\begin{array}{l}\text { 无危 } \\
\text { /LC }\end{array}$ & 安春林 & 蓑羽鹤繁殖新记录 \\
\hline Grus virgo & 蓑羽鹤 & II & $\begin{array}{l}\text { 无危 } \\
\text { /LC }\end{array}$ & 任永奇 & 袁羽鹤在鄂尔多斯桃-阿海子的繁殖记录 \\
\hline Gyps bengalensis & 白背兀鹑 & I & 极危 & 杨岗 & 西双版纳热带地区的几种大型鸟类 \\
\hline Habenaria delavayi & 厚瓣玉凤花 & $\begin{array}{l}\text { 未列 } \\
\text { 入 }\end{array}$ & $\begin{array}{l}\text { 易危 } \\
\text { /VU }\end{array}$ & YI-BO LUO & $\begin{array}{l}\text { Ctyological studies on some representative species of the tribe Orchideae (Orchidaceae) from } \\
\text { China }\end{array}$ \\
\hline Habenaria delavayi & 厚瓣玉凤花 & $\begin{array}{l}\text { 未列 } \\
\lambda\end{array}$ & $\begin{array}{l}\text { 易危 } \\
\text { /VU }\end{array}$ & Hong-Hwa Chen & OrchidBase 2.0: Comprehensive Collection of Orchidaceae Floral Transcriptomes \\
\hline Habenaria delavayi & 厚瓣玉凤花 & $\begin{array}{l}\text { 未列 } \\
\lambda\end{array}$ & $\begin{array}{l}\text { 易危 } \\
\text { /VU }\end{array}$ & Jeffrey Wang & Phytochemical Analysis of Medicinal Plants with kidney Protective Activities \\
\hline Habenaria fargesii & 雅致玉凤花 & $\begin{array}{l}\text { 未列 } \\
\lambda\end{array}$ & $\begin{array}{l}\text { 易危 } \\
\text { /VU }\end{array}$ & 吴振涛 & 雅致玉凤花一一陕西省兰科一新分布种 \\
\hline Habenaria mairei & 棒距玉凤花 & $\begin{array}{l}\text { 未列 } \\
\lambda\end{array}$ & $\begin{array}{l}\text { 易危 } \\
\text { /VU }\end{array}$ & YI-BO LUO & $\begin{array}{l}\text { Ctyological studies on some representative species of the tribe Orchideae (Orchidaceae) from } \\
\text { China }\end{array}$ \\
\hline Helarctos malayanus & 马来熊 & I & 数据 & Ya-ping Zhang & Phylogeny of the bears (Ursidae) based on nuclear and mitochondrial genes \\
\hline
\end{tabular}


顾垒，闻丞，罗玫，王吴，吕植. 中国最受关注濒危物种保护现状快速评价的新方法探讨. 生物多样性，2015，23(5)：583-590. http://www. biodiversity-science. net/CN/article/downloadArticleFile. do?attachType=PDF\&id=10075

\begin{tabular}{|c|c|c|c|c|c|}
\hline & & & 不足 & & \\
\hline Helarctos malayanus & 马来熊 & I & $\begin{array}{l}/ \mathrm{DD} \\
\text { 数据 } \\
\text { 不足 }\end{array}$ & 陈国亮 & 雌性马来熊亲仔行为的初步观察 \\
\hline Helarctos malayanus & 马来熊 & I & $\begin{array}{l}/ \mathrm{DD} \\
\text { 数据 } \\
\text { 不足 }\end{array}$ & 刘群秀 & 马来熊的研究现状及保护对策探析 \\
\hline Helarctos malayanus & 马来熊 & I & $\begin{array}{l}\text { /DD } \\
\text { 数据 } \\
\text { 不足 }\end{array}$ & 曹继兴 & 马来熊亲密关系和等级序位的研究 \\
\hline Helarctos malayanus & 马来熊 & I & $\begin{array}{l}/ \mathrm{DD} \\
\text { 数据 } \\
\text { 不足 }\end{array}$ & 刘振生 & 圈养马来熊行为节律和时间分配的季节变化 \\
\hline Helarctos malayanus & 马来熊 & I & $\begin{array}{l}/ \mathrm{DD} \\
\text { 数据 } \\
\text { 不足 }\end{array}$ & 兰存子 & 圈养马来熊行为节律及其影响因子的研究 \\
\hline Helarctos malayanus & 马来熊 & I & $\begin{array}{l}/ \mathrm{DD} \\
\text { 数据 } \\
\text { 不足 }\end{array}$ & 郑建清 & 圈养马来熊夏季对运动场区域利用研究 \\
\hline
\end{tabular}


顾垒，闻丞，罗玫，王吴，吕植. 中国最受关注濒危物种保护现状快速评价的新方法探讨. 生物多样性，2015，23(5)：583-590. http://www biodiversity-science. net/CN/article/downloadArticleFile. do?attachType=PDF\&id=10075

\begin{tabular}{|c|c|c|c|c|c|}
\hline & & & $/ \mathrm{DD}$ & & \\
\hline \multirow[t]{2}{*}{ Hirundapus cochinchinensis } & 灰喉针尾雨燕 & II & 无危 & & 我国南海热带珊瑚礁岛屿生物多样性研究 \\
\hline & & & $/ \mathrm{LC}$ & & \\
\hline \multirow[t]{2}{*}{ Holcoglossum quasipinifolium } & 槽舌兰 & II & 濒危 & 秦小波 & 槽舌兰资源调查及特有品种试验研究 \\
\hline & & & $/ \mathrm{EN}$ & & \\
\hline \multirow[t]{2}{*}{ Holcoglossum quasipinifolium } & 槽舌兰 & II & 濒危 & 胡浩 & 兰科槽舌兰属 DNA 条形码研究及其系统发育分析 \\
\hline & & & /EN & & \\
\hline \multirow{2}{*}{ Holcoglossum quasipinifolium } & 槽舌兰 & II & 濒危 & 金效华 & 兰科槽舌兰属的系统学研究 \\
\hline & & & $/ \mathrm{EN}$ & & \\
\hline \multirow[t]{2}{*}{ Hoplobatrachus rugulosus } & 虎纹蛙 & II & 无危 & Lin Haoran & EFFEC TS OF DOPAMINE , ESTRADIOL AND TESTOSTERONE ON GONADOTROPIN \\
\hline & & & $/ \mathrm{LC}$ & & RELEASE FROM THE PITUITARY FRAGMENTS OF Rana rugulosa \\
\hline \multirow[t]{2}{*}{ Hoplobatrachus rugulosus } & 虎纹蛙 & II & 无危 & Chen Shao & Isolation and characterization of microsatellite loci in tiger frog(Hoplobatrachus rugulosus) \\
\hline & & & $/ \mathrm{LC}$ & & \\
\hline \multirow[t]{2}{*}{ Hoplobatrachus rugulosus } & 虎纹蛙 & II & 无危 & Liqun Lu, Xianle & Phenotypic characterization and phylogenetic analysis of a virulent Bacillus cereus strain from \\
\hline & & & $/ \mathrm{LC}$ & Yang & the Tiger frog,Hoplobatrachus rugulosus Wiegmann \\
\hline \multirow[t]{2}{*}{ Hoplobatrachus rugulosus } & 虎纹蛙 & II & 无危 & 邹佩贞 & 广东韶关地区虎纹蛙・黑斑蛙染色体核型分析 \\
\hline & & & $/ \mathrm{LC}$ & & \\
\hline \multirow[t]{2}{*}{ Hoplobatrachus rugulosus } & 虎纹蛙 & II & 无危 & 江剑平 & 虎纹蛙( RANA RUGULOSA) 视网膜结构与环境适应性的研究 \\
\hline & & & $/ \mathrm{LC}$ & & \\
\hline
\end{tabular}


顾垒，闻丞，罗玫，王吴，吕植. 中国最受关注濒危物种保护现状快速评价的新方法探讨. 生物多样性，2015，23(5)：583-590. http://www biodiversity-science. net/CN/article/downloadArticleFile. do?attachType=PDF\&id=10075

\begin{tabular}{|c|c|c|c|c|c|}
\hline Hoplobatrachus rugulosus & 虎纹蛙 & II & $\begin{array}{l}\text { 无危 } \\
\text { /LC }\end{array}$ & 张小爱 & 虎纹蛙 Sox 基因的 PCR 扩增及 SSCP 分析 \\
\hline Hoplobatrachus rugulosus & 虎纹蛙 & II & $\begin{array}{l}\text { 无危 } \\
\text { /LC }\end{array}$ & 张小爱 & 虎纹蛙 Sox 基因的研究 \\
\hline Hoplobatrachus rugulosus & 虎纹蛙 & II & $\begin{array}{l}\text { 无危 } \\
\text { /LC }\end{array}$ & 马小浩 & 虎纹蛙的繁殖特征及其蝌蚪攻击行为 \\
\hline Hoplobatrachus rugulosus & 虎纹蛙 & II & $\begin{array}{l}\text { 无危 } \\
\text { /LC }\end{array}$ & 邵晨 & 虎纹蛙的食物多样性及营养生态位 \\
\hline Hoplobatrachus rugulosus & 虎纹蛙 & II & $\begin{array}{l}\text { 无危 } \\
\text { /LC }\end{array}$ & 耿宝荣 & 虎纹蛙的食性与捕食行为的研究 \\
\hline Hoplobatrachus rugulosus & 虎纹蛙 & II & $\begin{array}{l}\text { 无危 } \\
\text { /LC }\end{array}$ & 潘鸿春 & 虎纹蛙和大树蛙肾细胞超微结构及其与环境适应性的关系 \\
\hline Hoplobatrachus rugulosus & 虎纹蛙 & II & $\begin{array}{l}\text { 无危 } \\
\text { /LC }\end{array}$ & 虞鹏程 & 虎纹蛙蝌蚪与幼蛙肌肉蛋白质的双向电泳图谱对比分析 \\
\hline Hoplobatrachus rugulosus & 虎纹蛙 & II & $\begin{array}{l}\text { 无危 } \\
\text { /LC }\end{array}$ & 江剑平 & 虎纹蛙视觉器官组织学研究 \\
\hline Hoplobatrachus rugulosus & 虎纹蛙 & II & $\begin{array}{l}\text { 无危 } \\
\text { /LC }\end{array}$ & 张小爱 & 虎纹蛙四个 Sox 基因的克隆及序列分析 \\
\hline Hoplobatrachus rugulosus & 虎纹蛙 & II & 无危 & 潘鸿春 & 虎纹蛙外周血细胞的超微结构 \\
\hline
\end{tabular}


顾垒，闻丞，罗玫，王吴，吕植. 中国最受关注濒危物种保护现状快速评价的新方法探讨. 生物多样性，2015，23(5)：583-590. http://www biodiversity-science. net/CN/article/downloadArticleFile. do?attachType=PDF\&id=10075

\begin{tabular}{|c|c|c|c|c|c|}
\hline & & & $/ \mathrm{LC}$ & & \\
\hline \multirow[t]{2}{*}{ Hoplobatrachus rugulosus } & 虎纹蛙 & II & 无危 & 江剑平 & 虎纹蛙消化道解剖学观察 \\
\hline & & & $/ \mathrm{LC}$ & & \\
\hline \multirow[t]{2}{*}{ Hoplobatrachus rugulosus } & 虎纹蛙 & II & 无危 & 张盛周 & 虎纹蛙消化道两种内分泌细胞的免疫组织化学定位 \\
\hline & & & $/ \mathrm{LC}$ & & \\
\hline \multirow[t]{2}{*}{ Hoplobatrachus rugulosus } & 虎纹蛙 & II & 无危 & 陈学棋 & 虎纹蛙消化腺组织学观察 \\
\hline & & & $/ \mathrm{LC}$ & & \\
\hline \multirow[t]{2}{*}{ Hoplobatrachus rugulosus } & 虎纹蛙 & II & 无危 & 林植华 & 虎纹蛙肢体超常再生和畸变二例 \\
\hline & & & $/ \mathrm{LC}$ & & \\
\hline \multirow[t]{2}{*}{ Hoplobatrachus rugulosus } & 虎纹蛙 & II & 无危 & 陈东海 & 华东地区虎纹蛙三个地理种群的遗传多样性与遗传结构研究 \\
\hline & & & $/ \mathrm{LC}$ & & \\
\hline \multirow[t]{2}{*}{ Hoplobatrachus rugulosus } & 虎纹蛙 & II & 无危 & 胡知洣 & 棘胸蛙、虎纹蛙、黑斑蛙血细胞的比较 \\
\hline & & & $/ \mathrm{LC}$ & & \\
\hline \multirow[t]{2}{*}{ Hoplobatrachus rugulosus } & 虎纹蛙 & II & 无危 & 邵晨 & 金华地区虎纹蛙消化道形态解剖学观察 \\
\hline & & & $/ \mathrm{LC}$ & & \\
\hline \multirow[t]{2}{*}{ Hoplobatrachus rugulosus } & 虎纹蛙 & II & 无危 & 李洋 & 三种蛙皮肤组织结构、生物活性物质的定位及其提取物的抑菌比较研究 \\
\hline & & & /LC & & \\
\hline \multirow[t]{2}{*}{ Hoplobatrachus rugulosus } & 虎纹蛙 & II & 无危 & 阮琴 & 酸胁迫对虎纹蛙血液流变学指标的影响 \\
\hline & & & /LC & & \\
\hline
\end{tabular}


顾垒，闻丞，罗玫，王吴，吕植. 中国最受关注濒危物种保护现状快速评价的新方法探讨. 生物多样性，2015，23(5)：583-590. http://www biodiversity-science. net/CN/article/downloadArticleFile. do?attachType=PDF\&id=10075

\begin{tabular}{|c|c|c|c|c|c|}
\hline Hoplobatrachus rugulosus & 虎纹蛙 & II & 无危 & 邵晨 & 浙江地区虎纹蛙肥满度研究 \\
\hline Hoplobatrachus rugulosus & 虎纹蛙 & II & 无危 & 王宇 & 浙江地区虎纹蛙遗传多样性与遗传结构研究 \\
\hline Hoplobatrachus rugulosus & 虎纹蛙 & II & 无危 & 计翔 & 浙江丽水虎纹蛙形态特征的两性异形和食性 \\
\hline Hoplobatrachus rugulosus & 虎纹蛙 & II & 无危 & 杜友爱 & 中国虎纹蛙脾微血管铸型的扫描电镜观察 \\
\hline Horsfieldia pandurifolia & 琴叶风吹楠 & II & 濒危 & Min Cao & $\begin{array}{l}\text { Ecology of seed germination of eight non-pioneer tree species from a tropical seasonal rain } \\
\text { forest in southwest China }\end{array}$ \\
\hline Horsfieldia pandurifolia & 琴叶风吹楠 & II & 濒危 & 段安安 & 几种风吹楠属植物脂肪酸成分分析 \\
\hline Horsfieldia pandurifolia & 琴叶风吹楠 & II & 濒危 & 张君鸿 & 琴叶风吹楠苗木年生长节律调查 \\
\hline Horsfieldia pandurifolia & 琴叶风吹楠 & II & $\begin{array}{l}\text { 濒危 } \\
\text { /EN }\end{array}$ & 吴裕 & 琴叶风吹楠生物学特征观察 \\
\hline Horsfieldia pandurifolia & 琴叶风吹楠 & II & $\begin{array}{l}\text { 濒危 } \\
\text { /EN }\end{array}$ & 曹敏 & 西双版纳热带季节雨林四种珍稀濒危树种种子萌发对脱水和光的响应 \\
\hline Horsfieldia pandurifolia & 琴叶风吹楠 & II & 濒危 & 杨晓玲 & 油料植物琴叶风吹楠种子萌发观察 \\
\hline
\end{tabular}


顾垒，闻丞，罗玫，王吴，吕植. 中国最受关注濒危物种保护现状快速评价的新方法探讨. 生物多样性，2015，23(5)：583-590. http://www. biodiversity-science. net/CN/article/downloadArticleFile. do?attachType=PDF\&id=10075

Horsfieldia pandurifolia

琴叶风吹楠

濒危

许玉兰

Horsfieldia pandurifolia

琴叶风吹楠

琴叶风吹楠

琴叶风吹楠

Horsfieldia pandurifolia

Horsfieldia pandurifolia

琴叶风吹楠

Horsfieldia pandurifolia

琴叶风吹楠

Horsfieldia pandurifolia

琴叶风吹楠

Horsfieldia pandurifolia

琴叶风吹楠

Horsfieldia tetratepala
濒危

II 濒危吴裕

/EN

II 濒危吴裕

/EN

II 濒危 段安安

珍稀油料树种琴叶风吹楠种子含油量及脂肪酸成分分析

II 濒危吴裕

珍稀油料树种琴叶风吹楠种子萌发习性

珍稀油料植物琴叶风吹楠种子性状及含油率的变异分析

/EN

II

濒危

/EN

II 未评 曹坤芳

价
不同生态习性执带雨林树种的幼苗对光能的利用与耗散 
顾垒，闻丞，罗玫，王吴，吕植. 中国最受关注濒危物种保护现状快速评价的新方法探讨. 生物多样性，2015，23(5)：583-590. http://www. biodiversity-science. net/CN/article/downloadArticleFile. do?attachType=PDF\&id=10075

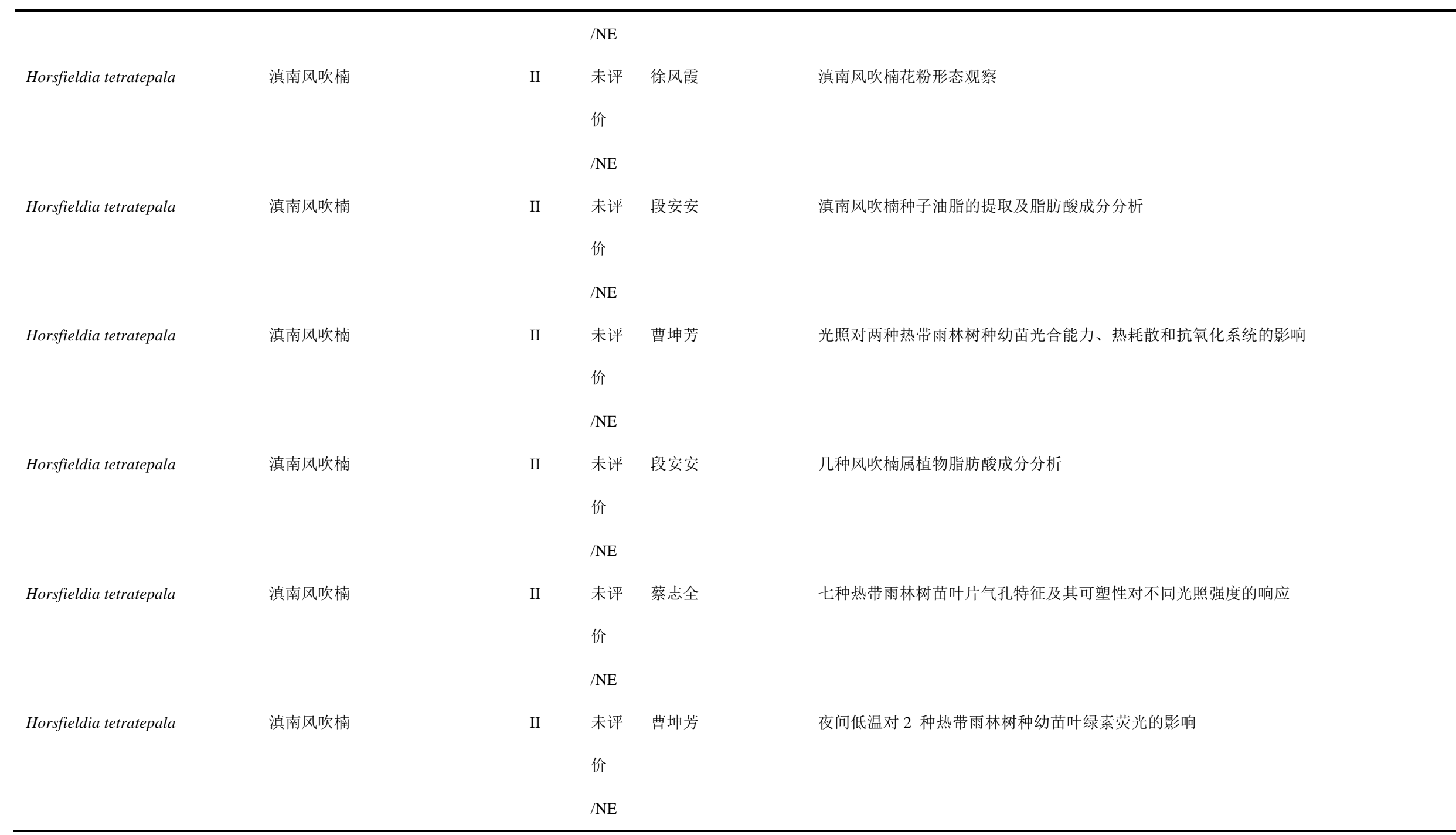


顾垒，闻丞，罗玫，王吴，吕植. 中国最受关注濒危物种保护现状快速评价的新方法探讨. 生物多样性，2015，23(5)：583-590. http://www biodiversity-science. net/CN/article/downloadArticleFile. do?attachType=PDF\&id=10075

\begin{tabular}{|c|c|c|c|c|c|}
\hline \multirow[t]{2}{*}{ Ianthocincla bieti } & 白点噪鹛 & 未列 & 易危 & 崔茂欢 & 兰坪云岭省级自然保护区及周边地区鸟类多样性 \\
\hline & & 入 & /VU & & \\
\hline \multirow[t]{2}{*}{ Ianthocincla bieti } & 白点噪䴗 & 未列 & 易危 & 刘阳 & 略谈白点噪倜的分类与分布 \\
\hline & & 入 & /VU & & \\
\hline \multirow[t]{2}{*}{ Ianthocincla bieti } & 白点噪鹤 & 未列 & 易危 & 符建荣 & 米亚罗自然保护区的鸟类资源 \\
\hline & & 入 & /VU & & \\
\hline \multirow[t]{2}{*}{ Ianthocincla bieti } & 白点噪倜 & 未列 & 易危 & 叶昌云 & 全球性易危物种“白点鹋”惊现螺䯽山 \\
\hline & & 入 & /VU & & \\
\hline \multirow[t]{2}{*}{ Ianthocincla bieti } & 白点噪䴗 & 未列 & 易危 & 刘鲁明 & 云南省玉龙雪山自然保护区鸟类资源调查 \\
\hline & & 入 & /VU & & \\
\hline \multirow[t]{2}{*}{ Ianthocincla bieti } & 白点噪䴗 & 未列 & 易危 & 李晶晶 & 珠穆朗玛峰国家级自然保护区鸟类区系及其垂直分布特征 \\
\hline & & 入 & $/ \mathrm{VU}$ & & \\
\hline \multirow[t]{2}{*}{ Ichthyaetus relictus } & 遗鸥 & I & 易危 & 陈劲 & 白银库伦遗鸥自然保护区鸟类群落结构的季节动态 \\
\hline & & & /VU & & \\
\hline \multirow[t]{2}{*}{ Ichthyaetus relictus } & 遗鸥 & I & 易危 & 吴秀杰 & 白银库伦自然保护区春季鸟类多样性研究 \\
\hline & & & /VU & & \\
\hline \multirow[t]{2}{*}{ Ichthyaetus relictus } & 遗鸥 & I & 易危 & 智颖鄚 & 包头南海湿地水体环境季节性变化与生态功能货币化评价 \\
\hline & & & /VU & & \\
\hline Ichthyaetus relictus & 遗鸥 & I & 易危 & 曲媛媛 & 北京野鸭湖湿地自然保护区迁徙水鸟调查 \\
\hline
\end{tabular}


顾垒，闻丞，罗玫，王吴，吕植. 中国最受关注濒危物种保护现状快速评价的新方法探讨. 生物多样性，2015，23(5)：583-590. http://www. biodiversity-science. net/CN/article/downloadArticleFile. do?attachType=PDF\&id=10075

\begin{tabular}{|c|c|c|c|c|c|}
\hline & & & $/ \mathrm{VU}$ & & \\
\hline \multirow[t]{2}{*}{ Ichthyaetus relictus } & 遗鸥 & I & 易危 & 赵格日乐图 & 达春湖自然保护区珍稀濒危水禽的分布特点及其保护研究 \\
\hline & & & $/ \mathrm{VU}$ & & \\
\hline \multirow[t]{2}{*}{ Ichthyaetus relictus } & 遗鸥 & I & 易危 & 梁犁丽 & 鄂尔多斯遗鸥保护区植被 2 水资源模拟及其调控 \\
\hline & & & $/ \mathrm{VU}$ & & \\
\hline \multirow[t]{2}{*}{ Ichthyaetus relictus } & 遗鸥 & I & 易危 & 邢小军 & 鄂尔多斯遗鸥自然保护区湿地水量平衡分析 \\
\hline & & & $/ \mathrm{VU}$ & & \\
\hline \multirow[t]{2}{*}{ Ichthyaetus relictus } & 遗鸥 & I & 易危 & 徐益力 & 杭州湾滨海湿地鸟类现状和资源保护对策研究 \\
\hline & & & $/ \mathrm{VU}$ & & \\
\hline \multirow[t]{2}{*}{ Ichthyaetus relictus } & 遗鸥 & I & 易危 & 孙砚峰 & 河北平山湿地水鸟群落结构及黑鹳的受食生境选择 \\
\hline & & & $/ \mathrm{VU}$ & & \\
\hline \multirow[t]{2}{*}{ Ichthyaetus relictus } & 遗鸥 & I & 易危 & 陈刚 & 黑河流域中游湿地水禽资源与保护 \\
\hline & & & $/ \mathrm{VU}$ & & \\
\hline \multirow[t]{2}{*}{ Ichthyaetus relictus } & 遗鸥 & I & 易危 & 问慧 & 内蒙古白银库伦鸟类多样性研究 \\
\hline & & & /VU & & \\
\hline \multirow[t]{2}{*}{ Ichthyaetus relictus } & 遗鸥 & I & 易危 & 陈劲 & 内蒙古白银库伦遗鸥自然保护区两栖爬行动物调查 \\
\hline & & & $/ \mathrm{VU}$ & & \\
\hline \multirow[t]{2}{*}{ Ichthyaetus relictus } & 遗鸥 & I & 易危 & 苗春林 & 内蒙古南海子湿地鸟类群落监测 \\
\hline & & & $/ \mathrm{VU}$ & & \\
\hline
\end{tabular}


顾垒，闻丞，罗玫，王吴，吕植. 中国最受关注濒危物种保护现状快速评价的新方法探讨. 生物多样性，2015，23(5)：583-590. http://www biodiversity-science. net/CN/article/downloadArticleFile. do?attachType=PDF\&id=10075

\begin{tabular}{|c|c|c|c|c|c|}
\hline \multirow[t]{2}{*}{ Ichthyaetus relictus } & 遗鸥 & I & 易危 & 李海清 & 内蒙古图牧吉国家级自然保护区珍稀濒危鸟类种类_分布特点及保护措施 \\
\hline & & & /VU & & \\
\hline \multirow[t]{2}{*}{ Ichthyaetus relictus } & 遗鸥 & I & 易危 & 陈文杰 & 宁德市三都湾湿地与水禽资源调查初报 \\
\hline & & & $/ \mathrm{VU}$ & & \\
\hline \multirow[t]{2}{*}{ Ichthyaetus relictus } & 遗鸥 & I & 易危 & 肖红 & 陕西定边荷池湿地发现遗鸥繁殖群分布 \\
\hline & & & /VU & & \\
\hline \multirow[t]{2}{*}{ Ichthyaetus relictus } & 遗鸥 & I & 易危 & 汪青雄 & 陕西红碱淖湿地鸥科鸟类组成及分布的研究 \\
\hline & & & /VU & & \\
\hline \multirow[t]{2}{*}{ Ichthyaetus relictus } & 遗鸥 & I & 易危 & 肖红 & 陕西红碱淖湿地水鸟组成及多样性分析 \\
\hline & & & /VU & & \\
\hline \multirow[t]{2}{*}{ Ichthyaetus relictus } & 遗鸥 & I & 易危 & 汪青雄 & 陕西红碱淖遗鸥的减少育维数和杀婴行为 \\
\hline & & & /VU & & \\
\hline \multirow[t]{2}{*}{ Ichthyaetus relictus } & 遗鸥 & I & 易危 & 王中强 & 陕西榆林红碱淖湿地遗鸥野外种群及栖息地专项调查报告 \\
\hline & & & /VU & & \\
\hline \multirow[t]{2}{*}{ Ichthyaetus relictus } & 遗鸥 & I & 易危 & 贾亦飞 & 水位波动对鄱阳湖越冬白鹤及其他水鸟的影响研究 \\
\hline & & & /VU & & \\
\hline \multirow[t]{2}{*}{ Ichthyaetus relictus } & 遗鸥 & I & 易危 & 韩丽萍 & 唐海湿地和鸟类省级自然保护区鸟类资源调查研究 \\
\hline & & & /VU & & \\
\hline Ichthyaetus relictus & 遗鸥 & I & 易危 & 贾新艳 & 乌梁素海湿地鹆形目鸟类资源调查、迁徙动态及普通燕鸥_白额燕鸥的繁殖生态学研究 \\
\hline
\end{tabular}


顾垒，闻丞，罗玫，王吴，吕植. 中国最受关注濒危物种保护现状快速评价的新方法探讨. 生物多样性，2015，23(5)：583-590. http://www. biodiversity-science. net/CN/article/downloadArticleFile. do?attachType=PDF\&id=10075

\begin{tabular}{|c|c|c|c|c|c|}
\hline & & & $/ \mathrm{VU}$ & & \\
\hline \multirow[t]{2}{*}{ Ichthyaetus relictus } & 遗鸥 & I & 易危 & 马鸣 & 新疆艾比湖湿地自然保护区鸟类清单及秋季迁徙数量统计 \\
\hline & & & /VU & & \\
\hline \multirow[t]{2}{*}{ Ichthyaetus relictus } & 遗鸥 & I & 易危 & 马鸣 & 新疆艾比湖遗鸥和细嘴鸥的数量现状 \\
\hline & & & /VU & & \\
\hline \multirow[t]{2}{*}{ Ichthyaetus relictus } & 遗鸥 & I & 易危 & 高明 & 鸭绿江下游鸟类资源与生态保护研究 \\
\hline & & & $/ \mathrm{VU}$ & & \\
\hline \multirow[t]{2}{*}{ Ichthyaetus relictus } & 遗鸥 & I & 易危 & 肖红 & 遗鸥鄂尔多斯种群及繁殖分布现状 \\
\hline & & & $/ \mathrm{VU}$ & & \\
\hline \multirow[t]{2}{*}{ Ichthyaetus relictus } & 遗鸥 & I & 易危 & 高立杰 & 遗鸥繁殖期新分布一一一内蒙古袄太湿地 \\
\hline & & & /VU & & \\
\hline \multirow[t]{2}{*}{ Ichthyophis bannanicus } & 版纳鱼螈 & 未列 & 无危 & Peng Zhang, & A mitogenomic perspective on the phylogeny and biogeography of living caecilians (Amphibia: \\
\hline & & 入 & $/ \mathrm{LC}$ & Marvalee H. Wake & Gymnophiona) \\
\hline \multirow[t]{2}{*}{ Ilex chengkouensis } & & 未列 & 濒危 & 曾沧江 & 中国冬青科植物志资料 \\
\hline & & 入 & /EN & & \\
\hline \multirow[t]{3}{*}{ Impatiens wilsonii } & 白花凤仙花 & 未列 & 未评 & 刘良源 & 江西白花风仙花的生物学特征与生态习性 \\
\hline & & 入 & 价 & & \\
\hline & & & $/ \mathrm{NE}$ & & \\
\hline Indotestudo elongata & 缅甸陆龟 & II & 濒危 & LUPING ZHANG & A new species of Meteterakis Karve, 1930 (Nematoda: Heterakoidea) from Indotestudo \\
\hline
\end{tabular}


顾垒，闻丞，罗玫，王吴，吕植. 中国最受关注濒危物种保护现状快速评价的新方法探讨. 生物多样性，2015，23(5)：583-590. http://www. biodiversity-science. net/CN/article/downloadArticleFile. do?attachType=PDF\&id=10075

\begin{tabular}{|c|c|c|c|c|c|}
\hline & & & /EN & & elongata (Blyth) in China with a key to the species of Meteterakis \\
\hline \multirow[t]{2}{*}{ Indotestudo elongata } & 缅甸陆龟 & II & 濒危 & 王继梅 & 缅甸陆龟的养殖技术 \\
\hline & & & /EN & & \\
\hline \multirow[t]{2}{*}{ Indotestudo elongata } & 缅甸陆龟 & II & 濒危 & 聂刘旺 & 缅甸陆龟线粒体全基因组的测序及分析 \\
\hline & & & /EN & & \\
\hline \multirow[t]{2}{*}{ Ketupa zeylonensis } & 褐渔鸮 & II & 无危 & 雷进宇 & 湖北鸟类种数的新统计 \\
\hline & & & $/ \mathrm{LC}$ & & \\
\hline Ke tupaf lavipe & 黄脚渔鸮 & II & 无危 & 任文博 & 秦岭南麓黄脚渔鸮新分布观察初报 \\
\hline$s$ & & & $/ \mathrm{LC}$ & & \\
\hline \multirow[t]{3}{*}{ Kingdonia uniflora } & 独叶草 & I & 未评 & 周兴文 & “独叶草”并非独叶 \\
\hline & & & 价 & & \\
\hline & & & $/ \mathrm{NE}$ & & \\
\hline \multirow[t]{3}{*}{ Kingdonia uniflora } & 独叶草 & I & 未评 & YI REN & Acene and seed abortion contribute to the rarity of Kingdonia uniflora \\
\hline & & & 价 & & \\
\hline & & & $/ \mathrm{NE}$ & & \\
\hline \multirow[t]{3}{*}{ Kingdonia uniflora } & 独叶草 & I & 未评 & Yi Ren & Floral development of Kingdonia (Ranunculaceae s. l., Ranunculales) \\
\hline & & & 价 & & \\
\hline & & & $/ \mathrm{NE}$ & & \\
\hline Kingdonia uniflora & 独叶草 & I & 未评 & Yi Ren & Heterodichogamy in Kingdonia (Circaeasteraceae, Ranunculales) \\
\hline
\end{tabular}


顾垒，闻丞，罗玫，王吴，吕植. 中国最受关注濒危物种保护现状快速评价的新方法探讨. 生物多样性，2015，23(5)：583-590. http://www. biodiversity-science. net/CN/article/downloadArticleFile. do?attachType=PDF\&id=10075

NE

Kingdonia uniflora

独叶草

Kingdonia uniflora

独叶草

YI REN

价

/NE

未评 辛存林

价

/NE

Kingdonia uniflora

独叶草

价

$/ \mathrm{NE}$

Kingdonia uniflora

独叶草

Kingdonia uniflora

独叶草

I 未

李红

价

$/ \mathrm{NE}$

I 未评 贺海霞

价

/NE

Kingdonia uniflora
Low genetic diversity among populations of the rare Chinese endemic Kingdonia uniflora

revealed by RAPD analysis

白水江国家级自然保护区珍稀濒危植物现状分析及保护

濒危植物独叶草 (毛莨科) 的传粉生物学及繁育系统研究

濒危植物独叶草种群生殖生态学研究

独叶草的不育雄䓌、花被片和可育雄䓌对传粉昆虫和传粉的影响

独叶草的光合生理生态特性 
顾垒，闻丞，罗玫，王吴，吕植. 中国最受关注濒危物种保护现状快速评价的新方法探讨. 生物多样性，2015，23(5)：583-590. http://www. biodiversity-science. net/CN/article/downloadArticleFile. do?attachType=PDF\&id=10075

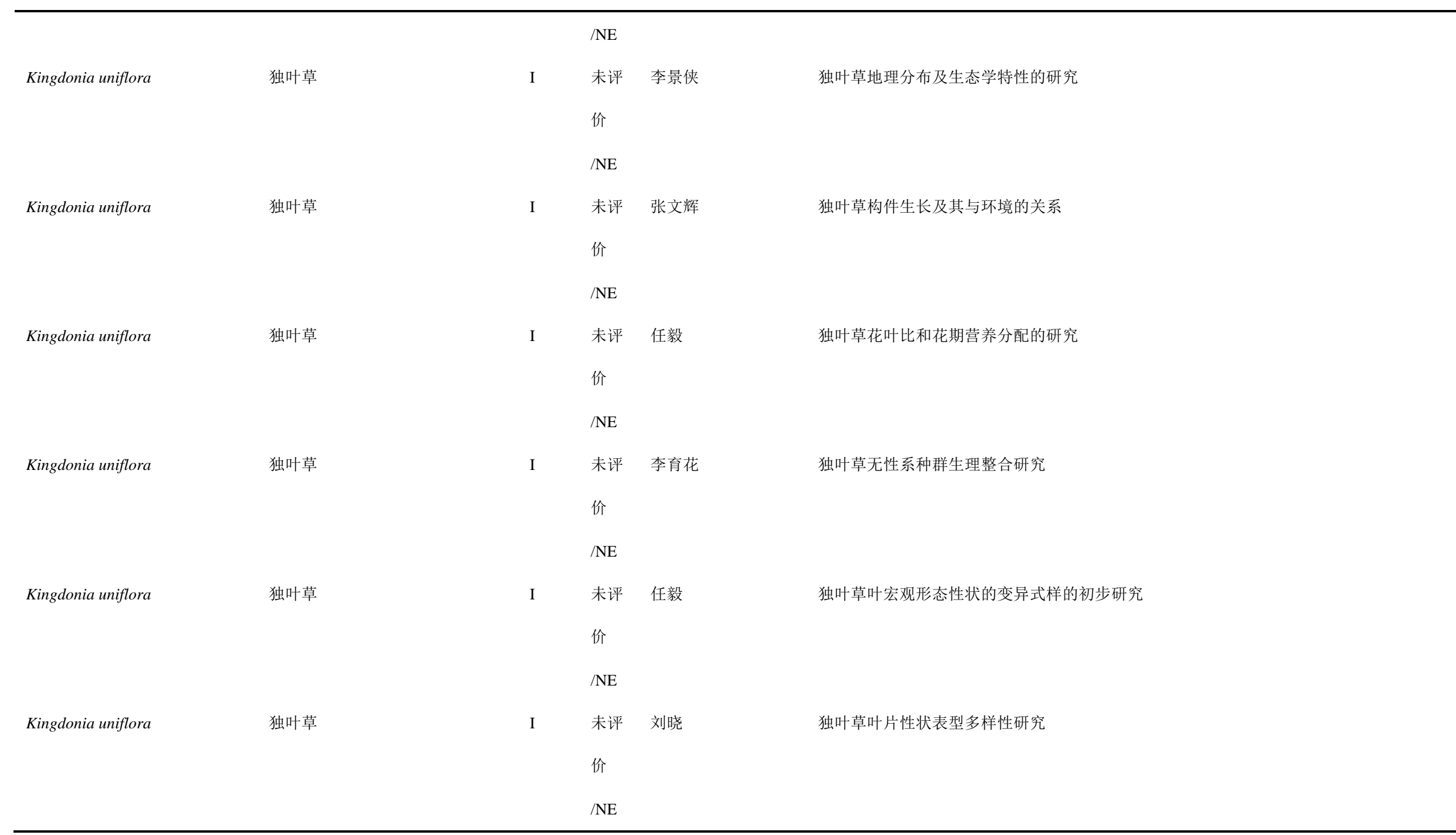


顾垒，闻丞，罗玫，王吴，吕植. 中国最受关注濒危物种保护现状快速评价的新方法探讨. 生物多样性，2015，23(5)：583-590. http://www. biodiversity-science. net/CN/article/downloadArticleFile. do?attachType=PDF\&id=10075

\begin{tabular}{|c|c|c|c|c|c|}
\hline Kingdonia uniflora & 独叶草 & I & $\begin{array}{l}\text { 未评 } \\
\text { 价 } \\
\text { /NE }\end{array}$ & 刘晓 & 独叶草叶形态性状变异与遗传多样性间的相关性研究 \\
\hline Kingdonia uniflora & 独叶草 & I & $\begin{array}{l}\text { 未评 } \\
\text { 价 } \\
\text { /NE }\end{array}$ & 任毅 & 独叶草营养繁殖方式的研究 \\
\hline Kingdonia uniflora & 独叶草 & I & $\begin{array}{l}\text { 未评 } \\
\text { 价 } \\
\text { /NE }\end{array}$ & 张文辉 & 独叶草种群年龄结构及动态分析 \\
\hline Kingdonia uniflora & 独叶草 & I & $\begin{array}{l}\text { 未评 } \\
\text { 价 } \\
\text { /NE }\end{array}$ & 李景侠 & 独叶草种群无性繁殖特性的研究 \\
\hline Kingdonia uniflora & 独叶草 & I & $\begin{array}{l}\text { 未评 } \\
\text { 价 } \\
\text { /NE }\end{array}$ & 张尊听 & 分光光度法测定太白山 20 种中草药的抗氧化活性 \\
\hline Kingdonia uniflora & 独叶草 & I & $\begin{array}{l}\text { 未评 } \\
\text { 价 } \\
\text { /NE }\end{array}$ & 唐小华 & 毛莨科心皮多样性及其系统学研究 \\
\hline Kingdonia uniflora & 独叶草 & I & 未评 & 吴建国 & 气候变化对 5 种植物分布的潜在影响 \\
\hline
\end{tabular}


顾垒，闻丞，罗玫，王吴，吕植. 中国最受关注濒危物种保护现状快速评价的新方法探讨. 生物多样性，2015，23(5)：583-590. http://www. biodiversity-science. net/CN/article/downloadArticleFile. do?attachType=PDF\&id=10075

/NE

Kingdonia uniflora

Kingdonia uniflora

Kingdonia uniflora

独叶草

Kingdonia uniflora

Kingdonia uniflora
独叶草

独叶草

独叶草

独叶草

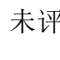

价

$/ \mathrm{NE}$

I

未评＼cjkstart贾良珍

价

$/ \mathrm{NE}$

I 未评岳明

价

$/ \mathrm{NE}$

I 未评刘喆

价

$/ \mathrm{NE}$

I 未评 王神玲

价

/NE

独叶草

张文辉

未评岳明
秦岭独叶草种群个体和构件生物量动态研究

人为干扰对独叶草生长的影响研究

太白山北坡光资源斑块与独叶草种群分布的耦合关系

太白山北坡资源斑块与独叶草种群分布耦合研究
太白山独叶草及其伴生种的种间关联研究 
顾垒，闻丞，罗玫，王吴，吕植. 中国最受关注濒危物种保护现状快速评价的新方法探讨. 生物多样性，2015，23(5)：583-590. http://www. biodiversity-science. net/CN/article/downloadArticleFile. do?attachType=PDF\&id=10075

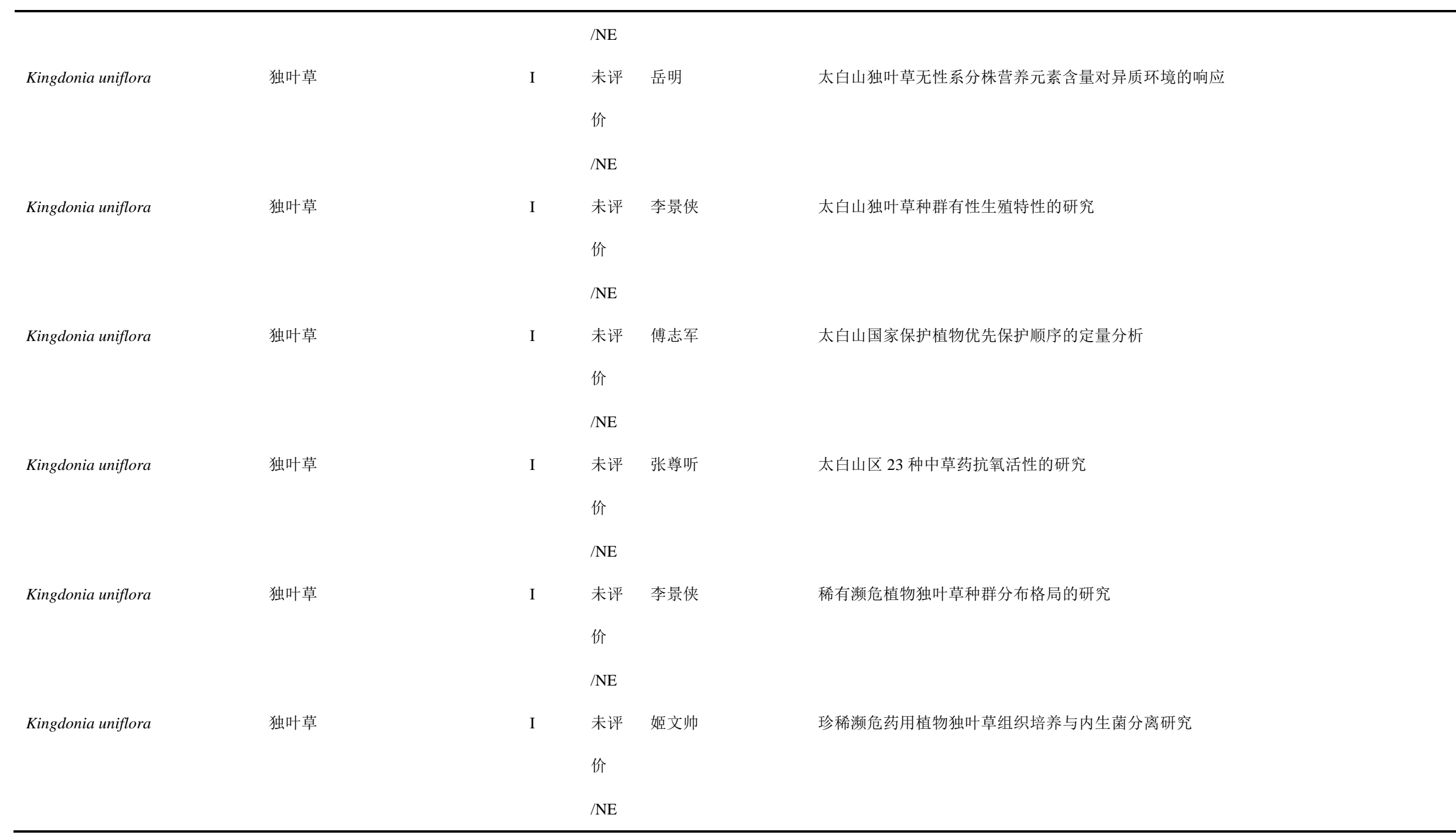


顾垒，闻丞，罗玫，王吴，吕植. 中国最受关注濒危物种保护现状快速评价的新方法探讨. 生物多样性，2015，23(5)：583-590. http://www. biodiversity-science. net/CN/article/downloadArticleFile. do?attachType=PDF\&id=10075

\begin{tabular}{|c|c|c|c|c|c|}
\hline Kingdonia uniflora & 独叶草 & I & $\begin{array}{l}\text { 未评 } \\
\text { 价 } \\
\text { /NE }\end{array}$ & 雷永吉 & 珍稀濒危植物独叶草的分布及现状研究 \\
\hline Kingdonia uniflora & 独叶草 & I & $\begin{array}{l}\text { 未评 } \\
\text { 价 } \\
\text { /NE }\end{array}$ & 程雪 & 珍稀濒危植物独叶草的生物学特性及保护对策 \\
\hline Kingdonia uniflora & 独叶草 & I & $\begin{array}{l}\text { 未评 } \\
\text { 价 } \\
\text { /NE }\end{array}$ & 李德铢 & 真双子叶基部类群十种植物的 CHS 基因家族成员分析 \\
\hline Kolkwitzia amabilis & 猬实 & $\begin{array}{l}\text { 未列 } \\
\text { 入 }\end{array}$ & $\begin{array}{l}\text { 未评 } \\
\text { 价 } \\
\text { /NE }\end{array}$ & 杨鹏 & 濒危植物猬实雄配子体发育及离体培养技术研究 \\
\hline Kolkwitzia amabilis & 猬实 & $\begin{array}{l}\text { 未列 } \\
入\end{array}$ & $\begin{array}{l}\text { 未评 } \\
\text { 价 } \\
\text { /NE }\end{array}$ & 石晓东 & 猬实不同分布区种子质量差异比较 \\
\hline Kolkwitzia amabilis & 猬实 & $\begin{array}{l}\text { 未列 } \\
\lambda\end{array}$ & $\begin{array}{l}\text { 未评 } \\
\text { 价 } \\
\text { /NE }\end{array}$ & 郭建喜 & 猬实的引种栽培 \\
\hline Kolkwitzia amabilis & 猬实 & 未列 & 未评 & 张涛 & 猬实繁殖及栽培技术 \\
\hline
\end{tabular}


顾垒，闻丞，罗玫，王吴，吕植. 中国最受关注濒危物种保护现状快速评价的新方法探讨. 生物多样性，2015，23(5)：583-590. http://www. biodiversity-science. net/CN/article/downloadArticleFile. do?attachType=PDF\&id=10075

\begin{tabular}{|c|c|c|c|c|c|}
\hline & & 入 & 价 & & \\
\hline Kolkwitzia amabilis & 猬实 & $\begin{array}{l}\text { 未列 } \\
入\end{array}$ & $\begin{array}{l}\text { /NE } \\
\text { 未评 } \\
\text { 价 }\end{array}$ & 沈植国 & 猬实花瓣色素成分及含量的初步分析 \\
\hline Kolkwitzia amabilis & 猬实 & $\begin{array}{l}\text { 未列 } \\
\text { 入 }\end{array}$ & $\begin{array}{l}\text { /NE } \\
\text { 未评 } \\
\text { 价 }\end{array}$ & 房铁梅 & 猬实下肧轴愈伤组织的生长和器官分化研究 \\
\hline Kolkwitzia amabilis & 猬实 & $\begin{array}{l}\text { 未列 } \\
\text { 入 }\end{array}$ & $\begin{array}{l}\text { /NE } \\
\text { 未评 } \\
\text { 价 }\end{array}$ & 姚雷 & 猬实引种的初步研究 \\
\hline Kolkwitzia amabilis & 猬实 & $\begin{array}{l}\text { 未列 } \\
\text { 入 }\end{array}$ & $\begin{array}{l}\text { /NE } \\
\text { 未评 } \\
\text { 价 }\end{array}$ & 高润梅 & 猬实植物群落外貌和物种多样性的研究 \\
\hline Kolkwitzia amabilis & 猬实 & $\begin{array}{l}\text { 未列 } \\
\text { 入 }\end{array}$ & $\begin{array}{l}\text { /NE } \\
\text { 未评 } \\
\text { 价 }\end{array}$ & 唐宇丹 & 猬实种子休眠特性研究 \\
\hline Kolkwitzia amabilis & 猬实 & $\begin{array}{l}\text { 未列 } \\
\text { 入 }\end{array}$ & $\begin{array}{l}\text { /NE } \\
\text { 未评 } \\
\text { 价 }\end{array}$ & 沈植国 & 我国稀有保护植物猬实研究进展 \\
\hline
\end{tabular}


顾垒，闻丞，罗玫，王吴，吕植. 中国最受关注濒危物种保护现状快速评价的新方法探讨. 生物多样性，2015，23(5)：583-590. http://www. biodiversity-science. net/CN/article/downloadArticleFile. do?attachType=PDF\&id=10075

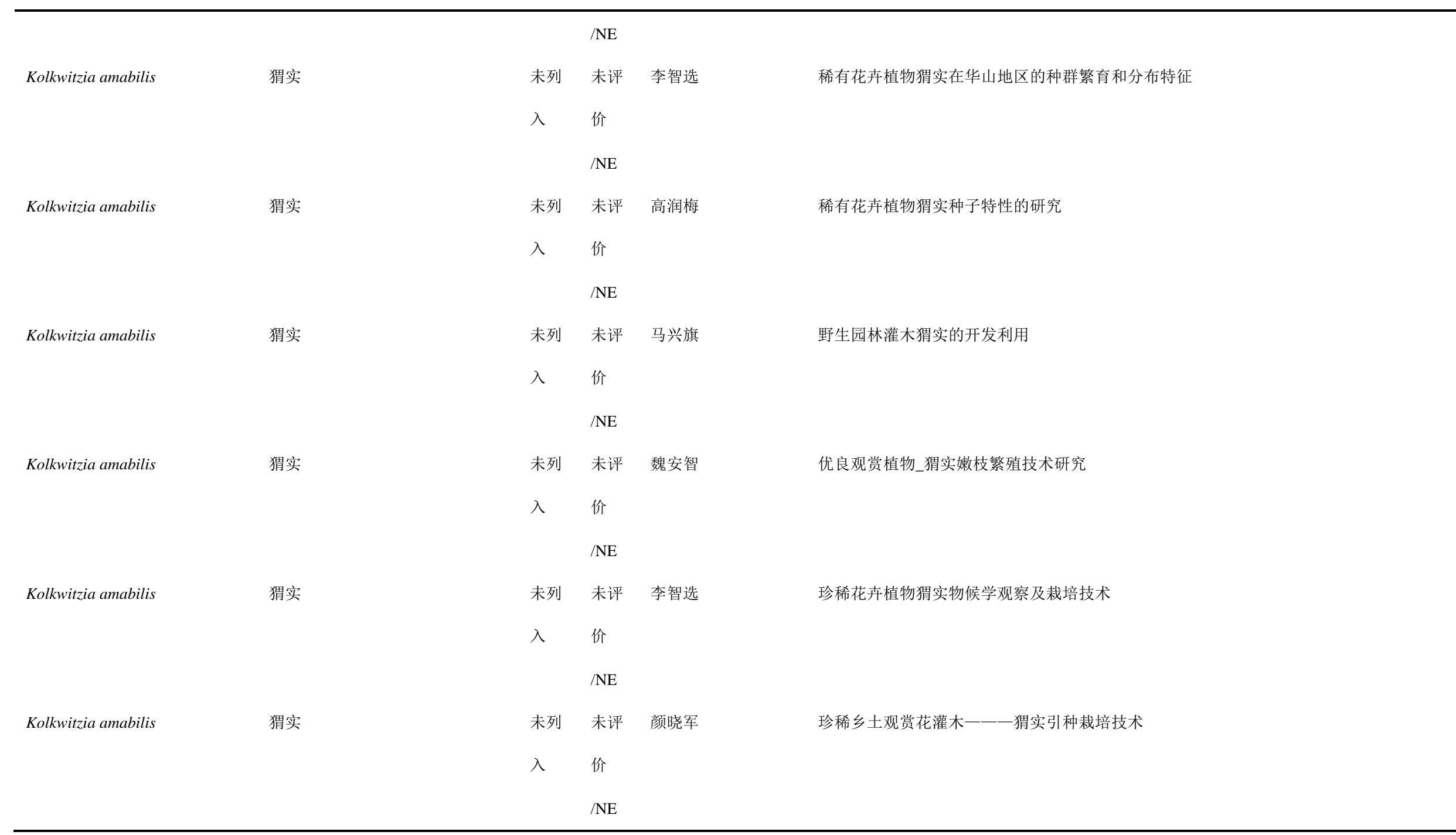


顾垒，闻丞，罗玫，王吴，吕植. 中国最受关注濒危物种保护现状快速评价的新方法探讨. 生物多样性，2015，23(5)：583-590. http://www biodiversity-science. net/CN/article/downloadArticleFile. do?attachType=PDF\&id=10075

\begin{tabular}{|c|c|c|c|c|c|}
\hline \multirow[t]{3}{*}{ Kolkwitzia amabilis } & 猬实 & 未列 & 未评 & 郭魏 & 珍稀园林植物猬实的繁殖栽培技术及其开发利用 \\
\hline & & 入 & 价 & & \\
\hline & & & $/ \mathrm{NE}$ & & \\
\hline \multirow[t]{3}{*}{ Kolkwitzia amabilis } & 猬实 & 未列 & 未评 & 许桂芳 & 珍稀植物猥实资源及应用研究 \\
\hline & & 入 & 价 & & \\
\hline & & & $/ \mathrm{NE}$ & & \\
\hline \multirow[t]{3}{*}{ Kolkwitzia amabilis } & 猬实 & 未列 & 未评 & 崔波 & 珍稀植物猬实的离体培养及快速繁殖 \\
\hline & & 入 & 价 & & \\
\hline & & & $/ \mathrm{NE}$ & & \\
\hline \multirow[t]{2}{*}{ Larix mastersiana } & 四川红杉 & 未列 & 濒危 & B.J. Fu & Effects of reforestation and deforestation on soil properties in humid mountainous areas a case \\
\hline & & 入 & /EN & & study in Wolong Nature Reserve, Sichuan province, China \\
\hline \multirow[t]{2}{*}{ Larix mastersiana } & 四川红杉 & 未列 & 濒危 & J.B.Bell & Isolation, characterizaton, and inheritance of microsatellite loci in alpine larch and western \\
\hline & & 入 & $/$ EN & & larch \\
\hline \multirow[t]{2}{*}{ Larix mastersiana } & 四川红杉 & 未列 & 濒危 & Bo-Jie FU & Soil quality regime in relation to land cover and slope position across a highly modified slope \\
\hline & & 入 & /EN & & landscape \\
\hline \multirow[t]{2}{*}{ Larix mastersiana } & 四川红杉 & 未列 & 濒危 & 马钦彦 & 川西山地主要人工林种群根系生物量与生产力 \\
\hline & & 入 & $/$ EN & & \\
\hline \multirow[t]{2}{*}{ Larix mastersiana } & 四川红杉 & 未列 & 濒危 & 何海 & 川西亚高山针叶林主要针叶树种年轮生态学研究 \\
\hline & & 入 & $/$ EN & & \\
\hline
\end{tabular}


顾垒，闻丞，罗玫，王吴，吕植. 中国最受关注濒危物种保护现状快速评价的新方法探讨. 生物多样性，2015，23(5)：583-590. http://www. biodiversity-science. net/CN/article/downloadArticleFile. do?attachType=PDF\&id=10075

\begin{tabular}{|c|c|c|c|c|c|}
\hline \multirow[t]{2}{*}{ Larix mastersiana } & 四川红杉 & 未列 & 濒危 & 杨武年 & 基于遥感信息的道孚县亚高山森林植被地上碳储量估算及其空间分布特征 \\
\hline & & 入 & /EN & & \\
\hline \multirow[t]{2}{*}{ Larix mastersiana } & 四川红杉 & 未列 & 濒危 & 包维楷 & 青藏高原东部采伐迹地早期人工重建序列梯度上植物多样性的变化 \\
\hline & & 入 & /EN & & \\
\hline \multirow[t]{2}{*}{ Larix mastersiana } & 四川红杉 & 未列 & 濒危 & 孙宇 & 全球落叶松属树轮气候学研究进展 \\
\hline & & 入 & $/ \mathrm{EN}$ & & \\
\hline \multirow[t]{2}{*}{ Larix mastersiana } & 四川红杉 & 未列 & 濒危 & 段建平 & 中国落叶松属树木年轮生长特性及其对气候变化的响应 \\
\hline & & 入 & $/ \mathrm{EN}$ & & \\
\hline \multirow[t]{3}{*}{ Leucomeris decora } & 白菊木 & 未列 & 数据 & Xun Gong & Genetic structure of the endangeredLeucomeris decora (Asteraceae) in China inferred from \\
\hline & & 入 & 不足 & & chloroplast and nuclear DNA markers \\
\hline & & & $/ \mathrm{DD}$ & & \\
\hline \multirow[t]{2}{*}{ Liocichla omeiensi } & 灰胸薮刷 & 未列 & 易危 & 付义强 & 春夏季异常低温气候对灰胸薮鹃繁殖的影响 \\
\hline & & 入 & /VU & & \\
\hline \multirow[t]{2}{*}{ Liocichla omeiensi } & 灰胸薮刷 & 未列 & 易危 & 付义强 & 峨眉山灰胸薮鹤冬季栖息地特征 \\
\hline & & 入 & /VU & & \\
\hline \multirow[t]{2}{*}{ Liocichla omeiensi } & 灰胸薮䴙 & 未列 & 易危 & 韩联宪 & 灰胸薮䴗繁殖行为初报 \\
\hline & & 入 & $/ \mathrm{VU}$ & & \\
\hline \multirow[t]{2}{*}{ Liocichla omeiensi } & 灰胸薮鸤 & 未列 & 易危 & 杨承忠 & 灰胸薮鹏鸣声及繁殖行为的初步研究 \\
\hline & & 入 & /VU & & \\
\hline
\end{tabular}


顾垒，闻丞，罗玫，王吴，吕植. 中国最受关注濒危物种保护现状快速评价的新方法探讨. 生物多样性，2015，23(5)：583-590. http://www. biodiversity-science. net/CN/article/downloadArticleFile. do?attachType=PDF\&id=10075

\begin{tabular}{|c|c|c|c|c|c|}
\hline \multirow[t]{2}{*}{ Liocichla omeiensi } & 灰胸薮鿬 & 未列 & 易危 & 徐会 & 灰胸薮鹤消化系统形态的初步研究 \\
\hline & & 入 & $/ \mathrm{VU}$ & & \\
\hline \multirow[t]{2}{*}{ Liocichla omeiensi } & 灰胸薮倜 & 未列 & 易危 & 付义强 & 灰胸薮觛种群、行为及保护 \\
\hline & & $\lambda$ & $/ \mathrm{VU}$ & & \\
\hline \multirow[t]{2}{*}{ Liocichla omeiensi } & 灰胸薮倜 & 未列 & 易危 & 符建荣 & 四川大相岭自然保护区的鸟类资源 \\
\hline & & 入 & $/ \mathrm{VU}$ & & \\
\hline \multirow[t]{2}{*}{ Liocichla omeiensi } & 灰胸薮鹋 & 未列 & 易危 & 付义强 & 四川峨眉山灰胸薮倜鸟冬季生态初报 \\
\hline & & 入 & $/ \mathrm{VU}$ & & \\
\hline \multirow[t]{2}{*}{ Liocichla omeiensi } & 灰胸薮倜乌 & 未列 & 易危 & 蒋迎听 & 四川老君山灰胸薮鸪繁殖巢的记述 \\
\hline & & 入 & $/ \mathrm{VU}$ & & \\
\hline \multirow[t]{2}{*}{ Lipotes vexillifer } & 白暨豚 & I & 极危 & Guang Yang & Baiji genomes reveal low genetic variability and new insights into secondary aquatic \\
\hline & & & /CR & & adaptations \\
\hline \multirow[t]{2}{*}{ Lipotes vexillifer } & 白㲘豚 & I & 极危 & DING WANG & Conservation of the Baiji: No Simple Solution \\
\hline & & & /CR & & \\
\hline \multirow[t]{2}{*}{ Lipotes vexillifer } & 白鷍豚 & I & 极危 & GUANG YANG & Conservation Options for the Baiji: Time for Realism? \\
\hline & & & /CR & & \\
\hline \multirow[t]{2}{*}{ Lipotes vexillifer } & 白塈豚 & I & 极危 & Guang Yang & Considerable MHC Diversity Suggests That the Functional Extinction of Baiji Is Not Related to \\
\hline & & & /CR & & Population Genetic Collapse \\
\hline Lipotes vexillifer & 白暨豚 & I & 极危 & Ding Wang & Construction and Characterization of a Lipotes vexillifer Genomic DNA BAC Library \\
\hline
\end{tabular}


顾垒，闻丞，罗玫，王吴，吕植. 中国最受关注濒危物种保护现状快速评价的新方法探讨. 生物多样性，2015，23(5)：583-590. http://www biodiversity-science. net/CN/article/downloadArticleFile. do?attachType=PDF\&id=10075

CR

Lipotes vexillifer

白鱀豚

白暨豚

Lipotes vexillifer

Lipotes vexillifer

白暨豚

Lipotes vexillifer

白鱀豚

Lipotes vexillifer

白暨豚

Lipotes vexillifer

Lipotes vexillifer

Lipotes vexillifer

Lipotes vexillifer
/CR

I

极危 Guang YANG

I

极危 Kaiya Zhou

/CR

I

极危 Ding Wang

/CR

I 极危

G. YANG

/CR

I 极危 X. ZHANG

/CR

I

CR

/CR

I 极伦

/CR

极危 宇辉
High similarity at three MHC loci between the baiji and finless porpoise: Trans-species or

convergent evolution?

Mitochondrial control region variability of baiji and the Yangtze finless porpoises, two

sympatric small cetaceans in the Yangtze rive

Molecular phylogenetics of river dolphins and the baiji mitochondrial genome

Range-Wide Yangtze Freshwater Dolphin Expedition: The Last Chance to See Baiji?

Sequence Variation and Gene Duplication at MHC DQB Loci of Baiji (Lipotes vexillifer),

Chinese River Dolphin

TheYangtze River dolphin or baiji (Lipotes vexillifer): population status and conservation

issues in theYangtze River, China

白暨豚保护研究的进展

白暨豚系统发生位置的研究

白鯺豚 Meta 种群灭绝原因及保护措施 
顾垒，闻丞，罗玫，王吴，吕植. 中国最受关注濒危物种保护现状快速评价的新方法探讨. 生物多样性，2015，23(5)：583-590. http://www, biodiversity-science. net/CN/article/downloadArticleFile. do?attachType=PDF\&id=10075

\begin{tabular}{|c|c|c|c|c|c|}
\hline Lipotes vexillifer & 白䁩豚 & I & $\begin{array}{l}\text { 极危 } \\
\text { /CR }\end{array}$ & 刘珊 & 淡水豚类 mtDNA 16S rRNA 基因的系统发生 \\
\hline Lipotes vexillifer & 白䈠豚 & I & $\begin{array}{l}\text { 极危 } \\
\text { /CR }\end{array}$ & 杨光 & 淡水豚类线粒体 DNA 12S rRNA 基因的序列变异及其分子系统学研究 \\
\hline Lipotes vexillifer & 白顋豚 & I & $\begin{array}{l}\text { 极危 } \\
\text { /CR }\end{array}$ & 于道平 & 铜陵江段豚类资源与保护措施的研究 \\
\hline Lipotes vexillifer & 白暨豚 & I & $\begin{array}{l}\text { 极危 } \\
\text { /CR }\end{array}$ & 陈辉霖 & 血清 TRIA 对人工饲养雄性白暨豚雄激素周期的观察与应用 \\
\hline Lipotes vexillifer & 白暨豚 & I & $\begin{array}{l}\text { 极危 } \\
\text { /CR }\end{array}$ & 崔鸿 & 长江新螺段白暨豚栖息地环境资源现状评估 \\
\hline Liriodendron chinense & 鹅掌楸 & II & $\begin{array}{l}\text { 近危 } \\
\text { /NT }\end{array}$ & 胡丁猛 & 10 个园林绿化树苗对 SO2 的反应特性 \\
\hline Liriodendron chinense & 鹅掌楸 & II & $\begin{array}{l}\text { 近危 } \\
\text { /NT }\end{array}$ & 胡丁猛 & 11 个园林绿化树种对 SO2 胁迫反应特性的研究 \\
\hline Liriodendron chinense & 我掌楸 & II & $\begin{array}{l}\text { 近危 } \\
\text { /NT }\end{array}$ & 于雅金金 & 12 种木兰科乔木的固碳释氧和降温增湿能力及景观评价研究 \\
\hline Liriodendron chinense & 鹅掌楸 & II & $\begin{array}{l}\text { 近危 } \\
\text { /NT }\end{array}$ & 胡希军 & 12 种木兰科乔木固碳释氧和降温增湿能力研究 \\
\hline Liriodendron chinense & 我掌楸 & II & 近危 & 柇华 & 15 种常见园林绿化植物的耐盐性研究 \\
\hline
\end{tabular}


顾垒，闻丞，罗玫，王吴，吕植. 中国最受关注濒危物种保护现状快速评价的新方法探讨. 生物多样性，2015，23(5)：583-590. http://www biodiversity-science. net/CN/article/downloadArticleFile. do?attachType=PDF\&id=10075

\begin{tabular}{|c|c|c|c|c|c|}
\hline & & & /NT & & \\
\hline \multirow[t]{2}{*}{ Liriodendron chinense } & 我掌楸 & II & 近危 & 李火根 & 2 种鹅掌梑的开花习性与传粉媒介 \\
\hline & & & $/ \mathrm{NT}$ & & \\
\hline \multirow[t]{2}{*}{ Liriodendron chinense } & 鹅掌楸 & II & 近危 & 焦江洪 & 3 种鹅掌楸引种的比较 \\
\hline & & & /NT & & \\
\hline \multirow[t]{2}{*}{ Liriodendron chinense } & 我掌梑 & II & 近危 & 间文德 & 4 种绿化树种盆栽土壤微生物对柴油污染响应及对 PAHs 的修复 \\
\hline & & & /NT & & \\
\hline \multirow{2}{*}{ Liriodendron chinense } & 鹅掌楸 & II & 近危 & 李学营 & 4 种园林植物的抗寒性比较研究 \\
\hline & & & /NT & & \\
\hline \multirow[t]{2}{*}{ Liriodendron chinense } & 鹅掌楸 & II & 近危 & 田保状 & 6 个园林绿化树种对 SO2 抗性的研究 \\
\hline & & & $/ \mathrm{NT}$ & & \\
\hline \multirow[t]{2}{*}{ Liriodendron chinense } & 鹅掌楸 & II & 近危 & 张悦 & 6 种植物粗提物对大肠杆菌的抑制效果 \\
\hline & & & /NT & & \\
\hline \multirow[t]{2}{*}{ Liriodendron chinense } & 我鸟掌楸 & II & 近危 & Hongwen Huang & Characterization of 14 novel microsatellite loci in the endangered Liriodendron chinense \\
\hline & & & $/ \mathrm{NT}$ & & (Magnoliaceae) and cross-species amplification in closely related taxa \\
\hline \multirow[t]{2}{*}{ Liriodendron chinense } & 我掌楸 & II & 近危 & XIAO-HONG YAO & Characterization of 39 novel EFT-SSR markers for Liriodendron tulipifera and cross-species \\
\hline & & & /NT & & amplification in L. chinense(Magnoliaceae) \\
\hline \multirow[t]{2}{*}{ Liriodendron chinense } & 我掌楸 & II & 近危 & Chung-Yi Chen & Chemical constituents of the leaves of Liriodendron chinense \\
\hline & & & /NT & & \\
\hline
\end{tabular}


顾垒，闻丞，罗玫，王昊，吕植. 中国最受关注濒危物种保护现状快速评价的新方法探讨．生物多样性，2015，23(5)：583-590. http://www. biodiversity-science. net/CN/article/downloadArticleFile. do?attachType=PDF\&id=10075

\begin{tabular}{|c|c|c|c|c|c|}
\hline Liriodendron chinense & 鹅掌楸 & II & $\begin{array}{l}\text { 近危 } \\
\text { /NT }\end{array}$ & Hong-Wen Huang & $\begin{array}{l}\text { Chloroplast microsatellite markers in Liriodendron tulipifera(Magnoliaceae)and cross-species } \\
\text { amplification in L.chinense }\end{array}$ \\
\hline Liriodendron chinense & 鹅掌楸 & II & $\begin{array}{l}\text { 近危 } \\
\text { /NT }\end{array}$ & Huogen Li & $\begin{array}{l}\text { De novo transcriptome analysis of Liriodendron chinense petals and leaves by Illumina } \\
\text { sequencing }\end{array}$ \\
\hline Liriodendron chinense & 鹅掌楸 & II & $\begin{array}{l}\text { 近危 } \\
\text { /NT }\end{array}$ & Jisen Shi & $\begin{array}{l}\text { Deep Sequencing and Microarray Hybridization Identify Conserved and Species-Specific } \\
\text { MicroRNAs during Somatic Embryogenesis in Hybrid Yellow Poplar }\end{array}$ \\
\hline Liriodendron chinense & 鹅掌楸 & II & $\begin{array}{l}\text { 近危 } \\
\text { /NT }\end{array}$ & Shi Jisen & $\begin{array}{l}\text { Deep sequencing combined with microarray hybridization to identify novel and conserved } \\
\text { microRNAs during somatic embryogenesis of hybrid yellow-poplar (Liriodendron chinense } \\
\text { (Hemsl.) }\end{array}$ \\
\hline Liriodendron chinense & 鹅掌楸 & II & $\begin{array}{l}\text { 近危 } \\
\text { /NT }\end{array}$ & J IKong-shu & $\begin{array}{l}\text { Effects of Drought Stress on Contents of Endogenous Hormones in Leaves ofDifferentClones } \\
\text { of Liriodendron chinense \& L.tulipifera }\end{array}$ \\
\hline Liriodendron chinense & 鹅掌楸 & II & $\begin{array}{l}\text { 近危 } \\
\text { /NT }\end{array}$ & Z.Z. FENG & $\begin{array}{l}\text { Effects of ozone exposure on growth and photosynthesis of the seedlings of Liriodendron } \\
\text { chinense (Hemsl.) Sarg, a native tree species of subtropical China }\end{array}$ \\
\hline Liriodendron chinense & 我掌楸 & II & $\begin{array}{l}\text { 近危 } \\
\text { /NT }\end{array}$ & Huogen Li & $\begin{array}{l}\text { High genetic diversity but limited gene flow among remnant and fragmented natural } \\
\text { populations of Liriodendron chinense Sarg }\end{array}$ \\
\hline Liriodendron chinense & 鹅掌楸 & II & $\begin{array}{l}\text { 近危 } \\
\text { /NT }\end{array}$ & Pingfang Yang & Identification of Conserved and Novel microRNAs from Liriodendron chinense Floral Tissues \\
\hline Liriodendron chinense & 鹅掌楸 & II & $\begin{array}{l}\text { 近危 } \\
\text { /NT }\end{array}$ & Ai-Qun Jia & In vitro tumor cytotoxic activities of extracts from three Liriodendron plants \\
\hline
\end{tabular}


顾垒，闻丞，罗玫，王昊，吕植. 中国最受关注濒危物种保护现状快速评价的新方法探讨．生物多样性，2015，23(5)：583-590. http://www. biodiversity-science. net/CN/article/downloadArticleFile. do?attachType=PDF\&id=10075

\begin{tabular}{|c|c|c|c|c|c|}
\hline Liriodendron chinense & 我鸟掌楸 & II & 近危 & Pingfang Yang & $\begin{array}{l}\text { Morphological and Proteomic Analysis Reveal the Role of Pistil under Pollination in } \\
\text { Liriodendron chinense (Hemsl.) Sarg. }\end{array}$ \\
\hline Liriodendron chinense & 鹅掌楸 & II & 近危 & ZHANG Xiao-ping & $\begin{array}{l}\text { Nutrient Element Contents of Cutting Seedlings of Hybrid Species (Liriodendron chinense } \times \\
\text { tulipifera) }\end{array}$ \\
\hline Liriodendron chinense & 我掌梑 & II & $\begin{array}{l}\text { 近危 } \\
\text { /NT }\end{array}$ & 梁小翠 & PAHs 对 4 种绿化树种盆栽土壤微生物和酶的影响 \\
\hline Liriodendron chinense & 我掌梑 & II & $\begin{array}{l}\text { 近危 } \\
\text { /NT }\end{array}$ & 郑威 & PAHs 在 4 种绿化树种体内的分布及对其生理生态特性的影响 \\
\hline Liriodendron chinense & 鹅掌楸 & II & 近危 & S. Shi & Phylogenetic relationships of the Magnoliaceae inferred from cpDNA matK sequences \\
\hline Liriodendron chinense & 鹅掌楸 & II & $\begin{array}{l}\text { 近危 } \\
\text { /NT }\end{array}$ & 李建民 & RAPD 标记研究马裬木地理种群的遗传分化 \\
\hline Liriodendron chinense & 我掌楸 & II & $\begin{array}{l}\text { 近危 } \\
\text { /NT }\end{array}$ & 孙明高 & SO2 对三种园林绿化苗木叶片膜脂过氧化和保护酶的影响 \\
\hline Liriodendron chinense & 我掌楸 & II & 近危 & Li Bin & Study on feasibility of earlier selection of main wood characteristics in Liriodendron Chinense \\
\hline Liriodendron chinense & 鹅掌楸 & II & $\begin{array}{l}\text { 近危 } \\
\text { /NT }\end{array}$ & CINDY Q. TANG & $\begin{array}{l}\text { Survival of tertiary relict species, liriodendron chinense(magnoliaceae),in soouthern china, with } \\
\text { special reference to village fengshui forests }\end{array}$ \\
\hline Liriodendron chinense & 我掌楸 & II & 近危 & SHUANG-QUAN & Variation of pollination and resource limitation in a low seed-set tree, Liriodendron chinense \\
\hline
\end{tabular}


顾垒，闻丞，罗玫，王吴，吕植. 中国最受关注濒危物种保护现状快速评价的新方法探讨. 生物多样性，2015，23(5)：583-590. http://www biodiversity-science. net/CN/article/downloadArticleFile. do?attachType=PDF\&id=10075

\begin{tabular}{|c|c|c|c|c|c|}
\hline & & & $/ \mathrm{NT}$ & HUANG & (Magnoliaceae) \\
\hline \multirow[t]{2}{*}{ Liriodendron chinense } & 我鸟掌楸 & II & 近危 & 刘嘉君 & 保定市 12 种彩叶树种光合特性及生态功能研究 \\
\hline & & & $/ \mathrm{NT}$ & & \\
\hline \multirow[t]{2}{*}{ Liriodendron chinense } & 鹅掌楸 & II & 近危 & 马履一 & 北京 3 个园林观赏树种苗木耗水特性初探 \\
\hline & & & /NT & & \\
\hline \multirow[t]{2}{*}{ Liriodendron chinense } & 鹅掌楸 & II & 近危 & 樊敏 & 北京常用 3 种观赏乔木耗水特性研究 \\
\hline & & & $/ \mathrm{NT}$ & & \\
\hline \multirow[t]{2}{*}{ Liriodendron chinense } & 鹅掌楸 & II & 近危 & 王玉涛 & 北京城市优良抗旱节水植物材料的笁选与评价研究 \\
\hline & & & $/ \mathrm{NT}$ & & \\
\hline \multirow[t]{2}{*}{ Liriodendron chinense } & 鹅掌楸 & II & 近危 & 占志勇 & 不同地理种源鹅掌楸的 ISSR 遗传分析 \\
\hline & & & /NT & & \\
\hline \multirow[t]{2}{*}{ Liriodendron chinense } & 鹅掌楸 & II & 近危 & 周志春 & 不同磷效率马补木种源对磷胁迫的生理反应 \\
\hline & & & $/ \mathrm{NT}$ & & \\
\hline \multirow[t]{2}{*}{ Liriodendron chinense } & 鹅掌楸 & II & 近危 & 罗祖树 & 不同坡位 5a 生杉木、厚朴及马补木混交林生物量分配格局 \\
\hline & & & $/ \mathrm{NT}$ & & \\
\hline \multirow[t]{2}{*}{ Liriodendron chinense } & 鹅掌楸 & II & 近危 & 吴树明 & 不同纬度对鹅掌楸次生木质部结构的影响 \\
\hline & & & /NT & & \\
\hline \multirow[t]{2}{*}{ Liriodendron chinense } & 我鸟掌楸 & II & 近危 & 张晓平 & 不同种源鹅掌梑和杂种鹅掌楸对淹水胁迫的响应 \\
\hline & & & $/ \mathrm{NT}$ & & \\
\hline
\end{tabular}


顾垒，闻丞，罗玫，王吴，吕植. 中国最受关注濒危物种保护现状快速评价的新方法探讨. 生物多样性，2015，23(5)：583-590. http://www biodiversity-science. net/CN/article/downloadArticleFile. do?attachType=PDF\&id=10075

\begin{tabular}{|c|c|c|c|c|c|}
\hline Liriodendron chinense & 鹅掌楸 & II & $\begin{array}{l}\text { 近危 } \\
\text { /NT }\end{array}$ & 季孔庶 & 不同种源鹅掌梑一年生播种苗的年生长规律 \\
\hline Liriodendron chinense & 我掌楸 & II & $\begin{array}{l}\text { 近危 } \\
\text { /NT }\end{array}$ & 刘桂林 & 春季常见园林植物卷叶原因调查研究 \\
\hline Liriodendron chinense & 我掌楸 & II & $\begin{array}{l}\text { 近危 } \\
\text { /NT }\end{array}$ & 杨水平 & 氮素营养对马裬木家系苗木生长效应分析 \\
\hline Liriodendron chinense & 鹅掌楸 & II & $\begin{array}{l}\text { 近危 } \\
\text { /NT }\end{array}$ & 郭治友 & 都匀市螺丝壳鹅掌楸种群生态学研究 \\
\hline Liriodendron chinense & 鹅掌楸 & II & $\begin{array}{l}\text { 近危 } \\
\text { /NT }\end{array}$ & 郭治友 & 都匀市螺丝壳水源林保护区现存珍稀濒危植物鹅掌楸天然分布 \\
\hline Liriodendron chinense & 我掌楸 & II & $\begin{array}{l}\text { 近危 } \\
\text { /NT }\end{array}$ & 朱凡 & 多环芳烃对 2 种南方绿化树种生长的影响 \\
\hline Liriodendron chinense & 鹅掌楸 & II & $\begin{array}{l}\text { 近危 } \\
\text { /NT }\end{array}$ & 李仲芳 & 峨眉山鹅掌楸组培过程中几种酶活性的变化 \\
\hline Liriodendron chinense & 我掌楸 & II & $\begin{array}{l}\text { 近危 } \\
\text { /NT }\end{array}$ & 高彦明 & 峨眉山珍稀植物鹅掌楸组培过程中的膜脂过氧化 \\
\hline Liriodendron chinense & 鹅掌楸 & II & $\begin{array}{l}\text { 近危 } \\
\text { /NT }\end{array}$ & 孙辉 & 鹅掌挟黑斑病的研究 \\
\hline Liriodendron chinense & 鹅掌楸 & II & 近危 & 王昊 & 鹅掌掞杂交种子园建立技术研究 \\
\hline
\end{tabular}


顾垒，闻丞，罗玫，王吴，吕植. 中国最受关注濒危物种保护现状快速评价的新方法探讨. 生物多样性，2015，23(5)：583-590. http://www biodiversity-science. net/CN/article/downloadArticleFile. do?attachType=PDF\&id=10075

\begin{tabular}{|c|c|c|c|c|c|}
\hline & & & $/ \mathrm{NT}$ & & \\
\hline \multirow[t]{2}{*}{ Liriodendron chinense } & 我鸟掌楸 & II & 近危 & 夏良放 & 鹅掌楸、桤木幼抚技术 \\
\hline & & & $/ \mathrm{NT}$ & & \\
\hline \multirow[t]{2}{*}{ Liriodendron chinense } & 鹅掌楸 & II & 近危 & 李火根 & 鹅掌楸 EST-SSR 引物开发及通用性分析 \\
\hline & & & $/ \mathrm{NT}$ & & \\
\hline \multirow[t]{2}{*}{ Liriodendron chinense } & 鹅掌楸 & II & 近危 & 施季森 & 鹅掌楸 Genomic-SSR 反应体系优化 \\
\hline & & & $/ \mathrm{NT}$ & & \\
\hline \multirow[t]{2}{*}{ Liriodendron chinense } & 鹅掌楸 & II & 近危 & 占志勇 & 找掌楸 ISSR-PCR 反应体系的建立及优化 \\
\hline & & & $/ \mathrm{NT}$ & & \\
\hline \multirow[t]{2}{*}{ Liriodendron chinense } & 鹅掌楸 & II & 近危 & 廖明 & 鹅掌楸播种苗生长发育规律及育苗技术研究 \\
\hline & & & /NT & & \\
\hline \multirow[t]{2}{*}{ Liriodendron chinense } & 找掌楸 & II & 近危 & 徐立安 & 鹅掌楸不同产地聚合果和种子性状差异分析 \\
\hline & & & /NT & & \\
\hline \multirow[t]{2}{*}{ Liriodendron chinense } & 鹅掌楸 & II & 近危 & 朱其卫 & 鹅掌梑不同交配类型子代遗传多样性研究 \\
\hline & & & $/ \mathrm{NT}$ & & \\
\hline \multirow[t]{2}{*}{ Liriodendron chinense } & 鹅掌楸 & II & 近危 & 李火根 & 鹅掌楸不同交配组合种子活力变异 \\
\hline & & & /NT & & \\
\hline \multirow[t]{2}{*}{ Liriodendron chinense } & 鹅掌楸 & II & 近危 & 李火根 & 鹅掌楸不同交配组合子代苗期生长变异及遗传稳定性分析 \\
\hline & & & /NT & & \\
\hline
\end{tabular}


顾垒，闻丞，罗玫，王吴，吕植. 中国最受关注濒危物种保护现状快速评价的新方法探讨. 生物多样性，2015，23(5)：583-590. http://www biodiversity-science. net/CN/article/downloadArticleFile. do?attachType=PDF\&id=10075

\begin{tabular}{|c|c|c|c|c|c|}
\hline Liriodendron chinense & 鹅掌楸 & II & $\begin{array}{l}\text { 近危 } \\
\text { /NT }\end{array}$ & 李火根 & 我掌梑不同交配组合子代遗传多样性分析 \\
\hline Liriodendron chinense & 我掌楸 & II & $\begin{array}{l}\text { 近危 } \\
\text { /NT }\end{array}$ & 张晓飞 & 鹅掌楸不同交配组合子代幼龄期生长性状的遗传分析 \\
\hline Liriodendron chinense & 我掌楸 & II & $\begin{array}{l}\text { 近危 } \\
\text { /NT }\end{array}$ & 金发根 & 我掌楸不同种源无性系嫁接母树林营建技术研究初报 \\
\hline Liriodendron chinense & 鹅掌楸 & II & $\begin{array}{l}\text { 近危 } \\
\text { /NT }\end{array}$ & 刘友良 & 我掌楸不同种源幼树高生长比较 \\
\hline Liriodendron chinense & 我掌楸 & II & $\begin{array}{l}\text { 近危 } \\
\text { /NT }\end{array}$ & 黄双全 & 我掌楸的传粉环境与性配置 \\
\hline Liriodendron chinense & 我掌楸 & II & $\begin{array}{l}\text { 近危 } \\
\text { /NT }\end{array}$ & 王光明 & 鹅掌楸的繁殖与园林应用 \\
\hline Liriodendron chinense & 鹅掌楸 & II & $\begin{array}{l}\text { 近危 } \\
\text { /NT }\end{array}$ & 陈红林 & 鹅掌楸的两个群体遗传结构的初步研究 \\
\hline Liriodendron chinense & 我掌楸 & II & $\begin{array}{l}\text { 近危 } \\
\text { /NT }\end{array}$ & 陈志刚 & 鹅掌楸的扞插繁育技术 \\
\hline Liriodendron chinense & 鹅掌楸 & II & $\begin{array}{l}\text { 近危 } \\
\text { /NT }\end{array}$ & 李兴鹏 & 鹅掌梑分子标记开发及遗传连锁框架图谱构建 \\
\hline Liriodendron chinense & 鹅掌楸 & II & 近危 & 李建 & 鹅掌楸分子标记遗传图谱构建 \\
\hline
\end{tabular}


顾垒，闻丞，罗玫，王吴，吕植. 中国最受关注濒危物种保护现状快速评价的新方法探讨. 生物多样性，2015，23(5)：583-590. http://www. biodiversity-science. net/CN/article/downloadArticleFile. do?attachType=PDF\&id=10075

\begin{tabular}{|c|c|c|c|c|c|}
\hline & & & $/ \mathrm{NT}$ & & \\
\hline \multirow[t]{2}{*}{ Liriodendron chinense } & 我掌楸 & II & 近危 & 陈辉 & 鹅掌楸光合性能的测定与分析 \\
\hline & & & $/ \mathrm{NT}$ & & \\
\hline \multirow[t]{2}{*}{ Liriodendron chinense } & 鹅掌楸 & II & 近危 & 陈辉 & 鹅掌楸和女贞同化 $\mathrm{CO} 2$ 和释 $\mathrm{O} 2$ 能力的比较 \\
\hline & & & /NT & & \\
\hline \multirow[t]{2}{*}{ Liriodendron chinense } & 鹅掌楸 & II & 近危 & 施季森 & 鹅掌楸花粉母细胞减数分裂进程的研究 \\
\hline & & & $/ \mathrm{NT}$ & & \\
\hline \multirow[t]{2}{*}{ Liriodendron chinense } & 鹅掌楸 & II & 近危 & 姜卫兵 & 鹅掌楸及其在园林绿化中的应用 \\
\hline & & & $/ \mathrm{NT}$ & & \\
\hline \multirow[t]{2}{*}{ Liriodendron chinense } & 鹅掌楸 & II & 近危 & 姚俊修 & 找掌楸近交子代群体的遗传分析 \\
\hline & & & $/ \mathrm{NT}$ & & \\
\hline \multirow[t]{2}{*}{ Liriodendron chinense } & 找掌楸 & II & 近危 & 刘志祥 & 鹅掌楸抗氧化物质提取及其特性的研究 \\
\hline & & & $/ \mathrm{NT}$ & & \\
\hline \multirow[t]{2}{*}{ Liriodendron chinense } & 鹅掌楸 & II & 近危 & 吴运辉 & 找掌楸两段育苗技术 \\
\hline & & & /NT & & \\
\hline \multirow[t]{2}{*}{ Liriodendron chinense } & 鹅掌楸 & II & 近危 & 曾瑞生 & 鹅掌楸裸根大苗移植技术初报 \\
\hline & & & /NT & & \\
\hline \multirow[t]{2}{*}{ Liriodendron chinense } & 鹅掌楸 & II & 近危 & 王顺庆 & 鹅掌楸苗期生存分析_王顺庆_ \\
\hline & & & $/ \mathrm{NT}$ & & \\
\hline
\end{tabular}


顾垒，闻丞，罗玫，王吴，吕植. 中国最受关注濒危物种保护现状快速评价的新方法探讨. 生物多样性，2015，23(5)：583-590. http://www biodiversity-science. net/CN/article/downloadArticleFile. do?attachType=PDF\&id=10075

\begin{tabular}{|c|c|c|c|c|c|}
\hline Liriodendron chinense & 鹅掌楸 & II & $\begin{array}{l}\text { 近危 } \\
\text { /NT }\end{array}$ & 李火根 & 鹅掌楸苗期生长杂种优势的 SSR 分析 \\
\hline Liriodendron chinense & 我掌楸 & II & $\begin{array}{l}\text { 近危 } \\
\text { /NT }\end{array}$ & 李火根 & 我掌楸配子选择与雄性繁殖适合度 \\
\hline Liriodendron chinense & 我掌楸 & II & $\begin{array}{l}\text { 近危 } \\
\text { /NT }\end{array}$ & 俞良亮 & 鹅掌楸扞插繁殖与植物生长物质的关系及苗期生长研究 \\
\hline Liriodendron chinense & 我掌梑 & II & $\begin{array}{l}\text { 近危 } \\
\text { /NT }\end{array}$ & 李博 & 我掌楸群体空间遗传结构研究 \\
\hline Liriodendron chinense & 我掌楸 & II & $\begin{array}{l}\text { 近危 } \\
\text { /NT }\end{array}$ & 李建民 & 鹅掌楸人工林的丰产特性 \\
\hline Liriodendron chinense & 找掌楸 & II & $\begin{array}{l}\text { 近危 } \\
\text { /NT }\end{array}$ & 黄蹈 & 鹅掌楸人工林生物量及生产力的研究 \\
\hline Liriodendron chinense & 鹅掌楸 & II & $\begin{array}{l}\text { 近危 } \\
\text { /NT }\end{array}$ & 彭秀 & 鹅掌楸容器育苗轻基质配方研究 \\
\hline Liriodendron chinense & 我掌楸 & II & $\begin{array}{l}\text { 近危 } \\
\text { /NT }\end{array}$ & 孟庆军 & 我掌楸山地造林技术 \\
\hline Liriodendron chinense & 鹅掌梑 & II & $\begin{array}{l}\text { 近危 } \\
\text { /NT }\end{array}$ & 方炎明 & 鹅掌楸生殖生态研究：果实与种子变异格局 \\
\hline Liriodendron chinense & 鹅掌楸 & II & 近危 & 方炎明 & 鹅掌楸生殖生态研究: 生殖分配与生活史对策 \\
\hline
\end{tabular}


顾垒，闻丞，罗玫，王吴，吕植. 中国最受关注濒危物种保护现状快速评价的新方法探讨. 生物多样性，2015，23(5)：583-590. http://www. biodiversity-science. net/CN/article/downloadArticleFile. do?attachType=PDF\&id=10075

\begin{tabular}{|c|c|c|c|c|c|}
\hline & & & $/ \mathrm{NT}$ & & \\
\hline \multirow[t]{2}{*}{ Liriodendron chinense } & 我掌楸 & II & 近危 & 张琰 & 鹅掌梑实生苗生长规律研究 \\
\hline & & & $/ \mathrm{NT}$ & & \\
\hline \multirow[t]{2}{*}{ Liriodendron chinense } & 鹅掌楸 & II & 近危 & 张琰 & 鹅掌楸实生苗生长规律研究初报 \\
\hline & & & /NT & & \\
\hline \multirow[t]{2}{*}{ Liriodendron chinense } & 鹅掌楸 & II & 近危 & 罗群凤 & 鹅掌楸属基因进化差异研究 \\
\hline & & & $/ \mathrm{NT}$ & & \\
\hline \multirow[t]{2}{*}{ Liriodendron chinense } & 鹅掌楸 & II & 近危 & 吕伟光 & 我掌梑属内种间体细胞原生质体融合研究 \\
\hline & & & $/ \mathrm{NT}$ & & \\
\hline \multirow[t]{2}{*}{ Liriodendron chinense } & 鹅掌楸 & II & 近危 & 李康琴 & 鹅掌楸属群体遗传结构及分子系统地理学研究 \\
\hline & & & $/ \mathrm{NT}$ & & \\
\hline \multirow[t]{2}{*}{ Liriodendron chinense } & 找掌楸 & II & 近危 & 尹增芳 & 鹅掌楸属树种的胚胎学研究进展 \\
\hline & & & $/ \mathrm{NT}$ & & \\
\hline \multirow[t]{2}{*}{ Liriodendron chinense } & 鹅掌楸 & II & 近危 & 李火根 & 找掌楸属树种繁殖性能的遗传分析 \\
\hline & & & /NT & & \\
\hline \multirow[t]{2}{*}{ Liriodendron chinense } & 鹅掌楸 & II & 近危 & 于静 & 鹅掌楸属树种花被片色素与花果数量性状遗传变异研究 \\
\hline & & & /NT & & \\
\hline \multirow[t]{2}{*}{ Liriodendron chinense } & 鹅掌楸 & II & 近危 & 李火根 & 鹅掌楸属树种近交衰退分析 \\
\hline & & & $/ \mathrm{NT}$ & & \\
\hline
\end{tabular}


顾垒，闻丞，罗玫，王吴，吕植. 中国最受关注濒危物种保护现状快速评价的新方法探讨. 生物多样性，2015，23(5)：583-590. http://www biodiversity-science. net/CN/article/downloadArticleFile. do?attachType=PDF\&id=10075

\begin{tabular}{|c|c|c|c|c|c|}
\hline Liriodendron chinense & 鹅掌楸 & II & $\begin{array}{l}\text { 近危 } \\
\text { /NT }\end{array}$ & 王贝 & 我掌楸属树种配子选择的细胞学研究 \\
\hline Liriodendron chinense & 我掌楸 & II & $\begin{array}{l}\text { 近危 } \\
\text { /NT }\end{array}$ & 冯源恒 & 鹅掌楸属树种配子选择与雄性繁殖适合度 \\
\hline Liriodendron chinense & 我掌楸 & II & $\begin{array}{l}\text { 近危 } \\
\text { /NT }\end{array}$ & 王章荣 & 我掌楸属杂交育种成就与育种策略 \\
\hline Liriodendron chinense & 鹅掌楸 & II & $\begin{array}{l}\text { 近危 } \\
\text { /NT }\end{array}$ & 宋开秀 & 鹅掌楸属杂交育种研究初报 \\
\hline Liriodendron chinense & 鹅掌楸 & II & $\begin{array}{l}\text { 近危 } \\
\text { /NT }\end{array}$ & 徐进 & 我掌楸属植物生长旺盛期叶芽基因差异表达与杂种优势关系的分析 \\
\hline Liriodendron chinense & 我掌楸 & II & $\begin{array}{l}\text { 近危 } \\
\text { /NT }\end{array}$ & 罗玉兰 & 鹅掌楸属植物叶表皮扫描电镜观察 \\
\hline Liriodendron chinense & 鹅掌楸 & II & $\begin{array}{l}\text { 近危 } \\
\text { /NT }\end{array}$ & 李火根 & 鹅掌楸属种及杂种的 SSR 分子鉴定 \\
\hline Liriodendron chinense & 鹅掌楸 & II & $\begin{array}{l}\text { 近危 } \\
\text { /NT }\end{array}$ & 李周岐 & 鹅掌楸属种间杂种优势的研究 \\
\hline Liriodendron chinense & 鹅掌楸 & II & $\begin{array}{l}\text { 近危 } \\
\text { /NT }\end{array}$ & 徐进 & 鹅掌楸属种间杂种与亲本花粉壁的超微结构的比较观察 \\
\hline Liriodendron chinense & 鹅掌楸 & II & 近危 & 王雄清 & 鹅掌楸树皮提取物的抑菌作用 \\
\hline
\end{tabular}


顾垒，闻丞，罗玫，王吴，吕植. 中国最受关注濒危物种保护现状快速评价的新方法探讨. 生物多样性，2015，23(5)：583-590. http://www biodiversity-science. net/CN/article/downloadArticleFile. do?attachType=PDF\&id=10075

\begin{tabular}{|c|c|c|c|c|c|}
\hline & & & /NT & & \\
\hline \multirow[t]{2}{*}{ Liriodendron chinense } & 我掌楸 & II & 近危 & 陈锡雄 & 鹅掌楸天然林群落结构的初步研究 \\
\hline & & & /NT & & \\
\hline \multirow[t]{2}{*}{ Liriodendron chinense } & 鹅掌楸 & II & 近危 & 冯汀 & 找掌楸研究文献的计量评价 \\
\hline & & & /NT & & \\
\hline \multirow[t]{2}{*}{ Liriodendron chinense } & 鹅掌楸 & II & 近危 & 刘建 & 鹅掌楸叶片发育相关蛋白的双向电泳分析 \\
\hline & & & /NT & & \\
\hline \multirow[t]{2}{*}{ Liriodendron chinense } & 鹅掌楸 & II & 近危 & 曾超珍 & 鹅掌楸抑菌物质的体外抗菌活性及稳定性试验 \\
\hline & & & /NT & & \\
\hline \multirow[t]{2}{*}{ Liriodendron chinense } & 鹅掌楸 & II & 近危 & 胡正海 & 找掌楸油细胞的发育解剖学研究 \\
\hline & & & $/ \mathrm{NT}$ & & \\
\hline \multirow[t]{2}{*}{ Liriodendron chinense } & 找掌楸 & II & 近危 & 胡正海 & 鹅掌楸油细胞发育过程中超微结构的变化与挥发油产生的关系 \\
\hline & & & /NT & & \\
\hline \multirow[t]{2}{*}{ Liriodendron chinense } & 鹅掌楸 & II & 近危 & 杨汉远 & 鹅掌楸幼林施肥试验初报 \\
\hline & & & $/ \mathrm{NT}$ & & \\
\hline \multirow[t]{2}{*}{ Liriodendron chinense } & 鹅掌楸 & II & 近危 & 吴运辉 & 鹅掌楸育苗技术研究初报 \\
\hline & & & /NT & & \\
\hline \multirow[t]{2}{*}{ Liriodendron chinense } & 我鸟掌楸 & II & 近危 & 袁晓峰 & 鹅掌楸杂交组合选择及无性系苗期测定 \\
\hline & & & /NT & & \\
\hline
\end{tabular}


顾垒，闻丞，罗玫，王吴，吕植. 中国最受关注濒危物种保护现状快速评价的新方法探讨. 生物多样性，2015，23(5)：583-590. http://www biodiversity-science. net/CN/article/downloadArticleFile. do?attachType=PDF\&id=10075

\begin{tabular}{|c|c|c|c|c|c|}
\hline Liriodendron chinense & 鹅掌楸 & II & $\begin{array}{l}\text { 近危 } \\
\text { /NT }\end{array}$ & 袁俊修 & 我掌楸杂种优势分子机理研究 \\
\hline Liriodendron chinense & 我掌楸 & II & $\begin{array}{l}\text { 近危 } \\
\text { /NT }\end{array}$ & 骆翠 & 鹅掌楸纸浆林种源选择与生长过程研究 \\
\hline Liriodendron chinense & 我掌楸 & II & $\begin{array}{l}\text { 近危 } \\
\text { /NT }\end{array}$ & 李斌 & 鹅掌楸种源材性遗传变异与选择 \\
\hline Liriodendron chinense & 鹅掌楸 & II & $\begin{array}{l}\text { 近危 } \\
\text { /NT }\end{array}$ & 管兰华 & 我掌楸种源试验研究 \\
\hline Liriodendron chinense & 鹅掌楸 & II & $\begin{array}{l}\text { 近危 } \\
\text { /NT }\end{array}$ & 冯继荣 & 鹅掌楸种子发芽试验 \\
\hline Liriodendron chinense & 我掌楸 & II & $\begin{array}{l}\text { 近危 } \\
\text { /NT }\end{array}$ & 周仁爱 & 鹅掌楸种子育苗技术 \\
\hline Liriodendron chinense & 鹅掌楸 & II & $\begin{array}{l}\text { 近危 } \\
\text { /NT }\end{array}$ & 陈金慧 & 鹅掌楸组培苗的生根及移栽技术 \\
\hline Liriodendron chinense & 我掌楸 & II & $\begin{array}{l}\text { 近危 } \\
\text { /NT }\end{array}$ & 路承香 & 鹅掌楸组织培养及其再生过程中生理生化特性研究 \\
\hline Liriodendron chinense & 鹅掌楸 & II & $\begin{array}{l}\text { 近危 } \\
\text { /NT }\end{array}$ & 蒋祥娥 & 我鸟掌楸组织培养技术初探 \\
\hline Liriodendron chinense & 鹅掌楸 & II & 近危 & 郝会军 & 鹅掌楸组织培养技术研究 \\
\hline
\end{tabular}


顾垒，闻丞，罗玫，王吴，吕植. 中国最受关注濒危物种保护现状快速评价的新方法探讨. 生物多样性，2015，23(5)：583-590. http://www biodiversity-science. net/CN/article/downloadArticleFile. do?attachType=PDF\&id=10075

\begin{tabular}{|c|c|c|c|c|c|}
\hline & & & $/ \mathrm{NT}$ & & \\
\hline \multirow[t]{2}{*}{ Liriodendron chinense } & 鹅掌楸 & II & 近危 & 季孔庶 & 干旱胁迫对杂交鹅掌楸无性系叶片内源激素含量的影响 \\
\hline & & & $/ \mathrm{NT}$ & & \\
\hline \multirow[t]{2}{*}{ Liriodendron chinense } & 鹅掌楸 & II & 近危 & 季孔庶 & 镉胁迫对不同家系杂交鹅掌楸生长及抗性的影响 \\
\hline & & & /NT & & \\
\hline \multirow[t]{2}{*}{ Liriodendron chinense } & 鹅掌楸 & II & 近危 & 石晓蒙 & 补木遗传多样性研究 \\
\hline & & & $/ \mathrm{NT}$ & & \\
\hline \multirow[t]{2}{*}{ Liriodendron chinense } & 鹅掌楸 & II & 近危 & 李火根 & 广西猫儿山鹅掌楸天然种群动态研究 \\
\hline & & & $/ \mathrm{NT}$ & & \\
\hline \multirow[t]{2}{*}{ Liriodendron chinense } & 鹅掌楸 & II & 近危 & 金荷仙 & 杭州地区常见行道树滞尘效益研究 \\
\hline & & & /NT & & \\
\hline \multirow[t]{2}{*}{ Liriodendron chinense } & 鹅掌楸 & II & 近危 & 张琰 & 河南大别山引种鹅掌梑生长规律研究 \\
\hline & & & /NT & & \\
\hline \multirow[t]{2}{*}{ Liriodendron chinense } & 鹅掌楸 & II & 近危 & 丁贵杰 & 猴樟、鹅掌楸对马尾松苗木生理活性的他感效应 \\
\hline & & & /NT & & \\
\hline \multirow[t]{2}{*}{ Liriodendron chinense } & 鹅掌楸 & II & 近危 & 吴展波 & 湖北二仙岩找掌楸群落初步研究 \\
\hline & & & /NT & & \\
\hline \multirow[t]{2}{*}{ Liriodendron chinense } & 我鸟掌楸 & II & 近危 & 林亲众 & 湖南三道坑自然保护区珍稀濒危植物鹅掌楸群落的研究 \\
\hline & & & /NT & & \\
\hline
\end{tabular}


顾垒，闻丞，罗玫，王吴，吕植. 中国最受关注濒危物种保护现状快速评价的新方法探讨. 生物多样性，2015，23(5)：583-590. http://www biodiversity-science. net/CN/article/downloadArticleFile. do?attachType=PDF\&id=10075

\begin{tabular}{|c|c|c|c|c|c|}
\hline Liriodendron chinense & 鹅掌楸 & II & $\begin{array}{l}\text { 近危 } \\
\text { /NT }\end{array}$ & 梁东 & 华东蓝刺头和鹅掌楸化学成分的研究 \\
\hline Liriodendron chinense & 我掌楸 & II & $\begin{array}{l}\text { 近危 } \\
\text { /NT }\end{array}$ & 余发新 & 基于 SketchUp 的杂种马补木年轮形态模拟技术 \\
\hline Liriodendron chinense & 我掌楸 & II & $\begin{array}{l}\text { 近危 } \\
\text { /NT }\end{array}$ & 王改萍 & 几种木本植物蛋白质的电泳分析 \\
\hline Liriodendron chinense & 鹅掌楸 & II & $\begin{array}{l}\text { 近危 } \\
\text { /NT }\end{array}$ & 周顺亮 & 江西常见树种失水率分析 \\
\hline Liriodendron chinense & 我掌楸 & II & $\begin{array}{l}\text { 近危 } \\
\text { /NT }\end{array}$ & 朱秋生 & 子遗植物鹅掌梑的研究现状与保护对策 \\
\hline Liriodendron chinense & 我掌楸 & II & $\begin{array}{l}\text { 近危 } \\
\text { /NT }\end{array}$ & 石杨文 & 黎平县鹅掌楸人工林的生长状况调查 \\
\hline Liriodendron chinense & 鹅掌楸 & II & $\begin{array}{l}\text { 近危 } \\
\text { /NT }\end{array}$ & 李火根 & 利用 EST-SSR 分子标记检测鹅掌楸种间渐渗杂交 \\
\hline Liriodendron chinense & 我掌楸 & II & $\begin{array}{l}\text { 近危 } \\
\text { /NT }\end{array}$ & 罗光佐 & 利用 RAPD 标记分析北美鹅掌楸与鹅掌楸种间遗传多样性 \\
\hline Liriodendron chinense & 鹅掌楸 & II & $\begin{array}{l}\text { 近危 } \\
\text { /NT }\end{array}$ & 李火根 & 利用 SSR 分子标记对鹅掌楸自由授粉子代的父本分析 \\
\hline Liriodendron chinense & 鹅掌楸 & II & 近危 & 孙亚光 & 利用 SSR 分子标记检测鹅掌楸属树种交配格局与基因流 \\
\hline
\end{tabular}


顾垒，闻丞，罗玫，王吴，吕植. 中国最受关注濒危物种保护现状快速评价的新方法探讨. 生物多样性，2015，23(5)：583-590. http://www biodiversity-science. net/CN/article/downloadArticleFile. do?attachType=PDF\&id=10075

\begin{tabular}{|c|c|c|c|c|c|}
\hline & & & $/ \mathrm{NT}$ & & \\
\hline \multirow[t]{2}{*}{ Liriodendron chinense } & 我掌楸 & II & 近危 & 李火根 & 利用 SSR 分子标记检测鹅掌楸雄性繁殖适合度与性选择 \\
\hline & & & $/ \mathrm{NT}$ & & \\
\hline \multirow[t]{2}{*}{ Liriodendron chinense } & 鹅掌楸 & II & 近危 & 王晓阳 & 利用 SSR 分子标记探测鹅掌揪杂种优势 \\
\hline & & & /NT & & \\
\hline \multirow[t]{2}{*}{ Liriodendron chinense } & 鹅掌楸 & II & 近危 & 陈龙 & 利用 SSR 分子标记研究鹅掌楸天然群体遗传结构 \\
\hline & & & /NT & & \\
\hline \multirow[t]{2}{*}{ Liriodendron chinense } & 鹅掌楸 & II & 近危 & 施季森 & 利用嫁接技术保存鹅掌楸属种质资源的试验 \\
\hline & & & $/ \mathrm{NT}$ & & \\
\hline \multirow[t]{2}{*}{ Liriodendron chinense } & 鹅掌楸 & II & 近危 & 李火根 & 两种鹅掌楸繁殖成效的比较 \\
\hline & & & /NT & & \\
\hline \multirow[t]{2}{*}{ Liriodendron chinense } & 鹅掌楸 & II & 近危 & 李火根 & 两种鹅掌楸繁殖成效的比较 \\
\hline & & & /NT & & \\
\hline \multirow[t]{2}{*}{ Liriodendron chinense } & 鹅掌楸 & II & 近危 & 魏勇 & 龙王山鹅掌楸种群的静态生命表 \\
\hline & & & /NT & & \\
\hline \multirow[t]{2}{*}{ Liriodendron chinense } & 鹅掌楸 & II & 近危 & 校瑞怀 & 马褂木 $\mathrm{N}$ 高效家系选择和菌根化育苗效果研究 \\
\hline & & & /NT & & \\
\hline \multirow[t]{2}{*}{ Liriodendron chinense } & 我鸟掌楸 & II & 近危 & 周志春 & 马补木 $\mathrm{N}$ 素吸收和利用效率家系遗传及 $\mathrm{N}$ 素影响 \\
\hline & & & /NT & & \\
\hline
\end{tabular}


顾垒，闻丞，罗玫，王吴，吕植. 中国最受关注濒危物种保护现状快速评价的新方法探讨. 生物多样性，2015，23(5)：583-590. http://www biodiversity-science. net/CN/article/downloadArticleFile. do?attachType=PDF\&id=10075

\begin{tabular}{|c|c|c|c|c|c|}
\hline Liriodendron chinense & 鹅掌楸 & II & $\begin{array}{l}\text { 近危 } \\
\text { /NT }\end{array}$ & 葛永金 & 马补木等 3 个树种人工林生长量及生物量调查研究 \\
\hline Liriodendron chinense & 我掌楸 & II & $\begin{array}{l}\text { 近危 } \\
\text { /NT }\end{array}$ & 李建民 & 马褂木地理遗传变异和优良种源选择 \\
\hline Liriodendron chinense & 我掌楸 & II & $\begin{array}{l}\text { 近危 } \\
\text { /NT }\end{array}$ & 李秀芹 & 马补木繁殖与栽培技术 \\
\hline Liriodendron chinense & 我掌梑 & II & $\begin{array}{l}\text { 近危 } \\
\text { /NT }\end{array}$ & 间文德 & 马补木盆栽土壤酶活性对 PAHs 胁迫的响应 \\
\hline Liriodendron chinense & 鹅掌楸 & II & $\begin{array}{l}\text { 近危 } \\
\text { /NT }\end{array}$ & 李建民 & 马补木人工林的生长和制浆造纸性能 \\
\hline Liriodendron chinense & 我掌楸 & II & $\begin{array}{l}\text { 近危 } \\
\text { /NT }\end{array}$ & 惠利省 & 马补木遗传多样性及系统地理学研究 \\
\hline Liriodendron chinense & 鹅掌楸 & II & $\begin{array}{l}\text { 近危 } \\
\text { /NT }\end{array}$ & 杨春惠 & 马补木优良地理种源试验及造林技术 \\
\hline Liriodendron chinense & 我掌楸 & II & $\begin{array}{l}\text { 近危 } \\
\text { /NT }\end{array}$ & 李秋荔 & 马褂木种源苗期性状变异研究 \\
\hline Liriodendron chinense & 鹅掌楸 & II & $\begin{array}{l}\text { 近危 } \\
\text { /NT }\end{array}$ & 徐小牛 & 马尾松与 4 种阔叶树混交林生长效果调查分析 \\
\hline Liriodendron chinense & 鹅掌楸 & II & 近危 & 李博 & 猫儿山鹅掌楸种群不同龄级立木的点格局分析 \\
\hline
\end{tabular}


顾垒，闻丞，罗玫，王吴，吕植. 中国最受关注濒危物种保护现状快速评价的新方法探讨. 生物多样性，2015，23(5)：583-590. http://www biodiversity-science. net/CN/article/downloadArticleFile. do?attachType=PDF\&id=10075

\begin{tabular}{|c|c|c|c|c|c|}
\hline & & & $/ \mathrm{NT}$ & & \\
\hline \multirow[t]{2}{*}{ Liriodendron chinense } & 鹅掌楸 & II & 近危 & 彭小林 & 闽北 5 种乡土阔叶树种幼林生长量及其对土壤肥力的影响 \\
\hline & & & $/ \mathrm{NT}$ & & \\
\hline \multirow[t]{2}{*}{ Liriodendron chinense } & 鹅掌楸 & II & 近危 & 丁贵杰 & 木荷和鹅掌楸萃取物及其活性铝溶液对马尾松种子发芽的影响 \\
\hline & & & /NT & & \\
\hline \multirow[t]{2}{*}{ Liriodendron chinense } & 鹅掌楸 & II & 近危 & 周俊 & 木兰科植物鹅掌楸和合果木的化学成分及其分类学意义 \\
\hline & & & /NT & & \\
\hline \multirow[t]{2}{*}{ Liriodendron chinense } & 鹅掌楸 & II & 近危 & 吴建国 & 气候变化对 5 种植物分布的潜在影响 \\
\hline & & & /NT & & \\
\hline \multirow[t]{2}{*}{ Liriodendron chinense } & 鹅掌楸 & II & 近危 & 王旭军 & 铅胁迫对 4 种行道树生长的影响 \\
\hline & & & $/ \mathrm{NT}$ & & \\
\hline \multirow[t]{2}{*}{ Liriodendron chinense } & 鹅掌楸 & II & 近危 & 李斌 & 铅胁迫对 4 种行道树种幼苗叶片丙二醛含量的影响 \\
\hline & & & /NT & & \\
\hline \multirow[t]{2}{*}{ Liriodendron chinense } & 鹅掌楸 & II & 近危 & 吴际友 & 铅胁迫对 4 种苗木叶片过氧化物酶和超氧化物歧化酶的影响 \\
\hline & & & /NT & & \\
\hline \multirow[t]{2}{*}{ Liriodendron chinense } & 鹅掌楸 & II & 近危 & 马丙尧 & 蚟蚓粪对鹅掌楸容器苗生长及养分吸收的影响 \\
\hline & & & /NT & & \\
\hline \multirow[t]{2}{*}{ Liriodendron chinense } & 我鸟掌楸 & II & 近危 & 熊冬连 & 三峡库区马补木水源涵养林复合经营模式研究 \\
\hline & & & /NT & & \\
\hline
\end{tabular}


顾垒，闻丞，罗玫，王吴，吕植. 中国最受关注濒危物种保护现状快速评价的新方法探讨. 生物多样性，2015，23(5)：583-590. http://www biodiversity-science. net/CN/article/downloadArticleFile. do?attachType=PDF\&id=10075

\begin{tabular}{|c|c|c|c|c|c|}
\hline Liriodendron chinense & 鹅掌楸 & II & $\begin{array}{l}\text { 近危 } \\
\text { /NT }\end{array}$ & 范彩霞 & 三种落叶阔叶幼树光合特性及其叶片养分动态特征的研究 \\
\hline Liriodendron chinense & 我掌楸 & II & $\begin{array}{l}\text { 近危 } \\
\text { /NT }\end{array}$ & 何斌 & 杉木采伐迹地鹅掌楸和杉木生长特性的研究 \\
\hline Liriodendron chinense & 我掌楸 & II & $\begin{array}{l}\text { 近危 } \\
\text { /NT }\end{array}$ & 莫海智 & 杉木鹅掌楸混交林结构特征研究-以广西大山塘林场为例 \\
\hline Liriodendron chinense & 我掌梑 & II & $\begin{array}{l}\text { 近危 } \\
\text { /NT }\end{array}$ & 吴兴德 & 杉木马补木不同混交比例土壤团粒结构的分形特征研究 \\
\hline Liriodendron chinense & 我掌楸 & II & $\begin{array}{l}\text { 近危 } \\
\text { /NT }\end{array}$ & 何贵平 & 杉木与马裬木、檫树混交林及其纯林生物量和土壤肥力研究 \\
\hline Liriodendron chinense & 我掌楸 & II & $\begin{array}{l}\text { 近危 } \\
\text { /NT }\end{array}$ & 李志先 & 施肥对盆栽杂交鹅掌楸幼苗生长的影响 \\
\hline Liriodendron chinense & 鹅掌楸 & II & $\begin{array}{l}\text { 近危 } \\
\text { /NT }\end{array}$ & 陈际伸 & 湿地松鹅掌楸混交林营养元素生物循环的研究 \\
\hline Liriodendron chinense & 我掌楸 & II & $\begin{array}{l}\text { 近危 } \\
\text { /NT }\end{array}$ & 黄韶承 & 水分胁迫对找掌楸属苗木生理影响的研究 \\
\hline Liriodendron chinense & 鹅掌楸 & II & $\begin{array}{l}\text { 近危 } \\
\text { /NT }\end{array}$ & 张祖荣 & 四面山野生鹅掌楸扞插繁殖技术初探 \\
\hline Liriodendron chinense & 鹅掌楸 & II & 近危 & 柳新红 & 速生五金木柄原料林树种评价体系构建与应用 \\
\hline
\end{tabular}


顾垒，闻丞，罗玫，王吴，吕植. 中国最受关注濒危物种保护现状快速评价的新方法探讨. 生物多样性，2015，23(5)：583-590. http://www biodiversity-science. net/CN/article/downloadArticleFile. do?attachType=PDF\&id=10075

\begin{tabular}{|c|c|c|c|c|c|}
\hline & & & $/ \mathrm{NT}$ & & \\
\hline \multirow[t]{2}{*}{ Liriodendron chinense } & 我掌楸 & II & 近危 & 方禄明 & 体细胞胚胎发生杂种马补木造林密度试验 \\
\hline & & & $/ \mathrm{NT}$ & & \\
\hline \multirow[t]{2}{*}{ Liriodendron chinense } & 鹅掌楸 & II & 近危 & 周志凯 & 土壤养分含量对杂交马补木生长的影响 \\
\hline & & & /NT & & \\
\hline \multirow[t]{2}{*}{ Liriodendron chinense } & 鹅掌楸 & II & 近危 & 冯汀 & 我国鹅掌楸文献分析 \\
\hline & & & $/ \mathrm{NT}$ & & \\
\hline \multirow[t]{2}{*}{ Liriodendron chinense } & 鹅掌楸 & II & 近危 & 卢志强 & 五种木本园林植物叶片对镉污染胁迫的反应 \\
\hline & & & /NT & & \\
\hline \multirow[t]{2}{*}{ Liriodendron chinense } & 鹅掌楸 & II & 近危 & 刘蓉蓉 & 芽苗移栽技术的运用对促进鹅掌楸苗木质量提高的影响 \\
\hline & & & /NT & & \\
\hline \multirow[t]{2}{*}{ Liriodendron chinense } & 鹅掌楸 & II & 近危 & 方炎明 & 淹水胁迫对浙江种源鹅掌楸光合特征的影响 \\
\hline & & & $/ \mathrm{NT}$ & & \\
\hline \multirow[t]{2}{*}{ Liriodendron chinense } & 鹅掌楸 & II & 近危 & 季孔庶 & 淹水胁迫下杂交鹅掌楸无性系几种酶活性的变化 \\
\hline & & & $/ \mathrm{NT}$ & & \\
\hline \multirow[t]{2}{*}{ Liriodendron chinense } & 鹅掌楸 & II & 近危 & 任晓冬 & 以社区为主体的自然保护机制研究-贵州剑河鹅掌楸自然保护区案例 \\
\hline & & & /NT & & \\
\hline \multirow[t]{2}{*}{ Liriodendron chinense } & 我掌楸 & II & 近危 & 卜基保 & 优良生态树种杂种鹅掌楸引种研究 \\
\hline & & & $/ \mathrm{NT}$ & & \\
\hline
\end{tabular}


顾垒，闻丞，罗玫，王吴，吕植. 中国最受关注濒危物种保护现状快速评价的新方法探讨. 生物多样性，2015，23(5)：583-590. http://www biodiversity-science. net/CN/article/downloadArticleFile. do?attachType=PDF\&id=10075

\begin{tabular}{|c|c|c|c|c|c|}
\hline Liriodendron chinense & 鹅掌楸 & II & $\begin{array}{l}\text { 近危 } \\
\text { /NT }\end{array}$ & 赵志新 & 幼苗期杂交鹅掌楸无性系和家系抗 $\mathrm{Pb}$ 和 Cd 胁迫的研究 \\
\hline Liriodendron chinense & 我掌楸 & II & $\begin{array}{l}\text { 近危 } \\
\text { /NT }\end{array}$ & 杨林 & 豫南大别山中国马褂木林木生长规律分析研究 \\
\hline Liriodendron chinense & 我掌楸 & II & $\begin{array}{l}\text { 近危 } \\
\text { /NT }\end{array}$ & 徐玉杰 & 豫南地区鹅掌楸丰产栽培技术 \\
\hline Liriodendron chinense & 鹅掌楸 & II & $\begin{array}{l}\text { 近危 } \\
\text { /NT }\end{array}$ & 张礼军 & 豫南山区鹅掌楸引种栽培试验初报 \\
\hline Liriodendron chinense & 我掌楸 & II & $\begin{array}{l}\text { 近危 } \\
\text { /NT }\end{array}$ & 陈金慧 & 杂交鹅掌揪体细胞胚胎发生研究 \\
\hline Liriodendron chinense & 我掌楸 & II & $\begin{array}{l}\text { 近危 } \\
\text { /NT }\end{array}$ & 左克锐 & 杂交鹅掌掞无性系苗期光合特性研究 \\
\hline Liriodendron chinense & 鹅掌楸 & II & $\begin{array}{l}\text { 近危 } \\
\text { /NT }\end{array}$ & 季孔庶 & 杂交鹅掌楸不同无性系对 $\mathrm{Pb}$ 胁迫的生理响应及抗性比较 \\
\hline Liriodendron chinense & 我掌楸 & II & $\begin{array}{l}\text { 近危 } \\
\text { /NT }\end{array}$ & 孙志勇 & 杂交鹅掌楸不同无性系对水分胁迫的响应 \\
\hline Liriodendron chinense & 鹅掌楸 & II & $\begin{array}{l}\text { 近危 } \\
\text { /NT }\end{array}$ & 潘向艳 & 杂交鹅掌楸不同无性系对淹水胁迫的反应 \\
\hline Liriodendron chinense & 鹅掌楸 & II & 近危 & 吴淑芳 & 杂交鹅掌楸材性、纤维特性及制浆性能研究 \\
\hline
\end{tabular}


顾垒，闻丞，罗玫，王吴，吕植. 中国最受关注濒危物种保护现状快速评价的新方法探讨. 生物多样性，2015，23(5)：583-590. http://www. biodiversity-science. net/CN/article/downloadArticleFile. do?attachType=PDF\&id=10075

\begin{tabular}{|c|c|c|c|c|c|}
\hline & & & $/ \mathrm{NT}$ & & \\
\hline \multirow[t]{2}{*}{ Liriodendron chinense } & 我掌楸 & II & 近危 & 高捍东 & 杂交鹅掌楸插穗提取物对白菜种子萌发的影响 \\
\hline & & & /NT & & \\
\hline \multirow[t]{2}{*}{ Liriodendron chinense } & 鹅掌楸 & II & 近危 & 季孔庶 & 杂交鹅掌楸的无性繁殖 \\
\hline & & & /NT & & \\
\hline \multirow[t]{2}{*}{ Liriodendron chinense } & 鹅掌楸 & II & 近危 & 徐柏森 & 杂交鹅掌楸花粉败育的结构变异与分析 \\
\hline & & & /NT & & \\
\hline \multirow[t]{2}{*}{ Liriodendron chinense } & 鹅掌楸 & II & 近危 & 郑兴峰 & 杂交鹅掌楸花芽发育的形态结构特征 \\
\hline & & & $/ \mathrm{NT}$ & & \\
\hline \multirow[t]{2}{*}{ Liriodendron chinense } & 鹅掌楸 & II & 近危 & 田敏 & 杂交鹅掌楸离体培养中器官发生的研究 \\
\hline & & & $/ \mathrm{NT}$ & & \\
\hline \multirow[t]{2}{*}{ Liriodendron chinense } & 鹅掌楸 & II & 近危 & 季孔庶 & 杂交鹅掌楸苗期超氧化物歧化酶和过氧化物酶的活力变异 \\
\hline & & & /NT & & \\
\hline \multirow[t]{2}{*}{ Liriodendron chinense } & 鹅掌楸 & II & 近危 & 潘彪 & 杂交鹅掌楸木材解剖性质及其径向变异规律 \\
\hline & & & /NT & & \\
\hline \multirow[t]{2}{*}{ Liriodendron chinense } & 鹅掌楸 & II & 近危 & 李志先 & 杂交鹅掌楸施肥效益研究 \\
\hline & & & /NT & & \\
\hline \multirow[t]{2}{*}{ Liriodendron chinense } & 我鸟掌楸 & II & 近危 & 施季森 & 杂交鹅掌梑体胚发生过程中 ATP 酶活性的超微细胞化学定位 \\
\hline & & & /NT & & \\
\hline
\end{tabular}


顾垒，闻丞，罗玫，王吴，吕植. 中国最受关注濒危物种保护现状快速评价的新方法探讨. 生物多样性，2015，23(5)：583-590. http://www biodiversity-science. net/CN/article/downloadArticleFile. do?attachType=PDF\&id=10075

\begin{tabular}{|c|c|c|c|c|c|}
\hline Liriodendron chinense & 鹅掌楸 & II & $\begin{array}{l}\text { 近危 } \\
\text { /NT }\end{array}$ & 魏丕伟 & 杂交鹅掌楸体细胞胚胎发生标志基因克隆及表达分析 \\
\hline Liriodendron chinense & 我掌楸 & II & $\begin{array}{l}\text { 近危 } \\
\text { /NT }\end{array}$ & 陈金慧 & 杂交鹅掌楸体细胞胚胎发生的扫描电镜观察 \\
\hline Liriodendron chinense & 我掌楸 & II & $\begin{array}{l}\text { 近危 } \\
\text { /NT }\end{array}$ & 杨国旭 & 杂交鹅掌梑植物中生物活性成分研究 \\
\hline Liriodendron chinense & 鹅掌楸 & II & $\begin{array}{l}\text { 近危 } \\
\text { /NT }\end{array}$ & 章义 & 杂交马补木嫁接繁殖技术初探 \\
\hline Liriodendron chinense & 我掌楸 & II & $\begin{array}{l}\text { 近危 } \\
\text { /NT }\end{array}$ & 蔡伟建 & 杂交马补木人工林培育技术研究 \\
\hline Liriodendron chinense & 我掌楸 & II & $\begin{array}{l}\text { 近危 } \\
\text { /NT }\end{array}$ & 高捍东 & 杂交马补木人工林生长规律及趋势研究 \\
\hline Liriodendron chinense & 鹅掌楸 & II & $\begin{array}{l}\text { 近危 } \\
\text { /NT }\end{array}$ & 张往祥 & 杂交马褂木叶片发育过程中资源利用效率的变化格局 \\
\hline Liriodendron chinense & 鹅掌楸 & II & $\begin{array}{l}\text { 近危 } \\
\text { /NT }\end{array}$ & 王齐瑞 & 杂种鹅掌楸嫁接繁育技术初探 \\
\hline Liriodendron chinense & 鹅掌楸 & II & $\begin{array}{l}\text { 近危 } \\
\text { /NT }\end{array}$ & 施季森 & 杂种鹅掌楸体胚苗根尖染色体核型分析 \\
\hline Liriodendron chinense & 鹅掌楸 & II & 近危 & 黄淑婧 & 杂种马补木采穗母株性状观察及亲缘关系分析 \\
\hline
\end{tabular}


顾垒，闻丞，罗玫，王吴，吕植. 中国最受关注濒危物种保护现状快速评价的新方法探讨. 生物多样性，2015，23(5)：583-590. http://www. biodiversity-science. net/CN/article/downloadArticleFile. do?attachType=PDF\&id=10075

\begin{tabular}{|c|c|c|c|c|c|}
\hline & & & $/ \mathrm{NT}$ & & \\
\hline \multirow[t]{2}{*}{ Liriodendron chinense } & 鹅掌楸 & II & 近危 & 金国庆 & 杂种马补木扞插繁殖技术的研究 \\
\hline & & & $/ \mathrm{NT}$ & & \\
\hline \multirow[t]{2}{*}{ Liriodendron chinense } & 鹅掌楸 & II & 近危 & 余发新 & 杂种马补木扞插繁殖技术研究-- I 穗条产量及促根剂配方试验 \\
\hline & & & /NT & & \\
\hline \multirow[t]{2}{*}{ Liriodendron chinense } & 鹅掌楸 & II & 近危 & 余发新 & 杂种马补木扞插繁殖技术研究-- II 插穗粗细及环境条件与生根的关系 \\
\hline & & & /NT & & \\
\hline \multirow[t]{2}{*}{ Liriodendron chinense } & 鹅掌楸 & II & 近危 & 沈植国 & 杂种马补木栽培技术规程 \\
\hline & & & $/ \mathrm{NT}$ & & \\
\hline \multirow[t]{2}{*}{ Liriodendron chinense } & 鹅掌楸 & II & 近危 & 李斌 & 长沙市四种行道树抗铅胁迫能力的研究 \\
\hline & & & $/ \mathrm{NT}$ & & \\
\hline \multirow[t]{2}{*}{ Liriodendron chinense } & 找掌楸 & II & 近危 & 郭治友 & 珍稀植物鹅掌楸组织培养与离体快繁技术 \\
\hline & & & /NT & & \\
\hline \multirow[t]{2}{*}{ Liriodendron chinense } & 鹅掌楸 & II & 近危 & 郭治友 & 珍稀植物鹅掌楸组织培养与离体快繁技术研究 \\
\hline & & & /NT & & \\
\hline \multirow[t]{2}{*}{ Liriodendron chinense } & 鹅掌楸 & II & 近危 & 赵燕 & 中国鹅掌楸扦插繁殖试验研究 \\
\hline & & & /NT & & \\
\hline \multirow[t]{2}{*}{ Liriodendron chinense } & 我鸟掌楸 & II & 近危 & 顾万春 & 中国鹅掌楸遗传多样性研究 \\
\hline & & & /NT & & \\
\hline
\end{tabular}


顾垒，闻丞，罗玫，王吴，吕植. 中国最受关注濒危物种保护现状快速评价的新方法探讨. 生物多样性，2015，23(5)：583-590. http://www. biodiversity-science. net/CN/article/downloadArticleFile. do?attachType=PDF\&id=10075

\begin{tabular}{|c|c|c|c|c|c|}
\hline Liriodendron chinense & 鹅掌楸 & II & $\begin{array}{l}\text { 近危 } \\
\text { /NT }\end{array}$ & 谭飞燕 & 中国马补木无性系多性状变异研究及 ISSR 指纹图谱的构建 \\
\hline Liriodendron chinense & 我掌楸 & II & $\begin{array}{l}\text { 近危 } \\
\text { /NT }\end{array}$ & 黄寿先 & 中国马褂木无性系嫁接繁殖性状变异 \\
\hline Liriodendron chinense & 我鸟掌楸 & II & $\begin{array}{l}\text { 近危 } \\
\text { /NT }\end{array}$ & 李明子 & 专著《鹅掌楸属树种杂交育种与利用》的引文分析 \\
\hline Locustella pleskei & 史氏蝗莺 & $\begin{array}{l}\text { 未列 } \\
\lambda\end{array}$ & $\begin{array}{l}\text { 易危 } \\
\text { /VU }\end{array}$ & & 广西鸟类新纪录--史氏蝗莺 \\
\hline Locustella pleskei & 史氏蝗莺 & $\begin{array}{l}\text { 未列 } \\
\text { 入 }\end{array}$ & $\begin{array}{l}\text { 易危 } \\
\text { /VU }\end{array}$ & & 上海地区鸟类新记录 3 种: 史氏蝗莺、斑背大尾莺、钝翅苇莺 \\
\hline Locustella tacsanowskia & 中华短翅莺 & $\begin{array}{l}\text { 未列 } \\
\text { 入 }\end{array}$ & $\begin{array}{l}\text { 数据 } \\
\text { 不足 } \\
\text { /DD }\end{array}$ & 罗康 & 哀牢山北段大中山候鸟聚集地秋季夜间迁徙鸟类多样性 \\
\hline Locustella tacsanowskia & 中华短翅莺 & $\begin{array}{l}\text { 未列 } \\
\text { 入 }\end{array}$ & $\begin{array}{l}\text { 数据 } \\
\text { 不足 } \\
\text { /DD }\end{array}$ & 韩九㚖 & 衡水湖国家级自然保护区鸟类调查 \\
\hline Locustella tacsanowskia & 中华短翅莺 & $\begin{array}{l}\text { 未列 } \\
\lambda\end{array}$ & $\begin{array}{l}\text { 数据 } \\
\text { 不足 } \\
\text { /DD }\end{array}$ & 单凯 & 黄河三角洲发现的山东省鸟类新纪录 \\
\hline
\end{tabular}


顾垒，闻丞，罗玫，王吴，吕植. 中国最受关注濒危物种保护现状快速评价的新方法探讨. 生物多样性，2015，23(5)：583-590. http://www. biodiversity-science. net/CN/article/downloadArticleFile. do?attachType=PDF\&id=10075

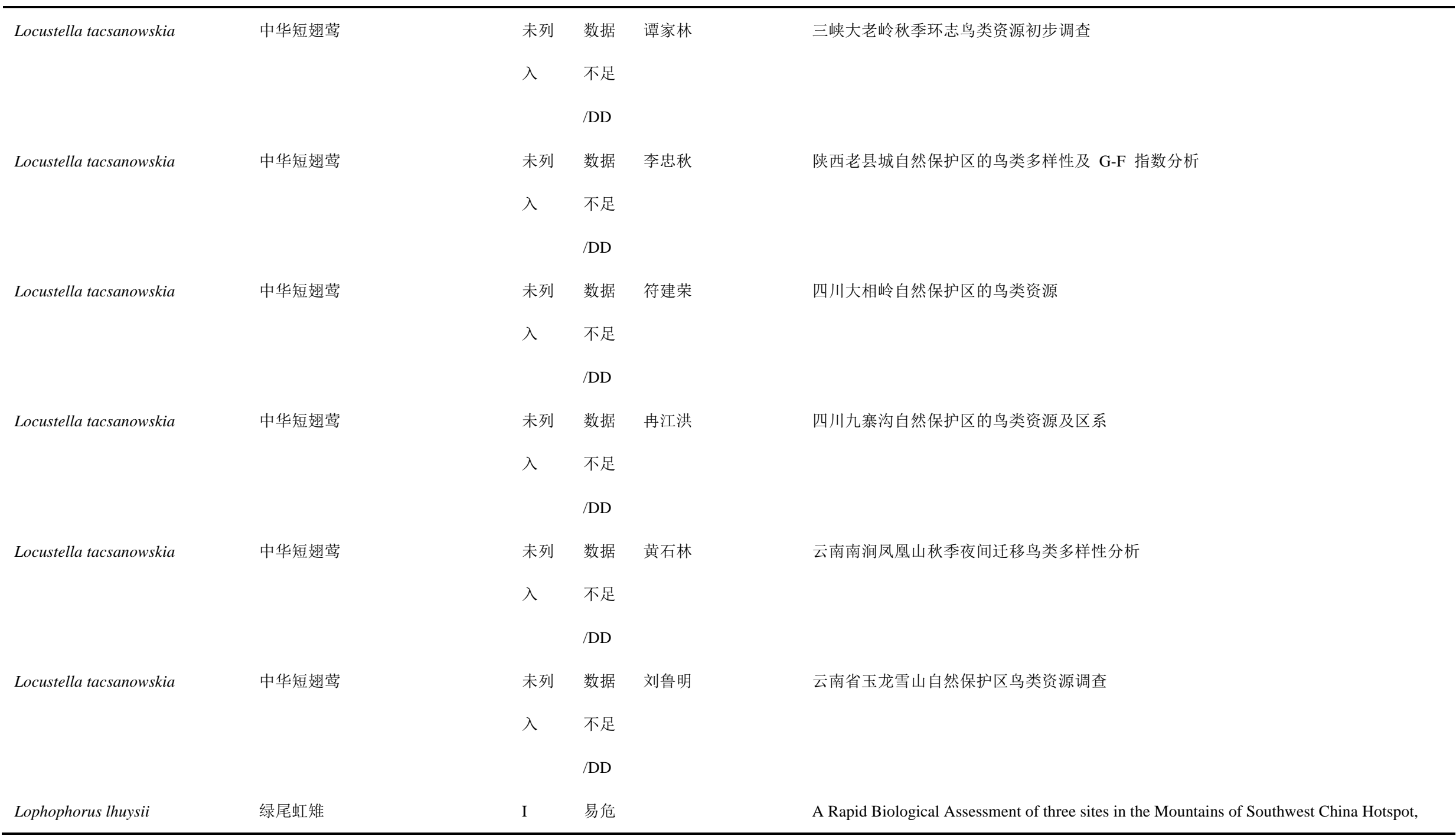


顾垒，闻丞，罗玫，王吴，吕植. 中国最受关注濒危物种保护现状快速评价的新方法探讨. 生物多样性，2015，23(5)：583-590. http://www biodiversity-science. net/CN/article/downloadArticleFile. do?attachType=PDF\&id=10075

\begin{tabular}{|c|c|c|c|c|c|}
\hline & & & /VU & & Ganzi Prefecture, Sichuan Province \\
\hline \multirow[t]{2}{*}{ Lophophorus Ihuysii } & 绿尾虹雉 & I & 易危 & 韩联宪 & Appendix 4. Birds Species Recorded \\
\hline & & & /VU & & \\
\hline \multirow[t]{2}{*}{ Lophophorus lhuysii } & 绿尾虹雉 & I & 易危 & 李晟 & The use of infrared-triggered cameras for surveying phasianids in Sichuan Province, China \\
\hline & & & /VU & & \\
\hline \multirow[t]{2}{*}{ Lophophorus Ihuysii } & 绿尾虹雉 & I & 易危 & Jesper Hornskov & Wolong \& Wawu Shan, Sichuan, China:22 Apr - 1 May 2008 \\
\hline & & & /VU & & \\
\hline \multirow[t]{2}{*}{ Lophophorus lhuysii } & 绿尾虹雉 & I & 易危 & 格玛江初 & 白马雪山自然保护区德钦分局鸡类多样性及保护管理研究 \\
\hline & & & $/ \mathrm{VU}$ & & \\
\hline \multirow[t]{2}{*}{ Lophophorus lhuysii } & 绿尾虹雉 & I & 易危 & 王育章 & 绿尾虹雉消化系统形态学的初步研究 \\
\hline & & & /VU & & \\
\hline \multirow[t]{2}{*}{ Lophophorus lhuysii } & 绿尾虹雉 & I & 易危 & 熊芙蓉 & 在唐家河建“绿尾虹雉小屋” \\
\hline & & & /VU & & \\
\hline \multirow[t]{2}{*}{ Lophophorus lhuysii } & 绿尾虹雉 & I & 易危 & 董佲 & 在西部的高山之巅 \\
\hline & & & /VU & & \\
\hline \multirow[t]{2}{*}{ Lophophorus lhuysii } & 绿尾虹雉 & I & 易危 & 沈尤 & 震后再寻绿尾虹雉 \\
\hline & & & /VU & & \\
\hline \multirow[t]{2}{*}{ Lophophorus sclateri } & 白尾梢虹雉 & I & 易危 & WEI WANG & Habitat Degradation and Conservation Status Assessment of Gallinaceous Birds in the \\
\hline & & & /VU & & Trans-Himalayas,China \\
\hline
\end{tabular}


顾垒，闻丞，罗玫，王吴，吕植. 中国最受关注濒危物种保护现状快速评价的新方法探讨. 生物多样性，2015，23(5)：583-590. http://www biodiversity-science. net/CN/article/downloadArticleFile. do?attachType=PDF\&id=10075

\begin{tabular}{|c|c|c|c|c|c|}
\hline Lophophorus sclateri & 白尾梢虹雉 & I & $\begin{array}{l}\text { 易危 } \\
\text { /VU }\end{array}$ & 罗旭 & 高黎贡山白尾梢虹雉春季食谱及食物营养成分分析 \\
\hline Lophophorus sclateri & 白尾梢虹雉 & I & $\begin{array}{l}\text { 易危 } \\
\text { /VU }\end{array}$ & 罗旭 & 高黎贡山白尾梢虹雉繁殖生态观察 \\
\hline Lophophorus sclateri & 白尾梢虹雉 & I & $\begin{array}{l}\text { 易危 } \\
\text { /VU }\end{array}$ & 罗旭 & 高黎贡山白尾梢虹雉取食行为及春季取食地特征 \\
\hline Lophophorus sclateri & 白尾梢虹雉 & I & $\begin{array}{l}\text { 易危 } \\
\text { /VU }\end{array}$ & 罗旭 & 高黎贡山白尾梢虹雉生态研究 \\
\hline Lophophorus sclateri & 白尾梢虹雉 & I & $\begin{array}{l}\text { 易危 } \\
\text { /VU }\end{array}$ & 罗旭 & 高黎贡山冬季白尾梢虹雉运动方式和生境偏好的初步观察 \\
\hline Lophophorus sclateri & 白尾梢虹雉 & I & $\begin{array}{l}\text { 易危 } \\
\text { /VU }\end{array}$ & 张永 & 目击蛮荒秘境中的白尾梢虹雉 \\
\hline Lophophorus sclateri & 白尾梢虹雉 & I & $\begin{array}{l}\text { 易危 } \\
\text { /VU }\end{array}$ & 韩联宪 & 云南白尾梢虹雉的分布与保护 \\
\hline Lophophorus sclateri & 白尾梢虹雉 & I & $\begin{array}{l}\text { 易危 } \\
\text { /VU }\end{array}$ & 吴波 & 长江上游森林生态区生物多样性保护优先区确定 \\
\hline Lophura leucomelanos & 黑滒 & II & $\begin{array}{l}\text { 无危 } \\
\text { /LC }\end{array}$ & 王 斌 & 西藏珠穆朗玛峰国家级自然保护区鸟类群落结构与多样性 \\
\hline Lophura leucomelanos & 黑酠 & II & 无危 & 李晶晶 & 珠穆朗玛峰国家级自然保护区鸟类区系及其垂直分布特征 \\
\hline
\end{tabular}


顾垒，闻丞，罗玫，王吴，吕植. 中国最受关注濒危物种保护现状快速评价的新方法探讨. 生物多样性，2015，23(5)：583-590. http://www biodiversity-science. net/CN/article/downloadArticleFile. do?attachType=PDF\&id=10075

\begin{tabular}{|c|c|c|c|c|c|}
\hline & & & $/ \mathrm{LC}$ & & \\
\hline Lophura nycthemera & 白鹂 & II & $\begin{array}{l}\text { 无危 } \\
\text { /LC }\end{array}$ & Ning LI & $\begin{array}{l}\text { Comparison of roosting habitat characteristics of two sympatric pheasants during springtime at } \\
\text { Dazhong Mountain,southwesternChina }\end{array}$ \\
\hline Lophura nycthemera & 白鹝 & II & $\begin{array}{l}\text { 无危 } \\
\text { /LC }\end{array}$ & 韦月鸾 & GIS 技术在木论自然保护区白酠种群动态监测中的应用 \\
\hline Lophura nycthemera & 白鹝 & II & $\begin{array}{l}\text { 无危 } \\
\text { /LC }\end{array}$ & 李 伟 & 哀牢山国家级自然保护区南华片三种雉类春季取食地利用比较 \\
\hline Lophura nycthemera & 白满 & II & $\begin{array}{l}\text { 无危 } \\
\text { /LC }\end{array}$ & 陈俊豪 & 白颈长尾雉与白鹇秋冬季空间生态位比较 \\
\hline Lophura nycthemera & 白闲 & II & $\begin{array}{l}\text { 无危 } \\
\text { /LC }\end{array}$ & 邵 晨 & 白酠的夜栖息地选择及夜栖息行为 \\
\hline Lophura nycthemera & 白鹕 & II & $\begin{array}{l}\text { 无危 } \\
\text { /LC }\end{array}$ & 金国龙 & 东白山自然保护区鸟类资源调查 \\
\hline Lophura nycthemera & 白洞 & II & $\begin{array}{l}\text { 无危 } \\
\text { /LC }\end{array}$ & 刘 鹏 & 官山自然保护区四种雉类的生境选择 \\
\hline Lophura nycthemera & 白鹕 & II & $\begin{array}{l}\text { 无危 } \\
\text { /LC }\end{array}$ & 李小燕 & 广东莲花山白盆珠省级自然保护区鸟类资源调查 \\
\hline Lophura nycthemera & 白鹝 & II & $\begin{array}{l}\text { 无危 } \\
\text { /LC }\end{array}$ & 陆 舟 & 广西弄岗喀斯特森林繁殖鸟群落的集团结构 \\
\hline
\end{tabular}


顾垒，闻丞，罗玫，王吴，吕植. 中国最受关注濒危物种保护现状快速评价的新方法探讨. 生物多样性，2015，23(5)：583-590. http://www biodiversity-science. net/CN/article/downloadArticleFile. do?attachType=PDF\&id=10075

\begin{tabular}{|c|c|c|c|c|c|}
\hline Lophura nycthemera & 白唡 & II & $\begin{array}{l}\text { 无危 } \\
\text { /LC }\end{array}$ & 熊志斌 & 贵州茂兰自然保护区的雉类资源及其保护 \\
\hline Lophura nycthemera & 白閜 & II & $\begin{array}{l}\text { 无危 } \\
\text { /LC }\end{array}$ & 余辰星 & 桂西南喀斯特山地雉类的生态分布和空间生态位分析 \\
\hline Lophura nycthemera & 白闲岛 & II & $\begin{array}{l}\text { 无危 } \\
\text { /LC }\end{array}$ & 郑伟成 & 红外相机技术监测九龙山国家级自然保护区鸟兽多样性 \\
\hline Lophura nycthemera & 白閜 & II & $\begin{array}{l}\text { 无危 } \\
\text { /LC }\end{array}$ & 刘 鹏 & 江西官山自然保护区四种雉类的生境选择差异 \\
\hline Lophura nycthemera & 白鸨 & II & $\begin{array}{l}\text { 无危 } \\
\text { /LC }\end{array}$ & 黄晓凤 & 江西齐云山自然保护区冬季鸟类调查及多样性分析 \\
\hline Lophura nycthemera & 白閜 & II & $\begin{array}{l}\text { 无危 } \\
\text { /LC }\end{array}$ & 黄晓凤 & 江西齐云山自然保护区鸟类区系与多样性分析 \\
\hline Lophura nycthemera & 白片 & II & $\begin{array}{l}\text { 无危 } \\
\text { /LC }\end{array}$ & 程松林 & 江西武夷山自然保护区的雉类资源及其保护 \\
\hline Lophura nycthemera & 白閜 & II & $\begin{array}{l}\text { 无危 } \\
\text { /LC }\end{array}$ & 王 钰 & 临沧澜沧江自然保护区双江片区生态旅游开发探索 \\
\hline Lophura nycthemera & 白㜀 & II & $\begin{array}{l}\text { 无危 } \\
\text { /LC }\end{array}$ & 罗盛金 & 庐山鸟类多样性及季节动态分析 \\
\hline Lophura nycthemera & 白丽鸟 & II & 无危 & 谢再成 & 三百山自然保护区鸟类资源及其评价 \\
\hline
\end{tabular}


顾垒，闻丞，罗玫，王吴，吕植. 中国最受关注濒危物种保护现状快速评价的新方法探讨. 生物多样性，2015，23(5)：583-590. http://www. biodiversity-science. net/CN/article/downloadArticleFile. do?attachType=PDF\&id=10075

\begin{tabular}{|c|c|c|c|c|c|}
\hline & & & $/ \mathrm{LC}$ & & \\
\hline \multirow[t]{2}{*}{ Lophura nycthemera } & 白閜 & II & 无危 & 孙 岳 & 武夷山鸡形目鸟类多样性及冰冻灾害对其影响研究 \\
\hline & & & $/ \mathrm{LC}$ & & \\
\hline \multirow[t]{2}{*}{ Lophura nycthemera } & 白姵 & II & 无危 & 武丙琳 & 西天目山旅游区鸟类群落结构变化及保护对策研究 \\
\hline & & & $/ \mathrm{LC}$ & & \\
\hline \multirow[t]{2}{*}{ Lophura swinhoii } & 蓝鸼 & I & 近危 & & 台湾山林里的瑰宝_美丽绝伦的蓝鹇 \\
\hline & & & /NT & & \\
\hline \multirow[t]{2}{*}{ Lophura swinhoii } & 蓝㸞 & I & 近危 & 刘阳 & 中国鸟类研究的先驱-罗伯特・斯温侯 \\
\hline & & & /NT & & \\
\hline \multirow[t]{2}{*}{ Luscinia obscura } & 黑喉歌鸲 & 未列 & 易危 & 何 屹 & 从黑喉歌鸲的出现看城市停歇地的重要性 \\
\hline & & 入 & $/ \mathrm{VU}$ & & \\
\hline \multirow[t]{2}{*}{ Luscinia obscura } & 黑喉歌鸲 & 未列 & 易危 & 张永文 & 发现黑喉歌鸲 \\
\hline & & 入 & /VU & & \\
\hline \multirow[t]{2}{*}{ Luscinia obscura } & 黑喉歌鸲 & 未列 & 易危 & 韩宁 & 黑喉歌鸲繁殖生态初报 \\
\hline & & 入 & /VU & & \\
\hline \multirow[t]{2}{*}{ Luscinia obscura } & 黑喉歌鸲 & 未列 & 易危 & 张永文 & 陕西秦岭地区黑喉歌鸲繁殖行为监测简报 \\
\hline & & 入 & /VU & & \\
\hline \multirow[t]{2}{*}{ Luscinia pectardens } & 金胸歌鸲 & 未列 & 近危 & & 陕西秦岭及大巴山地区的鸟类资源调查 \\
\hline & & 入 & /NT & & \\
\hline
\end{tabular}


顾垒，闻丞，罗玫，王吴，吕植. 中国最受关注濒危物种保护现状快速评价的新方法探讨. 生物多样性，2015，23(5)：583-590. http://www biodiversity-science. net/CN/article/downloadArticleFile. do?attachType=PDF\&id=10075

\begin{tabular}{|c|c|c|c|c|c|}
\hline Luscinia ruficeps & 棕头歌鸲 & 未列 & 濒危 & 巩会生 & 陕西秦岭及大巴山地区的鸟类资源调查 \\
\hline & & 入 & $/ \mathrm{EN}$ & & \\
\hline \multirow[t]{2}{*}{ M. foveolata var. eineraseens } & 灰毛含笑 & 未列 & 濒危 & 邹昊 & 野生木兰科植物种子采集及育苗技术 \\
\hline & & 入 & /EN & & \\
\hline M1 foveolata var1 ci nerascens & 灰毛含笑 & 未列 & 濒危 & 储德裕 & 观赏木兰在千岛湖适应性及绿化大苗培育的研究 \\
\hline Law et Y1F1wu & & 入 & $/ \mathrm{EN}$ & & \\
\hline \multirow[t]{2}{*}{ Macaca arctoides } & 红面猴 & II & 易危 & 李进华 & 2006_短尾猴与红面猴细胞色素 $\mathrm{b}$ 基因变异特点及系统发育分析_柳杨 \\
\hline & & & $/ \mathrm{VU}$ & & \\
\hline \multirow[t]{2}{*}{ Macaca arctoides } & 短尾猴 & II & 易危 & Ruliang Pan & Craniodental variation among Macaques (Macaca), nonhuman \\
\hline & & & $/ \mathrm{VU}$ & & \\
\hline \multirow[t]{2}{*}{ Macaca arctoides } & 短尾猴 & II & 易危 & RULIANG PAN & Mandibular Variation Among Chinese Macaques \\
\hline & & & /VU & & \\
\hline \multirow[t]{2}{*}{ Macaca arctoides } & 短尾猴 & II & 易危 & ANTHONY J. Tosi, & Paternal, maternal, and biparental molecular markers provide unique windows onto the \\
\hline & & & /VU & & evolutionary history of macaque monkeys \\
\hline \multirow[t]{2}{*}{ Macaca arctoides } & 短尾猴 & II & 易危 & 姚平 & 短尾猴出血性肠炎的诊疗和预防_姚平 \\
\hline & & & $/ \mathrm{VU}$ & & \\
\hline \multirow[t]{2}{*}{ Macaca arctoides } & 短尾猴 & II & 易危 & 水波 & 三种猕猴属动物 Fas 基因的克隆_水波 \\
\hline & & & /VU & & \\
\hline Macaca assamensis & 熊猴 & I & 易危 & Don J. Melnick & Comparison of Y chromosome and mtDNA phylogenies leads to unique inferences of macaque \\
\hline
\end{tabular}


顾垒，闻丞，罗玫，王吴，吕植. 中国最受关注濒危物种保护现状快速评价的新方法探讨. 生物多样性，2015，23(5)：583-590. http://www. biodiversity-science. net/CN/article/downloadArticleFile. do?attachType=PDF\&id=10075

\begin{tabular}{|c|c|c|c|c|c|}
\hline & & & /VU & & evolutionary histor \\
\hline \multirow[t]{2}{*}{ Macaca assamensis } & 熊猴 & I & 易危 & B. THIERRY & Macaque evolution and dispersal in insular south - east Asia \\
\hline & & & $/ \mathrm{VU}$ & & \\
\hline \multirow[t]{2}{*}{ Macaca assamensis } & 熊猴 & I & 易危 & Chengming Huang & Niche separation of sympatric macaques, Macaca assamensis and M. mulatta, in limestone \\
\hline & & & /VU & & habitats of Nonggang, China \\
\hline \multirow[t]{2}{*}{ Macaca assamensis } & 熊猴 & I & 易危 & 张中伟 & 从熊猴肺脏中检出大肠埃希氏菌 O157：H7 \\
\hline & & & /VU & & \\
\hline \multirow[t]{2}{*}{ Macaca assamensis } & 熊猴 & I & 易危 & 阙腾程 & 笼养熊猴等级结构及其对育婴影响的研究 \\
\hline & & & $/ \mathrm{VU}$ & & \\
\hline \multirow[t]{2}{*}{ Macaca assamensis } & 熊猴 & I & 易危 & 黄金艳 & 笼养熊猴繁殖行为学研究 \\
\hline & & & $/ \mathrm{VU}$ & & \\
\hline \multirow[t]{2}{*}{ Macaca assamensis } & 熊猴 & I & 易危 & 周岐海 & 笼养熊猴幼体玩要行为的性别差异 \\
\hline & & & /VU & & \\
\hline \multirow[t]{2}{*}{ Macaca assamensis } & 熊猴 & I & 易危 & 黄乘明 & 弄岗熊猴的活动节律和活动时间分配 \\
\hline & & & /VU & & \\
\hline \multirow[t]{2}{*}{ Macaca assamensis } & 熊猴 & I & 易危 & 韦华 & 弄岗熊猴的食性、活动节律和活动时间分配 \\
\hline & & & /VU & & \\
\hline \multirow[t]{2}{*}{ Macaca assamensis } & 熊猴 & I & 易危 & 黄乘明 & 三种笼养灵长类活动时间分配的比较研究 \\
\hline & & & /VU & & \\
\hline
\end{tabular}


顾垒，闻丞，罗玫，王吴，吕植. 中国最受关注濒危物种保护现状快速评价的新方法探讨. 生物多样性，2015，23(5)：583-590. http://www. biodiversity-science. net/CN/article/downloadArticleFile. do?attachType=PDF\&id=10075

\begin{tabular}{|c|c|c|c|c|c|}
\hline Macaca assamensis & 熊猴 & I & 易危 & 江峡 & 三种笼养灵长类幼体的玩要行为 \\
\hline & & & $/ \mathrm{VU}$ & & \\
\hline \multirow[t]{2}{*}{ Macaca assamensis } & 熊猴 & I & 易危 & 黄乘明 & 同域分布黑叶猴和熊猴的活动时间分配比较 \\
\hline & & & /VU & & \\
\hline \multirow[t]{2}{*}{ Macaca leonina } & 北豚尾猴 & I & 易危 & Yong-Tang ZHENG & Analysis of immunoglobulin, complements and CRP levels in serum of captive northern \\
\hline & & & /VU & & pig-tailed macaques (Macaca leonina) \\
\hline \multirow[t]{2}{*}{ Macaca mulatta } & 猕猴 & II & 近危 & 罗启慧 & 感染肺炎链球菌猕猴消化系统白细胞介素 6 的表达观察 \\
\hline & & & $/ \mathrm{NT}$ & & \\
\hline \multirow[t]{2}{*}{ Macaca mulatta } & 猕猴 & II & 近危 & 隋丽华 & 猕猴 B 病毒 gC 蛋白特异性抗原表位的合成和表达 \\
\hline & & & /NT & & \\
\hline \multirow[t]{2}{*}{ Macaca mulatta } & 猕猴 & II & 近危 & 陈子亮 & 1 例猕猴尿潴留的诊断与治疗方法初探 \\
\hline & & & /NT & & \\
\hline \multirow[t]{2}{*}{ Macaca mulatta } & 猕猴 & II & 近危 & LI Qing-qing & A Molecular Phylogeny of Macaca Based on Mitochondrial Control Region Sequences \\
\hline & & & $/ \mathrm{NT}$ & & \\
\hline \multirow[t]{2}{*}{ Macaca mulatta } & 猕猴 & II & 近危 & XUE De-ming & Allometric Analysis on Variables of Humerus and Clavicle of Rhesus Macaques in Taihang \\
\hline & & & /NT & & MountainsX \\
\hline \multirow[t]{2}{*}{ Macaca mulatta } & 猕猴 & II & 近危 & Chuan Qin & An animal model of SARS produced by infection of Macaca mulatta with SARS coronavirus \\
\hline & & & /NT & & \\
\hline Macaca mulatta & 猕猴 & II & 近危 & 范春梅 & B 型超声显像技术在实验猕猴繁殖中的应用 \\
\hline
\end{tabular}


顾垒，闻丞，罗玫，王昊，吕植. 中国最受关注濒危物种保护现状快速评价的新方法探讨．生物多样性，2015，23(5)：583-590.

\section{$/ \mathrm{N}$}

Macaca mulatta

猕猴

猕猴

猕猴

Macaca mulatta

Macaca mulatta

猕猴

Macaca mulatta

Macaca mulatta

Macaca mulatta

猕猴

Macaca mulatta

猕猴

猕猴
近危

/NT$$
\text { 近危 }
$$$$
\text { NT }
$$

II

近危 Xiaobing Wu

/NT

II

近危 Hongmei Wang

PAN Ru-Liang

PAN Ru-liang

(a)

CHEN Dong-liang

近危 Cyril C GRUETER

/NT

$$
\text { 近危 }
$$

$$
\text { 近危 }
$$

Macaca mulatta
Comparative Analysis of Five Different Homologous Feeder Cell Lines in the Ability to

Support Rhesus Embryonic Stem Cells

CRANIODENTAL VARIATION OF MACAQUES (Macaca):SIZE, FUNCTION AND

\section{PHYLOGENY}

Dental Variation Among Asian Colobines, with Specific Reference to the Macaques on the

Same Continent

DNA-based species identification for faecal samples An application on the mammalian survey

in Mountain Huangshan Scenic Spot

Expression of Matrix Metalloproteinase-2, -9, -14, and Tissue Inhibitors of

Metalloproteinase-1, -2, -3 in the Endometrium and Placenta of Rhesus Monkey (Macaca mulatta) During Early Preg

Niche partitioning between sympatric rhesus macaques and Yunnan snub-nosed monkeys at Baimaxueshan Nature Reserve, China

Positive Selection on the Gene RNASEL Correlation between Patterns of Evolution and

Function

Primary research on changes of ASPP family in the process of neural differentiation from

Rhesus embryonic stem cells

primates 
顾垒，闻丞，罗玫，王吴，吕植. 中国最受关注濒危物种保护现状快速评价的新方法探讨. 生物多样性，2015，23(5)：583-590. http://www biodiversity-science. net/CN/article/downloadArticleFile. do?attachType=PDF\&id=10075

\begin{tabular}{|c|c|c|c|c|c|}
\hline & & & $/ \mathrm{NT}$ & & \\
\hline \multirow[t]{2}{*}{ Macaca mulatta } & 猕猴 & II & 近危 & 肖建华 & RM 合剂对猕猴的麻醉效果观察 \\
\hline & & & $/ \mathrm{NT}$ & & \\
\hline \multirow[t]{2}{*}{ Macaca mulatta } & 猕猴 & II & 近危 & ZHAO Xiao- jin & Study on the Dermatoglyphics of the Palms of Taihang Macaques mulatta \\
\hline & & & /NT & & \\
\hline \multirow[t]{2}{*}{ Macaca mulatta } & 猕猴 & II & 近危 & 史阳 & 八达岭野生动物世界圈养半野生猕猴行为生态 \\
\hline & & & /NT & & \\
\hline \multirow[t]{2}{*}{ Macaca mulatta } & 猕猴 & II & 近危 & 黎大勇 & 白马雪山自然保护区狝猴冬季栖息地的选择 \\
\hline & & & $/ \mathrm{NT}$ & & \\
\hline \multirow[t]{2}{*}{ Macaca mulatta } & 猕猴 & II & 近危 & 岳占碰 & 白血病抑制因子及其受体在月经周期猕猴输卵管内的表达 \\
\hline & & & $/ \mathrm{NT}$ & & \\
\hline \multirow[t]{2}{*}{ Macaca mulatta } & 猕猴 & II & 近危 & 王俊斌 & 保留灌肠与输液治疗繁殖猕猴菌痢疗效观察 \\
\hline & & & /NT & & \\
\hline \multirow[t]{2}{*}{ Macaca mulatta } & 猕猴 & II & 近危 & 岳占碰 & 表皮生长因子家族及其受体在月经周期猕猴输卵管内的表达 \\
\hline & & & /NT & & \\
\hline \multirow[t]{2}{*}{ Macaca mulatta } & 猕猴 & II & 近危 & 王海苹 & 不同地位猕猴正常月经周期血清中孕酮、雌二醇、泌乳素的变化 \\
\hline & & & /NT & & \\
\hline \multirow[t]{2}{*}{ Macaca mulatta } & 猕猴 & II & 近危 & 采克俊 & 不同渗透压的稀释液对猕猴精子低温冷冻保存的影响 \\
\hline & & & /NT & & \\
\hline
\end{tabular}


顾垒，闻丞，罗玫，王吴，吕植. 中国最受关注濒危物种保护现状快速评价的新方法探讨. 生物多样性，2015，23(5)：583-590. http://www. biodiversity-science. net/CN/article/downloadArticleFile. do?attachType=PDF\&id=10075

\begin{tabular}{|c|c|c|c|c|c|}
\hline Macaca mulatta & 猕猴 & II & $\begin{array}{l}\text { 近危 } \\
\text { /NT }\end{array}$ & 鲁帅尧 & 不同生活环境猕猴血清中矿物元素含量的测定与分析 \\
\hline Macaca mulatta & 猕猴 & II & $\begin{array}{l}\text { 近危 } \\
\text { /NT }\end{array}$ & 郭梅梅 & 称猴发育过程中肠肝组织生长抑素及其受体表达演变规律 \\
\hline Macaca mulatta & 猕猴 & II & $\begin{array}{l}\text { 近危 } \\
\text { /NT }\end{array}$ & 吕九全 & 成年太行山猕猴头骨变量相关性及比较研究 \\
\hline Macaca mulatta & 猕猴 & II & $\begin{array}{l}\text { 近危 } \\
\text { /NT }\end{array}$ & 陈正礼 & 雌激素受体在老年和青年猕猴下丘脑中表达的比较 \\
\hline Macaca mulatta & 猕猴 & II & $\begin{array}{l}\text { 近危 } \\
\text { /NT }\end{array}$ & 陈学进 & 雌性猕猴尿中生殖激素的变化 \\
\hline Macaca mulatta & 猕猴 & II & $\begin{array}{l}\text { 近危 } \\
\text { /NT }\end{array}$ & 邓兴力 & 雌雄猕猴束缚时应激的情绪反应差异 \\
\hline Macaca mulatta & 猕猴 & II & $\begin{array}{l}\text { 近危 } \\
\text { /NT }\end{array}$ & 汪涛 & 大熊猫和川西猕猴胃肠道寄生虫研究 \\
\hline Macaca mulatta & 猕猴 & II & $\begin{array}{l}\text { 近危 } \\
\text { /NT }\end{array}$ & 彭逸生 & 担杆岛自然保护区种子植物区系及猕猴食物资源研究 \\
\hline Macaca mulatta & 猕猴 & II & $\begin{array}{l}\text { 近危 } \\
\text { /NT }\end{array}$ & 叶尤松 & 电磁波治疗仪佐治猕猴腹泻疗效观察 \\
\hline Macaca mulatta & 猕猴 & II & 近危 & 杨纪峰 & 靛玉红-3c-单肜对猕猴成纤维细胞增殖和调亡及周期同步化的影响 \\
\hline
\end{tabular}


顾垒，闻丞，罗玫，王吴，吕植. 中国最受关注濒危物种保护现状快速评价的新方法探讨. 生物多样性，2015，23(5)：583-590. http://www. biodiversity-science. net/CN/article/downloadArticleFile. do?attachType=PDF\&id=10075

\begin{tabular}{|c|c|c|c|c|c|}
\hline & & & $/ \mathrm{NT}$ & & \\
\hline \multirow[t]{2}{*}{ Macaca mulatta } & 猕猴 & II & 近危 & 苏彦捷 & 对猕猴嗅觉的研究 \\
\hline & & & $/ \mathrm{NT}$ & & \\
\hline \multirow[t]{2}{*}{ Macaca mulatta } & 猕猴 & II & 近危 & 李国刚 & 峨眉山藏猕猴与游客的人猴关系 \\
\hline & & & /NT & & \\
\hline \multirow[t]{2}{*}{ Macaca mulatta } & 猕猴 & II & 近危 & 罗启慧 & 肺炎链球菌感染的猕猴肺及气管内 IFN- $\gamma$ 蛋白与 m R N A 表达 \\
\hline & & & $/ \mathrm{NT}$ & & \\
\hline \multirow[t]{2}{*}{ Macaca mulatta } & 猕猴 & II & 近危 & 季芳 & 分子标记在猕猴遗传多样性研究中的应用 \\
\hline & & & /NT & & \\
\hline \multirow[t]{2}{*}{ Macaca mulatta } & 猕猴 & II & 近危 & 刘玉宝 & 福建鸳鸯猕猴自然保护区的植物区系 \\
\hline & & & /NT & & \\
\hline \multirow[t]{2}{*}{ Macaca mulatta } & 猕猴 & II & 近危 & 刘玉宝 & 福建鹗鸢猕猴自然保护区经济植物资源调查 \\
\hline & & & /NT & & \\
\hline \multirow[t]{2}{*}{ Macaca mulatta } & 猕猴 & II & 近危 & 赵远 & 腹泻猕猴肠道致病菌感染状况及药物敏感性调查 \\
\hline & & & $/ \mathrm{NT}$ & & \\
\hline \multirow[t]{2}{*}{ Macaca mulatta } & 猕猴 & II & 近危 & 黄璋琼 & 弓形虫( Toxoplasma gondii) 的 PCR 检测方法在笼养猕猴群中的应用 \\
\hline & & & $/ \mathrm{NT}$ & & \\
\hline \multirow[t]{2}{*}{ Macaca mulatta } & 猕猴 & II & 近危 & 胡军 & 构建猕猴组织工程化周围神经的实验研究 \\
\hline & & & /NT & & \\
\hline
\end{tabular}


顾垒，闻丞，罗玫，王吴，吕植. 中国最受关注濒危物种保护现状快速评价的新方法探讨. 生物多样性，2015，23(5)：583-590. http://www. biodiversity-science. net/CN/article/downloadArticleFile. do?attachType=PDF\&id=10075

\begin{tabular}{|c|c|c|c|c|c|}
\hline Macaca mulatta & 猕猴 & II & $\begin{array}{l}\text { 近危 } \\
\text { /NT }\end{array}$ & 鲁帅尧 & 关于大笼群养猕猴科学饲养管理的探讨 \\
\hline Macaca mulatta & 猕猴 & II & $\begin{array}{l}\text { 近危 } \\
\text { /NT }\end{array}$ & 常弘 & 广东内伶仃岛猕猴种群年龄结构及发展趋势 \\
\hline Macaca mulatta & 猕猴 & II & $\begin{array}{l}\text { 近危 } \\
\text { /NT }\end{array}$ & 周维官 & 广西 F3 狝猴(Macaca mulatta) 生长发育观察 \\
\hline Macaca mulatta & 猕猴 & II & $\begin{array}{l}\text { 近危 } \\
\text { /NT }\end{array}$ & 李友邦 & 广西猕猴分布数量及其保护 \\
\hline Macaca mulatta & 猕猴 & II & $\begin{array}{l}\text { 近危 } \\
\text { /NT }\end{array}$ & 张顺祥 & 广西猕猴体内枝腺科吸虫一新属新种记述(吸虫纲, 枝腺科) \\
\hline Macaca mulatta & 猕猴 & II & $\begin{array}{l}\text { 近危 } \\
\text { /NT }\end{array}$ & 和占龙 & 规模化猕猴养殖场寄生虫病综合防治措施 \\
\hline Macaca mulatta & 猕猴 & II & $\begin{array}{l}\text { 近危 } \\
\text { /NT }\end{array}$ & 李 旭 & 贵阳黔灵公园半野生猕猴管理探讨 \\
\hline Macaca mulatta & 猕猴 & II & $\begin{array}{l}\text { 近危 } \\
\text { /NT }\end{array}$ & 林 虹 & 贵州猕猴的人工驯养与繁殖 \\
\hline Macaca mulatta & 猕猴 & II & $\begin{array}{l}\text { 近危 } \\
\text { /NT }\end{array}$ & 周岐海 & 桂林七星公园猕猴的食物组成及季节性变化 \\
\hline Macaca mulatta & 猕猴 & II & 近危 & 周岐海 & 桂林七星景区猕猴的活动时间分配 \\
\hline
\end{tabular}


顾垒，闻丞，罗玫，王吴，吕植. 中国最受关注濒危物种保护现状快速评价的新方法探讨. 生物多样性，2015，23(5)：583-590. http://www. biodiversity-science. net/CN/article/downloadArticleFile. do?attachType=PDF\&id=10075

\begin{tabular}{|c|c|c|c|c|c|}
\hline & & & $/ \mathrm{NT}$ & & \\
\hline \multirow[t]{2}{*}{ Macaca mulatta } & 猕猴 & II & 近危 & 和占龙 & 害获灭和虫克星驱除猕猴体内寄生虫比较实验 \\
\hline & & & /NT & & \\
\hline \multirow[t]{2}{*}{ Macaca mulatta } & 猕猴 & II & 近危 & 牛红星 & 河南省太行山国家级猕猴自然保护区鸟类区系调查 \\
\hline & & & /NT & & \\
\hline \multirow[t]{2}{*}{ Macaca mulatta } & 猕猴 & II & 近危 & 牛红星 & 河南太行山国家级猕猴自然保护区翼手类初步研究 \\
\hline & & & $/ \mathrm{NT}$ & & \\
\hline \multirow[t]{2}{*}{ Macaca mulatta } & 猕猴 & II & 近危 & 郭相保 & 河南太行山自然保护区猕猴冬春季食性分析 \\
\hline & & & $/ \mathrm{NT}$ & & \\
\hline \multirow[t]{2}{*}{ Macaca mulatta } & 猕猴 & II & 近危 & 郭相保 & 河南太行山自然保护区猕猴夜宿地选择研究 \\
\hline & & & $/ \mathrm{NT}$ & & \\
\hline \multirow[t]{2}{*}{ Macaca mulatta } & 猕猴 & II & 近危 & 陈兵 & 湖北恩施二璐宕林瘪、称猴有然保护区维管植扬区系及植被群落介析 \\
\hline & & & /NT & & \\
\hline \multirow[t]{2}{*}{ Macaca mulatta } & 猕猴 & II & 近危 & 田军东 & 基于 PAE 编码系统的太行山猕猴行为谱 \\
\hline & & & /NT & & \\
\hline \multirow[t]{2}{*}{ Macaca mulatta } & 猕猴 & II & 近危 & 王白石 & 基于分块主成分分析的太行山猕猴面部相似性 \\
\hline & & & /NT & & \\
\hline \multirow[t]{2}{*}{ Macaca mulatta } & 猕猴 & II & 近危 & 鹿鹤 & 基于团抱行为的太行山猕猴社会联属 \\
\hline & & & /NT & & \\
\hline
\end{tabular}


顾垒，闻丞，罗玫，王吴，吕植. 中国最受关注濒危物种保护现状快速评价的新方法探讨. 生物多样性，2015，23(5)：583-590. http://www. biodiversity-science. net/CN/article/downloadArticleFile. do?attachType=PDF\&id=10075

\begin{tabular}{|c|c|c|c|c|c|}
\hline Macaca mulatta & 猕猴 & II & $\begin{array}{l}\text { 近危 } \\
\text { /NT }\end{array}$ & 黄晓峰 & 基于微卫星 DNA 的猕猴川西亚种遗传多样性研究 \\
\hline Macaca mulatta & 猕猴 & II & $\begin{array}{l}\text { 近危 } \\
\text { /NT }\end{array}$ & 再晓琳 & 济源旅游区太行山猕猴的应激反应和肠道寄生虫研究 \\
\hline Macaca mulatta & 猕猴 & II & $\begin{array}{l}\text { 近危 } \\
\text { /NT }\end{array}$ & 李孝伟 & 济源猕猴自然保护区南方红豆杉群落调查 \\
\hline Macaca mulatta & 猕猴 & II & $\begin{array}{l}\text { 近危 } \\
\text { /NT }\end{array}$ & 胡玉梅 & 济源市太行山猕猴自然保护区气候资源分析 \\
\hline Macaca mulatta & 猕猴 & II & $\begin{array}{l}\text { 近危 } \\
\text { /NT }\end{array}$ & 孔小刚 & 济源五龙口景区猕猴资源现状与可持续利用分析 \\
\hline Macaca mulatta & 猕猴 & II & $\begin{array}{l}\text { 近危 } \\
\text { /NT }\end{array}$ & 赵远 & 检疫期内猕猴肠道致病菌自然感染情况的调查 \\
\hline Macaca mulatta & 猕猴 & II & $\begin{array}{l}\text { 近危 } \\
\text { /NT }\end{array}$ & 余泽平 & 谨防猕猴应激症及并发症 \\
\hline Macaca mulatta & 猕猴 & II & $\begin{array}{l}\text { 近危 } \\
\text { /NT }\end{array}$ & 唐华兴 & 喀斯特生境中猕猴的活动节律和时间分配 \\
\hline Macaca mulatta & 猕猴 & II & $\begin{array}{l}\text { 无危 } \\
\text { /LC }\end{array}$ & 冯子山 & 澜沧县野生动物肇事情况调查报告 \\
\hline Macaca mulatta & 猕猴 & II & 近危 & 杨䏒 & 老年猕猴中题视区细胞的功能性退化 \\
\hline
\end{tabular}


顾垒，闻丞，罗玫，王吴，吕植. 中国最受关注濒危物种保护现状快速评价的新方法探讨. 生物多样性，2015，23(5)：583-590. http://www. biodiversity-science. net/CN/article/downloadArticleFile. do?attachType=PDF\&id=10075

\begin{tabular}{|c|c|c|c|c|c|}
\hline & & & $/ \mathrm{NT}$ & & \\
\hline \multirow[t]{2}{*}{ Macaca mulatta } & 猕猴 & II & 近危 & 林光 & 雷藤氯内酯醇对雄性猕猴的抗生育药效及可复性观察 \\
\hline & & & $/ \mathrm{NT}$ & & \\
\hline \multirow[t]{2}{*}{ Macaca mulatta } & 猕猴 & II & 近危 & 李志雄 & 利用 B- 型超声波诊断狝猴早早期妊娠 \\
\hline & & & /NT & & \\
\hline \multirow[t]{2}{*}{ Macaca mulatta } & 猕猴 & II & 近危 & 饶军华 & 两种方法检测称猴病毒抗体的初步探讨 \\
\hline & & & $/ \mathrm{NT}$ & & \\
\hline \multirow[t]{2}{*}{ Macaca mulatta } & 猕猴 & II & 近危 & 陈炜 & 笼养猕猴(Macaca mulatta)夏季昼间活动时间分配研究 \\
\hline & & & $/ \mathrm{NT}$ & & \\
\hline \multirow[t]{2}{*}{ Macaca mulatta } & 猕猴 & II & 近危 & 李晓丽 & 笼养猕猴巨细胞病毒的流行病学调查及组织分布研究 \\
\hline & & & $/ \mathrm{NT}$ & & \\
\hline \multirow[t]{2}{*}{ Macaca mulatta } & 猕猴 & II & 近危 & 匡德宣 & 笼养猕猴疝根治手术的探讨 \\
\hline & & & $/ \mathrm{NT}$ & & \\
\hline \multirow[t]{2}{*}{ Macaca mulatta } & 猕猴 & II & 近危 & 匡德宣 & 笼养猕猴瘫疾症防治的探讨 \\
\hline & & & /NT & & \\
\hline \multirow[t]{2}{*}{ Macaca mulatta } & 猕猴 & II & 近危 & 黄璋琼 & 笼养猕猴种群妊娠异常的相关因素调查分析 \\
\hline & & & $/ \mathrm{NT}$ & & \\
\hline \multirow[t]{2}{*}{ Macaca mulatta } & 猕猴 & II & 近危 & 黄璋琼 & 笼养猕猴种群异常妊娠原因的分析研究 \\
\hline & & & /NT & & \\
\hline
\end{tabular}


顾垒，闻丞，罗玫，王吴，吕植. 中国最受关注濒危物种保护现状快速评价的新方法探讨. 生物多样性，2015，23(5)：583-590. http://www. biodiversity-science. net/CN/article/downloadArticleFile. do?attachType=PDF\&id=10075

\begin{tabular}{|c|c|c|c|c|c|}
\hline Macaca mulatta & 猕猴 & II & $\begin{array}{l}\text { 近危 } \\
\text { /NT }\end{array}$ & 侯进怀 & 笼养太行山猕猴的理毛行为 \\
\hline Macaca mulatta & 猕猴 & II & $\begin{array}{l}\text { 近危 } \\
\text { /NT }\end{array}$ & 梁方刚 & 笼养太行山狝猴妊娠诊断方法 \\
\hline Macaca mulatta & 猕猴 & II & $\begin{array}{l}\text { 近危 } \\
\text { /NT }\end{array}$ & 朱志茹 & 吗啡导致猕猴海马神经元自发放电节律转变 \\
\hline Macaca mulatta & 猕猴 & II & $\begin{array}{l}\text { 近危 } \\
\text { /NT }\end{array}$ & 田随味 & 蟒河保护区猕猴生态观察与种群监测 \\
\hline Macaca mulatta & 猕猴 & II & $\begin{array}{l}\text { 近危 } \\
\text { /NT }\end{array}$ & 令狐克鸿 & 茂兰自然保护区野生动物危害农作物现状与缓解对策研究 \\
\hline Macaca mulatta & 猕猴 & II & $\begin{array}{l}\text { 近危 } \\
\text { /NT }\end{array}$ & 饶军华 & 猕猴、食蟹猴群中 STLV-1 病毒感染状况的研究 \\
\hline Macaca mulatta & 猕猴 & II & $\begin{array}{l}\text { 近危 } \\
\text { /NT }\end{array}$ & 李蛋业 & 猕猴 A 群链球菌感染的调查与控制 \\
\hline Macaca mulatta & 猕猴 & II & $\begin{array}{l}\text { 近危 } \\
\text { /NT }\end{array}$ & 姜勇 & 狝猴 IFN_基因的克隆表达及其检测方法的建立 \\
\hline Macaca mulatta & 猕猴 & II & $\begin{array}{l}\text { 近危 } \\
\text { /NT }\end{array}$ & 徐怀亮 & 猕猴 MHC-DPB1 基因外显子 2 多态性研究 \\
\hline Macaca mulatta & 猕猴 & II & 近危 & 张桂清 & 猕猴 Trim5_及 MHCII 类基因多态性研究 \\
\hline
\end{tabular}


顾垒，闻丞，罗玫，王吴，吕植. 中国最受关注濒危物种保护现状快速评价的新方法探讨. 生物多样性，2015，23(5)：583-590. http://www. biodiversity-science. net/CN/article/downloadArticleFile. do?attachType=PDF\&id=10075

\begin{tabular}{|c|c|c|c|c|c|}
\hline & & & $/ \mathrm{NT}$ & & \\
\hline \multirow[t]{2}{*}{ Macaca mulatta } & 猕猴 & II & 近危 & 张亚平 & 猕猴白化病基因的研究 \\
\hline & & & $/ \mathrm{NT}$ & & \\
\hline \multirow[t]{2}{*}{ Macaca mulatta } & 猕猴 & II & 近危 & 鲁帅尧 & 猕猴被毛氨基酸含量的初步研究 \\
\hline & & & /NT & & \\
\hline \multirow[t]{2}{*}{ Macaca mulatta } & 猕猴 & II & 近危 & 鲁帅尧 & 猕猴被毛微量元素含量的测定与分析 \\
\hline & & & $/ \mathrm{NT}$ & & \\
\hline \multirow[t]{2}{*}{ Macaca mulatta } & 猕猴 & II & 近危 & 杨丽芬 & 猕猴病毒性肝炎血清学调查 \\
\hline & & & $/ \mathrm{NT}$ & & \\
\hline \multirow[t]{2}{*}{ Macaca mulatta } & 猕猴 & II & 近危 & 王俊斌 & 猕猴不同年龄阶段繁殖率比较 \\
\hline & & & $/ \mathrm{NT}$ & & \\
\hline \multirow[t]{2}{*}{ Macaca mulatta } & 猕猴 & II & 近危 & 黎大勇 & 猕猴不同性别年龄组个体时间分配和姿态行为的差异分析 \\
\hline & & & /NT & & \\
\hline \multirow[t]{2}{*}{ Macaca mulatta } & 猕猴 & II & 近危 & 钟妮娜 & 猕猴肠侵袭型大肠杆菌的分离鉴定及其毒力因子基因的检测 \\
\hline & & & $/ \mathrm{NT}$ & & \\
\hline \multirow[t]{2}{*}{ Macaca mulatta } & 猕猴 & II & 近危 & 黄㓞 & 猕猴胆囊胆汁成分的测定 \\
\hline & & & /NT & & \\
\hline \multirow[t]{2}{*}{ Macaca mulatta } & 猕猴 & II & 近危 & 余泽平 & 猕猴的后肢瘫疾症 \\
\hline & & & /NT & & \\
\hline
\end{tabular}


顾垒，闻丞，罗玫，王吴，吕植. 中国最受关注濒危物种保护现状快速评价的新方法探讨. 生物多样性，2015，23(5)：583-590. http://www. biodiversity-science. net/CN/article/downloadArticleFile. do?attachType=PDF\&id=10075

\begin{tabular}{|c|c|c|c|c|c|}
\hline Macaca mulatta & 猕猴 & II & $\begin{array}{l}\text { 近危 } \\
\text { /NT }\end{array}$ & 吴晓娟 & 猕猴的人工育幼 \\
\hline Macaca mulatta & 猕猴 & II & $\begin{array}{l}\text { 近危 } \\
\text { /NT }\end{array}$ & 王明 & 猕猴的饲料与饲养管理技术 \\
\hline Macaca mulatta & 猕猴 & II & $\begin{array}{l}\text { 近危 } \\
\text { /NT }\end{array}$ & 张金宁 & 猕猴耳廓软骨细胞的体外培养与鉴定 \\
\hline Macaca mulatta & 猕猴 & II & $\begin{array}{l}\text { 近危 } \\
\text { /NT }\end{array}$ & 肖建华 & 猕猴复合麻醉剂的实验研究 \\
\hline Macaca mulatta & 猕猴 & II & $\begin{array}{l}\text { 近危 } \\
\text { /NT }\end{array}$ & 李六金 & 狝猴腹泻症轮状病毒病油剂灭活疫苗研制与免疫效果观察报告 \\
\hline Macaca mulatta & 猕猴 & II & $\begin{array}{l}\text { 近危 } \\
\text { /NT }\end{array}$ & $\begin{array}{l}\text { 猕猴肝片形吸虫病 } \\
2 \text { 例 }\end{array}$ & 猕猴肝片形吸虫病 2 例 \\
\hline Macaca mulatta & 猕猴 & II & $\begin{array}{l}\text { 近危 } \\
\text { /NT }\end{array}$ & 陈峥宏 & 猕猴肝脏实验感染猪囊尾蚴的观察 \\
\hline Macaca mulatta & 猕猴 & II & $\begin{array}{l}\text { 近危 } \\
\text { /NT }\end{array}$ & 胡军 & 猕猴骨髓基质干细胞体外培养及其生物学特性的研究 \\
\hline Macaca mulatta & 猕猴 & II & $\begin{array}{l}\text { 近危 } \\
\text { /NT }\end{array}$ & 朱志茹 & 猕猴海马参与痛觉感受与调制过程中的非线性信息编码探索 \\
\hline Macaca mulatta & 猕猴 & II & 近危 & 朱志茹 & 猕猴海马神经元自发放电节律及其确定性研究 \\
\hline
\end{tabular}


顾垒，闻丞，罗玫，王吴，吕植. 中国最受关注濒危物种保护现状快速评价的新方法探讨. 生物多样性，2015，23(5)：583-590. http://www. biodiversity-science. net/CN/article/downloadArticleFile. do?attachType=PDF\&id=10075

\begin{tabular}{|c|c|c|c|c|c|}
\hline & & & $/ \mathrm{NT}$ & & \\
\hline \multirow[t]{2}{*}{ Macaca mulatta } & 猕猴 & II & 近危 & 胡春红 & 猕猴和叶猴掌面花纹强度的比较分析 \\
\hline & & & $/ \mathrm{NT}$ & & \\
\hline \multirow[t]{2}{*}{ Macaca mulatta } & 猕猴 & II & 近危 & 职丽娟 & 猕猴活体形态指标相关性分析 \\
\hline & & & /NT & & \\
\hline \multirow[t]{2}{*}{ Macaca mulatta } & 猕猴 & II & 近危 & 赵晓进 & 猕猴项齿大小的性差研究初报 \\
\hline & & & /NT & & \\
\hline \multirow[t]{2}{*}{ Macaca mulatta } & 猕猴 & II & 近危 & 哈力克 $\cdot$ 热合曼 & 猕猴贾第虫病的诊治 \\
\hline & & & $/ \mathrm{NT}$ & & \\
\hline \multirow[t]{2}{*}{ Macaca mulatta } & 猕猴 & II & 近危 & 贾建军 & 猕猴结核病的诊断 \\
\hline & & & /NT & & \\
\hline \multirow[t]{2}{*}{ Macaca mulatta } & 猕猴 & II & 近危 & 罕园园 & 猕猴结核分枝杆菌 PCR 检测方法的建立与初步应用 \\
\hline & & & /NT & & \\
\hline \multirow[t]{2}{*}{ Macaca mulatta } & 猕猴 & II & 近危 & 陈永昌 & 猕猴精子优选及体外获能的研究 \\
\hline & & & $/ \mathrm{NT}$ & & \\
\hline \multirow[t]{2}{*}{ Macaca mulatta } & 猕猴 & II & 近危 & 蔡秋云 & 猕猴颈髓的 GABA 能神经元分布 \\
\hline & & & /NT & & \\
\hline \multirow[t]{2}{*}{ Macaca mulatta } & 猕猴 & II & 近危 & 黄璋琼 & 猕猴巨细胞病毒(RhCMV)研究进展 \\
\hline & & & /NT & & \\
\hline
\end{tabular}


顾垒，闻丞，罗玫，王吴，吕植. 中国最受关注濒危物种保护现状快速评价的新方法探讨. 生物多样性，2015，23(5)：583-590. http://www. biodiversity-science. net/CN/article/downloadArticleFile. do?attachType=PDF\&id=10075

\begin{tabular}{|c|c|c|c|c|c|}
\hline Macaca mulatta & 猕猴 & II & $\begin{array}{l}\text { 近危 } \\
\text { /NT }\end{array}$ & 黄璋琼 & 猕猴巨细胞病毒 PCR 检测方法的建立与初步应用 \\
\hline Macaca mulatta & 猕猴 & II & $\begin{array}{l}\text { 近危 } \\
\text { /NT }\end{array}$ & 杨智勇 & 猕猴痢疾治疗初探 \\
\hline Macaca mulatta & 猕猴 & II & $\begin{array}{l}\text { 近危 } \\
\text { /NT }\end{array}$ & 赵晓进 & 猕猴颖骨变量和面角的性差研究 \\
\hline Macaca mulatta & 猕猴 & II & $\begin{array}{l}\text { 近危 } \\
\text { /NT }\end{array}$ & 李春禄 & 猕猴毛发皮质醇测量方法探索 \\
\hline Macaca mulatta & 猕猴 & II & $\begin{array}{l}\text { 近危 } \\
\text { /NT }\end{array}$ & 李少雄 & 猕猴逆过程回归放养中几种主要病原监测 \\
\hline Macaca mulatta & 猕猴 & II & $\begin{array}{l}\text { 近危 } \\
\text { /NT }\end{array}$ & 李晓燕 & 猕猴逆转录病毒多重套式 PCR 检测方法的建立 \\
\hline Macaca mulatta & 猕猴 & II & $\begin{array}{l}\text { 近危 } \\
\text { /NT }\end{array}$ & 马岗 & 猕猴胚胎干细胞的分离、鉴定、培养及应用研究 \\
\hline Macaca mulatta & 猕猴 & II & $\begin{array}{l}\text { 近危 } \\
\text { /NT }\end{array}$ & 马岗 & 猕猴胚胎干细胞的分离培养和鉴定 \\
\hline Macaca mulatta & 猕猴 & II & $\begin{array}{l}\text { 近危 } \\
\text { /NT }\end{array}$ & 裴轶劲 & 猕猴胚胎干细胞的诱导分化和调亡 \\
\hline Macaca mulatta & 猕猴 & II & 近危 & 陈瑜 & 猕猴配合饲料氨基酸含量测定及比较分析 \\
\hline
\end{tabular}


顾垒，闻丞，罗玫，王吴，吕植. 中国最受关注濒危物种保护现状快速评价的新方法探讨. 生物多样性，2015，23(5)：583-590. http://www. biodiversity-science. net/CN/article/downloadArticleFile. do?attachType=PDF\&id=10075

\begin{tabular}{|c|c|c|c|c|c|}
\hline & & & $/ \mathrm{NT}$ & & \\
\hline \multirow[t]{2}{*}{ Macaca mulatta } & 猕猴 & II & 近危 & 祝春梅 & 猕猴脾脏中雌激素受体的表达及其性别差异 \\
\hline & & & $/ \mathrm{NT}$ & & \\
\hline \multirow[t]{2}{*}{ Macaca mulatta } & 猕猴 & II & 近危 & 和占龙 & 猕猴热应激临床病理学分析 \\
\hline & & & /NT & & \\
\hline \multirow[t]{2}{*}{ Macaca mulatta } & 猕猴 & II & 近危 & 姜波 & 猕猴溶组织内阿米巴原虫病病原分离鉴定及凝集素 $\mathrm{hgl}$ 基因的原核表达 \\
\hline & & & /NT & & \\
\hline \multirow[t]{2}{*}{ Macaca mulatta } & 猕猴 & II & 近危 & 刘爱琼 & 猕猴腮腺肿瘤的治疗 \\
\hline & & & $/ \mathrm{NT}$ & & \\
\hline \multirow[t]{2}{*}{ Macaca mulatta } & 猕猴 & II & 近危 & 王斌 & 猕猴饲养的遗传管理措施 \\
\hline & & & $/ \mathrm{NT}$ & & \\
\hline \multirow[t]{2}{*}{ Macaca mulatta } & 猕猴 & II & 近危 & 陈永昌 & 猕猴体外受精的研究 \\
\hline & & & /NT & & \\
\hline \multirow[t]{2}{*}{ Macaca mulatta } & 猕猴 & II & 近危 & 鲁帅尧 & 猕猴脱毛的营养学因素分析 \\
\hline & & & /NT & & \\
\hline \multirow[t]{2}{*}{ Macaca mulatta } & 猕猴 & II & 近危 & 杨光照 & 猕猴项目基地建设可行性分析 \\
\hline & & & /NT & & \\
\hline \multirow[t]{2}{*}{ Macaca mulatta } & 猕猴 & II & 近危 & 胡延春 & 猕猴小袋纤毛虫和志贺氏菌混合感染的诊断与治疗 \\
\hline & & & /NT & & \\
\hline
\end{tabular}


顾垒，闻丞，罗玫，王吴，吕植. 中国最受关注濒危物种保护现状快速评价的新方法探讨. 生物多样性，2015，23(5)：583-590. http://www. biodiversity-science. net/CN/article/downloadArticleFile. do?attachType=PDF\&id=10075

\begin{tabular}{|c|c|c|c|c|c|}
\hline Macaca mulatta & 猕猴 & II & $\begin{array}{l}\text { 近危 } \\
\text { /NT }\end{array}$ & 许兰文 & 猕猴心功能观察 \\
\hline Macaca mulatta & 猕猴 & II & $\begin{array}{l}\text { 近危 } \\
\text { /NT }\end{array}$ & 范春梅 & 猕猴新生仔猴发育指标的建立 \\
\hline Macaca mulatta & 猕猴 & II & $\begin{array}{l}\text { 近危 } \\
\text { /NT }\end{array}$ & 邢旭光 & 猕猴胸腰段脊神经节 nNOS 免疫阳性神经元的分布 \\
\hline Macaca mulatta & 猕猴 & II & $\begin{array}{l}\text { 近危 } \\
\text { /NT }\end{array}$ & 赵晓进 & 猕猴牙齿的性别判别分析 \\
\hline Macaca mulatta & 猕猴 & II & $\begin{array}{l}\text { 近危 } \\
\text { /NT }\end{array}$ & 郭常安 & 猕猴腰椎观察 \\
\hline Macaca mulatta & 猕猴 & II & $\begin{array}{l}\text { 近危 } \\
\text { /NT }\end{array}$ & 邱伯房 & 狝猴早期胚胎脑的发育与 NF-JB 的表达 \\
\hline Macaca mulatta & 猕猴 & II & $\begin{array}{l}\text { 近危 } \\
\text { /NT }\end{array}$ & 胡显辉 & 猕猴早期胚胎脑的发育与调亡相关蛋白 P53 的表达 \\
\hline Macaca mulatta & 猕猴 & II & $\begin{array}{l}\text { 近危 } \\
\text { /NT }\end{array}$ & 邱伯房 & 猕猴早期胚胎脑的发育与调亡相关蛋白 p53 和 Bcl_2 的表达 \\
\hline Macaca mulatta & 猕猴 & II & $\begin{array}{l}\text { 近危 } \\
\text { /NT }\end{array}$ & 范春梅 & 猕猴早期妊娠的 B 型超声测值 \\
\hline Macaca mulatta & 猕猴 & II & 近危 & 范春梅 & 猕猴早孕模型的建立及超声学诊断 \\
\hline
\end{tabular}


顾垒，闻丞，罗玫，王吴，吕植. 中国最受关注濒危物种保护现状快速评价的新方法探讨. 生物多样性，2015，23(5)：583-590. http://www. biodiversity-science. net/CN/article/downloadArticleFile. do?attachType=PDF\&id=10075

\begin{tabular}{|c|c|c|c|c|c|}
\hline & & & $/ \mathrm{NT}$ & & \\
\hline \multirow[t]{2}{*}{ Macaca mulatta } & 猕猴 & II & 近危 & 程如意 & 猕猴长骨的不对称性研究 \\
\hline & & & $/ \mathrm{NT}$ & & \\
\hline \multirow[t]{2}{*}{ Macaca mulatta } & 猕猴 & II & 近危 & 赵晓进 & 猕猴掌骨长比、性差与活动强度关系研究 \\
\hline & & & $/ \mathrm{NT}$ & & \\
\hline \multirow[t]{2}{*}{ Macaca mulatta } & 猕猴 & II & 近危 & 罗桐秀 & 猕猴掌纹特征的研究 \\
\hline & & & /NT & & \\
\hline \multirow[t]{2}{*}{ Macaca mulatta } & 猕猴 & II & 近危 & 田浩 & 猕猴志贺菌感染状况及药物敏感性调查 \\
\hline & & & $/ \mathrm{NT}$ & & \\
\hline \multirow[t]{2}{*}{ Macaca mulatta } & 猕猴 & II & 近危 & 和占龙 & 猕猴自发性糖尿病的临床病理学分析 \\
\hline & & & /NT & & \\
\hline \multirow[t]{2}{*}{ Macaca mulatta } & 猕猴 & II & 近危 & 廖国阳 & 猕猴自然感染肝片吸虫诱发胆管结石的形成 \\
\hline & & & /NT & & \\
\hline \multirow[t]{2}{*}{ Macaca mulatta } & 猕猴 & II & 近危 & 贾姣 & 猕猴自然流产胎儿胸腺白细胞介素 2 和 10 的分布与表达 \\
\hline & & & /NT & & \\
\hline \multirow[t]{2}{*}{ Macaca mulatta } & 猕猴 & II & 近危 & 王训立 & 米非司酮对早孕称猴孕酮和雌二醇分泌的研究 \\
\hline & & & /NT & & \\
\hline \multirow[t]{2}{*}{ Macaca mulatta } & 猕猴 & II & 近危 & 唐华兴 & 弄岗猕猴（Macaca mulatta）的受食生态学 \\
\hline & & & /NT & & \\
\hline
\end{tabular}


顾垒，闻丞，罗玫，王吴，吕植. 中国最受关注濒危物种保护现状快速评价的新方法探讨. 生物多样性，2015，23(5)：583-590. http://www. biodiversity-science. net/CN/article/downloadArticleFile. do?attachType=PDF\&id=10075

\begin{tabular}{|c|c|c|c|c|c|}
\hline Macaca mulatta & 猕猴 & II & $\begin{array}{l}\text { 近危 } \\
\text { /NT }\end{array}$ & 赵玲玲 & 膨化饲料饲喂猕猴试验研究 \\
\hline Macaca mulatta & 猕猴 & II & $\begin{array}{l}\text { 近危 } \\
\text { /NT }\end{array}$ & 陈武 & 奇异变形杆菌引发猕猴腹泻暴发流行的调查研究 \\
\hline Macaca mulatta & 猕猴 & II & $\begin{array}{l}\text { 近危 } \\
\text { /NT }\end{array}$ & 匡中帆 & 黔灵山公园野放猕猴伤人事件分析 \\
\hline Macaca mulatta & 猕猴 & II & $\begin{array}{l}\text { 近危 } \\
\text { /NT }\end{array}$ & 吕向辉 & 圈养川金丝猴、猕猴肠道寄生虫感染及其形态观察 \\
\hline Macaca mulatta & 猕猴 & II & $\begin{array}{l}\text { 近危 } \\
\text { /NT }\end{array}$ & 赵金凤 & 圈养猕猴肠道寄生虫感染情况调查 \\
\hline Macaca mulatta & 猕猴 & II & $\begin{array}{l}\text { 近危 } \\
\text { /NT }\end{array}$ & 陈希文 & 圈养猕猴志贺氏菌的分离鉴定及药敏分析 \\
\hline Macaca mulatta & 猕猴 & II & $\begin{array}{l}\text { 近危 } \\
\text { /NT }\end{array}$ & 鲁帅尧 & 人工繁育幼年猕猴部分生物学特性的初步研究 \\
\hline Macaca mulatta & 猕猴 & II & $\begin{array}{l}\text { 近危 } \\
\text { /NT }\end{array}$ & 鲁帅尧 & 人工饲养娇猴蛋白质和脂肪营养状况分析 \\
\hline Macaca mulatta & 猕猴 & II & $\begin{array}{l}\text { 近危 } \\
\text { /NT }\end{array}$ & 黄璋琼 & 人工饲养树鼠和猕猴的部分凝血因子凝集时间的测定及分析 \\
\hline Macaca mulatta & 猕猴 & II & 近危 & 赵远 & 人工饲养幼猴粪便的正常菌群研究 \\
\hline
\end{tabular}


顾垒，闻丞，罗玫，王吴，吕植. 中国最受关注濒危物种保护现状快速评价的新方法探讨. 生物多样性，2015，23(5)：583-590. http://www. biodiversity-science. net/CN/article/downloadArticleFile. do?attachType=PDF\&id=10075

\begin{tabular}{|c|c|c|c|c|c|}
\hline & & & $/ \mathrm{NT}$ & & \\
\hline \multirow[t]{2}{*}{ Macaca mulatta } & 猕猴 & II & 近危 & 朱林 & 人工饲养中国猕猴中 SRV、STLV 和 BV 的流行病学调查 \\
\hline & & & $/ \mathrm{NT}$ & & \\
\hline \multirow[t]{2}{*}{ Macaca mulatta } & 猕猴 & II & 近危 & 吴庆书 & 三亚市火岭自然保护区猕猴栖息地植被特征及采食植物生态位特点 \\
\hline & & & /NT & & \\
\hline \multirow[t]{2}{*}{ Macaca mulatta } & 猕猴 & II & 近危 & 刘荣 & 山西历山国家级自然保护区猕猴分布及种群数量调查 \\
\hline & & & $/ \mathrm{NT}$ & & \\
\hline \multirow[t]{2}{*}{ Macaca mulatta } & 猕猴 & II & 近危 & 李宝堂 & 山西泽州自然保护区生物多样性及保护研究 \\
\hline & & & $/ \mathrm{NT}$ & & \\
\hline \multirow[t]{2}{*}{ Macaca mulatta } & 猕猴 & II & 近危 & 谈建文 & 神农架野生猕猴及其生境现状 \\
\hline & & & $/ \mathrm{NT}$ & & \\
\hline \multirow[t]{2}{*}{ Macaca mulatta } & 猕猴 & II & 近危 & 徐海滨 & 实验猕猴肠道病原菌检测分析 \\
\hline & & & /NT & & \\
\hline \multirow[t]{2}{*}{ Macaca mulatta } & 猕猴 & II & 近危 & 周勤 & 实验猕猴肠道耶尔森菌感染状况调查及鉴定 \\
\hline & & & $/ \mathrm{NT}$ & & \\
\hline \multirow[t]{2}{*}{ Macaca mulatta } & 猕猴 & II & 近危 & 范春梅 & 实验猕猴肺部 CT 影像断层初步观察 \\
\hline & & & /NT & & \\
\hline \multirow[t]{2}{*}{ Macaca mulatta } & 猕猴 & II & 近危 & 范春梅 & 实验猕猴头颈部 CT 影像学观察 \\
\hline & & & /NT & & \\
\hline
\end{tabular}


顾垒，闻丞，罗玫，王吴，吕植. 中国最受关注濒危物种保护现状快速评价的新方法探讨. 生物多样性，2015，23(5)：583-590. http://www. biodiversity-science. net/CN/article/downloadArticleFile. do?attachType=PDF\&id=10075

\begin{tabular}{|c|c|c|c|c|c|}
\hline Macaca mulatta & 猕猴 & II & $\begin{array}{l}\text { 近危 } \\
\text { /NT }\end{array}$ & 王志鹏 & 实验用猕猴某些生理生化指标的测定 \\
\hline Macaca mulatta & 猕猴 & II & $\begin{array}{l}\text { 近危 } \\
\text { /NT }\end{array}$ & 宁章勇 & 食蟹猴和猕猴朊蛋白基因的克隆与序列分析 \\
\hline Macaca mulatta & 猕猴 & II & $\begin{array}{l}\text { 近危 } \\
\text { /NT }\end{array}$ & 陈钰皓 & 试论自然保护区的合理开发与设计一一以台山市上川岛猕猴自然保护区为例 \\
\hline Macaca mulatta & 猕猴 & II & $\begin{array}{l}\text { 近危 } \\
\text { /NT }\end{array}$ & 钟国娟 & 试用中药治疗母猕猴生殖系统疾病 \\
\hline Macaca mulatta & 猕猴 & II & $\begin{array}{l}\text { 近危 } \\
\text { /NT }\end{array}$ & 平述煌 & 树䳔和猕猴精子冷冻保存工艺的创建和优化的研究 \\
\hline Macaca mulatta & 猕猴 & II & $\begin{array}{l}\text { 近危 } \\
\text { /NT }\end{array}$ & 余 山 & 衰老对猕猴视觉反应潜伏期及反应变异性的影响 \\
\hline Macaca mulatta & 猕猴 & II & $\begin{array}{l}\text { 近危 } \\
\text { /NT }\end{array}$ & 徐怀亮 & 四川地区狝猴线粒体 DNA 控制区遗传多样性及其种群遗传结构 \\
\hline Macaca mulatta & 猕猴 & II & $\begin{array}{l}\text { 近危 } \\
\text { /NT }\end{array}$ & 胡延春 & 四川绵阳地区野生猕猴肠道寄生虫感染的调查研究 \\
\hline Macaca mulatta & 猕猴 & II & $\begin{array}{l}\text { 近危 } \\
\text { /NT }\end{array}$ & 司 维 & 四种渗透性防冻剂在猕猴精子低温冷冻保存中对精子功能状态的影响 \\
\hline Macaca mulatta & 猕猴 & II & 近危 & 鲁帅尧 & 饲料钙磷比对生长期称猴钲磷利用率的影响 \\
\hline
\end{tabular}


顾垒，闻丞，罗玫，王吴，吕植. 中国最受关注濒危物种保护现状快速评价的新方法探讨. 生物多样性，2015，23(5)：583-590. http://www. biodiversity-science. net/CN/article/downloadArticleFile. do?attachType=PDF\&id=10075

\begin{tabular}{|c|c|c|c|c|c|}
\hline & & & $/ \mathrm{NT}$ & & \\
\hline \multirow[t]{2}{*}{ Macaca mulatta } & 猕猴 & II & 近危 & 宾石玉 & 饲料形态对育成猕猴生长性能和生化指标的影响 \\
\hline & & & $/ \mathrm{NT}$ & & \\
\hline \multirow[t]{2}{*}{ Macaca mulatta } & 猕猴 & II & 近危 & 张 敬 & 饲养层 FGF2 表达量对猕猴胚胎干细胞自我更新及多能性的影响 \\
\hline & & & /NT & & \\
\hline \multirow[t]{2}{*}{ Macaca mulatta } & 猕猴 & II & 近危 & 申友奎 & 索风营水电站国家二级保护动物猕猴_藏酋猴保护措施_申友奎 \\
\hline & & & $/ \mathrm{NT}$ & & \\
\hline \multirow[t]{2}{*}{ Macaca mulatta } & 猕猴 & II & 近危 & 卢芹 & 太行猕猴掌面花纹研究・III \\
\hline & & & /NT & & \\
\hline \multirow[t]{2}{*}{ Macaca mulatta } & 猕猴 & II & 近危 & 赵玉廷 & 太行山称猴距骨的性别判别分析 \\
\hline & & & /NT & & \\
\hline \multirow[t]{2}{*}{ Macaca mulatta } & 猕猴 & II & 近危 & 卢萍 & 太行山称猴下领骨变量性别判别分析 \\
\hline & & & $/ \mathrm{NT}$ & & \\
\hline \multirow[t]{2}{*}{ Macaca mulatta } & 猕猴 & II & 近危 & 胡春红 & 太行山称猴掌(拓)面花纹强度的比较分析 \\
\hline & & & /NT & & \\
\hline \multirow[t]{2}{*}{ Macaca mulatta } & 猕猴 & II & 近危 & 雷梦云 & 太行山称猴掌面和拓面的花纹强度 \\
\hline & & & $/ \mathrm{NT}$ & & \\
\hline \multirow[t]{2}{*}{ Macaca mulatta } & 猕猴 & II & 近危 & 薛德明 & 太行山地区成年猕猴下领骨形态学变量 \\
\hline & & & /NT & & \\
\hline
\end{tabular}


顾垒，闻丞，罗玫，王吴，吕植. 中国最受关注濒危物种保护现状快速评价的新方法探讨. 生物多样性，2015，23(5)：583-590. http://www. biodiversity-science. net/CN/article/downloadArticleFile. do?attachType=PDF\&id=10075

\begin{tabular}{|c|c|c|c|c|c|}
\hline Macaca mulatta & 猕猴 & II & $\begin{array}{l}\text { 近危 } \\
\text { /NT }\end{array}$ & 赵晓进 & 太行山地区猕猴肩胛骨变量主成分分析 \\
\hline Macaca mulatta & 猕猴 & II & $\begin{array}{l}\text { 近危 } \\
\text { /NT }\end{array}$ & 赵晓进 & 太行山拂猴肩脚骨和肚骨变量相关与异速生长分析 \\
\hline Macaca mulatta & 猕猴 & II & $\begin{array}{l}\text { 近危 } \\
\text { /NT }\end{array}$ & 赵晓进 & 太行山猕猴部分活体形态指标的异速生长分析 \\
\hline Macaca mulatta & 猕猴 & II & $\begin{array}{l}\text { 近危 } \\
\text { /NT }\end{array}$ & 谢东明 & 太行山猕猴的冬季生境选择 \\
\hline Macaca mulatta & 猕猴 & II & $\begin{array}{l}\text { 近危 } \\
\text { /NT }\end{array}$ & 侯进怀 & 太行山猕猴的肥满度 \\
\hline Macaca mulatta & 猕猴 & II & $\begin{array}{l}\text { 近危 } \\
\text { /NT }\end{array}$ & 鹿鹤 & 太行山猕猴的社会联属和行为发育研究 \\
\hline Macaca mulatta & 猕猴 & II & $\begin{array}{l}\text { 近危 } \\
\text { /NT }\end{array}$ & 吕九全 & 太行山猕猴的食性 \\
\hline Macaca mulatta & 猕猴 & II & $\begin{array}{l}\text { 近危 } \\
\text { /NT }\end{array}$ & 薛德明 & 太行山猕猴第 VII 颈椎变量的异速生长分析 \\
\hline Macaca mulatta & 猕猴 & II & $\begin{array}{l}\text { 近危 } \\
\text { /NT }\end{array}$ & 赵晓进 & 太行山猕猴肤纹聚类研究 \\
\hline Macaca mulatta & 猕猴 & II & 近危 & 赵晓进 & 太行山猕猴跟骨性差 \\
\hline
\end{tabular}


顾垒，闻丞，罗玫，王吴，吕植. 中国最受关注濒危物种保护现状快速评价的新方法探讨. 生物多样性，2015，23(5)：583-590. http://www. biodiversity-science. net/CN/article/downloadArticleFile. do?attachType=PDF\&id=10075

\begin{tabular}{|c|c|c|c|c|c|}
\hline & & & $/ \mathrm{NT}$ & & \\
\hline \multirow[t]{2}{*}{ Macaca mulatta } & 猕猴 & II & 近危 & 薛德明 & 太行山猕猴肱骨最大长与第 I 胸椎变量的相关性研究 \\
\hline & & & $/ \mathrm{NT}$ & & \\
\hline \multirow[t]{2}{*}{ Macaca mulatta } & 猕猴 & II & 近危 & 徐丽敏 & 太行山猕猴国家级自然保护区管理现状及对策 \\
\hline & & & /NT & & \\
\hline \multirow[t]{2}{*}{ Macaca mulatta } & 猕猴 & II & 近危 & 薛德明 & 太行山猕猴寰椎和枢椎的初步研究 \\
\hline & & & $/ \mathrm{NT}$ & & \\
\hline \multirow[t]{2}{*}{ Macaca mulatta } & 猕猴 & II & 近危 & 薛德明 & 太行山猕猴肩胛骨变量间的相关性和异速生长分析 \\
\hline & & & $/ \mathrm{NT}$ & & \\
\hline \multirow[t]{2}{*}{ Macaca mulatta } & 猕猴 & II & 近危 & 赵晓进 & 太行山猕猴肩胛骨和肱骨的性别判别 \\
\hline & & & /NT & & \\
\hline \multirow[t]{2}{*}{ Macaca mulatta } & 猕猴 & II & 近危 & 雷梦云 & 太行山猕猴肩胛骨和肱骨性差的研究 \\
\hline & & & $/ \mathrm{NT}$ & & \\
\hline \multirow[t]{2}{*}{ Macaca mulatta } & 猕猴 & II & 近危 & 段锋 & 太行山狝猴肩胛骨长与肩胛骨其它变量生长速度的比较研究 \\
\hline & & & $/ \mathrm{NT}$ & & \\
\hline \multirow[t]{2}{*}{ Macaca mulatta } & 猕猴 & II & 近危 & 赵晓进 & 太行山猕猴胫骨的性别判别分析 \\
\hline & & & $/ \mathrm{NT}$ & & \\
\hline \multirow[t]{2}{*}{ Macaca mulatta } & 猕猴 & II & 近危 & 郭相保 & 太行山猕猴空间利用和冬春季食性分析 \\
\hline & & & /NT & & \\
\hline
\end{tabular}


顾垒，闻丞，罗玫，王吴，吕植. 中国最受关注濒危物种保护现状快速评价的新方法探讨. 生物多样性，2015，23(5)：583-590. http://www. biodiversity-science. net/CN/article/downloadArticleFile. do?attachType=PDF\&id=10075

\begin{tabular}{|c|c|c|c|c|c|}
\hline Macaca mulatta & 猕猴 & II & $\begin{array}{l}\text { 近危 } \\
\text { /NT }\end{array}$ & 赵晓进 & 太行山狝猴髋骨变量研究初报 \\
\hline Macaca mulatta & 猕猴 & II & $\begin{array}{l}\text { 近危 } \\
\text { /NT }\end{array}$ & 路纪琪 & 太行山猕猴㐿骨变量的异速生长研究 \\
\hline Macaca mulatta & 猕猴 & II & $\begin{array}{l}\text { 近危 } \\
\text { /NT }\end{array}$ & 赵晓进 & 太行山狝猴㧫骨变量主成分分析 \\
\hline Macaca mulatta & 猕猴 & II & $\begin{array}{l}\text { 近危 } \\
\text { /NT }\end{array}$ & 吕九全 & 太行山猕猴领骨的形态学及多变量研究 \\
\hline Macaca mulatta & 猕猴 & II & $\begin{array}{l}\text { 近危 } \\
\text { /NT }\end{array}$ & 靳想 & 太行山猕猴预骨的形态学研究 \\
\hline Macaca mulatta & 猕猴 & II & $\begin{array}{l}\text { 近危 } \\
\text { /NT }\end{array}$ & 卢芹 & 太行山猕猴颖骨的性别判别分析 \\
\hline Macaca mulatta & 猕猴 & II & $\begin{array}{l}\text { 近危 } \\
\text { /NT }\end{array}$ & 路纪琪 & 太行山猕猴㐿容量与㐿骨其他变量的相关性研究 \\
\hline Macaca mulatta & 猕猴 & II & $\begin{array}{l}\text { 近危 } \\
\text { /NT }\end{array}$ & 侯进怀 & 太行山猕猴头形研究 \\
\hline Macaca mulatta & 猕猴 & II & $\begin{array}{l}\text { 近危 } \\
\text { /NT }\end{array}$ & 路纪琪 & 太行山猕猴下领的生物力学研究 \\
\hline Macaca mulatta & 猕猴 & II & 近危 & 雷梦云 & 太行山猕猴下领骨、颅骨和骼骨变量的性别判别分析 \\
\hline
\end{tabular}


顾垒，闻丞，罗玫，王吴，吕植. 中国最受关注濒危物种保护现状快速评价的新方法探讨. 生物多样性，2015，23(5)：583-590. http://www. biodiversity-science. net/CN/article/downloadArticleFile. do?attachType=PDF\&id=10075

\begin{tabular}{|c|c|c|c|c|c|}
\hline & & & $/ \mathrm{NT}$ & & \\
\hline \multirow[t]{2}{*}{ Macaca mulatta } & 猕猴 & II & 近危 & 翟鹏飞 & 太行山猕猴下领骨的异速生长分析 \\
\hline & & & $/ \mathrm{NT}$ & & \\
\hline \multirow[t]{2}{*}{ Macaca mulatta } & 猕猴 & II & 近危 & 赵晓进 & 太行山猕猴牙齿和掌_跖_骨性差研究 \\
\hline & & & /NT & & \\
\hline \multirow[t]{2}{*}{ Macaca mulatta } & 猕猴 & II & 近危 & 刘延霆 & 太行山猕猴牙齿性别差异研究 \\
\hline & & & $/ \mathrm{NT}$ & & \\
\hline \multirow[t]{2}{*}{ Macaca mulatta } & 猕猴 & II & 近危 & 赵璇 & 太行山猕猴牙齿性差的分布模式和相关性研究 \\
\hline & & & $/ \mathrm{NT}$ & & \\
\hline \multirow[t]{2}{*}{ Macaca mulatta } & 猕猴 & II & 近危 & 路纪琪 & 太行山猕猴牙齿与乑长的相关性 \\
\hline & & & $/ \mathrm{NT}$ & & \\
\hline \multirow[t]{2}{*}{ Macaca mulatta } & 猕猴 & II & 近危 & 路纪琪 & 太行山狝猴研究进展与展望 \\
\hline & & & $/ \mathrm{NT}$ & & \\
\hline \multirow[t]{2}{*}{ Macaca mulatta } & 猕猴 & II & 近危 & 赵璇 & 太行山猕猴远侧段指(趾)骨形态学 \\
\hline & & & $/ \mathrm{NT}$ & & \\
\hline \multirow[t]{2}{*}{ Macaca mulatta } & 猕猴 & II & 近危 & 侯进怀 & 太行山猕猴脏器测量报告 \\
\hline & & & /NT & & \\
\hline \multirow[t]{2}{*}{ Macaca mulatta } & 猕猴 & II & 近危 & 雷梦云 & 太行山猕猴掌( 跖) 面花纹类型 \\
\hline & & & $/ \mathrm{NT}$ & & \\
\hline
\end{tabular}


顾垒，闻丞，罗玫，王吴，吕植. 中国最受关注濒危物种保护现状快速评价的新方法探讨. 生物多样性，2015，23(5)：583-590. http://www. biodiversity-science. net/CN/article/downloadArticleFile. do?attachType=PDF\&id=10075

\begin{tabular}{|c|c|c|c|c|c|}
\hline Macaca mulatta & 猕猴 & II & $\begin{array}{l}\text { 近危 } \\
\text { /NT }\end{array}$ & 赵阳 & 太行山猕猴掌(跖)骨残损标本复原回归分析 \\
\hline Macaca mulatta & 猕猴 & II & $\begin{array}{l}\text { 近危 } \\
\text { /NT }\end{array}$ & 党晓云 & 太行山狝猴掌(跖)骨重量与颖长的异速生长分析 \\
\hline Macaca mulatta & 猕猴 & II & $\begin{array}{l}\text { 近危 } \\
\text { /NT }\end{array}$ & 赵晓进 & 太行山猕猴掌(蹠)骨长度与频长相关性 \\
\hline Macaca mulatta & 猕猴 & II & $\begin{array}{l}\text { 近危 } \\
\text { /NT }\end{array}$ & 胡春红 & 太行山猕猴掌_跖_面肤纹脊数的比较分析 \\
\hline Macaca mulatta & 猕猴 & II & $\begin{array}{l}\text { 近危 } \\
\text { /NT }\end{array}$ & 赵璇 & 太行山猕猴掌_跖_面肤纹类型研究 \\
\hline Macaca mulatta & 猕猴 & II & $\begin{array}{l}\text { 近危 } \\
\text { /NT }\end{array}$ & 赵晓进 & 太行山猕猴掌骨和骨长度的性别判别 \\
\hline Macaca mulatta & 猕猴 & II & $\begin{array}{l}\text { 近危 } \\
\text { /NT }\end{array}$ & 翟頔 & 太行山猕猴掌骨和跖骨的不对称性 \\
\hline Macaca mulatta & 猕猴 & II & $\begin{array}{l}\text { 近危 } \\
\text { /NT }\end{array}$ & 赵晓进 & 太行山猕猴掌骨和跖骨的形态学 \\
\hline Macaca mulatta & 猕猴 & II & $\begin{array}{l}\text { 近危 } \\
\text { /NT }\end{array}$ & 党晓云 & 太行山猕猴掌骨和跖骨重量比率性别差异 \\
\hline Macaca mulatta & 猕猴 & II & 近危 & 雷梦云 & 太行山猕猴掌骨和跖骨重量与颓长的异速生长分析 \\
\hline
\end{tabular}


顾垒，闻丞，罗玫，王吴，吕植. 中国最受关注濒危物种保护现状快速评价的新方法探讨. 生物多样性，2015，23(5)：583-590. http://www. biodiversity-science. net/CN/article/downloadArticleFile. do?attachType=PDF\&id=10075

\begin{tabular}{|c|c|c|c|c|c|}
\hline & & & $/ \mathrm{NT}$ & & \\
\hline \multirow[t]{2}{*}{ Macaca mulatta } & 猕猴 & II & 近危 & 赵晓进 & 太行山猕猴掌骨和蹠骨长度变量研究 \\
\hline & & & $/ \mathrm{NT}$ & & \\
\hline \multirow[t]{2}{*}{ Macaca mulatta } & 猕猴 & II & 近危 & 王耿 & 太行山猕猴掌骨和蹠骨长度顺序研究 \\
\hline & & & /NT & & \\
\hline \multirow[t]{2}{*}{ Macaca mulatta } & 猕猴 & II & 近危 & 胡海洋 & 太行山猕猴掌骨性别判别分析 \\
\hline & & & $/ \mathrm{NT}$ & & \\
\hline \multirow[t]{2}{*}{ Macaca mulatta } & 猕猴 & II & 近危 & 卢芹 & 太行山猕猴掌面肤纹研究 \\
\hline & & & $/ \mathrm{NT}$ & & \\
\hline \multirow[t]{2}{*}{ Macaca mulatta } & 猕猴 & II & 近危 & 段文存 & 太行山猕猴掌面花纹的形态学 \\
\hline & & & $/ \mathrm{NT}$ & & \\
\hline \multirow[t]{2}{*}{ Macaca mulatta } & 猕猴 & II & 近危 & 靳想 & 太行山猕猴掌面花纹嵴数不对称性研究 \\
\hline & & & $/ \mathrm{NT}$ & & \\
\hline \multirow[t]{2}{*}{ Macaca mulatta } & 猕猴 & II & 近危 & 丁金芝 & 太行山猕猴掌面花纹崉数的形态学研究 \\
\hline & & & $/ \mathrm{NT}$ & & \\
\hline \multirow[t]{2}{*}{ Macaca mulatta } & 猕猴 & II & 近危 & 赵璇 & 太行山猕猴掌面花纹嵴数的性差 \\
\hline & & & $/ \mathrm{NT}$ & & \\
\hline \multirow[t]{2}{*}{ Macaca mulatta } & 猕猴 & II & 近危 & 薛峰 & 太行山猕猴掌面花纹密度的性别差异分析 \\
\hline & & & $/ \mathrm{NT}$ & & \\
\hline
\end{tabular}


顾垒，闻丞，罗玫，王吴，吕植. 中国最受关注濒危物种保护现状快速评价的新方法探讨. 生物多样性，2015，23(5)：583-590. http://www. biodiversity-science. net/CN/article/downloadArticleFile. do?attachType=PDF\&id=10075

\begin{tabular}{|c|c|c|c|c|c|}
\hline Macaca mulatta & 猕猴 & II & $\begin{array}{l}\text { 近危 } \\
\text { /NT }\end{array}$ & 党晓云 & 太行山猕猴掌跖骨_指趾骨_的形态学性差及不对称性研究 \\
\hline Macaca mulatta & 猕猴 & II & $\begin{array}{l}\text { 近危 } \\
\text { /NT }\end{array}$ & 苏亚 & 太行山猕猴肢骨形态学研究 \\
\hline Macaca mulatta & 猕猴 & II & $\begin{array}{l}\text { 近危 } \\
\text { /NT }\end{array}$ & 燕帅国 & 太行山猕猴蹠骨形态学判别分析 \\
\hline Macaca mulatta & 猕猴 & II & $\begin{array}{l}\text { 近危 } \\
\text { /NT }\end{array}$ & 谢东明 & 太行山猕猴种群 mtDNA 遗传多样性研究 \\
\hline Macaca mulatta & 猕猴 & II & $\begin{array}{l}\text { 近危 } \\
\text { /NT }\end{array}$ & 刘藏 & 太行山猕猴自然保护区苔蘚植物区系研究 \\
\hline Macaca mulatta & 猕猴 & II & $\begin{array}{l}\text { 近危 } \\
\text { /NT }\end{array}$ & 张玉兰 & 太行山猕猴自然保护区药用植物资源调查研究 \\
\hline Macaca mulatta & 猕猴 & II & $\begin{array}{l}\text { 近危 } \\
\text { /NT }\end{array}$ & 张玉兰 & 太行山猕猴自然保护区野菜资源调查及开发利用的研究 \\
\hline Macaca mulatta & 猕猴 & II & $\begin{array}{l}\text { 近危 } \\
\text { /NT }\end{array}$ & 刘荣 & 太行山猕猴自然保护区野生草本有毒植物资源调查研究 \\
\hline Macaca mulatta & 猕猴 & II & $\begin{array}{l}\text { 近危 } \\
\text { /NT }\end{array}$ & 李保印 & 太行山猕猴自然保护区野生木本观赏植物资源研究 \\
\hline Macaca mulatta & 猕猴 & II & 近危 & 李喜龙 & 糖在猕猴精子低温冷冻保存过程中的作用 \\
\hline
\end{tabular}


顾垒，闻丞，罗玫，王吴，吕植. 中国最受关注濒危物种保护现状快速评价的新方法探讨. 生物多样性，2015，23(5)：583-590. http://www. biodiversity-science. net/CN/article/downloadArticleFile. do?attachType=PDF\&id=10075

\begin{tabular}{|c|c|c|c|c|c|}
\hline & & & $/ \mathrm{NT}$ & & \\
\hline \multirow[t]{2}{*}{ Macaca mulatta } & 猕猴 & II & 近危 & 金立方 & 体外分步诱导猕猴胚胎干细胞为肝细胞 \\
\hline & & & $/ \mathrm{NT}$ & & \\
\hline \multirow[t]{2}{*}{ Macaca mulatta } & 猕猴 & II & 近危 & 郭祥玉 & 体外培养猕猴穆勒细胞经诱导可表现出视网膜前体细胞特征 \\
\hline & & & /NT & & \\
\hline \multirow[t]{2}{*}{ Macaca mulatta } & 猕猴 & II & 近危 & 胡军 & 体外诱导猕猴骨髓基质干细胞向雪旺细胞分化 \\
\hline & & & $/ \mathrm{NT}$ & & \\
\hline \multirow[t]{2}{*}{ Macaca mulatta } & 猕猴 & II & 近危 & 陈峥宏 & 头节小钩数目异常链状带绦虫的鉴定 \\
\hline & & & /NT & & \\
\hline \multirow[t]{2}{*}{ Macaca mulatta } & 猕猴 & II & 近危 & 张卉 & 皖南山区猕猴种群的形态特征与微卫星遗传多样性初步分析 \\
\hline & & & /NT & & \\
\hline \multirow[t]{2}{*}{ Macaca mulatta } & 猕猴 & II & 近危 & 齐会娟 & 王屋山景区生态旅游与猕猴保护问题探讨 \\
\hline & & & /NT & & \\
\hline \multirow[t]{2}{*}{ Macaca mulatta } & 猕猴 & II & 近危 & 王代平 & 我国部分地区猕猴的猴 B 病毒感染情况及膜蛋白 gC_ELISA 的建立 \\
\hline & & & $/ \mathrm{NT}$ & & \\
\hline \multirow[t]{2}{*}{ Macaca mulatta } & 猕猴 & II & 近危 & 赵远 & 无草粉日粮饲喂生长期猕猴的初步研究 \\
\hline & & & $/ \mathrm{NT}$ & & \\
\hline \multirow[t]{2}{*}{ Macaca mulatta } & 猕猴 & II & 近危 & 王秀中 & 无胶笁分毛细管电泳法测定猕猴血浆中的反义寡核苷酸药物癌泰得 \\
\hline & & & /NT & & \\
\hline
\end{tabular}


顾垒，闻丞，罗玫，王吴，吕植. 中国最受关注濒危物种保护现状快速评价的新方法探讨. 生物多样性，2015，23(5)：583-590. http://www. biodiversity-science. net/CN/article/downloadArticleFile. do?attachType=PDF\&id=10075

\begin{tabular}{|c|c|c|c|c|c|}
\hline Macaca mulatta & 猕猴 & II & $\begin{array}{l}\text { 近危 } \\
\text { /NT }\end{array}$ & 魏鹏 & 细胞外基质在称猴月经周期和早期妊娠子宫中的表达 \\
\hline Macaca mulatta & 猕猴 & II & $\begin{array}{l}\text { 近危 } \\
\text { /NT }\end{array}$ & 郑萍 & 纤溶酶原激活因子与猕猴精子运动力的关系及其在附睪和附性腺中的表达调节 \\
\hline Macaca mulatta & 猕猴 & II & $\begin{array}{l}\text { 近危 } \\
\text { /NT }\end{array}$ & 胡品昌 & 新进野生猕猴暴发细菌性痢疾治疗与探讨 \\
\hline Macaca mulatta & 猕猴 & II & $\begin{array}{l}\text { 近危 } \\
\text { /NT }\end{array}$ & 花秀春 & 新引进猕猴的检疫、隔离与饲养管理 \\
\hline Macaca mulatta & 猕猴 & II & $\begin{array}{l}\text { 近危 } \\
\text { /NT }\end{array}$ & 唐东红 & 野生及笼养猕猴 SV40 T 抗原基因检测方法的建立 \\
\hline Macaca mulatta & 猕猴 & II & $\begin{array}{l}\text { 近危 } \\
\text { /NT }\end{array}$ & 彭 玲 & 野生猕猴打斗模式的初步观察 \\
\hline Macaca mulatta & 猕猴 & II & $\begin{array}{l}\text { 近危 } \\
\text { /NT }\end{array}$ & 江燕 & 野生猕猴应激与抗应激的研究 \\
\hline Macaca mulatta & 猕猴 & II & $\begin{array}{l}\text { 近危 } \\
\text { /NT }\end{array}$ & 吕超超 & 野生太行猕猴肠道寄生虫感染的初步调查 \\
\hline Macaca mulatta & 猕猴 & II & $\begin{array}{l}\text { 近危 } \\
\text { /NT }\end{array}$ & 田军东 & 野生太行山猕猴的社会结构 \\
\hline Macaca mulatta & 猕猴 & II & 近危 & 田军东 & 野生太行山猕猴的种群生态和社会结构 \\
\hline
\end{tabular}


顾垒，闻丞，罗玫，王吴，吕植. 中国最受关注濒危物种保护现状快速评价的新方法探讨. 生物多样性，2015，23(5)：583-590. http://www. biodiversity-science. net/CN/article/downloadArticleFile. do?attachType=PDF\&id=10075

\begin{tabular}{|c|c|c|c|c|c|}
\hline & & & $/ \mathrm{NT}$ & & \\
\hline \multirow[t]{2}{*}{ Macaca mulatta } & 猕猴 & II & 近危 & 沈果 & 野生太行山猕猴血液生理生化指标测定与分析 \\
\hline & & & $/ \mathrm{NT}$ & & \\
\hline \multirow[t]{2}{*}{ Macaca mulatta } & 猕猴 & II & 近危 & 王斌, & 一例白变猕猴的酪氨酸酶基因及病因分析 \\
\hline & & & /NT & & \\
\hline \multirow[t]{2}{*}{ Macaca mulatta } & 猕猴 & II & 近危 & 金石军 & 一例实验猕猴猴虫感染的诊治 \\
\hline & & & $/ \mathrm{NT}$ & & \\
\hline \multirow[t]{2}{*}{ Macaca mulatta } & 猕猴 & II & 近危 & 徐嘉泽 & 一起猕猴结核病的诊治报告 \\
\hline & & & $/ \mathrm{NT}$ & & \\
\hline \multirow[t]{2}{*}{ Macaca mulatta } & 猕猴 & II & 近危 & 王翠萍 & 一氧化氮合酶在猕猴中枢神经系统中的表达 \\
\hline & & & /NT & & \\
\hline \multirow[t]{2}{*}{ Macaca mulatta } & 猕猴 & II & 近危 & 熊成培 & 影响称猴体外受精与胚胎移植成功率的因素分析 \\
\hline & & & $/ \mathrm{NT}$ & & \\
\hline \multirow[t]{2}{*}{ Macaca mulatta } & 猕猴 & II & 近危 & 李瑞生 & 用微卫星 DNA 标记技术建立猕猴遗传检测方法及对群体遗传多样性的分析 \\
\hline & & & $/ \mathrm{NT}$ & & \\
\hline \multirow[t]{2}{*}{ Macaca mulatta } & 猕猴 & II & 近危 & 金宇娟 & 用血液生化标记法和微卫星标记法建立两个猕猴种群的遗传概貌 \\
\hline & & & $/ \mathrm{NT}$ & & \\
\hline \multirow[t]{2}{*}{ Macaca mulatta } & 猕猴 & II & 近危 & 杨彩侠 & 用于克隆的称猴耳成纤维细胞的培养及其有关生物学特性 \\
\hline & & & /NT & & \\
\hline
\end{tabular}


顾垒，闻丞，罗玫，王吴，吕植. 中国最受关注濒危物种保护现状快速评价的新方法探讨. 生物多样性，2015，23(5)：583-590. http://www. biodiversity-science. net/CN/article/downloadArticleFile. do?attachType=PDF\&id=10075

\begin{tabular}{|c|c|c|c|c|c|}
\hline Macaca mulatta & 猕猴 & II & $\begin{array}{l}\text { 近危 } \\
\text { /NT }\end{array}$ & 黄勉 & 幼猕猴粪类圆线虫感染的诊治 \\
\hline Macaca mulatta & 猕猴 & II & $\begin{array}{l}\text { 近危 } \\
\text { /NT }\end{array}$ & 刘其建 & 云南红河哈尼族彝族自治州猕猴资源调查 \\
\hline Macaca mulatta & 猕猴 & II & $\begin{array}{l}\text { 近危 } \\
\text { /NT }\end{array}$ & 张忠员 & 云南华坪县永兴乡狝猴生境比较 \\
\hline Macaca mulatta & 猕猴 & II & $\begin{array}{l}\text { 近危 } \\
\text { /NT }\end{array}$ & 赵远 & 云南三个地区野生猕猴的种群结构分析 \\
\hline Macaca mulatta & 猕猴 & II & $\begin{array}{l}\text { 近危 } \\
\text { /NT }\end{array}$ & 杨光照 & 云南省的猕猴资源现状及其保护与开发利用 \\
\hline Macaca mulatta & 猕猴 & II & $\begin{array}{l}\text { 近危 } \\
\text { /NT }\end{array}$ & 李志雄 & 早期妊娠猕猴孕激素水平的检测 \\
\hline Macaca mulatta & 猕猴 & II & $\begin{array}{l}\text { 近危 } \\
\text { /NT }\end{array}$ & 郑荣泉 & 浙江金华南山猕猴资源初步调查 \\
\hline Macaca mulatta & 猕猴 & II & $\begin{array}{l}\text { 近危 } \\
\text { /NT }\end{array}$ & 张惠云 & 正常猕猴性周期相关指标的检测 \\
\hline Macaca mulatta & 猕猴 & II & $\begin{array}{l}\text { 近危 } \\
\text { /NT }\end{array}$ & 孔祥梅 & 正常猕猴与人视网膜血管的比较 \\
\hline Macaca mulatta & 猕猴 & II & 近危 & 魏 盛 & 正常猕猴月经周期表情行为变化特点及其评价 \\
\hline
\end{tabular}


顾垒，闻丞，罗玫，王吴，吕植. 中国最受关注濒危物种保护现状快速评价的新方法探讨. 生物多样性，2015，23(5)：583-590. http://www. biodiversity-science. net/CN/article/downloadArticleFile. do?attachType=PDF\&id=10075

\begin{tabular}{|c|c|c|c|c|c|}
\hline & & & $/ \mathrm{NT}$ & & \\
\hline \multirow[t]{2}{*}{ Macaca mulatta } & 猕猴 & II & 近危 & 鲁帅尧 & 植酸酶对猕猴蛋白质消化率和钙、磷利用率的影响 \\
\hline & & & $/ \mathrm{NT}$ & & \\
\hline \multirow[t]{2}{*}{ Macaca mulatta } & 猕猴 & II & 近危 & 和占龙 & 植酸酶在实验猕猴饲料中的应用研究 \\
\hline & & & /NT & & \\
\hline \multirow[t]{2}{*}{ Macaca mulatta } & 猕猴 & II & 近危 & 李冰 & 治疗猕猴营养性脱毛的试验研究 \\
\hline & & & /NT & & \\
\hline \multirow[t]{2}{*}{ Macaca mulatta } & 猕猴 & II & 近危 & 周月才 & 中国大陆猕猴属物种资源快速鉴定方法的研究 \\
\hline & & & $/ \mathrm{NT}$ & & \\
\hline \multirow[t]{2}{*}{ Macaca mulatta } & 猕猴 & II & 近危 & 张俊明 & 中国猕猴属进化分析及物种特异性遗传标记的研究 \\
\hline & & & /NT & & \\
\hline \multirow[t]{2}{*}{ Macaca mulatta } & 猕猴 & II & 近危 & 李地艳 & 中国猕猴遗传多样性研究进展 \\
\hline & & & /NT & & \\
\hline \multirow[t]{2}{*}{ Macaca mulatta } & 猕猴 & II & 近危 & 和占龙 & 中国西南地区猕猴 MHC_类部分等位基因调查 \\
\hline & & & /NT & & \\
\hline \multirow[t]{2}{*}{ Macaca mulatta } & 猕猴 & II & 近危 & 周建华 & 中西药合治猕猴奇异变形杆菌性腹泻的临床观察 \\
\hline & & & /NT & & \\
\hline \multirow[t]{2}{*}{ Macaca mulatta } & 猕猴 & II & 近危 & 禹文海 & 转移因子 TF 对幼年猕猴生理生化指标的影响 \\
\hline & & & /NT & & \\
\hline
\end{tabular}


顾垒，闻丞，罗玫，王吴，吕植. 中国最受关注濒危物种保护现状快速评价的新方法探讨. 生物多样性，2015，23(5)：583-590. http://www, biodiversity-science, net/CN/article/downloadArticleFile. do?attachType=PDF\&id=10075

\begin{tabular}{|c|c|c|c|c|c|}
\hline Macaca mulatta & 猕猴 & II & 近危 & 和占龙 & 自繁猕猴肠道寄生虫的调查报告 \\
\hline Macaca thibetana & 藏酋猴 & II & $\begin{array}{l}\text { 无危 } \\
\text { /LC }\end{array}$ & 岳碧松 & 2012_藏酋猴微卫星富集文库的构建及微卫星分子标记的篮选_贾小东 \\
\hline Macaca thibetana & 藏酋猴 & II & $\begin{array}{l}\text { 无危 } \\
\text { /LC }\end{array}$ & Xuyang Liu & Characterization of intraocular pressure responses of the Tibetan monkey (Macaca thibetana) \\
\hline Macaca thibetana & 黄山短尾猴 & II & $\begin{array}{l}\text { 无危 } \\
\text { /LC }\end{array}$ & Jinhua LI & $\begin{array}{l}\text { Discovery of the Tibetan Macaque (Macaca thibetana) as a New Primate Host of the Gullet } \\
\text { Worm (Gongylonema pulchrum) }\end{array}$ \\
\hline Macaca thibetana & 藏酋猴 & II & $\begin{array}{l}\text { 无危 } \\
\text { /LC }\end{array}$ & Carol M. Berman & Dominance style among Macaca thibetana on Mt. Huangshan, China \\
\hline Macaca thibetana & 藏酋猴 & II & $\begin{array}{l}\text { 无危 } \\
\text { /LC }\end{array}$ & 向左甫 & Ecotourism disturbances to non-human primates \\
\hline Macaca thibetana & 藏酋猴 & II & $\begin{array}{l}\text { 无危 } \\
\text { /LC }\end{array}$ & Huai-Liang Xu & $\begin{array}{l}\text { Evolutionary analysis of the short-type peptidoglycan-recognition protein gene (PGLYRP1) in } \\
\text { primates }\end{array}$ \\
\hline Macaca thibetana & 藏酋猴 & II & $\begin{array}{l}\text { 无危 } \\
\text { /LC }\end{array}$ & Xu-YangLiu & $\begin{array}{l}\text { Experimental Tibetan monkey domestication and its application for intraocular pressure } \\
\text { measurement }\end{array}$ \\
\hline Macaca thibetana & 黄山短尾猴 & II & $\begin{array}{l}\text { 无危 } \\
\text { /LC }\end{array}$ & Jinhua LI & $\begin{array}{l}\text { First occurrence of twins in provisioned free-ranging Tibetan macaques (Macaca thibetana) at } \\
\text { Huangshan, China }\end{array}$ \\
\hline Macaca thibetana & 藏酋猴 & II & 无危 & Huai-Liang Xu & Genetic diversity of two Tibetan macaque (Macaca thibetana) populations from Guizhou and \\
\hline
\end{tabular}


顾垒，闻丞，罗玫，王昊，吕植. 中国最受关注濒危物种保护现状快速评价的新方法探讨．生物多样性，2015，23(5)：583-590. http://www, biodiversity-science, net/CN/article/downloadArticleFile. do?attachType=PDF\&id=10075

\begin{tabular}{|c|c|c|c|c|c|}
\hline & & & $/ \mathrm{LC}$ & & Yunnan in China based on mitochondrial DNA D-loop sequences \\
\hline \multirow[t]{2}{*}{ Macaca thibetana } & 黄山短尾猴 & II & 无危 & Jinhua LI & Grooming facilitate male-male bonds in Tibetan macaques Macaca thibetana \\
\hline & & & $/ \mathrm{LC}$ & & \\
\hline \multirow[t]{2}{*}{ Macaca thibetana } & 黄山短尾猴 & II & 无危 & Jinhua LI & Grooming reciprocity and reduced female aggression in Tibetan macaques Macaca thibetana \\
\hline & & & $/ \mathrm{LC}$ & & \\
\hline \multirow[t]{2}{*}{ Macaca thibetana } & 黄山短尾猴 & II & 无危 & Jinhua LI & Grooming Reciprocity in Male Tibetan Macaques \\
\hline & & & $/ \mathrm{LC}$ & & \\
\hline \multirow[t]{2}{*}{ Macaca thibetana } & 黄山短尾猴 & II & 无危 & Jinhua LI & Human and macaques interactions at Mt.Huangshan, China: Implications for pathogen \\
\hline & & & $/ \mathrm{LC}$ & & transmission \\
\hline \multirow[t]{2}{*}{ Macaca thibetana } & 藏酋猴 & II & 无危 & Huai-Liang Xu & Identification and characterization of the major histocompatibility complex class II DQB \\
\hline & & & $/ \mathrm{LC}$ & & (MhcMath-DQB1) alleles in Tibetan macaques (Macaca thibetana) \\
\hline \multirow[t]{2}{*}{ Macaca thibetana } & 藏酋猴 & II & 无危 & Huai-Liang Xu & Identification and molecular evolutionary analysis of TLR5 gene from the Tibetan macaque \\
\hline & & & $/ \mathrm{LC}$ & & (Macaca thibetana) \\
\hline \multirow[t]{2}{*}{ Macaca thibetana } & 藏酋猴 & II & 无危 & Zhaozeng Sun & Identification of MHC class I sequences in four species of Macaca of China \\
\hline & & & $/ \mathrm{LC}$ & & \\
\hline \multirow[t]{2}{*}{ Macaca thibetana } & 黄山短尾猴 & II & 无危 & Carol M. Berman & Impact of translocation, provisioning and range restriction on a group of Macaca thibetana \\
\hline & & & $/ \mathrm{LC}$ & & \\
\hline \multirow[t]{2}{*}{ Macaca thibetana } & 藏酋猴 & II & 无危 & Y.R. Lu & Induction of Diabetes in Rhesus Monkeys and Establishment of Insulin Administration Strategy \\
\hline & & & $/ \mathrm{LC}$ & & \\
\hline
\end{tabular}


顾垒，闻丞，罗玫，王昊，吕植. 中国最受关注濒危物种保护现状快速评价的新方法探讨．生物多样性，2015，23(5)：583-590. http://www. biodiversity-science. net/CN/article/downloadArticleFile. do?attachType=PDF\&id=10075

\begin{tabular}{|c|c|c|c|c|c|}
\hline Macaca thibetana & 藏酉猴 & II & $\begin{array}{l}\text { 无危 } \\
\text { /LC }\end{array}$ & X. Y. Zhang & $\begin{array}{l}\text { Isolation and characterization of twenty-one polymorphic microsatellite loci in the Tibetan } \\
\text { macaque (Macaca thibetana) }\end{array}$ \\
\hline Macaca thibetana & 黄山短尾猴 & II & $\begin{array}{l}\text { 无危 } \\
\text { /LC }\end{array}$ & Jinhua LI & Male mate choice in Tibetan macaques Macaca thibetana at Mt. Huangshan, China \\
\hline Macaca thibetana & 黄山短尾猴 & II & $\begin{array}{l}\text { 无危 } \\
\text { /LC }\end{array}$ & Jinhua LI & $\begin{array}{l}\text { Male-to-female agonistic support for copulation in Tibetan macaques (Macaca thibetana) at } \\
\text { Huangshan, China }\end{array}$ \\
\hline Macaca thibetana & 黄山短尾猴 & II & $\begin{array}{l}\text { 无危 } \\
\text { /LC }\end{array}$ & 李进华 & Mitochondrial DNA variation in Tibetan macaque (Macaca thibetana) \\
\hline Macaca thibetana & 黄山短尾猴 & II & $\begin{array}{l}\text { 无危 } \\
\text { /LC }\end{array}$ & Jinhua LI & Mitochondrial DNA variation in Tibetan macaque (Macaca thibetana) \\
\hline Macaca thibetana & 藏酋猴 & II & $\begin{array}{l}\text { 无危 } \\
\text { /LC }\end{array}$ & Bisong Yue & $\begin{array}{l}\text { Molecular cloning and sequence analysis of interferon-gamma and interleukin-6 from Tibetan } \\
\text { macaque (Macaca thibetana) }\end{array}$ \\
\hline Macaca thibetana & 藏酋猴 & II & $\begin{array}{l}\text { 无危 } \\
\text { /LC }\end{array}$ & R. S. WAGNER & $\begin{array}{l}\text { Noninvasive Saliva Collection for DNA Analyses From Free - Ranging Tibetan Macaques } \\
\text { (Macaca thibetana) }\end{array}$ \\
\hline Macaca thibetana & 黄山短尾猴 & II & $\begin{array}{l}\text { 无危 } \\
\text { /LC }\end{array}$ & 李进华 & $\begin{array}{l}\text { Non-reproductive copulation behavior among Tibetan macaques (Macaca thibetana) at } \\
\text { Huangshan, China }\end{array}$ \\
\hline Macaca thibetana & 黄山短尾猴 & II & $\begin{array}{l}\text { 无危 } \\
\text { /LC }\end{array}$ & Carol M. Berman & $\begin{array}{l}\text { Postconflict affiliation between former opponents in Macaca thibetana on Mt. Huangshan, } \\
\text { China }\end{array}$ \\
\hline Macaca thibetana & 黄山短尾猴 & II & 无危 & Carol M. Berman & Primate tourism, range restriction, and infant risk among Macaca thibetana at Mt. Huangshan, \\
\hline
\end{tabular}


顾垒，闻丞，罗玫，王昊，吕植. 中国最受关注濒危物种保护现状快速评价的新方法探讨．生物多样性，2015，23(5)：583-590. http://www, biodiversity-science, net/CN/article/downloadArticleFile. do?attachType=PDF\&id=10075

\begin{tabular}{|c|c|c|c|c|c|}
\hline & & & $/ \mathrm{LC}$ & & China \\
\hline Macaca thibetana & 黄山短尾猴 & II & $\begin{array}{l}\text { 无危 } \\
\text { /LC }\end{array}$ & Jinhua LI & $\begin{array}{l}\text { Seasonal variation and synchronization of sexual behaviors in free-ranging male Tibetan } \\
\text { macaques (Macaca thibetana) at Huangshan, China }\end{array}$ \\
\hline Macaca thibetana & 黄山短尾猴 & II & $\begin{array}{l}\text { 无危 } \\
\text { /LC }\end{array}$ & 李进华 & $\begin{array}{l}\text { Seasonality of reproduction and sexual activity in female Tibetan macaques Macaca thibetana } \\
\text { at Huangshan, China }\end{array}$ \\
\hline Macaca thibetana & 黄山短尾猴 & II & $\begin{array}{l}\text { 无危 } \\
\text { /LC }\end{array}$ & 李进华 & $\begin{array}{l}\text { Seasonality of reproduction and sexual activity in female Tibetan macaques Macaca thibetana } \\
\text { at Huangshan, China (In English) }\end{array}$ \\
\hline Macaca thibetana & 黄山短尾猴 & II & $\begin{array}{l}\text { 无危 } \\
\text { /LC }\end{array}$ & Maureen S. McCarthy & $\begin{array}{l}\text { Sequences of Tibetan macaque (Macaca thibetana) and tourist behaviors at Mt. Huangshan, } \\
\text { China }\end{array}$ \\
\hline Macaca thibetana & 藏酋猴 & II & $\begin{array}{l}\text { 无危 } \\
\text { /LC }\end{array}$ & Feng Yue & $\begin{array}{l}\text { Somatometric measurements, and clinical chemistry and hematology parameters in Tibetan } \\
\text { macaque (Macaca thibetana }\end{array}$ \\
\hline Macaca thibetana & 黄山短尾猴 & II & $\begin{array}{l}\text { 无危 } \\
\text { /LC }\end{array}$ & Carol M. Berman & Supportive and Tolerant Relationships among Male Tibetan Macaques at Huangshan, China \\
\hline Macaca thibetana & 藏酋猴 & II & $\begin{array}{l}\text { 无危 } \\
\text { /LC }\end{array}$ & Bisong Yue & $\begin{array}{l}\text { The complete mitochondrial genome of Macaca thibetana and a novel nuclear mitochondrial } \\
\text { pseudogene }\end{array}$ \\
\hline Macaca thibetana & 黄山短尾猴 & II & $\begin{array}{l}\text { 无危 } \\
\text { /LC }\end{array}$ & 李进华 & Tourism and infant risk among tibetan macaques Huangshan,China \\
\hline Macaca thibetana & 黄山短尾猴 & II & $\begin{array}{l}\text { 无危 } \\
\text { /LC }\end{array}$ & Lori K. Sheeran & $\begin{array}{l}\text { Tourist behavior and decibel levels correlate with threat frequency in Tibetan macaques } \\
\text { (Macaca thibetana) at Mt. Huangshan, China }\end{array}$ \\
\hline
\end{tabular}


顾垒，闻丞，罗玫，王吴，吕植. 中国最受关注濒危物种保护现状快速评价的新方法探讨. 生物多样性，2015，23(5)：583-590. http://www biodiversity-science. net/CN/article/downloadArticleFile. do?attachType=PDF\&id=10075

\begin{tabular}{|c|c|c|c|c|c|}
\hline Macaca thibetana & 黄山短尾猴 & II & $\begin{array}{l}\text { 无危 } \\
\text { /LC }\end{array}$ & Hideshi Ogawa & Triadic positions of Tibetan macaques huddling at a sleeping site \\
\hline Macaca thibetana & 藏酋猴 & II & $\begin{array}{l}\text { 无危 } \\
\text { /LC }\end{array}$ & $\begin{array}{l}\text { K.N. } \\
\text { BALASUBRAMANI } \\
\text { AM }\end{array}$ & $\begin{array}{l}\text { Using Biological Markets Principles to Examine Patterns of Grooming Exchange in Macaca } \\
\text { thibetana }\end{array}$ \\
\hline Macaca thibetana & 藏酋猴 & II & $\begin{array}{l}\text { 无危 } \\
\text { /LC }\end{array}$ & Carol M. Berman & $\begin{array}{l}\text { Variation in kin bias over time in a group of Tibetan macaques at Huangshan, China contest } \\
\text { competition, time constraints or risk respons }\end{array}$ \\
\hline Macaca thibetana & 黄山短尾猴 & II & $\begin{array}{l}\text { 无危 } \\
\text { /LC }\end{array}$ & 孙丙华 & 比较不同旅游管理模式对短尾猴_M_省略_athibetana_分群的影响_孙丙华 \\
\hline Macaca thibetana & 藏酋猴 & II & $\begin{array}{l}\text { 无危 } \\
\text { /LC }\end{array}$ & 肖文 & 藏猕猴_Macacathibetana_叫声的研究_肖文 \\
\hline Macaca thibetana & 藏酋猴 & II & $\begin{array}{l}\text { 无危 } \\
\text { /LC }\end{array}$ & 徐怀亮 & 藏酋猴 Mhc_DPB1 基因 exon2 的多态性_李佳薏 \\
\hline Macaca thibetana & 藏酋猴 & II & $\begin{array}{l}\text { 无危 } \\
\text { /LC }\end{array}$ & 李佳薏 & 藏酋猴 MHC_DPB1 基因 exon2 的多态性研究 \\
\hline Macaca thibetana & 藏酋猴 & II & $\begin{array}{l}\text { 无危 } \\
\text { /LC }\end{array}$ & 徐怀亮 & 藏酋猴达菲抗原_趋化因子受体基因的克隆与序列分析_司晓辉 \\
\hline Macaca thibetana & 藏酋猴 & II & $\begin{array}{l}\text { 无危 } \\
\text { /LC }\end{array}$ & 王正荣 & 藏酋猴类似人 clock 基因片段的克隆_李韦 \\
\hline
\end{tabular}


顾垒，闻丞，罗玫，王吴，吕植. 中国最受关注濒危物种保护现状快速评价的新方法探讨. 生物多样性，2015，23(5)：583-590. http://www, biodiversity-science. net/CN/article/downloadArticleFile. do?attachType=PDF\&id=10075

\begin{tabular}{|c|c|c|c|c|c|}
\hline Macaca thibetana & 藏酋猴 & II & $\begin{array}{l}\text { 无危 } \\
\text { /LC }\end{array}$ & 姚永芳 & 藏酋猴毛干 DNA 的 3 种提取方法_徐怀亮 \\
\hline Macaca thibetana & 藏酋猴 & II & $\begin{array}{l}\text { 无危 } \\
\text { /LC }\end{array}$ & 周亮 & 藏酋猴人工繁育中腹江疾病治疗体会_周亮 \\
\hline Macaca thibetana & 藏酋猴 & II & $\begin{array}{l}\text { 无危 } \\
\text { /LC }\end{array}$ & 杨锋 & 藏酋猴外周血细胞及血清生化指标测定与分析_杨锋 \\
\hline Macaca thibetana & 藏酋猴 & II & $\begin{array}{l}\text { 无危 } \\
\text { /LC }\end{array}$ & 董高华 & 藏酋猴线粒体基因组序列测定与进化分析 \\
\hline Macaca thibetana & 藏酋猴 & II & $\begin{array}{l}\text { 无危 } \\
\text { /LC }\end{array}$ & 黄颖 & 藏酋猴与川金丝猴 TLR 基因家族序列测定与进化分析 \\
\hline Macaca thibetana & 黄山短尾猴 & II & $\begin{array}{l}\text { 无危 } \\
\text { /LC }\end{array}$ & 尹华宝 & 成年黄山短尾猴春季昼间行为时间分配_王贵林 \\
\hline Macaca thibetana & 黄山短尾猴 & II & $\begin{array}{l}\text { 无危 } \\
\text { /LC }\end{array}$ & 李进华 & 成年黄山短尾猴雌性等级结构稳定性_朱否 \\
\hline Macaca thibetana & 黄山短尾猴 & II & $\begin{array}{l}\text { 无危 } \\
\text { /LC }\end{array}$ & 李进华 & 雌性黄山短尾猴回避近亲交配_朱勇 \\
\hline Macaca thibetana & 黄山短尾猴 & II & $\begin{array}{l}\text { 无危 } \\
\text { /LC }\end{array}$ & 李进华 & 短尾猴陈旧粪便中 DNA 的提取 \\
\hline Macaca thibetana & 黄山短尾猴 & II & 无危 & 吴治安 & 短尾猴的配偶关系_吴治安 \\
\hline
\end{tabular}


顾垒，闻丞，罗玫，王吴，吕植. 中国最受关注濒危物种保护现状快速评价的新方法探讨. 生物多样性，2015，23(5)：583-590. http://www. biodiversity-science. net/CN/article/downloadArticleFile. do?attachType=PDF\&id=10075

\begin{tabular}{|c|c|c|c|c|c|}
\hline & & & $/ \mathrm{LC}$ & & \\
\hline \multirow[t]{2}{*}{ Macaca thibetana } & 黄山短尾猴 & II & 无危 & 李进华 & 短尾猴的社会行为与社会关系_李进华 \\
\hline & & & $/ \mathrm{LC}$ & & \\
\hline \multirow[t]{2}{*}{ Macaca thibetana } & 黄山短尾猴 & II & 无危 & 王岐山 & 短尾猴的种群生物学_李进华 \\
\hline & & & $/ \mathrm{LC}$ & & \\
\hline \multirow[t]{2}{*}{ Macaca thibetana } & 黄山短尾猴 & II & 无危 & 李进华 & 短尾猴对顺位关系的认知_李进华 \\
\hline & & & $/ \mathrm{LC}$ & & \\
\hline \multirow[t]{2}{*}{ Macaca thibetana } & 藏酋猴 & II & 无危 & 夏东坡 & 短尾猴理毛行为交换策略与群体稳定性研究 \\
\hline & & & $/ \mathrm{LC}$ & & \\
\hline \multirow[t]{2}{*}{ Macaca thibetana } & 藏酋猴 & II & 无危 & 吴华彰 & 短尾猴雄婴照料行为研究 \\
\hline & & & $/ \mathrm{LC}$ & & \\
\hline \multirow[t]{2}{*}{ Macaca thibetana } & 藏酋猴 & II & 无危 & 李进华 & 短尾猴样品常见污染的检测方法 \\
\hline & & & $/ \mathrm{LC}$ & & \\
\hline \multirow[t]{2}{*}{ Macaca thibetana } & 黄山短尾猴 & II & 无危 & 李进华 & 短尾猴样品中常见哺乳动物及人源污染的特异性研究_吴华彰 \\
\hline & & & $/ \mathrm{LC}$ & & \\
\hline \multirow[t]{2}{*}{ Macaca thibetana } & 藏酋猴 & II & 无危 & 王钢 & 峨眉山藏猕猴粪源大肠杆菌耐药性的调查研究 \\
\hline & & & /LC & & \\
\hline \multirow[t]{2}{*}{ Macaca thibetana } & 藏酋猴 & II & 无危 & 丁伟 & 峨眉山藏猕猴与游客的人猴关系_李国刚 \\
\hline & & & /LC & & \\
\hline
\end{tabular}


顾垒，闻丞，罗玫，王吴，吕植. 中国最受关注濒危物种保护现状快速评价的新方法探讨. 生物多样性，2015，23(5)：583-590. http://www biodiversity-science. net/CN/article/downloadArticleFile. do?attachType=PDF\&id=10075

\begin{tabular}{|c|c|c|c|c|c|}
\hline Macaca thibetana & 藏酋猴 & II & $\begin{array}{l}\text { 无危 } \\
\text { /LC }\end{array}$ & 徐怀亮 & 峨眉山藏酋猴 mtDNA 控制区序列变异及种群遗传多样性_徐怀亮 \\
\hline Macaca thibetana & 藏酋猴 & II & $\begin{array}{l}\text { 无危 } \\
\text { /LC }\end{array}$ & 徐怀亮 & 峨眉山藏酋猴 mtDNA 控制区序列变异及种群遗传多样性_姚永芳 \\
\hline Macaca thibetana & 藏酋猴 & II & $\begin{array}{l}\text { 无危 } \\
\text { /LC }\end{array}$ & 王洪建 & 甘肃白水江自然保护区藏酋猴的生态习性与资源现状_张涛 \\
\hline Macaca thibetana & 黄山短尾猴 & II & $\begin{array}{l}\text { 无危 } \\
\text { /LC }\end{array}$ & 尹华宝 & 黄山短尾猴_Macacathibetana_的主要食性分析_尤硕愚 \\
\hline Macaca thibetana & 藏酋猴 & II & $\begin{array}{l}\text { 无危 } \\
\text { /LC }\end{array}$ & 李进华 & 黄山短尾猴 mtDNA 控制区序列变异及种群的遗传多样性 \\
\hline Macaca thibetana & 黄山短尾猴 & II & $\begin{array}{l}\text { 无危 } \\
\text { /LC }\end{array}$ & 李进华 & 黄山短尾猴不同顺位等级雄性个体友好行为的比较研究_陈燃 \\
\hline Macaca thibetana & 黄山短尾猴 & II & $\begin{array}{l}\text { 无危 } \\
\text { /LC }\end{array}$ & 李进华 & 黄山短尾猴的冬季产仔_尹华宝 \\
\hline Macaca thibetana & 黄山短尾猴 & II & $\begin{array}{l}\text { 无危 } \\
\text { /LC }\end{array}$ & Kunio WATANABE & 黄山短尾猴的左右手倾向_英文_KunioWATANABE \\
\hline Macaca thibetana & 黄山短尾猴 & II & $\begin{array}{l}\text { 无危 } \\
\text { /LC }\end{array}$ & 李进华 & 黄山短尾猴对游人攻击行为比较_纪欢 \\
\hline Macaca thibetana & 黄山短尾猴 & II & 无危 & 李进华 & 黄山短尾猴母系亲属近交回避_谁更主动_朱勇 \\
\hline
\end{tabular}


顾垒，闻丞，罗玫，王吴，吕植. 中国最受关注濒危物种保护现状快速评价的新方法探讨. 生物多样性，2015，23(5)：583-590. http://www biodiversity-science. net/CN/article/downloadArticleFile. do?attachType=PDF\&id=10075

\begin{tabular}{|c|c|c|c|c|c|}
\hline & & & $/ \mathrm{LC}$ & & \\
\hline \multirow[t]{2}{*}{ Macaca thibetana } & 黄山短尾猴 & II & 无危 & 李进华 & 黄山短尾猴社群中的架桥行为_王贵林 \\
\hline & & & $/ \mathrm{LC}$ & & \\
\hline \multirow[t]{2}{*}{ Macaca thibetana } & 藏酋猴 & II & 无危 & 尹华宝 & 黄山短尾猴食土行为 \\
\hline & & & $/ \mathrm{LC}$ & & \\
\hline \multirow[t]{2}{*}{ Macaca thibetana } & 黄山短尾猴 & II & 无危 & 李进华 & 黄山短尾猴雄_婴照料社会行为的研究_吴华彰 \\
\hline & & & $/ \mathrm{LC}$ & & \\
\hline \multirow[t]{2}{*}{ Macaca thibetana } & 藏酋猴 & II & 无危 & 纪欢 & 黄山短尾猴与游人接触行为及肠道寄生虫感染的研究 \\
\hline & & & $/ \mathrm{LC}$ & & \\
\hline \multirow[t]{2}{*}{ Macaca thibetana } & 黄山短尾猴 & II & 无危 & 李进华 & 两种性比类群的雄性黄山短尾猴繁殖行为和攻击行为比较_王希 \\
\hline & & & $/ \mathrm{LC}$ & & \\
\hline \multirow[t]{2}{*}{ Macaca thibetana } & 藏酋猴 & II & 无危 & 周亮 & 人工繁育环境下藏酋猴的分娩特点 \\
\hline & & & $/ \mathrm{LC}$ & & \\
\hline \multirow[t]{2}{*}{ Macaca thibetana } & 藏酋猴 & II & 无危 & 凌娟 & 实验藏酋猴日粮蛋白质营养水平研究 \\
\hline & & & $/ \mathrm{LC}$ & & \\
\hline \multirow[t]{2}{*}{ Macaca thibetana } & 藏酋猴 & II & 无危 & 胡大明 & 四川白水河国家级自然保护区野外藏酋猴活动初步调查_张强 \\
\hline & & & $/ \mathrm{LC}$ & & \\
\hline \multirow[t]{2}{*}{ Macaca thibetana } & 藏酋猴 & II & 无危 & 赵晶晶 & 四川地区藏酋猴和猕猴 MHC_DQB1 基因外显子 2 多态性研究 \\
\hline & & & /LC & & \\
\hline
\end{tabular}


顾垒，闻丞，罗玫，王吴，吕植. 中国最受关注濒危物种保护现状快速评价的新方法探讨. 生物多样性，2015，23(5)：583-590. http://www. biodiversity-science. net/CN/article/downloadArticleFile. do?attachType=PDF\&id=10075

\begin{tabular}{|c|c|c|c|c|c|}
\hline \multirow[t]{2}{*}{ Macaca thibetana } & \multirow[t]{2}{*}{ 黄山短尾猴 } & \multirow[t]{2}{*}{ II } & \multicolumn{2}{|l|}{ 无危 } & \multirow[t]{2}{*}{ 雄性黄山短尾猴_Macacath_省略_na_攻击支持雌性以换取交配回报_汪爽 } \\
\hline & & & $/ \mathrm{LC}$ & & \\
\hline \multirow[t]{2}{*}{ Macaca thibetana } & 黄山短尾猴 & II & 无危 & 李进华 & 雄性黄山短尾猴攻击行为和粪便睪酮水平季节性变化_陈燃 \\
\hline & & & $/ \mathrm{LC}$ & & \\
\hline \multirow[t]{2}{*}{ Macaca thibetana } & 黄山短尾猴 & II & 无危 & 李进华 & 雄性黄山短尾猴交配季节与非交配季节攻击行为比较_陈燃 \\
\hline & & & $/ \mathrm{LC}$ & & \\
\hline \multirow[t]{2}{*}{ Macaca thibetana } & 黄山短尾猴 & II & 无危 & 尹华宝 & 雄性黄山短尾猴顽骨变量的异速生长研究_武梅梅 \\
\hline & & & $/ \mathrm{LC}$ & & \\
\hline \multirow[t]{2}{*}{ Macaca thibetana } & 黄山短尾猴 & II & 无危 & 李进华 & 野生黄山短尾猴雄性睪酮的季节性变化_夏东坡 \\
\hline & & & $/ \mathrm{LC}$ & & \\
\hline \multirow[t]{2}{*}{ Macaca thibetana } & 黄山短尾猴 & II & 无危 & 李进华 & 野生雄性黄山短尾猴粪样睪酮水平日变化_夏东坡 \\
\hline & & & $/ \mathrm{LC}$ & & \\
\hline \multirow[t]{2}{*}{ Macaca thibetana } & 黄山短尾猴 & II & 无危 & 李进华 & 野生雄性黄山短尾猴性行为季节性变化同步性_英文_夏东坡 \\
\hline & & & $/ \mathrm{LC}$ & & \\
\hline \multirow[t]{2}{*}{ Macaca thibetana } & 藏酋猴 & II & 无危 & 夏东坡 & 野生雄性黄山短尾猴性腺激素与性行为关系研究 \\
\hline & & & $/ \mathrm{LC}$ & & \\
\hline \multirow[t]{2}{*}{ Macaca thibetana } & 黄山短尾猴 & II & 无危 & 李进华 & 一例成年雌性黄山短尾猴长时间照料死婴行为_陈燃 \\
\hline & & & $/ \mathrm{LC}$ & & \\
\hline Macaca thibetana & 藏酋猴 & II & 无危 & 王红星 & 幼龄藏酋猴对人工饲料采食与营养成分的消化率的影响_朱姝 \\
\hline
\end{tabular}


顾垒，闻丞，罗玫，王吴，吕植. 中国最受关注濒危物种保护现状快速评价的新方法探讨. 生物多样性，2015，23(5)：583-590. http://www. biodiversity-science. net/CN/article/downloadArticleFile. do?attachType=PDF\&id=10075

\begin{tabular}{|c|c|c|c|c|c|}
\hline & & & $/ \mathrm{LC}$ & & \\
\hline \multirow[t]{2}{*}{ Macaca thibetana } & 藏酋猴 & II & 无危 & 张春润 & 幼年黄山短尾猴社会玩要行为研究 \\
\hline & & & $/ \mathrm{LC}$ & & \\
\hline \multirow[t]{2}{*}{ Macropygia unchall } & 斑尾鹃鸠 & II & 无危 & 谢再成 & 三百山自然保护区鸟类资源及其评价 \\
\hline & & & $/ \mathrm{LC}$ & & \\
\hline \multirow[t]{2}{*}{ Magnolia delavayi } & 山玉兰 & 未列 & 濒危 & 王奇 & 红花山玉兰组织培养研究 \\
\hline & & 入 & /EN & & \\
\hline \multirow[t]{2}{*}{ Magnolia delavayi } & 山玉兰 & 未列 & 濒危 & 龚洵 & 山玉兰中 3〜7 个胚珠的发现 \\
\hline & & 入 & /EN & & \\
\hline \multirow[t]{2}{*}{ Magnolia delavayi } & 山玉兰 & 未列 & 濒危 & 龚洵 & 栽培红花山玉兰的传粉生物学 \\
\hline & & 入 & /EN & & \\
\hline \multirow[t]{2}{*}{ Magnolia officinalis } & 厚朴 & II & 近危 & 余启高 & 3 种药剂解除厚朴种子休眠方法研究 \\
\hline & & & /NT & & \\
\hline \multirow[t]{2}{*}{ Magnolia officinalis } & 厚朴 & II & 近危 & 张硕新 & 4 种药用植物光合特性的研究 \\
\hline & & & /NT & & \\
\hline \multirow[t]{2}{*}{ Magnolia officinalis } & 厚朴 & II & 近危 & Ling-Yi Kong & A novel aporphine alkaloid from Magnolia officinalis \\
\hline & & & /NT & & \\
\hline \multirow[t]{2}{*}{ Magnolia officinalis } & 厚朴 & II & 近危 & Bin Yang & Bioactive polar compounds from stem bark of Magnolia officinalis \\
\hline & & & /NT & & \\
\hline
\end{tabular}


顾垒，闻丞，罗玫，王吴，吕植. 中国最受关注濒危物种保护现状快速评价的新方法探讨. 生物多样性，2015，23(5)：583-590. http://www. biodiversity-science. net/CN/article/downloadArticleFile. do?attachType=PDF\&id=10075

\begin{tabular}{|c|c|c|c|c|c|}
\hline Magnolia officinalis & 厚朴 & II & 近危 & Zhi-Ling Yang & $\begin{array}{l}\text { Genetic diversity and relationship of endangered plant Magnoliaofficinalis (Magnoliaceae) } \\
\text { assessed with ISSR polymorphisms }\end{array}$ \\
\hline Magnolia officinalis & 厚朴 & II & $\begin{array}{l}\text { 近危 } \\
\text { /NT }\end{array}$ & Youwei Wang & $\begin{array}{l}\text { Population structure and genetic diversity distribution in wild and cultivated populations of the } \\
\text { traditional Chinese medicinal plant Magnolia officinalis subsp. biloba (Magnoliaceae) }\end{array}$ \\
\hline Magnolia officinalis & 厚朴 & II & 近危 & Zhiling YANG & $\begin{array}{l}\text { Variation in Seed and Seedling Traits among Fifteen Chinese Provenances of Magnolia } \\
\text { officinalis }\end{array}$ \\
\hline Magnolia officinalis & 厚朴 & II & $\begin{array}{l}\text { 近危 } \\
\text { /NT }\end{array}$ & TONG Zai-kang & $\begin{array}{l}\text { Variation, heredity and selection of effective ingredients in Magnolis officinalis of different } \\
\text { provenances }\end{array}$ \\
\hline Magnolia officinalis & 厚朴 & II & $\begin{array}{l}\text { 近危 } \\
\text { /NT }\end{array}$ & 杨志玲 & 濒危药用植物厚朴 ISSR 引物篮选及反应条件的优化 \\
\hline Magnolia officinalis & 厚朴 & II & $\begin{array}{l}\text { 近危 } \\
\text { /NT }\end{array}$ & 杨志玲 & 濒危植物厚朴种子萌发特性研究 \\
\hline Magnolia officinalis & 厚朴 & II & $\begin{array}{l}\text { 近危 } \\
\text { /NT }\end{array}$ & 杨志玲 & 不同产地厚朴种子性状的变异分析 \\
\hline Magnolia officinalis & 厚朴 & II & $\begin{array}{l}\text { 近危 } \\
\text { /NT }\end{array}$ & 杨志玲 & 不同产区厚朴ｎｒＤＮＡＩＴＳ序列分析及亲缘关系鉴定 \\
\hline Magnolia officinalis & 厚朴 & II & $\begin{array}{l}\text { 近危 } \\
\text { /NT }\end{array}$ & 周利兵 & 不同地区厚朴中 6 种微量元素的主成分分析和聚类分析 \\
\hline Magnolia officinalis & 厚朴 & II & 近危 & 罗成荣 & 不同海拔高度对厚朴生长量的影响 \\
\hline
\end{tabular}


顾垒，闻丞，罗玫，王吴，吕植. 中国最受关注濒危物种保护现状快速评价的新方法探讨. 生物多样性，2015，23(5)：583-590. http://www. biodiversity-science. net/CN/article/downloadArticleFile. do?attachType=PDF\&id=10075

\begin{tabular}{|c|c|c|c|c|c|}
\hline & & & $/ \mathrm{NT}$ & & \\
\hline \multirow[t]{2}{*}{ Magnolia officinalis } & 厚朴 & II & 近危 & 杨志玲 & 不同花期厚朴雌雄荵和花瓣香气组成成分的分析和比较 \\
\hline & & & $/ \mathrm{NT}$ & & \\
\hline \multirow[t]{2}{*}{ Magnolia officinalis } & 厚朴 & II & 近危 & 田光辉 & 不同季节厚朴树叶挥发性物质分析及其抗氧化活性的研究 \\
\hline & & & /NT & & \\
\hline \multirow[t]{2}{*}{ Magnolia officinalis } & 厚朴 & II & 近危 & 罗祖树 & 不同坡位 5a 生杉木、厚朴及马补木混交林生物量分配格局 \\
\hline & & & /NT & & \\
\hline \multirow[t]{2}{*}{ Magnolia officinalis } & 厚朴 & II & 近危 & 黄修麟 & 不同坡位 6 年生厚朴药用林生物量分布格局 \\
\hline & & & $/ \mathrm{NT}$ & & \\
\hline \multirow[t]{2}{*}{ Magnolia officinalis } & 厚朴 & II & 近危 & 余正文 & 不同树龄厚朴生物活性成分的比较分析 \\
\hline & & & $/ \mathrm{NT}$ & & \\
\hline \multirow[t]{2}{*}{ Magnolia officinalis } & 厚朴 & II & 近危 & 杨志玲 & 不同提取方法对厚朴叶片总 DNA 提取效果的影响 \\
\hline & & & /NT & & \\
\hline \multirow[t]{2}{*}{ Magnolia officinalis } & 厚朴 & II & 近危 & 童再康 & 不同种源厚朴酚类物质含量变异与遗传的初步研究 \\
\hline & & & /NT & & \\
\hline \multirow[t]{2}{*}{ Magnolia officinalis } & 厚朴 & II & 近危 & 杨志玲 & 不同种源厚朴苗期性状变异及主成分分析 \\
\hline & & & /NT & & \\
\hline \multirow[t]{2}{*}{ Magnolia officinalis } & 厚朴 & II & 近危 & 杨志玲 & 不同种源厚朴叶片性状变异及幼苗生长量研究 \\
\hline & & & /NT & & \\
\hline
\end{tabular}


顾垒，闻丞，罗玫，王吴，吕植. 中国最受关注濒危物种保护现状快速评价的新方法探讨. 生物多样性，2015，23(5)：583-590. http://www. biodiversity-science. net/CN/article/downloadArticleFile. do?attachType=PDF\&id=10075

\begin{tabular}{|c|c|c|c|c|c|}
\hline Magnolia officinalis & 厚朴 & II & $\begin{array}{l}\text { 近危 } \\
\text { /NT }\end{array}$ & 李国栋 & 赤水河流域厚朴生物学特性及栽培技术初探 \\
\hline Magnolia officinalis & 厚朴 & II & $\begin{array}{l}\text { 近危 } \\
\text { /NT }\end{array}$ & 王跃华 & 川厚朴染色体制作和核型分析研究 \\
\hline Magnolia officinalis & 厚朴 & II & $\begin{array}{l}\text { 近危 } \\
\text { /NT }\end{array}$ & 孙雁霞 & 川厚朴愈伤组织培养的初步研究 \\
\hline Magnolia officinalis & 厚朴 & II & $\begin{array}{l}\text { 近危 } \\
\text { /NT }\end{array}$ & 张艳红 & 丹东地区日本厚朴繁育的关键技术 \\
\hline Magnolia officinalis & 厚朴 & II & $\begin{array}{l}\text { 近危 } \\
\text { /NT }\end{array}$ & 黄璐琦 & 道地产区不同产地厚朴种子的电泳指纹图谱研究 \\
\hline Magnolia officinalis & 厚朴 & II & $\begin{array}{l}\text { 近危 } \\
\text { /NT }\end{array}$ & 杨志玲 & 方位及冠层对厚朴果实和种子形态变异的影响 \\
\hline Magnolia officinalis & 厚朴 & II & $\begin{array}{l}\text { 近危 } \\
\text { /NT }\end{array}$ & 庄国庆 & 干旱胁迫对厚朴幼苗生理生化影响的研究 \\
\hline Magnolia officinalis & 厚朴 & II & $\begin{array}{l}\text { 近危 } \\
\text { /NT }\end{array}$ & 郑小江 & 干旱胁迫下吸水剂对厚朴幼苗生理生化影响 \\
\hline Magnolia officinalis & 厚朴 & II & $\begin{array}{l}\text { 近危 } \\
\text { /NT }\end{array}$ & 傅大立 & 关于木兰属厚朴组叶位的初步研究 \\
\hline Magnolia officinalis & 厚朴 & II & 近危 & 斯金平 & 厚朴 AFLP 分子标记体系的建立 \\
\hline
\end{tabular}


顾垒，闻丞，罗玫，王吴，吕植. 中国最受关注濒危物种保护现状快速评价的新方法探讨. 生物多样性，2015，23(5)：583-590. http://www. biodiversity-science. net/CN/article/downloadArticleFile. do?attachType=PDF\&id=10075

\begin{tabular}{|c|c|c|c|c|c|}
\hline & & & /NT & & \\
\hline \multirow[t]{2}{*}{ Magnolia officinalis } & 厚朴 & II & 近危 & 刘日林 & 厚朴矮林经营技术的初步研究 \\
\hline & & & /NT & & \\
\hline \multirow[t]{2}{*}{ Magnolia officinalis } & 厚朴 & II & 近危 & 张强 & 厚朴标准化栽培技术 \\
\hline & & & /NT & & \\
\hline \multirow[t]{2}{*}{ Magnolia officinalis } & 厚朴 & II & 近危 & 王柏泉 & 厚朴病虫害种类的初步调查 \\
\hline & & & /NT & & \\
\hline \multirow[t]{2}{*}{ Magnolia officinalis } & 厚朴 & II & 近危 & 王柏泉 & 厚朴不同栽培模式的生物多样性 \\
\hline & & & /NT & & \\
\hline \multirow[t]{2}{*}{ Magnolia officinalis } & 厚朴 & II & 近危 & 杨志玲 & 厚朴不同种源及家系种子性状的变异 \\
\hline & & & $/ \mathrm{NT}$ & & \\
\hline \multirow[t]{2}{*}{ Magnolia officinalis } & 厚朴 & II & 近危 & 杨志玲 & 厚朴不同种源苗期生长模型的拟合 \\
\hline & & & /NT & & \\
\hline \multirow[t]{2}{*}{ Magnolia officinalis } & 厚朴 & II & 近危 & 庄国庆 & 厚朴次生林的优化管理研究 \\
\hline & & & $/ \mathrm{NT}$ & & \\
\hline \multirow[t]{2}{*}{ Magnolia officinalis } & 厚朴 & II & 近危 & 郭宝林 & 厚朴道地性的遗传学证据 \\
\hline & & & /NT & & \\
\hline \multirow[t]{2}{*}{ Magnolia officinalis } & 厚朴 & II & 近危 & 张秉君 & 厚朴的繁育技术 \\
\hline & & & /NT & & \\
\hline
\end{tabular}


顾垒，闻丞，罗玫，王吴，吕植. 中国最受关注濒危物种保护现状快速评价的新方法探讨. 生物多样性，2015，23(5)：583-590. http://www. biodiversity-science. net/CN/article/downloadArticleFile. do?attachType=PDF\&id=10075

\begin{tabular}{|c|c|c|c|c|c|}
\hline Magnolia officinalis & 厚朴 & II & $\begin{array}{l}\text { 近危 } \\
\text { /NT }\end{array}$ & 胡风莲 & 厚朴的栽培管理技术及应用 \\
\hline Magnolia officinalis & 厚朴 & II & $\begin{array}{l}\text { 近危 } \\
\text { /NT }\end{array}$ & 翁剑 & 厚朴分子标记技术应用现状及建议 \\
\hline Magnolia officinalis & 厚朴 & II & $\begin{array}{l}\text { 近危 } \\
\text { /NT }\end{array}$ & 楚毛德 & 厚朴丰产栽培技术 \\
\hline Magnolia officinalis & 厚朴 & II & $\begin{array}{l}\text { 近危 } \\
\text { /NT }\end{array}$ & 王柏泉 & 厚朴害虫藤壶蚧化学防治试验 \\
\hline Magnolia officinalis & 厚朴 & II & $\begin{array}{l}\text { 近危 } \\
\text { /NT }\end{array}$ & 王柏泉 & 厚朴害虫藤盇蚧生物学与发生规律研究 \\
\hline Magnolia officinalis & 厚朴 & II & $\begin{array}{l}\text { 近危 } \\
\text { /NT }\end{array}$ & 刘日林 & 厚朴横沟象防治技术 \\
\hline Magnolia officinalis & 厚朴 & II & $\begin{array}{l}\text { 近危 } \\
\text { /NT }\end{array}$ & 田光辉 & 厚朴活性成分研究进展 \\
\hline Magnolia officinalis & 厚朴 & II & $\begin{array}{l}\text { 近危 } \\
\text { /NT }\end{array}$ & 林先明 & 厚朴基部萌萺的培育利用研究 \\
\hline Magnolia officinalis & 厚朴 & II & $\begin{array}{l}\text { 近危 } \\
\text { /NT }\end{array}$ & 孟 洁 & 厚朴抗氧化作用研究 \\
\hline Magnolia officinalis & 厚朴 & II & 近危 & 王鹏程 & 厚朴立体栽培模式及技术研究 \\
\hline
\end{tabular}


顾垒，闻丞，罗玫，王吴，吕植. 中国最受关注濒危物种保护现状快速评价的新方法探讨. 生物多样性，2015，23(5)：583-590. http://www. biodiversity-science. net/CN/article/downloadArticleFile. do?attachType=PDF\&id=10075

\begin{tabular}{|c|c|c|c|c|c|}
\hline & & & $/ \mathrm{NT}$ & & \\
\hline \multirow[t]{2}{*}{ Magnolia officinalis } & 厚朴 & II & 近危 & 吴传达 & 厚朴良种母树林和种子园改造营建技术 \\
\hline & & & $/ \mathrm{NT}$ & & \\
\hline \multirow[t]{2}{*}{ Magnolia officinalis } & 厚朴 & II & 近危 & 侯长红 & 厚朴林和杜仲林间作玉米与大豆系统的土地利用率研究 \\
\hline & & & /NT & & \\
\hline \multirow[t]{2}{*}{ Magnolia officinalis } & 厚朴 & II & 近危 & 林孝培 & 厚朴林下轮作玄参、大黄种植技术研究 \\
\hline & & & /NT & & \\
\hline \multirow[t]{2}{*}{ Magnolia officinalis } & 厚朴 & II & 近危 & 杨志玲 & 厚朴苗期性状及种源选择初步研究 \\
\hline & & & $/ \mathrm{NT}$ & & \\
\hline \multirow[t]{2}{*}{ Magnolia officinalis } & 厚朴 & II & 近危 & 郑郁善 & 厚朴苗愈伤组织启动培养研究 \\
\hline & & & /NT & & \\
\hline \multirow[t]{2}{*}{ Magnolia officinalis } & 厚朴 & II & 近危 & 张芳芹 & 厚朴皮中多糖含量的测定及其工艺条件的研究 \\
\hline & & & /NT & & \\
\hline \multirow[t]{2}{*}{ Magnolia officinalis } & 厚朴 & II & 近危 & 胡瑞文 & 厚朴轻基质网袋容器育苗技术研究 \\
\hline & & & /NT & & \\
\hline \multirow[t]{2}{*}{ Magnolia officinalis } & 厚朴 & II & 近危 & 王跃华 & 厚朴染色体装片制作的研究 \\
\hline & & & $/ \mathrm{NT}$ & & \\
\hline \multirow[t]{2}{*}{ Magnolia officinalis } & 厚朴 & II & 近危 & 王乃江 & 厚朴人工林优树选择研究 \\
\hline & & & /NT & & \\
\hline
\end{tabular}


顾垒，闻丞，罗玫，王吴，吕植. 中国最受关注濒危物种保护现状快速评价的新方法探讨. 生物多样性，2015，23(5)：583-590. http://www. biodiversity-science. net/CN/article/downloadArticleFile. do?attachType=PDF\&id=10075

\begin{tabular}{|c|c|c|c|c|c|}
\hline Magnolia officinalis & 厚朴 & II & $\begin{array}{l}\text { 近危 } \\
\text { /NT }\end{array}$ & 杨旭静 & 厚朴人工药用原料林生物量测定分析 \\
\hline Magnolia officinalis & 厚朴 & II & $\begin{array}{l}\text { 近危 } \\
\text { /NT }\end{array}$ & 熊晓姣 & 厚朴一一箬竹不同造林密度对其生长的影响 \\
\hline Magnolia officinalis & 厚朴 & II & $\begin{array}{l}\text { 近危 } \\
\text { /NT }\end{array}$ & 王柏泉 & 厚朴藤壶蚧寄生蜂调查研究 \\
\hline Magnolia officinalis & 厚朴 & II & $\begin{array}{l}\text { 近危 } \\
\text { /NT }\end{array}$ & 宋庆安 & 厚朴无性繁殖技术研究 \\
\hline Magnolia officinalis & 厚朴 & II & $\begin{array}{l}\text { 近危 } \\
\text { /NT }\end{array}$ & 魏初认 & 厚朴药材两用林主要营林技术措施试验 \\
\hline Magnolia officinalis & 厚朴 & II & $\begin{array}{l}\text { 近危 } \\
\text { /NT }\end{array}$ & 童再康 & 厚朴药材品质差异评价及遗传稳定性研究 \\
\hline Magnolia officinalis & 厚朴 & II & $\begin{array}{l}\text { 近危 } \\
\text { /NT }\end{array}$ & 陈东阳 & 厚朴药用林的生长特性及人工培育技术 \\
\hline Magnolia officinalis & 厚朴 & II & $\begin{array}{l}\text { 近危 } \\
\text { /NT }\end{array}$ & 杨志玲 & 厚朴野生种与栽培种花不同部位香气成分分析 \\
\hline Magnolia officinalis & 厚朴 & II & $\begin{array}{l}\text { 近危 } \\
\text { /NT }\end{array}$ & 傅大立 & 厚朴一新变种 \\
\hline Magnolia officinalis & 厚朴 & II & 近危 & 斯金平 & 厚朴遗传多样性层次变异规律研究 \\
\hline
\end{tabular}


顾垒，闻丞，罗玫，王吴，吕植. 中国最受关注濒危物种保护现状快速评价的新方法探讨. 生物多样性，2015，23(5)：583-590. http://www. biodiversity-science. net/CN/article/downloadArticleFile. do?attachType=PDF\&id=10075

\begin{tabular}{|c|c|c|c|c|c|}
\hline & & & $/ \mathrm{NT}$ & & \\
\hline \multirow[t]{2}{*}{ Magnolia officinalis } & 厚朴 & II & 近危 & 杨志玲 & 厚朴遗传多样性和遗传关系研究及 ITS 序列分析 \\
\hline & & & $/ \mathrm{NT}$ & & \\
\hline \multirow[t]{2}{*}{ Magnolia officinalis } & 厚朴 & II & 近危 & 郑郁善 & 厚朴遗传多样性研究及指纹图谱的构建 \\
\hline & & & $/ \mathrm{NT}$ & & \\
\hline \multirow[t]{2}{*}{ Magnolia officinalis } & 厚朴 & II & 近危 & 童再康 & 厚朴遗传改良策略的研究 \\
\hline & & & $/ \mathrm{NT}$ & & \\
\hline \multirow[t]{2}{*}{ Magnolia officinalis } & 厚朴 & II & 近危 & 郑郁善 & 厚朴营林现状及资源开发的研究 \\
\hline & & & $/ \mathrm{NT}$ & & \\
\hline \multirow[t]{2}{*}{ Magnolia officinalis } & 厚朴 & II & 近危 & 袁瑾 & 厚朴营养成分分析 \\
\hline & & & /NT & & \\
\hline \multirow[t]{2}{*}{ Magnolia officinalis } & 厚朴 & II & 近危 & 王乃江 & 厚朴有效成分含量分析及优树选择初步研究 \\
\hline & & & /NT & & \\
\hline \multirow[t]{2}{*}{ Magnolia officinalis } & 厚朴 & II & 近危 & 伍石林 & 厚朴与日本落叶松造林模式研究 \\
\hline & & & /NT & & \\
\hline \multirow[t]{2}{*}{ Magnolia officinalis } & 厚朴 & II & 近危 & 林先明 & 厚朴育苗戋光照时间对苗木质量的影响 \\
\hline & & & $/ \mathrm{NT}$ & & \\
\hline \multirow[t]{2}{*}{ Magnolia officinalis } & 厚朴 & II & 近危 & 叶火宝 & 厚朴育苗造林技术 \\
\hline & & & /NT & & \\
\hline
\end{tabular}


顾垒，闻丞，罗玫，王吴，吕植. 中国最受关注濒危物种保护现状快速评价的新方法探讨. 生物多样性，2015，23(5)：583-590. http://www. biodiversity-science. net/CN/article/downloadArticleFile. do?attachType=PDF\&id=10075

\begin{tabular}{|c|c|c|c|c|c|}
\hline Magnolia officinalis & 厚朴 & II & $\begin{array}{l}\text { 近危 } \\
\text { /NT }\end{array}$ & 方小平 & 厚朴愈伤组织诱导条件的优化 \\
\hline Magnolia officinalis & 厚朴 & II & $\begin{array}{l}\text { 近危 } \\
\text { /NT }\end{array}$ & 斯金平 & 厚朴原植物现行分类法的商榷 \\
\hline Magnolia officinalis & 厚朴 & II & $\begin{array}{l}\text { 近危 } \\
\text { /NT }\end{array}$ & 伍四釡 & 厚朴栽植密度的探讨 \\
\hline Magnolia officinalis & 厚朴 & II & $\begin{array}{l}\text { 近危 } \\
\text { /NT }\end{array}$ & 杨志玲 & 厚朴种源间苗期生物量的变异、分配格局及遗传稳定性 \\
\hline Magnolia officinalis & 厚朴 & II & $\begin{array}{l}\text { 近危 } \\
\text { /NT }\end{array}$ & 谢群芳 & 厚朴种源苗期生长差异性分析 \\
\hline Magnolia officinalis & 厚朴 & II & $\begin{array}{l}\text { 近危 } \\
\text { /NT }\end{array}$ & 朱玉球 & 厚朴种源同工酶初步研究 \\
\hline Magnolia officinalis & 厚朴 & II & $\begin{array}{l}\text { 近危 } \\
\text { /NT }\end{array}$ & 余启高 & 厚朴种子发芽检验标准化研究 \\
\hline Magnolia officinalis & 厚朴 & II & $\begin{array}{l}\text { 近危 } \\
\text { /NT }\end{array}$ & 杨占南 & 厚朴种子挥发性物质的评价 \\
\hline Magnolia officinalis & 厚朴 & II & $\begin{array}{l}\text { 近危 } \\
\text { /NT }\end{array}$ & 高捍东 & 厚朴种子解除休眠及萌发生理的研究 \\
\hline Magnolia officinalis & 厚朴 & II & 近危 & 余启高 & 厚朴种子吸水速度的研究 \\
\hline
\end{tabular}


顾垒，闻丞，罗玫，王吴，吕植. 中国最受关注濒危物种保护现状快速评价的新方法探讨. 生物多样性，2015，23(5)：583-590. http://www. biodiversity-science. net/CN/article/downloadArticleFile. do?attachType=PDF\&id=10075

\begin{tabular}{|c|c|c|c|c|c|}
\hline & & & $/ \mathrm{NT}$ & & \\
\hline \multirow[t]{2}{*}{ Magnolia officinalis } & 厚朴 & II & 近危 & 周建青 & 厚朴种子园植株密度与母树生长关系初步研究 \\
\hline & & & $/ \mathrm{NT}$ & & \\
\hline \multirow[t]{2}{*}{ Magnolia officinalis } & 厚朴 & II & 近危 & 甘国菊 & 厚朴主要病虫害的发生与防治 \\
\hline & & & /NT & & \\
\hline \multirow[t]{2}{*}{ Magnolia officinalis } & 厚朴 & II & 近危 & 郑郁善 & 厚朴组织培养技术研究 \\
\hline & & & /NT & & \\
\hline \multirow[t]{2}{*}{ Magnolia officinalis } & 厚朴 & II & 近危 & 童再康 & 厚朴组织培养与高产细胞系建立的研究 \\
\hline & & & $/ \mathrm{NT}$ & & \\
\hline \multirow[t]{2}{*}{ Magnolia officinalis } & 厚朴 & II & 近危 & 廖朝林 & 湖北恩施紫油厚朴高效立体复合种植模式研究 (I ) \\
\hline & & & /NT & & \\
\hline \multirow[t]{2}{*}{ Magnolia officinalis } & 厚朴 & II & 近危 & 蓝闽波 & 基于抗氧化活性的厚朴有效组分的研究 \\
\hline & & & /NT & & \\
\hline \multirow[t]{2}{*}{ Magnolia officinalis } & 厚朴 & II & 近危 & 余启高 & 几种处理对厚朴种子活力的影响 \\
\hline & & & /NT & & \\
\hline \multirow[t]{2}{*}{ Magnolia officinalis } & 厚朴 & II & 近危 & 杏亚婷 & 陇南厚朴生态、生物学特性及栽培技术 \\
\hline & & & /NT & & \\
\hline \multirow[t]{2}{*}{ Magnolia officinalis } & 厚朴 & II & 近危 & 洪震 & 毛竹厚朴混交林对杉木林迹地土壤肥力的影响 \\
\hline & & & /NT & & \\
\hline
\end{tabular}


顾垒，闻丞，罗玫，王吴，吕植. 中国最受关注濒危物种保护现状快速评价的新方法探讨. 生物多样性，2015，23(5)：583-590. http://www. biodiversity-science. net/CN/article/downloadArticleFile. do?attachType=PDF\&id=10075

\begin{tabular}{|c|c|c|c|c|c|}
\hline Magnolia officinalis & 厚朴 & II & $\begin{array}{l}\text { 近危 } \\
\text { /NT }\end{array}$ & 赖普辉 & 秦巴山区不同季节厚朴叶中厚朴酚含量的测定 \\
\hline Magnolia officinalis & 厚朴 & II & $\begin{array}{l}\text { 近危 } \\
\text { /NT }\end{array}$ & 周广柱 & 日本厚朴防寒技术研究 \\
\hline Magnolia officinalis & 厚朴 & II & $\begin{array}{l}\text { 近危 } \\
\text { /NT }\end{array}$ & 周广柱 & 日本厚朴抗寒生理研究 \\
\hline Magnolia officinalis & 厚朴 & II & $\begin{array}{l}\text { 近危 } \\
\text { /NT }\end{array}$ & 付晓云 & 日本厚朴愈伤组织诱导的研究 \\
\hline Magnolia officinalis & 厚朴 & II & $\begin{array}{l}\text { 近危 } \\
\text { /NT }\end{array}$ & 于光艳 & 日本厚朴种子催芽及穴盘育苗技术的研究 \\
\hline Magnolia officinalis & 厚朴 & II & $\begin{array}{l}\text { 近危 } \\
\text { /NT }\end{array}$ & 于光艳 & 日本厚朴种子催芽试验 \\
\hline Magnolia officinalis & 厚朴 & II & $\begin{array}{l}\text { 近危 } \\
\text { /NT }\end{array}$ & 付晓云 & 日本厚朴种子休眠原因初探 \\
\hline Magnolia officinalis & 厚朴 & II & $\begin{array}{l}\text { 近危 } \\
\text { /NT }\end{array}$ & 张秀峰 & 日本厚朴组织培养技术的研究 \\
\hline Magnolia officinalis & 厚朴 & II & $\begin{array}{l}\text { 近危 } \\
\text { /NT }\end{array}$ & 张强 & 山区厚朴栽培及采收、加工技术探析 \\
\hline Magnolia officinalis & 厚朴 & II & 近危 & 伍泽文 & 杉木、厚朴混交林邻体干扰效应研究 \\
\hline
\end{tabular}


顾垒，闻丞，罗玫，王吴，吕植. 中国最受关注濒危物种保护现状快速评价的新方法探讨. 生物多样性，2015，23(5)：583-590. http://www. biodiversity-science. net/CN/article/downloadArticleFile. do?attachType=PDF\&id=10075

\begin{tabular}{|c|c|c|c|c|c|}
\hline & & & $/ \mathrm{NT}$ & & \\
\hline \multirow[t]{2}{*}{ Magnolia officinalis } & 厚朴 & II & 近危 & 伍泽文 & 杉木厚朴混交林木邻体竞争的研究 \\
\hline & & & $/ \mathrm{NT}$ & & \\
\hline \multirow[t]{2}{*}{ Magnolia officinalis } & 厚朴 & II & 近危 & 刘正忠 & 杉木厚朴人工混交林模式生长及土壤特性研究 \\
\hline & & & $/ \mathrm{NT}$ & & \\
\hline \multirow[t]{2}{*}{ Magnolia officinalis } & 厚朴 & II & 近危 & 刘日林 & 杉木人工采伐迹地更新厚朴试验研究 \\
\hline & & & /NT & & \\
\hline \multirow[t]{2}{*}{ Magnolia officinalis } & 厚朴 & II & 近危 & 王永进 & 陕南厚朴生产存在的问题及对策 \\
\hline & & & $/ \mathrm{NT}$ & & \\
\hline \multirow[t]{2}{*}{ Magnolia officinalis } & 厚朴 & II & 近危 & 郑志雷 & 适用于厚朴的 SRAP 反应体系的建立与优化 \\
\hline & & & /NT & & \\
\hline \multirow[t]{2}{*}{ Magnolia officinalis } & 厚朴 & II & 近危 & 杨志玲 & 四川六个厚朴种群遗传结构 \\
\hline & & & /NT & & \\
\hline \multirow[t]{2}{*}{ Magnolia officinalis } & 厚朴 & II & 近危 & 杨锋利 & 汶川地震灾区受损厚朴林的恢复和培育技术 \\
\hline & & & /NT & & \\
\hline \multirow[t]{2}{*}{ Magnolia officinalis } & 厚朴 & II & 近危 & 郑志雷 & 药用植物厚朴开发利用现状、问题及对策 \\
\hline & & & $/ \mathrm{NT}$ & & \\
\hline \multirow[t]{2}{*}{ Magnolia officinalis } & 厚朴 & II & 近危 & 杨志玲 & 药用植物厚朴种子研究进展 \\
\hline & & & /NT & & \\
\hline
\end{tabular}


顾垒，闻丞，罗玫，王吴，吕植. 中国最受关注濒危物种保护现状快速评价的新方法探讨. 生物多样性，2015，23(5)：583-590. http://www biodiversity-science. net/CN/article/downloadArticleFile. do?attachType=PDF\&id=10075

\begin{tabular}{|c|c|c|c|c|c|}
\hline Magnolia officinalis & 厚朴 & II & $\begin{array}{l}\text { 近危 } \\
\text { /NT }\end{array}$ & 杨志玲 & 野生厚朴花粉萌发及花粉管生长过程观察 \\
\hline Magnolia officinalis & 厚朴 & II & $\begin{array}{l}\text { 近危 } \\
\text { /NT }\end{array}$ & 严铸云 & 银杏_厚朴内生真菌的初步研究 \\
\hline Magnolia officinalis & 厚朴 & II & $\begin{array}{l}\text { 近危 } \\
\text { /NT }\end{array}$ & 郑孝严 & 影响厚朴一一 箬竹立体套种造林成活率和出笋数的因素分析 \\
\hline Magnolia officinalis & 厚朴 & II & $\begin{array}{l}\text { 近危 } \\
\text { /NT }\end{array}$ & 张少华 & 植物生长调节剂对厚朴结果影响的试验 \\
\hline Magnolia officinalis & 厚朴 & II & $\begin{array}{l}\text { 近危 } \\
\text { /NT }\end{array}$ & 卢宗荣 & 紫油厚朴藤壶蚧发生与防治 \\
\hline Magnolia omeiensis & 峨嵋拟单性木兰 & I & $\begin{array}{l}\text { 极危 } \\
\text { /CR }\end{array}$ & 陈英 & 濒危植物峨眉拟单性木兰茎段腋芽及愈伤组织诱导 \\
\hline Magnolia omeiensis & 峨嵋拟单性木兰 & I & $\begin{array}{l}\text { 极危 } \\
\text { /CR }\end{array}$ & 陈英 & 濒危植物峨眉拟单性木兰群落特征及繁育技术研究 \\
\hline Magnolia omeiensis & 峨嵋拟单性木兰 & I & $\begin{array}{l}\text { 极危 } \\
\text { /CR }\end{array}$ & 余道平 & 峨眉拟单性木兰种子特性及离体培养初报 \\
\hline Magnolia omeiensis & 峨嵋拟单性木兰 & I & $\begin{array}{l}\text { 极危 } \\
\text { /CR }\end{array}$ & 林祁 & 拟单性木兰属 (木兰科)植物的分类学修订 \\
\hline Magnolia omeiensis & 峨嵋拟单性木兰 & I & 极危 & 马明东 & 拟单性木兰属种质资源及其繁育技术研究进展 \\
\hline
\end{tabular}


顾垒，闻丞，罗玫，王吴，吕植. 中国最受关注濒危物种保护现状快速评价的新方法探讨. 生物多样性，2015，23(5)：583-590. http://www. biodiversity-science. net/CN/article/downloadArticleFile. do?attachType=PDF\&id=10075

\begin{tabular}{|c|c|c|c|c|c|}
\hline & & & /CR & & \\
\hline \multirow[t]{2}{*}{ Magnolia rostrata } & 长缘厚朴 & II & 易危 & 周俊 & 长缘厚朴中的新苯醒及新木脂素类化合物 \\
\hline & & & $/ \mathrm{VU}$ & & \\
\hline \multirow[t]{2}{*}{ Magnolia sargentiana } & 凹叶木兰 & 未列 & 濒危 & 向成华 & 凹叶木兰茎叶解剖学及其遗传多样性研究 \\
\hline & & 入 & $/$ EN & & \\
\hline \multirow[t]{2}{*}{ Magnolia sargentiana } & 凹叶木兰 & 未列 & 濒危 & 唐亚 & 凹叶木兰萌枝更新及其在物种保存中的意义 \\
\hline & & 入 & $/ \mathrm{EN}$ & & \\
\hline \multirow[t]{2}{*}{ Magnolia sargentiana } & 凹叶木兰 & 未列 & 濒危 & 向成华 & 凹叶木兰营养器官解剖结构的生态适应性 \\
\hline & & 入 & $/$ EN & & \\
\hline \multirow[t]{2}{*}{ Magnolia sargentiana } & 凹叶木兰 & 未列 & 濒危 & 唐亚 & 基于 SNP 分子标记的凹叶木兰遗传多样性初步研究 \\
\hline & & 入 & $/$ EN & & \\
\hline \multirow[t]{2}{*}{ Magnolia wilsonii } & 西康玉兰 & II & 濒危 & 龙春林 & 濒危植物西康玉兰种子休眠、萌发及陉藏特性 \\
\hline & & & /EN & & \\
\hline \multirow[t]{2}{*}{ Magnolia wilsonii } & 西康玉兰 & II & 濒危 & 张寿洲 & 用 matK 序列分析探讨木兰属植物的系统发育关系 \\
\hline & & & /EN & & \\
\hline \multirow[t]{2}{*}{ Malania oleifera } & 赫头果 & II & 易危 & 赖家业 & 3 个分布区赫头果叶的解剖特征及其生态适应性 \\
\hline & & & $/ \mathrm{VU}$ & & \\
\hline \multirow[t]{2}{*}{ Malania oleifera } & 蒜头果 & II & 易危 & 袁燕 & BCA 法测定新的植物毒素一一 蒜头果蛋白质量浓度 \\
\hline & & & /VU & & \\
\hline
\end{tabular}


顾垒，闻丞，罗玫，王吴，吕植. 中国最受关注濒危物种保护现状快速评价的新方法探讨. 生物多样性，2015，23(5)：583-590. http://www biodiversity-science. net/CN/article/downloadArticleFile. do?attachType=PDF\&id=10075

\begin{tabular}{|c|c|c|c|c|c|}
\hline Malania oleifera & 蒜头果 & II & $\begin{array}{l}\text { 易危 } \\
\text { /VU }\end{array}$ & Xun Gong & Benzophenone glycosides and epicatechin derivatives from Malania oleifer \\
\hline Malania oleifera & 蒜头果 & II & 易危 & Xiong-Min Liu & Constituents of the essential oil and fatty acid from Malania oleifera \\
\hline Malania oleifera & 蒜头果 & II & $\begin{array}{l}\text { 易危 } \\
\text { /VU }\end{array}$ & Yan Yuan & $\begin{array}{l}\text { Purification, characterization and cytotoxicity of malanin, a novel plant toxin from the seeds of } \\
\text { Malania oleifera }\end{array}$ \\
\hline Malania oleifera & 蒜头果 & II & $\begin{array}{l}\text { 易危 } \\
\text { /VU }\end{array}$ & 周永红 & 不同产地蒜头果中脂肪酸的 GC- MS 分析 \\
\hline Malania oleifera & 蒜头果 & II & $\begin{array}{l}\text { 易危 } \\
\text { /VU }\end{array}$ & 黎向东 & 不同分布区蒜头果叶的比较研究 \\
\hline Malania oleifera & 蒜头果 & II & $\begin{array}{l}\text { 易危 } \\
\text { /VU }\end{array}$ & 余慧嵘 & 不同基肥对蒜头果幼苗生长的影响 \\
\hline Malania oleifera & 蒜头果 & II & $\begin{array}{l}\text { 易危 } \\
\text { /VU }\end{array}$ & 戴晓畅 & 改良 CTAB 法对蒜头果基因组 DNA 提纯效果的影响 \\
\hline Malania oleifera & 蒜头果 & II & $\begin{array}{l}\text { 易危 } \\
\text { /VU }\end{array}$ & 张光飞 & 蒜头果(Malana oleif era)幼苗的光合生理生态特征 \\
\hline Malania oleifera & 赫头果 & II & $\begin{array}{l}\text { 易危 } \\
\text { /VU }\end{array}$ & 黎向东 & 蒜头果保护的初步研究 \\
\hline Malania oleifera & 赫头果 & II & 易危 & 袁燕 & 蒜头果蛋白的提取及凝血活性测定 \\
\hline
\end{tabular}


顾垒，闻丞，罗玫，王吴，吕植. 中国最受关注濒危物种保护现状快速评价的新方法探讨. 生物多样性，2015，23(5)：583-590. http://www. biodiversity-science. net/CN/article/downloadArticleFile. do?attachType=PDF\&id=10075

\begin{tabular}{|c|c|c|c|c|c|}
\hline & & & /VU & & \\
\hline \multirow[t]{2}{*}{ Malania oleifera } & 蒜头果 & II & 易危 & 袁燕 & 蒜头果蛋白性质的鉴定及其中性糖含量的测定 \\
\hline & & & /VU & & \\
\hline \multirow[t]{2}{*}{ Malania oleifera } & 蒜头果 & II & 易危 & 梁月芳 & 蒜头果的濒危原因研究 \\
\hline & & & /VU & & \\
\hline \multirow[t]{2}{*}{ Malania oleifera } & 蒜头果 & II & 易危 & 黎向东 & 蒜头果的濒危原因研究及挽救对策 \\
\hline & & & /VU & & \\
\hline \multirow[t]{2}{*}{ Malania oleifera } & 蒜头果 & II & 易危 & 陆树刚 & 蒜头果的核型 \\
\hline & & & /VU & & \\
\hline \multirow[t]{2}{*}{ Malania oleifera } & 赫头果 & II & 易危 & 陈建华 & 赫头果地理分布与水热关系分析 \\
\hline & & & /VU & & \\
\hline \multirow[t]{2}{*}{ Malania oleifera } & 蒜头果 & II & 易危 & 袁燕 & 蒜头果多糖的提取及含量测定 \\
\hline & & & /VU & & \\
\hline \multirow[t]{2}{*}{ Malania oleifera } & 蒜头果 & II & 易危 & 刘雄民 & 赫头果果仁中 7 种金属元素含量的测定 \\
\hline & & & /VU & & \\
\hline \multirow[t]{2}{*}{ Malania oleifera } & 赫头果 & II & 易危 & 刘雄民 & 蒜头果挥发油提取及化学成分分析 \\
\hline & & & /VU & & \\
\hline \multirow[t]{2}{*}{ Malania oleifera } & 蒜头果 & II & 易危 & 袁燕 & 蒜头果凝集素的提取及血凝效果研究 \\
\hline & & & /VU & & \\
\hline
\end{tabular}


顾垒，闻丞，罗玫，王吴，吕植. 中国最受关注濒危物种保护现状快速评价的新方法探讨. 生物多样性，2015，23(5)：583-590. http://www. biodiversity-science. net/CN/article/downloadArticleFile. do?attachType=PDF\&id=10075

\begin{tabular}{|c|c|c|c|c|c|}
\hline Malania oleifera & 蒜头果 & II & $\begin{array}{l}\text { 易危 } \\
\text { /VU }\end{array}$ & 刘雄民 & 蒜头果皮果肉抗氧化成分提取及其抗氧化性质研究 \\
\hline Malania oleifera & 赫头果 & II & $\begin{array}{l}\text { 易危 } \\
\text { /VU }\end{array}$ & 吴彦琼 & 蒜头果生殖生物学特性研究 \\
\hline Malania oleifera & 赫头果 & II & $\begin{array}{l}\text { 易危 } \\
\text { /VU }\end{array}$ & 潘晓芳 & 蒜头果他感作用的初步研究 \\
\hline Malania oleifera & 蒜头果 & II & $\begin{array}{l}\text { 易危 } \\
\text { /VU }\end{array}$ & 陈放 & 蒜头果细胞悬浮培养的研究 \\
\hline Malania oleifera & 蒜头果 & II & $\begin{array}{l}\text { 易危 } \\
\text { /VU }\end{array}$ & 刘雄民 & 蒜头果有效成分及其生物活性研究 \\
\hline Malania oleifera & 赫头果 & II & $\begin{array}{l}\text { 易危 } \\
\text { /VU }\end{array}$ & 袁燕 & 蒜头果中黄酮类化合物的提取及含量测定 \\
\hline Malania oleifera & 蒜头果 & II & $\begin{array}{l}\text { 易危 } \\
\text { /VU }\end{array}$ & 刘雄民 & 蒜头果中金属元素与多糖的研究 \\
\hline Malania oleifera & 蒜头果 & II & $\begin{array}{l}\text { 易危 } \\
\text { /VU }\end{array}$ & 袁燕 & 蒜头果中一种新的植物蛋白(malanin)的分离纯化 \\
\hline Malania oleifera & 蒜头果 & II & $\begin{array}{l}\text { 易危 } \\
\text { /VU }\end{array}$ & 熊英 & 蒜头果种腐病病原菌生物学特性的研究 \\
\hline Malania oleifera & 赫头果 & II & 易危 & 熊英 & 蒜头果种腐病研究初报 \\
\hline
\end{tabular}


顾垒，闻丞，罗玫，王吴，吕植. 中国最受关注濒危物种保护现状快速评价的新方法探讨. 生物多样性，2015，23(5)：583-590. http://www. biodiversity-science. net/CN/article/downloadArticleFile. do?attachType=PDF\&id=10075

\begin{tabular}{|c|c|c|c|c|c|}
\hline & & & $/ \mathrm{VU}$ & & \\
\hline \multirow[t]{2}{*}{ Malania oleifera } & 蒜头果 & II & 易危 & 熊英 & 蒜头果种腐率高的原因探究 \\
\hline & & & /VU & & \\
\hline \multirow[t]{2}{*}{ Malania oleifera } & 赫头果 & II & 易危 & 彭琼 & 蒜头果种仁的化学成分分析 \\
\hline & & & /VU & & \\
\hline \multirow[t]{2}{*}{ Malania oleifera } & 蒜头果 & II & 易危 & 赖家业 & 蒜头果种子育苗试验初报 \\
\hline & & & /VU & & \\
\hline \multirow[t]{2}{*}{ Malania oleifera } & 蒜头果 & II & 易危 & 韦鹏霄 & 蒜头果组培微繁体系的建立及细胞悬浮培养技术研究 \\
\hline & & & $/ \mathrm{VU}$ & & \\
\hline \multirow[t]{2}{*}{ Malania oleifera } & 赫头果 & II & 易危 & 石大兴 & 赫头果组织培养体系的建立及细胞悬浮培养技术研究 \\
\hline & & & /VU & & \\
\hline \multirow[t]{2}{*}{ Malania oleifera } & 蒜头果 & II & 易危 & 陈放 & 蒜头果组织培养再生系统的初步研究 \\
\hline & & & /VU & & \\
\hline \multirow[t]{2}{*}{ Malania oleifera } & 蒜头果 & II & 易危 & 赖家业 & 我国特有单种属植物蒜头果的保护与利用研究状况 \\
\hline & & & /VU & & \\
\hline \multirow[t]{2}{*}{ Malania oleifera } & 赫头果 & II & 易危 & 戴晓畅 & 稀有植物赫头果基因组 DNA 提取方法的研究 \\
\hline & & & $/ \mathrm{VU}$ & & \\
\hline \multirow[t]{2}{*}{ Malania oleifera } & 蒜头果 & II & 易危 & 袁燕 & 新的植物毒素蒜头果蛋白的苂光光谱研究 \\
\hline & & & /VU & & \\
\hline
\end{tabular}


顾垒，闻丞，罗玫，王吴，吕植. 中国最受关注濒危物种保护现状快速评价的新方法探讨. 生物多样性，2015，23(5)：583-590. http://www. biodiversity-science. net/CN/article/downloadArticleFile. do?attachType=PDF\&id=10075

\begin{tabular}{|c|c|c|c|c|c|}
\hline Malania oleifera & 蒜头果 & II & $\begin{array}{l}\text { 易危 } \\
\text { /VU }\end{array}$ & 骆绪美 & 引种蒜头果的幼苗生长表现及区位生长差异性分析 \\
\hline Malania oleifera & 赫头果 & II & $\begin{array}{l}\text { 易危 } \\
\text { /VU }\end{array}$ & 韦鹏霄 & 影响蒜头果离体胚乳愈伤组织培养的几种因子 \\
\hline Malania oleifera & 蒜头果 & II & $\begin{array}{l}\text { 易危 } \\
\text { /VU }\end{array}$ & 余慧嵘 & 珍稀濒危树种蒜头果引种育苗技术及生长节律研究 \\
\hline Malania oleifera & 蒜头果 & II & $\begin{array}{l}\text { 易危 } \\
\text { /VU }\end{array}$ & 陈放 & 珍稀濒危植物蒜头果传粉生物学研究 \\
\hline Malania oleifera & 赫头果 & II & $\begin{array}{l}\text { 易危 } \\
\text { /VU }\end{array}$ & 丁俊峰 & 珍稀濒危植物蒜头果果实发芽抑制物研究 \\
\hline Malania oleifera & 蒜头果 & II & $\begin{array}{l}\text { 易危 } \\
\text { /VU }\end{array}$ & 吕仕洪 & 珍稀濒危植物蒜头果天然林优势种群的生态位研究 \\
\hline Malania oleifera & 蒜头果 & II & $\begin{array}{l}\text { 易危 } \\
\text { /VU }\end{array}$ & 陈建华 & 珍稀濒危植物蒜头果种群生命表分析 \\
\hline Malania oleifera & 蒜头果 & II & $\begin{array}{l}\text { 易危 } \\
\text { /VU }\end{array}$ & 陈放 & 珍稀植物蒜头果保护生物学研究 \\
\hline Malania oleifera & 蒜头果 & II & $\begin{array}{l}\text { 易危 } \\
\text { /VU }\end{array}$ & 赖家业 & 珍稀植物蒜头果组织培养的研究 \\
\hline Manglietia aromatica & 香木莲 & II & 易危 & 马小英 & 2 种木莲光合生理特性研究及光响应校正模型的应用 \\
\hline
\end{tabular}


顾垒，闻丞，罗玫，王吴，吕植. 中国最受关注濒危物种保护现状快速评价的新方法探讨. 生物多样性，2015，23(5)：583-590. http://www. biodiversity-science. net/CN/article/downloadArticleFile. do?attachType=PDF\&id=10075

\begin{tabular}{|c|c|c|c|c|c|}
\hline & & & $/ \mathrm{VU}$ & & \\
\hline \multirow[t]{2}{*}{ Manglietia aromatica } & 香木莲 & II & 易危 & 汪玉林 & 8 种木兰科树种苗期在呈贡的适应性研究 \\
\hline & & & $/ \mathrm{VU}$ & & \\
\hline \multirow[t]{2}{*}{ Manglietia aromatica } & 香木莲 & II & 易危 & 龚洵 & 濒危植物香木莲的胚胎学研究 \\
\hline & & & /VU & & \\
\hline \multirow[t]{2}{*}{ Manglietia aromatica } & 香木莲 & II & 易危 & 姜霞 & 木兰科主要树种幼苗的光合生理特征比较 \\
\hline & & & /VU & & \\
\hline \multirow[t]{2}{*}{ Manglietia aromatica } & 香木莲 & II & 易危 & 彭长连 & 三种濒危木兰植物幼树光合特性对高温的响应 \\
\hline & & & $/ \mathrm{VU}$ & & \\
\hline \multirow[t]{2}{*}{ Manglietia aromatica } & 香木莲 & II & 易危 & 黎明 & 香木莲对短时低温胁迫处理的生理生态响应 \\
\hline & & & $/ \mathrm{VU}$ & & \\
\hline \multirow[t]{2}{*}{ Manglietia aromatica } & 香木莲 & II & 易危 & 李福秀 & 香木莲扞插繁殖初报 \\
\hline & & & /VU & & \\
\hline \multirow[t]{2}{*}{ Manglietia grandis } & 大果木莲 & II & 易危 & 汪玉林 & 8 种木兰科树种苗期在呈贡的适应性研究 \\
\hline & & & /VU & & \\
\hline \multirow[t]{2}{*}{ Manglietia grandis } & 大果木莲 & II & 易危 & 陈少瑜 & 濒危植物大果木莲与中缅木莲的花部特征及繁育系统比较 \\
\hline & & & /VU & & \\
\hline \multirow[t]{2}{*}{ Manglietia grandis } & 大果木莲 & II & 易危 & 陈少瑜 & 濒危植物大果木莲种群格局及濒危原因分析 \\
\hline & & & /VU & & \\
\hline
\end{tabular}


顾垒，闻丞，罗玫，王吴，吕植. 中国最受关注濒危物种保护现状快速评价的新方法探讨. 生物多样性，2015，23(5)：583-590. http://www biodiversity-science. net/CN/article/downloadArticleFile. do?attachType=PDF\&id=10075

\begin{tabular}{|c|c|c|c|c|c|}
\hline Manglietia grandis & 大果木莲 & II & $\begin{array}{l}\text { 易危 } \\
\text { /VU }\end{array}$ & 董文洣 & 不同抚育措施对大果木莲生长的影响 \\
\hline Manglietia grandis & 大果木莲 & II & $\begin{array}{l}\text { 易危 } \\
\text { /VU }\end{array}$ & 徐亮 & 大果木莲的花部数量变异研究 \\
\hline Manglietia grandis & 大果木莲 & II & $\begin{array}{l}\text { 易危 } \\
\text { /VU }\end{array}$ & 张品英 & 大果木莲的育苗技术 \\
\hline Manglietia grandis & 大果木莲 & II & $\begin{array}{l}\text { 易危 } \\
\text { /VU }\end{array}$ & 杨卫 & 大果木莲天然林地土壤特性及其枝叶磷含量的研究 \\
\hline Manglietia grandis & 大果木莲 & II & $\begin{array}{l}\text { 易危 } \\
\text { /VU }\end{array}$ & 李宗艳 & 大果木莲种子冷藏初期糖代谢和蛋白质代谢的变化 \\
\hline Manglietia grandis & 大果木莲 & II & $\begin{array}{l}\text { 易危 } \\
\text { /VU }\end{array}$ & 孙卫邦 & 极度濒危植物大果木莲种子的休眠与萌发 \\
\hline Manglietia grandis & 大果木莲 & II & $\begin{array}{l}\text { 易危 } \\
\text { /VU }\end{array}$ & 徐涛 & 极危物种大果木莲麻栗坡种群分布研究 \\
\hline Manglietia grandis & 大果木莲 & II & $\begin{array}{l}\text { 易危 } \\
\text { /VU }\end{array}$ & 陈少瑜 & 麻栗坡大果木莲的居群结构及动态研究 \\
\hline Manglietia grandis & 大果木莲 & II & $\begin{array}{l}\text { 易危 } \\
\text { /VU }\end{array}$ & 陈少瑜 & 木兰科濒危植物大果木莲遗传多样性的 ISSR 分析 \\
\hline Manglietia grandis & 大果木莲 & II & 易危 & 彭长连 & 三种濒危木兰植物幼树光合特性对高温的响应 \\
\hline
\end{tabular}


顾垒，闻丞，罗玫，王吴，吕植. 中国最受关注濒危物种保护现状快速评价的新方法探讨. 生物多样性，2015，23(5)：583-590. http://www. biodiversity-science. net/CN/article/downloadArticleFile. do?attachType=PDF\&id=10075

\begin{tabular}{|c|c|c|c|c|c|}
\hline & & & $/ \mathrm{VU}$ & & \\
\hline \multirow[t]{2}{*}{ Manglietia grandis } & 大果木莲 & II & 易危 & 陈少瑜 & 珍稀濒危植物大果木莲 ISSR-PCR 反应体系的建立 \\
\hline & & & $/ \mathrm{VU}$ & & \\
\hline \multirow[t]{2}{*}{ Manglietia grandis } & 大果木莲 & II & 易危 & 陈少瑜 & 中缅木莲与大果木莲种子形态特征及萌发特性的比较 \\
\hline & & & /VU & & \\
\hline \multirow[t]{2}{*}{ Manglietia megaphylla } & 大叶木莲 & II & 易危 & 彭长连 & 三种濒危木兰植物幼树光合特性对高温的响应 \\
\hline & & & $/ \mathrm{VU}$ & & \\
\hline \multirow[t]{3}{*}{ Manglietia patungensis } & 巴东木莲 & 未列 & 未评 & 杨秋生 & 21 种木兰科常绿植物的遗传多样性分析 \\
\hline & & 入 & 价 & & \\
\hline & & & $/ \mathrm{NE}$ & & \\
\hline \multirow[t]{3}{*}{ Manglietia patungensis } & 巴东木莲 & 未列 & 未评 & 陈发菊 & 22 种木莲属植物亲缘关系的 ISSR 分析 \\
\hline & & 入 & 价 & & \\
\hline & & & $/ \mathrm{NE}$ & & \\
\hline \multirow[t]{3}{*}{ Manglietia patungensis } & 巴东木莲 & 未列 & 未评 & 林新春 & 9 种木兰科植物的花粉形态观察 \\
\hline & & 入 & 价 & & \\
\hline & & & $/ \mathrm{NE}$ & & \\
\hline \multirow[t]{3}{*}{ Manglietia patungensis } & 巴东木莲 & 未列 & 未评 & 李晓玲 & 巴东木莲 DNA 的提取及 SRAP- PCR 反应体系的正交优化 \\
\hline & & 入 & 价 & & \\
\hline & & & $/ \mathrm{NE}$ & & \\
\hline
\end{tabular}


顾垒，闻丞，罗玫，王吴，吕植. 中国最受关注濒危物种保护现状快速评价的新方法探讨. 生物多样性，2015，23(5)：583-590. http://www. biodiversity-science. net/CN/article/downloadArticleFile. do?attachType=PDF\&id=10075

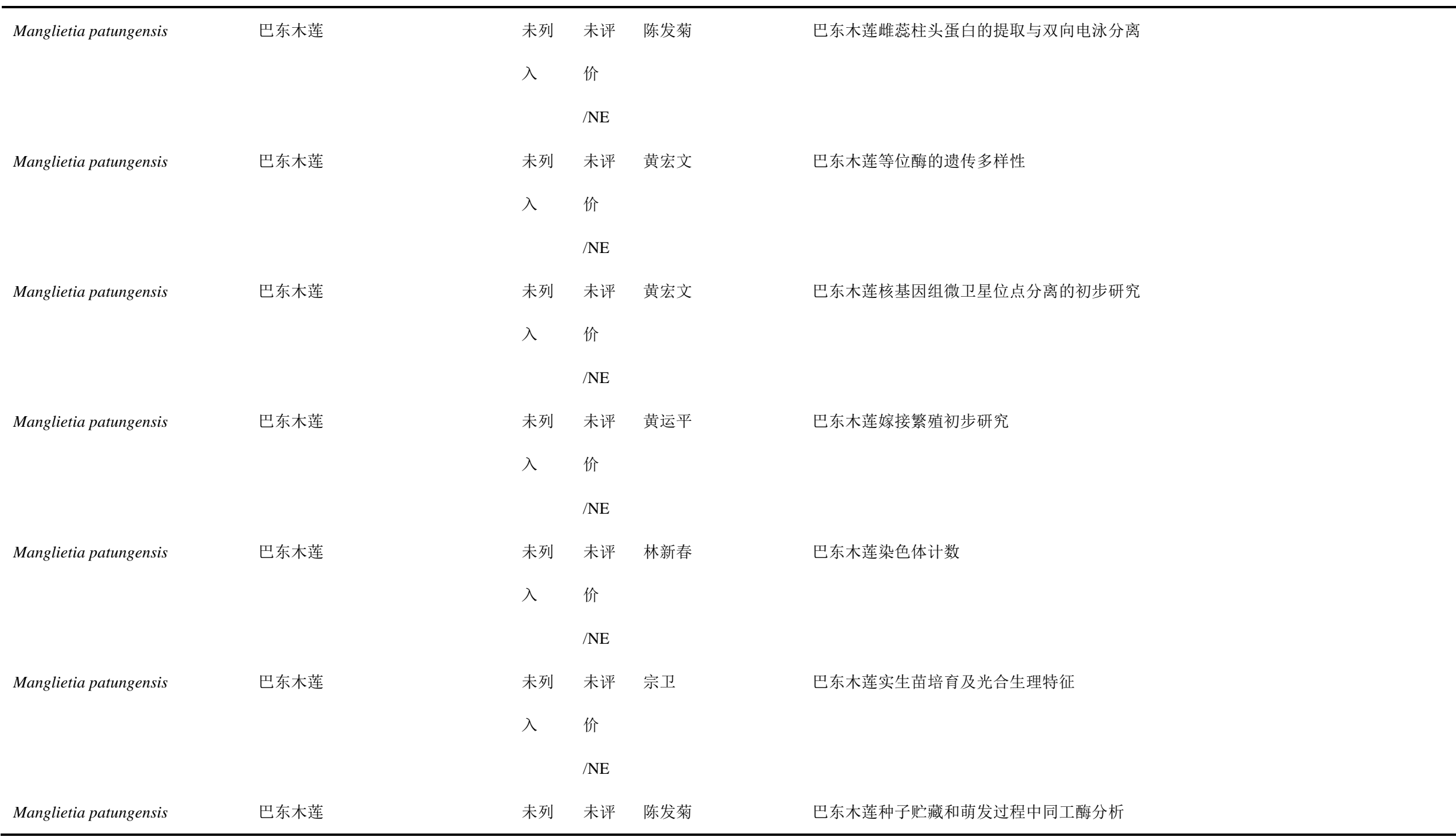


顾垒，闻丞，罗玫，王吴，吕植. 中国最受关注濒危物种保护现状快速评价的新方法探讨. 生物多样性，2015，23(5)：583-590. http://www. biodiversity-science. net/CN/article/downloadArticleFile. do?attachType=PDF\&id=10075

\begin{tabular}{|c|c|c|c|c|c|}
\hline & & 入 & 价 & & \\
\hline Manglietia patungensis & 巴东木莲 & $\begin{array}{l}\text { 未列 } \\
\text { 入 }\end{array}$ & $\begin{array}{l}\text { /NE } \\
\text { 未评 } \\
\text { 价 }\end{array}$ & 黄宏文 & 濒危物种巴东木莲的等位酶遗传多样性及其保护策略 \\
\hline Manglietia patungensis & 巴东木莲 & $\begin{array}{l}\text { 未列 } \\
\text { 入 }\end{array}$ & $\begin{array}{l}\text { /NE } \\
\text { 未评 } \\
\text { 价 }\end{array}$ & 黄宏文 & 濒危物种巴东木莲等位酶遗传变异的空间自相关分析 \\
\hline Manglietia patungensis & 巴东木莲 & $\begin{array}{l}\text { 未列 } \\
\lambda\end{array}$ & $\begin{array}{l}\text { /NE } \\
\text { 未评 } \\
\text { 价 }\end{array}$ & 陈发菊 & 濒危植物巴东木莲 I S S R 分子标记技术体系的建立 \\
\hline Manglietia patungensis & 巴东木莲 & $\begin{array}{l}\text { 未列 } \\
入\end{array}$ & $\begin{array}{l}\text { /NE } \\
\text { 未评 } \\
\text { 价 }\end{array}$ & 何正权 & 濒危植物巴东木莲 RAPD 扩增反应体系的建立 \\
\hline Manglietia patungensis & 巴东木莲 & $\begin{array}{l}\text { 未列 } \\
入\end{array}$ & $\begin{array}{l}\text { /NE } \\
\text { 未评 } \\
\text { 价 }\end{array}$ & 李建强 & 濒危植物巴东木莲的分布及保护策略 \\
\hline Manglietia patungensis & 巴东木莲 & $\begin{array}{l}\text { 未列 } \\
\text { 入 }\end{array}$ & $\begin{array}{l}/ \mathrm{NE} \\
\text { 未评 } \\
\text { 价 }\end{array}$ & 李建强 & 濒危植物巴东木莲花粉母细胞减数分裂观察 \\
\hline
\end{tabular}


顾垒，闻丞，罗玫，王吴，吕植. 中国最受关注濒危物种保护现状快速评价的新方法探讨. 生物多样性，2015，23(5)：583-590. http://www. biodiversity-science. net/CN/article/downloadArticleFile. do?attachType=PDF\&id=10075

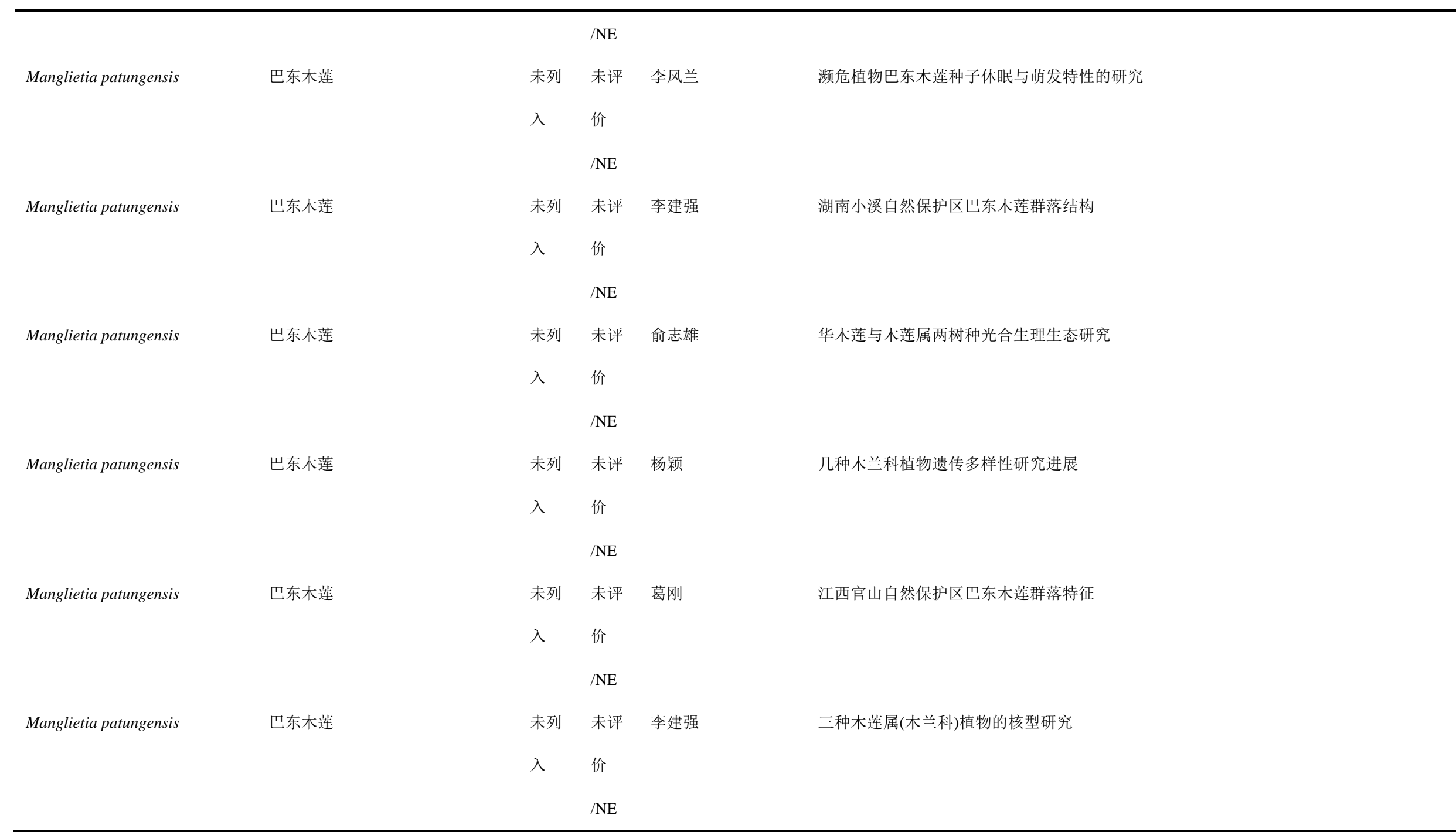


顾垒，闻丞，罗玫，王吴，吕植. 中国最受关注濒危物种保护现状快速评价的新方法探讨. 生物多样性，2015，23(5)：583-590. http://www. biodiversity-science. net/CN/article/downloadArticleFile. do?attachType=PDF\&id=10075

\begin{tabular}{|c|c|c|c|c|c|}
\hline \multirow[t]{2}{*}{ Manglietia patungensis } & 巴东木莲 & 未列 & 未评 & 陈发菊 & 长江三峡珍稀植物一一巴东木莲冬芽的组织培养 \\
\hline & & 入 & $\begin{array}{l}\text { 价 } \\
\text { /NE }\end{array}$ & & \\
\hline \multirow[t]{3}{*}{ Manglietia patungensis } & 巴东木莲 & 未列 & 未评 & 李风兰 & 珍稀濒危植物巴东木莲胚胎学研究 \\
\hline & & 入 & 价 & & \\
\hline & & & $/ \mathrm{NE}$ & & \\
\hline \multirow[t]{2}{*}{ Manglietia sinica } & 华盖木 & I & 极危 & 楚永兴 & 华盖木扦插育苗技术 \\
\hline & & & /CR & & \\
\hline \multirow[t]{2}{*}{ Manglietia sinica } & 华盖木 & I & 极危 & 袁永俊 & 华盖木生存现状及其保护对策 \\
\hline & & & /CR & & \\
\hline \multirow[t]{2}{*}{ Manglietia sinica } & 华盖木 & I & 极危 & 马明东 & 华盖木组织培养过程中 PPO 活性及总酚含量与褐化的关系研究 \\
\hline & & & /CR & & \\
\hline \multirow[t]{2}{*}{ Manglietia sinica } & 华盖木 & I & 极危 & 马明东 & 华盖木组织培养中褐化控制研究 \\
\hline & & & $/ \mathrm{CR}$ & & \\
\hline \multirow[t]{2}{*}{ Manglietia sinica } & 华盖木 & I & 极危 & 孙卫邦 & 极度濒危植物华盖木的种子休眠与萌发 \\
\hline & & & $/ \mathrm{CR}$ & & \\
\hline \multirow[t]{2}{*}{ Manglietia sinica } & 华盖木 & I & 极危 & 田昆 & 木兰科濒危植物华盖木的生境脆弱性 \\
\hline & & & /CR & & \\
\hline Manglietia sinica & 华盖木 & I & 极危 & 马明东 & 培养基激素组成对华盖木腋芽萌发的影响 \\
\hline
\end{tabular}


顾垒，闻丞，罗玫，王吴，吕植. 中国最受关注濒危物种保护现状快速评价的新方法探讨. 生物多样性，2015，23(5)：583-590. http://www. biodiversity-science. net/CN/article/downloadArticleFile. do?attachType=PDF\&id=10075

\begin{tabular}{|c|c|c|c|c|c|}
\hline & & & /CR & & \\
\hline \multirow[t]{2}{*}{ Manis pentadactyla } & 穿山甲 & II & 濒危 & 赵玉波 & 穿山甲的驯养与管理 \\
\hline & & & $/$ EN & & \\
\hline \multirow[t]{2}{*}{ Manis pentadactyla } & 穿山甲 & II & 濒危 & 刘曦庆 & 穿山甲的走私贸易概况_物种鉴定与形态比较 \\
\hline & & & /EN & & \\
\hline \multirow[t]{2}{*}{ Manis pentadactyla } & 穿山甲 & II & 濒危 & 吴诗宝 & 穿山甲洞穴生态学初步研究 \\
\hline & & & /EN & & \\
\hline \multirow[t]{2}{*}{ Manis pentadactyla } & 穿山甲 & II & 濒危 & 鲁庆彬 & 穿山甲日粮适宜配方的优化篮选 \\
\hline & & & /EN & & \\
\hline \multirow[t]{2}{*}{ Manis pentadactyla } & 穿山甲 & II & 濒危 & 吴诗宝 & 穿山甲生态学研究概况 \\
\hline & & & /EN & & \\
\hline \multirow[t]{2}{*}{ Manis pentadactyla } & 穿山甲 & II & 濒危 & 向建洲 & 穿山甲心脏的组织结构研究 \\
\hline & & & /EN & & \\
\hline \multirow[t]{2}{*}{ Manis pentadactyla } & 穿山甲 & II & 濒危 & 程地芸 & 穿山甲在人工饲养条件下的食物研究 \\
\hline & & & /EN & & \\
\hline \multirow[t]{2}{*}{ Manis pentadactyla } & 穿山甲 & II & 濒危 & 张立 & 穿山甲种群概况及保护 \\
\hline & & & /EN & & \\
\hline \multirow[t]{2}{*}{ Manis pentadactyla } & 穿山甲 & II & 濒危 & 吴诗宝 & 大雾岭保护区穿山甲冬季生境选择 \\
\hline & & & /EN & & \\
\hline
\end{tabular}


顾垒，闻丞，罗玫，王吴，吕植. 中国最受关注濒危物种保护现状快速评价的新方法探讨. 生物多样性，2015，23(5)：583-590. http://www. biodiversity-science. net/CN/article/downloadArticleFile. do?attachType=PDF\&id=10075

\begin{tabular}{|c|c|c|c|c|c|}
\hline Manis pentadactyla & 穿山甲 & II & $\begin{array}{l}\text { 濒危 } \\
\text { /EN }\end{array}$ & 吴诗宝 & 广东省穿山甲种群数量调查与资源蕴藏量 \\
\hline Manis pentadactyla & 穿山甲 & II & $\begin{array}{l}\text { 濒危 } \\
\text { /EN }\end{array}$ & 高赛飞 & 蛤蚧微卫星位点的笚选及微卫星标记在穿山甲个体识别中的应用 \\
\hline Manis pentadactyla & 穿山甲 & II & $\begin{array}{l}\text { 濒危 } \\
\text { /EN }\end{array}$ & 覃屏生 & 基于线粒体基因组的穿山甲系统发育研究 \\
\hline Manis pentadactyla & 穿山甲 & II & $\begin{array}{l}\text { 濒危 } \\
\text { /EN }\end{array}$ & 徐良 & 名贵中药穿山甲的规范化养殖技术 \\
\hline Manis pentadactyla & 穿山甲 & II & $\begin{array}{l}\text { 濒危 } \\
\text { /EN }\end{array}$ & 王才益 & 人工饲养穿山甲行为的观察 \\
\hline Manis pentadactyla & 穿山甲 & II & $\begin{array}{l}\text { 濒危 } \\
\text { /EN }\end{array}$ & 高赛飞 & 微卫星标记在穿山甲个体识别中的应用 \\
\hline Manis pentadactyla & 穿山甲 & II & $\begin{array}{l}\text { 濒危 } \\
\text { /EN }\end{array}$ & 李旭 & 西双版纳地区穿山甲取食的几种蚂蚁营养成分分析 \\
\hline Manis pentadactyla & 穿山甲 & II & $\begin{array}{l}\text { 濒危 } \\
\text { /EN }\end{array}$ & 吴诗宝 & 中国穿山甲的食性与受食行为初步观察 \\
\hline Manis pentadactyla & 穿山甲 & II & $\begin{array}{l}\text { 濒危 } \\
\text { /EN }\end{array}$ & 吴诗宝 & 中国穿山甲和马来穿山甲头骨量度的测定及比较 \\
\hline Manis pentadactyla & 穿山甲 & II & 濒危 & 吴诗宝 & 中国穿山甲受危状况评估 \\
\hline
\end{tabular}


顾垒，闻丞，罗玫，王吴，吕植. 中国最受关注濒危物种保护现状快速评价的新方法探讨. 生物多样性，2015，23(5)：583-590. http://www. biodiversity-science. net/CN/article/downloadArticleFile. do?attachType=PDF\&id=10075

\begin{tabular}{|c|c|c|c|c|c|}
\hline & & & /EN & & \\
\hline \multirow[t]{2}{*}{ Manis pentadactyla } & 穿山甲 & II & 濒危 & 唐松元 & 中国穿山甲体征及内脏器官解剖学观察 \\
\hline & & & /EN & & \\
\hline \multirow[t]{2}{*}{ Manis pentadactyla } & 穿山甲 & II & 濒危 & 周昭敏 & 中国穿山甲与爪哇穿山甲甲片异速生长分析及其在司法鉴定中的应用 \\
\hline & & & /EN & & \\
\hline \multirow[t]{2}{*}{ Manis pentadactyla } & 穿山甲 & II & 濒危 & 吴诗宝 & 中国兽类一新纪录一一爪哇穿山甲 \\
\hline & & & /EN & & \\
\hline \multirow[t]{2}{*}{ Manis pentadactyla } & 穿山甲 & II & 濒危 & 胡诗佳 & 中华穿山甲的研究及保护现状 \\
\hline & & & /EN & & \\
\hline \multirow[t]{2}{*}{ Manis pentadactyla } & 穿山甲 & II & 濒危 & 豆市荣 & 中华穿山甲线粒体基因组及分子系统学研究 \\
\hline & & & /EN & & \\
\hline \multirow[t]{2}{*}{ Manouria impressa } & 凹甲陆龟 & II & 易危 & 赛道建 & 凹甲陆龟的泌尿生殖系统 \\
\hline & & & /VU & & \\
\hline \multirow[t]{2}{*}{ Martes flavigula } & 黄喉貂 & II & 无危 & 张建军 & 黄喉貂生态特性的初步观察 \\
\hline & & & $/ \mathrm{LC}$ & & \\
\hline \multirow[t]{2}{*}{ Martes flavigula } & 黄喉貂 & II & 无危 & 廖谢茗 & 黄喉貂直针毛扫描电镜特征观察 \\
\hline & & & $/ \mathrm{LC}$ & & \\
\hline \multirow[t]{2}{*}{ Martes flavigula } & 黄喉貂 & II & 无危 & 周正 & 辽宁首次发现兽类分布新记录一黄喉貂 \\
\hline & & & /LC & & \\
\hline
\end{tabular}


顾垒，闻丞，罗玫，王吴，吕植. 中国最受关注濒危物种保护现状快速评价的新方法探讨. 生物多样性，2015，23(5)：583-590. http://www. biodiversity-science. net/CN/article/downloadArticleFile. do?attachType=PDF\&id=10075

\begin{tabular}{|c|c|c|c|c|c|}
\hline \multirow[t]{2}{*}{ Martes foina } & 石貂 & II & 无危 & 李维红 & 旱獭、戕鼠、兔狲、青鼠、石貂毛线纤维超微结构比较 \\
\hline & & & $/ \mathrm{LC}$ & & \\
\hline \multirow[t]{2}{*}{ Martes foina } & 石貂 & II & 无危 & 吴建国 & 气候变化对 6 种荒漠动物分布的潜在影响 \\
\hline & & & $/ \mathrm{LC}$ & & \\
\hline \multirow[t]{2}{*}{ Mauremys mutica } & 黄喉拟水龟 & 未列 & 濒危 & 李贵生 & 3 种龟卵的孵化研究 \\
\hline & & $\lambda$ & /EN & & \\
\hline \multirow[t]{2}{*}{ Mauremys mutica } & 黄喉拟水龟 & 未列 & 濒危 & Chau-Hwa Chi & Hematologic and plasma biochemical reference values of the yellow pond turtle Mauremys \\
\hline & & 入 & /EN & & mutica and the effects of sex and season \\
\hline \multirow[t]{2}{*}{ Mauremys mutica } & 黄喉拟水龟 & 未列 & 濒危 & Rong-Quan Zheng & Isolation and characterization of 14 polymorphic microsatellite loci in the Asian yellow pond \\
\hline & & 入 & /EN & & turtle,Mauremys mutica(Cantor, 1842) \\
\hline \multirow[t]{2}{*}{ Mauremys mutica } & 黄喉拟水龟 & 未列 & 濒危 & 周贵潭 & I 龄乌龟与黄喉拟水龟生长的初步研究 \\
\hline & & 入 & /EN & & \\
\hline \multirow[t]{2}{*}{ Mauremys mutica } & 黄喉拟水龟 & 未列 & 濒危 & Xinping Zhu & Molecular Characterization and Expression Analysis of VSIG4 from the Asian Yellow Pond \\
\hline & & 入 & /EN & & Turtle,Mauremys mutica \\
\hline \multirow[t]{2}{*}{ Mauremys mutica } & 黄喉拟水龟 & 未列 & 濒危 & Chau-Hwa Chi & Observations on the Female Reproductive Cycles of Captive Asian Yellow Pond Turtles \\
\hline & & 入 & /EN & & (Mauremys mutica) With Radiography and Ultrasonography \\
\hline \multirow[t]{2}{*}{ Mauremys mutica } & 黄喉拟水龟 & 未列 & 濒危 & Wei-Guo Du & Optimal temperatures for egg incubation in two Geoemydid turtles:Ocadia sinensis and \\
\hline & & 入 & /EN & & Mauremys mutica \\
\hline Mauremys mutica & 黄喉拟水龟 & 未列 & 濒危 & 周维官 & 不同蛋白质水平的饵料对黄喉拟水龟生长影响的研究 \\
\hline
\end{tabular}


顾垒，闻丞，罗玫，王吴，吕植. 中国最受关注濒危物种保护现状快速评价的新方法探讨. 生物多样性，2015，23(5)：583-590. http://www. biodiversity-science. net/CN/article/downloadArticleFile. do?attachType=PDF\&id=10075

\begin{tabular}{|c|c|c|c|c|c|}
\hline & & 入 & $/ \mathrm{EN}$ & & \\
\hline \multirow[t]{2}{*}{ Mauremys mutica } & 黄喉拟水龟 & 未列 & 濒危 & 魏成清 & 不同饵料对黄喉拟水龟稚龟生长的影响 \\
\hline & & 入 & $/ \mathrm{EN}$ & & \\
\hline \multirow[t]{2}{*}{ Mauremys mutica } & 黄喉拟水龟 & 未列 & 濒危 & 周维官 & 不同饵料养殖黄喉拟水龟效果的研究 \\
\hline & & 入 & $/ \mathrm{EN}$ & & \\
\hline \multirow[t]{2}{*}{ Mauremys mutica } & 黄喉拟水龟 & 未列 & 濒危 & 覃国森 & 不同养殖方式下黄喉拟水龟的增重及其经济效益的对比研究 \\
\hline & & 入 & $/ \mathrm{EN}$ & & \\
\hline \multirow[t]{2}{*}{ Mauremys mutica } & 黄喉拟水龟 & 未列 & 濒危 & 赵忠添 & 黄喉拟水龟 “白眼病” 防治初探 \\
\hline & & 入 & /EN & & \\
\hline \multirow[t]{2}{*}{ Mauremys mutica } & 黄喉拟水龟 & 未列 & 濒危 & 赵忠添 & 黄喉拟水龟"白眼病"防治初探 \\
\hline & & 入 & /EN & & \\
\hline \multirow[t]{2}{*}{ Mauremys mutica } & 黄喉拟水龟 & 未列 & 濒危 & 朱新平 & 黄喉拟水龟(早)与三线闭壳龟(令)杂交后代的形态特征及其与父母本的比较研究 \\
\hline & & 入 & /EN & & \\
\hline \multirow[t]{2}{*}{ Mauremys mutica } & 黄喉拟水龟 & 未列 & 濒危 & 朱新平 & 黄喉拟水龟、三线闭壳龟、鲻龟的生长比较研究 \\
\hline & & 入 & /EN & & \\
\hline \multirow[t]{2}{*}{ Mauremys mutica } & 黄喉拟水龟 & 未列 & 濒危 & 何成伟 & 黄喉拟水龟 “ 腐壳病” 的病原分离与鉴定 \\
\hline & & 入 & $/ \mathrm{EN}$ & & \\
\hline \multirow[t]{2}{*}{ Mauremys mutica } & 黄喉拟水龟 & 未列 & 濒危 & 龙建杰 & 黄喉拟水龟 CCL20 基因序列特征及表达分析 \\
\hline & & 入 & $/ \mathrm{EN}$ & & \\
\hline
\end{tabular}


顾垒，闻丞，罗玫，王吴，吕植. 中国最受关注濒危物种保护现状快速评价的新方法探讨. 生物多样性，2015，23(5)：583-590. http://www. biodiversity-science. net/CN/article/downloadArticleFile. do?attachType=PDF\&id=10075

\begin{tabular}{|c|c|c|c|c|c|}
\hline \multirow[t]{2}{*}{ Mauremys mutica } & 黄喉拟水龟 & 未列 & 濒危 & 朱新平 & 黄喉拟水龟产卵行为的观察 \\
\hline & & 入 & $/ \mathrm{EN}$ & & \\
\hline \multirow[t]{2}{*}{ Mauremys mutica } & 黄喉拟水龟 & 未列 & 濒危 & 朱新平 & 黄喉拟水龟雌、雄生长及形态差异 \\
\hline & & 入 & $/ \mathrm{EN}$ & & \\
\hline \multirow[t]{2}{*}{ Mauremys mutica } & 黄喉拟水龟 & 未列 & 濒危 & 朱新平 & 黄喉拟水龟的繁殖生物学研究 \\
\hline & & 入 & /EN & & \\
\hline \multirow[t]{2}{*}{ Mauremys mutica } & 黄喉拟水龟 & 未列 & 濒危 & 于明泉 & 黄喉拟水龟的人工养殖技术 \\
\hline & & 入 & /EN & & \\
\hline \multirow[t]{2}{*}{ Mauremys mutica } & 黄喉拟水龟 & 未列 & 濒危 & 周维官 & 黄喉拟水龟的研究进展 \\
\hline & & 入 & $/ \mathrm{EN}$ & & \\
\hline \multirow[t]{2}{*}{ Mauremys mutica } & 黄喉拟水龟 & 未列 & 濒危 & 何成伟 & 黄喉拟水龟腹泻病的病原分离与鉴定 \\
\hline & & 入 & $/ \mathrm{EN}$ & & \\
\hline \multirow[t]{2}{*}{ Mauremys mutica } & 黄喉拟水龟 & 未列 & 濒危 & 赵春光 & 黄喉拟水龟高效生态养殖技术研究 \\
\hline & & 入 & $/ \mathrm{EN}$ & & \\
\hline \multirow[t]{2}{*}{ Mauremys mutica } & 黄喉拟水龟 & 未列 & 濒危 & 赵春光 & 黄喉拟水龟工厂化控温养殖试验 \\
\hline & & 入 & /EN & & \\
\hline \multirow[t]{2}{*}{ Mauremys mutica } & 黄喉拟水龟 & 未列 & 濒危 & 宋娇莲 & 黄喉拟水龟和四眼斑水龟线粒体全序列分析及龟鳖类系统发生关系的讨论 \\
\hline & & 入 & $/ \mathrm{EN}$ & & \\
\hline Mauremys mutica & 黄喉拟水龟 & 未列 & 濒危 & 朱新平 & 黄喉拟水龟巨噬细胞炎症蛋白-3a基因的序列特征与组织表达 \\
\hline
\end{tabular}


顾垒，闻丞，罗玫，王吴，吕植. 中国最受关注濒危物种保护现状快速评价的新方法探讨. 生物多样性，2015，23(5)：583-590. http://www. biodiversity-science. net/CN/article/downloadArticleFile. do?attachType=PDF\&id=10075

\begin{tabular}{|c|c|c|c|c|c|}
\hline & & 入 & $/$ EN & & \\
\hline \multirow[t]{2}{*}{ Mauremys mutica } & 黄喉拟水龟 & 未列 & 濒危 & 朱新平 & 黄喉拟水龟巨検细胞炎症蛋白-3a重组表达及抗菌活性分析 \\
\hline & & 入 & $/ \mathrm{EN}$ & & \\
\hline \multirow[t]{2}{*}{ Mauremys mutica } & 黄喉拟水龟 & 未列 & 濒危 & 黎小正 & 黄喉拟水龟摩氏摩根菌的分离鉴定及系统发育分析 \\
\hline & & 入 & $/$ EN & & \\
\hline \multirow[t]{2}{*}{ Mauremys mutica } & 黄喉拟水龟 & 未列 & 濒危 & 况绍祥 & 黄喉拟水龟摩氏摩根菌的分离鉴定及致病性研究 \\
\hline & & 入 & $/ \mathrm{EN}$ & & \\
\hline \multirow[t]{2}{*}{ Mauremys mutica } & 黄喉拟水龟 & 未列 & 濒危 & 朱新平 & 黄喉拟水龟母体大小对繁殖性能的影响 \\
\hline & & 入 & $/$ EN & & \\
\hline \multirow[t]{2}{*}{ Mauremys mutica } & 黄喉拟水龟 & 未列 & 濒危 & 朱新平 & 黄喉拟水龟胚胎发育的观察 \\
\hline & & 入 & $/$ EN & & \\
\hline \multirow[t]{2}{*}{ Mauremys mutica } & 黄喉拟水龟 & 未列 & 濒危 & 赵忠添 & 黄喉拟水龟人工繁殖技术 \\
\hline & & 入 & /EN & & \\
\hline \multirow[t]{2}{*}{ Mauremys mutica } & 黄喉拟水龟 & 未列 & 濒危 & 陈武 & 黄喉拟水龟人工孵化技术的研究 \\
\hline & & 入 & $/$ EN & & \\
\hline \multirow[t]{2}{*}{ Mauremys mutica } & 黄喉拟水龟 & 未列 & 濒危 & 蔡嘉庆 & 黄喉拟水龟人工养殖技术 \\
\hline & & 入 & $/ \mathrm{EN}$ & & \\
\hline \multirow[t]{2}{*}{ Mauremys mutica } & 黄喉拟水龟 & 未列 & 濒危 & 邓厚群 & 黄喉拟水龟生态养殖技术 \\
\hline & & 入 & /EN & & \\
\hline
\end{tabular}


顾垒，闻丞，罗玫，王吴，吕植. 中国最受关注濒危物种保护现状快速评价的新方法探讨. 生物多样性，2015，23(5)：583-590. http://www biodiversity-science. net/CN/article/downloadArticleFile. do?attachType=PDF\&id=10075

\begin{tabular}{|c|c|c|c|c|c|}
\hline \multirow[t]{2}{*}{ Mauremys mutica } & 黄喉拟水龟 & 未列 & 濒危 & 韦信贤 & 黄喉拟水龟松鼠葡萄球菌 16SrDNA 的序列测定和系统进化分析 \\
\hline & & 入 & $/$ EN & & \\
\hline \multirow[t]{2}{*}{ Mauremys mutica } & 黄喉拟水龟 & 未列 & 濒危 & 邹为民 & 黄喉拟水龟体表溃疡病原菌 SG24 的分类鉴定 \\
\hline & & 入 & $/ \mathrm{EN}$ & & \\
\hline \multirow[t]{2}{*}{ Mauremys mutica } & 黄喉拟水龟 & 未列 & 濒危 & 唐群 & 黄喉拟水龟庭院养殖成龟技术初探 \\
\hline & & 入 & /EN & & \\
\hline \multirow[t]{2}{*}{ Mauremys mutica } & 黄喉拟水龟 & 未列 & 濒危 & 桂建芳 & 黄喉拟水龟细胞核 DNA 含量的分析 \\
\hline & & 入 & /EN & & \\
\hline \multirow[t]{2}{*}{ Mauremys mutica } & 黄喉拟水龟 & 未列 & 濒危 & 朱新平 & 黄喉拟水龟一龄龟生长的研究 \\
\hline & & 入 & $/$ EN & & \\
\hline \multirow[t]{2}{*}{ Mauremys mutica } & 黄喉拟水龟 & 未列 & 濒危 & 黎小正 & 黄喉拟水龟一种慢性传染病的病原鉴定与防治 \\
\hline & & 入 & /EN & & \\
\hline \multirow[t]{2}{*}{ Mauremys mutica } & 黄喉拟水龟 & 未列 & 濒危 & 韦信贤 & 黄喉拟水龟致病菌一一松鼠葡萄球菌的分离鉴定及药敏试验 \\
\hline & & 入 & /EN & & \\
\hline \multirow[t]{2}{*}{ Mauremys mutica } & 黄喉拟水龟 & 未列 & 濒危 & 魏成清 & 黄喉拟水龟稚龟的饲养及病害防治研究 \\
\hline & & 入 & $/$ EN & & \\
\hline \multirow[t]{2}{*}{ Mauremys mutica } & 黄喉拟水龟 & 未列 & 濒危 & 朱新平 & 黄喉拟水龟稚龟冬季生长的研究 \\
\hline & & 入 & $/ \mathrm{EN}$ & & \\
\hline Mauremys mutica & 黄喉拟水龟 & 未列 & 濒危 & 覃毅 & 黄喉拟水龟稚龟越冬饲养小实验 \\
\hline
\end{tabular}


顾垒，闻丞，罗玫，王吴，吕植. 中国最受关注濒危物种保护现状快速评价的新方法探讨. 生物多样性，2015，23(5)：583-590. http://www. biodiversity-science. net/CN/article/downloadArticleFile. do?attachType=PDF\&id=10075

\begin{tabular}{|c|c|c|c|c|c|}
\hline & & 入 & $/$ EN & & \\
\hline \multirow[t]{2}{*}{ Mauremys mutica } & 黄喉拟水龟 & 未列 & 濒危 & 高明英 & 黄喉拟水龟转铁蛋白基因的克隆、表达及重组蛋白的抗菌性分析 \\
\hline & & 入 & $/ \mathrm{EN}$ & & \\
\hline \multirow[t]{2}{*}{ Mauremys mutica } & 黄喉拟水龟 & 未列 & 濒危 & 朱新平 & 黄喉拟水龟转铁蛋白基因的克隆以及表达特征分析 \\
\hline & & 入 & $/$ EN & & \\
\hline \multirow[t]{2}{*}{ Mauremys mutica } & 黄喉拟水龟 & 未列 & 濒危 & 朱新平 & 黄喉拟水龟转铁蛋白重组表达及抗菌活性分析 \\
\hline & & 入 & $/$ EN & & \\
\hline \multirow[t]{2}{*}{ Mauremys mutica } & 黄喉拟水龟 & 未列 & 濒危 & 章芸 & 两种淡水龟微卫星标记的篮选及乌龟养殖群体遗传多样性分析 \\
\hline & & 入 & $/$ EN & & \\
\hline \multirow[t]{2}{*}{ Mauremys mutica } & 黄喉拟水龟 & 未列 & 濒危 & 朱新平 & 黏质沙雷氏菌诱导的黄喉拟水龟 SMART cDNA 文库构建及相关基因的鉴定 \\
\hline & & 入 & $/$ EN & & \\
\hline \multirow[t]{2}{*}{ Mauremys mutica } & 黄喉拟水龟 & 未列 & 濒危 & 朱新平 & 人工饲养对黄喉拟水龟繁殖力的影响 \\
\hline & & 入 & $/$ EN & & \\
\hline \multirow[t]{2}{*}{ Mauremys mutica } & 黄喉拟水龟 & 未列 & 濒危 & 吴遵霖 & 三线闭壳龟、黄喉拟水龟、黄缘盒龟及其地方品系外部形态特征比较研究 \\
\hline & & 入 & $/$ EN & & \\
\hline \multirow[t]{2}{*}{ Mauremys mutica } & 黄喉拟水龟 & 未列 & 濒危 & 朱新平 & 三种孵化介质对黄喉拟水龟卵睬化期、孵化成功率和孵出幼体特征的影响 \\
\hline & & 入 & $/ \mathrm{EN}$ & & \\
\hline \multirow[t]{2}{*}{ Mauremys mutica } & 黄喉拟水龟 & 未列 & 濒危 & 陈敏瑶 & 三种介质对黄喉拟水龟孵化率的影响 \\
\hline & & 入 & /EN & & \\
\hline
\end{tabular}


顾垒，闻丞，罗玫，王吴，吕植. 中国最受关注濒危物种保护现状快速评价的新方法探讨. 生物多样性，2015，23(5)：583-590. http://www. biodiversity-science. net/CN/article/downloadArticleFile. do?attachType=PDF\&id=10075

\begin{tabular}{|c|c|c|c|c|c|}
\hline \multirow[t]{2}{*}{ Mauremys mutica } & 黄喉拟水龟 & 未列 & 濒危 & 朱新平 & 湿度对黄喉拟水龟胚胎发育与新生幼体特征的影响 \\
\hline & & 入 & $/ \mathrm{EN}$ & & \\
\hline \multirow[t]{2}{*}{ Mauremys mutica } & 黄喉拟水龟 & 未列 & 濒危 & 朱新平 & 温度、湿度对黄喉拟水龟胚胎发育的影响 \\
\hline & & 入 & $/ \mathrm{EN}$ & & \\
\hline \multirow[t]{2}{*}{ Mauremys mutica } & 黄喉拟水龟 & 未列 & 濒危 & 桂建芳 & 温度对黄喉拟水龟性别决定的影响 \\
\hline & & 入 & /EN & & \\
\hline \multirow[t]{2}{*}{ Mauremys mutica } & 黄喉拟水龟 & 未列 & 濒危 & 李贵生 & 温度对黄喉拟水龟稚龟生长的影响 \\
\hline & & 入 & /EN & & \\
\hline \multirow[t]{2}{*}{ Mauremys mutica } & 黄喉拟水龟 & 未列 & 濒危 & 周贵谭 & 乌龟、黄喉拟水鱼及黄缘盒龟生长特征的比较 \\
\hline & & 入 & /EN & & \\
\hline \multirow[t]{2}{*}{ Mauremys mutica } & 黄喉拟水龟 & 未列 & 濒危 & 李贵生 & 乌龟与黄喉拟水龟稚龟的比较 \\
\hline & & 入 & $/ \mathrm{EN}$ & & \\
\hline \multirow[t]{2}{*}{ Mauremys nigricans } & 广东乌龟 & 未列 & 濒危 & 陈晓艳 & 广东乌龟受水需菌感染后的组织病理观察_付晓艳 \\
\hline & & 入 & /EN & & \\
\hline \multirow[t]{2}{*}{ Mauremys nigricans } & 广东乌龟 & 未列 & 濒危 & 贺刚 & 黑颈乌龟野生群体的形态学分析_贺刚 \\
\hline & & 入 & /EN & & \\
\hline \multirow[t]{2}{*}{ Megophrys omeimontis } & 峨嵋角蟾 & 未列 & 近危 & 卢建利 & 湖北二仙岩亚高山泥炭蘚沼泽湿地两栖爬行动物资源调查 \\
\hline & & 入 & /NT & & \\
\hline Megophrys omeimontis & 峨嵋角蟾 & 未列 & 近危 & 徐剑 & 中国角蟾科动物系统发育研究中的几个问题 \\
\hline
\end{tabular}


顾垒，闻丞，罗玫，王吴，吕植. 中国最受关注濒危物种保护现状快速评价的新方法探讨. 生物多样性，2015，23(5)：583-590. http://www. biodiversity-science. net/CN/article/downloadArticleFile. do?attachType=PDF\&id=10075

\begin{tabular}{|c|c|c|c|c|c|}
\hline & & 入 & /NT & & \\
\hline \multirow[t]{2}{*}{ Melodinus yunnanensis } & 云南山橙 & 未列 & 易危 & Xiang-Hai Cai & Alkaloids from Melodinus yunnanensis \\
\hline & & 入 & $/ \mathrm{VU}$ & & \\
\hline \multirow[t]{2}{*}{ Mergus squamatus } & 中华秋沙鸭 & I & 濒危 & & 广东惠州白盆珠水库中华秋沙鸭越冬群体监测 \\
\hline & & & /EN & & \\
\hline \multirow[t]{2}{*}{ Mergus squamatus } & 中华秋沙鸭 & I & 濒危 & 李小燕 & 广东莲花山白盆珠省级自然保护区鸟类资源调查 \\
\hline & & & /EN & & \\
\hline \multirow[t]{2}{*}{ Mergus squamatus } & 中华秋沙鸭 & I & 濒危 & 宋丽萍 & 黑龙江红星自然保护区湿地保护价值评价 \\
\hline & & & /EN & & \\
\hline \multirow[t]{2}{*}{ Mergus squamatus } & 中华秋沙鸭 & I & 濒危 & 韩九慕 & 衡水湖国家级自然保护区鸟类调查 \\
\hline & & & /EN & & \\
\hline \multirow[t]{2}{*}{ Mergus squamatus } & 中华秋沙鸭 & I & 濒危 & 刘东平 & 湖南沅陵发现中华秋沙鸭越冬种群 \\
\hline & & & /EN & & \\
\hline \multirow[t]{2}{*}{ Mergus squamatus } & 中华秋沙鸭 & I & 濒危 & 张进江 & 黄河三门峡库区的雁鸭类 \\
\hline & & & /EN & & \\
\hline \multirow[t]{2}{*}{ Mergus squamatus } & 中华秋沙鸭 & I & 濒危 & 王加连 & 江苏盐城滩涂湿地雁鸭类资源调查及保护对策 \\
\hline & & & /EN & & \\
\hline \multirow[t]{2}{*}{ Mergus squamatus } & 中华秋沙鸭 & I & 濒危 & 刘武华 & 江西龙虎山中华秋沙鸭自然保护区野生动植物资源调查 \\
\hline & & & /EN & & \\
\hline
\end{tabular}


顾垒，闻丞，罗玫，王吴，吕植. 中国最受关注濒危物种保护现状快速评价的新方法探讨. 生物多样性，2015，23(5)：583-590. http://www. biodiversity-science. net/CN/article/downloadArticleFile. do?attachType=PDF\&id=10075

\begin{tabular}{|c|c|c|c|c|c|}
\hline Mergus squamatus & 中华秋沙鸭 & I & $\begin{array}{l}\text { 濒危 } \\
\text { /EN }\end{array}$ & 邵明勤 & 江西鄱阳湖流域中华秋沙鸭越冬期间的集群特征 \\
\hline Mergus squamatus & 中华秋沙鸭 & I & $\begin{array}{l}\text { 濒危 } \\
\text { /EN }\end{array}$ & 程松林 & 江西武夷山国家级自然保护区鸟类多样性调查 \\
\hline Mergus squamatus & 中华秋沙鸭 & I & $\begin{array}{l}\text { 濒危 } \\
\text { /EN }\end{array}$ & 张绪良 & 胶州湾滨海湿地的水禽多样性特征及保护 \\
\hline Mergus squamatus & 中华秋沙鸭 & I & $\begin{array}{l}\text { 濒危 } \\
\text { /EN }\end{array}$ & 舒特生 & 九岭山国家级自然保护区鸟类资源的研究 \\
\hline Mergus squamatus & 中华秋沙鸭 & I & $\begin{array}{l}\text { 濒危 } \\
\text { /EN }\end{array}$ & 盛显和 & 康山湖区候鸟自然保护区鸟类资源现状及保护 \\
\hline Mergus squamatus & 中华秋沙鸭 & I & $\begin{array}{l}\text { 濒危 } \\
\text { /EN }\end{array}$ & 杜天奎 & 宁夏沙湖自然保护区春季鸟类群落组成及多样性研究 \\
\hline Mergus squamatus & 中华秋沙鸭 & I & $\begin{array}{l}\text { 濒危 } \\
\text { /EN }\end{array}$ & 邵明勤 & 鄱阳湖流域非繁殖期鸟类多样性 \\
\hline Mergus squamatus & 中华秋沙鸭 & I & $\begin{array}{l}\text { 濒危 } \\
\text { /EN }\end{array}$ & 符建荣 & 四川大相岭自然保护区的鸟类资源 \\
\hline Mergus squamatus & 中华秋沙鸭 & I & $\begin{array}{l}\text { 濒危 } \\
\text { /EN }\end{array}$ & 符建荣 & 四川海子山自然保护区鸟类资源及区系 \\
\hline Mergus squamatus & 中华秋沙鸭 & I & 濒危 & 陈顺德 & 四川壤塘县绰斯甲河段鸟类资源初步调查及区系分析 \\
\hline
\end{tabular}


顾垒，闻丞，罗玫，王吴，吕植. 中国最受关注濒危物种保护现状快速评价的新方法探讨. 生物多样性，2015，23(5)：583-590. http://www. biodiversity-science. net/CN/article/downloadArticleFile. do?attachType=PDF\&id=10075

\begin{tabular}{|c|c|c|c|c|c|}
\hline & & & /EN & & \\
\hline \multirow[t]{2}{*}{ Mergus squamatus } & 中华秋沙鸭 & I & 濒危 & 符建荣 & 四川长沙贡玛自然保护区的鸟类资源 \\
\hline & & & /EN & & \\
\hline \multirow[t]{2}{*}{ Mergus squamatus } & 中华秋沙鸭 & I & 濒危 & 韩丽萍 & 唐海湿地和鸟类省级自然保护区乌类资源调查研究 \\
\hline & & & /EN & & \\
\hline \multirow[t]{2}{*}{ Mergus squamatus } & 中华秋沙鸭 & I & 濒危 & 孟德荣 & 天津北大港湿地鸭科鸟类调查 \\
\hline & & & /EN & & \\
\hline \multirow[t]{2}{*}{ Mergus squamatus } & 中华秋沙鸭 & I & 濒危 & 何芬奇 & 繁源鸟类纪录解析 \\
\hline & & & /EN & & \\
\hline \multirow[t]{2}{*}{ Mergus squamatus } & 中华秋沙鸭 & I & 濒危 & 于文涛 & 兴凯湖春季鸟类迁徙监测分析报告 \\
\hline & & & /EN & & \\
\hline \multirow[t]{2}{*}{ Mergus squamatus } & 中华秋沙鸭 & I & 濒危 & 曾宾宾 & 性别和温度对中华秋沙鸭越冬行为的影响 \\
\hline & & & /EN & & \\
\hline \multirow[t]{2}{*}{ Mergus squamatus } & 中华秋沙鸭 & I & 濒危 & 李 国 刚 & 云南省会泽黑颈鹤国家级自然保护区大桥片区水禽资源调查 \\
\hline & & & /EN & & \\
\hline \multirow[t]{2}{*}{ Mergus squamatus } & 中华秋沙鸭 & I & 濒危 & 付俊卿 & 中华秋沙鸭巢址选择及孵化期活动节律 \\
\hline & & & /EN & & \\
\hline \multirow[t]{2}{*}{ Mergus squamatus } & 中华秋沙鸭 & I & 濒危 & 邵明勤 & 中华秋沙鸭冬季行为初步分析 \\
\hline & & & /EN & & \\
\hline
\end{tabular}


顾垒，闻丞，罗玫，王吴，吕植. 中国最受关注濒危物种保护现状快速评价的新方法探讨. 生物多样性，2015，23(5)：583-590. http://www. biodiversity-science. net/CN/article/downloadArticleFile. do?attachType=PDF\&id=10075

\begin{tabular}{|c|c|c|c|c|c|}
\hline Mergus squamatus & 中华秋沙鸭 & I & $\begin{array}{l}\text { 濒危 } \\
\text { /EN }\end{array}$ & 邵明勤 & 中华秋沙鸭冬季生态习性的初步观察 \\
\hline Mergus squamatus & 中华秋沙鸭 & I & $\begin{array}{l}\text { 濒危 } \\
\text { /EN }\end{array}$ & 方弟安 & 中华秋沙鸭越冬生物学特性的初步研究 \\
\hline Mergus squamatus & 中华秋沙鸭 & I & $\begin{array}{l}\text { 濒危 } \\
\text { /EN }\end{array}$ & 任 巍 & 中华秋沙鸭在湖南的新分布 \\
\hline Mergus squamatus & 中华秋沙鸭 & I & $\begin{array}{l}\text { 濒危 } \\
\text { /EN }\end{array}$ & 孙本栋 & 中华秋沙鸭在小北湖自然保护区中的地位 \\
\hline Mergus squamatus & 中华秋沙鸭 & I & $\begin{array}{l}\text { 濒危 } \\
\text { /EN }\end{array}$ & 洪兆春 & 重庆江津冬季中华秋沙鸭初步调查 \\
\hline Merrilliopanax chinensis & 常春木 & $\begin{array}{l}\text { 未列 } \\
入\end{array}$ & $\begin{array}{l}\text { 极危 } \\
\text { /CR }\end{array}$ & 向其柏 & 中国五加科花粉形态研究 \\
\hline Metasequoia glyptostroboides & 水杉 & I & $\begin{array}{l}\text { 濒危 } \\
\text { /EN }\end{array}$ & 付静静 & 基于 GIS 的四川盆地秋季红叶指数与银杏_水杉秋叶变色过程分析 \\
\hline Metasequoia glyptostroboides & 水杉 & I & $\begin{array}{l}\text { 濒危 } \\
\text { /EN }\end{array}$ & 胡茂成 & 23 个水杉子遗单株子代变异性的研究 \\
\hline Metasequoia glyptostroboides & 水杉 & I & $\begin{array}{l}\text { 濒危 } \\
\text { /EN }\end{array}$ & 胡茂成 & 23 个水杉子遗单株子代变异性的研究 \\
\hline Metasequoia glyptostroboides & 水杉 & I & 濒危 & 常崇艳 & 4 种活化石裸子植物的叶和种子的元素 X 射线微区分析 \\
\hline
\end{tabular}


顾垒，闻丞，罗玫，王昊，吕植. 中国最受关注濒危物种保护现状快速评价的新方法探讨．生物多样性，2015，23(5)：583-590. http://www biodiversity-science. net/CN/article/downloadArticleFile. do?attachType=PDF\&id=10075

Metasequoia glyptostroboides

Metasequoia glyptostroboides

Metasequoia glyptostroboides

Metasequoia glyptostroboides

Metasequoia glyptostroboides

Metasequoia glyptostroboides

Metasequoia glyptostroboides
I

李建强

EN

贱危李建强

I

Weilun Yin

I 濒危 LIN Jinxing

EN

I 濒危 Hui-Zi Jin

I 濒危 H. K. Wu

I 濒危 Zican He

EN

I 濒危 Tonggui Wu

/EN

I 濒危 XIAO-YONG CHEN
8 个栽培水杉居群遗传多样性的等位酶分析

8 个栽培水杉居群遗传多样性的等位酶分析

An EST dataset for Metasequoia glyptostroboides buds: the Wrst EST resource for molecular genomics studies in Metasequoi

Atomic force microscopic observation on substructure of pollen exine in Cedrus deodara and

\section{Metasequoia glyptostroboides}

Chemical constituents from Metasequoia glyptostroboides Hu et Cheng

COMPOSITION OF ESSENTIAL OIL FROM SEEDS OF Metasequoia glyptostroboides

GROWING IN CHINA

Cytogenetic studies on Metasequoia glyptostroboides, a living fossil species

Effects of stand structure on wind speed reduction in a Metasequoia glyptostroboides

shelterbelt

Genetic differences between wild and artificial populations of Metasequoia glyptostroboides

Implications for species recovery 
顾垒，闻丞，罗玫，王昊，吕植. 中国最受关注濒危物种保护现状快速评价的新方法探讨．生物多样性，2015，23(5)：583-590. http://www. biodiversity-science. net/CN/article/downloadArticleFile. do?attachType=PDF\&id=10075

\begin{tabular}{|c|c|c|c|c|c|}
\hline Metasequoia glyptostroboides & 水杉 & I & $\begin{array}{l}\text { 濒危 } \\
\text { /EN }\end{array}$ & Yuan-Yuan Li & $\begin{array}{l}\text { Isolation and characterization of polymorphic microsatellite markers in Metasequoia } \\
\text { glyptostroboides (Taxodiaceae) }\end{array}$ \\
\hline Metasequoia glyptostroboides & 水杉 & I & $\begin{array}{l}\text { 濒危 } \\
\text { /EN }\end{array}$ & Wei-Dong Zhang & Norlignans and Phenylpropanoids from Metasequoia glyptostroboides Hu et Cheng \\
\hline Metasequoia glyptostroboides & 水杉 & I & $\begin{array}{l}\text { 濒危 } \\
\text { /EN }\end{array}$ & Q. Tang & $\begin{array}{l}\text { Population structure of relict Metasequoia glyptostroboides and its habitat fragmentation and } \\
\text { degradation in south-central China }\end{array}$ \\
\hline Metasequoia glyptostroboides & 水杉 & I & $\begin{array}{l}\text { 濒危 } \\
\text { /EN }\end{array}$ & Z.-Z. FENG & Sensitivity of Metasequoia glyptostroboides to ozone stress \\
\hline Metasequoia glyptostroboides & 水杉 & I & $\begin{array}{l}\text { 濒危 } \\
\text { /EN }\end{array}$ & XIAO-YONG CHEN & $\begin{array}{l}\text { Size-class Differences in Genetic Structure of Metasequoia glyptostroboides Hu et Cheng } \\
\text { (Taxodiaceae) Plantations in Shanghai }\end{array}$ \\
\hline Metasequoia glyptostroboides & 水杉 & I & $\begin{array}{l}\text { 濒危 } \\
\text { /EN }\end{array}$ & Xiao-Yong Chen & $\begin{array}{l}\text { Too early to call it success: An evaluation of the natural regeneration of the endangered } \\
\text { Metasequoia glyptostroboides }\end{array}$ \\
\hline Metasequoia glyptostroboides & 水杉 & I & $\begin{array}{l}\text { 濒危 } \\
\text { /EN }\end{array}$ & QIN LENGA & Variation of cuticle micromorphology of Metasequoia glyptostroboides (Taxodiaceae) \\
\hline Metasequoia glyptostroboides & 水杉 & I & $\begin{array}{l}\text { 濒危 } \\
\text { /EN }\end{array}$ & 张静 & 阿克苏市南昌路行道树水杉生长及发病情况的调查研究 \\
\hline Metasequoia glyptostroboides & 水杉 & I & $\begin{array}{l}\text { 濒危 } \\
\text { /EN }\end{array}$ & 崔敏燕 & 濒危物种水杉种群的引种和生存力分析 \\
\hline Metasequoia glyptostroboides & 水杉 & I & 濒危 & 崔敏燕 & 濒危物种水杉种群的引种和生存力分析 \\
\hline
\end{tabular}


顾垒，闻丞，罗玫，王吴，吕植. 中国最受关注濒危物种保护现状快速评价的新方法探讨. 生物多样性，2015，23(5)：583-590. http://www. biodiversity-science. net/CN/article/downloadArticleFile. do?attachType=PDF\&id=10075

\begin{tabular}{|c|c|c|c|c|c|}
\hline & & & /EN & & \\
\hline \multirow[t]{2}{*}{ Metasequoia glyptostroboides } & 水杉 & I & 濒危 & 景丹龙 & 不同光照及储藏温度对水杉种子萌发及酶活性的影响 \\
\hline & & & $/$ EN & & \\
\hline \multirow[t]{2}{*}{ Metasequoia glyptostroboides } & 水杉 & I & 濒危 & 张德春 & 不同光照及储藏温度对水杉种子萌发及酶活性的影响 \\
\hline & & & /EN & & \\
\hline \multirow[t]{2}{*}{ Metasequoia glyptostroboides } & 水杉 & I & 濒危 & 王有为 & 不同季节水杉叶总黄酮含量变化的研究 \\
\hline & & & /EN & & \\
\hline \multirow[t]{2}{*}{ Metasequoia glyptostroboides } & 水杉 & I & 濒危 & 周大寨 & 不同类型吸水剂提高水杉抗旱耐盐性比较研究 \\
\hline & & & /EN & & \\
\hline \multirow[t]{2}{*}{ Metasequoia glyptostroboides } & 水杉 & I & 濒危 & 周大寨 & 不同类型吸水剂提高水杉抗旱耐盐性比较研究 \\
\hline & & & /EN & & \\
\hline \multirow[t]{2}{*}{ Metasequoia glyptostroboides } & 水杉 & I & 濒危 & 谢天时 & 不同林龄和坡位水杉人工林生长状况的比较 \\
\hline & & & /EN & & \\
\hline \multirow[t]{2}{*}{ Metasequoia glyptostroboides } & 水杉 & I & 濒危 & 谢天时 & 不同林龄水杉人工林群落特征比较研究 \\
\hline & & & /EN & & \\
\hline \multirow[t]{2}{*}{ Metasequoia glyptostroboides } & 水杉 & I & 濒危 & 李玥 & 不同林龄水杉人工林下土壤微生物量的变化研究 \\
\hline & & & /EN & & \\
\hline \multirow[t]{2}{*}{ Metasequoia glyptostroboides } & 水杉 & I & 濒危 & 李玥 & 不同林龄水杉人工林下土壤微生物量的变化研究 \\
\hline & & & /EN & & \\
\hline
\end{tabular}


顾垒，闻丞，罗玫，王吴，吕植. 中国最受关注濒危物种保护现状快速评价的新方法探讨. 生物多样性，2015，23(5)：583-590. http://www biodiversity-science. net/CN/article/downloadArticleFile. do?attachType=PDF\&id=10075

\begin{tabular}{|c|c|c|c|c|c|}
\hline Metasequoia glyptostroboides & 水杉 & I & $\begin{array}{l}\text { 濒危 } \\
\text { /EN }\end{array}$ & 梁兴贵 & 茶袋蛾生物学特性研究及危害水杉的防治试验 \\
\hline Metasequoia glyptostroboides & 水杉 & I & $\begin{array}{l}\text { 濒危 } \\
\text { /EN }\end{array}$ & 李君玲 & 超声提取水杉叶总黄酮的工艺研究 \\
\hline Metasequoia glyptostroboides & 水杉 & I & $\begin{array}{l}\text { 濒危 } \\
\text { /EN }\end{array}$ & 达良俊 & $\begin{array}{l}\text { 城市化进程中上海植被的多样性、空间格局和动态响应:管护放弃后城市水杉林林下植被 } \\
\text { 自然演替格局的研究 }\end{array}$ \\
\hline Metasequoia glyptostroboides & 水杉 & I & $\begin{array}{l}\text { 濒危 } \\
\text { /EN }\end{array}$ & 刘春江 & 崇明岛不同年龄水杉人工林生态系统碳储量的特点及估测 \\
\hline Metasequoia glyptostroboides & 水杉 & I & $\begin{array}{l}\text { 濒危 } \\
\text { /EN }\end{array}$ & 刘春江 & 崇明岛不同年龄水杉人工林生态系统碳储量的特点及估测 \\
\hline Metasequoia glyptostroboides & 水杉 & I & $\begin{array}{l}\text { 濒危 } \\
\text { /EN }\end{array}$ & 肖春波 & 崇明岛不同年龄水杉人工林生态系统特点及其碳储量估测 \\
\hline Metasequoia glyptostroboides & 水杉 & I & $\begin{array}{l}\text { 濒危 } \\
\text { /EN }\end{array}$ & 张德春 & 储藏湿度对水杉种子同工酶的影响 \\
\hline Metasequoia glyptostroboides & 水杉 & I & $\begin{array}{l}\text { 濒危 } \\
\text { /EN }\end{array}$ & 张德春 & 储藏湿度对水杉种子同工酶的影响 \\
\hline Metasequoia glyptostroboides & 水杉 & I & $\begin{array}{l}\text { 濒危 } \\
\text { /EN }\end{array}$ & 刘玲 & 大规格水杉移栽技术浅谈———以大明湖扩建改造工程为例 \\
\hline Metasequoia glyptostroboides & 水杉 & I & 濒危 & 叶益萍 & 单种属植物水杉的化学成分及药理研究进展 \\
\hline
\end{tabular}


顾垒，闻丞，罗玫，王吴，吕植. 中国最受关注濒危物种保护现状快速评价的新方法探讨. 生物多样性，2015，23(5)：583-590. http://www. biodiversity-science. net/CN/article/downloadArticleFile. do?attachType=PDF\&id=10075

\begin{tabular}{|c|c|c|c|c|c|}
\hline & & & /EN & & \\
\hline \multirow[t]{2}{*}{ Metasequoia glyptostroboides } & 水杉 & I & 濒危 & 钟华 & 分子标记技术在水杉研究中的应用 \\
\hline & & & $/$ EN & & \\
\hline \multirow[t]{2}{*}{ Metasequoia glyptostroboides } & 水杉 & I & 濒危 & 王希群 & 关于对水杉保护和研究的若干建议 \\
\hline & & & /EN & & \\
\hline \multirow[t]{2}{*}{ Metasequoia glyptostroboides } & 水杉 & I & 濒危 & 张德春 & 光暗交替及全黑暗对水杉种子萌发过程中同工酶的影响 \\
\hline & & & /EN & & \\
\hline \multirow[t]{2}{*}{ Metasequoia glyptostroboides } & 水杉 & I & 濒危 & 杨冬梅 & 光照条件、植株冠层结构和枝条寿命的关系-——以桂花和水杉为例 \\
\hline & & & /EN & & \\
\hline \multirow[t]{2}{*}{ Metasequoia glyptostroboides } & 水杉 & I & 濒危 & 刘毅 & 国家一级珍稀植物水杉母树资源调查及其保护 \\
\hline & & & /EN & & \\
\hline \multirow[t]{2}{*}{ Metasequoia glyptostroboides } & 水杉 & I & 濒危 & 刘毅 & 国家一级珍稀植物水杉母树资源调查及其保护 \\
\hline & & & /EN & & \\
\hline \multirow[t]{2}{*}{ Metasequoia glyptostroboides } & 水杉 & I & 濒危 & 杨登俊 & 洪泽湖湿地周边地区水杉繁殖与营造技术 \\
\hline & & & /EN & & \\
\hline \multirow[t]{2}{*}{ Metasequoia glyptostroboides } & 水杉 & I & 濒危 & 杨建明 & 湖北利川水杉阴沉木的发现及意义 \\
\hline & & & /EN & & \\
\hline \multirow[t]{2}{*}{ Metasequoia glyptostroboides } & 水杉 & I & 濒危 & 程小玲 & 湖北利川水杉原生种群保护的研究 \\
\hline & & & /EN & & \\
\hline
\end{tabular}


顾垒，闻丞，罗玫，王吴，吕植. 中国最受关注濒危物种保护现状快速评价的新方法探讨. 生物多样性，2015，23(5)：583-590. http://www biodiversity-science. net/CN/article/downloadArticleFile. do?attachType=PDF\&id=10075

\begin{tabular}{|c|c|c|c|c|c|}
\hline Metasequoia glyptostroboides & 水杉 & I & $\begin{array}{l}\text { 濒危 } \\
\text { /EN }\end{array}$ & 程小玲 & 湖北利川水杉原生种群保护的研究 \\
\hline Metasequoia glyptostroboides & 水杉 & I & $\begin{array}{l}\text { 濒危 } \\
\text { /EN }\end{array}$ & 周成河 & 湖北利川水杉原生种群的生态学研究 \\
\hline Metasequoia glyptostroboides & 水杉 & I & $\begin{array}{l}\text { 濒危 } \\
\text { /EN }\end{array}$ & 周成河 & 湖北利川水杉原生种群的生态学研究 \\
\hline Metasequoia glyptostroboides & 水杉 & I & $\begin{array}{l}\text { 濒危 } \\
\text { /EN }\end{array}$ & 马履一 & 湖北利川水杉原生种群及其生境 1948 2003 年间变化分析 \\
\hline Metasequoia glyptostroboides & 水杉 & I & $\begin{array}{l}\text { 濒危 } \\
\text { /EN }\end{array}$ & 马履一 & 湖北利川水杉原生种群及其生境 1948 2003 年间变化分析 \\
\hline Metasequoia glyptostroboides & 水杉 & I & $\begin{array}{l}\text { 濒危 } \\
\text { /EN }\end{array}$ & 迟西文 & 华西雨屏区柳杉与水杉人工林生态系统碳、氮储量研究 \\
\hline Metasequoia glyptostroboides & 水杉 & I & $\begin{array}{l}\text { 濒危 } \\
\text { /EN }\end{array}$ & 李淑涃 & 环境条件和播后覆土对水杉种子出苗率的影响 \\
\hline Metasequoia glyptostroboides & 水杉 & I & $\begin{array}{l}\text { 濒危 } \\
\text { /EN }\end{array}$ & 尤冬梅 & 环境因子对水杉种子萌发与幼苗生长的影响研究 \\
\hline Metasequoia glyptostroboides & 水杉 & I & $\begin{array}{l}\text { 濒危 } \\
\text { /EN }\end{array}$ & 尤冬梅 & 环境因子对水杉种子萌发与幼苗生长的影响研究 \\
\hline Metasequoia glyptostroboides & 水杉 & I & 濒危 & 方德年 & 黄山水杉生长的初步研究 \\
\hline
\end{tabular}


顾垒，闻丞，罗玫，王吴，吕植. 中国最受关注濒危物种保护现状快速评价的新方法探讨. 生物多样性，2015，23(5)：583-590. http://www. biodiversity-science. net/CN/article/downloadArticleFile. do?attachType=PDF\&id=10075

\begin{tabular}{|c|c|c|c|c|c|}
\hline & & & /EN & & \\
\hline \multirow[t]{2}{*}{ Metasequoia glyptostroboides } & 水杉 & I & 濒危 & 李德民 & 基于 GreenLab 理论的水杉结构-功能模型 \\
\hline & & & $/$ EN & & \\
\hline \multirow[t]{2}{*}{ Metasequoia glyptostroboides } & 水杉 & I & 濒危 & 李德民 & 基于 GreenLab 理论的水杉结构功能模型 \\
\hline & & & /EN & & \\
\hline \multirow[t]{2}{*}{ Metasequoia glyptostroboides } & 水杉 & I & 濒危 & 丁次平 & 江汉平原水杉、池杉、落羽杉物理力学性能比较研究 \\
\hline & & & /EN & & \\
\hline \multirow[t]{2}{*}{ Metasequoia glyptostroboides } & 水杉 & I & 濒危 & 江津凡 & 江汉平原水杉人工林生长规律研究 \\
\hline & & & /EN & & \\
\hline \multirow[t]{2}{*}{ Metasequoia glyptostroboides } & 水杉 & I & 濒危 & 李建强 & 子遗植物水杉的遗传多样性研究 \\
\hline & & & /EN & & \\
\hline \multirow[t]{2}{*}{ Metasequoia glyptostroboides } & 水杉 & I & 濒危 & 李建强 & 子遗植物水杉的遗传多样性研究 \\
\hline & & & /EN & & \\
\hline \multirow[t]{2}{*}{ Metasequoia glyptostroboides } & 水杉 & I & 濒危 & 景新明 & 子遗植物水杉种子萌发的生理生态特性研究 \\
\hline & & & /EN & & \\
\hline \multirow[t]{2}{*}{ Metasequoia glyptostroboides } & 水杉 & I & 濒危 & 景新明 & 子遗植物水杉种子萌发的生理生态特性研究 \\
\hline & & & /EN & & \\
\hline \multirow[t]{2}{*}{ Metasequoia glyptostroboides } & 水杉 & I & 濒危 & 王雪英 & 榉属和水杉属的叶片气孔频率对大气 CO2 浓度变化的响应 \\
\hline & & & /EN & & \\
\hline
\end{tabular}


顾垒，闻丞，罗玫，王吴，吕植. 中国最受关注濒危物种保护现状快速评价的新方法探讨. 生物多样性，2015，23(5)：583-590. http://www biodiversity-science. net/CN/article/downloadArticleFile. do?attachType=PDF\&id=10075

\begin{tabular}{|c|c|c|c|c|c|}
\hline Metasequoia glyptostroboides & 水杉 & I & $\begin{array}{l}\text { 濒危 } \\
\text { /EN }\end{array}$ & 贺新生 & 巨大节毛菌在水杉上的发现 \\
\hline Metasequoia glyptostroboides & 水杉 & I & $\begin{array}{l}\text { 濒危 } \\
\text { /EN }\end{array}$ & 马清温 & 巨杉的叶表皮结构及其与红杉和水杉的比较 \\
\hline Metasequoia glyptostroboides & 水杉 & I & $\begin{array}{l}\text { 濒危 } \\
\text { /EN }\end{array}$ & 牟新利 & 利川土壤-水杉系统中重金属的分布特征 \\
\hline Metasequoia glyptostroboides & 水杉 & I & $\begin{array}{l}\text { 濒危 } \\
\text { /EN }\end{array}$ & 郝德君 & 刘氏短须螨危害对水杉生理生化物质及挥发物的影响 \\
\hline Metasequoia glyptostroboides & 水杉 & I & $\begin{array}{l}\text { 濒危 } \\
\text { /EN }\end{array}$ & 郝德君 & 刘氏短须螨危害对水杉生理生化物质及挥发物的影响 \\
\hline Metasequoia glyptostroboides & 水杉 & I & $\begin{array}{l}\text { 濒危 } \\
\text { /EN }\end{array}$ & 刘国武 & 绿色植物生长调节剂对水杉幼苗生长的影响 \\
\hline Metasequoia glyptostroboides & 水杉 & I & $\begin{array}{l}\text { 濒危 } \\
\text { /EN }\end{array}$ & 王利萍 & 沐川天然林与人工水杉林保水功能比较 \\
\hline Metasequoia glyptostroboides & 水杉 & I & $\begin{array}{l}\text { 濒危 } \\
\text { /EN }\end{array}$ & 谢天时 & 南方山地水杉人工林生态系统生产力及养分循环研究 \\
\hline Metasequoia glyptostroboides & 水杉 & I & $\begin{array}{l}\text { 濒危 } \\
\text { /EN }\end{array}$ & 谢天时 & 南方山地水杉人工林生态系统生产力及养分循环研究 \\
\hline Metasequoia glyptostroboides & 水杉 & I & 濒危 & 汤艳 & 䂙州部分路段水杉死亡原因探析及复壮措施 \\
\hline
\end{tabular}


顾垒，闻丞，罗玫，王吴，吕植. 中国最受关注濒危物种保护现状快速评价的新方法探讨. 生物多样性，2015，23(5)：583-590. http://www. biodiversity-science. net/CN/article/downloadArticleFile. do?attachType=PDF\&id=10075

\begin{tabular}{|c|c|c|c|c|c|}
\hline & & & /EN & & \\
\hline \multirow[t]{2}{*}{ Metasequoia glyptostroboides } & 水杉 & I & 濒危 & 张乃华 & 千岛湖畔水杉引种栽培技术 \\
\hline & & & /EN & & \\
\hline \multirow[t]{2}{*}{ Metasequoia glyptostroboides } & 水杉 & I & 濒危 & 侯利峰 & 浅谈水杉在豫西山区的育苗造林技术 \\
\hline & & & /EN & & \\
\hline \multirow[t]{2}{*}{ Metasequoia glyptostroboides } & 水杉 & I & 濒危 & 彭红丽 & 秦皇岛水杉栽培及养护管理技术 \\
\hline & & & /EN & & \\
\hline \multirow[t]{2}{*}{ Metasequoia glyptostroboides } & 水杉 & I & 濒危 & 庄红蕾 & 上海崇明岛水杉人工林生态系统碳动态研究 \\
\hline & & & /EN & & \\
\hline \multirow[t]{2}{*}{ Metasequoia glyptostroboides } & 水杉 & I & 濒危 & 刘春江 & 上海崇明岛水杉人工林生态系统碳动态研究 \\
\hline & & & /EN & & \\
\hline \multirow[t]{2}{*}{ Metasequoia glyptostroboides } & 水杉 & I & 濒危 & 刘春江 & 上海崇明岛水杉人工林生物量方程构建及固碳潜力研究 \\
\hline & & & /EN & & \\
\hline \multirow[t]{2}{*}{ Metasequoia glyptostroboides } & 水杉 & I & 濒危 & 孙兴全 & 上海地区为害水杉的茶尺蛾生物学特性研究 \\
\hline & & & /EN & & \\
\hline \multirow[t]{2}{*}{ Metasequoia glyptostroboides } & 水杉 & I & 濒危 & 孙兴全 & 上海地区为害水杉的茶尺蛾生物学特性研究 \\
\hline & & & /EN & & \\
\hline \multirow[t]{2}{*}{ Metasequoia glyptostroboides } & 水杉 & I & 濒危 & 赵敏 & 上海水杉树高与胸径关系模式分析 \\
\hline & & & /EN & & \\
\hline
\end{tabular}


顾垒，闻丞，罗玫，王吴，吕植. 中国最受关注濒危物种保护现状快速评价的新方法探讨. 生物多样性，2015，23(5)：583-590. http://www. biodiversity-science. net/CN/article/downloadArticleFile. do?attachType=PDF\&id=10075

\begin{tabular}{|c|c|c|c|c|c|}
\hline Metasequoia glyptostroboides & 水杉 & I & $\begin{array}{l}\text { 濒危 } \\
\text { /EN }\end{array}$ & 钟昌东 & 十五年生水杉无性系选育测定 \\
\hline Metasequoia glyptostroboides & 水杉 & I & $\begin{array}{l}\text { 濒危 } \\
\text { /EN }\end{array}$ & 谢寅峰 & 水分胁迫下 3 种针叶树幼苗抗旱性与硝酸还原酶和超氧化物歧化酶活性的关系 \\
\hline Metasequoia glyptostroboides & 水杉 & I & $\begin{array}{l}\text { 濒危 } \\
\text { /EN }\end{array}$ & 谢寅峰 & 水分胁迫下抗旱剂对南方 6 种林木幼苗光合作用的影响 \\
\hline Metasequoia glyptostroboides & 水杉 & I & $\begin{array}{l}\text { 濒危 } \\
\text { /EN }\end{array}$ & 马清温 & 水杉( 杉科) 的叶表皮结构 \\
\hline Metasequoia glyptostroboides & 水杉 & I & $\begin{array}{l}\text { 濒危 } \\
\text { /EN }\end{array}$ & 马清温 & 水杉（杉科）的叶表皮结构 \\
\hline Metasequoia glyptostroboides & 水杉 & I & $\begin{array}{l}\text { 濒危 } \\
\text { /EN }\end{array}$ & 胡兴宜 & 水杉、池杉、落羽杉人工林的生长规律 \\
\hline Metasequoia glyptostroboides & 水杉 & I & $\begin{array}{l}\text { 濒危 } \\
\text { /EN }\end{array}$ & 王思健 & 水杉、池杉幼龄林内气象因子的测定 \\
\hline Metasequoia glyptostroboides & 水杉 & I & $\begin{array}{l}\text { 濒危 } \\
\text { /EN }\end{array}$ & 边才苗 & 水杉 RAPD 扩增条件的优化 \\
\hline Metasequoia glyptostroboides & 水杉 & I & $\begin{array}{l}\text { 濒危 } \\
\text { /EN }\end{array}$ & 边才苗 & 水杉 RAPD 扩增条件的优化 \\
\hline Metasequoia glyptostroboides & 水杉 & I & 濒危 & 郭宏伟 & 水杉北方扞插育苗试验 \\
\hline
\end{tabular}


顾垒，闻丞，罗玫，王吴，吕植. 中国最受关注濒危物种保护现状快速评价的新方法探讨. 生物多样性，2015，23(5)：583-590. http://www. biodiversity-science. net/CN/article/downloadArticleFile. do?attachType=PDF\&id=10075

\begin{tabular}{|c|c|c|c|c|c|}
\hline & & & /EN & & \\
\hline \multirow[t]{2}{*}{ Metasequoia glyptostroboides } & 水杉 & I & 濒危 & 张惠兰 & 水杉播种育苗技术 \\
\hline & & & /EN & & \\
\hline \multirow[t]{2}{*}{ Metasequoia glyptostroboides } & 水杉 & I & 濒危 & 汪来宝 & 水杉尺蛾堵截法防治用具橡胶药环的研制 \\
\hline & & & /EN & & \\
\hline \multirow[t]{2}{*}{ Metasequoia glyptostroboides } & 水杉 & I & 濒危 & 汪来宝 & 水杉尺蛾防治技术研究 \\
\hline & & & /EN & & \\
\hline \multirow[t]{2}{*}{ Metasequoia glyptostroboides } & 水杉 & I & 濒危 & 叶建仁 & 水杉赤枯病病原形态及分子鉴定 \\
\hline & & & /EN & & \\
\hline \multirow[t]{2}{*}{ Metasequoia glyptostroboides } & 水杉 & I & 濒危 & 杨士杰 & 水杉赤枯病的发生及防治技术探索初报 \\
\hline & & & /EN & & \\
\hline \multirow[t]{2}{*}{ Metasequoia glyptostroboides } & 水杉 & $\mathrm{I}$ & 濒危 & 匙明强 & 水杉赤枯病发生规律及防治技术研究 \\
\hline & & & /EN & & \\
\hline \multirow[t]{2}{*}{ Metasequoia glyptostroboides } & 水杉 & I & 濒危 & 匙明强 & 水杉赤枯病发生规律及防治技术研究 \\
\hline & & & /EN & & \\
\hline \multirow[t]{2}{*}{ Metasequoia glyptostroboides } & 水杉 & I & 濒危 & 武朝菊 & 水杉大树引种栽培技术研究———以济南现代林业示范园水杉林为例 \\
\hline & & & $/ \mathrm{EN}$ & & \\
\hline \multirow[t]{2}{*}{ Metasequoia glyptostroboides } & 水杉 & I & 濒危 & 马履一 & 水杉的保护历程和存在的问题 \\
\hline & & & /EN & & \\
\hline
\end{tabular}


顾垒，闻丞，罗玫，王吴，吕植. 中国最受关注濒危物种保护现状快速评价的新方法探讨. 生物多样性，2015，23(5)：583-590. http://www. biodiversity-science. net/CN/article/downloadArticleFile. do?attachType=PDF\&id=10075

\begin{tabular}{|c|c|c|c|c|c|}
\hline Metasequoia glyptostroboides & 水杉 & I & $\begin{array}{l}\text { 濒危 } \\
\text { /EN }\end{array}$ & 于泽波 & 水杉的繁殖栽培 \\
\hline Metasequoia glyptostroboides & 水杉 & I & $\begin{array}{l}\text { 濒危 } \\
\text { /EN }\end{array}$ & 李媛媛 & 水杉的系统发育地位及恢复评价 \\
\hline Metasequoia glyptostroboides & 水杉 & I & $\begin{array}{l}\text { 濒危 } \\
\text { /EN }\end{array}$ & 李媛媛 & 水杉的系统发育地位及恢复评价 \\
\hline Metasequoia glyptostroboides & 水杉 & I & $\begin{array}{l}\text { 濒危 } \\
\text { /EN }\end{array}$ & 代静玉 & 水杉调落物分解过程中溶解性有机质的分组组成变化 \\
\hline Metasequoia glyptostroboides & 水杉 & I & $\begin{array}{l}\text { 濒危 } \\
\text { /EN }\end{array}$ & 代静玉 & 水杉调落物分解过程中溶解性有机质的分组组成变化 \\
\hline Metasequoia glyptostroboides & 水杉 & I & $\begin{array}{l}\text { 濒危 } \\
\text { /EN }\end{array}$ & 马履一 & 水杉发现过程的系统研究 \\
\hline Metasequoia glyptostroboides & 水杉 & I & $\begin{array}{l}\text { 濒危 } \\
\text { /EN }\end{array}$ & 王鸣凤 & 水杉覆膜扦插育苗技术及效果 \\
\hline Metasequoia glyptostroboides & 水杉 & I & $\begin{array}{l}\text { 濒危 } \\
\text { /EN }\end{array}$ & 李德民 & 水杉功能_结构模型的研究 \\
\hline Metasequoia glyptostroboides & 水杉 & I & $\begin{array}{l}\text { 濒危 } \\
\text { /EN }\end{array}$ & 李德民 & 水杉功能-结构模型的研究 \\
\hline Metasequoia glyptostroboides & 水杉 & I & 濒危 & 杨彦伶 & 水杉基因组微卫星分析及标记开发 \\
\hline
\end{tabular}


顾垒，闻丞，罗玫，王吴，吕植. 中国最受关注濒危物种保护现状快速评价的新方法探讨. 生物多样性，2015，23(5)：583-590. http://www. biodiversity-science. net/CN/article/downloadArticleFile. do?attachType=PDF\&id=10075

\begin{tabular}{|c|c|c|c|c|c|}
\hline & & & /EN & & \\
\hline \multirow[t]{2}{*}{ Metasequoia glyptostroboides } & 水杉 & I & 濒危 & 杨彦伶 & 水杉基因组微卫星分析及标记开发 \\
\hline & & & $/$ EN & & \\
\hline \multirow[t]{2}{*}{ Metasequoia glyptostroboides } & 水杉 & I & 濒危 & 黄宏文 & 水杉子遗居群 AFLP 遗传变异的空间分布 \\
\hline & & & /EN & & \\
\hline \multirow[t]{2}{*}{ Metasequoia glyptostroboides } & 水杉 & I & 濒危 & 黄宏文 & 水杉子遗居群 AFLP 遗传变异的空间分布 \\
\hline & & & /EN & & \\
\hline \multirow[t]{2}{*}{ Metasequoia glyptostroboides } & 水杉 & I & 濒危 & 尤冬梅 & 水杉枯落物对其种子萌发的影响初探 \\
\hline & & & /EN & & \\
\hline \multirow[t]{2}{*}{ Metasequoia glyptostroboides } & 水杉 & I & 濒危 & 吴大椿 & 水杉枯萎病病原初步研究 \\
\hline & & & /EN & & \\
\hline \multirow[t]{2}{*}{ Metasequoia glyptostroboides } & 水杉 & $\mathrm{I}$ & 濒危 & 吴大椿 & 水杉枯萎病病原初步研究 \\
\hline & & & /EN & & \\
\hline \multirow[t]{2}{*}{ Metasequoia glyptostroboides } & 水杉 & I & 濒危 & 于飞飞 & 水杉离体组织培养及其影响黄酮类物质合成因素的研究 \\
\hline & & & /EN & & \\
\hline \multirow[t]{2}{*}{ Metasequoia glyptostroboides } & 水杉 & I & 濒危 & 翁德宝 & 水杉落叶中黄酮类化合物的测定与抗氧化作用的初步研究 \\
\hline & & & /EN & & \\
\hline \multirow[t]{2}{*}{ Metasequoia glyptostroboides } & 水杉 & I & 濒危 & 谷尘平 & 水杉苗期对氮素营养需求的研究 \\
\hline & & & /EN & & \\
\hline
\end{tabular}


顾垒，闻丞，罗玫，王吴，吕植. 中国最受关注濒危物种保护现状快速评价的新方法探讨. 生物多样性，2015，23(5)：583-590. http://www. biodiversity-science. net/CN/article/downloadArticleFile. do?attachType=PDF\&id=10075

\begin{tabular}{|c|c|c|c|c|c|}
\hline Metasequoia glyptostroboides & 水杉 & I & $\begin{array}{l}\text { 濒危 } \\
\text { /EN }\end{array}$ & 范里 & 水杉苗无性系群体选优扞插试验 \\
\hline Metasequoia glyptostroboides & 水杉 & I & $\begin{array}{l}\text { 濒危 } \\
\text { /EN }\end{array}$ & 杨路路 & 水杉木材 DNA 提取及 DNA 条形码分析 \\
\hline Metasequoia glyptostroboides & 水杉 & I & $\begin{array}{l}\text { 濒危 } \\
\text { /EN }\end{array}$ & 杨星宇 & 水杉木材 DNA 提取及条形码分子鉴定 \\
\hline Metasequoia glyptostroboides & 水杉 & I & $\begin{array}{l}\text { 濒危 } \\
\text { /EN }\end{array}$ & 杨建明 & 水杉木材 D N A 提取及条形码分子鉴定 \\
\hline Metasequoia glyptostroboides & 水杉 & I & $\begin{array}{l}\text { 濒危 } \\
\text { /EN }\end{array}$ & 艾卿 & 水杉木材化学成份变异模式及其纸浆林的采伐年龄 \\
\hline Metasequoia glyptostroboides & 水杉 & I & $\begin{array}{l}\text { 濒危 } \\
\text { /EN }\end{array}$ & 冯德君 & 水杉木材受伤树脂道的观察 \\
\hline Metasequoia glyptostroboides & 水杉 & I & $\begin{array}{l}\text { 濒危 } \\
\text { /EN }\end{array}$ & 卢东升 & 水杉内生真菌生物多样性与生态分布 \\
\hline Metasequoia glyptostroboides & 水杉 & I & $\begin{array}{l}\text { 濒危 } \\
\text { /EN }\end{array}$ & 卢东升 & 水杉内生真菌生物多样性与生态分布 \\
\hline Metasequoia glyptostroboides & 水杉 & I & $\begin{array}{l}\text { 濒危 } \\
\text { /EN }\end{array}$ & 田爱芳 & 水杉嫩枝扞插育苗技术 \\
\hline Metasequoia glyptostroboides & 水杉 & I & 濒危 & 李德志 & 水杉人工林建植 50 年后的分化特征 \\
\hline
\end{tabular}


顾垒，闻丞，罗玫，王吴，吕植. 中国最受关注濒危物种保护现状快速评价的新方法探讨. 生物多样性，2015，23(5)：583-590. http://www. biodiversity-science. net/CN/article/downloadArticleFile. do?attachType=PDF\&id=10075

\begin{tabular}{|c|c|c|c|c|c|}
\hline & & & /EN & & \\
\hline \multirow[t]{2}{*}{ Metasequoia glyptostroboides } & 水杉 & I & 濒危 & 郭小鹏 & 水杉人工林引种实验生长量与经济效益分析 \\
\hline & & & /EN & & \\
\hline \multirow[t]{2}{*}{ Metasequoia glyptostroboides } & 水杉 & I & 濒危 & 吴大椿 & 水杉色二孢毒素生物活性研究 \\
\hline & & & /EN & & \\
\hline \multirow[t]{2}{*}{ Metasequoia glyptostroboides } & 水杉 & I & 濒危 & 马清温 & 水杉属和红杉属化石叶表皮鉴定参照系的特殊性 \\
\hline & & & /EN & & \\
\hline \multirow[t]{2}{*}{ Metasequoia glyptostroboides } & 水杉 & I & 濒危 & 欧容 & 水杉属化学成分及药理活性研究进展 \\
\hline & & & /EN & & \\
\hline \multirow[t]{2}{*}{ Metasequoia glyptostroboides } & 水杉 & I & 濒危 & 苏定昌 & 水杉树总 RNA 提取实验探析 \\
\hline & & & /EN & & \\
\hline \multirow[t]{2}{*}{ Metasequoia glyptostroboides } & 水杉 & I & 濒危 & 孟昭礼 & 水杉叶甲醇提取物的农用抑菌活性研究 \\
\hline & & & /EN & & \\
\hline \multirow[t]{2}{*}{ Metasequoia glyptostroboides } & 水杉 & I & 濒危 & 吴国平 & 水杉移植苗最佳追肥期的探讨 \\
\hline & & & /EN & & \\
\hline \multirow[t]{2}{*}{ Metasequoia glyptostroboides } & 水杉 & I & 濒危 & 马履一 & 水杉引种及迁地保护进展 \\
\hline & & & /EN & & \\
\hline \multirow[t]{2}{*}{ Metasequoia glyptostroboides } & 水杉 & I & 濒危 & 马履一 & 水杉引种及迁地保护进展 \\
\hline & & & /EN & & \\
\hline
\end{tabular}


顾垒，闻丞，罗玫，王吴，吕植. 中国最受关注濒危物种保护现状快速评价的新方法探讨. 生物多样性，2015，23(5)：583-590. http://www. biodiversity-science. net/CN/article/downloadArticleFile. do?attachType=PDF\&id=10075

\begin{tabular}{|c|c|c|c|c|c|}
\hline Metasequoia glyptostroboides & 水杉 & I & $\begin{array}{l}\text { 濒危 } \\
\text { /EN }\end{array}$ & 王继成 & 水杉硬枝扦插育苗技术 \\
\hline Metasequoia glyptostroboides & 水杉 & I & $\begin{array}{l}\text { 濒危 } \\
\text { /EN }\end{array}$ & 于永根 & 水杉羽叶扞插育苗技术 \\
\hline Metasequoia glyptostroboides & 水杉 & I & $\begin{array}{l}\text { 濒危 } \\
\text { /EN }\end{array}$ & 于永根 & 水杉育苗关键技术 \\
\hline Metasequoia glyptostroboides & 水杉 & I & $\begin{array}{l}\text { 濒危 } \\
\text { /EN }\end{array}$ & 陈发菊 & 水杉愈伤组织诱导及植株再生 \\
\hline Metasequoia glyptostroboides & 水杉 & I & $\begin{array}{l}\text { 濒危 } \\
\text { /EN }\end{array}$ & 陈发菊 & 水杉愈伤组织诱导及植株再生 \\
\hline Metasequoia glyptostroboides & 水杉 & I & $\begin{array}{l}\text { 濒危 } \\
\text { /EN }\end{array}$ & 文甲举 & 水杉原生古树保护工作现状及存在的问题 \\
\hline Metasequoia glyptostroboides & 水杉 & I & $\begin{array}{l}\text { 濒危 } \\
\text { /EN }\end{array}$ & 文甲举 & 水杉原生古树保护工作现状及存在的问题 \\
\hline Metasequoia glyptostroboides & 水杉 & I & $\begin{array}{l}\text { 濒危 } \\
\text { /EN }\end{array}$ & 熊彪 & 水杉原生母树生长势调查研究 \\
\hline Metasequoia glyptostroboides & 水杉 & I & $\begin{array}{l}\text { 濒危 } \\
\text { /EN }\end{array}$ & 熊彪 & 水杉原生母树种群及群落特征研究 \\
\hline Metasequoia glyptostroboides & 水杉 & I & 濒危 & 艾训儒 & 水杉原生母树种群及群落特征研究 \\
\hline
\end{tabular}


顾垒，闻丞，罗玫，王吴，吕植. 中国最受关注濒危物种保护现状快速评价的新方法探讨. 生物多样性，2015，23(5)：583-590. http://www. biodiversity-science. net/CN/article/downloadArticleFile. do?attachType=PDF\&id=10075

\begin{tabular}{|c|c|c|c|c|c|}
\hline & & & /EN & & \\
\hline \multirow[t]{2}{*}{ Metasequoia glyptostroboides } & 水杉 & I & 濒危 & 艾训儒 & 水杉原生母树种群研究 \\
\hline & & & $/$ EN & & \\
\hline \multirow[t]{2}{*}{ Metasequoia glyptostroboides } & 水杉 & I & 濒危 & 艾训儒 & 水杉原生母树种群研究 \\
\hline & & & /EN & & \\
\hline \multirow[t]{2}{*}{ Metasequoia glyptostroboides } & 水杉 & I & 濒危 & 王柏泉 & 水杉原生群落病虫害及其防治 \\
\hline & & & /EN & & \\
\hline \multirow[t]{2}{*}{ Metasequoia glyptostroboides } & 水杉 & I & 濒危 & 王柏泉 & 水杉原生群落病虫害及其防治 \\
\hline & & & /EN & & \\
\hline \multirow[t]{2}{*}{ Metasequoia glyptostroboides } & 水杉 & I & 濒危 & 李建强 & 水杉栽培居群的遗传多样性研究 \\
\hline & & & /EN & & \\
\hline \multirow[t]{2}{*}{ Metasequoia glyptostroboides } & 水杉 & I & 濒危 & 李建强 & 水杉栽培居群的遗传多样性研究 \\
\hline & & & /EN & & \\
\hline \multirow[t]{2}{*}{ Metasequoia glyptostroboides } & 水杉 & I & 濒危 & 张玉钧 & 水杉在日本的引种保护及其社会影响 \\
\hline & & & /EN & & \\
\hline \multirow[t]{2}{*}{ Metasequoia glyptostroboides } & 水杉 & I & 濒危 & 陈玮 & 水杉在中国北方城市中的应用研究 \\
\hline & & & /EN & & \\
\hline \multirow[t]{2}{*}{ Metasequoia glyptostroboides } & 水杉 & I & 濒危 & 陈玮 & 水杉在中国北方城市中的应用研究 \\
\hline & & & /EN & & \\
\hline
\end{tabular}


顾垒，闻丞，罗玫，王吴，吕植. 中国最受关注濒危物种保护现状快速评价的新方法探讨. 生物多样性，2015，23(5)：583-590. http://www. biodiversity-science. net/CN/article/downloadArticleFile. do?attachType=PDF\&id=10075

\begin{tabular}{|c|c|c|c|c|c|}
\hline Metasequoia glyptostroboides & 水杉 & I & $\begin{array}{l}\text { 濒危 } \\
\text { /EN }\end{array}$ & 冯朝元 & 水杉造林密度试验 \\
\hline Metasequoia glyptostroboides & 水杉 & I & $\begin{array}{l}\text { 濒危 } \\
\text { /EN }\end{array}$ & 陆军 & 水杉脂的组成及基本理化性质研究 \\
\hline Metasequoia glyptostroboides & 水杉 & I & $\begin{array}{l}\text { 濒危 } \\
\text { /EN }\end{array}$ & 马履一 & 水杉种苗学研究的重要里程碑 \\
\hline Metasequoia glyptostroboides & 水杉 & I & $\begin{array}{l}\text { 濒危 } \\
\text { /EN }\end{array}$ & 杨俊杰 & 水杉种子挥发物质的鉴定及其抗菌活性测定 \\
\hline Metasequoia glyptostroboides & 水杉 & I & $\begin{array}{l}\text { 濒危 } \\
\text { /EN }\end{array}$ & 杨俊杰 & 水杉种子挥发物质的鉴定及其抗菌活性测定 \\
\hline Metasequoia glyptostroboides & 水杉 & I & $\begin{array}{l}\text { 濒危 } \\
\text { /EN }\end{array}$ & 杨俊杰 & 水杉种子提取物抑菌机理研究 \\
\hline Metasequoia glyptostroboides & 水杉 & I & $\begin{array}{l}\text { 濒危 } \\
\text { /EN }\end{array}$ & 杨俊杰 & 水杉种子提取物抑菌机理研究 \\
\hline Metasequoia glyptostroboides & 水杉 & I & $\begin{array}{l}\text { 濒危 } \\
\text { /EN }\end{array}$ & 杨俊杰 & 水杉种子中总黄酮含量及其清除自由基能力分析 \\
\hline Metasequoia glyptostroboides & 水杉 & I & $\begin{array}{l}\text { 濒危 } \\
\text { /EN }\end{array}$ & 杨俊杰 & 水杉种子中总黄酮含量及其清除自由基能力分析 \\
\hline Metasequoia glyptostroboides & 水杉 & I & 濒危 & 赵自明 & 水杉主要立木缺陷、成因及应对措施 \\
\hline
\end{tabular}


顾垒，闻丞，罗玫，王吴，吕植. 中国最受关注濒危物种保护现状快速评价的新方法探讨. 生物多样性，2015，23(5)：583-590. http://www. biodiversity-science. net/CN/article/downloadArticleFile. do?attachType=PDF\&id=10075

\begin{tabular}{|c|c|c|c|c|c|}
\hline & & & /EN & & \\
\hline \multirow[t]{2}{*}{ Metasequoia glyptostroboides } & 水杉 & I & 濒危 & 高政权 & 水杉贮藏蛋白的初步研究 \\
\hline & & & /EN & & \\
\hline \multirow[t]{2}{*}{ Metasequoia glyptostroboides } & 水杉 & I & 濒危 & 孟春晓 & 水杉拒藏蛋白的初步研究 \\
\hline & & & /EN & & \\
\hline \multirow[t]{2}{*}{ Metasequoia glyptostroboides } & 水杉 & I & 濒危 & 田伟 & 水杉总黄酮对 IGF1 诱导的心肌成纤维细胞增殖和胶原合成的影响 \\
\hline & & & /EN & & \\
\hline \multirow[t]{2}{*}{ Metasequoia glyptostroboides } & 水杉 & I & 濒危 & 刘云 & 水杉总黄酮提取工艺及其抗氧化、降血脂作用研究 \\
\hline & & & /EN & & \\
\hline \multirow[t]{2}{*}{ Metasequoia glyptostroboides } & 水杉 & I & 濒危 & 李守剑 & 四川盆周西缘水杉人工林地立地类型划分 \\
\hline & & & /EN & & \\
\hline \multirow[t]{2}{*}{ Metasequoia glyptostroboides } & 水杉 & I & 濒危 & 李守剑 & 四川盆周西缘水杉人工林地立地类型划分 \\
\hline & & & /EN & & \\
\hline \multirow[t]{2}{*}{ Metasequoia glyptostroboides } & 水杉 & I & 濒危 & 李贤伟 & 四川盆周西缘水杉人工林林地立地质量评价研究 \\
\hline & & & /EN & & \\
\hline \multirow[t]{2}{*}{ Metasequoia glyptostroboides } & 水杉 & I & 濒危 & 李贤伟 & 四川盆周西缘水杉人工林林地立地质量评价研究 \\
\hline & & & $/ \mathrm{EN}$ & & \\
\hline \multirow[t]{2}{*}{ Metasequoia glyptostroboides } & 水杉 & I & 濒危 & 张金池 & 苏北泥质海岸水杉林地土壤的异养呼吸 \\
\hline & & & /EN & & \\
\hline
\end{tabular}


顾垒，闻丞，罗玫，王吴，吕植. 中国最受关注濒危物种保护现状快速评价的新方法探讨. 生物多样性，2015，23(5)：583-590. http://www biodiversity-science. net/CN/article/downloadArticleFile. do?attachType=PDF\&id=10075

\begin{tabular}{|c|c|c|c|c|c|}
\hline Metasequoia glyptostroboides & 水杉 & I & $\begin{array}{l}\text { 濒危 } \\
\text { /EN }\end{array}$ & 苟姝贞 & 酸雨胁迫对水杉生理特性的影响 \\
\hline Metasequoia glyptostroboides & 水杉 & I & $\begin{array}{l}\text { 濒危 } \\
\text { /EN }\end{array}$ & 苟姝贞 & 酸雨胁迫对水杉生理特性的影响 \\
\hline Metasequoia glyptostroboides & 水杉 & I & $\begin{array}{l}\text { 濒危 } \\
\text { /EN }\end{array}$ & 尤冬梅 & 天然水杉林的群落分类及演替动态 \\
\hline Metasequoia glyptostroboides & 水杉 & I & $\begin{array}{l}\text { 濒危 } \\
\text { /EN }\end{array}$ & 尤冬梅 & 天然水杉林的群落分类及演替动态 \\
\hline Metasequoia glyptostroboides & 水杉 & I & $\begin{array}{l}\text { 濒危 } \\
\text { /EN }\end{array}$ & 牟新利 & 微波提取水杉种子总黄酮工艺研究 \\
\hline Metasequoia glyptostroboides & 水杉 & I & $\begin{array}{l}\text { 濒危 } \\
\text { /EN }\end{array}$ & 林玲 & 西藏林芝地区引种水杉扦插繁殖试验 \\
\hline Metasequoia glyptostroboides & 水杉 & I & $\begin{array}{l}\text { 濒危 } \\
\text { /EN }\end{array}$ & 王有为 & 吸附法提取分离水杉总黄酮的研究 \\
\hline Metasequoia glyptostroboides & 水杉 & I & $\begin{array}{l}\text { 濒危 } \\
\text { /EN }\end{array}$ & 陈绍林 & 星斗山自然保护区水杉母树的生长状况及保护策略 \\
\hline Metasequoia glyptostroboides & 水杉 & I & $\begin{array}{l}\text { 濒危 } \\
\text { /EN }\end{array}$ & 陈绍林 & 星斗山自然保护区水杉母树的生长状况及保护策略 \\
\hline Metasequoia glyptostroboides & 水杉 & I & 濒危 & 陈绍林 & 星斗山自然保护区水杉阴沉木的分布及保护对策 \\
\hline
\end{tabular}


顾垒，闻丞，罗玫，王吴，吕植. 中国最受关注濒危物种保护现状快速评价的新方法探讨. 生物多样性，2015，23(5)：583-590. http://www. biodiversity-science. net/CN/article/downloadArticleFile. do?attachType=PDF\&id=10075

\begin{tabular}{|c|c|c|c|c|c|}
\hline & & & /EN & & \\
\hline \multirow[t]{2}{*}{ Metasequoia glyptostroboides } & 水杉 & I & 濒危 & 林金星 & 雪松和水杉花粉外壁亚结构的原子力显微镜研究 \\
\hline & & & $/$ EN & & \\
\hline \multirow[t]{2}{*}{ Metasequoia glyptostroboides } & 水杉 & I & 濒危 & 钟哲科 & 杨树、水杉林带枯落物对土壤微生物 C、 $\mathrm{N}$ 的影响 \\
\hline & & & /EN & & \\
\hline \multirow[t]{2}{*}{ Metasequoia glyptostroboides } & 水杉 & I & 濒危 & 牟慧敏 & 原生水杉母树保护措施探讨 \\
\hline & & & /EN & & \\
\hline \multirow[t]{2}{*}{ Metasequoia glyptostroboides } & 水杉 & I & 濒危 & 牟慧敏 & 原生水杉母树保护措施探讨 \\
\hline & & & /EN & & \\
\hline \multirow[t]{2}{*}{ Metasequoia glyptostroboides } & 水杉 & I & 濒危 & 程丹丹 & 原生水杉种群的现状及其保护对策 \\
\hline & & & /EN & & \\
\hline \multirow[t]{2}{*}{ Metasequoia glyptostroboides } & 水杉 & I & 濒危 & 程丹丹 & 原生水杉种群的现状及其保护对策 \\
\hline & & & /EN & & \\
\hline \multirow[t]{2}{*}{ Metasequoia glyptostroboides } & 水杉 & I & 濒危 & 刘艳菊 & 中国辽宁省始新世水杉的研究 \\
\hline & & & /EN & & \\
\hline \multirow[t]{2}{*}{ Metasequoia glyptostroboides } & 水杉 & I & 濒危 & 马履一 & 中国水杉引种研究 \\
\hline & & & /EN & & \\
\hline \multirow[t]{2}{*}{ Metasequoia glyptostroboides } & 水杉 & I & 濒危 & 马履一 & 中国水杉引种研究 \\
\hline & & & /EN & & \\
\hline
\end{tabular}


顾垒，闻丞，罗玫，王吴，吕植. 中国最受关注濒危物种保护现状快速评价的新方法探讨. 生物多样性，2015，23(5)：583-590. http://www. biodiversity-science. net/CN/article/downloadArticleFile. do?attachType=PDF\&id=10075

\begin{tabular}{|c|c|c|c|c|c|}
\hline Metasequoia glyptostroboides & 水杉 & I & $\begin{array}{l}\text { 濒危 } \\
\text { /EN }\end{array}$ & 马履一 & 中国水杉造林历史和造林技术研究进展 \\
\hline Metasequoia glyptostroboides & 水杉 & I & $\begin{array}{l}\text { 濒危 } \\
\text { /EN }\end{array}$ & 张孝民 & 主要气候因子对水杉径生长的影响 \\
\hline Metasequoia glyptostroboides & 水杉 & I & $\begin{array}{l}\text { 濒危 } \\
\text { /EN }\end{array}$ & 张孝民 & 主要气候因子对水杉径生长的影响 \\
\hline Michelia aenea & 灰毛含笑 & $\begin{array}{l}\text { 未列 } \\
\text { 入 }\end{array}$ & $\begin{array}{l}\text { 濒危 } \\
\text { /EN }\end{array}$ & 何国生 & 福建 8 种维管束植物分布新记录 \\
\hline Michelia aenea & 灰毛含笑 & $\begin{array}{l}\text { 未列 } \\
\text { 入 }\end{array}$ & $\begin{array}{l}\text { 濒危 } \\
\text { /EN }\end{array}$ & 於风林 & 灰毛含笑 \\
\hline Michelia aenea & 灰毛含笑 & $\begin{array}{l}\text { 未列 } \\
\text { 入 }\end{array}$ & $\begin{array}{l}\text { 濒危 } \\
\text { /EN }\end{array}$ & 孙起梦 & 灰毛含笑在南京的引种与繁殖 \\
\hline Michelia coriacea & 西畴含笑 & $\begin{array}{l}\text { 未列 } \\
\text { 入 }\end{array}$ & $\begin{array}{l}\text { 濒危 } \\
\text { /EN }\end{array}$ & Cindy Q. Tang & $\begin{array}{l}\text { Habitat Fragmentation, Degradation, and Population Status of Endangered } \\
\text { Michelia coriacea in Southeastern Yunnan, China }\end{array}$ \\
\hline Michelia coriacea & 西畴含笑 & $\begin{array}{l}\text { 未列 } \\
\text { 入 }\end{array}$ & $\begin{array}{l}\text { 濒危 } \\
/ \mathrm{EN}\end{array}$ & Xing-Feng Zhao & $\begin{array}{l}\text { Isolation and characterization of } 12 \text { microsatellite loci } \\
\text { for Michelia coriacea (Magnoliaceae), a critically endangered } \\
\text { endemic to Southeast Yunnan, China }\end{array}$ \\
\hline Michelia coriacea & 西畴含笑 & $\begin{array}{l}\text { 未列 } \\
\text { 入 }\end{array}$ & $\begin{array}{l}\text { 濒危 } \\
/ \mathrm{EN}\end{array}$ & 孙卫邦 & 极度濒危植物西畴含笑的大小孢子发生及雌雄配子体发育 \\
\hline
\end{tabular}


顾垒，闻丞，罗玫，王吴，吕植. 中国最受关注濒危物种保护现状快速评价的新方法探讨. 生物多样性，2015，23(5)：583-590. http://www. biodiversity-science. net/CN/article/downloadArticleFile. do?attachType=PDF\&id=10075

\begin{tabular}{|c|c|c|c|c|c|}
\hline \multirow[t]{2}{*}{ Michelia coriacea } & 西畴含笑 & 未列 & 濒危 & 张寿洲 & 木兰科 13 个分类群和 12 个杂交组合的染色体数目 \\
\hline & & 入 & $/ \mathrm{EN}$ & & \\
\hline \multirow[t]{3}{*}{ Michelia coriacea } & 西畴含笑 & 未列 & 濒危 & Weibang Sun & Abnormalities insexualdevelopmentandpollinatorlimitationin \\
\hline & & 入 & $/ \mathrm{EN}$ & & Michelia coriacea (Magnoliaceae), acriticallyendangered \\
\hline & & & & & endemic toSoutheastYunnan,China \\
\hline Michelia coriacea H. T. Chang & 多脉含笑 & 未列 & 极危 & 司马永康 & 极危植物多脉含笑的花部变异研究 \\
\hline etB. L. Chen) & & 入 & /CR & & \\
\hline \multirow[t]{2}{*}{ Michelia coriacea, } & 西畴含笑 & 未列 & 极危 & Weibang Sun & High Genetic Diversity and Low Differentiation of Michelia coriacea (Magnoliaceae), a \\
\hline & & 入 & /CR & & Critically Endangered Endemic in Southeast Yunnan, China \\
\hline \multirow[t]{3}{*}{ Michelia hedyosperma } & 香子含笑 & II & 未评 & Chong-Ren Yang & Phenylpropanoid glycosides from the seeds of Michelia hedyosperma \\
\hline & & & 价 & & \\
\hline & & & $/ \mathrm{NE}$ & & \\
\hline \multirow[t]{3}{*}{ Michelia hedyosperma } & 香子含笑 & II & 未评 & 管志斌 & 濒危植物香籽含笑的保护与利用研究 \\
\hline & & & 价 & & \\
\hline & & & $/ \mathrm{NE}$ & & \\
\hline \multirow[t]{3}{*}{ Michelia hedyosperma } & 香子含笑 & II & 未评 & 李国红 & 香子含笑中的杀线虫活性成分及其毒力测定 \\
\hline & & & 价 & & \\
\hline & & & $/ \mathrm{NE}$ & & \\
\hline Michelia wilsonii & 峨眉含笑 & II & 濒危 & 向成华 & 濒危植物峨眉含笑的遗传多样性研究 \\
\hline
\end{tabular}


顾垒，闻丞，罗玫，王吴，吕植. 中国最受关注濒危物种保护现状快速评价的新方法探讨. 生物多样性，2015，23(5)：583-590. http://www. biodiversity-science. net/CN/article/downloadArticleFile. do?attachType=PDF\&id=10075

\begin{tabular}{|c|c|c|c|c|c|}
\hline & & & /EN & & \\
\hline \multirow[t]{2}{*}{ Michelia wilsonii } & 峨眉含笑 & II & 濒危 & 张红 & 不同基质对峨眉含笑扞插繁殖的影响 \\
\hline & & & $/$ EN & & \\
\hline \multirow[t]{2}{*}{ Michelia wilsonii } & 峨眉含笑 & II & 濒危 & 朱秀志 & 峨眉含笑基因组 DNA 提取及 RAPD 反应体系的优化 \\
\hline & & & /EN & & \\
\hline \multirow[t]{2}{*}{ Michelia wilsonii } & 峨眉含笑 & II & 濒危 & 刘芳 & 峨眉含笑精油对冬查保鲜的研究 \\
\hline & & & /EN & & \\
\hline \multirow[t]{2}{*}{ Michelia wilsonii } & 峨眉含笑 & II & 濒危 & 刘芳 & 峨眉含笑精油抑菌作用研究 \\
\hline & & & /EN & & \\
\hline \multirow[t]{2}{*}{ Michelia wilsonii } & 峨眉含笑 & II & 濒危 & 刘晓捷 & 峨眉含笑扞插繁殖研究 \\
\hline & & & /EN & & \\
\hline \multirow[t]{2}{*}{ Michelia wilsonii } & 峨眉含笑 & II & 濒危 & 张建华 & 峨嵋含笑引种栽培技术的研究 \\
\hline & & & /EN & & \\
\hline \multirow[t]{2}{*}{ Michelia wilsonii } & 峨眉含笑 & II & 濒危 & 谷凤平 & 峨嵋含笑引种栽培技术研究 \\
\hline & & & /EN & & \\
\hline \multirow[t]{2}{*}{ Michelia wilsonii } & 峨眉含笑 & II & 濒危 & 裴文 & 九种木兰科常绿植物低温冷害生理指标的测定及耐寒性评价 \\
\hline & & & /EN & & \\
\hline \multirow[t]{2}{*}{ Michelia xanthantha } & 黄花含笑 & 未列 & 濒危 & 刘玉壸 & 中国含笑属新植物 \\
\hline & & 入 & /EN & & \\
\hline
\end{tabular}


顾垒，闻丞，罗玫，王吴，吕植. 中国最受关注濒危物种保护现状快速评价的新方法探讨. 生物多样性，2015，23(5)：583-590. http://www. biodiversity-science. net/CN/article/downloadArticleFile. do?attachType=PDF\&id=10075

\begin{tabular}{|c|c|c|c|c|c|}
\hline \multirow[t]{2}{*}{ Mitrephora wangii } & 云南银钩花 & 未列 & 易危 & 张成刚 & 云南银钩花中的 4 个生物碱 \\
\hline & & $\lambda$ & $/ \mathrm{VU}$ & & \\
\hline \multirow[t]{3}{*}{ Montifringilla henrici } & 藏雪雀 & 未列 & 数据 & 包新康 & 甘肃安西国家级自然保护区脊椎动物 20 年间的变化 \\
\hline & & $\lambda$ & 不足 & & \\
\hline & & & $/ \mathrm{DD}$ & & \\
\hline \multirow[t]{3}{*}{ Montifringilla henrici } & 藏雪雀 & 未列 & 数据 & 李靖 & 青藏铁路可可西里区段沿线的夏季鸟类 \\
\hline & & $\lambda$ & 不足 & & \\
\hline & & & $/ \mathrm{DD}$ & & \\
\hline \multirow[t]{3}{*}{ Montifringilla henrici } & 藏雪雀 & 未列 & 数据 & 杨乐 & 西藏 “一江两河” 流域鸟类资源调查初报 \\
\hline & & 入 & 不足 & & \\
\hline & & & $/ \mathrm{DD}$ & & \\
\hline \multirow[t]{2}{*}{ Moschus chrysogaster } & 马碍 & I & $\mathrm{LR} / \mathrm{n}$ & 胡锦毒 & 川西北高原马戕横断山亚种的夏季生境选择 \\
\hline & & & $\mathrm{t}$ & & \\
\hline \multirow[t]{2}{*}{ Moschus chrysogaster } & 马䳸 & I & $\mathrm{LR} / \mathrm{n}$ & 刘志霄 & 甘肃寿鹿山马䴤隔离小种群的资源现状与保护 \\
\hline & & & $\mathrm{t}$ & & \\
\hline \multirow[t]{2}{*}{ Moschus chrysogaster } & 马㯍 & I & $\mathrm{LR} / \mathrm{n}$ & 王功 & 甘肃兴隆山保护区马瘪资源的分布特征 \\
\hline & & & $\mathrm{t}$ & & \\
\hline \multirow[t]{2}{*}{ Moschus chrysogaster } & 马䴤 & I & $\mathrm{LR} / \mathrm{n}$ & 裴应泰 & 甘肃兴隆山马鹰资源现状及保护管理对策 \\
\hline & & & $\mathrm{t}$ & & \\
\hline
\end{tabular}


顾垒，闻丞，罗玫，王吴，吕植. 中国最受关注濒危物种保护现状快速评价的新方法探讨. 生物多样性，2015，23(5)：583-590. http://www biodiversity-science. net/CN/article/downloadArticleFile. do?attachType=PDF\&id=10075

\begin{tabular}{|c|c|c|c|c|c|}
\hline Moschus chrysogaster & 马廄 & I & $\mathrm{LR} / \mathrm{n}$ & 孟秀祥 & 甘肃兴隆山自然保护区马樃冬季生境喜好初步研究 \\
\hline Moschus chrysogaster & 马廄 & I & $\mathrm{LR} / \mathrm{n}$ & 孟秀祥 & 甘肃兴隆山自然保护区马瘪夏季栖息地特征及生境选择格局 \\
\hline Moschus chrysogaster & 马廐 & I & $\mathrm{LR} / \mathrm{n}$ & 刘志霄 & 贺兰山林区马榭隔离种群的生存现状及保护 \\
\hline Moschus chrysogaster & 马廄 & I & $\mathrm{LR} / \mathrm{n}$ & 梁军 & 贺兰山野生有蹄类动物的经济价值及种群动态变化 \\
\hline Moschus chrysogaster & 马廂 & I & $\mathrm{LR} / \mathrm{n}$ & 胡锦真 & 几种㯍分类地位的探讨 \\
\hline Moschus chrysogaster & 马廄 & I & $\mathrm{LR} / \mathrm{n}$ & 张亮 & $\begin{array}{l}\text { 林鹰、马㬭 SRY 基因的克隆与编码蛋白质的结构和功能预测及其在系统进化分析中的应 } \\
\text { 用 }\end{array}$ \\
\hline Moschus chrysogaster & 马楕 & I & $\mathrm{LR} / \mathrm{n}$ & 岳碧松 & 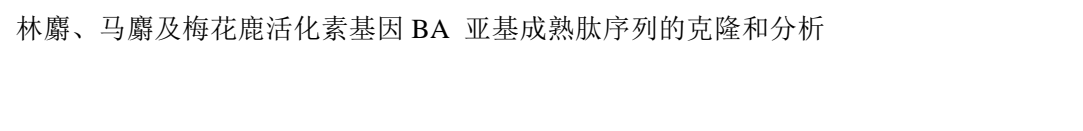 \\
\hline Moschus chrysogaster & 马廄 & I & $\mathrm{LR} / \mathrm{n}$ & 岳碧松 & 林㢒及马瘪 SRY 基因片段克隆及其在系统进化分析中的应用 \\
\hline Moschus chrysogaster & 马廄 & I & $\begin{array}{l}\mathrm{LR} / \mathrm{n} \\
\mathrm{t}\end{array}$ & 孟秀祥 & 马瘪( Moschus sif anicus ) 的分婏时间格局 \\
\hline Moschus chrysogaster & 马楕 & I & $\mathrm{LR} / \mathrm{n}$ & 胡锦青 & 马穏年龄指标的判别分析 \\
\hline
\end{tabular}


顾垒，闻丞，罗玫，王吴，吕植. 中国最受关注濒危物种保护现状快速评价的新方法探讨. 生物多样性，2015，23(5)：583-590. http://www. biodiversity-science. net/CN/article/downloadArticleFile. do?attachType=PDF\&id=10075

\begin{tabular}{|c|c|c|c|c|c|}
\hline & & & $\mathrm{t}$ & & \\
\hline Moschus chrysogaster & 马㭩 & I & $\begin{array}{l}\mathrm{LR} / \mathrm{n} \\
\mathrm{t}\end{array}$ & 吴润 & 马瘪朊蛋白（PrP）基因的克隆和序列分析 \\
\hline Moschus chrysogaster & 马楾 & I & $\begin{array}{l}\mathrm{LR} / \mathrm{n} \\
\mathrm{t}\end{array}$ & 姜中毅 & 马榭朊蛋白基因的克隆与原核表达 \\
\hline Moschus chrysogaster & 马鹰 & I & $\mathrm{LR} / \mathrm{n}$ & 吴润 & 马麾朊蛋白基因的克隆与原核表达 \\
\hline Moschus chrysogaster & 马榒 & I & $\mathrm{LR} / \mathrm{n}$ & 黄有德 & 马㯍生理生化正常值的测定 \\
\hline Moschus chrysogaster & 马㯍 & I & $\mathrm{LR} / \mathrm{n}$ & 杨奇森 & 圈养马戕发情交配后期的日活动格局 \\
\hline Moschus chrysogaster & 马瘒 & I & $\mathrm{LR} / \mathrm{n}$ & 何玲 & 四川平武水牛家水电站工程影响区及火溪河流域的兽类研究 \\
\hline Moschus chrysogaster & 马瘪 & I & $\begin{array}{l}\mathrm{LR} / \mathrm{n} \\
\mathrm{t}\end{array}$ & 胡锦囁 & 四川石渠县有蹄类动物夏季群落特征初步分析 \\
\hline Moschus chrysogaster & 马穏 & I & $\mathrm{LR} / \mathrm{n}$ & 刘务林 & 西藏㯍类资源研究 \\
\hline Moschus chrysogaster & 马㯍 & I & $\mathrm{LR} / \mathrm{n}$ & 潘世秀 & 兴隆山马熨栖息地选择研究 \\
\hline
\end{tabular}


顾垒，闻丞，罗玫，王吴，吕植. 中国最受关注濒危物种保护现状快速评价的新方法探讨. 生物多样性，2015，23(5)：583-590. http://www biodiversity-science. net/CN/article/downloadArticleFile. do?attachType=PDF\&id=10075

\begin{tabular}{|c|c|c|c|c|c|}
\hline Moschus chrysogaster & 马鹰 & I & $\begin{array}{l}\mathrm{LR} / \mathrm{n} \\
\mathrm{t}\end{array}$ & 康发功 & 兴隆山马瘪栖息生境种群数量变化分析及保护 \\
\hline Moschus chrysogaster & 马鹰 & I & $\begin{array}{l}\mathrm{LR} / \mathrm{n} \\
\mathrm{t}\end{array}$ & 康发功 & 兴隆山马穏资源种群数量变化研究 \\
\hline Moschus chrysogaster & 马㭩 & I & $\begin{array}{l}\mathrm{LR} / \mathrm{n} \\
\mathrm{t}\end{array}$ & 杨奇森 & 兴隆山圈养马看的行为多样性 \\
\hline Moschus chrysogaster & 马鹰 & I & $\begin{array}{l}\mathrm{LR} / \mathrm{n} \\
\mathrm{t}\end{array}$ & 冯金朝 & 兴隆山自然保护区马楾春季生境选择 \\
\hline Moschus chrysogaster & 马廄 & I & $\begin{array}{l}\mathrm{LR} / \mathrm{n} \\
\mathrm{t}\end{array}$ & 王向伟 & 野生马㭩功能性生境选择 \\
\hline Myospalax fontanierii & 中华鼬鼠 & $\begin{array}{l}\text { 未列 } \\
\text { 入 }\end{array}$ & $\begin{array}{l}\text { 易危 } \\
\text { /VU }\end{array}$ & 李晓晨 & 3 种䧟鼠牙齿釉质超微结构的比较 \\
\hline Myospalax fontanierii & 中华鼠鼠 & $\begin{array}{l}\text { 未列 } \\
\text { 入 }\end{array}$ & $\begin{array}{l}\text { 易危 } \\
\text { /VU }\end{array}$ & Yanming Zhang & $\begin{array}{l}\text { Burrowing rodents as ecosystem engineers: the ecology and management of plateau zokors } \\
\text { Myospalax fontanierii in alpine meadow ecosystems on the Tibetan Plateau }\end{array}$ \\
\hline Myospalax fontanierii & 中华鼠鼠 & 未列 & $\begin{array}{l}\text { 易危 } \\
\text { /VU }\end{array}$ & $\begin{array}{l}\text { ZHOU Cai- Quan; } \\
\text { HU Jin-Chu }\end{array}$ & $\begin{array}{l}\text { THE TAXONOMIC STATUSES OF MYOSPALAX CANSUS , M . BAILEYI AND M . } \\
\text { RUFESCENS , BASED ON THE COMPARISONS OF MEDULLARY INDEXES OF HAIRS }\end{array}$ \\
\hline Myospalax fontanierii & 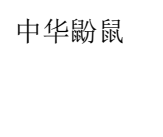 & 未列 & $\begin{array}{l}\text { 易危 } \\
\text { /VU }\end{array}$ & 周材权 & 山西隰县中华夦鼠洞址选择 \\
\hline Myristica yunnanensis & 云南肉豆冦 & II & 极危 & WEN-BIN YU & NOMENCLATURAL NOTES ON MYRISTICA YUNNANENSIS AND \\
\hline
\end{tabular}


顾垒，闻丞，罗玫，王吴，吕植. 中国最受关注濒危物种保护现状快速评价的新方法探讨. 生物多样性，2015，23(5)：583-590. http://www biodiversity-science. net/CN/article/downloadArticleFile. do?attachType=PDF\&id=10075

\begin{tabular}{|c|c|c|c|c|c|}
\hline & & & /CR & & CYCLOBALANOPSIS YONGANENSIS \\
\hline \multirow[t]{2}{*}{ Myristica yunnanensis } & 云南肉豆冦 & II & 极危 & 曹坤芳 & 四种热带雨林树种光合和形态解剖特征对不同生长光强的适应 \\
\hline & & & /CR & & \\
\hline \multirow[t]{2}{*}{ Myristica yunnanensis } & 云南肉豆蔻 & II & 极危 & 郑征 & 西双版纳不同海拔 4 种雨林幼苗的光合特性和生物量 \\
\hline & & & /CR & & \\
\hline \multirow[t]{2}{*}{ Myristica yunnanensis } & 云南肉豆冦 & II & 极危 & 郑征 & 西双版纳热带季节雨林 4 种树种幼苗生长死亡对海拔变化的反应 \\
\hline & & & /CR & & \\
\hline \multirow[t]{2}{*}{ Myristica yunnanensis } & 云南肉豆冦 & II & 极危 & 李建北 & 云南肉豆冦化学成分的研究 \\
\hline & & & /CR & & \\
\hline \multirow[t]{2}{*}{ Naemorhedus baileyi } & 赤斑羚 & I & 易危 & 吴鹏举 & 慈巴沟自然保护区内的大中型动物 \\
\hline & & & /VU & & \\
\hline \multirow[t]{2}{*}{ Naemorhedus baileyi } & 赤斑羚 & I & 易危 & 郑建清 & 圈养条件下赤斑羚夏季昼间行为时间分配及活动规律 \\
\hline & & & /VU & & \\
\hline \multirow[t]{2}{*}{ Naemorhedus goral } & 斑羚 & 未列 & 近危 & Woo -Shin LEE & CHANGES IN DISTRIBUTION OF AMUR GORAL (NEMORHAEDUS CAUDATUS)IN \\
\hline & & 入 & /NT & & SOUTH KOREA \\
\hline \multirow[t]{2}{*}{ Naemorhedus goral } & 斑羚 & 未列 & 近危 & 王春艳 & 黑斑羚溶血性巴氏杆菌病一例 \\
\hline & & 入 & /NT & & \\
\hline \multirow[t]{2}{*}{ Naemorhedus goral } & 斑羚 & 未列 & 近危 & 王文 & 黑龙江龙口自然保护区斑羚冬季食性分析 \\
\hline & & 入 & /NT & & \\
\hline
\end{tabular}


顾垒，闻丞，罗玫，王吴，吕植. 中国最受关注濒危物种保护现状快速评价的新方法探讨. 生物多样性，2015，23(5)：583-590. http://www. biodiversity-science. net/CN/article/downloadArticleFile. do?attachType=PDF\&id=10075

\begin{tabular}{|c|c|c|c|c|c|}
\hline \multirow[t]{2}{*}{ Naemorhedus goral } & 斑羚 & 未列 & 近危 & 郭文利 & 笼养红斑羚生态生物学的初步观察 \\
\hline & & 入 & /NT & & \\
\hline \multirow[t]{2}{*}{ Naemorhedus goral } & 斑羚 & 未列 & 近危 & 谢燕 & 圈养条件下赤斑羚发情期行为研究 \\
\hline & & 入 & /NT & & \\
\hline \multirow[t]{2}{*}{ Naemorhedus goral } & 斑羚 & 未列 & 近危 & 郑建清 & 圈养条件下赤斑羚夏季昼间行为时间分配及活动规律 \\
\hline & & 入 & /NT & & \\
\hline \multirow[t]{2}{*}{ Naemorhedus goral } & 斑羚 & 未列 & 近危 & 张君 & 四川蜂桶寨自然保护区斑羚春季生境选择 \\
\hline & & 入 & /NT & & \\
\hline \multirow[t]{2}{*}{ Naemorhedus goral } & 斑羚 & 未列 & 近危 & 王淯 & 四川省巴塘县矮岩羊与斑羚冬季生境比较 \\
\hline & & 入 & /NT & & \\
\hline \multirow[t]{2}{*}{ Naemorhedus goral } & 斑羚 & 未列 & 近危 & 吴华 & 四川唐家河羚牛、鬛羚、斑羚春冬季生境选择比较研究 \\
\hline & & 入 & /NT & & \\
\hline \multirow[t]{2}{*}{ Naemorhedus goral } & 斑羚 & 未列 & 近危 & 陈伟 & 唐家河国家级自然保护区斑羚夏季生境选择研究 \\
\hline & & 入 & /NT & & \\
\hline \multirow[t]{2}{*}{ Naemorhedus goral } & 斑羚 & 未列 & 近危 & 吴华 & 唐家河自然保护区斑羚春冬季对生境的选择 \\
\hline & & 入 & /NT & & \\
\hline \multirow[t]{2}{*}{ Naemorhedus goral } & 斑羚 & 未列 & 近危 & 吴建平 & 小兴安岭通河林区斑羚冬季食性分析 \\
\hline & & 入 & /NT & & \\
\hline Naemorhedus goral & 斑羚 & 未列 & 近危 & 于三科 & 一例死亡野生斑羚寄生虫种类的调查研究 \\
\hline
\end{tabular}


顾垒，闻丞，罗玫，王吴，吕植. 中国最受关注濒危物种保护现状快速评价的新方法探讨. 生物多样性，2015，23(5)：583-590. http://www. biodiversity-science. net/CN/article/downloadArticleFile. do?attachType=PDF\&id=10075

\begin{tabular}{|c|c|c|c|c|c|}
\hline & & 入 & /NT & & \\
\hline \multirow[t]{2}{*}{ Naemorhedus goral } & 斑羚 & 未列 & 近危 & 于孝臣 & 原㯍和斑羚冬季种间关系的研究 \\
\hline & & 入 & /NT & & \\
\hline \multirow[t]{2}{*}{ Naemorhedus goral } & 斑羚 & 未列 & 近危 & 吴建平 & 原㯍与斑羚冬季家域的对比 \\
\hline & & 入 & /NT & & \\
\hline \multirow[t]{2}{*}{ Nanorana pleskei } & 倭蛙 & 未列 & 近危 & 王跃招 & 若尔盖湿地 3 种无尾两栖类不同发育阶段的生态位宽度 \\
\hline & & 入 & /NT & & \\
\hline \multirow[t]{2}{*}{ Nanorana pleskei } & 倭蛙 & 未列 & 近危 & 王跃招 & 若尔盖湿地国家自然保护区三种无尾两栖类夏秋季生境选择 \\
\hline & & 入 & /NT & & \\
\hline \multirow[t]{2}{*}{ Nanorana pleskei } & 倭蛙 & 未列 & 近危 & 赵尔宓 & 倭蛙属(无尾目：蛙科)肩带研究 \\
\hline & & 入 & /NT & & \\
\hline \multirow[t]{2}{*}{ Neocheiropteris palmatopedata } & 扇蕨 & II & 濒危 & Ye-Gao Chen & Isolation and evaluation of kaempferol glycosides from the fern Neocheiropteris palmatopedata \\
\hline & & & /EN & & \\
\hline \multirow[t]{2}{*}{ Neocheiropteris palmatopedata } & 扇瞢 & II & 濒危 & 叶晓青 & 不同类型细胞分裂素对扇蕨不定芽诱导和植株再生的影响 \\
\hline & & & /EN & & \\
\hline \multirow[t]{2}{*}{ Neocheiropteris palmatopedata } & 扇蕨 & II & 濒危 & 张光飞 & 光照和温度对扇蕨狍子萌发的影响 \\
\hline & & & /EN & & \\
\hline \multirow[t]{2}{*}{ Neocheiropteris palmatopedata } & 扇偋 & II & 濒危 & 张光飞 & 扇硕狍子的组织培养 \\
\hline & & & /EN & & \\
\hline
\end{tabular}


顾垒，闻丞，罗玫，王吴，吕植. 中国最受关注濒危物种保护现状快速评价的新方法探讨. 生物多样性，2015，23(5)：583-590. http://www biodiversity-science. net/CN/article/downloadArticleFile. do?attachType=PDF\&id=10075

\begin{tabular}{|c|c|c|c|c|c|}
\hline Neocheiropteris palmatopedata & 扇䓲 & II & $\begin{array}{l}\text { 濒危 } \\
\text { /EN }\end{array}$ & 张光飞 & 扇蒴绿色小球体的诱导和植株再生 \\
\hline Neocheiropteris palmatopedata & 扇蕨 & II & $\begin{array}{l}\text { 濒危 } \\
\text { /EN }\end{array}$ & 成晓 & 扇葓配子体发育与濒危机制的探讨 \\
\hline Neocheiropteris palmatopedata & 扇蕨 & II & $\begin{array}{l}\text { 濒危 } \\
\text { /EN }\end{array}$ & 张光飞 & 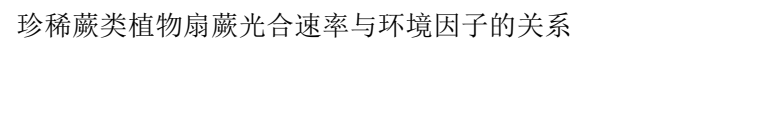 \\
\hline Neocheiropteris palmatopedata & 扇荻 & II & $\begin{array}{l}\text { 濒危 } \\
\text { /EN }\end{array}$ & 张光飞 & 珍稀蔗类植物扇蔗光合作用与环境因子的关系 \\
\hline Neocheiropteris palmatopedata & 扇䓲 & II & $\begin{array}{l}\text { 濒危 } \\
\text { /EN }\end{array}$ & 成晓 & 中国特有濒危植物扇蔽的生物生态学特性及其濒危机制初探 \\
\hline Neophron percnopterus & 白兀鹑 & $\begin{array}{l}\text { 未列 } \\
\text { 入 }\end{array}$ & $\begin{array}{l}\text { 濒危 } \\
\text { /EN }\end{array}$ & 刘阳 & 近年来中国鸟类野外新纪录的解析 \\
\hline Neophron percnopterus & 白兀鹑 & $\begin{array}{l}\text { 未列 } \\
\text { 入 }\end{array}$ & $\begin{array}{l}\text { 濒危 } \\
\text { /EN }\end{array}$ & 郭宏 & 中国鸟类新纪录一一白兀鹑(Neophron percnopterus) \\
\hline Ninox scutulata & 鹰鸮 & II & $\begin{array}{l}\text { 无危 } \\
\text { /LC }\end{array}$ & 李永民 & 安徽颖州西湖省级湿地自然保护区鸟类资源调查初报 \\
\hline Ninox scutulata & 鹰鸮 & II & $\begin{array}{l}\text { 无危 } \\
\text { /LC }\end{array}$ & 闻丞 & 北京大学燕园鸟类组成 \\
\hline Ninox scutulata & 鹰鸮 & II & 无危 & 唐 巍 & 川东北_川西输气联络线工程对驱马保护区的影响评价及对策 \\
\hline
\end{tabular}


顾垒，闻丞，罗玫，王吴，吕植. 中国最受关注濒危物种保护现状快速评价的新方法探讨. 生物多样性，2015，23(5)：583-590. http://www. biodiversity-science. net/CN/article/downloadArticleFile. do?attachType=PDF\&id=10075

\begin{tabular}{|c|c|c|c|c|c|}
\hline & & & $/ \mathrm{LC}$ & & \\
\hline \multirow[t]{2}{*}{ Ninox scutulata } & 鹰鸮 & II & 无危 & 江建国 & 鄂西野三河自然保护区鸟类资源调查报告 \\
\hline & & & $/ \mathrm{LC}$ & & \\
\hline \multirow[t]{2}{*}{ Ninox scutulata } & 鹰鸮 & II & 无危 & 蒋爱伍 & 河池学院校园鸟类初步调查 \\
\hline & & & $/ \mathrm{LC}$ & & \\
\hline \multirow[t]{2}{*}{ Ninox scutulata } & 鹰鸮 & II & 无危 & 金志民 & 黑龙江牡丹峰自然保护区鸟类多样性分析 \\
\hline & & & $/ \mathrm{LC}$ & & \\
\hline \multirow[t]{2}{*}{ Ninox scutulata } & 鹰鸮 & II & 无危 & 杜艳玲 & 珲春自然保护区首现鹰鸮 \\
\hline & & & $/ \mathrm{LC}$ & & \\
\hline \multirow[t]{2}{*}{ Ninox scutulata } & 鹰鸮 & II & 无危 & 黄晓凤 & 江西齐云山自然保护区鸟类区系与多样性分析 \\
\hline & & & $/ \mathrm{LC}$ & & \\
\hline \multirow[t]{2}{*}{ Ninox scutulata } & 鹰鸮 & II & 无危 & 程松林 & 江西武夷山国家级自然保护区鸟类多样性调查 \\
\hline & & & $/ \mathrm{LC}$ & & \\
\hline \multirow[t]{2}{*}{ Ninox scutulata } & 鹰鸮 & II & 无危 & 苏秀 & 龙王山自然保护区生物物种多样性及其保护 \\
\hline & & & $/ \mathrm{LC}$ & & \\
\hline \multirow[t]{2}{*}{ Ninox scutulata } & 鹰鸮 & II & 无危 & 谭家林 & 三峡大老岭秋季环志鸟类资源初步调查 \\
\hline & & & $/ \mathrm{LC}$ & & \\
\hline \multirow[t]{2}{*}{ Ninox scutulata } & 鹰鸮 & II & 无危 & 符建荣 & 四川大相岭自然保护区的鸟类资源 \\
\hline & & & /LC & & \\
\hline
\end{tabular}


顾垒，闻丞，罗玫，王吴，吕植. 中国最受关注濒危物种保护现状快速评价的新方法探讨. 生物多样性，2015，23(5)：583-590. http://www. biodiversity-science. net/CN/article/downloadArticleFile. do?attachType=PDF\&id=10075

\begin{tabular}{|c|c|c|c|c|c|}
\hline Ninox scutulata & 鹰鸮 & II & $\begin{array}{l}\text { 无危 } \\
\text { /LC }\end{array}$ & 张 君 & 四川东阳沟自然保护区鸟类区系初步调查 \\
\hline Ninox scutulata & 鹰鸮 & II & $\begin{array}{l}\text { 无危 } \\
\text { /LC }\end{array}$ & 武丙琳 & 西天目山旅游区鸟类群落结构变化及保护对策研究 \\
\hline Ninox scutulata & 鹰鸮 & II & $\begin{array}{l}\text { 无危 } \\
\text { /LC }\end{array}$ & 舒 实 & 茢山自然保护区珍稀濒危野生脊椎动物调查 \\
\hline Nipponia nippon & 朱哭 & I & $\begin{array}{l}\text { 濒危 } \\
\text { /EN }\end{array}$ & 付志超 & 城固县 $20003-20012$ 年野生朱睘繁殖数量统计 \\
\hline Nipponia nippon & 朱器 & I & $\begin{array}{l}\text { 濒危 } \\
\text { /EN }\end{array}$ & 付志超 & 城固县野生朱噮种群面临的困境与保护对策 \\
\hline Nipponia nippon & 朱哭 & I & $\begin{array}{l}\text { 濒危 } \\
\text { /EN }\end{array}$ & 祝国军 & 佛坪首次发现朱噮巢穴 \\
\hline Nipponia nippon & 朱哭鸟 & I & $\begin{array}{l}\text { 濒危 } \\
\text { /EN }\end{array}$ & 朱家贵 & 迁地朱鹮人工繁殖维鸟的生长发育观察 \\
\hline Nipponia nippon & 朱器 & I & $\begin{array}{l}\text { 濒危 } \\
\text { /EN }\end{array}$ & 李 夏 & 陕西宁陕朱鹑再引入种群个体死亡原因分析 \\
\hline Nipponia nippon & 朱哭 & I & $\begin{array}{l}\text { 濒危 } \\
\text { /EN }\end{array}$ & 赵洪峰 & 陕西湑水河下游城固段朱鰾游荡期的食物丰富度 \\
\hline Nipponia nippon & 朱鹮 & I & 濒危 & 周华明 & 西乡县鸟类资源及保护对策 \\
\hline
\end{tabular}


顾垒，闻丞，罗玫，王昊，吕植. 中国最受关注濒危物种保护现状快速评价的新方法探讨．生物多样性，2015，23(5)：583-590. http://www. biodiversity-science. net/CN/article/downloadArticleFile. do?attachType=PDF\&id=10075

Nomascus concolor

黑长臂猿

极危

蒋学龙

Nomascus concolor

黑长臂猿

蒋学龙

Nomascus concolor

黑长臂猿

及蒋学龙

Nomascus concolor

黑长臂猿

极危蒋学龙

Nomascus concolor

黑长臂猿

黑长臂猿

Nomascus concolor

Nomascus concolor

黑长臂猿

黑长臂猿

Nomascus concolor

黑长臂猿

Nomascus concolor
Yunnan,China: the role of forest types in the species'conservation

哀牢山国家级自然保护区黑长臂猿栖息地森林群落结构研究

jingdongensis) at Mt. Wuliang, Central Yunnan, Chin
(Nomascus concolor jingdongensis) in Central Yunnan, China

Effects of Food and Topography on Ranging Behavior of Black Crested Gibbon(Nomascus concolor jingdongensis) in Wuliang Mountain, Yunnan, China

Proximity association in polygynous western black crested gibbons(Nomascus concolor

jingdongensis): network structure and seasonality

Singing Behavior and Singing Functions of Black-Crested Gibbons(Nomascus concolor

Sleeping Sites, Sleeping Trees, and Sleep-related Behaviors of Black Crested Gibbons

(Nomascus concolor jingdongensis) at Mt. Wuliang,Central Yunnan, China

Social Structure and Group Dynamics of the Cao Vit Gibbon (Nomascus nasutus) i

The Critically Endangered black crested gibbon Nomascus concoloron Wuliang Mountain, 
顾垒，闻丞，罗玫，王吴，吕植. 中国最受关注濒危物种保护现状快速评价的新方法探讨. 生物多样性，2015，23(5)：583-590. http://www, biodiversity-science. net/CN/article/downloadArticleFile. do?attachType=PDF\&id=10075

\begin{tabular}{|c|c|c|c|c|c|}
\hline & & & /CR & & \\
\hline \multirow[t]{2}{*}{ Nomascus concolor } & 黑长臂猿 & I & 极危 & 李永昌 & 哀牢山自然保护区黑长臂猿数量与分布调查与分析 \\
\hline & & & /CR & & \\
\hline \multirow[t]{2}{*}{ Nomascus concolor } & 黑长臂猿 & I & 极危 & 马世来 & 滇南、滇东南黑冠长臂猿分布与数量 \\
\hline & & & /CR & & \\
\hline \multirow[t]{2}{*}{ Nomascus concolor } & 黑长臂猿 & I & 极危 & 田长城 & 滇中无量山黑长臂猿栖息地乔木层物种多样性研究 \\
\hline & & & /CR & & \\
\hline \multirow[t]{2}{*}{ Nomascus concolor } & 黑长臂猿 & I & 极危 & 费汉榄 & 东黑冠长臂猿 Nomascusnasutus 鸣叫行为研究 \\
\hline & & & /CR & & \\
\hline \multirow[t]{2}{*}{ Nomascus concolor } & 黑长臂猿 & I & 极危 & 范朋飞 & 东黑冠长臂猿鸣叫声谱分析 \\
\hline & & & /CR & & \\
\hline \multirow[t]{2}{*}{ Nomascus concolor } & 黑长臂猿 & I & 极危 & 范朋飞 & 东黑冠长臂猿鸣叫特征及气象因子对鸣叫的影响 \\
\hline & & & /CR & & \\
\hline \multirow[t]{2}{*}{ Nomascus concolor } & 黑长臂猿 & I & 极危 & 张文 & 广西靖西县东黑冠长臂猿_Nomascusnasutus_取食生态初步研究 \\
\hline & & & /CR & & \\
\hline \multirow[t]{2}{*}{ Nomascus concolor } & 黑长臂猿 & I & 极危 & 吴巍 & 海南黑冠长臂猿(Nomascus sp.cf.nasutus hainanus)保护生物学现状及保护对策 \\
\hline & & & /CR & & \\
\hline \multirow[t]{2}{*}{ Nomascus concolor } & 黑长臂猿 & I & 极危 & 周江 & 海南黑冠长臂猿的生态学及行为特征 \\
\hline & & & /CR & & \\
\hline
\end{tabular}


顾垒，闻丞，罗玫，王吴，吕植. 中国最受关注濒危物种保护现状快速评价的新方法探讨. 生物多样性，2015，23(5)：583-590. http://www. biodiversity-science. net/CN/article/downloadArticleFile. do?attachType=PDF\&id=10075

\begin{tabular}{|c|c|c|c|c|c|}
\hline Nomascus concolor & 黑长臂猿 & I & $\begin{array}{l}\text { 极危 } \\
\text { /CR }\end{array}$ & 王应祥 & 黑长臂猿的现状、分布与保护 \\
\hline Nomascus concolor & 黑长臂猿 & I & $\begin{array}{l}\text { 极危 } \\
\text { /CR }\end{array}$ & 范朋飞 & 黑长臂猿哥本的一天 \\
\hline Nomascus concolor & 黑长臂猿 & I & $\begin{array}{l}\text { 极危 } \\
\text { /CR }\end{array}$ & 周守标 & 黑长臂猿栖息地旱冬瓜和渌槁木姜子种群分布格局和动态 \\
\hline Nomascus concolor & 黑长臂猿 & I & $\begin{array}{l}\text { 极危 } \\
\text { /CR }\end{array}$ & 蒋学龙 & 无量山大寨子黑长臂猿（Nomascus concolor jingdongensis）种群生存力 \\
\hline Nomascus concolor & 黑长臂猿 & I & $\begin{array}{l}\text { 极危 } \\
\text { /CR }\end{array}$ & 蒋学龙 & 无量山大寨子黑长臂猿一夫二妻制的群体结构及其行为学原因 \\
\hline Nomascus concolor & 黑长臂猿 & I & $\begin{array}{l}\text { 极危 } \\
\text { /CR }\end{array}$ & 刘长铭 & 无量山黑长臂猿保护现状及问题分析 \\
\hline Nomascus concolor & 黑长臂猿 & I & $\begin{array}{l}\text { 极危 } \\
\text { /CR }\end{array}$ & 蒋学龙 & 无量山西黑冠长臂猿二重唱的声谱结构和时间特征 \\
\hline Nomascus concolor & 黑长臂猿 & I & $\begin{array}{l}\text { 极危 } \\
\text { /CR }\end{array}$ & 蒋学龙 & 西黑冠长臂猿雄性取代前后鸣叫行为的变化 \\
\hline Nomascus concolor & 黑长臂猿 & I & $\begin{array}{l}\text { 极危 } \\
\text { /CR }\end{array}$ & 罗文寿 & 云南哀牢山国家级自然保护区景东辖区黑长臂猿种群数量和分布 \\
\hline Nomascus concolor & 黑长臂猿 & I & 极危 & 蒋学龙 & 云南哀牢山平河黑长臂猿栖息地乔木结构分析 \\
\hline
\end{tabular}


顾垒，闻丞，罗玫，王吴，吕植. 中国最受关注濒危物种保护现状快速评价的新方法探讨. 生物多样性，2015，23(5)：583-590. http://www. biodiversity-science. net/CN/article/downloadArticleFile. do?attachType=PDF\&id=10075

\begin{tabular}{|c|c|c|c|c|c|}
\hline & & & /CR & & \\
\hline \multirow[t]{2}{*}{ Nomascus concolor } & 黑长臂猿 & I & 极危 & 华朝朗 & 云南省西黑冠长臂猿现状及保护对策 \\
\hline & & & /CR & & \\
\hline \multirow[t]{2}{*}{ Nomascus concolor } & 黑长臂猿 & I & 极危 & 罗忠华 & 云南无量山国家级自然保护区西部黑冠长臂猿景东亚种的群体数量与分布调查 \\
\hline & & & /CR & & \\
\hline \multirow[t]{2}{*}{ Nomascus concolor } & 黑长臂猿 & I & 极危 & 蒋学龙 & 云南无量山黑长臂猿对植物种子的传播作用 \\
\hline & & & /CR & & \\
\hline \multirow[t]{2}{*}{ Nomascus concolor } & 黑长臂猿 & I & 极危 & 李国松 & 云南新平哀牢山西黑冠长臂猿分布与群体数量 \\
\hline & & & /CR & & \\
\hline \multirow[t]{2}{*}{ Nomascus concolor } & 黑长臂猿 & I & 极危 & 蒋学龙 & 云南中部无量山黑长臂猿 (Nomascus concolor jingdongensis)栖息地乔木层物种多样性和 \\
\hline & & & /CR & & 结构特征 \\
\hline \multirow[t]{2}{*}{ Nomascus leucogenys } & 白㚘长臂猿 & I & 极危 & 张可晶 & 白㚘长臂猿发情与交配行为的观察 \\
\hline & & & /CR & & \\
\hline \multirow[t]{2}{*}{ Nomascus leucogenys } & 白项长臂猿 & I & 极危 & 刘燕 & 肺炎克雷伯氏菌致白颊长臂猿脓肿一例 \\
\hline & & & /CR & & \\
\hline \multirow[t]{2}{*}{ Nomascus leucogenys } & 白㚘长臂猿 & I & 极危 & 李国锋 & 雄性白㚘长臂猿的饲养 \\
\hline & & & /CR & & \\
\hline \multirow[t]{2}{*}{ Nomascus leucogenys } & 白㚘长臂猿 & I & 极危 & 黄宁 & 治疗白颊长臂猿破伤风病例 \\
\hline & & & /CR & & \\
\hline
\end{tabular}


顾垒，闻丞，罗玫，王吴，吕植. 中国最受关注濒危物种保护现状快速评价的新方法探讨. 生物多样性，2015，23(5)：583-590. http://www. biodiversity-science. net/CN/article/downloadArticleFile. do?attachType=PDF\&id=10075

\begin{tabular}{|c|c|c|c|c|c|}
\hline Nomascus leucogenys & 白颊长臂猿 & I & 极危 & 张可晶 & 自然育幼的成功 \\
\hline Nouelia insignis & 栌菊木 & II & $\begin{array}{l}\text { 近危 } \\
\text { /NT }\end{array}$ & 周乐 & 2D NMR 对栌菊木中的一个倍半萜内酯进行结构解析 \\
\hline Nouelia insignis & 栌菊木 & II & $\begin{array}{l}\text { 近危 } \\
\text { /NT }\end{array}$ & GUOLIN ZHANG & Chemical constituents of Nouelia insignis Franch \\
\hline Nouelia insignis & 栌菊木 & II & $\begin{array}{l}\text { 近危 } \\
\text { /NT }\end{array}$ & XUN GONG & $\begin{array}{l}\text { High Genetic Diversity vs. Low Genetic Differentiation in Nouelia insignis (Asteraceae), a } \\
\text { Narrowly Distributed and Endemic Species in China, Revealed by ISSR Fingerprinting }\end{array}$ \\
\hline Nouelia insignis & 栌菊木 & II & $\begin{array}{l}\text { 近危 } \\
\text { /NT }\end{array}$ & XUN GONG & $\begin{array}{l}\text { Population structure of Nouelia insignis (Asteraceae), an endangered species in southwestern } \\
\text { China, based on chloroplast DNA sequences: recent demographic shrinking }\end{array}$ \\
\hline Nouelia insignis & 栌菊木 & II & $\begin{array}{l}\text { 近危 } \\
\text { /NT }\end{array}$ & 孙航 & 栌菊木的等位酶分析及其在生物地理和保护生物学上的意义 \\
\hline Nouelia insignis & 栌菊木 & II & $\begin{array}{l}\text { 近危 } \\
\text { /NT }\end{array}$ & 周乐 & 栌菊木地上部分化学成分的研究 \\
\hline Nouelia insignis & 栌菊木 & II & $\begin{array}{l}\text { 近危 } \\
\text { /NT }\end{array}$ & 顾志建 & 栌菊木属及白菊木属的细胞学研究 \\
\hline Nouelia insignis & 栌菊木 & II & $\begin{array}{l}\text { 近危 } \\
\text { /NT }\end{array}$ & 龚洵 & 栌菊木遗传多样性研究 \\
\hline Nouelia insignis & 栌菊木 & II & 近危 & 唐宇 & 攀西珍稀濒危植物护菊木的现状及保护措施 \\
\hline
\end{tabular}


顾垒，闻丞，罗玫，王吴，吕植. 中国最受关注濒危物种保护现状快速评价的新方法探讨. 生物多样性，2015，23(5)：583-590. http://www. biodiversity-science. net/CN/article/downloadArticleFile. do?attachType=PDF\&id=10075

\begin{tabular}{|c|c|c|c|c|c|}
\hline & & & /NT & & \\
\hline \multirow[t]{2}{*}{ Nouelia insignis } & 栌菊木 & II & 近危 & 黄中强 & 攀枝花市护菊木资源的调查与应用初探 \\
\hline & & & /NT & & \\
\hline \multirow[t]{3}{*}{ Nouelia insignis Franch } & 栌菊木 & 未列 & 未评 & 顾志建 & 栌菊木属及白菊木属的细胞学研究 \\
\hline & & 入 & 价 & & \\
\hline & & & $/ \mathrm{NE}$ & & \\
\hline \multirow[t]{2}{*}{ Nyctea scandiaca } & 雪鸮 & II & 无危 & 王 山 & 阿尔泰两河源物种多样性及其保护 \\
\hline & & & $/ \mathrm{LC}$ & & \\
\hline \multirow[t]{2}{*}{ Nyctea scandiaca } & 雪鸮 & II & 无危 & 李艳 & 达麥湖保护区湿地鸟类多样性 \\
\hline & & & $/ \mathrm{LC}$ & & \\
\hline \multirow[t]{2}{*}{ Nyctea scandiaca } & 雪鸮 & II & 无危 & 张佰莲 & 黑龙江大沾河湿地自然保护区鸟类群落结构调查及其多样性分析 \\
\hline & & & $/ \mathrm{LC}$ & & \\
\hline \multirow[t]{2}{*}{ Nyctea scandiaca } & 雪鸮 & II & 无危 & 宋丽萍 & 黑龙江红星自然保护区湿地保护价值评价 \\
\hline & & & $/ \mathrm{LC}$ & & \\
\hline \multirow[t]{2}{*}{ Nyctea scandiaca } & 雪鸮 & II & 无危 & 唐志强 & 呼中国家级自然保护区的野生动物资源 \\
\hline & & & $/ \mathrm{LC}$ & & \\
\hline \multirow[t]{2}{*}{ Nyctea scandiaca } & 雪鸮 & II & 无危 & 李福震 & 辉河自然保护区鸟类多样性保护现状与对策 \\
\hline & & & $/ \mathrm{LC}$ & & \\
\hline Nyctea scandiaca & 雪鸮 & II & 无危 & 乌力吉 & 蒙古达乌尔草原生态区的现状与保护 \\
\hline
\end{tabular}


顾垒，闻丞，罗玫，王吴，吕植. 中国最受关注濒危物种保护现状快速评价的新方法探讨. 生物多样性，2015，23(5)：583-590. http://www. biodiversity-science. net/CN/article/downloadArticleFile. do?attachType=PDF\&id=10075

\begin{tabular}{|c|c|c|c|c|c|}
\hline & & & $/ \mathrm{LC}$ & & \\
\hline \multirow[t]{2}{*}{ Nyctea scandiaca } & 雪鸮 & II & 无危 & 赵格日乐图 & 内蒙古达麥湖国家级自然保护区鸟类群落结构和动态研究 \\
\hline & & & $/ \mathrm{LC}$ & & \\
\hline \multirow[t]{2}{*}{ Nyctea scandiaca } & 雪鸮 & II & 无危 & 孙林静 & 内蒙古得耳布尔林业局森林病虫害的探讨 \\
\hline & & & $/ \mathrm{LC}$ & & \\
\hline \multirow[t]{2}{*}{ Nyctea scandiaca } & 雪鸮 & II & 无危 & 巩会生 & 陕西秦岭及大巴山地区的鸟类资源调查 \\
\hline & & & $/ \mathrm{LC}$ & & \\
\hline \multirow[t]{2}{*}{ Nyctea scandiaca } & 雪鸮 & II & 无危 & 田振环 & 图牧吉国家级自然保护区鸟类资源 \\
\hline & & & $/ \mathrm{LC}$ & & \\
\hline \multirow[t]{2}{*}{ Nyctea scandiaca } & 雪鸮 & II & 无危 & 阿德克・乌拉孜汉 & 新疆阿勒泰地区主要草地害鼠的危害及防治 \\
\hline & & & $/ \mathrm{LC}$ & & \\
\hline \multirow[t]{2}{*}{ Nyctea scandiaca } & 雪鸮 & II & 无危 & 李如意 & 扎兰屯市的鸟类研究 \\
\hline & & & $/ \mathrm{LC}$ & & \\
\hline \multirow[t]{2}{*}{ Nyctea scandiaca } & 雪鸮 & II & 无危 & 关键 & 肇源西海湿地公园生物资源调查与分析 \\
\hline & & & $/ \mathrm{LC}$ & & \\
\hline \multirow[t]{2}{*}{ Nyssa yunnanensis } & 云南蓝果树 & I & 极危 & Weibang Sun & Conserving plant species with extremely small populations (PSESP) in China \\
\hline & & & /CR & & \\
\hline \multirow[t]{2}{*}{ Nyssa yunnanensis } & 云南蓝果树 & I & 极危 & Changqin Zhang & Cryptic Dioecy in Nyssa Yunnanensis (Nyssaceae), A Critically Endangered Species from \\
\hline & & & /CR & & Tropical Eastern Asia \\
\hline
\end{tabular}


顾垒，闻丞，罗玫，王吴，吕植. 中国最受关注濒危物种保护现状快速评价的新方法探讨. 生物多样性，2015，23(5)：583-590. http://www biodiversity-science. net/CN/article/downloadArticleFile. do?attachType=PDF\&id=10075

\begin{tabular}{|c|c|c|c|c|c|}
\hline Nyssa yunnanensis & 云南蓝果树 & I & 极危 & Changqin Zhang & $\begin{array}{l}\text { Phylogeny and a revised classification of the Chinese species of Nyssa (Nyssaceae) based on } \\
\text { morphological and molecular data }\end{array}$ \\
\hline Nyssa yunnanensis & 云南蓝果树 & I & 极危 & 郭贤明 & 不同生境下云南蓝果树幼苗生长状况分析 \\
\hline Nyssa yunnanensis & 云南蓝果树 & I & 极危 & 马赛宇 & 不同云南蓝果树枯落物厚度对其种子萌发影响的初探 \\
\hline Nyssa yunnanensis & 云南蓝果树 & I & $\begin{array}{l}\text { 极危 } \\
\text { /CR }\end{array}$ & 孙宝玲 & 极度濒危植物 - 云南蓝果树的种子形态和不同处理条件对种子萌发的影响 \\
\hline Nyssa yunnanensis & 云南蓝果树 & I & 极危 & 张长芹 & 极度濒危植物云南蓝果树的形态修订 \\
\hline Nyssa yunnanensis & 云南蓝果树 & I & 极危 & 李思广 & 毛叶紫树育苗技术 \\
\hline Nyssa yunnanensis & 云南蓝果树 & I & $\begin{array}{l}\text { 极危 } \\
\text { /CR }\end{array}$ & 杨文忠 & 云南蓝果树的种群状况及生态习性 \\
\hline Nyssa yunnanensis & 云南蓝果树 & I & $\begin{array}{l}\text { 极危 } \\
\text { /CR }\end{array}$ & 杨德军 & 云南蓝果树嫩枝扦插繁殖试验 \\
\hline Nyssa yunnanensis & 云南蓝果树 & I & $\begin{array}{l}\text { 极危 } \\
\text { /CR }\end{array}$ & 杨德军 & 云南蓝果树容器苗分级标准探讨 \\
\hline Nyssa yunnanensis & 云南蓝果树 & I & 极危 & 杨文忠 & 云南蓝果树种子休眠与萌发特性 \\
\hline
\end{tabular}


顾垒，闻丞，罗玫，王吴，吕植. 中国最受关注濒危物种保护现状快速评价的新方法探讨. 生物多样性，2015，23(5)：583-590. http://www. biodiversity-science. net/CN/article/downloadArticleFile. do?attachType=PDF\&id=10075

\begin{tabular}{|c|c|c|c|c|c|}
\hline & & & /CR & & \\
\hline \multirow[t]{2}{*}{ Nyssa yunnanensis } & 云南蓝果树 & I & 极危 & 杨德军 & 珍稀濒危树种云南蓝果树育苗技术研究 \\
\hline & & & /CR & & \\
\hline \multirow[t]{3}{*}{ Ochotona gaoligongensis } & 高黎贡山鼠兔 & 未列 & 未评 & 李璋鸿 & 高黎贡山东坡怒江段小型兽类调查与疾病关系 \\
\hline & & 入 & 价 & & \\
\hline & & & $/ \mathrm{NE}$ & & \\
\hline \multirow{3}{*}{ Ochotona gaoligongensis } & 高黎贡山鼠兔 & 未列 & 未评 & 王应样 & 高黎贡山鼠兔一新种 \\
\hline & & 入 & 价 & & \\
\hline & & & $/ \mathrm{NE}$ & & \\
\hline \multirow[t]{2}{*}{ Ochotona koslowi } & 柯氏鼠兔 & 未列 & 濒危 & 苏建平 & 柯氏鼠兔的食性分析 \\
\hline & & 入 & /EN & & \\
\hline \multirow[t]{2}{*}{ Ochotona koslowi } & 柯氏鼠兔 & 未列 & 濒危 & 苏建平 & 柯氏鼠兔胃肠道线虫的调查 \\
\hline & & 入 & $/ \mathrm{EN}$ & & \\
\hline \multirow[t]{2}{*}{ Ochotona koslowi } & 柯氏鼠兔 & 未列 & 濒危 & 李维东 & 柯氏鼠兔在东昆仑山的生存现状 \\
\hline & & 入 & /EN & & \\
\hline \multirow[t]{2}{*}{ Ochotona koslowi } & 柯氏鼠兔 & 未列 & 濒危 & 李裕东 & 四川几种鼠兔的分类、分布及生境差异研究 \\
\hline & & 入 & $/ \mathrm{EN}$ & & \\
\hline \multirow[t]{2}{*}{ Ochotona koslowi } & 柯氏鼠兔 & 未列 & 濒危 & 王思博 & 新疆啮齿动物新种新亚种新记录种 \\
\hline & & $\lambda$ & /EN & & 与某些鼠种的新分布 \\
\hline
\end{tabular}


顾垒，闻丞，罗玫，王吴，吕植. 中国最受关注濒危物种保护现状快速评价的新方法探讨. 生物多样性，2015，23(5)：583-590. http://www. biodiversity-science. net/CN/article/downloadArticleFile. do?attachType=PDF\&id=10075

\begin{tabular}{|c|c|c|c|c|c|}
\hline \multirow[t]{2}{*}{ Ochotona koslowi } & 柯氏鼠兔 & 未列 & 濒危 & 马勇 & 中国干旱地区啮齿动物物种分布的区域分异 \\
\hline & & 入 & /EN & & \\
\hline \multirow[t]{3}{*}{ ochotona muliensis } & 木里鼠兔 & 未列 & 数据 & 李裕东 & 四川几种鼠兔的分类、分布及生境差异研究 \\
\hline & & 入 & 不足 & & \\
\hline & & & /DD & & \\
\hline \multirow[t]{3}{*}{ ochotona muliensis } & 木里鼠兔 & 未列 & 数据 & 冯祚建 & 中国耗兔亚属分类现状及分布 \\
\hline & & 入 & 不足 & & \\
\hline & & & $/ \mathrm{DD}$ & & \\
\hline \multirow[t]{2}{*}{ Ochotona thomasi } & 狭颖鼠兔 & 未列 & 近危 & 张三亮 & 甘肃省森林鼠类区系调查初报 \\
\hline & & 入 & $/ \mathrm{NT}$ & & \\
\hline \multirow[t]{2}{*}{ Ochotona thomasi } & 狭颖鼠兔 & 未列 & 近危 & 李裕东 & 四川几种鼠兔的分类、分布及生境差异研究 \\
\hline & & 入 & /NT & & \\
\hline \multirow[t]{2}{*}{ Oligodon bellus } & 方花小头蛇 & 未列 & 无危 & Cheng Chang & Effects of ultraviolet B on epidermal morphology, shedding, lipid peroxide, and antioxidant \\
\hline & & 入 & $/ \mathrm{LC}$ & & enzymes in Cope' s rat snake (Elaphe taeniura) \\
\hline \multirow[t]{2}{*}{ Oligodon bellus } & 方花小头蛇 & 未列 & 无危 & 蒋爱伍 & 广西蛇类一新记录一一方花小头蛇 \\
\hline & & 入 & $/ \mathrm{LC}$ & & \\
\hline \multirow[t]{2}{*}{ Oligodon lacroixi } & 圆斑小头蛇 & 未列 & 易危 & 邓其祥 & 四川省蛇类一新记录一 圆斑小头蛇 \\
\hline & & 入 & /VU & & \\
\hline Ophiophagus hannah & 眼镜王蛇 & 未列 & 未评 & 曾燕玲 & 1 例眼镜王蛇咬伤致自主呼吸停止 $122 \mathrm{~h}$ 报告 \\
\hline
\end{tabular}


顾垒，闻丞，罗玫，王吴，吕植. 中国最受关注濒危物种保护现状快速评价的新方法探讨. 生物多样性，2015，23(5)：583-590.

\begin{tabular}{|c|c|c|c|c|c|}
\hline & & 入 & 价 & & \\
\hline & & & $/ \mathrm{NE}$ & & \\
\hline \multirow[t]{2}{*}{ Ophiophagus hannah } & 眼镜王蛇 & 未列 & 易危 & Yun Zhang & Cloning and sequence analysis of an Ophiophagus hannah cDNA encoding a precursor of two \\
\hline & & 入 & /VU & & natriuretic pepide domains \\
\hline \multirow[t]{2}{*}{ Ophiophagus hannah } & 眼镜王蛇 & 未列 & 易危 & Zhengjiong Lin & Crystallization and preliminary X-ray analysis of cardiotoxic phospholipase A2 from \\
\hline & & 入 & /VU & & Ophiophagus hannah (king cobra) \\
\hline \multirow[t]{2}{*}{ Ophiophagus hannah } & 眼镜王蛇 & 未列 & 易危 & Long-sen Chang & Differential contribution of the conserved tyrosine residues to activity and structural stability of \\
\hline & & 入 & /VU & & Ophiophagus hannah a-neurotoxins \\
\hline \multirow[t]{2}{*}{ Ophiophagus hannah } & 眼镜王蛇 & 未列 & 易危 & Yun Zhang & Molecular cloning and characterization of a complement-depleting factor from king cobra, \\
\hline & & 入 & /VU & & Ophiophagus hannah \\
\hline \multirow[t]{2}{*}{ Ophiophagus hannah } & 眼镜王蛇 & 未列 & 易危 & Jing LI & Novel genes encoding six kinds of three-finger toxins in Ophiophagus hannah (king cobra) and \\
\hline & & 入 & /VU & & function characterization of two recombinant long-chain neurotoxins \\
\hline \multirow[t]{2}{*}{ Ophiophagus hannah } & 眼镜王蛇 & 未列 & 易危 & Zhengjiong Lin & Preliminary crystallographic study of an acidic phospholipase A2 from Ophiophagus hannah \\
\hline & & 入 & $/ \mathrm{VU}$ & & (king cobra) \\
\hline \multirow[t]{2}{*}{ Ophiophagus hannah } & 眼镜王蛇 & 未列 & 易危 & LI Qibin & Sequence analysis of cDNA encoding an A-neurotoxin from king cobra (Ophiophagus hannah) \\
\hline & & 入 & /VU & & with PCR techniques \\
\hline \multirow[t]{2}{*}{ Ophiophagus hannah } & 眼镜王蛇 & 未列 & 易危 & Zhengjiong Lin & Structure of a cardiotoxic phospholipase A2 from Ophiophagus hannah with the "pancreatic \\
\hline & & 入 & /VU & & loop” \\
\hline Ophiophagus hannah & 眼镜王蛇 & 未列 & 未评 & 罗铭 & 成功救治 1 例眼镜王蛇咬伤致严重呼吸衰竭病人的护理体会 \\
\hline
\end{tabular}


顾垒，闻丞，罗玫，王吴，吕植. 中国最受关注濒危物种保护现状快速评价的新方法探讨. 生物多样性，2015，23(5)：583-590. http://www. biodiversity-science. net/CN/article/downloadArticleFile. do?attachType=PDF\&id=10075

\begin{tabular}{|c|c|c|c|c|c|}
\hline & & 入 & 价 & & \\
\hline & & & $/ \mathrm{NE}$ & & \\
\hline \multirow[t]{2}{*}{ Ophiophagus hannah } & 眼镜王蛇 & 未列 & 易危 & 舒雨雁 & 广西眼镜王蛇毒两种酸性磷脂酶 A2 的 cDNA 克隆及序列分析 \\
\hline & & 入 & $/ \mathrm{VU}$ & & \\
\hline \multirow[t]{2}{*}{ Ophiophagus hannah } & 眼镜王蛇 & 未列 & 易危 & 王秋雁 & 广西眼镜王蛇毒酸性磷脂酶 A2 的分离纯化、性质研究及基因克隆 \\
\hline & & 入 & $/ \mathrm{VU}$ & & \\
\hline \multirow[t]{3}{*}{ Ophiophagus hannah } & 眼镜王蛇 & 未列 & 未评 & 王秋雁 & 广西眼镜王蛇毒酸性磷脂酶 A2 的分离纯化和性质研究 \\
\hline & & 入 & 价 & & \\
\hline & & & $/ \mathrm{NE}$ & & \\
\hline \multirow[t]{3}{*}{ Ophiophagus hannah } & 眼镜王蛇 & 未列 & 未评 & 王秋雁 & 广西眼镜王蛇毒酸性磷脂酶 A2 的肌毒性研究 \\
\hline & & 入 & 价 & & \\
\hline & & & $/ \mathrm{NE}$ & & \\
\hline \multirow[t]{3}{*}{ Ophiophagus hannah } & 眼镜王蛇 & 未列 & 未评 & 舒雨雁 & 广西眼镜王蛇毒一种碱性蛋白的分离纯化及性质研究 \\
\hline & & 入 & 价 & & \\
\hline & & & $/ \mathrm{NE}$ & & \\
\hline \multirow[t]{3}{*}{ Ophiophagus hannah } & 眼镜王蛇 & 未列 & 未评 & 范泉水 & 精制抗眼镜王蛇毒血清的制备 \\
\hline & & 入 & 价 & & \\
\hline & & & $/ \mathrm{NE}$ & & \\
\hline Ophiophagus hannah & 眼镜王蛇 & 未列 & 未评 & 余清声 & 抗眼镜王蛇毒鸡卵黄抗体的研制及初步应用 \\
\hline
\end{tabular}


顾垒，闻丞，罗玫，王吴，吕植. 中国最受关注濒危物种保护现状快速评价的新方法探讨. 生物多样性，2015，23(5)：583-590. http://www. biodiversity-science. net/CN/article/downloadArticleFile. do?attachType=PDF\&id=10075

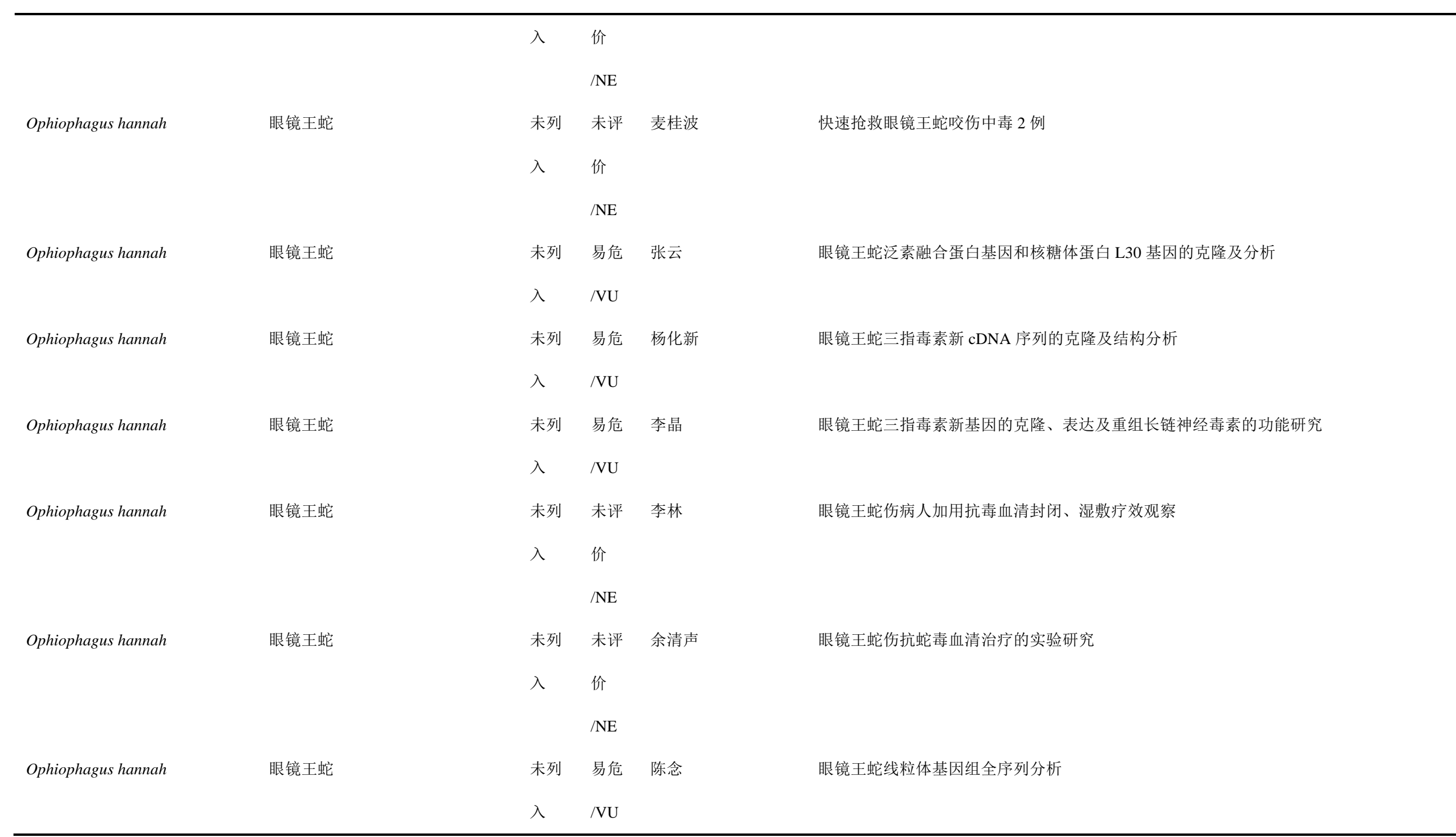


顾垒，闻丞，罗玫，王吴，吕植. 中国最受关注濒危物种保护现状快速评价的新方法探讨. 生物多样性，2015，23(5)：583-590. http://www. biodiversity-science. net/CN/article/downloadArticleFile. do?attachType=PDF\&id=10075

\begin{tabular}{|c|c|c|c|c|c|}
\hline \multirow[t]{2}{*}{ Ophiophagus hannah } & 眼镜王蛇 & 未列 & 未评 & 陈念 & 眼镜王蛇线粒体基因组全序列分析 \\
\hline & & 入 & $\begin{array}{l}\text { 价 } \\
\text { /NE }\end{array}$ & & \\
\hline \multirow[t]{3}{*}{ Ophiophagus hannah } & 眼镜王蛇 & 未列 & 未评 & 覃永安 & 眼镜王蛇咬伤 21 例治疗体会 \\
\hline & & 入 & 价 & & \\
\hline & & & $/ \mathrm{NE}$ & & \\
\hline \multirow[t]{3}{*}{ Ophiophagus hannah } & 眼镜王蛇 & 未列 & 未评 & 钟伟明 & 眼镜王蛇咬伤 73 例治疗体会 \\
\hline & & 入 & 价 & & \\
\hline & & & $/ \mathrm{NE}$ & & \\
\hline \multirow[t]{3}{*}{ Ophiophagus hannah } & 眼镜王蛇 & 未列 & 未评 & 刘本光 & 眼镜王蛇咬伤的救治体会 \\
\hline & & 入 & 价 & & \\
\hline & & & $/ \mathrm{NE}$ & & \\
\hline \multirow[t]{3}{*}{ Ophiophagus hannah } & 眼镜王蛇 & 未列 & 未评 & 林起庆 & 眼镜王蛇咬伤的临床特点及抗蛇毒血清治疗效果分析 \\
\hline & & 入 & 价 & & \\
\hline & & & $/ \mathrm{NE}$ & & \\
\hline \multirow[t]{3}{*}{ Ophiophagus hannah } & 眼镜王蛇 & 未列 & 未评 & 庞家善 & 眼镜王蛇咬伤的治疗体会 \\
\hline & & 入 & 价 & & \\
\hline & & & $/ \mathrm{NE}$ & & \\
\hline Ophiophagus hannah & 眼镜王蛇 & 未列 & 未评 & 钟健荣 & 眼镜王蛇咬伤救治成功临床分析 \\
\hline
\end{tabular}


顾垒，闻丞，罗玫，王吴，吕植. 中国最受关注濒危物种保护现状快速评价的新方法探讨. 生物多样性，2015，23(5)：583-590. http://www. biodiversity-science. net/CN/article/downloadArticleFile. do?attachType=PDF\&id=10075

\begin{tabular}{|c|c|c|c|c|c|}
\hline \multirow[b]{2}{*}{ Ophiophagus hannah } & \multirow[b]{2}{*}{ 眼镜王蛇 } & \multirow{2}{*}{$\begin{array}{l}\text { 入 } \\
\text { 未列 }\end{array}$} & \multicolumn{2}{|l|}{$\begin{array}{l}\text { 价 } \\
\text { /NE }\end{array}$} & \multirow[b]{2}{*}{ 眼镜王蛇咬伤致呼吸麻瘰抢救成功 2 例 } \\
\hline & & & $\begin{array}{l}\text { /NE } \\
\text { 未评 } \\
\text { 价 }\end{array}$ & 王淑萍 & \\
\hline Ophiophagus hannah & 眼镜王蛇 & $\begin{array}{l}\text { 未列 } \\
\text { 入 }\end{array}$ & $\begin{array}{l}\text { /NE } \\
\text { 未评 } \\
\text { 价 }\end{array}$ & 庞家善 & 眼镜王蛇咬伤致呼吸心博停止抢救成功 1 例 \\
\hline Ophiophagus hannah & 眼镜王蛇 & $\begin{array}{l}\text { 未列 } \\
\text { 入 }\end{array}$ & $\begin{array}{l}\text { /NE } \\
\text { 未评 } \\
\text { 价 }\end{array}$ & 罗阳 & 眼镜王蛇咬伤致昏迷及呼吸停止 1 例的急救 \\
\hline Ophiophagus hannah & 眼镜王蛇 & $\begin{array}{l}\text { 未列 } \\
入\end{array}$ & $\begin{array}{l}\text { /NE } \\
\text { 未评 } \\
\text { 价 }\end{array}$ & 罗威 & 眼镜王蛇咬伤中毒的早期处理体会 \\
\hline Ophiophagus hannah & 眼镜王蛇 & $\begin{array}{l}\text { 未列 } \\
\text { 入 }\end{array}$ & $\begin{array}{l}\text { /NE } \\
\text { 未评 } \\
\text { 价 }\end{array}$ & 梁平 & 眼镜王蛇咬伤中毒的治疗进展 \\
\hline Ophiophagus hannah & 眼镜王蛇 & $\begin{array}{l}\text { 未列 } \\
\text { 入 }\end{array}$ & $\begin{array}{l}/ \mathrm{NE} \\
\text { 易危 } \\
\text { /VU }\end{array}$ & 王稣武 & 一起王锦蛇、眼镜王蛇 \\
\hline
\end{tabular}


顾垒，闻丞，罗玫，王吴，吕植. 中国最受关注濒危物种保护现状快速评价的新方法探讨. 生物多样性，2015，23(5)：583-590. http://www. biodiversity-science. net/CN/article/downloadArticleFile. do?attachType=PDF\&id=10075

\begin{tabular}{|c|c|c|c|c|c|}
\hline Ophiophagus hannah & 眼镜王蛇 & 未列 & 未评 & 梁平 & 中西医结合抢救眼镜王蛇咬伤中毒 32 例 \\
\hline & & 入 & $\begin{array}{l}\text { 价 } \\
/ \mathrm{NE}\end{array}$ & & \\
\hline \multirow[t]{3}{*}{ Ophiophagus hannah } & 眼镜王蛇 & 未列 & 未评 & 罗威 & 中西医结合治疗眼镜王蛇咬伤中毒体会 \\
\hline & & 入 & 价 & & \\
\hline & & & $/ \mathrm{NE}$ & & \\
\hline \multirow[t]{2}{*}{ Ophisaurus harti } & 脆蛇 & 未列 & 无危 & Zheng-Liang Liu & The complete mitochondrial genome of Chinese glass lizard Ophisaurus harti (Squamata \\
\hline & & 入 & $/ \mathrm{LC}$ & & Anguidae) \\
\hline \multirow[t]{2}{*}{ Ophisaurus harti } & 脆蛇 & 未列 & 无危 & 胡慧建 & 广东省爬行动物分布新纪录一一脆蛇蚚 \\
\hline & & 入 & $/ \mathrm{LC}$ & & \\
\hline \multirow[t]{2}{*}{ Ophisaurus harti } & 脆蛇 & 未列 & 无危 & 王本菊 & 攀枝花市蜥蜴类一新记录一脆蛇蜊 \\
\hline & & 入 & $/ \mathrm{LC}$ & & \\
\hline \multirow[t]{2}{*}{ Oreolalax schmidti } & 无蹼齿蟾 & 未列 & 近危 & 江建平 & 瓦屋山国家森林公园锄足蟾科 6 种的繁殖鸣声特性 \\
\hline & & $\lambda$ & $/ \mathrm{NT}$ & & \\
\hline \multirow[t]{2}{*}{ Otis tarda } & 大铇 & I & 易危 & 白福春 & 2004-GMP 达乌尔国际自然保护区 \\
\hline & & & $/ \mathrm{VU}$ & & \\
\hline \multirow[t]{2}{*}{ Otis tarda } & 大鸨 & I & 易危 & 赵志轩 & 白洋淀流域大鸨越冬栖息地的适宜性评价 \\
\hline & & & $/ \mathrm{VU}$ & & \\
\hline Otis tarda & 大铇 & I & 易危 & 时否 & 察布查尔县陆栖脊椎动物生物多样性调查 \\
\hline
\end{tabular}


顾垒，闻丞，罗玫，王吴，吕植. 中国最受关注濒危物种保护现状快速评价的新方法探讨. 生物多样性，2015，23(5)：583-590. http://www. biodiversity-science. net/CN/article/downloadArticleFile. do?attachType=PDF\&id=10075

\begin{tabular}{|c|c|c|c|c|c|}
\hline & & & $/ \mathrm{VU}$ & & \\
\hline \multirow[t]{2}{*}{ Otis tarda } & 大昷 & I & 易危 & 张宝亮 & 大铇繁殖前期行为观察 \\
\hline & & & $/ \mathrm{VU}$ & & \\
\hline \multirow[t]{2}{*}{ Otis tarda } & 大铇 & I & 易危 & 袁超群 & 大鸨绝迹 30 多年如今再现周至县 \\
\hline & & & /VU & & \\
\hline \multirow[t]{2}{*}{ Otis tarda } & 大铇 & I & 易危 & 乔桂芬 & 大铇越冬习性观察与研究 \\
\hline & & & $/ \mathrm{VU}$ & & \\
\hline \multirow[t]{2}{*}{ Otis tarda } & 大鸨 & I & 易危 & 于国海 & 大岗附近大鸨越冬种群数量及生态观察 \\
\hline & & & $/ \mathrm{VU}$ & & \\
\hline \multirow[t]{2}{*}{ Otis tarda } & 大鸨 & I & 易危 & 武明录 & 河北省大铇的分布与保护 \\
\hline & & & $/ \mathrm{VU}$ & & \\
\hline \multirow[t]{2}{*}{ Otis tarda } & 大鸨 & I & 易危 & 赵匠 & 环境因子对大铇种群数量的影响 \\
\hline & & & $/ \mathrm{VU}$ & & \\
\hline \multirow[t]{2}{*}{ Otis tarda } & 大鸨 & I & 易危 & 张希涛 & 黄河三角洲大铇越冬状况及保护对策 \\
\hline & & & /VU & & \\
\hline \multirow[t]{2}{*}{ Otis tarda } & 大鸨 & I & 易危 & 王景祥 & 吉林大布苏自然保护区现状分析与保护对策研究 \\
\hline & & & /VU & & \\
\hline \multirow[t]{2}{*}{ Otis tarda } & 大铇 & I & 易危 & 孟宪毅 & 内蒙古大青山国家级自然保护区成功救助一只国家一级保护动物大铇 \\
\hline & & & $/ \mathrm{VU}$ & & \\
\hline
\end{tabular}


顾垒，闻丞，罗玫，王吴，吕植. 中国最受关注濒危物种保护现状快速评价的新方法探讨. 生物多样性，2015，23(5)：583-590. http://www. biodiversity-science. net/CN/article/downloadArticleFile. do?attachType=PDF\&id=10075

\begin{tabular}{|c|c|c|c|c|c|}
\hline Otis tarda & 大鸨 & I & $\begin{array}{l}\text { 易危 } \\
\text { /VU }\end{array}$ & 李晓民 & 内蒙古图牧吉冬季大鸨调查初报 \\
\hline Otis tarda & 大铇 & I & $\begin{array}{l}\text { 易危 } \\
\text { /VU }\end{array}$ & 张宝亮 & 内蒙古图牧吉自然保护区大鸫繁殖期行为时间分配与日节律研究 \\
\hline Otis tarda & 大鸨 & I & $\begin{array}{l}\text { 易危 } \\
\text { /VU }\end{array}$ & 伊国良 & 内蒙古图牧吉自然保护区大钨资源现状及保护 \\
\hline Otis tarda & 大鸨 & I & $\begin{array}{l}\text { 易危 } \\
\text { /VU }\end{array}$ & 李元刚 & 宁夏贺兰山东麓荒漠草原区五种生境鸟类资源的调查研究 \\
\hline Otis tarda & 大铇 & I & $\begin{array}{l}\text { 易危 } \\
\text { /VU }\end{array}$ & 张帅 & 赛罕乌拉探大铇 \\
\hline Otis tarda & 大铇 & I & $\begin{array}{l}\text { 易危 } \\
\text { /VU }\end{array}$ & 何冰 & 陕西黄河湿地大铇活动情况调查 \\
\hline Otis tarda & 大鸨 & I & $\begin{array}{l}\text { 易危 } \\
\text { /VU }\end{array}$ & 吴逸群 & 陕西黄河湿地大铇越冬种群受胁因素分析 \\
\hline Otis tarda & 大铇 & I & $\begin{array}{l}\text { 易危 } \\
\text { /VU }\end{array}$ & 吴逸群 & 陕西黄河湿地大铇越冬种群调查研究 \\
\hline Otis tarda & 大鸨 & I & $\begin{array}{l}\text { 易危 } \\
\text { /VU }\end{array}$ & 赵俊 & 向海湿地保护成果显著获殊荣 \\
\hline Otis tarda & 大铇 & I & 易危 & 马鸣 & 新疆艾比湖湿地自然保护区鸟类清单及秋季迁徙数量统计 \\
\hline
\end{tabular}


顾垒，闻丞，罗玫，王吴，吕植. 中国最受关注濒危物种保护现状快速评价的新方法探讨．生物多样性，2015，23(5)：583-590。 http://www. biodiversity-science. net/CN/article/downloadArticleFile. do?attachType=PDF\&id=10075

\begin{tabular}{|c|c|c|c|c|c|}
\hline & & & $/ \mathrm{VU}$ & & \\
\hline \multirow[t]{2}{*}{ Otis tarda } & 大昷 & I & 易危 & 马鸣 & 新疆青格达湖湿地自然保护区及周边地区的鸟类 \\
\hline & & & $/ \mathrm{VU}$ & & \\
\hline \multirow[t]{2}{*}{ Otis tarda } & 大胡 & I & 易危 & 吴逸群 & 越冬期大铇羽毛九种重金属测定 \\
\hline & & & $/ \mathrm{VU}$ & & \\
\hline \multirow[t]{2}{*}{ Otis tarda } & 大鸨 & I & 易危 & 王恒瑞 & 郑州黄河湿地大铇越冬情况及保护对策 \\
\hline & & & /VU & & \\
\hline \multirow[t]{2}{*}{ Otis tetrax } & 小铇 & I & 近危 & 黄族豪 & 安西极旱荒漠国家级自然保护区鸟类资源的消长变化 \\
\hline & & & $/ \mathrm{NT}$ & & \\
\hline \multirow[t]{2}{*}{ Otis tetrax } & 小铇 & I & 近危 & 张 立 勋 & 甘肃省 10 种 鸟类新记录 \\
\hline & & & $/ \mathrm{NT}$ & & \\
\hline \multirow[t]{2}{*}{ Otocolobus manul } & 兔狲 & II & 近危 & Janine L. Brown & Reproductive Endocrine Responses to Photoperiod and Exogenous Gonadotropins in the \\
\hline & & & /NT & & Pallas’ Cat (Otocolobus manul) \\
\hline \multirow[t]{2}{*}{ Otocolobus manul } & 兔狲 & II & 近危 & 朱安国 & 兔狲泌尿器官的形态特征 \\
\hline & & & /NT & & \\
\hline \multirow[t]{2}{*}{ Otocolobus manul } & 兔狲 & II & 近危 & 朱安国 & 兔狲消化系统解剖 \\
\hline & & & /NT & & \\
\hline \multirow[t]{2}{*}{ Otocolobus manul } & 兔狲 & II & 近危 & 朱安国 & 兔狲消化腺特征 \\
\hline & & & /NT & & \\
\hline
\end{tabular}


顾垒，闻丞，罗玫，王吴，吕植. 中国最受关注濒危物种保护现状快速评价的新方法探讨. 生物多样性，2015，23(5)：583-590. http://www. biodiversity-science. net/CN/article/downloadArticleFile. do?attachType=PDF\&id=10075

\begin{tabular}{|c|c|c|c|c|c|}
\hline Otus lettia & 领角鸮 & II & $\begin{array}{l}\text { 无危 } \\
\text { /LC }\end{array}$ & 黄希 & 河南省鸟类新纪录一一一日本领角鸮 \\
\hline Otus lettia & 领角鸮 & II & $\begin{array}{l}\text { 无危 } \\
\text { /LC }\end{array}$ & 周天福 & 柳州白莲机场鸟类威胁及鸟击防范对策 \\
\hline Otus scops & 红角鸮 & II & $\begin{array}{l}\text { 无危 } \\
\text { /LC }\end{array}$ & 袁玉川 & 2011 年南涧风凰山夜间鸟类环志研究 \\
\hline Otus scops & 红角鸮 & II & $\begin{array}{l}\text { 无危 } \\
\text { /LC }\end{array}$ & 关贯勋 & 澳门鸟类资源调查报告 \\
\hline Otus scops & 红角鸮 & II & $\begin{array}{l}\text { 无危 } \\
\text { /LC }\end{array}$ & 陈璐璐 & 北竿山鸟类资源调查 \\
\hline Otus scops & 红角鸮 & II & $\begin{array}{l}\text { 无危 } \\
\text { /LC }\end{array}$ & 闻丞 & 北京大学燕园鸟类组成 \\
\hline Otus scops & 红角鸮 & II & $\begin{array}{l}\text { 无危 } \\
\text { /LC }\end{array}$ & 舒晓莲 & 广西涠洲岛鸟类自然保护区的鸟类资源 \\
\hline Otus scops & 红角鸮 & II & $\begin{array}{l}\text { 无危 } \\
\text { /LC }\end{array}$ & 蒋爱伍 & 河池学院校园鸟类初步调查 \\
\hline Otus scops & 红角鸮 & II & $\begin{array}{l}\text { 无危 } \\
\text { /LC }\end{array}$ & 方克艰 & 黑龙江嫩江高峰林区鸟类环志监测报告 \\
\hline Otus scops & 红角鸮 & II & 无危 & 杨书香 & 湖北省七姊妹山夏季鸟类多样性研究及生境分析 \\
\hline
\end{tabular}


顾垒，闻丞，罗玫，王吴，吕植. 中国最受关注濒危物种保护现状快速评价的新方法探讨. 生物多样性，2015，23(5)：583-590. http://www. biodiversity-science. net/CN/article/downloadArticleFile. do?attachType=PDF\&id=10075

\begin{tabular}{|c|c|c|c|c|c|}
\hline & & & $/ \mathrm{LC}$ & & \\
\hline \multirow[t]{2}{*}{ Otus scops } & 红角鸮 & II & 无危 & 承勇 & 江西井冈山国家级自然保护区鸟类资源调查与分析 \\
\hline & & & $/ \mathrm{LC}$ & & \\
\hline \multirow[t]{2}{*}{ Otus scops } & 红角鸮 & II & 无危 & 符建荣 & 米亚罗自然保护区的鸟类资源 \\
\hline & & & $/ \mathrm{LC}$ & & \\
\hline \multirow[t]{2}{*}{ Otus scops } & 红角鸮 & II & 无危 & 胡 否 & 赛罕乌拉国家级自然保护区红角鸮的繁殖生态观察 \\
\hline & & & $/ \mathrm{LC}$ & & \\
\hline \multirow[t]{2}{*}{ Otus scops } & 红角鸮 & II & 无危 & 谭家林 & 三峡大老岭秋季环志鸟类资源初步调查 \\
\hline & & & $/ \mathrm{LC}$ & & \\
\hline \multirow[t]{2}{*}{ Otus scops } & 红角鸮 & II & 无危 & 郝映红 & 山西庞泉沟保护区三种鸮的繁殖生态特性研究 \\
\hline & & & $/ \mathrm{LC}$ & & \\
\hline \multirow[t]{2}{*}{ Otus scops } & 红角鸮 & II & 无危 & 张 君 & 四川东阳沟自然保护区鸟类区系初步调查 \\
\hline & & & $/ \mathrm{LC}$ & & \\
\hline \multirow[t]{2}{*}{ Otus scops } & 红角鸮 & II & 无危 & 符建荣 & 四川雪宝顶自然保护区的鸟类资源 \\
\hline & & & $/ \mathrm{LC}$ & & \\
\hline \multirow[t]{2}{*}{ Otus scops } & 红角鸮 & II & 无危 & 田振环 & 图牧吉国家级自然保护区鸟类资源 \\
\hline & & & $/ \mathrm{LC}$ & & \\
\hline \multirow[t]{2}{*}{ Otus scops } & 红角鸮 & II & 无危 & 武丙琳 & 西天目山区鸟类多样性动态研究 \\
\hline & & & /LC & & \\
\hline
\end{tabular}


顾垒，闻丞，罗玫，王吴，吕植. 中国最受关注濒危物种保护现状快速评价的新方法探讨. 生物多样性，2015，23(5)：583-590. http://www. biodiversity-science. net/CN/article/downloadArticleFile. do?attachType=PDF\&id=10075

\begin{tabular}{|c|c|c|c|c|c|}
\hline Otus scops & 红角鸮 & II & $\begin{array}{l}\text { 无危 } \\
\text { /LC }\end{array}$ & 舒实 & 茢山自然保护区珍稀濒危野生脊椎动物调查 \\
\hline Otus scops & 红角鸮 & II & $\begin{array}{l}\text { 无危 } \\
\text { /LC }\end{array}$ & 杨 婷 & 云南新平哀牢山夜间捕获鸟类的多样性 \\
\hline Otus spilocephalus & 黄嘴角鸮 & II & $\begin{array}{l}\text { 无危 } \\
\text { /LC }\end{array}$ & 关贯勋 & 澳门鸟类资源调查报告 \\
\hline Otus spilocephalus & 黄嘴角鸮 & II & $\begin{array}{l}\text { 无危 } \\
\text { /LC }\end{array}$ & 李小燕 & 广东莲花山白盆珠省级自然保护区鸟类资源调查 \\
\hline Otus spilocephalus & 黄嘴角鸮 & II & $\begin{array}{l}\text { 无危 } \\
\text { /LC }\end{array}$ & 余丽江 & 桂西南青龙山自然保护区鸟类多样性和区系分析 \\
\hline Otus spilocephalus & 黄嘴角鸮 & II & $\begin{array}{l}\text { 无危 } \\
\text { /LC }\end{array}$ & 廖承开 & 江西九连山国家级自然保护区鸟类新记录 \\
\hline Otus spilocephalus & 黄嘴角鸮 & II & $\begin{array}{l}\text { 无危 } \\
\text { /LC }\end{array}$ & 程松林 & 江西武夷山国家级自然保护区动物名录增补 \\
\hline Otus spilocephalus & 黄嘴角鸮 & II & $\begin{array}{l}\text { 无危 } \\
\text { /LC }\end{array}$ & 李仕宁 & 茄新省级森林经营所鸟类资源调查 \\
\hline Otus spilocephalus & 黄嘴角鸮 & II & $\begin{array}{l}\text { 无危 } \\
\text { /LC }\end{array}$ & 蔡燕 & 人工林对海南鹦哥岭鸟类多样性的影响 \\
\hline Otus spilocephalus & 黄嘴角鸮 & II & 无危 & 谭家林 & 三峡大老岭秋季环志鸟类资源初步调查 \\
\hline
\end{tabular}


顾垒，闻丞，罗玫，王吴，吕植. 中国最受关注濒危物种保护现状快速评价的新方法探讨. 生物多样性，2015，23(5)：583-590. http://www biodiversity-science. net/CN/article/downloadArticleFile. do?attachType=PDF\&id=10075

\begin{tabular}{|c|c|c|c|c|c|}
\hline & & & $/ \mathrm{LC}$ & & \\
\hline \multirow[t]{2}{*}{ Otus spilocephalus } & 黄嘴角鸮 & II & 无危 & 黄俊辉 & 西双版纳预养早季季风常绿阔叶林的林下鸟类群落组成和特点 \\
\hline & & & $/ \mathrm{LC}$ & & \\
\hline \multirow[t]{2}{*}{ Ovis ammon } & 盘羊 & II & 近危 & Richard B. Harris & Incentives toward conservation of argali Ovis ammon: A case study of trophy hunting in \\
\hline & & & $/ \mathrm{NT}$ & & Western China \\
\hline \multirow[t]{2}{*}{ Ovis ammon } & 盘羊 & II & 近危 & C.H.WU & Mitochondrial control region sequence variation within the argali wild sheep (Ovis ammon): \\
\hline & & & /NT & & evolution and conservation relevance \\
\hline \multirow[t]{2}{*}{ Ovis ammon } & 盘羊 & II & 近危 & George B. Schaller & Status of Marco Polo sheep Ovis ammon polii in China and adjacent countries: conservation of \\
\hline & & & $/ \mathrm{NT}$ & & a Vulnerable subspecies \\
\hline \multirow[t]{2}{*}{ Ovis ammon } & 盘羊 & II & 近危 & Fangdong Zou & The complete mitochondrial genome sequence analysis of Tibetan argali (Ovis ammon \\
\hline & & & $/ \mathrm{NT}$ & & hodgsoni): Implications of Tibetan argali and Gansu argali as the same subspecies \\
\hline \multirow[t]{2}{*}{ Ovis ammon } & 盘羊 & II & 近危 & 蒋志刚 & 阿尔泰山南部科克森山和卡拉麦里山盘羊冬季卧息地的选择 \\
\hline & & & $/ \mathrm{NT}$ & & \\
\hline \multirow[t]{2}{*}{ Ovis ammon } & 盘羊 & II & 近危 & 阿布力米提・阿布都 & 阿克苏拜城天山区盘羊和北山羊的分布与种群资源现状 \\
\hline & & & $/ \mathrm{NT}$ & 卡迪尔 & \\
\hline \multirow[t]{2}{*}{ Ovis ammon } & 盘羊 & II & 近危 & 刘楚光 & 甘肃马鬃山盘羊春季卧息地的利用 \\
\hline & & & $/ \mathrm{NT}$ & & \\
\hline \multirow[t]{2}{*}{ Ovis ammon } & 盘羊 & II & 近危 & 刘迺发 & 甘肃盐池湾自然保护区有蹄类动物资源变化 \\
\hline & & & $/ \mathrm{NT}$ & & \\
\hline
\end{tabular}


顾垒，闻丞，罗玫，王吴，吕植. 中国最受关注濒危物种保护现状快速评价的新方法探讨. 生物多样性，2015，23(5)：583-590. http://www. biodiversity-science. net/CN/article/downloadArticleFile. do?attachType=PDF\&id=10075

\begin{tabular}{|c|c|c|c|c|c|}
\hline Ovis ammon & 盘羊 & II & $\begin{array}{l}\text { 近危 } \\
\text { /NT }\end{array}$ & 王玉涛 & 马可波罗盘羊研究现状与保护对策 \\
\hline Ovis ammon & 盘羊 & II & $\begin{array}{l}\text { 近危 } \\
\text { /NT }\end{array}$ & 刘楚光 & 马可波罗羊(Ovis ammon polii)在中国境内的分布与现状 \\
\hline Ovis ammon & 盘羊 & II & $\begin{array}{l}\text { 近危 } \\
\text { /NT }\end{array}$ & 余玉群 & 天山盘羊集群行为的研究 \\
\hline Ovis ammon & 盘羊 & II & $\begin{array}{l}\text { 近危 } \\
\text { /NT }\end{array}$ & 李保国 & 天山盘羊秋季集群习性和日活动节律初步观察 \\
\hline Ovis ammon & 盘羊 & II & $\begin{array}{l}\text { 近危 } \\
\text { /NT }\end{array}$ & 时否 & 天山盘羊夏季采食地和卧息地生境选择 \\
\hline Ovis ammon & 盘羊 & II & $\begin{array}{l}\text { 近危 } \\
/ \mathrm{NT}\end{array}$ & 余玉群 & 我国马可波罗盘羊种群数量和年龄结构 \\
\hline Ovis ammon & 盘羊 & II & $\begin{array}{l}\text { 近危 } \\
\text { /NT }\end{array}$ & 张银国 & 新疆盘羊电刺激采精和死精症治疗的研究 \\
\hline Ovis ammon & 盘羊 & II & $\begin{array}{l}\text { 近危 } \\
\text { /NT }\end{array}$ & $\begin{array}{l}\text { 阿布力米提 - 阿布都 } \\
\text { 卡迪尔 }\end{array}$ & 新疆塔什库尔干高山一高原区盘羊和北山羊冬季资源调查报告 \\
\hline Ovis ammon & 盘羊 & II & $\begin{array}{l}\text { 近危 } \\
/ \mathrm{NT}\end{array}$ & 宋延龄 & 新疆塔什库尔干自然保护区马可波罗盘羊种群数量和栖息地初步调查 \\
\hline Ovis ammon & 盘羊 & II & 近危 & 时磊 & 新疆天山野生动物园散放盘羊夏季昼间活动节律及时间分配 \\
\hline
\end{tabular}


顾垒，闻丞，罗玫，王吴，吕植. 中国最受关注濒危物种保护现状快速评价的新方法探讨. 生物多样性，2015，23(5)：583-590. http://www. biodiversity-science. net/CN/article/downloadArticleFile. do?attachType=PDF\&id=10075

\begin{tabular}{|c|c|c|c|c|c|}
\hline & & & $/ \mathrm{NT}$ & & \\
\hline \multirow[t]{2}{*}{ Ovis ammon } & 盘羊 & II & 近危 & 孙延鸣 & 新疆野生盘羊 mtDNA D-loop 序列的多态性 \\
\hline & & & $/ \mathrm{NT}$ & & \\
\hline \multirow[t]{2}{*}{ Ovis ammon } & 盘羊 & II & 近危 & 余玉群 & 中国盘羊的地理分布和历史变迁 \\
\hline & & & /NT & & \\
\hline \multirow[t]{2}{*}{ Oxyura leucocephala } & 白头硬尾鸭 & I & 濒危 & 赵序茅 & 白头硬尾鸭行为时间分配及日活动节律 \\
\hline & & & /EN & & \\
\hline \multirow[t]{2}{*}{ Oxyura leucocephala } & 白头硬尾鸭 & I & 濒危 & 彭 健 & 绿洲夏季鸟类群落特征研究 \\
\hline & & & /EN & & \\
\hline \multirow[t]{2}{*}{ Oxyura leucocephala } & 白头硬尾鸭 & I & 濒危 & 马鸣 & 新疆艾比湖湿地自然保护区鸟类清单及秋季迁徙数量统计 \\
\hline & & & /EN & & \\
\hline \multirow[t]{2}{*}{ Oxyura leucocephala } & 白头硬尾鸭 & I & 濒危 & 苟 军 & 新疆北部发现白头硬尾鸭繁殖 \\
\hline & & & /EN & & \\
\hline \multirow[t]{2}{*}{ Oxyura leucocephala } & 白头硬尾鸭 & I & 濒危 & 马鸣 & 新疆青格达湖湿地自然保护区及周边地区的鸟类 \\
\hline & & & /EN & & \\
\hline \multirow[t]{2}{*}{ Oxyura leucocephala } & 白头硬尾鸭 & I & 濒危 & 马鸣 & 在新疆发现两种珍稀野鸭 \\
\hline & & & /EN & & \\
\hline \multirow[t]{2}{*}{ Paa boulengeri } & 棘腹蛙 & 未列 & 濒危 & 陈高鹏 & 不同开口饵料对棘腹蛙幼蛙生长和存活的影响 \\
\hline & & 入 & /EN & & \\
\hline
\end{tabular}


顾垒，闻丞，罗玫，王吴，吕植. 中国最受关注濒危物种保护现状快速评价的新方法探讨. 生物多样性，2015，23(5)：583-590. http://www. biodiversity-science. net/CN/article/downloadArticleFile. do?attachType=PDF\&id=10075

\begin{tabular}{|c|c|c|c|c|c|}
\hline \multirow[t]{2}{*}{ Paa boulengeri } & 棘腹蛙 & 未列 & 濒危 & 龚大洁 & 甘肃康县棘腹蛙种群资源调查与分析 \\
\hline & & 入 & $/ \mathrm{EN}$ & & \\
\hline \multirow[t]{2}{*}{ Paa boulengeri } & 棘腹蛙 & 未列 & 濒危 & 熊建利 & 湖南壶瓶山国家级自然保护区棘腹蛙种群初探 \\
\hline & & 入 & $/ \mathrm{EN}$ & & \\
\hline \multirow[t]{2}{*}{ Paa boulengeri } & 棘腹蛙 & 未列 & 濒危 & 李文健 & 棘腹蛙(Rana boulengeri Gtinther)幼蛙人工试养的研究 \\
\hline & & 入 & /EN & & \\
\hline \multirow[t]{2}{*}{ Paa boulengeri } & 棘腹蛙 & 未列 & 濒危 & 田应洲 & 棘腹蛙、棘胸蛙和双团棘胸蛙血细胞的比较研究 \\
\hline & & 入 & /EN & & \\
\hline \multirow[t]{2}{*}{ Paa boulengeri } & 棘腹蛙 & 未列 & 濒危 & 邓一德 & 棘腹蛙的生物学特性及养殖技术 \\
\hline & & 入 & /EN & & \\
\hline \multirow[t]{2}{*}{ Paa boulengeri } & 棘腹蛙 & 未列 & 濒危 & 杨道德 & 棘腹蛙规模化养殖过程中饵料因子的讨论 \\
\hline & & 入 & $/ \mathrm{EN}$ & & \\
\hline \multirow[t]{2}{*}{ Paa boulengeri } & 棘腹蛙 & 未列 & 濒危 & 温安祥 & 棘腹蛙肌肉嫩度及营养成分的初步分析 \\
\hline & & 入 & /EN & & \\
\hline \multirow[t]{2}{*}{ Paa boulengeri } & 棘腹蛙 & 未列 & 濒危 & 温安祥 & 棘腹蛙肌肉中氨基酸含量的初步测定 \\
\hline & & 入 & /EN & & \\
\hline \multirow[t]{2}{*}{ Paa boulengeri } & 棘腹蛙 & 未列 & 濒危 & 徐敬明 & 棘腹蛙消化道脂肪酶的分布及 $\mathrm{pH}$ 和温度对脂肪酶活力的影响 \\
\hline & & 入 & $/ \mathrm{EN}$ & & \\
\hline Paa boulengeri & 棘腹蛙 & 未列 & 濒危 & 周庆萍 & 棘腹蛙血细胞的形态特征及染色特性 \\
\hline
\end{tabular}


顾垒，闻丞，罗玫，王吴，吕植. 中国最受关注濒危物种保护现状快速评价的新方法探讨. 生物多样性，2015，23(5)：583-590. http://www. biodiversity-science. net/CN/article/downloadArticleFile. do?attachType=PDF\&id=10075

\begin{tabular}{|c|c|c|c|c|c|}
\hline & & 入 & $/$ EN & & \\
\hline \multirow[t]{2}{*}{ Paa boulengeri } & 棘腹蛙 & 未列 & 濒危 & 江智龙 & 棘腹蛙驯养繁殖试验 \\
\hline & & 入 & $/ \mathrm{EN}$ & & \\
\hline \multirow[t]{2}{*}{ Paa boulengeri } & 棘腹蛙 & 未列 & 濒危 & 王云 & 棘腹蛙与棘侧蛙的外形区别及食物分析 \\
\hline & & 入 & $/$ EN & & \\
\hline \multirow[t]{2}{*}{ Paa boulengeri } & 棘腹蛙 & 未列 & 濒危 & 吴洪超 & 康县棘腹蛙（Paa boulengeri）种群生态学研究及物种保护 \\
\hline & & 入 & $/ \mathrm{EN}$ & & \\
\hline \multirow[t]{2}{*}{ Paa boulengeri } & 棘腹蛙 & 未列 & 濒危 & 廖常乐 & 利用地下采矿水养殖棘腹蛙的初步研究 \\
\hline & & 入 & $/$ EN & & \\
\hline \multirow[t]{2}{*}{ Paa boulengeri } & 棘腹蛙 & 未列 & 濒危 & 廖常乐 & 利用地下采矿水养殖棘腹蛙研究初报 \\
\hline & & 入 & $/$ EN & & \\
\hline \multirow[t]{2}{*}{ Paa boulengeri } & 棘腹蛙 & 未列 & 濒危 & 杨林元 & 庐山棘腹蛙生活习性及食性的研究初报 \\
\hline & & 入 & $/$ EN & & \\
\hline \multirow[t]{2}{*}{ Paa boulengeri } & 棘腹蛙 & 未列 & 濒危 & 杨道德 & 人工环境下棘腹蛙(Paa boulengeri)非繁殖期摄食行为的研究 \\
\hline & & 入 & /EN & & \\
\hline \multirow[t]{2}{*}{ Paa boulengeri } & 棘腹蛙 & 未列 & 濒危 & 陈高鹏 & 人工环境下棘腹蛙生物学特性与生态饲养技术的研究 \\
\hline & & 入 & $/ \mathrm{EN}$ & & \\
\hline \multirow[t]{2}{*}{ Paa boulengeri } & 棘腹蛙 & 未列 & 濒危 & 廖常乐 & 人工条件下棘腹蛙（Paa boulengeri）繁殖技术研究 \\
\hline & & 入 & /EN & & \\
\hline
\end{tabular}


顾垒，闻丞，罗玫，王吴，吕植. 中国最受关注濒危物种保护现状快速评价的新方法探讨. 生物多样性，2015，23(5)：583-590. http://www. biodiversity-science. net/CN/article/downloadArticleFile. do?attachType=PDF\&id=10075

\begin{tabular}{|c|c|c|c|c|c|}
\hline \multirow[t]{2}{*}{ Paa boulengeri } & 棘腹蛙 & 未列 & 濒危 & 孙爱群 & 双团棘胸蛙与棘腹蛙酯酶同工酶的比较研究 \\
\hline & & 入 & $/ \mathrm{EN}$ & & \\
\hline \multirow[t]{2}{*}{ Paa boulengeri } & 棘腹蛙 & 未列 & 濒危 & 徐敬明 & 四面山棘腹蛙在渝西地区饲养繁殖初步研究 \\
\hline & & 入 & $/ \mathrm{EN}$ & & \\
\hline \multirow[t]{2}{*}{ Paa boulengeri } & 棘腹蛙 & 未列 & 濒危 & 温涛 & 我国棘蛙（Paa）资源利用模式探悉 \\
\hline & & 入 & /EN & & \\
\hline \multirow[t]{2}{*}{ Paa boulengeri } & 棘腹蛙 & 未列 & 濒危 & 李益得 & 我国珍稀两栖动物一一 棘腹蛙 \\
\hline & & 入 & /EN & & \\
\hline \multirow[t]{2}{*}{ Paa boulengeri } & 棘腹蛙 & 未列 & 濒危 & 李文健 & 湘西棘腹蛙性腺发育的研究 \\
\hline & & 入 & $/ \mathrm{EN}$ & & \\
\hline \multirow[t]{2}{*}{ Paa boulengeri } & 棘腹蛙 & 未列 & 濒危 & 龚大洁 & 珍稀两栖动物一一棘腹蛙及其保护 \\
\hline & & 入 & $/ \mathrm{EN}$ & & \\
\hline \multirow[t]{2}{*}{ Paa liui } & 无声囊棘蛙 & 未列 & 易危 & CHEN YouHua & Habitat suitability modeling of amphibian species in southern and central China: environmental \\
\hline & & 入 & /VU & & correlates and potential richness mapping \\
\hline \multirow[t]{2}{*}{ Paa liui } & 无声囊棘蛙 & 未列 & 易危 & Ya-ping Zhang & Phylogeny of the Asian spiny frog tribe Paini (Family Dicroglossidae) sensu Dubois \\
\hline & & 入 & /VU & & \\
\hline \multirow[t]{2}{*}{ Paa liui } & 无声囊棘蛙 & 未列 & 易危 & 胡健生 & 刘氏棘蛙的分类修订 \\
\hline & & 入 & /VU & & \\
\hline Paa liui & 无声囊棘蛙 & 未列 & 易危 & 胡健生 & 中国几种棘蛙的核型 C一带和 Ag 一 NORs 研究 \\
\hline
\end{tabular}


顾垒，闻丞，罗玫，王吴，吕植. 中国最受关注濒危物种保护现状快速评价的新方法探讨. 生物多样性，2015，23(5)：583-590. http://www. biodiversity-science. net/CN/article/downloadArticleFile. do?attachType=PDF\&id=10075

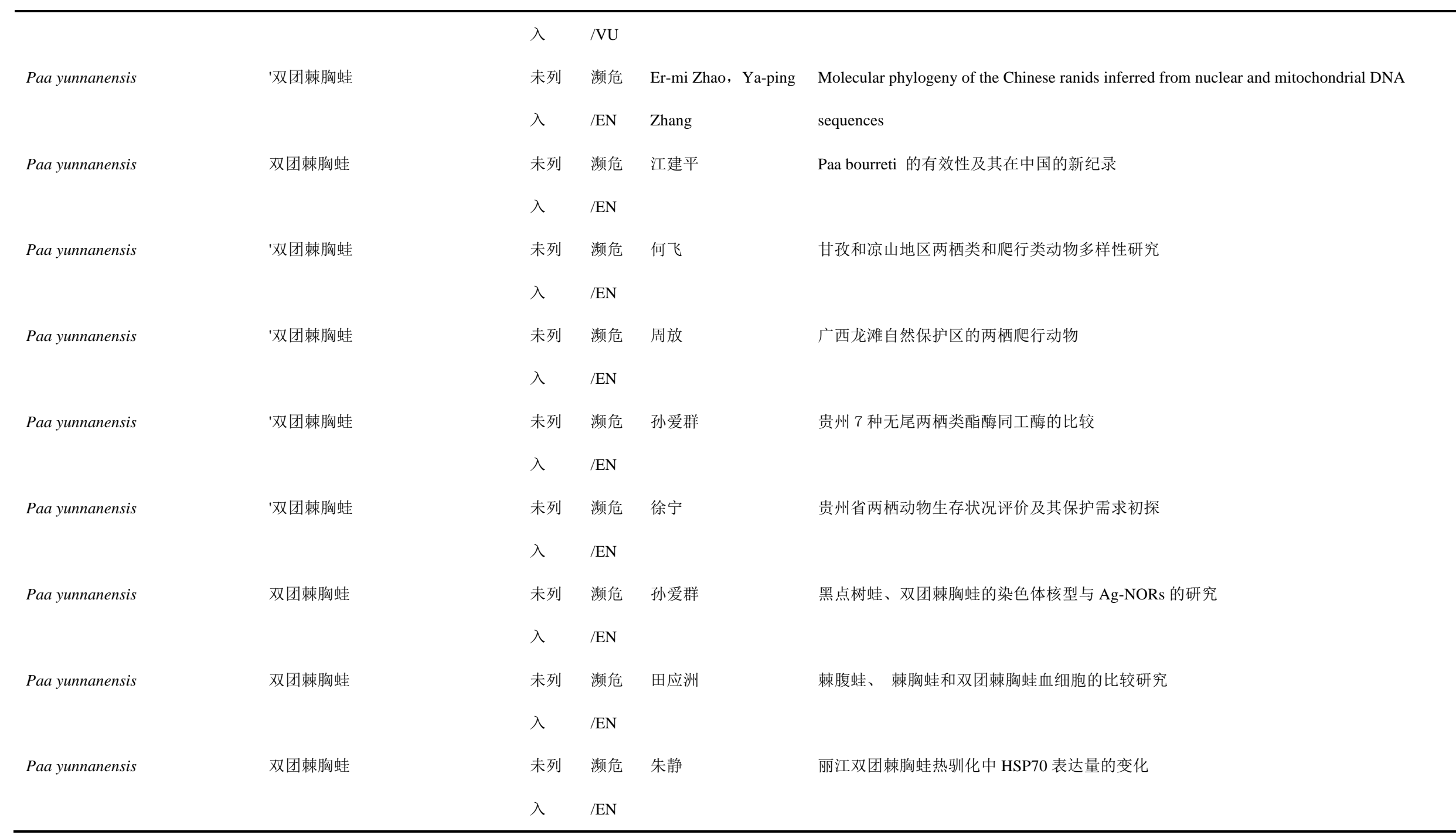


顾垒，闻丞，罗玫，王吴，吕植. 中国最受关注濒危物种保护现状快速评价的新方法探讨. 生物多样性，2015，23(5)：583-590. http.//www. biodiversity-science. net/CN/article/downloadArticleFile. do?attachType=PDF\&id=10075

\begin{tabular}{|c|c|c|c|c|c|}
\hline \multirow[t]{2}{*}{ Paa yunnanensis } & 双团棘胸蛙 & 未列 & 濒危 & 李灿鹏 & 双团棘胸蛙(Paa yunnanensis)肌肉营养成分分析与评价 \\
\hline & & 入 & $/ \mathrm{EN}$ & & \\
\hline \multirow[t]{2}{*}{ Paa yunnanensis } & 双团棘胸蛙 & 未列 & 濒危 & 王志坚 & 双团棘胸蛙消化道解剖学及组织学观察 \\
\hline & & 入 & $/$ EN & & \\
\hline \multirow[t]{2}{*}{ Paa yunnanensis } & 双团棘胸蛙 & 未列 & 濒危 & 周庆萍 & 双团棘胸蛙血细胞的显微观察 \\
\hline & & 入 & $/ \mathrm{EN}$ & & \\
\hline \multirow[t]{2}{*}{ Paa yunnanensis } & 双团棘胸蛙 & 未列 & 濒危 & 孙爱群 & 双团棘胸蛙与棘腹蛙酯酶同工酶的比较研究 \\
\hline & & 入 & /EN & & \\
\hline \multirow[t]{2}{*}{ Paa yunnanensis } & 双团棘胸蛙 & 未列 & 濒危 & 刘万国 & 蛙属中的一个特殊核型一双团棘胸蛙的核型及其 C 带和银带的研究 \\
\hline & & 入 & $/$ EN & & \\
\hline \multirow[t]{2}{*}{ Paa yunnanensis } & 双团棘胸蛙 & 未列 & 濒危 & 温涛 & 我国棘蛙（Paa）资源利用模式探悉 \\
\hline & & 入 & /EN & & \\
\hline \multirow[t]{2}{*}{ Paa yunnanensis } & 双团棘胸蛙 & 未列 & 濒危 & 胡健生 & 云南三种同域分布的棘蛙(蛙科 Ranidae:无尾目 Anura)的核型和银带研究 \\
\hline & & 入 & $/ \mathrm{EN}$ & & \\
\hline \multirow[t]{2}{*}{ Paa yunnanensis } & 双团棘胸蛙 & 未列 & 濒危 & 叶辉 & 云南省双团棘胸蛙的地理分布 \\
\hline & & 入 & /EN & & \\
\hline Paeonia szechuanica & 四川牡丹 & II & & 刘 光 立 & 层积处理对四川牡丹种子生理生化特性的影响 \\
\hline Paeonia szechuanica & 四川牡丹 & II & & 王士泉 & 苻药属两物种染色体结构变异杂合性研究 \\
\hline
\end{tabular}


顾垒，闻丞，罗玫，王吴，吕植. 中国最受关注濒危物种保护现状快速评价的新方法探讨. 生物多样性，2015，23(5)：583-590. http://www biodiversity-science. net/CN/article/downloadArticleFile. do?attachType=PDF\&id=10075

\begin{tabular}{|c|c|c|c|c|c|}
\hline Paeonia szechuanica & 四川牡丹 & II & & 骆劲涛 & 四川牡丹的传粉生物学研究 \\
\hline Paeonia szechuanica & 四川牡丹 & II & & 张大明 & 四川牡丹和块根莐药第五号染色体异常的减数分裂证据 \\
\hline Paeonia szechuanica & 四川牡丹 & II & & 刘光立 & 四川牡丹胚乳浸提液对油菜种子萌发与幼苗生长的影响 \\
\hline Paeonia szechuanica & 四川牡丹 & II & & 马莘 & 四川牡丹群落物种生态位及空间关联度分析 \\
\hline Paeonia szechuanica & 四川牡丹 & II & & 陈其兵 & 四川牡丹种子浸提液内源抑制物活性初探 \\
\hline Palea steindachneri & 山瑞鳖 & II & $\begin{array}{l}\text { 濒危 } \\
\text { /EN }\end{array}$ & 聂刘旺 & 基于线粒体 Cytb 基因全序列探讨两爪鳖和山瑞鳖的系统进化关系 \\
\hline Palea steindachneri & 山瑞鳖 & II & $\begin{array}{l}\text { 濒危 } \\
\text { /EN }\end{array}$ & 李小三 & 两爪鳖和山瑞鳖线粒体全基因组分析及其在龟鳖目中的系统学地位 \\
\hline Palea steindachneri & 山瑞鳖 & II & $\begin{array}{l}\text { 濒危 } \\
\text { /EN }\end{array}$ & 周运和 & 两种饲料养殖山瑞鳖成鳖的比较试验 \\
\hline Palea steindachneri & 山瑞鳖 & II & $\begin{array}{l}\text { 濒危 } \\
\text { /EN }\end{array}$ & 陈合格 & $\begin{array}{l}\text { 三种鳖线粒体 DNA 部分基因序列的比较 } \\
\text { 分析和分子鉴定标记 }\end{array}$ \\
\hline Palea steindachneri & 山瑞鳖 & II & $\begin{array}{l}\text { 濒危 } \\
\text { /EN }\end{array}$ & 张轩杰 & 三种鳖线粒体 DNA 细胞色素 $\mathrm{b}$ 基因序列的比较分析 \\
\hline Palea steindachneri & 山瑞鳖 & II & $\begin{array}{l}\text { 濒危 } \\
\text { /EN }\end{array}$ & 阳建春 & 山瑞鳖产卵与孵化研究 \\
\hline Palea steindachneri & 山瑞鳖 & II & 濒危 & 李应森 & 山瑞鳖的繁殖生态 \\
\hline
\end{tabular}


顾垒，闻丞，罗玫，王吴，吕植. 中国最受关注濒危物种保护现状快速评价的新方法探讨. 生物多样性，2015，23(5)：583-590. http://www biodiversity-science. net/CN/article/downloadArticleFile. do?attachType=PDF\&id=10075

\begin{tabular}{|c|c|c|c|c|c|}
\hline & & & /EN & & \\
\hline \multirow[t]{2}{*}{ Palea steindachneri } & 山瑞鳖 & II & 濒危 & 黎小正 & 山瑞鳖塞氏柠檬酸杆菌的分离鉴定及药物敏感性研究 \\
\hline & & & /EN & & \\
\hline \multirow[t]{2}{*}{ Palea steindachneri } & 山瑞鳖 & II & 濒危 & 黎小正 & 山瑞鳖嗜水气单胞菌感染的诊断及防治 \\
\hline & & & $/ \mathrm{EN}$ & & \\
\hline \multirow[t]{2}{*}{ Palea steindachneri } & 山瑞鳖 & II & 濒危 & 寇治通 & 山瑞鳖驯化养殖、保护及其开发利用 1 .山瑞鳖的繁殖习性 \\
\hline & & & /EN & & \\
\hline \multirow[t]{2}{*}{ Palea steindachneri } & 山瑞鳖 & II & 濒危 & 寇治通 & 山瑞鳖驯化养殖、保护及其开发利用的初步研究 2. 山瑞鳖的生长、饲养管理及保护利用 \\
\hline & & & /EN & & \\
\hline \multirow[t]{2}{*}{ Panax pseudoginseng } & 三七 & 未列 & $\mathrm{NE}$ & 崔秀明 & 三七及其混淆品的 HPLC 指纹图谱鉴定 \\
\hline & & 入 & & & \\
\hline \multirow[t]{2}{*}{ Panthera tigris altaica } & 东北虎 & I & 极危 & 孙海义 & 哺乳类珍稀濒危物种网络监测技术 \\
\hline & & & /CR & & \\
\hline \multirow[t]{2}{*}{ Panthera uncia } & 雪豹 & I & 濒危 & Juan Li; Zhi Lu & Human-snow leopard conflicts in the Sanjiangyuan Region of the Tibetan \\
\hline & & & /EN & & Plateau \\
\hline \multirow[t]{2}{*}{ Panthera uncia } & 雪豹 & I & 濒危 & 周芸芸 & 基于分子粪便学的雪豹保护遗传学研究 \\
\hline & & & $/ \mathrm{EN}$ & & \\
\hline \multirow[t]{2}{*}{ Panthera uncia } & 雪豹 & I & 濒危 & 张于光 & 基于粪便 DNA 的雪豹种群调查和遗传多样性 \\
\hline & & & /EN & & \\
\hline
\end{tabular}


顾垒，闻丞，罗玫，王吴，吕植. 中国最受关注濒危物种保护现状快速评价的新方法探讨. 生物多样性，2015，23(5)：583-590. http://www. biodiversity-science. net/CN/article/downloadArticleFile. do?attachType=PDF\&id=10075

\begin{tabular}{|c|c|c|c|c|c|}
\hline Panthera uncia & 雪豹 & I & $\begin{array}{l}\text { 濒危 } \\
/ \mathrm{EN}\end{array}$ & 张于光 & 基于粪便 DNA 的青海雪豹种群遗传结构初步研究 \\
\hline Panthera uncia & 雪豹 & I & $\begin{array}{l}\text { 濒危 } \\
\text { /EN }\end{array}$ & 马鸣 & 利用自动照相术获得天山雪豹拍摄率与个体数量 \\
\hline Panthera uncia & 雪豹 & I & $\begin{array}{l}\text { 濒危 } \\
/ \mathrm{EN}\end{array}$ & 徐峰 & 新疆北塔山地区雪豹及其食物资源调查初报 \\
\hline Panthera uncia & 雪豹 & I & $\begin{array}{l}\text { 濒危 } \\
\text { /EN }\end{array}$ & 徐峰 & 新疆北塔山雪豹对秋季栖息地的选择 \\
\hline Panthera uncia & 雪豹 & I & $\begin{array}{l}\text { 濒危 } \\
/ \mathrm{EN}\end{array}$ & 王君 & 新疆塔什库尔干地区雪豹生态位研究及种群估算 \\
\hline Panthera uncia & 雪豹 & I & $\begin{array}{l}\text { 濒危 } \\
\text { /EN }\end{array}$ & 徐峰 & 新疆托木尔峰国家级自然保护区雪豹的种群密度 \\
\hline Panthera uncia & 雪豹 & I & $\begin{array}{l}\text { 濒危 } \\
\text { /EN }\end{array}$ & 马鸣 & 新疆雪豹调查中的痕迹分析 \\
\hline Panthera uncia & 雪豹 & I & $\begin{array}{l}\text { 濒危 } \\
/ \mathrm{EN}\end{array}$ & 马鸣 & 新疆雪豹种群密度监测方法探讨 \\
\hline Panthera uncia & 雪豹 & I & $\begin{array}{l}\text { 濒危 } \\
/ \mathrm{EN}\end{array}$ & 刘楚光 & 雪豹的食性与食源调查研究 \\
\hline Panthera uncia & 雪豹 & I & 濒危 & 吴秀山 & 雪豹佝偻病 \\
\hline
\end{tabular}


顾垒，闻丞，罗玫，王吴，吕植. 中国最受关注濒危物种保护现状快速评价的新方法探讨. 生物多样性，2015，23(5)：583-590. http://www. biodiversity-science. net/CN/article/downloadArticleFile. do?attachType=PDF\&id=10075

\begin{tabular}{|c|c|c|c|c|c|}
\hline & & & /EN & & \\
\hline \multirow[t]{2}{*}{ Panthera uncia } & 雪豹 & I & 濒危 & 哈力克・热合曼 & 雪豹急性出血性膀胱炎的诊治 \\
\hline & & & /EN & & \\
\hline \multirow[t]{2}{*}{ Panthera uncia } & 雪豹 & I & 濒危 & 汪晓飞 & 雪豹急性出血性胃肠炎的诊疗 \\
\hline & & & /EN & & \\
\hline \multirow[t]{2}{*}{ Panthera uncia } & 雪豹 & I & 濒危 & 汪晓飞 & 雪豹截肢手术一例 \\
\hline & & & /EN & & \\
\hline \multirow[t]{2}{*}{ Panthera uncia } & 雪豹 & I & 濒危 & 程晓明 & 雪豹两种人工育幼方式比较 \\
\hline & & & /EN & & \\
\hline \multirow[t]{2}{*}{ Panthera uncia } & 雪豹 & I & 濒危 & 徐峰 & 雪豹栖息地选择研究初报 \\
\hline & & & /EN & & \\
\hline \multirow[t]{2}{*}{ Panthera uncia } & 雪豹 & I & 濒危 & Juan Li & A Communal Sign Post of Snow Leopards ( Pantherauncia ) and Other Species on the Tibetan \\
\hline & & & /EN & & Plateau,China \\
\hline \multirow[t]{2}{*}{ Panthera uncia } & 雪豹 & I & 濒危 & RODNEY M. & A Community-Based Approach to Mitigating Livestock Depredation by Snow Leopards \\
\hline & & & /EN & JACKSON & \\
\hline \multirow[t]{2}{*}{ Panthera uncia } & 雪豹 & I & 濒危 & Zhigang Jiang & Development of primers to characterize the mitochondrial control region of the snow leopard \\
\hline & & & /EN & & (Uncia uncia) \\
\hline \multirow[t]{2}{*}{ Panthera uncia } & 雪豹 & I & 濒危 & WU XiaoBing & Mitogenomic analysis of the genus Panthera \\
\hline & & & /EN & & \\
\hline
\end{tabular}


顾垒，闻丞，罗玫，王昊，吕植. 中国最受关注濒危物种保护现状快速评价的新方法探讨．生物多样性，2015，23(5)：583-590. http://www. biodiversity-science. net/CN/article/downloadArticleFile. do?attachType=PDF\&id=10075

\begin{tabular}{|c|c|c|c|c|c|}
\hline Panthera uncia & 雪豹 & I & $\begin{array}{l}\text { 濒危 } \\
\text { /EN }\end{array}$ & Stephen J O’' Brien & Phylogenetics, genome diversity and origin of modern leopard, Panthera pardus \\
\hline Panthera uncia & 雪豹 & I & $\begin{array}{l}\text { 濒危 } \\
\text { /EN }\end{array}$ & J. E. Janec ${ }^{\sim}$ ka & $\begin{array}{l}\text { Population monitoring of snow leopards using noninvasive collection of scat samples: a pilot } \\
\text { study }\end{array}$ \\
\hline Panthera uncia & 雪豹 & I & $\begin{array}{l}\text { 濒危 } \\
\text { /EN }\end{array}$ & Pierre Taberlet & Prey Preference of Snow Leopard (Panthera uncia ) in South Gobi, Mongolia \\
\hline Panthera uncia & 雪豹 & I & $\begin{array}{l}\text { 濒危 } \\
\text { /EN }\end{array}$ & Feng Xu & $\begin{array}{l}\text { Recovery of Snow Leopard Uncia uncia in Tomur National Nature } \\
\text { Reserve of Xinjiang, Northwestern China }\end{array}$ \\
\hline Panthera uncia & 雪豹 & I & $\begin{array}{l}\text { 濒危 } \\
\text { /EN }\end{array}$ & & $\begin{array}{l}\text { RESOLUTION OF PHYLOGENETIC RELATIONSHIPS AND CHARACTERIZATION OF } \\
\text { Y-LINKED MICROSATELLITES WITHIN THE BIG CATS, PANTHERA }\end{array}$ \\
\hline Panthera uncia & 雪豹 & I & $\begin{array}{l}\text { 濒危 } \\
\text { /EN }\end{array}$ & Zhigang Jiang & $\begin{array}{l}\text { Status and conservation of the snow leopardPanthera uncia in the Gouli Region, Kunlun } \\
\text { Mountains, China }\end{array}$ \\
\hline Panthera uncia & 雪豹 & I & $\begin{array}{l}\text { 濒危 } \\
\text { /EN }\end{array}$ & Ming Ma & $\begin{array}{l}\text { Status of snow leopard Uncia uncia and its conservation in the tumor peak natural reserve in } \\
\text { Xinjiang, China }\end{array}$ \\
\hline Panthera uncia & 雪豹 & I & $\begin{array}{l}\text { 濒危 } \\
\text { /EN }\end{array}$ & Xiaobing Wu & The complete mitochondrial genome structure of snow leopard Panthera uncia \\
\hline Panthera uncia & 雪豹 & I & $\begin{array}{l}\text { 濒危 } \\
\text { /EN }\end{array}$ & Ming MA & $\begin{array}{l}\text { Winter habitat use of snow leopards in Tomur National Nature Reserve of Xinjiang, Northwest } \\
\text { China }\end{array}$ \\
\hline Panthera uncia & 雪豹 & I & 濒危 & 吴孝兵 & 豹属线粒体基因组分析 \\
\hline
\end{tabular}


顾垒，闻丞，罗玫，王吴，吕植. 中国最受关注濒危物种保护现状快速评价的新方法探讨. 生物多样性，2015，23(5)：583-590. http://www. biodiversity-science. net/CN/article/downloadArticleFile. do?attachType=PDF\&id=10075

\begin{tabular}{|c|c|c|c|c|c|}
\hline & & & /EN & & \\
\hline \multirow[t]{2}{*}{ Panthera uncia } & 雪豹 & I & 濒危 & 周芸芸 & 基于分子粪便学的雪豹保护遗传学研究 \\
\hline & & & /EN & & \\
\hline \multirow[t]{2}{*}{ Panthera uncia } & 雪豹 & I & 濒危 & 魏 磊 & 基于线粒体 ND2 和 ND4 基因合并序列探讨豹属的分子系统关系 \\
\hline & & & /EN & & \\
\hline \multirow[t]{2}{*}{ Panthera uncia } & 雪豹 & I & 濒危 & 吴孝兵 & 基于线粒体控制区序列探讨豹属分子系统发生关系 \\
\hline & & & /EN & & \\
\hline \multirow[t]{2}{*}{ Panthera uncia } & 雪豹 & I & 濒危 & 王 彦 & 近 年来雪豹( Uncia uncia) 研究的文献分析 \\
\hline & & & /EN & & \\
\hline \multirow[t]{2}{*}{ Panthera uncia } & 雪豹 & I & 濒危 & 彭基泰 & 青藏高原东南横断山脉甘孜地区雪豹资源调查研究 \\
\hline & & & /EN & & \\
\hline \multirow[t]{2}{*}{ Panthera uncia } & 雪豹 & I & 濒危 & 吴国生 & 青海省都兰县沟里乡智玉村野生雪豹调查 \\
\hline & & & /EN & & \\
\hline \multirow[t]{2}{*}{ Panthera uncia } & 雪豹 & I & 濒危 & 张于光 & 青海省雪豹数量调查和遗传结构初步研究 \\
\hline & & & /EN & & \\
\hline \multirow[t]{2}{*}{ Panthera uncia } & 雪豹 & I & 濒危 & 徐峰 & 新疆北塔山雪豹队秋季栖息地的选择 \\
\hline & & & /EN & & \\
\hline \multirow[t]{2}{*}{ Panthera uncia } & 雪豹 & I & 濒危 & 徐峰 & 新疆托木尔峰自然保护区雪豹调查初报 \\
\hline & & & /EN & & \\
\hline
\end{tabular}


顾垒，闻丞，罗玫，王吴，吕植. 中国最受关注濒危物种保护现状快速评价的新方法探讨. 生物多样性，2015，23(5)：583-590. http://www. biodiversity-science. net/CN/article/downloadArticleFile. do?attachType=PDF\&id=10075

\begin{tabular}{|c|c|c|c|c|c|}
\hline Panthera uncia & 雪豹 & I & $\begin{array}{l}\text { 濒危 } \\
\text { /EN }\end{array}$ & 蒋志刚 & 雪 豹 \\
\hline Panthera uncia & 雪豹 & I & $\begin{array}{l}\text { 濒危 } \\
\text { /EN }\end{array}$ & 王 彦 & 雪豹( Uncia uncia) 研究的文献计量评价 \\
\hline Panthera uncia & 雪豹 & I & $\begin{array}{l}\text { 濒危 } \\
\text { /EN }\end{array}$ & 张晓军 & 雪豹针毛表面超微结构的观察分析 \\
\hline Panthera uncia & 雪豹 & I & $\begin{array}{l}\text { 濒危 } \\
\text { /EN }\end{array}$ & 张得良 & 幼年雪豹的试养报告 \\
\hline Panthera uncia & 雪豹 & I & $\begin{array}{l}\text { 濒危 } \\
\text { /EN }\end{array}$ & 李娟 & 中国青藏高原雪豹和其他物种的共同标记位点 \\
\hline Pantholops hodgsonii & 藏羚 & I & $\begin{array}{l}\text { 濒危 } \\
\text { /EN }\end{array}$ & Xiao-Guang Zheng & A Mitochondrial Genome Sequence of the Tibetan Antelope (Pantholops hodgsonii) \\
\hline Pantholops hodgsonii & 藏羚 & I & $\begin{array}{l}\text { 濒危 } \\
\text { /EN }\end{array}$ & Yuwei Gao & Contagious Caprine Pleuropneumonia in Endangered Tibetan Antelope,China, 2012 \\
\hline Pantholops hodgsonii & 藏羚 & I & $\begin{array}{l}\text { 濒危 } \\
\text { /EN }\end{array}$ & Jian-Ping SU & Demographic history of the Tibetan antelope Pantholops hodgsoni(chiru) \\
\hline Pantholops hodgsonii & 藏羚 & I & $\begin{array}{l}\text { 濒危 } \\
\text { /EN }\end{array}$ & Florent Rivals & $\begin{array}{l}\text { Diet of Mongolian gazelles and Tibetan antelopes from steppe habitats using premaxillary } \\
\text { shape, tooth mesowear and microwear analyses }\end{array}$ \\
\hline Pantholops hodgsonii & 藏羚 & I & 濒危 & Ri-Li Ge & Draft genome sequence of the Tibetan antelope \\
\hline
\end{tabular}


顾垒，闻丞，罗玫，王昊，吕植. 中国最受关注濒危物种保护现状快速评价的新方法探讨．生物多样性，2015，23(5)：583-590.

Pantholops hodgsonii

Pantholops hodgsonii

Pantholops hodgsonii

Pantholops hodgsonii

Pantholops hodgsonii

Pantholops hodgsonii

Pantholops hodgsonii

Pantholops hodgsonii

Pantholops hodgsonii
藏羚
濒危 /EN 濒危 EN 版危 Jun Yu /EN

I 濒危 Diqiang Li

/EN

I

I I 濒危
Evaluation the possibility of ex situ conservation of plateau antelopes according to food content

with stable isotope $\mathrm{C}$ and $\mathrm{N}$ analysis

Evolutionary history and current population relationships of the chiru (Pantholops hodgsonii)

inferred from mtDNA variation

Expression profiling of abundant genes in pulmonary and cardiac muscle tissues of Tibetan

Antelope (Pantholops hodgsonii)

Genetic Diversity of Microsatellite DNA Loci of Tibetan Antelope (Chiru, Pantholops

hodgsonii) in Hoh Xil National Nature Reserve, Qinghai, China

Habitat selection by sympatric chiru and Tibetan gazelle in the Aru Basin, Chang Tang Nature

Reserve, Tibet Autonomous Region, China

In vivo and in vitro development of Tibetan antelope (Pantholops hodgsonii) interspecific

cloned embryos

Interspecies embryo reconstruction in Tibetan antelope Pantholops hodgsonii by handmade

cloning

Molecular characteristics of Tibetan antelope (Pantholops hodgsonii) mitochondrial DNA control region and phylogenetic inferences with related species

Molecular Cloning of Hemoglobin Alpha-chain Gene from Pantholops hodgsonii, a Hypoxic

Tolerance Species 
顾垒，闻丞，罗玫，王昊，吕植. 中国最受关注濒危物种保护现状快速评价的新方法探讨．生物多样性，2015，23(5)：583-590. http://www. biodiversity-science. net/CN/article/downloadArticleFile. do?attachType=PDF\&id=10075

\begin{tabular}{|c|c|c|c|c|c|}
\hline Pantholops hodgsonii & 藏羚 & I & $\begin{array}{l}\text { 濒危 } \\
\text { /EN }\end{array}$ & Ri-Li Ge & $\begin{array}{l}\text { Molecular cloning, characterization and expression of myoglobin in Tibetan antelope } \\
\text { (Pantholops hodgsonii), a species with hypoxic tolerance }\end{array}$ \\
\hline Pantholops hodgsonii & 藏羚 & I & $\begin{array}{l}\text { 濒危 } \\
\text { /EN }\end{array}$ & DAVID M. LESLIE & Pantholops hodgsonii (Artiodactyla Bovidae) \\
\hline Pantholops hodgsonii & 藏羚 & I & $\begin{array}{l}\text { 濒危 } \\
\text { /EN }\end{array}$ & Hoshino Buho & $\begin{array}{l}\text { Preliminary study on migration pattern of the Tibetan antelope (Pantholops hodgsonii) based on } \\
\text { satellite tracking }\end{array}$ \\
\hline Pantholops hodgsonii & 藏羚 & I & $\begin{array}{l}\text { 濒危 } \\
\text { /EN }\end{array}$ & Zhigang Jiang & $\begin{array}{l}\text { Recent Geological Events and Intrinsic Behavior Influence the Population Genetic Structure of } \\
\text { the Chiru and Tibetan Gazelle on the Tibetan Plateau }\end{array}$ \\
\hline Pantholops hodgsonii & 藏羚 & I & $\begin{array}{l}\text { 濒危 } \\
\text { /EN }\end{array}$ & Xinming Lian & $\begin{array}{l}\text { Road proximity and traffic flow perceived as potential predation risks evidence from the } \\
\text { Tibetan antelope in the Kekexili National Nature Reserve, China }\end{array}$ \\
\hline Pantholops hodgsonii & 藏羚 & I & $\begin{array}{l}\text { 濒危 } \\
\text { /EN }\end{array}$ & Karina Manayeva & Spatial and temporal distribution of Tibetan antelope at Hoh Xil national reserve \\
\hline Pantholops hodgsonii & 藏羚 & I & $\begin{array}{l}\text { 濒危 } \\
\text { /EN }\end{array}$ & Lin Xia & $\begin{array}{l}\text { The effect of the Qinghai-Tibet railway on the migration of Tibetan antelope Pantholops } \\
\text { hodgsonii in Hoh-xil National Nature Reserve, China }\end{array}$ \\
\hline Pantholops hodgsonii & 藏羚 & I & $\begin{array}{l}\text { 濒危 } \\
\text { /EN }\end{array}$ & 苏建平 & 爱羚: 第一只家养成功的藏羚 \\
\hline Pantholops hodgsonii & 藏羚 & I & $\begin{array}{l}\text { 濒危 } \\
\text { /EN }\end{array}$ & 冯政 & 藏羚、藏绵羊、藏山羊 mtDNAD-loop 区序列变异与系统发生关系的研究 \\
\hline Pantholops hodgsonii & 藏羚 & I & 濒危 & 周用武 & 藏羚的分布与迁移 \\
\hline
\end{tabular}


顾垒，闻丞，罗玫，王吴，吕植. 中国最受关注濒危物种保护现状快速评价的新方法探讨. 生物多样性，2015，23(5)：583-590. http://www. biodiversity-science. net/CN/article/downloadArticleFile. do?attachType=PDF\&id=10075

\begin{tabular}{|c|c|c|c|c|c|}
\hline & & & /EN & & \\
\hline \multirow[t]{2}{*}{ Pantholops hodgsonii } & 藏羚 & I & 濒危 & 吴晓民 & 藏羚的受食生物学 \\
\hline & & & $/$ EN & & \\
\hline \multirow[t]{2}{*}{ Pantholops hodgsonii } & 藏羚 & I & 濒危 & 张伟 & 藏羚冬季绒毛的形态结构 \\
\hline & & & /EN & & \\
\hline \multirow[t]{2}{*}{ Pantholops hodgsonii } & 藏羚 & I & 濒危 & 苏建平 & 藏羚寄生蠕虫卵粪检调查初报 \\
\hline & & & /EN & & \\
\hline \multirow[t]{2}{*}{ Pantholops hodgsonii } & 藏羚 & I & 濒危 & 吴晓民 & 藏羚迁徙对青藏公路的行为适应与保护 \\
\hline & & & /EN & & \\
\hline \multirow[t]{2}{*}{ Pantholops hodgsonii } & 藏羚 & I & 濒危 & 李迪强 & 藏羚羊 mtDNA D-Loop 区遗传多样性研究 \\
\hline & & & /EN & & \\
\hline \multirow[t]{2}{*}{ Pantholops hodgsonii } & 藏羚 & $\mathrm{I}$ & 濒危 & 邹兴淮 & 藏羚羊的保护 \\
\hline & & & /EN & & \\
\hline \multirow[t]{2}{*}{ Pantholops hodgsonii } & 藏羚 & I & 濒危 & 孟庆漫 & 藏羚羊的保护与开发 \\
\hline & & & /EN & & \\
\hline \multirow[t]{2}{*}{ Pantholops hodgsonii } & 藏羚 & I & 濒危 & 吴逸群 & 藏羚羊的生存现状与保护 \\
\hline & & & /EN & & \\
\hline \multirow[t]{2}{*}{ Pantholops hodgsonii } & 藏羚 & I & 濒危 & 常荣 & 藏羚羊高海拔低氧适应的心脏特征及 CaMK_ANP_BNP 基因的克隆与表达 \\
\hline & & & /EN & & \\
\hline
\end{tabular}


顾垒，闻丞，罗玫，王吴，吕植. 中国最受关注濒危物种保护现状快速评价的新方法探讨. 生物多样性，2015，23(5)：583-590. http://www biodiversity-science. net/CN/article/downloadArticleFile. do?attachType=PDF\&id=10075

\begin{tabular}{|c|c|c|c|c|c|}
\hline Pantholops hodgsonii & 藏羚 & I & $\begin{array}{l}\text { 濒危 } \\
\text { /EN }\end{array}$ & 李光鹏 & 藏羚与几种牛科动物成纤维细胞的特性比较 \\
\hline Pantholops hodgsonii & 藏羚 & I & $\begin{array}{l}\text { 濒危 } \\
\text { /EN }\end{array}$ & 武永华 & 雌性藏羚迁徙对青藏高原降水时空分布的适应性分析 \\
\hline Pantholops hodgsonii & 藏羚 & I & $\begin{array}{l}\text { 濒危 } \\
\text { /EN }\end{array}$ & 彭毛 & 高原珍稀野生动物藏羚羊体内发现蒙古马歇尔线虫 \\
\hline Pantholops hodgsonii & 藏羚 & I & $\begin{array}{l}\text { 濒危 } \\
\text { /EN }\end{array}$ & 郑中朝 & 关于藏羚羊保护的思考 \\
\hline Pantholops hodgsonii & 藏羚 & I & $\begin{array}{l}\text { 濒危 } \\
\text { /EN }\end{array}$ & 杨奇森 & 交通设施对可可西里藏羚季节性迁移的影响 \\
\hline Pantholops hodgsonii & 藏羚 & I & $\begin{array}{l}\text { 濒危 } \\
\text { /EN }\end{array}$ & 苏建平 & 可可西里地区藏羚的社群特征 \\
\hline Pantholops hodgsonii & 藏羚 & I & $\begin{array}{l}\text { 濒危 } \\
\text { /EN }\end{array}$ & 魏万红 & 可可西里地区藏羚羊、藏原羚和藏野驴的营养生态位 \\
\hline Pantholops hodgsonii & 藏羚 & I & $\begin{array}{l}\text { 濒危 } \\
\text { /EN }\end{array}$ & 连新明 & 可可西里四种有蹄类动物对道路的回避距离及保护建议 \\
\hline Pantholops hodgsonii & 藏羚 & I & $\begin{array}{l}\text { 濒危 } \\
\text { /EN }\end{array}$ & 李晓晓 & 可可西里同域分布藏羚与藏原羚生境选择研究 \\
\hline Pantholops hodgsonii & 藏羚 & I & 濒危 & 任宏 & 内蒙古白线山羊、藏羚羊、岩羊头骨比较解剖 \\
\hline
\end{tabular}


顾垒，闻丞，罗玫，王吴，吕植. 中国最受关注濒危物种保护现状快速评价的新方法探讨. 生物多样性，2015，23(5)：583-590. http://www. biodiversity-science. net/CN/article/downloadArticleFile. do?attachType=PDF\&id=10075

\begin{tabular}{|c|c|c|c|c|c|}
\hline & & & /EN & & \\
\hline \multirow[t]{2}{*}{ Pantholops hodgsonii } & 藏羚 & I & 濒危 & 苏建平 & 青藏高原藏羚生物学研究现状 \\
\hline & & & $/$ EN & & \\
\hline \multirow[t]{2}{*}{ Pantholops hodgsonii } & 藏羚 & I & 濒危 & 赵新全 & 青藏高原异地半圈养藏羚警戒行为的适应性研究 \\
\hline & & & /EN & & \\
\hline \multirow[t]{2}{*}{ Pantholops hodgsonii } & 藏羚 & I & 濒危 & 魏万红 & 青藏公路对藏羚羊、藏原羚和藏野驴活动的影响 \\
\hline & & & /EN & & \\
\hline \multirow[t]{2}{*}{ Pantholops hodgsonii } & 藏羚 & I & 濒危 & 冯祚建 & 青藏公路沿线白昼交通运输等人类活动对藏羚羊迁徙的影响 \\
\hline & & & /EN & & \\
\hline \multirow[t]{2}{*}{ Pantholops hodgsonii } & 藏羚 & I & 濒危 & 郑杰 & 青海藏羚资源现状与保护 \\
\hline & & & /EN & & \\
\hline \multirow[t]{2}{*}{ Pantholops hodgsonii } & 藏羚 & I & 濒危 & 苏建平 & 青海省可可西里地区几种有蹄类动物的食物重叠初步分析 \\
\hline & & & /EN & & \\
\hline \multirow[t]{2}{*}{ Pantholops hodgsonii } & 藏羚 & I & 濒危 & 苏建平 & 夏季雌性藏羚昼间行为时间分配及活动节律 \\
\hline & & & /EN & & \\
\hline \multirow[t]{2}{*}{ Pantholops hodgsonii } & 藏羚 & I & 濒危 & 连新明 & 夏季可可西里雌性藏原羚行为时间分配及活动节律 \\
\hline & & & /EN & & \\
\hline \multirow[t]{2}{*}{ Pantholops hodgsonii } & 藏羚 & I & 濒危 & 赵新全 & 异地半圈养藏羚卧息行为适应性的初步研究 \\
\hline & & & /EN & & \\
\hline
\end{tabular}


顾垒，闻丞，罗玫，王吴，吕植. 中国最受关注濒危物种保护现状快速评价的新方法探讨. 生物多样性，2015，23(5)：583-590. http://www biodiversity-science. net/CN/article/downloadArticleFile. do?attachType=PDF\&id=10075

\begin{tabular}{|c|c|c|c|c|c|}
\hline Pantholops hodgsonii & 藏羚 & I & $\begin{array}{l}\text { 濒危 } \\
\text { /EN }\end{array}$ & 刘丑生 & 应用动物生物技术保护藏羚羊遗传资源 \\
\hline Pantholops hodgsonii & 藏羚 & I & $\begin{array}{l}\text { 濒危 } \\
\text { /EN }\end{array}$ & 蒋志刚 & 原羚属分类地位研究兼论中国羚羊的分类 \\
\hline Paphiopedilum armeniacum & 杏黄兒兰 & I & $\begin{array}{l}\text { 濒危 } \\
\text { /EN }\end{array}$ & 董艳莉 & 杏黄兜兰的生物生态学特性及迁地栽培试验研究 \\
\hline Paphiopedilum armeniacum & 杏黄晲兰 & I & $\begin{array}{l}\text { 濒危 } \\
\text { /EN }\end{array}$ & Jih Min Sungb & $\begin{array}{l}\text { Development of ITS sequence based SCAR markers for discrimination of Paphiopedilum } \\
\text { armeniacum, Paphiopedilum micranthum, Paphiopedilum delenatii and their hybrids }\end{array}$ \\
\hline Paphiopedilum armeniacum & 杏黄覑兰 & I & $\begin{array}{l}\text { 濒危 } \\
\text { /EN }\end{array}$ & Chun-lin Long & In vitro propagation of four threatened Paphiopedilum species (Orchidaceae) \\
\hline Paphiopedilum armeniacum & 杏黄皃兰 & I & $\begin{array}{l}\text { 濒危 } \\
\text { /EN }\end{array}$ & Hong Hu & $\begin{array}{l}\text { Slow photosynthetic induction and low photosynthesis in Paphiopedilum armeniacum are } \\
\text { related to its lack of guard cell chloroplast and peculiar stomatal anatomy }\end{array}$ \\
\hline Paphiopedilum armeniacum & 杏黄皃兰 & I & $\begin{array}{l}\text { 濒危 } \\
\text { /EN }\end{array}$ & 黄来强 & 濒危物种杏黄皃兰的保育生态学 \\
\hline Paphiopedilum armeniacum & 杏黄兒兰 & I & $\begin{array}{l}\text { 濒危 } \\
\text { /EN }\end{array}$ & 罗毅波 & 初论中国晁兰属植物的保护策略及其潜在资源优势 \\
\hline Paphiopedilum armeniacum & 杏黄皃兰 & I & $\begin{array}{l}\text { 濒危 } \\
\text { /EN }\end{array}$ & 朱根发 & 㝸兰宽瓣亚属 8 种植物的核型比较 \\
\hline Paphiopedilum armeniacum & 杏黄兒兰 & I & 濒危 & 王贞 & 㝸兰属植物研究现状 \\
\hline
\end{tabular}


顾垒，闻丞，罗玫，王吴，吕植. 中国最受关注濒危物种保护现状快速评价的新方法探讨. 生物多样性，2015，23(5)：583-590. http://www. biodiversity-science. net/CN/article/downloadArticleFile. do?attachType=PDF\&id=10075

\begin{tabular}{|c|c|c|c|c|c|}
\hline & & & /EN & & \\
\hline \multirow[t]{2}{*}{ Paphiopedilum armeniacum } & 杏黄咸兰 & I & 濒危 & 邓克云 & 贵州省兴义市兜兰属植物引种驯化研究 \\
\hline & & & $/$ EN & & \\
\hline \multirow[t]{2}{*}{ Paphiopedilum armeniacum } & 杏黄兒兰 & I & 濒危 & 李雪 & 六种㝸兰属植物的叶面积和叶幅与开花的关系 \\
\hline & & & /EN & & \\
\hline \multirow[t]{2}{*}{ Paphiopedilum armeniacum } & 杏黄兒兰 & I & 濒危 & 胡虹 & 内生真菌与两种樂兰共培养过程中的相互作用 \\
\hline & & & /EN & & \\
\hline \multirow[t]{2}{*}{ Paphiopedilum armeniacum } & 杏黄咸兰 & I & 濒危 & 刘仲健 & 杏黄兒兰传粉生物学的研究 \\
\hline & & & /EN & & \\
\hline \multirow[t]{2}{*}{ Paphiopedilum armeniacum } & 杏黄兒兰 & I & 濒危 & 胡 虹 & 杏黄㿟兰的花发育过程及引种栽培 \\
\hline & & & /EN & & \\
\hline \multirow[t]{2}{*}{ Paphiopedilum armeniacum } & 杏黄咸兰 & I & 濒危 & 叶秀奔 & 杏黄兒兰和硬叶䚌兰的种子试管培养 \\
\hline & & & /EN & & \\
\hline \multirow[t]{2}{*}{ Paphiopedilum armeniacum } & 杏黄兒兰 & I & 濒危 & 李明 & 杏黄㭡兰菌根研究与应用 \\
\hline & & & /EN & & \\
\hline \multirow[t]{2}{*}{ Paphiopedilum armeniacum } & 杏黄咸兰 & I & 濒危 & 虞泓 & 杏黄皃兰胚培养与快速繁殖 \\
\hline & & & /EN & & \\
\hline \multirow[t]{2}{*}{ Paphiopedilum armeniacum } & 杏黄咸兰 & I & 濒危 & 虞泓 & 影响杏黄咸兰种子萌发的因素 \\
\hline & & & /EN & & \\
\hline
\end{tabular}


顾垒，闻丞，罗玫，王吴，吕植. 中国最受关注濒危物种保护现状快速评价的新方法探讨. 生物多样性，2015，23(5)：583-590. http://www biodiversity-science. net/CN/article/downloadArticleFile. do?attachType=PDF\&id=10075

\begin{tabular}{|c|c|c|c|c|c|}
\hline Paphiopedilum armeniacum & 杏黄㹸兰 & I & $\begin{array}{l}\text { 濒危 } \\
\text { /EN }\end{array}$ & 阎 洪 & 珍稀濒危植物杏黄兒兰的生境调查和栽培试验 \\
\hline Paphiopedilum armeniacum & 杏黄㹸兰 & I & $\begin{array}{l}\text { 濒危 } \\
\text { /EN }\end{array}$ & 王英强 & 中国㝸兰属野生花卉资源 \\
\hline Paphiopedilum armeniacum & 杏黄㹸兰 & I & $\begin{array}{l}\text { 濒危 } \\
\text { /EN }\end{array}$ & 王英强 & 中国皃兰属植物生态地理分布 \\
\hline Paphiopedilum armeniacum & 杏黄皃兰 & I & $\begin{array}{l}\text { 濒危 } \\
\text { /EN }\end{array}$ & 陈庆文 & 中国兜兰属植物研究现状综述 \\
\hline Paphiopedilum dianthum & 长瓣㕷兰 & I & $\begin{array}{l}\text { 濒危 } \\
\text { /EN }\end{array}$ & 罗毅波 & 初论中国兜兰属植物的保护策略及其潜在资源优势 \\
\hline Paphiopedilum dianthum & 长瓣㕷兰 & I & $\begin{array}{l}\text { 濒危 } \\
\text { /EN }\end{array}$ & 王 贞 & 㝸兰属植物研究现状 \\
\hline Paphiopedilum dianthum & 长瓣㕷兰 & I & $\begin{array}{l}\text { 濒危 } \\
\text { /EN }\end{array}$ & 邓克云 & 贵州省兴义市樂兰属植物引种驯化研究 \\
\hline Paphiopedilum dianthum & 长瓣兜兰 & I & $\begin{array}{l}\text { 濒危 } \\
\text { /EN }\end{array}$ & 罗毅波 & 利用传粉综合征预测 长瓣樂兰模拟繁殖地欺骗雌性食蚜蝇传粉 \\
\hline Paphiopedilum dianthum & 长瓣兜兰 & I & $\begin{array}{l}\text { 濒危 } \\
\text { /EN }\end{array}$ & 李雪 & 六种㝸兰属植物的叶面积和叶幅与开花的关系 \\
\hline Paphiopedilum dianthum & 长瓣㝸兰 & I & 濒危 & 陈景艳 & 长瓣兜兰的组织培养与快速繁殖 \\
\hline
\end{tabular}


顾垒，闻丞，罗玫，王吴，吕植. 中国最受关注濒危物种保护现状快速评价的新方法探讨. 生物多样性，2015，23(5)：583-590. http://www. biodiversity-science. net/CN/article/downloadArticleFile. do?attachType=PDF\&id=10075

\begin{tabular}{|c|c|c|c|c|c|}
\hline & & & /EN & & \\
\hline \multirow[t]{2}{*}{ Paphiopedilum dianthum } & 长瓣㝸兰 & I & 濒危 & 王英强 & 中国㕷兰属野生花卉资源 \\
\hline & & & $/$ EN & & \\
\hline \multirow[t]{2}{*}{ Paphiopedilum dianthum } & 长瓣咸兰 & I & 濒危 & 王英强 & 中国㕷兰属植物生态地理分布 \\
\hline & & & /EN & & \\
\hline \multirow[t]{2}{*}{ Paphiopedilum dianthum } & 长瓣兜兰 & I & 濒危 & 陈庆文 & 中国晦兰属植物研究现状综述 \\
\hline & & & /EN & & \\
\hline \multirow[t]{2}{*}{ Paphiopedilum tigrinum } & 虎斑自兰 & I & 极危 & 罗毅波 & 初论中国皇兰属植物的保护策略及其潜在资源优势 \\
\hline & & & /CR & & \\
\hline \multirow[t]{2}{*}{ Paphiopedilum tigrinum } & 虎斑兒兰 & I & 极危 & 王贞 & 㝸兰属植物研究现状 \\
\hline & & & /CR & & \\
\hline \multirow[t]{2}{*}{ Paphiopedilum tigrinum } & 虎斑㿟兰 & I & 极危 & 朱根发 & 兒兰亚属 12 种植物的核型分析 \\
\hline & & & /CR & & \\
\hline \multirow[t]{2}{*}{ Paphiopedilum tigrinum } & 虎斑兒兰 & I & 濒危 & 邓克云 & 贵州省兴义市淣兰属植物引种驯化研究 \\
\hline & & & /EN & & \\
\hline \multirow[t]{2}{*}{ Paphiopedilum tigrinum } & 虎斑㹸兰 & I & 极危 & 段 俊 & 国产兒兰属植物观赏价值评价及其在华南地区的应用前景分析 \\
\hline & & & /CR & & \\
\hline \multirow[t]{2}{*}{ Paphiopedilum tigrinum } & 虎斑淣兰 & I & 濒危 & 王英强 & 中国兜兰属野生花卉资源 \\
\hline & & & /EN & & \\
\hline
\end{tabular}


顾垒，闻丞，罗玫，王吴，吕植. 中国最受关注濒危物种保护现状快速评价的新方法探讨. 生物多样性，2015，23(5)：583-590. http://www. biodiversity-science. net/CN/article/downloadArticleFile. do?attachType=PDF\&id=10075

\begin{tabular}{|c|c|c|c|c|c|}
\hline Paphiopedilum tigrinum & 虎斑兒兰 & I & 濒危 & 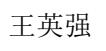 & 中国㭡兰属植物生态地理分布 \\
\hline & & & /EN & & \\
\hline \multirow[t]{2}{*}{ Paphiopedilum tigrinum } & 虎斑兒兰 & I & 濒危 & 陈庆文 & 中国㿟兰属植物研究现状综述 \\
\hline & & & /EN & & \\
\hline \multirow[t]{3}{*}{ Paradoxornis conspicillatus } & 白眶鸦雀 & 未列 & 数据 & 巩会生 & 陕西米仓山自然保护区鸟类组成与分布格局 \\
\hline & & 入 & 不足 & & \\
\hline & & & /DD & & \\
\hline \multirow[t]{2}{*}{ Paradoxornis heudei } & 震旦鸦雀 & 未列 & 近危 & 周立志 & 安徽省鸟类分布新记录- 震旦鸦雀 \\
\hline & & 入 & /NT & & \\
\hline \multirow[t]{2}{*}{ Paradoxornis heudei } & 震旦鸦雀 & 未列 & 近危 & 蒋科毅 & 杭州湾及钱塘江河口南岸滨海湿地鸟类群落多样性及其对滩涂围层的响应 \\
\hline & & 入 & /NT & & \\
\hline \multirow[t]{2}{*}{ Paradoxornis heudei } & 震旦鸦雀 & 未列 & 近危 & 牛俊英 & 河南省鸟类新纪录 - 震旦鸦雀、红胸黑雁 \\
\hline & & 入 & /NT & & \\
\hline \multirow[t]{2}{*}{ Paradoxornis heudei } & 震旦鸦雀 & 未列 & 近危 & 熊李虎 & 季节和集群大小影响震旦鸦雀对人类接近的响应 \\
\hline & & 入 & /NT & & \\
\hline \multirow[t]{2}{*}{ Paradoxornis heudei } & 震旦鸦雀 & 未列 & 近危 & 熊李虎 & 芦苇收割对震旦鸦雀受食活动的影响 \\
\hline & & 入 & /NT & & \\
\hline \multirow[t]{2}{*}{ Paradoxornis heudei } & 震旦鸦雀 & 未列 & 近危 & 蔡音亭 & 鸟类调查的样线法和样点法比较_以崇明东滩春季盐沼鸟类调查为例 \\
\hline & & 入 & /NT & & \\
\hline
\end{tabular}


顾垒，闻丞，罗玫，王吴，吕植. 中国最受关注濒危物种保护现状快速评价的新方法探讨. 生物多样性，2015，23(5)：583-590. http://www biodiversity-science. net/CN/article/downloadArticleFile. do?attachType=PDF\&id=10075

\begin{tabular}{|c|c|c|c|c|c|}
\hline \multirow[t]{2}{*}{ Paradoxornis heudei } & 震旦鸦雀 & 未列 & 近危 & 董 斌 & 上海崇明东滩震旦鸦雀冬季种群栖息地的生境选择 \\
\hline & & 入 & /NT & & \\
\hline \multirow[t]{2}{*}{ Paradoxornis heudei } & 震旦鸦雀 & 未列 & 近危 & 董斌 & 上海崇明东滩震旦鸦雀冬季种群生态学研究 \\
\hline & & 入 & /NT & & \\
\hline \multirow[t]{2}{*}{ Paradoxornis heudei } & 震旦鸦雀 & 未列 & 近危 & 邓永身 & 苏州太湖湖滨带芦苇湿地鸟类群落研究 \\
\hline & & 入 & /NT & & \\
\hline \multirow[t]{2}{*}{ Paradoxornis heudei } & 震旦鸦雀 & 未列 & 近危 & 孙伟民 & 兴凯湖新发现 6 种鸟类 \\
\hline & & 入 & /NT & & \\
\hline \multirow[t]{2}{*}{ Paradoxornis przewalskii } & 灰冠鸦雀 & 未列 & 易危 & 张 琼 & 甘肃白水江灰冠鸦雀栖息地研究 \\
\hline & & 入 & /VU & & \\
\hline \multirow[t]{2}{*}{ Paradoxornis przewalskii } & 灰冠鸦雀 & 未列 & 易危 & 李 戟 & 灰冠鸦雀巢及巢址生境的首次报道 \\
\hline & & 入 & $/ \mathrm{VU}$ & & \\
\hline \multirow[t]{2}{*}{ Paradoxornis przewalskii } & 灰冠鸦雀 & 未列 & 易危 & 董否 & 四川唐家河自然保护区发现灰冠鸦雀 \\
\hline & & 入 & /VU & & \\
\hline \multirow[t]{2}{*}{ Paradoxornis zappeyi } & 暗色鸦雀 & 未列 & 易危 & 罗祖奎 & 贵州草海冬季鸟类群落特征 \\
\hline & & 入 & /VU & & \\
\hline \multirow[t]{2}{*}{ Paradoxornis zappeyi } & 暗色鸦雀 & 未列 & 易危 & 陈 红 & 贵州省六盘水明湖国家湿地公园脊椎动物资源调查研究 \\
\hline & & 入 & $/ \mathrm{VU}$ & & \\
\hline Paradoxornis zappeyi & 暗色鸦雀 & 未列 & 易危 & 符建荣 & 米亚罗自然保护区的鸟类资源 \\
\hline
\end{tabular}


顾垒，闻丞，罗玫，王吴，吕植. 中国最受关注濒危物种保护现状快速评价的新方法探讨. 生物多样性，2015，23(5)：583-590. http://www biodiversity-science. net/CN/article/downloadArticleFile. do?attachType=PDF\&id=10075

\begin{tabular}{|c|c|c|c|c|c|}
\hline & & 入 & $/ \mathrm{VU}$ & & \\
\hline \multirow[t]{2}{*}{ Paradoxornis zappeyi } & 暗色鸦雀 & 未列 & 易危 & 彭基泰 & 青藏高原东南横断山脉甘孜地区鸟类调查区系及地理分布型研究报告 \\
\hline & & 入 & $/ \mathrm{VU}$ & & \\
\hline \multirow[t]{2}{*}{ Paradoxornis zappeyi } & 暗色鸦雀 & 未列 & 易危 & 陈本平 & 四川老君山国家级自然保护区的鸟类资源概况 \\
\hline & & 入 & $/ \mathrm{VU}$ & & \\
\hline \multirow[t]{2}{*}{ Paradoxornis zappeyi } & 暗色鸦雀 & 未列 & 易危 & 杨杰 & 四川老君山自然保护区鸟类群落结构及多样性研究 \\
\hline & & 入 & $/ \mathrm{VU}$ & & \\
\hline \multirow[t]{2}{*}{ Paradoxornis zappeyi } & 暗色鸦雀 & 未列 & 易危 & 张秀雷 & 四川嘛咪泽自然保护区鸟类多样性研究 \\
\hline & & 入 & $/ \mathrm{VU}$ & & \\
\hline Parakmeria lotungensis, & 乐东拟单性木兰、云南拟单性木兰 & II & 近危 & 徐奎源 & 乐东拟单性木兰、云南拟单性木兰引种试验初报 \\
\hline Parakmeria yunnanensis & & & $/ \mathrm{NT}$ & & \\
\hline \multirow[t]{3}{*}{ Parakmeria yunnanensis } & 云南拟单性木兰 & II & 数据 & Han-Dong Sun & Phenolic constituents from Parakmeria yunnanensis and their anti-HIV-1 activity \\
\hline & & & 不足 & & \\
\hline & & & $/ \mathrm{DD}$ & & \\
\hline \multirow[t]{3}{*}{ Parakmeria yunnanensis } & 云南拟单性木兰 & II & 数据 & 陈强 & 不同断根处理对云南拟单性木兰苗木生长影响的研究 \\
\hline & & & 不足 & & \\
\hline & & & $/ \mathrm{DD}$ & & \\
\hline \multirow[t]{2}{*}{ Parakmeria yunnanensis } & 云南拟单性木兰 & II & 数据 & 刘云彩 & 不同季节断根处理的云南拟单性木兰苗木根系萌发生长效应 \\
\hline & & & 不足 & & \\
\hline
\end{tabular}


顾垒，闻丞，罗玫，王吴，吕植. 中国最受关注濒危物种保护现状快速评价的新方法探讨. 生物多样性，2015，23(5)：583-590. http://www. biodiversity-science. net/CN/article/downloadArticleFile. do?attachType=PDF\&id=10075

\begin{tabular}{|c|c|c|c|c|c|}
\hline & & & $/ \mathrm{DD}$ & & \\
\hline \multirow[t]{2}{*}{ Parakmeria yunnanensis } & 云南拟单性木兰 & II & $\begin{array}{l}\text { 数据 } \\
\text { 不足 }\end{array}$ & 杨耀海 & 断根处理对云南拟单性木兰大苗移栽的影响 \\
\hline & & & $/ \mathrm{DD}$ & & \\
\hline \multirow[t]{3}{*}{ Parakmeria yunnanensis } & 云南拟单性木兰 & II & 数据 & 杨耀海 & 云南拟单性木兰大苗培育及移栽技术 \\
\hline & & & 不足 & & \\
\hline & & & $/ \mathrm{DD}$ & & \\
\hline \multirow[t]{3}{*}{ Parakmeria yunnanensis } & 云南拟单性木兰 & II & 数据 & 司马永康 & 云南拟单性木兰的地理分布与气候因子的关系 \\
\hline & & & 不足 & & \\
\hline & & & /DD & & \\
\hline \multirow[t]{3}{*}{ Parakmeria yunnanensis } & 云南拟单性木兰 & II & 数据 & 周俊 & 云南拟单性木兰的化学成分 \\
\hline & & & 不足 & & \\
\hline & & & $/ \mathrm{DD}$ & & \\
\hline \multirow[t]{3}{*}{ Parakmeria yunnanensis } & 云南拟单性木兰 & II & 数据 & 蒋继宏 & 云南拟单性木兰挥发物质及其抗肿瘤和抑菌活性初步研究 \\
\hline & & & 不足 & & \\
\hline & & & $/ \mathrm{DD}$ & & \\
\hline \multirow[t]{3}{*}{ Parakmeria yunnanensis } & 云南拟单性木兰 & II & 数据 & 郝小燕 & 云南拟单性木兰精油化学成分的研究 \\
\hline & & & 不足 & & \\
\hline & & & $/ \mathrm{DD}$ & & \\
\hline
\end{tabular}


顾垒，闻丞，罗玫，王吴，吕植. 中国最受关注濒危物种保护现状快速评价的新方法探讨. 生物多样性，2015，23(5)：583-590. http://www. biodiversity-science. net/CN/article/downloadArticleFile. do?attachType=PDF\&id=10075

\begin{tabular}{|c|c|c|c|c|c|}
\hline \multirow[t]{2}{*}{ Parakmeria yunnanensis } & 云南拟单性木兰 & II & 数据 & 刘英杰 & 云南拟单性木兰绿化大苗培育的关键技术 \\
\hline & & & $\begin{array}{l}\text { 不足 } \\
\text { /DD }\end{array}$ & & \\
\hline \multirow[t]{3}{*}{ Parakmeria yunnanensis } & 云南拟单性木兰 & II & 数据 & 郭勇 & 云南拟单性木兰苗木猝倒病防治试验 \\
\hline & & & 不足 & & \\
\hline & & & $/ \mathrm{DD}$ & & \\
\hline \multirow[t]{3}{*}{ Parakmeria yunnanensis } & 云南拟单性木兰 & II & 数据 & 吴纪华 & 云南拟单性木兰容器育苗实验研究 \\
\hline & & & 不足 & & \\
\hline & & & $/ \mathrm{DD}$ & & \\
\hline \multirow[t]{3}{*}{ Parakmeria yunnanensis } & 云南拟单性木兰 & II & 数据 & 杨耀海 & 云南拟单性木兰弱苗复壮技术 \\
\hline & & & 不足 & & \\
\hline & & & /DD & & \\
\hline \multirow[t]{3}{*}{ Parakmeria yunnanensis } & 云南拟单性木兰 & II & 数据 & 桑林 & 云南拟单性木兰生理生态学的初步研究 \\
\hline & & & 不足 & & \\
\hline & & & $/ \mathrm{DD}$ & & \\
\hline \multirow[t]{3}{*}{ Parakmeria yunnanensis } & 云南拟单性木兰 & II & 数据 & 徐加汉 & 云南拟单性木兰生物生态学特性及其城市绿化的作用 \\
\hline & & & 不足 & & \\
\hline & & & $/ \mathrm{DD}$ & & \\
\hline Parakmeria yunnanensis & 云南拟单性木兰 & II & 数据 & 徐加汉 & 云南拟单性木兰育苗技术 \\
\hline
\end{tabular}


顾垒，闻丞，罗玫，王吴，吕植. 中国最受关注濒危物种保护现状快速评价的新方法探讨. 生物多样性，2015，23(5)：583-590. http://www. biodiversity-science. net/CN/article/downloadArticleFile. do?attachType=PDF\&id=10075

\begin{tabular}{|c|c|c|c|c|c|}
\hline & & & 不足 & & \\
\hline Parakmeria yunnanensis & 云南拟单性木兰 & II & $\begin{array}{l}/ \mathrm{DD} \\
\text { 数据 } \\
\text { 不足 }\end{array}$ & 陶鹏云 & 云南拟单性木兰育苗技术 \\
\hline Parakmeria yunnanensis & 云南拟单性木兰 & II & $\begin{array}{l}/ \mathrm{DD} \\
\text { 数据 } \\
\text { 不足 }\end{array}$ & 杨德军 & 云南拟单性木兰育苗技术 \\
\hline Parakmeria yunnanensis & 云南拟单性木兰 & II & $\begin{array}{l}\text { /DD } \\
\text { 数据 } \\
\text { 不足 }\end{array}$ & 冯祥麟 & 云南拟单性木兰育苗技术 \\
\hline Parakmeria yunnanensis & 云南拟单性木兰 & II & $\begin{array}{l}/ \mathrm{DD} \\
\text { 数据 } \\
\text { 不足 }\end{array}$ & 许杰 & 云南拟单性木兰育苗试验 \\
\hline Parakmeria yunnanensis & 云南拟单性木兰 & II & $\begin{array}{l}/ \mathrm{DD} \\
\text { 数据 } \\
\text { 不足 }\end{array}$ & 杨德军 & 云南拟单性木兰在普文引种栽培初报 \\
\hline Parakmeria yunnanensis & 云南拟单性木兰 & II & $\begin{array}{l}/ \mathrm{DD} \\
\text { 数据 } \\
\text { 不足 }\end{array}$ & 董芫划 & 云南拟单性木兰造林技术 \\
\hline
\end{tabular}


顾垒，闻丞，罗玫，王吴，吕植. 中国最受关注濒危物种保护现状快速评价的新方法探讨. 生物多样性，2015，23(5)：583-590. http://www biodiversity-science. net/CN/article/downloadArticleFile. do?attachType=PDF\&id=10075

\begin{tabular}{|c|c|c|c|c|c|}
\hline & & & $/ \mathrm{DD}$ & & \\
\hline \multirow[t]{3}{*}{ Parakmeria yunnanensis } & 云南拟单性木兰 & II & 数据 & 陈雄庭 & 云南拟单性木兰组织培养初步研究 \\
\hline & & & 不足 & & \\
\hline & & & $/ \mathrm{DD}$ & & \\
\hline Paramichelia baillonii & 合果木 & II & & 蒋云东 & 7 种热带阔叶树种的苗木施肥试验 \\
\hline Paramichelia baillonii & 合果木 & II & & 王凌晖 & $\mathrm{NaCl}$ 胁迫对山白兰幼苗细胞膜透性及渗透调节物质含量的影响 \\
\hline \multirow[t]{2}{*}{ Paramichelia baillonii } & 合果木 & II & & Siming Gan & RAPD and morphological diversity among four populations of thetropical tree species \\
\hline & & & & & Paramichelia baillonii (Pierre) Hu in China \\
\hline Paramichelia baillonii & 合果木 & II & & 郑海水 & 不同施肥措施对 3 年生山桂花人工林林木生长的影响 * \\
\hline Paramichelia baillonii & 合果木 & II & & 史富强 & 不同种源及家系山桂花 3 年生人工幼林林木的高、径生长效应 \\
\hline Paramichelia baillonii & 合果木 & II & & 杨德军 & 滇南热区 4 种主要用材树种主伐年龄确定研究 \\
\hline Paramichelia baillonii & 合果木 & II & & 谢安德 & 观光木和山白兰苗木的耐盐性与耐镉性研究 \\
\hline Paramichelia baillonii & 合果木 & II & & 焦根林 & 合果木光合生理特性及水分利用特点的研究 \\
\hline Paramichelia baillonii & 合果木 & II & & 黄丹 & 合果木在良风江的引种试验 \\
\hline
\end{tabular}


顾垒，闻丞，罗玫，王吴，吕植. 中国最受关注濒危物种保护现状快速评价的新方法探讨. 生物多样性，2015，23(5)：583-590. http://www biodiversity-science. net/CN/article/downloadArticleFile. do?attachType=PDF\&id=10075

\begin{tabular}{|c|c|c|c|c|}
\hline Paramichelia baillonii & 合果木 & II & 林玉清 & 华安县引种山桂花的效果 \\
\hline Paramichelia baillonii & 合果木 & II & 王凌晖 & 基于偏最小二乘法的山白兰叶面积分析及测定方法的研究 \\
\hline Paramichelia baillonii & 合果木 & II & 王 凌 晖 & 聚乙二醇-6000 对山白兰苗木生理特性的影响 \\
\hline Paramichelia baillonii & 合果木 & II & 杜凡 & 澜沧江自然保护区珍稀濒危保护植物研究 \\
\hline Paramichelia baillonii & 合果木 & II & 胡正海 & 木兰科 14 种植物叶片中油细胞的比较研究 \\
\hline Paramichelia baillonii & 合果木 & II & 周俊 & 木兰科植物鹅掌揪和合果木的化学成分及其分类学意义, \\
\hline Paramichelia baillonii & 合果木 & II & 陈宏伟 & 南亚热带山地山桂花人工纯林与混交林群落学特征比较 \\
\hline Paramichelia baillonii & 合果木 & II & 李莲芳 & 热带山桂花、西南桦人工幼林植物区系成分分析 \\
\hline Paramichelia baillonii & 合果木 & II & 蒋云东 & 热区几种阔叶树种的育苗基质和容器规格研究 \\
\hline Paramichelia baillonii & 合果木 & II & 符韵林 & 山白兰木材干燥特性研究 \\
\hline Paramichelia baillonii & 合果木 & II & 苏勇 & 山白兰人工林经济效益评价 \\
\hline Paramichelia baillonii & 合果木 & II & 吴庆标 & 山白兰人工林生态系统碳储量及空间分布特征 \\
\hline Paramichelia baillonii & 合果木 & II & 秦武明 & 山白兰人工林生物量及生长规律 \\
\hline
\end{tabular}


顾垒，闻丞，罗玫，王吴，吕植. 中国最受关注濒危物种保护现状快速评价的新方法探讨. 生物多样性，2015，23(5)：583-590. http://www biodiversity-science. net/CN/article/downloadArticleFile. do?attachType=PDF\&id=10075

\begin{tabular}{|c|c|c|c|c|}
\hline Paramichelia baillonii & 合果木 & II & 苏勇 & 山白兰树皮率、心材率及木材密度研究 \\
\hline Paramichelia baillonii & 合果木 & II & 黄承标 & 山白兰引种新区林分生长表现及土壤理化性质的研究 \\
\hline Paramichelia baillonii & 合果木 & II & 王凌晖 & 山白兰资源研究利用现状及展望 \\
\hline Paramichelia baillonii & 合果木 & II & 尚富 & 山桂花的显微鉴别 \\
\hline Paramichelia baillonii & 合果木 & II & 蒋谦才 & 山桂花的种子繁殖与栽培管理 \\
\hline Paramichelia baillonii & 合果木 & II & 郑海水 & 山桂花人工林 3 年生幼林期的施肥效应研究 \\
\hline Paramichelia baillonii & 合果木 & II & 姜远标 & 山桂花人工林的生长过程研究 \\
\hline Paramichelia baillonii & 合果木 & II & 冯 弦 & 山桂花人工林林木材性与生长特性关系研究 \\
\hline Paramichelia baillonii & 合果木 & II & 冯弦 & 山桂花人工林木材基本密度和纤维长度变异规律的研究 \\
\hline Paramichelia baillonii & 合果木 & II & 杨斌 & 山桂花人工林生长过程 \\
\hline Paramichelia baillonii & 合果木 & II & 苏俊武 & 山桂花引种栽培试验研究 \\
\hline Paramichelia baillonii & 合果木 & II & 邱琼 & 山桂花育苗基质的研究 \\
\hline Paramichelia baillonii & 合果木 & II & 杨斌 & 山桂花育苗造林技术 \\
\hline Paramichelia baillonii & 合果木 & II & 翁启杰 & 山桂花栽培技术 \\
\hline Paramichelia baillonii & 合果木 & II & 刘庆云 & 思茅市山桂花育苗技术研究 \\
\hline
\end{tabular}


顾垒，闻丞，罗玫，王吴，吕植. 中国最受关注濒危物种保护现状快速评价的新方法探讨. 生物多样性，2015，23(5)：583-590. http://www biodiversity-science. net/CN/article/downloadArticleFile. do?attachType=PDF\&id=10075

\begin{tabular}{|c|c|c|c|c|c|}
\hline Paramichelia baillonii & 合果木 & \multicolumn{2}{|l|}{ II } & 蒋云东 & 西双版纳几种人工林地力恢复趋势研究 \\
\hline Paramichelia baillonii & 合果木 & \multicolumn{2}{|l|}{ II } & 刘永刚 & 西双版纳几种人工林类型的经济效益评价 \\
\hline Paramichelia baillonii & 合果木 & \multicolumn{2}{|l|}{ II } & 曾觉民 & 西双版纳热带人工林群落结构及生态功能恢复的研究 \\
\hline Paramichelia baillonii & 合果木 & \multicolumn{2}{|l|}{ II } & 王达明 & 西双版纳人工林可持续经营研究 \\
\hline Paramichelia baillonii & 合果木 & \multicolumn{2}{|l|}{ II } & 孟梦 & 西双版纳西南桦、山桂花人工林水源涵养效能研究 \\
\hline Paramichelia baillonii & 合果木 & \multicolumn{2}{|l|}{ II } & 王卫斌 & 云南热区 4 种乡土阔叶树种人工林营建技术研究 \\
\hline Paramichelia baillonii & 合果木 & \multicolumn{2}{|l|}{ II } & 李江 & 云南热区几种阔叶人工林 C 储量的研究 \\
\hline Paramichelia baillonii & 合果木 & \multicolumn{2}{|l|}{ II } & 蒋云东 & 云南热区几种人工林土壤变化研究 \\
\hline Paramichelia baillonii & 合果木 & \multicolumn{2}{|l|}{ II } & 乔梦吉 & 珍贵树种山白兰的组织培养研究 \\
\hline Paramichelia baillonii & 合果木 & \multicolumn{2}{|l|}{ II } & 王献溥 & 中国木兰科植物受威胁的状况及其保护措施 \\
\hline Paramichelia baillonii & 合果木 & \multicolumn{2}{|l|}{ II } & 龚 洵 & 中国木兰亚科植物的主要分类性状观察 \\
\hline \multirow[t]{2}{*}{ Parashorea chinensis } & 望天树 & I & 濒危 & 蔡志全 & 6 种热带雨林木本植物幼苗光合诱导的研究 \\
\hline & & \multicolumn{3}{|c|}{ /EN } & \\
\hline Parashorea chinensis & 望天树 & I & 濒危 & Ji-Yue Li & Changes of Leaf Morphological, Anatomical Structure and Carbon Isotope Ratio with the \\
\hline
\end{tabular}


顾垒，闻丞，罗玫，王昊，吕植. 中国最受关注濒危物种保护现状快速评价的新方法探讨．生物多样性，2015，23(5)：583-590. http://www biodiversity-science. net/CN/article/downloadArticleFile. do?attachType=PDF\&id=10075

\begin{tabular}{|c|c|c|c|c|c|}
\hline & & & /EN & & Height of the Wangtian Tree (Parashorea chinensis) in Xishuangbanna, China \\
\hline \multirow[t]{2}{*}{ Parashorea chinensis } & 望天树 & I & 濒危 & Qiao-Ming Li & Generic relationships of Parashorea chinensis Wang Hsie (Dipterocarpaceae) based on cpDNA \\
\hline & & & $/ \mathrm{EN}$ & & sequences \\
\hline \multirow[t]{2}{*}{ Parashorea chinensis } & 望天树 & I & 濒危 & Tianhua He & Genetic Evaluation of the Efficacy of In Situ and Ex Situ Conservation of Parashorea chinensis \\
\hline & & & $/ \mathrm{EN}$ & & (Dipterocarpaceae) in Southwestern China \\
\hline \multirow[t]{2}{*}{ Parashorea chinensis } & 望天树 & I & 濒危 & Jun Wen & Parashorea chinensis Wang Hsie and P. chinensis var. kwangsiensis Lin Chi Two exceptional \\
\hline & & & /EN & & cases of names with a corporate authorship \\
\hline \multirow[t]{2}{*}{ Parashorea chinensis } & 望天树 & I & 濒危 & Jun-Wen Chen & Steady and dynamic photosynthetic responses of seedlings from contrasting successional \\
\hline & & & /EN & & groups under low-light growth conditions_Jun-Wen Chen \\
\hline \multirow[t]{2}{*}{ Parashorea chinensis } & 望天树 & I & 濒危 & Kun-Fang Cao & Stem hydraulics mediates leaf water status, carbon gain,nutrient use efficiencies and plant \\
\hline & & & /EN & & growth rates across dipterocarp species \\
\hline \multirow[t]{2}{*}{ Parashorea chinensis } & 望天树 & I & 濒危 & K.-F. CAO & Sustained diurnal photosynthetic depression in uppermost-canopy leaves of four dipterocarp \\
\hline & & & /EN & & species in the rainy and dry seasons does photorespiration play a role \\
\hline \multirow[t]{2}{*}{ Parashorea chinensis } & 望天树 & I & 濒危 & 曹敏 & 濒危树种望天树大量结实后幼苗的生长和存活 \\
\hline & & & /EN & & \\
\hline \multirow[t]{2}{*}{ Parashorea chinensis } & 望天树 & I & 濒危 & 李巧明 & 濒危植物望天树 SSR_PCR 反应体系的优化 \\
\hline & & & /EN & & \\
\hline \multirow[t]{2}{*}{ Parashorea chinensis } & 望天树 & I & 濒危 & 曹敏 & 不同光照对望天树种子萌发和幼苗早期生长的影响 \\
\hline & & & /EN & & \\
\hline
\end{tabular}


顾垒，闻丞，罗玫，王吴，吕植. 中国最受关注濒危物种保护现状快速评价的新方法探讨. 生物多样性，2015，23(5)：583-590. http://www. biodiversity-science. net/CN/article/downloadArticleFile. do?attachType=PDF\&id=10075

\begin{tabular}{|c|c|c|c|c|c|}
\hline Parashorea chinensis & 望天树 & I & $\begin{array}{l}\text { 濒危 } \\
\text { /EN }\end{array}$ & 梁机 & 不同育苗基质对擎天树容器苗生长的影响 \\
\hline Parashorea chinensis & 望天树 & I & $\begin{array}{l}\text { 濒危 } \\
\text { /EN }\end{array}$ & 朱华 & 滇东南马关古林等热带雨林望天树群落的研究 \\
\hline Parashorea chinensis & 望天树 & I & $\begin{array}{l}\text { 濒危 } \\
\text { /EN }\end{array}$ & 曹敏 & 光照和温度对望天树种子萌发的影响 \\
\hline Parashorea chinensis & 望天树 & I & $\begin{array}{l}\text { 濒危 } \\
\text { /EN }\end{array}$ & 李巧明 & 龙脑香科两种濒危植物的保护遗传学研究 \\
\hline Parashorea chinensis & 望天树 & I & $\begin{array}{l}\text { 濒危 } \\
\text { /EN }\end{array}$ & 李巧明 & 龙脑香科植物望天树的居群遗传结构及分化 \\
\hline Parashorea chinensis & 望天树 & I & $\begin{array}{l}\text { 濒危 } \\
\text { /EN }\end{array}$ & 孟令曾 & 迁地保护的 4 种龙脑香冠层叶光合速率和叶绿素荧光参数的日变化 \\
\hline Parashorea chinensis & 望天树 & I & $\begin{array}{l}\text { 濒危 } \\
\text { /EN }\end{array}$ & 朱栗琼 & 擎天树茎叶解剖结构及其环境适应性 \\
\hline Parashorea chinensis & 望天树 & I & $\begin{array}{l}\text { 濒危 } \\
\text { /EN }\end{array}$ & 邱炳发 & 擎天树木材干燥特性研究 \\
\hline Parashorea chinensis & 望天树 & I & $\begin{array}{l}\text { 濒危 } \\
\text { /EN }\end{array}$ & 杨梅 & 擎天树组培外植体消毒与褐化抑制的研究 \\
\hline Parashorea chinensis & 望天树 & I & 濒危 & 曹敏 & 热带雨林濒危树种望天树的致危原因及保护策略 \\
\hline
\end{tabular}


顾垒，闻丞，罗玫，王吴，吕植. 中国最受关注濒危物种保护现状快速评价的新方法探讨. 生物多样性，2015，23(5)：583-590. http://www. biodiversity-science. net/CN/article/downloadArticleFile. do?attachType=PDF\&id=10075

\begin{tabular}{|c|c|c|c|c|c|}
\hline & & & /EN & & \\
\hline \multirow[t]{2}{*}{ Parashorea chinensis } & 望天树 & I & 濒危 & 李晓亮 & 望天树(Parashore chinensis)林优势树种种子雨和乔木幼苗动态的初步研究 \\
\hline & & & $/$ EN & & \\
\hline \multirow[t]{2}{*}{ Parashorea chinensis } & 望天树 & I & 濒危 & 闯兴富 & 望天树和线毛番龙眼的种子萌发、幼苗生长及其生境选择特征 \\
\hline & & & /EN & & \\
\hline \multirow[t]{2}{*}{ Parashorea chinensis } & 望天树 & I & 濒危 & 谌红辉 & 望天树苗木分级技术研究 \\
\hline & & & /EN & & \\
\hline \multirow[t]{2}{*}{ Parashorea chinensis } & 望天树 & I & 濒危 & 谌红辉 & 望天树嫩枝扦插技术初步研究 \\
\hline & & & /EN & & \\
\hline \multirow[t]{2}{*}{ Parashorea chinensis } & 望天树 & I & 濒危 & 唐建维 & 望天树人工林林分生长与林分密度的关系 \\
\hline & & & /EN & & \\
\hline \multirow[t]{2}{*}{ Parashorea chinensis } & 望天树 & I & 濒危 & 唐建维 & 望天树人工林林木个体前期生长节律的研究 \\
\hline & & & /EN & & \\
\hline \multirow[t]{2}{*}{ Parashorea chinensis } & 望天树 & I & 濒危 & 黄承标 & 望天树人工林生长量及土壤理化性质 \\
\hline & & & /EN & & \\
\hline \multirow[t]{2}{*}{ Parashorea chinensis } & 望天树 & I & 濒危 & 文进 & 望天树育苗技术 \\
\hline & & & /EN & & \\
\hline \multirow[t]{2}{*}{ Parashorea chinensis } & 望天树 & I & 濒危 & 宋军平 & 望天树在不同生境条件下自然更新调查 \\
\hline & & & /EN & & \\
\hline
\end{tabular}


顾垒，闻丞，罗玫，王吴，吕植. 中国最受关注濒危物种保护现状快速评价的新方法探讨. 生物多样性，2015，23(5)：583-590. http://www. biodiversity-science. net/CN/article/downloadArticleFile. do?attachType=PDF\&id=10075

\begin{tabular}{|c|c|c|c|c|c|}
\hline Parashorea chinensis & 望天树 & I & $\begin{array}{l}\text { 濒危 } \\
\text { /EN }\end{array}$ & 许海龙 & 望天树自然更新与保护初探 \\
\hline Parashorea chinensis & 望天树 & I & $\begin{array}{l}\text { 濒危 } \\
\text { /EN }\end{array}$ & 朱华 & 西双版纳补蚌地区望天树林近 20a 来物种多样性变化研究 \\
\hline Parashorea chinensis & 望天树 & I & $\begin{array}{l}\text { 濒危 } \\
\text { /EN }\end{array}$ & 唐建维 & 西双版纳不同斑块望天树种群的密度、结构和生物量 \\
\hline Parashorea chinensis & 望天树 & I & $\begin{array}{l}\text { 濒危 } \\
\text { /EN }\end{array}$ & 张良 & 西双版纳望天树生长规律研究 \\
\hline Parashorea chinensis & 望天树 & I & $\begin{array}{l}\text { 濒危 } \\
\text { /EN }\end{array}$ & 王兰新 & 西双版纳自然保护区望天树群落结构分析 \\
\hline Parashorea chinensis & 望天树 & I & $\begin{array}{l}\text { 濒危 } \\
\text { /EN }\end{array}$ & 郭贤明 & 西双版纳自然保护区望天树现状及保护对策 \\
\hline Parashorea chinensis & 望天树 & I & $\begin{array}{l}\text { 濒危 } \\
\text { /EN }\end{array}$ & 杜加加 & 珍稀濒危树种擎天树繁殖技术研究 \\
\hline Parashorea chinensis & 望天树 & I & $\begin{array}{l}\text { 濒危 } \\
\text { /EN }\end{array}$ & 杨永康 & 中国龙脑香科植物分类研究(一) \\
\hline Parashorea chinensis & 望天树 & I & $\begin{array}{l}\text { 濒危 } \\
\text { /EN }\end{array}$ & 李婕 & 中国龙脑香科植物纪要 \\
\hline Parashorea chinensis & 望天树 & I & 濒危 & 孟令曾 & 中国龙脑香科植物受胁状况及迁地群落保护探讨 \\
\hline
\end{tabular}


顾垒，闻丞，罗玫，王吴，吕植. 中国最受关注濒危物种保护现状快速评价的新方法探讨. 生物多样性，2015，23(5)：583-590. http://www. biodiversity-science. net/CN/article/downloadArticleFile. do?attachType=PDF\&id=10075

\begin{tabular}{|c|c|c|c|c|c|}
\hline & & & /EN & & \\
\hline \multirow[t]{2}{*}{ Parepigynum funingense } & 富宁藤 & II & 濒危 & 曹建新 & 富宁藤、思茅藤、山玉兰和挖耳草的化学成分研究 \\
\hline & & & $/$ EN & & \\
\hline \multirow[t]{2}{*}{ Pavo muticus } & 绿孔雀 & I & 濒危 & 李学红 & 恐龙河自然保护区保护价值及保护措施 \\
\hline & & & /EN & & \\
\hline \multirow[t]{2}{*}{ Pavo muticus } & 绿孔雀 & I & 濒危 & 王恒颖 & 恐龙河自然保护区的动植物资源现状及保护对策研究 \\
\hline & & & /EN & & \\
\hline \multirow[t]{2}{*}{ Pavo muticus } & 绿孔雀 & I & 濒危 & 胡箭 & 铜壁关自然保护区鸟类区系研究 \\
\hline & & & /EN & & \\
\hline \multirow[t]{2}{*}{ Pavo muticus } & 绿孔雀 & I & 濒危 & 卫 凡 & 铜壁关自然保护区盈江片区生物多样性评价 \\
\hline & & & /EN & & \\
\hline \multirow[t]{2}{*}{ Pavo muticus } & 绿孔雀 & I & 濒危 & 何顺强 & 西双版纳自然保护区野生动物资源监测概述 \\
\hline & & & /EN & & \\
\hline \multirow[t]{2}{*}{ Pavo muticus } & 绿孔雀 & I & 濒危 & 阮方佑 & 云南哀牢山自然保护区南华片区项目建设必要性分析 \\
\hline & & & /EN & & \\
\hline \multirow[t]{2}{*}{ Pavo muticus } & 绿孔雀 & I & 濒危 & 张淑霞 & 云南省澜沧江自然保护区鸟类资源调查 \\
\hline & & & /EN & & \\
\hline \multirow[t]{2}{*}{ Pavo muticus } & 绿孔雀 & I & 濒危 & 刘钊 & 云南元江上游石羊江河谷绿孔雀不同季节受食地选择 \\
\hline & & & /EN & & \\
\hline
\end{tabular}


顾垒，闻丞，罗玫，王吴，吕植. 中国最受关注濒危物种保护现状快速评价的新方法探讨. 生物多样性，2015，23(5)：583-590. http://www biodiversity-science. net/CN/article/downloadArticleFile. do?attachType=PDF\&id=10075

\begin{tabular}{|c|c|c|c|c|c|}
\hline \multirow[t]{2}{*}{ Pelodiscus sinensis } & 中华鳖 & 未列 & 易危 & 王志铮 & 3 种常见农药对中华鳖稚鳖的急性致毒效应研究 \\
\hline & & 入 & /VU & & \\
\hline \multirow[t]{2}{*}{ Pelodiscus sinensis } & 中华鳖 & 未列 & 易危 & 何力 & 4 个不同地理群体中华鳖 pomc 基因 PC R-R FLP 分析 \\
\hline & & 入 & $/ \mathrm{VU}$ & & \\
\hline \multirow[t]{2}{*}{ Pelodiscus sinensis } & 中华鳖 & 未列 & 易危 & 王志铮 & 4 种重金属离子对中华鳖(Trionyx sinensis)稚鳖的急性致毒效应 \\
\hline & & 入 & /VU & & \\
\hline \multirow[t]{2}{*}{ Pelodiscus sinensis } & 中华鳖 & 未列 & 易危 & 石存斌 & 45 种中草药提取物对中华鳘源嗜水气单胞菌的体外抑菌作用 \\
\hline & & 入 & $/ \mathrm{VU}$ & & \\
\hline \multirow[t]{2}{*}{ Pelodiscus sinensis } & 中华鳖 & 未列 & 易危 & 邹世平 & 4 个不同地理种群中华鳖 P O M C 基因全长 c D N A 克隆及其序列分析 \\
\hline & & 入 & $/ \mathrm{VU}$ & & \\
\hline \multirow[t]{2}{*}{ Pelodiscus sinensis } & 中华鳖 & 未列 & 易危 & 刘浩明 & 5 种水产动物血红细胞形态显微观察比较及进化分析 \\
\hline & & 入 & /VU & & \\
\hline \multirow[t]{2}{*}{ Pelodiscus sinensis } & 中华鳖 & 未列 & 易危 & 杨敬辉 & BARODON 对中华鳖免疫功能的影响 \\
\hline & & 入 & $/ \mathrm{VU}$ & & \\
\hline \multirow[t]{2}{*}{ Pelodiscus sinensis } & 中华鳖 & 未列 & 易危 & 陈秋生 & Cajal 间质细胞在中华鳖肠道的分布差异和超微特征 \\
\hline & & 入 & $/ \mathrm{VU}$ & & \\
\hline \multirow[t]{2}{*}{ Pelodiscus sinensis } & 中华鳖 & 未列 & 易危 & Shangquan Zhu & cDNA Cloning and Functional Expression of Growth Hormone Receptor from Soft-Shelled \\
\hline & & 入 & $/ \mathrm{VU}$ & & Turtle (Pelodiscus sinensis japonicus) \\
\hline Pelodiscus sinensis & 中华鳖 & 未列 & 易危 & Cuijuan Niu & cDNA cloning and tissue expression for L-gulonolactone oxidase gene in soft-shelled turtle \\
\hline
\end{tabular}


顾垒，闻丞，罗玫，王昊，吕植. 中国最受关注濒危物种保护现状快速评价的新方法探讨．生物多样性，2015，23(5)：583-590. http://www. biodiversity-science. net/CN/article/downloadArticleFile. do?attachType=PDF\&id=10075

\begin{tabular}{|c|c|c|c|c|c|}
\hline & & 入 & /VU & & Pelodiscus sinensis a species with the ability to synthesize ascorbic acid \\
\hline \multirow[t]{2}{*}{ Pelodiscus sinensis } & 中华鳖 & 未列 & 易危 & Guo-ying QIAN & De-novo characterization of the soft-shelled turtle Pelodiscus sinensis transcriptome using \\
\hline & & 入 & /VU & & Illumina RNA-Seq technology*\# \\
\hline \multirow[t]{2}{*}{ Pelodiscus sinensis } & 中华鳖 & 未列 & 易危 & 赵海泉 & Diff-Quik 染色法在中华鳖血细胞染色中的应用 \\
\hline & & 入 & /VU & & \\
\hline \multirow[t]{2}{*}{ Pelodiscus sinensis } & 中华鳖 & 未列 & 易危 & Xiang Ji & Do fluctuations in incubation temperature affect hatchling quality in the Chinese soft-shelled \\
\hline & & 入 & /VU & & turtle Pelodiscus sinensis? \\
\hline \multirow[t]{2}{*}{ Pelodiscus sinensis } & 中华鳖 & 未列 & 易危 & CUIJUAN NIU & Effect of Chronic Ammonia Exposure on Energy Budget of Juvenile Soft-shelled Turtle, \\
\hline & & 入 & /VU & & Pelodiscus sinensis \\
\hline \multirow[t]{2}{*}{ Pelodiscus sinensis } & 中华鳖 & 未列 & 易危 & Zhen-Cai Yang & Effect of protein restriction with subsequent re-alimentation on compensatory growth of \\
\hline & & 入 & /VU & & juvenile soft-shelled turtles (Pelodiscus sinensis) \\
\hline \multirow[t]{2}{*}{ Pelodiscus sinensis } & 中华鳖 & 未列 & 易危 & Zhencai Yang & Effects of animal - plant protein ratio in extruded and expanded diets on nitrogen and energy \\
\hline & & 入 & $/ \mathrm{VU}$ & & budgets of juvenile Chinese soft-shelled turtle (Pelodiscus sinensis Wiegmann) \\
\hline \multirow[t]{3}{*}{ Pelodiscus sinensis } & 中华鳖 & 未列 & 易危 & AI Qinghui & Effects of Brown Fish Meal Replacement with Fermented Soybean Meal on Growth \\
\hline & & 入 & /VU & & Performance, Feed Efficiency and Enzyme Activities of Chinese Soft-shelled Turtle, Pelodiscus \\
\hline & & & & & sinensis \\
\hline \multirow[t]{2}{*}{ Pelodiscus sinensis } & 中华鳖 & 未列 & 易危 & Guo-Ying Qian & Effects of osmolytes on Pelodiscus sinensis creatine kinase: A study on thermal denaturation \\
\hline & & 入 & /VU & & and aggregation \\
\hline Pelodiscus sinensis & 中华鳖 & 未列 & 易危 & Cuijuan Niu & Effects of stocking density on growth and non-specific immune responses in juvenile \\
\hline
\end{tabular}


顾垒，闻丞，罗玫，王吴，吕植. 中国最受关注濒危物种保护现状快速评价的新方法探讨. 生物多样性，2015，23(5)：583-590. http://www biodiversity-science. net/CN/article/downloadArticleFile. do?attachType=PDF\&id=10075

\begin{tabular}{|c|c|c|c|c|c|}
\hline & & 入 & /VU & & soft-shelled turtle, Pelodiscus sinensis \\
\hline \multirow[t]{2}{*}{ Pelodiscus sinensis } & 中华鳖 & 未列 & 易危 & Zhencai Yang & Effects of Taurine Supplementation on Growth Performance and Antioxidative Capacity of \\
\hline & & 入 & /VU & & Chinese Soft-shelled Turtles, Pelodiscus sinensis, Fed a Diet of Low Fish Meal Content \\
\hline \multirow[t]{2}{*}{ Pelodiscus sinensis } & 中华鳖 & 未列 & 易危 & MIN XUE & Efficacy and tolerance of lutein as colourant in diet of juvenile soft-shelled turtle Pelodiscus \\
\hline & & 入 & /VU & & sinensis \\
\hline \multirow[t]{2}{*}{ Pelodiscus sinensis } & 中华鳖 & 未列 & 易危 & Guo-Ying Qian & Folding studies on muscle type of creatine kinase from Pelodiscus sinensis \\
\hline & & 入 & /VU & & \\
\hline \multirow[t]{2}{*}{ Pelodiscus sinensis } & 中华鳖 & 未列 & 易危 & Zhongqian Li & Genetic Diversity of Farmed Chinese Soft-Shelled Turtle (Pelodiscus sinensis) Evaluated from \\
\hline & & 入 & /VU & & Microsatellite Analysis \\
\hline \multirow[t]{2}{*}{ Pelodiscus sinensis } & 中华鳖 & 未列 & 易危 & 温安祥 & Gln 对嗜水气单胞菌感染中华鳖的保护作用 \\
\hline & & 入 & /VU & & \\
\hline \multirow[t]{2}{*}{ Pelodiscus sinensis } & 中华鳖 & 未列 & 易危 & 周定刚 & GLN 对中华鳖免疫应激后肝脏、脾脏及肠道 HSP70 表达的影响 \\
\hline & & 入 & $/ \mathrm{VU}$ & & \\
\hline \multirow[t]{2}{*}{ Pelodiscus sinensis } & 中华鳖 & 未列 & 易危 & 周定刚 & G L N 缓解中华鳖免疫应激反应机制的初步研究 \\
\hline & & 入 & /VU & & \\
\hline \multirow[t]{2}{*}{ Pelodiscus sinensis } & 中华鳖 & 未列 & 易危 & Wei-huan FANG & Identification of a heat shock cognate protein 70 gene in Chinese soft-shell turtle (Pelodiscus \\
\hline & & 入 & /VU & & sinensis) and its expression profiles under thermal stress \\
\hline \multirow[t]{2}{*}{ Pelodiscus sinensis } & 中华鳖 & 未列 & 易危 & P. Nie & IgM, IgD and IgY and their expression pattern in the Chinese soft-shelled turtle Pelodiscus \\
\hline & & 入 & /VU & & sinensis \\
\hline
\end{tabular}


顾垒，闻丞，罗玫，王昊，吕植. 中国最受关注濒危物种保护现状快速评价的新方法探讨．生物多样性，2015，23(5)：583-590. http://www. biodiversity-science. net/CN/article/downloadArticleFile. do?attachType=PDF\&id=10075

\begin{tabular}{|c|c|c|c|c|c|}
\hline \multirow[t]{2}{*}{ Pelodiscus sinensis } & 中华鳖 & 未列 & 易危 & P. Nie & Immunoglobulin joining $(\mathrm{J})$ chain and its expression in the Chinese soft-shelled turtle \\
\hline & & 入 & /VU & & (Pelodiscus sinensis) \\
\hline \multirow[t]{2}{*}{ Pelodiscus sinensis } & 中华鳖 & 未列 & 易危 & Xiang Ji & Incubation temperature affects hatchling growth but not sexual phenotype in the Chinese \\
\hline & & 入 & /VU & & soft-shelled turtle, Pelodiscus sinensis (Trionychidae) \\
\hline \multirow[t]{2}{*}{ Pelodiscus sinensis } & 中华鳖 & 未列 & 易危 & L.W. Nie & Isolation and characterization of 21 novel polymorphic microsatellite loci in the Chinese \\
\hline & & 入 & /VU & & soft-shelled turtle Pelodiscus sinensis \\
\hline \multirow[t]{2}{*}{ Pelodiscus sinensis } & 中华鳖 & 未列 & 易危 & JIANBO CHANG & Isolation and characterization of microsatellites in Chinese soft-shelled turtle, Pelodiscus \\
\hline & & 入 & $/ \mathrm{VU}$ & & sinensis \\
\hline \multirow[t]{2}{*}{ Pelodiscus sinensis } & 中华鳖 & 未列 & 易危 & Guoying Qian & Morphologic analysis of atretic follicles in the Chinese soft-shelledturtle, Pelodiscus sinensis \\
\hline & & 入 & /VU & & \\
\hline \multirow[t]{2}{*}{ Pelodiscus sinensis } & 中华鳖 & 未列 & 易危 & ShaoJu Zeng & Neurogenic development of the visual areas in the Chinese softshell turtle (Pelodiscus sinensis) \\
\hline & & 入 & /VU & & and evolutionary implications \\
\hline \multirow[t]{2}{*}{ Pelodiscus sinensis } & 中华鳖 & 未列 & 易危 & 王海涛 & P53 蛋白在三种爬行动物卵泡内的免疫组织化学定位 \\
\hline & & 入 & $/ \mathrm{VU}$ & & \\
\hline \multirow[t]{2}{*}{ Pelodiscus sinensis } & 中华鳖 & 未列 & 易危 & Q.-S. Chen & Seasonal effects on apoptosis and proliferation of germ cells in the testes of the Chinese \\
\hline & & 入 & /VU & & soft-shelled turtle, Pelodiscus sinensis \\
\hline \multirow[t]{2}{*}{ Pelodiscus sinensis } & 中华鳖 & 未列 & 易危 & Ming-Xue Zuo & Sites of Origin and Developmental Dynamics of the Neurons in the Core and Shell Regions of \\
\hline & & 入 & $/ \mathrm{VU}$ & & Torus Semicircularis in the Chinese Softshell Turtle (Pelodiscus sinensis) \\
\hline Pelodiscus sinensis & 中华鳖 & 未列 & 易危 & Z. Q. Li & Sixteen polymorphic microsatellites for breeding of Chinese soft-shelled turtles (Pelodiscus \\
\hline
\end{tabular}


顾垒，闻丞，罗玫，王昊，吕植. 中国最受关注濒危物种保护现状快速评价的新方法探讨．生物多样性，2015，23(5)：583-590. http://www, biodiversity-science, net/CN/article/downloadArticleFile. do?attachType=PDF\&id=10075

\begin{tabular}{|c|c|c|c|c|c|}
\hline & & 入 & /VU & & sinensis) \\
\hline \multirow[t]{2}{*}{ Pelodiscus sinensis } & 中华鳖 & 未列 & 易危 & QIU-SHENG CHEN & Spermiogenesis in Soft-Shelled Turtle, Pelodiscus sinensis \\
\hline & & 入 & /VU & & \\
\hline \multirow[t]{2}{*}{ Pelodiscus sinensis } & 中华鳖 & 未列 & 易危 & Xue-yan Ding & The dietary protein requirement of a new Japanese strain of juvenile Chinese soft shell turtle, \\
\hline & & 入 & /VU & & Pelodiscus sinensis \\
\hline \multirow[t]{2}{*}{ Pelodiscus sinensis } & 中华鳖 & 未列 & 易危 & CUI-JUAN NIU & The effect of vitamin C on stress withstanding capability in the juvenile soft-shelled turtle \\
\hline & & 入 & /VU & & (Pelodiscus sinensis) \\
\hline \multirow[t]{2}{*}{ Pelodiscus sinensis } & 中华鳖 & 未列 & 易危 & Shang-Jun Yin & The effect of Zn2+ on Pelodiscus sinensis creatine kinase: unfolding and aggregation studies \\
\hline & & 入 & /VU & & \\
\hline \multirow[t]{2}{*}{ Pelodiscus sinensis } & 中华鳖 & 未列 & 易危 & Cuijuan Niu & The effects of dietary vitamin C on growth, liver vitamin C and serum cortisol in stressed and \\
\hline & & 入 & /VU & & unstressed juvenile soft-shelled turtles (Pelodiscus sinensis) \\
\hline \multirow[t]{2}{*}{ Pelodiscus sinensis } & 中华鳖 & 未列 & 易危 & Wei-Guo Du & The effects of incubation thermal environments on size, locomotor performance and early \\
\hline & & 入 & /VU & & growth of hatchling soft-shelled turtles, Pelodiscus sinensis \\
\hline \multirow[t]{2}{*}{ Pelodiscus sinensis } & 中华鳖 & 未列 & 易危 & Cuijuan Niu & The effects of vitamin $\mathrm{E}$ on antiacid stress ability in juvenile soft-shelled turtles (Pelodiscus \\
\hline & & 入 & /VU & & sinensis) \\
\hline \multirow[t]{2}{*}{ Pelodiscus sinensis } & 中华鳖 & 未列 & 易危 & CUI-JUAN NIU & The effects of vitamin E on non-specific immune response of the juvenile soft-shelled turtle \\
\hline & & 入 & /VU & & Pelodiscus sinensis \\
\hline \multirow[t]{2}{*}{ Pelodiscus sinensis } & 中华鳖 & 未列 & 易危 & Qiusheng Chen & The ultrastructural characteristics of the spermatozoa stored in the cauda epididymidis in \\
\hline & & 入 & /VU & & Chinese soft-shelled turtle Pelodiscus sinensis during the breeding season \\
\hline
\end{tabular}


顾垒，闻丞，罗玫，王吴，吕植. 中国最受关注濒危物种保护现状快速评价的新方法探讨. 生物多样性，2015，23(5)：583-590. http://www. biodiversity-science. net/CN/article/downloadArticleFile. do?attachType=PDF\&id=10075

\begin{tabular}{|c|c|c|c|c|c|}
\hline \multirow[t]{2}{*}{ Pelodiscus sinensis } & 中华鳖 & 未列 & 易危 & Qiusheng Chen & Ultrastructure of epididymal epithelium and its interaction with the sperm in the soft-shelled \\
\hline & & 入 & /VU & & turtle Pelodiscus sinensis \\
\hline \multirow[t]{2}{*}{ Pelodiscus sinensis } & 中华鳖 & 未列 & 易危 & Qiusheng Chen & Ultrastructure of the nephron in the soft-shelled turtle, Pelodiscus sinensis (Reptilia, Chelonia, \\
\hline & & 入 & /VU & & Trionychidae) \\
\hline \multirow[t]{2}{*}{ Pelodiscus sinensis } & 中华鳖 & 未列 & 易危 & 楚德昌 & 巴西彩龟与中华鳖消化道嗜银细胞的观察 \\
\hline & & 入 & /VU & & \\
\hline \multirow[t]{2}{*}{ Pelodiscus sinensis } & 中华鳖 & 未列 & 易危 & 邓振旭 & 巴西彩龟与中华鳖消化道粘液细胞组织化学染色 \\
\hline & & 入 & /VU & & \\
\hline \multirow[t]{2}{*}{ Pelodiscus sinensis } & 中华鳖 & 未列 & 易危 & 陈安国 & 半胱胺对中华鳖生长性能和非特异性免疫功能的影响研究 \\
\hline & & 入 & /VU & & \\
\hline \multirow[t]{2}{*}{ Pelodiscus sinensis } & 中华鳖 & 未列 & 易危 & 孙红祥 & 鳖保宁对中华鳖气单胞菌病的药效学研究 \\
\hline & & 入 & $/ \mathrm{VU}$ & & \\
\hline \multirow[t]{2}{*}{ Pelodiscus sinensis } & 中华鳖 & 未列 & 易危 & 江剑平 & 鳖鳃腺炎与腐皮病并发症的组织病理学研究 \\
\hline & & 入 & /VU & & \\
\hline \multirow[t]{2}{*}{ Pelodiscus sinensis } & 中华鳖 & 未列 & 易危 & 沈锦玉 & 鳖用四价细菌灭活疫苗免疫防治应用研究 \\
\hline & & 入 & /VU & & \\
\hline \multirow[t]{2}{*}{ Pelodiscus sinensis } & 中华鳖 & 未列 & 易危 & 王志铮 & 鳖源嗜水气单胞菌 ZHYYZ-1 表型、致病机制及抑菌中草药复方篮选的研究 \\
\hline & & 入 & /VU & & \\
\hline Pelodiscus sinensis & 中华鳖 & 未列 & 易危 & 聂刘旺 & 不同产地中华鳖的线粒体控制区序列分析及结构比较 \\
\hline
\end{tabular}


顾垒，闻丞，罗玫，王吴，吕植. 中国最受关注濒危物种保护现状快速评价的新方法探讨. 生物多样性，2015，23(5)：583-590. http://www. biodiversity-science. net/CN/article/downloadArticleFile. do?attachType=PDF\&id=10075

\begin{tabular}{|c|c|c|c|c|c|}
\hline & & 入 & $/ \mathrm{VU}$ & & \\
\hline \multirow[t]{2}{*}{ Pelodiscus sinensis } & 中华鳖 & 未列 & 易危 & 张秋明 & 不同池塘环境和饲料条件对中华鳖生产性能及经济效益影响试验 \\
\hline & & 入 & $/ \mathrm{VU}$ & & \\
\hline \multirow{2}{*}{ Pelodiscus sinensis } & 中华鳖 & 未列 & 易危 & 龚建辉 & 不同雌雄配比对中华鳖人工繁殖受精率的影响 \\
\hline & & $\lambda$ & $/ \mathrm{VU}$ & & \\
\hline \multirow[t]{2}{*}{ Pelodiscus sinensis } & 中华鳖 & 未列 & 易危 & 陈德富 & 不同密度的中华鳖孵化试验 \\
\hline & & 入 & $/ \mathrm{VU}$ & & \\
\hline \multirow[t]{2}{*}{ Pelodiscus sinensis } & 中华鳖 & 未列 & 易危 & 蒋业林 & 不同生态装备对中华鳖稚鳖生长・抗病力和品质的影响 \\
\hline & & 入 & $/ \mathrm{VU}$ & & \\
\hline \multirow[t]{2}{*}{ Pelodiscus sinensis } & 中华鳖 & 未列 & 易危 & 王晓清 & 不同养殖模式对中华鳖营养品质的影响 \\
\hline & & 入 & /VU & & \\
\hline \multirow[t]{2}{*}{ Pelodiscus sinensis } & 中华鳖 & 未列 & 易危 & 郭琼林 & 草鱼、中华鳖 IL-2 活性影响因素的研究 \\
\hline & & 入 & $/ \mathrm{VU}$ & & \\
\hline \multirow[t]{2}{*}{ Pelodiscus sinensis } & 中华鳖 & 未列 & 易危 & 郭琼林 & 草鱼、中华鳖 $\mathrm{T}$ 淋巴细胞表面抗原的研究 \\
\hline & & 入 & $/ \mathrm{VU}$ & & \\
\hline \multirow[t]{2}{*}{ Pelodiscus sinensis } & 中华鳖 & 未列 & 易危 & 郭琼林 & 草鱼、中华鳖淋巴细胞扫描电镜结构特征及其绵羊红细胞受体(CD2)的检测 \\
\hline & & 入 & $/ \mathrm{VU}$ & & \\
\hline \multirow[t]{2}{*}{ Pelodiscus sinensis } & 中华鳖 & 未列 & 易危 & 郭琼林 & 草鱼、中华鳖脾细胞培养上清液 IL-2 物质的检测 \\
\hline & & 入 & /VU & & \\
\hline
\end{tabular}


顾垒，闻丞，罗玫，王吴，吕植. 中国最受关注濒危物种保护现状快速评价的新方法探讨. 生物多样性，2015，23(5)：583-590. http://www biodiversity-science. net/CN/article/downloadArticleFile. do?attachType=PDF\&id=10075

\begin{tabular}{|c|c|c|c|c|c|}
\hline \multirow[t]{2}{*}{ Pelodiscus sinensis } & 中华鳖 & 未列 & 易危 & 郭琼林 & 草鱼、中华鳖造血器官和血细胞凝集素结合部位的观察 \\
\hline & & 入 & /VU & & \\
\hline \multirow[t]{2}{*}{ Pelodiscus sinensis } & 中华鳖 & 未列 & 易危 & 陈秋生 & 雌性中华鳖生殖前期输卵管组织结构观察 \\
\hline & & 入 & /VU & & \\
\hline \multirow[t]{2}{*}{ Pelodiscus sinensis } & 中华鳖 & 未列 & 易危 & 陈秋生 & 雌性中华鳖输卵管精子储存结构的研究 \\
\hline & & 入 & /VU & & \\
\hline \multirow[t]{2}{*}{ Pelodiscus sinensis } & 中华鳖 & 未列 & 易危 & 王珺 & 蛋白质含量对中华鳖稚鳖能量收支和氮收支的影响 \\
\hline & & 入 & /VU & & \\
\hline \multirow[t]{2}{*}{ Pelodiscus sinensis } & 中华鳖 & 未列 & 易危 & 高永利 & 低蛋白饲料添加肉毒碱养殖中华鳖试验研究 \\
\hline & & 入 & /VU & & \\
\hline \multirow[t]{2}{*}{ Pelodiscus sinensis } & 中华鳖 & 未列 & 易危 & 刘凯 & 低聚异麦芽糖和酵母细胞壁对中华鳖肠道菌群的影响 \\
\hline & & 入 & $/ \mathrm{VU}$ & & \\
\hline \multirow[t]{2}{*}{ Pelodiscus sinensis } & 中华鳖 & 未列 & 易危 & 刘凯 & 低聚异麦芽糖和酵母细胞壁对中华鳖肝脏中溶菌酶基因表达的半定量分析 \\
\hline & & 入 & /VU & & \\
\hline \multirow[t]{2}{*}{ Pelodiscus sinensis } & 中华鳖 & 未列 & 易危 & 牛翠娟 & 冬眠及外源维生素 C 对中华鳖(Pelodiscus sinensis)稚鳖能量代谢的影响 \\
\hline & & 入 & /VU & & \\
\hline \multirow[t]{2}{*}{ Pelodiscus sinensis } & 中华鳖 & 未列 & 易危 & 陈秋生 & 冬眠中华鳖雌、雄生殖道的精子储存 \\
\hline & & 入 & /VU & & \\
\hline Pelodiscus sinensis & 中华鳖 & 未列 & 易危 & 杨振才 & 动植物蛋白比对中华鳖稚鳖能量和氮收支的影响 \\
\hline
\end{tabular}


顾垒，闻丞，罗玫，王吴，吕植. 中国最受关注濒危物种保护现状快速评价的新方法探讨. 生物多样性，2015，23(5)：583-590. http://www. biodiversity-science. net/CN/article/downloadArticleFile. do?attachType=PDF\&id=10075

\begin{tabular}{|c|c|c|c|c|c|}
\hline & & 入 & $/ \mathrm{VU}$ & & \\
\hline \multirow[t]{2}{*}{ Pelodiscus sinensis } & 中华鳖 & 未列 & 易危 & 杨振才 & 多重周期禁食-饱食对中华鳖补偿生长影响 \\
\hline & & 入 & $/ \mathrm{VU}$ & & \\
\hline \multirow{2}{*}{ Pelodiscus sinensis } & 中华鳖 & 未列 & 易危 & 何丰 & 恩诺沙星注射对中华鳖肝脏 I 相、II 相酶活性的影响 \\
\hline & & 入 & $/ \mathrm{VU}$ & & \\
\hline \multirow[t]{2}{*}{ Pelodiscus sinensis } & 中华鳖 & 未列 & 易危 & 雷思佳 & 饵料类型、摄食水平和体重对中华鳖生化成分和比能值的影响 \\
\hline & & 入 & $/ \mathrm{VU}$ & & \\
\hline \multirow[t]{2}{*}{ Pelodiscus sinensis } & 中华鳖 & 未列 & 易危 & 牛翠娟 & 饵料维生素 $\mathrm{E}$ 含量对酸应激中华鳖幼鳖血清补体 C3 和 C4 的影响 \\
\hline & & 入 & $/ \mathrm{VU}$ & & \\
\hline \multirow[t]{2}{*}{ Pelodiscus sinensis } & 中华鳖 & 未列 & 易危 & 陈昌福 & 饵料中添加酵母水解物对中华鳖成鳖的诱食效果 \\
\hline & & 入 & $/ \mathrm{VU}$ & & \\
\hline \multirow[t]{2}{*}{ Pelodiscus sinensis } & 中华鳖 & 未列 & 易危 & 陈秋生 & 繁殖期中华鳖输卵管 5 种酶的组织化学研究 \\
\hline & & 入 & /VU & & \\
\hline \multirow[t]{2}{*}{ Pelodiscus sinensis } & 中华鳖 & 未列 & 易危 & 叶玉珍 & 睬化温度对中华鳖 4 种同工酶和肌肉蛋白基因表达的影响 \\
\hline & & 入 & $/ \mathrm{VU}$ & & \\
\hline \multirow[t]{2}{*}{ Pelodiscus sinensis } & 中华鳖 & 未列 & 易危 & 杜卫国 & 孵化温度对中华鳖胚胎物质和能量利用的影响 \\
\hline & & 入 & $/ \mathrm{VU}$ & & \\
\hline \multirow[t]{2}{*}{ Pelodiscus sinensis } & 中华鳖 & 未列 & 易危 & 王晓清 & 孵化温度对中华鳖性别分化的影响 \\
\hline & & 入 & /VU & & \\
\hline
\end{tabular}


顾垒，闻丞，罗玫，王吴，吕植. 中国最受关注濒危物种保护现状快速评价的新方法探讨. 生物多样性，2015，23(5)：583-590. http://www. biodiversity-science. net/CN/article/downloadArticleFile. do?attachType=PDF\&id=10075

\begin{tabular}{|c|c|c|c|c|c|}
\hline \multirow[t]{2}{*}{ Pelodiscus sinensis } & 中华鳖 & 未列 & 易危 & 阮成旭 & 孵卵温度与中华鳖性别决定 \\
\hline & & 入 & /VU & & \\
\hline \multirow[t]{2}{*}{ Pelodiscus sinensis } & 中华鳖 & 未列 & 易危 & 陈昌福 & 获苓多糖对中华鳖非特异性免疫功能的免疫调节作用 \\
\hline & & 入 & /VU & & \\
\hline \multirow[t]{2}{*}{ Pelodiscus sinensis } & 中华鳖 & 未列 & 易危 & 张海琪 & 氟甲喹在中华鳖日本品系组织中的残留代谢规律研究 \\
\hline & & 入 & /VU & & \\
\hline \multirow[t]{2}{*}{ Pelodiscus sinensis } & 中华鳖 & 未列 & 易危 & 王正健 & 复合植物源抗应激剂的研制及在中华鳖养殖上的应用研究 \\
\hline & & 入 & /VU & & \\
\hline \multirow[t]{2}{*}{ Pelodiscus sinensis } & 中华鳖 & 未列 & 易危 & 陈昌福 & 高活性干酵母对水产动物非特异性免疫功能和抗病力的影响 \\
\hline & & 入 & /VU & & \\
\hline \multirow[t]{2}{*}{ Pelodiscus sinensis } & 中华鳖 & 未列 & 易危 & 陈昌福 & 高活性干酵母对中华鳖非特异性免疫功能和抗病力的影响 \\
\hline & & 入 & $/ \mathrm{VU}$ & & \\
\hline \multirow[t]{2}{*}{ Pelodiscus sinensis } & 中华鳖 & 未列 & 易危 & 周定刚 & 谷氨酰胺对内毒素刺激下中华鳖免疫功能和生产性能的影响 \\
\hline & & 入 & /VU & & \\
\hline \multirow[t]{2}{*}{ Pelodiscus sinensis } & 中华鳖 & 未列 & 易危 & 周定刚 & 谷氨酰胺缓解中华鳖免疫应激反应作用机理的研究 \\
\hline & & 入 & /VU & & \\
\hline \multirow[t]{2}{*}{ Pelodiscus sinensis } & 中华鳖 & 未列 & 易危 & 叶金云 & 固定化微生物菌剂与䔨菜对中华鳖养殖污水的净化效果研究 \\
\hline & & 入 & $/ \mathrm{VU}$ & & \\
\hline Pelodiscus sinensis & 中华鳖 & 未列 & 易危 & 徐长安 & 光合细菌 FP04 的篮选及对中华鳖养殖水质和生产效益的影响 \\
\hline
\end{tabular}


顾垒，闻丞，罗玫，王吴，吕植. 中国最受关注濒危物种保护现状快速评价的新方法探讨. 生物多样性，2015，23(5)：583-590. http://www. biodiversity-science. net/CN/article/downloadArticleFile. do?attachType=PDF\&id=10075

\begin{tabular}{|c|c|c|c|c|c|}
\hline & & 入 & $/ \mathrm{VU}$ & & \\
\hline \multirow[t]{2}{*}{ Pelodiscus sinensis } & 中华鳖 & 未列 & 易危 & 钱国英 & 龟鳖类动物热休克蛋白研究进展 \\
\hline & & 入 & $/ \mathrm{VU}$ & & \\
\hline \multirow[t]{2}{*}{ Pelodiscus sinensis } & 中华鳖 & 未列 & 易危 & 肖明松 & 果寡糖和糖萜素对中华鳖生长性能及免疫功能的影响 \\
\hline & & 入 & $/ \mathrm{VU}$ & & \\
\hline \multirow[t]{2}{*}{ Pelodiscus sinensis } & 中华鳖 & 未列 & 易危 & 肖明松 & 果寡糖与糖萜素对中华鳖生长性能影响的正交试验 \\
\hline & & 入 & $/ \mathrm{VU}$ & & \\
\hline \multirow[t]{2}{*}{ Pelodiscus sinensis } & 中华鳖 & 未列 & 易危 & 肖明松 & 果寡糖与糖萂素对中华鳖消化率的影响 \\
\hline & & 入 & $/ \mathrm{VU}$ & & \\
\hline \multirow[t]{2}{*}{ Pelodiscus sinensis } & 中华鳖 & 未列 & 易危 & 肖明松 & 果寡糖与糖萜素对中华鳖血清生化指标的影响 \\
\hline & & 入 & $/ \mathrm{VU}$ & & \\
\hline \multirow[t]{2}{*}{ Pelodiscus sinensis } & 中华鳖 & 未列 & 易危 & 杨振才 & 红鱼粉替代白鱼粉对中华鳖饲料性能的影响 \\
\hline & & 入 & /VU & & \\
\hline \multirow[t]{2}{*}{ Pelodiscus sinensis } & 中华鳖 & 未列 & 易危 & 李登峰 & 患暴发性败血症中华鳖体内细菌的分离与鉴定 \\
\hline & & 入 & $/ \mathrm{VU}$ & & \\
\hline \multirow[t]{2}{*}{ Pelodiscus sinensis } & 中华鳖 & 未列 & 易危 & 朱庆红 & 患病中华鳖消化道菌群的研究 \\
\hline & & 入 & $/ \mathrm{VU}$ & & \\
\hline \multirow[t]{2}{*}{ Pelodiscus sinensis } & 中华鳖 & 未列 & 易危 & 刘莉 & 患红底板症的中华鳖幼鳖的病原菌分离与鉴定 \\
\hline & & 入 & /VU & & \\
\hline
\end{tabular}


顾垒，闻丞，罗玫，王吴，吕植. 中国最受关注濒危物种保护现状快速评价的新方法探讨. 生物多样性，2015，23(5)：583-590. http://www, biodiversity-science. net/CN/article/downloadArticleFile. do?attachType=PDF\&id=10075

\begin{tabular}{|c|c|c|c|c|c|}
\hline \multirow[t]{2}{*}{ Pelodiscus sinensis } & 中华鳖 & 未列 & 易危 & 周显青 & 黄芪对中华鳖免疫和抗酸应激能力的影响 \\
\hline & & 入 & /VU & & \\
\hline \multirow[t]{2}{*}{ Pelodiscus sinensis } & 中华鳖 & 未列 & 易危 & 周显青 & 黄芪和酸应激对中华鳖幻鳖血清补体 C3 和 C4 含量的影响 \\
\hline & & 入 & /VU & & \\
\hline \multirow[t]{2}{*}{ Pelodiscus sinensis } & 中华鳖 & 未列 & 易危 & 朱丽敏 & 肌注和口服氟苯尼考在中华鳖体内残留分析及药代动力学 \\
\hline & & 入 & /VU & & \\
\hline \multirow[t]{2}{*}{ Pelodiscus sinensis } & 中华鳖 & 未列 & 易危 & 许国焕 & 几种促生长剂对中华鳖养殖效果的研究 \\
\hline & & 入 & /VU & & \\
\hline \multirow[t]{2}{*}{ Pelodiscus sinensis } & 中华鳖 & 未列 & 易危 & 蔡完其 & 几种免疫增强剂对中华鳖红细胞数量及免疫功能的影响 \\
\hline & & 入 & /VU & & \\
\hline \multirow[t]{2}{*}{ Pelodiscus sinensis } & 中华鳖 & 未列 & 易危 & 魏文志 & 甲壳素在中华鳖养殖中的应用 \\
\hline & & 入 & $/ \mathrm{VU}$ & & \\
\hline \multirow[t]{2}{*}{ Pelodiscus sinensis } & 中华鳖 & 未列 & 易危 & 洪一江 & 江西省中华鳖种质状况及养殖方式调查 \\
\hline & & 入 & /VU & & \\
\hline \multirow[t]{2}{*}{ Pelodiscus sinensis } & 中华鳖 & 未列 & 易危 & 张世水 & 江西省中华鳖种质状况调查及群体遗传多样性 \\
\hline & & 入 & /VU & & \\
\hline \multirow[t]{2}{*}{ Pelodiscus sinensis } & 中华鳖 & 未列 & 易危 & 李莉 & 抗生素药饵对中华鳘稚鳖摄食和生长的影响 \\
\hline & & 入 & $/ \mathrm{VU}$ & & \\
\hline Pelodiscus sinensis & 中华鳖 & 未列 & 易危 & 陈超然 & 抗生素与㒣定性粉状二氮化氯结吕应用对巾华鳖细菌性疾病前舫治效果 \\
\hline
\end{tabular}


顾垒，闻丞，罗玫，王吴，吕植. 中国最受关注濒危物种保护现状快速评价的新方法探讨. 生物多样性，2015，23(5)：583-590. http://www, biodiversity-science. net/CN/article/downloadArticleFile. do?attachType=PDF\&id=10075

\begin{tabular}{|c|c|c|c|c|c|}
\hline & & 入 & $/ \mathrm{VU}$ & & \\
\hline \multirow[t]{2}{*}{ Pelodiscus sinensis } & 中华鳖 & 未列 & 易危 & 郭琼林 & 抗胸腺细胞抗体对中华鳖免疫系统的影响 \\
\hline & & 入 & $/ \mathrm{VU}$ & & \\
\hline \multirow{2}{*}{ Pelodiscus sinensis } & 中华鳖 & 未列 & 易危 & 牛翠娟 & 壳聚糖对急性氨氮胁迫下中华鳖稚鳖非特异性免疫反应的影响 \\
\hline & & 入 & $/ \mathrm{VU}$ & & \\
\hline \multirow[t]{2}{*}{ Pelodiscus sinensis } & 中华鳖 & 未列 & 易危 & 陈超然 & 口服甘草素对中华鳖稚鳖抗嗜水气单胞菌感染的作用 \\
\hline & & 入 & $/ \mathrm{VU}$ & & \\
\hline \multirow[t]{2}{*}{ Pelodiscus sinensis } & 中华鳖 & 未列 & 易危 & 操玉涛 & 口灌呋喃唑酮对中华鳖消化道菌群的影响 \\
\hline & & 入 & $/ \mathrm{VU}$ & & \\
\hline \multirow[t]{2}{*}{ Pelodiscus sinensis } & 中华鳖 & 未列 & 易危 & 陈孝煊 & 口灌复方磺胺甲基异口恶唑对中华鳖消化道菌群的影响 \\
\hline & & 入 & $/ \mathrm{VU}$ & & \\
\hline \multirow[t]{2}{*}{ Pelodiscus sinensis } & 中华鳖 & 未列 & 易危 & 管越强 & 枯草芽狍杆菌对中华鳖生长性能、消化酶活性和血液生化指标的影响 \\
\hline & & 入 & /VU & & \\
\hline \multirow[t]{2}{*}{ Pelodiscus sinensis } & 中华鳖 & 未列 & 易危 & 管越强 & 枯草芽狍杆菌与低聚木糖组合对中华鳖生长、消化酶及血液生化指标的影响 \\
\hline & & 入 & $/ \mathrm{VU}$ & & \\
\hline \multirow[t]{2}{*}{ Pelodiscus sinensis } & 中华鳖 & 未列 & 易危 & 刘海燕 & 喹乙醇对中华鳖稚鳖的影响及其促生长机制的探讨 \\
\hline & & 入 & $/ \mathrm{VU}$ & & \\
\hline \multirow[t]{2}{*}{ Pelodiscus sinensis } & 中华鳖 & 未列 & 易危 & 范红结 & 雷氏普罗威登菌引致中华鳖脏器脓肿 \\
\hline & & 入 & $/ \mathrm{VU}$ & & \\
\hline
\end{tabular}


顾垒，闻丞，罗玫，王吴，吕植. 中国最受关注濒危物种保护现状快速评价的新方法探讨. 生物多样性，2015，23(5)：583-590. http://www. biodiversity-science. net/CN/article/downloadArticleFile. do?attachType=PDF\&id=10075

\begin{tabular}{|c|c|c|c|c|c|}
\hline \multirow[t]{2}{*}{ Pelodiscus sinensis } & 中华鳖 & 未列 & 易危 & 陈强 & 卵黄抗体在防治中华鳖气单胞菌病中的应用 \\
\hline & & 入 & /VU & & \\
\hline \multirow[t]{2}{*}{ Pelodiscus sinensis } & 中华鳖 & 未列 & 易危 & 温安祥 & 绿原酸对中华鳖生产性能和抗氧化功能的影响 \\
\hline & & 入 & /VU & & \\
\hline \multirow[t]{2}{*}{ Pelodiscus sinensis } & 中华鳖 & 未列 & 易危 & 牛翠娟 & 慢性氨暴露对中华鳖幼鳖生长及非特异性免疫反应的影响 \\
\hline & & 入 & /VU & & \\
\hline \multirow[t]{2}{*}{ Pelodiscus sinensis } & 中华鳖 & 未列 & 易危 & 牛翠娟 & 慢性氨暴露对中华鳖幼鳖血浆总氨氮、皮质酮浓度及组织氨代谢酶活性的影响 \\
\hline & & 入 & /VU & & \\
\hline \multirow[t]{2}{*}{ Pelodiscus sinensis } & 中华鳖 & 未列 & 易危 & 莫介化 & 酶解植物蛋白粉部分替代中华鳖饲料中白鱼粉的试验研究 \\
\hline & & 入 & /VU & & \\
\hline \multirow[t]{2}{*}{ Pelodiscus sinensis } & 中华鳖 & 未列 & 易危 & 熊传喜 & 免疫刺激剂对水产动物免疫机能的影响 \\
\hline & & 入 & $/ \mathrm{VU}$ & & \\
\hline \multirow[t]{2}{*}{ Pelodiscus sinensis } & 中华鳖 & 未列 & 易危 & 陈昌福 & 免疫多糖( 酵母细胞壁) 对中华鳖非特异性免疫功能的影响 \\
\hline & & 入 & /VU & & \\
\hline \multirow[t]{2}{*}{ Pelodiscus sinensis } & 中华鳖 & 未列 & 易危 & 周定刚 & 内毒素诱导中华鳖免疫应激的研究 \\
\hline & & 入 & /VU & & \\
\hline \multirow[t]{2}{*}{ Pelodiscus sinensis } & 中华鳖 & 未列 & 易危 & 胡毅钟 & 牛蛙和中华鳖甲状腺、肾上腺显微结构的比较研究 \\
\hline & & 入 & $/ \mathrm{VU}$ & & \\
\hline Pelodiscus sinensis & 中华鳖 & 未列 & 易危 & 陈孝煊 & 诺氟沙星对中华鳖消化道菌群的影响 \\
\hline
\end{tabular}


顾垒，闻丞，罗玫，王吴，吕植. 中国最受关注濒危物种保护现状快速评价的新方法探讨. 生物多样性，2015，23(5)：583-590. http://www. biodiversity-science. net/CN/article/downloadArticleFile. do?attachType=PDF\&id=10075

\begin{tabular}{|c|c|c|c|c|c|}
\hline & & 入 & $/ \mathrm{VU}$ & & \\
\hline \multirow[t]{2}{*}{ Pelodiscus sinensis } & 中华鳖 & 未列 & 易危 & 杨振才 & 喷雾干燥血粉在中华鳖饲料中的使用效果研究 \\
\hline & & 入 & $/ \mathrm{VU}$ & & \\
\hline \multirow{2}{*}{ Pelodiscus sinensis } & 中华鳖 & 未列 & 易危 & 杨振才 & 喷雾干燥血粉在中华鳖稚鳖饲料中替代白鱼粉的研究 \\
\hline & & 入 & $/ \mathrm{VU}$ & & \\
\hline \multirow[t]{2}{*}{ Pelodiscus sinensis } & 中华鳖 & 未列 & 易危 & 杨振才 & 膨化饲料动植物蛋白比对中华鳖稚鳖生长特性的影响 \\
\hline & & 入 & $/ \mathrm{VU}$ & & \\
\hline \multirow[t]{2}{*}{ Pelodiscus sinensis } & 中华鳖 & 未列 & 易危 & 曹培彦 & 膨化饲料养殖中华鳖试验研究 \\
\hline & & 入 & $/ \mathrm{VU}$ & & \\
\hline \multirow[t]{2}{*}{ Pelodiscus sinensis } & 中华鳖 & 未列 & 易危 & 洪一江 & 鄱阳湖中华鳖染色体核型、G 带和 $\mathrm{A} g-\mathrm{N} O \mathrm{R} s$ 的分析 \\
\hline & & 入 & /VU & & \\
\hline \multirow[t]{2}{*}{ Pelodiscus sinensis } & 中华鳖 & 未列 & 易危 & 杨再福 & 人工饲养条件下水温对中华鳖消化时间和生长影响的实验观察 \\
\hline & & 入 & /VU & & \\
\hline \multirow[t]{2}{*}{ Pelodiscus sinensis } & 中华鳖 & 未列 & 易危 & 谭乾开 & 人工提前破壳对中华鳖(Trionyx siensis)卵的睬化和稚鳖生长的影响研究 \\
\hline & & 入 & $/ \mathrm{VU}$ & & \\
\hline \multirow[t]{2}{*}{ Pelodiscus sinensis } & 中华鳖 & 未列 & 易危 & 雷思佳 & 日粮水平对中华鳖稚鳖生长的影响 \\
\hline & & 入 & $/ \mathrm{VU}$ & & \\
\hline \multirow[t]{2}{*}{ Pelodiscus sinensis } & 中华鳖 & 未列 & 易危 & 占秀安 & 肉碱对中华鳖脂肪代谢的影响 \\
\hline & & 入 & /VU & & \\
\hline
\end{tabular}


顾垒，闻丞，罗玫，王吴，吕植. 中国最受关注濒危物种保护现状快速评价的新方法探讨. 生物多样性，2015，23(5)：583-590. http://www. biodiversity-science. net/CN/article/downloadArticleFile. do?attachType=PDF\&id=10075

\begin{tabular}{|c|c|c|c|c|c|}
\hline \multirow[t]{2}{*}{ Pelodiscus sinensis } & 中华鳖 & 未列 & 易危 & 钱国英 & 三段式中华鳖生态养殖技术研究与应用 \\
\hline & & 入 & /VU & & \\
\hline \multirow[t]{2}{*}{ Pelodiscus sinensis } & 中华鳖 & 未列 & 易危 & 张海琪 & 三聚氰胺在中华鳘组织中的代谢动力学研究 \\
\hline & & 入 & /VU & & \\
\hline \multirow[t]{2}{*}{ Pelodiscus sinensis } & 中华鳖 & 未列 & 易危 & 沈锦玉 & 三氯异氧尿酸在中华鳖病防治上应用研究 \\
\hline & & 入 & /VU & & \\
\hline \multirow[t]{2}{*}{ Pelodiscus sinensis } & 中华鳖 & 未列 & 易危 & 陈合格 & 三种鳖线粒体 DNA 部分基因序列的比较分析和分子鉴定标记 \\
\hline & & 入 & /VU & & \\
\hline \multirow[t]{2}{*}{ Pelodiscus sinensis } & 中华鳖 & 未列 & 易危 & 张轩杰 & 三种鳖线粒体 DNA 细胞色素 $\mathrm{b}$ 基因序列的比较分析 \\
\hline & & 入 & /VU & & \\
\hline \multirow[t]{2}{*}{ Pelodiscus sinensis } & 中华鳖 & 未列 & 易危 & 张奇亚 & 三种水生动物病毒感染鱼类细胞的扫描电镜观察 \\
\hline & & 入 & $/ \mathrm{VU}$ & & \\
\hline \multirow[t]{2}{*}{ Pelodiscus sinensis } & 中华鳖 & 未列 & 易危 & 王爱英 & 山东白云湖中华鳖养殖池塘浮游植物调查 \\
\hline & & 入 & /VU & & \\
\hline \multirow[t]{2}{*}{ Pelodiscus sinensis } & 中华鳖 & 未列 & 易危 & 雷思佳 & 摄食水平对中华鳖( Trionyx sinensis) 幼鳖生长和能量收支的影响 \\
\hline & & 入 & /VU & & \\
\hline \multirow[t]{2}{*}{ Pelodiscus sinensis } & 中华鳖 & 未列 & 易危 & 陈孝煊 & 摄食水平对中华鳖幼鳖氮收支的影响 \\
\hline & & 入 & $/ \mathrm{VU}$ & & \\
\hline Pelodiscus sinensis & 中华鳖 & 未列 & 易危 & 叶世洲 & 摄食水平对中华鳖幼鳖生长的影响 \\
\hline
\end{tabular}


顾垒，闻丞，罗玫，王吴，吕植. 中国最受关注濒危物种保护现状快速评价的新方法探讨. 生物多样性，2015，23(5)：583-590. http://www biodiversity-science. net/CN/article/downloadArticleFile. do?attachType=PDF\&id=10075

\begin{tabular}{|c|c|c|c|c|c|}
\hline & & 入 & $/ \mathrm{VU}$ & & \\
\hline \multirow[t]{2}{*}{ Pelodiscus sinensis } & 中华鳖 & 未列 & 易危 & 雷思佳 & 摄食水平对中华鳖稚鳖生长、氮排泄和能量收支的影响 \\
\hline & & 入 & /VU & & \\
\hline \multirow[t]{2}{*}{ Pelodiscus sinensis } & 中华鳖 & 未列 & 易危 & 叶世洲 & 摄食水平和投喂频率对中华鳖幼鳖消化率影响 \\
\hline & & 入 & /VU & & \\
\hline \multirow[t]{2}{*}{ Pelodiscus sinensis } & 中华鳖 & 未列 & 易危 & 吴惠仙 & 生物防治用途芽狍杆菌对水产条件致病菌抑制作用与对中华线鳌蟹、日本沼虾及中华鳖 \\
\hline & & 入 & /VU & & 保护效果的评价 \\
\hline \multirow[t]{2}{*}{ Pelodiscus sinensis } & 中华鳖 & 未列 & 易危 & 何瑞国 & 生长期中华鳖饲料适宜能量、蛋白质水平及必需氨基酸模式的研究 \\
\hline & & 入 & $/ \mathrm{VU}$ & & \\
\hline \multirow[t]{2}{*}{ Pelodiscus sinensis } & 中华鳖 & 未列 & 易危 & 陈昌福 & 嗜水气单胞菌 BA-ELISA 的建立及其在病原检测中的应用 \\
\hline & & 入 & /VU & & \\
\hline \multirow[t]{2}{*}{ Pelodiscus sinensis } & 中华鳖 & 未列 & 易危 & 赵海泉 & 嗜水气单胞菌 T0608 菌株对中华鳖血液免疫相关指标的影响 \\
\hline & & 入 & /VU & & \\
\hline \multirow[t]{2}{*}{ Pelodiscus sinensis } & 中华鳖 & 未列 & 易危 & 郭琼林 & 嗜水气单胞菌感染的中华鳖主要器官差减 cDNA 文库的构建 \\
\hline & & 入 & /VU & & \\
\hline \multirow[t]{2}{*}{ Pelodiscus sinensis } & 中华鳖 & 未列 & 易危 & 艾晓辉 & 嗜水气单胞菌佐剂灭活苗免疫中华鳖抵抗嗜水气单胞菌的致死性感染 \\
\hline & & 入 & /VU & & \\
\hline \multirow[t]{2}{*}{ Pelodiscus sinensis } & 中华鳖 & 未列 & 易危 & 王志铮 & 四株鳖源致病性嗜水气单胞菌(Aeromonas hydrophila)的表型、分子鉴定及其毒力基因检测 \\
\hline & & $\lambda$ & $/ \mathrm{VU}$ & & \\
\hline
\end{tabular}


顾垒，闻丞，罗玫，王吴，吕植. 中国最受关注濒危物种保护现状快速评价的新方法探讨. 生物多样性，2015，23(5)：583-590. http://www. biodiversity-science. net/CN/article/downloadArticleFile. do?attachType=PDF\&id=10075

\begin{tabular}{|c|c|c|c|c|c|}
\hline \multirow[t]{2}{*}{ Pelodiscus sinensis } & 中华鳖 & 未列 & 易危 & 杨振才 & 饲料含盐量对稚鳖生长和咬伤后果的影响 \\
\hline & & 入 & /VU & & \\
\hline \multirow[t]{2}{*}{ Pelodiscus sinensis } & 中华鳖 & 未列 & 易危 & 杨振才 & 饲料膨化处理对中华鳖氮和能量收支的影响 \\
\hline & & 入 & /VU & & \\
\hline \multirow[t]{2}{*}{ Pelodiscus sinensis } & 中华鳖 & 未列 & 易危 & 聂月美 & 饲料维生素 C 对中华鳖免疫_抗应激和体组成的影响 \\
\hline & & 入 & /VU & & \\
\hline \multirow[t]{2}{*}{ Pelodiscus sinensis } & 中华鳖 & 未列 & 易危 & 王鸿泰 & 饲料质量与中华鳖白底板病的关系 \\
\hline & & 入 & /VU & & \\
\hline \multirow[t]{2}{*}{ Pelodiscus sinensis } & 中华鳖 & 未列 & 易危 & 邵庆均 & 饲料中 Vc 水平对中华鳖幼鳖生长及其组织中含量的影响 \\
\hline & & 入 & /VU & & \\
\hline \multirow[t]{2}{*}{ Pelodiscus sinensis } & 中华鳖 & 未列 & 易危 & 季高华 & 饲料中添加 B-葡聚糖和低聚果糖对中华鳖幼鳖生长和血清 SOD、溶菌酶活力的影响 \\
\hline & & 入 & /VU & & \\
\hline \multirow[t]{2}{*}{ Pelodiscus sinensis } & 中华鳖 & 未列 & 易危 & 肖明松 & 饲料中添加果寡糖和糖萜素对中华鳖消化酶活力的影响 \\
\hline & & 入 & /VU & & \\
\hline \multirow[t]{2}{*}{ Pelodiscus sinensis } & 中华鳖 & 未列 & 易危 & 蔡完其 & 饲料中添加花粉和酵母硒对中华鳖幼鳖生长和非特异性免疫功能的影响 \\
\hline & & 入 & /VU & & \\
\hline \multirow[t]{2}{*}{ Pelodiscus sinensis } & 中华鳖 & 未列 & 易危 & 宁运旺 & 饲料中添加螺旋藻对中华鳖生长的影响 \\
\hline & & 入 & /VU & & \\
\hline Pelodiscus sinensis & 中华鳖 & 未列 & 易危 & 钱国英 & 饲料种类对中华鳖营养成分的影响 \\
\hline
\end{tabular}


顾垒，闻丞，罗玫，王吴，吕植. 中国最受关注濒危物种保护现状快速评价的新方法探讨. 生物多样性，2015，23(5)：583-590. http://www biodiversity-science. net/CN/article/downloadArticleFile. do?attachType=PDF\&id=10075

\begin{tabular}{|c|c|c|c|c|c|}
\hline & & 入 & $/ \mathrm{VU}$ & & \\
\hline \multirow[t]{2}{*}{ Pelodiscus sinensis } & 中华鳖 & 未列 & 易危 & 康现江 & 塑膜大棚内中华鳖发育过程血清性激素与性腺发育的研究 \\
\hline & & 入 & $/ \mathrm{VU}$ & & \\
\hline \multirow[t]{2}{*}{ Pelodiscus sinensis } & 中华鳖 & 未列 & 易危 & 肖明松 & 糖萜素对中华鳖的生长性能及其血清生化指标的影响 \\
\hline & & 入 & /VU & & \\
\hline \multirow[t]{2}{*}{ Pelodiscus sinensis } & 中华鳖 & 未列 & 易危 & 林星 & 特异性鸡蛋抗体防治中华鳖红脖子病的初步研究 \\
\hline & & 入 & $/ \mathrm{VU}$ & & \\
\hline \multirow[t]{2}{*}{ Pelodiscus sinensis } & 中华鳖 & 未列 & 易危 & 李肖梁 & 特异性卵黄抗体添加剂对中华鳖摄食和生长的影响 \\
\hline & & 入 & /VU & & \\
\hline \multirow[t]{2}{*}{ Pelodiscus sinensis } & 中华鳖 & 未列 & 易危 & 牛翠娟 & 体质量对中华鳖(Pelodiscus sinensis)生化组成和质量能的影响 \\
\hline & & 入 & /VU & & \\
\hline \multirow[t]{2}{*}{ Pelodiscus sinensis } & 中华鳖 & 未列 & 易危 & 李本旺 & 投喂 3 种不同饲料的中华鳖品质比较分析及评价 \\
\hline & & 入 & /VU & & \\
\hline \multirow[t]{2}{*}{ Pelodiscus sinensis } & 中华鳖 & 未列 & 易危 & 牛翠娟 & 外源维生素 C 及冬眠对中华鳖稚鳖生长、维生素 C 合成和肝脏维生素 C 含量的影响 \\
\hline & & 入 & /VU & & \\
\hline \multirow[t]{2}{*}{ Pelodiscus sinensis } & 中华鳖 & 未列 & 易危 & 牛翠娟 & 完全或部分的食物剥夺对中华鳖( Pelodiscus sinensis) 幼体补偿生长反应的影响: 生长率 \\
\hline & & 入 & /VU & & 的时间变化模式与体组成的变化 \\
\hline \multirow[t]{2}{*}{ Pelodiscus sinensis } & 中华鳖 & 未列 & 易危 & 邵庆均 & 维生素 C 对中华鳖体组成及胶原蛋白含量的影响 \\
\hline & & 入 & $/ \mathrm{VU}$ & & \\
\hline
\end{tabular}


顾垒，闻丞，罗玫，王吴，吕植. 中国最受关注濒危物种保护现状快速评价的新方法探讨. 生物多样性，2015，23(5)：583-590. http://www. biodiversity-science. net/CN/article/downloadArticleFile. do?attachType=PDF\&id=10075

\begin{tabular}{|c|c|c|c|c|c|}
\hline \multirow[t]{2}{*}{ Pelodiscus sinensis } & 中华鳖 & 未列 & 易危 & 牛翠娟 & 维生素 $\mathrm{C}$ 和 $\mathrm{E}$ 合用对应激和非应激中华鳖幼鳖生长、肝脏维生素 $\mathrm{C}$ 和 $\mathrm{E}$ 以及血清皮质 \\
\hline & & 入 & $/ \mathrm{VU}$ & & 醇含量的影响 \\
\hline \multirow[t]{2}{*}{ Pelodiscus sinensis } & 中华鳖 & 未列 & 易危 & 牛翠娟 & 维生素 C 和 $\mathrm{E}$ 合用对中华鳖幼鳖非特异性免疫功能的影响 \\
\hline & & 入 & $/ \mathrm{VU}$ & & \\
\hline \multirow[t]{2}{*}{ Pelodiscus sinensis } & 中华鳖 & 未列 & 易危 & 周显青 & 维生素 C 和 $\mathrm{E}$ 混合饲喂对中华鳖幼鳖抗酸应激能力的影响 \\
\hline & & 入 & $/ \mathrm{VU}$ & & \\
\hline \multirow[t]{2}{*}{ Pelodiscus sinensis } & 中华鳖 & 未列 & 易危 & 牛翠娟 & 维生素 C 和酸应激对中华鳖幼鳖血清补体 C3 和 C4 含量的影响 \\
\hline & & 入 & $/ \mathrm{VU}$ & & \\
\hline \multirow[t]{2}{*}{ Pelodiscus sinensis } & 中华鳖 & 未列 & 易危 & 孙儒泳 & 维生素 $\mathrm{E}$ 对中华鳖幼鳖生长、肝脏维生素 $\mathrm{E}$ 以及血清皮质醇含量的影响 \\
\hline & & 入 & $/ \mathrm{VU}$ & & \\
\hline \multirow[t]{2}{*}{ Pelodiscus sinensis } & 中华鳖 & 未列 & 易危 & 蒋业林 & 温度・湿度・孵化介质对中华鳖睬化率的影响 \\
\hline & & 入 & $/ \mathrm{VU}$ & & \\
\hline \multirow[t]{2}{*}{ Pelodiscus sinensis } & 中华鳖 & 未列 & 易危 & 杨振才 & 温度对中华鳖卵睬化和胚胎发育的影响 \\
\hline & & 入 & $/ \mathrm{VU}$ & & \\
\hline \multirow[t]{2}{*}{ Pelodiscus sinensis } & 中华鳖 & 未列 & 易危 & 朱新平 & 温度对中华鳖胚胎发育和初生幼体形态特征及活动能力的影响 \\
\hline & & 入 & /VU & & \\
\hline \multirow[t]{2}{*}{ Pelodiscus sinensis } & 中华鳖 & 未列 & 易危 & 雷思佳 & 温度对中华鳖稚鳖氮收支的影响 \\
\hline & & 入 & $/ \mathrm{VU}$ & & \\
\hline Pelodiscus sinensis & 中华鳖 & 未列 & 易危 & 雷思佳 & 温度对中华鳖稚鳖最大摄食率、转化效率和生长的影响 \\
\hline
\end{tabular}


顾垒，闻丞，罗玫，王吴，吕植. 中国最受关注濒危物种保护现状快速评价的新方法探讨. 生物多样性，2015，23(5)：583-590. http://www. biodiversity-science. net/CN/article/downloadArticleFile. do?attachType=PDF\&id=10075

\begin{tabular}{|c|c|c|c|c|c|}
\hline & & 入 & $/ \mathrm{VU}$ & & \\
\hline \multirow[t]{2}{*}{ Pelodiscus sinensis } & 中华鳖 & 未列 & 易危 & 周显青 & 温度对中华大蟾蜍和中华鳖冬眠前离体红细胞免疫功能及其大小的影响 \\
\hline & & 入 & $/ \mathrm{VU}$ & & \\
\hline \multirow[t]{2}{*}{ Pelodiscus sinensis } & 中华鳖 & 未列 & 易危 & 李双安 & 五种变温动物抗凝血酶和纤溶酶原相对含量比较 \\
\hline & & 入 & $/ \mathrm{VU}$ & & \\
\hline \multirow[t]{2}{*}{ Pelodiscus sinensis } & 中华鳖 & 未列 & 易危 & 卢美浩 & 鲜活饵料防治中华鳖亲本白底板病试验初探 \\
\hline & & 入 & $/ \mathrm{VU}$ & & \\
\hline \multirow[t]{2}{*}{ Pelodiscus sinensis } & 中华鳖 & 未列 & 易危 & 刘丽艳 & 小凌河中华鳖自然保护区的管理及开发 \\
\hline & & 入 & $/ \mathrm{VU}$ & & \\
\hline \multirow[t]{2}{*}{ Pelodiscus sinensis } & 中华鳖 & 未列 & 易危 & 赵宏 & 小凌河中华鳖自然资源的保护途径 \\
\hline & & 入 & $/ \mathrm{VU}$ & & \\
\hline \multirow[t]{2}{*}{ Pelodiscus sinensis } & 中华鳖 & 未列 & 易危 & 陈秋生 & 雄性中华鳖生殖生物学特性研究 \\
\hline & & 入 & /VU & & \\
\hline \multirow[t]{2}{*}{ Pelodiscus sinensis } & 中华鳖 & 未列 & 易危 & 吴红松 & 休眠期中华鳖消化器官中主要消化酶活性分布 \\
\hline & & 入 & $/ \mathrm{VU}$ & & \\
\hline \multirow[t]{2}{*}{ Pelodiscus sinensis } & 中华鳖 & 未列 & 易危 & 郑济芳 & 扬子鳃与中华鳖的 Sox 基因研究 \\
\hline & & 入 & $/ \mathrm{VU}$ & & \\
\hline \multirow[t]{2}{*}{ Pelodiscus sinensis } & 中华鳖 & 未列 & 易危 & 陈永辉 & 养鳖池水体中优势菌的初步研究 \\
\hline & & 入 & /VU & & \\
\hline
\end{tabular}


顾垒，闻丞，罗玫，王吴，吕植. 中国最受关注濒危物种保护现状快速评价的新方法探讨. 生物多样性，2015，23(5)：583-590. http://www. biodiversity-science. net/CN/article/downloadArticleFile. do?attachType=PDF\&id=10075

\begin{tabular}{|c|c|c|c|c|c|}
\hline \multirow[t]{2}{*}{ Pelodiscus sinensis } & 中华鳖 & 未列 & 易危 & 管越强 & 养殖中华鳖肠道中芽狍杆菌的分离鉴定及其噬菌体的分离和性质分析 \\
\hline & & 入 & /VU & & \\
\hline \multirow[t]{2}{*}{ Pelodiscus sinensis } & 中华鳖 & 未列 & 易危 & 宋理平 & 野生与仿生中华鳖营养成分分析 \\
\hline & & 入 & /VU & & \\
\hline \multirow[t]{2}{*}{ Pelodiscus sinensis } & 中华鳖 & 未列 & 易危 & 赵玉蓉 & 一种复方植物提取物对中华鳖生长性能及血液生化指标的影响 \\
\hline & & 入 & /VU & & \\
\hline \multirow[t]{2}{*}{ Pelodiscus sinensis } & 中华鳖 & 未列 & 易危 & 马有智 & 一种中华鳖穿孔病病原菌的分离和特性研究 \\
\hline & & 入 & /VU & & \\
\hline \multirow[t]{2}{*}{ Pelodiscus sinensis } & 中华鳖 & 未列 & 易危 & 肖调义 & 一株嗜水气单胞菌对中华鳖腐皮症的致病性及其生物学特性研究 \\
\hline & & 入 & /VU & & \\
\hline \multirow[t]{2}{*}{ Pelodiscus sinensis } & 中华鳖 & 未列 & 易危 & 钱国英 & 遗传标记技术在中华鳖研究中的应用 \\
\hline & & 入 & $/ \mathrm{VU}$ & & \\
\hline \multirow[t]{2}{*}{ Pelodiscus sinensis } & 中华鳖 & 未列 & 易危 & 洪一江 & 英明中华鳖的选育及其养殖性能研究 \\
\hline & & 入 & /VU & & \\
\hline \multirow[t]{2}{*}{ Pelodiscus sinensis } & 中华鳖 & 未列 & 易危 & 何中央 & 蝇蛆蛋白粉在中华鳖日本品系饲料中应用效果初探 \\
\hline & & 入 & /VU & & \\
\hline \multirow[t]{2}{*}{ Pelodiscus sinensis } & 中华鳖 & 未列 & 易危 & 杨先乐 & 影响中华鳖免疫应答因素的探讨一 免疫原(菌苗)与环境条件 \\
\hline & & 入 & $/ \mathrm{VU}$ & & \\
\hline Pelodiscus sinensis & 中华鳖 & 未列 & 易危 & 钱国英 & 杂交对中华鳖遗传多样性的影响 \\
\hline
\end{tabular}


顾垒，闻丞，罗玫，王吴，吕植. 中国最受关注濒危物种保护现状快速评价的新方法探讨. 生物多样性，2015，23(5)：583-590. http://www. biodiversity-science, net/CN/article/downloadArticleFile, do?attachType=PDF\&id=10075

\begin{tabular}{|c|c|c|c|c|c|}
\hline & & 入 & $/ \mathrm{VU}$ & & \\
\hline \multirow[t]{2}{*}{ Pelodiscus sinensis } & 中华鳖 & 未列 & 易危 & 吴惠仙 & 浙江地区中华鳖腐皮病的病原与药敏研究 \\
\hline & & 入 & /VU & & \\
\hline \multirow[t]{2}{*}{ Pelodiscus sinensis } & 中华鳖 & 未列 & 易危 & 陈昌福 & 浙江余杭中华鳖暴发性疾病主要病原及诊断技术研究 \\
\hline & & 入 & /VU & & \\
\hline \multirow[t]{2}{*}{ Pelodiscus sinensis } & 中华鳖 & 未列 & 易危 & 王安利 & 植物蛋白部分替代鱼粉对中华鳖血清生化指标及非特异性免疫机能的影响 \\
\hline & & 入 & /VU & & \\
\hline \multirow[t]{2}{*}{ Pelodiscus sinensis } & 中华鳖 & 未列 & 易危 & 刘凯 & 致病性气单胞菌外膜蛋白型的差异分析 \\
\hline & & 入 & $/ \mathrm{VU}$ & & \\
\hline \multirow[t]{2}{*}{ Pelodiscus sinensis } & 中华鳖 & 未列 & 易危 & 张永正 & 中华鳖(Pelodiscus sinensis)5 个不同地理种群细胞色素 $\mathrm{b}$ 基因序列变异及种群遗传结构 \\
\hline & & 入 & /VU & & 分析 \\
\hline \multirow[t]{2}{*}{ Pelodiscus sinensis } & 中华鳖 & 未列 & 易危 & 黄鹤忠 & 中华鳖(Pelodiscus sinensis)EST-SSR 标记与生长性状相关性分析 \\
\hline & & 入 & /VU & & \\
\hline \multirow[t]{2}{*}{ Pelodiscus sinensis } & 中华鳖 & 未列 & 易危 & 张海琪 & 中华鳖(Pelodiscus sinensis)不同种群酪氨酸酶(TYR)基因的克隆及其多态性分析 \\
\hline & & 入 & /VU & & \\
\hline \multirow[t]{2}{*}{ Pelodiscus sinensis } & 中华鳖 & 未列 & 易危 & 陈健舜 & 中华鳖(Pelodiscus sinensis)摩氏摩根菌(Morganella morganii)的鉴定及致病性研究 \\
\hline & & 入 & /VU & & \\
\hline \multirow[t]{2}{*}{ Pelodiscus sinensis } & 中华鳖 & 未列 & 易危 & 赵忠添 & 中华鳘、黄沙鳖及黄沙鳖 F1 代生长性状比较分析 \\
\hline & & 入 & /VU & & \\
\hline
\end{tabular}


顾垒，闻丞，罗玫，王吴，吕植. 中国最受关注濒危物种保护现状快速评价的新方法探讨. 生物多样性，2015，23(5)：583-590. http://www. biodiversity-science. net/CN/article/downloadArticleFile. do?attachType=PDF\&id=10075

\begin{tabular}{|c|c|c|c|c|c|}
\hline \multirow[t]{2}{*}{ Pelodiscus sinensis } & 中华鳖 & 未列 & 易危 & 朱芸 & 中华鳖_浮肿病_病原菌的鉴定及迟钝爱德华氏菌溶血活化基因的克隆 \\
\hline & & 入 & $/ \mathrm{VU}$ & & \\
\hline \multirow[t]{2}{*}{ Pelodiscus sinensis } & 中华鳖 & 未列 & 易危 & 郑永华 & 中华鳖 “灹颈病” 病因学的初步研究 \\
\hline & & 入 & $/ \mathrm{VU}$ & & \\
\hline \multirow[t]{2}{*}{ Pelodiscus sinensis } & 中华鳖 & 未列 & 易危 & 颜远义 & 中华鳖 “拟白斑病”病原菌分离鉴定及药敏实验 \\
\hline & & 入 & $/ \mathrm{VU}$ & & \\
\hline \multirow[t]{2}{*}{ Pelodiscus sinensis } & 中华鳖 & 未列 & 易危 & 钟蕾 & 中华鳖 “腐皮、疤疮” 并发症致病菌的病原分离与药敏试验分析 \\
\hline & & 入 & $/ \mathrm{VU}$ & & \\
\hline \multirow[t]{2}{*}{ Pelodiscus sinensis } & 中华鳖 & 未列 & 易危 & 储卫华 & 中华鳖 “腐皮病” 病原的研究 \\
\hline & & 入 & $/ \mathrm{VU}$ & & \\
\hline \multirow[t]{2}{*}{ Pelodiscus sinensis } & 中华鳖 & 未列 & 易危 & 钱国英 & 中华鳖 3 个地理群体线粒体基因 D-loop 区遗传多样性分析 \\
\hline & & $\lambda$ & $/ \mathrm{VU}$ & & \\
\hline \multirow[t]{2}{*}{ Pelodiscus sinensis } & 中华鳖 & 未列 & 易危 & 聂刘旺 & 中华鳖 4 个 Sox 基因保守区的序列分析 \\
\hline & & 入 & $/ \mathrm{VU}$ & & \\
\hline \multirow[t]{2}{*}{ Pelodiscus sinensis } & 中华鳖 & 未列 & 易危 & 黄丽英 & 中华鳖 4 个不同种群的遗传结构和分子遗传标记研究 \\
\hline & & 入 & $/ \mathrm{VU}$ & & \\
\hline \multirow[t]{2}{*}{ Pelodiscus sinensis } & 中华鳖 & 未列 & 易危 & 朱新平 & 中华鳖 5 个不同群体的形态差异分析 \\
\hline & & 入 & $/ \mathrm{VU}$ & & \\
\hline Pelodiscus sinensis & 中华鳖 & 未列 & 易危 & 朱新平 & 中华鳖 5 个群体遗传多样性的微卫星分析 \\
\hline
\end{tabular}


顾垒，闻丞，罗玫，王吴，吕植. 中国最受关注濒危物种保护现状快速评价的新方法探讨. 生物多样性，2015，23(5)：583-590. http://www. biodiversity-science. net/CN/article/downloadArticleFile. do?attachType=PDF\&id=10075

\begin{tabular}{|c|c|c|c|c|c|}
\hline & & 入 & $/ \mathrm{VU}$ & & \\
\hline \multirow[t]{2}{*}{ Pelodiscus sinensis } & 中华鳖 & 未列 & 易危 & 陈献稿 & 中华鳖 5 群体稚鳖阶段养殖性能比较 \\
\hline & & 入 & $/ \mathrm{VU}$ & & \\
\hline \multirow{2}{*}{ Pelodiscus sinensis } & 中华鳖 & 未列 & 易危 & 曾令兵 & 中华鳖 5 种组织细胞的离体培养实验 \\
\hline & & 入 & $/ \mathrm{VU}$ & & \\
\hline \multirow[t]{2}{*}{ Pelodiscus sinensis } & 中华鳖 & 未列 & 易危 & 聂刘旺 & 中华鳖 7 种组织 SOX 基因表达的 RT-PCR 分析 \\
\hline & & 入 & $/ \mathrm{VU}$ & & \\
\hline \multirow[t]{2}{*}{ Pelodiscus sinensis } & 中华鳖 & 未列 & 易危 & 吴端生 & 中华鳖 HMG1 基因的克隆与序列分析 \\
\hline & & 入 & $/ \mathrm{VU}$ & & \\
\hline \multirow[t]{2}{*}{ Pelodiscus sinensis } & 中华鳖 & 未列 & 易危 & 李肖梁 & 中华鳖 MyD88 部分序列克隆及其在组织中的表达差异分析 \\
\hline & & 入 & $/ \mathrm{VU}$ & & \\
\hline \multirow[t]{2}{*}{ Pelodiscus sinensis } & 中华鳖 & 未列 & 易危 & 李肖梁 & 中华鳖 T L R 2 部分序列的克隆及其组织表达差异分析 \\
\hline & & 入 & /VU & & \\
\hline \multirow[t]{2}{*}{ Pelodiscus sinensis } & 中华鳖 & 未列 & 易危 & 潘晓艺 & 中华鳖爱德华菌病病原菌的分离鉴定及致病因子研究 \\
\hline & & 入 & /VU & & \\
\hline \multirow[t]{2}{*}{ Pelodiscus sinensis } & 中华鳖 & 未列 & 易危 & 江为民 & 中华鳖爱德华氏菌病的病原与防治研究 \\
\hline & & 入 & $/ \mathrm{VU}$ & & \\
\hline \multirow[t]{2}{*}{ Pelodiscus sinensis } & 中华鳖 & 未列 & 易危 & 祁保民 & 中华鳖白底板病病理形态学研究 \\
\hline & & 入 & /VU & & \\
\hline
\end{tabular}


顾垒，闻丞，罗玫，王吴，吕植. 中国最受关注濒危物种保护现状快速评价的新方法探讨. 生物多样性，2015，23(5)：583-590. http://www. biodiversity-science. net/CN/article/downloadArticleFile. do?attachType=PDF\&id=10075

\begin{tabular}{|c|c|c|c|c|c|}
\hline \multirow[t]{2}{*}{ Pelodiscus sinensis } & 中华鳖 & 未列 & 易危 & 沈锦玉 & 中华鳖白底板病病原的分析 \\
\hline & & 入 & $/ \mathrm{VU}$ & & \\
\hline \multirow[t]{2}{*}{ Pelodiscus sinensis } & 中华鳖 & 未列 & 易危 & 周兵 & 中华鳖白底板病病原体及组织病理研究 \\
\hline & & 入 & /VU & & \\
\hline \multirow[t]{2}{*}{ Pelodiscus sinensis } & 中华鳖 & 未列 & 易危 & 杨振才 & 中华鳖白底板病的病因和防治 \\
\hline & & $\lambda$ & $/ \mathrm{VU}$ & & \\
\hline \multirow[t]{2}{*}{ Pelodiscus sinensis } & 中华鳖 & 未列 & 易危 & 叶巧真 & 中华鳖白底板病和红底板病细菌的分离鉴定及致病性 \\
\hline & & 入 & $/ \mathrm{VU}$ & & \\
\hline \multirow[t]{2}{*}{ Pelodiscus sinensis } & 中华鳖 & 未列 & 易危 & 潘连德 & 中华鳖白底板病及有白底板症状疾病的诊断和控制 \\
\hline & & 入 & /VU & & \\
\hline \multirow[t]{2}{*}{ Pelodiscus sinensis } & 中华鳖 & 未列 & 易危 & 张俊杰 & 中华鳖白底板病综合防治研究进展 \\
\hline & & 入 & $/ \mathrm{VU}$ & & \\
\hline \multirow[t]{2}{*}{ Pelodiscus sinensis } & 中华鳖 & 未列 & 易危 & 江剑平 & 中华鳖白细胞发生的观察 \\
\hline & & 入 & /VU & & \\
\hline \multirow[t]{2}{*}{ Pelodiscus sinensis } & 中华鳖 & 未列 & 易危 & 胡广洲 & 中华鳖暴发性败血症的研究 \\
\hline & & 入 & /VU & & \\
\hline \multirow[t]{2}{*}{ Pelodiscus sinensis } & 中华鳖 & 未列 & 易危 & 宋铁英 & 中华鳖爆发性传染病研究: 不同生化类型嗜水气单胞菌 aer 基因的 PCR 比较 \\
\hline & & 入 & $/ \mathrm{VU}$ & & \\
\hline Pelodiscus sinensis & 中华鳖 & 未列 & 易危 & 何中央 & 中华鳖表达序列标签资源中的微卫星信息分析 \\
\hline
\end{tabular}


顾垒，闻丞，罗玫，王吴，吕植. 中国最受关注濒危物种保护现状快速评价的新方法探讨. 生物多样性，2015，23(5)：583-590. http://www. biodiversity-science. net/CN/article/downloadArticleFile. do?attachType=PDF\&id=10075

\begin{tabular}{|c|c|c|c|c|c|}
\hline & & 入 & $/ \mathrm{VU}$ & & \\
\hline \multirow[t]{2}{*}{ Pelodiscus sinensis } & 中华鳖 & 未列 & 易危 & 张奇亚 & 中华鳖病毒的血清学检测 \\
\hline & & 入 & $/ \mathrm{VU}$ & & \\
\hline \multirow{2}{*}{ Pelodiscus sinensis } & 中华鳖 & 未列 & 易危 & 王玲 & 中华鳖病毒和克氏原螯虾白斑综合征病毒危害机理和集成防治 \\
\hline & & $\lambda$ & $/ \mathrm{VU}$ & & \\
\hline \multirow[t]{2}{*}{ Pelodiscus sinensis } & 中华鳖 & 未列 & 易危 & 赵宝华 & 中华鳖病原菌菌种的分离鉴定及多重 $\mathrm{P} \mathrm{C} \mathrm{R}$ 的初步建立 \\
\hline & & 入 & $/ \mathrm{VU}$ & & \\
\hline \multirow[t]{2}{*}{ Pelodiscus sinensis } & 中华鳖 & 未列 & 易危 & 赵宝华 & 中华鳖病原维氏气单胞菌的分子鉴定及分子分类学研究 \\
\hline & & 入 & $/ \mathrm{VU}$ & & \\
\hline \multirow[t]{2}{*}{ Pelodiscus sinensis } & 中华鳖 & 未列 & 易危 & 李卫芬 & 中华鳖病原性维隆气单胞菌的分离及药敏试验 \\
\hline & & 入 & $/ \mathrm{VU}$ & & \\
\hline \multirow[t]{2}{*}{ Pelodiscus sinensis } & 中华鳖 & 未列 & 易危 & 钱国英 & 中华鳖不同地理群体遗传多样性研究 \\
\hline & & 入 & $/ \mathrm{VU}$ & & \\
\hline \multirow[t]{2}{*}{ Pelodiscus sinensis } & 中华鳖 & 未列 & 易危 & 段登选 & 中华鳖不同生态养殖模式对池塘水环境及养殖效果的影响 \\
\hline & & 入 & /VU & & \\
\hline \multirow[t]{2}{*}{ Pelodiscus sinensis } & 中华鳖 & 未列 & 易危 & 聂刘旺 & 中华鳖不同组织 Sox 基因表达的 RT- PCR 分析 \\
\hline & & 入 & $/ \mathrm{VU}$ & & \\
\hline \multirow[t]{2}{*}{ Pelodiscus sinensis } & 中华鳖 & 未列 & 易危 & 方维焕 & 中华鳖部分免疫相关基因克隆及其功能研究 \\
\hline & & 入 & /VU & & \\
\hline
\end{tabular}


顾垒，闻丞，罗玫，王吴，吕植. 中国最受关注濒危物种保护现状快速评价的新方法探讨. 生物多样性，2015，23(5)：583-590. http://www biodiversity-science. net/CN/article/downloadArticleFile. do?attachType=PDF\&id=10075

\begin{tabular}{|c|c|c|c|c|c|}
\hline \multirow[t]{2}{*}{ Pelodiscus sinensis } & 中华鳖 & 未列 & 易危 & 陈秋生 & 中华鳖肠道黏膜免疫相关细胞的形态学研究 \\
\hline & & 入 & /VU & & \\
\hline \multirow[t]{2}{*}{ Pelodiscus sinensis } & 中华鳖 & 未列 & 易危 & 陈秋生 & 中华鳖肠道黏膜上皮细胞的超微结构 \\
\hline & & 入 & /VU & & \\
\hline \multirow[t]{2}{*}{ Pelodiscus sinensis } & 中华鳖 & 未列 & 易危 & 赵宝华 & 中华鳖常见疾病的诊断及其综合防治 \\
\hline & & 入 & /VU & & \\
\hline \multirow[t]{2}{*}{ Pelodiscus sinensis } & 中华鳖 & 未列 & 易危 & 吴惠仙 & 中华鳖常见细菌病的病原鉴定及药物体外拮抗比较 \\
\hline & & 入 & /VU & & \\
\hline \multirow[t]{2}{*}{ Pelodiscus sinensis } & 中华鳖 & 未列 & 易危 & 石灵 & 中华鳖常见致病菌对 13 种抗菌药物的敏感性测定 \\
\hline & & 入 & /VU & & \\
\hline \multirow[t]{2}{*}{ Pelodiscus sinensis } & 中华鳖 & 未列 & 易危 & 张士峰 & 中华鳖成鳖对低蛋白饲料的适应性研究 \\
\hline & & 入 & $/ \mathrm{VU}$ & & \\
\hline \multirow[t]{2}{*}{ Pelodiscus sinensis } & 中华鳖 & 未列 & 易危 & 马黎 & 中华鳖成鳖集约化养殖中基础饲粮与核心料配方的优化篮选 \\
\hline & & 入 & /VU & & \\
\hline \multirow[t]{2}{*}{ Pelodiscus sinensis } & 中华鳖 & 未列 & 易危 & 吴惠仙 & 中华鳖出血性肠道坏死症病原及其药敏性 \\
\hline & & 入 & /VU & & \\
\hline \multirow[t]{2}{*}{ Pelodiscus sinensis } & 中华鳖 & 未列 & 易危 & 罗晓松 & 中华鳖出血性肠道坏死症及中草药防治实验 \\
\hline & & 入 & $/ \mathrm{VU}$ & & \\
\hline Pelodiscus sinensis & 中华鳖 & 未列 & 易危 & 吴礼龙 & 中华鳖出血性肠炎的药物防治研究 \\
\hline
\end{tabular}


顾垒，闻丞，罗玫，王吴，吕植. 中国最受关注濒危物种保护现状快速评价的新方法探讨．生物多样性，2015，23(5)：583-590。 http://www. biodiversity-science. net/CN/article/downloadArticleFile. do?attachType=PDF\&id=10075

\begin{tabular}{|c|c|c|c|c|c|}
\hline & & 入 & $/ \mathrm{VU}$ & & \\
\hline \multirow[t]{2}{*}{ Pelodiscus sinensis } & 中华鳖 & 未列 & 易危 & 张元柱 & 中华鳖穿孔病的血液病理研究 \\
\hline & & 入 & $/ \mathrm{VU}$ & & \\
\hline \multirow[t]{2}{*}{ Pelodiscus sinensis } & 中华鳖 & 未列 & 易危 & 朱炳全 & 中华鳖的孵化技术 \\
\hline & & 入 & /VU & & \\
\hline \multirow[t]{2}{*}{ Pelodiscus sinensis } & 中华鳖 & 未列 & 易危 & 王海文 & 中华鳖的人工加温养殖操作规程 \\
\hline & & 入 & $/ \mathrm{VU}$ & & \\
\hline \multirow[t]{2}{*}{ Pelodiscus sinensis } & 中华鳖 & 未列 & 易危 & 王晓清 & 中华鳖的体重与形态特征的关联分析 \\
\hline & & 入 & $/ \mathrm{VU}$ & & \\
\hline \multirow[t]{2}{*}{ Pelodiscus sinensis } & 中华鳖 & 未列 & 易危 & 叶均安 & 中华鳖的消化道指数和血液生化指标 \\
\hline & & 入 & /VU & & \\
\hline \multirow[t]{2}{*}{ Pelodiscus sinensis } & 中华鳖 & 未列 & 易危 & 朱道玉 & 中华鳖的性别决定 \\
\hline & & 入 & $/ \mathrm{VU}$ & & \\
\hline \multirow[t]{2}{*}{ Pelodiscus sinensis } & 中华鳖 & 未列 & 易危 & 聂刘旺 & 中华鳖的性别决定机制 \\
\hline & & 入 & $/ \mathrm{VU}$ & & \\
\hline \multirow[t]{2}{*}{ Pelodiscus sinensis } & 中华鳖 & 未列 & 易危 & 钱国英 & 中华鳖的营养研究 \\
\hline & & 入 & $/ \mathrm{VU}$ & & \\
\hline \multirow[t]{2}{*}{ Pelodiscus sinensis } & 中华鳖 & 未列 & 易危 & 刘云 & 中华鳖冬眠期与活动期部分生理生化性质的比较研究 \\
\hline & & 入 & /VU & & \\
\hline
\end{tabular}


顾垒，闻丞，罗玫，王吴，吕植. 中国最受关注濒危物种保护现状快速评价的新方法探讨. 生物多样性，2015，23(5)：583-590. http://www. biodiversity-science. net/CN/article/downloadArticleFile. do?attachType=PDF\&id=10075

\begin{tabular}{|c|c|c|c|c|c|}
\hline \multirow[t]{2}{*}{ Pelodiscus sinensis } & 中华鳖 & 未列 & 易危 & 朱新平 & 中华鳖洞庭湖群体、黄河群体及其杂交种稚幼体生长对比试验 \\
\hline & & 入 & /VU & & \\
\hline \multirow[t]{2}{*}{ Pelodiscus sinensis } & 中华鳖 & 未列 & 易危 & 杨先乐 & 中华鳖对 T3 菌苗的回忆应答 \\
\hline & & 入 & /VU & & \\
\hline \multirow[t]{2}{*}{ Pelodiscus sinensis } & 中华鳖 & 未列 & 易危 & 杨先乐 & 中华鳖对 T3 菌苗抗原的免疫应答 \\
\hline & & 入 & /VU & & \\
\hline \multirow[t]{2}{*}{ Pelodiscus sinensis } & 中华鳖 & 未列 & 易危 & 高永利 & 中华鳖对低蛋白和红鱼粉饲料利用的研究 \\
\hline & & 入 & /VU & & \\
\hline \multirow[t]{2}{*}{ Pelodiscus sinensis } & 中华鳖 & 未列 & 易危 & 陈昌福 & 中华鳖对嗜水气单胞菌粗脂多糖(LPS)的免疫应答 \\
\hline & & 入 & /VU & & \\
\hline \multirow[t]{2}{*}{ Pelodiscus sinensis } & 中华鳖 & 未列 & 易危 & 齐占会 & 中华鳖对饲料蛋白质水平适应性研究 \\
\hline & & 入 & $/ \mathrm{VU}$ & & \\
\hline \multirow[t]{2}{*}{ Pelodiscus sinensis } & 中华鳖 & 未列 & 易危 & 孙红祥 & 中华鳖对温和气单胞菌口服微球缓释疫苗的免疫应答 \\
\hline & & 入 & /VU & & \\
\hline \multirow[t]{2}{*}{ Pelodiscus sinensis } & 中华鳖 & 未列 & 易危 & 沈锦玉 & 中华鳖对温和气单胞菌体液免疫应答规律的研究 \\
\hline & & 入 & /VU & & \\
\hline \multirow[t]{2}{*}{ Pelodiscus sinensis } & 中华鳖 & 未列 & 易危 & 郝玉江 & 中华鳖对养殖环境的生态需求及调控措施 \\
\hline & & 入 & $/ \mathrm{VU}$ & & \\
\hline Pelodiscus sinensis & 中华鳖 & 未列 & 易危 & 马艳霞 & 中华鳖放养密度对养殖效果的影响 \\
\hline
\end{tabular}


顾垒，闻丞，罗玫，王吴，吕植. 中国最受关注濒危物种保护现状快速评价的新方法探讨. 生物多样性，2015，23(5)：583-590. http://www. biodiversity-science. net/CN/article/downloadArticleFile. do?attachType=PDF\&id=10075

\begin{tabular}{|c|c|c|c|c|c|}
\hline & & 入 & $/ \mathrm{VU}$ & & \\
\hline \multirow[t]{2}{*}{ Pelodiscus sinensis } & 中华鳖 & 未列 & 易危 & 刘至治 & 中华鳖非特异性免疫功能的群体差异研究 \\
\hline & & 入 & $/ \mathrm{VU}$ & & \\
\hline \multirow[t]{2}{*}{ Pelodiscus sinensis } & 中华鳖 & 未列 & 易危 & 徐海圣 & 中华鳖肺炎克雷伯氏菌病的病原研究 \\
\hline & & 入 & $/ \mathrm{VU}$ & & \\
\hline \multirow[t]{2}{*}{ Pelodiscus sinensis } & 中华鳖 & 未列 & 易危 & 朱睦元 & 中华鳖稃化一周胚胎的肾脏/尿生殖嵴混合组织的 cDNA 文库构建与特征 \\
\hline & & 入 & $/ \mathrm{VU}$ & & \\
\hline \multirow[t]{2}{*}{ Pelodiscus sinensis } & 中华鳖 & 未列 & 易危 & 林启存 & 中华鳖弗氏柠檬酸杆菌败血症病原分离鉴定与药敏试验 \\
\hline & & 入 & $/ \mathrm{VU}$ & & \\
\hline \multirow[t]{2}{*}{ Pelodiscus sinensis } & 中华鳖 & 未列 & 易危 & 田飞炎 & 中华鳖弗氏柠檬酸杆菌的分离、鉴定及药物敏感性试验 \\
\hline & & 入 & $/ \mathrm{VU}$ & & \\
\hline \multirow[t]{2}{*}{ Pelodiscus sinensis } & 中华鳖 & 未列 & 易危 & 黄钧 & 中华鳖浮肿病致病菌的分离与鉴定 \\
\hline & & 入 & $/ \mathrm{VU}$ & & \\
\hline \multirow[t]{2}{*}{ Pelodiscus sinensis } & 中华鳖 & 未列 & 易危 & 吴惠仙 & 中华鳖腐皮病的病理组织学研究 \\
\hline & & 入 & $/ \mathrm{VU}$ & & \\
\hline \multirow[t]{2}{*}{ Pelodiscus sinensis } & 中华鳖 & 未列 & 易危 & 肖调义 & 中华鳖腐皮病的病原鉴定与药敏试验 \\
\hline & & 入 & $/ \mathrm{VU}$ & & \\
\hline \multirow[t]{2}{*}{ Pelodiscus sinensis } & 中华鳖 & 未列 & 易危 & 张泰蒂 & 中华鳖腐皮病的药物控制 \\
\hline & & 入 & /VU & & \\
\hline
\end{tabular}


顾垒，闻丞，罗玫，王吴，吕植. 中国最受关注濒危物种保护现状快速评价的新方法探讨. 生物多样性，2015，23(5)：583-590. http://www biodiversity-science. net/CN/article/downloadArticleFile. do?attachType=PDF\&id=10075

\begin{tabular}{|c|c|c|c|c|c|}
\hline \multirow[t]{2}{*}{ Pelodiscus sinensis } & 中华鳖 & 未列 & 易危 & 薛红玲 & 中华鳖腐皮病防治的研究 \\
\hline & & 入 & /VU & & \\
\hline \multirow[t]{2}{*}{ Pelodiscus sinensis } & 中华鳖 & 未列 & 易危 & 林稚兰 & 中华鳖肝金属硫蛋白的分离、纯化及鉴定 \\
\hline & & 入 & /VU & & \\
\hline \multirow[t]{2}{*}{ Pelodiscus sinensis } & 中华鳖 & 未列 & 易危 & 陆红法 & 中华鳖肝脏蛋白磷酸酶的酶学特性分析 \\
\hline & & 入 & /VU & & \\
\hline \multirow[t]{2}{*}{ Pelodiscus sinensis } & 中华鳖 & 未列 & 易危 & 陆红法 & 中华鳖肝脏蛋白磷酸酶的提取纯化及其酶学特性研究 \\
\hline & & 入 & /VU & & \\
\hline \multirow[t]{2}{*}{ Pelodiscus sinensis } & 中华鳖 & 未列 & 易危 & 姚卫建 & 中华鳖工厂化养殖技术: 亲鳖产卵和鳖卵孵化试验 \\
\hline & & 入 & /VU & & \\
\hline \multirow[t]{2}{*}{ Pelodiscus sinensis } & 中华鳖 & 未列 & 易危 & 姚卫建 & 中华鳖工厂化养殖技术 II 中华鳖病防治药物的分类、选购与使用 \\
\hline & & 入 & $/ \mathrm{VU}$ & & \\
\hline \multirow[t]{2}{*}{ Pelodiscus sinensis } & 中华鳖 & 未列 & 易危 & 姚雁鸿 & 中华鳖和台湾鳖的同工酶初步比较 \\
\hline & & 入 & /VU & & \\
\hline \multirow[t]{2}{*}{ Pelodiscus sinensis } & 中华鳖 & 未列 & 易危 & 刘凯 & 中华鳖和杂交鳢血清免疫球蛋白免疫印迹和酶联免疫分析 \\
\hline & & 入 & /VU & & \\
\hline \multirow[t]{2}{*}{ Pelodiscus sinensis } & 中华鳖 & 未列 & 易危 & 虞蕴如 & 中华鳘红脖子、红底板病的病原分离鉴定 \\
\hline & & 入 & $/ \mathrm{VU}$ & & \\
\hline Pelodiscus sinensis & 中华鳖 & 未列 & 易危 & 江剑平 & 中华鳖红细胞发育过程的观察 \\
\hline
\end{tabular}


顾垒，闻丞，罗玫，王吴，吕植. 中国最受关注濒危物种保护现状快速评价的新方法探讨. 生物多样性，2015，23(5)：583-590. http://www. biodiversity-science. net/CN/article/downloadArticleFile. do?attachType=PDF\&id=10075

\begin{tabular}{|c|c|c|c|c|c|}
\hline & & 入 & $/ \mathrm{VU}$ & & \\
\hline \multirow[t]{2}{*}{ Pelodiscus sinensis } & 中华鳖 & 未列 & 易危 & 朱春华 & 中华鳖虹彩病毒单克隆抗体的制备_特性分析及应用研究 \\
\hline & & 入 & $/ \mathrm{VU}$ & & \\
\hline \multirow[t]{2}{*}{ Pelodiscus sinensis } & 中华鳖 & 未列 & 易危 & 林天龙 & 中华鳖虹彩病毒单克隆抗体的制备及其抗原表位的初步分析 \\
\hline & & 入 & $/ \mathrm{VU}$ & & \\
\hline \multirow[t]{2}{*}{ Pelodiscus sinensis } & 中华鳖 & 未列 & 易危 & 林天龙 & 中华鳖虹彩病毒的纯化及分析 \\
\hline & & 入 & $/ \mathrm{VU}$ & & \\
\hline \multirow[t]{2}{*}{ Pelodiscus sinensis } & 中华鳖 & 未列 & 易危 & 李思发 & 中华鳖黄河群体 F1、F2、F3 世代选育效应的评估 \\
\hline & & 入 & $/ \mathrm{VU}$ & & \\
\hline \multirow[t]{2}{*}{ Pelodiscus sinensis } & 中华鳖 & 未列 & 易危 & 李思发 & 中华鳖黄河群体选育 F1-3 世代生长性能比较试验 \\
\hline & & 入 & $/ \mathrm{VU}$ & & \\
\hline \multirow[t]{2}{*}{ Pelodiscus sinensis } & 中华鳖 & 未列 & 易危 & 李思发 & 中华鳖黄河群体选育 F3 与大陆代表性群体遗传变异的微卫星分析 \\
\hline & & 入 & /VU & & \\
\hline \multirow[t]{2}{*}{ Pelodiscus sinensis } & 中华鳖 & 未列 & 易危 & 李思发 & 中华鳖黄河群体选育世代 F1 、F2 及 F3 遗传变异微卫星分析 \\
\hline & & 入 & $/ \mathrm{VU}$ & & \\
\hline \multirow[t]{2}{*}{ Pelodiscus sinensis } & 中华鳖 & 未列 & 易危 & 何中央 & 中华鳖肌肉组织双向电泳的条件优化 \\
\hline & & 入 & $/ \mathrm{VU}$ & & \\
\hline \multirow[t]{2}{*}{ Pelodiscus sinensis } & 中华鳖 & 未列 & 易危 & 彭巧玲 & 中华鳖及中国平胸龟线粒体全基因组研究 \\
\hline & & 入 & /VU & & \\
\hline
\end{tabular}


顾垒，闻丞，罗玫，王吴，吕植. 中国最受关注濒危物种保护现状快速评价的新方法探讨. 生物多样性，2015，23(5)：583-590. http://www. biodiversity-science. net/CN/article/downloadArticleFile. do?attachType=PDF\&id=10075

\begin{tabular}{|c|c|c|c|c|c|}
\hline \multirow[t]{2}{*}{ Pelodiscus sinensis } & 中华鳖 & 未列 & 易危 & 陆承平 & 中华鳖急性出血性综合症的病原学研究 \\
\hline & & 入 & /VU & & \\
\hline \multirow[t]{2}{*}{ Pelodiscus sinensis } & 中华鳖 & 未列 & 易危 & 赵宝华 & 中华鳖疾病综合防控技术的研究 \\
\hline & & 入 & /VU & & \\
\hline \multirow[t]{2}{*}{ Pelodiscus sinensis } & 中华鳖 & 未列 & 易危 & 孙红祥 & 中华鳖几种常见疾病病原的分离鉴定及药敏试验 \\
\hline & & 入 & /VU & & \\
\hline \multirow[t]{2}{*}{ Pelodiscus sinensis } & 中华鳖 & 未列 & 易危 & 周本翔 & 中华鳖健康养殖方式的新探讨 \\
\hline & & 入 & $/ \mathrm{VU}$ & & \\
\hline \multirow[t]{2}{*}{ Pelodiscus sinensis } & 中华鳖 & 未列 & 易危 & 李世敏 & 中华鳖健康养殖模式对成鳖营养成分的影响 \\
\hline & & 入 & /VU & & \\
\hline \multirow[t]{2}{*}{ Pelodiscus sinensis } & 中华鳖 & 未列 & 易危 & 朱道玉 & 中华鳖精巢发育的组织学观察 \\
\hline & & 入 & $/ \mathrm{VU}$ & & \\
\hline \multirow[t]{2}{*}{ Pelodiscus sinensis } & 中华鳖 & 未列 & 易危 & 李林春 & 中华鳖精液保存技术研究 \\
\hline & & 入 & /VU & & \\
\hline \multirow[t]{2}{*}{ Pelodiscus sinensis } & 中华鳖 & 未列 & 易危 & 陈秋生 & 中华鳖精子的超微结构 \\
\hline & & 入 & /VU & & \\
\hline \multirow[t]{2}{*}{ Pelodiscus sinensis } & 中华鳖 & 未列 & 易危 & 陈秋生 & 中华鳘精子的储存及其相关结构研究 \\
\hline & & 入 & $/ \mathrm{VU}$ & & \\
\hline Pelodiscus sinensis & 中华鳖 & 未列 & 易危 & 陈秋生 & 中华鳖精子头部的形成 \\
\hline
\end{tabular}


顾垒，闻丞，罗玫，王吴，吕植. 中国最受关注濒危物种保护现状快速评价的新方法探讨. 生物多样性，2015，23(5)：583-590. http://www. biodiversity-science. net/CN/article/downloadArticleFile. do?attachType=PDF\&id=10075

\begin{tabular}{|c|c|c|c|c|c|}
\hline & & 入 & $/ \mathrm{VU}$ & & \\
\hline \multirow[t]{2}{*}{ Pelodiscus sinensis } & 中华鳖 & 未列 & 易危 & 杨春明 & 中华鳖抗病优质养殖技术的研究 \\
\hline & & 入 & $/ \mathrm{VU}$ & & \\
\hline \multirow[t]{2}{*}{ Pelodiscus sinensis } & 中华鳖 & 未列 & 易危 & 赵宝华 & 中华鳖抗菌肽 Hepcidin 成熟肽基因的克隆及同源性的初步研究 \\
\hline & & 入 & /VU & & \\
\hline \multirow[t]{2}{*}{ Pelodiscus sinensis } & 中华鳖 & 未列 & 易危 & 王金锋 & 中华鳖抗嗜水气单胞菌 SRAP 分子标记的篮选 \\
\hline & & 入 & $/ \mathrm{VU}$ & & \\
\hline \multirow[t]{2}{*}{ Pelodiscus sinensis } & 中华鳖 & 未列 & 易危 & 李本旺 & 中华鳖口咽腔溃烂综合症病原的研究 \\
\hline & & 入 & /VU & & \\
\hline \multirow[t]{2}{*}{ Pelodiscus sinensis } & 中华鳖 & 未列 & 易危 & 梁红蕾 & 中华鳖两个地理群体遗传多样性的 ISSR 分析 \\
\hline & & 入 & $/ \mathrm{VU}$ & & \\
\hline \multirow[t]{2}{*}{ Pelodiscus sinensis } & 中华鳖 & 未列 & 易危 & 鲍传和 & 中华鳖两个地理种群遗传多样性的 ISSR 分析 \\
\hline & & 入 & /VU & & \\
\hline \multirow[t]{2}{*}{ Pelodiscus sinensis } & 中华鳖 & 未列 & 易危 & 赵宝华 & 中华鳖两株气单胞菌外膜蛋白及 IL_8 的克隆与表达 \\
\hline & & 入 & /VU & & \\
\hline \multirow[t]{2}{*}{ Pelodiscus sinensis } & 中华鳖 & 未列 & 易危 & 王军萍 & 中华鳖淋巴心的组织学研究 \\
\hline & & 入 & /VU & & \\
\hline \multirow[t]{2}{*}{ Pelodiscus sinensis } & 中华鳖 & 未列 & 易危 & 吴惠仙 & 中华鳖六株病原菌的分类鉴定及其中草药拮抗研究 \\
\hline & & 入 & /VU & & \\
\hline
\end{tabular}


顾垒，闻丞，罗玫，王吴，吕植. 中国最受关注濒危物种保护现状快速评价的新方法探讨. 生物多样性，2015，23(5)：583-590. http://www. biodiversity-science. net/CN/article/downloadArticleFile. do?attachType=PDF\&id=10075

\begin{tabular}{|c|c|c|c|c|c|}
\hline \multirow[t]{2}{*}{ Pelodiscus sinensis } & 中华鳖 & 未列 & 易危 & 朱道玉 & 中华鳖卵巢的发育 \\
\hline & & $\lambda$ & /VU & & \\
\hline \multirow[t]{2}{*}{ Pelodiscus sinensis } & 中华鳖 & 未列 & 易危 & 朱道玉 & 中华鳖卵的形态结构 \\
\hline & & 入 & /VU & & \\
\hline \multirow[t]{2}{*}{ Pelodiscus sinensis } & 中华鳖 & 未列 & 易危 & 杜卫国 & 中华鳖卵睬化过程中物质和能量的动态 \\
\hline & & $\lambda$ & /VU & & \\
\hline \multirow[t]{2}{*}{ Pelodiscus sinensis } & 中华鳖 & 未列 & 易危 & 段彪 & 中华鳖卵孵化生态的探讨 \\
\hline & & 入 & /VU & & \\
\hline \multirow[t]{2}{*}{ Pelodiscus sinensis } & 中华鳖 & 未列 & 易危 & 简纪常 & 中华鳖卵黄抗体的检测 \\
\hline & & 入 & /VU & & \\
\hline \multirow[t]{2}{*}{ Pelodiscus sinensis } & 中华鳖 & 未列 & 易危 & 蔡亚非 & 中华鳖卵泡免疫组织化学研究 \\
\hline & & 入 & /VU & & \\
\hline \multirow[t]{2}{*}{ Pelodiscus sinensis } & 中华鳖 & 未列 & 易危 & 陈秋生 & 中华鳖卵子发生与卵黄形成的细胞学研究 \\
\hline & & $\lambda$ & /VU & & \\
\hline \multirow[t]{2}{*}{ Pelodiscus sinensis } & 中华鳖 & 未列 & 易危 & 简纪常 & 中华鳖免疫球蛋白的理化特性一一中华鳖 IgM 对 2-巯基乙醇敏感性、与人 IgM 的同源 \\
\hline & & 入 & /VU & & 性及其相对分子质量的研究 \\
\hline \multirow[t]{2}{*}{ Pelodiscus sinensis } & 中华鳖 & 未列 & 易危 & 徐镇 & 中华鳖免疫球蛋白连接链和重链基因与抗体产生规律 \\
\hline & & 入 & /VU & & \\
\hline Pelodiscus sinensis & 中华鳖 & 未列 & 易危 & 陈秋生 & 中华鳖脑垂体的显微与超微结构观察 \\
\hline
\end{tabular}


顾垒，闻丞，罗玫，王吴，吕植. 中国最受关注濒危物种保护现状快速评价的新方法探讨. 生物多样性，2015，23(5)：583-590. http://www. biodiversity-science. net/CN/article/downloadArticleFile. do?attachType=PDF\&id=10075

\begin{tabular}{|c|c|c|c|c|c|}
\hline & & 入 & $/ \mathrm{VU}$ & & \\
\hline \multirow[t]{2}{*}{ Pelodiscus sinensis } & 中华鳖 & 未列 & 易危 & 朱道玉 & 中华鳖胚胎肾脏的发育 \\
\hline & & 入 & $/ \mathrm{VU}$ & & \\
\hline \multirow[t]{2}{*}{ Pelodiscus sinensis } & 中华鳖 & 未列 & 易危 & 吴康 & 中华鳖胚胎细胞体外培养的研究 \\
\hline & & 入 & /VU & & \\
\hline \multirow[t]{2}{*}{ Pelodiscus sinensis } & 中华鳖 & 未列 & 易危 & 何中央 & 中华鳖培育新品种群体遗传多样性的比较研究 \\
\hline & & 入 & $/ \mathrm{VU}$ & & \\
\hline \multirow[t]{2}{*}{ Pelodiscus sinensis } & 中华鳖 & 未列 & 易危 & 方维焕 & 中华鳖脾淋巴细胞体外转化的实验条件研究 \\
\hline & & 入 & /VU & & \\
\hline \multirow[t]{2}{*}{ Pelodiscus sinensis } & 中华鳖 & 未列 & 易危 & 陈秋生 & 中华鳖脾脏的特殊结构及雄激素受体 mRNA 表达 \\
\hline & & 入 & /VU & & \\
\hline \multirow[t]{2}{*}{ Pelodiscus sinensis } & 中华鳖 & 未列 & 易危 & 陈秋生 & 中华鳖脾脏网状纤维的结构与分布特征 \\
\hline & & 入 & $/ \mathrm{VU}$ & & \\
\hline \multirow[t]{2}{*}{ Pelodiscus sinensis } & 中华鳖 & 未列 & 易危 & 陈秋生 & 中华鳖脾脏雄激素受体 mRNA 的原位杂交检测 \\
\hline & & 入 & $/ \mathrm{VU}$ & & \\
\hline \multirow[t]{2}{*}{ Pelodiscus sinensis } & 中华鳖 & 未列 & 易危 & 李思发 & 中华鳘七群体体形和腹部黑斑图案的差异比较 \\
\hline & & 入 & $/ \mathrm{VU}$ & & \\
\hline \multirow[t]{2}{*}{ Pelodiscus sinensis } & 中华鳖 & 未列 & 易危 & 蔡完其 & 中华鳖七群体稚鳖) 成鳖阶段养殖性能评估 \\
\hline & & 入 & /VU & & \\
\hline
\end{tabular}


顾垒，闻丞，罗玫，王吴，吕植. 中国最受关注濒危物种保护现状快速评价的新方法探讨. 生物多样性，2015，23(5)：583-590. http://www. biodiversity-science. net/CN/article/downloadArticleFile. do?attachType=PDF\&id=10075

\begin{tabular}{|c|c|c|c|c|c|}
\hline \multirow[t]{2}{*}{ Pelodiscus sinensis } & 中华鳖 & 未列 & 易危 & 王小君 & 中华鳖气单孢菌类疾病研究 \\
\hline & & 入 & /VU & & \\
\hline \multirow[t]{2}{*}{ Pelodiscus sinensis } & 中华鳖 & 未列 & 易危 & 叶巧真 & 中华鳖气单胞菌菌细胞苗和菌化学成份疫苗研制 \\
\hline & & 入 & /VU & & \\
\hline \multirow[t]{2}{*}{ Pelodiscus sinensis } & 中华鳖 & 未列 & 易危 & 张敏 & 中华鳖全血呼吸爆发化学发光检测方法的建立 \\
\hline & & 入 & /VU & & \\
\hline \multirow[t]{2}{*}{ Pelodiscus sinensis } & 中华鳖 & 未列 & 易危 & 钱国英 & 中华鳖群体 DNA 指纹分析中的 RAPD 技术优化 \\
\hline & & 入 & $/ \mathrm{VU}$ & & \\
\hline \multirow[t]{2}{*}{ Pelodiscus sinensis } & 中华鳖 & 未列 & 易危 & 蔡完其 & 中华鳖群体间编码 MHC I 类分子 a 2 结构域基因的克隆及序列分析 \\
\hline & & 入 & /VU & & \\
\hline \multirow[t]{2}{*}{ Pelodiscus sinensis } & 中华鳖 & 未列 & 易危 & 赵宝华 & 中华鳖群体死亡症病原菌的分离鉴定及其预防的研究 \\
\hline & & 入 & $/ \mathrm{VU}$ & & \\
\hline \multirow[t]{2}{*}{ Pelodiscus sinensis } & 中华鳖 & 未列 & 易危 & 龚建辉 & 中华鳖人工繁殖不同雌雄配比对捊化率的影响研究 \\
\hline & & 入 & /VU & & \\
\hline \multirow[t]{2}{*}{ Pelodiscus sinensis } & 中华鳖 & 未列 & 易危 & 龚建辉 & 中华鳖人工繁殖不同雌雄配比对受精率和睬化率的影响研究 \\
\hline & & 入 & /VU & & \\
\hline \multirow[t]{2}{*}{ Pelodiscus sinensis } & 中华鳖 & 未列 & 易危 & 李林春 & 中华鳖人工授精技术研究 \\
\hline & & 入 & $/ \mathrm{VU}$ & & \\
\hline Pelodiscus sinensis & 中华鳖 & 未列 & 易危 & 孟庆辉 & 中华鳖日本品系、清溪乌鳖及其杂交子代微卫星分析 \\
\hline
\end{tabular}


顾垒，闻丞，罗玫，王吴，吕植. 中国最受关注濒危物种保护现状快速评价的新方法探讨. 生物多样性，2015，23(5)：583-590. http://www. biodiversity-science. net/CN/article/downloadArticleFile. do?attachType=PDF\&id=10075

\begin{tabular}{|c|c|c|c|c|c|}
\hline & & 入 & $/ \mathrm{VU}$ & & \\
\hline \multirow[t]{2}{*}{ Pelodiscus sinensis } & 中华鳖 & 未列 & 易危 & 何中央 & 中华鳖日本品系和清溪乌鳖线粒体 $12 \mathrm{~S}$ rRNA 基因部分序列分析 \\
\hline & & 入 & $/ \mathrm{VU}$ & & \\
\hline \multirow{2}{*}{ Pelodiscus sinensis } & 中华鳖 & 未列 & 易危 & 张海琪 & 中华鳖日本品系体内氟苯尼考药物代谢动力学研究 \\
\hline & & $\lambda$ & /VU & & \\
\hline \multirow[t]{2}{*}{ Pelodiscus sinensis } & 中华鳖 & 未列 & 易危 & 孙红祥 & 中华鳖溶血性腹水病病原菌的分离鉴定及药敏性研究 \\
\hline & & 入 & $/ \mathrm{VU}$ & & \\
\hline \multirow[t]{2}{*}{ Pelodiscus sinensis } & 中华鳖 & 未列 & 易危 & 陈秋生 & 中华鳖肾脏 ACE2 基因克隆及其遗传进化分析 \\
\hline & & 入 & /VU & & \\
\hline \multirow[t]{2}{*}{ Pelodiscus sinensis } & 中华鳖 & 未列 & 易危 & 陈秋生 & 中华鳖肾脏的组织化学特性研究 \\
\hline & & 入 & /VU & & \\
\hline \multirow[t]{2}{*}{ Pelodiscus sinensis } & 中华鳖 & 未列 & 易危 & 钱利纯 & 中华鳖生理生化参数研究 \\
\hline & & 入 & /VU & & \\
\hline \multirow[t]{2}{*}{ Pelodiscus sinensis } & 中华鳖 & 未列 & 易危 & 茅树杰 & 中华鳖生态养殖过程中的健康管理 \\
\hline & & 入 & /VU & & \\
\hline \multirow[t]{2}{*}{ Pelodiscus sinensis } & 中华鳖 & 未列 & 易危 & 郝玉江 & 中华鳖生态养殖模式的原理、结构和特点 \\
\hline & & 入 & /VU & & \\
\hline \multirow[t]{2}{*}{ Pelodiscus sinensis } & 中华鳖 & 未列 & 易危 & 赵汉取 & 中华鳖生态养殖期的死亡率及其在不同池塘环境下的差异 \\
\hline & & 入 & /VU & & \\
\hline
\end{tabular}


顾垒，闻丞，罗玫，王吴，吕植. 中国最受关注濒危物种保护现状快速评价的新方法探讨. 生物多样性，2015，23(5)：583-590. http://www. biodiversity-science. net/CN/article/downloadArticleFile. do?attachType=PDF\&id=10075

\begin{tabular}{|c|c|c|c|c|c|}
\hline \multirow[t]{2}{*}{ Pelodiscus sinensis } & 中华鳖 & 未列 & 易危 & 陈蓝荪 & 中华鳖市场分析及其养殖对策 \\
\hline & & 入 & /VU & & \\
\hline \multirow[t]{2}{*}{ Pelodiscus sinensis } & 中华鳖 & 未列 & 易危 & 陈建酬 & 中华鳖嗜水气单胞菌病的研究 \\
\hline & & 入 & /VU & & \\
\hline \multirow[t]{2}{*}{ Pelodiscus sinensis } & 中华鳖 & 未列 & 易危 & 张林 & 中华鳖嗜水气单胞菌的生物学特性 \\
\hline & & 入 & /VU & & \\
\hline \multirow[t]{2}{*}{ Pelodiscus sinensis } & 中华鳖 & 未列 & 易危 & 潘连德 & 中华鳖嗜中性粒细胞吞噬功能的研究 \\
\hline & & 入 & $/ \mathrm{VU}$ & & \\
\hline \multirow[t]{2}{*}{ Pelodiscus sinensis } & 中华鳖 & 未列 & 易危 & 陈秋生 & 中华鳖输卵管雄激素受体的分布 \\
\hline & & 入 & $/ \mathrm{VU}$ & & \\
\hline \multirow[t]{2}{*}{ Pelodiscus sinensis } & 中华鳖 & 未列 & 易危 & 陈秋生 & 中华鳖输卵管组织细胞学特征及其功能意义 \\
\hline & & 入 & $/ \mathrm{VU}$ & & \\
\hline \multirow[t]{2}{*}{ Pelodiscus sinensis } & 中华鳖 & 未列 & 易危 & 蔡完其 & 中华鳖太湖群体和台湾群体非特异性免疫功能比较 \\
\hline & & 入 & /VU & & \\
\hline \multirow[t]{2}{*}{ Pelodiscus sinensis } & 中华鳖 & 未列 & 易危 & 张海琪 & 中华鳖太湖养殖种群和日本引进种群线粒体 DNA Cyt b 基因片段序列分析及分子进化初 \\
\hline & & 入 & /VU & & 探 \\
\hline \multirow[t]{2}{*}{ Pelodiscus sinensis } & 中华鳖 & 未列 & 易危 & 熊良伟 & 中华鳖太湖种群淋巴细胞培养及染色体核型分析 \\
\hline & & 入 & /VU & & \\
\hline Pelodiscus sinensis & 中华鳖 & 未列 & 易危 & 李登峰 & 中华鳖体表和体内菌群多样性分析 \\
\hline
\end{tabular}


顾垒，闻丞，罗玫，王吴，吕植. 中国最受关注濒危物种保护现状快速评价的新方法探讨. 生物多样性，2015，23(5)：583-590. http://www. biodiversity-science. net/CN/article/downloadArticleFile. do?attachType=PDF\&id=10075

\begin{tabular}{|c|c|c|c|c|c|}
\hline & & 入 & $/ \mathrm{VU}$ & & \\
\hline \multirow[t]{2}{*}{ Pelodiscus sinensis } & 中华鳖 & 未列 & 易危 & 许梓荣 & 中华鳖体内 Vc 合成及其对饲料 Vc 需求的研究 \\
\hline & & 入 & $/ \mathrm{VU}$ & & \\
\hline \multirow{2}{*}{ Pelodiscus sinensis } & 中华鳖 & 未列 & 易危 & 王鸣 & 中华鳖外塘养殖技术 \\
\hline & & 入 & $/ \mathrm{VU}$ & & \\
\hline \multirow[t]{2}{*}{ Pelodiscus sinensis } & 中华鳖 & 未列 & 易危 & 刘金兰 & 中华鳖外周血细胞病理显微结构研究 \\
\hline & & 入 & $/ \mathrm{VU}$ & & \\
\hline \multirow[t]{2}{*}{ Pelodiscus sinensis } & 中华鳖 & 未列 & 易危 & 孙效文 & 中华鳖微卫星座位的分离与鉴定 \\
\hline & & 入 & $/ \mathrm{VU}$ & & \\
\hline \multirow[t]{2}{*}{ Pelodiscus sinensis } & 中华鳖 & 未列 & 易危 & 陈秋生 & 中华鳖胃肠道 5-羟色胺和胃泌素内分泌细胞的免疫细胞化学研究 \\
\hline & & 入 & $/ \mathrm{VU}$ & & \\
\hline \multirow[t]{2}{*}{ Pelodiscus sinensis } & 中华鳖 & 未列 & 易危 & 林树根 & 中华鳖胃肠胰内分泌细胞的鉴定与定位 \\
\hline & & 入 & $/ \mathrm{VU}$ & & \\
\hline \multirow[t]{2}{*}{ Pelodiscus sinensis } & 中华鳖 & 未列 & 易危 & 梁福广 & 中华鳖胃的显微和亚显微结构 \\
\hline & & 入 & $/ \mathrm{VU}$ & & \\
\hline \multirow[t]{2}{*}{ Pelodiscus sinensis } & 中华鳖 & 未列 & 易危 & 陈秋生 & 中华鳖胃黏膜和胃腺上皮细胞的超微结构 \\
\hline & & 入 & $/ \mathrm{VU}$ & & \\
\hline \multirow[t]{2}{*}{ Pelodiscus sinensis } & 中华鳖 & 未列 & 易危 & 马有智 & 中华鳖温和气单胞菌病的病原研究 \\
\hline & & 入 & /VU & & \\
\hline
\end{tabular}


顾垒，闻丞，罗玫，王吴，吕植. 中国最受关注濒危物种保护现状快速评价的新方法探讨. 生物多样性，2015，23(5)：583-590. http://www biodiversity-science. net/CN/article/downloadArticleFile. do?attachType=PDF\&id=10075

\begin{tabular}{|c|c|c|c|c|c|}
\hline \multirow[t]{2}{*}{ Pelodiscus sinensis } & 中华鳖 & 未列 & 易危 & 蔡完其 & 中华鳖温和气单胞菌病对其免疫功能的影响 \\
\hline & & 入 & /VU & & \\
\hline \multirow[t]{2}{*}{ Pelodiscus sinensis } & 中华鳖 & 未列 & 易危 & 孙红祥 & 中华鳖温和气单胞菌口服缓释微球疫苗的研究: 疫苗生产菌株灭活方法的优化 \\
\hline & & 入 & /VU & & \\
\hline \multirow[t]{2}{*}{ Pelodiscus sinensis } & 中华鳖 & 未列 & 易危 & 孙红祥 & 中华鳖温和气单胞菌口服缓释微球疫苗的研究: 疫苗用菌液培养条件的优化 \\
\hline & & 入 & /VU & & \\
\hline \multirow[t]{2}{*}{ Pelodiscus sinensis } & 中华鳖 & 未列 & 易危 & 王秀菊 & 中华鳖无公害养殖技术研究 \\
\hline & & 入 & $/ \mathrm{VU}$ & & \\
\hline \multirow[t]{2}{*}{ Pelodiscus sinensis } & 中华鳖 & 未列 & 易危 & 蔡完其 & 中华鳖五群体遗传变异的 RAPD 分析 \\
\hline & & 入 & /VU & & \\
\hline \multirow[t]{2}{*}{ Pelodiscus sinensis } & 中华鳖 & 未列 & 易危 & 沈锦玉 & 中华鳖细菌性疾病免疫防治的研究 \\
\hline & & 入 & $/ \mathrm{VU}$ & & \\
\hline \multirow[t]{2}{*}{ Pelodiscus sinensis } & 中华鳖 & 未列 & 易危 & 沈锦玉 & 中华鳖细菌疫苗免疫佐剂的篮选及其初步应用 \\
\hline & & 入 & /VU & & \\
\hline \multirow[t]{2}{*}{ Pelodiscus sinensis } & 中华鳖 & 未列 & 易危 & 聂刘旺 & 中华鳖线粒体基因组序列分析 \\
\hline & & 入 & /VU & & \\
\hline \multirow[t]{2}{*}{ Pelodiscus sinensis } & 中华鳖 & 未列 & 易危 & 章群 & 中华鳖线粒体遗传变异的细胞色素 $\mathrm{b}$ 序列分析 \\
\hline & & 入 & $/ \mathrm{VU}$ & & \\
\hline Pelodiscus sinensis & 中华鳖 & 未列 & 易危 & 刘岗 & 中华鳖消化道固有层免疫细胞的形态学观察 \\
\hline
\end{tabular}


顾垒，闻丞，罗玫，王吴，吕植. 中国最受关注濒危物种保护现状快速评价的新方法探讨. 生物多样性，2015，23(5)：583-590. http://www. biodiversity-science. net/CN/article/downloadArticleFile. do?attachType=PDF\&id=10075

\begin{tabular}{|c|c|c|c|c|c|}
\hline & & 入 & $/ \mathrm{VU}$ & & \\
\hline \multirow[t]{2}{*}{ Pelodiscus sinensis } & 中华鳖 & 未列 & 易危 & 肖明松 & 中华鳖消化系统组织学的研究 \\
\hline & & 入 & $/ \mathrm{VU}$ & & \\
\hline \multirow{2}{*}{ Pelodiscus sinensis } & 中华鳖 & 未列 & 易危 & 潘连德 & 中华鳖小肠出血病的组织病理学诊断 \\
\hline & & 入 & $/ \mathrm{VU}$ & & \\
\hline \multirow[t]{2}{*}{ Pelodiscus sinensis } & 中华鳖 & 未列 & 易危 & 李正秋 & 中华鳖心组织成纤维细胞系的建立及特性 \\
\hline & & 入 & $/ \mathrm{VU}$ & & \\
\hline \multirow[t]{2}{*}{ Pelodiscus sinensis } & 中华鳖 & 未列 & 易危 & 计翔 & 中华鳖新捊幼体的热耐受性、体温昼夜变化和运动能力的热依赖性 \\
\hline & & 入 & $/ \mathrm{VU}$ & & \\
\hline \multirow[t]{2}{*}{ Pelodiscus sinensis } & 中华鳖 & 未列 & 易危 & 朱新平 & 中华鳖形态_遗传与生长分析 \\
\hline & & 入 & $/ \mathrm{VU}$ & & \\
\hline \multirow[t]{2}{*}{ Pelodiscus sinensis } & 中华鳖 & 未列 & 易危 & 孙西寨 & 中华鳖性别分化和睬化温度关系的研究 \\
\hline & & 入 & $/ \mathrm{VU}$ & & \\
\hline \multirow[t]{2}{*}{ Pelodiscus sinensis } & 中华鳖 & 未列 & 易危 & 朱道玉 & 中华鳖性别决定敏感期的研究 \\
\hline & & 入 & $/ \mathrm{VU}$ & & \\
\hline \multirow[t]{2}{*}{ Pelodiscus sinensis } & 中华鳖 & 未列 & 易危 & 朱道玉 & 中华鳖性腺的发生与发育研究 \\
\hline & & 入 & $/ \mathrm{VU}$ & & \\
\hline \multirow[t]{2}{*}{ Pelodiscus sinensis } & 中华鳖 & 未列 & 易危 & 王军萍 & 中华鳖血清蛋白聚丙烯酰胺凝胶电泳的初步分析 \\
\hline & & 入 & /VU & & \\
\hline
\end{tabular}


顾垒，闻丞，罗玫，王吴，吕植. 中国最受关注濒危物种保护现状快速评价的新方法探讨. 生物多样性，2015，23(5)：583-590. http://www. biodiversity-science. net/CN/article/downloadArticleFile. do?attachType=PDF\&id=10075

\begin{tabular}{|c|c|c|c|c|c|}
\hline \multirow[t]{2}{*}{ Pelodiscus sinensis } & 中华鳖 & 未列 & 易危 & 简纪常 & 中华鳖血清中抗体含量的研究 \\
\hline & & 入 & /VU & & \\
\hline \multirow[t]{2}{*}{ Pelodiscus sinensis } & 中华鳖 & 未列 & 易危 & 李双安 & 中华鳖血液凝固特性研究 \\
\hline & & 入 & /VU & & \\
\hline \multirow[t]{2}{*}{ Pelodiscus sinensis } & 中华鳖 & 未列 & 易危 & 王军萍 & 中华鳖血液生物化学指标的研究 \\
\hline & & 入 & /VU & & \\
\hline \multirow[t]{2}{*}{ Pelodiscus sinensis } & 中华鳖 & 未列 & 易危 & 朱道玉 & 中华鳖眼睛发育的形态及组织学观察 \\
\hline & & 入 & $/ \mathrm{VU}$ & & \\
\hline \multirow[t]{2}{*}{ Pelodiscus sinensis } & 中华鳖 & 未列 & 易危 & 唐金生生 & 中华鳖养殖技术研究进展 \\
\hline & & 入 & $/ \mathrm{VU}$ & & \\
\hline \multirow[t]{2}{*}{ Pelodiscus sinensis } & 中华鳖 & 未列 & 易危 & 徐寿山 & 中华鳖养殖生产现状及有关问题探讨 \\
\hline & & 入 & $/ \mathrm{VU}$ & & \\
\hline \multirow[t]{2}{*}{ Pelodiscus sinensis } & 中华鳖 & 未列 & 易危 & 张否 & 中华鳖养殖水体的环境因子调查与机体致病菌研究 \\
\hline & & 入 & /VU & & \\
\hline \multirow[t]{2}{*}{ Pelodiscus sinensis } & 中华鳖 & 未列 & 易危 & 管越强 & 中华鳖养殖水体理化指标及浮游植物的研究 \\
\hline & & 入 & /VU & & \\
\hline \multirow[t]{2}{*}{ Pelodiscus sinensis } & 中华鳖 & 未列 & 易危 & 张耀红 & 中华殂养殖用微生态制剂的研制及应用效果评价 \\
\hline & & 入 & $/ \mathrm{VU}$ & & \\
\hline Pelodiscus sinensis & 中华鳖 & 未列 & 易危 & 潘连德 & 中华鳖药源性肝病及其转归模型的构建和组织病理研究 \\
\hline
\end{tabular}


顾垒，闻丞，罗玫，王吴，吕植. 中国最受关注濒危物种保护现状快速评价的新方法探讨. 生物多样性，2015，23(5)：583-590. http://www. biodiversity-science. net/CN/article/downloadArticleFile. do?attachType=PDF\&id=10075

\begin{tabular}{|c|c|c|c|c|c|}
\hline & & 入 & $/ \mathrm{VU}$ & & \\
\hline \multirow[t]{2}{*}{ Pelodiscus sinensis } & 中华鳖 & 未列 & 易危 & 潘连德 & 中华鳖药源性肝病模型的构建及其病理学观察 \\
\hline & & 入 & $/ \mathrm{VU}$ & & \\
\hline \multirow[t]{2}{*}{ Pelodiscus sinensis } & 中华鳖 & 未列 & 易危 & 张轩杰 & 中华鳖与砂鳖线粒体 DNA $12 \mathrm{~S}$ rRNA 基因序列的比较分析和分子鉴定标记 \\
\hline & & 入 & $/ \mathrm{VU}$ & & \\
\hline \multirow[t]{2}{*}{ Pelodiscus sinensis } & 中华鳖 & 未列 & 易危 & 王晓清 & 中华鳖原生态养殖技术研究 \\
\hline & & 入 & $/ \mathrm{VU}$ & & \\
\hline \multirow[t]{2}{*}{ Pelodiscus sinensis } & 中华鳖 & 未列 & 易危 & 谢 晶 & 中华鳖在温室养殖、仿生态养殖条件下的营养成分比较研究 \\
\hline & & 入 & $/ \mathrm{VU}$ & & \\
\hline \multirow[t]{2}{*}{ Pelodiscus sinensis } & 中华鳖 & 未列 & 易危 & 郭琼林 & 中华鳖造血和免疫器官的个体发育 \\
\hline & & 入 & $/ \mathrm{VU}$ & & \\
\hline \multirow[t]{2}{*}{ Pelodiscus sinensis } & 中华鳖 & 未列 & 易危 & 向静 & 中华鳖粘液性肠炎病与出血性肠炎病的流行病学 \\
\hline & & 入 & /VU & & \\
\hline \multirow[t]{2}{*}{ Pelodiscus sinensis } & 中华鳖 & 未列 & 易危 & 汤显春 & 中华鳖致病病原菌的分离及药物试验研究 \\
\hline & & 入 & $/ \mathrm{VU}$ & & \\
\hline \multirow[t]{2}{*}{ Pelodiscus sinensis } & 中华鳖 & 未列 & 易危 & 姜兰 & 中华鳖致病性蜡样芽孢杆菌的分离鉴定与特性分析 \\
\hline & & 入 & $/ \mathrm{VU}$ & & \\
\hline \multirow[t]{2}{*}{ Pelodiscus sinensis } & 中华鳖 & 未列 & 易危 & 邓舜洲 & 中华鳖致病性嗜水气单胞菌的分离鉴定及药敏试验 \\
\hline & & 入 & /VU & & \\
\hline
\end{tabular}


顾垒，闻丞，罗玫，王吴，吕植. 中国最受关注濒危物种保护现状快速评价的新方法探讨. 生物多样性，2015，23(5)：583-590. http://www. biodiversity-science. net/CN/article/downloadArticleFile. do?attachType=PDF\&id=10075

\begin{tabular}{|c|c|c|c|c|c|}
\hline \multirow[t]{2}{*}{ Pelodiscus sinensis } & 中华鳖 & 未列 & 易危 & 邓舜洲 & 中华鳖致病性嗜水气单胞菌分离鉴定与药敏试验 \\
\hline & & 入 & $/ \mathrm{VU}$ & & \\
\hline \multirow[t]{2}{*}{ Pelodiscus sinensis } & 中华鳖 & 未列 & 易危 & 杨振才 & 中华鳖稚鳖继饥饿后的补偿生长研究 \\
\hline & & 入 & $/ \mathrm{VU}$ & & \\
\hline \multirow[t]{2}{*}{ Pelodiscus sinensis } & 中华鳖 & 未列 & 易危 & 肖亚梅 & 中华鳖种群 RAPD 分析 \\
\hline & & 入 & /VU & & \\
\hline \multirow[t]{2}{*}{ Pelodiscus sinensis } & 中华鳖 & 未列 & 易危 & 黄丽英 & 中华鳖种质资源的研究现状及保护、利用对策 \\
\hline & & 入 & $/ \mathrm{VU}$ & & \\
\hline \multirow[t]{2}{*}{ Pelodiscus sinensis } & 中华鳖 & 未列 & 易危 & 王志铮 & 注射鳖源致病性嗜水气单胞菌 ZHYYZ-1 引发中华鳖(Trionyx sinensis)稚鳖感染和致死的 \\
\hline & & 入 & /VU & & 定量研究 \\
\hline \multirow[t]{2}{*}{ Pelodiscus sinensis } & 中华鳖 & 未列 & 易危 & 牛翠娟 & 注射壳聚糖对氨氮胁迫下中华鳖(Pelodiscus sinensis)血细胞形态及白细胞分型的影响 \\
\hline & & 入 & $/ \mathrm{VU}$ & & \\
\hline \multirow[t]{2}{*}{ Perisoreus internigrans } & 黑头噪鸦 & 未列 & 易危 & & Alloparenting in the Rare Sichuan Jay (Perisoreus internigrans) \\
\hline & & 入 & $/ \mathrm{VU}$ & & \\
\hline \multirow[t]{2}{*}{ Perisoreus internigrans } & 黑头噪鸦 & 未列 & 易危 & & Assessing the Distributions and Potential Risks from Climate Change for the Sichuan Jay \\
\hline & & 入 & $/ \mathrm{VU}$ & & (Perisoreus internigrans) \\
\hline \multirow[t]{2}{*}{ Perisoreus internigrans } & 黑头噪鸦 & 未列 & 易危 & & Homerange, population density, and habitat utilization of the Sichuan Jay( Perisoreus \\
\hline & & 入 & $/ \mathrm{VU}$ & & internigrans) \\
\hline Perisoreus internigrans & 黑头噪鸦 & 未列 & 易危 & & The distribution and status of Sichuan Grey Jay (Perisoreus internigrans) \\
\hline
\end{tabular}


顾垒，闻丞，罗玫，王吴，吕植. 中国最受关注濒危物种保护现状快速评价的新方法探讨. 生物多样性，2015，23(5)：583-590. http://www. biodiversity-science. net/CN/article/downloadArticleFile. do?attachType=PDF\&id=10075

\begin{tabular}{|c|c|c|c|c|c|}
\hline & & 入 & $/ \mathrm{VU}$ & & \\
\hline \multirow[t]{2}{*}{ Perisoreus internigrans } & 黑头噪鸦 & 未列 & 易危 & & The social unit and habitat of the Sichuan jay (Perisoreus internigrans) in Zhuoni, Gansu, China \\
\hline & & 入 & /VU & & \\
\hline \multirow[t]{2}{*}{ Perisoreus internigrans } & 黑头噪鸦 & 未列 & 易危 & & 黑头噪鸦的繁殖及生活史特征 \\
\hline & & 入 & /VU & & \\
\hline \multirow[t]{2}{*}{ Perisoreus internigrans } & 黑头噪鸦 & 未列 & 易危 & & 黑头噪鸦的鸣声分析及其繁殖行为联系 \\
\hline & & 入 & /VU & & \\
\hline \multirow[t]{2}{*}{ Phodilus badius } & 栗鸮 & II & 无危 & 李肇天 & 广西邦亮长臂猿自然保护区的鸟类 \\
\hline & & & $/ \mathrm{LC}$ & & \\
\hline \multirow[t]{2}{*}{ Phodilus badius } & 栗鸮 & II & 无危 & 滕丽微 & 栗鸮繁殖习性的观察 \\
\hline & & & $/ \mathrm{LC}$ & & \\
\hline \multirow[t]{2}{*}{ Phodilus badius } & 栗鸮 & II & 无危 & 胡 箭 & 铜壁关自然保护区鸟类区系研究 \\
\hline & & & $/ \mathrm{LC}$ & & \\
\hline \multirow[t]{2}{*}{ Phoebe nanmu } & 滇楠 & II & 濒危 & 孙祥水 & 间伐对楠木杉木混交林生长影响的研究 \\
\hline & & & /EN & & \\
\hline \multirow[t]{2}{*}{ Phoebe zhennan } & 楠木 & II & 易危 & 蔡世锋 & 26 年生楠木人工林和杉木人工林 C 库及分配 \\
\hline & & & /VU & & \\
\hline \multirow[t]{2}{*}{ Phoebe zhennan } & 楠木 & II & 易危 & 彭龙福 & 35 年生楠木人工林生物量及生产力的研究 \\
\hline & & & /VU & & \\
\hline
\end{tabular}


顾垒，闻丞，罗玫，王吴，吕植. 中国最受关注濒危物种保护现状快速评价的新方法探讨. 生物多样性，2015，23(5)：583-590. http://www. biodiversity-science. net/CN/article/downloadArticleFile. do?attachType=PDF\&id=10075

\begin{tabular}{|c|c|c|c|c|c|}
\hline Phoebe zhennan & 楠木 & II & $\begin{array}{l}\text { 易危 } \\
\text { /VU }\end{array}$ & 童再康 & 4 种楠木 AFLP 反应体系优化建立 \\
\hline Phoebe zhennan & 楠木 & II & $\begin{array}{l}\text { 易危 } \\
\text { /VU }\end{array}$ & 奉向阳 & GGR6 对楠木春季造林的效果研究 \\
\hline Phoebe zhennan & 楠木 & II & $\begin{array}{l}\text { 易危 } \\
\text { /VU }\end{array}$ & LU Chang-tai & Study on the Landscape Application of Phoebe zhennan in Chengdu Campagna \\
\hline Phoebe zhennan & 楠木 & II & $\begin{array}{l}\text { 易危 } \\
\text { /VU }\end{array}$ & 尉海东 & 不同发育阶段楠木人工林生态系统碳则量研究 \\
\hline Phoebe zhennan & 楠木 & II & $\begin{array}{l}\text { 易危 } \\
\text { /VU }\end{array}$ & 黄晓蓉 & 不同基质对三种樟科植物种子萌发及幼苗生长的影响 \\
\hline Phoebe zhennan & 楠木 & II & $\begin{array}{l}\text { 易危 } \\
\text { /VU }\end{array}$ & 彭龙福 & 不同立地条件楠木人工林养分研究 \\
\hline Phoebe zhennan & 楠木 & II & $\begin{array}{l}\text { 易危 } \\
\text { /VU }\end{array}$ & 陈淑容 & 不同立地因子对楠木生长的影响 \\
\hline Phoebe zhennan & 楠木 & II & $\begin{array}{l}\text { 易危 } \\
\text { /VU }\end{array}$ & 彭龙福 & 不同林分密度楠木人工林生物量初步研究 \\
\hline Phoebe zhennan & 楠木 & II & $\begin{array}{l}\text { 易危 } \\
\text { /VU }\end{array}$ & 林思祖 & 不同密度与立地楠木人工林生物生长特性与养分的研究 \\
\hline Phoebe zhennan & 楠木 & II & 易危 & 陈恩群 & 不同郁闭度人工林套种楠木影响研究 \\
\hline
\end{tabular}


顾垒，闻丞，罗玫，王吴，吕植. 中国最受关注濒危物种保护现状快速评价的新方法探讨. 生物多样性，2015，23(5)：583-590. http://www. biodiversity-science. net/CN/article/downloadArticleFile. do?attachType=PDF\&id=10075

\begin{tabular}{|c|c|c|c|c|c|}
\hline & & & $/ \mathrm{VU}$ & & \\
\hline \multirow[t]{2}{*}{ Phoebe zhennan } & 楠木 & II & 易危 & 欧阳勋志 & 多因子对楠木容器苗造林生长影响的分析 \\
\hline & & & $/ \mathrm{VU}$ & & \\
\hline \multirow[t]{2}{*}{ Phoebe zhennan } & 楠木 & II & 易危 & 陈德叶 & 福建柏等 4 个珍贵树种人工纯林涵养水源研究 \\
\hline & & & /VU & & \\
\hline \multirow[t]{2}{*}{ Phoebe zhennan } & 楠木 & II & 易危 & 郑金兴 & 福建南平 $35 \mathrm{a}$ 生楠木林生态系统碳库及分配 \\
\hline & & & /VU & & \\
\hline \multirow[t]{2}{*}{ Phoebe zhennan } & 楠木 & II & 易危 & 杨柳林 & 福建樟湖 35 年生楠木人工林水源涵养功能研究 \\
\hline & & & /VU & & \\
\hline \multirow[t]{2}{*}{ Phoebe zhennan } & 楠木 & II & 易危 & 陈勇 & 格氏栲等 3 种珍贵用材树种栽培模式研究 \\
\hline & & & $/ \mathrm{VU}$ & & \\
\hline \multirow[t]{2}{*}{ Phoebe zhennan } & 楠木 & II & 易危 & 吴载璋 & 光照条件对楠木人工林生长的影响 \\
\hline & & & /VU & & \\
\hline \multirow[t]{2}{*}{ Phoebe zhennan } & 楠木 & II & 易危 & 喻勋林 & 湖南永顺楠木林群落研究 \\
\hline & & & /VU & & \\
\hline \multirow[t]{2}{*}{ Phoebe zhennan } & 楠木 & II & 易危 & 廖为民 & 基于 FORECAST 模型的楠木人工林固碳量研究 \\
\hline & & & /VU & & \\
\hline \multirow[t]{2}{*}{ Phoebe zhennan } & 楠木 & II & 易危 & 刘苑秋 & 基于 FORECAST 模型楠木人工林碳储量及 NPP 的研究 \\
\hline & & & /VU & & \\
\hline
\end{tabular}


顾垒，闻丞，罗玫，王吴，吕植. 中国最受关注濒危物种保护现状快速评价的新方法探讨. 生物多样性，2015，23(5)：583-590. http://www. biodiversity-science. net/CN/article/downloadArticleFile. do?attachType=PDF\&id=10075

\begin{tabular}{|c|c|c|c|c|c|}
\hline Phoebe zhennan & 楠木 & II & $\begin{array}{l}\text { 易危 } \\
\text { /VU }\end{array}$ & 谢耿雄 & 基于多项生长指标的楠木胸径估测模型研究 \\
\hline Phoebe zhennan & 楠木 & II & $\begin{array}{l}\text { 易危 } \\
\text { /VU }\end{array}$ & 徐有明 & 基质组配和缓释肥施肥量对楠木容器苗质量的影响 \\
\hline Phoebe zhennan & 楠木 & II & $\begin{array}{l}\text { 易危 } \\
\text { /VU }\end{array}$ & 孙祥水 & 间伐对楠木杉木混交林生长影响的研究 \\
\hline Phoebe zhennan & 楠木 & II & $\begin{array}{l}\text { 易危 } \\
\text { /VU }\end{array}$ & 李海燕 & 江汉平原地区 3 种楠属植物叶片生长规律的研究 \\
\hline Phoebe zhennan & 楠木 & II & $\begin{array}{l}\text { 易危 } \\
\text { /VU }\end{array}$ & 张群英 & 密度和施肥对楠木播种苗生长的影响 \\
\hline Phoebe zhennan & 楠木 & II & $\begin{array}{l}\text { 易危 } \\
\text { /VU }\end{array}$ & 林思祖 & 密度与立地异质空间条件下楠木人工林生物量与养分研究 \\
\hline Phoebe zhennan & 楠木 & II & $\begin{array}{l}\text { 易危 } \\
\text { /VU }\end{array}$ & 马祥庆 & 南方主要造林树种对异质供磷及邻株竞争的适应机制 \\
\hline Phoebe zhennan & 楠木 & II & $\begin{array}{l}\text { 易危 } \\
\text { /VU }\end{array}$ & 邱盛樑 & 楠木不同混交造林模式的生长效果比较 \\
\hline Phoebe zhennan & 楠木 & II & $\begin{array}{l}\text { 易危 } \\
\text { /VU }\end{array}$ & 黄萍 & 楠木轻基质容器袋育苗技术 \\
\hline Phoebe zhennan & 楠木 & II & 易危 & 吴旺民 & 楠木人工近熟林林分结构与生长规律 \\
\hline
\end{tabular}


顾垒，闻丞，罗玫，王吴，吕植. 中国最受关注濒危物种保护现状快速评价的新方法探讨. 生物多样性，2015，23(5)：583-590. http://www. biodiversity-science. net/CN/article/downloadArticleFile. do?attachType=PDF\&id=10075

\begin{tabular}{|c|c|c|c|c|c|}
\hline & & & $/ \mathrm{VU}$ & & \\
\hline \multirow[t]{2}{*}{ Phoebe zhennan } & 楠木 & II & 易危 & 张戊英 & 楠木人工林不同抚育措施试验研究 \\
\hline & & & $/ \mathrm{VU}$ & & \\
\hline \multirow[t]{2}{*}{ Phoebe zhennan } & 楠木 & II & 易危 & 卢昌泰 & 楠木人工林的研究现状与展望 \\
\hline & & & /VU & & \\
\hline \multirow[t]{2}{*}{ Phoebe zhennan } & 楠木 & II & 易危 & 郑金兴 & 楠木人工林调落物的产量与月动态 \\
\hline & & & /VU & & \\
\hline \multirow[t]{2}{*}{ Phoebe zhennan } & 楠木 & II & 易危 & 潘远智 & 楠木人工林林下植物物种多样性研究 \\
\hline & & & $/ \mathrm{VU}$ & & \\
\hline \multirow[t]{2}{*}{ Phoebe zhennan } & 楠木 & II & 易危 & 马明东 & 楠木人工林生态系统生物量、碳含量、碳拒量及其分布 \\
\hline & & & $/ \mathrm{VU}$ & & \\
\hline \multirow[t]{2}{*}{ Phoebe zhennan } & 楠木 & II & 易危 & 卢昌泰 & 楠木人工林生长规律的研究 \\
\hline & & & /VU & & \\
\hline \multirow[t]{2}{*}{ Phoebe zhennan } & 楠木 & II & 易危 & 卢昌泰 & 楠木人工林树冠体积与叶面积指数预估模型的研究 \\
\hline & & & /VU & & \\
\hline \multirow[t]{2}{*}{ Phoebe zhennan } & 楠木 & II & 易危 & 刘其文 & 楠木人工林土壤肥力研究 \\
\hline & & & /VU & & \\
\hline \multirow[t]{2}{*}{ Phoebe zhennan } & 楠木 & II & 易危 & 林桂芳 & 楠木人工林营造、培育技术初探 \\
\hline & & & /VU & & \\
\hline
\end{tabular}


顾垒，闻丞，罗玫，王吴，吕植. 中国最受关注濒危物种保护现状快速评价的新方法探讨. 生物多样性，2015，23(5)：583-590. http://www. biodiversity-science. net/CN/article/downloadArticleFile. do?attachType=PDF\&id=10075

\begin{tabular}{|c|c|c|c|c|c|}
\hline Phoebe zhennan & 楠木 & II & $\begin{array}{l}\text { 易危 } \\
\text { /VU }\end{array}$ & 陈淑容 & 楠木人工育苗试验研究 \\
\hline Phoebe zhennan & 楠木 & II & $\begin{array}{l}\text { 易危 } \\
\text { /VU }\end{array}$ & 王伙琴 & 楠木容器播种育苗技术研究 \\
\hline Phoebe zhennan & 楠木 & II & $\begin{array}{l}\text { 易危 } \\
\text { /VU }\end{array}$ & 吴载璋 & 楠木杉木混交林生长效应研究 \\
\hline Phoebe zhennan & 楠木 & II & $\begin{array}{l}\text { 易危 } \\
\text { /VU }\end{array}$ & 卢学琴 & 楠木胸径一材积相关方程初步研究 \\
\hline Phoebe zhennan & 楠木 & II & $\begin{array}{l}\text { 易危 } \\
\text { /VU }\end{array}$ & 郭玉硕 & 楠木叶调落物的分解及其养分动态 \\
\hline Phoebe zhennan & 楠木 & II & $\begin{array}{l}\text { 易危 } \\
\text { /VU }\end{array}$ & 邓集杰 & 楠木移植苗造林试验 \\
\hline Phoebe zhennan & 楠木 & II & $\begin{array}{l}\text { 易危 } \\
\text { /VU }\end{array}$ & 刘芳 & 楠木优树子代苗期性状遗传变异研究 \\
\hline Phoebe zhennan & 楠木 & II & $\begin{array}{l}\text { 易危 } \\
\text { /VU }\end{array}$ & 潘 彪 & 楠木与香樟木材降解特性的比较研究 \\
\hline Phoebe zhennan & 楠木 & II & $\begin{array}{l}\text { 易危 } \\
\text { /VU }\end{array}$ & 奉向阳 & 楠木育苗与造林技术之浅谈 \\
\hline Phoebe zhennan & 楠木 & II & 易危 & 范剑明 & 楠木栽培技术 \\
\hline
\end{tabular}


顾垒，闻丞，罗玫，王吴，吕植. 中国最受关注濒危物种保护现状快速评价的新方法探讨. 生物多样性，2015，23(5)：583-590. http://www. biodiversity-science. net/CN/article/downloadArticleFile. do?attachType=PDF\&id=10075

\begin{tabular}{|c|c|c|c|c|c|}
\hline & & & $/ \mathrm{VU}$ & & \\
\hline \multirow[t]{2}{*}{ Phoebe zhennan } & 楠木 & II & 易危 & 卢昌泰 & 楠木在成都平原区园林绿化中的应用分析 \\
\hline & & & /VU & & \\
\hline \multirow[t]{2}{*}{ Phoebe zhennan } & 楠木 & II & 易危 & 朱定军 & 楠木种子处理办法初探 \\
\hline & & & /VU & & \\
\hline \multirow[t]{2}{*}{ Phoebe zhennan } & 楠木 & II & 易危 & 李铁华 & 楠木种子活力变化机制的研究 \\
\hline & & & /VU & & \\
\hline \multirow[t]{2}{*}{ Phoebe zhennan } & 楠木 & II & 易危 & 李铁华 & 楠木种子活力下降机制研究 \\
\hline & & & $/ \mathrm{VU}$ & & \\
\hline \multirow[t]{2}{*}{ Phoebe zhennan } & 楠木 & II & 易危 & 李铁华 & 楠木种子休眠与萌发特性的研究 \\
\hline & & & /VU & & \\
\hline \multirow[t]{2}{*}{ Phoebe zhennan } & 楠木 & II & 易危 & 吴建国 & 气候变化对 7 种乔木植物分布的潜在影响 \\
\hline & & & $/ \mathrm{VU}$ & & \\
\hline \multirow[t]{2}{*}{ Phoebe zhennan } & 楠木 & II & 易危 & 袁政和 & 浅析黔东南州的楠木栽培技术及其保护措施 \\
\hline & & & /VU & & \\
\hline \multirow[t]{2}{*}{ Phoebe zhennan } & 楠木 & II & 易危 & 宋金聪 & 人工楠木林分结构及生长状况分析 \\
\hline & & & /VU & & \\
\hline \multirow[t]{2}{*}{ Phoebe zhennan } & 楠木 & II & 易危 & 黄辉 & 杉木林与楠木林土壤呼吸昼夜变化及与土温变化的关系 \\
\hline & & & /VU & & \\
\hline
\end{tabular}


顾垒，闻丞，罗玫，王吴，吕植. 中国最受关注濒危物种保护现状快速评价的新方法探讨. 生物多样性，2015，23(5)：583-590. http://www. biodiversity-science. net/CN/article/downloadArticleFile. do?attachType=PDF\&id=10075

\begin{tabular}{|c|c|c|c|c|c|}
\hline Phoebe zhennan & 楠木 & II & $\begin{array}{l}\text { 易危 } \\
\text { /VU }\end{array}$ & 林开敏 & 杉木人工林下杉木、楠木和木荷叶调落物分解特征及营养元素含量变化的动态分析 \\
\hline Phoebe zhennan & 楠木 & II & $\begin{array}{l}\text { 易危 } \\
\text { /VU }\end{array}$ & 林开敏 & 杉木与阔叶树调落物分解特征的比较及其混合分解研究 \\
\hline Phoebe zhennan & 楠木 & II & $\begin{array}{l}\text { 易危 } \\
\text { /VU }\end{array}$ & 林开敏 & 杉木与楠木叶调落物混合分解及其养分动态 \\
\hline Phoebe zhennan & 楠木 & II & $\begin{array}{l}\text { 易危 } \\
\text { /VU }\end{array}$ & 潘文忠 & 杉楠混交林生长及生态效应研究 \\
\hline Phoebe zhennan & 楠木 & II & $\begin{array}{l}\text { 易危 } \\
\text { /VU }\end{array}$ & 刘志雄 & 我国楠木类种质资源现状及保育对策 \\
\hline Phoebe zhennan & 楠木 & II & $\begin{array}{l}\text { 易危 } \\
\text { /VU }\end{array}$ & 李冬林 & 我国楠木属植物资源的地理分布、研究现状和开发利用前景 \\
\hline Phoebe zhennan & 楠木 & II & $\begin{array}{l}\text { 易危 } \\
\text { /VU }\end{array}$ & 林亦䂀 & 在杉木伴生下的闽楠人工林生产力研究 \\
\hline Phoebe zhennan & 楠木 & II & $\begin{array}{l}\text { 易危 } \\
\text { /VU }\end{array}$ & 王玉国 & 樟科两个近缘属润楠属和楠木属花粉形态的比较研究 \\
\hline Phoebe zhennan & 楠木 & II & $\begin{array}{l}\text { 易危 } \\
\text { /VU }\end{array}$ & 杨秋生 & 樟科三种常绿榈叶树种抗寒生理的研究 \\
\hline Phoebe zhennan & 楠木 & II & 易危 & 朱雁 & 珍贵树种楠木容器苗芽苗移栽技术 \\
\hline
\end{tabular}


顾垒，闻丞，罗玫，王吴，吕植. 中国最受关注濒危物种保护现状快速评价的新方法探讨. 生物多样性，2015，23(5)：583-590. http://www biodiversity-science. net/CN/article/downloadArticleFile. do?attachType=PDF\&id=10075

\begin{tabular}{|c|c|c|c|c|c|}
\hline & & & $/ \mathrm{VU}$ & & \\
\hline \multirow[t]{2}{*}{ Phoebe zhennan } & 楠木 & II & 易危 & 周永丽 & 桢楠扞插繁育试验研究 \\
\hline & & & $/ \mathrm{VU}$ & & \\
\hline \multirow[t]{2}{*}{ Phoebe zhennan } & 楠木 & II & 易危 & 殷国兰 & 桢楠容器育苗试验 \\
\hline & & & /VU & & \\
\hline \multirow[t]{2}{*}{ Phoenicurus alaschanicus } & 贺兰山红尾鸲 & 未列 & 近危 & 包新康 & 甘肃安西国家级自然保护区脊椎动物 20 年间的变化 \\
\hline & & 入 & /NT & & \\
\hline \multirow[t]{2}{*}{ Phoenicurus alaschanicus } & 贺兰山红尾鸲 & 未列 & 近危 & 黄族豪 & 甘肃安西极旱荒漠国家级自然保护区鸟类群落结构的季节性变化 \\
\hline & & 入 & /NT & & \\
\hline \multirow[t]{2}{*}{ Phoenicurus alaschanicus } & 贺兰山红尾鸲 & 未列 & 近危 & 刘晓红 & 宁夏贺兰山国家级自然保护区脊椎动物调查研究 \\
\hline & & 入 & /NT & & \\
\hline \multirow[t]{2}{*}{ Phoenicurus alaschanicus } & 贺兰山红尾鸲 & 未列 & 近危 & 李元刚 & 宁夏贺兰山国家级自然保护区鸟类区系组成及其特征研究 \\
\hline & & 入 & /NT & & \\
\hline \multirow[t]{2}{*}{ Phoenicurus alaschanicus } & 贺兰山红尾鸲 & 未列 & 近危 & 杨贵军 & 宁夏罗山国家级自然保护区鸟类区系特征及群落结构 \\
\hline & & 入 & /NT & & \\
\hline \multirow[t]{2}{*}{ Phoenicurus alaschanicus } & 贺兰山红尾鸲 & 未列 & 近危 & 杜天奎 & 宁夏沙湖自然保护区春季鸟类群落组成及多样性研究 \\
\hline & & 入 & /NT & & \\
\hline \multirow[t]{2}{*}{ Phoenicurus alaschanicus } & 贺兰山红尾鸲 & 未列 & 近危 & 李宏群 & 陕西延安黄龙山褐马鸡自然保护区鸟类资源调查 \\
\hline & & 入 & /NT & & \\
\hline
\end{tabular}


顾垒，闻丞，罗玫，王吴，吕植. 中国最受关注濒危物种保护现状快速评价的新方法探讨. 生物多样性，2015，23(5)：583-590. http://www. biodiversity-science. net/CN/article/downloadArticleFile. do?attachType=PDF\&id=10075

\begin{tabular}{|c|c|c|c|c|c|}
\hline \multirow[t]{2}{*}{ Phylloscopus hainanus } & 海南柳蒀 & 未列 & \multicolumn{2}{|l|}{ 易危 } & A new species of Phylloscopus warbler from Hainan Island, China \\
\hline & & 入 & \multicolumn{2}{|l|}{ /VU } & \\
\hline \multirow[t]{2}{*}{ Phylloscopus hainanus } & 海南柳莺 & 未列 & \multicolumn{2}{|l|}{ 易危 } & A new species of Phylloscopus warbler from Hainan Island, China \\
\hline & & 入 & \multicolumn{2}{|l|}{ /VU } & \\
\hline \multirow[t]{3}{*}{ Phylloscopus occisinensis } & 华西柳莺 & 未列 & 数据 & 四川西部生物多样 & 布拖乐安地区生物 多样性调查报告 \\
\hline & & 入 & 不足 & 性调查队 & \\
\hline & & & \multicolumn{2}{|l|}{ /DD } & \\
\hline \multirow[t]{3}{*}{ Phylloscopus occisinensis } & 华西柳荁 & 未列 & 数据 & \multirow[t]{3}{*}{ 蒋爱伍 } & 广西柳莺科鸟类一新记录 \\
\hline & & 入 & 不足 & & \\
\hline & & & /DD & & \\
\hline \multirow[t]{3}{*}{ Phylloscopus occisinensis } & 华西柳蒀 & 未列 & 数据 & \multirow[t]{3}{*}{ 粟通萍 } & 广西猫儿山地区鸟类组成及垂直分布格局 \\
\hline & & 入 & 不足 & & \\
\hline & & & /DD & & \\
\hline \multirow[t]{3}{*}{ Phylloscopus occisinensis } & 华西柳莺 & 未列 & 数据 & \multirow[t]{3}{*}{ 李显达 } & 黑龙江省鸟类新纪录 ———黄腹柳莺 \\
\hline & & 入 & 不足 & & \\
\hline & & & /DD & & \\
\hline \multirow[t]{3}{*}{ Phylloscopus occisinensis } & 华西柳莺 & 未列 & 数据 & \multirow[t]{3}{*}{ 杨书香 } & \multirow[t]{3}{*}{ 湖北省七姊妹山夏季鸟类多样性研究及生境分析 } \\
\hline & & 入 & 不足 & & \\
\hline & & & /DD & & \\
\hline
\end{tabular}


顾垒，闻丞，罗玫，王吴，吕植. 中国最受关注濒危物种保护现状快速评价的新方法探讨. 生物多样性，2015，23(5)：583-590. http://www. biodiversity-science. net/CN/article/downloadArticleFile. do?attachType=PDF\&id=10075

\begin{tabular}{|c|c|c|c|c|c|}
\hline Picea aurantiaca & 白皮云杉 & II & 濒危 & 孙凯 & 红皮云杉、油松和白皮松幼苗对不同 NH//NCV 的形态响应 \\
\hline Picea brachytyla & 麦吊云杉 & II & $\begin{array}{l}\text { 易危 } \\
\text { /VU }\end{array}$ & 王建宏 & 白水江自然保护区麦吊云杉群落类型与垂直格局初步分析 \\
\hline Picea brachytyla & 麦吊云杉 & II & $\begin{array}{l}\text { 易危 } \\
\text { /VU }\end{array}$ & 刘建全 & 结合叶绿体和核 DNA 序列变异可提高云杉属物种的分子鉴别率 \\
\hline Picea brachytyla & 麦吊云杉 & II & $\begin{array}{l}\text { 易危 } \\
\text { /VU }\end{array}$ & 李龙 & 麦吊云杉及其相关物种的群体遗传学研究 \\
\hline Picea montigena & 康定云杉 & $\begin{array}{l}\text { 未列 } \\
\text { 入 }\end{array}$ & $\begin{array}{l}\text { 数据 } \\
\text { 不足 } \\
\text { /DD }\end{array}$ & 耿海清 & 甘孜州矿产资源开发利用与保护规划对生物多样性的影响 \\
\hline Picea montigena & 康定云杉 & $\begin{array}{l}\text { 未列 } \\
\text { 入 }\end{array}$ & $\begin{array}{l}\text { 数据 } \\
\text { 不足 } \\
\text { /DD }\end{array}$ & 彭培好 & 九龙县珍稀濒危植物多样性快速评估 \\
\hline Picea montigena & 康定云杉 & $\begin{array}{l}\text { 未列 } \\
\lambda\end{array}$ & $\begin{array}{l}\text { 数据 } \\
\text { 不足 } \\
\text { /DD }\end{array}$ & 唐连友 & 康定云杉扞插繁育技术试验 \\
\hline Picea montigena & 康定云杉 & $\begin{array}{l}\text { 未列 } \\
\text { 入 }\end{array}$ & $\begin{array}{l}\text { 数据 } \\
\text { 不足 }\end{array}$ & 李林初 & 四种云杉的核型分析 \\
\hline
\end{tabular}


顾垒，闻丞，罗玫，王吴，吕植. 中国最受关注濒危物种保护现状快速评价的新方法探讨. 生物多样性，2015，23(5)：583-590. http://www biodiversity-science. net/CN/article/downloadArticleFile. do?attachType=PDF\&id=10075

Picea neoveitchii

大果青扞

大果青扞

Picea neoveitchii

Picea neoveitchii

大果青扞

Picea neoveitchii

大果青扞

Picea neoveitchi

大果青扞

Picea neoveitchi

Picea neoveitchii

Picea neoveitchii

Picea neoveitchii
大果青扞

大果青扞

大果青扞

大果青扞
及危 Han-Hong Xu

极危 Susanne S. Renner

Xiao-Quan Wang

及危 T. Wang

/CR

II

极危 Hanhong X

II

及危 Ting Wang

/CR
极危 Xiao-Quan Wang
A new antifungal and cytotoxic C-methylated flavone glycoside from Picea neoveitchii

A new phylogeny for the genus Picea from plastid, mitochondrial, and nuclear sequences

A test of seven candidate barcode regions from the plastome in Picea (Pinaceae)

Adaptive Evolution in the GAF Domain of Phytochromes in Gymnosperms

Antioxidant activities and phenolic constituents of Cephalotaxus oliveri Mast. aerial parts

Chemical constituents of Picea neoveitchii

Discrimination and genetic diversity of Cephalotaxus accessions using AFLP markers

Molecular evolution of rbcL in three gymnosperm families identifying adaptive and

coevolutionary patterns

Molecular phylogeny and biogeography of Picea(Pinaceae) Implications for phylogeographical

studies using cytoplasmic haplotypes 
顾垒，闻丞，罗玫，王吴，吕植. 中国最受关注濒危物种保护现状快速评价的新方法探讨. 生物多样性，2015，23(5)：583-590. http://www biodiversity-science. net/CN/article/downloadArticleFile. do?attachType=PDF\&id=10075

\begin{tabular}{|c|c|c|c|c|c|}
\hline Picea neoveitchii & 大果青扦 & II & $\begin{array}{l}\text { 极危 } \\
\text { /CR }\end{array}$ & DA CHENG HAO & Physicochemical evolution and positive selection of the gymnosperm matK proteins \\
\hline Picea neoveitchii & 大果青扞 & II & 极危 & Jianquan Liu & $\begin{array}{l}\text { Population genetic evidence for speciation pattern and gene flow between Picea wilsonii, P. } \\
\text { morrisonicola and P. neoveitchii }\end{array}$ \\
\hline Picea neoveitchii & 大果青扞 & II & $\begin{array}{l}\text { 极危 } \\
\text { /CR }\end{array}$ & Zhang Deshun & The Conservation Status and Conservation Strategy of Picea neoveitchii \\
\hline Picea neoveitchii & 大果青扞 & II & $\begin{array}{l}\text { 极危 } \\
\text { /CR }\end{array}$ & 王明亮 & 濒危植物大果青扞的残存分布群落特性和种群动态研究 \\
\hline Picea neoveitchii & 大果青扦 & II & $\begin{array}{l}\text { 极危 } \\
\text { /CR }\end{array}$ & 王明亮 & 濒危植物大果青扞地理分布和群落特性研究 \\
\hline Picea neoveitchii & 大果青扞 & II & $\begin{array}{l}\text { 极危 } \\
\text { /CR }\end{array}$ & 戴振伦 & 独特的大果青杆群落吸引国际保护组织关注 \\
\hline Picea neoveitchii & 大果青扞 & II & 极危 & 杜芳 & 基因流速度与种间渐渗和物种界定：云杉属线粒体和叶绿体 DNA 群体遗传学的证据 \\
\hline Picea neoveitchii & 大果青扦 & II & $\begin{array}{l}\text { 极危 } \\
\text { /CR }\end{array}$ & 朱洪涛 & 三种云杉的谱系地理与物种界定 \\
\hline Picea neoveitchii & 大果青扦 & II & $\begin{array}{l}\text { 极危 } \\
\text { /CR }\end{array}$ & 沈泽昊 & 神农架南坡植物群落多样性的海拔梯度格局 \\
\hline Picea neoveitchii & 大果青扦 & II & 极危 & 戴振伦 & 珍稀濒危国家二级重点保护树种大果青杆繁育初探 \\
\hline
\end{tabular}


顾垒，闻丞，罗玫，王吴，吕植. 中国最受关注濒危物种保护现状快速评价的新方法探讨. 生物多样性，2015，23(5)：583-590. http://www biodiversity-science. net/CN/article/downloadArticleFile. do?attachType=PDF\&id=10075

Picea smithiana

长叶云杉

长叶云杉

Picea smithiana

Pinus squamata

巧家五针松

Pinus squamata

巧家五针松

Pinus squamata

巧家五针松

Pinus wangi

Pinus wangii

Pinus wangii

Pinus wangii
毛枝五针松

毛枝五针松

毛枝五针松

毛枝五针松
未列无危

邓辉胜

入 $/ \mathrm{LC}$

未列 无危

ZHANG Yili

入 $/ \mathrm{LC}$

极危 张志勇

/CR

I 极危 邬琰

/CR

I 极危 贺佳飞

CR

II

II

濒危

/EN

II
3 种云杉小狍子母细胞减数分裂研究

Predicting Potential Distribution of Tibetan Spruce (Picea smithiana) in Qomolangma (Mount

Everest) National Nature Preserve Using Maximum Entropy Niche-based Model

极度濒危植物五针白皮松解剖生态学研究

巧家五针松育苗阶段病害及防治方法

云南省有效保护珍稀濒危植物巧家五针松

A Revision of the Asian Pinus Subsection Strobus (Pinaceae)

Development and Characterization of Nine Microsatellites for an Endangered Tree, Pinus

wangii (Pinaceae)

濒危植物的区系性质与迁地保护

海松酸型树脂酸资源分布及组成研究 
顾垒，闻丞，罗玫，王吴，吕植. 中国最受关注濒危物种保护现状快速评价的新方法探讨. 生物多样性，2015，23(5)：583-590. http://www. biodiversity-science. net/CN/article/downloadArticleFile. do?attachType=PDF\&id=10075

\begin{tabular}{|c|c|c|c|c|c|}
\hline Pinus wangii & 毛枝五针松 & II & $\begin{array}{l}\text { 濒危 } \\
\text { /EN }\end{array}$ & 周 云 & 极小种群植物毛枝五针松的野生资源状况研究 \\
\hline Pitta nympha & 仙八色冻 & II & $\begin{array}{l}\text { 易危 } \\
\text { /VU }\end{array}$ & & 湖北省鸟类新记录一仙八色冻 \\
\hline Pitta nympha & 仙八色鸫 & II & $\begin{array}{l}\text { 易危 } \\
\text { /VU }\end{array}$ & & 仙八色鸫繁殖习性及雏鸟生长的研究 \\
\hline Pitta sordida & 绿胸八色冻 & II & $\begin{array}{l}\text { 无危 } \\
\text { /LC }\end{array}$ & 王育章 & 四川鸟类一新记录 ———绿胸八色鸫 \\
\hline Pitta soror & 蓝背八色鸫 & II & $\begin{array}{l}\text { 无危 } \\
\text { /LC }\end{array}$ & 邹发生 & 海南岛尖峰岭热带山地雨林林下鸟类群落研究 \\
\hline Platalea minor & 黑脸琵啔 & I & $\begin{array}{l}\text { 濒危 } \\
\text { /EN }\end{array}$ & 关贯勋 & 澳门鸟类资源调查报告 \\
\hline Platalea minor & 黑脸琵䀾 & I & $\begin{array}{l}\text { 濒危 } \\
\text { /EN }\end{array}$ & 袁 晓 & 崇明东滩黑脸琵鹭迁徙种群的初步研究 \\
\hline Platalea minor & 黑脸琵鹭 & I & $\begin{array}{l}\text { 濒危 } \\
\text { /EN }\end{array}$ & 钟福生 & 洞庭湖湿地珍稀濒危鸟类群落组成及多样性 \\
\hline Platalea minor & 黑脸琵鹭 & I & $\begin{array}{l}\text { 濒危 } \\
\text { /EN }\end{array}$ & 金杰锋 & 福建省兴化湾黑脸琵鹭的越冬及迁徙 \\
\hline Platalea minor & 黑脸琵路 & I & 濒危 & 金杰锋 & 福建兴化湾黑脸琵鹭受食生境的鱼类和虾类组成 \\
\hline
\end{tabular}


顾垒，闻丞，罗玫，王吴，吕植. 中国最受关注濒危物种保护现状快速评价的新方法探讨. 生物多样性，2015，23(5)：583-590. http://www. biodiversity-science. net/CN/article/downloadArticleFile. do?attachType=PDF\&id=10075

\begin{tabular}{|c|c|c|c|c|c|}
\hline & & & /EN & & \\
\hline \multirow[t]{2}{*}{ Platalea minor } & 黑脸琵鹭 & I & 濒危 & 郑丁团 & 福建漳江口红树林国家级自然保护区水鸟种类组成及其区系的研究 \\
\hline & & & $/$ EN & & \\
\hline \multirow[t]{2}{*}{ Platalea minor } & 黑脸琵鹭 & I & 濒危 & 陈友明 & 福清市江镜华侨农场鸟类资源调查及保护对策 \\
\hline & & & /EN & & \\
\hline \multirow[t]{2}{*}{ Platalea minor } & 黑脸琵鹭 & I & 濒危 & 胡军华 & 广东海丰鸟类自然保护区黑脸琵鹞越冬种群现状 \\
\hline & & & /EN & & \\
\hline \multirow[t]{2}{*}{ Platalea minor } & 黑脸琵鹭 & I & 濒危 & 王广豪 & 黄河三角洲自然保护区黑脸琵鹭野外调查及其生境分析 \\
\hline & & & /EN & & \\
\hline \multirow[t]{2}{*}{ Platalea minor } & 黑脸琵鹭 & I & 濒危 & 单凯 & 黄河三角洲自然保护区黑脸琵鹭野外调查及其生境分析 \\
\hline & & & /EN & & \\
\hline \multirow[t]{2}{*}{ Platalea minor } & 黑脸琵鹭 & I & 濒危 & 朱书玉 & 黄河三角洲自然保护区湿地恢复与生物多样性保护 \\
\hline & & & /EN & & \\
\hline \multirow[t]{2}{*}{ Platalea minor } & 黑脸琵鹭 & I & 濒危 & 邱英杰 & 辽宁省再次发现濒危涉禽黑脸琵鹭的新繁殖地 \\
\hline & & & /EN & & \\
\hline \multirow[t]{2}{*}{ Platalea minor } & 黑脸琵鹭 & I & 濒危 & 张国钢 & 辽宁长山群岛及东部沿海夏季水鸟资源调查 \\
\hline & & & /EN & & \\
\hline \multirow[t]{2}{*}{ Platalea minor } & 黑脸琵鹭 & I & 濒危 & 张国钢 & 临高后水湾、东方北黎湾和三亚河 \\
\hline & & & /EN & & \\
\hline
\end{tabular}


顾垒，闻丞，罗玫，王吴，吕植. 中国最受关注濒危物种保护现状快速评价的新方法探讨. 生物多样性，2015，23(5)：583-590. http://www biodiversity-science. net/CN/article/downloadArticleFile. do?attachType=PDF\&id=10075

\begin{tabular}{|c|c|c|c|c|c|}
\hline Platalea minor & 黑脸琵鹭 & I & 濒危 & 陈若海 & 泉州湾河口湿地自然保护区珍稀濒危鸟类的分布特点及其保护 \\
\hline Platalea minor & 黑脸琵鹭 & I & 濒危 & 王献溥 & 山口红树林生态自然保护区有效管理的成就和展望 \\
\hline Platalea minor & 黑脸琵鹭 & I & $\begin{array}{l}\text { 濒危 } \\
\text { /EN }\end{array}$ & 徐华林 & 深圳湾水鸟生物多样性初步研究 \\
\hline Platalea minor & 黑脸琵鹭 & I & $\begin{array}{l}\text { 濒危 } \\
/ \mathrm{EN}\end{array}$ & 周俊启 & 天津大黄堡湿地资源现状及保护利用 \\
\hline Platuysternon megacephalum & 平胸龟 & $\begin{array}{l}\text { 未列 } \\
\text { 入 }\end{array}$ & $\begin{array}{l}\text { 未评 } \\
\text { 价 } \\
\text { /NE }\end{array}$ & 宋憬愚 & 平胸龟的生物学及人工养殖 \\
\hline Platycerium wallichii & 鹿角偋 & $\begin{array}{l}\text { 未列 } \\
\lambda\end{array}$ & $\begin{array}{l}\text { 数据 } \\
\text { 不足 } \\
\text { /DD }\end{array}$ & Ying-Juan Su & $\begin{array}{l}\text { Evolution of therpoB-psbZ region in fern plastid genomes: notable structural rearrangements } \\
\text { and highly variable intergenic spacers }\end{array}$ \\
\hline Platycerium wallichii & 鹿角偋 & $\begin{array}{l}\text { 未列 } \\
\text { 入 }\end{array}$ & $\begin{array}{l}\text { 数据 } \\
\text { 不足 } \\
\text { /DD }\end{array}$ & LI ChunXiang & $\begin{array}{l}\text { From the Himalayan region orthe Malay Archipelago: Molecular dating to trace the origin of a } \\
\text { fern genus Phymatopteris(Polypodiaceae) }\end{array}$ \\
\hline Platycerium wallichii & 鹿角硕 & $\begin{array}{l}\text { 未列 } \\
\text { 入 }\end{array}$ & $\begin{array}{l}\text { 数据 } \\
\text { 不足 }\end{array}$ & Fang Chen & $\begin{array}{l}\text { Nutrient Elements in Leaves of Rare and Endangered Species in Wuhan Botanical Garden, } \\
\text { China }\end{array}$ \\
\hline
\end{tabular}


顾垒，闻丞，罗玫，王吴，吕植. 中国最受关注濒危物种保护现状快速评价的新方法探讨. 生物多样性，2015，23(5)：583-590. http://www. biodiversity-science. net/CN/article/downloadArticleFile. do?attachType=PDF\&id=10075

\begin{tabular}{|c|c|c|c|c|c|}
\hline & & & $/ \mathrm{DD}$ & & \\
\hline \multirow[t]{3}{*}{ Platycerium wallichii } & 鹿角蕨 & 未列 & 数据 & Hang SUN & Phylogenetic position of Kontumia(Polypodiaceae) inferred from four chloroplast DNA regions \\
\hline & & 入 & 不足 & & \\
\hline & & & $/ \mathrm{DD}$ & & \\
\hline \multirow[t]{3}{*}{ Platycerium wallichii } & 鹿角蕨 & 未列 & 数据 & 黄执缨 & 二歧鹿角蕨组织的培养 \\
\hline & & 入 & 不足 & & \\
\hline & & & $/ \mathrm{DD}$ & & \\
\hline \multirow[t]{3}{*}{ Platycerium wallichii } & 鹿角鰀 & 未列 & 数据 & 成晓 & 鹿角蕨(鹿角蕨科)配子体发育及其濒危机制探讨 \\
\hline & & 入 & 不足 & & \\
\hline & & & $/ \mathrm{DD}$ & & \\
\hline \multirow[t]{3}{*}{ Platycerium wallichii } & 鹿角蕨 & 未列 & 数据 & 刘保东 & 鹿角䒜的孢子培养及其繁殖 \\
\hline & & 入 & 不足 & & \\
\hline & & & /DD & & \\
\hline \multirow[t]{3}{*}{ Platycerium wallichii } & 鹿角蒝 & 未列 & 数据 & 向燕 & 鹿角莜化学成分的研究 \\
\hline & & 入 & 不足 & & \\
\hline & & & $/ \mathrm{DD}$ & & \\
\hline \multirow[t]{3}{*}{ Platycerium wallichii } & 鹿角蕨 & 未列 & 数据 & 刘保东 & 鹿角蕨有性世代发育及繁殖技术研究 \\
\hline & & 入 & 不足 & & \\
\hline & & & $/ \mathrm{DD}$ & & \\
\hline
\end{tabular}


顾垒，闻丞，罗玫，王吴，吕植. 中国最受关注濒危物种保护现状快速评价的新方法探讨. 生物多样性，2015，23(5)：583-590. http://www. biodiversity-science. net/CN/article/downloadArticleFile. do?attachType=PDF\&id=10075

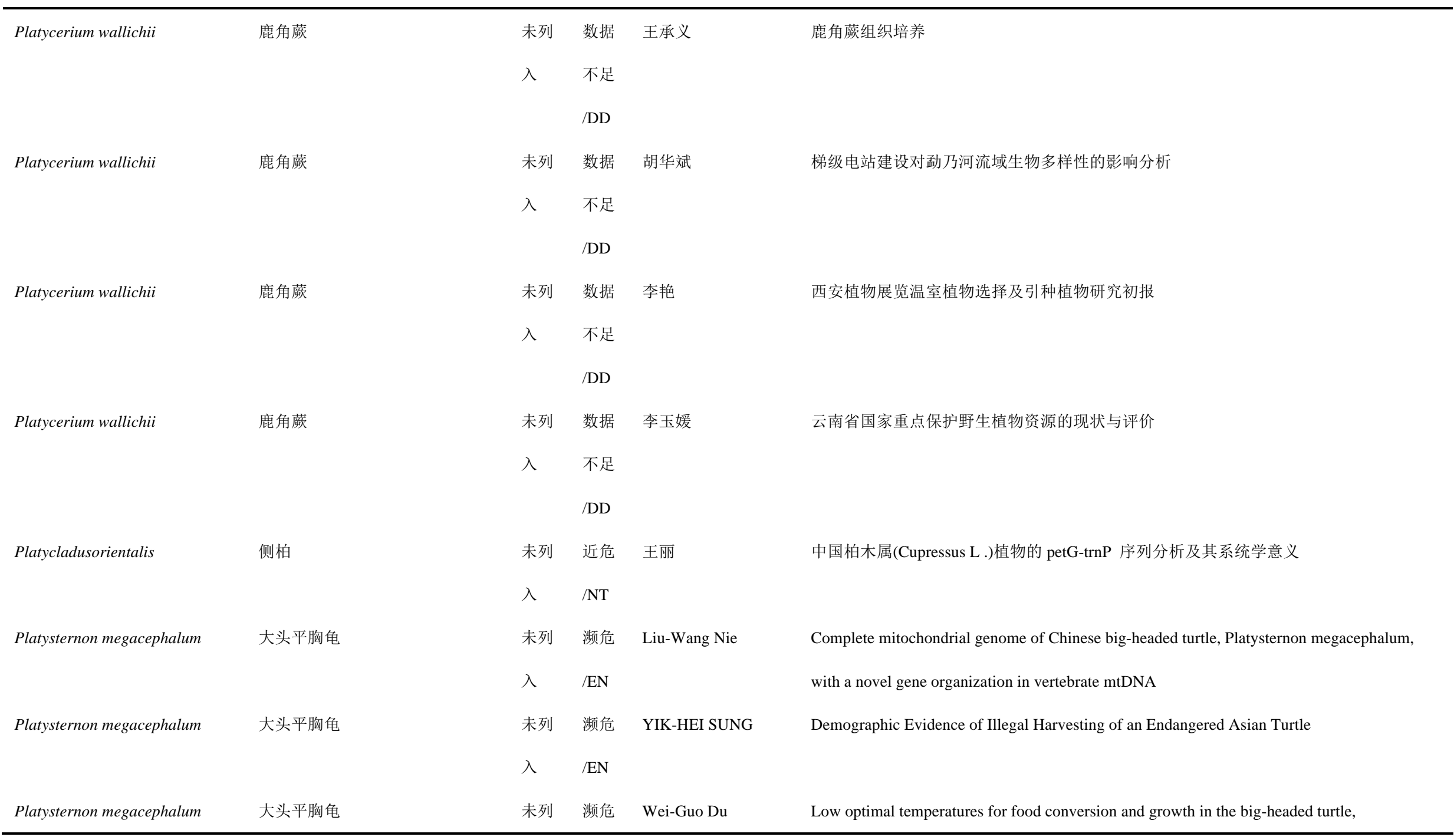


顾垒，闻丞，罗玫，王吴，吕植. 中国最受关注濒危物种保护现状快速评价的新方法探讨. 生物多样性，2015，23(5)：583-590. http://www biodiversity-science. net/CN/article/downloadArticleFile. do?attachType=PDF\&id=10075

\begin{tabular}{|c|c|c|c|c|c|}
\hline & & 入 & /EN & & Platysternon megacephalum \\
\hline \multirow[t]{2}{*}{ Platysternon megacephalum } & 大头平胸龟 & 未列 & 濒危 & WEI-GUO DU & Movements and Microhabitat Use of Translocated Big-Headed Turtles (Platysternon \\
\hline & & 入 & /EN & & megacephalum) in Southern China \\
\hline \multirow[t]{2}{*}{ Platysternon megacephalum } & 大头平胸龟 & 未列 & 濒危 & Huijian Hu & New microsatellite resources in Chinese big-headed turtle (Platysternon megacephalum) \\
\hline & & 入 & /EN & & \\
\hline \multirow[t]{2}{*}{ Platysternon megacephalum } & 大头平胸龟 & 未列 & 濒危 & 唐伯平 & 大头平胸龟体色,体形随年龄变化的初步观察 \\
\hline & & 入 & $/ \mathrm{EN}$ & & \\
\hline \multirow[t]{2}{*}{ Pleione formosana } & 台湾一叶兰 & 未列 & 易危 & 华健 & 台湾一叶兰生产技术 \\
\hline & & 入 & /VU & & \\
\hline \multirow[t]{2}{*}{ Podoces biddulphi } & 白尾地鸦 & 未列 & 近危 & Tiziano LONDEI & About the geographic distribution of the Xinjiang Ground Jay (Podoces biddulphi) \\
\hline & & 入 & /NT & & \\
\hline \multirow[t]{2}{*}{ Podoces biddulphi } & 白尾地鸦 & 未列 & 近危 & 马 鸣 & Status of the Xinjiang Ground Jay: population, breeding ecology and conservation \\
\hline & & 入 & $/ \mathrm{NT}$ & & \\
\hline \multirow[t]{2}{*}{ Podoces biddulphi } & 白尾地鸦 & 未列 & 近危 & 孙志成 & 敦煌西湖保护区发现濒危鸟类 )) ) 白尾地鸦 \\
\hline & & 入 & /NT & & \\
\hline \multirow[t]{2}{*}{ Podoces biddulphi } & 白尾地鸦 & 未列 & 近危 & 邱观华 & 甘肃敦煌西湖湿地鸟类调查及其栖息地重要性评价 \\
\hline & & 入 & /NT & & \\
\hline \multirow[t]{2}{*}{ Podoces biddulphi } & 白尾地鸦 & 未列 & 近危 & 马 鸣 & 罗布泊野骆驼自然保护区的鸟类记录 \\
\hline & & 入 & /NT & & \\
\hline
\end{tabular}


顾垒，闻丞，罗玫，王吴，吕植. 中国最受关注濒危物种保护现状快速评价的新方法探讨. 生物多样性，2015，23(5)：583-590. http://www. biodiversity-science. net/CN/article/downloadArticleFile. do?attachType=PDF\&id=10075

\begin{tabular}{|c|c|c|c|c|c|}
\hline Podoces biddulphi & 白尾地鸦 & $\begin{array}{l}\text { 未列 } \\
\text { 入 }\end{array}$ & $\begin{array}{l}\text { 近危 } \\
\text { /NT }\end{array}$ & 殷守敬 & 我国西部珍稀濒危物种 ———白尾地鸦 \\
\hline Polyplectron katsumatae & 海南孔雀雉 & I & $\begin{array}{l}\text { 濒危 } \\
\text { /EN }\end{array}$ & 谢 屹 & 海南霸王岭国家级自然保护区管理现状及对策建议 \\
\hline Polyplectron katsumatae & 海南孔雀雉 & I & $\begin{array}{l}\text { 濒危 } \\
\text { /EN }\end{array}$ & 李国诚 & 海南俄贤岭及周边地区乌类调查报告_含一海南省新记录 \\
\hline Polyplectron katsumatae & 海南孔雀雉 & I & $\begin{array}{l}\text { 濒危 } \\
\text { /EN }\end{array}$ & 李仕宁 & 茄新省级森林经营所鸟类资源调查 \\
\hline Porzana bicolor & 棕背田鸡 & II & $\begin{array}{l}\text { 无危 } \\
\text { /LC }\end{array}$ & 袁玉川 & 2011 年南涧风凰山夜间鸟类环志研究 \\
\hline Porzana bicolor & 棕背田鸡 & II & $\begin{array}{l}\text { 无危 } \\
\text { /LC }\end{array}$ & 罗康 & 哀牢山北段大中山候鸟聚集地秋季夜间迁徙鸟类多样性 \\
\hline Porzana bicolor & 棕背田鸡 & II & $\begin{array}{l}\text { 无危 } \\
\text { /LC }\end{array}$ & 蒋光伟 & 广西北部湾沿海地区水鸟多样性及季节变动 \\
\hline Porzana bicolor & 棕背田鸡 & II & $\begin{array}{l}\text { 无危 } \\
\text { /LC }\end{array}$ & 黄石林 & 云南南涧风凰山秋季夜间迁移鸟类多样性分析 \\
\hline Porzana bicolor & 棕背田鸡 & II & $\begin{array}{l}\text { 无危 } \\
\text { /LC }\end{array}$ & 刘鲁明 & 云南省玉龙雪山自然保护区鸟类资源调查 \\
\hline Porzana bicolor & 棕背田鸡 & II & 无危 & 李晶晶 & 珠穆朗玛峰国家级自然保护区鸟类区系及其垂直分布特征 \\
\hline
\end{tabular}


顾垒，闻丞，罗玫，王吴，吕植. 中国最受关注濒危物种保护现状快速评价的新方法探讨. 生物多样性，2015，23(5)：583-590. http://www biodiversity-science. net/CN/article/downloadArticleFile. do?attachType=PDF\&id=10075

\begin{tabular}{|c|c|c|c|c|c|}
\hline & & & $/ \mathrm{LC}$ & & \\
\hline \multirow[t]{2}{*}{ Porzana parva } & 姬田鸡 & II & 无危 & 马 鸣 & 罗布泊野骆驼自然保护区的鸟类记录 \\
\hline & & & $/ \mathrm{LC}$ & & \\
\hline \multirow[t]{2}{*}{ Porzana parva } & 姬田鸡 & II & 无危 & 马 鸣 & 新疆艾比湖湿地自然保护区鸟类清单及秋季迁徙数量统计 \\
\hline & & & $/ \mathrm{LC}$ & & \\
\hline \multirow[t]{2}{*}{ Prionailurus bengalensis } & 豹猫 & II & 无危 & 侯森林 & 豹猫直针毛的显微形态学特征观察 \\
\hline & & & $/ \mathrm{LC}$ & & \\
\hline \multirow[t]{2}{*}{ Prionailurus bengalensis } & 豹猫 & II & 无危 & 白素英 & 中国豹猫 6 个群体的 RAPD 分析 \\
\hline & & & $/ \mathrm{LC}$ & & \\
\hline \multirow[t]{2}{*}{ Procapra picticaudata } & 藏原羚 & II & 无危 & Peishi Yan & Avoidance distance from Qinghai - Tibet Highway in sympatric Tibetan antelope and gazelle \\
\hline & & & $/ \mathrm{LC}$ & & \\
\hline \multirow[t]{2}{*}{ Procapra picticaudata } & 藏原羚 & II & 无危 & Lei Zhu & Craniometrical Studies on the Skull of Tibetan Gazelle (Procapra Picticaudata) \\
\hline & & & $/ \mathrm{LC}$ & & \\
\hline \multirow[t]{2}{*}{ Procapra picticaudata } & 藏原羚 & II & 无危 & Zhigang Jiang & Dietary Overlap of Przewalski's Gazelle, Tibetan Gazelle, and Tibetan Sheep on the \\
\hline & & & $/ \mathrm{LC}$ & & Qinghai-Tibet Plateau \\
\hline \multirow[t]{2}{*}{ Procapra picticaudata } & 藏原羚 & II & 无危 & Zhigang Jiang & Group size effect on vigilance: Evidence from Tibetan gazelle in Upper Buha River, \\
\hline & & & $/ \mathrm{LC}$ & & Qinghai-Tibet Plateau \\
\hline \multirow[t]{2}{*}{ Procapra picticaudata } & 藏原羚 & II & 无危 & Wei Wanhong & Influence of the Qinghai-Tibetan railway and highway on the activities of wild animals \\
\hline & & & /LC & & \\
\hline
\end{tabular}


顾垒，闻丞，罗玫，王吴，吕植. 中国最受关注濒危物种保护现状快速评价的新方法探讨. 生物多样性，2015，23(5)：583-590. http://www. biodiversity-science. net/CN/article/downloadArticleFile. do?attachType=PDF\&id=10075

\begin{tabular}{|c|c|c|c|c|c|}
\hline Procapra picticaudata & 藏原羚 & II & $\begin{array}{l}\text { 无危 } \\
\text { /LC }\end{array}$ & Zhigang Jiang & $\begin{array}{l}\text { Mitochondrial phylogeography and genetic diversity of Tibetan gazelle (Procapra picticaudata): } \\
\text { Implications for conservation }\end{array}$ \\
\hline Procapra picticaudata & 藏原羚 & II & $\begin{array}{l}\text { 无危 } \\
\text { /LC }\end{array}$ & ZHIGANG JIANG & Nonrandom mixing between groups of Przewalski’ s gazelle and Tibetan gazelle \\
\hline Procapra picticaudata & 藏原羚 & II & $\begin{array}{l}\text { 无危 } \\
\text { /LC }\end{array}$ & Zhigang Jiang & $\begin{array}{l}\text { Phylogenetic relationships of Chinese antelopes (subfamily Antilopinae) based on } \\
\text { mitochondrial ribosomal RNA gene sequences }\end{array}$ \\
\hline Procapra picticaudata & 藏原羚 & II & $\begin{array}{l}\text { 无危 } \\
\text { /LC }\end{array}$ & & $\begin{array}{l}\text { Recent Geological Events and Intrinsic Behavior Influence the Population Genetic Structure of } \\
\text { the Chiru and Tibetan Gazelle on the Tibetan Plateau }\end{array}$ \\
\hline Procapra picticaudata & 藏原羚 & II & $\begin{array}{l}\text { 无危 } \\
\text { /LC }\end{array}$ & Z. Li & Sexual segregation in Tibetan gazelle: a test of the activity budget hypothesis \\
\hline Procapra picticaudata & 藏原羚 & II & $\begin{array}{l}\text { 无危 } \\
\text { /LC }\end{array}$ & Xiaoyun Shen & Studies of ' 'Unsteady Gait Disease’ ' of the Tibetan Gazelle (Procapra picticaudata) \\
\hline Procapra picticaudata & 藏原羚 & II & $\begin{array}{l}\text { 无危 } \\
\text { /LC }\end{array}$ & 王 勇 & 藏羚羊、藏原羚和普氏原羚部分血液生理生化指标的测定 \\
\hline Procapra picticaudata & 藏原羚 & II & $\begin{array}{l}\text { 无危 } \\
\text { /LC }\end{array}$ & 鲁庆彬 & 藏原羚产仔期社群结构与昼间行为规律 \\
\hline Procapra picticaudata & 藏原羚 & II & $\begin{array}{l}\text { 无危 } \\
\text { /LC }\end{array}$ & 董永鸿 & 藏原羚肠毒血症的诊断 \\
\hline Procapra picticaudata & 藏原羚 & II & 无危 & 鲁庆彬 & 藏原羚的生物学研究概况 \\
\hline
\end{tabular}


顾垒，闻丞，罗玫，王吴，吕植. 中国最受关注濒危物种保护现状快速评价的新方法探讨. 生物多样性，2015，23(5)：583-590. http://www. biodiversity-science. net/CN/article/downloadArticleFile. do?attachType=PDF\&id=10075

\begin{tabular}{|c|c|c|c|c|c|}
\hline & & & $/ \mathrm{LC}$ & & \\
\hline \multirow[t]{2}{*}{ Procapra picticaudata } & 藏原羚 & II & 无危 & 鲁庆彬 & 藏原羚的生物学研究概况 \\
\hline & & & $/ \mathrm{LC}$ & & \\
\hline \multirow[t]{2}{*}{ Procapra picticaudata } & 藏原羚 & II & 无危 & 苏建平 & 藏原羚集群行为的初步研究 \\
\hline & & & $/ \mathrm{LC}$ & & \\
\hline \multirow[t]{2}{*}{ Procapra picticaudata } & 藏原羚 & II & 无危 & 鲁庆彬 & 藏原羚研究现状与进展 \\
\hline & & & $/ \mathrm{LC}$ & & \\
\hline \multirow[t]{2}{*}{ Procapra picticaudata } & 藏原羚 & II & 无危 & 董永鸿 & 藏原羚与藏羊并发肠毒血症 \\
\hline & & & $/ \mathrm{LC}$ & & \\
\hline \multirow[t]{2}{*}{ Procapra picticaudata } & 藏原羚 & II & 无危 & 张洪茂 & 川西北高原藏原羚夏季生境选择 \\
\hline & & & $/ \mathrm{LC}$ & & \\
\hline \multirow[t]{2}{*}{ Procapra picticaudata } & 藏原羚 & II & 无危 & 刘迺发 & 甘肃盐池湾自然保护区有蹄类动物资源变化 \\
\hline & & & $/ \mathrm{LC}$ & & \\
\hline \multirow[t]{2}{*}{ Procapra picticaudata } & 藏原羚 & II & 无危 & 方盛国 & 基于 Cyt b 基因探讨羚羊亚科原羚属系统发生关系 \\
\hline & & & $/ \mathrm{LC}$ & & \\
\hline \multirow[t]{2}{*}{ Procapra picticaudata } & 藏原羚 & II & 无危 & 蒋志刚 & 景观尺度上原羚属物种的竞争共存机制 \\
\hline & & & /LC & & \\
\hline \multirow[t]{2}{*}{ Procapra picticaudata } & 藏原羚 & II & 无危 & 苏建平 & 可可西里藏羚羊、野牦牛、藏野驴和藏原羚冬季蠕虫卵粪检研究初报 \\
\hline & & & /LC & & \\
\hline
\end{tabular}


顾垒，闻丞，罗玫，王吴，吕植. 中国最受关注濒危物种保护现状快速评价的新方法探讨. 生物多样性，2015，23(5)：583-590. http://www biodiversity-science. net/CN/article/downloadArticleFile. do?attachType=PDF\&id=10075

\begin{tabular}{|c|c|c|c|c|c|}
\hline Procapra picticaudata & 藏原羚 & II & $\begin{array}{l}\text { 无危 } \\
\text { /LC }\end{array}$ & 魏万红 & 可可西里地区藏羚羊、藏原羚和藏野驴的营养生态位 \\
\hline Procapra picticaudata & 藏原羚 & II & $\begin{array}{l}\text { 无危 } \\
\text { /LC }\end{array}$ & 连新明 & 可可西里四种有蹄类动物对道路的回避距离及保护建议 \\
\hline Procapra picticaudata & 藏原羚 & II & $\begin{array}{l}\text { 无危 } \\
\text { /LC }\end{array}$ & 李晓晓 & 可可西里同域分布藏羚与藏原羚生境选择研究 \\
\hline Procapra picticaudata & 藏原羚 & II & $\begin{array}{l}\text { 无危 } \\
\text { /LC }\end{array}$ & 魏万红 & 青藏公路对藏羚羊、藏原羚和藏野驴活动的影响 \\
\hline Procapra picticaudata & 藏原羚 & II & $\begin{array}{l}\text { 无危 } \\
\text { /LC }\end{array}$ & 于智勇 & 青藏公路沿线藏羚羊、藏野驴和藏原羚的行为比较 \\
\hline Procapra picticaudata & 藏原羚 & II & $\begin{array}{l}\text { 无危 } \\
\text { /LC }\end{array}$ & 魏万红 & 青藏铁路、公路对野生动物活动的影响 \\
\hline Procapra picticaudata & 藏原羚 & II & $\begin{array}{l}\text { 无危 } \\
\text { /LC }\end{array}$ & 张洪峰 & 青藏铁路小桥被藏羚羊等高原野生动物利用的监测研究 \\
\hline Procapra picticaudata & 藏原羚 & II & $\begin{array}{l}\text { 无危 } \\
\text { /LC }\end{array}$ & 付鹏 & 青藏铁路野生动物通道有效性分析 \\
\hline Procapra picticaudata & 藏原羚 & II & $\begin{array}{l}\text { 无危 } \\
\text { /LC }\end{array}$ & 靳铁治 & 青藏铁路野生动物通道周边主要野生动物分布调查 \\
\hline Procapra picticaudata & 藏原羚 & II & 无危 & 蒋志刚 & 青海布哈河上游地区同域分布的普氏原羚与藏原羚草青期的集群比较 \\
\hline
\end{tabular}


顾垒，闻丞，罗玫，王吴，吕植. 中国最受关注濒危物种保护现状快速评价的新方法探讨. 生物多样性，2015，23(5)：583-590. http://www. biodiversity-science. net/CN/article/downloadArticleFile. do?attachType=PDF\&id=10075

\begin{tabular}{|c|c|c|c|c|c|}
\hline & & & $/ \mathrm{LC}$ & & \\
\hline \multirow[t]{2}{*}{ Procapra picticaudata } & 藏原羚 & II & 无危 & 苏建平 & 青海省可可西里地区几种有蹄类动物的食物重叠初步分析 \\
\hline & & & $/ \mathrm{LC}$ & & \\
\hline \multirow[t]{2}{*}{ Procapra picticaudata } & 藏原羚 & II & 无危 & 蒋志刚 & 青海省天峻地区藏原羚的食性分析 \\
\hline & & & $/ \mathrm{LC}$ & & \\
\hline \multirow[t]{2}{*}{ Procapra picticaudata } & 藏原羚 & II & 无危 & 刘少英 & 四川若尔盖湿地国家级自然保护区兽类资源调查 \\
\hline & & & $/ \mathrm{LC}$ & & \\
\hline \multirow[t]{2}{*}{ Procapra picticaudata } & 藏原羚 & II & 无危 & 鲁庆彬 & 四川省石渠县藏原羚秋季取食行为特征 \\
\hline & & & $/ \mathrm{LC}$ & & \\
\hline \multirow[t]{2}{*}{ Procapra picticaudata } & 藏原羚 & II & 无危 & 鲁庆彬 & 四川石渠县藏原羚夏季数量集群及分布特点 \\
\hline & & & $/ \mathrm{LC}$ & & \\
\hline \multirow[t]{2}{*}{ Procapra picticaudata } & 藏原羚 & II & 无危 & 鲁庆彬 & 四川石渠县藏原羚种群观察 \\
\hline & & & $/ \mathrm{LC}$ & & \\
\hline \multirow[t]{2}{*}{ Procapra picticaudata } & 藏原羚 & II & 无危 & 王小明 & 四川石渠县夏季藏原羚的分布和栖息地特征 \\
\hline & & & $/ \mathrm{LC}$ & & \\
\hline \multirow[t]{2}{*}{ Procapra picticaudata } & 藏原羚 & II & 无危 & 鲁庆彬 & 四少 11 石渠县藏原羚夏秋两季的昼间行为观察 \\
\hline & & & $/ \mathrm{LC}$ & & \\
\hline \multirow[t]{2}{*}{ Procapra picticaudata } & 藏原羚 & II & 无危 & Migmar Wangdwei & 西藏差塘自然保护区藏羚和藏原羚的生境选择 \\
\hline & & & /LC & & \\
\hline
\end{tabular}


顾垒，闻丞，罗玫，王吴，吕植. 中国最受关注濒危物种保护现状快速评价的新方法探讨. 生物多样性，2015，23(5)：583-590. http://www. biodiversity-science. net/CN/article/downloadArticleFile. do?attachType=PDF\&id=10075

\begin{tabular}{|c|c|c|c|c|c|}
\hline \multirow[t]{2}{*}{ Procapra picticaudata } & 藏原羚 & II & 无危 & Joseph L .FOX & 西藏差塘自然保护区与人类活动有关的藏羚、藏野驴和藏原羚密度 \\
\hline & & & $/ \mathrm{LC}$ & & \\
\hline \multirow[t]{2}{*}{ Procapra picticaudata } & 藏原羚 & II & 无危 & 连新明 & 夏季可可西里雌性藏原羚行为时间分配及活动节律 \\
\hline & & & $/ \mathrm{LC}$ & & \\
\hline \multirow[t]{2}{*}{ Procapra przewalskii } & 普氏原羚 & I & 濒危 & Zhigang Jiang & A Spatially Explicit Model of Functional Connectivity for the Endangered Przewalski' s \\
\hline & & & /EN & & Gazelle (Procapra przewalskii) in a Patchy Landscape \\
\hline \multirow[t]{2}{*}{ Procapra przewalskii } & 普氏原羚 & I & 濒危 & Zhigang Jiang & Detecting the potential sympatric range and niche divergence between Asian endemic ungulates \\
\hline & & & /EN & & of Procapra \\
\hline \multirow[t]{2}{*}{ Procapra przewalskii } & 普氏原羚 & I & 濒危 & Zhigang Jiang & Genetic diversity, population genetic structure and demographic history of Przewalski’s gazelle \\
\hline & & & /EN & & (Procapra przewalskii): implications for conservation \\
\hline \multirow[t]{2}{*}{ Procapra przewalskii } & 普氏原羚 & I & 濒危 & Zhigang Jiang & Group pattern and social segregation in Przewalski's gazelle (Procapra przewalskii) around \\
\hline & & & /EN & & Qinghai Lake, China \\
\hline \multirow[t]{2}{*}{ Procapra przewalskii } & 普氏原羚 & I & 濒危 & 刘毅 & SSR 在普氏原羚个体识别和分子保护遗传学中的应用 \\
\hline & & & /EN & & \\
\hline \multirow[t]{2}{*}{ Procapra przewalskii } & 普氏原羚 & I & 濒危 & 王勇 & 藏羚羊、藏原羚和普氏原羚部分血液生理生化指标的测定 \\
\hline & & & $/ \mathrm{EN}$ & & \\
\hline \multirow[t]{2}{*}{ Procapra przewalskii } & 普氏原羚 & I & 濒危 & 蒋志刚 & 草原围栏对普氏原羚行为和栖息地面积的影响 \\
\hline & & & /EN & & \\
\hline Procapra przewalskii & 普氏原羚 & I & 濒危 & 李迪强 & 粪便 DNA 中篮选普氏原羚微卫星引物并应用于个体识别 \\
\hline
\end{tabular}


顾垒，闻丞，罗玫，王吴，吕植. 中国最受关注濒危物种保护现状快速评价的新方法探讨. 生物多样性，2015，23(5)：583-590. http://www. biodiversity-science. net/CN/article/downloadArticleFile. do?attachType=PDF\&id=10075

\begin{tabular}{|c|c|c|c|c|c|}
\hline & & & /EN & & \\
\hline \multirow[t]{2}{*}{ Procapra przewalskii } & 普氏原羚 & I & 濒危 & 李迪强 & 粪便不同保存方法对动物基因组 D N A 提取效果的影响 \\
\hline & & & $/$ EN & & \\
\hline \multirow[t]{2}{*}{ Procapra przewalskii } & 普氏原羚 & I & 濒危 & 张耀南 & 基于空间建模语言的普氏原羚生存能力模型的构建 \\
\hline & & & /EN & & \\
\hline \multirow[t]{2}{*}{ Procapra przewalskii } & 普氏原羚 & I & 濒危 & 李迪强 & 普氏原羚保护区建立与社区不同收入牧民群体的关系分析 \\
\hline & & & /EN & & \\
\hline \multirow[t]{2}{*}{ Procapra przewalskii } & 普氏原羚 & I & 濒危 & 郑杰 & 普氏原羚保护巫待关注与解决的问题 \\
\hline & & & /EN & & \\
\hline \multirow[t]{2}{*}{ Procapra przewalskii } & 普氏原羚 & I & 濒危 & 高岗 & 普氏原羚保护与社区的相互关系研究 \\
\hline & & & /EN & & \\
\hline \multirow[t]{2}{*}{ Procapra przewalskii } & 普氏原羚 & I & 濒危 & 李迪强 & 普氏原羚保护中牧民行为及参与保护意愿分析 \\
\hline & & & /EN & & \\
\hline \multirow[t]{2}{*}{ Procapra przewalskii } & 普氏原羚 & I & 濒危 & 蒋志刚 & 普氏原羚的采食对策 \\
\hline & & & /EN & & \\
\hline \multirow[t]{2}{*}{ Procapra przewalskii } & 普氏原羚 & I & 濒危 & 叶润蓉 & 普氏原羚的分布和种群数量调查 \\
\hline & & & /EN & & \\
\hline \multirow[t]{2}{*}{ Procapra przewalskii } & 普氏原羚 & I & 濒危 & 蒋志刚 & 普氏原羚的求偶交配行为 \\
\hline & & & /EN & & \\
\hline
\end{tabular}


顾垒，闻丞，罗玫，王吴，吕植. 中国最受关注濒危物种保护现状快速评价的新方法探讨. 生物多样性，2015，23(5)：583-590. http://www. biodiversity-science. net/CN/article/downloadArticleFile. do?attachType=PDF\&id=10075

\begin{tabular}{|c|c|c|c|c|c|}
\hline Procapra przewalskii & 普氏原羚 & I & $\begin{array}{l}\text { 濒危 } \\
\text { /EN }\end{array}$ & 刘毅 & 普氏原羚的食性研究 \\
\hline Procapra przewalskii & 普氏原羚 & I & $\begin{array}{l}\text { 濒危 } \\
\text { /EN }\end{array}$ & 李迪强 & 普氏原羚粪便 DNA 提取方法的改进与比较 \\
\hline Procapra przewalskii & 普氏原羚 & I & $\begin{array}{l}\text { 濒危 } \\
\text { /EN }\end{array}$ & 马瑞俊 & 普氏原羚和蒙古瞪羚的分布和数量变化研究 \\
\hline Procapra przewalskii & 普氏原羚 & I & $\begin{array}{l}\text { 濒危 } \\
\text { /EN }\end{array}$ & 石建斌 & 普氏原羚集群的群体决策过程 \\
\hline Procapra przewalskii & 普氏原羚 & I & $\begin{array}{l}\text { 濒危 } \\
\text { /EN }\end{array}$ & 沈明华 & 普氏原羚若干血液生理生化指标测定 \\
\hline Procapra przewalskii & 普氏原羚 & I & $\begin{array}{l}\text { 濒危 } \\
\text { /EN }\end{array}$ & 李迪强 & 普氏原羚生境的景观动态与适宜性评价研究 \\
\hline Procapra przewalskii & 普氏原羚 & I & $\begin{array}{l}\text { 濒危 } \\
\text { /EN }\end{array}$ & 蒋志刚 & 普氏原羚生境选择的数量化分析 \\
\hline Procapra przewalskii & 普氏原羚 & I & $\begin{array}{l}\text { 濒危 } \\
\text { /EN }\end{array}$ & 刘毅 & 普氏原羚食性分析及分子生态学研究 \\
\hline Procapra przewalskii & 普氏原羚 & I & $\begin{array}{l}\text { 濒危 } \\
\text { /EN }\end{array}$ & 蒋志刚 & 普氏原羚研究概述 \\
\hline Procapra przewalskii & 普氏原羚 & I & 濒危 & 郑杰 & 普氏原羚种群现状与保护 \\
\hline
\end{tabular}


顾垒，闻丞，罗玫，王吴，吕植. 中国最受关注濒危物种保护现状快速评价的新方法探讨. 生物多样性，2015，23(5)：583-590. http://www. biodiversity-science. net/CN/article/downloadArticleFile. do?attachType=PDF\&id=10075

\begin{tabular}{|c|c|c|c|c|c|}
\hline & & & /EN & & \\
\hline \multirow[t]{2}{*}{ Procapra przewalskii } & 普氏原羚 & I & 濒危 & 蒋志刚 & 青海布哈河上游地区同域分布的普氏原羚与藏原羚草青期的集群比较 \\
\hline & & & $/$ EN & & \\
\hline \multirow[t]{2}{*}{ Procapra przewalskii } & 普氏原羚 & I & 濒危 & 蒋志刚 & 青海湖草原围栏对植物群落的影响兼论濒危动物普氏原羚的保护 \\
\hline & & & /EN & & \\
\hline \multirow[t]{2}{*}{ Procapra przewalskii } & 普氏原羚 & I & 濒危 & 蒋志刚 & 青海湖地区普氏原羚的种群结构 \\
\hline & & & /EN & & \\
\hline \multirow[t]{2}{*}{ Procapra przewalskii } & 普氏原羚 & I & 濒危 & 李迪强 & 青海湖东－克图地区普氏原羚生境适宜性评价 \\
\hline & & & /EN & & \\
\hline \multirow[t]{2}{*}{ Procapra przewalskii } & 普氏原羚 & I & 濒危 & 龙瑞军 & 青海湖东普氏原羚及生境地微量元素季节变化研究 \\
\hline & & & /EN & & \\
\hline \multirow[t]{2}{*}{ Procapra przewalskii } & 普氏原羚 & I & 濒危 & 周立业 & 青海湖湖东区土一草一普氏原羚系统中微量元素含量研究 \\
\hline & & & /EN & & \\
\hline \multirow[t]{2}{*}{ Procapra przewalskii } & 普氏原羚 & I & 濒危 & 孙建青 & 青海湖区普氏原羚及鸟类栖息草地的调查与研究 \\
\hline & & & /EN & & \\
\hline \multirow[t]{2}{*}{ Procapra przewalskii } & 普氏原羚 & I & 濒危 & 吴永林 & 青海湖区普氏原羚与鸟类种群监测 \\
\hline & & & /EN & & \\
\hline \multirow[t]{2}{*}{ Procapra przewalskii } & 普氏原羚 & I & 濒危 & 王光明 & 青海天峻普氏原羚生存环境调查 \\
\hline & & & /EN & & \\
\hline
\end{tabular}


顾垒，闻丞，罗玫，王吴，吕植. 中国最受关注濒危物种保护现状快速评价的新方法探讨. 生物多样性，2015，23(5)：583-590. http://www. biodiversity-science. net/CN/article/downloadArticleFile. do?attachType=PDF\&id=10075

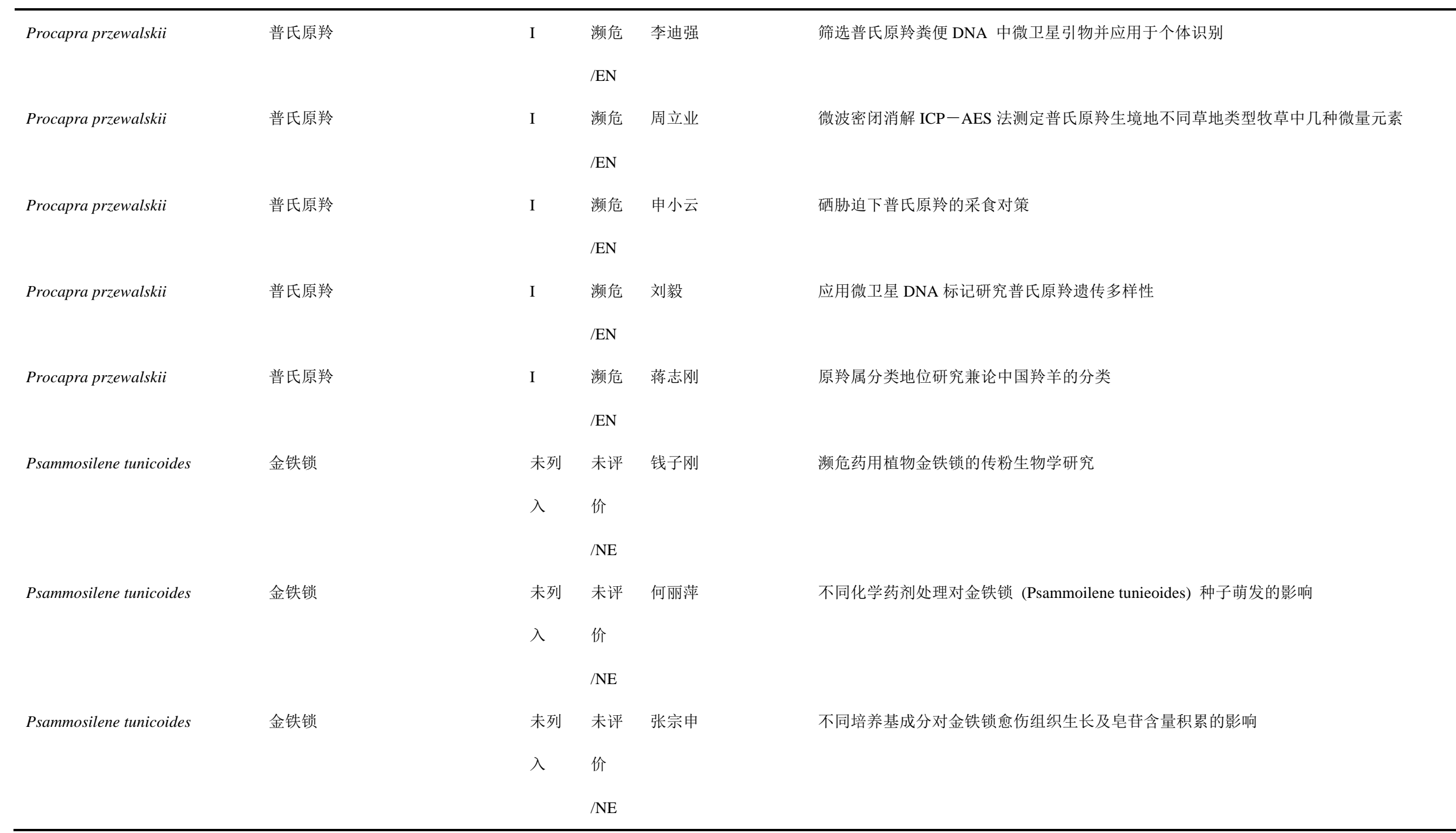


顾垒，闻丞，罗玫，王吴，吕植. 中国最受关注濒危物种保护现状快速评价的新方法探讨. 生物多样性，2015，23(5)：583-590. http://www. biodiversity-science. net/CN/article/downloadArticleFile. do?attachType=PDF\&id=10075

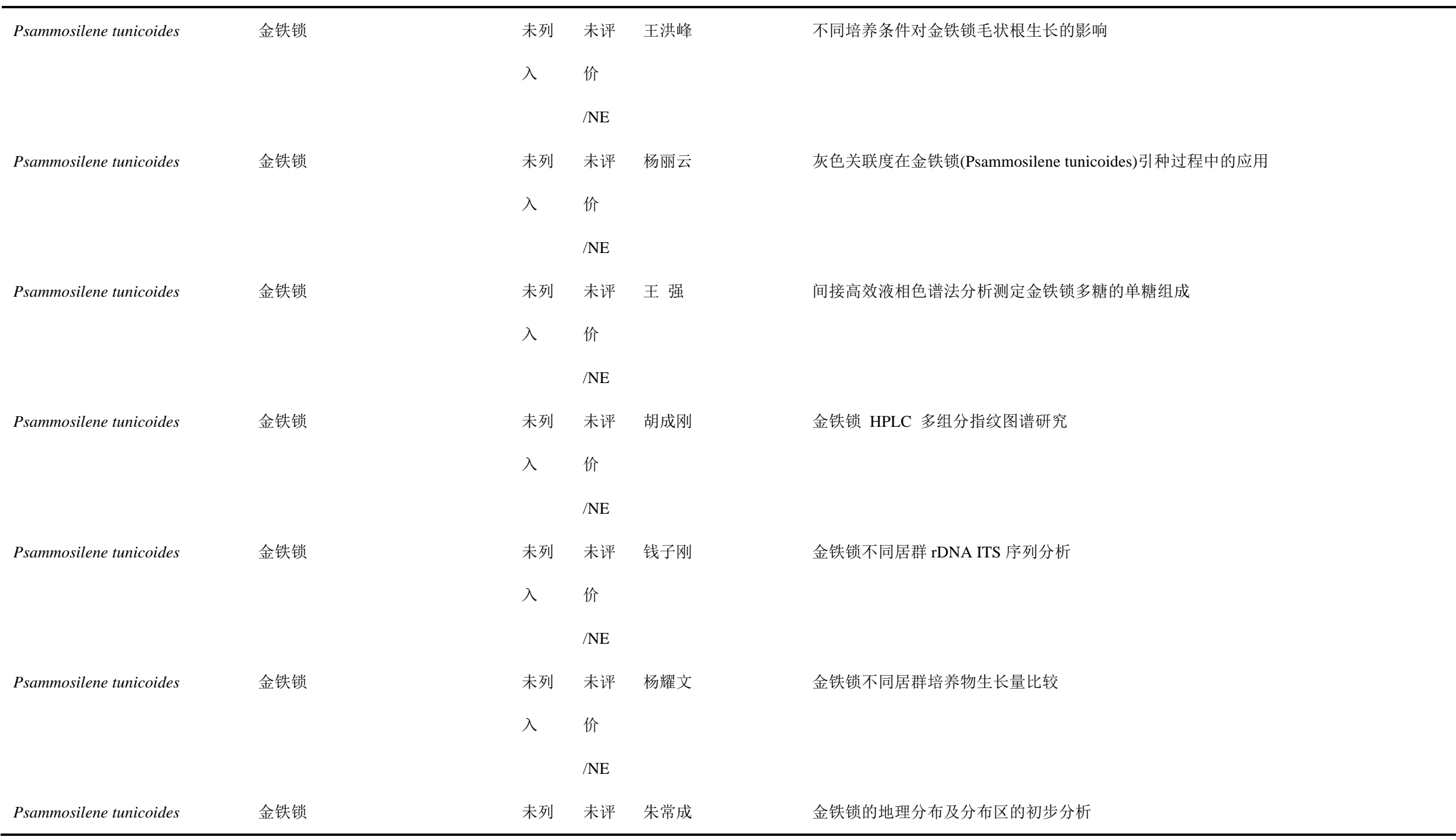


顾垒，闻丞，罗玫，王吴，吕植. 中国最受关注濒危物种保护现状快速评价的新方法探讨. 生物多样性，2015，23(5)：583-590. http://www. biodiversity-science. net/CN/article/downloadArticleFile. do?attachType=PDF\&id=10075

\begin{tabular}{|c|c|c|c|c|c|}
\hline & & $\lambda$ & 价 & & \\
\hline Psammosilene tunicoides & 金铁锁 & $\begin{array}{l}\text { 未列 } \\
入\end{array}$ & $\begin{array}{l}/ \mathrm{NE} \\
\text { 未评 } \\
\text { 价 }\end{array}$ & 朱瑞良 & 金铁锁的化学成分和药理活性研究进展 \\
\hline Psammosilene tunicoides & 金铁锁 & $\begin{array}{l}\text { 未列 } \\
入\end{array}$ & $\begin{array}{l}\text { /NE } \\
\text { 未评 } \\
\text { 价 }\end{array}$ & 陈昌祥 & 金铁锁的两个新三萜㿝苷 \\
\hline Psammosilene tunicoides & 金铁锁 & $\begin{array}{l}\text { 未列 } \\
入\end{array}$ & $\begin{array}{l}/ \mathrm{NE} \\
\text { 未评 } \\
\text { 价 }\end{array}$ & 王世清 & 金铁锁的显微和理化鉴定研究 \\
\hline Psammosilene tunicoides & 金铁锁 & $\begin{array}{l}\text { 未列 } \\
入\end{array}$ & $\begin{array}{l}\text { /NE } \\
\text { 未评 } \\
\text { 价 }\end{array}$ & 陈昌祥 & 金铁锁的新三萜㿝式 \\
\hline Psammosilene tunicoides & 金铁锁 & $\begin{array}{l}\text { 未列 } \\
入\end{array}$ & $\begin{array}{l}\text { /NE } \\
\text { 未评 } \\
\text { 价 }\end{array}$ & 黄春青 & 金铁锁的研究进展 \\
\hline Psammosilene tunicoides & 金铁锁 & $\begin{array}{l}\text { 未列 } \\
\text { 入 }\end{array}$ & $\begin{array}{l}\text { /NE } \\
\text { 未评 } \\
\text { 价 }\end{array}$ & 许建阳 & 金铁锁对实验性 RA 小鼠痛阈及血清 NO/NOS 含量的影响 \\
\hline
\end{tabular}


顾垒，闻丞，罗玫，王吴，吕植. 中国最受关注濒危物种保护现状快速评价的新方法探讨．生物多样性，2015，23(5)：583-590。 http://www. biodiversity-science. net/CN/article/downloadArticleFile. do?attachType=PDF\&id=10075

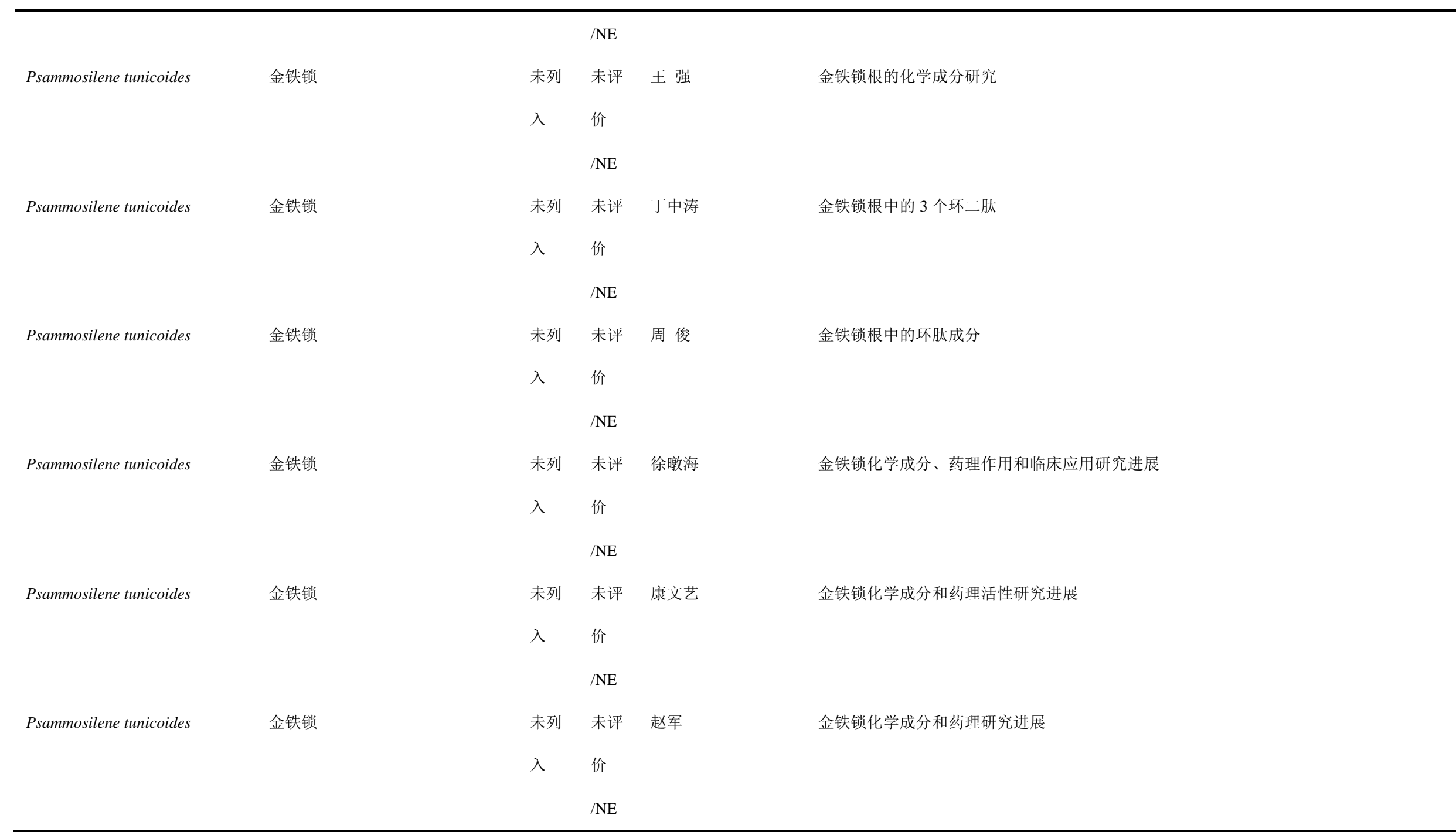


顾垒，闻丞，罗玫，王吴，吕植. 中国最受关注濒危物种保护现状快速评价的新方法探讨. 生物多样性，2015，23(5)：583-590. http://www. biodiversity-science. net/CN/article/downloadArticleFile. do?attachType=PDF\&id=10075

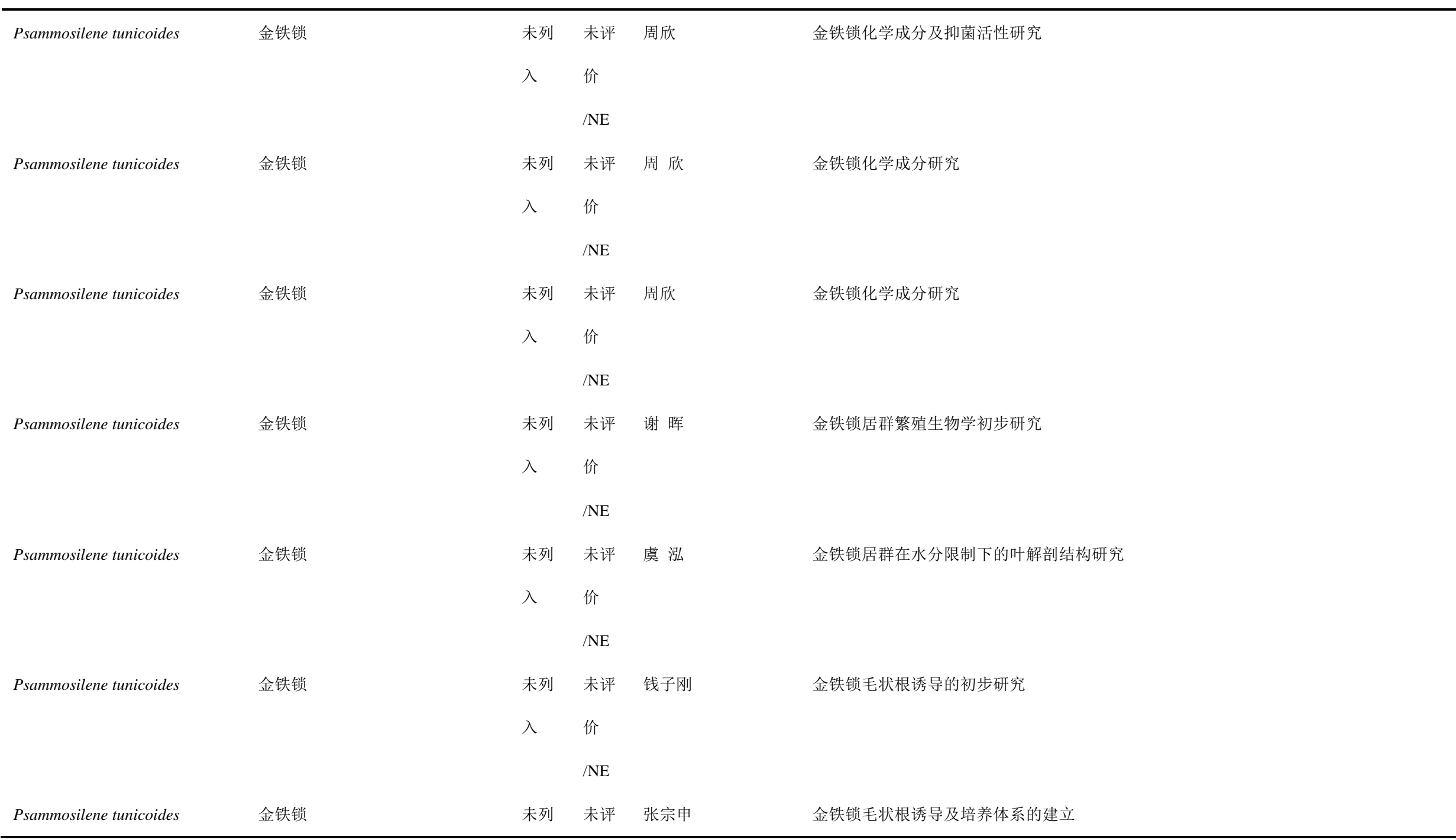


顾垒，闻丞，罗玫，王吴，吕植. 中国最受关注濒危物种保护现状快速评价的新方法探讨．生物多样性，2015，23(5)：583-590。 http://www. biodiversity-science. net/CN/article/downloadArticleFile. do?attachType=PDF\&id=10075

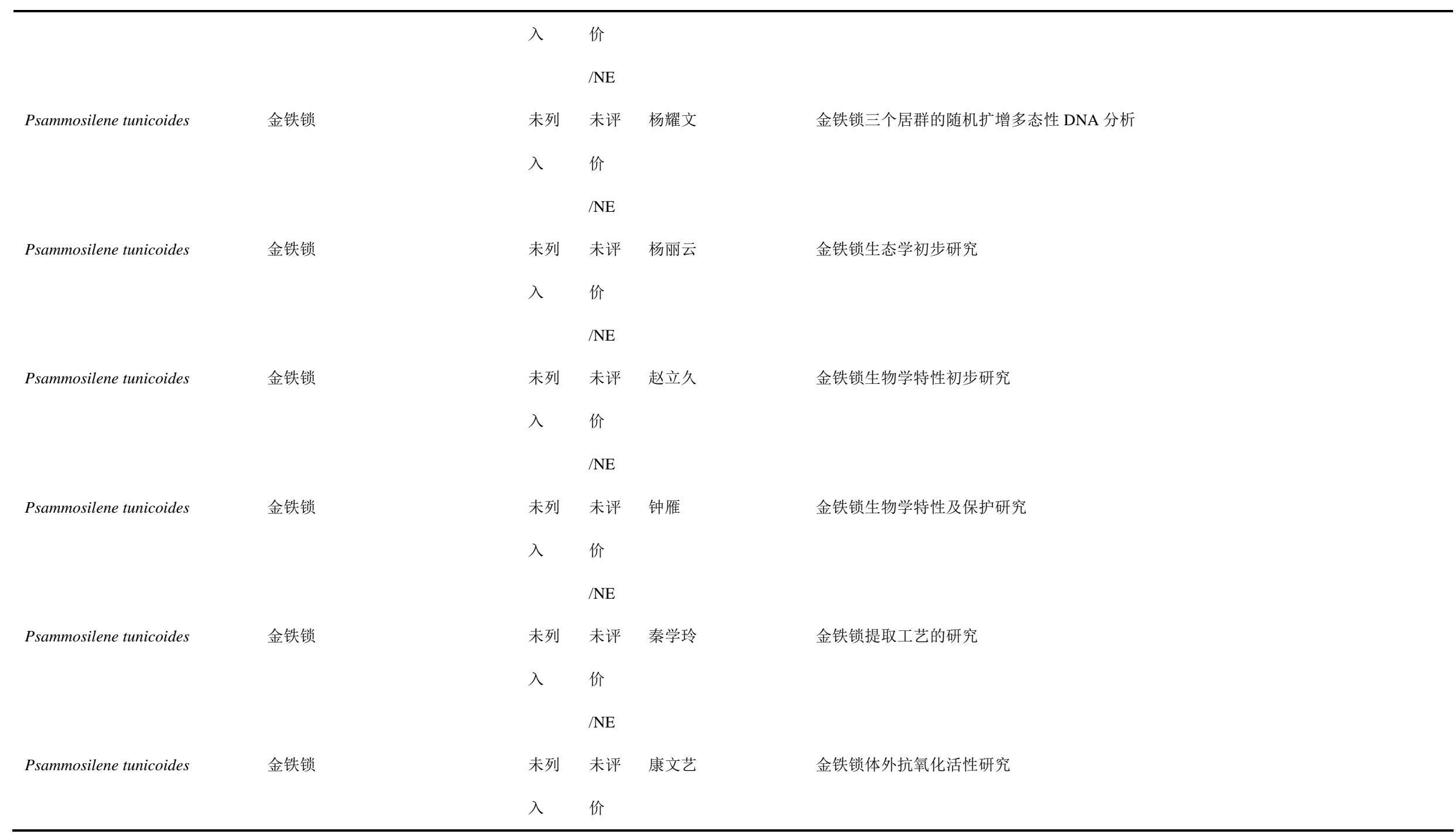


顾垒，闻丞，罗玫，王吴，吕植. 中国最受关注濒危物种保护现状快速评价的新方法探讨．生物多样性，2015，23(5)：583-590。 http://www. biodiversity-science. net/CN/article/downloadArticleFile. do?attachType=PDF\&id=10075

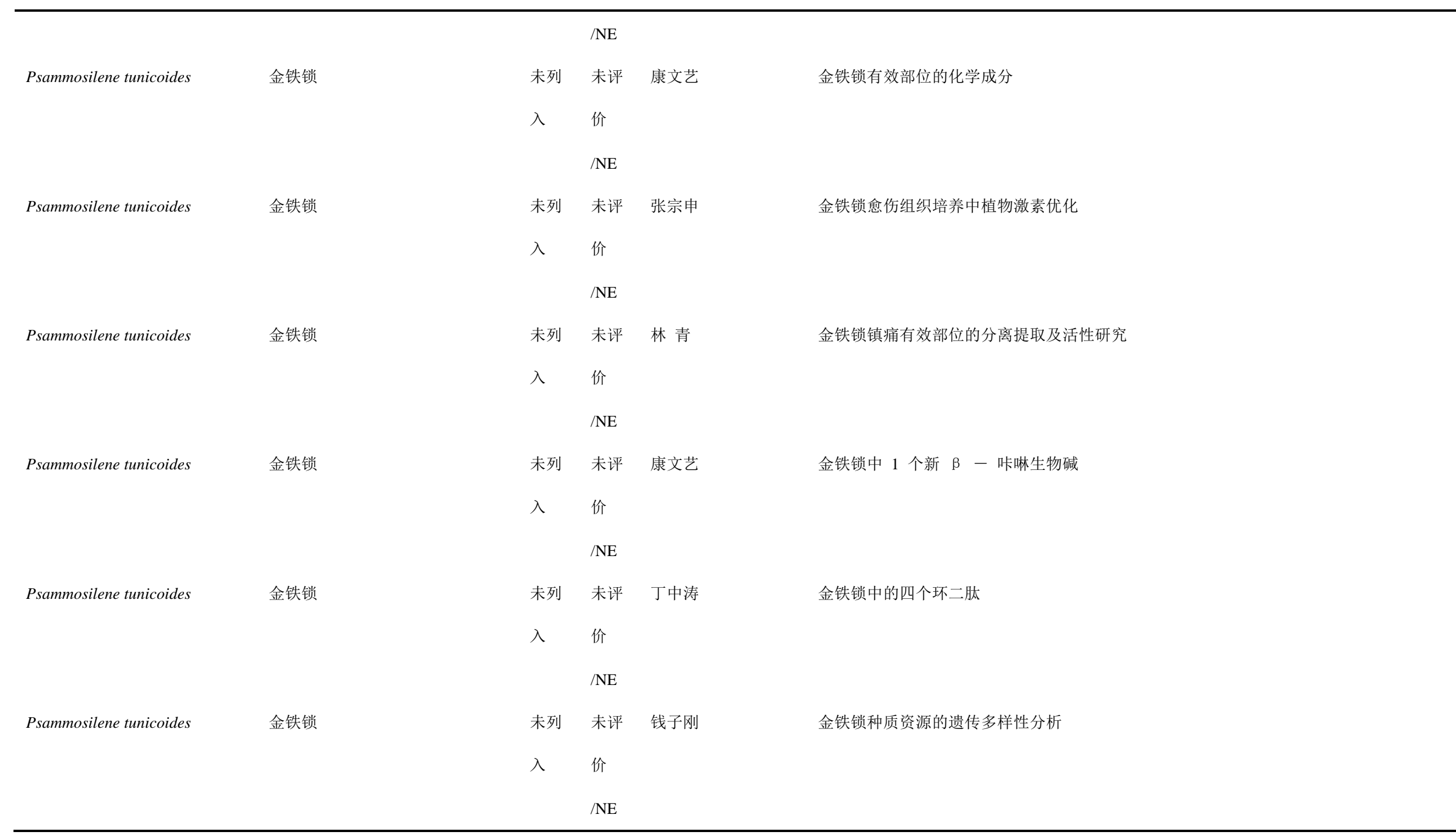


顾垒，闻丞，罗玫，王吴，吕植. 中国最受关注濒危物种保护现状快速评价的新方法探讨. 生物多样性，2015，23(5)：583-590. http://www. biodiversity-science. net/CN/article/downloadArticleFile. do?attachType=PDF\&id=10075

\begin{tabular}{|c|c|c|c|c|c|}
\hline Psammosilene tunicoides & 金铁锁 & $\begin{array}{l}\text { 未列 } \\
\lambda\end{array}$ & $\begin{array}{l}\text { 未评 } \\
\text { 价 } \\
\text { /NE }\end{array}$ & 周欣 & 金铁锁总㿝苷含量测定 \\
\hline Psammosilene tunicoides & 金铁锁 & $\begin{array}{l}\text { 未列 } \\
\text { 入 }\end{array}$ & $\begin{array}{l}\text { 未评 } \\
\text { 价 } \\
\text { /NE }\end{array}$ & 王学勇 & 金铁锁总㿝苷抗类风湿性关节炎作用及其作用机制研究 \\
\hline Psammosilene tunicoides & 金铁锁 & $\begin{array}{l}\text { 未列 } \\
\text { 入 }\end{array}$ & $\begin{array}{l}\text { 未评 } \\
\text { 价 } \\
\text { /NE }\end{array}$ & 王学勇 & 金铁锁总㿝苷抗炎镇痛作用及作用机理研究 \\
\hline Psammosilene tunicoides & 金铁锁 & $\begin{array}{l}\text { 未列 } \\
\text { 入 }\end{array}$ & $\begin{array}{l}\text { 未评 } \\
\text { 价 } \\
\text { /NE }\end{array}$ & 王华磊 & 金铁锁总㿝苷提取工艺研究 \\
\hline Psammosilene tunicoides & 金铁锁 & $\begin{array}{l}\text { 未列 } \\
\text { 入 }\end{array}$ & $\begin{array}{l}\text { 未评 } \\
\text { 价 } \\
\text { /NE }\end{array}$ & 林亚平 & 均匀设计法结合药效学指标优选金铁锁提取工艺 \\
\hline Psammosilene tunicoides & 金铁锁 & $\begin{array}{l}\text { 未列 } \\
\lambda\end{array}$ & $\begin{array}{l}\text { 未评 } \\
\text { 价 } \\
\text { /NE }\end{array}$ & 陈华国 & 苗药金铁锁的薄层色谱研究 \\
\hline Psammosilene tunicoides & 金铁锁 & 未列 & 未评 & 胡成刚 & 苗药金铁锁的本草考证 \\
\hline
\end{tabular}


顾垒，闻丞，罗玫，王吴，吕植. 中国最受关注濒危物种保护现状快速评价的新方法探讨. 生物多样性，2015，23(5)：583-590. http://www. biodiversity-science. net/CN/article/downloadArticleFile. do?attachType=PDF\&id=10075

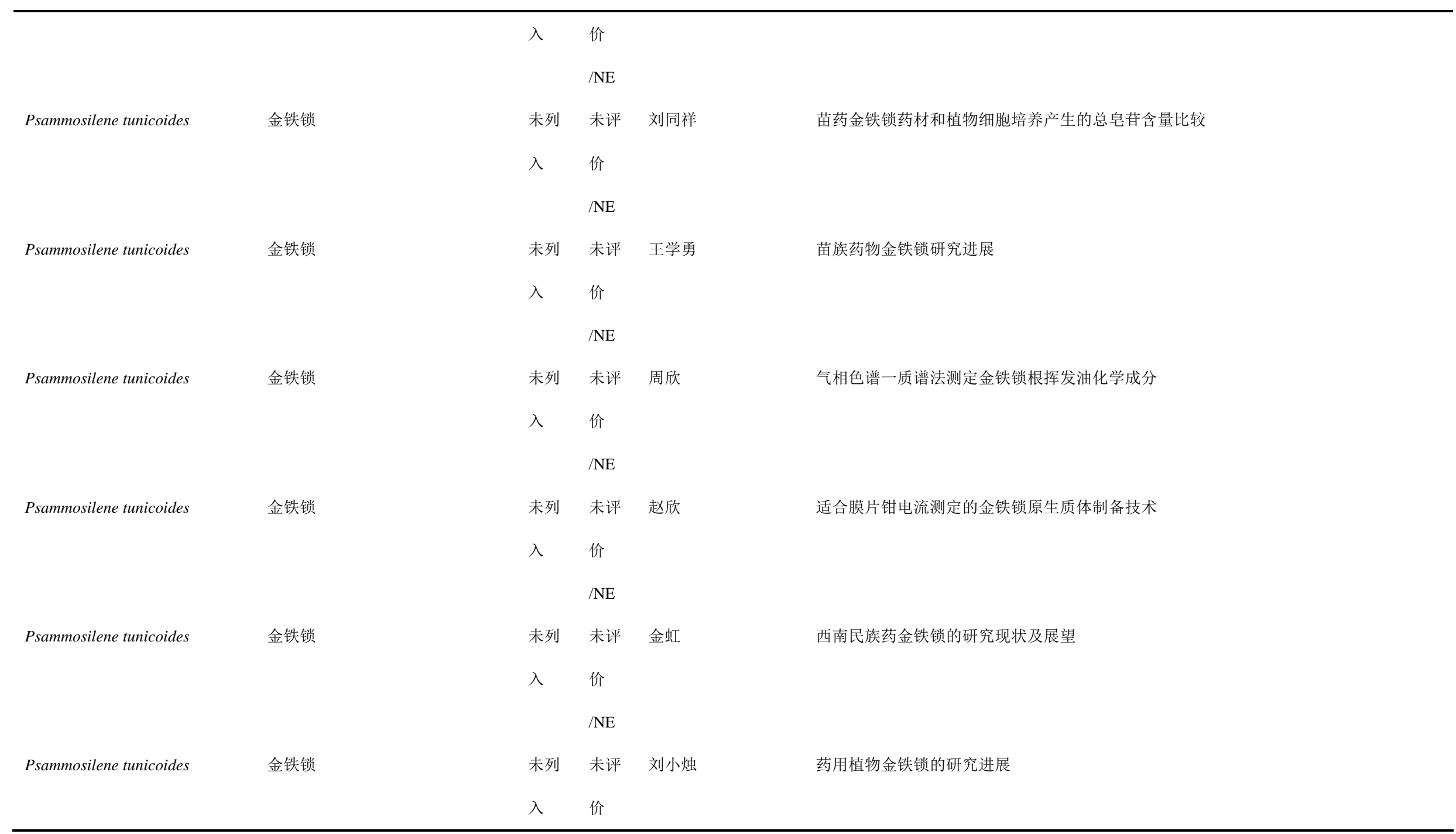


顾垒，闻丞，罗玫，王吴，吕植. 中国最受关注濒危物种保护现状快速评价的新方法探讨．生物多样性，2015，23(5)：583-590。 http://www. biodiversity-science. net/CN/article/downloadArticleFile. do?attachType=PDF\&id=10075

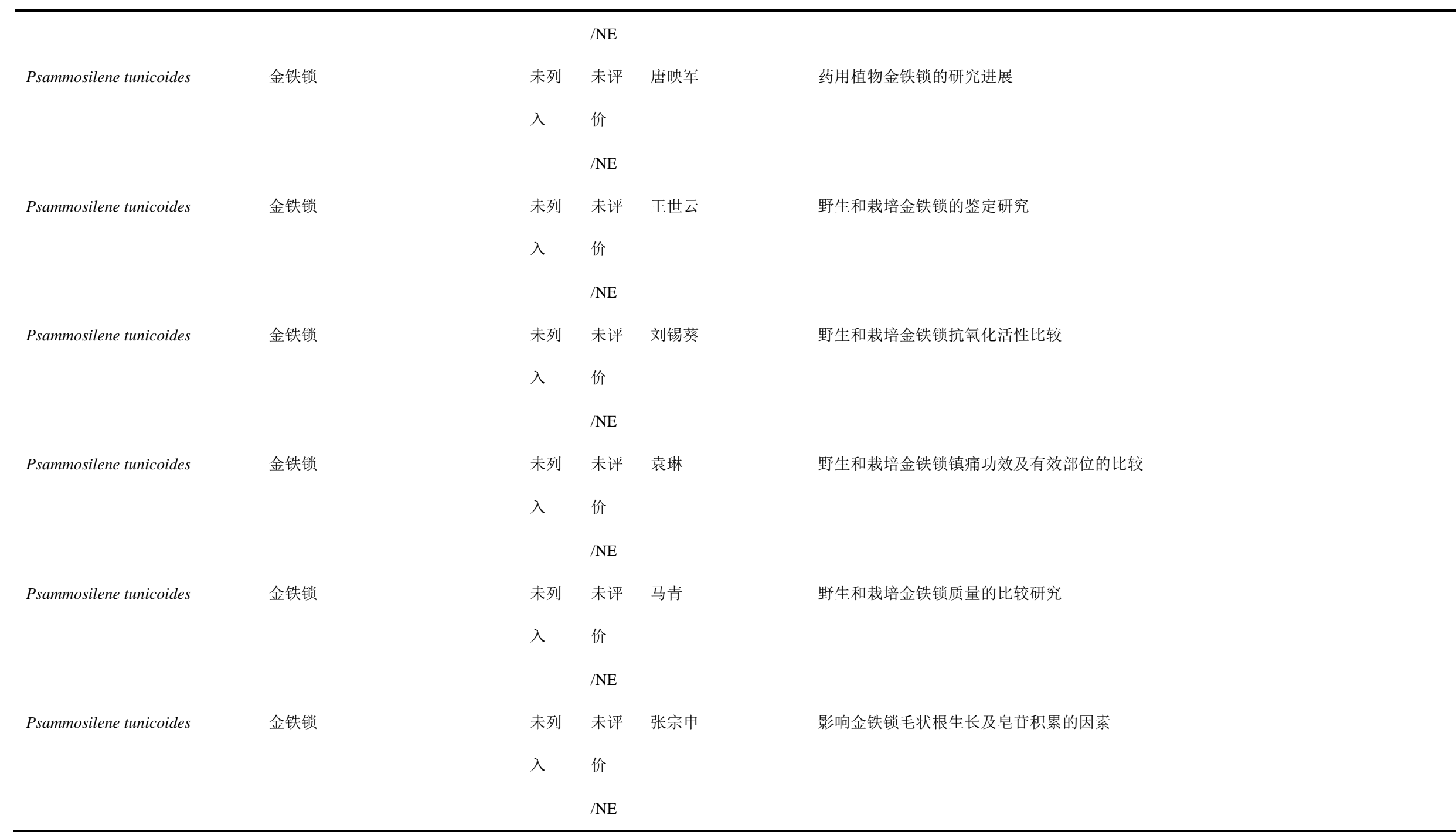


顾垒，闻丞，罗玫，王吴，吕植. 中国最受关注濒危物种保护现状快速评价的新方法探讨. 生物多样性，2015，23(5)：583-590. http://www. biodiversity-science. net/CN/article/downloadArticleFile. do?attachType=PDF\&id=10075

\begin{tabular}{|c|c|c|c|c|c|}
\hline Psammosilene tunicoides & 金铁锁 & $\begin{array}{l}\text { 未列 } \\
\lambda\end{array}$ & $\begin{array}{l}\text { 未评 } \\
\text { 价 } \\
\text { /NE }\end{array}$ & 谢 晖 & 云南金铁锁的生物学特性及其保护的初步研究 \\
\hline Psammosilene tunicoides & 金铁锁 & $\begin{array}{l}\text { 未列 } \\
入\end{array}$ & $\begin{array}{l}\text { 未评 } \\
\text { 价 } \\
\text { /NE }\end{array}$ & 杨耀文 & 珍稀濒危药用植物金铁锁的组织培养和快速繁殖研究 \\
\hline Psammosilene tunicoides & 金铁锁 & $\begin{array}{l}\text { 未列 } \\
入\end{array}$ & $\begin{array}{l}\text { 未评 } \\
\text { 价 } \\
\text { /NE }\end{array}$ & 屈燕 & 珍稀濒危药用植物金铁锁研究进展 \\
\hline Psammosilene tunicoides & 金铁锁 & $\begin{array}{l}\text { 未列 } \\
\lambda\end{array}$ & $\begin{array}{l}\text { 未评 } \\
\text { 价 } \\
\text { /NE }\end{array}$ & 龚 洵 & 中国特有植物金铁锁的细胞学研究 \\
\hline Psarisomus dalhousiae & 长尾阔嘴鸟 & II & $\begin{array}{l}\text { 无危 } \\
\text { /LC }\end{array}$ & 李肇天 & 广西邦亮长臂猿自然保护区的鸟类 \\
\hline Psarisomus dalhousiae & 长尾阔嘴鸟 & II & $\begin{array}{l}\text { 无危 } \\
\text { /LC }\end{array}$ & 陆 舟 & 广西弄岗喀斯特森林繁殖鸟群落的集团结构 \\
\hline Psarisomus dalhousiae & 长尾阔嘴鸟 & II & $\begin{array}{l}\text { 无危 } \\
\text { /LC }\end{array}$ & 雷 桂 林 & 思茅菜阳河自然保护区鸟类研究 \\
\hline Psarisomus dalhousiae & 长尾阔嘴鸟 & II & 无危 & 罗增阳 & 无量山自然保护区鸟类多样性及保护管理对策 \\
\hline
\end{tabular}


顾垒，闻丞，罗玫，王吴，吕植. 中国最受关注濒危物种保护现状快速评价的新方法探讨. 生物多样性，2015，23(5)：583-590. http://www biodiversity-science. net/CN/article/downloadArticleFile. do?attachType=PDF\&id=10075

\begin{tabular}{|c|c|c|c|c|c|}
\hline & & & $/ \mathrm{LC}$ & & \\
\hline \multirow[t]{2}{*}{ Psarisomus dalhousiae } & 长尾阔嘴鸟 & II & 无危 & 黄俊辉 & 西双版纳预养早季季风常绿阔叶林的林下鸟类群落组成和特点 \\
\hline & & & $/ \mathrm{LC}$ & & \\
\hline \multirow[t]{2}{*}{ Psarisomus dalhousiae } & 长尾阔嘴鸟 & II & 无危 & 苏栋栋 & 云南大围山和鸡足山常绿阔叶林林下鸟类群落比较 \\
\hline & & & $/ \mathrm{LC}$ & & \\
\hline \multirow[t]{2}{*}{ Psarisomus dalhousiae } & 长尾阔嘴鸟 & II & 无危 & 王云 & 云南三江并流区六库-片马公路车辆运营对路域鸟类行为的影响 \\
\hline & & & $/ \mathrm{LC}$ & & \\
\hline \multirow[t]{2}{*}{ Pseudois nayaur } & 岩羊 & II & 无危 & Zhensheng Liu & Estimating seasonal density of blue sheep ( Pseudois nayaur ) \\
\hline & & & $/ \mathrm{LC}$ & & in the Helan Mountain region using distance sampling methods \\
\hline \multirow[t]{2}{*}{ Pseudois nayaur } & 岩羊 & II & 无危 & Zhensheng LIU & Food habits of blue sheep, Pseudois nayaur in the Helan Mountains, \\
\hline & & & $/ \mathrm{LC}$ & & China \\
\hline \multirow[t]{2}{*}{ Pseudois nayaur } & 岩羊 & II & 无危 & 申定健 & 矮岩羊行为生态的初步研究 \\
\hline & & & $/ \mathrm{LC}$ & & \\
\hline \multirow[t]{2}{*}{ Pseudois nayaur } & 岩羊 & II & 无危 & 龙帅 & 矮岩羊夏季活动节律、时间分配和集群行为 \\
\hline & & & $/ \mathrm{LC}$ & & \\
\hline \multirow[t]{2}{*}{ Pseudois nayaur } & 岩羊 & II & 无危 & 王淯 & 矮岩羊种群生态的初步研究 \\
\hline & & & /LC & & \\
\hline \multirow[t]{2}{*}{ Pseudois nayaur } & 岩羊 & II & 无危 & 曹丽荣 & 从细胞色素 $\mathrm{b}$ 基因全序列差异分析岩羊和矮岩羊的系统进化关系 \\
\hline & & & /LC & & \\
\hline
\end{tabular}


顾垒，闻丞，罗玫，王吴，吕植. 中国最受关注濒危物种保护现状快速评价的新方法探讨. 生物多样性，2015，23(5)：583-590. http://www, biodiversity-science. net/CN/article/downloadArticleFile. do?attachType=PDF\&id=10075

\begin{tabular}{|c|c|c|c|c|c|}
\hline Pseudois nayaur & 岩羊 & II & $\begin{array}{l}\text { 无危 } \\
\text { /LC }\end{array}$ & 周材权 & 从线粒体细胞色素 b 基因探讨矮岩羊物种地位的有效性 \\
\hline Pseudois nayaur & 岩羊 & II & $\begin{array}{l}\text { 无危 } \\
\text { /LC }\end{array}$ & 刘建泉 & 东大山保护区岩羊对繁殖地的选择及其对气候变化的适应 \\
\hline Pseudois nayaur & 岩羊 & II & $\begin{array}{l}\text { 无危 } \\
\text { /LC }\end{array}$ & 李新庆 & 发情交配期贺兰山岩羊的集群特征 \\
\hline Pseudois nayaur & 岩羊 & II & $\begin{array}{l}\text { 无危 } \\
\text { /LC }\end{array}$ & 间永峰 & 甘肃东大山自然保护区夏季岩羊种群的初步调查 \\
\hline Pseudois nayaur & 岩羊 & II & $\begin{array}{l}\text { 无危 } \\
\text { /LC }\end{array}$ & 昶野 & 贺兰山同域分布岩羊和马鹿的夏季食性 \\
\hline Pseudois nayaur & 岩羊 & II & $\begin{array}{l}\text { 无危 } \\
\text { /LC }\end{array}$ & 骆颖 & 贺兰山同域分布岩羊和马鹿发情季节的生境选择差异 \\
\hline Pseudois nayaur & 岩羊 & II & $\begin{array}{l}\text { 无危 } \\
\text { /LC }\end{array}$ & 赵登海 & 贺兰山西坡岩羊种群现状调查研究 \\
\hline Pseudois nayaur & 岩羊 & II & $\begin{array}{l}\text { 无危 } \\
\text { /LC }\end{array}$ & 刘振生 & 贺兰山岩羊 (Pseudois nayaur)集群特征的季节变化 \\
\hline Pseudois nayaur & 岩羊 & II & $\begin{array}{l}\text { 无危 } \\
\text { /LC }\end{array}$ & 刘振生 & 贺兰山岩羊 (P s e u d o i s n a y a u r ) 夏季取食和卧息生境选择 \\
\hline Pseudois nayaur & 岩羊 & II & 无危 & 梁云㜏 & 贺兰山岩羊的生命表和春夏季节社群结构的研究 \\
\hline
\end{tabular}


顾垒，闻丞，罗玫，王吴，吕植. 中国最受关注濒危物种保护现状快速评价的新方法探讨. 生物多样性，2015，23(5)：583-590. http://www. biodiversity-science. net/CN/article/downloadArticleFile. do?attachType=PDF\&id=10075

\begin{tabular}{|c|c|c|c|c|c|}
\hline & & & $/ \mathrm{LC}$ & & \\
\hline \multirow[t]{2}{*}{ Pseudois nayaur } & 岩羊 & II & 无危 & 刘振生 & 贺兰山岩羊的数量与分布 \\
\hline & & & $/ \mathrm{LC}$ & & \\
\hline \multirow[t]{2}{*}{ Pseudois nayaur } & 岩羊 & II & 无危 & 刘振生 & 贺兰山岩羊冬季对卧息地的选择 \\
\hline & & & $/ \mathrm{LC}$ & & \\
\hline \multirow[t]{2}{*}{ Pseudois nayaur } & 岩羊 & II & 无危 & 余玉群 & 贺兰山岩羊种群结构的季节性变化 \\
\hline & & & $/ \mathrm{LC}$ & & \\
\hline \multirow[t]{2}{*}{ Pseudois nayaur } & 岩羊 & II & 无危 & 徐凯宏 & 基于识别技术的岩羊步态分析 \\
\hline & & & $/ \mathrm{LC}$ & & \\
\hline \multirow[t]{2}{*}{ Pseudois nayaur } & 岩羊 & II & 无危 & 李楠楠 & 基于细胞色素 $\mathrm{b}$ 基因的中国岩羊不同地理种群遗传差异分析 \\
\hline & & & $/ \mathrm{LC}$ & & \\
\hline \multirow[t]{2}{*}{ Pseudois nayaur } & 岩羊 & II & 无危 & 张才骏 & 借羊血液生化遗传多态性的研究 \\
\hline & & & $/ \mathrm{LC}$ & & \\
\hline \multirow[t]{2}{*}{ Pseudois nayaur } & 岩羊 & II & 无危 & 刘楚光 & 宁夏贺兰 山 自然保护区岩羊种群数量变化调查 \\
\hline & & & $/ \mathrm{LC}$ & & \\
\hline \multirow[t]{2}{*}{ Pseudois nayaur } & 岩羊 & II & 无危 & 刘建泉 & 祁连山中部岩羊繁殖地的选择及其对气候变化的适应 \\
\hline & & & $/ \mathrm{LC}$ & & \\
\hline \multirow[t]{2}{*}{ Pseudois nayaur } & 岩羊 & II & 无危 & 刘振生 & 圈养条件下岩羊冬季昼间的行为及活动规律 \\
\hline & & & /LC & & \\
\hline
\end{tabular}


顾垒，闻丞，罗玫，王吴，吕植. 中国最受关注濒危物种保护现状快速评价的新方法探讨. 生物多样性，2015，23(5)：583-590. http://www, biodiversity-science. net/CN/article/downloadArticleFile. do?attachType=PDF\&id=10075

\begin{tabular}{|c|c|c|c|c|c|}
\hline Pseudois nayaur & 岩羊 & II & $\begin{array}{l}\text { 无危 } \\
\text { /LC }\end{array}$ & 王正寰 & 人类游㮩行为对岩羊(Pseudois nayaur)反应行为的影响 \\
\hline Pseudois nayaur & 岩羊 & II & $\begin{array}{l}\text { 无危 } \\
\text { /LC }\end{array}$ & 蒋天一 & 人为干扰下宁夏贺兰山岩羊反应的群体差异 \\
\hline Pseudois nayaur & 岩羊 & II & $\begin{array}{l}\text { 无危 } \\
\text { /LC }\end{array}$ & 申定健 & 四川省竹巴笼自然保护区矮岩羊的集群特征 \\
\hline Pseudois nayaur & 岩羊 & II & $\begin{array}{l}\text { 无危 } \\
\text { /LC }\end{array}$ & 戴鬼斗 & 西昆仑地区北山羊和岩羊种群数量及分布特征研究 \\
\hline Pseudois nayaur & 岩羊 & II & $\begin{array}{l}\text { 无危 } \\
\text { /LC }\end{array}$ & 王君 & 新疆塔什库尔干岩羊和北山羊种群密度调查 \\
\hline Pseudois nayaur & 岩羊 & II & $\begin{array}{l}\text { 无危 } \\
\text { /LC }\end{array}$ & 曹丽荣 & 岩羊_Pseudoisnayaur_的社群结构和保护遗传学研究 \\
\hline Pseudois nayaur & 岩羊 & II & $\begin{array}{l}\text { 无危 } \\
\text { /LC }\end{array}$ & 潘秀文 & 岩羊病原性大肠埃希氏菌及 $\mathrm{A}$ 型产气荚膜梭菌的分离与鉴定 \\
\hline Pseudois nayaur & 岩羊 & II & $\begin{array}{l}\text { 无危 } \\
\text { /LC }\end{array}$ & 胡玉苗 & 岩羊传染性角膜结膜炎 \\
\hline Pseudois nayaur & 岩羊 & II & $\begin{array}{l}\text { 无危 } \\
\text { /LC }\end{array}$ & 邓强 & 岩羊的繁殖行为学研究 \\
\hline Pseudois nayaur & 岩羊 & II & 无危 & 再多良 & 野生岩羊金黄色葡萄球菌分离与鉴定 \\
\hline
\end{tabular}


顾垒，闻丞，罗玫，王吴，吕植. 中国最受关注濒危物种保护现状快速评价的新方法探讨. 生物多样性，2015，23(5)：583-590. http://www biodiversity-science. net/CN/article/downloadArticleFile. do?attachType=PDF\&id=10075

\begin{tabular}{|c|c|c|c|c|c|}
\hline & & & $/ \mathrm{LC}$ & & \\
\hline \multirow[t]{2}{*}{ Pseudois nayaur } & 岩羊 & II & 无危 & 高丽英 & 一起岩羊传染性角膜结膜炎的诊断报告 \\
\hline & & & $/ \mathrm{LC}$ & & \\
\hline \multirow[t]{2}{*}{ Pseudois nayaur } & 岩羊 & II & 无危 & 钟妮娜 & 一起自然保护区岩羊皮肤病的诊断 \\
\hline & & & $/ \mathrm{LC}$ & & \\
\hline \multirow[t]{2}{*}{ Pseudois nayaur } & 岩羊 & II & 无危 & 吕海军 & 中德合作宁夏贺兰山封山育林育草项目区岩羊监测调查 \\
\hline & & & $/ \mathrm{LC}$ & & \\
\hline \multirow[t]{2}{*}{ Pseudois nayaur } & 岩羊 & II & 无危 & 刘国库 & 竹巴笼矮岩羊昼间行为节律和时间分配 \\
\hline & & & $/ \mathrm{LC}$ & & \\
\hline \multirow[t]{2}{*}{ Pseudotsuga sinensis } & 黄杉 & II & 易危 & LIU You-qiao & A new species of the genus Retinia attacking Pseudotsuga sinensis Dode in China (Lepidoptera \\
\hline & & & /VU & & Tortricidae) \\
\hline \multirow[t]{2}{*}{ Pseudotsuga sinensis } & 黄杉 & II & 易危 & Xiao-Quan Wang & Phylogeny and Divergence Times in Pinaceae Evidence from Three Genomes \\
\hline & & & /VU & & \\
\hline \multirow[t]{2}{*}{ Pseudotsuga sinensis } & 黄杉 & II & 易危 & Xiao-Xin Wei & Range-wide chloroplast and mitochondrial DNA imprints reveal multiple lineages and complex \\
\hline & & & /VU & & biogeographic history for Douglas-fir \\
\hline \multirow[t]{2}{*}{ Pseudotsuga sinensis } & 黄杉 & II & 易危 & 刘晓燕 & 濒危植物华东黄杉遗传多样性分析及保育 \\
\hline & & & /VU & & \\
\hline \multirow[t]{2}{*}{ Pseudotsuga sinensis } & 黄杉 & II & 易危 & 孟广涛 & 滇东北黄杉种群数量动态的初步研究 \\
\hline & & & /VU & & \\
\hline
\end{tabular}


顾垒，闻丞，罗玫，王吴，吕植. 中国最受关注濒危物种保护现状快速评价的新方法探讨. 生物多样性，2015，23(5)：583-590. http://www. biodiversity-science. net/CN/article/downloadArticleFile. do?attachType=PDF\&id=10075

\begin{tabular}{|c|c|c|c|c|c|}
\hline Pseudotsuga sinensis & 黄杉 & II & $\begin{array}{l}\text { 易危 } \\
\text { /VU }\end{array}$ & 张少冰 & 湖南阳明山黄杉林群落的研究 \\
\hline Pseudotsuga sinensis & 黄杉 & II & $\begin{array}{l}\text { 易危 } \\
\text { /VU }\end{array}$ & 徐期瑚 & 湖南阳明山黄杉群落特征的初步研究 \\
\hline Pseudotsuga sinensis & 黄杉 & II & $\begin{array}{l}\text { 易危 } \\
\text { /VU }\end{array}$ & 李培荣 & 黄杉害虫马尾松尺蛾生物学特性及防治研究 \\
\hline Pseudotsuga sinensis & 黄杉 & II & $\begin{array}{l}\text { 易危 } \\
\text { /VU }\end{array}$ & 易进海 & 黄杉化学成分的研究 \\
\hline Pseudotsuga sinensis & 黄杉 & II & $\begin{array}{l}\text { 易危 } \\
\text { /VU }\end{array}$ & 张晓峰 & 黄杉实小卷蛾生物学特性研究 \\
\hline Pseudotsuga sinensis & 黄杉 & II & $\begin{array}{l}\text { 易危 } \\
\text { /VU }\end{array}$ & 李岩 & 黄杉属的分子系统发育与生物地理学 \\
\hline Pseudotsuga sinensis & 黄杉 & II & $\begin{array}{l}\text { 易危 } \\
\text { /VU }\end{array}$ & 孙卫邦 & 黄杉属植物在云南的资源现状及保护利用研究 \\
\hline Pseudotsuga sinensis & 黄杉 & II & $\begin{array}{l}\text { 易危 } \\
\text { /VU }\end{array}$ & 高顺良 & 黄杉育苗造林技术 \\
\hline Pseudotsuga sinensis & 黄杉 & II & $\begin{array}{l}\text { 易危 } \\
\text { /VU }\end{array}$ & 朱泰恩 & 简述黄杉容器育苗技术 \\
\hline Pseudotsuga sinensis & 黄杉 & II & 易危 & 高菊芬 & 云南曲靖市黄杉种群的群落生态学特征分析 \\
\hline
\end{tabular}


顾垒，闻丞，罗玫，王吴，吕植. 中国最受关注濒危物种保护现状快速评价的新方法探讨. 生物多样性，2015，23(5)：583-590. http://www. biodiversity-science. net/CN/article/downloadArticleFile. do?attachType=PDF\&id=10075

\begin{tabular}{|c|c|c|c|c|c|}
\hline & & & $/ \mathrm{VU}$ & & \\
\hline \multirow[t]{2}{*}{ Pseudotsuga sinensis } & 黄杉 & II & 易危 & 陈文红 & 云南易门翠柏和黄杉的群落调查及保护 \\
\hline & & & $/ \mathrm{VU}$ & & \\
\hline \multirow[t]{2}{*}{ Pseudotsuga sinensis } & 黄杉 & II & 易危 & 彭辅松 & 中国特有珍贵树种 \\
\hline & & & /VU & & \\
\hline \multirow[t]{2}{*}{ Psittacula alexandri } & 绯胸鹦武 & II & 无危 & 杨宇明 & 澜沧江自然保护区生物多样性特征及其保护 \\
\hline & & & $/ \mathrm{LC}$ & & \\
\hline \multirow[t]{2}{*}{ Psittacula alexandri } & 绯胸鹦武 & II & 无危 & 黄复生 & 西藏东南部生物多样性和生态环境脆弱性分析 \\
\hline & & & $/ \mathrm{LC}$ & & \\
\hline \multirow[t]{2}{*}{ Psittacula alexandri } & 绯胸鹦武 & II & 无危 & 索朗次仁 & 西藏尼洋河流域陆生脊椎动物的夏季调查 \\
\hline & & & $/ \mathrm{LC}$ & & \\
\hline \multirow[t]{2}{*}{ Psittacula derbiana } & 大紫胸鹦武 & II & 无危 & 四川西部生物多样 & 布拖乐安地区生物＼cjkstart多样性调查报告 \\
\hline & & & $/ \mathrm{LC}$ & 性调查队 & \\
\hline \multirow[t]{2}{*}{ Psittacula derbiana } & 大紫胸鹦鹉 & II & 无危 & 石妍 & 大理苍山洱海国家级自然保护区专项规划_2011_2020 \\
\hline & & & $/ \mathrm{LC}$ & & \\
\hline \multirow[t]{2}{*}{ Psittacula derbiana } & 大紫胸鹦鹉 & II & 无危 & 崔茂欢 & 兰坪云岭省级自然保护区及周边地区鸟类多样性 \\
\hline & & & $/ \mathrm{LC}$ & & \\
\hline \multirow[t]{2}{*}{ Psittacula derbiana } & 大紫胸鹦武 & II & 无危 & 杨沛芳 & 梅里雪山国家公园生物多样性监测 \\
\hline & & & /LC & & \\
\hline
\end{tabular}


顾垒，闻丞，罗玫，王吴，吕植. 中国最受关注濒危物种保护现状快速评价的新方法探讨. 生物多样性，2015，23(5)：583-590. http://www biodiversity-science. net/CN/article/downloadArticleFile. do?attachType=PDF\&id=10075

\begin{tabular}{|c|c|c|c|c|c|}
\hline Psittacula derbiana & 大紫胸鹦鹉 & II & $\begin{array}{l}\text { 无危 } \\
\text { /LC }\end{array}$ & 唐 平 & 四川省盐边县鸟类多样性调查 \\
\hline Psittacula derbiana & 大紫胸鹦鹉 & II & $\begin{array}{l}\text { 无危 } \\
\text { /LC }\end{array}$ & 刘鲁明 & 云南省玉龙雪山自然保护区乌类资源调查 \\
\hline Psittacula finschii & 灰头鹦鹉 & II & $\begin{array}{l}\text { 无危 } \\
\text { /LC }\end{array}$ & 袁玉川 & 2011 年南涧风凰山夜间鸟类环志研究 \\
\hline Psittacula finschii & 灰头鹦武 & II & $\begin{array}{l}\text { 无危 } \\
\text { /LC }\end{array}$ & 石妍 & 大理苍山洱海国家级自然保护区专项规划_2011_2020 \\
\hline Psittacula finschii & 灰头鹦鹉 & II & $\begin{array}{l}\text { 无危 } \\
\text { /LC }\end{array}$ & 黄石林 & 云南南涧风凰山秋季夜间迁移鸟类多样性分析 \\
\hline Psittacula finschii & 灰头鹦武 & II & $\begin{array}{l}\text { 无危 } \\
\text { /LC }\end{array}$ & 刘鲁明 & 云南省玉龙雪山自然保护区鸟类资源调查 \\
\hline Pterocles orientalis & 黑腹沙鸡 & II & $\begin{array}{l}\text { 无危 } \\
\text { /LC }\end{array}$ & 彭健 & 奎屯垦区鸟类群落特征及影响因素研究 \\
\hline Pterocles orientalis & 黑腹沙鸡 & II & $\begin{array}{l}\text { 无危 } \\
\text { /LC }\end{array}$ & 马鸣 & 新疆艾比湖湿地自然保护区鸟类清单及秋季迁徙数量统计 \\
\hline Pucrasia macrolopha & 勺鸡 & II & $\begin{array}{l}\text { 无危 } \\
\text { /LC }\end{array}$ & 刘 鹏 & 官山自然保护区勺鸡冬季栖息地选择 \\
\hline Pucrasia macrolopha & 勺鸡 & II & 无危 & 刘 鹏 & 官山自然保护区四种雉类的生境选择 \\
\hline
\end{tabular}


顾垒，闻丞，罗玫，王吴，吕植. 中国最受关注濒危物种保护现状快速评价的新方法探讨. 生物多样性，2015，23(5)：583-590. http://www. biodiversity-science. net/CN/article/downloadArticleFile. do?attachType=PDF\&id=10075

\begin{tabular}{|c|c|c|c|c|c|}
\hline & & & $/ \mathrm{LC}$ & & \\
\hline \multirow[t]{2}{*}{ Pucrasia macrolopha } & 勺鸡 & II & 无危 & 游 群 & 广西猫儿山动物分类 、区系与多样性的研究概况 \\
\hline & & & $/ \mathrm{LC}$ & & \\
\hline \multirow[t]{2}{*}{ Pucrasia macrolopha } & 勺鸡 & II & 无危 & 薛辉 & 红外感应相机在牯牛降国家级自然保护区雉类和兽类调查中的应用 \\
\hline & & & $/ \mathrm{LC}$ & & \\
\hline \multirow[t]{2}{*}{ Pucrasia macrolopha } & 勺鸡 & II & 无危 & 郑伟成 & 红外相机技术监测九龙山国家级自然保护区鸟兽多样性 \\
\hline & & & $/ \mathrm{LC}$ & & \\
\hline \multirow[t]{2}{*}{ Pucrasia macrolopha } & 勺鸡 & II & 无危 & 阎中军 & 湖南永顺小溪国家自然保护区的鸟类资源 \\
\hline & & & $/ \mathrm{LC}$ & & \\
\hline \multirow[t]{2}{*}{ Pucrasia macrolopha } & 勺鸡 & II & 无危 & 刘 鹏 & 江西官山自然保护区四种雉类的生境选择差异 \\
\hline & & & $/ \mathrm{LC}$ & & \\
\hline \multirow[t]{2}{*}{ Pucrasia macrolopha } & 勺鸡 & II & 无危 & 程松林 & 江西武夷山自然保护区的雉类资源及其保护 \\
\hline & & & $/ \mathrm{LC}$ & & \\
\hline \multirow[t]{2}{*}{ Pucrasia macrolopha } & 勺鸡 & II & 无危 & 蒲发光 & 金寨天马国家级自然保护区鸟类多样性监测 \\
\hline & & & $/ \mathrm{LC}$ & & \\
\hline \multirow[t]{2}{*}{ Pucrasia macrolopha } & 勺鸡 & II & 无危 & 刘 芳 & 利用红外相机调查北京松山国家级自然保护区的野生动物物种 \\
\hline & & & $/ \mathrm{LC}$ & & \\
\hline \multirow[t]{2}{*}{ Pucrasia macrolopha } & 勺鸡 & II & 无危 & 彭保明 & 赛罕乌拉自然保护区珍稀鸟兽多样性监测初步研究 \\
\hline & & & $/ \mathrm{LC}$ & & \\
\hline
\end{tabular}


顾垒，闻丞，罗玫，王吴，吕植. 中国最受关注濒危物种保护现状快速评价的新方法探讨. 生物多样性，2015，23(5)：583-590. http://www biodiversity-science. net/CN/article/downloadArticleFile. do?attachType=PDF\&id=10075

\begin{tabular}{|c|c|c|c|c|c|}
\hline Pucrasia macrolopha & 勺鸡 & II & $\begin{array}{l}\text { 无危 } \\
\text { /LC }\end{array}$ & 张书理 & 赛罕乌拉自然保护区珍稀野生动物多样性及动态监测初探 \\
\hline Pucrasia macrolopha & 勺鸡 & II & $\begin{array}{l}\text { 无危 } \\
\text { /LC }\end{array}$ & 成鸿飞 & 陕西观音山自然保护区脊柱动物资源与区系特征研究 \\
\hline Pucrasia macrolopha & 勺鸡 & II & $\begin{array}{l}\text { 无危 } \\
\text { /LC }\end{array}$ & 门桂荣 & 陕西长青保护区勺鸡种群密度、分布及繁殖 \\
\hline Pucrasia macrolopha & 勺鸡 & II & $\begin{array}{l}\text { 无危 } \\
\text { /LC }\end{array}$ & 伍自力 & 四川平武火溪河水牛家水电站对库区鸟类的影响 \\
\hline Pycnonotus taivanus & 台湾鹅 & $\begin{array}{l}\text { 未列 } \\
\text { 入 }\end{array}$ & $\begin{array}{l}\text { 易危 } \\
\text { /VU }\end{array}$ & & Breeding ecology of Styan's Bulbul Pgcnonotus taivanus in Taiwan \\
\hline Python molurus & 蟒蛇 & I & $\begin{array}{l}\text { 近危 } \\
\text { /NT }\end{array}$ & 符秀娟 & HPLC 法测定人工养殖蟒蛇胆汁中牛磺蟒胆酸钠的含量 \\
\hline Python molurus & 蟒蛇 & I & $\begin{array}{l}\text { 近危 } \\
\text { /NT }\end{array}$ & 丁利 & 超声雾化吸入治疗蟒蛇呼吸道感染 1 例 \\
\hline Python molurus & 蟒蛇 & I & $\begin{array}{l}\text { 近危 } \\
\text { /NT }\end{array}$ & 苏子仁 & 精制蟒蛇油抗炎抗过敏止痒作用的实验研究 \\
\hline Python molurus & 蟒蛇 & I & $\begin{array}{l}\text { 近危 } \\
\text { /NT }\end{array}$ & 苏子仁 & 精制蜯蛇油延缓皮肤衰老的实验研究 \\
\hline Python molurus & 蟒蛇 & I & 近危 & 周娜 & 蟒蛇的人工饲养与繁殖技术 \\
\hline
\end{tabular}


顾垒，闻丞，罗玫，王吴，吕植. 中国最受关注濒危物种保护现状快速评价的新方法探讨. 生物多样性，2015，23(5)：583-590. http://www. biodiversity-science. net/CN/article/downloadArticleFile. do?attachType=PDF\&id=10075

\begin{tabular}{|c|c|c|c|c|c|}
\hline & & & $/ \mathrm{NT}$ & & \\
\hline \multirow[t]{2}{*}{ Python molurus } & 蟒蛇 & I & 近危 & 周娜 & 蟒蛇的人工饲养与繁殖技术 \\
\hline & & & $/ \mathrm{NT}$ & & \\
\hline \multirow[t]{2}{*}{ Python molurus } & 蟒蛇 & I & 近危 & 苏子仁 & 蟒蛇的药用价值 \\
\hline & & & $/ \mathrm{NT}$ & & \\
\hline \multirow[t]{2}{*}{ Python molurus } & 蟒蛇 & I & 近危 & 苏子仁 & 蟒蛇的药用价值 \\
\hline & & & $/ \mathrm{NT}$ & & \\
\hline \multirow[t]{2}{*}{ Python molurus } & 蟒蛇 & I & 近危 & 郑继平 & 蟒蛇肺炎克雷伯氏菌的分离与鉴定 \\
\hline & & & $/ \mathrm{NT}$ & & \\
\hline \multirow[t]{2}{*}{ Python molurus } & 蟒蛇 & I & 近危 & 张辉 & 蟒蛇活性肽抗氧化作用的研究 \\
\hline & & & /NT & & \\
\hline \multirow[t]{2}{*}{ Python molurus } & 蟒蛇 & I & 近危 & 赖文凤 & 蟒蛇口腔炎的诊治 \\
\hline & & & /NT & & \\
\hline \multirow[t]{2}{*}{ Python molurus } & 蟒蛇 & I & 近危 & 林建新 & 蟒蛇皮制品的鉴别方法及其应用 \\
\hline & & & /NT & & \\
\hline \multirow[t]{2}{*}{ Python molurus } & 蟒蛇 & I & 近危 & 何成伟 & 蟒蛇气单胞菌病的病原鉴定 \\
\hline & & & $/ \mathrm{NT}$ & & \\
\hline \multirow[t]{2}{*}{ Python molurus } & 蟒蛇 & I & 近危 & 林杰材 & 蟒蛇铜绿假单胞菌的分离鉴定及抗药性分析 \\
\hline & & & /NT & & \\
\hline
\end{tabular}


顾垒，闻丞，罗玫，王吴，吕植. 中国最受关注濒危物种保护现状快速评价的新方法探讨. 生物多样性，2015，23(5)：583-590. http://www. biodiversity-science. net/CN/article/downloadArticleFile. do?attachType=PDF\&id=10075

\begin{tabular}{|c|c|c|c|c|c|}
\hline Python molurus & 蟒蛇 & I & 近危 & 李婉萍 & 蟒蛇铜绿假单胞菌感染的诊断 \\
\hline & & & /NT & & \\
\hline \multirow[t]{2}{*}{ Python molurus } & 蟒蛇 & I & 近危 & 李婉萍 & 蟒蛇铜绿假单胞菌感染的诊断 \\
\hline & & & $/ \mathrm{NT}$ & & \\
\hline \multirow[t]{2}{*}{ Python molurus } & 蟒蛇 & I & 近危 & 杨丽君 & 蟒蛇豚鼠气单胞菌病诊疗 \\
\hline & & & $/ \mathrm{NT}$ & & \\
\hline \multirow[t]{2}{*}{ Python molurus } & 蟒蛇 & I & 近危 & 杨丽君 & 蟒蛇豚鼠气单胞菌病诊疗 \\
\hline & & & /NT & & \\
\hline \multirow[t]{2}{*}{ Python molurus } & 蜯蛇 & I & 近危 & 张立岭 & 蟒蛇性别鉴定技术 \\
\hline & & & /NT & & \\
\hline \multirow[t]{2}{*}{ Python molurus } & 蜍蛇 & I & 近危 & 张立岭 & 蜯蛇性别鉴定技术 \\
\hline & & & /NT & & \\
\hline \multirow[t]{2}{*}{ Python molurus } & 蟒蛇 & I & 近危 & 曾惠芳 & 蟒蛇油 GC 指纹图谱研究 \\
\hline & & & /NT & & \\
\hline \multirow[t]{2}{*}{ Python molurus } & 蟒蛇 & I & 近危 & 符明利 & 蟒蛇种群动态、空间分布对海南坡鹿种群动态的影响 \\
\hline & & & /NT & & \\
\hline \multirow[t]{2}{*}{ Python molurus } & 蟒蛇 & I & 近危 & 符明利 & 蟒蛇种群动态、空间分布对海南坡鹿种群动态的影响 \\
\hline & & & /NT & & \\
\hline Python molurus & 蟒蛇 & I & 近危 & 陈志维 & 人工养殖蜍蛇胆汁中牛磺胆酸钠的含量测定 \\
\hline
\end{tabular}


顾垒，闻丞，罗玫，王吴，吕植. 中国最受关注濒危物种保护现状快速评价的新方法探讨. 生物多样性，2015，23(5)：583-590. http://www. biodiversity-science. net/CN/article/downloadArticleFile. do?attachType=PDF\&id=10075

\begin{tabular}{|c|c|c|c|c|c|}
\hline & & & /NT & & \\
\hline \multirow[t]{2}{*}{ Python molurus } & 蟒蛇 & I & 近危 & 张立岭 & 速眠新和异氟烷对蟒蛇的全麻效果研究 \\
\hline & & & /NT & & \\
\hline \multirow[t]{2}{*}{ Python molurus } & 蟒蛇 & I & 近危 & 黎宗强 & 一起蟒蛇由口腔炎诱发肺炎而死亡的报告 \\
\hline & & & /NT & & \\
\hline \multirow{2}{*}{ Python molurus } & 蟒蛇 & I & 近危 & 黎宗强 & 一起蟒蛇由口腔炎诱发肺炎而死亡的报告 \\
\hline & & & /NT & & \\
\hline \multirow[t]{2}{*}{ Python molurus } & 蟒蛇 & I & 近危 & 叶五曲 & 中西药结合治疗蟒蛇口腔炎 \\
\hline & & & /NT & & \\
\hline \multirow[t]{2}{*}{ Python molurus } & 蟒蛇 & I & 近危 & 叶五曲 & 中西药结合治疗蟒蛇口腔炎 \\
\hline & & & /NT & & \\
\hline \multirow[t]{2}{*}{ Python molurus } & 蟒蛇 & I & 近危 & 冯华娟 & 中西医结合治疗网纹蟒蛇铜绿假单胞菌病 \\
\hline & & & /NT & & \\
\hline \multirow[t]{2}{*}{ Python molurus } & 蟒蛇 & I & 近危 & 冯华娟 & 中西医结合治疗网纹蟒蛇铜绿假单胞菌病 \\
\hline & & & $/ \mathrm{NT}$ & & \\
\hline \multirow[t]{2}{*}{ Pyxidea mouhotii } & 锯缘龟 & 未列 & 濒危 & Liuwang Nie & The complete mitochondrial genome of the Keeled box turtle Pyxidea mouhotii and \\
\hline & & 入 & /EN & & phylogenetic analysis of major turtle groups \\
\hline \multirow[t]{2}{*}{ Qiongzhuea tumidinoda } & 筇竹 & 未列 & 未评 & 董文渊 & 不同水分条件下筑竹无性系的生态适应性研究 \\
\hline & & 入 & 价 & & \\
\hline
\end{tabular}


顾垒，闻丞，罗玫，王吴，吕植. 中国最受关注濒危物种保护现状快速评价的新方法探讨. 生物多样性，2015，23(5)：583-590. http://www. biodiversity-science. net/CN/article/downloadArticleFile. do?attachType=PDF\&id=10075

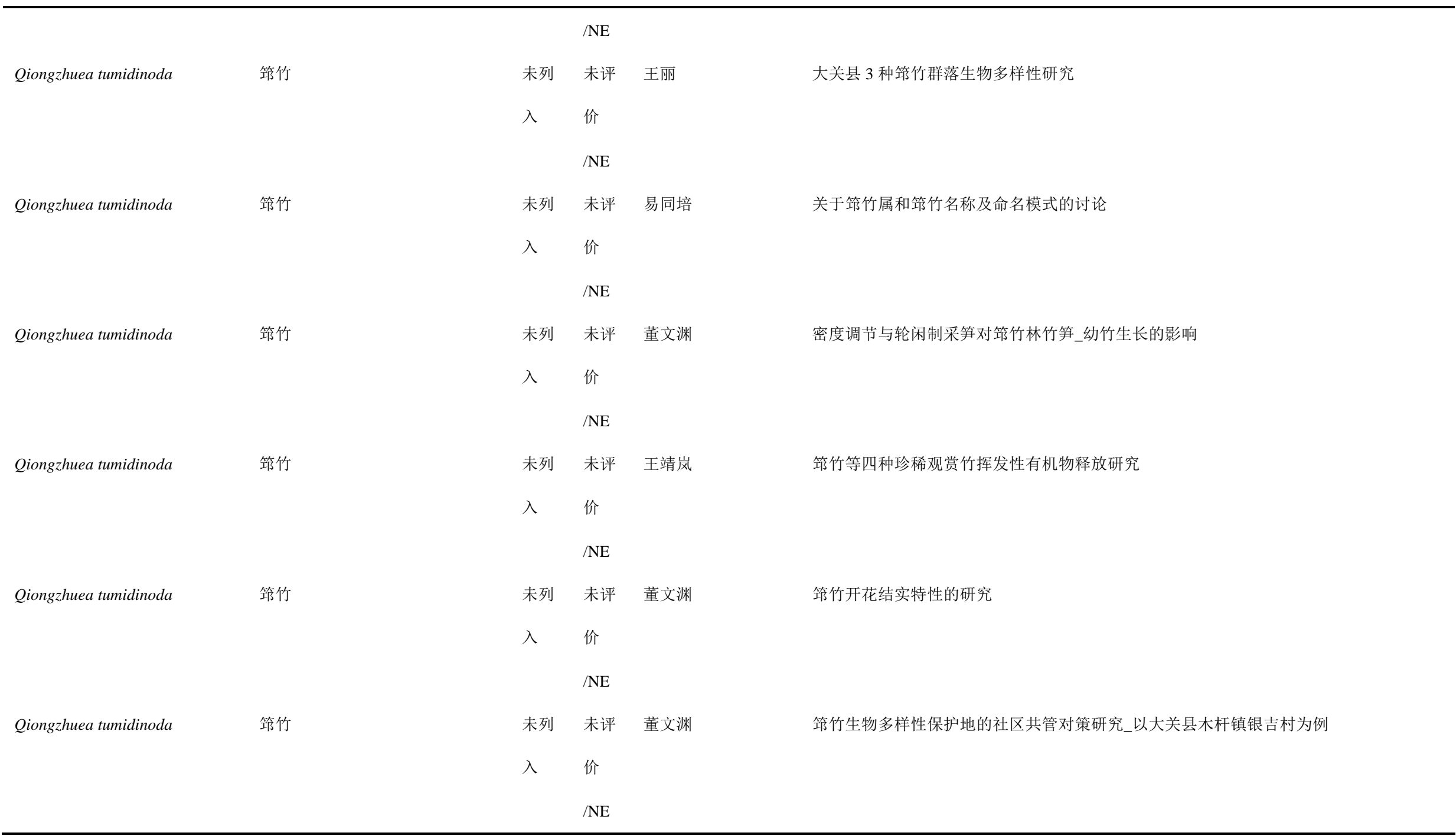


顾垒，闻丞，罗玫，王吴，吕植. 中国最受关注濒危物种保护现状快速评价的新方法探讨. 生物多样性，2015，23(5)：583-590. http://www. biodiversity-science. net/CN/article/downloadArticleFile. do?attachType=PDF\&id=10075

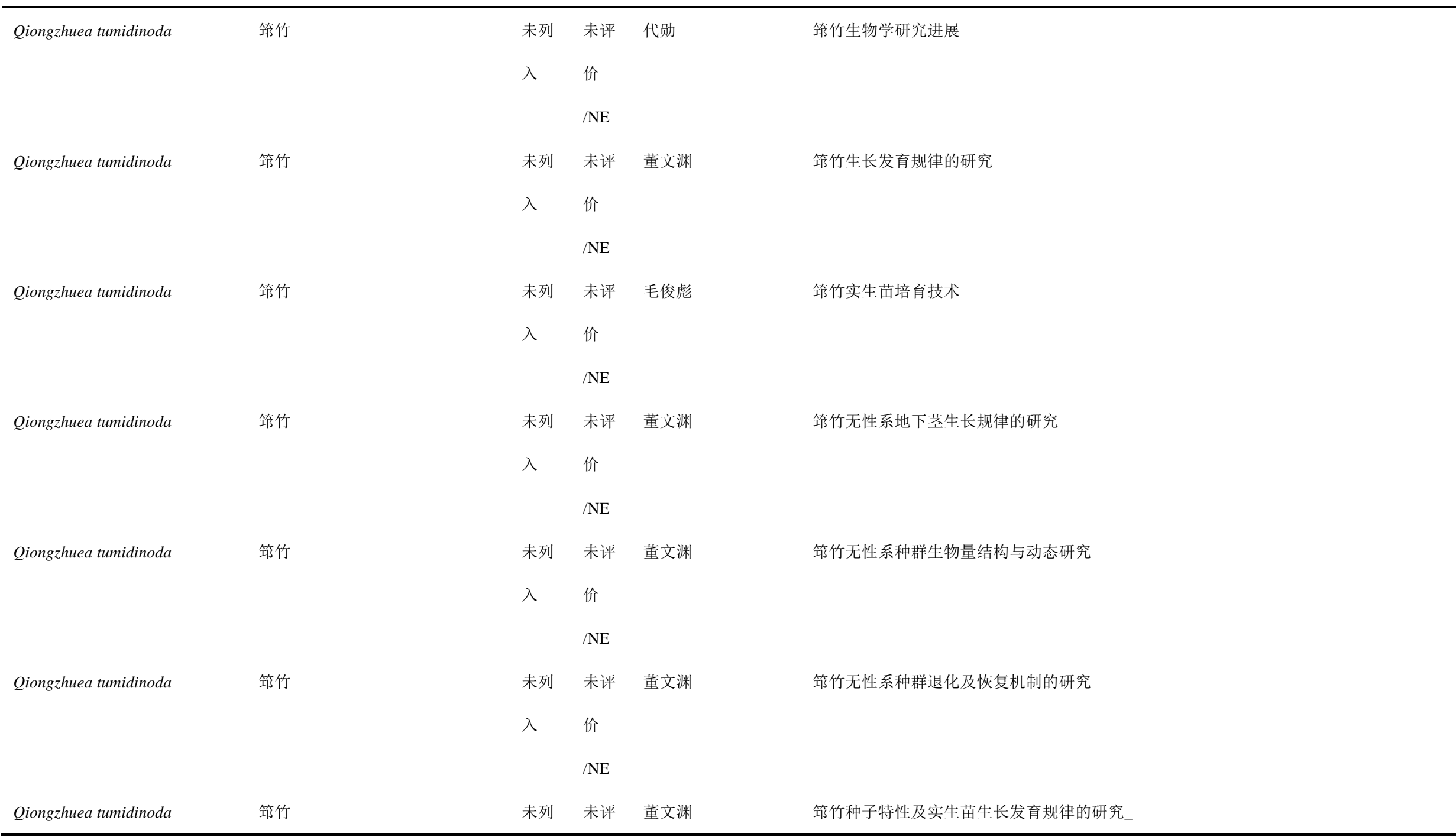


顾垒，闻丞，罗玫，王吴，吕植. 中国最受关注濒危物种保护现状快速评价的新方法探讨. 生物多样性，2015，23(5)：583-590. http://www. biodiversity-science. net/CN/article/downloadArticleFile. do?attachType=PDF\&id=10075

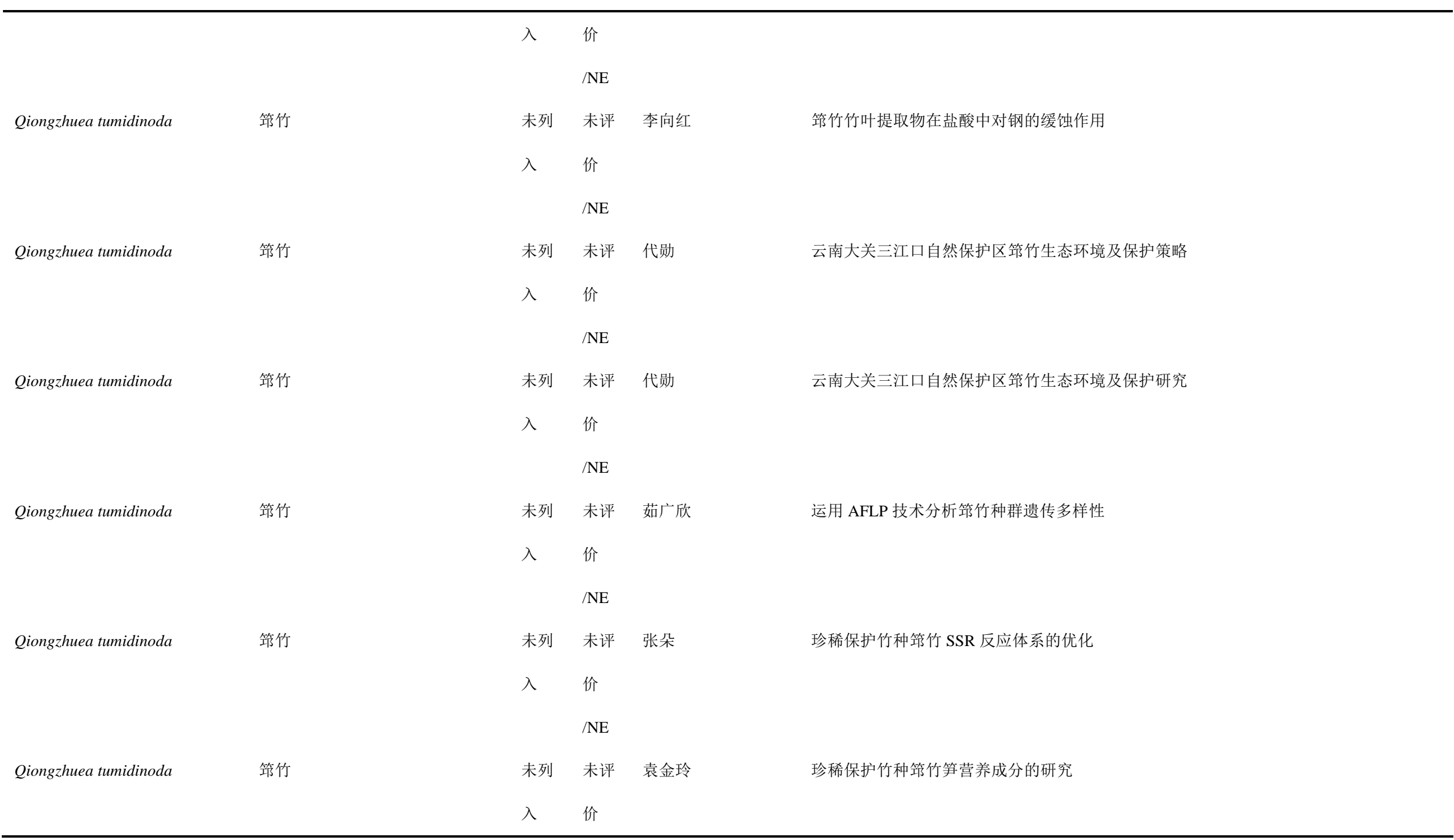


顾垒，闻丞，罗玫，王吴，吕植. 中国最受关注濒危物种保护现状快速评价的新方法探讨. 生物多样性，2015，23(5)：583-590. http://www. biodiversity-science. net/CN/article/downloadArticleFile. do?attachType=PDF\&id=10075

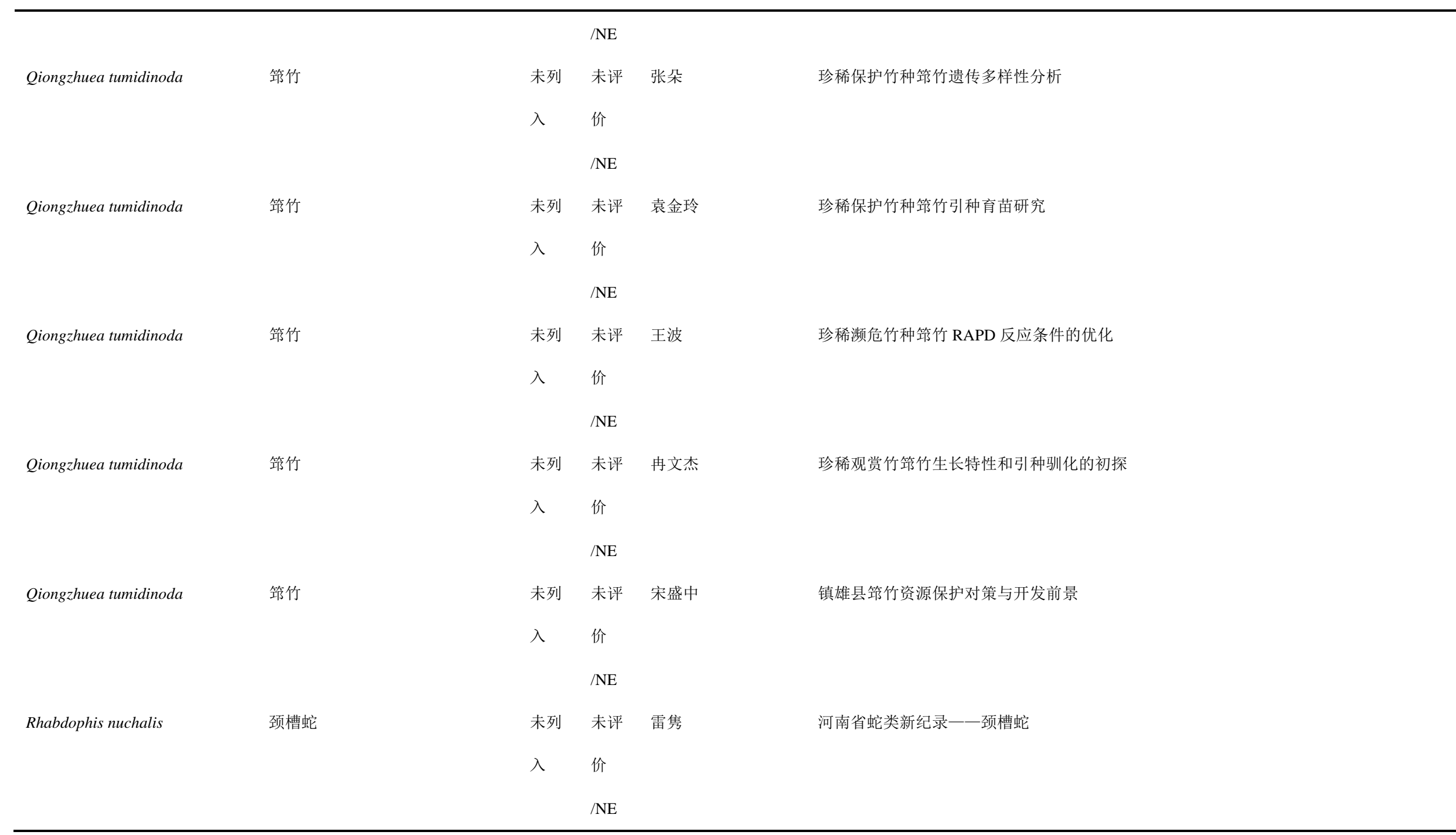


顾垒，闻丞，罗玫，王吴，吕植. 中国最受关注濒危物种保护现状快速评价的新方法探讨. 生物多样性，2015，23(5)：583-590. http://www. biodiversity-science. net/CN/article/downloadArticleFile. do?attachType=PDF\&id=10075

\begin{tabular}{|c|c|c|c|c|c|}
\hline \multirow[t]{3}{*}{ Rhabdophis nuchalis } & 颈槽蛇 & 未列 & 未评 & 杨道德 & 吉瓶山发现湖南蛇类新纪录二种一一双全白环蛇和颈槽蛇 \\
\hline & & 入 & 价 & & \\
\hline & & & $/ \mathrm{NE}$ & & \\
\hline \multirow[t]{3}{*}{ Rhabdophis nuchalis } & 颈槽蛇 & 未列 & 未评 & 郭鹏 & 西藏蛇类两新纪录种 \\
\hline & & 入 & 价 & & \\
\hline & & & $/ \mathrm{NE}$ & & \\
\hline \multirow[t]{2}{*}{ Rhinolophus rex } & 贵州菊头蝠 & 未列 & 易危 & Zhang Shuyi & Correlations between call frequency and ear length in bats belonging to the families \\
\hline & & 入 & /VU & & Rhinolophidae and Hipposideridae \\
\hline \multirow[t]{2}{*}{ Rhinolophus rex } & 贵州菊头蝠 & 未列 & 易危 & GANG LI & Molecular cloning and evolutionary analysis of the GJA1 (connexin43) gene from bats \\
\hline & & 入 & /VU & & (Chiroptera \\
\hline \multirow[t]{2}{*}{ Rhinolophus rex } & 贵州菊头蝠 & 未列 & 易危 & Shuyi ZHANG & Molecular phylogenetic of Hipposiderids (Chiroptera: Hipposideridae)and Rhinolophids \\
\hline & & 入 & /VU & & (Chiroptera: Rhinolophidae) in China based on mitochondrial cytochrome b sequences \\
\hline \multirow[t]{3}{*}{ Rhinolophus rex } & 贵州菊头蝠 & 未列 & 易危 & Xiao-Ming Gu & Molecular Phylogenetics among Three Families of Bats (Chiroptera:Rhinolophidae, \\
\hline & & 入 & /VU & & Hipposideridae, and Vespertilionidae) Based on PartialSequences of the Mitochondrial 12S and \\
\hline & & & & & 16S rRNA Genes \\
\hline \multirow[t]{2}{*}{ Rhinolophus rex } & 贵州菊头蝠 & 未列 & 易危 & 冯江 & 八种菊头蝠回声定位声波频率与体型的相关性 \\
\hline & & 入 & /VU & & \\
\hline \multirow[t]{2}{*}{ Rhinolophus rex } & 贵州菊头蝠 & 未列 & 易危 & 谷晓明 & 二种菊头蝠的核型分析 \\
\hline & & 入 & /VU & & \\
\hline
\end{tabular}


顾垒，闻丞，罗玫，王吴，吕植. 中国最受关注濒危物种保护现状快速评价的新方法探讨. 生物多样性，2015，23(5)：583-590. http://www biodiversity-science. net/CN/article/downloadArticleFile. do?attachType=PDF\&id=10075

\begin{tabular}{|c|c|c|c|c|c|}
\hline \multirow[t]{2}{*}{ Rhinolophus rex } & 贵州菊头蝠 & 未列 & 易危 & 谷晓明 & 贵州五种菊头蝠的核型分析 \\
\hline & & 入 & $/ \mathrm{VU}$ & & \\
\hline \multirow[t]{2}{*}{ Rhinolophus rex } & 贵州菊头蝠 & 未列 & 易危 & 张礼标 & 湖南省翼手目新纪录———贵州菊头蝠 \\
\hline & & 入 & $/ \mathrm{VU}$ & & \\
\hline \multirow[t]{2}{*}{ Rhinolophus rex } & 贵州菊头蝠 & 未列 & 易危 & 金龙如 & 菊头蝠科蝙蝠鼻叶宽与回声定位声波主频率的相关分析 \\
\hline & & 入 & $/ \mathrm{VU}$ & & \\
\hline \multirow[t]{2}{*}{ Rhinomyias brunneata } & 白喉林鹟 & 未列 & 易危 & 钟福生 & 东洞庭湖湿地鸟类群落结构及其多样性 \\
\hline & & 入 & $/ \mathrm{VU}$ & & \\
\hline \multirow[t]{2}{*}{ Rhinomyias brunneata } & 白喉林鹟 & 未列 & 易危 & 溪波 & 董寨国家级自然保护区繁殖鸟类现状调查 \\
\hline & & 入 & $/ \mathrm{VU}$ & & \\
\hline \multirow[t]{2}{*}{ Rhinomyias brunneata } & 白喉林鹃 & 未列 & 易危 & 粟通萍 & 广西猫儿山地区鸟类组成及垂直分布格局 \\
\hline & & 入 & $/ \mathrm{VU}$ & & \\
\hline \multirow[t]{2}{*}{ Rhinomyias brunneata } & 白喉林㰸 & 未列 & 易危 & 王绍能 & 广西猫儿山自然保护区珍稀鸟类资源及保护对策 \\
\hline & & 入 & $/ \mathrm{VU}$ & & \\
\hline \multirow[t]{2}{*}{ Rhinomyias brunneata } & 白喉林㰸 & 未列 & 易危 & 李 慧 & 广州市中心城区公园鸟类多样性及季节动态 \\
\hline & & 入 & $/ \mathrm{VU}$ & & \\
\hline \multirow[t]{2}{*}{ Rhinomyias brunneata } & 白喉林鹟 & 未列 & 易危 & 再江洪 & 四川九寨沟自然保护区的鸟类资源及区系 \\
\hline & & 入 & $/ \mathrm{VU}$ & & \\
\hline Rhinomyias brunneata & 白喉林鹟 & 未列 & 易危 & 黄俊辉 & 西双版纳预养旱季季风常绿阔叶林的林下鸟类群落组成和特点 \\
\hline
\end{tabular}


顾垒，闻丞，罗玫，王吴，吕植. 中国最受关注濒危物种保护现状快速评价的新方法探讨. 生物多样性，2015，23(5)：583-590. http://www. biodiversity-science. net/CN/article/downloadArticleFile. do?attachType=PDF\&id=10075

\begin{tabular}{|c|c|c|c|c|c|}
\hline & & 入 & $/ \mathrm{VU}$ & & \\
\hline \multirow[t]{2}{*}{ Rhinopithecus bieti } & 滇金丝猴 & I & 濒危 & 施方勤 & 白马雪山滇金丝猴种群数量分布调查研究 \\
\hline & & & /EN & & \\
\hline \multirow[t]{2}{*}{ Rhinopithecus bieti } & 滇金丝猴 & I & 濒危 & 黎大勇 & 白马雪山自然保护区格花箐滇金丝猴夜宿地的季节性选择 \\
\hline & & & /EN & & \\
\hline \multirow[t]{2}{*}{ Rhinopithecus bieti } & 滇金丝猴 & I & 濒危 & 赵卫东 & 白马雪山自然保护区南部塔城地区滇金丝猴食性及食物资源调查 \\
\hline & & & /EN & & \\
\hline \multirow[t]{2}{*}{ Rhinopithecus bieti } & 滇金丝猴 & I & 濒危 & 黎大勇 & 白马雪山自然保护区响古箐滇金丝猴 Rhinopithecus bieti 活动时间分配、夜宿行为和食性 \\
\hline & & & /EN & & 研究 \\
\hline \multirow[t]{2}{*}{ Rhinopithecus bieti } & 滇金丝猴 & I & 濒危 & 李保国/李明 & 白马雪山自然保护区响古箐滇金丝猴的食性 \\
\hline & & & /EN & & \\
\hline \multirow[t]{2}{*}{ Rhinopithecus bieti } & 滇金丝猴 & I & 濒危 & 李保国/李明 & 白马雪山自然保护区响古箐滇金丝猴活动时间分配 \\
\hline & & & /EN & & \\
\hline \multirow[t]{2}{*}{ Rhinopithecus bieti } & 滇金丝猴 & I & 濒危 & 黎大勇、胡杰 & 滇金丝猴的行为谱及 PAE 编码系统 \\
\hline & & & /EN & & \\
\hline \multirow[t]{2}{*}{ Rhinopithecus bieti } & 滇金丝猴 & I & 濒危 & 陈永春 & 滇金丝猴的生境适应对策 \\
\hline & & & /EN & & \\
\hline \multirow[t]{2}{*}{ Rhinopithecus bieti } & 滇金丝猴 & I & 濒危 & 周汝良 & 滇金丝猴栖息地的空间格局分析 \\
\hline & & & /EN & & \\
\hline
\end{tabular}


顾垒，闻丞，罗玫，王吴，吕植. 中国最受关注濒危物种保护现状快速评价的新方法探讨. 生物多样性，2015，23(5)：583-590. http://www biodiversity-science. net/CN/article/downloadArticleFile. do?attachType=PDF\&id=10075

\begin{tabular}{|c|c|c|c|c|c|}
\hline Rhinopithecus bieti & 滇金丝猴 & I & $\begin{array}{l}\text { 濒危 } \\
\text { /EN }\end{array}$ & 杨宇明 & 滇金丝猴栖息地植被类型研究 \\
\hline Rhinopithecus bieti & 滇金丝猴 & I & $\begin{array}{l}\text { 濒危 } \\
\text { /EN }\end{array}$ & 黎国强 & 滇金丝猴栖息地植物多样性研究 \\
\hline Rhinopithecus bieti & 滇金丝猴 & I & $\begin{array}{l}\text { 濒危 } \\
\text { /EN }\end{array}$ & 杨宇明 & 滇金丝猴栖息地竹类资源及群落学特征 \\
\hline Rhinopithecus bieti & 滇金丝猴 & I & $\begin{array}{l}\text { 濒危 } \\
\text { /EN }\end{array}$ & 向左甫 & 滇金丝猴群中全雄单位在移动时的空间结构与功能 \\
\hline Rhinopithecus bieti & 滇金丝猴 & I & $\begin{array}{l}\text { 濒危 } \\
\text { /EN }\end{array}$ & 李学友 & 滇金丝猴现状与研究进展 \\
\hline Rhinopithecus bieti & 滇金丝猴 & I & $\begin{array}{l}\text { 濒危 } \\
\text { /EN }\end{array}$ & 李明 & 滇金丝猴线粒体 D-loop 片段 SNPs 位点的鉴别及初步分析 \\
\hline Rhinopithecus bieti & 滇金丝猴 & I & $\begin{array}{l}\text { 濒危 } \\
\text { /EN }\end{array}$ & 宁俊勇 & 滇金丝猴研究现状 \\
\hline Rhinopithecus bieti & 滇金丝猴 & I & $\begin{array}{l}\text { 濒危 } \\
\text { /EN }\end{array}$ & 王亚明 & 滇西北滇金丝猴栖息地景观格局分析及其破碎化评价 \\
\hline Rhinopithecus bieti & 滇金丝猴 & I & $\begin{array}{l}\text { 濒危 } \\
\text { /EN }\end{array}$ & 李丽 & 基于景观遗传学的滇金丝猴栖息地连接度分析 \\
\hline Rhinopithecus bieti & 滇金丝猴 & I & 濒危 & 薛亚东 & 结合景观遗传学的滇金丝猴栖息地景观连接度分析 \\
\hline
\end{tabular}


顾垒，闻丞，罗玫，王吴，吕植. 中国最受关注濒危物种保护现状快速评价的新方法探讨. 生物多样性，2015，23(5)：583-590. http://www. biodiversity-science. net/CN/article/downloadArticleFile. do?attachType=PDF\&id=10075

\begin{tabular}{|c|c|c|c|c|c|}
\hline & & & /EN & & \\
\hline \multirow[t]{2}{*}{ Rhinopithecus bieti } & 滇金丝猴 & I & 濒危 & 杨士剑 & 兰坪云岭省级自然保护区滇金丝猴保护现状及管理建议 \\
\hline & & & $/$ EN & & \\
\hline \multirow[t]{2}{*}{ Rhinopithecus bieti } & 滇金丝猴 & I & 濒危 & 和育超 & 兰坪云岭自然保护区滇金丝猴考察 \\
\hline & & & /EN & & \\
\hline \multirow[t]{2}{*}{ Rhinopithecus bieti } & 滇金丝猴 & I & 濒危 & 黎国强 & 龙马山滇金丝猴栖息地物种多样性研究 \\
\hline & & & /EN & & \\
\hline \multirow[t]{2}{*}{ Rhinopithecus bieti } & 滇金丝猴 & I & 濒危 & 吴建国 & 气候变化对滇金丝猴分布的潜在影响 \\
\hline & & & /EN & & \\
\hline \multirow[t]{2}{*}{ Rhinopithecus bieti } & 滇金丝猴 & I & 濒危 & 郭程 & 人工投食滇金丝猴(Rhinopithecus bieti)群中全雄单位的生存策略分析 \\
\hline & & & /EN & & \\
\hline \multirow[t]{2}{*}{ Rhinopithecus bieti } & 滇金丝猴 & I & 濒危 & 向左甫 & 西藏红拉雪山滇金丝猴的夜宿地与夜宿树选择 \\
\hline & & & $/ \mathrm{EN}$ & & \\
\hline \multirow[t]{2}{*}{ Rhinopithecus bieti } & 滇金丝猴 & I & 濒危 & 徐志高 & 西藏芒康滇金丝猴国家级自然保护区范围与功能区调整初探 \\
\hline & & & /EN & & \\
\hline \multirow[t]{2}{*}{ Rhinopithecus bieti } & 滇金丝猴 & I & 濒危 & 李明 & 西藏小昌都滇金丝猴游走行为和种群结构对保护的启示 \\
\hline & & & /EN & & \\
\hline \multirow[t]{2}{*}{ Rhinopithecus bieti } & 滇金丝猴 & I & 濒危 & 胡杰 & 响古等滇金丝猴对落叶阔叶林夜宿地的选择 \\
\hline & & & /EN & & \\
\hline
\end{tabular}


顾垒，闻丞，罗玫，王吴，吕植. 中国最受关注濒危物种保护现状快速评价的新方法探讨. 生物多样性，2015，23(5)：583-590. http://www biodiversity-science. net/CN/article/downloadArticleFile. do?attachType=PDF\&id=10075

\begin{tabular}{|c|c|c|c|c|c|}
\hline \multirow[t]{2}{*}{ Rhinopithecus bieti } & 滇金丝猴 & I & 濒危 & 龙春林 & 云南老君山金丝厂滇金丝猴群栖息地的环境特征 \\
\hline & & & $/ \mathrm{EN}$ & & \\
\hline \multirow[t]{2}{*}{ Rhinopithecus bieti } & 滇金丝猴 & I & 濒危 & 杨士剑 & 云南龙马山滇金丝猴(Rhinopithecus bieti)冬季食性分析 \\
\hline & & & $/ \mathrm{EN}$ & & \\
\hline \multirow[t]{2}{*}{ Rhinopithecus bieti } & 滇金丝猴 & I & 濒危 & 魏辅文 & 云南塔城滇金丝猴掘食行为的初步研究 \\
\hline & & & $/ \mathrm{EN}$ & & \\
\hline \multirow[t]{2}{*}{ Rhinopithecus bieti } & 滇金丝猴 & I & 濒危 & 赵娟钧 & 自然保护区滇金丝猴保护现状及管理建议 \\
\hline & & & /EN & & \\
\hline \multirow[t]{2}{*}{ Rhinopithecus brelichi } & 黔金丝猴 & I & 濒危 & Ming Li & A short note on extractive foraging behavior in gray snub-nosed monkeys \\
\hline & & & /EN & & \\
\hline \multirow[t]{3}{*}{ Rhinopithecus brelichi } & 黔金丝猴 & I & 濒危 & Yeqin Yang & Altitudinal Movements of Guizhou Snub-Nosed Monkeys (Rhinopithecus brelichi) in \\
\hline & & & /EN & & Fanjingshan National Nature Reserve, China Implications for Conservation Management of a \\
\hline & & & & & Flagship Species \\
\hline \multirow[t]{2}{*}{ Rhinopithecus brelichi } & 黔金丝猴 & I & 濒危 & Ming Li & Current status and conservation of the gray snub-nosed monkey Rhinopithecus brelichi \\
\hline & & & /EN & & (Colobinae) in Guizhou, China \\
\hline \multirow[t]{2}{*}{ Rhinopithecus brelichi } & 黔金丝猴 & I & 濒危 & Ming Li & Diet and Feeding Behavior of Rhinopithecus brelichi at Yangaoping, Guizhou \\
\hline & & & /EN & & \\
\hline \multirow[t]{2}{*}{ Rhinopithecus brelichi } & 黔金丝猴 & I & 濒危 & Christian Roos & Genetic Diversity in Endangered Guizhou Snub-Nosed Monkeys (Rhinopithecus brelichi) \\
\hline & & & /EN & & Contrasting Results from Microsatellite and Mitochondrial DNA Data \\
\hline
\end{tabular}


顾垒，闻丞，罗玫，王吴，吕植. 中国最受关注濒危物种保护现状快速评价的新方法探讨. 生物多样性，2015，23(5)：583-590. http://www biodiversity-science. net/CN/article/downloadArticleFile. do?attachType=PDF\&id=10075

\begin{tabular}{|c|c|c|c|c|c|}
\hline Rhinopithecus brelichi & 黔金丝猴 & I & $\begin{array}{l}\text { 濒危 } \\
\text { /EN }\end{array}$ & LI Ming & $\begin{array}{l}\text { Mitochondrial DNA variation analysis suggests extreme low genetic diversity in Guizhou } \\
\text { snub-nosed monkeys (Rhinopithecus brelichi) }\end{array}$ \\
\hline Rhinopithecus brelichi & 黔金丝猴 & I & $\begin{array}{l}\text { 濒危 } \\
\text { /EN }\end{array}$ & Ming Li & $\begin{array}{l}\text { Mitochondrial DNA variation analysis suggests extreme low genetic diversity in Guizhou } \\
\text { snub-nosed monkeys (Rhinopithecus brelichi) }\end{array}$ \\
\hline Rhinopithecus brelichi & 黔金丝猴 & I & $\begin{array}{l}\text { 濒危 } \\
\text { /EN }\end{array}$ & Mouyu Yang & $\begin{array}{l}\text { Population Genetic Structure of Guizhou Snub-Nosed } \\
\text { Monkeys (Rhinopithecus brelichi) as Inferred From } \\
\text { Mitochondrial Control Region Sequences, and } \\
\text { Comparison With R. roxellana and R. bieti }\end{array}$ \\
\hline Rhinopithecus brelichi & 黔金丝猴 & I & $\begin{array}{l}\text { 濒危 } \\
\text { /EN }\end{array}$ & Zuo-Fu Xiang & $\begin{array}{l}\text { Preliminary reports on extractive foraging behavior in gray } \\
\text { snub-nosed monkeys }\end{array}$ \\
\hline Rhinopithecus brelichi & 黔金丝猴 & I & $\begin{array}{l}\text { 濒危 } \\
\text { /EN }\end{array}$ & William Bleisch & $\begin{array}{l}\text { Preliminary Results from a Field Study of Wild Guizhou Snub-Nosed Monkeys (Rhinopithecus } \\
\text { brelichi) }\end{array}$ \\
\hline Rhinopithecus brelichi & 黔金丝猴 & I & $\begin{array}{l}\text { 濒危 } \\
\text { /EN }\end{array}$ & MOUYU YANG & Reproductive parameters in Guizhou snub-nosed monkeys (Rhinopithecus brelichi) \\
\hline Rhinopithecus brelichi & 黔金丝猴 & I & $\begin{array}{l}\text { 濒危 } \\
\text { /EN }\end{array}$ & Ming Li & Sleeping Sites of Rhinopithecus brelichi at Yangaoping, Guizhou \\
\hline Rhinopithecus brelichi & 黔金丝猴 & I & $\begin{array}{l}\text { 濒危 } \\
\text { /EN }\end{array}$ & 吴钢 & 校净山自然保护区黔金丝猴生境选择的研究 \\
\hline Rhinopithecus brelichi & 黔金丝猴 & I & 濒危 & 杨龙 & 梵净山贵州金丝猴生境食用植物资源与植被组合特征 \\
\hline
\end{tabular}


顾垒，闻丞，罗玫，王吴，吕植. 中国最受关注濒危物种保护现状快速评价的新方法探讨. 生物多样性，2015，23(5)：583-590. http://www. biodiversity-science. net/CN/article/downloadArticleFile. do?attachType=PDF\&id=10075

\begin{tabular}{|c|c|c|c|c|c|}
\hline & & & /EN & & \\
\hline \multirow[t]{2}{*}{ Rhinopithecus brelichi } & 黔金丝猴 & I & 濒危 & 杨海龙 & 梵净山国家级自然保护区植被分布与黔金丝猴生境选择 \\
\hline & & & $/$ EN & & \\
\hline \multirow[t]{2}{*}{ Rhinopithecus brelichi } & 黔金丝猴 & I & 濒危 & 杨海龙 & 贵州梵净山国家级自然保护区黔金丝猴生境分析 \\
\hline & & & /EN & & \\
\hline \multirow[t]{2}{*}{ Rhinopithecus brelichi } & 黔金丝猴 & I & 濒危 & 杨海龙 & 贵州梵净山黔金丝猴生境适宜性评价 \\
\hline & & & /EN & & \\
\hline \multirow[t]{2}{*}{ Rhinopithecus brelichi } & 黔金丝猴 & I & 濒危 & 史芳磊 & 黔金丝猴和圈养黑叶猴保护遗传学研究 \\
\hline & & & /EN & & \\
\hline \multirow[t]{2}{*}{ Rhinopithecus brelichi } & 黔金丝猴 & I & 濒危 & 熊源新 & 黔金丝猴活动区苔蘚植物多样性研究 \\
\hline & & & /EN & & \\
\hline \multirow[t]{2}{*}{ Rhinopithecus brelichi } & 黔金丝猴 & I & 濒危 & 向左甫 & 黔金丝猴食性及社会结构的初步研究 \\
\hline & & & /EN & & \\
\hline \multirow[t]{2}{*}{ Rhinopithecus brelichi } & 黔金丝猴 & I & 濒危 & 向左甫 & 黔金丝猴食性及社会结构研究简报 \\
\hline & & & /EN & & \\
\hline \multirow[t]{2}{*}{ Rhinopithecus brelichi } & 黔金丝猴 & I & 濒危 & 聂帅国 & 黔金丝猴食性研究 \\
\hline & & & /EN & & \\
\hline \multirow[t]{2}{*}{ Rhinopithecus brelichi } & 黔金丝猴 & I & 濒危 & 杨业勤 & 黔金丝猴种群数量的调查研究 \\
\hline & & & /EN & & \\
\hline
\end{tabular}


顾垒，闻丞，罗玫，王昊，吕植。中国最受关注濒危物种保护现状快速评价的新方法探讨．生物多样性，2015，23(5)：583-590. http://www. biodiversity-science. net/CN/article/downloadArticleFile. do?attachType=PDF\&id=10075

\begin{tabular}{|c|c|c|c|c|c|}
\hline Rhinopithecus roxellana & 川金丝猴 & I & $\begin{array}{l}\text { 易危 } \\
\text { /VU }\end{array}$ & 李阳 & “3S” 技术在神农架川金丝猴栖息地选择及动态迁徙中的应用 \\
\hline Rhinopithecus roxellana & 川金丝猴 & I & $\begin{array}{l}\text { 易危 } \\
\text { /VU }\end{array}$ & D.Pan.Y-P.Zhang & A High Polymorphism Level in Rhinopithecus roxellana \\
\hline Rhinopithecus roxellana & 川金丝猴 & I & $\begin{array}{l}\text { 易危 } \\
\text { /VU }\end{array}$ & Yiming LI & $\begin{array}{l}\text { Activity budgets in a group of Sichuan snub-nosed monkeys in Shennongjia Nature } \\
\text { Reserve,China }\end{array}$ \\
\hline Rhinopithecus roxellana & 川金丝猴 & I & $\begin{array}{l}\text { 易危 } \\
\text { /VU }\end{array}$ & Baoguo Li & $\begin{array}{l}\text { Copulation behavior within one-male groups of wild Rhinopithecus roxellana in the Qinling } \\
\text { Mountains of China }\end{array}$ \\
\hline Rhinopithecus roxellana & 川金丝猴 & I & $\begin{array}{l}\text { 易危 } \\
\text { /VU }\end{array}$ & Baoguo Li & Diet and activity budget of Rhinopithecus roxellana in the Qinling Mountains, China \\
\hline Rhinopithecus roxellana & 川金丝猴 & I & $\begin{array}{l}\text { 易危 } \\
\text { /VU }\end{array}$ & LI BaoGuo & $\begin{array}{l}\text { Dominance rank of adult females and mating competition in Sichuan snub-nosed monkeys } \\
\text { (Rhinopithecus roxellana) in the Qinling Mountains, China }\end{array}$ \\
\hline Rhinopithecus roxellana & 川金丝猴 & I & $\begin{array}{l}\text { 易危 } \\
\text { /VU }\end{array}$ & Baoguo Li & $\begin{array}{l}\text { First evidence on foot preference during locomotion in Old World monkeys- a study of } \\
\text { quadrupedal and bipedal actions in Sichuan snub-nosed monkeys (Rhinopithecus roxellana) }\end{array}$ \\
\hline Rhinopithecus roxellana & 川金丝猴 & I & $\begin{array}{l}\text { 易危 } \\
\text { /VU }\end{array}$ & 张炎 & Fisher 判别分析法在川金丝猴亚种鉴定中的应用 \\
\hline Rhinopithecus roxellana & 川金丝猴 & I & $\begin{array}{l}\text { 易危 } \\
\text { /VU }\end{array}$ & Ya-Ping Zhang & Genetic diversity and population history of golden monkeys (Rhinopithecus roxellana) \\
\hline Rhinopithecus roxellana & 川金丝猴 & I & 易危 & Ming Li & Human influence on the population decline and loss of genetic diversity in a small and isolated \\
\hline
\end{tabular}


顾垒，闻丞，罗玫，王昊，吕植. 中国最受关注濒危物种保护现状快速评价的新方法探讨．生物多样性，2015，23(5)：583-590. http://www, biodiversity-science, net/CN/article/downloadArticleFile. do?attachType=PDF\&id=10075

\begin{tabular}{|c|c|c|c|c|c|}
\hline & & & $/ \mathrm{VU}$ & & population of Sichuan snub-nosed monkeys (Rhinopithecus roxellana) \\
\hline \multirow[t]{2}{*}{ Rhinopithecus roxellana } & 川金丝猴 & I & 易危 & 徐卫华 & MAXENT 模型在秦岭川金丝猴生境评价中的应用 \\
\hline & & & $/ \mathrm{VU}$ & & \\
\hline \multirow[t]{2}{*}{ Rhinopithecus roxellana } & 川金丝猴 & I & 易危 & Baoguo Li & Population Structure and Ranging Patterns of Rhinopithecus roxellana in Zhouzhi National \\
\hline & & & /VU & & Nature Reserve, Shaanxi, China \\
\hline \multirow[t]{2}{*}{ Rhinopithecus roxellana } & 川金丝猴 & I & 易危 & Baoguo Li & Seasonal home range changes of the Sichuan snub-nosed monkey (Rhinopithecus roxellana) in \\
\hline & & & $/ \mathrm{VU}$ & & the Qinling Mountains of China \\
\hline \multirow[t]{2}{*}{ Rhinopithecus roxellana } & 川金丝猴 & I & 易危 & Caie Yan & Social interaction and dispersal patterns of golden snub-nosed monkeys (Rhinopithecus \\
\hline & & & /VU & & roxellana) living in multi-level societies \\
\hline \multirow[t]{2}{*}{ Rhinopithecus roxellana } & 川金丝猴 & I & 易危 & Zhi-Xiang Zhang & Species Diversity of the Tree Layer with Changes in Altitudes in Rhinopithecus roxellana \\
\hline & & & $/ \mathrm{VU}$ & & Habitats at Shennongjia\%2CChina \\
\hline \multirow[t]{2}{*}{ Rhinopithecus roxellana } & 川金丝猴 & I & 易危 & Li GuangLiang & Study on Habitat Forest Type and Plant Diversity of Sichuan snub-nosed monkeys in \\
\hline & & & $/ \mathrm{VU}$ & & Shennongjia Nature Reserve \\
\hline \multirow[t]{2}{*}{ Rhinopithecus roxellana } & 川金丝猴 & I & 易危 & Baoguo Li & Vertical distribution of different age-sex classes in a foraging group of Sichuan golden \\
\hline & & & /VU & & monkeys (Rhinopithecus roxellana) \\
\hline \multirow[t]{2}{*}{ Rhinopithecus roxellana } & 川金丝猴 & I & 易危 & 金芘 & 白河自然保护区川金丝猴栖息地景观格局分析 \\
\hline & & & /VU & & \\
\hline \multirow[t]{2}{*}{ Rhinopithecus roxellana } & 川金丝猴 & I & 易危 & 胡刚 & 白河自然保护区川金丝猴秋季生境的选择性 \\
\hline & & & $/ \mathrm{VU}$ & & \\
\hline
\end{tabular}


顾垒，闻丞，罗玫，王吴，吕植. 中国最受关注濒危物种保护现状快速评价的新方法探讨. 生物多样性，2015，23(5)：583-590. http://www biodiversity-science. net/CN/article/downloadArticleFile. do?attachType=PDF\&id=10075

\begin{tabular}{|c|c|c|c|c|c|}
\hline Rhinopithecus roxellana & 川金丝猴 & I & $\begin{array}{l}\text { 易危 } \\
\text { /VU }\end{array}$ & 顾志宏 & 白河自然保护区川金丝猴生境选择与生境评价 \\
\hline Rhinopithecus roxellana & 川金丝猴 & I & $\begin{array}{l}\text { 易危 } \\
\text { /VU }\end{array}$ & 张鹏 & 川金丝猴(Rhinopithecus roxellana)的社群结构和理毛行为的研究 \\
\hline Rhinopithecus roxellana & 川金丝猴 & I & $\begin{array}{l}\text { 易危 } \\
\text { /VU }\end{array}$ & 任宝平 & 川金丝猴(Rhinopithecus roxellana)繁殖行为学研究 \\
\hline Rhinopithecus roxellana & 川金丝猴 & I & $\begin{array}{l}\text { 易危 } \\
\text { /VU }\end{array}$ & 缑敬轩 & 川金丝猴(Rhinopithecus roxellanae)种群遗传结构和分子系统地理学初步研究 \\
\hline Rhinopithecus roxellana & 川金丝猴 & I & $\begin{array}{l}\text { 易危 } \\
\text { /VU }\end{array}$ & 禹洋 & 川金丝猴(Rhinopithecusroxellana)相互理毛行为研究 \\
\hline Rhinopithecus roxellana & 川金丝猴 & I & $\begin{array}{l}\text { 易危 } \\
\text { /VU }\end{array}$ & 何丽 & 川金丝猴(Rhinopithecusroxellana)遗传学与栖息地分析 \\
\hline Rhinopithecus roxellana & 川金丝猴 & I & $\begin{array}{l}\text { 易危 } \\
\text { /VU }\end{array}$ & 陈嘉绩 & 川金丝猴雌性生殖器官的观察 \\
\hline Rhinopithecus roxellana & 川金丝猴 & I & $\begin{array}{l}\text { 易危 } \\
\text { /VU }\end{array}$ & 篗馨 & 川金丝猴的阿姨行为 \\
\hline Rhinopithecus roxellana & 川金丝猴 & I & $\begin{array}{l}\text { 易危 } \\
\text { /VU }\end{array}$ & 李保国 & 川金丝猴的相互理毛行为是否具有卫生功能 \\
\hline Rhinopithecus roxellana & 川金丝猴 & I & 易危 & 李保国 & 川金丝猴的一次食物转变 \\
\hline
\end{tabular}


顾垒，闻丞，罗玫，王吴，吕植. 中国最受关注濒危物种保护现状快速评价的新方法探讨. 生物多样性，2015，23(5)：583-590. http://www. biodiversity-science. net/CN/article/downloadArticleFile. do?attachType=PDF\&id=10075

\begin{tabular}{|c|c|c|c|c|c|}
\hline & & & /VU & & \\
\hline \multirow[t]{2}{*}{ Rhinopithecus roxellana } & 川金丝猴 & I & 易危 & 李保国 & 川金丝猴粪尿中类固醇性激素抽提方法比较 \\
\hline & & & /VU & & \\
\hline \multirow[t]{2}{*}{ Rhinopithecus roxellana } & 川金丝猴 & I & 易危 & 俞诗源 & 川金丝猴冠状动脉的解剖 \\
\hline & & & $/ \mathrm{VU}$ & & \\
\hline \multirow[t]{2}{*}{ Rhinopithecus roxellana } & 川金丝猴 & I & 易危 & 王子仁 & 川金丝猴和人子宫动脉的铸型观察 \\
\hline & & & /VU & & \\
\hline \multirow[t]{2}{*}{ Rhinopithecus roxellana } & 川金丝猴 & I & 易危 & 高丰 & 川金丝猴柯萨奇病毒的分离鉴定 \\
\hline & & & /VU & & \\
\hline \multirow[t]{2}{*}{ Rhinopithecus roxellana } & 川金丝猴 & I & 易危 & 俞诗源 & 川金丝猴卵巢的组织学研究 \\
\hline & & & $/ \mathrm{VU}$ & & \\
\hline \multirow[t]{2}{*}{ Rhinopithecus roxellana } & 川金丝猴 & I & 易危 & 朱朝君 & 川金丝猴毛首线虫新种记录 \\
\hline & & & $/ \mathrm{VU}$ & & \\
\hline \multirow[t]{2}{*}{ Rhinopithecus roxellana } & 川金丝猴 & I & 易危 & 陈嘉绩 & 川金丝猴内分泌腺的大体解剖 \\
\hline & & & /VU & & \\
\hline \multirow[t]{2}{*}{ Rhinopithecus roxellana } & 川金丝猴 & I & 易危 & 李保国 & 川金丝猴尿液中睪酮水平的季节性变化 \\
\hline & & & /VU & & \\
\hline \multirow[t]{2}{*}{ Rhinopithecus roxellana } & 川金丝猴 & I & 易危 & 刘广超 & 川金丝猴栖息地质量评价和保护对策研究 \\
\hline & & & /VU & & \\
\hline
\end{tabular}


顾垒，闻丞，罗玫，王吴，吕植. 中国最受关注濒危物种保护现状快速评价的新方法探讨. 生物多样性，2015，23(5)：583-590. http://www biodiversity-science. net/CN/article/downloadArticleFile. do?attachType=PDF\&id=10075

\begin{tabular}{|c|c|c|c|c|c|}
\hline Rhinopithecus roxellana & 川金丝猴 & I & $\begin{array}{l}\text { 易危 } \\
\text { /VU }\end{array}$ & 苏彦捷 & 川金丝猴社会行为节目及其动作模式 \\
\hline Rhinopithecus roxellana & 川金丝猴 & I & $\begin{array}{l}\text { 易危 } \\
\text { /VU }\end{array}$ & 李保国 & 川金丝猴射精标准的量化辅助 \\
\hline Rhinopithecus roxellana & 川金丝猴 & I & $\begin{array}{l}\text { 易危 } \\
\text { /VU }\end{array}$ & 吴逸群 & 川金丝猴生态生物学研究进展 \\
\hline Rhinopithecus roxellana & 川金丝猴 & I & $\begin{array}{l}\text { 易危 } \\
\text { /VU }\end{array}$ & 魏辅文 & 川金丝猴食谱的地域性差异比较 \\
\hline Rhinopithecus roxellana & 川金丝猴 & I & $\begin{array}{l}\text { 易危 } \\
\text { /VU }\end{array}$ & 李保国 & 川金丝猴食土行为的首次报道 \\
\hline Rhinopithecus roxellana & 川金丝猴 & I & $\begin{array}{l}\text { 易危 } \\
\text { /VU }\end{array}$ & 俞诗源 & 川金丝猴输卵管和子宫的组织学研究 \\
\hline Rhinopithecus roxellana & 川金丝猴 & I & $\begin{array}{l}\text { 易危 } \\
\text { /VU }\end{array}$ & 张炎 & 川金丝猴亚种的支持向量机分类(SVC)模型研究 \\
\hline Rhinopithecus roxellana & 川金丝猴 & I & $\begin{array}{l}\text { 易危 } \\
\text { /VU }\end{array}$ & 马战 & 川金丝猴移地驯养繁殖技术研究 \\
\hline Rhinopithecus roxellana & 川金丝猴 & I & $\begin{array}{l}\text { 易危 } \\
\text { /VU }\end{array}$ & 王晓卫 & 川金丝猴遗传多样性研究进展 \\
\hline Rhinopithecus roxellana & 川金丝猴 & I & 易危 & 贺文琦 & 川金丝猴源柯萨奇 B3 病毒的分子特征及其致病性初步研究 \\
\hline
\end{tabular}


顾垒，闻丞，罗玫，王吴，吕植. 中国最受关注濒危物种保护现状快速评价的新方法探讨. 生物多样性，2015，23(5)：583-590. http://www. biodiversity-science. net/CN/article/downloadArticleFile. do?attachType=PDF\&id=10075

\begin{tabular}{|c|c|c|c|c|c|}
\hline & & & $/ \mathrm{VU}$ & & \\
\hline \multirow[t]{2}{*}{ Rhinopithecus roxellana } & 川金丝猴 & I & 易危 & 俞诗源 & 川金丝猴子宫动脉的铸型观察 \\
\hline & & & /VU & & \\
\hline \multirow[t]{2}{*}{ Rhinopithecus roxellana } & 川金丝猴 & I & 易危 & 蒋志刚 & 雌性川金丝猴的邀配行为与尿液雌二醇水平的关系 \\
\hline & & & /VU & & \\
\hline \multirow[t]{2}{*}{ Rhinopithecus roxellana } & 川金丝猴 & I & 易危 & 高云芳 & 雌性川金丝猴尿液中雌二醇与孕酮水平的季节性变化 \\
\hline & & & /VU & & \\
\hline \multirow[t]{2}{*}{ Rhinopithecus roxellana } & 川金丝猴 & I & 易危 & 刘瑛 & 地震灾后卧龙川金丝猴栖息地恢复指标研究 \\
\hline & & & /VU & & \\
\hline \multirow[t]{2}{*}{ Rhinopithecus roxellana } & 川金丝猴 & I & 易危 & 鲍伟东 & 湖北神农架川金丝猴投食群结构与繁殖 \\
\hline & & & $/ \mathrm{VU}$ & & \\
\hline \multirow[t]{2}{*}{ Rhinopithecus roxellana } & 川金丝猴 & I & 易危 & 苏化龙 & 湖北省巴东县小神农架地区川金丝猴的种群调查 \\
\hline & & & /VU & & \\
\hline \multirow[t]{2}{*}{ Rhinopithecus roxellana } & 川金丝猴 & I & 易危 & 苗秀莲 & 几种生态因子对笼养川金丝猴行为的影响 \\
\hline & & & /VU & & \\
\hline \multirow[t]{2}{*}{ Rhinopithecus roxellana } & 川金丝猴 & I & 易危 & 李大全 & 利用非损伤性方法评估神农架保护区川金丝猴种群遗传多样性 \\
\hline & & & /VU & & \\
\hline \multirow[t]{2}{*}{ Rhinopithecus roxellana } & 川金丝猴 & I & 易危 & 蒋志刚 & 利用尿液中的雌二醇、孕酮含量监测雌性川金丝猴的月经周期和妊娠 \\
\hline & & & /VU & & \\
\hline
\end{tabular}


顾垒，闻丞，罗玫，王吴，吕植. 中国最受关注濒危物种保护现状快速评价的新方法探讨. 生物多样性，2015，23(5)：583-590. http://www biodiversity-science. net/CN/article/downloadArticleFile. do?attachType=PDF\&id=10075

\begin{tabular}{|c|c|c|c|c|c|}
\hline Rhinopithecus roxellana & 川金丝猴 & I & $\begin{array}{l}\text { 易危 } \\
\text { /VU }\end{array}$ & 高丰 & 临床死亡川金丝猴心肌炎病例的诊断及病因分析 \\
\hline Rhinopithecus roxellana & 川金丝猴 & I & $\begin{array}{l}\text { 易危 } \\
\text { /VU }\end{array}$ & 彭红兰 & 气候变化对川金丝猴栖息地的影响研究 \\
\hline Rhinopithecus roxellana & 川金丝猴 & I & $\begin{array}{l}\text { 易危 } \\
\text { /VU }\end{array}$ & 王铭 & 秦岭川金丝猴(Rhinopithecusr roxellana)抱团行为及睡眠位置空间选择研究 \\
\hline Rhinopithecus roxellana & 川金丝猴 & I & $\begin{array}{l}\text { 易危 } \\
\text { /VU }\end{array}$ & 朱紫瑞 & 秦岭川金丝猴(Rhinopithecusr roxellana)雌性相互理毛的时间匹配性以及理毛策略的研究 \\
\hline Rhinopithecus roxellana & 川金丝猴 & I & $\begin{array}{l}\text { 易危 } \\
\text { /VU }\end{array}$ & 齐晓光 & 秦岭川金丝猴(Rhinopithecusr roxellana)的繁殖策略,社会组织与个体扩散迁移机制的研究 \\
\hline Rhinopithecus roxellana & 川金丝猴 & I & $\begin{array}{l}\text { 易危 } \\
\text { /VU }\end{array}$ & 赵大鹏 & 秦岭川金丝猴(Rhinopithecusr roxellana)繁殖竞争与肢体偏好的研究 \\
\hline Rhinopithecus roxellana & 川金丝猴 & I & $\begin{array}{l}\text { 易危 } \\
\text { /VU }\end{array}$ & 王程亮 & 秦岭川金丝猴(Rhinopithecusr roxellana)社会单元内个体空间分布研究 \\
\hline Rhinopithecus roxellana & 川金丝猴 & I & $\begin{array}{l}\text { 易危 } \\
\text { /VU }\end{array}$ & 郗文忠 & 秦岭川金丝猴(Rhinopithecusr roxellana)樱儿携带行为的母亲受益分析研究 \\
\hline Rhinopithecus roxellana & 川金丝猴 & I & $\begin{array}{l}\text { 易危 } \\
\text { /VU }\end{array}$ & 李保国 & 秦岭川金丝猴 1 至 2 岁个体的社会玩要行为 \\
\hline Rhinopithecus roxellana & 川金丝猴 & I & 易危 & 付卫伟 & 秦岭川金丝猴不同年龄性别组的手偏好及其对新事物反应的研究 \\
\hline
\end{tabular}


顾垒，闻丞，罗玫，王吴，吕植. 中国最受关注濒危物种保护现状快速评价的新方法探讨. 生物多样性，2015，23(5)：583-590. http://www. biodiversity-science. net/CN/article/downloadArticleFile. do?attachType=PDF\&id=10075

\begin{tabular}{|c|c|c|c|c|c|}
\hline & & & /VU & & \\
\hline \multirow[t]{2}{*}{ Rhinopithecus roxellana } & 川金丝猴 & I & 易危 & 赵海涛 & 秦岭川金丝猴成年雌性等级与交配的相关性研究 \\
\hline & & & $/ \mathrm{VU}$ & & \\
\hline \multirow[t]{2}{*}{ Rhinopithecus roxellana } & 川金丝猴 & I & 易危 & 李保国 & 秦岭川金丝猴成年雌性优势资源占有与社会等级的判定 \\
\hline & & & $/ \mathrm{VU}$ & & \\
\hline \multirow[t]{2}{*}{ Rhinopithecus roxellana } & 川金丝猴 & I & 易危 & 张剑 & 秦岭川金丝猴冲突及冲突后行为研究 \\
\hline & & & /VU & & \\
\hline \multirow[t]{2}{*}{ Rhinopithecus roxellana } & 川金丝猴 & I & 易危 & 李保国 & 秦岭川金丝猴崔性携抱偏好与婴儿吸乳偏好 \\
\hline & & & /VU & & \\
\hline \multirow[t]{2}{*}{ Rhinopithecus roxellana } & 川金丝猴 & I & 易危 & 李保国 & 秦岭川金丝猴单元内成年雌性的等级关系与交配竞争 \\
\hline & & & /VU & & \\
\hline \multirow[t]{2}{*}{ Rhinopithecus roxellana } & 川金丝猴 & I & 易危 & 李保国 & 秦岭川金丝猴的母系投入与生殖性别偏倚 \\
\hline & & & /VU & & \\
\hline \multirow[t]{2}{*}{ Rhinopithecus roxellana } & 川金丝猴 & I & 易危 & 高云芳 & 秦岭川金丝猴的一次家庭雄性替代 \\
\hline & & & /VU & & \\
\hline \multirow[t]{2}{*}{ Rhinopithecus roxellana } & 川金丝猴 & I & 易危 & 李保国 & 秦岭川金丝猴的一种自发性双足姿势的脚偏好 \\
\hline & & & /VU & & \\
\hline \multirow[t]{2}{*}{ Rhinopithecus roxellana } & 川金丝猴 & I & 易危 & 李保国 & 秦岭川金丝猴的昼间活动时间分配 \\
\hline & & & /VU & & \\
\hline
\end{tabular}


顾垒，闻丞，罗玫，王吴，吕植. 中国最受关注濒危物种保护现状快速评价的新方法探讨. 生物多样性，2015，23(5)：583-590. http://www biodiversity-science. net/CN/article/downloadArticleFile. do?attachType=PDF\&id=10075

\begin{tabular}{|c|c|c|c|c|c|}
\hline Rhinopithecus roxellana & 川金丝猴 & I & $\begin{array}{l}\text { 易危 } \\
\text { /VU }\end{array}$ & 李保国 & 秦岭川金丝猴冬季和春季在自然栖息地的空间利用 \\
\hline Rhinopithecus roxellana & 川金丝猴 & I & $\begin{array}{l}\text { 易危 } \\
\text { /VU }\end{array}$ & 高云芳 & 秦岭川金丝猴对高海拔栖息地的某些生理适应 \\
\hline Rhinopithecus roxellana & 川金丝猴 & I & $\begin{array}{l}\text { 易危 } \\
\text { /VU }\end{array}$ & 李保国 & 秦岭川金丝猴非成年个体行为发育的研究 \\
\hline Rhinopithecus roxellana & 川金丝猴 & I & $\begin{array}{l}\text { 易危 } \\
\text { /VU }\end{array}$ & 李宏群 & 秦岭川金丝猴个体行为研究 \\
\hline Rhinopithecus roxellana & 川金丝猴 & I & $\begin{array}{l}\text { 易危 } \\
\text { /VU }\end{array}$ & 李保国 & 秦岭川金丝猴个体间团抱模式及其影响因素 \\
\hline Rhinopithecus roxellana & 川金丝猴 & I & $\begin{array}{l}\text { 易危 } \\
\text { /VU }\end{array}$ & 李宏群 & 秦岭川金丝猴秋冬季节活动时间分配的初步研究 \\
\hline Rhinopithecus roxellana & 川金丝猴 & I & $\begin{array}{l}\text { 易危 } \\
\text { /VU }\end{array}$ & 李保国 & 秦岭川金丝猴群在非移动时的空间结构 \\
\hline Rhinopithecus roxellana & 川金丝猴 & I & $\begin{array}{l}\text { 易危 } \\
\text { /VU }\end{array}$ & 张东 & 秦岭川金丝猴社会中亚成年雄性个体的留群现象 \\
\hline Rhinopithecus roxellana & 川金丝猴 & I & $\begin{array}{l}\text { 易危 } \\
\text { /VU }\end{array}$ & 李保国 & 秦岭川金丝猴下地活动的初步调查 \\
\hline Rhinopithecus roxellana & 川金丝猴 & I & 易危 & 杨斌 & 秦岭川金丝猴性打搅行为研究 \\
\hline
\end{tabular}


顾垒，闻丞，罗玫，王吴，吕植. 中国最受关注濒危物种保护现状快速评价的新方法探讨. 生物多样性，2015，23(5)：583-590. http://www biodiversity-science. net/CN/article/downloadArticleFile. do?attachType=PDF\&id=10075

\begin{tabular}{|c|c|c|c|c|c|}
\hline & & & $/ \mathrm{VU}$ & & \\
\hline \multirow[t]{2}{*}{ Rhinopithecus roxellana } & 川金丝猴 & I & 易危 & 李保国 & 秦岭川金丝猴一个群的社会结构 \\
\hline & & & /VU & & \\
\hline \multirow[t]{2}{*}{ Rhinopithecus roxellana } & 川金丝猴 & I & 易危 & 李保国 & 秦岭川金丝猴一个投食群等级关系的研究 \\
\hline & & & /VU & & \\
\hline \multirow[t]{2}{*}{ Rhinopithecus roxellana } & 川金丝猴 & I & 易危 & 芦竹艳 & 秦岭川金丝猴一个投食群组成和结构的观察 \\
\hline & & & /VU & & \\
\hline \multirow[t]{2}{*}{ Rhinopithecus roxellana } & 川金丝猴 & I & 易危 & 李保国 & 秦岭川金丝猴一周岁内个体的行为发育 \\
\hline & & & $/ \mathrm{VU}$ & & \\
\hline \multirow[t]{2}{*}{ Rhinopithecus roxellana } & 川金丝猴 & I & 易危 & 李保国 & 秦岭川金丝猴长时间携带死贞行为 \\
\hline & & & /VU & & \\
\hline \multirow[t]{2}{*}{ Rhinopithecus roxellana } & 川金丝猴 & I & 易危 & 赵大鹏 & 秦岭金丝猴(Rhinopithecusr roxellana)交配行为的研究 \\
\hline & & & /VU & & \\
\hline \multirow[t]{2}{*}{ Rhinopithecus roxellana } & 川金丝猴 & I & 易危 & 余小玉 & 秦岭金丝猴(Rhinopithecusr roxellana)母婴关系,雄性照顾及一至二岁内幼猴发育行为的研 \\
\hline & & & /VU & & 究 \\
\hline \multirow[t]{2}{*}{ Rhinopithecus roxellana } & 川金丝猴 & I & 易危 & 李银华 & 秦岭金丝猴(Rhinopithecusr roxellana)婴幼儿行为发育的研究 \\
\hline & & & /VU & & \\
\hline \multirow[t]{2}{*}{ Rhinopithecus roxellana } & 川金丝猴 & I & 易危 & 李宏群 & 秦岭金丝猴一个投食猴群等级关系的研究 \\
\hline & & & /VU & & \\
\hline
\end{tabular}


顾垒，闻丞，罗玫，王吴，吕植. 中国最受关注濒危物种保护现状快速评价的新方法探讨. 生物多样性，2015，23(5)：583-590. http://www biodiversity-science. net/CN/article/downloadArticleFile. do?attachType=PDF\&id=10075

\begin{tabular}{|c|c|c|c|c|c|}
\hline \multirow[t]{2}{*}{ Rhinopithecus roxellana } & 川金丝猴 & I & 易危 & 王慧平 & 秦岭野生川金丝猴不同季节粪便中性腺激素水平的变化及其与繁殖行为的关系 \\
\hline & & & $/ \mathrm{VU}$ & & \\
\hline \multirow[t]{2}{*}{ Rhinopithecus roxellana } & 川金丝猴 & I & 易危 & 高云芳 & 秦岭野生雌性川金丝猴粪便睪酮水平与邀配频次的季节性变化 \\
\hline & & & /VU & & \\
\hline \multirow[t]{2}{*}{ Rhinopithecus roxellana } & 川金丝猴 & I & 易危 & 李保国 & 秦岭玉皇庙川金丝猴 2-3 岁内个体社会行为的性别差异 \\
\hline & & & /VU & & \\
\hline \multirow[t]{2}{*}{ Rhinopithecus roxellana } & 川金丝猴 & I & 易危 & 蒋志刚 & 青木川自然保护区川金丝猴食性的季节性变化 \\
\hline & & & $/ \mathrm{VU}$ & & \\
\hline \multirow[t]{2}{*}{ Rhinopithecus roxellana } & 川金丝猴 & I & 易危 & 杨 旭 & 三打古自然保护区川金丝猴栖息地现状及发展建议 \\
\hline & & & /VU & & \\
\hline \multirow[t]{2}{*}{ Rhinopithecus roxellana } & 川金丝猴 & I & 易危 & 任保平 & 森林采伐导致秦岭川金丝猴夏季活动范围变化 \\
\hline & & & /VU & & \\
\hline \multirow[t]{2}{*}{ Rhinopithecus roxellana } & 川金丝猴 & I & 易危 & 李义明 & 社群大小的年变化、气候和人类活动对神农架自然保护区川金丝猴日移动距离的影响 \\
\hline & & & /VU & & \\
\hline \multirow[t]{2}{*}{ Rhinopithecus roxellana } & 川金丝猴 & I & 易危 & 李广良 & 神农架保护区川金丝猴活动区域动植物群落研究 \\
\hline & & & /VU & & \\
\hline \multirow[t]{2}{*}{ Rhinopithecus roxellana } & 川金丝猴 & I & 易危 & 张志翔 & 神农架川金丝猴冬春季节取食影响因素 \\
\hline & & & $/ \mathrm{VU}$ & & \\
\hline Rhinopithecus roxellana & 川金丝猴 & $\mathrm{I}$ & 易危 & 张志翔 & 神农架川金丝猴冬春季节食性分析 \\
\hline
\end{tabular}


顾垒，闻丞，罗玫，王吴，吕植. 中国最受关注濒危物种保护现状快速评价的新方法探讨. 生物多样性，2015，23(5)：583-590. http://www. biodiversity-science. net/CN/article/downloadArticleFile. do?attachType=PDF\&id=10075

\begin{tabular}{|c|c|c|c|c|c|}
\hline & & & $/ \mathrm{VU}$ & & \\
\hline \multirow[t]{2}{*}{ Rhinopithecus roxellana } & 川金丝猴 & I & 易危 & 向左甫 & 神农架川金丝猴粪便和尿液中类固醇激素的检测 \\
\hline & & & /VU & & \\
\hline \multirow[t]{2}{*}{ Rhinopithecus roxellana } & 川金丝猴 & I & 易危 & 黄英 & 神农架川金丝猴粪便类固醇激素的非损伤性测定及其指示作用研究 \\
\hline & & & /VU & & \\
\hline \multirow[t]{2}{*}{ Rhinopithecus roxellana } & 川金丝猴 & I & 易危 & 张志翔 & 神农架川金丝猴栖息地乔木层物种多样性及其海拔梯度变化 \\
\hline & & & /VU & & \\
\hline \multirow[t]{2}{*}{ Rhinopithecus roxellana } & 川金丝猴 & I & 易危 & 李迪强 & 神农架川金丝猴栖息地森林类型与植物多样性研究 \\
\hline & & & $/ \mathrm{VU}$ & & \\
\hline \multirow[t]{2}{*}{ Rhinopithecus roxellana } & 川金丝猴 & I & 易危 & 李迪强 & 神农架川金丝猴栖息地森林群落的数量分类与排序 \\
\hline & & & $/ \mathrm{VU}$ & & \\
\hline \multirow[t]{2}{*}{ Rhinopithecus roxellana } & 川金丝猴 & I & 易危 & 李迪强 & 神农架川金丝猴栖息地优势树种生态位及食源植物 \\
\hline & & & /VU & & \\
\hline \multirow[t]{2}{*}{ Rhinopithecus roxellana } & 川金丝猴 & I & 易危 & 李迪强 & 神农架川金丝猴栖息地植物区系特征及食物资源研究 \\
\hline & & & /VU & & \\
\hline \multirow[t]{2}{*}{ Rhinopithecus roxellana } & 川金丝猴 & I & 易危 & 罗芳 & 神农架川金丝猴社会单元组成变化及育幼行为研究 \\
\hline & & & /VU & & \\
\hline \multirow[t]{2}{*}{ Rhinopithecus roxellana } & 川金丝猴 & I & 易危 & 鲍伟东 & 神农架川金丝猴社会单元组成的变化 \\
\hline & & & /VU & & \\
\hline
\end{tabular}


顾垒，闻丞，罗玫，王吴，吕植. 中国最受关注濒危物种保护现状快速评价的新方法探讨. 生物多样性，2015，23(5)：583-590. http://www biodiversity-science. net/CN/article/downloadArticleFile. do?attachType=PDF\&id=10075

\begin{tabular}{|c|c|c|c|c|c|}
\hline Rhinopithecus roxellana & 川金丝猴 & I & $\begin{array}{l}\text { 易危 } \\
\text { /VU }\end{array}$ & 鲍伟东 & 神农架川金丝猴投食群 0-6 月龄的母亲照顾行为 \\
\hline Rhinopithecus roxellana & 川金丝猴 & I & $\begin{array}{l}\text { 易危 } \\
\text { /VU }\end{array}$ & 鲍伟东 & 神农架川金丝猴投食群的攻击行为及等级序列 \\
\hline Rhinopithecus roxellana & 川金丝猴 & I & $\begin{array}{l}\text { 易危 } \\
\text { /VU }\end{array}$ & 鲍伟东 & 神农架川金丝猴投食群的取食优先序 \\
\hline Rhinopithecus roxellana & 川金丝猴 & I & $\begin{array}{l}\text { 易危 } \\
\text { /VU }\end{array}$ & 鲍伟东 & 神农架川金丝猴投食群的社会行为谱 \\
\hline Rhinopithecus roxellana & 川金丝猴 & I & $\begin{array}{l}\text { 易危 } \\
\text { /VU }\end{array}$ & 蔚培龙 & 神农架川金丝猴投食群的社会行为学研究 \\
\hline Rhinopithecus roxellana & 川金丝猴 & I & $\begin{array}{l}\text { 易危 } \\
\text { /VU }\end{array}$ & 毕帅奇 & 神农架大龙潭投食点川金丝猴群春季日活动情况的初步观察 \\
\hline Rhinopithecus roxellana & 川金丝猴 & I & $\begin{array}{l}\text { 易危 } \\
\text { /VU }\end{array}$ & 李义明 & 神农架自然保护区川金丝猴(Rhinopithecus roxellana)海拔高度分布的生态限制因素 \\
\hline Rhinopithecus roxellana & 川金丝猴 & I & $\begin{array}{l}\text { 易危 } \\
\text { /VU }\end{array}$ & 鲍伟东 & 神农架自然保护区川金丝猴投食群友好行为的初步观察 \\
\hline Rhinopithecus roxellana & 川金丝猴 & I & $\begin{array}{l}\text { 易危 } \\
\text { /VU }\end{array}$ & 邓龙强 & 神农架自然保护区金丝猴投食群性行为的初步观察 \\
\hline Rhinopithecus roxellana & 川金丝猴 & I & 易危 & 金崑 & 四川省白河自然保护区川金丝猴生境评价 \\
\hline
\end{tabular}


顾垒，闻丞，罗玫，王吴，吕植. 中国最受关注濒危物种保护现状快速评价的新方法探讨. 生物多样性，2015，23(5)：583-590. http://www biodiversity-science. net/CN/article/downloadArticleFile. do?attachType=PDF\&id=10075

\begin{tabular}{|c|c|c|c|c|c|}
\hline & & & $/ \mathrm{VU}$ & & \\
\hline \multirow[t]{2}{*}{ Rhinopithecus roxellana } & 川金丝猴 & I & 易危 & 任保平 & 饲养条件下川金丝猴群中主雄的移除和替换对社群行为的影响 \\
\hline & & & $/ \mathrm{VU}$ & & \\
\hline \multirow[t]{2}{*}{ Rhinopithecus roxellana } & 川金丝猴 & I & 易危 & 郑维超 & 唐家河国家级自然保护区川金丝猴冬季栖息地选择 \\
\hline & & & /VU & & \\
\hline \multirow[t]{2}{*}{ Rhinopithecus roxellana } & 川金丝猴 & I & 易危 & 张志翔 & 夏秋季节神农架川金丝猴取食主要影响因素分析 \\
\hline & & & /VU & & \\
\hline \multirow[t]{2}{*}{ Rhinopithecus roxellana } & 川金丝猴 & I & 易危 & 马强 & 小神农架川金丝猴的行为和生态研究 \\
\hline & & & $/ \mathrm{VU}$ & & \\
\hline \multirow[t]{2}{*}{ Rhinopithecus roxellana } & 川金丝猴 & I & 易危 & 张树义 & 雄性川金丝猴睪酮分泌与其社群环境变化的关系 \\
\hline & & & /VU & & \\
\hline \multirow[t]{2}{*}{ Rhinopithecus roxellana } & 川金丝猴 & I & 易危 & 李保国 & 野生川金丝猴一个全雄青年猴群的同性爬背行为 \\
\hline & & & /VU & & \\
\hline \multirow[t]{2}{*}{ Rhinopithecus roxellana } & 川金丝猴 & I & 易危 & 李文俊 & 野生秦岭川金丝猴(Rhinopithecusr roxellana)理毛与交配的相互关系及其影响因素 \\
\hline & & & /VU & & \\
\hline \multirow[t]{2}{*}{ Rhinopithecus roxellana } & 川金丝猴 & I & 易危 & 高翔 & 野生秦岭川金丝猴(Rhinopithecusr roxellana)母婴偏好及生物市场的研究 \\
\hline & & & $/ \mathrm{VU}$ & & \\
\hline \multirow[t]{2}{*}{ Rhinopithecus roxellana } & 川金丝猴 & I & 易危 & 李保国 & 依据取食优势判断秦岭川金丝猴群 OMU 的等级地位 \\
\hline & & & /VU & & \\
\hline
\end{tabular}


顾垒，闻丞，罗玫，王吴，吕植. 中国最受关注濒危物种保护现状快速评价的新方法探讨. 生物多样性，2015，23(5)：583-590. http://www biodiversity-science. net/CN/article/downloadArticleFile. do?attachType=PDF\&id=10075

\begin{tabular}{|c|c|c|c|c|c|}
\hline Rhinopithecus roxellana & 川金丝猴 & I & $\begin{array}{l}\text { 易危 } \\
\text { /VU }\end{array}$ & 陈超 & $\begin{array}{l}\text { 应用尿液中性甾体激素 } 17 \beta-\mathrm{E} 2, \mathrm{P} \text { 和 } \mathrm{T} \text { 的代谢状况进行笼养川金丝猴(Rhinopithecusr } \\
\text { roxellana)生殖生理状评估的研究 }\end{array}$ \\
\hline Rhinopithecus roxellana & 川金丝猴 & I & $\begin{array}{l}\text { 易危 } \\
\text { /VU }\end{array}$ & 刘瑛 & 灾后川金丝猴适宜栖息地恢复指标的研究 \\
\hline Rhinopithecus roxellana & 川金丝猴 & I & $\begin{array}{l}\text { 易危 } \\
\text { /VU }\end{array}$ & 胡永乐 & 周至国家级自然保护区川金丝猴个体社群行为观察 \\
\hline Rhododendron cyanocarpum & 蓝果杜鹃 & $\begin{array}{l}\text { 未列 } \\
\text { 入 }\end{array}$ & $\begin{array}{l}\text { 易危 } \\
\text { /VU }\end{array}$ & Chang-Qin Zhang & $\begin{array}{l}\text { Unusual Patterns Of Hybridization Involving A Narrow Endemic Rhoodendron } \\
\text { Species(Ericaceae) In Yunnan, China }\end{array}$ \\
\hline Rhododendron delavayi Franch & 马缨杜鹃 & $\begin{array}{l}\text { 未列 } \\
\text { 入 }\end{array}$ & $\begin{array}{l}\text { 未评 } \\
\text { 价 } \\
\text { /NE }\end{array}$ & Chang-Qin Zhang & $\begin{array}{l}\text { Natural Hybridization between Rhododendron delavayi and R. cyanocarpum(Ericaceae), from } \\
\text { Morphological, Molecular and Reproductive Evidence }\end{array}$ \\
\hline $\begin{array}{l}\text { Rhododendron protistum var. } \\
\text { giganteum }\end{array}$ & 大树杜鹃 & $\begin{array}{l}\text { 未列 } \\
\text { 入 }\end{array}$ & $\begin{array}{l}\text { 未评 } \\
\text { 价 } \\
\text { /NE }\end{array}$ & 张长芹 & $\begin{array}{l}\text { 大树杜鹃 Rhododendron protistum var. giganteum 和蓝果杜鹃 Rhododendron cyanocarpum 的 } \\
\text { 濒危原因研究 }\end{array}$ \\
\hline Sacalia bealei & 眼斑龟 & $\begin{array}{l}\text { 未列 } \\
\lambda\end{array}$ & 濒危 & Shi-ping Gong & $\begin{array}{l}\text { Isolation and characterization of microsatellite markers from the Chinese endemic species, } \\
\text { Beal's-eyed turtle (Sacalia bealei) }\end{array}$ \\
\hline Sarcogyps calvus & 黑而鹑 & I & 极危 & 杨岗 & 西双版纳热带地区的几种大型鸟类 \\
\hline Sarcogyps calvus & 黑兀鹑 & I & 极危 & 舒晓莲 & 中国西南部石灰岩地区受威胁动物的现状及保护 \\
\hline
\end{tabular}


顾垒，闻丞，罗玫，王吴，吕植. 中国最受关注濒危物种保护现状快速评价的新方法探讨. 生物多样性，2015，23(5)：583-590. http://www. biodiversity-science. net/CN/article/downloadArticleFile. do?attachType=PDF\&id=10075

\begin{tabular}{|c|c|c|c|c|c|}
\hline & & & /CR & & \\
\hline \multirow[t]{2}{*}{ Saruma henryi } & 马蹄香 & II & 濒危 & 马养民 & 2DNMR 对马蹄香中马兒铃内酰胺 IV 的结构解析 \\
\hline & & & $/$ EN & & \\
\hline \multirow[t]{2}{*}{ Saruma henryi } & 马蹄香 & II & 濒危 & 董珊珊 & 濒危植物马蹄香的遗传多样性与遗传分化研究 \\
\hline & & & /EN & & \\
\hline \multirow[t]{2}{*}{ Saruma henryi } & 马蹄香 & II & 濒危 & 娄方明 & 顶空固相微萃取-气相色谱-质谱联用分析马蹄香中的挥发油成分 \\
\hline & & & /EN & & \\
\hline \multirow[t]{2}{*}{ Saruma henryi } & 马蹄香 & II & 濒危 & 赵桦 & 高效液相色谱法测定马蹄香中马兒铃酸 A 含量 \\
\hline & & & /EN & & \\
\hline \multirow[t]{2}{*}{ Saruma henryi } & 马蹄香 & II & 濒危 & 程舟 & 马蹄香表达序列标签资源的 SSR 信息分析 \\
\hline & & & /EN & & \\
\hline \multirow[t]{2}{*}{ Saruma henryi } & 马蹄香 & II & 濒危 & 赵桦 & 马蹄香雌荵形态及传粉生物学研究 \\
\hline & & & /EN & & \\
\hline \multirow[t]{2}{*}{ Saruma henryi } & 马蹄香 & II & 濒危 & 彭强 & 马蹄香的生药鉴定及其与华细辛的鉴别 \\
\hline & & & /EN & & \\
\hline \multirow[t]{2}{*}{ Saruma henryi } & 马蹄香 & II & 濒危 & 陈业高 & 马蹄香化学成分的分离与鉴定 \\
\hline & & & /EN & & \\
\hline \multirow[t]{2}{*}{ Saruma henryi } & 马蹄香 & II & 濒危 & 马养民 & 马蹄香化学成分的研究 \\
\hline & & & /EN & & \\
\hline
\end{tabular}


顾垒，闻丞，罗玫，王吴，吕植. 中国最受关注濒危物种保护现状快速评价的新方法探讨. 生物多样性，2015，23(5)：583-590. http://www. biodiversity-science. net/CN/article/downloadArticleFile. do?attachType=PDF\&id=10075

\begin{tabular}{|c|c|c|c|c|c|}
\hline Saruma henryi & 马蹄香 & II & $\begin{array}{l}\text { 濒危 } \\
/ \mathrm{EN}\end{array}$ & 赵桦 & 马蹄香及其易混品华细辛的薄层鉴别 \\
\hline Saruma henryi & 马蹄香 & II & $\begin{array}{l}\text { 濒危 } \\
/ \mathrm{EN}\end{array}$ & 张萍 & 马蹄香植物不同器官中马兒铃酸 $\mathrm{A}$ 含量的测定 \\
\hline Saruma henryi & 马蹄香 & II & $\begin{array}{l}\text { 濒危 } \\
/ \mathrm{EN}\end{array}$ & 陈业高 & 马蹄香中的新环烯梄萜酯 \\
\hline Saruma henryi & 马蹄香 & II & $\begin{array}{l}\text { 濒危 } \\
/ \mathrm{EN}\end{array}$ & 赵桦 & 马蹄香种子生物学特性研究 \\
\hline Saruma henryi & 马蹄香 & II & $\begin{array}{l}\text { 濒危 } \\
/ \mathrm{EN}\end{array}$ & 王喆之 & 马蹄香组织培养研究初报 \\
\hline Saruma henryi & 马蹄香 & II & $\begin{array}{l}\text { 濒危 } \\
/ \mathrm{EN}\end{array}$ & 张萍 & 紫外分光光度法测定马蹄香植物不同器官中马兒铃酸 A 的含量 \\
\hline Saurauia erythrocarpa & 红果水东哥 & $\begin{array}{l}\text { 未列 } \\
\text { 入 }\end{array}$ & $\begin{array}{l}\text { 易危 } \\
\text { /VU }\end{array}$ & 梁畴芬 & 红果水东哥（新种），中国植物志 49 卷第二分册 330 \\
\hline Saurauia punduana & 大花水东哥 & $\begin{array}{l}\text { 未列 } \\
\text { 入 }\end{array}$ & $\begin{array}{l}\text { 极危 } \\
\text { /CR }\end{array}$ & Nathaniel Wallich & Plantae Asiaticae Rariores 2: 49. \\
\hline Saxicola insignis & 白喉石鵖 & $\begin{array}{l}\text { 未列 } \\
\text { 入 }\end{array}$ & $\begin{array}{l}\text { 易危 } \\
\text { /VU }\end{array}$ & 汪青雄 & 近 40 年陕西榆林地区鸟类组成和区系变化 \\
\hline Saxicola insignis & 白喉石鵖 & 未列 & 易危 & 应 钦 & 鄱阳湖吴城半岛鸟类群落组成及多样性分析 \\
\hline
\end{tabular}


顾垒，闻丞，罗玫，王吴，吕植. 中国最受关注濒危物种保护现状快速评价的新方法探讨. 生物多样性，2015，23(5)：583-590. http://www. biodiversity-science. net/CN/article/downloadArticleFile. do?attachType=PDF\&id=10075

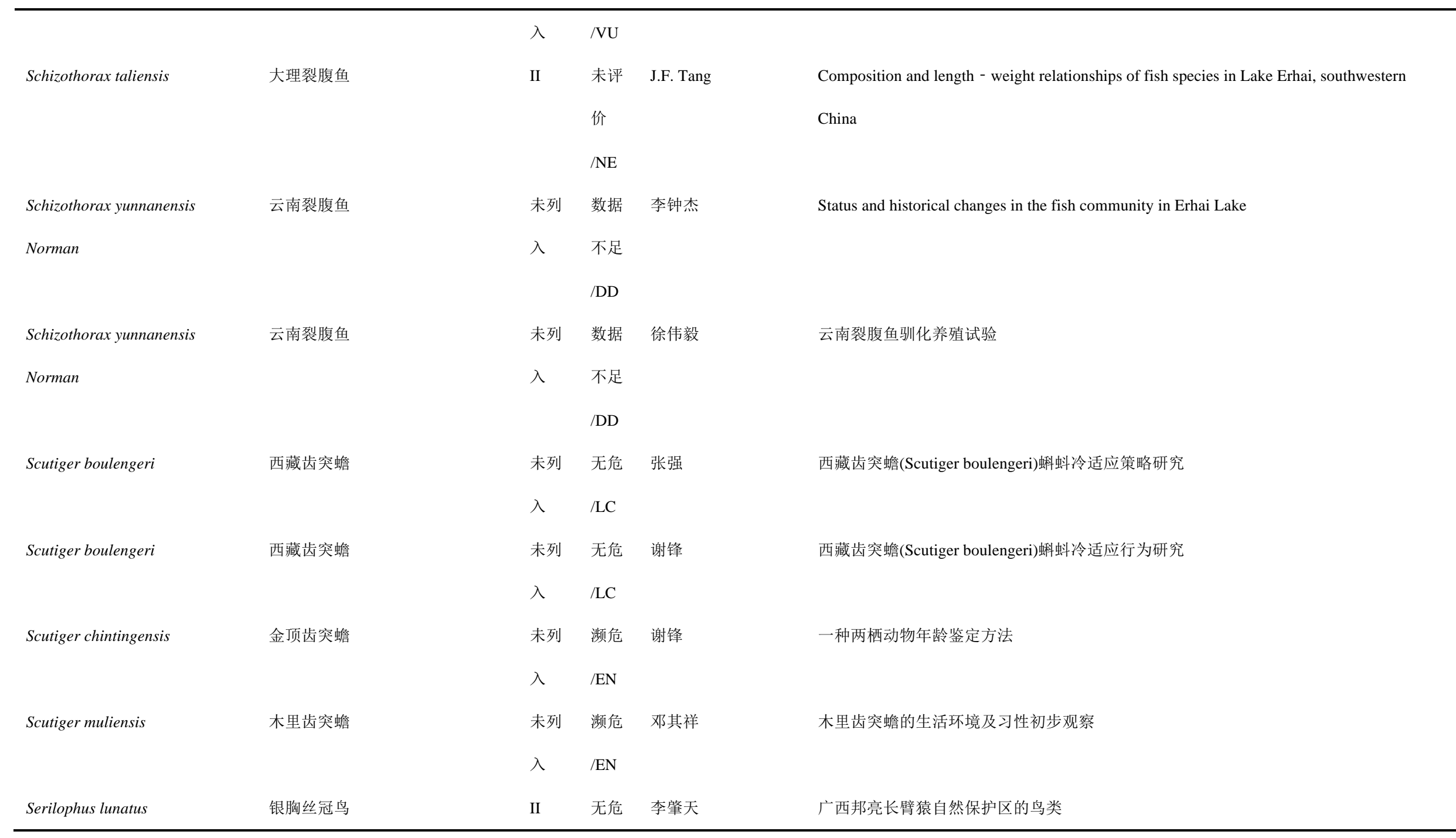


顾垒，闻丞，罗玫，王吴，吕植. 中国最受关注濒危物种保护现状快速评价的新方法探讨. 生物多样性，2015，23(5)：583-590. http://www, biodiversity-science. net/CN/article/downloadArticleFile. do?attachType=PDF\&id=10075

\begin{tabular}{|c|c|c|c|c|c|}
\hline & & & $/ \mathrm{LC}$ & & \\
\hline \multirow[t]{2}{*}{ Serilophus lunatus } & 银胸丝冠鸟 & II & 无危 & 邹发生 & 海南岛尖峰岭热带森林中几种雀形目鸟的移动 \\
\hline & & & $/ \mathrm{LC}$ & & \\
\hline \multirow[t]{2}{*}{ Serilophus lunatus } & 银胸丝冠鸟 & II & 无危 & 邹发生 & 海南岛尖峰岭热带山地雨林林下鸟类群落研究 \\
\hline & & & /LC & & \\
\hline \multirow[t]{2}{*}{ Serilophus lunatus } & 银胸丝冠鸟 & II & 无危 & 李国诚 & 海南俄贤岭及周边地区鸟类调查报告_含一海南省新记录 \\
\hline & & & /LC & & \\
\hline \multirow[t]{2}{*}{ Serilophus lunatus } & 银胸丝冠鸟 & II & 无危 & 符腾霆 & 海南佳西省级自然保护区动植物资源探讨 \\
\hline & & & $/ \mathrm{LC}$ & & \\
\hline \multirow[t]{2}{*}{ Serilophus lunatus } & 银胸丝冠鸟 & II & 无危 & 高建云 & 海南热带雨林次生林边缘至林内鸟类群落组成与功能集团比较 \\
\hline & & & $/ \mathrm{LC}$ & & \\
\hline \multirow[t]{2}{*}{ Serilophus lunatus } & 银胸丝冠鸟 & II & 无危 & 蔡燕 & 人工林对海南鹦哥岭鸟类多样性的影响 \\
\hline & & & $/ \mathrm{LC}$ & & \\
\hline \multirow[t]{2}{*}{ Serilophus lunatus } & 银胸丝冠鸟 & II & 无危 & 雷 桂 林 & 思茅菜阳河自然保护区鸟类研究 \\
\hline & & & $/ \mathrm{LC}$ & & \\
\hline \multirow[t]{2}{*}{ Serilophus lunatus } & 银胸丝冠鸟 & II & 无危 & 黄俊辉 & 西双版纳预养早季季风常绿阔叶林的林下鸟类群落组成和特点 \\
\hline & & & /LC & & \\
\hline \multirow[t]{2}{*}{ Serilophus lunatus } & 银胸丝冠鸟 & II & 无危 & 苏栋栋 & 云南大围山和鸡足山常绿阔叶林林下鸟类群落比较 \\
\hline & & & /LC & & \\
\hline
\end{tabular}


顾垒，闻丞，罗玫，王吴，吕植. 中国最受关注濒危物种保护现状快速评价的新方法探讨. 生物多样性，2015，23(5)：583-590. http://www. biodiversity-science. net/CN/article/downloadArticleFile. do?attachType=PDF\&id=10075

\begin{tabular}{|c|c|c|c|c|c|}
\hline \multirow[t]{2}{*}{ Sinadoxa corydalifolia } & 华福花 & 未列 & 易危 & Liu Jian quan & The Phylogenetic Relationships of an Endemic GenusSinadoxain the Qinghai Xizang \\
\hline & & 入 & /VU & & Plateau:Evidence from ITS Sequence Analysis \\
\hline \multirow[t]{2}{*}{ Sinocyclocheilus hyalinus } & 透明金线鲃 & 未列 & 易危 & 杨君兴 & 透明金线鲃口鼻部感觉系统的同步辐射研究 \\
\hline & & 入 & /VU & & \\
\hline \multirow[t]{3}{*}{ Sinosuthora webbiana } & 棕头鸦雀 & 未列 & 数据 & 陈志强 & 北京圆明园遗址公园鸟类组成 \\
\hline & & 入 & 不足 & & \\
\hline & & & $/ \mathrm{DD}$ & & \\
\hline \multirow[t]{3}{*}{ Sinosuthora webbiana } & 棕头鸦雀 & 未列 & 数据 & 刘 涁 & 大别山山地次生林鸟类群落集团结构的季节变化 \\
\hline & & 入 & 不足 & & \\
\hline & & & $/ \mathrm{DD}$ & & \\
\hline \multirow[t]{3}{*}{ Sinosuthora webbiana } & 棕头鸦雀 & 未列 & 数据 & 韦福民 & 大盘山国家级自然保护区鸟类群落及其分布特征 \\
\hline & & 入 & 不足 & & \\
\hline & & & $/ \mathrm{DD}$ & & \\
\hline \multirow[t]{3}{*}{ Sinosuthora webbiana } & 棕头鸦雀 & 未列 & 数据 & 江建国 & 鄂西野三河自然保护区鸟类资源调查报告 \\
\hline & & 入 & 不足 & & \\
\hline & & & $/ \mathrm{DD}$ & & \\
\hline \multirow[t]{3}{*}{ Sinosuthora webbiana } & 棕头鸦雀 & 未列 & 数据 & 李巨勇 & 河北唐海湿地不同生境鸟类群落结构的变化 \\
\hline & & 入 & 不足 & & \\
\hline & & & $/ \mathrm{DD}$ & & \\
\hline
\end{tabular}


顾垒，闻丞，罗玫，王吴，吕植. 中国最受关注濒危物种保护现状快速评价的新方法探讨. 生物多样性，2015，23(5)：583-590. http://www. biodiversity-science. net/CN/article/downloadArticleFile. do?attachType=PDF\&id=10075

\begin{tabular}{|c|c|c|c|c|c|}
\hline \multirow[t]{2}{*}{ Sinosuthora webbiana } & 棕头鸦雀 & 未列 & 数据 & 杜志勇 & 河南董寨国家级自然保护区棕头鸦雀体重的季节性变化 \\
\hline & & 入 & $\begin{array}{l}\text { 不足 } \\
\text { /DD }\end{array}$ & & \\
\hline \multirow[t]{3}{*}{ Sinosuthora webbiana } & 棕头鸦雀 & 未列 & 数据 & 王德良 & 湖北五龙河自然保护区鸟类群落多样性分析 \\
\hline & & 入 & 不足 & & \\
\hline & & & /DD & & \\
\hline \multirow[t]{3}{*}{ Sinosuthora webbiana } & 棕头鸦雀 & 未列 & 数据 & 王 晶 & 湖北仙桃沙湖湿地自然保护区夏季鸟类群落结构及多样性分析 \\
\hline & & 入 & 不足 & & \\
\hline & & & /DD & & \\
\hline \multirow[t]{3}{*}{ Sinosuthora webbiana } & 棕头鸦雀 & 未列 & 数据 & 单凯 & 黄河三角洲发现的山东省鸟类新纪录 \\
\hline & & 入 & 不足 & & \\
\hline & & & $/ \mathrm{DD}$ & & \\
\hline \multirow[t]{3}{*}{ Sinosuthora webbiana } & 棕头鸦雀 & 未列 & 数据 & 李丽纯 & 三峡重庆库区不同鸟类群落的物种组成及多样性研究 \\
\hline & & 入 & 不足 & & \\
\hline & & & $/ \mathrm{DD}$ & & \\
\hline \multirow[t]{3}{*}{ Sinosuthora webbiana } & 棕头鸦雀 & 未列 & 数据 & 罗 否 & 太白山北坡冬、春季鸟类群落多样性 \\
\hline & & 入 & 不足 & & \\
\hline & & & $/ \mathrm{DD}$ & & \\
\hline Sinosuthora webbiana & 棕头鸦雀 & 未列 & 数据 & 万 亮 & 永州夏季城市鸟类群落结构与多样性分析 \\
\hline
\end{tabular}


顾垒，闻丞，罗玫，王吴，吕植. 中国最受关注濒危物种保护现状快速评价的新方法探讨. 生物多样性，2015，23(5)：583-590. http://www biodiversity-science. net/CN/article/downloadArticleFile. do?attachType=PDF\&id=10075

\begin{tabular}{|c|c|c|c|c|c|}
\hline & & $\lambda$ & 不足 & & \\
\hline & & & $/ \mathrm{DD}$ & & \\
\hline \multirow[t]{3}{*}{ Sinosuthora webbiana } & 棕头鸦雀 & 未列 & 数据 & 郭宗明 & 棕头鸦雀的巢生境因子分析和维鸟的生长发育 \\
\hline & & 入 & 不足 & & \\
\hline & & & $/ \mathrm{DD}$ & & \\
\hline \multirow[t]{2}{*}{ Sinowilsonia henryi } & 山白树 & II & $\mathrm{LR} / \mathrm{n}$ & 令狐昱慰 & 3 种外源激素对山白树种子无菌萌发的影响 \\
\hline & & & $\mathrm{t}$ & & \\
\hline \multirow[t]{2}{*}{ Sinowilsonia henryi } & 山白树 & II & $\mathrm{LR} / \mathrm{n}$ & 熊向阳 & 山白树属雄荵数目和形态的变异及其系统学意义 \\
\hline & & & $\mathrm{t}$ & & \\
\hline \multirow[t]{2}{*}{ Sinowilsonia henryi } & 山白树 & II & $\mathrm{LR} / \mathrm{n}$ & 张荣 & 山白树种子营养成分及萌发特性研究 \\
\hline & & & $\mathrm{t}$ & & \\
\hline \multirow[t]{2}{*}{ Sinowilsonia henryi } & 山白树 & II & $\mathrm{LR} / \mathrm{n}$ & 张立军 & 中国特有属珍稀濒危植物山白树的研究进展 \\
\hline & & & $\mathrm{t}$ & & \\
\hline \multirow[t]{2}{*}{ Sousa chinensis } & 中华白海豚 & I & 近危 & Guang Yang & A prelim inary analysis of genetic variation at threeMHC loci of the Indo-Pacific humpback \\
\hline & & & /NT & & dolphin ( Sousa chinensis ) \\
\hline \multirow[t]{2}{*}{ Sousa chinensis } & 中华白海豚 & I & 近危 & Yuping Wu & A preliminary investigation on genetic diversity of Sousa chinensis in the Pearl River Estuary \\
\hline & & & /NT & & and Xiamen of Chinese waters \\
\hline \multirow[t]{2}{*}{ Sousa chinensis } & 中华白海豚 & I & 近危 & Guang Yang & A set of polymorphic dinucleotide and tetranucleotide microsatellite markers for the \\
\hline & & & /NT & & Indo-Pacific humpback dolphin (Sousa chinensis) and cross-amplification in other cetacean \\
\hline
\end{tabular}


顾垒，闻丞，罗玫，王昊，吕植. 中国最受关注濒危物种保护现状快速评价的新方法探讨．生物多样性，2015，23(5)：583-590. http://www biodiversity-science, net/CN/article/downloadArticleFile. do?attachType=PDF\&id=10075

\section{species}

\begin{tabular}{|c|c|c|c|c|c|}
\hline Sousa chinensis & 中华白海豚 & I & 近危 & G. Yang & $\begin{array}{l}\text { Abundance, distribution and conservation of Chinese White Dolphins (Sousa chinensis) in } \\
\text { Xiamen, China }\end{array}$ \\
\hline Sousa chinensis & 中华白海豚 & I & $\begin{array}{l}\text { 近危 } \\
\text { /NT }\end{array}$ & Yuping Wu & $\begin{array}{l}\text { Derivation and characterization of cell cultures from the skin of the Indo-Pacific humpback } \\
\text { dolphin Sousa chinensis }\end{array}$ \\
\hline Sousa chinensis & 中华白海豚 & I & $\begin{array}{l}\text { 近危 } \\
\text { /NT }\end{array}$ & Yuping Wu & $\begin{array}{l}\text { Differentiated or not? An assessment of current knowledge of genetic structure of Sousa } \\
\text { chinensis in China }\end{array}$ \\
\hline Sousa chinensis & 中华白海豚 & I & $\begin{array}{l}\text { 近危 } \\
\text { /NT }\end{array}$ & Tao Chen & $\begin{array}{l}\text { Distribution andgroupdynamicsofIndo-Pacifichumpbackdolphins (Sousa chinensis) } \\
\text { inthewesternPearlRiverEstuary,China }\end{array}$ \\
\hline Sousa chinensis & 中华白海豚 & I & $\begin{array}{l}\text { 近危 } \\
\text { /NT }\end{array}$ & Wenhua Liu & $\begin{array}{l}\text { Evaluation of organochlorine contamination in Indo-Pacific humpback dolphins (Sousa } \\
\text { chinensis) from the Pearl River Estuary, China }\end{array}$ \\
\hline Sousa chinensis & 中华白海豚 & I & $\begin{array}{l}\text { 近危 } \\
\text { /NT }\end{array}$ & Yuping Wu & Evolution of Sousa chinensis: A scenario based on mitochondrial DNA study \\
\hline Sousa chinensis & 中华白海豚 & I & $\begin{array}{l}\text { 近危 } \\
\text { /NT }\end{array}$ & QIAN ZHU & $\begin{array}{l}\text { Indo-Pacific humpback dolphins (Sousa chinensis) assist a finless porpoise (Neophocaena } \\
\text { phocaenoides sunameri) calf: evidence from Xiamen waters in China }\end{array}$ \\
\hline Sousa chinensis & 中华白海豚 & I & $\begin{array}{l}\text { 近危 } \\
\text { /NT }\end{array}$ & Guang Yang & $\begin{array}{l}\text { Molecular phylogenetics and population structure of Sousa chinensis in Chinese waters inferred } \\
\text { from mitochondrial control region sequences }\end{array}$ \\
\hline Sousa chinensis & 中华白海豚 & I & $\begin{array}{l}\text { 近危 } \\
\text { /NT }\end{array}$ & 杨光 & 北部湾沙田水域中华白海豚和江豚的同域分布格局及时空变化 \\
\hline
\end{tabular}


顾垒，闻丞，罗玫，王吴，吕植. 中国最受关注濒危物种保护现状快速评价的新方法探讨. 生物多样性，2015，23(5)：583-590. http://www biodiversity-science. net/CN/article/downloadArticleFile. do?attachType=PDF\&id=10075

\begin{tabular}{|c|c|c|c|c|c|}
\hline Sousa chinensis & 中华白海豚 & I & $\begin{array}{l}\text { 近危 } \\
\text { /NT }\end{array}$ & 方展强 & 川山群岛海区大襟岛附近水域发现的中华白海豚 \\
\hline Sousa chinensis & 中华白海豚 & I & $\begin{array}{l}\text { 近危 } \\
\text { /NT }\end{array}$ & 方展强 & 大襟岛海域中华白海豚体内的重金属含量测定与评价 \\
\hline Sousa chinensis & 中华白海豚 & I & $\begin{array}{l}\text { 近危 } \\
\text { /NT }\end{array}$ & 方展强 & 大襟岛海域中华白海豚体内及栖息地持久性有毒物质含量与评价 \\
\hline Sousa chinensis & 中华白海豚 & I & $\begin{array}{l}\text { 近危 } \\
\text { /NT }\end{array}$ & 祝茜 & 福建沿海中华白海豚的分布与种群数量调查 \\
\hline Sousa chinensis & 中华白海豚 & I & $\begin{array}{l}\text { 近危 } \\
\text { /NT }\end{array}$ & 刘文华 & 广东省中华白海豚生存状况研究 \\
\hline Sousa chinensis & 中华白海豚 & I & $\begin{array}{l}\text { 近危 } \\
\text { /NT }\end{array}$ & 陈晓汉 & 广西北部湾珍稀动物现状调查与研究 \\
\hline Sousa chinensis & 中华白海豚 & I & $\begin{array}{l}\text { 近危 } \\
\text { /NT }\end{array}$ & 吴孝兵 & 广西北海水域中华白海豚种群数量和分布动态及保护对策研究 \\
\hline Sousa chinensis & 中华白海豚 & I & $\begin{array}{l}\text { 近危 } \\
\text { /NT }\end{array}$ & 韩家波 & 黄海北部发现的中华白海豚 I . 外形和内脏器官的测定结果 \\
\hline Sousa chinensis & 中华白海豚 & I & $\begin{array}{l}\text { 近危 } \\
\text { /NT }\end{array}$ & 韩家波 & 黄海北部发现的中华白海豚 II. 脊柱、肋骨、胸骨和肢带骨测定结果 \\
\hline Sousa chinensis & 中华白海豚 & I & 近危 & 杨健 & 几种鲸类动物铁积累和血. 清转铁蛋白的初步研究 \\
\hline
\end{tabular}


顾垒，闻丞，罗玫，王吴，吕植. 中国最受关注濒危物种保护现状快速评价的新方法探讨. 生物多样性，2015，23(5)：583-590. http://www. biodiversity-science. net/CN/article/downloadArticleFile. do?attachType=PDF\&id=10075

\begin{tabular}{|c|c|c|c|c|c|}
\hline & & & $/ \mathrm{NT}$ & & \\
\hline \multirow[t]{2}{*}{ Sousa chinensis } & 中华白海豚 & I & 近危 & 孙典荣 & 江门中华白海豚自然保护区调整对中华白海豚的影响 \\
\hline & & & $/ \mathrm{NT}$ & & \\
\hline \multirow[t]{2}{*}{ Sousa chinensis } & 中华白海豚 & I & 近危 & 喻达辉 & 瓶鼻海豚、中华白海豚和粘齿海豚线粒体 16S rRNA 基因的序列分析 \\
\hline & & & $/ \mathrm{NT}$ & & \\
\hline \multirow[t]{2}{*}{ Sousa chinensis } & 中华白海豚 & I & 近危 & 喻达辉 & 三种海豚线粒体 COI 基因的序列分析 \\
\hline & & & $/ \mathrm{NT}$ & & \\
\hline \multirow[t]{2}{*}{ Sousa chinensis } & 中华白海豚 & I & 近危 & 刘文华 & 厦门港的中华白海豚 $\mathrm{V}$.对水生生活的适应 \\
\hline & & & /NT & & \\
\hline \multirow[t]{2}{*}{ Sousa chinensis } & 中华白海豚 & I & 近危 & 杨健 & 厦门海域两头中华白海豚体内铁的含量 \\
\hline & & & $/ \mathrm{NT}$ & & \\
\hline \multirow[t]{2}{*}{ Sousa chinensis } & 中华白海豚 & I & 近危 & 杨健 & 厦门海域两头中华白海豚体内微量元素的积累 \\
\hline & & & /NT & & \\
\hline \multirow[t]{2}{*}{ Sousa chinensis } & 中华白海豚 & I & 近危 & 许肖梅 & 厦门海域中华白海豚定位 click 信号特性 \\
\hline & & & /NT & & \\
\hline \multirow[t]{2}{*}{ Sousa chinensis } & 中华白海豚 & I & 近危 & 祝茜 & 厦门市珍稀海洋物种国家级自然保护区中华白海豚的保护和管理的分析与评价 \\
\hline & & & /NT & & \\
\hline \multirow[t]{2}{*}{ Sousa chinensis } & 中华白海豚 & I & 近危 & 杨光 & 厦门水域中华白海豚栖息地选择的初步研究 \\
\hline & & & /NT & & \\
\hline
\end{tabular}


顾垒，闻丞，罗玫，王吴，吕植. 中国最受关注濒危物种保护现状快速评价的新方法探讨. 生物多样性，2015，23(5)：583-590. http://www biodiversity-science. net/CN/article/downloadArticleFile. do?attachType=PDF\&id=10075

\begin{tabular}{|c|c|c|c|c|c|}
\hline Sousa chinensis & 中华白海豚 & I & $\begin{array}{l}\text { 近危 } \\
\text { /NT }\end{array}$ & 祝茜 & 厦门至珠江口间沿岸海域中华白海豚分布的调查研究 \\
\hline Sousa chinensis & 中华白海豚 & I & $\begin{array}{l}\text { 近危 } \\
\text { /NT }\end{array}$ & 刘文华 & 厦门中华白海豚的分布和数量 \\
\hline Sousa chinensis & 中华白海豚 & I & $\begin{array}{l}\text { 近危 } \\
\text { /NT }\end{array}$ & 杨光 & 厦门中华白海豚的社会组织结构!行为和栖息地选择研究 \\
\hline Sousa chinensis & 中华白海豚 & I & $\begin{array}{l}\text { 近危 } \\
\text { /NT }\end{array}$ & 杨光 & 厦门中华白海豚体内微量元素的初步分析 \\
\hline Sousa chinensis & 中华白海豚 & I & $\begin{array}{l}\text { 近危 } \\
\text { /NT }\end{array}$ & 杨光 & 厦门中华白海豚种群生物学与保护研究 \\
\hline Sousa chinensis & 中华白海豚 & I & $\begin{array}{l}\text { 近危 } \\
\text { /NT }\end{array}$ & 许肖梅 & 水下打桩噪声对我国珍稀海洋哺乳动（中华白海豚与斑海豹）的影响研究 \\
\hline Sousa chinensis & 中华白海豚 & I & $\begin{array}{l}\text { 近危 } \\
\text { /NT }\end{array}$ & 王丁 & 一头中华白海豚的病理解剖及死因分析 \\
\hline Sousa chinensis & 中华白海豚 & I & $\begin{array}{l}\text { 近危 } \\
\text { /NT }\end{array}$ & 陈裕隆 & 应用微卫星标记分析中华白海豚遗传多样性 \\
\hline Sousa chinensis & 中华白海豚 & I & $\begin{array}{l}\text { 近危 } \\
\text { /NT }\end{array}$ & 王丕烈 & 中国水域中华白海豚种群分布现状与保护 \\
\hline Sousa chinensis & 中华白海豚 & I & 近危 & 唐森铭 & 中国沿海中华白海豚种群的分布区 \\
\hline
\end{tabular}


顾垒，闻丞，罗玫，王吴，吕植. 中国最受关注濒危物种保护现状快速评价的新方法探讨. 生物多样性，2015，23(5)：583-590. http://www. biodiversity-science. net/CN/article/downloadArticleFile. do?attachType=PDF\&id=10075

\begin{tabular}{|c|c|c|c|c|c|}
\hline & & & $/ \mathrm{NT}$ & & \\
\hline \multirow[t]{2}{*}{ Sousa chinensis } & 中华白海豚 & I & 近危 & 孟凡信 & 中国中华白海豚的研究和保护现状 \\
\hline & & & $/ \mathrm{NT}$ & & \\
\hline \multirow[t]{2}{*}{ Sousa chinensis } & 中华白海豚 & I & 近危 & 陈炳耀 & 中华白海豚( Sousa chinensis) 生物学研究进展 \\
\hline & & & /NT & & \\
\hline \multirow[t]{2}{*}{ Sousa chinensis } & 中华白海豚 & I & 近危 & 江海声 & 中华白海豚(Sousa chinensis)的栖息地选择 \\
\hline & & & /NT & & \\
\hline \multirow[t]{2}{*}{ Sousa chinensis } & 中华白海豚 & I & 近危 & 贾晓平 & 中华白海豚(Sousa chinensis)组织中多氯联苯的研究 \\
\hline & & & $/ \mathrm{NT}$ & & \\
\hline \multirow[t]{2}{*}{ Sousa chinensis } & 中华白海豚 & I & 近危 & 祝茜 & 中华白海豚 SRAP 分子标记多态性的初步研究 \\
\hline & & & /NT & & \\
\hline \multirow[t]{2}{*}{ Sousa chinensis } & 中华白海豚 & I & 近危 & 吴玉萍 & 中华白海豚保护与研究进展 \\
\hline & & & /NT & & \\
\hline \multirow[t]{2}{*}{ Sousa chinensis } & 中华白海豚 & I & 近危 & 张婷 & 中华白海豚的研究概况 \\
\hline & & & /NT & & \\
\hline \multirow[t]{2}{*}{ Sousa chinensis } & 中华白海豚 & I & 近危 & 唐森铭 & 中华白海豚环境压力分析和保护对策研究 \\
\hline & & & /NT & & \\
\hline \multirow[t]{2}{*}{ Sousa chinensis } & 中华白海豚 & I & 近危 & 李来好 & 中华白海豚肌肉组织营养组成特征分析 \\
\hline & & & /NT & & \\
\hline
\end{tabular}


顾垒，闻丞，罗玫，王吴，吕植. 中国最受关注濒危物种保护现状快速评价的新方法探讨. 生物多样性，2015，23(5)：583-590. http://www biodiversity-science. net/CN/article/downloadArticleFile. do?attachType=PDF\&id=10075

\begin{tabular}{|c|c|c|c|c|c|}
\hline Sousa chinensis & 中华白海豚 & I & $\begin{array}{l}\text { 近危 } \\
\text { /NT }\end{array}$ & 吴玉萍 & 中华白海豚气管和肺的组织学初步研究 \\
\hline Sousa chinensis & 中华白海豚 & I & $\begin{array}{l}\text { 近危 } \\
\text { /NT }\end{array}$ & 吴玉萍 & 中华白海豚雄性生殖系统组织学初步研究 \\
\hline Sousa chinensis & 中华白海豚 & I & $\begin{array}{l}\text { 近危 } \\
\text { /NT }\end{array}$ & 吴玉萍 & 珠江口雌雄中华白海豚外部特征、颖骨和肢带骨的比较 \\
\hline Sousa chinensis & 中华白海豚 & I & $\begin{array}{l}\text { 近危 } \\
\text { /NT }\end{array}$ & 吴玉萍 & 珠江口海域 4 头中华白海豚的病理解剖及死因鉴定 \\
\hline Sousa chinensis & 中华白海豚 & I & $\begin{array}{l}\text { 近危 } \\
\text { /NT }\end{array}$ & 吴玉萍 & 珠江口中华白海豚主要栖息地的细菌菌群结构 \\
\hline Sousa chinensis & 中华白海豚 & I & $\begin{array}{l}\text { 近危 } \\
\text { /NT }\end{array}$ & 邱永松 & 珠江西部河口中华白海豚的分布和季节变化 \\
\hline Stachyris nonggangensis & 弄岗穗扸 & $\begin{array}{l}\text { 未列 } \\
\text { 入 }\end{array}$ & $\begin{array}{l}\text { 易危 } \\
\text { /VU }\end{array}$ & & $\begin{array}{l}\text { A New Species of Babbler (Timaliidae Stachyris) from the Sino-Vietnamese Border Region of } \\
\text { China }\end{array}$ \\
\hline Stachyris nonggangensis & 弄岗穗鹤 & $\begin{array}{l}\text { 未列 } \\
\text { 入 }\end{array}$ & $\begin{array}{l}\text { 易危 } \\
\text { /VU }\end{array}$ & & Distribution, habitat and status of the new species Nonggang Babbler Stachyris nonggangensis \\
\hline Stachyris nonggangensis & 弄岗穗鹋 & $\begin{array}{l}\text { 未列 } \\
\text { 入 }\end{array}$ & $\begin{array}{l}\text { 易危 } \\
\text { /VU }\end{array}$ & & 广西弄岗穗䳭不同季节的受食地选择 \\
\hline Stachyris nonggangensis & 弄岗穗鹛 & 未列 & 易危 & & 弄岗穗䴗卵壳的超微结构及部分元素组成的初步研究 \\
\hline
\end{tabular}


顾垒，闻丞，罗玫，王吴，吕植. 中国最受关注濒危物种保护现状快速评价的新方法探讨. 生物多样性，2015，23(5)：583-590. http://www. biodiversity-science. net/CN/article/downloadArticleFile. do?attachType=PDF\&id=10075

\begin{tabular}{|c|c|c|c|c|c|}
\hline & & 入 & $/ \mathrm{VU}$ & & \\
\hline \multirow[t]{2}{*}{ Strix aluco } & 灰林鸮 & II & 无危 & 唐 巍 & 川东北_川西输气联络线工程对驱马保护区的影响评价及对策 \\
\hline & & & $/ \mathrm{LC}$ & & \\
\hline \multirow[t]{2}{*}{ Strix aluco } & 灰林鸮 & II & 无危 & 江建国 & 鄂西野三河自然保护区鸟类资源调查报告 \\
\hline & & & $/ \mathrm{LC}$ & & \\
\hline \multirow[t]{2}{*}{ Strix aluco } & 灰林鸮 & II & 无危 & 乔 亮 & 广州白云机场鸟情调查及鸟撞风险分析 \\
\hline & & & $/ \mathrm{LC}$ & & \\
\hline \multirow[t]{3}{*}{ Strix davidi } & 四川林鸮 & II & 数据 & 孙悦华 & 甘肃莲花山四川林鸮初步观察 \\
\hline & & & 不足 & & \\
\hline & & & $/ \mathrm{DD}$ & & \\
\hline \multirow[t]{3}{*}{ Strix davidi } & 四川林鸮 & II & 数据 & 符建荣 & 四川大相岭自然保护区的鸟类资源 \\
\hline & & & 不足 & & \\
\hline & & & $/ \mathrm{DD}$ & & \\
\hline \multirow[t]{3}{*}{ Strix davidi } & 四川林鸮 & II & 数据 & 符建荣 & 四川千佛山自然保护区的鸟类资源 \\
\hline & & & 不足 & & \\
\hline & & & $/ \mathrm{DD}$ & & \\
\hline \multirow[t]{2}{*}{ Strix leptogrammica } & 褐林鸮 & II & 无危 & 王晓辉 & GAP 分析法在生物物种研究中的应用_以安徽省自然保护区为例 \\
\hline & & & $/ \mathrm{LC}$ & & \\
\hline Strix leptogrammica & 褐林鸮 & II & 无危 & 江建国 & 鄂西野三河自然保护区鸟类资源调查报告 \\
\hline
\end{tabular}


顾垒，闻丞，罗玫，王吴，吕植. 中国最受关注濒危物种保护现状快速评价的新方法探讨. 生物多样性，2015，23(5)：583-590. http://www. biodiversity-science. net/CN/article/downloadArticleFile. do?attachType=PDF\&id=10075

\begin{tabular}{|c|c|c|c|c|c|}
\hline & & & $/ \mathrm{LC}$ & & \\
\hline \multirow[t]{2}{*}{ Strix leptogrammica } & 褐林鸮 & II & 无危 & 崔茂欢 & 兰坪云岭省级自然保护区及周边地区鸟类多样性 \\
\hline & & & $/ \mathrm{LC}$ & & \\
\hline \multirow[t]{2}{*}{ Strix nebulosa } & 乌林鸮 & II & 无危 & 邸志鹰 & 森林中的_夜游神_乌林鸮 \\
\hline & & & $/ \mathrm{LC}$ & & \\
\hline \multirow[t]{2}{*}{ Strix uralensis } & 长尾林鸮 & II & 无危 & 张佰莲 & 黑龙江大沾河湿地自然保护区鸟类群落结构调查及其多样性分析 \\
\hline & & & $/ \mathrm{LC}$ & & \\
\hline \multirow[t]{2}{*}{ Strix uralensis } & 长尾林鸮 & II & 无危 & 王 云 & 环长白山旅游公路对野生动物的影响 \\
\hline & & & $/ \mathrm{LC}$ & & \\
\hline \multirow[t]{2}{*}{ Strix uralensis } & 长尾林鸮 & II & 无危 & 李欣 & 环长白山旅游公路建设野生动物资源保护研究 \\
\hline & & & $/ \mathrm{LC}$ & & \\
\hline \multirow[t]{2}{*}{ Strix uralensis } & 长尾林鸮 & II & 无危 & 常家传 & 长尾林鸮繁殖巢纪实 \\
\hline & & & $/ \mathrm{LC}$ & & \\
\hline \multirow[t]{3}{*}{ Sturnus sericeus } & 丝光椋鸟 & 未列 & 数据 & 杨 萌 & 北京天坛公园鸟类群落结构调查 \\
\hline & & 入 & 不足 & & \\
\hline & & & $/ \mathrm{DD}$ & & \\
\hline \multirow[t]{3}{*}{ Sturnus sericeus } & 丝光椋鸟 & 未列 & 数据 & 李 琳 & 广东珠海市鹤洲湿地鸟类多样性的动态变化 \\
\hline & & 入 & 不足 & & \\
\hline & & & $/ \mathrm{DD}$ & & \\
\hline
\end{tabular}


顾垒，闻丞，罗玫，王吴，吕植. 中国最受关注濒危物种保护现状快速评价的新方法探讨. 生物多样性，2015，23(5)：583-590. http://www. biodiversity-science. net/CN/article/downloadArticleFile. do?attachType=PDF\&id=10075

\begin{tabular}{|c|c|c|c|c|c|}
\hline \multirow[t]{2}{*}{ Sturnus sericeus } & 丝光椋鸟 & 未列 & 数据 & 赵海鹏 & 河南大学校园鸟类初步调查 \\
\hline & & 入 & $\begin{array}{l}\text { 不足 } \\
\text { /DD }\end{array}$ & & \\
\hline \multirow[t]{3}{*}{ Sturnus sericeus } & 丝光椋鸟 & 未列 & 数据 & 李丽平 & 湖南东洞庭湖湿地夏季鸟类及多样性分析 \\
\hline & & 入 & 不足 & & \\
\hline & & & /DD & & \\
\hline \multirow[t]{3}{*}{ Sturnus sericeus } & 丝光椋鸟 & 未列 & 数据 & 牛艳东 & 环洞庭湖防护林体系四种造林模式夏季鸟类多样性初步研究 \\
\hline & & 入 & 不足 & & \\
\hline & & & /DD & & \\
\hline \multirow[t]{3}{*}{ Sturnus sericeus } & 丝光椋鸟 & 未列 & 数据 & 单凯 & 黄河三角洲发现的山东省鸟类新纪录 \\
\hline & & 入 & 不足 & & \\
\hline & & & $/ \mathrm{DD}$ & & \\
\hline \multirow[t]{3}{*}{ Sturnus sericeus } & 丝光椋鸟 & 未列 & 数据 & 章旭日 & 江西南矶山国家级自然保护区非繁殖期鸟类多样性研究 \\
\hline & & 入 & 不足 & & \\
\hline & & & $/ \mathrm{DD}$ & & \\
\hline \multirow[t]{3}{*}{ Sturnus sericeus } & 丝光椋鸟 & 未列 & 数据 & 汪志如 & 江西省林业科学院秋冬季鸟类调查及多样性分析 \\
\hline & & 入 & 不足 & & \\
\hline & & & $/ \mathrm{DD}$ & & \\
\hline Sturnus sericeus & 丝光椋鸟 & 未列 & 数据 & 白 清 泉 & 辽宁鸟类新记录 3 种_暗灰鹃鵙_丝光椋鸟和渔鸥 \\
\hline
\end{tabular}


顾垒，闻丞，罗玫，王吴，吕植. 中国最受关注濒危物种保护现状快速评价的新方法探讨. 生物多样性，2015，23(5)：583-590. http://www. biodiversity-science. net/CN/article/downloadArticleFile. do?attachType=PDF\&id=10075

\begin{tabular}{|c|c|c|c|c|c|}
\hline & & 入 & 不足 & & \\
\hline & & & $/ \mathrm{DD}$ & & \\
\hline \multirow[t]{3}{*}{ Sturnus sericeus } & 丝光椋鸟 & 未列 & 数据 & 姜学雷 & 同域分布下丝光椋鸟与灰椋鸟的繁殖行为 \\
\hline & & 入 & 不足 & & \\
\hline & & & $/ \mathrm{DD}$ & & \\
\hline \multirow[t]{3}{*}{ Sturnus sericeus } & 丝光椋鸟 & 未列 & 数据 & 李法玲 & 文山洲湿地鸟类调查与保护对策 \\
\hline & & 入 & 不足 & & \\
\hline & & & $/ \mathrm{DD}$ & & \\
\hline \multirow[t]{3}{*}{ Sturnus sericeus } & 丝光椋鸟 & 未列 & 数据 & 易 兰 & 武汉中山公园冬季鸟类群落研究 \\
\hline & & 入 & 不足 & & \\
\hline & & & $/ \mathrm{DD}$ & & \\
\hline \multirow[t]{3}{*}{ Sturnus sericeus } & 丝光椋鸟 & 未列 & 数据 & 宫 蕾 & 长江中下游安庆沿江湖泊湿地夏季鸟类多样性调查 \\
\hline & & 入 & 不足 & & \\
\hline & & & $/ \mathrm{DD}$ & & \\
\hline \multirow[t]{2}{*}{ Surnia ulula } & 猛鸮 & II & 无危 & 张佰莲 & 黑龙江大沾河湿地自然保护区鸟类群落结构调查及其多样性分析 \\
\hline & & & $/ \mathrm{LC}$ & & \\
\hline \multirow[t]{2}{*}{ Surnia ulula } & 猛鸮 & II & 无危 & 宋丽萍 & 黑龙江红星自然保护区湿地保护价值评价 \\
\hline & & & $/ \mathrm{LC}$ & & \\
\hline Surnia ulula & 猛鸮 & II & 无危 & 唐志强 & 呼中国家级自然保护区的野生动物资源 \\
\hline
\end{tabular}


顾垒，闻丞，罗玫，王吴，吕植. 中国最受关注濒危物种保护现状快速评价的新方法探讨. 生物多样性，2015，23(5)：583-590. http://www. biodiversity-science. net/CN/article/downloadArticleFile. do?attachType=PDF\&id=10075

\begin{tabular}{|c|c|c|c|c|c|}
\hline & & & $/ \mathrm{LC}$ & & \\
\hline \multirow[t]{2}{*}{ Surnia ulula } & 猛鸮 & II & 无危 & 邸志鹰 & 猛鸮_猫头鹰中的异类 \\
\hline & & & $/ \mathrm{LC}$ & & \\
\hline \multirow[t]{2}{*}{ Surnia ulula } & 猛鸮 & II & 无危 & 田振环 & 图牧吉国家级自然保护区鸟类资源 \\
\hline & & & $/ \mathrm{LC}$ & & \\
\hline \multirow[t]{2}{*}{ SusScrofa } & 野猪 & 未列 & 无危 & 冯子山 & 澜沧县野生动物肇事情况调查报告 \\
\hline & & 入 & $/ \mathrm{LC}$ & & \\
\hline \multirow[t]{2}{*}{ Syrmaticus ellioti } & 白颈长尾雉 & I & 近危 & 蔡路昀 & 白颈长尾雉的活动区和日活动距离 \\
\hline & & & /NT & & \\
\hline \multirow[t]{2}{*}{ Syrmaticus ellioti } & 白颈长尾雉 & I & 近危 & 陈俊豪 & 白颈长尾雉与白鸿秋冬季空间生态位比较 \\
\hline & & & /NT & & \\
\hline \multirow[t]{2}{*}{ Syrmaticus ellioti } & 白颈长尾雉 & I & 近危 & 江建国 & 鄂西野三河自然保护区鸟类资源调查报告 \\
\hline & & & /NT & & \\
\hline \multirow[t]{2}{*}{ Syrmaticus ellioti } & 白颈长尾雉 & I & 近危 & 谢少和 & 福建武夷山自然保护区挂墩鸟类资源现状的初步研究 \\
\hline & & & /NT & & \\
\hline \multirow[t]{2}{*}{ Syrmaticus ellioti } & 白颈长尾雉 & I & 近危 & 徐言朋 & 官山白颈长尾雉活动区域海拔高度的季节变化及其影响因素 \\
\hline & & & $/ \mathrm{NT}$ & & \\
\hline \multirow[t]{2}{*}{ Syrmaticus ellioti } & 白颈长尾雉 & I & 近危 & 陈俊豪 & 官山保护区白颈长尾雉栖息地适宜性评价 \\
\hline & & & /NT & & \\
\hline
\end{tabular}


顾垒，闻丞，罗玫，王吴，吕植. 中国最受关注濒危物种保护现状快速评价的新方法探讨. 生物多样性，2015，23(5)：583-590. http://www biodiversity-science. net/CN/article/downloadArticleFile. do?attachType=PDF\&id=10075

\begin{tabular}{|c|c|c|c|c|c|}
\hline Syrmaticus ellioti & 白颈长尾雉 & I & $\begin{array}{l}\text { 近危 } \\
\text { /NT }\end{array}$ & 郑艳霞 & 官山国家级自然保护区白颈长尾雉冬季生境选择 \\
\hline Syrmaticus ellioti & 白颈长尾雉 & I & $\begin{array}{l}\text { 近危 } \\
\text { /NT }\end{array}$ & 王绍能 & 广西猫儿山自然保护区珍稀鸟类资源及保护对策 \\
\hline Syrmaticus ellioti & 白颈长尾雉 & I & $\begin{array}{l}\text { 近危 } \\
\text { /NT }\end{array}$ & 熊志斌 & 贵州茂兰自然保护区的雉类资源及其保护 \\
\hline Syrmaticus ellioti & 白颈长尾雉 & I & $\begin{array}{l}\text { 近危 } \\
\text { /NT }\end{array}$ & 刘 鹏 & 江西官山自然保护区四种雉类的生境选择差异 \\
\hline Syrmaticus ellioti & 白颈长尾雉 & I & $\begin{array}{l}\text { 近危 } \\
\text { /NT }\end{array}$ & 熊彩云 & 江西南风面自然保护区野生动物资源调查分析 \\
\hline Syrmaticus ellioti & 白颈长尾雉 & I & $\begin{array}{l}\text { 近危 } \\
\text { /NT }\end{array}$ & 宋玉赞 & 江西七溪岭自然保护区珍稀动物资源调查 \\
\hline Syrmaticus ellioti & 白颈长尾雉 & I & $\begin{array}{l}\text { 近危 } \\
\text { /NT }\end{array}$ & 黄晓凤 & 江西齐云山自然保护区鸟类区系与多样性分析 \\
\hline Syrmaticus ellioti & 白颈长尾雉 & I & $\begin{array}{l}\text { 近危 } \\
\text { /NT }\end{array}$ & 陈武华 & 江西武功山国家森林公园野生动物资源及保护对策 \\
\hline Syrmaticus ellioti & 白颈长尾雉 & I & $\begin{array}{l}\text { 近危 } \\
\text { /NT }\end{array}$ & 程松林 & 江西武夷山国家级自然保护区鸟类多样性调查 \\
\hline Syrmaticus ellioti & 白颈长尾雉 & I & 近危 & 程松林 & 江西武夷山自然保护区的雉类资源及其保护 \\
\hline
\end{tabular}


顾垒，闻丞，罗玫，王吴，吕植. 中国最受关注濒危物种保护现状快速评价的新方法探讨. 生物多样性，2015，23(5)：583-590. http://www biodiversity-science. net/CN/article/downloadArticleFile. do?attachType=PDF\&id=10075

\begin{tabular}{|c|c|c|c|c|c|}
\hline & & & $/ \mathrm{NT}$ & & \\
\hline \multirow[t]{2}{*}{ Syrmaticus ellioti } & 白颈长尾雉 & I & 近危 & 黄族豪 & 井冈山国家级自然保护区鸟类资源研究 \\
\hline & & & /NT & & \\
\hline \multirow[t]{2}{*}{ Syrmaticus ellioti } & 白颈长尾雉 & I & 近危 & 郑发辉 & 井冈山国家级自然保护区自然资源评价 \\
\hline & & & /NT & & \\
\hline \multirow[t]{2}{*}{ Syrmaticus ellioti } & 白颈长尾雉 & I & 近危 & 陈 静 & 清凉峰旅游区鸟类多样性及季节变动 \\
\hline & & & /NT & & \\
\hline \multirow[t]{2}{*}{ Syrmaticus ellioti } & 白颈长尾雉 & I & 近危 & 孙 岳 & 武夷山鸡形目鸟类多样性及冰冻灾害对其影响研究 \\
\hline & & & /NT & & \\
\hline \multirow[t]{2}{*}{ Syrmaticus ellioti } & 白颈长尾雉 & I & 近危 & 李海洋 & 小溪国家级自然保护区白颈长尾雉生境分析 \\
\hline & & & /NT & & \\
\hline \multirow[t]{2}{*}{ Syrmaticus humiae } & 黑颈长尾雉 & I & 无危 & Ning LI & Comparison of roosting habitat characteristics of two sympatric pheasants during springtime at \\
\hline & & & $/ \mathrm{LC}$ & & Dazhong Mountain,southwesternChina \\
\hline \multirow[t]{2}{*}{ Syrmaticus humiae } & 黑颈长尾雉 & I & 无危 & Aiwu JIANG & Discovery of Hume' s Pheasant (Syrmaticus humiae) in Guizhou Province, southwestern China \\
\hline & & & $/ \mathrm{LC}$ & & \\
\hline \multirow[t]{2}{*}{ Syrmaticus humiae } & 黑颈长尾雉 & I & 无危 & Wei ZHOU & Modeling foraging habitats of Hume’ s Pheasant (Syrmaticus humiae) in Dazhong Mountain, \\
\hline & & & $/ \mathrm{LC}$ & & Yunnan, southwestern China \\
\hline \multirow[t]{2}{*}{ Syrmaticus humiae } & 黑颈长尾雉 & I & 无危 & 自正权 & 哀牢山国家级自然保护区南华片区黑颈长尾雉种群数量调查及其保护措施思考 \\
\hline & & & $/ \mathrm{LC}$ & & \\
\hline
\end{tabular}


顾垒，闻丞，罗玫，王吴，吕植. 中国最受关注濒危物种保护现状快速评价的新方法探讨. 生物多样性，2015，23(5)：583-590. http://www biodiversity-science. net/CN/article/downloadArticleFile. do?attachType=PDF\&id=10075

\begin{tabular}{|c|c|c|c|c|c|}
\hline Syrmaticus humiae & 黑颈长尾雉 & I & $\begin{array}{l}\text { 无危 } \\
\text { /LC }\end{array}$ & 李 伟 & 哀牢山自然保护区南华分区黑颈长尾雉春季栖息地利用 \\
\hline Syrmaticus humiae & 黑颈长尾雉 & I & $\begin{array}{l}\text { 无危 } \\
\text { /LC }\end{array}$ & 刘 钊 & 哀牢山自然保护区南华片黑颈长尾雉春季受食地植物群落特征与选择 \\
\hline Syrmaticus humiae & 黑颈长尾雉 & I & $\begin{array}{l}\text { 无危 } \\
\text { /LC }\end{array}$ & 曹明 & 哀牢山自然保护区南华片黑颈长尾雉繁殖早期取食地选择 \\
\hline Syrmaticus humiae & 黑颈长尾雉 & I & $\begin{array}{l}\text { 无危 } \\
\text { /LC }\end{array}$ & 姚小刚 & 哀牢山自然保护区南华片黑颈长尾雉生境适宜性评价 \\
\hline Syrmaticus humiae & 黑颈长尾雉 & I & $\begin{array}{l}\text { 无危 } \\
\text { /LC }\end{array}$ & 格玛江初 & 白马雪山自然保护区德钦分局鸡类多样性及保护管理研究 \\
\hline Syrmaticus humiae & 黑颈长尾雉 & I & $\begin{array}{l}\text { 无危 } \\
\text { /LC }\end{array}$ & 贝永建 & 岑王老山再引进黑颈长尾雉种群扩散的研究 \\
\hline Syrmaticus humiae & 黑颈长尾雉 & I & $\begin{array}{l}\text { 无危 } \\
\text { /LC }\end{array}$ & 蒋爱伍 & 广西黑颈长尾雉对夜宿地的选择 \\
\hline Syrmaticus humiae & 黑颈长尾雉 & I & $\begin{array}{l}\text { 无危 } \\
\text { /LC }\end{array}$ & 原宝东 & 广西金钟山片段化生境中黑颈长尾雉夏季栖息地选择 \\
\hline Syrmaticus humiae & 黑颈长尾雉 & I & $\begin{array}{l}\text { 无危 } \\
\text { /LC }\end{array}$ & 陈伟才 & 黑颈长尾雉的巢址选择 \\
\hline Syrmaticus humiae & 黑颈长尾雉 & I & 无危 & 王恒颖 & 恐龙河自然保护区的动植物资源现状及保护对策研究 \\
\hline
\end{tabular}


顾垒，闻丞，罗玫，王吴，吕植. 中国最受关注濒危物种保护现状快速评价的新方法探讨. 生物多样性，2015，23(5)：583-590. http://www. biodiversity-science. net/CN/article/downloadArticleFile. do?attachType=PDF\&id=10075

\begin{tabular}{|c|c|c|c|c|c|}
\hline & & & $/ \mathrm{LC}$ & & \\
\hline \multirow[t]{2}{*}{ Syrmaticus humiae } & 黑颈长尾雉 & I & 无危 & 崔茂欢 & 兰坪云岭省级自然保护区及周边地区鸟类多样性 \\
\hline & & & $/ \mathrm{LC}$ & & \\
\hline \multirow[t]{2}{*}{ Syrmaticus humiae } & 黑颈长尾雉 & I & 无危 & 贝永建 & 栖息地破碎化背景下黑颈长尾雉保护遗传学研究 \\
\hline & & & $/ \mathrm{LC}$ & & \\
\hline \multirow[t]{2}{*}{ Syrmaticus humiae } & 黑颈长尾雉 & I & 无危 & 胡 箭 & 铜壁关自然保护区鸟类区系研究 \\
\hline & & & $/ \mathrm{LC}$ & & \\
\hline \multirow[t]{2}{*}{ Syrmaticus humiae } & 黑颈长尾雉 & I & 无危 & 常丽娜 & 云南大中山黑颈长尾雉活动区种群密度及空间分布 \\
\hline & & & $/ \mathrm{LC}$ & & \\
\hline \multirow[t]{2}{*}{ Syrmaticus humiae } & 黑颈长尾雉 & I & 无危 & 周 伟 & 云南大中山黑颈长尾雉栖境生态系统稳定性 \\
\hline & & & $/ \mathrm{LC}$ & & \\
\hline \multirow[t]{2}{*}{ Syrmaticus humiae } & 黑颈长尾雉 & I & 无危 & 李 伟 & 云南大中山黑颈长尾雉栖息地选择与种间栖息地利用比较 \\
\hline & & & $/ \mathrm{LC}$ & & \\
\hline \multirow[t]{2}{*}{ Syrmaticus humiae } & 黑颈长尾雉 & I & 无危 & 李 伟 & 云南大中山黑颈长尾雉栖息地选择周年变化 \\
\hline & & & $/ \mathrm{LC}$ & & \\
\hline \multirow[t]{2}{*}{ Syrmaticus humiae } & 黑颈长尾雉 & I & 无危 & 陈伟才 & 再引入黑颈长尾雉繁殖的无线电遥测研究 \\
\hline & & & $/ \mathrm{LC}$ & & \\
\hline \multirow[t]{2}{*}{ Syrmaticus humiae } & 黑颈长尾雉 & I & 无危 & 贝永建 & 再引入黑颈长尾雉夏季栖息地选择 \\
\hline & & & /LC & & \\
\hline
\end{tabular}


顾垒，闻丞，罗玫，王昊，吕植. 中国最受关注濒危物种保护现状快速评价的新方法探讨．生物多样性，2015，23(5)：583-590. http://www biodiversity-science. net/CN/article/downloadArticleFile. do?attachType=PDF\&id=10075

\begin{tabular}{|c|c|c|c|c|c|}
\hline Syrmaticus mikado & 黑长尾雉 & I & $\begin{array}{l}\text { 近危 } \\
\text { /NT }\end{array}$ & 卢汰春 & 宝岛上的中国特产鸟类_黑长尾雉 \\
\hline Syrmaticus reevesii & 白冠长尾雉 & II & $\begin{array}{l}\text { 易危 } \\
\text { /VU }\end{array}$ & $\begin{array}{l}\text { Philip J. K. } \\
\text { McGowan }\end{array}$ & Galliformes - barometers of the state of applied ecology and wildlife conservation in China \\
\hline Syrmaticus reevesii & 白冠长尾雉 & II & $\begin{array}{l}\text { 易危 } \\
\text { /VU }\end{array}$ & 徐基良 & $\begin{array}{l}\text { Home range and habitat composition of male Reeves' s Pheasants in an agricultural-forest } \\
\text { plantation landscape in central China a preliminary report }\end{array}$ \\
\hline Syrmaticus reevesii & 白冠长尾雉 & II & $\begin{array}{l}\text { 易危 } \\
\text { /VU }\end{array}$ & 徐基良 & $\begin{array}{l}\text { Home range and habitat use of Reeves's Pheasant Syrmaticus reevesii in the protected areas } \\
\text { created from forest farms in the Dabie Mountains, central China }\end{array}$ \\
\hline Syrmaticus reevesii & 白冠长尾雉 & II & $\begin{array}{l}\text { 易危 } \\
\text { /VU }\end{array}$ & 徐基良 & $\begin{array}{l}\text { Multi-scale analysis on wintering habitat selection of Reeves Pheasant(Syrmaticus reevesii) In } \\
\text { Dongzhai National Nature Reserve,Henan Province,China }\end{array}$ \\
\hline Syrmaticus reevesii & 白冠长尾雉 & II & $\begin{array}{l}\text { 易危 } \\
\text { /VU }\end{array}$ & Ning Wang & Polymorphic microsatellites in the Reeves's pheasant developed by cross-species amplification \\
\hline Syrmaticus reevesii & 白冠长尾雉 & II & $\begin{array}{l}\text { 易危 } \\
\text { /VU }\end{array}$ & 徐基良 & $\begin{array}{l}\text { Spatio-temporal responses of male Reeves's pheasants Syrmaticus reevesii to forest edges in the } \\
\text { Dabie Mountains , central China }\end{array}$ \\
\hline Syrmaticus reevesii & 白冠长尾雉 & II & $\begin{array}{l}\text { 易危 } \\
\text { /VU }\end{array}$ & 马静 & 白冠长尾雉保护中的社区影响一以董寨自然保护区为例 \\
\hline Syrmaticus reevesii & 白冠长尾雉 & II & $\begin{array}{l}\text { 易危 } \\
\text { /VU }\end{array}$ & 张晓辉 & 白冠长尾雉睬卵行为的无线电遥测研究 \\
\hline Syrmaticus reevesii & 白冠长尾雉 & II & 易危 & 卜艳珍 & 白冠长尾雉感染鸡异刺线虫的报道 \\
\hline
\end{tabular}


顾垒，闻丞，罗玫，王吴，吕植. 中国最受关注濒危物种保护现状快速评价的新方法探讨. 生物多样性，2015，23(5)：583-590. http://www. biodiversity-science. net/CN/article/downloadArticleFile. do?attachType=PDF\&id=10075

\begin{tabular}{|c|c|c|c|c|c|}
\hline & & & /VU & & \\
\hline \multirow[t]{2}{*}{ Syrmaticus reevesii } & 白冠长尾雉 & II & 易危 & 徐基良 & 白冠长尾雉雄鸟的冬季活动区与栖息地利用研究 \\
\hline & & & /VU & & \\
\hline \multirow[t]{2}{*}{ Syrmaticus reevesii } & 白冠长尾雉 & II & 易危 & 徐基良 & 白冠长尾雉越冬期栖息地选择的多尺度分析 \\
\hline & & & /VU & & \\
\hline \multirow[t]{2}{*}{ Syrmaticus reevesii } & 白冠长尾雉 & II & 易危 & 田春 & 白云山申报国家级自然保护区通过省级评审 \\
\hline & & & /VU & & \\
\hline \multirow[t]{2}{*}{ Syrmaticus reevesii } & 白冠长尾雉 & II & 易危 & 丁振 & 薄山将成为我市首个市级湿地自然保护区 \\
\hline & & & /VU & & \\
\hline \multirow[t]{2}{*}{ Syrmaticus reevesii } & 白冠长尾雉 & II & 易危 & 王佳佳 & 贵州宽阔水自然保护区鸟类地面巢捕食者的调查 \\
\hline & & & /VU & & \\
\hline \multirow[t]{2}{*}{ Syrmaticus reevesii } & 白冠长尾雉 & II & 易危 & 徐基良 & 河南董寨白冠长尾雉繁殖期栖息地选择 \\
\hline & & & /VU & & \\
\hline \multirow[t]{2}{*}{ Syrmaticus reevesii } & 白冠长尾雉 & II & 易危 & 张晓辉 & 河南陕西两地白冠长尾雉的集群行为 \\
\hline & & & /VU & & \\
\hline \multirow[t]{2}{*}{ Syrmaticus reevesii } & 白冠长尾雉 & II & 易危 & 于大宝 & 后河国家级自然保护区鸟类资源调查 \\
\hline & & & /VU & & \\
\hline \multirow[t]{2}{*}{ Syrmaticus reevesii } & 白冠长尾雉 & II & 易危 & 刘艳燕 & 湖北后河国家级自然保护区生态旅游资源调查及评价 \\
\hline & & & /VU & & \\
\hline
\end{tabular}


顾垒，闻丞，罗玫，王吴，吕植. 中国最受关注濒危物种保护现状快速评价的新方法探讨. 生物多样性，2015，23(5)：583-590. http://www. biodiversity-science. net/CN/article/downloadArticleFile. do?attachType=PDF\&id=10075

\begin{tabular}{|c|c|c|c|c|c|}
\hline Syrmaticus reevesii & 白冠长尾雉 & II & $\begin{array}{l}\text { 易危 } \\
\text { /VU }\end{array}$ & 白娜 & 鸡公山森林生态旅游资源开发的几点构想 \\
\hline Syrmaticus reevesii & 白冠长尾雉 & II & $\begin{array}{l}\text { 易危 } \\
\text { /VU }\end{array}$ & 赵玉泽 & 利用红外照相技术分析野生白冠长尾雉活动节律及时间分配_赵玉泽 \\
\hline Syrmaticus reevesii & 白冠长尾雉 & II & $\begin{array}{l}\text { 易危 } \\
\text { /VU }\end{array}$ & 白洁 & 人工林对白冠长尾雉活动区的影响研究 \\
\hline Syrmaticus reevesii & 白冠长尾雉 & II & $\begin{array}{l}\text { 易危 } \\
\text { /VU }\end{array}$ & 李春宁 & 陕西省牛背梁国家级自然保护区生物多样性及其保护研究 \\
\hline Syrmaticus reevesii & 白冠长尾雉 & II & $\begin{array}{l}\text { 易危 } \\
\text { /VU }\end{array}$ & 蒋国福 & 石柱土家族自治县的鸟类资源 \\
\hline Syrmaticus reevesii & 白冠长尾雉 & II & $\begin{array}{l}\text { 易危 } \\
\text { /VU }\end{array}$ & 余志刚 & 妥打自然保护区人为干扰对白冠长尾雉分布的影响 \\
\hline Syrmaticus reevesii & 白冠长尾雉 & II & $\begin{array}{l}\text { 易危 } \\
\text { /VU }\end{array}$ & 李正军 & 威宁县妥打自然保护区建设现状及存在问题分析 \\
\hline Syrmaticus reevesii & 白冠长尾雉 & II & $\begin{array}{l}\text { 易危 } \\
\text { /VU }\end{array}$ & 张维宾 & 重庆奉节天坑地缝自然保护区动植物资源调查 \\
\hline Taiwania cryptomerioides & 台湾杉 & II & $\begin{array}{l}\text { 易危 } \\
\text { /VU }\end{array}$ & XUE-JUN GE & $\begin{array}{l}\text { Genetic Diversity of the Relict Plant Taiwania cryptomerioides Hayata (Cupressaceae) in } \\
\text { Mainland China }\end{array}$ \\
\hline Taiwania cryptomerioides & 台湾杉 & II & 易危 & 廖凤林 & 贵州雷公山台湾杉种群结构及空间分布格局 \\
\hline
\end{tabular}


顾垒，闻丞，罗玫，王吴，吕植. 中国最受关注濒危物种保护现状快速评价的新方法探讨. 生物多样性，2015，23(5)：583-590. http://www. biodiversity-science. net/CN/article/downloadArticleFile. do?attachType=PDF\&id=10075

\begin{tabular}{|c|c|c|c|c|c|}
\hline & & & $/ \mathrm{VU}$ & & \\
\hline \multirow[t]{2}{*}{ Taiwania cryptomerioides } & 台湾杉 & II & 易危 & 陈龙清 & 湖北省原生台湾杉资源及其保护 \\
\hline & & & /VU & & \\
\hline \multirow[t]{2}{*}{ Taiwania cryptomerioides } & 台湾杉 & II & 易危 & 陈龙清 & 湖北星斗山台湾杉居群的遗传多样性研究 \\
\hline & & & $/ \mathrm{VU}$ & & \\
\hline \multirow[t]{2}{*}{ Taiwania cryptomerioides } & 台湾杉 & II & 易危 & 杨秀钟 & 金叶台湾杉果实形态特征的初步研究 \\
\hline & & & /VU & & \\
\hline \multirow[t]{2}{*}{ Taiwania cryptomerioides } & 台湾杉 & II & 易危 & 杨秀钟 & 金叶台湾杉育苗及造林技术 \\
\hline & & & /VU & & \\
\hline \multirow[t]{2}{*}{ Taiwania cryptomerioides } & 台湾杉 & II & 易危 & 王子明 & 雷公山台湾杉资源初步调查 \\
\hline & & & /VU & & \\
\hline \multirow[t]{2}{*}{ Taiwania cryptomerioides } & 台湾杉 & II & 易危 & 王子明 & 雷公山自然保护区台湾杉资源调查分析 \\
\hline & & & /VU & & \\
\hline \multirow[t]{2}{*}{ Taiwania cryptomerioides } & 台湾杉 & II & 易危 & 王晓丽 & 杉木及其近缘种的分子标记和遗传分析 \\
\hline & & & /VU & & \\
\hline \multirow[t]{2}{*}{ Taiwania cryptomerioides } & 台湾杉 & II & 易危 & 童再康 & 杉木与台湾杉 EST-SS R 标记的开发与应用 \\
\hline & & & /VU & & \\
\hline \multirow[t]{2}{*}{ Taiwania cryptomerioides } & 台湾杉 & II & 易危 & 李林初 & 台湾扁柏和台湾杉的核型分析 \\
\hline & & & /VU & & \\
\hline
\end{tabular}


顾垒，闻丞，罗玫，王吴，吕植. 中国最受关注濒危物种保护现状快速评价的新方法探讨. 生物多样性，2015，23(5)：583-590. http://www biodiversity-science. net/CN/article/downloadArticleFile. do?attachType=PDF\&id=10075

\begin{tabular}{|c|c|c|c|c|c|}
\hline Taiwania cryptomerioides & 台湾杉 & II & 易危 & 黄财声 & 台湾杉、秃杉引种栽培试验及生长效果分析 \\
\hline & & & $/ \mathrm{VU}$ & & \\
\hline \multirow[t]{2}{*}{ Taiwania cryptomerioides } & 台湾杉 & II & 易危 & 杨琴军 & 台湾杉 DNA 提取及 RAPD 反应体系的建立 \\
\hline & & & $/ \mathrm{VU}$ & & \\
\hline \multirow[t]{2}{*}{ Taiwania cryptomerioides } & 台湾杉 & II & 易危 & 陈龙清 & 台湾杉 ISSR 反应体系的建立及检测 \\
\hline & & & $/ \mathrm{VU}$ & & \\
\hline \multirow[t]{2}{*}{ Taiwania cryptomerioides } & 台湾杉 & II & 易危 & 相卫国 & 台湾杉的研究与保护现状 \\
\hline & & & $/ \mathrm{VU}$ & & \\
\hline \multirow[t]{2}{*}{ Taiwania cryptomerioides } & 台湾杉 & II & 易危 & 陈道林 & 台湾杉和秃杉两种珍稀树种种苗形态及引种栽培试验 \\
\hline & & & $/ \mathrm{VU}$ & & \\
\hline \multirow[t]{2}{*}{ Taiwania cryptomerioides } & 台湾杉 & II & 易危 & 孙勇 & 台湾杉叶挥发油的成分及其生物活性 \\
\hline & & & $/ \mathrm{VU}$ & & \\
\hline \multirow[t]{2}{*}{ Taiwania cryptomerioides } & 台湾杉 & II & 易危 & 张纪卯 & 台湾杉与秃杉的幼苗形态特征研究及其栽培效果 \\
\hline & & & $/ \mathrm{VU}$ & & \\
\hline \multirow[t]{2}{*}{ Taiwania cryptomerioides } & 台湾杉 & II & 易危 & 陶菊 & 夏季不同浓度的 NAA 对台湾杉扦插苗的影响 \\
\hline & & & $/ \mathrm{VU}$ & & \\
\hline Taiwania flousiana Gaussen & 秃杉 & I & 易危 & 潘否 & \\
\hline Gaussen & & & $/ \mathrm{VU}$ & & 秃杉种源试验研究进展 \\
\hline Taiwania flousiana Gaussen & 秃杉 & I & 易危 & 周宗哲 & 安溪秃杉引种造林试验初报 \\
\hline
\end{tabular}


顾垒，闻丞，罗玫，王吴，吕植. 中国最受关注濒危物种保护现状快速评价的新方法探讨. 生物多样性，2015，23(5)：583-590. http://www biodiversity-science. net/CN/article/downloadArticleFile. do?attachType=PDF\&id=10075

\begin{tabular}{|c|c|c|c|c|c|}
\hline Gaussen & & & $/ \mathrm{VU}$ & & \\
\hline Taiwania flousiana Gaussen & 秃杉 & I & 易危 & 彭良茂 & 保存世界古老珍稀树种秃杉的思考 \\
\hline Gaussen & & & $/ \mathrm{VU}$ & & \\
\hline Taiwania flousiana Gaussen & 秃杉 & I & 易危 & 连勇机 & 不同海拔高度引种秃杉试验初报 \\
\hline Gaussen & & & $/ \mathrm{VU}$ & & \\
\hline Taiwania flousiana Gaussen & 秃杉 & I & 易危 & 何斌 & 不同林龄秃杉人工林调落物储量及其持水特性 \\
\hline Gaussen & & & $/ \mathrm{VU}$ & & \\
\hline Taiwania flousiana Gaussen & 秃杉 & I & 易危 & 黄钦忠 & 不同坡位 9 年生秃杉人工林生物量分布规律研究 \\
\hline Gaussen & & & $/ \mathrm{VU}$ & & \\
\hline Taiwania flousiana Gaussen & 秃杉 & I & 易危 & 梁宏温 & 不同树龄秃杉与杉木人工林木材物理力学性质的比较 \\
\hline Gaussen & & & $/ \mathrm{VU}$ & & \\
\hline Taiwania flousiana Gaussen & 秃杉 & I & 易危 & 陈元品 & 不同整地方式及抚育措施对秃杉幼林生长的影响 \\
\hline Gaussen & & & $/ \mathrm{VU}$ & & \\
\hline Taiwania flousiana Gaussen & 秃杉 & I & 易危 & 王雨水 & 低海拔地区秃杉造林关键技术研究 \\
\hline Gaussen & & & $/ \mathrm{VU}$ & & \\
\hline Taiwania flousiana Gaussen & 秃杉 & I & 易危 & 谢吉策 & 鄂西北秃杉引种栽培试脸研究 \\
\hline Gaussen & & & $/ \mathrm{VU}$ & & \\
\hline Taiwania flousiana Gaussen & 秃杉 & I & 易危 & 许平华 & 高海拔山区引进秃杉栽培试验研究 \\
\hline Gaussen & & & $/ \mathrm{VU}$ & & \\
\hline
\end{tabular}


顾垒，闻丞，罗玫，王吴，吕植. 中国最受关注濒危物种保护现状快速评价的新方法探讨. 生物多样性，2015，23(5)：583-590. http://www biodiversity-science. net/CN/article/downloadArticleFile. do?attachType=PDF\&id=10075

\begin{tabular}{|c|c|c|c|c|c|}
\hline Taiwania flousiana Gaussen & 秃杉 & I & 易危 & 邹冬生 & 贵州雷公山秃杉的种群结构和空间分布格局 \\
\hline Gaussen & & & $/ \mathrm{VU}$ & & \\
\hline Taiwania flousiana Gaussen & 秃杉 & I & 易危 & 赵峰 & 贵州雷公山秃杉优势种群的生态位特征 \\
\hline Gaussen & & & /VU & & \\
\hline Taiwania flousiana Gaussen & 秃杉 & I & 易危 & 李性苑 & 贵州雷公山秃杉种群分布格局的研究 \\
\hline Gaussen & & & $/ \mathrm{VU}$ & & \\
\hline Taiwania flousiana Gaussen & 秃杉 & I & 易危 & 李性苑 & 贵州雷公山秃杉种群格局的分形特征_信息维数 \\
\hline Gaussen & & & $/ \mathrm{VU}$ & & \\
\hline Taiwania flousiana Gaussen & 秃杉 & I & 易危 & 李性苑 & 贵州雷公山秃杉种群空间分布格局和分形特征研究 \\
\hline Gaussen & & & /VU & & \\
\hline Taiwania flousiana Gaussen & 秃杉 & I & 易危 & 杨宁 & 贵州雷公山秃杉种群生活史特征与空间分布格局 \\
\hline Gaussen & & & /VU & & \\
\hline Taiwania flousiana Gaussen & 秃杉 & I & 易危 & 李性苑 & 贵州雷公山秃杉种群生态学研究 \\
\hline Gaussen & & & /VU & & \\
\hline Taiwania flousiana Gaussen & 秃杉 & I & 易危 & 李性苑 & 贵州雷公山秃杉种群统计分析 \\
\hline Gaussen & & & /VU & & \\
\hline Taiwania flousiana Gaussen & 秃杉 & I & 易危 & 冯金朝 & 贵州雷公山自然保护区秃杉天然种群生命表 \\
\hline Gaussen & & & /VU & & \\
\hline Taiwania flousiana Gaussen & 秃杉 & I & 易危 & 漆 荣 & 国家一级保护树种秃杉观赏价值的利用* \\
\hline
\end{tabular}


顾垒，闻丞，罗玫，王吴，吕植. 中国最受关注濒危物种保护现状快速评价的新方法探讨. 生物多样性，2015，23(5)：583-590. http://www biodiversity-science. net/CN/article/downloadArticleFile. do?attachType=PDF\&id=10075

\begin{tabular}{|c|c|c|c|c|c|}
\hline Gaussen & & & /VU & & \\
\hline Taiwania flousiana Gaussen & 秃杉 & I & 易危 & 胡兴宜 & 湖北省秃杉立地类型划分及立地质量评价 \\
\hline Gaussen & & & $/ \mathrm{VU}$ & & \\
\hline Taiwania flousiana Gaussen & 秃杉 & I & 易危 & 陈绍林 & 湖北星斗山自然保护区秃杉原生种群生境现状及保护对策 \\
\hline Gaussen & & & $/ \mathrm{VU}$ & & \\
\hline Taiwania flousiana Gaussen & 秃杉 & I & 易危 & 李性苑 & 雷公山秃杉群落多样性分析 \\
\hline Gaussen & & & /VU & & \\
\hline Taiwania flousiana Gaussen & 秃杉 & I & 易危 & 陈涛 & 雷公山珍稀植物秃杉的栽培技术及造林管理 \\
\hline Gaussen & & & /VU & & \\
\hline Taiwania flousiana Gaussen & 秃杉 & I & 易危 & 何斌 & 速生阶段秃杉与杉木人工林营养元素积累及其分配特征 \\
\hline Gaussen & & & /VU & & \\
\hline Taiwania flousiana Gaussen & 秃杉 & I & 易危 & 黄财声 & 台湾杉、秃杉引种栽培试验及生长效果分析 \\
\hline Gaussen & & & $/ \mathrm{VU}$ & & \\
\hline Taiwania flousiana Gaussen & 秃杉 & I & 易危 & 陈道林 & 台湾杉和秃杉两种珍稀树种种苗形态及引种栽培试验 \\
\hline Gaussen & & & /VU & & \\
\hline Taiwania flousiana Gaussen & 秃杉 & I & 易危 & 陈道林 & 台湾杉与秃杉的幼苗形态特征研究及其栽培效果 \\
\hline Gaussen & & & $/ \mathrm{VU}$ & & \\
\hline Taiwania flousiana Gaussen & 秃杉 & I & 易危 & 袁明 & 秃杉的物种确立, 天然林种群特征、保护、引种和种源选择研究 \\
\hline Gaussen & & & /VU & & \\
\hline
\end{tabular}


顾垒，闻丞，罗玫，王吴，吕植. 中国最受关注濒危物种保护现状快速评价的新方法探讨. 生物多样性，2015，23(5)：583-590. http://www biodiversity-science. net/CN/article/downloadArticleFile. do?attachType=PDF\&id=10075

\begin{tabular}{|c|c|c|c|c|c|}
\hline Taiwania flousiana Gaussen & 秃杉 & I & 易危 & 庞惠仙 & 秃杉的组织培养及植株再生 \\
\hline Gaussen & & & $/ \mathrm{VU}$ & & \\
\hline Taiwania flousiana Gaussen & 秃杉 & I & 易危 & 漆荣 & 秃杉地理种源变异的研究 \\
\hline Gaussen & & & /VU & & \\
\hline Taiwania flousiana Gaussen & 秃杉 & I & 易危 & 张伯聪 & 秃杉混交林生产力及其对土壤肥力的影响 \\
\hline Gaussen & & & $/ \mathrm{VU}$ & & \\
\hline Taiwania flousiana Gaussen & 秃杉 & I & 易危 & 肖石海 & 秃杉混交林生产力研究 \\
\hline Gaussen & & & $/ \mathrm{VU}$ & & \\
\hline Taiwania flousiana Gaussen & 秃杉 & I & 易危 & 陈卓梅 & 秃杉混交林水源涵养功能的研究 \\
\hline Gaussen & & & $/ \mathrm{VU}$ & & \\
\hline Taiwania flousiana Gaussen & 秃杉 & I & 易危 & 黄承标 & 秃杉林与杉木连栽林的土壤理化性质及林木生长量比较 \\
\hline Gaussen & & & $/ \mathrm{VU}$ & & \\
\hline Taiwania flousiana Gaussen & 秃杉 & I & 易危 & 连勇机 & 秃杉苗高生长期划分的有序样本聚类分析 \\
\hline Gaussen & & & $/ \mathrm{VU}$ & & \\
\hline Taiwania flousiana Gaussen & 秃杉 & I & 易危 & 章健 & 秃杉苗期生长分析及不同种源比较 \\
\hline Gaussen & & & $/ \mathrm{VU}$ & & \\
\hline Taiwania flousiana Gaussen & 秃杉 & I & 易危 & 黄海仲 & 秃杉苗期生长特性研究 \\
\hline Gaussen & & & $/ \mathrm{VU}$ & & \\
\hline Taiwania flousiana Gaussen & 秃杉 & I & 易危 & 熊晓南 & 秃杉迁地保护试验研究初报 \\
\hline
\end{tabular}


顾垒，闻丞，罗玫，王吴，吕植. 中国最受关注濒危物种保护现状快速评价的新方法探讨. 生物多样性，2015，23(5)：583-590. http://www. biodiversity-science. net/CN/article/downloadArticleFile. do?attachType=PDF\&id=10075

\begin{tabular}{|c|c|c|c|c|c|}
\hline Gaussen & & & $/ \mathrm{VU}$ & & \\
\hline Taiwania flousiana Gaussen & 秃杉 & I & 易危 & 刘永刚 & 秃杉球果形态的变异研究 \\
\hline Gaussen & & & $/ \mathrm{VU}$ & & \\
\hline Taiwania flousiana Gaussen & 秃杉 & I & 易危 & 段成波 & 秃杉人工林的培育技术* \\
\hline Gaussen & & & $/ \mathrm{VU}$ & & \\
\hline Taiwania flousiana Gaussen & 秃杉 & I & 易危 & 邹礼光 & 秃杉人工林林下植物和土壤肥力的研究 \\
\hline Gaussen & & & $/ \mathrm{VU}$ & & \\
\hline Taiwania flousiana Gaussen & 秃杉 & I & 易危 & 谢文雷 & 秃杉人工林密度管理技术研究 \\
\hline Gaussen & & & /VU & & \\
\hline Taiwania flousiana Gaussen & 秃杉 & I & 易危 & 何斌 & 秃杉人工林生态系统碳素积累的动态特征 \\
\hline Gaussen & & & /VU & & \\
\hline Taiwania flousiana Gaussen & 秃杉 & I & 易危 & 何斌 & 秃杉人工林生物量与生产力的变化规律 \\
\hline Gaussen & & & /VU & & \\
\hline Taiwania flousiana Gaussen & 秃杉 & I & 易危 & 陈建新 & 秃杉人工林生长过程 \\
\hline Gaussen & & & /VU & & \\
\hline Taiwania flousiana Gaussen & 秃杉 & I & 易危 & 何斌 & 秃杉人工林速生阶段的碳库与碳吸存 \\
\hline Gaussen & & & /VU & & \\
\hline Taiwania flousiana Gaussen & 秃杉 & I & 易危 & 何斌 & 秃杉人工林营养元素含量_积累与分配特征的研究 \\
\hline Gaussen & & & $/ \mathrm{VU}$ & & \\
\hline
\end{tabular}


顾垒，闻丞，罗玫，王吴，吕植. 中国最受关注濒危物种保护现状快速评价的新方法探讨．生物多样性，2015，23(5)：583-590。 http://www biodiversity-science. net/CN/article/downloadArticleFile. do?attachType=PDF\&id=10075

\begin{tabular}{|c|c|c|c|c|c|}
\hline Taiwania flousiana Gaussen & 秃杉 & I & 易危 & 刘毅 & 秃杉生物量及其生长规律研究 \\
\hline Gaussen & & & $/ \mathrm{VU}$ & & \\
\hline Taiwania flousiana Gaussen & 秃杉 & I & 易危 & 李晓储 & 秃杉异龄复层混交林群落抑菌功能研究 \\
\hline Gaussen & & & /VU & & \\
\hline Taiwania flousiana Gaussen & 秃杉 & I & 易危 & 李晓储 & 秃杉引种潜力及迁地保存利用研究 \\
\hline Gaussen & & & $/ \mathrm{VU}$ & & \\
\hline Taiwania flousiana Gaussen & 秃杉 & I & 易危 & 连勇机 & 秃杉引种效果分析 \\
\hline Gaussen & & & $/ \mathrm{VU}$ & & \\
\hline Taiwania flousiana Gaussen & 秃杉 & I & 易危 & 黄海仲 & 秃杉引种育苗技术研究 \\
\hline Gaussen & & & /VU & & \\
\hline Taiwania flousiana Gaussen & 秃杉 & I & 易危 & 汪雪文 & 秃杉引种栽培技术 \\
\hline Gaussen & & & $/ \mathrm{VU}$ & & \\
\hline Taiwania flousiana Gaussen & 秃杉 & I & 易危 & 贾生华 & 秃杉引种造林试验 \\
\hline Gaussen & & & $/ \mathrm{VU}$ & & \\
\hline Taiwania flousiana Gaussen & 秃杉 & I & 易危 & 王明怀 & 秃杉优良种源选择及种源区划 \\
\hline Gaussen & & & $/ \mathrm{VU}$ & & \\
\hline Taiwania flousiana Gaussen & 秃杉 & I & 易危 & 白中萍 & 秃杉优树选择及无性系种子园营建技术研究 \\
\hline Gaussen & & & $/ \mathrm{VU}$ & & \\
\hline Taiwania flousiana Gaussen & 秃杉 & I & 易危 & 王明怀 & 秃杉优树自由授粉子代测定研究 \\
\hline
\end{tabular}


顾垒，闻丞，罗玫，王吴，吕植. 中国最受关注濒危物种保护现状快速评价的新方法探讨．生物多样性，2015，23 (5)：583-590。 http://www. biodiversity-science. net/CN/article/downloadArticleFile. do?attachType=PDF\&id=10075

\begin{tabular}{|c|c|c|c|c|c|}
\hline \multicolumn{3}{|l|}{ Gaussen } & \multicolumn{3}{|l|}{$/ \mathrm{VU}$} \\
\hline Taiwania flousiana Gaussen & 秃杉 & I & 易危 & 张先动 & 秃杉与杉木_木荷混交林林分结构和生物量研究 \\
\hline Gaussen & & & /VU & & \\
\hline Taiwania flousiana Gaussen & 秃杉 & I & 易危 & 陈元品 & 秃杉与杉木_木荷混交林林分生长初步研究 \\
\hline Gaussen & & & /VU & & \\
\hline Taiwania flousiana Gaussen & 秃杉 & I & 易危 & 林文华 & 秃杉在福建省永春县造林试验及效果分析 \\
\hline Gaussen & & & /VU & & \\
\hline Taiwania flousiana Gaussen & 秃杉 & I & 易危 & 胡 立 & 秃杉早晚生长性状的相关性分析 \\
\hline Gaussen & & & /VU & & \\
\hline Taiwania flousiana Gaussen & 秃杉 & I & 易危 & 宋丛文 & 秃杉种内遗传多样性的 RAPD 分析 \\
\hline Gaussen & & & /VU & & \\
\hline Taiwania flousiana Gaussen & 秃杉 & I & 易危 & 李性苑 & 秃杉种群更新与环境因子的关系 \\
\hline Gaussen & & & /VU & & \\
\hline Taiwania flousiana Gaussen & 秃杉 & I & 易危 & 王明怀 & 秃杉种源-家系遗传变异研究 \\
\hline Gaussen & & & $/ \mathrm{VU}$ & & \\
\hline Taiwania flousiana Gaussen & 秃杉 & I & 易危 & 吴代坤 & 秃杉组织培养技术研究 \\
\hline Gaussen & & & /VU & & \\
\hline Taiwania flousiana Gaussen & 秃杉 & I & 易危 & 漆 荣 & 秃杉组织培养研究 \\
\hline Gaussen & & & /VU & & \\
\hline
\end{tabular}


顾垒，闻丞，罗玫，王吴，吕植. 中国最受关注濒危物种保护现状快速评价的新方法探讨. 生物多样性，2015，23(5)：583-590. http://www biodiversity-science. net/CN/article/downloadArticleFile. do?attachType=PDF\&id=10075

\begin{tabular}{|c|c|c|c|c|c|}
\hline Taiwania flousiana Gaussen & 秃杉 & I & 易危 & 邱琼 & 西双版纳普文山地的秃杉引种试验初报 \\
\hline Gaussen & & & $/ \mathrm{VU}$ & & \\
\hline Taiwania flousiana Gaussen & 秃杉 & I & 易危 & 陈绍林 & 星斗山自然保护区秃杉原生种群生境现状及保护对策 \\
\hline Gaussen & & & /VU & & \\
\hline Taiwania flousiana Gaussen & 秃杉 & I & 易危 & 鲁胜平 & 星斗山自然保护区秃杉资源及人工林生物量生长规律研究 \\
\hline Gaussen & & & $/ \mathrm{VU}$ & & \\
\hline Taiwania flousiana Gaussen & 秃杉 & I & 易危 & 吴文勇 & 沿海较高海拔山地引种秃杉适应性研究 \\
\hline Gaussen & & & $/ \mathrm{VU}$ & & \\
\hline Taiwania flousiana Gaussen & 秃杉 & I & 易危 & 李性苑 & 异质环境条件下秃杉种群的更新 \\
\hline Gaussen & & & $/ \mathrm{VU}$ & & \\
\hline Taiwania flousiana Gaussen & 秃杉 & I & 易危 & 梁胜耀 & 优良濒危珍稀树种_秃杉 \\
\hline Gaussen & & & $/ \mathrm{VU}$ & & \\
\hline Taiwania flousiana Gaussen & 秃杉 & I & 易危 & 张新华 & 豫南引种秃杉生长规律研究 \\
\hline Gaussen & & & $/ \mathrm{VU}$ & & \\
\hline Taiwania flousiana Gaussen & 秃杉 & I & 易危 & 张学顺 & 珍稀濒危物种秃杉繁殖技术研究 \\
\hline Gaussen & & & $/ \mathrm{VU}$ & & \\
\hline Taiwania flousiana Gaussen & 秃杉 & I & 易危 & 翁怀锋 & 珍稀树种秃杉引种栽培试验初报 \\
\hline Gaussen & & & $/ \mathrm{VU}$ & & \\
\hline Taiwania flousiana Gaussen & 秃杉 & I & 易危 & 李晓储 & 中山陵景区秃杉优良种源引种试验 \\
\hline
\end{tabular}


顾垒，闻丞，罗玫，王吴，吕植. 中国最受关注濒危物种保护现状快速评价的新方法探讨．生物多样性，2015，23 (5)：583-590。 http://www. biodiversity-science. net/CN/article/downloadArticleFile. do?attachType=PDF\&id=10075

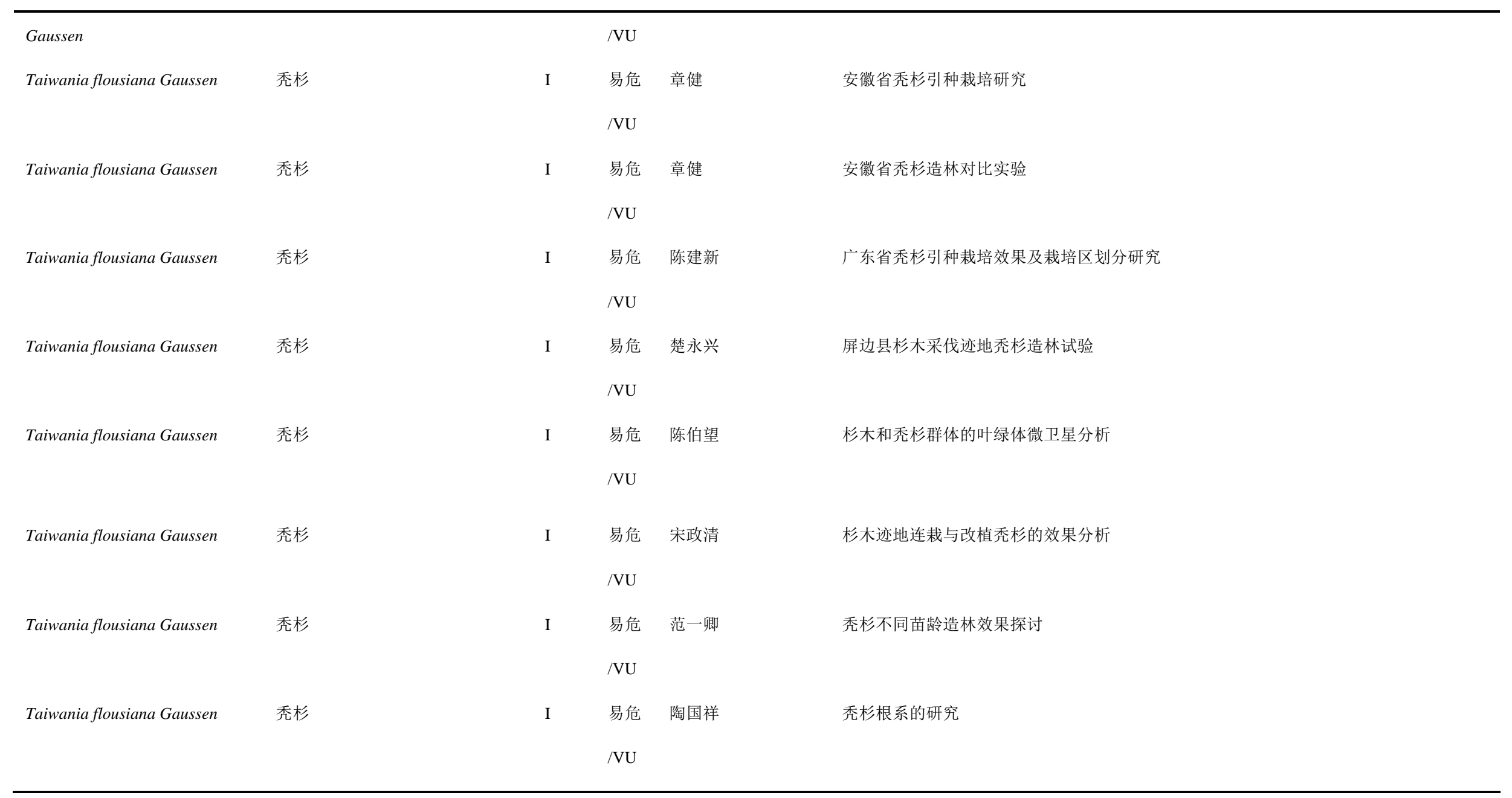


顾垒，闻丞，罗玫，王吴，吕植. 中国最受关注濒危物种保护现状快速评价的新方法探讨. 生物多样性，2015，23(5)：583-590. http://www biodiversity-science. net/CN/article/downloadArticleFile. do?attachType=PDF\&id=10075

\begin{tabular}{|c|c|c|c|c|c|}
\hline Taiwania flousiana Gaussen & 秃杉 & I & $\begin{array}{l}\text { 易危 } \\
\text { /VU }\end{array}$ & 楼浙辉 & 秃杉种源家系变异及选择研究 \\
\hline Taiwania flousiana Gaussen & 秃杉 & I & $\begin{array}{l}\text { 易危 } \\
\text { /VU }\end{array}$ & 李晓储 & 秃杉种质资源迁地保存育苗技术研究 \\
\hline Taiwania flousiana Gaussen & 秃杉 & I & $\begin{array}{l}\text { 易危 } \\
\text { /VU }\end{array}$ & 李晓储 & 秃杉种质资源迁地保存栽培技术的研究 \\
\hline Taiwania flousiana Gaussen & 秃杉 & I & $\begin{array}{l}\text { 易危 } \\
\text { /VU }\end{array}$ & 陶国祥 & 云南省秃杉气候区划的研究 \\
\hline Taxus chinensis & 红豆杉 & I & $\begin{array}{l}\text { 濒危 } \\
\text { /EN }\end{array}$ & 高必达 & 湖南野生红豆杉的 rDNA_ITS 系统进化及分类探讨 \\
\hline Taxus chinensis & 红豆杉 & I & $\begin{array}{l}\text { 濒危 } \\
\text { /EN }\end{array}$ & 藏 新 & 2 种红豆杉的离体胚培养 \\
\hline Taxus chinensis & 红豆杉 & I & $\begin{array}{l}\text { 濒危 } \\
\text { /EN }\end{array}$ & Deyou Qiu & $\begin{array}{l}\text { High throughput sequencing technology reveals that the taxoid elicitor methyl jasmonate } \\
\text { regulates microRNA expression in Chinese yew (Taxus chinensis) }\end{array}$ \\
\hline Taxus chinensis & 红豆杉 & I & $\begin{array}{l}\text { 濒危 } \\
\text { /EN }\end{array}$ & 韦美玉 & 斗蓬山高山沼泽化红豆杉衰老的相关生理指标 \\
\hline Taxus chinensis & 红豆杉 & I & $\begin{array}{l}\text { 濒危 } \\
\text { /EN }\end{array}$ & 丁炳扬 & 凤阳山红豆杉群落乔木层主要种群生态位研究 \\
\hline
\end{tabular}


顾垒，闻丞，罗玫，王吴，吕植. 中国最受关注濒危物种保护现状快速评价的新方法探讨. 生物多样性，2015，23(5)：583-590. http://www biodiversity-science. net/CN/article/downloadArticleFile. do?attachType=PDF\&id=10075

\begin{tabular}{|c|c|c|c|c|c|}
\hline Taxus chinensis & 红豆杉 & I & $\begin{array}{l}\text { 濒危 } \\
\text { /EN }\end{array}$ & 唐功 & 甘肃陇南林区红豆杉濒危原因分析 \\
\hline Taxus chinensis & 红豆杉 & I & $\begin{array}{l}\text { 濒危 } \\
\text { /EN }\end{array}$ & 周洪英 & 贵州红豆杉属植物资源与保护利用初探 \\
\hline Taxus chinensis & 红豆杉 & I & $\begin{array}{l}\text { 濒危 } \\
\text { /EN }\end{array}$ & 余龙江 & 红豆杉的 18SrRNA 基因的分子进化研究 \\
\hline Taxus chinensis & 红豆杉 & I & $\begin{array}{l}\text { 濒危 } \\
\text { /EN }\end{array}$ & 林金星 & 红豆杉的胚珠发育、传粉滴形成和传粉过程 \\
\hline Taxus chinensis & 红豆杉 & I & $\begin{array}{l}\text { 濒危 } \\
\text { /EN }\end{array}$ & 郭顺星 & 红豆杉根的显微结构及其内生真菌分布 \\
\hline Taxus chinensis & 红豆杉 & I & $\begin{array}{l}\text { 濒危 } \\
\text { /EN }\end{array}$ & 王艇 & 红豆杉科及其相关类群的 RAPD 分析 \\
\hline Taxus chinensis & 红豆杉 & I & $\begin{array}{l}\text { 濒危 } \\
\text { /EN }\end{array}$ & 周其兴 & 红豆杉科及其相关类群的分支分析 \\
\hline Taxus chinensis & 红豆杉 & I & $\begin{array}{l}\text { 濒危 } \\
\text { /EN }\end{array}$ & 汪小全 & 红豆杉科及三尖杉科的分子系统发育一一一兼论竹柏属的系统位置 \\
\hline Taxus chinensis & 红豆杉 & I & $\begin{array}{l}\text { 濒危 } \\
\text { /EN }\end{array}$ & 王艇 & 红豆杉科及相关类群 rbcL 基因 PCR_RFLP 分析 \\
\hline Taxus chinensis & 红豆杉 & I & 濒危 & 王艇 & 红豆杉科及相关类群叶绿体 rbcL 基因与 trnL_trnF 间隔区序列的分支分析 \\
\hline
\end{tabular}


顾垒，闻丞，罗玫，王吴，吕植. 中国最受关注濒危物种保护现状快速评价的新方法探讨. 生物多样性，2015，23(5)：583-590. http://www. biodiversity-science. net/CN/article/downloadArticleFile. do?attachType=PDF\&id=10075

\begin{tabular}{|c|c|c|c|c|c|}
\hline & & & /EN & & \\
\hline \multirow[t]{2}{*}{ Taxus chinensis } & 红豆杉 & I & 濒危 & 郑博 & 红豆杉科及相关类群叶绿体 rbcL 基因与 $\operatorname{trnL}-\operatorname{trnF}$ 间隔区序列的分支分析 \\
\hline & & & $/$ EN & & \\
\hline \multirow[t]{2}{*}{ Taxus chinensis } & 红豆杉 & I & 濒危 & 王艇 & 红豆杉科植物 RAPD 分析及其系统学意义 \\
\hline & & & /EN & & \\
\hline \multirow[t]{2}{*}{ Taxus chinensis } & 红豆杉 & I & 濒危 & 杨栋梁 & 红豆杉内生真菌遗传多样性分析及生物转化研究 \\
\hline & & & /EN & & \\
\hline \multirow[t]{2}{*}{ Taxus chinensis } & 红豆杉 & I & 濒危 & 余龙江 & 红豆杉脱分化过程中的遗传和表观遗传变异 \\
\hline & & & /EN & & \\
\hline \multirow[t]{2}{*}{ Taxus chinensis } & 红豆杉 & I & 濒危 & 江建铭 & 红豆杉种质资源遗传多样性的 AFLP 分析 \\
\hline & & & /EN & & \\
\hline \multirow[t]{2}{*}{ Taxus chinensis } & 红豆杉 & I & 濒危 & 荣剑 & 红豆杉种子休眠机理及休眠解除研究进展 \\
\hline & & & $/ \mathrm{EN}$ & & \\
\hline \multirow[t]{2}{*}{ Taxus chinensis } & 红豆杉 & I & 濒危 & 杨文忠 & 红豆杉种子休眠原因及提高萌发率方法的研究进展 \\
\hline & & & /EN & & \\
\hline \multirow[t]{2}{*}{ Taxus chinensis } & 红豆杉 & I & 濒危 & 何水林 & 红豆杉资源遗传多样性分析及南方红豆杉愈伤组织诱导体系的建立 \\
\hline & & & /EN & & \\
\hline \multirow[t]{2}{*}{ Taxus chinensis } & 红豆杉 & I & 濒危 & 关良福 & 湖北十八里长峡自然保护区红豆杉林的调查研究 \\
\hline & & & /EN & & \\
\hline
\end{tabular}


顾垒，闻丞，罗玫，王吴，吕植. 中国最受关注濒危物种保护现状快速评价的新方法探讨. 生物多样性，2015，23(5)：583-590. http://www biodiversity-science. net/CN/article/downloadArticleFile. do?attachType=PDF\&id=10075

\begin{tabular}{|c|c|c|c|c|c|}
\hline Taxus chinensis & 红豆杉 & I & $\begin{array}{l}\text { 濒危 } \\
\text { /EN }\end{array}$ & 藏 新 & 激素对 2 种红豆杉离体胚培养的影响 \\
\hline Taxus chinensis & 红豆杉 & I & $\begin{array}{l}\text { 濒危 } \\
\text { /EN }\end{array}$ & 庞云海 & 剑川县野生红豆杉资源及生存状况的调查分析 \\
\hline Taxus chinensis & 红豆杉 & I & $\begin{array}{l}\text { 濒危 } \\
\text { /EN }\end{array}$ & 邱兴银 & 金川县红豆杉生态群落结构及其演替规律 \\
\hline Taxus chinensis & 红豆杉 & I & $\begin{array}{l}\text { 濒危 } \\
\text { /EN }\end{array}$ & 杨代强 & 金川县红豆杉生态群落结构及其演替规律 \\
\hline Taxus chinensis & 红豆杉 & I & $\begin{array}{l}\text { 濒危 } \\
\text { /EN }\end{array}$ & 胥晓 & 利用斑块信息研究冶勒的红豆杉种群分布格局与坡度的关系 \\
\hline Taxus chinensis & 红豆杉 & I & $\begin{array}{l}\text { 濒危 } \\
\text { /EN }\end{array}$ & 彭少麟 & 模拟酸雨对珍稀濒危植物红豆杉幼苗的影响研究 \\
\hline Taxus chinensis & 红豆杉 & I & $\begin{array}{l}\text { 濒危 } \\
\text { /EN }\end{array}$ & 胥晓 & 坡向对四川冶勒红豆杉种群分布格局的影响一一基于斑块信息的分析 \\
\hline Taxus chinensis & 红豆杉 & I & $\begin{array}{l}\text { 濒危 } \\
\text { /EN }\end{array}$ & 宋西德 & 秦岭紫柏山中国红豆杉的保护生物学研究 \\
\hline Taxus chinensis & 红豆杉 & I & $\begin{array}{l}\text { 濒危 } \\
\text { /EN }\end{array}$ & 田先华 & 陕西红豆杉资源研究 \\
\hline Taxus chinensis & 红豆杉 & I & 濒危 & 张九东 & 陕西省秦巴山区红豆杉居群紫杉醇含量比较分析研究 \\
\hline
\end{tabular}


顾垒，闻丞，罗玫，王吴，吕植. 中国最受关注濒危物种保护现状快速评价的新方法探讨. 生物多样性，2015，23(5)：583-590. http://www. biodiversity-science. net/CN/article/downloadArticleFile. do?attachType=PDF\&id=10075

\begin{tabular}{|c|c|c|c|c|c|}
\hline & & & /EN & & \\
\hline \multirow[t]{2}{*}{ Taxus chinensis } & 红豆杉 & I & 濒危 & 鲁长虎 & 食果鸟类在红豆杉天然更新中的作用 \\
\hline & & & $/$ EN & & \\
\hline \multirow[t]{2}{*}{ Taxus chinensis } & 红豆杉 & I & 濒危 & 鲁长虎 & 食果鸟类在红豆杉天然种群形成中的作用 \\
\hline & & & /EN & & \\
\hline \multirow[t]{2}{*}{ Taxus chinensis } & 红豆杉 & I & 濒危 & 蔡小虎 & 四川省红豆杉种群结构和动态的初步研究 \\
\hline & & & /EN & & \\
\hline \multirow[t]{2}{*}{ Taxus chinensis } & 红豆杉 & I & 濒危 & 严贤春 & 四川冶勒红豆杉迁地保护调查与设计研究 \\
\hline & & & /EN & & \\
\hline \multirow[t]{2}{*}{ Taxus chinensis } & 红豆杉 & I & 濒危 & 间玉荣 & 太行山辉县野生红豆杉资源调查报告 \\
\hline & & & /EN & & \\
\hline \multirow[t]{2}{*}{ Taxus chinensis } & 红豆杉 & $\mathrm{I}$ & 濒危 & 孟丽 & 太行山野生红豆杉菌根菌的生态效应 \\
\hline & & & /EN & & \\
\hline \multirow[t]{2}{*}{ Taxus chinensis } & 红豆杉 & I & 濒危 & 巨天珍 & 天水小陇山红豆杉( Taxus chinensis ( Pilg. ) Rehd)林土壤真菌多样性及其与生态因子的相 \\
\hline & & & /EN & & 关性 \\
\hline \multirow[t]{2}{*}{ Taxus chinensis } & 红豆杉 & I & 濒危 & 高山林 & 我国境内几种红豆杉的 RAPD 分析和染色体鉴定 \\
\hline & & & /EN & & \\
\hline \multirow[t]{2}{*}{ Taxus chinensis } & 红豆杉 & I & 濒危 & 王金金 & 我国境内野生红豆杉的生物学特性及资源现状 \\
\hline & & & /EN & & \\
\hline
\end{tabular}


顾垒，闻丞，罗玫，王吴，吕植. 中国最受关注濒危物种保护现状快速评价的新方法探讨. 生物多样性，2015，23(5)：583-590. http://www biodiversity-science. net/CN/article/downloadArticleFile. do?attachType=PDF\&id=10075

\begin{tabular}{|c|c|c|c|c|c|}
\hline Taxus chinensis & 红豆杉 & I & 濒危 & 王玉震 & 我国天然红豆杉资源濒危因子分析及其保护途径探讨 \\
\hline & & & \multicolumn{3}{|l|}{ /EN } \\
\hline \multirow[t]{2}{*}{ Taxus chinensis } & 红豆杉 & I & 濒危 & 胡国武 & 稀土对红豆杉细胞中紫杉烯合成酶基因转录的影响 \\
\hline & & & /EN & & \\
\hline \multirow[t]{2}{*}{ Taxus chinensis } & 红豆杉 & I & 濒危 & 独军 & 小陇山林区红豆杉种质资源的开发与保护 \\
\hline & & & /EN & & \\
\hline \multirow[t]{2}{*}{ Taxus chinensis } & 红豆杉 & I & 濒危 & 彭少麟 & 影响红豆杉生长的主要生态因子 \\
\hline & & & /EN & & \\
\hline \multirow[t]{2}{*}{ Taxus chinensis } & 红豆杉 & I & 濒危 & 巨天珍 & 珍稀濒危植物中国红豆杉种群生态学研究 \\
\hline & & & /EN & & \\
\hline \multirow[t]{2}{*}{ Taxus chinensis } & 红豆杉 & I & 濒危 & 高素萍 & 珍稀植物红豆杉生长动态及环境与保健效益的研究 \\
\hline & & & /EN & & \\
\hline \multirow[t]{2}{*}{ Taxus chinensis } & 红豆杉 & I & 濒危 & 戴怡龄 & 中国红豆杉 ( T. chinensis) 和曼地亚( T. medta cv. Hickii ) 叶茎储存结构性状的比较 \\
\hline & & & /EN & & \\
\hline \multirow[t]{2}{*}{ Taxus chinensis } & 红豆杉 & I & 濒危 & 张宗勤 & 中国红豆杉种内和种间竞争关系的研究 \\
\hline & & & /EN & & \\
\hline \multirow[t]{2}{*}{ Taxus chinensis } & 红豆杉 & I & 濒危 & 巨天珍 & 中国小陇山国家级自然保护区珍稀濒危植物红豆杉林土壤微生物生态学研究 \\
\hline & & & /EN & & \\
\hline Taxus cuspidata & 东北红豆杉 & I & 无危 & 周志强 & 3 种红豆杉光合特性及叶绿素荧光差异比较 \\
\hline
\end{tabular}


顾垒，闻丞，罗玫，王吴，吕植. 中国最受关注濒危物种保护现状快速评价的新方法探讨. 生物多样性，2015，23(5)：583-590. http://www biodiversity-science. net/CN/article/downloadArticleFile. do?attachType=PDF\&id=10075

Taxus cuspidata

东北红豆杉

东北红豆杉

东北红豆杉

Taxus cuspidata

东北红豆杉

东北红豆杉

Taxus cuspidata

Taxus cuspidata

Taxus cuspidata

Taxus cuspidata

Taxus cuspidata
无伦

$/ \mathrm{LC}$

I 无危

X. L. Li

无危 Kexuan Tang

$/ \mathrm{LC}$

Ying-Jin Yuan

I 无危

ZU Yuan-gang

I 无危 董学会

LC

I 无危 刘制

/LC

I 无危 杨波

/LC

无危 许明子
Characteristics of natural Japanese yew population in Muling Nature Reserve of Heilongjiang Province, China

Genomic Diversity within Taxus cuspidata var. nana Revealed by Random Amplified

Polymorphic DNA Markers

Isolation and characterization of a novel cDNA encoding methyl jasmonate-responsive

transcription factor TcAP2 from Taxus cuspidata

Isolation of Differential Genes in Suspension Cultures of Taxus cuspidata Induced by

Additional Taxol

Population structure and distribution pattern of Taxus cuspidata in Muling region of

Heilongjiang Province, China

不同变温层积过程中东北红豆杉种子生理生化特性和胚形态的变化

不同光环境下东北红豆杉幼树叶光合和荧光特性比较

不同温度对东北红豆杉种子活力的影响

东北红豆杉 RAPD 反应体系的优化 
顾垒，闻丞，罗玫，王吴，吕植. 中国最受关注濒危物种保护现状快速评价的新方法探讨. 生物多样性，2015，23(5)：583-590. http://www biodiversity-science. net/CN/article/downloadArticleFile. do?attachType=PDF\&id=10075

\begin{tabular}{|c|c|c|c|c|c|}
\hline Taxus cuspidata & 东北红豆杉 & I & $\begin{array}{l}\text { 无危 } \\
\text { /LC }\end{array}$ & 赵秀海 & 东北红豆杉雌雄植株径向生长对邻体竞争和气候因子的响应 \\
\hline Taxus cuspidata & 东北红豆杉 & I & $\begin{array}{l}\text { 无危 } \\
\text { /LC }\end{array}$ & 葛丽丽 & 东北红豆杉雌株枝、叶生长过程中内源激素变化的实验研究 \\
\hline Taxus cuspidata & 东北红豆杉 & I & $\begin{array}{l}\text { 无危 } \\
\text { /LC }\end{array}$ & 张艳平 & 东北红豆杉的研究进展 \\
\hline Taxus cuspidata & 东北红豆杉 & I & $\begin{array}{l}\text { 无危 } \\
\text { /LC }\end{array}$ & 程广有 & 东北红豆杉开花结实的规律 \\
\hline Taxus cuspidata & 东北红豆杉 & I & $\begin{array}{l}\text { 无危 } \\
\text { /LC }\end{array}$ & 李玉 & 东北红豆杉内生真菌的多样性 \\
\hline Taxus cuspidata & 东北红豆杉 & I & $\begin{array}{l}\text { 无危 } \\
\text { /LC }\end{array}$ & 项勇 & 东北红豆杉内生真菌的分离和篮选 \\
\hline Taxus cuspidata & 东北红豆杉 & I & $\begin{array}{l}\text { 无危 } \\
\text { /LC }\end{array}$ & 王升忠 & 东北红豆杉树轮记录的 200 年来气候变化过程研究 \\
\hline Taxus cuspidata & 东北红豆杉 & I & $\begin{array}{l}\text { 无危 } \\
\text { /LC }\end{array}$ & 许明子 & 东北红豆杉性别相关的 A F L P 标记研究 \\
\hline Taxus cuspidata & 东北红豆杉 & I & $\begin{array}{l}\text { 无危 } \\
\text { /LC }\end{array}$ & 元英进 & 东北红豆杉愈伤组织细胞分裂及染色体稳定性 \\
\hline Taxus cuspidata & 东北红豆杉 & I & 无危 & 张启昌 & 东北红豆杉枝叶对不同 $\mathrm{CO} 2$ 浓度的光合生理响应 \\
\hline
\end{tabular}


顾垒，闻丞，罗玫，王吴，吕植. 中国最受关注濒危物种保护现状快速评价的新方法探讨. 生物多样性，2015，23(5)：583-590. http://www biodiversity-science. net/CN/article/downloadArticleFile. do?attachType=PDF\&id=10075

\begin{tabular}{|c|c|c|c|c|c|}
\hline \multirow[b]{2}{*}{ Taxus cuspidata } & \multirow[b]{2}{*}{ 东北红豆杉 } & \multirow[b]{2}{*}{ I } & \multicolumn{2}{|l|}{$/ \mathrm{LC}$} & \multirow{3}{*}{ 东北红豆杉种子休眠机理与解除技术探讨 } \\
\hline & & & 无危 & 程广有 & \\
\hline & & & $/ \mathrm{LC}$ & & \\
\hline \multirow[t]{2}{*}{ Taxus cuspidata } & 东北红豆杉 & I & 无危 & 狍金福 & 抚松县东北红豆杉资源状况及保护策略 \\
\hline & & & $/ \mathrm{LC}$ & & \\
\hline \multirow[t]{2}{*}{ Taxus cuspidata } & 东北红豆杉 & I & 无危 & 周志强 & 黑龙江穆棱天然东北红豆杉种群资源特征研究 \\
\hline & & & $/ \mathrm{LC}$ & & \\
\hline \multirow[t]{2}{*}{ Taxus cuspidata } & 东北红豆杉 & I & 无危 & 李玉 & 吉林省金沟岭东北红豆杉自然保护区大型真菌多样性研究 \\
\hline & & & $/ \mathrm{LC}$ & & \\
\hline \multirow[t]{2}{*}{ Taxus cuspidata } & 东北红豆杉 & I & 无危 & 刘娅 & 立地条件差异对天然东北红豆杉(Taxus cuspidata)种间竞争的影响 \\
\hline & & & $/ \mathrm{LC}$ & & \\
\hline \multirow[t]{2}{*}{ Taxus cuspidata } & 东北红豆杉 & I & 无危 & 王晓春 & 穆棱东北红豆杉年轮-气候关系及其濒危机制 \\
\hline & & & $/ \mathrm{LC}$ & & \\
\hline \multirow[t]{2}{*}{ Taxus cuspidata } & 东北红豆杉 & I & 无危 & 时德群 & 穆棱林业局天然东北红豆杉种群特征的调查分析 \\
\hline & & & $/ \mathrm{LC}$ & & \\
\hline \multirow[t]{2}{*}{ Taxus cuspidata } & 东北红豆杉 & I & 无危 & 周志强 & 秋冬季自然降温过程中东北红豆杉幼苗的生理生化特性 \\
\hline & & & $/ \mathrm{LC}$ & & \\
\hline \multirow[t]{2}{*}{ Taxus cuspidata } & 东北红豆杉 & I & 无危 & 周志强 & 天然东北红豆杉(Taxus cuspidata)种内和种间竞争 \\
\hline & & & $/ \mathrm{LC}$ & & \\
\hline
\end{tabular}


顾垒，闻丞，罗玫，王吴，吕植. 中国最受关注濒危物种保护现状快速评价的新方法探讨. 生物多样性，2015，23(5)：583-590. http://www biodiversity-science. net/CN/article/downloadArticleFile. do?attachType=PDF\&id=10075

\begin{tabular}{|c|c|c|c|c|c|}
\hline Taxus cuspidata & 东北红豆杉 & I & $\begin{array}{l}\text { 无危 } \\
\text { /LC }\end{array}$ & 严善春 & 天然东北红豆杉_Taxuscuspidata_抗虫性研究 \\
\hline Taxus cuspidata & 东北红豆杉 & I & $\begin{array}{l}\text { 无危 } \\
\text { /LC }\end{array}$ & 周志强 & 天然东北红豆杉生殖生态学研究 \\
\hline Taxus cuspidata & 东北红豆杉 & I & $\begin{array}{l}\text { 无危 } \\
\text { /LC }\end{array}$ & 周志强 & 天然东北红豆杉土壤种子库研究 \\
\hline Taxus cuspidata & 东北红豆杉 & I & $\begin{array}{l}\text { 无危 } \\
\text { /LC }\end{array}$ & 刘䑣 & 天然东北红豆杉种群生殖力与开花结实特性 \\
\hline Taxus cuspidata & 东北红豆杉 & I & $\begin{array}{l}\text { 无危 } \\
\text { /LC }\end{array}$ & 高山林 & 我国境内几种红豆杉的 RAPD 分析和染色体鉴定 \\
\hline Taxus cuspidata & 东北红豆杉 & I & $\begin{array}{l}\text { 无危 } \\
\text { /LC }\end{array}$ & 丁磊 & 遮荫对东北红豆杉苗期生长及光合特性的影响 \\
\hline Taxus cuspidata & 东北红豆杉 & I & $\begin{array}{l}\text { 无危 } \\
\text { /LC }\end{array}$ & 程广有 & 中国境内东北红豆杉天然群体紫杉醇含量变异规律 \\
\hline Taxus mairei & 南方红豆杉 & I & $\begin{array}{l}\text { 易危 } \\
\text { /VU }\end{array}$ & 周志强 & 3 种红豆杉光合特性及叶绿素苂光差异比较 \\
\hline Taxus mairei & 南方红豆杉 & I & $\begin{array}{l}\text { 易危 } \\
\text { /VU }\end{array}$ & 郑玉红 & 4 种红豆杉属植物遗传多样性和遗传关系的 RAPD 分析 \\
\hline Taxus mairei & 南方红豆杉 & I & 易危 & C.H. Lu & Development and characterization of microsatellite markers for the endangered Chinese yew \\
\hline
\end{tabular}


顾垒，闻丞，罗玫，王吴，吕植. 中国最受关注濒危物种保护现状快速评价的新方法探讨. 生物多样性，2015，23(5)：583-590. http://www. biodiversity-science. net/CN/article/downloadArticleFile. do?attachType=PDF\&id=10075

\begin{tabular}{|c|c|c|c|c|c|}
\hline & & & /VU & & Taxus chinensis var. mairei (Taxaceae) \\
\hline \multirow[t]{2}{*}{ Taxus mairei } & 南方红豆杉 & I & 易危 & ZHANG J-T & ECOLOGICAL STUDY OF FORESTS DOMINATED BY ENDANGERED SPECIES, \\
\hline & & & /VU & & TAXUS CHINENSIS VAR. MAIREI, IN SHANXI OF CHINA \\
\hline \multirow[t]{2}{*}{ Taxus mairei } & 南方红豆杉 & I & 易危 & Jin-Tun Zhang & Population characteristics of endangered species Taxus chinensis var. mairei and its \\
\hline & & & /VU & & conservation strategy in Shanxi, China \\
\hline \multirow[t]{2}{*}{ Taxus mairei } & 南方红豆杉 & I & 易危 & 张金屯 & 濒危植物南方红豆杉濒危原因分析 \\
\hline & & & /VU & & \\
\hline \multirow[t]{2}{*}{ Taxus mairei } & 南方红豆杉 & I & 易危 & 茄文明 & 濒危植物南方红豆杉的研究进展 \\
\hline & & & $/ \mathrm{VU}$ & & \\
\hline \multirow[t]{2}{*}{ Taxus mairei } & 南方红豆杉 & I & 易危 & 张金屯 & 濒危植物南方红豆杉生态学研究 \\
\hline & & & $/ \mathrm{VU}$ & & \\
\hline \multirow[t]{2}{*}{ Taxus mairei } & 南方红豆杉 & I & 易危 & 茹文明 & 濒危植物南方红豆杉遗传多样性的 RAPD 分析 \\
\hline & & & /VU & & \\
\hline \multirow[t]{2}{*}{ Taxus mairei } & 南方红豆杉 & I & 易危 & 李先琨 & 濒危植物南方红豆杉种群克隆生长空间格局与动态 \\
\hline & & & /VU & & \\
\hline \multirow[t]{2}{*}{ Taxus mairei } & 南方红豆杉 & I & 易危 & 吴承祯 & 濒危植物南方红豆杉种群生命表及谱分析 \\
\hline & & & $/ \mathrm{VU}$ & & \\
\hline \multirow[t]{2}{*}{ Taxus mairei } & 南方红豆杉 & I & 易危 & 全川 & 濒危植物南方红豆杉种子雨和土壤种子库特征 \\
\hline & & & /VU & & \\
\hline
\end{tabular}


顾垒，闻丞，罗玫，王吴，吕植. 中国最受关注濒危物种保护现状快速评价的新方法探讨. 生物多样性，2015，23(5)：583-590. http://www biodiversity-science. net/CN/article/downloadArticleFile. do?attachType=PDF\&id=10075

\begin{tabular}{|c|c|c|c|c|c|}
\hline Taxus mairei & 南方红豆杉 & I & $\begin{array}{l}\text { 易危 } \\
\text { /VU }\end{array}$ & 龙启德 & 不同光照与土壤肥力下南方红豆杉形态响应研究 \\
\hline Taxus mairei & 南方红豆杉 & I & $\begin{array}{l}\text { 易危 } \\
\text { /VU }\end{array}$ & 鲁长虎 & 动物与南方红豆杉天然更新的关系研究 \\
\hline Taxus mairei & 南方红豆杉 & I & $\begin{array}{l}\text { 易危 } \\
\text { /VU }\end{array}$ & 王济红 & 梵净山自然保护区南方红豆杉资源分布现状调查 \\
\hline Taxus mairei & 南方红豆杉 & I & $\begin{array}{l}\text { 易危 } \\
\text { /VU }\end{array}$ & 孙晓冬 & 福建南方红豆杉群落种间关系的研究 \\
\hline Taxus mairei & 南方红豆杉 & I & $\begin{array}{l}\text { 易危 } \\
\text { /VU }\end{array}$ & 李朝阳 & 古丈县南方红豆杉的植物群落 \\
\hline Taxus mairei & 南方红豆杉 & I & $\begin{array}{l}\text { 易危 } \\
\text { /VU }\end{array}$ & 李朝阳 & 古丈县南方红豆杉天然群体的遗传多样性研究 \\
\hline Taxus mairei & 南方红豆杉 & I & $\begin{array}{l}\text { 易危 } \\
\text { /VU }\end{array}$ & 祖元刚 & 光胁迫对南方红豆杉叶片中叶绿体色素和紫杉醇含量的影响 \\
\hline Taxus mairei & 南方红豆杉 & I & $\begin{array}{l}\text { 易危 } \\
\text { /VU }\end{array}$ & 苏宗明 & 广西元宝山南方红豆杉群落特征的研究 \\
\hline Taxus mairei & 南方红豆杉 & I & $\begin{array}{l}\text { 易危 } \\
\text { /VU }\end{array}$ & 王宇 & 贵州省镇远县南方红豆杉资源调查 \\
\hline Taxus mairei & 南方红豆杉 & I & 易危 & 李孝伟 & 河南太行山南方红豆杉濒危原因分析 \\
\hline
\end{tabular}


顾垒，闻丞，罗玫，王吴，吕植. 中国最受关注濒危物种保护现状快速评价的新方法探讨. 生物多样性，2015，23(5)：583-590. http://www. biodiversity-science. net/CN/article/downloadArticleFile. do?attachType=PDF\&id=10075

\begin{tabular}{|c|c|c|c|c|c|}
\hline & & & /VU & & \\
\hline \multirow[t]{2}{*}{ Taxus mairei } & 南方红豆杉 & I & 易危 & 李孝伟 & 河南太行山南方红豆杉种子催芽研究 \\
\hline & & & /VU & & \\
\hline \multirow[t]{2}{*}{ Taxus mairei } & 南方红豆杉 & I & 易危 & 唐代生 & 湖南阳明山国家自然保护区南方红豆杉林分结构研究 \\
\hline & & & /VU & & \\
\hline \multirow[t]{2}{*}{ Taxus mairei } & 南方红豆杉 & I & 易危 & 唐代生 & 湖南阳明山国家自然保护区南方红豆杉群落特征研究 \\
\hline & & & /VU & & \\
\hline \multirow[t]{2}{*}{ Taxus mairei } & 南方红豆杉 & I & 易危 & 曹基武 & 湖南芷江县南方红豆杉群落特征及植物区系分析 \\
\hline & & & $/ \mathrm{VU}$ & & \\
\hline \multirow[t]{2}{*}{ Taxus mairei } & 南方红豆杉 & I & 易危 & 彭峰 & 基于 ISSR 标记的南方红豆杉野生种群和迁地保护种群的遗传多样性和遗传结构分析 \\
\hline & & & /VU & & \\
\hline \multirow[t]{2}{*}{ Taxus mairei } & 南方红豆杉 & I & 易危 & 李孝伟 & 济源猕猴自然保护区南方红豆杉群落调查 \\
\hline & & & /VU & & \\
\hline \multirow[t]{2}{*}{ Taxus mairei } & 南方红豆杉 & I & 易危 & 邓贤兰 & 井冈山自然保护区南方红豆杉群落物种多样性研究 \\
\hline & & & /VU & & \\
\hline \multirow[t]{2}{*}{ Taxus mairei } & 南方红豆杉 & I & 易危 & 黄彩霞 & 井冈山自然保护区南方红豆杉群落优势种种间联结性研究 \\
\hline & & & /VU & & \\
\hline \multirow[t]{2}{*}{ Taxus mairei } & 南方红豆杉 & I & 易危 & 龙婉婉 & 井冈山自然保护区南方红豆杉群落植物区系分析 \\
\hline & & & /VU & & \\
\hline
\end{tabular}


顾垒，闻丞，罗玫，王吴，吕植. 中国最受关注濒危物种保护现状快速评价的新方法探讨. 生物多样性，2015，23(5)：583-590. http://www biodiversity-science. net/CN/article/downloadArticleFile. do?attachType=PDF\&id=10075

\begin{tabular}{|c|c|c|c|c|c|}
\hline Taxus mairei & 南方红豆杉 & I & $\begin{array}{l}\text { 易危 } \\
\text { /VU }\end{array}$ & 王惠玲 & 历山南方红豆杉的种质资源及其保护 \\
\hline Taxus mairei & 南方红豆杉 & I & $\begin{array}{l}\text { 易危 } \\
\text { /VU }\end{array}$ & 李孝伟 & 两地区南方红豆杉叶片解剖结构观察 \\
\hline Taxus mairei & 南方红豆杉 & I & $\begin{array}{l}\text { 易危 } \\
\text { /VU }\end{array}$ & 王祖良 & 临安桐坑南方红豆杉群落区系组成和群落学特征研究 \\
\hline Taxus mairei & 南方红豆杉 & I & $\begin{array}{l}\text { 易危 } \\
\text { /VU }\end{array}$ & 张军 & 蟒河自然保护区南方红豆杉种群的数量分布 \\
\hline Taxus mairei & 南方红豆杉 & I & $\begin{array}{l}\text { 易危 } \\
\text { /VU }\end{array}$ & 鲁长虎 & 梅花山保护区动物对南方红豆杉种子命运的影响 \\
\hline Taxus mairei & 南方红豆杉 & I & $\begin{array}{l}\text { 易危 } \\
\text { /VU }\end{array}$ & 张盛钟 & 梅花山南方红豆杉资源现状及其保护对策 \\
\hline Taxus mairei & 南方红豆杉 & I & $\begin{array}{l}\text { 易危 } \\
\text { /VU }\end{array}$ & 刘建福 & 模拟酸雨对南方红豆杉生理特性的影响 \\
\hline Taxus mairei & 南方红豆杉 & I & $\begin{array}{l}\text { 易危 } \\
\text { /VU }\end{array}$ & 谢吉容 & 南方红豆杉(Taxus Chinensis Var .Mairei)叶片膜保护系统与温度的关系 \\
\hline Taxus mairei & 南方红豆杉 & I & $\begin{array}{l}\text { 易危 } \\
\text { /VU }\end{array}$ & 李亚 & 南方红豆杉 ISSR-PCR 反应体系的建立与优化 \\
\hline Taxus mairei & 南方红豆杉 & I & 易危 & 卢泳全 & 南方红豆杉 SSR 分布特征分析及分子标记的开发 \\
\hline
\end{tabular}


顾垒，闻丞，罗玫，王吴，吕植. 中国最受关注濒危物种保护现状快速评价的新方法探讨. 生物多样性，2015，23(5)：583-590. http://www. biodiversity-science. net/CN/article/downloadArticleFile. do?attachType=PDF\&id=10075

\begin{tabular}{|c|c|c|c|c|c|}
\hline & & & $/ \mathrm{VU}$ & & \\
\hline \multirow[t]{2}{*}{ Taxus mairei } & 南方红豆杉 & I & 易危 & 费永俊 & 南方红豆杉表型多样性及变异 \\
\hline & & & $/ \mathrm{VU}$ & & \\
\hline \multirow[t]{2}{*}{ Taxus mairei } & 南方红豆杉 & I & 易危 & 廖文波 & 南方红豆杉不同居群遗传多样性的 RAPD 研究 \\
\hline & & & /VU & & \\
\hline \multirow[t]{2}{*}{ Taxus mairei } & 南方红豆杉 & I & 易危 & 任嘉红 & 南方红豆杉从枝菌根( AM) 的研究 \\
\hline & & & $/ \mathrm{VU}$ & & \\
\hline \multirow[t]{2}{*}{ Taxus mairei } & 南方红豆杉 & I & 易危 & 彭峰 & 南方红豆杉的 ISSR 遗传多样性分析 \\
\hline & & & /VU & & \\
\hline \multirow[t]{2}{*}{ Taxus mairei } & 南方红豆杉 & I & 易危 & 鲁长虎 & 南方红豆杉的天然更新格局及食果鸟类对其种子的传播 \\
\hline & & & /VU & & \\
\hline \multirow[t]{2}{*}{ Taxus mairei } & 南方红豆杉 & I & 易危 & 谢春平 & 南方红豆杉地理分布与保护建议 \\
\hline & & & /VU & & \\
\hline \multirow[t]{2}{*}{ Taxus mairei } & 南方红豆杉 & I & 易危 & 费永俊 & 南方红豆杉冠层不同部位的光合生理研究 \\
\hline & & & /VU & & \\
\hline \multirow[t]{2}{*}{ Taxus mairei } & 南方红豆杉 & I & 易危 & 张小平 & 南方红豆杉活性成分含量差异分析及其与生态因子的关系研究 \\
\hline & & & /VU & & \\
\hline \multirow[t]{2}{*}{ Taxus mairei } & 南方红豆杉 & I & 易危 & 谈锋 & 南方红豆杉抗寒性的变化与内源激素的关系 \\
\hline & & & /VU & & \\
\hline
\end{tabular}


顾垒，闻丞，罗玫，王吴，吕植. 中国最受关注濒危物种保护现状快速评价的新方法探讨. 生物多样性，2015，23(5)：583-590. http://www. biodiversity-science. net/CN/article/downloadArticleFile. do?attachType=PDF\&id=10075

\begin{tabular}{|c|c|c|c|c|c|}
\hline Taxus mairei & 南方红豆杉 & I & $\begin{array}{l}\text { 易危 } \\
\text { /VU }\end{array}$ & 谢吉容 & 南方红豆杉抗寒性生理指标的主分量分析 \\
\hline Taxus mairei & 南方红豆杉 & I & $\begin{array}{l}\text { 易危 } \\
\text { /VU }\end{array}$ & 黄丽春 & 南方红豆杉离体肧培养诱导不定芽研究 \\
\hline Taxus mairei & 南方红豆杉 & I & $\begin{array}{l}\text { 易危 } \\
\text { /VU }\end{array}$ & 张雪梅 & 南方红豆杉谱系地理学研究 \\
\hline Taxus mairei & 南方红豆杉 & I & $\begin{array}{l}\text { 易危 } \\
\text { /VU }\end{array}$ & 贺善安 & 南方红豆杉迁地保护小种群动态的研究 \\
\hline Taxus mairei & 南方红豆杉 & I & $\begin{array}{l}\text { 易危 } \\
\text { /VU }\end{array}$ & 张光富 & 南方红豆杉迁地保护种群的点格局分析 \\
\hline Taxus mairei & 南方红豆杉 & I & $\begin{array}{l}\text { 易危 } \\
\text { /VU }\end{array}$ & 夏金鍂 & 南方红豆杉群落物种的多样性 \\
\hline Taxus mairei & 南方红豆杉 & I & $\begin{array}{l}\text { 易危 } \\
\text { /VU }\end{array}$ & 茹文明 & 南方红豆杉群落种间关系的数量分析 \\
\hline Taxus mairei & 南方红豆杉 & I & $\begin{array}{l}\text { 易危 } \\
\text { /VU }\end{array}$ & 陈立新 & 南方红豆杉人工授粉与雌雄同株现象研究 \\
\hline Taxus mairei & 南方红豆杉 & I & $\begin{array}{l}\text { 易危 } \\
\text { /VU }\end{array}$ & 祖元刚 & 南方红豆杉生长发育及其紫杉醇含量与环境因子的关系 \\
\hline Taxus mairei & 南方红豆杉 & I & 易危 & 温学军 & 南方红豆杉生长特性影响条件研究 \\
\hline
\end{tabular}


顾垒，闻丞，罗玫，王吴，吕植. 中国最受关注濒危物种保护现状快速评价的新方法探讨. 生物多样性，2015，23(5)：583-590. http://www. biodiversity-science. net/CN/article/downloadArticleFile. do?attachType=PDF\&id=10075

\begin{tabular}{|c|c|c|c|c|c|}
\hline & & & $/ \mathrm{VU}$ & & \\
\hline \multirow[t]{2}{*}{ Taxus mairei } & 南方红豆杉 & I & 易危 & 郭文硕 & 南方红豆杉炭疽病病原鉴定及其生物学特性 \\
\hline & & & $/ \mathrm{VU}$ & & \\
\hline \multirow[t]{2}{*}{ Taxus mairei } & 南方红豆杉 & I & 易危 & 罗文训 & 南方红豆杉天然林群落结构特征研究 \\
\hline & & & /VU & & \\
\hline \multirow[t]{2}{*}{ Taxus mairei } & 南方红豆杉 & I & 易危 & 朱锦森 & 南方红豆杉天然群落种子雨_土壤种子库及种群年龄结构特征的研究 \\
\hline & & & $/ \mathrm{VU}$ & & \\
\hline \multirow[t]{2}{*}{ Taxus mairei } & 南方红豆杉 & I & 易危 & 岳红娟 & 南方红豆杉土壤种子库特征初探 \\
\hline & & & /VU & & \\
\hline \multirow[t]{2}{*}{ Taxus mairei } & 南方红豆杉 & I & 易危 & 李先琨 & 南方红豆杉无性系种群结构和动态研究 \\
\hline & & & /VU & & \\
\hline \multirow[t]{2}{*}{ Taxus mairei } & 南方红豆杉 & I & 易危 & 王刚 & 南方红豆杉细胞紫杉醇代谢调节的研究 \\
\hline & & & /VU & & \\
\hline \multirow[t]{2}{*}{ Taxus mairei } & 南方红豆杉 & I & 易危 & 费永俊 & 南方红豆杉响应不同传粉式样的结实表现 \\
\hline & & & /VU & & \\
\hline \multirow[t]{2}{*}{ Taxus mairei } & 南方红豆杉 & I & 易危 & 元英进 & 南方红豆杉悬浮培养细胞调亡的组织学定位及与细胞分化的关系初探 \\
\hline & & & /VU & & \\
\hline \multirow[t]{2}{*}{ Taxus mairei } & 南方红豆杉 & I & 易危 & 欧建德 & 南方红豆杉叶片性状的遗传变异及相关性研究 \\
\hline & & & /VU & & \\
\hline
\end{tabular}


顾垒，闻丞，罗玫，王吴，吕植. 中国最受关注濒危物种保护现状快速评价的新方法探讨. 生物多样性，2015，23(5)：583-590. http://www. biodiversity-science. net/CN/article/downloadArticleFile. do?attachType=PDF\&id=10075

\begin{tabular}{|c|c|c|c|c|c|}
\hline Taxus mairei & 南方红豆杉 & I & $\begin{array}{l}\text { 易危 } \\
\text { /VU }\end{array}$ & 吴晓明 & 南方红豆杉幼树人工授粉技术研究 \\
\hline Taxus mairei & 南方红豆杉 & I & $\begin{array}{l}\text { 易危 } \\
\text { /VU }\end{array}$ & 郑郁善 & 南方红豆杉愈伤组织培养研究 \\
\hline Taxus mairei & 南方红豆杉 & I & $\begin{array}{l}\text { 易危 } \\
\text { /VU }\end{array}$ & 何水林 & 南方红豆杉愈伤组织诱导和继代培养体系的建立 \\
\hline Taxus mairei & 南方红豆杉 & I & $\begin{array}{l}\text { 易危 } \\
\text { /VU }\end{array}$ & 王德强 & 南方红豆杉愈伤组织诱导研究 \\
\hline Taxus mairei & 南方红豆杉 & I & $\begin{array}{l}\text { 易危 } \\
\text { /VU }\end{array}$ & 胡胜华 & 南方红豆杉在浙江丽水的自然分布与评价 \\
\hline Taxus mairei & 南方红豆杉 & I & $\begin{array}{l}\text { 易危 } \\
\text { /VU }\end{array}$ & 张小平 & 南方红豆杉种群生态学与种质资源评估 \\
\hline Taxus mairei & 南方红豆杉 & I & $\begin{array}{l}\text { 易危 } \\
\text { /VU }\end{array}$ & 周志春 & 南方红豆杉种源遗传多样性和遗传分化 \\
\hline Taxus mairei & 南方红豆杉 & I & $\begin{array}{l}\text { 易危 } \\
\text { /VU }\end{array}$ & 丁桂生 & 南方红豆杉种源遗传多样性和遗传分化 \\
\hline Taxus mairei & 南方红豆杉 & I & $\begin{array}{l}\text { 易危 } \\
\text { /VU }\end{array}$ & 黄儒珠 & 南方红豆杉种子的化学成分分析 \\
\hline Taxus mairei & 南方红豆杉 & I & 易危 & 郭惠红 & 南方红豆杉种子发芽抑制物质的初步研究 \\
\hline
\end{tabular}


顾垒，闻丞，罗玫，王吴，吕植. 中国最受关注濒危物种保护现状快速评价的新方法探讨. 生物多样性，2015，23(5)：583-590. http://www. biodiversity-science. net/CN/article/downloadArticleFile. do?attachType=PDF\&id=10075

\begin{tabular}{|c|c|c|c|c|c|}
\hline & & & $/ \mathrm{VU}$ & & \\
\hline \multirow[t]{2}{*}{ Taxus mairei } & 南方红豆杉 & I & 易危 & 张志权 & 南方红豆杉种子萌发生物学研究 \\
\hline & & & $/ \mathrm{VU}$ & & \\
\hline \multirow[t]{2}{*}{ Taxus mairei } & 南方红豆杉 & I & 易危 & 高捍东 & 南方红豆杉种子胚乳中发芽抑制物质的活性 \\
\hline & & & /VU & & \\
\hline \multirow[t]{2}{*}{ Taxus mairei } & 南方红豆杉 & I & 易危 & 高捍东 & 南方红豆杉种子生物学特性研究 \\
\hline & & & /VU & & \\
\hline \multirow[t]{2}{*}{ Taxus mairei } & 南方红豆杉 & I & 易危 & 高捍东 & 南方红豆杉种子休眠机理的研究 \\
\hline & & & /VU & & \\
\hline \multirow[t]{2}{*}{ Taxus mairei } & 南方红豆杉 & I & 易危 & 郭惠红 & 南方红豆杉种子休眠机理及催芽技术的研究 \\
\hline & & & $/ \mathrm{VU}$ & & \\
\hline \multirow[t]{2}{*}{ Taxus mairei } & 南方红豆杉 & I & 易危 & 郭惠红 & 南方红豆杉种子休眠解除过程中的生理生化特性 \\
\hline & & & /VU & & \\
\hline \multirow[t]{2}{*}{ Taxus mairei } & 南方红豆杉 & I & 易危 & 高捍东 & 南方红豆杉种子中发芽抑制物的研究 \\
\hline & & & /VU & & \\
\hline \multirow[t]{2}{*}{ Taxus mairei } & 南方红豆杉 & I & 易危 & 黎锡光 & 南岭秤架南方红豆杉资源的调查研究 \\
\hline & & & /VU & & \\
\hline \multirow[t]{2}{*}{ Taxus mairei } & 南方红豆杉 & I & 易危 & 徐刚标 & 南岭山地南方红豆杉的资源现状及其分布特点 \\
\hline & & & /VU & & \\
\hline
\end{tabular}


顾垒，闻丞，罗玫，王吴，吕植. 中国最受关注濒危物种保护现状快速评价的新方法探讨. 生物多样性，2015，23(5)：583-590. http://www biodiversity-science. net/CN/article/downloadArticleFile. do?attachType=PDF\&id=10075

\begin{tabular}{|c|c|c|c|c|c|}
\hline Taxus mairei & 南方红豆杉 & I & $\begin{array}{l}\text { 易危 } \\
\text { /VU }\end{array}$ & 鲁长虎 & 鸟类对南方红豆杉种子的取食与搬运 \\
\hline Taxus mairei & 南方红豆杉 & I & $\begin{array}{l}\text { 易危 } \\
\text { /VU }\end{array}$ & 熊耀康 & 破除南方红豆杉种子休眠方法的研究 \\
\hline Taxus mairei & 南方红豆杉 & I & $\begin{array}{l}\text { 易危 } \\
\text { /VU }\end{array}$ & 潘水年 & 庆元县南方红豆杉濒危原因及保护对策 \\
\hline Taxus mairei & 南方红豆杉 & I & $\begin{array}{l}\text { 易危 } \\
\text { /VU }\end{array}$ & 何平 & 人类干扰和竹类侵扰下的四面山南方红豆杉群落物种多样性研究 \\
\hline Taxus mairei & 南方红豆杉 & I & $\begin{array}{l}\text { 易危 } \\
\text { /VU }\end{array}$ & 李学东 & 山西陵川的南方红豆杉(Taxus chinensis var. mairei) 年轮特征的初步研究 \\
\hline Taxus mairei & 南方红豆杉 & I & $\begin{array}{l}\text { 易危 } \\
\text { /VU }\end{array}$ & 张桂萍 & 山西蟒河南方红豆杉群落和种群结构研究 \\
\hline Taxus mairei & 南方红豆杉 & I & $\begin{array}{l}\text { 易危 } \\
\text { /VU }\end{array}$ & 茹文明 & 山西蟒河自然保护区南方红豆杉林的调查研究 \\
\hline Taxus mairei & 南方红豆杉 & I & $\begin{array}{l}\text { 易危 } \\
/ \mathrm{VU}\end{array}$ & 张金屯 & 山西南方红豆杉分布区种子植物区系分析 \\
\hline Taxus mairei & 南方红豆杉 & I & $\begin{array}{l}\text { 易危 } \\
\text { /VU }\end{array}$ & 苏晋伙 & 杉木林下南方红豆杉初期生长分析 \\
\hline Taxus mairei & 南方红豆杉 & I & 易危 & 傅松玲 & 水分胁迫对南方红豆杉幼苗生长及生理特性的影响 \\
\hline
\end{tabular}


顾垒，闻丞，罗玫，王吴，吕植. 中国最受关注濒危物种保护现状快速评价的新方法探讨. 生物多样性，2015，23(5)：583-590. http://www. biodiversity-science. net/CN/article/downloadArticleFile. do?attachType=PDF\&id=10075

\begin{tabular}{|c|c|c|c|c|c|}
\hline & & & /VU & & \\
\hline \multirow[t]{2}{*}{ Taxus mairei } & 南方红豆杉 & I & 易危 & 鲁长虎 & 天目山地区南方红豆杉种子命运的研究 \\
\hline & & & $/ \mathrm{VU}$ & & \\
\hline \multirow[t]{2}{*}{ Taxus mairei } & 南方红豆杉 & I & 易危 & 张小平 & 皖南山区南方红豆杉种群不同龄级立木的点格局分析 \\
\hline & & & $/ \mathrm{VU}$ & & \\
\hline \multirow[t]{2}{*}{ Taxus mairei } & 南方红豆杉 & I & 易危 & 孙启武 & 皖南山区南方红豆杉种群动态研究 \\
\hline & & & /VU & & \\
\hline \multirow[t]{2}{*}{ Taxus mairei } & 南方红豆杉 & I & 易危 & 鲁长虎 & 皖南仙寓山南方红豆杉天然更新研究 \\
\hline & & & /VU & & \\
\hline \multirow[t]{2}{*}{ Taxus mairei } & 南方红豆杉 & I & 易危 & 高山林 & 我国境内几种红豆杉的 RAPD 分析和染色体鉴定 \\
\hline & & & /VU & & \\
\hline \multirow[t]{2}{*}{ Taxus mairei } & 南方红豆杉 & I & 易危 & 谢再成 & 武华山南方红豆杉资源分布现状及利用对策 \\
\hline & & & /VU & & \\
\hline \multirow[t]{2}{*}{ Taxus mairei } & 南方红豆杉 & I & 易危 & 陈绍林 & 星斗山自然保护区南方红豆杉群落的结构特征研究 \\
\hline & & & /VU & & \\
\hline \multirow[t]{2}{*}{ Taxus mairei } & 南方红豆杉 & I & 易危 & 檀庆忠 & 永泰扛轿山天然南方红豆杉群落结构的研究 \\
\hline & & & /VU & & \\
\hline \multirow[t]{2}{*}{ Taxus mairei } & 南方红豆杉 & I & 易危 & 梁士楚 & 元宝山南方红豆杉的解剖结构及其环境适应性 \\
\hline & & & /VU & & \\
\hline
\end{tabular}


顾垒，闻丞，罗玫，王吴，吕植. 中国最受关注濒危物种保护现状快速评价的新方法探讨. 生物多样性，2015，23(5)：583-590. http://www biodiversity-science. net/CN/article/downloadArticleFile. do?attachType=PDF\&id=10075

\begin{tabular}{|c|c|c|c|c|c|}
\hline Taxus mairei & 南方红豆杉 & I & $\begin{array}{l}\text { 易危 } \\
\text { /VU }\end{array}$ & 李先琨 & 元宝山南方红豆杉的群落及种群结构特征 \\
\hline Taxus mairei & 南方红豆杉 & I & $\begin{array}{l}\text { 易危 } \\
\text { /VU }\end{array}$ & 李先琨 & 元宝山南方红豆杉克隆种群分布格局的分形特征 \\
\hline Taxus mairei & 南方红豆杉 & I & $\begin{array}{l}\text { 易危 } \\
\text { /VU }\end{array}$ & 向悟生 & 元宝山南方红豆杉克隆种群生长型研究 \\
\hline Taxus mairei & 南方红豆杉 & I & $\begin{array}{l}\text { 易危 } \\
\text { /VU }\end{array}$ & 李先琨 & 元宝山南方红豆杉种群分布格局及动态 \\
\hline Taxus mairei & 南方红豆杉 & I & $\begin{array}{l}\text { 易危 } \\
\text { /VU }\end{array}$ & 黄玉清 & 元宝山南方红豆杉种群结构一 - II 、高度结构 \\
\hline Taxus mairei & 南方红豆杉 & I & $\begin{array}{l}\text { 易危 } \\
\text { /VU }\end{array}$ & 廖文波 & 粤北南方红豆杉的群落类型及物候与繁殖生物学特性 \\
\hline Taxus mairei & 南方红豆杉 & I & $\begin{array}{l}\text { 易危 } \\
\text { /VU }\end{array}$ & 伍建军 & 粤北南方红豆杉植物群落的物种多样性和种群格局 \\
\hline Taxus mairei & 南方红豆杉 & I & $\begin{array}{l}\text { 易危 } \\
\text { /VU }\end{array}$ & 廖文波 & 粤北南方红豆杉植物群落的研究 \\
\hline Taxus mairei & 南方红豆杉 & I & $\begin{array}{l}\text { 易危 } \\
\text { /VU }\end{array}$ & 谈锋 & 在自然降温过程中南方红豆杉抗寒性的变化及其适应性的研究 \\
\hline Taxus mairei & 南方红豆杉 & I & 易危 & 全川 & 遮光对南方红豆杉生长及紫杉醇含量的影响 \\
\hline
\end{tabular}


顾垒，闻丞，罗玫，王吴，吕植. 中国最受关注濒危物种保护现状快速评价的新方法探讨. 生物多样性，2015，23(5)：583-590. http://www biodiversity-science. net/CN/article/downloadArticleFile. do?attachType=PDF\&id=10075

\begin{tabular}{|c|c|c|c|c|c|}
\hline & & & $/ \mathrm{VU}$ & & \\
\hline \multirow[t]{2}{*}{ Taxus mairei } & 南方红豆杉 & I & 易危 & 祖元刚 & 遮荫对南方红豆杉光合特性及生活史型影响 \\
\hline & & & /VU & & \\
\hline \multirow[t]{2}{*}{ Taxus mairei } & 南方红豆杉 & I & 易危 & 朱志杰 & 浙江省莲都区南方红豆杉自然分布情况与保护对策 \\
\hline & & & /VU & & \\
\hline \multirow[t]{2}{*}{ Taxus mairei } & 南方红豆杉 & I & 易危 & 俞美星 & 浙江省仙居县南方红豆杉自然分布情况与人工繁育技术探讨 \\
\hline & & & /VU & & \\
\hline \multirow[t]{2}{*}{ Taxus mairei } & 南方红豆杉 & I & 易危 & 洪伟 & 珍稀濒危植物南方红豆杉种群数量特征的研究 \\
\hline & & & $/ \mathrm{VU}$ & & \\
\hline \multirow[t]{2}{*}{ Taxus mairei } & 南方红豆杉 & I & 易危 & 张尚炬 & 珍稀植物南方红豆杉群落物种- 多度关系 \\
\hline & & & /VU & & \\
\hline \multirow[t]{2}{*}{ Taxus mairei } & 南方红豆杉 & I & 易危 & 曾贤辉 & 竹类侵扰下的四面山南方红豆杉群落物种多样性研究 \\
\hline & & & /VU & & \\
\hline \multirow[t]{2}{*}{ Taxus wallichiana } & 西藏红豆杉 & I & 濒危 & De-Quan Zhang & Genetic diversity and population structure of the endangered conifer Taxus wallichiana var. \\
\hline & & & /EN & & mairei (Taxaceae) revealed by Simple Sequence Repeat (SSR) markers \\
\hline \multirow[t]{2}{*}{ Taxus wallichiana } & 西藏红豆杉 & I & 濒危 & Li De-Zhu & High variation and strong phylogeographic pattern among cpDNA haplotypes in Taxus \\
\hline & & & /EN & & wallichiana (Taxaceae) in China and North Vietnam \\
\hline \multirow[t]{2}{*}{ Taxus wallichiana } & 西藏红豆杉 & I & 濒危 & YING-JUAN SU & Microsatellite Loci for an Old Rare Species, Pseudotaxus chienii, and Transferability in Taxus \\
\hline & & & /EN & & wallichiana var. mairei (Taxaceae) \\
\hline
\end{tabular}


顾垒，闻丞，罗玫，王吴，吕植. 中国最受关注濒危物种保护现状快速评价的新方法探讨. 生物多样性，2015，23(5)：583-590. http://www. biodiversity-science. net/CN/article/downloadArticleFile. do?attachType=PDF\&id=10075

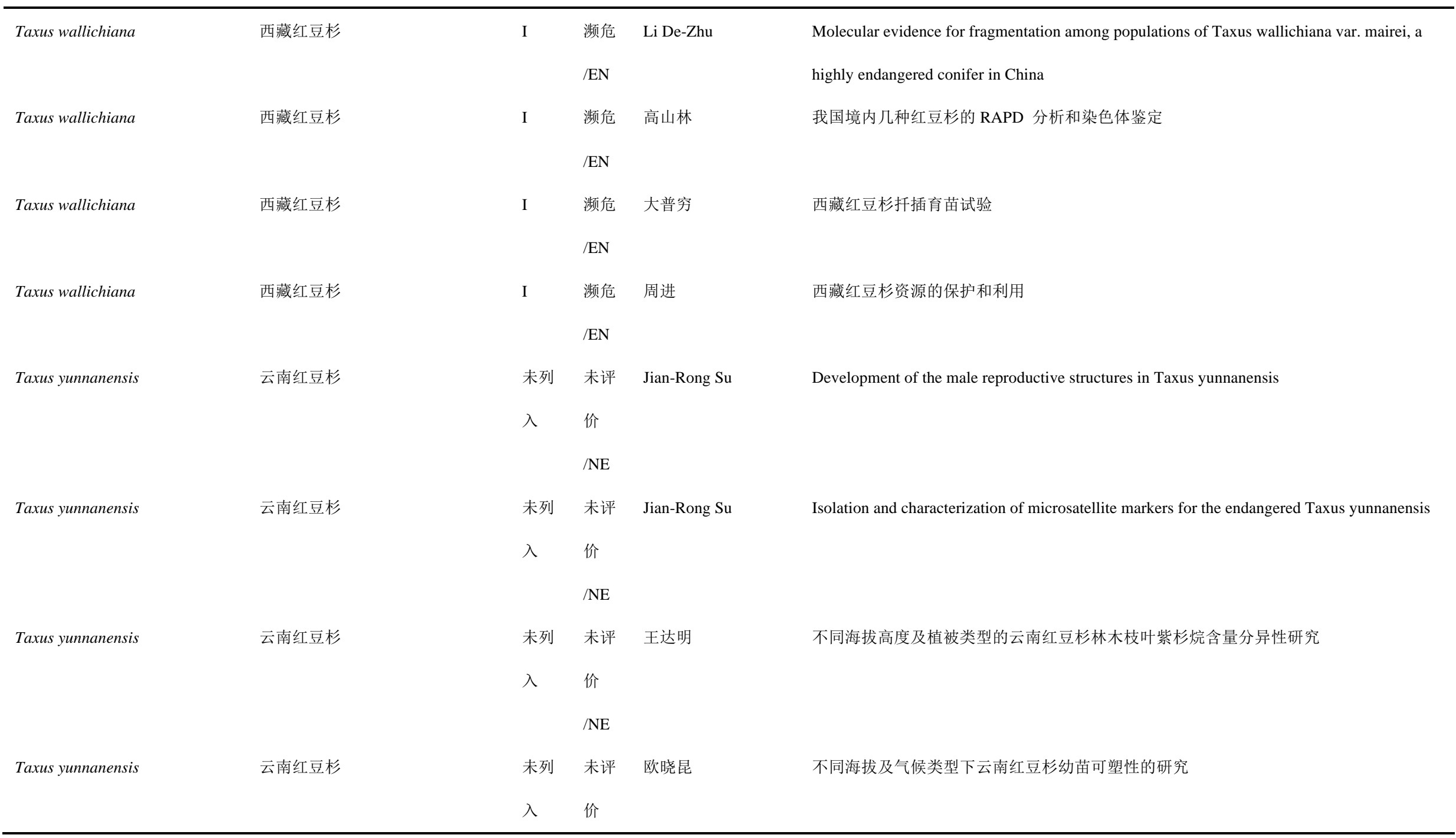


顾垒，闻丞，罗玫，王吴，吕植. 中国最受关注濒危物种保护现状快速评价的新方法探讨. 生物多样性，2015，23(5)：583-590. http://www. biodiversity-science. net/CN/article/downloadArticleFile. do?attachType=PDF\&id=10075

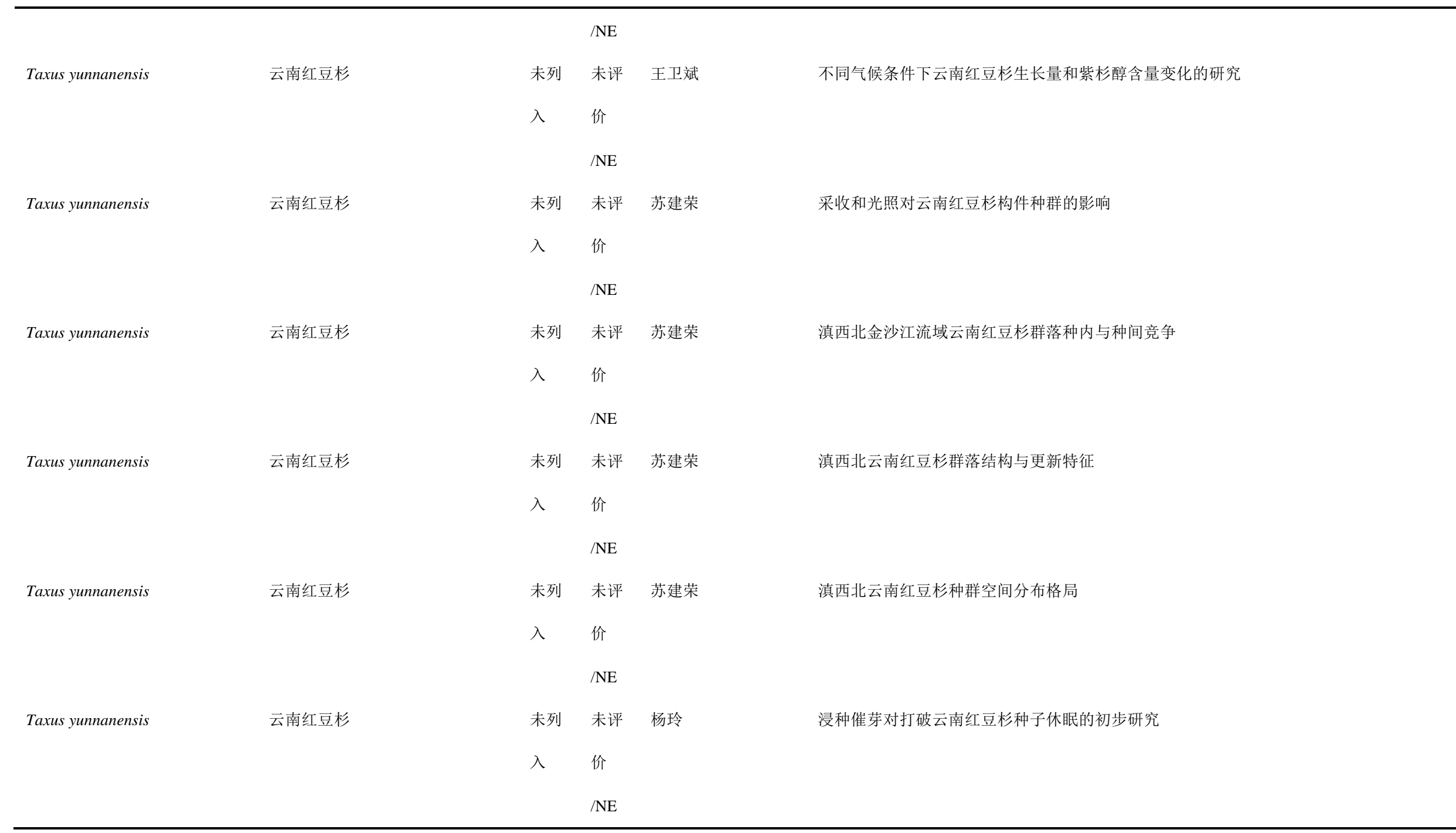


顾垒，闻丞，罗玫，王吴，吕植. 中国最受关注濒危物种保护现状快速评价的新方法探讨. 生物多样性，2015，23(5)：583-590. http://www. biodiversity-science. net/CN/article/downloadArticleFile. do?attachType=PDF\&id=10075

\begin{tabular}{|c|c|c|c|c|c|}
\hline \multirow[t]{2}{*}{ Taxus yunnanensis } & 云南红豆杉 & 未列 & 未评 & 郑法新 & 丽江塔城地区云南红豆杉内生真菌的多样性研究 \\
\hline & & 入 & $\begin{array}{l}\text { 价 } \\
\text { /NE }\end{array}$ & & \\
\hline \multirow[t]{3}{*}{ Taxus yunnanensis } & 云南红豆杉 & 未列 & 未评 & 陈永勤 & 前体物质和化学诱导子对云南红豆杉细胞生长和产生紫杉醇的影响 \\
\hline & & 入 & 价 & & \\
\hline & & & $/ \mathrm{NE}$ & & \\
\hline \multirow[t]{3}{*}{ Taxus yunnanensis } & 云南红豆杉 & 未列 & 未评 & 蒋会仙 & 四川木里县天然云南红豆杉复壮可行性研究 \\
\hline & & 入 & 价 & & \\
\hline & & & $/ \mathrm{NE}$ & & \\
\hline \multirow[t]{3}{*}{ Taxus yunnanensis } & 云南红豆杉 & 未列 & 未评 & 王卫斌 & 天然云南红豆杉林木及其派生扞插苗枝叶紫杉烷含量性状的遗传分析 \\
\hline & & 入 & 价 & & \\
\hline & & & $/ \mathrm{NE}$ & & \\
\hline \multirow[t]{3}{*}{ Taxus yunnanensis } & 云南红豆杉 & 未列 & 未评 & 高山林 & 我国境内几种红豆杉的 RAPD 分析和染色体鉴定 \\
\hline & & 入 & 价 & & \\
\hline & & & $/ \mathrm{NE}$ & & \\
\hline \multirow[t]{3}{*}{ Taxus yunnanensis } & 云南红豆杉 & 未列 & 未评 & 陈毅坚 & 云南红豆杉(Taxus Yunnanensis)皮下真菌类群初步研究 \\
\hline & & 入 & 价 & & \\
\hline & & & $/ \mathrm{NE}$ & & \\
\hline Taxus yunnanensis & 云南红豆杉 & 未列 & 未评 & 苏建荣 & 云南红豆杉传粉生物学研究 \\
\hline
\end{tabular}


顾垒，闻丞，罗玫，王吴，吕植. 中国最受关注濒危物种保护现状快速评价的新方法探讨．生物多样性，2015，23(5)：583-590。 http://www. biodiversity-science. net/CN/article/downloadArticleFile. do?attachType=PDF\&id=10075

\begin{tabular}{|c|c|c|c|c|c|}
\hline & & $\lambda$ & 价 & & \\
\hline Taxus yunnanensis & 云南红豆杉 & $\begin{array}{l}\text { 未列 } \\
\text { 入 }\end{array}$ & $\begin{array}{l}/ \mathrm{NE} \\
\text { 未评 } \\
\text { 价 }\end{array}$ & 李莲芳 & 云南红豆杉的濒危成因剖析 \\
\hline Taxus yunnanensis & 云南红豆杉 & $\begin{array}{l}\text { 未列 } \\
\text { 入 }\end{array}$ & $\begin{array}{l}\text { /NE } \\
\text { 未评 } \\
\text { 价 }\end{array}$ & 苏建荣 & 云南红豆杉的地理分布与气候关系 \\
\hline Taxus yunnanensis & 云南红豆杉 & $\begin{array}{l}\text { 未列 } \\
\text { 入 }\end{array}$ & $\begin{array}{l}/ \mathrm{NE} \\
\text { 未评 } \\
\text { 价 }\end{array}$ & 王卫斌 & 云南红豆杉的生物学与生态学特性 \\
\hline Taxus yunnanensis & 云南红豆杉 & $\begin{array}{l}\text { 未列 } \\
\text { 入 }\end{array}$ & $\begin{array}{l}\text { /NE } \\
\text { 未评 } \\
\text { 价 }\end{array}$ & 陈少瑜 & 云南红豆杉居群的等位酶分析方法 \\
\hline Taxus yunnanensis & 云南红豆杉 & $\begin{array}{l}\text { 未列 } \\
\text { 入 }\end{array}$ & $\begin{array}{l}\text { /NE } \\
\text { 未评 } \\
\text { 价 }\end{array}$ & 甘烦远 & 云南红豆杉离体胚的培养 \\
\hline Taxus yunnanensis & 云南红豆杉 & $\begin{array}{l}\text { 未列 } \\
\text { 入 }\end{array}$ & $\begin{array}{l}\text { /NE } \\
\text { 未评 } \\
\text { 价 }\end{array}$ & 郑法新 & 云南红豆杉内生菌的分离及拮抗植物病害菌的篮选 \\
\hline
\end{tabular}


顾垒，闻丞，罗玫，王吴，吕植. 中国最受关注濒危物种保护现状快速评价的新方法探讨. 生物多样性，2015，23(5)：583-590. http://www. biodiversity-science. net/CN/article/downloadArticleFile. do?attachType=PDF\&id=10075

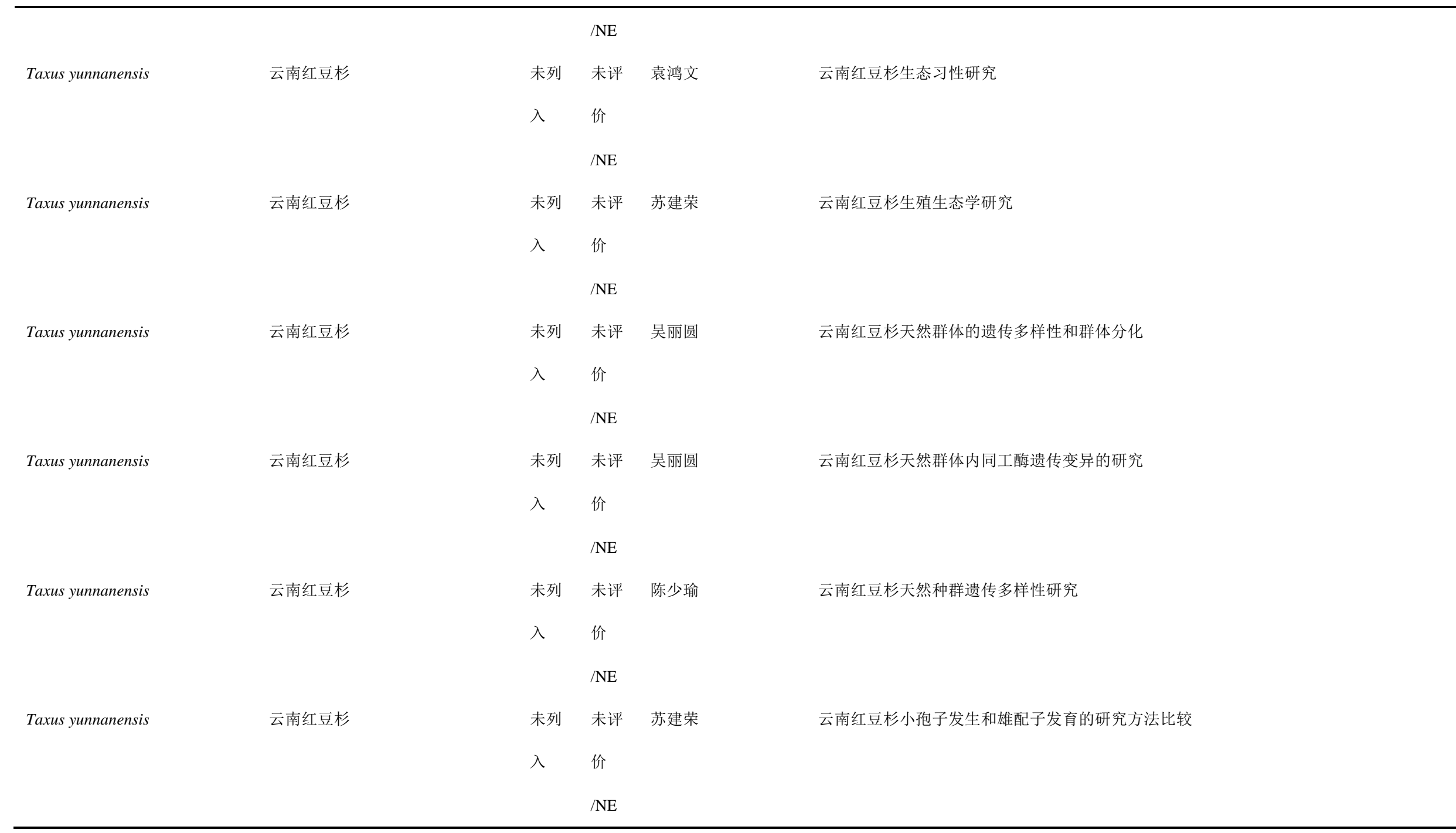


顾垒，闻丞，罗玫，王吴，吕植. 中国最受关注濒危物种保护现状快速评价的新方法探讨. 生物多样性，2015，23(5)：583-590. http://www. biodiversity-science. net/CN/article/downloadArticleFile. do?attachType=PDF\&id=10075

\begin{tabular}{|c|c|c|c|c|c|}
\hline \multirow[t]{2}{*}{ Taxus yunnanensis } & 云南红豆杉 & 未列 & 未评 & 苏建荣 & 云南红豆杉小孢子叶球和种子的时空分布规律 \\
\hline & & 入 & $\begin{array}{l}\text { 价 } \\
\text { /NE }\end{array}$ & & \\
\hline \multirow[t]{3}{*}{ Taxus yunnanensis } & 云南红豆杉 & 未列 & 未评 & 景跃波 & 云南红豆杉研究综述 \\
\hline & & 入 & 价 & & \\
\hline & & & $/ \mathrm{NE}$ & & \\
\hline \multirow[t]{3}{*}{ Taxus yunnanensis } & 云南红豆杉 & 未列 & 未评 & 苏建荣 & 云南红豆杉种群结构与生命表分析 \\
\hline & & 入 & 价 & & \\
\hline & & & $/ \mathrm{NE}$ & & \\
\hline \multirow[t]{3}{*}{ Taxus yunnanensis } & 云南红豆杉 & 未列 & 未评 & 苏建荣 & 云南红豆杉种群生物学研究 \\
\hline & & 入 & 价 & & \\
\hline & & & $/ \mathrm{NE}$ & & \\
\hline \multirow[t]{3}{*}{ Taxus yunnanensis } & 云南红豆杉 & 未列 & 未评 & 景跃波 & 云南红豆杉种子变温层积的萌发效应研究 \\
\hline & & 入 & 价 & & \\
\hline & & & $/ \mathrm{NE}$ & & \\
\hline \multirow[t]{3}{*}{ Taxus yunnanensis } & 云南红豆杉 & 未列 & 未评 & 苏建荣 & 云南兰坪云南红豆杉种群年龄结构与空间分布格局分析 \\
\hline & & 入 & 价 & & \\
\hline & & & $/ \mathrm{NE}$ & & \\
\hline Taxus yunnanensis & 云南红豆杉 & 未列 & 未评 & 包晴忠 & 云南省红豆杉树种生态特性的比较研究 \\
\hline
\end{tabular}


顾垒，闻丞，罗玫，王吴，吕植. 中国最受关注濒危物种保护现状快速评价的新方法探讨. 生物多样性，2015，23(5)：583-590. http://www. biodiversity-science. net/CN/article/downloadArticleFile. do?attachType=PDF\&id=10075

\begin{tabular}{|c|c|c|c|c|c|}
\hline & & 入 & 价 & & \\
\hline & & & $/ \mathrm{NE}$ & & \\
\hline \multirow[t]{3}{*}{ Testudo horsfieldii } & 四爪陆龟 & I & 未评 & 贾风勤 & 新疆四爪陆龟保护区陆龟洞穴生境特征 \\
\hline & & & 价 & & \\
\hline & & & $/ \mathrm{NE}$ & & \\
\hline Tetracentron sinense & 水青树 & II & $\mathrm{NE}$ & 甘小洪 & 濒危植物水青树结实特性研究 \\
\hline \multirow[t]{3}{*}{ Tetracentron sinense } & 水青树 & 未列 & 未评 & 甘小洪 & 濒危植物水青树结实特性研究 \\
\hline & & 入 & 价 & & \\
\hline & & & $/ \mathrm{NE}$ & & \\
\hline Tetracentron sinense & 水青树 & II & $\mathrm{NE}$ & 甘小洪 & 濒危植物水青树种子的萌发特性研究 \\
\hline \multirow[t]{3}{*}{ Tetracentron sinense } & 水青树 & 未列 & 未评 & 甘小洪 & 濒危植物水青树种子的萌发特性研究 \\
\hline & & 入 & 价 & & \\
\hline & & & $/ \mathrm{NE}$ & & \\
\hline Tetracentron sinense & 水青树 & II & $\mathrm{NE}$ & 甘小洪 & 濒危植物水青树种子的生物学特性 \\
\hline \multirow[t]{3}{*}{ Tetracentron sinense } & 水青树 & 未列 & 未评 & 甘小洪 & 濒危植物水青树种子的生物学特性 \\
\hline & & $\lambda$ & 价 & & \\
\hline & & & $/ \mathrm{NE}$ & & \\
\hline Tetracentron sinense & 水青树 & II & $\mathrm{NE}$ & 熊铁一 & 不同水分条件下水青树种子萌发特性研究 \\
\hline Tetracentron sinense & 水青树 & 未列 & 未评 & 熊铁一 & 不同水分条件下水青树种子萌发特性研究 \\
\hline
\end{tabular}


顾垒，闻丞，罗玫，王吴，吕植. 中国最受关注濒危物种保护现状快速评价的新方法探讨. 生物多样性，2015，23(5)：583-590. http://www. biodiversity-science. net/CN/article/downloadArticleFile. do?attachType=PDF\&id=10075

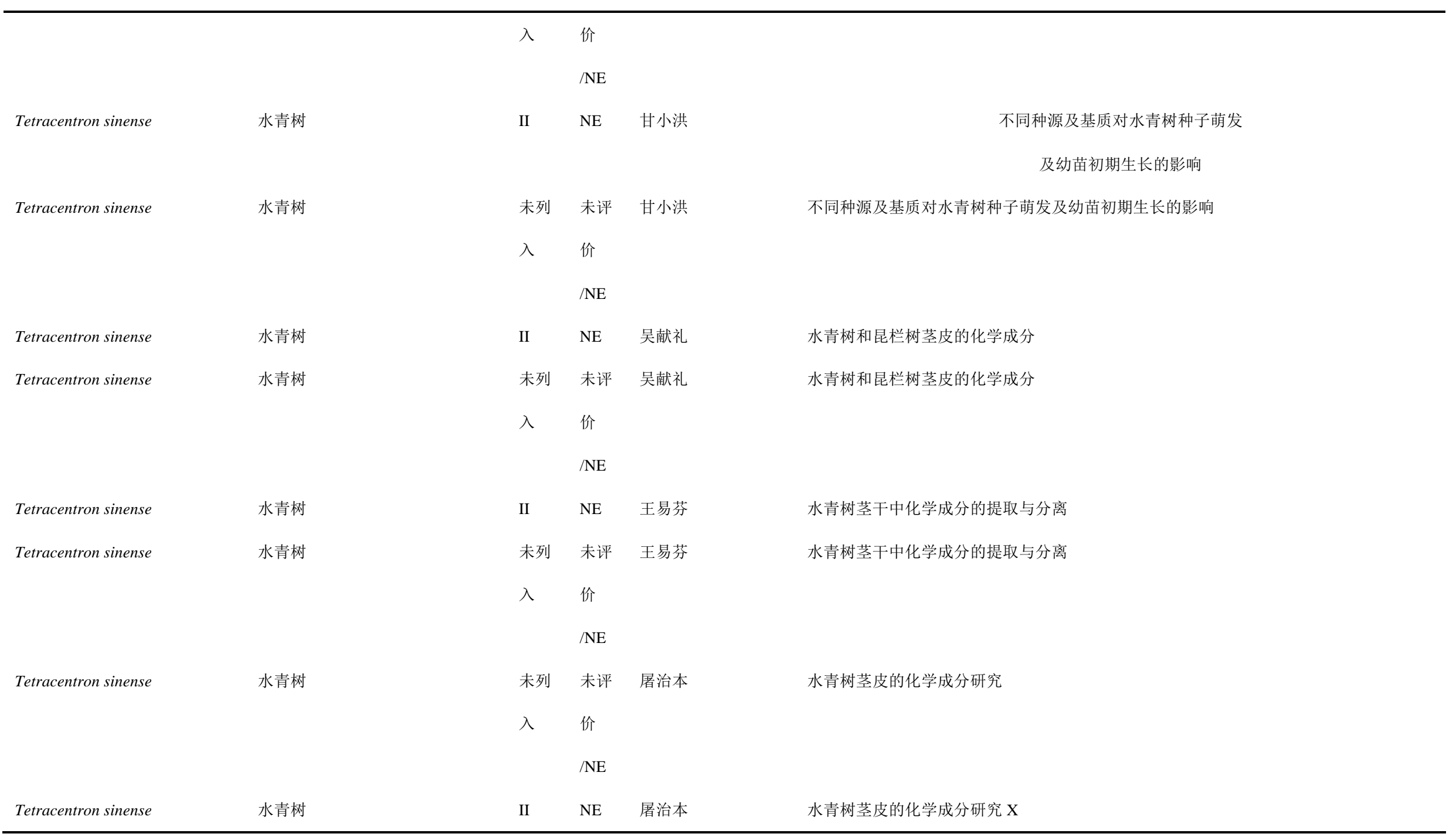


顾垒，闻丞，罗玫，王吴，吕植. 中国最受关注濒危物种保护现状快速评价的新方法探讨. 生物多样性，2015，23(5)：583-590. http://www. biodiversity-science. net/CN/article/downloadArticleFile. do?attachType=PDF\&id=10075

\begin{tabular}{|c|c|c|c|c|c|}
\hline Tetracentron sinense & 水青树 & II & $\mathrm{NE}$ & 周佑勋 & 水青树种子的需光萌发特性 \\
\hline \multirow[t]{3}{*}{ Tetracentron sinense } & 水青树 & 未列 & 未评 & 周佑勋 & 水青树种子的需光萌发特性 \\
\hline & & 入 & 价 & & \\
\hline & & & $/ \mathrm{NE}$ & & \\
\hline Tetracentron sinense & 水青树 & II & $\mathrm{NE}$ & 文晖 & 水青树种子萌发特性及幼苗对光环境的适应 \\
\hline \multirow[t]{3}{*}{ Tetracentron sinense } & 水青树 & 未列 & 未评 & 文晖 & 水青树种子萌发特性及幼苗对光环境的适应 \\
\hline & & 入 & 价 & & \\
\hline & & & $/ \mathrm{NE}$ & & \\
\hline \multirow[t]{3}{*}{ Tetracentron sinense } & 水青树 & 未列 & 未评 & 甘小洪 & 水青树组织培养中无菌苗培养条件的优化 \\
\hline & & 入 & 价 & & \\
\hline & & & $/ \mathrm{NE}$ & & \\
\hline Tetracentron sinense & 水青树 & II & $\mathrm{NE}$ & 甘小洪 & 水青树组织培养中无菌苗培养条件的优化 \\
\hline Tetracentron sinense & 水青树 & II & $\mathrm{NE}$ & 张和民 & 四川卧龙国家级自然保护区水青树生态特性的初步研究 \\
\hline \multirow[t]{3}{*}{ Tetracentron sinense } & 水青树 & 未列 & 未评 & 张和民 & 四川卧龙国家级自然保护区水青树生态特性的初步研究 \\
\hline & & 入 & 价 & & \\
\hline & & & $/ \mathrm{NE}$ & & \\
\hline Tetracentron sinense & 水青树 & II & $\mathrm{NE}$ & 杜 凡 & 珍稀树种水青树群落学特征及其保护研究 \\
\hline \multirow[t]{2}{*}{ Tetracentron sinense } & 水青树 & 未列 & 未评 & 杜凡 & 珍稀树种水青树群落学特征及其保护研究 \\
\hline & & 入 & 价 & & \\
\hline
\end{tabular}


顾垒，闻丞，罗玫，王吴，吕植. 中国最受关注濒危物种保护现状快速评价的新方法探讨. 生物多样性，2015，23(5)：583-590. http://www biodiversity-science. net/CN/article/downloadArticleFile. do?attachType=PDF\&id=10075

\begin{tabular}{|c|c|c|c|c|c|}
\hline \multirow{3}{*}{ Tetrameles nudiflora } & \multirow{3}{*}{ 四树木 } & \multirow{3}{*}{ II } & \multicolumn{2}{|l|}{$/ \mathrm{NE}$} & \multirow{3}{*}{ 不同水分梯度下珍稀植物四数木的光合特性及对变化光强的响应 } \\
\hline & & & $\mathrm{LR} /$ & 邓云 & \\
\hline & & & 无危 & & \\
\hline \multirow{3}{*}{ Thalasseus bernsteini } & \multirow{3}{*}{ 黑嘴端风头燕鸥 } & \multirow{3}{*}{ II } & $/ \mathrm{LC}$ & & \\
\hline & & & 极危 & 秦玉平 & Latest evidence of the existence of the northern flock of the Chinese Crested Tern (Sterna \\
\hline & & & /CR & & bernsteini) \\
\hline \multirow[t]{2}{*}{ Thalasseus bernsteini } & \multirow[t]{2}{*}{ 黑嘴端风头燕鸥 } & II & 极危 & 陈水华 & \multirow[t]{2}{*}{ 浙江非山列岛的黑嘴端风头燕鸥繁殖群调查初报 } \\
\hline & & \multirow{3}{*}{ II } & /CR & & \\
\hline \multirow[t]{2}{*}{ Thalasseus bernsteini } & \multirow[t]{2}{*}{ 黑嘴端风头燕鸥 } & & 极危 & 陈水华 & \multirow[t]{2}{*}{ 中华凤头燕鸥 } \\
\hline & & & /CR & & \\
\hline \multirow[t]{2}{*}{ Thermophis baileyi } & \multirow[t]{2}{*}{ 温泉蛇 } & 未列 & 易危 & S YLVIA H & \multirow[t]{2}{*}{ Evidence of Sex-biased Dispersal in Thermophis baileyi Inferred from Microsatellite Markers } \\
\hline & & 入 & /VU & OFMANN & \\
\hline \multirow[t]{2}{*}{ Thermophis baileyi } & \multirow[t]{2}{*}{ 温泉蛇 } & 未列 & 易危 & S YLVIA H & Population genetic structure and geographic differentiation in the hot spring snake Thermophis \\
\hline & & 入 & /VU & OFMANN & baileyi (Serpentes, Colubridae) Indications for glacial refuges in southern central Tibet \\
\hline \multirow[t]{2}{*}{ Thermophis baileyi } & \multirow[t]{2}{*}{ 温泉蛇 } & 未列 & 易危 & Song HUANG & Tibetan Plateau Relict Snakes of the Genus Thermophis and Their Relationship to New World \\
\hline & & 入 & /VU & & Relict Snakes \\
\hline \multirow[t]{2}{*}{ Thermophis baileyi } & \multirow[t]{2}{*}{ 温泉蛇 } & 未列 & 易危 & 赵尔宓 & What are the closest relatives of the hot-spring snakes (Colubridae, Thermophis), the relict \\
\hline & & 入 & /VU & & species endemic to the Tibetan Plateau \\
\hline Thermophis baileyi & 温泉蛇 & 未列 & 易危 & 赵尔宓 & 青藏高原的世界特有蛇种一一温泉蛇 \\
\hline
\end{tabular}


顾垒，闻丞，罗玫，王吴，吕植. 中国最受关注濒危物种保护现状快速评价的新方法探讨. 生物多样性，2015，23(5)：583-590. http://www. biodiversity-science. net/CN/article/downloadArticleFile. do?attachType=PDF\&id=10075

\begin{tabular}{|c|c|c|c|c|c|}
\hline & & 入 & $/ \mathrm{VU}$ & & \\
\hline \multirow[t]{2}{*}{ Thermophis baileyi } & 温泉蛇 & 未列 & 易危 & 赵尔密 & 西藏特有种温泉蛇在四川理塘县发现 \\
\hline & & $\lambda$ & $/ \mathrm{VU}$ & & \\
\hline \multirow[t]{2}{*}{ Thermophis baileyi } & 温泉蛇 & 未列 & 易危 & 胡晓林 & 西藏温泉蛇的活动规律和栖息地选挥 \\
\hline & & $\lambda$ & $/ \mathrm{VU}$ & & \\
\hline \multirow[t]{2}{*}{ Thermophis baileyi } & 温泉蛇 & 未列 & 易危 & 李键 & 中国特有物种西藏温泉蛇的食性及取食行为 \\
\hline & & 入 & /VU & & \\
\hline \multirow[t]{3}{*}{ Torreya yunnanensis } & 云南榧树 & II & 未评 & 胥辉 & ICP-OES 法测定云南榧树不同部位矿质元素 1 \\
\hline & & & 价 & & \\
\hline & & & $/ \mathrm{NE}$ & & \\
\hline \multirow[t]{2}{*}{ Trachycarpus nana } & 龙棕 & II & 濒危 & 董晓东 & 龙棕有性繁殖的初步研究 \\
\hline & & & $/ \mathrm{EN}$ & & \\
\hline \multirow[t]{2}{*}{ Trachycarpus nana } & 龙棕 & II & 濒危 & 董晓东 & 云南龙棕资源调查及生物学特性的研究 \\
\hline & & & $/ \mathrm{EN}$ & & \\
\hline \multirow[t]{2}{*}{ Trachycarpus nana } & 龙棕 & II & 濒危 & 许小妹 & 珍稀濒危植物龙棕的保护与开发利用 \\
\hline & & & /EN & & \\
\hline \multirow[t]{2}{*}{ Trachypithecus francoisi } & 黑叶猴 & I & 濒危 & Huang Cheng-ming & Activity patterns and their occurrence in day range of francois langur(Trachypithecus francoisi) \\
\hline & & & $/ \mathrm{EN}$ & & in Fusui reserve, Guangxi \\
\hline Trachypithecus francoisi & 黑叶猴 & I & 濒危 & HUANG Chengming & An Attack on Humans by Francois Langur(Trachypithecusfrancoisi)in the Wild \\
\hline
\end{tabular}


顾垒，闻丞，罗玫，王昊，吕植. 中国最受关注濒危物种保护现状快速评价的新方法探讨．生物多样性，2015，23(5)：583-590.

Trachypithecus francoisi

黑叶猴

黑叶猴

Trachypithecus francoisi

Trachypithecus francoisi

黑叶猴

Trachypithecus francoisi

黑叶猴

Trachypithecus francoisi

黑叶猴

Trachypithecus francoisi

黑叶猴

Trachypithecus francoisi

黑叶猴

Trachypithecus francoisi

黑叶猴

Trachypithecus francoisi

/EN

I

濒危 Cheng-Ming

/EN HUANG

I 濒危

/EN Zhaoyuan LI

I

濒危 Fuwen Wei

/EN

I 濒危 GANG HU

/EN

I 濒危 Ping Ding

/EN

$$
\text { 濒危 }
$$

I

濒危 CHENGMING

/EN HUANG

I 濒危 Jiliang Xu
An observation of Francois' Langurs using caves at Mayanghe National Nature Reaerve,

Guizhou, China

Attacks on adult females with infants by non-resident males in the François langur

Comparison of locomtor behaviour between white-headed langurs Trachypithecus

leucocephalus and Francois'langurs T.francoisi in Fusui,China

Diet and Food Choice of Trachypithecus francoisi

Dietary breadth and resource use of François' langur in a seasonal and disturbed habita

Dietary Response of a Group of François' Langur Trachypithecus francoisi in a Fragmented

Habitat in the County of Fusui, China Implications for Conservation

Factors Influencing Interannual and Intersite Variability in the Diet of Trachypithecus francoisi

Feeding Strategy of Francois’ Langur and White-Headed Langur at Fusui, China

Habitat Association and Conservation Implications of Endangered Francois' Langur

(Trachypithecus francoisi) 
顾垒，闻丞，罗玫，王昊，吕植. 中国最受关注濒危物种保护现状快速评价的新方法探讨．生物多样性，2015，23(5)：583-590. http://www. biodiversity-science. net/CN/article/downloadArticleFile. do?attachType=PDF\&id=10075

\begin{tabular}{|c|c|c|c|c|c|}
\hline Trachypithecus francoisi & 黑叶猴 & I & $\begin{array}{l}\text { 濒危 } \\
\text { /EN }\end{array}$ & Chengming HUANG & $\begin{array}{l}\text { Habitat use and locomotion of the François' langur (Trachypithecus francoisi) in limestone } \\
\text { habitats of Nonggang, China }\end{array}$ \\
\hline Trachypithecus francoisi & 黑叶猴 & I & $\begin{array}{l}\text { 濒危 } \\
\text { /EN }\end{array}$ & ZHOU Qihai & $\begin{array}{l}\text { Identification and characterization of microsatellite markers via crossspecies amplification from } \\
\text { Francois’ langur (Trachypithecus francoisi) }\end{array}$ \\
\hline Trachypithecus francoisi & 黑叶猴 & I & $\begin{array}{l}\text { 濒危 } \\
\text { /EN }\end{array}$ & Fuwen WEI & $\begin{array}{l}\text { Ranging behavior of the François’ langur (Trachypithecus francoisi) in limestone habitats of } \\
\text { Nonggang, China }\end{array}$ \\
\hline Trachypithecus francoisi & 黑叶猴 & I & $\begin{array}{l}\text { 濒危 } \\
\text { /EN }\end{array}$ & Qihai Zhou & $\begin{array}{l}\text { Ranging behavior of the Francois’ langur (Trachypithecus francoisi) in the Fusui Nature } \\
\text { Reserve, China }\end{array}$ \\
\hline Trachypithecus francoisi & 黑叶猴 & I & $\begin{array}{l}\text { 濒危 } \\
\text { /EN }\end{array}$ & Anjun LAN & $\begin{array}{l}\text { Remote Sensing Monitoring and Analysis of Responses of Ma Yang Francois Nature Reserve } \\
\text { to Impoundment of Pengshui Reservoir }\end{array}$ \\
\hline Trachypithecus francoisi & 黑叶猴 & I & $\begin{array}{l}\text { 濒危 } \\
\text { /EN }\end{array}$ & Fuwen Wei & $\begin{array}{l}\text { Seasonal Variation in the Activity Patterns and Time Budgets of Trachypithecus francoisi in the } \\
\text { Nonggang Nature Reserve, China }\end{array}$ \\
\hline Trachypithecus francoisi & 黑叶猴 & I & $\begin{array}{l}\text { 濒危 } \\
\text { /EN }\end{array}$ & Guofa Cui & $\begin{array}{l}\text { Sleeping site selection of Francois’ s langur (Trachypithecus francoisi) in two habitats in } \\
\text { Mayanghe National Nature Reserve,Guizhou, China }\end{array}$ \\
\hline Trachypithecus francoisi & 黑叶猴 & I & $\begin{array}{l}\text { 濒危 } \\
\text { /EN }\end{array}$ & Wei Fuwen & Sleeping Site Use by Trachypithecus francoisi at Nonggang Nature Reserve, China \\
\hline Trachypithecus francoisi & 黑叶猴 & I & $\begin{array}{l}\text { 濒危 } \\
\text { /EN }\end{array}$ & LI You-bang & $\begin{array}{l}\text { Survey on distribution and population of genus Trachypichecus in Longgang nature } \\
\text { reserve,Guangxi }\end{array}$ \\
\hline Trachypithecus francoisi & 黑叶猴 & I & 濒危 & Zhang Minghai & Time budget of daily activity of Francois' langur (Trachypithecus francoisi francoisi) in \\
\hline
\end{tabular}


顾垒，闻丞，罗玫，王吴，吕植. 中国最受关注濒危物种保护现状快速评价的新方法探讨. 生物多样性，2015，23(5)：583-590. http://www biodiversity-science. net/CN/article/downloadArticleFile. do?attachType=PDF\&id=10075

\begin{tabular}{|c|c|c|c|c|c|}
\hline & & & /EN & & disturbance habitat \\
\hline \multirow[t]{2}{*}{ Trachypithecus francoisi } & 黑叶猴 & I & 濒危 & 吴茜 & 白头叶猴和黑叶猴旱季食物的营养成分含量及其对食物选择的影响研究 \\
\hline & & & $/$ EN & & \\
\hline \multirow[t]{2}{*}{ Trachypithecus francoisi } & 黑叶猴 & I & 濒危 & 陶毅明 & 粗纤维对笼养黑叶猴食物选择的影响 \\
\hline & & & /EN & & \\
\hline \multirow[t]{2}{*}{ Trachypithecus francoisi } & 黑叶猴 & I & 濒危 & 胡刚 & 冬季麻阳河黑叶猴的食物营养组分及其对食物选择的影响 \\
\hline & & & /EN & & \\
\hline \multirow[t]{2}{*}{ Trachypithecus francoisi } & 黑叶猴 & I & 濒危 & 金兰梅 & 动物园笼养黑叶猴繁殖行为研究 \\
\hline & & & /EN & & \\
\hline \multirow[t]{2}{*}{ Trachypithecus francoisi } & 黑叶猴 & I & 濒危 & 韦显盛 & 扶绥黑叶猴(Trachypithecus francoisi)的活动时间分配及其对栖息地的利用 \\
\hline & & & /EN & & \\
\hline \multirow[t]{2}{*}{ Trachypithecus francoisi } & 黑叶猴 & I & 濒危 & 李友邦 & 扶绥黑叶猴食物多样性的初步研究 \\
\hline & & & /EN & & \\
\hline \multirow[t]{2}{*}{ Trachypithecus francoisi } & 黑叶猴 & I & 濒危 & 张明海 & 干扰生境下黑叶猴(Trachypithecus francoisi)日活动时间的分配 \\
\hline & & & /EN & & \\
\hline \multirow[t]{2}{*}{ Trachypithecus francoisi } & 黑叶猴 & I & 濒危 & 丁平 & 广西扶绥黑叶猴的主要食源植物及其粗蛋白含量 \\
\hline & & & /EN & & \\
\hline \multirow[t]{2}{*}{ Trachypithecus francoisi } & 黑叶猴 & I & 濒危 & 黄乘明 & 广西扶绥黑叶猴活动节律和日活动时间分配 \\
\hline & & & /EN & & \\
\hline
\end{tabular}


顾垒，闻丞，罗玫，王吴，吕植. 中国最受关注濒危物种保护现状快速评价的新方法探讨. 生物多样性，2015，23(5)：583-590. http://www biodiversity-science. net/CN/article/downloadArticleFile. do?attachType=PDF\&id=10075

\begin{tabular}{|c|c|c|c|c|c|}
\hline Trachypithecus francoisi & 黑叶猴 & I & $\begin{array}{l}\text { 濒危 } \\
\text { /EN }\end{array}$ & 李友邦 & 广西扶绥黑叶猴食物水分含量的研究 \\
\hline Trachypithecus francoisi & 黑叶猴 & I & $\begin{array}{l}\text { 濒危 } \\
\text { /EN }\end{array}$ & 李友邦 & 广西扶绥弄邓黑叶猴种群数量和保护 \\
\hline Trachypithecus francoisi & 黑叶猴 & I & $\begin{array}{l}\text { 濒危 } \\
\text { /EN }\end{array}$ & 李友邦 & 广西扶绥片段化栖息地中黑叶猴的食物选择 \\
\hline Trachypithecus francoisi & 黑叶猴 & I & $\begin{array}{l}\text { 濒危 } \\
\text { /EN }\end{array}$ & 李兆元 & 广西扶绥县黑叶猴的分布和种群数量调查 \\
\hline Trachypithecus francoisi & 黑叶猴 & I & $\begin{array}{l}\text { 濒危 } \\
\text { /EN }\end{array}$ & 朱兵 & 广西黑叶猴(Trachypithecus françoisi)遗传多样性研究 \\
\hline Trachypithecus francoisi & 黑叶猴 & I & $\begin{array}{l}\text { 濒危 } \\
\text { /EN }\end{array}$ & 李友邦 & 广西黑叶猴分布数量和行为生态学初步研究 \\
\hline Trachypithecus francoisi & 黑叶猴 & I & $\begin{array}{l}\text { 濒危 } \\
\text { /EN }\end{array}$ & 黄峥嵘 & 广西黑叶猴线粒体 DNA D-Loop 全序列的克隆与结构分析 \\
\hline Trachypithecus francoisi & 黑叶猴 & I & $\begin{array}{l}\text { 濒危 } \\
\text { /EN }\end{array}$ & 黄乘明 & 广西弄岗黑叶猴的家域和日漫游距离 \\
\hline Trachypithecus francoisi & 黑叶猴 & I & $\begin{array}{l}\text { 濒危 } \\
\text { /EN }\end{array}$ & 周岐海 & 广西弄岗黑叶猴食物的水分含量对食物选择的影响 \\
\hline Trachypithecus francoisi & 黑叶猴 & I & 濒危 & 陆茂新 & 广西弄岗自然保护区黑叶猴的种群动态 \\
\hline
\end{tabular}


顾垒，闻丞，罗玫，王吴，吕植. 中国最受关注濒危物种保护现状快速评价的新方法探讨. 生物多样性，2015，23(5)：583-590. http://www. biodiversity-science. net/CN/article/downloadArticleFile. do?attachType=PDF\&id=10075

\begin{tabular}{|c|c|c|c|c|c|}
\hline & & & /EN & & \\
\hline \multirow[t]{2}{*}{ Trachypithecus francoisi } & 黑叶猴 & I & 濒危 & 罗洪章 & 贵阳黔灵公园动物园笼养黑叶猴的行为观察 \\
\hline & & & $/$ EN & & \\
\hline \multirow[t]{2}{*}{ Trachypithecus francoisi } & 黑叶猴 & I & 濒危 & 罗杨 & 贵州黑叶猴日活动时间的分配 \\
\hline & & & /EN & & \\
\hline \multirow[t]{2}{*}{ Trachypithecus francoisi } & 黑叶猴 & I & 濒危 & 罗杨 & 贵州麻阳河地区黑叶猴的食性观察 \\
\hline & & & /EN & & \\
\hline \multirow[t]{2}{*}{ Trachypithecus francoisi } & 黑叶猴 & I & 濒危 & 胡刚 & 贵州麻阳河地区野生黑叶猴与同域放养山羊冬季食物重叠的初步分析 \\
\hline & & & /EN & & \\
\hline \multirow[t]{2}{*}{ Trachypithecus francoisi } & 黑叶猴 & I & 濒危 & 刘宁 & 贵州麻阳河公路沿线兴建住房对黑叶猴的影响 \\
\hline & & & /EN & & \\
\hline \multirow[t]{2}{*}{ Trachypithecus francoisi } & 黑叶猴 & I & 濒危 & 曾娅杰 & 贵州麻阳河国家级自然保护区黑叶猴栖息地适宜性和保护区最小面积研究 \\
\hline & & & /EN & & \\
\hline \multirow[t]{2}{*}{ Trachypithecus francoisi } & 黑叶猴 & I & 濒危 & 张明海 & 贵州麻阳河国家级自然保护区黑叶猴夜宿地选择的研究 \\
\hline & & & /EN & & \\
\hline \multirow[t]{2}{*}{ Trachypithecus francoisi } & 黑叶猴 & I & 濒危 & 陈正仁 & 贵州麻阳河黑叶猴家域及影响因素初探 \\
\hline & & & /EN & & \\
\hline \multirow[t]{2}{*}{ Trachypithecus francoisi } & 黑叶猴 & I & 濒危 & 胡刚 & 贵州麻阳河黑叶猴秋季主要食物营养分析及对食物选择的影响 \\
\hline & & & /EN & & \\
\hline
\end{tabular}


顾垒，闻丞，罗玫，王吴，吕植. 中国最受关注濒危物种保护现状快速评价的新方法探讨. 生物多样性，2015，23(5)：583-590. http://www biodiversity-science. net/CN/article/downloadArticleFile. do?attachType=PDF\&id=10075

\begin{tabular}{|c|c|c|c|c|c|}
\hline Trachypithecus francoisi & 黑叶猴 & I & $\begin{array}{l}\text { 濒危 } \\
\text { /EN }\end{array}$ & 吴安康 & 贵州麻阳河自然保护区黑叶猴繁殖周期的初步研究 \\
\hline Trachypithecus francoisi & 黑叶猴 & I & $\begin{array}{l}\text { 濒危 } \\
\text { /EN }\end{array}$ & 王双玲 & 贵州麻阳河自然保护区黑叶猴家域和生境特征研究 \\
\hline Trachypithecus francoisi & 黑叶猴 & I & $\begin{array}{l}\text { 濒危 } \\
\text { /EN }\end{array}$ & 周江 & 贵州省黑叶猴生育时间的观察报导 \\
\hline Trachypithecus francoisi & 黑叶猴 & I & $\begin{array}{l}\text { 濒危 } \\
\text { /EN }\end{array}$ & 罗杨 & 贵州沿河麻阳河自然保护区黑叶猴行为研究 \\
\hline Trachypithecus francoisi & 黑叶猴 & I & $\begin{array}{l}\text { 濒危 } \\
\text { /EN }\end{array}$ & 左经会 & 贵州野钟黑叶猴自然保护区种子植物区系研究 \\
\hline Trachypithecus francoisi & 黑叶猴 & I & $\begin{array}{l}\text { 濒危 } \\
\text { /EN }\end{array}$ & 黄乘明 & 国内喀斯特石山叶猴研究专题文献分析 \\
\hline Trachypithecus francoisi & 黑叶猴 & I & $\begin{array}{l}\text { 濒危 } \\
\text { /EN }\end{array}$ & 马强 & 黑叶猴（Trachypithecus francoisi） \\
\hline Trachypithecus francoisi & 黑叶猴 & I & $\begin{array}{l}\text { 濒危 } \\
\text { /EN }\end{array}$ & 周歧海 & 黑叶猴春夏季活动时间分配的初步研究 \\
\hline Trachypithecus francoisi & 黑叶猴 & I & $\begin{array}{l}\text { 濒危 } \\
\text { /EN }\end{array}$ & 周歧海 & 黑叶猴的活动时间分配和笼养状态下理毛行为研究 \\
\hline Trachypithecus francoisi & 黑叶猴 & I & 濒危 & 蔡湘文 & 黑叶猴的受食生物学和营养分析 \\
\hline
\end{tabular}


顾垒，闻丞，罗玫，王吴，吕植. 中国最受关注濒危物种保护现状快速评价的新方法探讨. 生物多样性，2015，23(5)：583-590. http://www. biodiversity-science. net/CN/article/downloadArticleFile. do?attachType=PDF\&id=10075

\begin{tabular}{|c|c|c|c|c|c|}
\hline & & & /EN & & \\
\hline \multirow[t]{2}{*}{ Trachypithecus francoisi } & 黑叶猴 & I & 濒危 & 伍清林 & 黑叶猴的人工饲养环境 \\
\hline & & & $/$ EN & & \\
\hline \multirow[t]{2}{*}{ Trachypithecus francoisi } & 黑叶猴 & I & 濒危 & 何厚能 & 黑叶猴的人工饲养与繁殖 \\
\hline & & & /EN & & \\
\hline \multirow[t]{2}{*}{ Trachypithecus francoisi } & 黑叶猴 & I & 濒危 & 黄乘明 & 黑叶猴对广西扶绥破碎生境的选择和利用 \\
\hline & & & /EN & & \\
\hline \multirow[t]{2}{*}{ Trachypithecus francoisi } & 黑叶猴 & I & 濒危 & 赖茂庆 & 黑叶猴肝脓肿一例 \\
\hline & & & /EN & & \\
\hline \multirow[t]{2}{*}{ Trachypithecus francoisi } & 黑叶猴 & I & 濒危 & 黄乘明 & 黑叶猴活动时间季节性变化 \\
\hline & & & /EN & & \\
\hline \multirow[t]{2}{*}{ Trachypithecus francoisi } & 黑叶猴 & I & 濒危 & 李毅峰 & 黑叶猴截肢一例 \\
\hline & & & /EN & & \\
\hline \multirow[t]{2}{*}{ Trachypithecus francoisi } & 黑叶猴 & I & 濒危 & 阙腾程 & 黑叶猴老年肾脏疾病的病因分析 \\
\hline & & & /EN & & \\
\hline \multirow[t]{2}{*}{ Trachypithecus francoisi } & 黑叶猴 & I & 濒危 & 李永明 & 黑叶猴淋巴肉瘤的病理形态观察 \\
\hline & & & /EN & & \\
\hline \multirow[t]{2}{*}{ Trachypithecus francoisi } & 黑叶猴 & I & 濒危 & 王荣琼 & 黑叶猴盲肠非特异性溃疡及病理学浅析 \\
\hline & & & /EN & & \\
\hline
\end{tabular}


顾垒，闻丞，罗玫，王吴，吕植. 中国最受关注濒危物种保护现状快速评价的新方法探讨. 生物多样性，2015，23(5)：583-590. http://www biodiversity-science. net/CN/article/downloadArticleFile. do?attachType=PDF\&id=10075

\begin{tabular}{|c|c|c|c|c|c|}
\hline Trachypithecus francoisi & 黑叶猴 & I & $\begin{array}{l}\text { 濒危 } \\
\text { /EN }\end{array}$ & 程家球 & 黑叶猴群发附红细胞体病 \\
\hline Trachypithecus francoisi & 黑叶猴 & I & $\begin{array}{l}\text { 濒危 } \\
\text { /EN }\end{array}$ & 黄乘明 & 黑叶猴食物组成及其季节性变化 \\
\hline Trachypithecus francoisi & 黑叶猴 & I & $\begin{array}{l}\text { 濒危 } \\
\text { /EN }\end{array}$ & 赖茂庆 & 黑叶猴胃肠阻塞三例 \\
\hline Trachypithecus francoisi & 黑叶猴 & I & $\begin{array}{l}\text { 濒危 } \\
\text { /EN }\end{array}$ & 赖茂庆 & 黑叶猴药物过敏 \\
\hline Trachypithecus francoisi & 黑叶猴 & I & $\begin{array}{l}\text { 濒危 } \\
\text { /EN }\end{array}$ & 赖茂庆 & 黑叶猴疑似眼肿瘤一例 \\
\hline Trachypithecus francoisi & 黑叶猴 & I & $\begin{array}{l}\text { 濒危 } \\
\text { /EN }\end{array}$ & 黄乘明 & 黑叶猴在旱季对喀斯特石山生境的利用 \\
\hline Trachypithecus francoisi & 黑叶猴 & I & $\begin{array}{l}\text { 濒危 } \\
\text { /EN }\end{array}$ & 黄乘明 & 黑叶猴在喀斯特石山生境的受食活动 \\
\hline Trachypithecus francoisi & 黑叶猴 & I & $\begin{array}{l}\text { 濒危 } \\
\text { /EN }\end{array}$ & 冯华娟 & 黑叶猴长臂猿甲哨唑中毒诊治病例 \\
\hline Trachypithecus francoisi & 黑叶猴 & I & $\begin{array}{l}\text { 濒危 } \\
\text { /EN }\end{array}$ & 兰安军 & 黑叶猴自然保护区生境对彭水水库蓄水响应的遥感监测分析 \\
\hline Trachypithecus francoisi & 黑叶猴 & I & 濒危 & 陈智 & 基于 3S 技术的黑叶猴生境破碎化研究 \\
\hline
\end{tabular}


顾垒，闻丞，罗玫，王吴，吕植. 中国最受关注濒危物种保护现状快速评价的新方法探讨. 生物多样性，2015，23(5)：583-590. http://www. biodiversity-science. net/CN/article/downloadArticleFile. do?attachType=PDF\&id=10075

\begin{tabular}{|c|c|c|c|c|c|}
\hline & & & /EN & & \\
\hline \multirow[t]{2}{*}{ Trachypithecus francoisi } & 黑叶猴 & I & 濒危 & 刘建宇 & 基于 3S 技术的武隆芙蓉江黑叶猴生态环境评价 \\
\hline & & & $/$ EN & & \\
\hline \multirow[t]{2}{*}{ Trachypithecus francoisi } & 黑叶猴 & I & 濒危 & 兰安军 & 基于 RS 与 GIS 的麻阳河黑叶猴自然保护区植被覆盖动态变化监测研究 \\
\hline & & & /EN & & \\
\hline \multirow[t]{2}{*}{ Trachypithecus francoisi } & 黑叶猴 & I & 濒危 & 韩宗先 & 金佛山黑叶猴春季活动节律和日活动时间分配 \\
\hline & & & /EN & & \\
\hline \multirow[t]{2}{*}{ Trachypithecus francoisi } & 黑叶猴 & I & 濒危 & 韩宗先 & 金佛山黑叶猴冬季的日活动时间分配研究 \\
\hline & & & /EN & & \\
\hline \multirow[t]{2}{*}{ Trachypithecus francoisi } & 黑叶猴 & I & 濒危 & 韩宗先 & 金佛山黑叶猴对阳光和降雨因子的行为对策 \\
\hline & & & /EN & & \\
\hline \multirow[t]{2}{*}{ Trachypithecus francoisi } & 黑叶猴 & I & 濒危 & 韩宗先 & 金佛山自然保护区黑叶猴个体行为研究 \\
\hline & & & /EN & & \\
\hline \multirow[t]{2}{*}{ Trachypithecus francoisi } & 黑叶猴 & I & 濒危 & 刘路 & 宽阔水国家级自然保护区黑叶猴生境利用的初步观察 \\
\hline & & & /EN & & \\
\hline \multirow[t]{2}{*}{ Trachypithecus francoisi } & 黑叶猴 & I & 濒危 & 胡刚 & 昆明动物园笼养黑叶猴日活动时间分配 \\
\hline & & & /EN & & \\
\hline \multirow[t]{2}{*}{ Trachypithecus francoisi } & 黑叶猴 & I & 濒危 & 赖茂庆 & 老龄黑叶猴的饲养 \\
\hline & & & /EN & & \\
\hline
\end{tabular}


顾垒，闻丞，罗玫，王吴，吕植. 中国最受关注濒危物种保护现状快速评价的新方法探讨. 生物多样性，2015，23(5)：583-590. http://www biodiversity-science. net/CN/article/downloadArticleFile. do?attachType=PDF\&id=10075

\begin{tabular}{|c|c|c|c|c|c|}
\hline Trachypithecus francoisi & 黑叶猴 & I & 濒危 & 胡春红 & 灵长类掌面和跖面花纹强度的种属间差异 \\
\hline & & & $/ \mathrm{EN}$ & & \\
\hline \multirow[t]{2}{*}{ Trachypithecus francoisi } & 黑叶猴 & I & 濒危 & 李宗瑜 & 六盘水市野钟黑叶猴自然保护区黑叶猴生态生活习性及保护调查研究 \\
\hline & & & /EN & & \\
\hline \multirow[t]{2}{*}{ Trachypithecus francoisi } & 黑叶猴 & I & 濒危 & 田应洲 & 六盘水市野钟自然保护区黑叶猴生态及种群数量的春季调查研究 \\
\hline & & & $/ \mathrm{EN}$ & & \\
\hline \multirow[t]{2}{*}{ Trachypithecus francoisi } & 黑叶猴 & I & 濒危 & 田应洲 & 六盘水野钟自然保护区黑叶猴种群数量及栖息地环境变化的调查 \\
\hline & & & $/ \mathrm{EN}$ & & \\
\hline \multirow[t]{2}{*}{ Trachypithecus francoisi } & 黑叶猴 & I & 濒危 & 黄乘明 & 笼养雌性黑叶猴尿中性腺激素水平变化与性行为、等级序位的关系 \\
\hline & & & $/ \mathrm{EN}$ & & \\
\hline \multirow[t]{2}{*}{ Trachypithecus francoisi } & 黑叶猴 & I & 濒危 & 王松 & 笼养黑叶猴 (Trachypith francoisi) 尿中性腺激素与繁殖行为关系的研究 \\
\hline & & & /EN & & \\
\hline \multirow[t]{2}{*}{ Trachypithecus francoisi } & 黑叶猴 & I & 濒危 & 胡艳玲 & 笼养黑叶猴（Trachypith francoisi）食物量的研究 \\
\hline & & & $/ \mathrm{EN}$ & & \\
\hline \multirow[t]{2}{*}{ Trachypithecus francoisi } & 黑叶猴 & I & 濒危 & 王宏 & 笼养黑叶猴的等级行为和友好行为研究 \\
\hline & & & $/ \mathrm{EN}$ & & \\
\hline \multirow[t]{2}{*}{ Trachypithecus francoisi } & 黑叶猴 & I & 濒危 & 胡艳玲 & 笼养黑叶猴的社会关系和食量的研究 \\
\hline & & & $/ \mathrm{EN}$ & & \\
\hline Trachypithecus francoisi & 黑叶猴 & I & 濒危 & 黄乘明 & 笼养黑叶猴的相互理毛行为 \\
\hline
\end{tabular}


顾垒，闻丞，罗玫，王吴，吕植. 中国最受关注濒危物种保护现状快速评价的新方法探讨. 生物多样性，2015，23(5)：583-590. http://www. biodiversity-science. net/CN/article/downloadArticleFile. do?attachType=PDF\&id=10075

\begin{tabular}{|c|c|c|c|c|c|}
\hline & & & /EN & & \\
\hline \multirow[t]{2}{*}{ Trachypithecus francoisi } & 黑叶猴 & I & 濒危 & 黄继志 & 笼养黑叶猴和白颊长臂猿的行为生态学研究 \\
\hline & & & $/$ EN & & \\
\hline \multirow[t]{2}{*}{ Trachypithecus francoisi } & 黑叶猴 & I & 濒危 & 周歧海 & 笼养黑叶猴活动时间分配的初步研究 \\
\hline & & & /EN & & \\
\hline \multirow[t]{2}{*}{ Trachypithecus francoisi } & 黑叶猴 & I & 濒危 & 黄乘明 & 笼养黑叶猴拟母亲行为的观察 \\
\hline & & & /EN & & \\
\hline \multirow[t]{2}{*}{ Trachypithecus francoisi } & 黑叶猴 & I & 濒危 & 黄乘明 & 笼养黑叶猴水分摄入与消耗 \\
\hline & & & /EN & & \\
\hline \multirow[t]{2}{*}{ Trachypithecus francoisi } & 黑叶猴 & I & 濒危 & 黄乘明 & 笼养黑叶猴未成年个体的玩要行为 \\
\hline & & & /EN & & \\
\hline \multirow[t]{2}{*}{ Trachypithecus francoisi } & 黑叶猴 & I & 濒危 & 周江 & 笼养黑叶猴与白头叶猴杂交后代可育一例 \\
\hline & & & /EN & & \\
\hline \multirow[t]{2}{*}{ Trachypithecus francoisi } & 黑叶猴 & I & 濒危 & 罗洪章 & 笼养黑叶猴自由取食和梳理时的单侧行为观察 \\
\hline & & & /EN & & \\
\hline \multirow[t]{2}{*}{ Trachypithecus francoisi } & 黑叶猴 & I & 濒危 & 胡保军 & 麻阳河国家级自然保护区人地关系研究 \\
\hline & & & /EN & & \\
\hline \multirow[t]{2}{*}{ Trachypithecus francoisi } & 黑叶猴 & I & 濒危 & 胡刚 & 麻阳河黑叶猴秋季食物营养组分及其对食物选择的影响 \\
\hline & & & /EN & & \\
\hline
\end{tabular}


顾垒，闻丞，罗玫，王吴，吕植. 中国最受关注濒危物种保护现状快速评价的新方法探讨. 生物多样性，2015，23(5)：583-590. http://www biodiversity-science. net/CN/article/downloadArticleFile. do?attachType=PDF\&id=10075

\begin{tabular}{|c|c|c|c|c|c|}
\hline Trachypithecus francoisi & 黑叶猴 & I & $\begin{array}{l}\text { 濒危 } \\
\text { /EN }\end{array}$ & 胡刚 & 麻阳河自然保护区黑叶猴夏季的夜宿行为 \\
\hline Trachypithecus francoisi & 黑叶猴 & I & $\begin{array}{l}\text { 濒危 } \\
\text { /EN }\end{array}$ & 张玲莉 & 难产黑叶猴的剖腹产手术治疗 \\
\hline Trachypithecus francoisi & 黑叶猴 & I & $\begin{array}{l}\text { 濒危 } \\
\text { /EN }\end{array}$ & 黄中豪 & 弄岗黑叶猴(Trachypithecus françoisi)的受食生态学 \\
\hline Trachypithecus francoisi & 黑叶猴 & I & $\begin{array}{l}\text { 濒危 } \\
\text { /EN }\end{array}$ & 罗帮 & 弄岗黑叶猴的受食生态学和营养分析 \\
\hline Trachypithecus francoisi & 黑叶猴 & I & $\begin{array}{l}\text { 濒危 } \\
\text { /EN }\end{array}$ & 黄乘明 & 弄岗黑叶猴的日活动类型和活动时间分配 \\
\hline Trachypithecus francoisi & 黑叶猴 & I & $\begin{array}{l}\text { 濒危 } \\
\text { /EN }\end{array}$ & 黄乘明 & 栖息地质量对黑叶猴活动时间分配的影响 \\
\hline Trachypithecus francoisi & 黑叶猴 & I & $\begin{array}{l}\text { 濒危 } \\
\text { /EN }\end{array}$ & 史芳否 & 黔金丝猴和圈养黑叶猴保护遗传学研究 \\
\hline Trachypithecus francoisi & 黑叶猴 & I & $\begin{array}{l}\text { 濒危 } \\
\text { /EN }\end{array}$ & 程家求 & 浅黄华丽单胞菌感染引起黑叶猴死亡 1 例 \\
\hline Trachypithecus francoisi & 黑叶猴 & I & $\begin{array}{l}\text { 濒危 } \\
\text { /EN }\end{array}$ & 黄乘明 & 同域分布黑叶猴和熊猴的活动时间分配比较 \\
\hline Trachypithecus francoisi & 黑叶猴 & I & 濒危 & 潘慧娟 & 梧州繁殖中心圈养黑叶猴遗传多样性分析和野外放归种源选择 \\
\hline
\end{tabular}


顾垒，闻丞，罗玫，王吴，吕植. 中国最受关注濒危物种保护现状快速评价的新方法探讨. 生物多样性，2015，23(5)：583-590. http://www biodiversity-science. net/CN/article/downloadArticleFile. do?attachType=PDF\&id=10075

\begin{tabular}{|c|c|c|c|c|c|}
\hline & & & /EN & & \\
\hline \multirow[t]{2}{*}{ Trachypithecus francoisi } & 黑叶猴 & I & 濒危 & 雷霄 & 野生动物类型自然保护区生态旅游活动开展对策探析一一以贵州麻阳河国家级自然保护 \\
\hline & & & $/ \mathrm{EN}$ & & 区为例 \\
\hline \multirow[t]{2}{*}{ Trachypithecus francoisi } & 黑叶猴 & I & 濒危 & 贾文君 & 脂肪含量对麻阳河黑叶猴冬季食物选择的影响 \\
\hline & & & $/ \mathrm{EN}$ & & \\
\hline \multirow[t]{2}{*}{ Trachypithecus francoisi } & 黑叶猴 & I & 濒危 & 李宏群 & 中国黑叶猴及其保护措施 \\
\hline & & & /EN & & \\
\hline \multirow{2}{*}{ Trachypithecus francoisi } & 黑叶猴 & I & 濒危 & 杨晓黎 & 中药治疗黑叶猴肠梗阻 \\
\hline & & & /EN & & \\
\hline \multirow[t]{2}{*}{ Trachypithecus francoisi } & 黑叶猴 & I & 濒危 & 韩宗先 & 重庆金佛山国家级自然保护区黑叶猴春季食物选择 \\
\hline & & & /EN & & \\
\hline \multirow[t]{2}{*}{ Trachypithecus francoisi } & 黑叶猴 & I & 濒危 & 韩宗先 & 重庆金佛山黑叶猴的春季生境选择 \\
\hline & & & /EN & & \\
\hline \multirow[t]{2}{*}{ Trachypithecus francoisi } & 黑叶猴 & I & 濒危 & 苏化龙 & 重庆市武隆县和彭水县交界处白㚘黑叶猴种群初步调查 \\
\hline & & & /EN & & \\
\hline \multirow[t]{2}{*}{ Tragopan caboti } & 黄腹角雉 & I & 易危 & 张雁云 & A population viability analysis (PVA) for Cabot's Tragopan( Tragopan caboti) in Wuyanling, \\
\hline & & & /VU & & south-east China \\
\hline \multirow[t]{2}{*}{ Tragopan caboti } & 黄腹角雉 & I & 易危 & LEE KWOK SHING & Forest bird fauna of South China: notes on current distribution and status \\
\hline & & & /VU & & \\
\hline
\end{tabular}


顾垒，闻丞，罗玫，王吴，吕植. 中国最受关注濒危物种保护现状快速评价的新方法探讨. 生物多样性，2015，23(5)：583-590. http://www. biodiversity-science. net/CN/article/downloadArticleFile. do?attachType=PDF\&id=10075

\begin{tabular}{|c|c|c|c|c|c|}
\hline Tragopan caboti & 黄腹角雉 & I & $\begin{array}{l}\text { 易危 } \\
\text { /VU }\end{array}$ & 欧志伟 & 板洞自然保护区野生动物资源调查 \\
\hline Tragopan caboti & 黄腹角雉 & I & $\begin{array}{l}\text { 易危 } \\
\text { /VU }\end{array}$ & 程松林 & 黄腹角推在江西省的地理分布与保护建议 \\
\hline Tragopan caboti & 黄腹角雉 & I & $\begin{array}{l}\text { 易危 } \\
\text { /VU }\end{array}$ & 翁国航 & 黄腹角雉栖息地恢复重建研究 \\
\hline Tragopan caboti & 黄腹角雉 & I & $\begin{array}{l}\text { 易危 } \\
\text { /VU }\end{array}$ & 桂小杰 & 黄腹角雉人工种群生存力初步分析 \\
\hline Tragopan caboti & 黄腹角雉 & I & $\begin{array}{l}\text { 易危 } \\
\text { /VU }\end{array}$ & 张雁云 & 黄腹角雉研究概述 \\
\hline Tragopan caboti & 黄腹角雉 & I & $\begin{array}{l}\text { 易危 } \\
\text { /VU }\end{array}$ & 宋玉赞 & 黄腹角雉在江西的分布与保护 \\
\hline Tragopan caboti & 黄腹角雉 & I & $\begin{array}{l}\text { 易危 } \\
\text { /VU }\end{array}$ & 陈武华 & 江西武功山国家森林公园野生动物资源及保护对策 \\
\hline Tragopan caboti & 黄腹角雉 & I & $\begin{array}{l}\text { 易危 } \\
\text { /VU }\end{array}$ & 程松林 & 江西武夷山黄腹角雉野外采食习性初步观察 \\
\hline Tragopan caboti & 黄腹角雉 & I & $\begin{array}{l}\text { 易危 } \\
\text { /VU }\end{array}$ & 程松林 & 江西武夷山黄腹角雉野外采食习性初步观察 \\
\hline Tragopan caboti & 黄腹角雉 & I & 易危 & 程松林 & 江西武夷山雉科鸟类研究初报 \\
\hline
\end{tabular}


顾垒，闻丞，罗玫，王吴，吕植. 中国最受关注濒危物种保护现状快速评价的新方法探讨. 生物多样性，2015，23(5)：583-590. http://www. biodiversity-science. net/CN/article/downloadArticleFile. do?attachType=PDF\&id=10075

\begin{tabular}{|c|c|c|c|c|c|}
\hline & & & $/ \mathrm{VU}$ & & \\
\hline \multirow[t]{2}{*}{ Tragopan caboti } & 黄腹角雉 & I & 易危 & 程松林 & 江西武夷山自然保护区的雉类资源及其保护 \\
\hline & & & $/ \mathrm{VU}$ & & \\
\hline \multirow[t]{2}{*}{ Tragopan caboti } & 黄腹角雉 & I & 易危 & 黄族豪 & 井冈山国家级自然保护区鸟类资源研究 \\
\hline & & & /VU & & \\
\hline \multirow[t]{2}{*}{ Tragopan caboti } & 黄腹角雉 & I & 易危 & 段世华 & 井冈山自然保护区夏季鸟类多样性分析 \\
\hline & & & $/ \mathrm{VU}$ & & \\
\hline \multirow[t]{2}{*}{ Tragopan caboti } & 黄腹角雉 & I & 易危 & 陈春泉 & 井冈山自然保护区珍稀动物资源及保护 \\
\hline & & & $/ \mathrm{VU}$ & & \\
\hline \multirow[t]{2}{*}{ Tragopan caboti } & 黄腹角雉 & I & 易危 & 邓文洪 & 栖息地破碎化对黄腹角雄分布模式的影响及保护对策 \\
\hline & & & $/ \mathrm{VU}$ & & \\
\hline \multirow[t]{2}{*}{ Tragopan caboti } & 黄腹角雉 & I & 易危 & 游卫云 & 清凉峰华南梅花鹿冬季食物资源特征研究 \\
\hline & & & /VU & & \\
\hline \multirow[t]{2}{*}{ Tragopan caboti } & 黄腹角雉 & I & 易危 & 李斌 & 韶赣高速公路( 粤境段) 建设对路域生态系统鸟类群落的影响 \\
\hline & & & /VU & & \\
\hline \multirow[t]{2}{*}{ Tragopan caboti } & 黄腹角雉 & I & 易危 & 谭益民 & 桃源洞国家级自然保护区的生态状况 \\
\hline & & & /VU & & \\
\hline \multirow[t]{2}{*}{ Tragopan caboti } & 黄腹角雉 & I & 易危 & 郑方东 & 乌岩岭保护区黄腹角雉栖息地植被类型及植食性食物研究 \\
\hline & & & /VU & & \\
\hline
\end{tabular}


顾垒，闻丞，罗玫，王吴，吕植. 中国最受关注濒危物种保护现状快速评价的新方法探讨. 生物多样性，2015，23(5)：583-590. http://www. biodiversity-science. net/CN/article/downloadArticleFile. do?attachType=PDF\&id=10075

\begin{tabular}{|c|c|c|c|c|c|}
\hline Tragopan caboti & 黄腹角雉 & I & $\begin{array}{l}\text { 易危 } \\
\text { /VU }\end{array}$ & 杨道德 & 武功山国家森林公园夏季鸟类资源调查 \\
\hline Tragopan caboti & 黄腹角雉 & I & $\begin{array}{l}\text { 易危 } \\
\text { /VU }\end{array}$ & 孙岳 & 武夷山鸡形目鸟类多样性及冰冻灾害对其影响研究 \\
\hline Tragopan caboti & 黄腹角雉 & I & $\begin{array}{l}\text { 易危 } \\
\text { /VU }\end{array}$ & 张家银 & 浙江九龙山陆生野生脊椎动物资源现状及保护对策 \\
\hline Tragopan caboti & 黄腹角雉 & I & $\begin{array}{l}\text { 易危 } \\
\text { /VU }\end{array}$ & 卢彰显 & 自然保护区生物多样性保护与社区经济发展探讨 \\
\hline Tragopan satyra & 红胸角雉 & I & $\begin{array}{l}\text { 近危 } \\
\text { /NT }\end{array}$ & 王 斌 & 西藏珠穆朗玛峰国家级自然保护区鸟类群落结构与多样性 \\
\hline Treron bicincta & 橙胸绿扸 & II & $\begin{array}{l}\text { 无危 } \\
\text { /LC }\end{array}$ & 李仕宁 & 茄新省级森林经营所鸟类资源调查 \\
\hline Treron sieboldii & 红翅绿扸 & II & $\begin{array}{l}\text { 无危 } \\
\text { /LC }\end{array}$ & 巩会生 & 陕西米仓山自然保护区鸟类组成与分布格局 \\
\hline Treron sphenura & 楔尾绿扸 & II & $\begin{array}{l}\text { 无危 } \\
\text { /LC }\end{array}$ & 黄石林 & 云南南涧风凰山秋季夜间迁移鸟类多样性分析 \\
\hline Trigonobalanus doichangensis & 三棱栎 & II & $\begin{array}{l}\text { 数据 } \\
\text { 不足 } \\
\text { /DD }\end{array}$ & Weibang Sun & Genetic diversity of the rare Asian plant, Trigonobalanus doichangensis(Fagaceae) \\
\hline
\end{tabular}


顾垒，闻丞，罗玫，王吴，吕植. 中国最受关注濒危物种保护现状快速评价的新方法探讨. 生物多样性，2015，23(5)：583-590. http://www. biodiversity-science. net/CN/article/downloadArticleFile. do?attachType=PDF\&id=10075

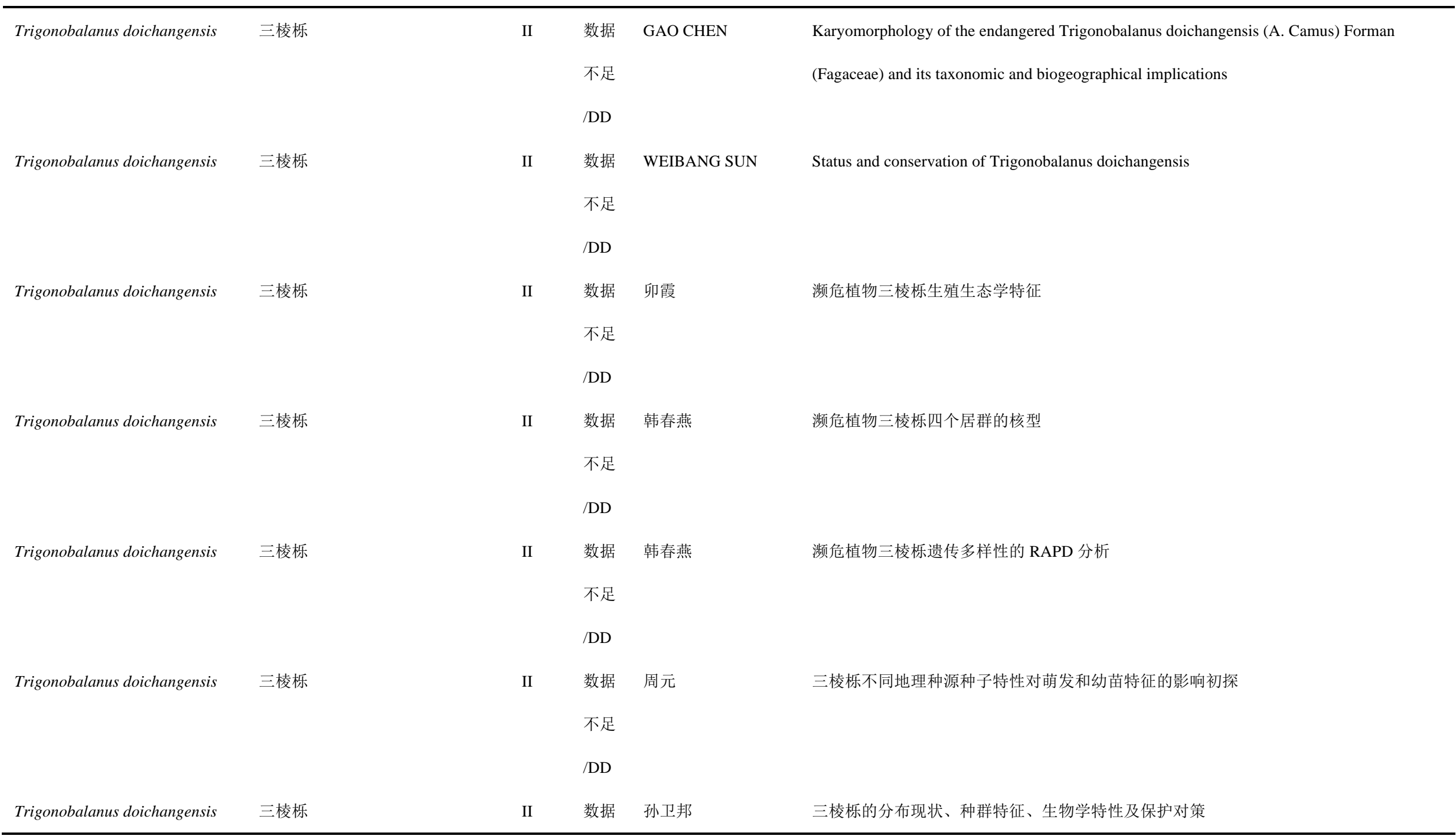


顾垒，闻丞，罗玫，王吴，吕植. 中国最受关注濒危物种保护现状快速评价的新方法探讨. 生物多样性，2015，23(5)：583-590. http://www. biodiversity-science. net/CN/article/downloadArticleFile. do?attachType=PDF\&id=10075

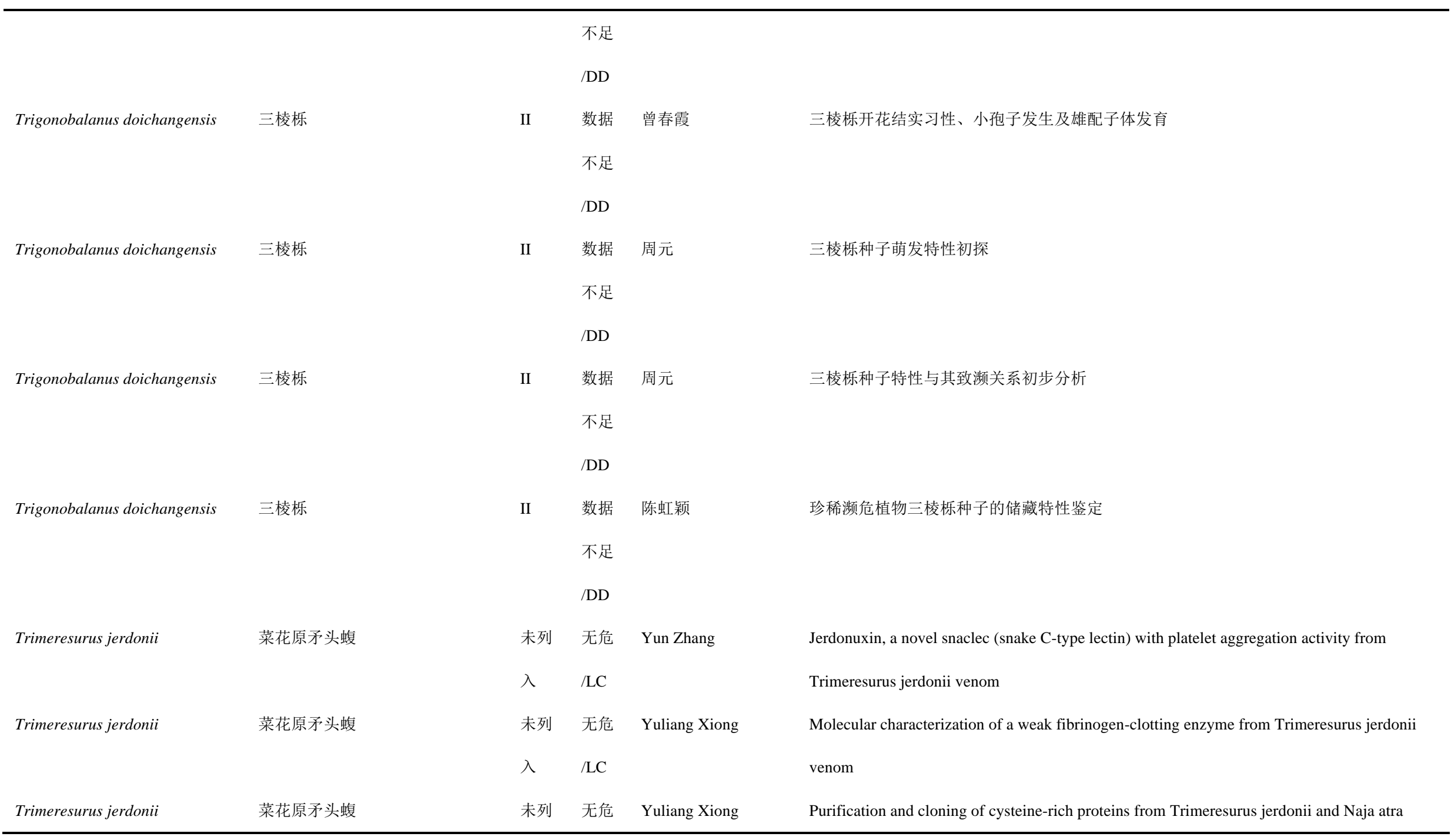


顾垒，闻丞，罗玫，王吴，吕植. 中国最受关注濒危物种保护现状快速评价的新方法探讨. 生物多样性，2015，23(5)：583-590. http://www biodiversity-science. net/CN/article/downloadArticleFile. do?attachType=PDF\&id=10075

\begin{tabular}{|c|c|c|c|c|c|}
\hline & & 入 & $/ \mathrm{LC}$ & & venoms \\
\hline \multirow[t]{2}{*}{ Trimeresurus jerdonii } & 菜花原矛头蝮 & 未列 & 无危 & Yuliang Xiong & Purification, cloning and biological characterization of a novel disintegrin from Trimeresurus \\
\hline & & 入 & $/ \mathrm{LC}$ & & jerdonii venom \\
\hline \multirow[t]{2}{*}{ Trimeresurus jerdonii } & 菜花原矛头蝮 & 未列 & 无危 & 樊龙锁 & 菜花原矛头蝮的分布及其在山西繁殖生态的观察 \\
\hline & & 入 & $/ \mathrm{LC}$ & & \\
\hline \multirow[t]{2}{*}{ Trimeresurus jerdonii } & 菜花原矛头蝮 & 未列 & 无危 & 王宏元 & 菜花原矛头蝮嗅觉系统和犁鼻系统的显微结构 \\
\hline & & 入 & $/ \mathrm{LC}$ & & \\
\hline \multirow[t]{2}{*}{ Tringa guttifer } & 小青脚鹬 & II & 濒危 & 关贯勋 & 澳门鸟类资源调查报告 \\
\hline & & & /EN & & \\
\hline \multirow[t]{2}{*}{ Tringa guttifer } & 小青脚桶 & II & 濒危 & 白清泉 & 东北鸟类新记录一一中白笉与小青脚䂆 \\
\hline & & & /EN & & \\
\hline \multirow[t]{2}{*}{ Tringa guttifer } & 小青脚鹬 & II & 濒危 & 郑丁团 & 福建兴化湾水鸟资源现状及保护对策 \\
\hline & & & /EN & & \\
\hline \multirow[t]{2}{*}{ Tringa guttifer } & 小青脚桶 & II & 濒危 & 黄 否 & 泉州湾河口湿地自然保护区鸟类多样性调查 \\
\hline & & & /EN & & \\
\hline \multirow[t]{2}{*}{ Tringa guttifer } & 小青脚劀 & II & 濒危 & 陈若海 & 泉州湾河口湿地自然保护区珍稀濒危鸟类的分布特点及其保护 \\
\hline & & & /EN & & \\
\hline \multirow[t]{2}{*}{ Tringa guttifer } & 小青脚鹬 & II & 濒危 & 林清贤 & 厦门东屿红树林湿地鸟类资源及其分布 \\
\hline & & & /EN & & \\
\hline
\end{tabular}


顾垒，闻丞，罗玫，王吴，吕植. 中国最受关注濒危物种保护现状快速评价的新方法探讨. 生物多样性，2015，23(5)：583-590. http://www. biodiversity-science. net/CN/article/downloadArticleFile. do?attachType=PDF\&id=10075

\begin{tabular}{|c|c|c|c|c|c|}
\hline \multirow[t]{2}{*}{ Tringa guttifer } & 小青脚鹬 & II & 濒危 & 谭飞 & 漳江口自然保护区胻形目鸟类适宜生境变化及驱动机制分析 \\
\hline & & & /EN & & \\
\hline \multirow[t]{2}{*}{ Trogopterus xanthipes } & 复齿鼠鼠 & 未列 & 濒危 & Jin-Ao Duan & Antithrombotic flavonoids from the faeces of Trogopterus xanthipes \\
\hline & & 入 & /EN & & \\
\hline \multirow[t]{2}{*}{ Trogopterus xanthipes } & 复齿稭鼠 & 未列 & 濒危 & Jin-Ao Duan & Four New Fatty Acid Esters from the Feces of Trogopterus \\
\hline & & 入 & /EN & & \\
\hline \multirow[t]{2}{*}{ Trogopterus xanthipes } & 复齿鼠鼠 & 未列 & 濒危 & Jin-Ao Duan & Two new isopimarane diterpenes from the feces of Trogopterus xanthipes \\
\hline & & 入 & $/ \mathrm{EN}$ & & \\
\hline \multirow[t]{2}{*}{ Trogopterus xanthipes } & 复齿鼎鼠 & 未列 & 濒危 & 谢硕 & 歌乐山黄桷洞复齿鼠鼠化石研究 \\
\hline & & 入 & /EN & & \\
\hline \multirow[t]{2}{*}{ Trogopterus xanthipes } & 复齿鼠鼠 & 未列 & 濒危 & 金一 & 中华鼠鼠的分类与分布 \\
\hline & & 入 & /EN & & \\
\hline \multirow[t]{2}{*}{ Trogopterus xanthipes } & 复齿鼠鼠 & 未列 & 近危 & 金一 & 中华鼠鼠的分类与分布 \\
\hline & & 入 & $/ \mathrm{NT}$ & & \\
\hline \multirow[t]{3}{*}{ Tsuga chinensis } & 南方铁杉 & 未列 & 无危 & LIU XiaoHong & Climatic significance of the stable carbon isotope composition of tree-ring cellulose: \\
\hline & & 入 & $/ \mathrm{LC}$ & & Comparison of Chinese hemlock (Tsuga chinensis Pritz) and alpine pine (Pinus densata Mast) \\
\hline & & & & & in a temperate-moist region of China \\
\hline \multirow[t]{2}{*}{ Tsuga chinensis } & 南方铁杉 & 未列 & 无危 & 市羽 & 不同坡向濒危植物南方铁杉的分布格局 \\
\hline & & 入 & $/ \mathrm{LC}$ & & \\
\hline
\end{tabular}


顾垒，闻丞，罗玫，王吴，吕植. 中国最受关注濒危物种保护现状快速评价的新方法探讨. 生物多样性，2015，23(5)：583-590. http://www biodiversity-science. net/CN/article/downloadArticleFile. do?attachType=PDF\&id=10075

\begin{tabular}{|c|c|c|c|c|c|}
\hline \multirow[t]{2}{*}{ Tsuga chinensis } & 南方铁杉 & 未列 & 无危 & 刘鹏 & 不同群落类型下南方铁杉金属元素含量差异及其与土壤养分因子的关系 \\
\hline & & 入 & $/ \mathrm{LC}$ & & \\
\hline \multirow[t]{2}{*}{ Tsuga chinensis } & 南方铁杉 & 未列 & 无危 & 谢旺生 & 福建光泽南方铁杉群落植物组成与多样性分析 \\
\hline & & 入 & $/ \mathrm{LC}$ & & \\
\hline \multirow[t]{2}{*}{ Tsuga chinensis } & 南方铁杉 & 未列 & 无危 & 罗金旺 & 福建光泽南方铁杉天然林的生长规律与生物量 \\
\hline & & 入 & $/ \mathrm{LC}$ & & \\
\hline \multirow[t]{2}{*}{ Tsuga chinensis } & 南方铁杉 & 未列 & 无危 & 罗金旺 & 福建光泽天然林中南方铁杉的种内与种间竞争 \\
\hline & & 入 & $/ \mathrm{LC}$ & & \\
\hline \multirow[t]{2}{*}{ Tsuga chinensis } & 南方铁杉 & 未列 & 无危 & 冯祥麟 & 贵阳高坡南方铁杉群落特征及种群动态调查研究 \\
\hline & & 入 & $/ \mathrm{LC}$ & & \\
\hline \multirow[t]{2}{*}{ Tsuga chinensis } & 南方铁杉 & 未列 & 无危 & 袁荣斌 & 江西武夷山国家级自然保护区南方铁杉资源调查初报 \\
\hline & & 入 & $/ \mathrm{LC}$ & & \\
\hline \multirow[t]{2}{*}{ Tsuga chinensis } & 南方铁杉 & 未列 & 无危 & 刘鹏 & 九龙山濒危植物南方铁杉的生态位研究 \\
\hline & & 入 & $/ \mathrm{LC}$ & & \\
\hline \multirow[t]{2}{*}{ Tsuga chinensis } & 南方铁杉 & 未列 & 无危 & 刘鹏 & 九龙山南方铁杉群落物种多样性及乔木种种间联结性 \\
\hline & & 入 & $/ \mathrm{LC}$ & & \\
\hline \multirow[t]{2}{*}{ Tsuga chinensis } & 南方铁杉 & 未列 & 无危 & 刘鹏 & 九龙山珍稀濒危植物南方铁杉种群数量动态 \\
\hline & & 入 & $/ \mathrm{LC}$ & & \\
\hline Tsuga chinensis & 南方铁杉 & 未列 & 无危 & 刘鹏 & 九龙山自然保护区珍稀濒危植物南方铁杉种群生态学研究 \\
\hline
\end{tabular}


顾垒，闻丞，罗玫，王吴，吕植. 中国最受关注濒危物种保护现状快速评价的新方法探讨. 生物多样性，2015，23(5)：583-590. http://www. biodiversity-science. net/CN/article/downloadArticleFile. do?attachType=PDF\&id=10075

\begin{tabular}{|c|c|c|c|c|c|}
\hline & & 入 & $/ \mathrm{LC}$ & & \\
\hline \multirow[t]{2}{*}{ Tsuga chinensis } & 南方铁杉 & 未列 & 无危 & 赵峰 & 䒭山南方铁杉群落种间关系研究 \\
\hline & & 入 & $/ \mathrm{LC}$ & & \\
\hline \multirow[t]{2}{*}{ Tsuga chinensis } & 南方铁杉 & 未列 & 无危 & 王大来 & 莽山南方铁杉种群格局分布格局研究 \\
\hline & & 入 & $/ \mathrm{LC}$ & & \\
\hline \multirow[t]{2}{*}{ Tsuga chinensis } & 南方铁杉 & 未列 & 无危 & 陈璟 & 䒪山自然保护区南方铁杉种群物种多样性和稳定性研究 \\
\hline & & 入 & $/ \mathrm{LC}$ & & \\
\hline \multirow[t]{2}{*}{ Tsuga chinensis } & 南方铁杉 & 未列 & 无危 & 魏识广 & 猫儿山两种子遗植物的更新状况和空间分布格局分析 \\
\hline & & 入 & $/ \mathrm{LC}$ & & \\
\hline \multirow[t]{2}{*}{ Tsuga chinensis } & 南方铁杉 & 未列 & 无危 & 黄宪刚 & 猫儿山南方铁杉种群结构和动态的初步研究 \\
\hline & & 入 & $/ \mathrm{LC}$ & & \\
\hline \multirow[t]{2}{*}{ Tsuga chinensis } & 南方铁杉 & 未列 & 无危 & 程飞侠 & 南方铁杉大苗培育技术研究 \\
\hline & & 入 & $/ \mathrm{LC}$ & & \\
\hline \multirow[t]{2}{*}{ Tsuga chinensis } & 南方铁杉 & 未列 & 无危 & 李维林 & 南方铁杉和长苞铁杉枝叶的挥发油成分 \\
\hline & & 入 & $/ \mathrm{LC}$ & & \\
\hline \multirow[t]{2}{*}{ Tsuga chinensis } & 南方铁杉 & 未列 & 无危 & 市羽 & 南方铁杉林林隙自然干扰规律 \\
\hline & & 入 & $/ \mathrm{LC}$ & & \\
\hline \multirow[t]{2}{*}{ Tsuga chinensis } & 南方铁杉 & 未列 & 无危 & 李晓铁 & 南方铁杉扞插繁殖技术 \\
\hline & & 入 & $/ \mathrm{LC}$ & & \\
\hline
\end{tabular}


顾垒，闻丞，罗玫，王吴，吕植. 中国最受关注濒危物种保护现状快速评价的新方法探讨. 生物多样性，2015，23(5)：583-590. http://www biodiversity-science. net/CN/article/downloadArticleFile. do?attachType=PDF\&id=10075

\begin{tabular}{|c|c|c|c|c|c|}
\hline \multirow[t]{2}{*}{ Tsuga chinensis } & 南方铁杉 & 未列 & 无危 & 谢琼中 & 南方铁杉群落物种多样性及乔木优势种生态位初步研究 \\
\hline & & $\lambda$ & $/ \mathrm{LC}$ & & \\
\hline \multirow[t]{2}{*}{ Tsuga chinensis } & 南方铁杉 & 未列 & 无危 & 钱晓鸣 & 南方铁杉外生菌根的扫描电镜观察 \\
\hline & & 入 & $/ \mathrm{LC}$ & & \\
\hline \multirow[t]{2}{*}{ Tsuga chinensis } & 南方铁杉 & 未列 & 无危 & 封否 & 南方铁杉种群结构动态与空间分布格局 \\
\hline & & 入 & $/ \mathrm{LC}$ & & \\
\hline \multirow[t]{2}{*}{ Tsuga chinensis } & 南方铁杉 & 未列 & 无危 & 何建源 & 武夷山南方铁杉群落乔木层种间联结研究 \\
\hline & & 入 & $/ \mathrm{LC}$ & & \\
\hline \multirow[t]{2}{*}{ Tsuga chinensis } & 南方铁杉 & 未列 & 无危 & 何建源 & 武夷山区域南方铁杉种群密度效应模型 \\
\hline & & 入 & $/ \mathrm{LC}$ & & \\
\hline \multirow[t]{2}{*}{ Tsuga chinensis } & 南方铁杉 & 未列 & 无危 & 郭连金 & 武夷山自然保护区濒危植物南方铁杉种群数量动态分析 \\
\hline & & $\lambda$ & $/ \mathrm{LC}$ & & \\
\hline \multirow[t]{2}{*}{ Tsuga chinensis } & 南方铁杉 & 未列 & 无危 & 钱晓鸣 & 武夷山自然保护区南方铁杉菌根系统研究 \\
\hline & & 入 & $/ \mathrm{LC}$ & & \\
\hline \multirow[t]{2}{*}{ Tsuga chinensis } & 南方铁杉 & 未列 & 无危 & 钱晓鸣 & 武夷山自然保护区南方铁杉外生菌根生物多样性 \\
\hline & & 入 & $/ \mathrm{LC}$ & & \\
\hline \multirow[t]{2}{*}{ Tsuga chinensis } & 南方铁杉 & 未列 & 无危 & 刘鹏 & 浙江九龙山南方铁杉(Tsuga tchekiangensis)群落结构及优势种群更新类型 \\
\hline & & 入 & $/ \mathrm{LC}$ & & \\
\hline Tsuga chinensis & 南方铁杉 & 未列 & 无危 & 张志祥 & 珍稀濒危植物南方铁杉研究进展 \\
\hline
\end{tabular}


顾垒，闻丞，罗玫，王吴，吕植. 中国最受关注濒危物种保护现状快速评价的新方法探讨. 生物多样性，2015，23(5)：583-590. http://www biodiversity-science, net/CN/article/downloadArticleFile. do?attachType=PDF\&id=10075

\begin{tabular}{|c|c|c|c|c|c|}
\hline & & 入 & $/ \mathrm{LC}$ & & \\
\hline \multirow[t]{2}{*}{ Tsuga chinensis } & 南方铁杉 & 未列 & 无危 & 洪伟 & 珍稀濒危植物南方铁杉种群动态研究 \\
\hline & & 入 & $/ \mathrm{LC}$ & & \\
\hline \multirow[t]{2}{*}{ Tsuga chinensis } & 南方铁杉 & 未列 & 无危 & 刘鹏 & 珍稀濒危植物南方铁杉种群结构与空间分布格局研究 \\
\hline & & 入 & $/ \mathrm{LC}$ & & \\
\hline \multirow[t]{2}{*}{ Tsuga forrestii } & 丽江铁杉 & 未列 & 易危 & Michael E. & Chinese Coccinellidae for biological control of the hemlock woolly adelgid description of \\
\hline & & 入 & $/ \mathrm{VU}$ & Montgomery & native habitat \\
\hline \multirow[t]{2}{*}{ Tylototriton asperrimus } & '细痣棘螈 & II & 近危 & David W. Weisrock & A molecular assessment of phylogenetic relationships and lineage accumulation rates within the \\
\hline & & & /NT & & family Salamandridae (Amphibia, Caudata) \\
\hline \multirow[t]{2}{*}{ Tylototriton asperrimus } & '细疬棘螈 & II & 近危 & Youhui SHEN & A New Species of the Genus Tylototriton (Amphibia, Salamandridae) from Hunan, China \\
\hline & & & /NT & & \\
\hline \multirow[t]{2}{*}{ Tylototriton asperrimus } & '细痣棘螈 & II & 近危 & Youhui SHEN & A New Species of the Genus Tylototriton(Urodela: Salamandridae) from Northeastern Hunan \\
\hline & & & /NT & & Province, China \\
\hline \multirow[t]{2}{*}{ Tylototriton asperrimus } & '细痣棘螈 & II & 近危 & CHE Jing & A phylogeny of the Tylototriton asperrimusgroup (Caudata: Salamandridae) based on a \\
\hline & & & /NT & & mitochondrial study: suggestions for a taxonomic revision \\
\hline \multirow[t]{2}{*}{ Tylototriton asperrimus } & '细痣棘螈 & II & 近危 & 覃文更 & 广西木论国家级自然保护区细瘱病螦栖息地环境的调查分析 \\
\hline & & & /NT & & \\
\hline \multirow[t]{2}{*}{ Tylototriton asperrimus } & '细痣棘螈 & II & 近危 & 谷晓明 & 贵州 5 种蝾螈几种组织中乳酸脱氢酶同工酶(LDH)的电泳分析 \\
\hline & & & /NT & & \\
\hline
\end{tabular}


顾垒，闻丞，罗玫，王吴，吕植. 中国最受关注濒危物种保护现状快速评价的新方法探讨. 生物多样性，2015，23(5)：583-590. http://www biodiversity-science. net/CN/article/downloadArticleFile. do?attachType=PDF\&id=10075

\begin{tabular}{|c|c|c|c|c|c|}
\hline Tylototriton asperrimus & '细痣棘螈 & II & $\begin{array}{l}\text { 近危 } \\
\text { /NT }\end{array}$ & 谷晓明 & 贵州 5 种蝾螈醌酶同工酶(EST)的比较研究 \\
\hline Tylototriton asperrimus & '细痣棘螈 & II & $\begin{array}{l}\text { 近危 } \\
\text { /NT }\end{array}$ & 李永通 & 贵州北部四种两栖类乳酸脱氢酶同工酶的比较研究 \\
\hline Tylototriton asperrimus & '细疬棘螈 & II & $\begin{array}{l}\text { 近危 } \\
\text { /NT }\end{array}$ & 陈继军 & 贵州雷公山自然保护区两栖动物调查报告 \\
\hline Tylototriton asperrimus & '细疬棘螈 & II & $\begin{array}{l}\text { 近危 } \\
\text { /NT }\end{array}$ & 谷晓明 & 贵州四种蝶螈科动物的核型和 C2 带比较研究 \\
\hline Tylototriton asperrimus & '细痣棘螈 & II & $\begin{array}{l}\text { 近危 } \\
\text { /NT }\end{array}$ & 张洪茂 & 后河自然保护区周边地区细痣疮螈资源及夏季生境选择 \\
\hline Tylototriton asperrimus & '细疬棘螈 & II & $\begin{array}{l}\text { 近危 } \\
\text { /NT }\end{array}$ & 沈奠慧 & 湖南省的有尾两栖动物 \\
\hline Tylototriton asperrimus & '细痣棘螈 & II & $\begin{array}{l}\text { 近危 } \\
\text { /NT }\end{array}$ & 谷晓明 & 基于部分线粒体 DNA 序列的病螈属亚属(有尾目, 蝶螈科, 病螈属)系统发育关系 \\
\hline Tylototriton asperrimus & '细疬棘螈 & II & $\begin{array}{l}\text { 近危 } \\
\text { /NT }\end{array}$ & 高正发 & 四川绵阳市两栖爬行动物区系及地理区划 \\
\hline Tylototriton asperrimus & '细疬棘螈 & II & $\begin{array}{l}\text { 近危 } \\
\text { /NT }\end{array}$ & 赵尔宓 & 我国棘螈属(Echinotriton)和病螈属(Tylototriton)的研究概况 \\
\hline Tylototriton asperrimus & '细痣棘螈 & II & 近危 & 谷晓明 & 细痣疮螈的核型研究 \\
\hline
\end{tabular}


顾垒，闻丞，罗玫，王吴，吕植. 中国最受关注濒危物种保护现状快速评价的新方法探讨. 生物多样性，2015，23(5)：583-590. http://www. biodiversity-science. net/CN/article/downloadArticleFile. do?attachType=PDF\&id=10075

\begin{tabular}{|c|c|c|c|c|c|}
\hline & & & $/ \mathrm{NT}$ & & \\
\hline \multirow[t]{2}{*}{ Tylototriton asperrimus } & '细疬棘螈 & II & 近危 & 侯勉 & 疮螈属形态学研究进展及四隐存居群地位的初步确定 \\
\hline & & & $/ \mathrm{NT}$ & & \\
\hline \multirow[t]{2}{*}{ Tylototriton asperrimus } & '细痣棘螈 & II & 近危 & 谢锋 & 中国两栖动物保护需求总述 \\
\hline & & & /NT & & \\
\hline \multirow[t]{2}{*}{ Tylototriton asperrimus } & '细痣棘螈 & II & 近危 & 罗键 & 重庆市两栖动物物种多样性研究及保护 \\
\hline & & & $/ \mathrm{NT}$ & & \\
\hline \multirow[t]{2}{*}{ Tylototriton kweichowensis } & 贵州疮螈 & 未列 & 易危 & 胡思玉 & 贵州疮螈繁殖期消化系统蛋白酶活性的研究 \\
\hline & & 入 & $/ \mathrm{VU}$ & & \\
\hline \multirow[t]{2}{*}{ Tylototriton kweichowensis } & 贵州病螈 & 未列 & 易危 & 白建梅 & 贵州病螈化学成分及消化系统蛋白酶活性的研究 \\
\hline & & 入 & /VU & & \\
\hline \multirow[t]{2}{*}{ Tylototriton kweichowensis } & 贵州疮螈 & 未列 & 易危 & 王延斌 & 贵州病螈越冬生态的观察 \\
\hline & & 入 & /VU & & \\
\hline \multirow[t]{2}{*}{ Tylototriton kweichowensis } & 贵州疮螈 & 未列 & 易危 & 白建梅 & 人工饲养贵州病螈营养成分的研究 \\
\hline & & 入 & /VU & & \\
\hline \multirow[t]{2}{*}{ Tylototriton Taliangensis } & 大凉病螈 & II & 近危 & 邹立扣 & 成体大凉病螈肺脏的组织形态学观察 \\
\hline & & & /NT & & \\
\hline \multirow[t]{2}{*}{ Tylototriton Taliangensis } & 大凉疮螈 & II & 近危 & 邹立扣 & 成体大凉疮螈肝脏的组织形态学观察 \\
\hline & & & /NT & & \\
\hline
\end{tabular}


顾垒，闻丞，罗玫，王吴，吕植. 中国最受关注濒危物种保护现状快速评价的新方法探讨. 生物多样性，2015，23(5)：583-590. http://www biodiversity-science. net/CN/article/downloadArticleFile. do?attachType=PDF\&id=10075

\begin{tabular}{|c|c|c|c|c|c|}
\hline Tylototriton Taliangensis & 大凉疮螈 & II & $\begin{array}{l}\text { 近危 } \\
\text { /NT }\end{array}$ & 刘绍龙 & 大凉疮螈的骨骼系统 \\
\hline Tylototriton Taliangensis & 大凉疮螈 & II & $\begin{array}{l}\text { 近危 } \\
\text { /NT }\end{array}$ & 刘晓雯 & 大凉疮螈碱性磷酸酶的分离纯化及部分性质 \\
\hline Tylototriton Taliangensis & 大凉疮螈 & II & $\begin{array}{l}\text { 近危 } \\
\text { /NT }\end{array}$ & 张义正 & 大凉病螈脑源性神经营养因子(BD NF)基因的克隆与序列分析 \\
\hline Tylototriton Taliangensis & 大凉疮螈 & II & $\begin{array}{l}\text { 近危 } \\
\text { /NT }\end{array}$ & 刘绍龙 & 大凉病䗷皮肤的组织学观察 \\
\hline Tylototriton Taliangensis & 大凉疮螈 & II & $\begin{array}{l}\text { 近危 } \\
\text { /NT }\end{array}$ & 邹立扣 & 大凉病螈栖息地现状调查及其保护 \\
\hline Tylototriton Taliangensis & 大凉疮螈 & II & $\begin{array}{l}\text { 近危 } \\
\text { /NT }\end{array}$ & 邹立扣 & 大凉疮螈形态学观察及消化呼吸系统解剖 \\
\hline Tylototriton Taliangensis & 大凉疮螈 & II & $\begin{array}{l}\text { 近危 } \\
\text { /NT }\end{array}$ & 邹立扣 & 一株大凉疮螈肠道弗氏柠檬酸杆菌的分离及其药敏试验 \\
\hline Tylototriton verrucosus & '棕黑疮螈 & II & $\begin{array}{l}\text { 无危 } \\
\text { /LC }\end{array}$ & David W. Weisrock & $\begin{array}{l}\text { A molecular assessment of phylogenetic relationships and lineage accumulation rates within the } \\
\text { family Salamandridae (Amphibia, Caudata) }\end{array}$ \\
\hline Tylototriton verrucosus & '棕黑疮螈 & II & $\begin{array}{l}\text { 无危 } \\
\text { /LC }\end{array}$ & 刘宁 饶定齐 & 棕黑病缐种组分子系统发育分析及大围山病缐新种描述 \\
\hline Tylototriton wenxianensis & 文县疮螈 & 未列 & 易危 & 鲍方印 & 安徽岳西䍃落坪自然保护区文县病螈的染色体组型分析 \\
\hline
\end{tabular}


顾垒，闻丞，罗玫，王吴，吕植. 中国最受关注濒危物种保护现状快速评价的新方法探讨. 生物多样性，2015，23(5)：583-590. http://www. biodiversity-science. net/CN/article/downloadArticleFile. do?attachType=PDF\&id=10075

\begin{tabular}{|c|c|c|c|c|c|}
\hline & & 入 & $/ \mathrm{VU}$ & & \\
\hline \multirow[t]{2}{*}{ Tylototriton wenxianensis } & 文县疮螈 & 未列 & 易危 & 龚大洁 & 甘肃白水江国家级自然保护区两栖爬行动物资源调查及保护对策 \\
\hline & & 入 & $/ \mathrm{VU}$ & & \\
\hline \multirow[t]{2}{*}{ Tylototriton wenxianensis } & 文县病螈 & 未列 & 易危 & 龚大洁 & 甘肃白水江国家级自然保护区有尾两栖动物资源现状及保护对策 \\
\hline & & $\lambda$ & /VU & & \\
\hline \multirow[t]{2}{*}{ Tylototriton wenxianensis } & 文县疮螈 & 未列 & 易危 & 魏刚 & 贵州省 8 个自然保护区两栖动物分布研究 \\
\hline & & 入 & /VU & & \\
\hline \multirow[t]{2}{*}{ Tylototriton wenxianensis } & 文县疮螈 & 未列 & 易危 & 龚大洁 & 文县疮螈繁殖初探 \\
\hline & & 入 & /VU & & \\
\hline \multirow[t]{2}{*}{ Tylototriton wenxianensis } & 文县疮螈 & 未列 & 易危 & 王昱 & 文县病螈消化道和肝脏的形态学及组织学观察 \\
\hline & & 入 & /VU & & \\
\hline \multirow[t]{2}{*}{ Tylototriton wenxianensis } & 文县疮螈 & 未列 & 易危 & 江建平 & 文县疮螈在重庆境内分布的补充调查 \\
\hline & & 入 & /VU & & \\
\hline \multirow[t]{2}{*}{ Tylototriton wenxianensis } & 文县疮螈 & 未列 & 易危 & 邓学建 & 文县疮螈早期胚胎发育 \\
\hline & & 入 & $/ \mathrm{VU}$ & & \\
\hline \multirow[t]{2}{*}{ Tylototriton wenxianensis } & 文县痰螈 & 未列 & 易危 & 李晓鸿 & 文县病螈资源现状、威胁因素及保护对策 \\
\hline & & 入 & /VU & & \\
\hline \multirow[t]{2}{*}{ Tylototriton wenxianensis } & 文县疮螈 & 未列 & 易危 & 鲍方印 & 鹞落坪自然保护区文县疮螈的生境选择和食性分析 \\
\hline & & 入 & /VU & & \\
\hline
\end{tabular}


顾垒，闻丞，罗玫，王吴，吕植. 中国最受关注濒危物种保护现状快速评价的新方法探讨. 生物多样性，2015，23(5)：583-590. http://www. biodiversity-science. net/CN/article/downloadArticleFile. do?attachType=PDF\&id=10075

\begin{tabular}{|c|c|c|c|c|c|}
\hline Tylototriton wenxianensis & 文县疮螈 & $\begin{array}{l}\text { 未列 } \\
\text { 入 }\end{array}$ & $\begin{array}{l}\text { 易危 } \\
\text { /VU }\end{array}$ & 侯勉 & 疫螈属形态学研究进展及四隐存居群地位的初步确定 \\
\hline Tylototriton wenxianensis & 文县病螈 & $\begin{array}{l}\text { 未列 } \\
\text { 入 }\end{array}$ & $\begin{array}{l}\text { 易危 } \\
\text { /VU }\end{array}$ & 陈晓虹 & 中国疮螈属一新亚种 \\
\hline Tylototriton wenxianensis & 文县病螈 & $\begin{array}{l}\text { 未列 } \\
\text { 入 }\end{array}$ & $\begin{array}{l}\text { 易危 } \\
\text { /VU }\end{array}$ & 罗键 & 重庆市两栖动物物种多样性研究及保护 \\
\hline Tyto alba & 仓鸮 & II & $\begin{array}{l}\text { 无危 } \\
\text { /LC }\end{array}$ & 周放 & 广西鸟类新纪录_仓鸮 \\
\hline Tyto longimembris & 草鸮 & II & $\begin{array}{l}\text { 无危 } \\
\text { /LC }\end{array}$ & 关贯勋 & 澳门鸟类资源调查报告 \\
\hline Tyto longimembris & 草鸮 & II & $\begin{array}{l}\text { 无危 } \\
\text { /LC }\end{array}$ & 溪波 & 董寨国家级自然保护区繁殖鸟类现状调查 \\
\hline Tyto longimembris & 草鸮 & II & $\begin{array}{l}\text { 无危 } \\
\text { /LC }\end{array}$ & 江建国 & 鄂西野三河自然保护区鸟类资源调查报告 \\
\hline Tyto longimembris & 草鸮 & II & $\begin{array}{l}\text { 无危 } \\
\text { /LC }\end{array}$ & 赵东东 & 广西防城金花茶国家级自然保护区鸟类群落研究 \\
\hline Tyto longimembris & 草鸮 & II & $\begin{array}{l}\text { 无危 } \\
\text { /LC }\end{array}$ & 舒晓莲 & 广西架桥岭自然保护区的鸟类 \\
\hline Tyto longimembris & 草鸮 & II & 无危 & 王绍能 & 广西猫儿山自然保护区珍稀鸟类资源及保护对策 \\
\hline
\end{tabular}


顾垒，闻丞，罗玫，王吴，吕植. 中国最受关注濒危物种保护现状快速评价的新方法探讨. 生物多样性，2015，23(5)：583-590. http://www. biodiversity-science. net/CN/article/downloadArticleFile. do?attachType=PDF\&id=10075

\begin{tabular}{|c|c|c|c|c|c|}
\hline & & & $/ \mathrm{LC}$ & & \\
\hline \multirow[t]{2}{*}{ Tyto longimembris } & 草鸮 & II & 无危 & 乔亮 & 广州白云机场鸟情调查及鸟撞风险分析 \\
\hline & & & $/ \mathrm{LC}$ & & \\
\hline \multirow[t]{2}{*}{ Tyto longimembris } & 草鸮 & II & 无危 & 杨书香 & 湖北省七姊妹山夏季鸟类多样性研究及生境分析 \\
\hline & & & $/ \mathrm{LC}$ & & \\
\hline \multirow[t]{2}{*}{ Tyto longimembris } & 草鸮 & II & 无危 & 黄晓凤 & 江西齐云山自然保护区鸟类区系与多样性分析 \\
\hline & & & $/ \mathrm{LC}$ & & \\
\hline \multirow[t]{2}{*}{ Tyto longimembris } & 草鸮 & II & 无危 & 黄族豪 & 井冈山国家级自然保护区鸟类资源研究 \\
\hline & & & $/ \mathrm{LC}$ & & \\
\hline \multirow[t]{2}{*}{ Tyto longimembris } & 草鸮 & II & 无危 & 张 君 & 四川东阳沟自然保护区鸟类区系初步调查 \\
\hline & & & $/ \mathrm{LC}$ & & \\
\hline \multirow[t]{2}{*}{ Tyto longimembris } & 草鸮 & II & 无危 & 舒 实 & 薤山自然保护区珍稀濒危野生脊椎动物调查 \\
\hline & & & $/ \mathrm{LC}$ & & \\
\hline \multirow[t]{3}{*}{ Ursus arctos } & 棕熊 & II & $\mathrm{LR} /$ & J.marc foggin & Conflicts between local villagers and Tibetan brown bears threaten conservation of bears in a \\
\hline & & & 无危 & & remote region of the Tibetan Plateau \\
\hline & & & $/ \mathrm{LC}$ & & \\
\hline \multirow[t]{3}{*}{ Ursus arctos } & 棕熊 & II & $\mathrm{LR} /$ & Xu Aichun & Summer food habits of brown bears in Kekexili Nature Reserve, Qinghai-Tibetan plateau, \\
\hline & & & 无危 & & China \\
\hline & & & $/ \mathrm{LC}$ & & \\
\hline
\end{tabular}


顾垒，闻丞，罗玫，王吴，吕植. 中国最受关注濒危物种保护现状快速评价的新方法探讨. 生物多样性，2015，23(5)：583-590. http://www. biodiversity-science. net/CN/article/downloadArticleFile. do?attachType=PDF\&id=10075

\begin{tabular}{|c|c|c|c|c|c|}
\hline Ursus arctos & 棕熊 & II & $\begin{array}{l}\text { LR/ } \\
\text { 无危 } \\
\text { /LC }\end{array}$ & 吴国生 & 可可西里地区的藏棕熊与其面临的潜在威胁 \\
\hline Ursus arctos & 棕熊 & II & $\begin{array}{l}\text { LR/ } \\
\text { 无危 } \\
\text { /LC }\end{array}$ & 赵怀东 & $\begin{array}{l}\text { 美塘国家级自然保护区社区防护措施 } \\
\text { 对减缓人 熊冲突的作用 }\end{array}$ \\
\hline Ursus arctos & 棕熊 & II & $\begin{array}{l}\text { LR/ } \\
\text { 无危 } \\
\text { /LC }\end{array}$ & 蒋志刚 & 青藏高原可可西里地区藏棕熊暖季食性及采食行为模式 \\
\hline Ursus arctos & 棕熊 & II & $\begin{array}{l}\text { LR/ } \\
\text { 无危 } \\
\text { /LC }\end{array}$ & 李崇民 & 乌玛保护区野生棕熊达 50 只 \\
\hline Ursus arctos & 棕熊 & II & $\begin{array}{l}\text { LR/ } \\
\text { 无危 } \\
\text { /LC }\end{array}$ & 刘务林 & 西藏棕熊生态学和资源状况研究 \\
\hline Ursus arctos & 棕熊 & II & $\begin{array}{l}\text { LR/ } \\
\text { 无危 } \\
\text { /LC }\end{array}$ & 高行宜 & 新疆棕熊的分布和种群数量 \\
\hline Ursus arctos & 棕熊 & II & $\mathrm{LR} /$ & 徐爱春 & 玉树藏族自治州人 \\
\hline
\end{tabular}


顾垒，闻丞，罗玫，王吴，吕植. 中国最受关注濒危物种保护现状快速评价的新方法探讨. 生物多样性，2015，23(5)：583-590. http://www. biodiversity-science. net/CN/article/downloadArticleFile. do?attachType=PDF\&id=10075

\begin{tabular}{|c|c|c|c|c|c|}
\hline & & & 无危 & & - \\
\hline & & & $/ \mathrm{LC}$ & & 藏棕熊冲突调查与解决对策 \\
\hline \multirow[t]{3}{*}{ Ursus arctos } & 棕熊 & II & $\mathrm{LR} /$ & 朴 正 吉 & 长白山自然保护区黑熊和棕熊种群数量动态分析 \\
\hline & & & 无危 & & \\
\hline & & & $/ \mathrm{LC}$ & & \\
\hline \multirow[t]{3}{*}{ Ursus arctos } & 棕熊 & II & $\mathrm{LR} /$ & 顾文华 & 棕熊的饲养与繁殖观察 \\
\hline & & & 无危 & & \\
\hline & & & $/ \mathrm{LC}$ & & \\
\hline \multirow[t]{2}{*}{ Ursus thibetanus } & 黑熊 & II & 易危 & Wan-ru Hou & A complete mitochondrial genome sequence of Asian black bear Sichuan subspecies (Ursus \\
\hline & & & /VU & & thibetanus mupinensis) \\
\hline \multirow[t]{2}{*}{ Ursus thibetanus } & 黑熊 & II & 易危 & M.-H. Hwang & Activity patterns of Asiatic black bears (Ursus thibetanus) in the Central Mountains of Taiwan \\
\hline & & & /VU & & \\
\hline \multirow[t]{2}{*}{ Ursus thibetanus } & 黑熊 & II & 易危 & K.D. Malcolm & Analyses of fecal and hair glucocorticoids to evaluate short- and long-term stress and recovery \\
\hline & & & /VU & & of Asiatic black bears (Ursus thibetanus) removed from bile farms in China \\
\hline \multirow[t]{2}{*}{ Ursus thibetanus } & 黑熊 & II & 易危 & MEI-HSIU HWANG & DIETS OF ASIATIC BLACK BEARS IN TAIWANW,WITH METHODOLOGICAL AND \\
\hline & & & /VU & & GEOGRAPHICAL COMPARISONS \\
\hline \multirow[t]{2}{*}{ Ursus thibetanus } & 黑熊 & II & 易危 & MEI-HSIU HWANG & ECOLOGY OF ASIATIC BLACK BEARS AND PEOPLE-BEAR INTERACTIONS IN \\
\hline & & & /VU & & YUSHAN NATIONAL PARK, TAIWAN \\
\hline Ursus thibetanus & 黑熊 & II & 易危 & M.J. Zhang & Electroejaculation and semen characteristics of Asiatic Black bears (Ursus thibetanus) \\
\hline
\end{tabular}


顾垒，闻丞，罗玫，王吴，吕植. 中国最受关注濒危物种保护现状快速评价的新方法探讨. 生物多样性，2015，23(5)：583-590. http://www biodiversity-science. net/CN/article/downloadArticleFile. do?attachType=PDF\&id=10075

\begin{tabular}{|c|c|c|c|c|c|}
\hline & & & $/ \mathrm{VU}$ & & \\
\hline \multirow[t]{2}{*}{ Ursus thibetanus } & 黑熊 & II & 易危 & Mei-Hsiu Hwang & Home ranges of Asiatic black bears in the Central Mountains of Taiwan: Gauging whether a \\
\hline & & & /VU & & reserve is big enough \\
\hline \multirow[t]{2}{*}{ Ursus thibetanus } & 黑熊 & II & 易危 & Fang Liu & Human-wildlife conflicts influence attitudes but not necessarily behaviors:Factors driving the \\
\hline & & & /VU & & poaching of bears in China \\
\hline \multirow[t]{2}{*}{ Ursus thibetanus } & 亚洲黑熊 & II & 易危 & Ya-ping Zhang & Phylogeny of the bears (Ursidae) based on nuclear and mitochondrial genes \\
\hline & & & $/ \mathrm{VU}$ & & \\
\hline \multirow[t]{2}{*}{ Ursus thibetanus } & 黑熊 & II & 易危 & Fang Liu & Spatial distribution as a measure of conservation needs: an example with Asiatic black bears in \\
\hline & & & /VU & & south-western China \\
\hline \multirow[t]{2}{*}{ Ursus thibetanus } & 黑熊 & II & 易危 & 杨文忠 & 白马雪山南段野生动物肇事的时空格局 \\
\hline & & & /VU & & \\
\hline \multirow[t]{2}{*}{ Ursus thibetanus } & 黑熊 & II & 易危 & 李 伟 & 白石砬子地区黑熊资源调查研究与保护建议 \\
\hline & & & /VU & & \\
\hline \multirow[t]{2}{*}{ Ursus thibetanus } & 黑熊 & II & 易危 & 铸钟源 & 北方地区进行黑熊繁殖的现状与对策 \\
\hline & & & /VU & & \\
\hline \multirow[t]{2}{*}{ Ursus thibetanus } & 黑熊 & II & 易危 & 薛京浩 & 北方地区室内温度对黑熊产胆量的影响 \\
\hline & & & /VU & & \\
\hline \multirow[t]{2}{*}{ Ursus thibetanus } & 黑熊 & II & 易危 & 刘德成 & 雌性黑熊发情期间尿液中雌二醇含量变化规律的研究 \\
\hline & & & $/ \mathrm{VU}$ & & \\
\hline
\end{tabular}


顾垒，闻丞，罗玫，王吴，吕植. 中国最受关注濒危物种保护现状快速评价的新方法探讨. 生物多样性，2015，23(5)：583-590. http://www, biodiversity-science. net/CN/article/downloadArticleFile. do?attachType=PDF\&id=10075

\begin{tabular}{|c|c|c|c|c|c|}
\hline Ursus thibetanus & 黑熊 & II & $\begin{array}{l}\text { 易危 } \\
\text { /VU }\end{array}$ & 崔成都 & 雌性黑熊发情期间阴道上皮细胞的变化与发情行为的关系 \\
\hline Ursus thibetanus & 黑熊 & II & $\begin{array}{l}\text { 易危 } \\
\text { /VU }\end{array}$ & 崔成都 & 雌性黑熊生殖系统的形态学观察 \\
\hline Ursus thibetanus & 黑熊 & II & $\begin{array}{l}\text { 易危 } \\
\text { /VU }\end{array}$ & 姚贵芳 & 胆汁引流对黑熊健康状况影响的研究 \\
\hline Ursus thibetanus & 黑熊 & II & $\begin{array}{l}\text { 易危 } \\
\text { /VU }\end{array}$ & 鲁承 & 东北黑熊不同基因组 DNA 模板来源的比较研究 \\
\hline Ursus thibetanus & 黑熊 & II & $\begin{array}{l}\text { 易危 } \\
\text { /VU }\end{array}$ & 鲁承 & 东北黑熊养殖群体 6 个微卫星基因座遗传多态性研究 \\
\hline Ursus thibetanus & 黑熊 & II & $\begin{array}{l}\text { 易危 } \\
\text { /VU }\end{array}$ & 刘中来 & 粪便取样对亚洲黑熊脑源性神经营养因子基因全长序列分析 \\
\hline Ursus thibetanus & 黑熊 & II & $\begin{array}{l}\text { 易危 } \\
\text { /VU }\end{array}$ & 廖丽晶 & 广东车八岭自然保护区疑似黑熊爪鞘的分子鉴定 \\
\hline Ursus thibetanus & 黑熊 & II & $\begin{array}{l}\text { 易危 } \\
/ \mathrm{VU}\end{array}$ & 莫运明 & 广西黑熊资源调查及保护对策 \\
\hline Ursus thibetanus & 黑熊 & II & $\begin{array}{l}\text { 易危 } \\
\text { /VU }\end{array}$ & 李友邦 & 广西猫儿山国家级自然保护区黑熊种群和数量分布调查 \\
\hline Ursus thibetanus & 黑熊 & II & 易危 & 原宝东 & 广西元宝山自然保护区黑熊春季受食生境特征 \\
\hline
\end{tabular}


顾垒，闻丞，罗玫，王吴，吕植. 中国最受关注濒危物种保护现状快速评价的新方法探讨. 生物多样性，2015，23(5)：583-590. http://www. biodiversity-science. net/CN/article/downloadArticleFile. do?attachType=PDF\&id=10075

\begin{tabular}{|c|c|c|c|c|c|}
\hline & & & /VU & & \\
\hline \multirow[t]{2}{*}{ Ursus thibetanus } & 黑熊 & II & 易危 & 原宝东 & 广西元宝山自然保护区黑熊春季受食生境选择分析 \\
\hline & & & /VU & & \\
\hline \multirow[t]{2}{*}{ Ursus thibetanus } & 黑熊 & II & 易危 & 原宝东 & 广西元宝山自然保护区黑熊春季栖息地选择 \\
\hline & & & /VU & & \\
\hline \multirow[t]{2}{*}{ Ursus thibetanus } & 黑熊 & II & 易危 & 王文 & 黑龙江龙口自然保护区黑熊春季生境选择 \\
\hline & & & /VU & & \\
\hline \multirow[t]{2}{*}{ Ursus thibetanus } & 黑熊 & II & 易危 & 王文 & 黑龙江省通河县乌拉浑林场黑熊的生境选择 \\
\hline & & & /VU & & \\
\hline \multirow[t]{2}{*}{ Ursus thibetanus } & 黑熊 & II & 易危 & 张明海 & 黑龙江省熊类资源现状及其保护对策 \\
\hline & & & /VU & & \\
\hline \multirow[t]{2}{*}{ Ursus thibetanus } & 黑熊 & II & 易危 & 安伟国 & 黑熊 846 麻醉药中毒病例报告 \\
\hline & & & $/ \mathrm{VU}$ & & \\
\hline \multirow[t]{2}{*}{ Ursus thibetanus } & 黑熊 & II & 易危 & 路一平 & 黑熊产后食仔的主要原因分析与预防 \\
\hline & & & /VU & & \\
\hline \multirow[t]{2}{*}{ Ursus thibetanus } & 黑熊 & II & 易危 & 庞丰丰 & 黑熊常见四种疾病的防治经验 \\
\hline & & & /VU & & \\
\hline \multirow[t]{2}{*}{ Ursus thibetanus } & 黑熊 & II & 易危 & 崔成都 & 黑熊雌性生殖系统的组织解剖学观察 \\
\hline & & & /VU & & \\
\hline
\end{tabular}


顾垒，闻丞，罗玫，王吴，吕植. 中国最受关注濒危物种保护现状快速评价的新方法探讨. 生物多样性，2015，23(5)：583-590. http://www. biodiversity-science. net/CN/article/downloadArticleFile. do?attachType=PDF\&id=10075

\begin{tabular}{|c|c|c|c|c|c|}
\hline Ursus thibetanus & 黑熊 & II & $\begin{array}{l}\text { 易危 } \\
\text { /VU }\end{array}$ & 崔岩 & 黑熊的人工饲养及繁殖期行为观察 \\
\hline Ursus thibetanus & 黑熊 & II & $\begin{array}{l}\text { 易危 } \\
\text { /VU }\end{array}$ & 安伟国 & 黑熊的人工饲养及疾病防治 \\
\hline Ursus thibetanus & 黑熊 & II & $\begin{array}{l}\text { 易危 } \\
\text { /VU }\end{array}$ & 林贤顺 & 黑熊的血液指标测定及初步分析 \\
\hline Ursus thibetanus & 黑熊 & II & $\begin{array}{l}\text { 易危 } \\
\text { /VU }\end{array}$ & 刘学龙 & 黑熊繁殖期行为特性的观察 \\
\hline Ursus thibetanus & 黑熊 & II & $\begin{array}{l}\text { 易危 } \\
\text { /VU }\end{array}$ & 金昌深 & 黑熊腹膜炎临床观察及腹腔引流疗法 \\
\hline Ursus thibetanus & 黑熊 & II & $\begin{array}{l}\text { 易危 } \\
\text { /VU }\end{array}$ & 崔成都 & 黑熊睪丸和附睪的组织学观察 \\
\hline Ursus thibetanus & 黑熊 & II & $\begin{array}{l}\text { 易危 } \\
\text { /VU }\end{array}$ & 俞曙林 & 黑熊股骨、胫骨和腓骨解剖特性的观察与比较 \\
\hline Ursus thibetanus & 黑熊 & II & $\begin{array}{l}\text { 易危 } \\
\text { /VU }\end{array}$ & 俞曙林 & 黑熊骨盆骨解剖特性的形态学观察 \\
\hline Ursus thibetanus & 黑熊 & II & $\begin{array}{l}\text { 易危 } \\
\text { /VU }\end{array}$ & 侯万儒 & 黑熊肌酸激酶及其同工酶活性的检测 \\
\hline Ursus thibetanus & 黑熊 & II & 易危 & 俞曙林 & 黑熊肩胛骨、臂骨解剖特性的观察与比较 \\
\hline
\end{tabular}


顾垒，闻丞，罗玫，王吴，吕植. 中国最受关注濒危物种保护现状快速评价的新方法探讨. 生物多样性，2015，23(5)：583-590. http://www. biodiversity-science. net/CN/article/downloadArticleFile. do?attachType=PDF\&id=10075

\begin{tabular}{|c|c|c|c|c|c|}
\hline & & & $/ \mathrm{VU}$ & & \\
\hline \multirow[t]{2}{*}{ Ursus thibetanus } & 黑熊 & II & 易危 & 王富安 & 黑熊笼养状态下的繁殖研究 \\
\hline & & & $/ \mathrm{VU}$ & & \\
\hline \multirow[t]{2}{*}{ Ursus thibetanus } & 黑熊 & II & 易危 & 夏茜 & 黑熊受食生境选择及植物性食物营养分析 \\
\hline & & & /VU & & \\
\hline \multirow[t]{2}{*}{ Ursus thibetanus } & 黑熊 & II & 易危 & 俞曙林 & 黑熊前肢静脉形态学观察 \\
\hline & & & /VU & & \\
\hline \multirow[t]{2}{*}{ Ursus thibetanus } & 黑熊 & II & 易危 & 李钟淑 & 黑熊染色体 C-带的研究 \\
\hline & & & /VU & & \\
\hline \multirow[t]{2}{*}{ Ursus thibetanus } & 黑熊 & II & 易危 & 崔成都 & 黑熊肾上腺的解剖及组织形态结构观察 \\
\hline & & & $/ \mathrm{VU}$ & & \\
\hline \multirow[t]{2}{*}{ Ursus thibetanus } & 黑熊 & II & 易危 & 白素英 & 黑熊四川亚种线粒体 DNA cytb 基因的克隆及全序列分析 \\
\hline & & & /VU & & \\
\hline \multirow[t]{2}{*}{ Ursus thibetanus } & 黑熊 & II & 易危 & 刘学龙 & 黑熊无管引流取胆术后继发症的治疗 \\
\hline & & & /VU & & \\
\hline \multirow[t]{2}{*}{ Ursus thibetanus } & 黑熊 & II & 易危 & 赵秀娟 & 黑熊研究中 DNA 分析方法的应用概述 \\
\hline & & & /VU & & \\
\hline \multirow[t]{2}{*}{ Ursus thibetanus } & 黑熊 & II & 易危 & 陈新敏 & 黑熊在冬眠时甲状腺激素的变化及其意义 \\
\hline & & & /VU & & \\
\hline
\end{tabular}


顾垒，闻丞，罗玫，王吴，吕植. 中国最受关注濒危物种保护现状快速评价的新方法探讨. 生物多样性，2015，23(5)：583-590. http://www. biodiversity-science. net/CN/article/downloadArticleFile. do?attachType=PDF\&id=10075

\begin{tabular}{|c|c|c|c|c|c|}
\hline Ursus thibetanus & 黑熊 & II & $\begin{array}{l}\text { 易危 } \\
\text { /VU }\end{array}$ & 侯万儒 & 黑熊种群年龄结构和生命表初探 \\
\hline Ursus thibetanus & 黑熊 & II & $\begin{array}{l}\text { 易危 } \\
\text { /VU }\end{array}$ & 邓学建 & 湖南黑熊资源消长趋势及种群数量增长的预测 \\
\hline Ursus thibetanus & 黑熊 & II & $\begin{array}{l}\text { 易危 } \\
\text { /VU }\end{array}$ & 徐卫华 & 基于 MAXENT 模型的秦岭山系黑熊潜在生境评价 \\
\hline Ursus thibetanus & 黑熊 & II & $\begin{array}{l}\text { 易危 } \\
\text { /VU }\end{array}$ & 张小芳 & 基于微卫星的亚洲黑熊个体识别技术研究 \\
\hline Ursus thibetanus & 黑熊 & II & $\begin{array}{l}\text { 易危 } \\
\text { /VU }\end{array}$ & 冯江 & 吉林省熊类资源现状及保护 \\
\hline Ursus thibetanus & 黑熊 & II & $\begin{array}{l}\text { 易危 } \\
\text { /VU }\end{array}$ & 冯子山 & 澜沧县野生动物肇事情况调查报告 \\
\hline Ursus thibetanus & 黑熊 & II & $\begin{array}{l}\text { 易危 } \\
\text { /VU }\end{array}$ & 肖常青 & 辽宁省黑熊养殖业发展对策的研究 \\
\hline Ursus thibetanus & 黑熊 & II & $\begin{array}{l}\text { 易危 } \\
\text { /VU }\end{array}$ & 张树清 & 辽宁省黑熊资源现状及保护 \\
\hline Ursus thibetanus & 黑熊 & II & $\begin{array}{l}\text { 易危 } \\
\text { /VU }\end{array}$ & 李良 & 美姑大风顶自然保护区 $20009 、 20010$ 年秋季黑熊监测分析 \\
\hline Ursus thibetanus & 黑熊 & II & 易危 & 鲁庆彬 & 岷山黑熊生境选择的初步分析 \\
\hline
\end{tabular}


顾垒，闻丞，罗玫，王吴，吕植. 中国最受关注濒危物种保护现状快速评价的新方法探讨. 生物多样性，2015，23(5)：583-590. http://www biodiversity-science. net/CN/article/downloadArticleFile. do?attachType=PDF\&id=10075

\begin{tabular}{|c|c|c|c|c|c|}
\hline & & & $/ \mathrm{VU}$ & & \\
\hline \multirow[t]{2}{*}{ Ursus thibetanus } & 黑熊 & II & 易危 & 鲁庆彬 & 岷山山系黑熊的种群数量及分析 \\
\hline & & & /VU & & \\
\hline \multirow[t]{2}{*}{ Ursus thibetanus } & 黑熊 & II & 易危 & 侯万儒 & 岷山山系黑熊种群生存力分析及黑熊分子生物学初探 \\
\hline & & & /VU & & \\
\hline \multirow[t]{2}{*}{ Ursus thibetanus } & 黑熊 & II & 易危 & 秦礼柱 & 浅谈亚洲黑熊的麻醉 \\
\hline & & & /VU & & \\
\hline \multirow[t]{2}{*}{ Ursus thibetanus } & 黑熊 & II & 易危 & 刘伟 & 圈养黑熊人工授精技术的研究 \\
\hline & & & /VU & & \\
\hline \multirow[t]{2}{*}{ Ursus thibetanus } & 黑熊 & II & 易危 & 刘伟石 & 圈养取胆黑熊的刻板行为 \\
\hline & & & $/ \mathrm{VU}$ & & \\
\hline \multirow[t]{2}{*}{ Ursus thibetanus } & 黑熊 & II & 易危 & 张明海 & 人工饲养条件下熊科动物的人工授精技术 \\
\hline & & & /VU & & \\
\hline \multirow[t]{2}{*}{ Ursus thibetanus } & 黑熊 & II & 易危 & 侯万儒 & 四川黑熊(Ursus thibetanus mupinensis) 线粒体 NADH 脱氢酶亚基 1 基因(ND1) 的序列分 \\
\hline & & & /VU & & 析 \\
\hline \multirow[t]{2}{*}{ Ursus thibetanus } & 黑熊 & II & 易危 & 侯万儒 & 四川黑熊 NADH 脱氢酶亚基 4 基因的序列分析 \\
\hline & & & /VU & & \\
\hline \multirow[t]{2}{*}{ Ursus thibetanus } & 黑熊 & II & 易危 & 侯万儒 & 四川黑熊 ND3、ND4L 和 tRNA-Arg 基因的克隆和序列分析 \\
\hline & & & /VU & & \\
\hline
\end{tabular}


顾垒，闻丞，罗玫，王吴，吕植. 中国最受关注濒危物种保护现状快速评价的新方法探讨. 生物多样性，2015，23(5)：583-590. http://www. biodiversity-science. net/CN/article/downloadArticleFile. do?attachType=PDF\&id=10075

\begin{tabular}{|c|c|c|c|c|c|}
\hline Ursus thibetanus & 黑熊 & II & $\begin{array}{l}\text { 易危 } \\
\text { /VU }\end{array}$ & 侯万儒 & 四川黑熊 RPS16 亚基基因的克隆与序列分析 \\
\hline Ursus thibetanus & 黑熊 & II & $\begin{array}{l}\text { 易危 } \\
\text { /VU }\end{array}$ & 侯万儒 & 四川黑熊线粒体 $12 \mathrm{~S}$ 和 $16 \mathrm{~S}$ rRNA 基因的克隆及序列分析 \\
\hline Ursus thibetanus & 黑熊 & II & $\begin{array}{l}\text { 易危 } \\
\text { /VU }\end{array}$ & 侯万儒 & 四川黑熊线粒体细胞色素 C 氧化酶亚基 I 基因的克隆及序列分析 \\
\hline Ursus thibetanus & 黑熊 & II & $\begin{array}{l}\text { 易危 } \\
\text { /VU }\end{array}$ & 侯万儒 & 四川九顶山自然保护区野生黑熊种群生存力初步分析 \\
\hline Ursus thibetanus & 黑熊 & II & $\begin{array}{l}\text { 易危 } \\
\text { /VU }\end{array}$ & 侯万儒 & 唐家河自然保护区黑熊种群生存力初步分析 \\
\hline Ursus thibetanus & 黑熊 & II & $\begin{array}{l}\text { 易危 } \\
\text { /VU }\end{array}$ & 张明华 & 提高黑熊繁殖率的主要措施 \\
\hline Ursus thibetanus & 黑熊 & II & $\begin{array}{l}\text { 易危 } \\
\text { /VU }\end{array}$ & 侯万儒 & 卧龙自然保护区黑熊种群生存力初步分析 \\
\hline Ursus thibetanus & 黑熊 & II & $\begin{array}{l}\text { 易危 } \\
\text { /VU }\end{array}$ & 刘务林 & 西藏黑熊生态学和资源状况研究 \\
\hline Ursus thibetanus & 黑熊 & II & $\begin{array}{l}\text { 易危 } \\
\text { /VU }\end{array}$ & 王文 & 小兴安岭地区黑熊的食性分析 \\
\hline Ursus thibetanus & 黑熊 & II & 易危 & 战如亮 & 小兴安岭地区森林资源利用对黑熊栖息地的时 \\
\hline
\end{tabular}


顾垒，闻丞，罗玫，王吴，吕植. 中国最受关注濒危物种保护现状快速评价的新方法探讨. 生物多样性，2015，23(5)：583-590. http://www biodiversity-science. net/CN/article/downloadArticleFile. do?attachType=PDF\&id=10075

\begin{tabular}{|c|c|c|c|c|c|}
\hline & & & /VU & & 空尺度和食物资源的影响 \\
\hline \multirow[t]{2}{*}{ Ursus thibetanus } & 黑熊 & II & 易危 & 张明海 & 小兴安岭林区黑熊对冬眠仓的选择 \\
\hline & & & /VU & & \\
\hline \multirow[t]{2}{*}{ Ursus thibetanus } & 黑熊 & II & 易危 & 王文 & 小兴安岭林区黑熊食性!家域和生境 \\
\hline & & & /VU & & 生态学研究 \\
\hline \multirow[t]{2}{*}{ Ursus thibetanus } & 黑熊 & II & 易危 & 王文 & 小兴安岭南坡黑熊植物性食物营养分析 \\
\hline & & & /VU & & \\
\hline \multirow[t]{2}{*}{ Ursus thibetanus } & 黑熊 & II & 易危 & 陈洋 & 小兴安岭乌拉浑和烟筒山林场黑熊生境选择和 \\
\hline & & & /VU & & 适宜性评价 \\
\hline \multirow[t]{2}{*}{ Ursus thibetanus } & 黑熊 & II & 易危 & 白素英 & 亚洲黑熊 COI 序列变异及其 DNA 条码的应用 1 \\
\hline & & & /VU & & \\
\hline \multirow[t]{2}{*}{ Ursus thibetanus } & 黑熊 & II & 易危 & 向余劲攻 & 亚洲黑熊的群体遗传学 \\
\hline & & & $/ \mathrm{VU}$ & & \\
\hline \multirow[t]{2}{*}{ Ursus thibetanus } & 黑熊 & II & 易危 & 张志敏 & 亚洲黑熊活化素 $\beta$ A 亚基基因克隆及分子进化分析 \\
\hline & & & /VU & & \\
\hline \multirow[t]{2}{*}{ Ursus thibetanus } & 黑熊 & II & 易危 & 张志敏 & 亚洲黑熊脑源性神经营养因子全长基因和活化素 $\mathrm{\beta} \mathrm{A}$ 亚基基因的克隆及分子进化分析 \\
\hline & & & /VU & & \\
\hline \multirow[t]{2}{*}{ Ursus thibetanus } & 黑熊 & II & 易危 & 侯万儒 & 亚洲黑熊四川亚种(U rsus thibetanus mupinensis)线粒体 ATP 合酶和亚基基因克隆及序列 \\
\hline & & & /VU & & 分析 \\
\hline
\end{tabular}


顾垒，闻丞，罗玫，王吴，吕植. 中国最受关注濒危物种保护现状快速评价的新方法探讨. 生物多样性，2015，23(5)：583-590. http://www. biodiversity-science. net/CN/article/downloadArticleFile. do?attachType=PDF\&id=10075

\begin{tabular}{|c|c|c|c|c|c|}
\hline Ursus thibetanus & 黑熊 & II & $\begin{array}{l}\text { 易危 } \\
\text { /VU }\end{array}$ & 侯万儒 & $\begin{array}{l}\text { 亚洲黑熊四川亚种 Ur sus thibetanus mup inensis 线粒体细胞色素 C 氧化酶亚基III基因的 } \\
\text { 克隆与初步分析 }\end{array}$ \\
\hline Ursus thibetanus & 黑熊 & II & $\begin{array}{l}\text { 易危 } \\
\text { /VU }\end{array}$ & 侯万儒 & 亚洲黑熊四川亚种线粒体 NADH 脱氢酶亚基 5 和亚基 6 基因的克隆与初步分析 \\
\hline Ursus thibetanus & 黑熊 & II & $\begin{array}{l}\text { 易危 } \\
\text { /VU }\end{array}$ & 侯万儒 & 亚洲黑熊四川亚种线粒体细胞色素氧化酶亚基 II 基因基因克隆与序列分析 \\
\hline Ursus thibetanus & 黑熊 & II & $\begin{array}{l}\text { 易危 } \\
\text { /VU }\end{array}$ & 金金金 & 延边地区黑熊资源开发利用的现状及发展趋势 \\
\hline Ursus thibetanus & 黑熊 & II & $\begin{array}{l}\text { 易危 } \\
\text { /VU }\end{array}$ & 农汝 & 一例黑熊脱毛症的治疗 \\
\hline Ursus thibetanus & 黑熊 & II & $\begin{array}{l}\text { 易危 } \\
\text { /VU }\end{array}$ & 高建伟 & $\begin{array}{l}\text { 应用微卫星 DNA 标记对延边圈养黑熊 } \\
\text { 进行亲子鉴定和遗传多样性研究 }\end{array}$ \\
\hline Ursus thibetanus & 黑熊 & II & $\begin{array}{l}\text { 易危 } \\
\text { /VU }\end{array}$ & 王妍 & 幼熊的人工饲养及疾病的预防 \\
\hline Ursus thibetanus & 黑熊 & II & $\begin{array}{l}\text { 易危 } \\
\text { /VU }\end{array}$ & 朴正吉 & 长白山自然保护区黑熊和棕熊种群数量动态分析 \\
\hline Ursus thibetanus & 黑熊 & II & 易危 & 朴正吉 & 长白山自然保护区黑熊和棕熊种群数量动态分析 \\
\hline
\end{tabular}


顾垒，闻丞，罗玫，王吴，吕植. 中国最受关注濒危物种保护现状快速评价的新方法探讨．生物多样性，2015，23(5)：583-590。 http://www. biodiversity-science. net/CN/article/downloadArticleFile. do?attachType=PDF\&id=10075

\begin{tabular}{|c|c|c|c|c|c|}
\hline & & & $/ \mathrm{VU}$ & & \\
\hline \multirow[t]{2}{*}{ Ursus thibetanus } & 黑熊 & II & 易危 & 李波 & 中国黑熊及其养殖业的发展现状 \\
\hline & & & /VU & & \\
\hline \multirow[t]{2}{*}{ Ursus thibetanus } & 黑熊 & II & 易危 & 李波 & 中国黑熊及其养殖业的现状 \\
\hline & & & /VU & & \\
\hline \multirow[t]{3}{*}{ Varanus salvator } & 巨蜥 & I & 未评 & Jianjun Peng & Isolation and characterization of novel microsatellite markers in Water monitor(Varanus \\
\hline & & & 价 & & salvator) \\
\hline & & & $/ \mathrm{NE}$ & & \\
\hline \multirow[t]{3}{*}{ Varanus salvator } & 巨蜥 & I & 未评 & 谢杰 & 阿维菌素和丙硫苯咪唑对巨蜊体内寄生虫的驱除试验 \\
\hline & & & 价 & & \\
\hline & & & $/ \mathrm{NE}$ & & \\
\hline \multirow[t]{3}{*}{ Varanus salvator } & 巨蜥 & I & 未评 & 蒲文珺 & 广东省巨蜊寄生虫感染状况的貂蝉 \\
\hline & & & 价 & & \\
\hline & & & $/ \mathrm{NE}$ & & \\
\hline \multirow[t]{3}{*}{ Varanus salvator } & 巨蜥 & I & 未评 & 徐正强 & 国内巨蚚的研究现状 \\
\hline & & & 价 & & \\
\hline & & & $/ \mathrm{NE}$ & & \\
\hline Varanus salvator & 巨蜥 & I & 未评 & 王春晓 & 巨蜊蛋人工孵化初探 \\
\hline
\end{tabular}


顾垒，闻丞，罗玫，王吴，吕植. 中国最受关注濒危物种保护现状快速评价的新方法探讨. 生物多样性，2015，23(5)：583-590. http://www. biodiversity-science. net/CN/article/downloadArticleFile. do?attachType=PDF\&id=10075

\begin{tabular}{|c|c|c|c|c|c|}
\hline & & & $/ \mathrm{NE}$ & & \\
\hline \multirow[t]{2}{*}{ Varanus salvator } & 巨蜲 & I & $\begin{array}{l}\text { 未评 } \\
\text { 价 }\end{array}$ & 毛杰 & 巨蚚的人工饲养初探 \\
\hline & & & $/ \mathrm{NE}$ & & \\
\hline \multirow[t]{3}{*}{ Varanus salvator } & 巨蜥 & I & 未评 & 阮桂文 & 巨蚚生态标本的制作技术 \\
\hline & & & 价 & & \\
\hline & & & $/ \mathrm{NE}$ & & \\
\hline \multirow[t]{3}{*}{ Varanus salvator } & 巨蜥 & I & 未评 & 沈怡萱 & 巨蜊喏水气单胞菌和保科爱德华菌混合感染诊治的初步研究 \\
\hline & & & 价 & & \\
\hline & & & $/ \mathrm{NE}$ & & \\
\hline \multirow[t]{3}{*}{ Varanus salvator } & 巨蜥 & I & 未评 & 陈武 & 巨蜊源嗜水气单胞菌分离株的病原特性分析 \\
\hline & & & 价 & & \\
\hline & & & $/ \mathrm{NE}$ & & \\
\hline \multirow[t]{3}{*}{ Varanus salvator } & 巨虲 & I & 未评 & 彭建军 & 利用特异引物和直接测序法鉴定圆鼻巨蝰和孟加拉巨蚚 \\
\hline & & & 价 & & \\
\hline & & & $/ \mathrm{NE}$ & & \\
\hline \multirow[t]{3}{*}{ Varanus salvator } & 巨蜥 & I & 未评 & 傅美兰 & 圆鼻巨蜥微卫星分子标记的制备和遗传多样性的 RAPD 分析 \\
\hline & & & 价 & & \\
\hline & & & $/ \mathrm{NE}$ & & \\
\hline
\end{tabular}


顾垒，闻丞，罗玫，王吴，吕植. 中国最受关注濒危物种保护现状快速评价的新方法探讨. 生物多样性，2015，23(5)：583-590. http://www. biodiversity-science. net/CN/article/downloadArticleFile. do?attachType=PDF\&id=10075

\begin{tabular}{|c|c|c|c|c|c|}
\hline Varanus salvator & 巨蚚 & I & $\begin{array}{l}\text { 未评 } \\
\text { 价 } \\
\text { /NE }\end{array}$ & 傅美兰 & 圆鼻巨蚚遗传多样性的 RAPD 分析 \\
\hline Vatica xishuangbannaensis & 版纳青梅 & II & $\begin{array}{l}\text { 极危 } \\
\text { /CR }\end{array}$ & Tianhua He & $\begin{array}{l}\text { A Preliminary Study on Conservation Genetics of Endangered Vatica guangxiensis } \\
\text { ( Dipterocarpaceae) }\end{array}$ \\
\hline Vatica xishuangbannaensis & 版纳青梅 & II & $\begin{array}{l}\text { 极危 } \\
\text { /CR }\end{array}$ & Kunfang Cao & $\begin{array}{l}\text { Stem hydraulics mediates leaf water status, carbon gain, nutrient use efficiencies and plant } \\
\text { growth rates across dipterocarp species }\end{array}$ \\
\hline Vatica xishuangbannaensis & 版纳青梅 & II & 极危 & Kunfang Cao & $\begin{array}{l}\text { Sustained diurnal photosynthetic depression in uppermost-canopy leaves of four dipterocarp } \\
\text { species in the rainy and dry seasons: does photorespiration play a role in photoprotection? }\end{array}$ \\
\hline Vatica xishuangbannaensis & 版纳青梅 & II & $\begin{array}{l}\text { 极危 } \\
\text { /CR }\end{array}$ & 李巧明 & 版纳青梅居群的遗传多样性和群体分化 \\
\hline Vatica xishuangbannaensis & 版纳青梅 & II & 极危 & 黄仕训 & 濒危树种广西青梅保护初步研究 \\
\hline Vatica xishuangbannaensis & 版纳青梅 & II & 极危 & 李巧明 & 龙脑香科两种濒危植物的保护遗传学研究 \\
\hline Vatica xishuangbannaensis & 版纳青梅 & II & $\begin{array}{l}\text { 极危 } \\
\text { /CR }\end{array}$ & 孟令曾 & 迁地保护的 4 种龙脑香冠层叶光合速率和叶绿素荧光参数的日变化 \\
\hline Vatica xishuangbannaensis & 版纳青梅 & II & $\begin{array}{l}\text { 极危 } \\
\text { /CR }\end{array}$ & 李宏伟 & 西双版纳茅草山广西青梅群落学研究 \\
\hline
\end{tabular}


顾垒，闻丞，罗玫，王吴，吕植. 中国最受关注濒危物种保护现状快速评价的新方法探讨. 生物多样性，2015，23(5)：583-590. http://www biodiversity-science. net/CN/article/downloadArticleFile. do?attachType=PDF\&id=10075

\begin{tabular}{|c|c|c|c|c|c|}
\hline Vatica xishuangbannaensis & 版纳青梅 & II & $\begin{array}{l}\text { 极危 } \\
\text { /CR }\end{array}$ & 杨永康 & 中国龙脑香科植物分类研究 (一) \\
\hline Vatica xishuangbannaensis & 版纳青梅 & II & $\begin{array}{l}\text { 极危 } \\
\text { /CR }\end{array}$ & 孟令曾 & 中国龙脑香科植物受胁状况及迁地群落保护探讨 \\
\hline Viverra zibetha & 大灵猫 & II & $\begin{array}{l}\text { 无危 } \\
\text { /LC }\end{array}$ & 侯森林 & 3 种灵猫科动物直针毛显微形态学特征研究 \\
\hline Viverra zibetha & 大灵猫 & II & $\begin{array}{l}\text { 无危 } \\
\text { /LC }\end{array}$ & 侯森林 & 4 种食肉动物直针毛的显微形态学观察 \\
\hline Viverra zibetha & 大灵猫 & II & $\begin{array}{l}\text { 无危 } \\
\text { /LC }\end{array}$ & 郭海涛 & 大灵猫、小灵猫的直针毛红外光谱比较研究 \\
\hline Viverra zibetha & 大灵猫 & II & $\begin{array}{l}\text { 无危 } \\
\text { /LC }\end{array}$ & 黎红辉 & 灵猫科 3 种兽针毛显微结构比较 \\
\hline Viverricula indica & 小灵猫 & II & $\begin{array}{l}\text { 无危 } \\
\text { /LC }\end{array}$ & 侯森林 & 3 种灵猫科动物直针毛显微形态学特征研究 \\
\hline Viverricula indica & 小灵猫 & II & $\begin{array}{l}\text { 无危 } \\
\text { /LC }\end{array}$ & 侯森林 & 4 种食肉动物直针毛的显微形态学观察 \\
\hline Viverricula indica & 小灵猫 & II & $\begin{array}{l}\text { 无危 } \\
\text { /LC }\end{array}$ & 郭海涛 & 大灵猫、小灵猫的直针毛红外光谱比较研究 \\
\hline Viverricula indica & 小灵猫 & II & 无危 & 黎红辉 & 灵猫科 3 种兽针毛显微结构比较 \\
\hline
\end{tabular}


顾垒，闻丞，罗玫，王吴，吕植. 中国最受关注濒危物种保护现状快速评价的新方法探讨. 生物多样性，2015，23(5)：583-590. http://www. biodiversity-science. net/CN/article/downloadArticleFile. do?attachType=PDF\&id=10075

\begin{tabular}{|c|c|c|c|c|c|}
\hline & & & $/ \mathrm{LC}$ & & \\
\hline \multirow[t]{2}{*}{ Viverricula indica } & 小灵猫 & II & 无危 & 钟福生 & 温湿度对小灵猫摄食活动及摄食量的影响 \\
\hline & & & $/ \mathrm{LC}$ & & \\
\hline \multirow[t]{2}{*}{ Viverricula indica } & 小灵猫 & II & 无危 & 罗冬梅 & 我国小灵猫的生物学特性及驯化研究现状 \\
\hline & & & $/ \mathrm{LC}$ & & \\
\hline \multirow[t]{2}{*}{ Viverricula indica } & 小灵猫 & II & 无危 & 宋建华 & 小灵猫的生态习性及其繁殖 \\
\hline & & & $/ \mathrm{LC}$ & & \\
\hline \multirow[t]{2}{*}{ Viverricula indica } & 小灵猫 & II & 无危 & 钟福生 & 小灵猫的资源、开发利用现状与分布 \\
\hline & & & $/ \mathrm{LC}$ & & \\
\hline \multirow[t]{2}{*}{ Viverricula indica } & 小灵猫 & II & 无危 & 刘济滨 & 小灵猫几种常见病防治 \\
\hline & & & $/ \mathrm{LC}$ & & \\
\hline \multirow[t]{2}{*}{ Viverricula indica } & 小灵猫 & II & 无危 & 钱伟平 & 小灵猫泌香规律试验研究 \\
\hline & & & $/ \mathrm{LC}$ & & \\
\hline \multirow[t]{2}{*}{ Viverricula indica } & 小灵猫 & II & 无危 & 谭玉琴 & 小灵猫能量收支及产香特点初探 \\
\hline & & & $/ \mathrm{LC}$ & & \\
\hline \multirow[t]{2}{*}{ Viverricula indica } & 小灵猫 & II & 无危 & 刘振湘 & 小灵猫葡萄球菌病的诊断和防治报告 \\
\hline & & & $/ \mathrm{LC}$ & & \\
\hline \multirow[t]{2}{*}{ Viverricula indica } & 小灵猫 & II & 无危 & 刘振湘 & 小灵猫葡萄球菌病的诊断和控制 \\
\hline & & & /LC & & \\
\hline
\end{tabular}


顾垒，闻丞，罗玫，王吴，吕植. 中国最受关注濒危物种保护现状快速评价的新方法探讨. 生物多样性，2015，23(5)：583-590. http://www. biodiversity-science. net/CN/article/downloadArticleFile. do?attachType=PDF\&id=10075

\begin{tabular}{|c|c|c|c|c|c|}
\hline Viverricula indica & 小灵猫 & II & 无危 & 刘振湘 & 小灵猫沙门氏菌病的诊断与控制报告 \\
\hline & & & $/ \mathrm{LC}$ & & \\
\hline \multirow[t]{2}{*}{ Viverricula indica } & 小灵猫 & II & 无危 & 杨东湘 & 小灵猫摄食行为研究 \\
\hline & & & $/ \mathrm{LC}$ & & \\
\hline \multirow[t]{2}{*}{ Viverricula indica } & 小灵猫 & II & 无危 & 刘振湘 & 小灵猫鼠伤寒沙门氏菌的分离与鉴定 \\
\hline & & & $/ \mathrm{LC}$ & & \\
\hline \multirow[t]{2}{*}{ Viverricula indica } & 小灵猫 & II & 无危 & 王水莲 & 小灵猫血液生理生化指标的测定 \\
\hline & & & $/ \mathrm{LC}$ & & \\
\hline \multirow[t]{2}{*}{ Viverricula indica } & 小灵猫 & II & 无危 & 宾冬梅 & 影响灵猫香产量的因素 \\
\hline & & & $/ \mathrm{LC}$ & & \\
\hline \multirow[t]{2}{*}{ Vulpes ferrilata } & 藏狐 & 未列 & 无危 & Wang Zhenghuan & Characteristics of the summer tibetan fox (Vulpes ferrilata) den habitats in Shiqu County, \\
\hline & & 入 & $/ \mathrm{LC}$ & & western Sichuan Province \\
\hline \multirow[t]{2}{*}{ Vulpes ferrilata } & 藏狐 & 未列 & 无危 & Xiao-Ming Wang & Den habitat characteristics of Tibetan foxes (Vulpes ferrilata) in Shiqu County, Sichuan \\
\hline & & 入 & $/ \mathrm{LC}$ & & Province, China \\
\hline \multirow[t]{2}{*}{ Vulpes ferrilata } & 藏狐 & 未列 & 无危 & Xiaoming Wang & Food habits of the Tibetan fox ( Vulpes ferrilata) in the Kunlun Mountains, Qinghai Province, \\
\hline & & 入 & $/ \mathrm{LC}$ & & China \\
\hline \multirow[t]{2}{*}{ Vulpes ferrilata } & 藏狐 & 未列 & 无危 & Zhenghuan Wang & Identification of the Tibetan fox (Vulpes ferrilata) and the red fox (Vulpes vulpes) by \\
\hline & & 入 & $/ \mathrm{LC}$ & & copro-DNA diagnosis \\
\hline Vulpes ferrilata & 藏狐 & 未列 & 无危 & Zhenghuan Wang & Identification of the Tibetan fox (Vulpes ferrilata) and the red fox (Vulpes vulpes) by \\
\hline
\end{tabular}


顾垒，闻丞，罗玫，王吴，吕植. 中国最受关注濒危物种保护现状快速评价的新方法探讨. 生物多样性，2015，23(5)：583-590. http://www, biodiversity-science, net/CN/article/downloadArticleFile. do?attachType=PDF\&id=10075

\begin{tabular}{|c|c|c|c|c|c|}
\hline & & 入 & $/ \mathrm{LC}$ & & copro-DNA diagnosis \\
\hline \multirow[t]{2}{*}{ Vulpes ferrilata } & 藏狐 & 未列 & 无危 & Zhenghuan Wang & Isolation and characterization of fifteen microsatellite loci in the Tibetan fox (Vulpes ferrilata) \\
\hline & & 入 & $/ \mathrm{LC}$ & & \\
\hline \multirow[t]{2}{*}{ Vulpes ferrilata } & 藏狐 & 未列 & 无危 & WANG Zhenghuan & Observation on the daytime behaviour of Tibetan for(Vulpes ferrilata) in Shiqu county,Sichuan \\
\hline & & 入 & $/ \mathrm{LC}$ & & province,China \\
\hline \multirow[t]{2}{*}{ Vulpes ferrilata } & 藏狐 & 未列 & 无危 & Zhenghuan WANG & Selection of land cover by the Tibetan fox Vulpes ferrilata on the eastern Tibetan Plateau, \\
\hline & & 入 & $/ \mathrm{LC}$ & & western Sichuan Province, China \\
\hline \multirow[t]{2}{*}{ Vulpes ferrilata } & 藏狐 & 未列 & 无危 & Z. Wang & Specific detection of Echinococcus spp. from the Tibetan fox (Vulpes ferrilata) and the red fox \\
\hline & & 入 & $/ \mathrm{LC}$ & & (V. vulpes) using copro-DNA PCR analysis \\
\hline \multirow[t]{2}{*}{ Vulpes ferrilata } & 藏狐 & 未列 & 无危 & Xiaoming Wang & Specific detection of Echinococcus spp. From the Tibetan fox (Vulpes ferrilata) and the red fox \\
\hline & & 入 & $/ \mathrm{LC}$ & & (V. vulpes) using copro-DNA PCR analysis \\
\hline \multirow[t]{2}{*}{ Vulpes ferrilata } & 藏狐 & 未列 & 无危 & Xiao-Ming Wang & The validity of using a resource selection functions model to predict den habitat of the Tibetan \\
\hline & & 入 & $/ \mathrm{LC}$ & & fox \\
\hline \multirow[t]{2}{*}{ Vulpes ferrilata } & 藏狐 & 未列 & 无危 & 李敏 & 藏狐（Vulpesferrilata）微卫星位点的篮选及应用 \\
\hline & & 入 & $/ \mathrm{LC}$ & & \\
\hline \multirow[t]{2}{*}{ Vulpes ferrilata } & 藏狐 & 未列 & 无危 & 戴捷 & 藏狐（Vulpesferrilata）系统发育研究 \\
\hline & & 入 & $/ \mathrm{LC}$ & & \\
\hline \multirow[t]{2}{*}{ Vulpes ferrilata } & 藏狐 & 未列 & 无危 & 李敏 & 藏狐_Vulpesferrilata_微卫星位点的篮选及应用 \\
\hline & & 入 & $/ \mathrm{LC}$ & & \\
\hline
\end{tabular}


顾垒，闻丞，罗玫，王吴，吕植. 中国最受关注濒危物种保护现状快速评价的新方法探讨. 生物多样性，2015，23(5)：583-590. http://www. biodiversity-science. net/CN/article/downloadArticleFile. do?attachType=PDF\&id=10075

\begin{tabular}{|c|c|c|c|c|c|}
\hline \multirow[t]{2}{*}{ Vulpes ferrilata } & 藏狐 & 未列 & 无危 & 刘群秀 & 藏狐的活动规律_家域特征及生境选择的研究 \\
\hline & & 入 & $/ \mathrm{LC}$ & & \\
\hline \multirow[t]{2}{*}{ Vulpes ferrilata } & 藏狐 & 未列 & 无危 & 刘群秀 & 藏狐的活动规律家域特征及生境选择的研究 \\
\hline & & 入 & $/ \mathrm{LC}$ & & \\
\hline \multirow[t]{2}{*}{ Vulpes ferrilata } & 藏狐 & 未列 & 无危 & 王小明 & 藏狐家域功能分区及其生物学特性比较 \\
\hline & & 入 & $/ \mathrm{LC}$ & & \\
\hline \multirow[t]{2}{*}{ Vulpes ferrilata } & 藏狐 & 未列 & 无危 & 王小明 & 藏狐家域功能分区及其生物学特性比较 \\
\hline & & 入 & $/ \mathrm{LC}$ & & \\
\hline \multirow[t]{2}{*}{ Vulpes ferrilata } & 藏狐 & 未列 & 无危 & 刘晓庆 & 藏狐家域计算方法的比较及其主要食物对家域分布特征的影响 \\
\hline & & 入 & $/ \mathrm{LC}$ & & \\
\hline \multirow[t]{2}{*}{ Vulpes ferrilata } & 藏狐 & 未列 & 无危 & 刘晓庆 & 藏狐家域计算方法的比较及其主要食物对家域分布特征的影响 \\
\hline & & 入 & $/ \mathrm{LC}$ & & \\
\hline \multirow[t]{2}{*}{ Vulpes ferrilata } & 藏狐 & 未列 & 无危 & 蒋韦斌 & 藏狐群体棘球绦虫感染率的流行病学研究 \\
\hline & & 入 & $/ \mathrm{LC}$ & & \\
\hline \multirow[t]{2}{*}{ Vulpes ferrilata } & 藏狐 & 未列 & 无危 & 戴捷 & 藏狐系统发育研究 \\
\hline & & 入 & $/ \mathrm{LC}$ & & \\
\hline \multirow[t]{2}{*}{ Vulpes ferrilata } & 藏狐 & 未列 & 无危 & 王小明 & 固定核空间法和最小凸多边形法估计藏狐家域的比较 \\
\hline & & 入 & $/ \mathrm{LC}$ & & \\
\hline Vulpes ferrilata & 藏狐 & 未列 & 无危 & 王小明 & 狐狸在两型包虫病传播途径中所起的重要作用 \\
\hline
\end{tabular}


顾垒，闻丞，罗玫，王吴，吕植. 中国最受关注濒危物种保护现状快速评价的新方法探讨. 生物多样性，2015，23(5)：583-590. http://www. biodiversity-science. net/CN/article/downloadArticleFile. do?attachType=PDF\&id=10075

\begin{tabular}{|c|c|c|c|c|c|}
\hline & & 入 & $/ \mathrm{LC}$ & & \\
\hline \multirow[t]{2}{*}{ Vulpes ferrilata } & 藏狐 & 未列 & 无危 & 刘群秀 & 基于地形因子的藏狐生境评价及其空间容纳量的估算 \\
\hline & & 入 & $/ \mathrm{LC}$ & & \\
\hline \multirow[t]{2}{*}{ Vulpes ferrilata } & 藏狐 & 未列 & 无危 & 王小明 & 基于地形因子的藏狐生境评价及其空间容纳量的估算 \\
\hline & & 入 & $/ \mathrm{LC}$ & & \\
\hline \multirow[t]{2}{*}{ Vulpes ferrilata } & 藏狐 & 未列 & 无危 & 刘楠 & 基于粪便 DNA 技术与样线法的藏狐种群数量估计 \\
\hline & & 入 & $/ \mathrm{LC}$ & & \\
\hline \multirow[t]{2}{*}{ Vulpes ferrilata } & 藏狐 & 未列 & 无危 & 刘群秀 & 两种核域估算方法在野生藏狐家域研究中的比较 \\
\hline & & 入 & $/ \mathrm{LC}$ & & \\
\hline \multirow[t]{2}{*}{ Vulpes ferrilata } & 藏狐 & 未列 & 无危 & 王小明 & 两种核域估算方法在野生藏狐家域研究中的比较 \\
\hline & & 入 & $/ \mathrm{LC}$ & & \\
\hline \multirow[t]{2}{*}{ Vulpes ferrilata } & 藏狐 & 未列 & 无危 & 李伟 & 青海省称多县藏狐和犬棘球绦虫感染 分离株的虫种鉴定 \\
\hline & & 入 & $/ \mathrm{LC}$ & & \\
\hline \multirow[t]{2}{*}{ Vulpes ferrilata } & 藏狐 & 未列 & 无危 & 王小明 & 青海省都兰县藏狐家域范围及重叠度 \\
\hline & & 入 & $/ \mathrm{LC}$ & & \\
\hline \multirow[t]{2}{*}{ Vulpes ferrilata } & 藏狐 & 未列 & 无危 & 王小明 & 青海省都兰县藏狐家域范围及重叠度 \\
\hline & & 入 & $/ \mathrm{LC}$ & & \\
\hline \multirow[t]{2}{*}{ Vulpes ferrilata } & 藏狐 & 未列 & 无危 & 刘群秀 & 青海省都兰县沟里乡幼龄藏狐昼间行为节律 \\
\hline & & 入 & $/ \mathrm{LC}$ & & \\
\hline
\end{tabular}


顾垒，闻丞，罗玫，王吴，吕植. 中国最受关注濒危物种保护现状快速评价的新方法探讨. 生物多样性，2015，23(5)：583-590. http://www. biodiversity-science. net/CN/article/downloadArticleFile. do?attachType=PDF\&id=10075

\begin{tabular}{|c|c|c|c|c|c|}
\hline \multirow[t]{2}{*}{ Vulpes ferrilata } & 藏狐 & 未列 & 无危 & 王小明 & 青海省都兰县沟里乡幼龄藏狐昼间行为节律 \\
\hline & & 入 & $/ \mathrm{LC}$ & & \\
\hline \multirow[t]{2}{*}{ Vulpes ferrilata } & 藏狐 & 未列 & 无危 & 王小明 & 四川省石 渠县藏狐洞穴的生态特征分析 \\
\hline & & 入 & $/ \mathrm{LC}$ & & \\
\hline \multirow[t]{2}{*}{ Vulpes ferrilata } & 藏狐 & 未列 & 无危 & 王正睘 & 四川省石渠县藏狐的生态学研究 \\
\hline & & 入 & $/ \mathrm{LC}$ & & \\
\hline \multirow[t]{2}{*}{ Vulpes ferrilata } & 藏狐 & 未列 & 无危 & 王正寰 & 四川省石渠县藏狐的生态学研究 \\
\hline & & 入 & $/ \mathrm{LC}$ & & \\
\hline \multirow[t]{2}{*}{ Vulpes ferrilata } & 藏狐 & 未列 & 无危 & 王小明 & 四川省石渠县藏狐洞穴的生态特征分析 \\
\hline & & 入 & $/ \mathrm{LC}$ & & \\
\hline \multirow[t]{2}{*}{ Vulpes ferrilata } & 藏狐 & 未列 & 无危 & 王小明 & 四川省石渠县藏狐昼间行为特征观察 \\
\hline & & 入 & $/ \mathrm{LC}$ & & \\
\hline \multirow[t]{2}{*}{ Vulpes ferrilata } & 藏狐 & 未列 & 无危 & 王小明 & 四川省石渠县藏狐昼间行为特征观察 \\
\hline & & 入 & $/ \mathrm{LC}$ & & \\
\hline \multirow[t]{2}{*}{ Vulpes ferrilata } & 藏狐 & 未列 & 无危 & 龚明昊 & 四川西北高原藏狐的夏季微生境选择 \\
\hline & & 入 & $/ \mathrm{LC}$ & & \\
\hline \multirow[t]{2}{*}{ Vulpes ferrilata } & 藏狐 & 未列 & 无危 & 龚明昊 & 四川西北高原藏狐的夏季微生境选择 \\
\hline & & 入 & $/ \mathrm{LC}$ & & \\
\hline Vulpes ferrilata & 藏狐 & 未列 & 无危 & 王小明 & 四川西部石渠地区夏季藏狐巢穴选择的生境分析 \\
\hline
\end{tabular}


顾垒，闻丞，罗玫，王吴，吕植. 中国最受关注濒危物种保护现状快速评价的新方法探讨. 生物多样性，2015，23(5)：583-590. http://www. biodiversity-science. net/CN/article/downloadArticleFile. do?attachType=PDF\&id=10075

\begin{tabular}{|c|c|c|c|c|c|}
\hline & & 入 & $/ \mathrm{LC}$ & & \\
\hline \multirow[t]{2}{*}{ Vulpes ferrilata } & 藏狐 & 未列 & 无危 & 王小明 & 四川西部石渠地区夏季藏狐巢穴选择的生境分析 \\
\hline & & 入 & $/ \mathrm{LC}$ & & \\
\hline \multirow[t]{2}{*}{ Vulpes ferrilata } & 藏狐 & 未列 & 无危 & 王小明 & 资源选择函数拟合藏狐洞穴生境利用特征的有效性分析 \\
\hline & & 入 & $/ \mathrm{LC}$ & & \\
\hline \multirow[t]{2}{*}{ Vulpes ferrilata } & 藏狐 & 未列 & 无危 & 王小明 & 资源选择函数拟合藏狐洞穴生境利用特征的有效性分析 \\
\hline & & 入 & $/ \mathrm{LC}$ & & \\
\hline \multirow[t]{2}{*}{ Vulpes vulpes } & 赤狐 & II & 无危 & A. V. K UKEKOVA & A Marker Set for Construction of a Genetic Map of the Silver Fox (Vulpes vulpes ) \\
\hline & & & $/ \mathrm{LC}$ & & \\
\hline \multirow[t]{2}{*}{ Vulpes vulpes } & 赤狐 & II & 无危 & 钟华明 & 赤狐（Vulpes vulpes)线粒体 DNA 全序列与犬科系统学研究 \\
\hline & & & $/ \mathrm{LC}$ & & \\
\hline \multirow[t]{2}{*}{ Vulpes vulpes } & 赤狐 & II & 无危 & 杨 福合 & 赤狐黑色素皮质激素受体-1 基因结构特征 \\
\hline & & & $/ \mathrm{LC}$ & & 预测及分子进化分析 \\
\hline \multirow[t]{2}{*}{ Vulpes vulpes } & 赤狐 & II & 无危 & 唐福全 & 赤狐华南亚种与东北亚种上毛髓质指数的比较研究 \\
\hline & & & $/ \mathrm{LC}$ & & \\
\hline \multirow[t]{2}{*}{ Vulpes vulpes } & 赤狐 & II & 无危 & 刘振生 & 赤狐生境选择研究进展 \\
\hline & & & $/ \mathrm{LC}$ & & \\
\hline \multirow[t]{2}{*}{ Vulpes vulpes } & 赤狐 & II & 无危 & 滕丽微 & 赤狐食性的研究进展 \\
\hline & & & $/ \mathrm{LC}$ & & \\
\hline
\end{tabular}


顾垒，闻丞，罗玫，王吴，吕植. 中国最受关注濒危物种保护现状快速评价的新方法探讨. 生物多样性，2015，23(5)：583-590. http://www. biodiversity-science. net/CN/article/downloadArticleFile. do?attachType=PDF\&id=10075

\begin{tabular}{|c|c|c|c|c|c|}
\hline Vulpes vulpes & 赤狐 & II & 无危 & 张洪海 & 赤狐线粒体全基因组及系统发育分析 \\
\hline & & & $/ \mathrm{LC}$ & & \\
\hline \multirow[t]{2}{*}{ Vulpes vulpes } & 赤狐 & II & 无危 & 侯森林 & 赤狐直针毛显微形态学特征观察 \\
\hline & & & $/ \mathrm{LC}$ & & \\
\hline \multirow[t]{2}{*}{ Vulpes vulpes } & 赤狐 & II & 无危 & 李成涛 & 达春湖保护区赤狐(Vulpes vulpes)的生境选择和景观特征分析 \\
\hline & & & $/ \mathrm{LC}$ & & \\
\hline \multirow[t]{2}{*}{ Vulpes vulpes } & 赤狐 & II & 无危 & 张洪海 & 内蒙古达麥湖地区赤狐生境选择及生境景观特征分析 \\
\hline & & & $/ \mathrm{LC}$ & & \\
\hline \multirow[t]{2}{*}{ Vulpes vulpes } & 赤狐 & II & 无危 & 张扬 & 赛罕乌拉自然保护区 5 种食肉目动物食性和栖息地选择的比较 \\
\hline & & & $/ \mathrm{LC}$ & & \\
\hline \multirow[t]{2}{*}{ Vulpes vulpes } & 赤狐 & II & 无危 & 时否 & 准噶尔盆地荒漠区赤狐的食性分析 \\
\hline & & & $/ \mathrm{LC}$ & & \\
\hline \multirow[t]{3}{*}{ Zaocys dhumnades } & 乌梢蛇 & 未列 & 未评 & LIANG Gang & Histological and immunocytochemical study of deferens ducts in the Chinese rat snake (Zaocys \\
\hline & & 入 & 价 & & dhumnades) \\
\hline & & & $/ \mathrm{NE}$ & & \\
\hline \multirow[t]{3}{*}{ Zaocys dhumnades } & 乌梢蛇 & 未列 & 未评 & Xiang Ji & PhenotypicvariationinhatchlingChineseratsnakes(Zaocys dhumnades) from eggs \\
\hline & & 入 & 价 & & incubatedatconstanttemperatures \\
\hline & & & $/ \mathrm{NE}$ & & \\
\hline Zaocys dhumnades & 乌梢蛇 & 未列 & 未评 & 杨超 & 两种蛇 Sox 基因的 PCR-SSCP 分析 \\
\hline
\end{tabular}


顾垒，闻丞，罗玫，王吴，吕植. 中国最受关注濒危物种保护现状快速评价的新方法探讨. 生物多样性，2015，23(5)：583-590. http://www. biodiversity-science. net/CN/article/downloadArticleFile. do?attachType=PDF\&id=10075

\begin{tabular}{|c|c|c|c|c|c|}
\hline & & 入 & 价 & & \\
\hline Zaocys dhumnades & 乌梢蛇 & $\begin{array}{l}\text { 未列 } \\
入\end{array}$ & $\begin{array}{l}\text { /NE } \\
\text { 未评 } \\
\text { 价 }\end{array}$ & 周艳妮 & 乌梢蛇（Zaocys dhumnades）精巢的超微结构 \\
\hline Zaocys dhumnades & 乌梢蛇 & $\begin{array}{l}\text { 未列 } \\
入\end{array}$ & $\begin{array}{l}\text { /NE } \\
\text { 未评 } \\
\text { 价 }\end{array}$ & 邵邻相 & 乌梢蛇 LDH 同工酶谱系的研究 \\
\hline Zaocys dhumnades & 乌梢蛇 & $\begin{array}{l}\text { 未列 } \\
入\end{array}$ & $\begin{array}{l}\text { /NE } \\
\text { 未评 } \\
\text { 价 }\end{array}$ & 赵彩虹 & 乌梢蛇䧳性生殖系统年周期的组织学及免疫细胞化学研究 \\
\hline Zaocys dhumnades & 乌梢蛇 & $\begin{array}{l}\text { 未列 } \\
\text { 入 }\end{array}$ & $\begin{array}{l}\text { /NE } \\
\text { 未评 } \\
\text { 价 }\end{array}$ & 刘军 & 乌梢蛇的仿生态饲养试验 \\
\hline Zaocys dhumnades & 乌梢蛇 & $\begin{array}{l}\text { 未列 } \\
入\end{array}$ & $\begin{array}{l}\text { /NE } \\
\text { 未评 } \\
\text { 价 }\end{array}$ & 刘军 & 乌梢蛇的人工睬化试验 \\
\hline Zaocys dhumnades & 乌梢蛇 & $\begin{array}{l}\text { 未列 } \\
入\end{array}$ & $\begin{array}{l}/ \mathrm{NE} \\
\text { 未评 } \\
\text { 价 }\end{array}$ & 叶红 & 乌梢蛇的人工捊化与冬眠前的人工饲养 \\
\hline
\end{tabular}


顾垒，闻丞，罗玫，王吴，吕植. 中国最受关注濒危物种保护现状快速评价的新方法探讨. 生物多样性，2015，23(5)：583-590. http://www. biodiversity-science. net/CN/article/downloadArticleFile. do?attachType=PDF\&id=10075

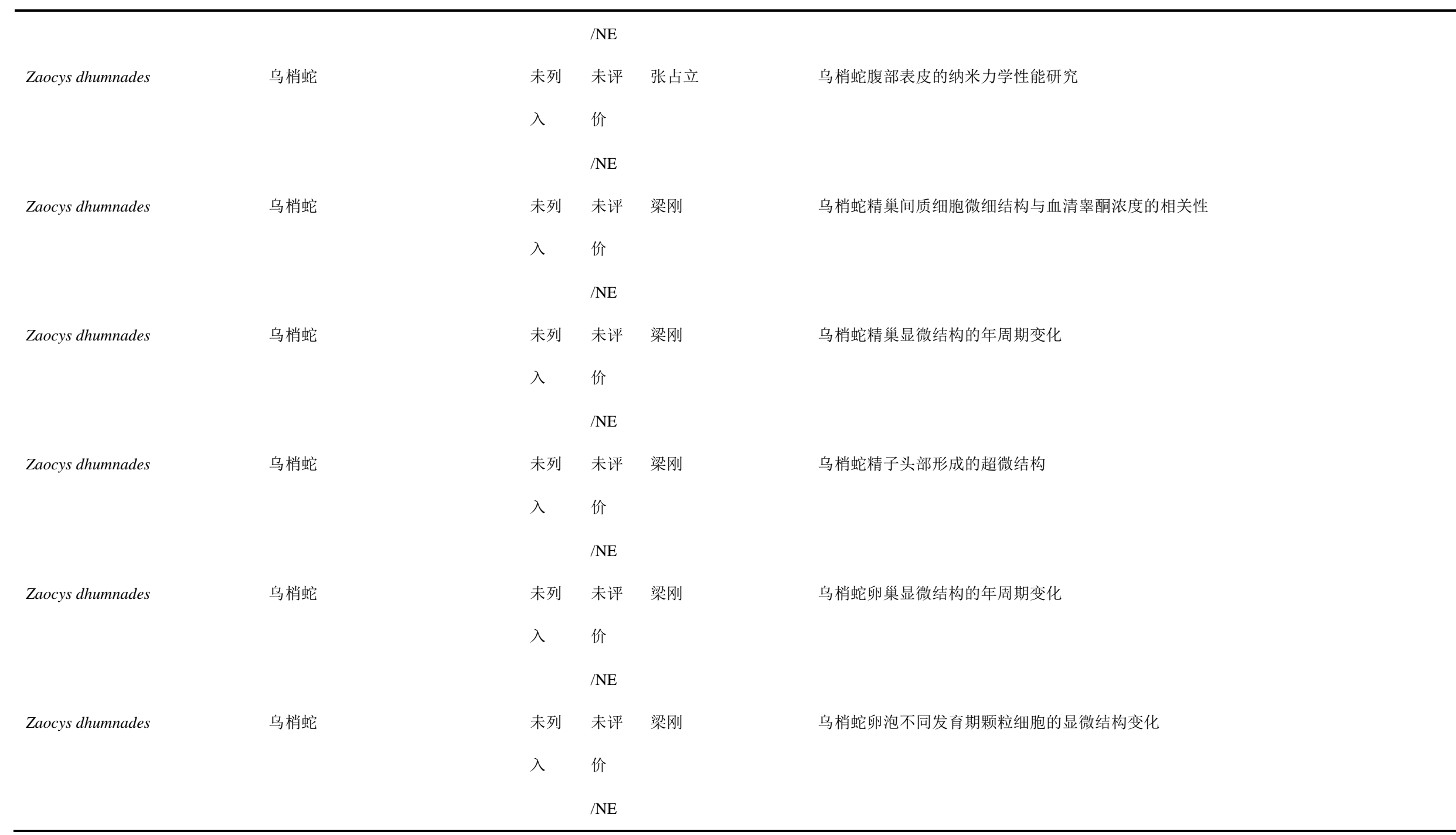


顾垒，闻丞，罗玫，王吴，吕植. 中国最受关注濒危物种保护现状快速评价的新方法探讨. 生物多样性，2015，23(5)：583-590. http://www. biodiversity-science. net/CN/article/downloadArticleFile. do?attachType=PDF\&id=10075

\begin{tabular}{|c|c|c|c|c|c|}
\hline \multirow[t]{2}{*}{ Zaocys dhumnades } & 乌梢蛇 & 未列 & 未评 & 叶效林 & 乌梢蛇卵泡发育的显微和超微结构 \\
\hline & & 入 & $\begin{array}{l}\text { 价 } \\
\text { /NE }\end{array}$ & & \\
\hline \multirow[t]{3}{*}{ Zaocys dhumnades } & 乌梢蛇 & 未列 & 未评 & 叶红 & 乌梢蛇人工饵料的配制 \\
\hline & & 入 & 价 & & \\
\hline & & & $/ \mathrm{NE}$ & & \\
\hline \multirow[t]{3}{*}{ Zaocys dhumnades } & 乌梢蛇 & 未列 & 未评 & 华田苗 & 乌梢蛇十二指肠粘膜上皮的组织学研究 \\
\hline & & 入 & 价 & & \\
\hline & & & $/ \mathrm{NE}$ & & \\
\hline \multirow[t]{3}{*}{ Zaocys dhumnades } & 乌梢蛇 & 未列 & 未评 & 梁刚 & 乌梢蛇视网膜的显微结构观察 \\
\hline & & 入 & 价 & & \\
\hline & & & $/ \mathrm{NE}$ & & \\
\hline \multirow[t]{3}{*}{ Zaocys dhumnades } & 乌梢蛇 & 未列 & 未评 & 华田苗 & 乌梢蛇胃上皮的组织学研究 \\
\hline & & 入 & 价 & & \\
\hline & & & $/ \mathrm{NE}$ & & \\
\hline \multirow[t]{3}{*}{ Zaocys dhumnades } & 乌梢蛇 & 未列 & 未评 & 王琼霞 & 乌梢蛇雄性生殖系统年周期的组织学及免疫细胞化学研究 \\
\hline & & 入 & 价 & & \\
\hline & & & $/ \mathrm{NE}$ & & \\
\hline Zaocys dhumnades & 乌梢蛇 & 未列 & 未评 & 黄松 & 乌梢蛇血清的抗出血因子:一个有前途的抗蛇毒药物原料 \\
\hline
\end{tabular}


顾垒，闻丞，罗玫，王吴，吕植. 中国最受关注濒危物种保护现状快速评价的新方法探讨．生物多样性，2015，23(5)：583-590。 http://www. biodiversity-science. net/CN/article/downloadArticleFile. do?attachType=PDF\&id=10075

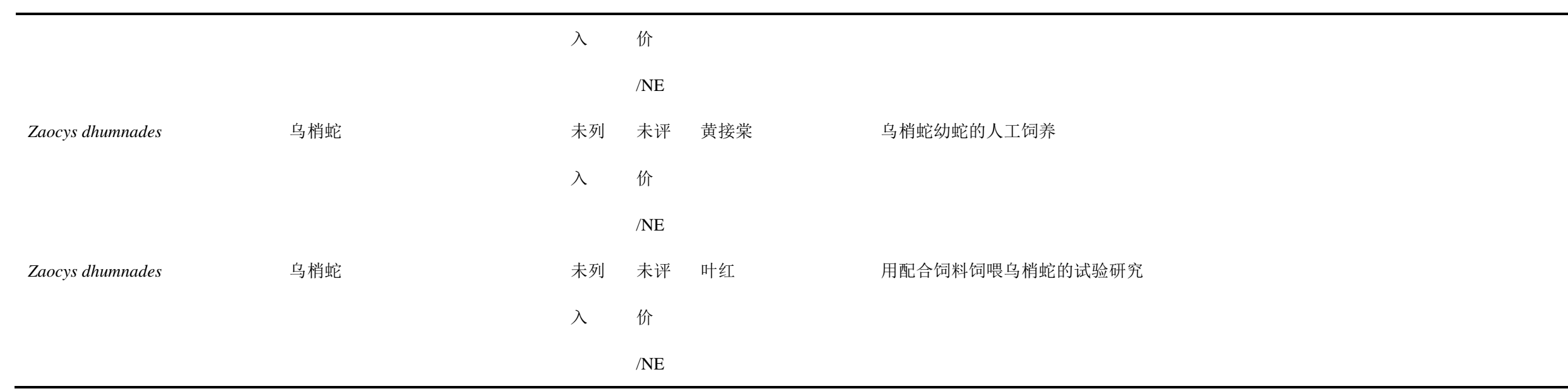

